Marcelo Rodrigo Carreira

\title{
AVALIAÇÃO DA RIGIDEZ À FLEXÃO DE TORAS DE MADEIRA POR MEIO DE VIBRAÇÃO TRANSVERSAL
}

Tese apresentada à Escola de Engenharia de São Carlos da Universidade de São Paulo, como parte dos requisitos para obtenção do Título de Doutor em Engenharia de Estruturas.

Área de concentração: Engenharia de Estruturas Orientador: Prof. Dr. Antonio Alves Dias 


\section{AUTORIZO A REPRODUÇÃO E DIVULGAÇÃO TOTAL OU PARCIAL DESTE TRABALHO, POR QUALQUER MEIO CONVENCIONAL OU ELETRÔNICO, PARA FINS DE ESTUDO E PESQUISA, DESDE QUE CITADA A FONTE.}

Ficha catalográfica preparada pela Seção de Tratamento da Informação do Serviço de Biblioteca - EESC/USP

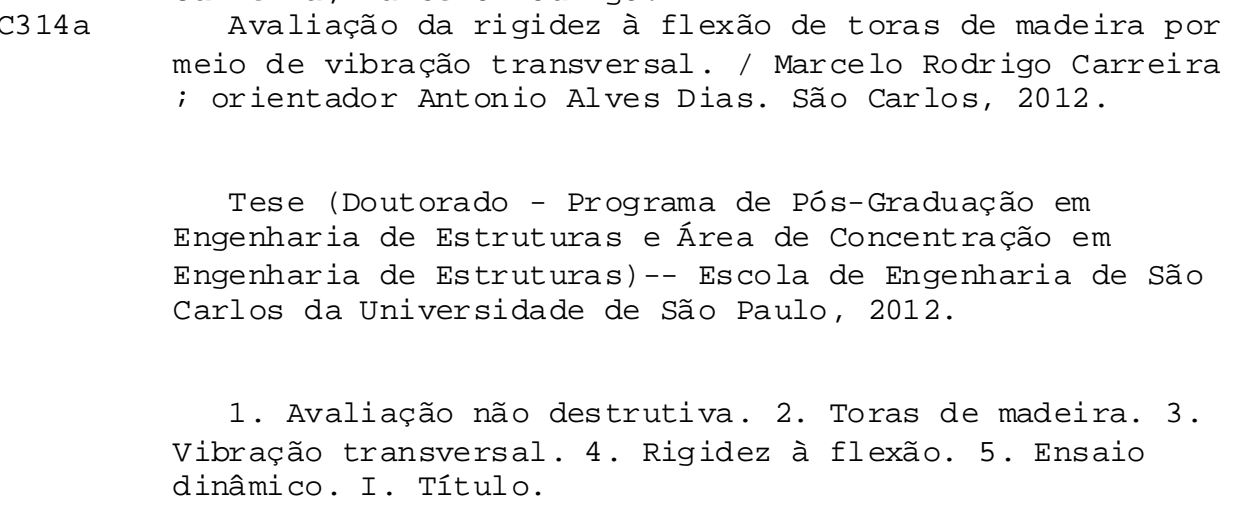




\section{ERRATA}

CARREIRA, M. R. Avaliação da rigidez à flexão de toras de madeira por meio de vibração transversal. 2012. 385 f. Tese (Doutorado) - Escola de Engenharia de São Carlos, Universidade de São Paulo, São Carlos, 2012.

\begin{tabular}{|c|c|c|c|}
\hline Página & Linha & Onde se lê & Leia-se \\
\hline 56 & 12 & “...domínio do espaço...” & “...espaço físico..." \\
\hline 56 & Equação 2.24 & $\{x\}=\frac{[A][A]^{T}\{F\}}{\left[K_{m}\right]\left([1]-[\alpha]^{2}+2[\xi][\alpha] i\right)}$ & $\{x\}=\sum_{j=1}^{n} \frac{\{A\}_{j} \cdot\{A\}_{j}{ }^{T}\{F\}}{k_{m, j}\left(1-\alpha_{j}{ }^{2}+2 \xi_{j} \alpha_{j} i\right)}$ \\
\hline 57 & 1 & $\begin{array}{l}\text { "Dividindo a entrada }\{F\} \text { pela } \\
\text { saída do sistema }\{x\} \ldots "\end{array}$ & $\begin{array}{c}\text { "Pós multiplicando a Equação } 2.24 \\
\text { por }\{F\}^{-1} \ldots \text {.." }\end{array}$ \\
\hline 57 & Equação 2.26 & {$[H(\omega)]=\frac{\{x\}}{\{F\}}=\frac{[A][A]^{T}}{\left[K_{m}\right]\left([1]-[\alpha]^{2}+2[\xi][\alpha] i\right)}$} & {$[H(\omega)]=\sum_{j=1}^{n} \frac{\{A\}_{j} \cdot\{A\}_{j}^{T}}{k_{m, j}\left(1-\alpha_{j}^{2}+2 \xi_{j} \alpha_{j} i\right)}$} \\
\hline 63 & Equação 2.36 & $-\int_{0}^{L} \frac{d^{2}}{d x^{2}}\left[E I \frac{d^{2} A_{p}}{d x^{2}}\right] A_{n}(x) d x=\left\{\begin{array}{ccc}0 & \text { para } & n \neq p \\
K_{p} & \text { para } & n=p\end{array}\right.$ & $\int_{0}^{L} \frac{d^{2}}{d x^{2}}\left[E I \frac{d^{2} A_{p}}{d x^{2}}\right] A_{n}(x) d x=\left\{\begin{array}{ccc}0 & \text { para } & n \neq p \\
K_{p} & \text { para } & n=p\end{array}\right.$ \\
\hline
\end{tabular}




\section{FOLHA DE JULGAMENTO}

Candidato: Engenheiro MARCELO RODRIGO CARREIRA.

Título da tese: "Avaliação da rigidez à flexão de toras de madeira por meio de vibração transversal".

Data da defesa: $12 / 03 / 2012$

\section{Comissão Julgadora:}

Prof. Dr. Antonio Alves Dias (Orientador)

(Escola de Engenharia de São Carlos/EESC)

Prof. Titular Francisco Antonio Rocco Lahr (Escola de Engenharia de São Carlos/EESC)
Resultado:
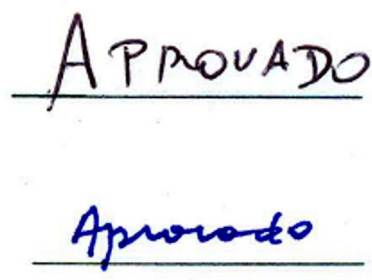

Prof. Titular Adriano Wagner Ballarin

APROVADO

(Universidade Estadual Paulista "Júlio de Mesquita Filho" /campus de Botucatu)

Prof. Titular Paulo Sergio Varoto

(Escola de Engenharia de São Carlos/EESC)

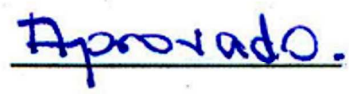

Prof. Titular Almir Sales

(Universidade Federal de São Carlos)

Coordenador do Programa de Pós-Graduação em Engenharia Civil (Engenharia de Estruturas):

Prof. ${ }^{a}$ Associada Ana Lucia Homce de Cresce El Debs

Presidente da Comissão de Pós-Graduação:

Prof. Associado Paulo Cesar Lima Segantine 

Dedico este trabalho às pessoas mais importantes de minha vida: meu pai Alcides (in memorian), minha mãe Lourdes e a minha esposa Elizângela pelo carinho, apoio, compreensão e pela paciência durante minha presença ausente necessária para que este trabalho pudesse ser desenvolvido. 


\section{AGRADECIMENTOS}

Em especial ao Prof. Dr. Antônio Alves Dias pela dedicação, confiança, amizade e pela excelente orientação.

Aos Professores Titulares Carlito Calil Jr e Francisco Antônio Rocco Lahr pela amizade e pelo incentivo à pesquisa.

Ao Professor Titular Paulo Sérgio Varoto pelas valiosas aulas de Análise Modal de Estruturas sem as quais não seria possível o desenvolvimento deste trabalho.

Ao professor Dr. Leopoldo Pisanelli Rodrigues de Oliveira pela paciência e por estar sempre disposto a auxiliar no entendimento dos resultados dos ensaios.

Aos técnicos do Departamento de Engenharia Mecânica (NeTEF/SEM) Jorge Nicolau dos Santos e Roberto Carlos Prataviera pela disposição em auxiliar no desenvolvimento do condicionador de sinais.

À Universidade Tecnológica Federal do Paraná (UTFPR) por conceder o afastamento integral de minhas atividades docentes pelo período de três anos.

A CAPES pela bolsa de estudos PICDTEC concedida durante o período de afastamento.

Aos amigos Júlio César Molina, Andrés Batista Cheung, José Luiz Miotto e Márcio Rogério da Silva pelo apoio e companheirismo que compartilhamos nestes anos em São Carlos.

Em especial ao grande amigo Pedro Gutemberg de Alcântara Segundinho pela amizade, apoio, compreensão e por auxiliar na execução dos ensaios.

A todos os funcionários do Departamento de Engenharia de Estruturas (SET) que, direta ou indiretamente, contribuíram para que este trabalho fosse realizado. 




\section{RESUMO}

CARREIRA, M. R. Avaliação da rigidez à flexão de toras de madeira por meio de vibração transversal. 2012. 385 f. Tese (Doutorado) - Escola de Engenharia de São Carlos, Universidade de São Paulo, São Carlos, 2012.

Antes de utilizar as toras de madeira como elemento estrutural é necessário avaliar as propriedades mecânicas desse material tanto por inspeção visual quanto por ensaio mecânico. A técnica de vibração transversal tem se destacado entre os demais métodos de Avaliação Não-Destrutiva para madeira serrada por obter estimativas acuradas do módulo de elasticidade à flexão. Contudo, testes prévios com essa técnica evidenciaram dificuldades de empregá-la na avaliação a rigidez à flexão de toras. O objetivo deste trabalho foi propor um método de ensaio para estimar o módulo de elasticidade na flexão de toras de madeira por meio de vibração transversal. O método proposto foi testado e validado em uma amostra de 40 toras de Eucalyptus sp. Foram obtidas boas correlações entre o módulo de elasticidade estático e o módulo de elasticidade dinâmico obtido pelo ensaio de vibração transversal.

Palavras-chave: Avaliação não-destrutiva; toras de madeira; vibração transversal; rigidez à flexão; ensaio dinâmico. 


\begin{abstract}
CARREIRA, M. R. Evaluation of bending stiffness of wood logs by means of transverse vibration. 2012. 386 f. Thesis (Doctoral) - Escola de Engenharia de São Carlos, Universidade de São Paulo, São Carlos, 2012.

Before using the wood $\operatorname{logs}$ as a structural element is necessary to evaluate the mechanical properties of this material by visual inspection and mechanical testing. The transverse vibration technique has stood out among the other methods of Non-Destructive Evaluation for lumber to obtain accurate estimates of the bending modulus of elasticity. However, previous tests showed difficulties with this technique to use it to evaluate the bending stiffness of logs. The aim of this work is to propose a test method to estimate the bending modulus of elasticity of wood logs by means of transverse vibration. The proposed method was tested and validated on a sample of $40 \mathrm{logs}$ of Eucalyptus sp. It was obtained good correlation between the static bending and dynamic modulus of elasticity obtained by transverse vibration test.
\end{abstract}

Keywords: Non-destructive evaluation; wood logs; transverse vibration; bending stiffness; dynamic test. 


\section{LISTA DE FIGURAS}

Figura 2.1 - Ensaio de flexão em postes de madeira: a) norma ASTM D 1036 (ASTM, 2005); b) norma NBR

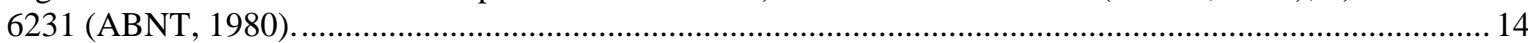

Figura 2.2 - Resistograph: a) Foto do aparelho; b) Gráfico obtido com o equipamento.............................. 15

Figura 2.3 - Ensaio de micro-perfuração na zona de afloramento de um poste............................................ 16

Figura 2.4 - Ensaio de micro-perfuração em treliça de edificação antiga: a) treliças inspecionadas; b) Ensaio de micro-perfuração.

Figura 2.5 - Correlação entre resistência à micro-perfuração e densidade.

Figura 2.6 - Ensaio de micro-perfuração na espécie Quercus sp: a) perfuração das seções dos troncos; b) comparação da resistência à perfuração com o estado da madeira. ............................................................ 19

Figura 2.7 - Projeção de objetos em diferentes planos...................................................................... 20

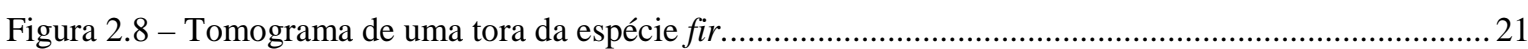

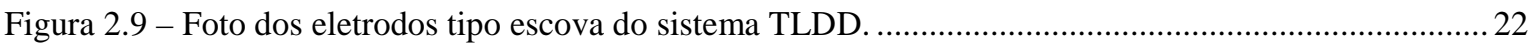

Figura 2.10 - Imagem tomográfica 3D de uma seção do tronco de uma árvore...........................................223

Figura 2.11 - Imagem tomográfica mostrando nós internos: a) Tomografia Computadorizada; b)

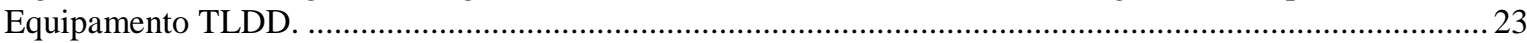

Figura 2.12 - Desvio dos sinais ultrassônicos por um defeito.............................................................. 24

Figura 2.13 - Tomografia ultrassônica de um tronco de Lindentree: a) posicionamento dos sensores; b) imagem gerada pelo Fakopp 2D.

Figura 2.14 - a) Posicionamento dos transdutores ultrassônicos no tronco de uma árvore; b) transdutor ultrassônico do aparelho Fakopp 2D.....

Figura 2.15 - Disposições dos transdutores no ensaio ultrassônico

Figura 2.16 - Correlação entre módulo de elasticidade dinâmico $\left(\mathrm{E}_{\mathrm{M}, \mathrm{din}}\right)$ e estático $\left(\mathrm{E}_{\mathrm{M}, \text { Stat }}\right)$ obtido por Miná et al (2004).

Figura 2.17 - Ensaio de emissão ultrassônica em seções de toras de Eucalyptus citriodora. 30

Figura 2.18 - Correlação entre o módulo de elasticidade dinâmico ( $\left.\mathrm{E}_{\mathrm{M}, \mathrm{din}}\right)$ com o módulo de elasticidade estático $\left(\mathrm{E}_{\mathrm{M}, \mathrm{Stat}}\right)$ e com o módulo de ruptura na flexão $\left(f_{\mathrm{M}}\right)$.

Figura 2.19 - Medição da velocidade de propagação da onda ultrassônica na direção radial de postes de madeira.

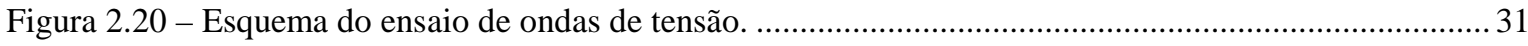

Figura 2.21 - Ensaio de ondas de tensão em toras de Pinus taeda ............................................................ 33

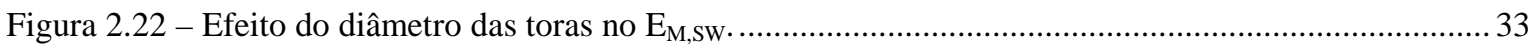

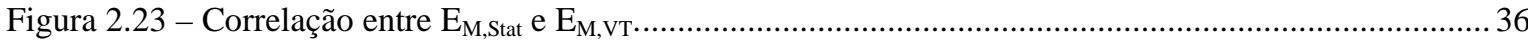

Figura 2.24 - Ensaio de vibração transversal realizado por Ballarin et al (2002). ........................................ 36

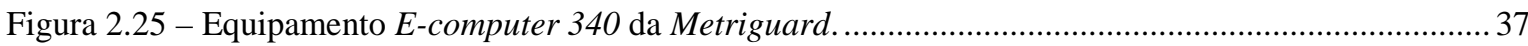

Figura 2.26 - Regressão linear entre $\mathrm{E}_{\mathrm{M}, \mathrm{Stat}} \mathrm{e} \mathrm{E}_{\mathrm{M}, \mathrm{VT}}$ obtida por Carreira et al (2003).................................3

Figura 2.27 - Ensaio de vibração transversal em vigas de Angelim Araroba............................................... 38

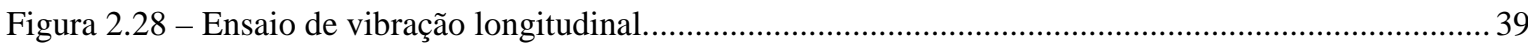

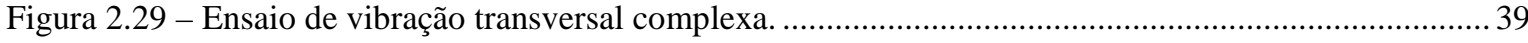

Figura 2.30 - Diagrama de dispersão e reta de regressão entre $E_{M, S t a t}$ e o $E_{M, V T}$ obtido com o equipamento desenvolvido pelo autor para avaliação de madeira serrada. ............................................................... 41

Figura 2.31 - Ensaio de vibração transversal em placa laminada............................................................ 41

Figura 2.32 - Forma dos dois primeiros modos de flexão de uma viga em suspensão livre-livre..................42 
Figura 2.33 - Esquema do ensaio de vibração transversal realizado por Chui (1991) .................................43

Figura 2.34 - Arranjo do ensaio de vibração livre realizado por Chui et al (1999).......................................43

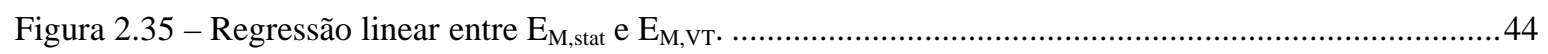

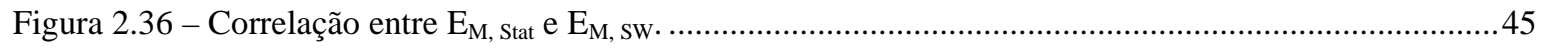

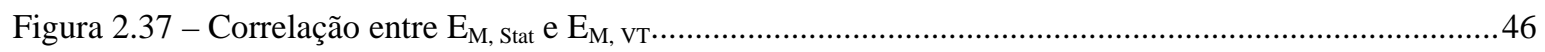

Figura 2.38 - Teste de vibração transversal com toras torneadas. ...........................................................47

Figura 2.39 - Ensaio de vibração transversal em toras de pequeno diâmetro..............................................48

Figura 2.40 - Diagrama de blocos de uma FRF.................................................................................49

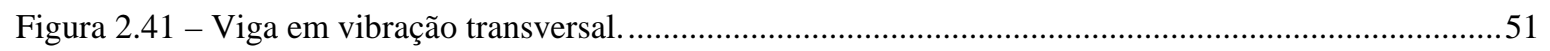

Figura 2.42 - Modelo discreto com dois graus de liberdade .............................................................51

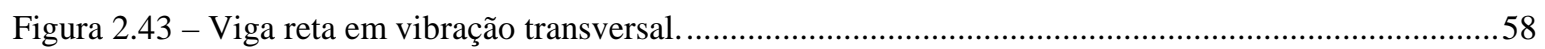

Figura 2.44 - Equilíbrio de um elemento infinitesimal $d x$ em uma viga de Timoshenko............................61

Figura 2.45 - Valores de $\mathrm{K}_{1}$ em função da relação $\mathrm{L}_{\text {apoio }}$ LL............................................................67

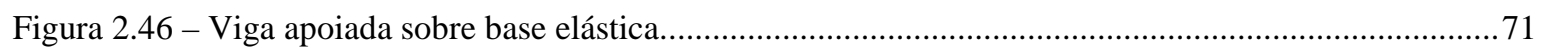

Figura 2.47 - Viga sobre dois apoios elásticos posicionados nas extremidades. .........................................71

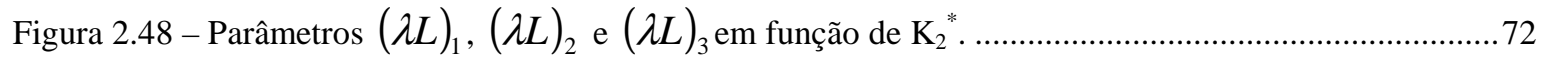

Figura 2.49 - Variação do parâmetro $(\lambda L)^{2}$ para uma viga de Bernoulli em função da rigidez relativa dos

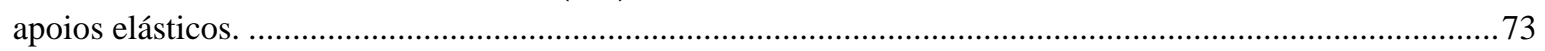

Figura 2.50 - Variação da frequência de uma viga de Bernoulli em função da rigidez relativa dos apoios

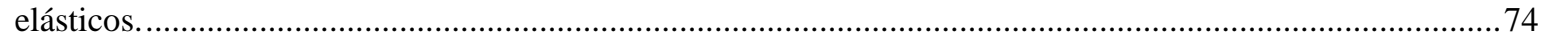

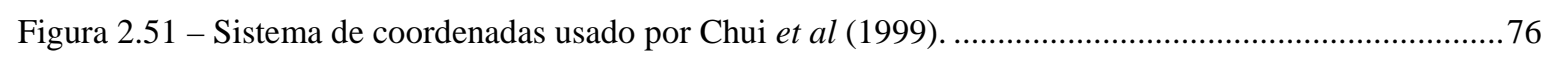

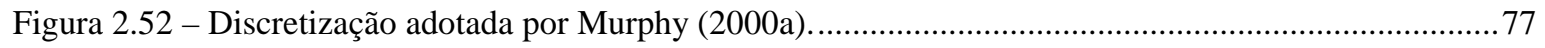

Figura 2.53 - Influência do nó no modo de vibração de uma viga. Linha tracejada: modo teórico; linha com

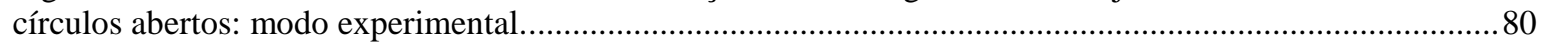

Figura 2.54 - Amplificadores de sinal: a) Amplificador de instrumentação; b) Amplificador de carga..........82

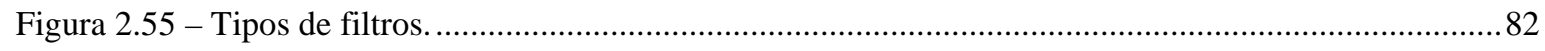

Figura 2.56 - Função de transferência de um conversor A/D de 3 bits......................................................8 83

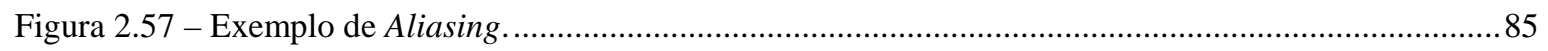

Figura 2.58 - Relação entre os domínios do tempo e da frequência: a) sistema de coordenadas tridimensionais mostrando tempo, frequência e amplitude; b) Observação no domínio do tempo; c) Observação no domínio da frequência.

Figura 2.59 - Transformada de Fourier: a) FFT de um sinal periódico; (b) presença de leakage na FFT de um sinal aperiódico.

Figura 2.60 - Formato de algumas funções janela observadas no domínio do tempo.

Figura 2.61 - Formato da função janela exponencial.

Figura 2.62 - Efeito da janela exponencial: a) Janela com muito amortecimento; b) Aumento do período de

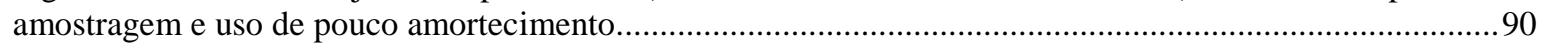

Figura 2.63 - Sobreposição das janelas de aquisição........................................................................91

Figura 2.64 - Efeito do cálculo da média: a) espectro instantâneo de um sinal aleatório; b) espectro resultante após 8 médias; c) espectro obtido após 128 médias. 
Figura 2.65 - Métodos de fixação do acelerômetro na estrutura: A) com prisioneiro de aço; B) fixação isolada eletricamente; C) com adesivo; D) prisioneiro colado; E) com fita dupla face; F) empregando uma base magnética.

Figura 2.66 - Resposta em frequência de alguns métodos de fixação do acelerômetro. .95

Figura 2.67 - FRF com dois acelerômetros de massas diferentes .96

Figura 2.68 - Excitadores mais comuns para uso em campo: a) marreta de impacto; b) shaker servohidráulico; c) caminhão vibratório; d) shaker de massa excêntrica.

Figura 2.69 - Excitadores mais comuns usados em laboratório: a) Martelo de impacto; b) Shaker eletrodinâmico.

Figura 2.70 - Exemplo do comportamento de diferentes pontas para o martelo de impulso modelo 8206 do fabricante Bruel \& Kjær: a) Força de excitação; b) espectro de frequências............................................. 97

Figura 2.71 - Ensaio dinâmico com saída fixa e excitação por impacto. .................................................. 98

Figura 2.72 - Ensaio dinâmico com entrada fixa e excitação por shaker ................................................... 100

Figura 2.73 - Suspensão da carroceria de um automóvel por cordas de Nylon........................................ 102

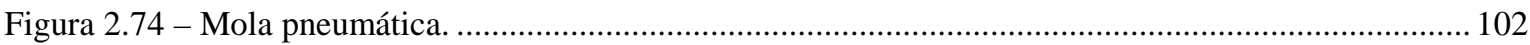

Figura 2.75 - Efeito do material de suspensão na FRF de um suporte de disco rígido............................... 102

Figura 2.76 - Exemplo de contribuição de diversos modos. .................................................................... 103

Figura 2.77 - Etapas envolvidas no processo de atualização de modelos................................................... 110

Figura 2.78 - Gráfico dos deslocamentos modais do modelo versus experimento..................................... 112

Figura 2.79 - Gráfico dos deslocamentos modais do modelo versus experimento................................... 115

Figura 3.1 - Coordenadas utilizadas no cálculo de $x$ '........................................................................ 121

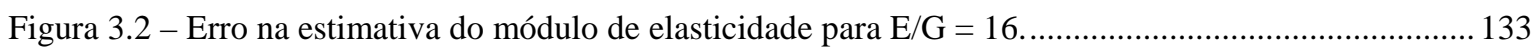

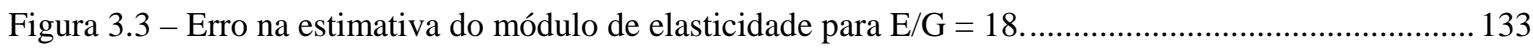

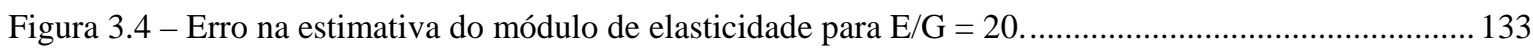

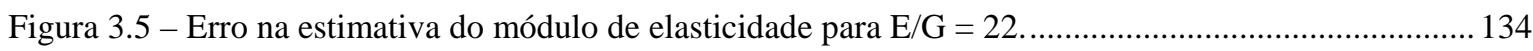

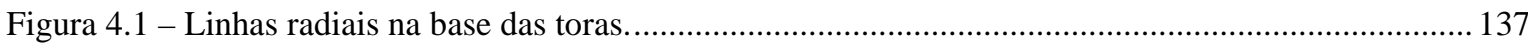

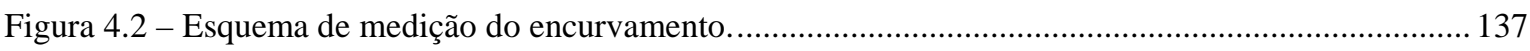

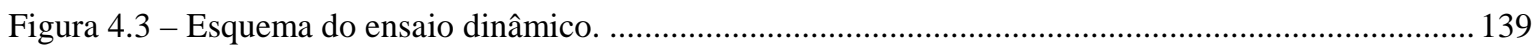

Figura 4.4 - Suspensão das toras com cordas de Nylon. .................................................................. 140

Figura 4.5 - Acelerômetro fixado em uma das toras. ......................................................................... 140

Figura 4.6 - Pino de impacto com a cabeça revestida de borracha........................................................ 141

Figura 4.7 - Equipamentos empregados no ensaio dinâmico com as toras. ............................................ 142

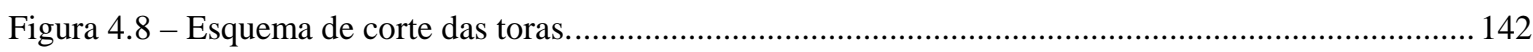

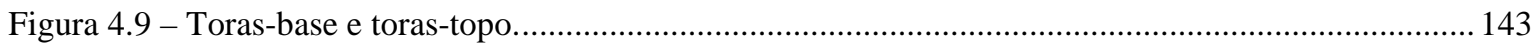

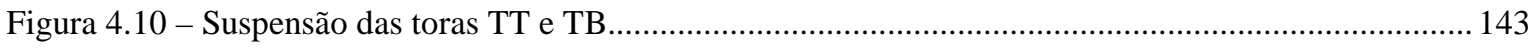

Figura 4.11 - Pino de impacto com cabeça de alumínio empregado nos ensaios com as toras mais curtas. . 144

Figura 4.12 - Identificação dos parâmetros modais com o programa Modal-Id....................................... 145

Figura 4.13 - Ensaio de flexão estática: a) esquema estático; b) visão geral do ensaio.............................. 146

Figura 4.14 - Esquema de extração de corpos-de-prova para determinação do teor de umidade.................. 149

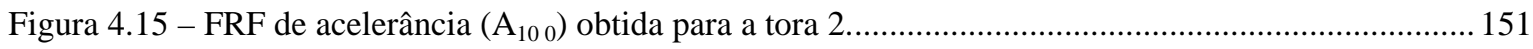

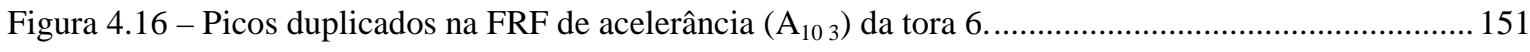

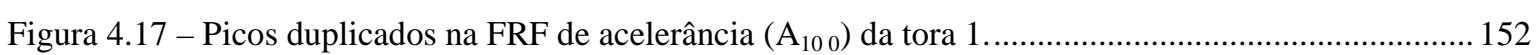




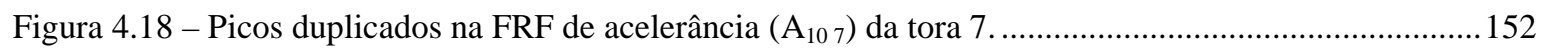

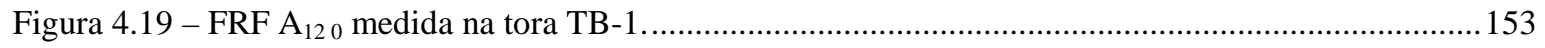

Figura 4.20 - Ajuste para a FRF A 100 medida na Tora 1 para o ensaio realizado no plano 5-1..................153

Figura 4.21 - Ajuste para a FRF $A_{10} 5$ medida na Tora 1 para o ensaio realizado no plano 2-6. .................154

Figura 4.22 - Exemplo de FRF com três picos de frequência (FRF $A_{10} 9$ plano 2-6 Tora 2)........................154

Figura 4.23 - Variação da geometria da base das toras integras: a) Tora $1\left(\Delta_{\text {circ }}=0,1 \%\right)$. b) tora $5\left(\Delta_{\text {circ }}\right.$

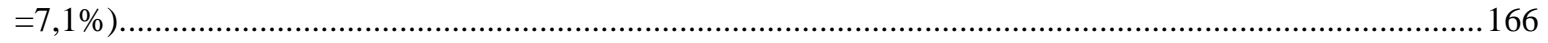

Figura 4.24 - Desalinhamento do acelerômetro na tora 6 devido à irregularidade na superfície..................168

Figura 4.25 - Correlação entre as FRF's $\mathrm{A}_{10} 9$ da tora 1 para os ensaios com excitação horizontal e vertical no

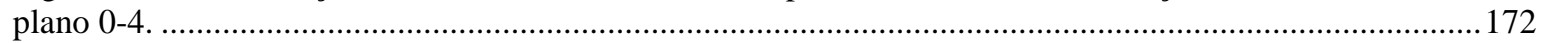

Figura 4.26 - Ensaio dinâmico: a) Tora 1; b) demais toras........................................................... 174

Figura 4.27 - Exemplo de atenuação da intensidade da acelerância no primeiro modo para o ensaio com

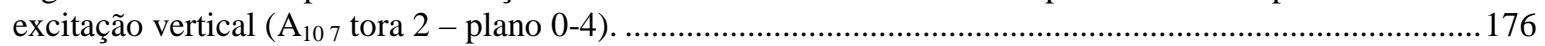

Figura 4.28 - Exemplo de ausência do modo de corpo rígido na FRF medida com excitação horizontal $\left(\mathrm{A}_{10} 5\right.$

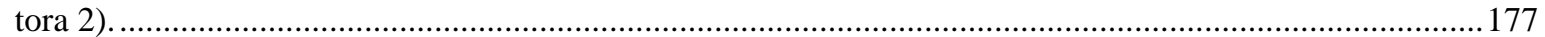

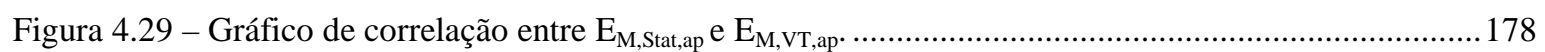

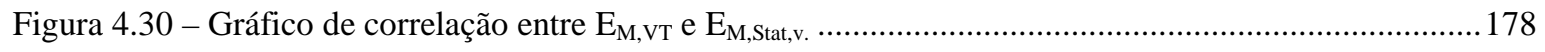

Figura 4.31 - Gráfico de dispersão entre $\mathrm{E}_{\mathrm{M}, \mathrm{VT}}$ e $\mathrm{E}_{\mathrm{M}, \mathrm{Stat}, \mathrm{v}^{*}}$ calculado pela Equação 4.6...............................179

Figura 4.32 - Gráfico de dispersão entre $\mathrm{E}_{\mathrm{M}, \mathrm{VT}} \mathrm{e} \mathrm{E}_{\mathrm{M}, \mathrm{Stat, \textrm {v }}}{ }^{*}$ para o primeiro pico de frequência.....................180

Figura 5.1 - Ensaio de vibração transversal nas vigas serradas de Pinus sp: a) vista geral do ensaio; b) acelerômetro fixado na extremidade da viga; c) mola empregada para suspensão.

Figura 5.2 - Esquema de extração de corpos-de-prova para determinação do teor de umidade das vigas de madeira serrada de Pinus sp. 186

Figura 5.3 - Associação do módulo de elasticidade estático com o teor de umidade.................................198

Figura 5.4 - Associação do módulo de elasticidade dinâmico com o teor de umidade. ...............................198

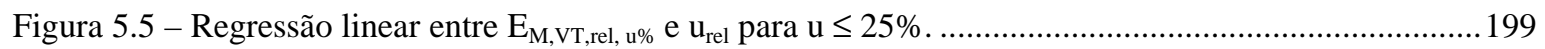

Figura 5.6 - Regressão linear entre $\mathrm{E}_{\mathrm{M}, \mathrm{VT}, \text { rel, } \mathrm{u} \%}$ e $\mathrm{u}_{\mathrm{rel}}$ para $\mathrm{u} \leq 25 \%$ sem os dados da viga 17....................199

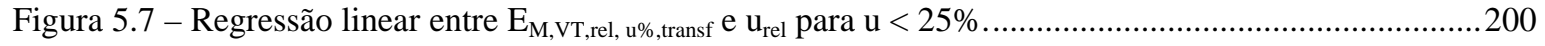

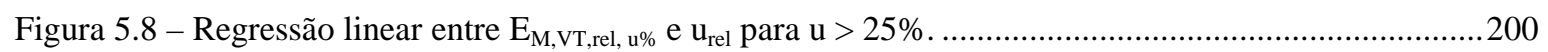

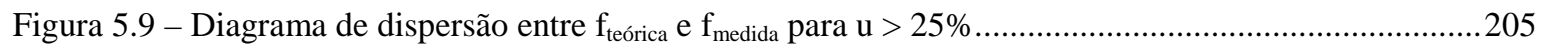

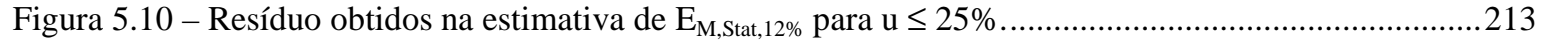

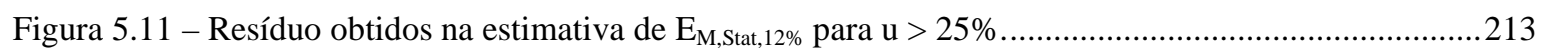

Figura 5.12 - Correlação entre $\mathrm{E}_{\mathrm{M}, \mathrm{Stat}} \mathrm{e} \mathrm{E}_{\mathrm{M}, \mathrm{VT}}$ no teor de umidade do ensaio.........................................214

Figura 5.13 - Correlação entre $\mathrm{E}_{\mathrm{M}, \mathrm{Stat}}$ e $\mathrm{E}_{\mathrm{M}, \mathrm{VT}} \mathrm{a} 12 \%$ de umidade......................................................215

Figura 5.14 - Correlação entre $\mathrm{E}_{\mathrm{M}, \mathrm{Stat}}$ e $\mathrm{E}_{\mathrm{M}, \mathrm{VT}}$ a $12 \%$ de umidade..........................................................215

Figura 6.1 - Esquema do ensaio de vibração transversal em toras de madeira........................................218

Figura 6.2 - Exemplo de Função de Resposta em Frequência com mais de um pico para o primeiro modo de

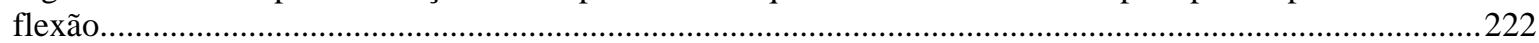

Figura 7.1 - Exemplo de características observadas na inspeção visual das toras....................................224

Figura 7.2 - Ensaio de vibração transversal na segunda amostra. ......................................................225

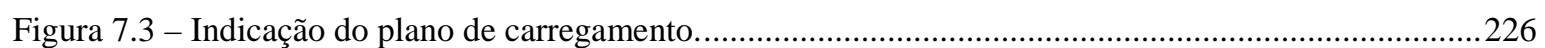

Figura 7.4 - FRF $A_{10} 0$ medida na tora 2 evidenciando 4 picos para o segundo modo..............................228 
Figura 7.5 - Gráfico de dispersão entre $\mathrm{E}_{\mathrm{M}, \mathrm{VT}}$ e $\mathrm{E}_{\mathrm{M}, \mathrm{Stat}, \mathrm{v}}{ }^{*}$.

Figura 7.6 - Gráfico de dispersão entre $\mathrm{E}_{\mathrm{M}, \mathrm{VT}, 12 \%}$ e $\mathrm{E}_{\mathrm{M}, \mathrm{Stat}, \mathrm{v}^{*}, 12 \%}$ após eliminação do outlier.

Figura 7.7 - Gráfico de dispersão entre $E_{M, V T}$ e $E_{M, S t a t, v}{ }^{*}$ para as toras com picos de frequência duplicados sendo $\mathrm{E}_{\mathrm{M}, \mathrm{VT}}$ calculado com a média aritmética das frequências.

Figura 7.8 - Gráfico de dispersão entre $\mathrm{E}_{\mathrm{M}, \mathrm{VT}}$ e $\mathrm{E}_{\mathrm{M}, \mathrm{Stat}, \mathrm{v}}{ }^{*}$ para as toras com picos de frequência duplicados sendo $\mathrm{E}_{\mathrm{M}, \mathrm{VT}}$ calculado com a frequência de maior pico de acelerância. 


\section{LISTA DE TABELAS}

Tabela 2.1 - Vantagens e desvantagens da AND em relação aos ensaios destrutivos convencionais. .............8

Tabela 2.2 - Comparação entre a $f_{\mathrm{M}}$ da madeira serrada e de toras de plantios jovens.

Tabela 2.3 - Limites no diâmetro dos nós e na inclinação das fibras e propriedades admissíveis para toras de Engelmann spruce com diâmetro de 228 mm segundo a norma TPI (1987). ...........................................10

Tabela 2.4 - Limitações no torcimento das fibras segundo a ANSI O5.1 (ANSI, 2002).............................11

Tabela 2.5 - Limite nas dimensões dos nós em postes segundo a ANSI O5.1 (ANSI, 2002). ......................12

Tabela 2.6 - Limitações dos defeitos nas toras de pequeno diâmetro segundo o projeto Round small-diameter timber for construction.

Tabela 2.7 - Coeficientes de correlação entre a densidade aparente verde e a resistência à perfuração com o Resistograph e com furadeira comum.

Tabela 2.8 - Alguns dos possíveis arranjos no ensaio de tomografia ultrassônica. ........................................25

Tabela 2.9 - Bandas de frequências do ultrassom para algumas aplicações. ..............................................28

Tabela 2.10 - Modelos de regressão estudados por Wang et al (2004). .........................................................34

Tabela 2.11 - Valores médios de E e G obtidos por Cho (2007) ..............................................................40

Tabela 2.12 - Resultados dos testes desenvolvidos por Chui et al (1999)..................................................44

Tabela 2.13 - Estudo de regressão linear entre as propriedades determinadas nos ensaios com toras de 229

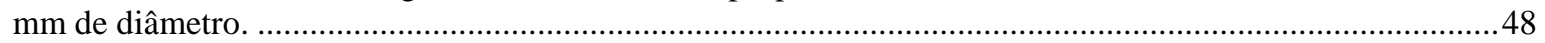

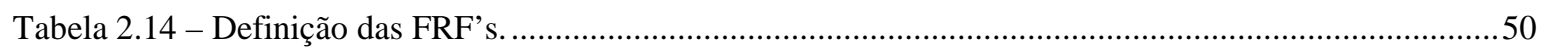

Tabela 2.15 - Frequências naturais e modos normais de algumas vigas prismáticas..................................60

Tabela 2.16 - Funções janelas mais comuns e suas características........................................................... 88

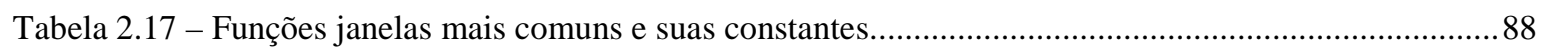

Tabela 2.18 - Localização do ruído em cada algoritmo para estimativa das FRF. .....................................92

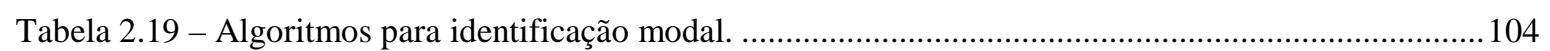

Tabela 3.1 - Determinação de $x^{\prime}{ }_{\text {ótimo }}$ para o ensaio de vibração transversal. ...............................................124

Tabela 3.2 - Determinação de $x^{\prime}$ ótimo para o ensaio de flexão estática na condição de contorno engastadolivre.

Tabela 3.3 - Determinação de $x^{\prime}{ }_{\text {ótimo }}$ para o ensaio de flexão estática na condição de contorno bi-apoiado. 126

Tabela 3.4 - Comparação entre os módulos de elasticidade calculados com $\mathrm{D}_{\mathrm{eq}}$ para $x^{\prime}{ }_{\text {ótimo }}=0,70$ e $\mathrm{D}_{\mathrm{eq}}$ adotado pelas normas NBR 6231 (ABNT, 1980) e ASTM D 1036 (ASTM, 2005) para o ensaio de flexão estática na condição de contorno engastada-livre.

Tabela 3.5 - Comparação entre os módulos de elasticidade calculados com $\mathrm{D}_{\text {eq }}$ para $x^{\prime}{ }_{\text {ótimo }}=0,47 \mathrm{e}$ o diâmetro medido na metade do comprimento das toras para o ensaio de flexão estática na condição de contorno bi-apoiada.

Tabela 3.6 - Cálculo do erro no módulo de elasticidade dinâmico para relações E/G iguais a 16 e $18 \ldots \ldots . . .131$

Tabela 3.7 - Cálculo do erro no módulo de elasticidade dinâmico para relações E/G iguais a 20 e $22 \ldots \ldots . . .132$

Tabela 3.8 - Limites de $\mathrm{L} / \mathrm{D}_{\text {meio }}$ para os quais o esforço cortante pode ser ignorado...................................134

Tabela 4.1 - Configurações do programa Impact nos ensaios dinâmicos com as toras. ...............................141

Tabela 4.2 - Configurações do programa Impact nos ensaios com as toras de menor comprimento. ........... 144

Tabela 4.3 - Características físicas das toras da amostra piloto............................................................... 149

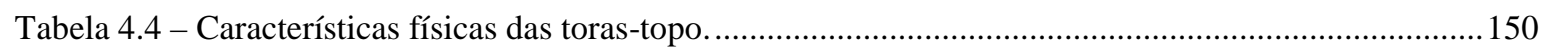

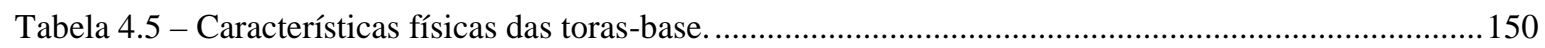


Tabela 4.6 - Frequências do $1^{\circ}$ modo de flexão das toras 1 e 2 para excitação nos planos horizontal e vertical. 155

Tabela 4.7 - Frequências do $1^{\circ}$ modo de flexão das toras 3 e 4 para excitação nos planos horizontal e vertical. 156

Tabela 4.8 - Frequências do $1^{\circ}$ modo de flexão das toras 5, 6 e 7 para excitação no plano horizontal. 157

Tabela 4.9 - Frequências do $1^{\circ}$ modo de flexão das toras 8, 9 e 10 para excitação no plano horizontal. 158

Tabela 4.10 - Frequências naturais das toras TB-1 a TB-5 obtidas com excitação no plano horizontal....... 159

Tabela 4.11 - Frequências naturais das toras TB-6 a TB-10 obtidas com excitação no plano horizontal. .... 159

Tabela 4.12 - Frequências naturais das toras TT-1 a TT-5 obtidas com excitação no plano horizontal........ 160

Tabela 4.13 - Frequências naturais das toras TT-6 a TT-10 obtidas com excitação no plano horizontal...... 160

Tabela 4.14 - Módulo de elasticidade dinâmico das toras da amostra piloto para excitação horizontal. ...... 161

Tabela 4.15 - Módulo de elasticidade dinâmico das toras da amostra piloto para excitação vertical. .......... 162

Tabela 4.16 - Módulo de elasticidade aparente das toras da amostra piloto. ......................................... 162

Tabela 4.17 - Módulo de elasticidade verdadeiro das toras da amostra piloto......................................... 162

Tabela 4.18 - Módulo de elasticidade das toras da amostra piloto levando em conta o efeito do esforço cortante. 163

Tabela 4.19 - Módulo de elasticidade aparente das toras-base........................................................... 163

Tabela 4.20 - Módulo de elasticidade aparente das toras-topo.................................................................... 163

Tabela 4.21 - Módulo de elasticidade verdadeiro das toras-base. .............................................................. 164

Tabela 4.22 - Módulo de elasticidade verdadeiro das toras-topo. ........................................................... 164

Tabela 4.23 - Módulo de elasticidade das toras-base levando em conta o efeito do esforço cortante........... 164

Tabela 4.24 - Módulo de elasticidade das toras-topo levando em conta o efeito do esforço cortante........... 165

Tabela 4.25 - Teor de umidade obtido com o medidor elétrico.......................................................... 165

Tabela 4.26 - Teor de umidade obtido pelo ensaio da norma NBR 7190 (ABNT, 1997)............................ 166

Tabela 4.27 - Comparação entre os resultados obtidos com o ensaio da norma NBR 7190 (ABNT, 1997) e

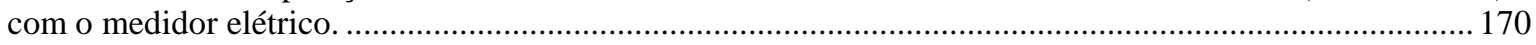

Tabela 4.28 - Diferença entre as frequências medidas nos ensaios vertical e horizontal. ...........................1 171

Tabela 4.29 - Parâmetros FRAC e GSF obtidos nos picos de frequência do primeiro modo de flexão na correlação entre os ensaios com excitação vertical e horizontal.....

Tabela 4.30 - Parâmetros FDAC e FRSF obtidos nos picos de frequência do primeiro modo de flexão na correlação entre os ensaios com excitação vertical e horizontal............................................................... 175

Tabela 4.31 - Coeficientes de correlação de Pearson entre as propriedades da toras da amostra piloto. ...... 180

Tabela 5.1 - Configurações do programa Impact no ensaio com vigas serradas de Pinus sp. ...................... 186

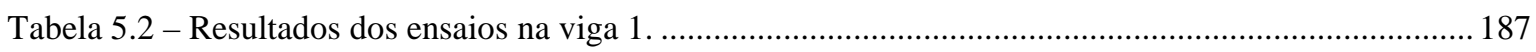

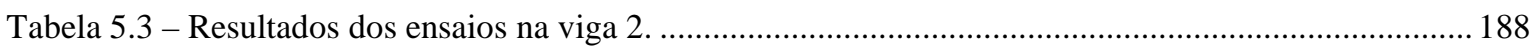

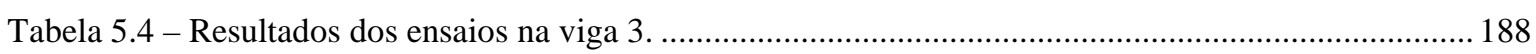

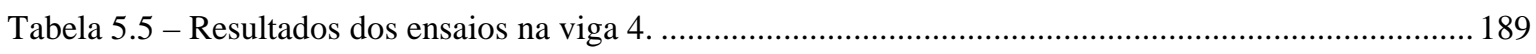

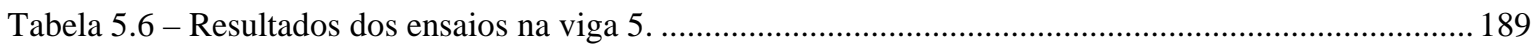

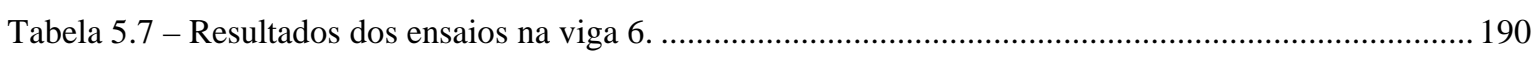

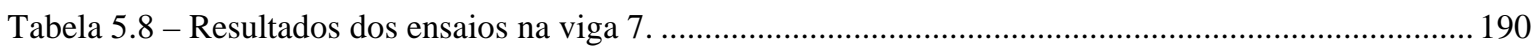

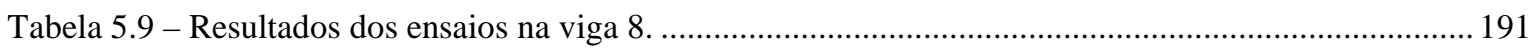

Tabela 5.10 - Resultados dos ensaios na viga 9. ............................................................................. 191 
Tabela 5.11 - Resultados dos ensaios na viga 10

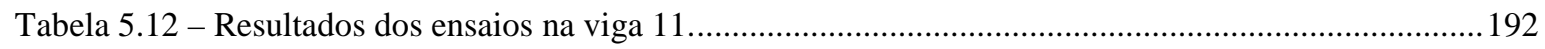

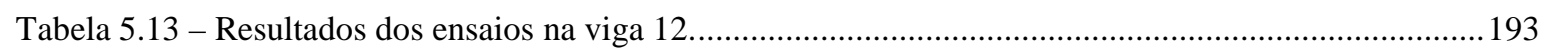

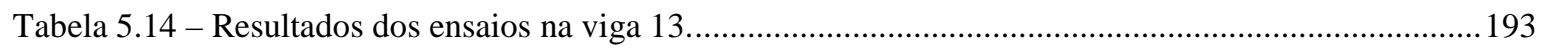

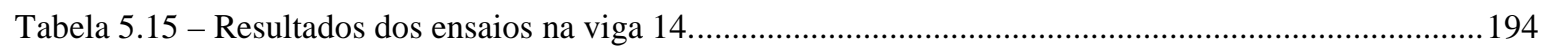

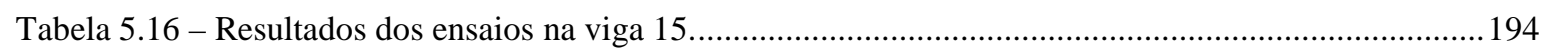

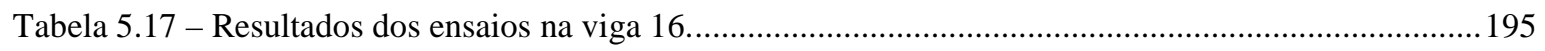

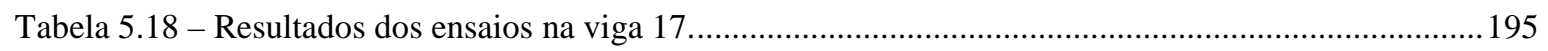

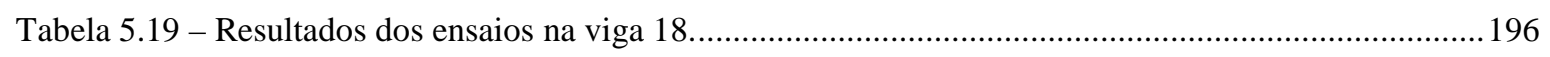

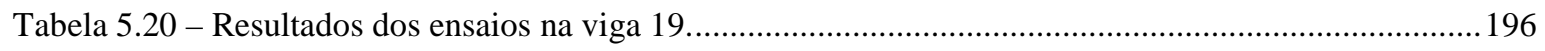

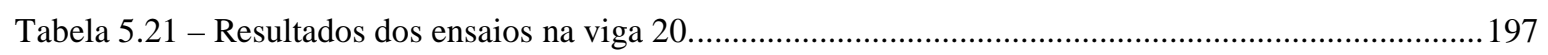

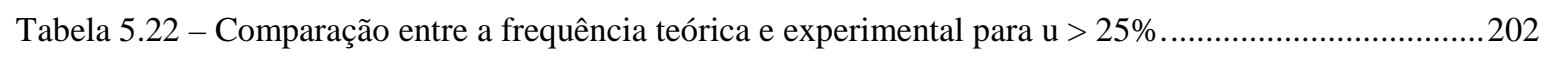

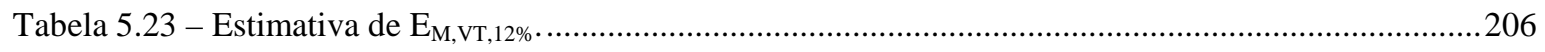

Tabela 7.1 - Configurações do programa Impact nos ensaios com as toras da amostra de validação ...........225

Tabela 7.2 - Resultado da inspeção visual das toras............................................................................222

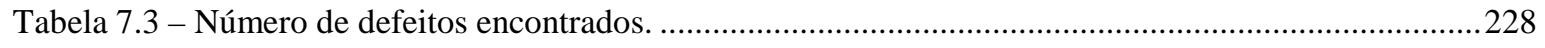

Tabela 7.4 - Frequências do primeiro modo de flexão. ............................................................................2229

Tabela 7.5 - Cálculo do módulo de elasticidade dinâmico das toras. ....................................................2230

Tabela 7.6 - Resultados do ensaio de flexão estática......................................................................231

Tabela 7.7 - Resultados dos ensaios para determinação do teor de umidade. ............................................2232

Tabela 7.8 - Resultados dos ensaios para determinação da densidade aparente.....................................2233

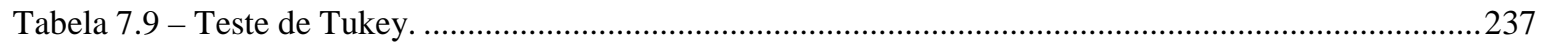

Tabela 7.10 - Classes definidas para as toras de Eucalyptus citriodora ..................................................2237

Tabela 7.11 - Classificação das toras em função do módulo de elasticidade na flexão...............................239

Tabela 7.12 - Matriz de confusão para a classificação das toras pelo ensaio de vibração transversal...........239

Tabela 7.13 - Coeficiente de determinação $\left(\mathrm{R}^{2}\right)$ entre as propriedades físicas e mecânicas.........................240 


\section{LISTA DE ABREVIATURAS E SIGLAS}

$\begin{array}{ll}\text { ABRAF } & \text { Associação Brasileira dos Produtores de Florestas Plantadas } \\ \text { AND } & \text { Avaliação Não-Destrutiva } \\ \text { ANSI } & \text { American National Standards Institute } \\ \text { ASA } & \text { American Standard Association } \\ \text { ASTM } & \text { American Society of Testing and Material } \\ \text { Coef. Var. } & \text { Coeficiente de variação } \\ \text { Desv. Pad } & \text { Desvio padrão } \\ \text { DFT } & \text { Discrete Fourier Transform } \\ \text { EESC } & \text { Escola de Engenharia da São Carlos } \\ \text { EL } & \text { apoio elástico } \\ \text { END } & \text { Ensaio Não-Destrutivo } \\ \text { Estim } & \text { estimado } \\ \text { FE } & \text { fundo de escala } \\ \text { FFT } & \text { Fast Fourier Transform } \\ \text { FRF } & \text { Função de Resposta em Frequência } \\ \text { FRI } & \text { Função de Resposta a Impulso } \\ \text { GL } & \text { grau de liberdade } \\ \text { IND } & \text { Inspeção Não-Destrutiva } \\ \text { LaMEM } & \text { Laboratório de Madeiras e Estruturas de Madeira } \\ \text { LSCE } & \text { Least Squares Complex Exponential } \\ \text { LL } & \text { suspensão livre-livre } \\ \text { MIMO } & \text { Multiple Input Multiple Output } \\ \text { MISO } & \text { Multiple Input Single Output } \\ \text { QM } & \text { quadrado médio } \\ \text { RMSE } & \text { Erro quadrado médio } \\ \text { SIMO } & \text { Single Input Multiple Output } \\ \text { SISO } & \text { Single Input Single Output } \\ \text { SQ } & \text { soma dos quadrados } \\ \text { SW } & \text { stress wave } \\ \text { TC } & \text { Tomografia Computadorizada } \\ \text { TPI } & \text { Timber Products Inspection } \\ \text { US } & \text { ultrassom } \\ \text { USP } & \text { Universidade de São Paulo } \\ \text { UTFPR } & \quad \text { Universidade Tecnológica Federal do Paraná } \\ \text { VT } & \end{array}$




\section{LISTA DE SIMBOLOS}

\section{Letras romanas maiúsculas}

A

$\mathrm{A} / \mathrm{D}$

$\mathrm{A}(\omega)$

$\mathrm{C}$

$\mathrm{C}_{\mathrm{m}}$

$\mathrm{D}$

E

$\mathrm{E}_{\text {din }}$

$\mathrm{E}_{\text {Stat }}$

$\mathrm{E}_{\mathrm{M}}$

$\mathrm{E}_{\mathrm{M}, \text { Stat }}$

$\mathrm{E}_{\mathrm{M}, \text { Stat,ap }}$

$\mathrm{E}_{\mathrm{M}, \mathrm{Stat}, \mathrm{V}}$

$\mathrm{E}_{\mathrm{M}, \mathrm{SW}}$

$\mathrm{E}_{\mathrm{M}, \mathrm{VL}}$

$\mathrm{E}_{\mathrm{M}, \mathrm{VT}}$

$\mathrm{E}_{\mathrm{M}, \mathrm{US}}$

$\mathrm{F}$

$\mathrm{F}_{\text {Ult }}$

G

$\mathrm{H}_{0}$

$\mathrm{H}_{1}$

$\mathrm{Hz}$

$\mathrm{H}(\omega)$

I

K

$\overline{\mathrm{K}}$

$\mathrm{K}_{\mathrm{m}}$

$\mathrm{L}$

$\mathrm{L}_{\text {apoio }}$

$\mathrm{M}$

$\mathrm{M}_{\mathrm{m}}$

$\mathrm{MHz}$

MOE

MOR

$\mathrm{MPa}$ vetor/matriz dos modos normais; área da seção transversal

analógico/digital

acelerância

velocidade de propagação da onda ultrassônica; matriz de amortecimento; capacitor

matriz de amortecimento modal

diâmetro

módulo de elasticidade

módulo de elasticidade dinâmico

módulo de elasticidade estático

módulo de elasticidade na flexão

módulo de elasticidade na flexão estática

módulo de elasticidade aparente na flexão estática

módulo de elasticidade verdadeiro flexão estática

módulo de elasticidade na flexão obtido por stress-wave

módulo de elasticidade na flexão obtido por vibração longitudinal

módulo de elasticidade na flexão obtido por vibração transversal

módulo de elasticidade na flexão obtido por ultrassom

força; coeficiente do teste $\mathrm{F}$

força última

módulo de elasticidade transversal

hipótese nula

hipótese alternativa

Hertz

receptância

momento de inércia da seção transversal

matriz de rigidez

rigidez por unidade de comprimento

matriz de rigidez modal

comprimento

distância entre apoios

matriz de massa

matriz de massa modal

megahertz

módulo de elasticidade na flexão

módulo de ruptura na flexão

megapascal 


$\begin{array}{ll}\mathrm{N} & \text { Newton } \\ \mathrm{P} & \text { peso } \\ \mathrm{Pa} & \text { Pascal } \\ \mathrm{R} & \text { receptor; resistência elétrica } \\ \mathrm{R}^{2} & \text { coeficiente de determinação } \\ \mathrm{T} & \text { transmissor } \\ \mathrm{U} & \text { teor de umidade } \\ \mathrm{V} & \text { volt } \\ \mathrm{X} & \text { deslocamento; variável independente } \\ \mathrm{Y}(\omega) & \text { mobilidade; variável dependente }\end{array}$

\section{Letras romanas minúsculas}

$\begin{array}{ll}\mathrm{a}_{0} & \text { constante de proporcionalidade } \\ \mathrm{a}_{1} & \text { constante de proporcionalidade } \\ \mathrm{c} & \text { coeficiente de amortecimento viscoso } \\ \mathrm{cm} & \text { centímetro } \\ \mathrm{dB} & \text { decibel } \\ \mathrm{dx} & \text { comprimento infinitesimal } \\ \mathrm{e} & \text { tensão } \\ \mathrm{eq} & \text { equivalente } \\ \mathrm{exp} & \text { experimental } \\ \mathrm{f} & \text { frequência } \\ \mathrm{f}_{1} & \text { frequência natural do primeiro modo } \\ f_{\mathrm{M}} & \text { módulo de ruptura na flexão } \\ f_{\mathrm{t}, 0} & \text { resistência à tração paralela às fibras da madeira } \\ f_{\mathrm{c}, 0} & \text { resistência à compressão paralela às fibras da madeira } \\ \mathrm{g} & \text { grama; aceleração da gravidade (g=9,80665 m/s }{ }^{2} \text { ) } \\ \mathrm{h} & \text { altura da seção transversal } \\ \mathrm{ha} & \text { Hectare } \\ \mathrm{i} & \text { unidade imaginária; raio de giração } \\ \mathrm{k} & \text { rigidez } \\ \mathrm{kg} & \text { quilograma } \\ \mathrm{kPa} & \text { quilopascal } \\ \mathrm{kHz} & \text { quilohertz } \\ \mathrm{kN} & \text { quilonewton } \\ \mathrm{m} & \text { metro; massa } \\ \mathrm{m}(\mathrm{x}) & \text { massa por unidade de comprimento } \\ \mathrm{mm} & \text { milímetro } \\ \mathrm{mod} & \text { modelo } \\ \mathrm{psi} & \text { libra-força/polegadas quadradas (unidade de tensão) } \\ & \end{array}$


q vetor de carregamento modal; intervalo de quantização

r coeficiente de regressão

s segundo

$\mathrm{t}$ tempo

$\mathrm{u}$ deslocamento na direção do eixo $\mathrm{x}$

v velocidade; deslocamento na direção do eixo y; verde

\section{Letras gregas minúsculas}

$\alpha$

$\beta$

$\varepsilon$

$\gamma$

$\eta$

$\lambda$

$\rho$

$\theta$

$\omega$

$\sigma^{2}$

$\xi$ relação entre frequência do carregamento pela frequência natural; ordenada à origem

coeficiente angular de uma reta

resíduo

coerência

fator de forma da seção transversal

constante de separação

densidade aparente

ângulo de fase

frequência angular

variância

amortecimento adimensional

\section{Letras gregas maiúsculas}

$\Delta$

variação; incremento

$\Psi$

relação entre as rigidezes dos apoios de uma viga 


\section{SUMÁRIO}

1. INTRODUÇÃO

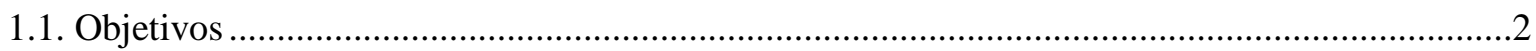

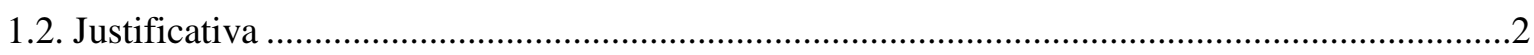

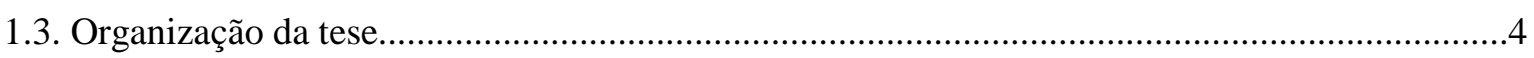

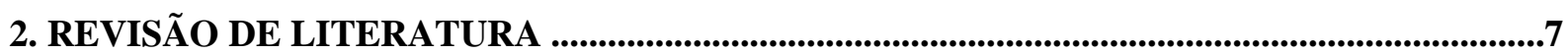

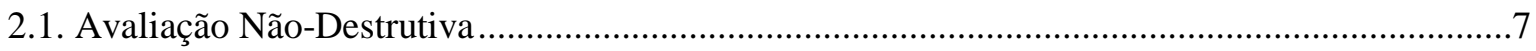

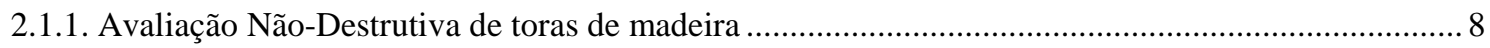

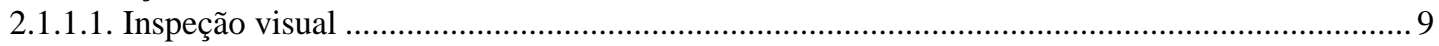

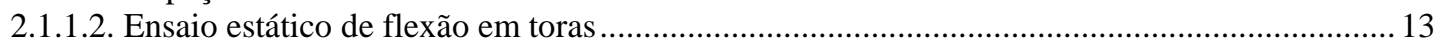

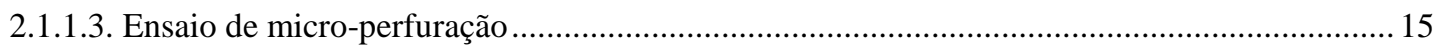

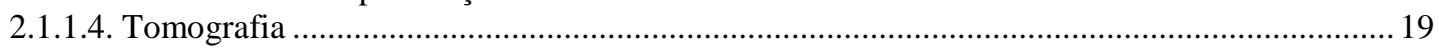

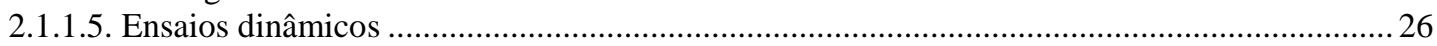

2.2. Fundamentos da Avaliação Não-Destrutiva por Vibração Transversal .....................................49

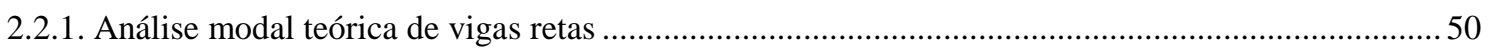

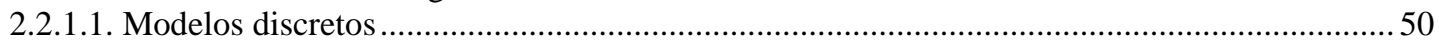

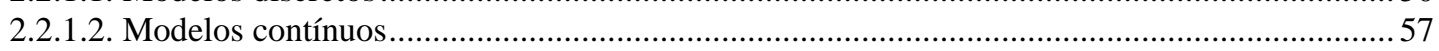

2.2.2. Fatores que afetam o ensaio de vibração transversal ........................................................................ 65

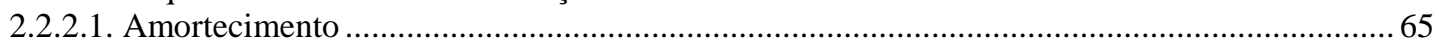

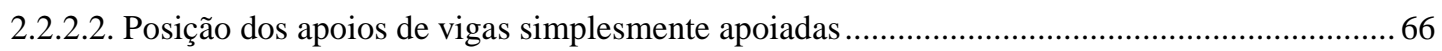

2.2.2.3. Influência da inércia a rotação e do esforço cortante .................................................................67 67

2.2.2.4. Influência da rigidez do sistema de suspensão .................................................................... 70

2.2.3. Outros aspectos que influenciam o ensaio de vibração transversal em toras ..................................... 75

2.2.3.1. Variações das propriedades geométricas da seção transversal .............................................. 75

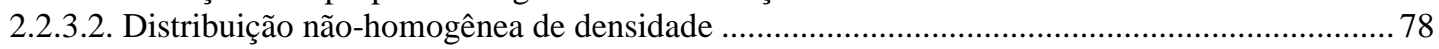

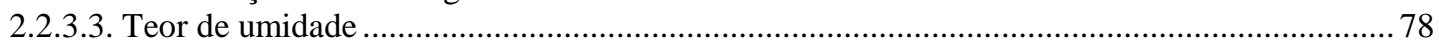

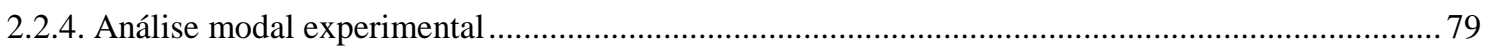

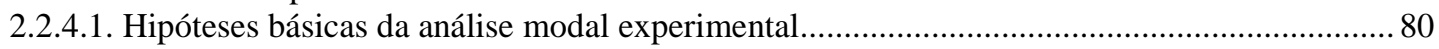

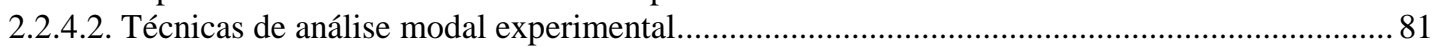

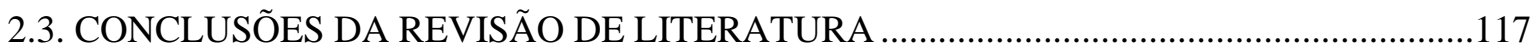

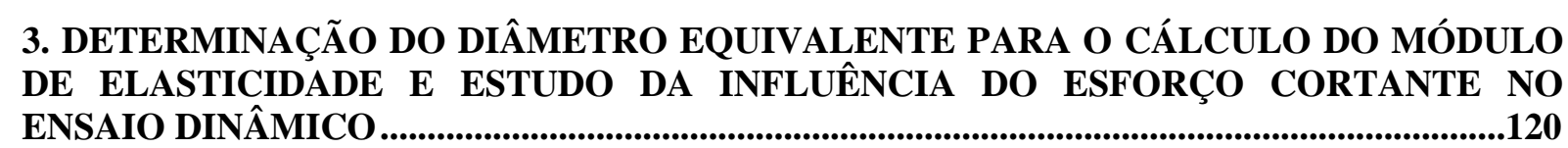

3.1. Determinação de um diâmetro equivalente para o cálculo do módulo de elasticidade nos

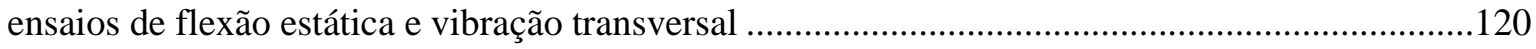

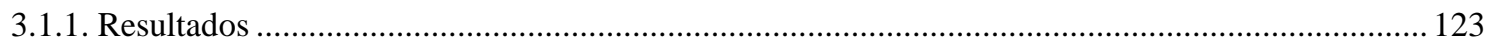

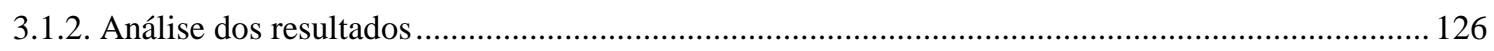

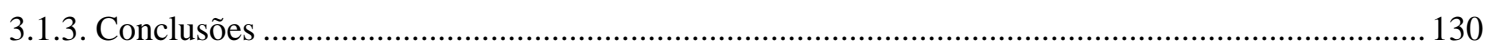

3.2. Estudo da influência do esforço cortante no módulo de elasticidade dinâmico........................130

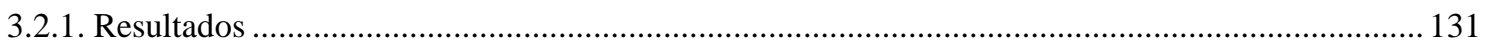

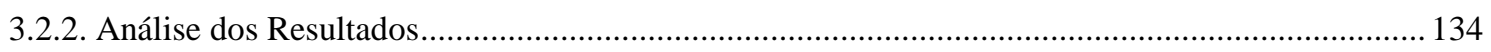

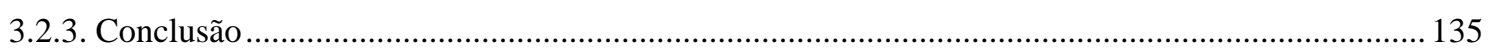

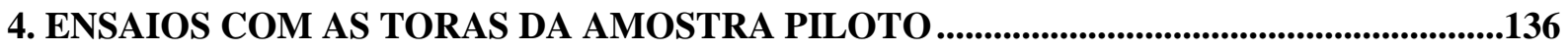

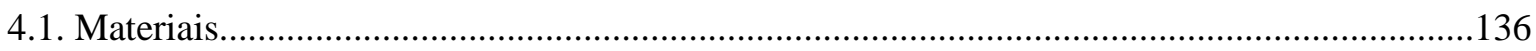

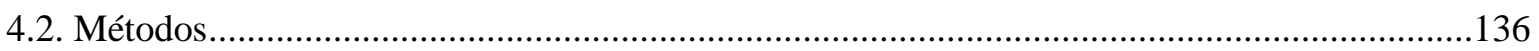

4.2.1. Propriedades dimensionais e de densidade aparente ............................................................... 136

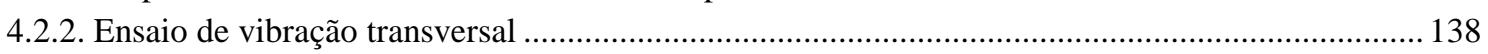

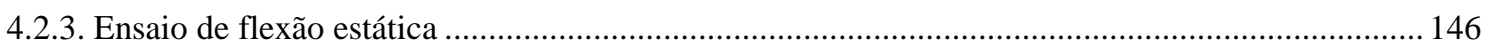

4.2.4. Determinação do teor de umidade das toras ........................................................................ 148 
4.3. Resultados ...................................................................................................... 149

4.3.1. Propriedades dimensionais e densidade aparente das toras ...................................................... 149

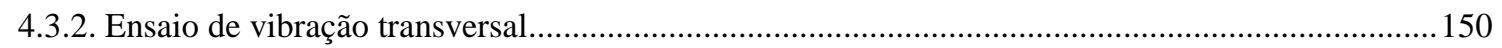

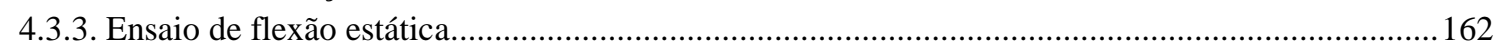

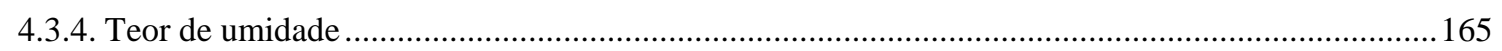

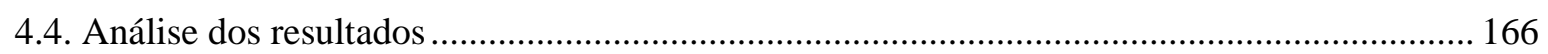

4.4.1. Propriedades dimensionais e densidade aparente das toras ..................................................... 166

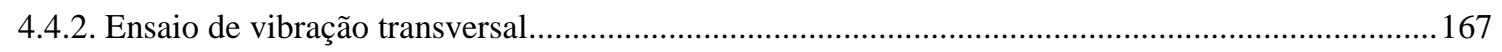

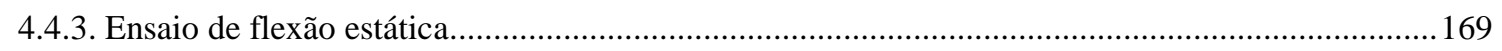

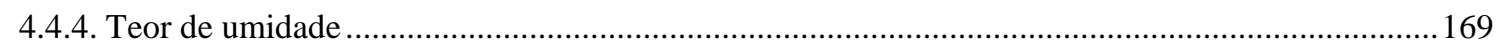

4.4.5. Avaliação da influência da direção do impacto em relação ao sistema de suspensão ....................170

4.4.6. Comparação entre os módulos de elasticidade estático e dinâmico...............................................177

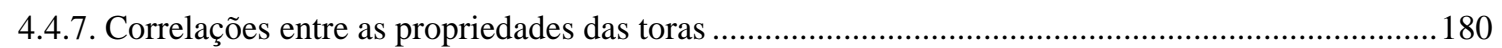

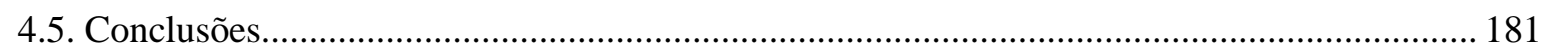

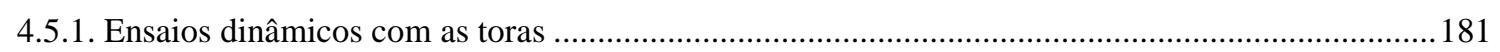

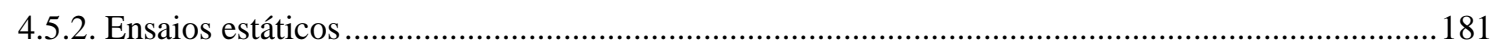

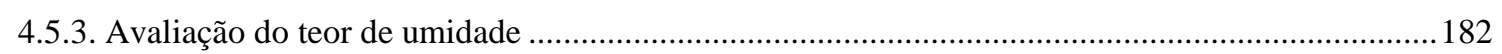

4.5.4. Avaliação da influência da direção do impacto em relação ao sistema de suspensão ....................182

4.5.5. Comparação entre os módulos de elasticidade estático e dinâmico...............................................182

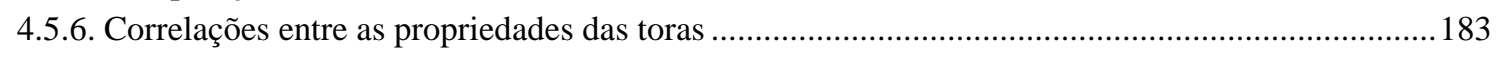

5. ESTUDO DA INFLUENCIA DO TEOR DE UMIDADE ..................................................... 184

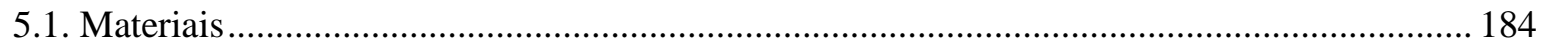

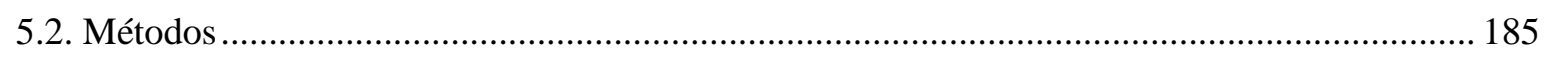

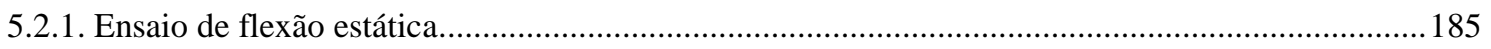

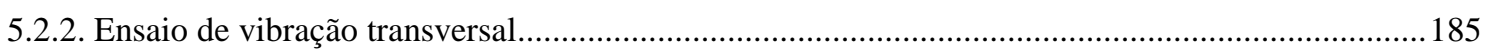

5.2.3. Determinação do teor de umidade final e correção das umidades dos ensaios..............................186

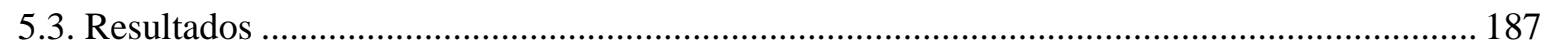

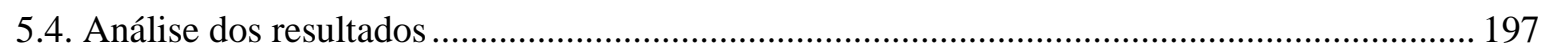

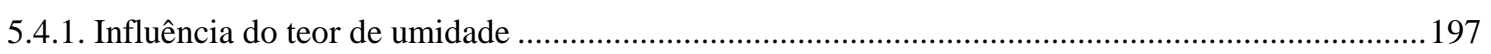

5.4.2. Determinação do módulo de elasticidade dinâmico a 12\% de umidade .......................................206

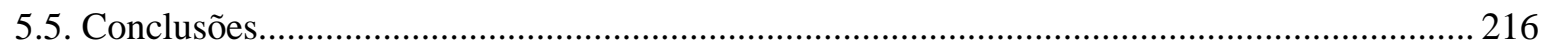

6. PROPOSTA DE UM MÉTODO DE ENSAIO PARA AVALIAR A RIGIDEZ À FLEXÃO DE TORAS DE MADEIRA POR MEIO DE VIBRAÇÃO TRANSVERSAL LIVRE ....................... 217

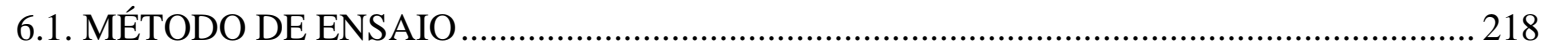

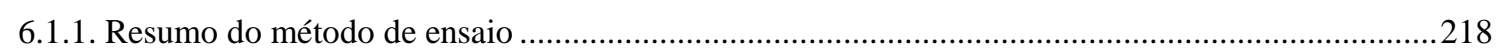

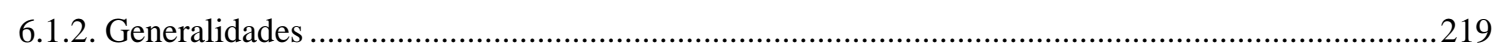

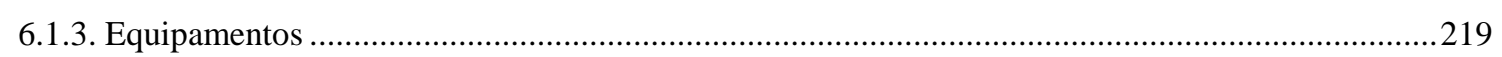

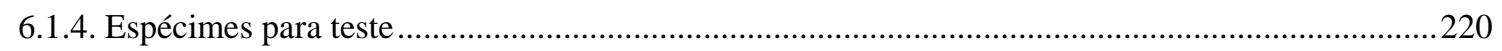

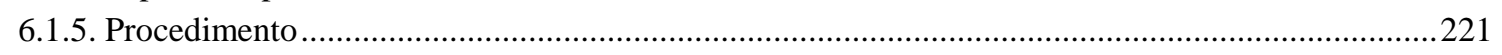

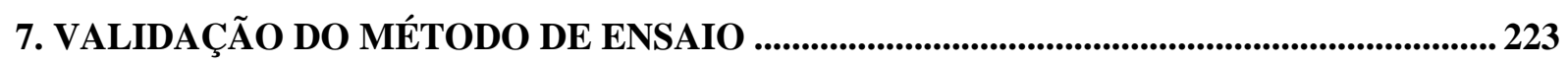

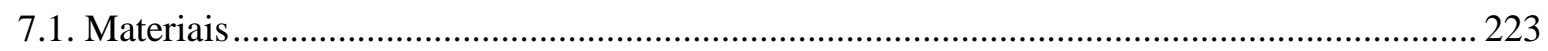

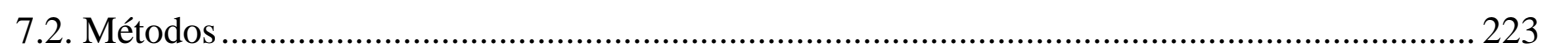

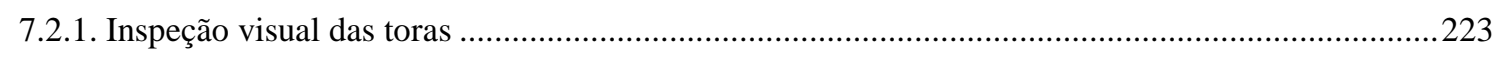

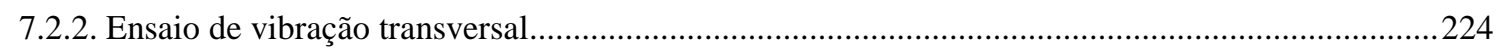

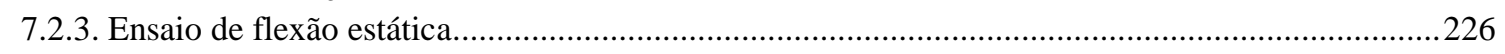

7.2.4. Determinação do teor de umidade e da densidade aparente ........................................................226

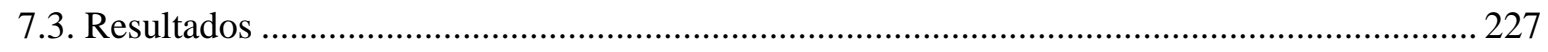

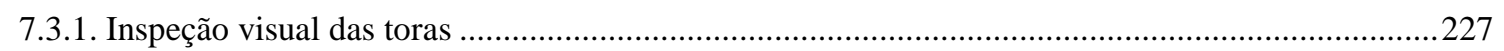




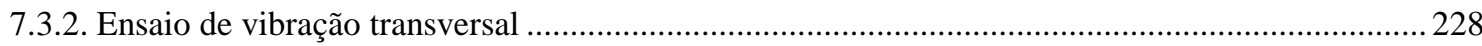

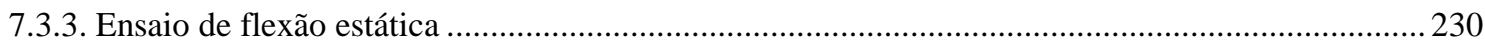

7.3.4. Determinação do teor de umidade e densidade aparente...........................................................232

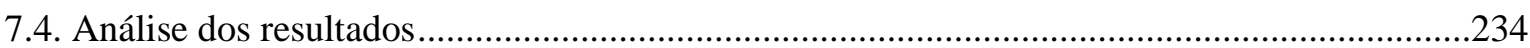

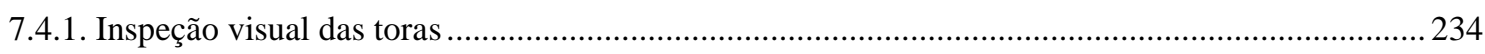

7.4.2. Correlação entre os módulos de elasticidade estático e dinâmico .................................................2234

7.4.3. Determinação do teor de umidade e densidade aparente ............................................................. 237

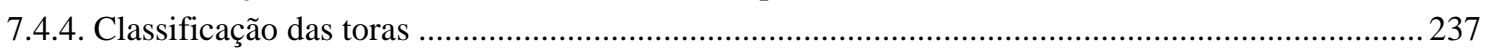

7.4.5. Correlação entre as propriedades físicas e mecânicas ...............................................................240

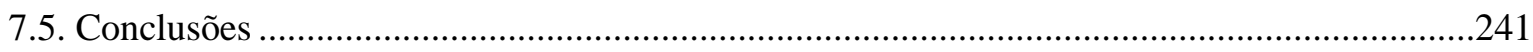

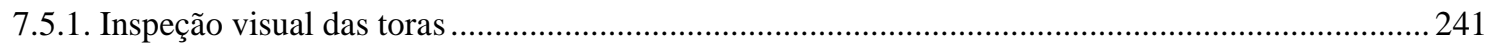

7.5.2. Correlação entre os módulos de elasticidade estático e dinâmico ................................................2241

7.5.3. Determinação do teor de umidade e densidade aparente ..............................................................2241

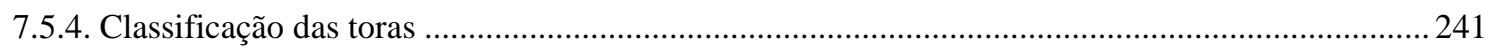

7.5.5. Correlação entre as propriedades físicas e mecânicas ................................................................2242

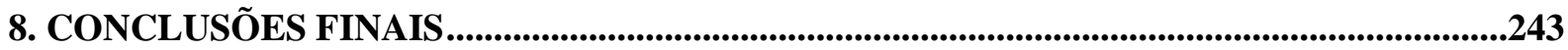

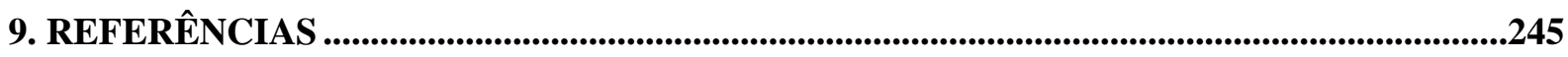

APÊNDICE A - DESENVOLVIMENTO E CALIBRAÇÃo DO SISTEMA DE ANÁLISE MODAL EXPERIMENTAL UTILIZADO NOS ENSAIOS COM AS TORAS ...........................257

APÊNDICE B - DADOS DAS TORAS DA AMOSTRA PILOTO ...............................................271

APÊNDICE C - IMPLEMENTAÇÃO DE UM PROGRAMA DE COMPUTADOR PARA IDENTIFICAÇÃO DE PARÂMETROS MODAIS PELO MÉTODO DA RAZÃO DE

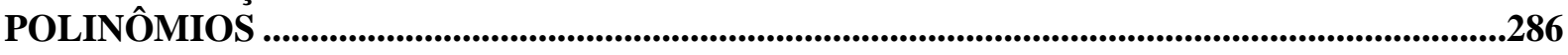

APÊNDICE D - TESTES ESTATÍSTICOS E VERIFICAÇÃO DA VALIDADE DOS MODELOS DE REGRESSÃO LINEAR APRESENTADOS NA TESE .....................................292

APÊNDICE E - RESULTADOS DA IDENTIFICAÇÃO DOS PARÂMETROS MODAIS DAS

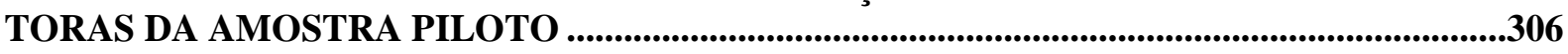

APÊNDICE F - DADOS DAS TORAS DA AMOSTRA DE VALIDAÇÃO................................341

ANEXO A - CRITÉRIOS DA NORMA ANSI O5.1 (2002) PARA INSPEÇÃO VISUAL DE

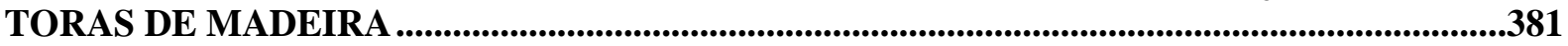





\section{INTRODUÇÃO}

No Brasil, as florestas plantadas representam cerca de $87 \%$ da produção nacional de madeira em toras. O gênero mais cultivado no país é o Eucalyptus $s p$ cujo preço competitivo aliado às boas propriedades mecânicas de certas espécies têm contribuindo para sua utilização em substituição às madeiras de lei. A madeira em tora foi um dos primeiros elementos estruturais usados pelo homem sendo atualmente ainda muito empregada em função de algumas vantagens em relação à madeira serrada como maior resistência mecânica, menor variabilidade de suas propriedades e menor preço.

Além de possuir menor custo as toras de madeira exibem outras vantagens, como continuidade das fibras longitudinais e confinamento dos nós, que lhe propiciam maior resistência e menor variabilidade nas propriedades mecânicas, em relação à madeira serrada. Para aplicações estruturais, com a finalidade de um melhor aproveitamento das toras, é interessante avaliar as suas propriedades mecânicas, tanto por inspeção visual quanto por meio de ensaio mecânico.

Nas técnicas de Avaliação Não-Destrutiva (AND) para a madeira, a qualidade visual e o módulo de elasticidade na flexão são propriedades usualmente empregadas para estimar a resistência mecânica sem a necessidade de romper o material.

A qualidade é determinada visualmente em função do diâmetro dos nós, inclinação das fibras, proporção de madeira de inverno, encurvamento e fendas, entre outras características. A mensuração e a análise dessas características constituem a técnica de classificação visual.

O módulo de elasticidade na flexão pode ser avaliado diretamente por meio de ensaio estático, ou estimado de forma indireta, por exemplo, a partir da velocidade de propagação de uma onda ultrassônica (ultrassom), ou da velocidade de propagação de uma onda de choque (ondas de tensão), ou, ainda, pela frequência fundamental de vibração transversal do elemento (vibração transversal). 
Entre esses métodos, a técnica de vibração transversal tem demonstrado melhor exatidão na estimativa da rigidez à flexão de peças estruturais de madeira serrada. Por outro lado, em uma investigação anterior conduzida pelo autor, foram encontradas dificuldades na avaliação do módulo de elasticidade de toras jovens de Eucalyptus sp empregando essa técnica. Nessa pesquisa foi usado o mesmo equipamento e a mesma metodologia empregada com sucesso na AND de peças de madeira serrada. Porém, não foi possível estabelecer correlação significativa entre o módulo de elasticidade estático e o módulo de elasticidade dinâmico.

\subsection{Objetivos}

O Objetivo geral deste trabalho foi propor e validar um método de ensaio para estimar o módulo de elasticidade à flexão de toras de madeira por meio de vibração transversal;

Os objetivos específicos deste trabalho foram:

- Definir um método de ensaio para avaliar o módulo de elasticidade à flexão de toras com base na Revisão de Literatura e em ensaios de vibração transversal em uma amostra piloto;

- Avaliar a influência da direção da excitação e da posição da tora na obtenção das frequências naturais;

- Determinar um diâmetro equivalente para o cálculo do módulo de elasticidade dinâmico;

- Avaliar os efeitos da umidade, conicidade, da forma da seção transversal e do encurvamento das toras na estimativa do módulo de elasticidade dinâmico $\left(\mathrm{E}_{\mathrm{M}, \mathrm{VT}}\right)$;

- Verificar a correlação entre o módulo de elasticidade obtido no ensaio de flexão estática ( $\left.\mathrm{E}_{\mathrm{M}, \mathrm{Stat}}\right)$ e estimado com o método de vibração transversal proposto $\left(\mathrm{E}_{\mathrm{M}, \mathrm{VT}}\right)$.

\subsection{Justificativa}

O Brasil produziu, em 2010, cerca de 116 milhões de $\mathrm{m}^{3}$ de madeira em tora, sendo $89 \%$ proveniente de cultivo, e o restante (11\%) coletado em vegetação nativa (IBGE, 2011).

De acordo com dados da Associação Brasileira dos Produtores de Florestas Plantadas (ABRAF, 2011), as florestas plantadas ocupam no Brasil uma área de cerca de 6,5 milhões de 
ha, dos quais o Pinus sp e o Eucalyptus sp ocupam respectivamente 1,8 e 4,7 milhões de ha, destacando-se como as espécies de reflorestamento mais plantadas no País.

As principais espécies atualmente cultivadas no Brasil são, o Eucalyptus grandis, Eucalyptus citriodora, Eucalyptus camaldulensis, Eucalyptus saligna, Eucalyptus urophylla.

O Eucalyptus sp é cultivado em três ciclos cujo período de corte varia em função da utilização da madeira. As indústrias de celulose e papel, as siderúrgicas e as indústrias de chapas de fibra utilizam o ciclo entre 5 e 7 anos, enquanto as indústrias de madeira serrada adotam três ciclos com períodos variando entre 12 e 20 anos.

No primeiro corte, dependendo das condições do solo e do clima, as toras chegam a alcançar diâmetros entre 7 a $20 \mathrm{~cm}$, sendo denominadas de toras provenientes de plantios jovens.

Essas toras, além do uso tradicional, podem ser utilizadas na construção civil com função estrutural.

A grande disponibilidade da madeira de Eucalyptus sp e o elevado custo das madeiras de espécies nativas fazem do Eucalyptus $s p$ um potencial candidato para o fornecimento de madeira na construção civil.

Para a utilização estrutural das toras de madeira é necessário avaliar suas propriedades mecânicas e agrupar as peças de mesmas características em classes, de modo a reduzir a variabilidade das propriedades mecânicas. Com essa prática, é possível utilizar as peças de melhor qualidade nas posições de maior solicitação da estrutura e as de qualidade inferior nas de baixa solicitação. Dessa maneira, a classificação contribui não só para o aumento na segurança das estruturas, como também para a racionalização do uso da madeira.

Todavia, a classificação visual das toras de madeira é deficiente pois, como os nós e outros defeitos internos são pouco visíveis, torna-se difícil a rápida avaliação da qualidade da tora apenas por inspeção visual. Por outro lado, o sucesso na avaliação da rigidez à flexão por meio de ensaio estático como recomenda a norma NBR 6231 (1980) "Postes de madeira resistência à flexão", depende da condição ideal de engaste que, na prática, é difícil de ser alcançada.

Outras técnicas capazes de gerar imagens internas das toras, como a tomografia, tornam-se inviáveis no Brasil devido ao elevado custo dos equipamentos. 
Por esses motivos, em muitos casos, as toras de madeira são utilizadas como elementos estruturais sem uma avaliação precisa de sua qualidade.

O ensaio de vibração transversal tem fornecido boas estimativas do módulo de elasticidade de elementos estruturais de madeira serrada. Acredita-se que essa técnica também possa ser útil na AND de toras de madeira. Entretanto, para que seja possível aplicar o ensaio de vibração transversal na avaliação desses elementos, é preciso resolver algumas questões como a identificação e o controle dos fatores que afetam o ensaio de vibração transversal para a definição de um método de ensaio que permita estimar o módulo de elasticidade das toras de madeira.

É possível que a determinação da rigidez à flexão das toras pelo ensaio de vibração transversal, considerando o modelo idealizado de Bernoulli, seja afetada por diversos fatores, como: anisotropia da madeira; variações na forma e nas dimensões da seção transversal ao longo do comprimento; não homogeneidade de distribuição da massa; presença de defeitos internos; encurvamento e também os efeitos do esforço cortante e da inércia à rotação.

Contudo, a inclusão de todas essas variáveis no modelo teórico pode tornar o problema tão complexo a ponto de inviabilizar a aplicação da técnica.

Visando garantir uma precisa avaliação da rigidez à flexão com a técnica de vibração transversal sem torná-la inviável, pode-se investigar os efeitos das principais variáveis envolvidas no cálculo do módulo de elasticidade e fixar condições de ensaio que não só minimizem a influência dessas variáveis no comportamento dinâmico das toras como também permitam a correta medição das frequências naturais das mesmas.

Nesse sentido, para a avaliação do módulo de elasticidade a flexão de toras de maneira de forma simples e com boa exatidão é imprescindível a definição de um método de ensaio que considere os principais fatores que afetam o comportamento das toras em vibração e que seja capaz de reproduzir com boa fidelidade o modelo matemático adotado.

\subsection{Organização da tese}

Para o desenvolvimento da tese o texto foi dividido em nove capítulos, um anexo e seis apêndices os quais são descritos a seguir. 
No Capítulo 1, além de uma breve introdução, são apresentados os objetivos geral e específicos da tese, e é feita a justificativa para a realização do trabalho.

No Capitulo 2 é apresentada uma extensa Revisão de Literatura abrangendo: os atuais métodos de Avaliação Não-Destrutiva destinados a toras de madeira; os principais estudos envolvendo a aplicação do ensaio de vibração transversal para a determinação da rigidez à flexão de elementos estruturais de madeira; os modelos analíticos para o estudo de vibração transversal em vigas, os fatores que interferem no desenvolvimento do ensaio de vibração transversal e as técnicas de análise modal experimental desde a escolha dos transdutores até os métodos de identificação modal e as técnicas de correlação modal.

No Capítulo 3 apresenta-se um estudo teórico sobre a determinação de um diâmetro equivalente para o cálculo do módulo de elasticidade das toras. Apresenta-se ainda um estudo para a determinação de um valor limite da relação $L / \mathrm{D}_{\text {meio }}$ (comprimento / diâmetro na metade do comprimento) a partir da qual o esforço cortante passa a ser significativo no cálculo do módulo de elasticidade dinâmico.

No Capítulo 4 são apresentados os ensaios preliminares de vibração transversal e flexão estática realizados em uma amostra piloto. As conclusões desse capítulo foram úteis para a definição do método de ensaio dinâmico.

No Capítulo 5 apresenta-se um estudo sobre a influência do teor de umidade na determinação do módulo de elasticidade dinâmico.

A partir das conclusões dos Capítulos 2 a 5 foi formulado um método de ensaio para avaliar o módulo de elasticidade na flexão de toras de madeira o qual é apresentado no Capítulo 6.

No Capítulo 7 apresenta-se a validação do método proposto, avaliando uma segunda amostra de toras;

O Capítulo 8 apresenta uma síntese das conclusões obtidas nos capítulos precedentes;

O Capítulo 9 mostra as referências bibliográficas citadas em todo o trabalho;

O Anexo A mostra um resumo da norma ANSI O5.1 (ANSI, 2002) utilizada na classificação visual das toras da segunda amostra;

Os Apêndices A e C mostram, respectivamente, os detalhes do desenvolvimento do sistema de vibração transversal e do programa de identificação modal os quais foram fundamentais para a realização dos ensaios dinâmicos apresentados nos Capítulos 4 e 7 . Embora o autor tenha dedicado um tempo razoável para a construção do sistema de aquisição 
de dados e a implementação do programa de identificação modal optou-se por colocá-los em apêndices uma vez que seu desenvolvimento não faz parte dos objetivos do trabalho.

Os dados da amostra piloto e da amostra de validação são mostrados nos Apêndices B e F respectivamente.

O Apêndice D mostra os testes estatísticos realizado no decorrer da tese.

E, por fim, o Apêndice E mostra os parâmetros modais das toras da amostra piloto. 


\section{REVISÃO DE LITERATURA}

Apresentam-se nas páginas seguintes, os assuntos de maior relevância para este trabalho. Inicialmente o trabalho aborda as técnicas mais usuais na AND de toras de madeira. Na sequência, são apresentados os fundamentos da técnica de vibração transversal, os fatores que afetam esse ensaio e as técnicas envolvidas na experimentação.

\subsection{Avaliação Não-Destrutiva}

A qualidade dos produtos de engenharia depende de certos fatores, como projeto, propriedades das matérias primas e tecnologia de fabricação.

Para avaliar a qualidade de seus produtos é conveniente à indústria empregar técnicas capazes de identificar defeitos sem, no entanto, afetar o desempenho futuro dos produtos acabados. Essas técnicas recebem diversas denominações, segundo Cartz (1996): Ensaios Não-Destrutivos (END); Avaliação Não-Destrutiva (AND); Caracterização Não-Destrutiva; ou ainda, Inspeção Não-Destrutiva (IND).

Kawamoto \& Williams (2002) definem as técnicas de AND como "métodos para examinar materiais ou componentes de modo a não prejudicar sua utilidade e durabilidade".

Oliveira \& Sales $^{1}$ (2000) apud Santos et al (2002) explicam que as técnicas nãodestrutivas apresentam vantagens em relação aos métodos convencionais como: possibilidade de avaliar a integridade estrutural de uma peça sem a extração de corpos-de-prova; maior rapidez para analisar uma grande amostra e versatilidade para se adequar a uma rotina padronizada numa linha de produção.

No entanto, Raj et al (2002), além das vantagens, também apontam algumas limitações, mostradas na Tabela 2.1 .

1 OLIVEIRA F. G. R.; SALES A. Propagação de Ondas Acústicas na Madeira. In: Encontro Brasileiro em Madeiras e em Estruturas de Madeira, 7. 2000. São Carlos. p.35. 
Tabela 2.1 - Vantagens e desvantagens da AND em relação aos ensaios destrutivos convencionais.

\begin{tabular}{|c|c|}
\hline Ensaios destrutivos & Ensaios Não-Destrutivos \\
\hline Vantagens & Limitações \\
\hline As medições são diretas e confiáveis. & $\begin{array}{l}\text { As medições são indiretas e a confiabilidade } \\
\text { deve ser verificada. }\end{array}$ \\
\hline Medições usualmente quantitativas. & Medições usualmente qualitativas. \\
\hline $\begin{array}{l}\text { As correlações entre as propriedades do } \\
\text { material e as medições do ensaio são diretas. }\end{array}$ & $\begin{array}{l}\text { Requer habilidade de julgamento } \\
\text { experiência para interpretar os resultados. }\end{array}$ \\
\hline Limitações & Vantagens \\
\hline $\begin{array}{l}\text { Os testes não são feitos diretamente no } \\
\text { produto acabado. A correlação entre a } \\
\text { amostra testada e os produtos deve ser } \\
\text { provada. }\end{array}$ & $\begin{array}{l}\text { Os ensaios podem ser realizados diretamente } \\
\text { nos produtos acabados. }\end{array}$ \\
\hline $\begin{array}{l}\text { Um único teste pode medir uma ou algumas } \\
\text { propriedades. }\end{array}$ & $\begin{array}{l}\text { Muitas técnicas de AND podem ser aplicadas } \\
\text { na mesma peça e por isso, muitas } \\
\text { propriedades podem ser medidas. }\end{array}$ \\
\hline Impossível testar o produto em serviço. & Podem ser aplicados a produtos em serviço. \\
\hline $\begin{array}{l}\text { Não é possível medir as propriedades em um } \\
\text { período de tempo cumulativo. }\end{array}$ & $\begin{array}{l}\text { É possível realizar repetidos ensaios em um } \\
\text { determinado período de tempo. }\end{array}$ \\
\hline $\begin{array}{l}\text { A preparação dos espécimes para o ensaio é } \\
\text { trabalhosa. }\end{array}$ & Envolve pouca preparação do espécime. \\
\hline Requer bastante tempo. & A maioria dos métodos de ensaio é rápida. \\
\hline
\end{tabular}

Fonte: Raj et al (2002).

As técnicas de AND variam desde uma simples inspeção visual até métodos mais complexos capazes de gerar imagens internas do objeto avaliado.

Os principais métodos de AND empregados em madeira são termografia, micro-ondas, raios $\mathrm{X}$, tomografia, inspeção visual, emissões acústicas, ultrassom, ondas de tensão e vibração transversal.

\subsubsection{Avaliação Não-Destrutiva de toras de madeira}

O desenvolvimento de técnicas de AND para madeira teve sua origem na necessidade de resolver o problema prático de conhecer as propriedades físicas de uma peça de madeira sem afetar a integridade do material inspecionado.

Nas páginas seguintes é apresentada uma revisão das principais técnicas de avaliação não-destrutiva aplicáveis às toras de madeira, sendo que algumas dessas técnicas podem inclusive ser utilizadas in vivo. 


\subsubsection{Inspeção visual}

A inspeção visual, ainda muito empregada atualmente, é o método mais antigo de AND. Essa técnica fundamenta-se na avaliação de certas características de crescimento, visíveis a olho nu, as quais são responsáveis pela diferença observada entre as propriedades mecânicas das peças estruturais e dos corpos-de-prova isentos de defeitos.

As características de crescimento das toras são usadas para selecionar a madeira em classes de qualidade visual com o auxílio de regras de classificação.

As primeiras normas norte-americanas para a classificação visual de toras de madeira, segundo Wolfe (2000), foram a "Specification for Round Timber Piles" publicada pela ASTM em 1915 e "Wood Pole Specification and Dimensions" publicada pela American Standards Association (ASA) em 1924. Essas normas especificavam um nível mínimo de qualidade e formaram a base para as atuais normas ASTM D25 (ASTM, 1991) "Standard Specification for Round Timber Piles" e ANSI O5.1 (ANSI, 2002) “American National Standard for Wood Poles: Specification and Dimensions"

Wolfe \& Hernandez (1999) relatam que, ao contrário do que ocorre na madeira serrada, as toras têm baixa sensibilidade às variações nas características avaliadas na classificação visual como nós e inclinação das fibras. Por esse motivo, Wolfe (2000) afirma que, para as toras, é preferível o uso de uma classificação simples por tensões ao invés de somente a classificação visual.

Um estudo apresentado por Ranta Maunus (1999) demonstra que a avaliação do módulo de elasticidade aliada à classificação visual fornece uma estimativa mais confiável das propriedades mecânicas do que somente o emprego da classificação visual.

De acordo com Wolfe (2000), as normas norte-americanas para projeto de estruturas de madeira consideram apenas uma classe de resistência para toras.

Para explicar o motivo das normas considerarem apenas uma classe de resistência, Wolfe \& Hernandez (1999) mostram uma comparação entre o módulo de ruptura na flexão $\left(f_{\mathrm{M}}\right)$ de tábuas de Douglas-fir classificadas visualmente como Select Structural (diâmetro dos nós na face < 1/6 da largura e inclinação de fibras < 1:12) com teores de umidade de $12 \%$ e $23 \%$ e o $f_{\mathrm{M}}$ de toras de pequeno diâmetro, também da espécie Douglas-fir, com teor de umidade acima de $30 \%$ (Tabela 2.2). 
Verifica-se que, na condição seca, a madeira serrada e visualmente classificada apresenta $f_{\mathrm{M}}$ médio ligeiramente superior ao da madeira roliça. Entretanto, seu coeficiente de variação é quase 3 vezes maior, resultando em uma resistência característica bastante inferior à das toras (WOLFE \& HERNANDEZ, 1999).

Tabela 2.2 - Comparação entre a $f_{\mathrm{M}}$ da madeira serrada e de toras de plantios jovens.

\begin{tabular}{lcc}
\hline \multicolumn{1}{c}{ Douglas-fir } & \multicolumn{2}{c}{$f_{\mathbf{M}}$} \\
\cline { 2 - 3 } & Média (MPa) & Coef. Var.(\%) \\
\hline SS 38 mm x 190mm a 12\% de umidade & 58,5 & 30,1 \\
SS 38 mm x 190mm a 23\% de umidade & 40,5 & 26,4 \\
Tora de pequeno diâmetro com umidade $>30 \%$ & 57,4 & 11,3 \\
\hline
\end{tabular}

Fonte: Adaptado de Wolfe \& Hernandez (1999).

Esse exemplo demonstra que, mesmo com a presença de nós e teor de umidade acima do ponto de saturação das fibras, a madeira em tora atinge resistência comparável à da madeira serrada de melhor qualidade (Select Structural).

Segundo Green et al (2006), a Timber Products Inspection (TPI) desenvolveu um conjunto de normas para a classificação de toras destinadas à construção de casas utilizando toras (log homes). Essa norma especificamente considera quatro classes de qualidade sendo: Unsawn, $\mathrm{N}^{\mathrm{o}} 1, \mathrm{~N}^{\mathrm{o}} 2$ e $\mathrm{N}^{\mathrm{o}} 3$. As toras classificadas como Unsawn são destinadas à aplicações nas quais não há necessidade de aplainamento de nenhuma de suas faces.

Como exemplo, a Tabela 2.3 mostra os valores limites para o diâmetro dos nós e inclinação das fibras, e os valores admissíveis de propriedades de resistência e elasticidade, para toras de Engelmann spruce com diâmetro de 228 mm (9"), segundo a TPI (1987).

Tabela 2.3 - Limites no diâmetro dos nós e na inclinação das fibras e propriedades admissíveis para toras de Engelmann spruce com diâmetro de $228 \mathrm{~mm}$ segundo a norma TPI (1987).

\begin{tabular}{ccccccc}
\hline \multirow{2}{*}{ Classe } & $\begin{array}{c}\text { Proporção do nó } \\
\text { (diâmetro da tora) }\end{array}$ & $\begin{array}{c}\text { Inclinação } \\
\text { das fibras }\end{array}$ & \multicolumn{4}{c}{ Propriedades admissíveis (MPa) } \\
\cline { 4 - 7 } & $1 / 2$ & $1: 15$ & $\boldsymbol{f}_{\mathbf{M}}$ & $\mathbf{E}_{\mathbf{M}}$ & $\boldsymbol{f}_{\mathbf{t}, \mathbf{0}}$ & $\boldsymbol{f}_{\mathbf{c}, \mathbf{0}}$ \\
\hline Unsawn & $1 / 3$ & $1: 14$ & 77,91 & 7734 & 50,97 & 43,91 \\
$\mathrm{~N}^{\circ} 1$ & $1 / 2$ & $1: 10$ & 63,27 & 7734 & 42,18 & 35,15 \\
$\mathrm{~N}^{0} 2$ & $3 / 4$ & $1: 6$ & 36,91 & 6327 & 35,15 & 29,88 \\
$\mathrm{~N}^{\circ} 3$ & & & & &
\end{tabular}

Fonte: Green et al (2006).

Além das características mostradas na Tabela 2.3, a norma de classificação de toras da TPI também limita outros fatores que podem afetar a resistência (podridão, fendas, rachas e madeira comprimida). 
As propriedades mecânicas admissíveis mostradas na Tabela 2.3 foram obtidas a partir das propriedades mecânicas de corpos-de-prova isentos de defeitos mediante a modificação por coeficientes apropriados definidos na norma ASTM D3957 (ASTM, 1990) "Standard practice for establishing stress grades for structural member in log homes" (GREEN et al, 2006).

Nos Estados Unidos da América, a norma ANSI O5.1 (ANSI, 2002) fornece as especificações mínimas de qualidade e dimensões para postes de madeira utilizados como viga engastada submetida exclusivamente a carregamento transversal. De acordo com essa norma, as toras são reunidas em 16 grupos em função do comprimento e das circunferências do topo e da base, sendo que esse agrupamento varia de acordo com a espécie. A norma ANSI O5.1 (2002) fornece os intervalos de valores das dimensões em cada grupo, para algumas das espécies mais empregadas nos Estados Unidos.

A seguir são citados os limites estipulados pela norma ANSI O5.1 (ANSI 2002) para alguns defeitos, independentemente do grupo:

- Inclusões contendo casca: Depressões contendo casca devem ter profundidade inferior a $5 \mathrm{~mm}$.

- Madeira comprimida: A costaneira de todas as toras deve ser livre de madeira comprimida em $2,5 \mathrm{~cm}$ de espessura;

- Furos de insetos: São permitidos desde que o diâmetro não seja maior do que 2 $\mathrm{mm}$. Qualquer outra forma de dano causado por insetos é proibida;

- Rachas: Fendas na base do poste cuja largura deixa uma folga igual ou maior do que $5 \mathrm{~cm}$ da superfície da tora são permitidas desde que seu comprimento não atinja a linha da superfície da terra. Fendas ou combinações de fendas com folga inferior a $5 \mathrm{~cm}$ são permitidas desde que tenha comprimento inferior a 60 $\mathrm{cm}$;

- Fibras torcidas: A limitação nessa característica é mostrada na Tabela 2.4.

Tabela 2.4 - Limitações no torcimento das fibras segundo a ANSI O5.1 (ANSI, 2002).

\begin{tabular}{lc}
\hline Comprimento do poste & Torcimento máximo permitido \\
\hline 9 metros ou inferior & 1 volta completa em $3 \mathrm{~m}$ \\
de $10,7 \mathrm{~m}$ a $13,7 \mathrm{~m}$ & 1 volta completa em $5 \mathrm{~m}$ \\
$15,2 \mathrm{~m}$ ou superior & 1 volta completa em $20 \mathrm{~m}$ \\
\hline
\end{tabular}

Fonte: ANSI O5.1 (ANSI, 2002).

Com relação aos nós, os limites são estipulados para cada grupo. O diâmetro de um único nó ou de um conjunto de nós em um comprimento de $30 \mathrm{~cm}$ não deve exceder os limites mostrados na Tabela 2.5. 
Tabela 2.5 - Limite nas dimensões dos nós em postes segundo a ANSI O5.1 (ANSI, 2002).

\begin{tabular}{|c|c|c|c|}
\hline \multirow{3}{*}{ Comprimento do poste } & \multicolumn{3}{|c|}{ Dimensões máximas permitidas } \\
\hline & \multicolumn{2}{|c|}{$\begin{array}{l}\text { Diâmetro de nós } \\
\text { individuais }\end{array}$} & \multirow{2}{*}{$\begin{array}{c}\text { Soma dos diâmetros de } \\
\text { todos os nós em } 30 \mathrm{~cm} \text { de } \\
\text { comprimento. }\end{array}$} \\
\hline & $\begin{array}{l}\text { Grupos } \\
\text { H6 a H3 }\end{array}$ & $\begin{array}{c}\text { Grupos } \\
4 \text { a } 10\end{array}$ & \\
\hline \multicolumn{3}{|c|}{$13,7 \mathrm{~m}$ ou inferior } & \multirow{3}{*}{$\begin{array}{l}\text { 1/3 da circunferência média na } \\
\text { seção transversal ou } 20 \mathrm{~cm} ; 0 \\
\text { que for maior, mas não } \\
\text { excedendo } 30 \mathrm{~cm}\end{array}$} \\
\hline Metade inferior & $8 \mathrm{~cm}$ & $5 \mathrm{~cm}$ & \\
\hline Metade superior & $13 \mathrm{~cm}$ & $10 \mathrm{~cm}$ & \\
\hline \multicolumn{3}{|c|}{$15,2 \mathrm{~m}$ ou superior } & \multirow{3}{*}{$\begin{array}{l}1 / 3 \text { da circunferência média na } \\
\text { seção transversal ou } 25 \mathrm{~cm} ; 0 \\
\text { que for maior, mas não } \\
\text { excedendo } 36 \mathrm{~cm}\end{array}$} \\
\hline Metade inferior & $10 \mathrm{~cm}$ & $10 \mathrm{~cm}$ & \\
\hline Metade superior & $15 \mathrm{~cm}$ & $15 \mathrm{~cm}$ & \\
\hline
\end{tabular}

Fonte: ANSI O5.1 (ANSI, 2002).

Salienta-se que a norma ANSI O5.1 (ANSI, 2002) é destinada a toras adultas e atualmente não existem normas específicas para a classificação de toras juvenis, pois até há bem pouco tempo essas toras não tinham aplicação estrutural.

Contudo, como resultado do desenvolvimento dos projetos "Round small-diameter timber for construction" e "Program on Small Diameter and Underutilized Forest Material" (SDU) respectivamente na Europa e nos Estados Unidos, essas toras passaram a ser empregadas como elementos estruturais. O objetivo principal de ambos os projetos foi estimular o uso das toras juvenis na construção civil de forma a aumentar o valor comercial das mesmas e assim viabilizar a remoção desse material das florestas evitando a formação de densa carga combustível capaz de produzir incêndios de grandes proporções (RANTA MAUNUS, 1999; LEVAN, 2003) .

Uma das linhas de pesquisa do projeto europeu foi o desenvolvimento de regras de classificação visual para toras de pequeno diâmetro.

Segundo Ranta Maunus (1999), as principais características adotadas pelos pesquisadores para a inspeção desse material foram: diâmetro do maior nó em relação ao diâmetro da tora, soma dos diâmetros dos nós em um comprimento de $150 \mathrm{~mm}$, inclinação de 
fibras e largura dos anéis de crescimento. A Tabela 2.6 mostra os limites aceitáveis para cada uma dessas características.

Tabela 2.6 - Limitações dos defeitos nas toras de pequeno diâmetro segundo o projeto Round small-diameter timber for construction.

\begin{tabular}{|c|c|c|}
\hline Características & Classe A & Classe B \\
\hline $\begin{array}{l}\text { Diâmetro do maior nó em relação ao } \\
\text { diâmetro da tora }\end{array}$ & $25 \%$ & $75 \%$ \\
\hline $\begin{array}{l}\text { Soma dos diâmetros de um conjunto de } \\
\text { nós em relação ao diâmetro da tora }\end{array}$ & $75 \%$ & $100 \%$ \\
\hline Inclinação de fibras espiraladas & $1: 10$ & $1: 7$ \\
\hline Espessura dos anéis de crescimento $(\mathrm{mm})$ & 3 & 5 \\
\hline $\begin{array}{l}\text { Fenda individual: profundidade em relação } \\
\text { ao diâmetro da tora }\end{array}$ & \multicolumn{2}{|c|}{$50 \%$} \\
\hline Fenda individual: comprimento $(\mathrm{mm})$ & \multicolumn{2}{|c|}{ Sem limite } \\
\hline $\begin{array}{l}\text { Soma de duas fendas em um comprimento } \\
\text { de } 150 \mathrm{~mm} \text { em relação ao diâmetro da tora }\end{array}$ & \multicolumn{2}{|c|}{$75 \%$} \\
\hline $\begin{array}{l}\text { Porcentagem de madeira comprimida na } \\
\text { seção transversal }\end{array}$ & \multicolumn{2}{|c|}{$10 \%$} \\
\hline Conicidade $(\mathrm{mm} / \mathrm{m})$ & 5 & 10 \\
\hline Ovalização da seção transversal & $10 \%$ & $20 \%$ \\
\hline Encurvamento em 2 m de comprimento & $5 \mathrm{~mm}$ & $10 \mathrm{~mm}$ \\
\hline Cambio & \multicolumn{2}{|c|}{$10 \%$} \\
\hline Furo de insetos & \multicolumn{2}{|c|}{ Não permitido } \\
\hline
\end{tabular}

Fonte: Ranta Maunus (1999).

A inspeção visual das toras destinadas a aplicação estrutural é indispensável. Porém, como na maioria dos casos não é possível identificar a presença de podridão e outros defeitos internos, muitas vezes essa técnica fornece resultados não-conclusivos. Nesses casos, o uso de uma técnica complementar contribui para uma melhor avaliação da integridade da tora.

A seguir são apresentadas algumas das técnicas de avaliação não-destrutiva que podem ser empregadas em paralelo com a inspeção visual.

\subsubsection{Ensaio estático de flexão em toras}

O módulo de elasticidade à flexão passou a ser usado como estimador do módulo de ruptura na flexão desde 1958 quando institutos de pesquisas em madeira da Inglaterra, 
Austrália e América do Norte concluíram que a resistência e a rigidez à flexão da madeira são altamente correlacionadas (PLESSEY TELECOMMUNICATIONS, 1973).

No Brasil, o ensaio para a determinação do módulo de elasticidade na flexão de toras é padronizado pela norma NBR 6231 (ABNT, 1980) "Postes de madeira - resistência à flexão", a qual fixa as condições para a execução do ensaio de flexão estática com o esquema estático de viga engastada. Nos Estados Unidos da América o método para a realização do teste de flexão estática em postes de madeira é definido pela norma ASTM D1036 (ASTM, 2005) "Standard Test Methods of Static Tests of Wood Poles". De acordo com essa norma, há duas possibilidades de ensaio sendo: método A: o poste é seco ao ar e sua base é molhada antes do ensaio; método B: o ensaio é realizado com o poste na condição saturada.

A Figura 2.1 mostra os esquemas dos ensaios de flexão padronizados pelas duas normas. O poste tem a sua base engastada entre dois blocos rígidos, e na extremidade livre é aplicada uma força.

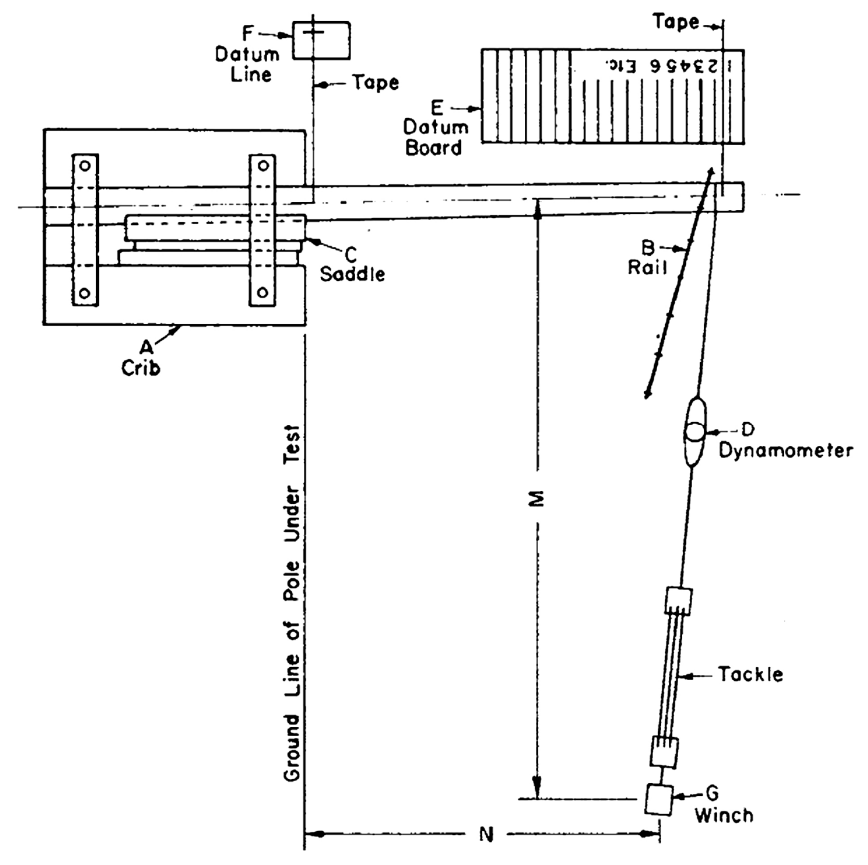

a)

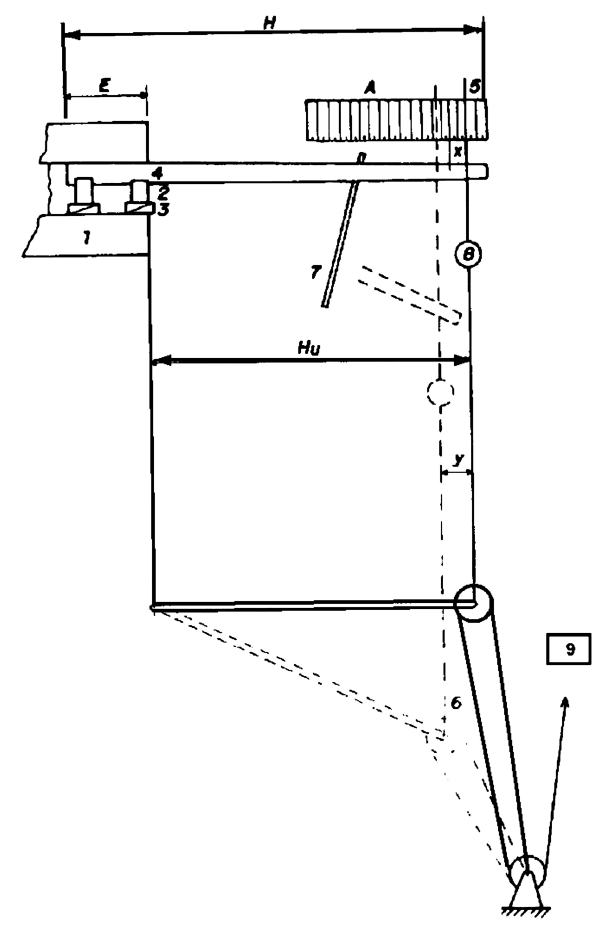

b)

Figura 2.1 - Ensaio de flexão em postes de madeira: a) norma ASTM D 1036 (ASTM, 2005); b) norma NBR 6231 (ABNT, 1980).

Fontes: ASTM D1036 (ASTM, 2005) e NBR 6231 (ABNT, 1980).

O módulo de elasticidade é calculado a partir da força aplicada e do deslocamento da extremidade livre da tora. 
Esses ensaios, além de perigosos, podem conduzir a resultados imprecisos. Acidentes graves podem acontecer quando ocorre a ruptura do poste ou, eventualmente, a ruptura do cabo de aço durante o ensaio. A movimentação e o posicionamento das toras no sistema de engastamento também é tarefa difícil devido ao elevado peso das toras. Além disso, as condições de engastamento não são ideais e, ao inicio do ensaio, a extremidade supostamente engastada começa a girar comprometendo a exatidão dos resultados.

Observando esses inconvenientes, pesquisadores buscaram novas técnicas para a avaliação da qualidade das toras de madeira. Entre as mais empregadas podem ser citadas: emissão ultrassônica, micro perfuração, vibração transversal, ondas de tensão (stress wave) e tomografia.

\subsubsection{Ensaio de micro-perfuração}

No ensaio de resistência à micro-perfuração (também denominado de perfuração controlada), a integridade interna da tora é inspecionada medindo-se a resistência da madeira à perfuração por uma broca de pequeno diâmetro.

O equipamento comercial que realiza esse ensaio é denominado Resistograph $^{\circledR}$ e é produzido pela empresa alemã IML (Figura 2.2a).

$\mathrm{O}$ equipamento perfura a tora com velocidade de avanço constante e mede o torque necessário para a perfuração da madeira. O resultado é plotado num gráfico de resistência à perfuração contra a profundidade da broca (Figura 2.2 b).

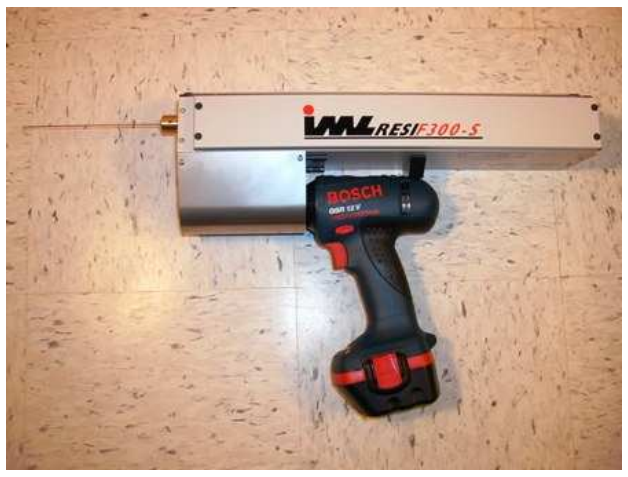

a)

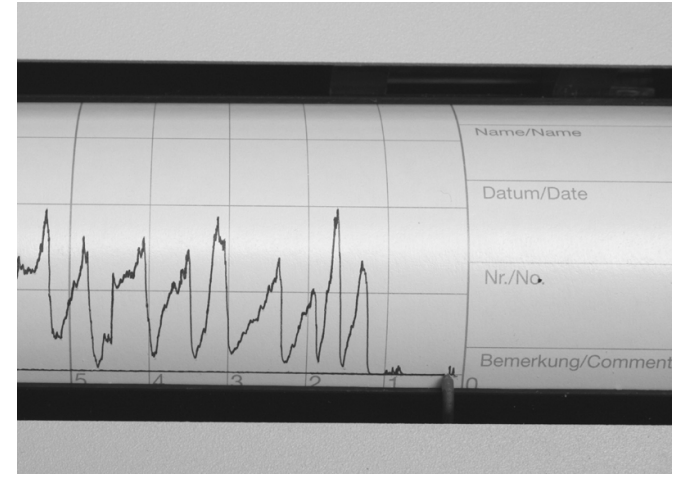

b)

Figura 2.2 - Resistograph: a) Foto do aparelho; b) Gráfico obtido com o equipamento. Fontes: (a) Shepard (2007); (b) IML (2008).

O diâmetro da broca é muito pequeno, cerca de $1,5 \mathrm{~mm}$, permitindo que o teste seja pouco invasivo e não cause nenhum dano estrutural. 
A resistência à micro-perfuração é eficiente na detecção e na determinação da extensão, mesmo em estágios iniciais, de podridão no interior das toras. Entretanto, é necessário prever a posição das zonas comprometidas para realizar a perfuração na direção da região possivelmente danificada pela podridão (WANG et al, 2005).

No caso de postes, a região mais susceptível à podridão é a zona de afloramento. Por isso, o ensaio de micro-perfuração geralmente é realizado nesse local (Figura 2.3).

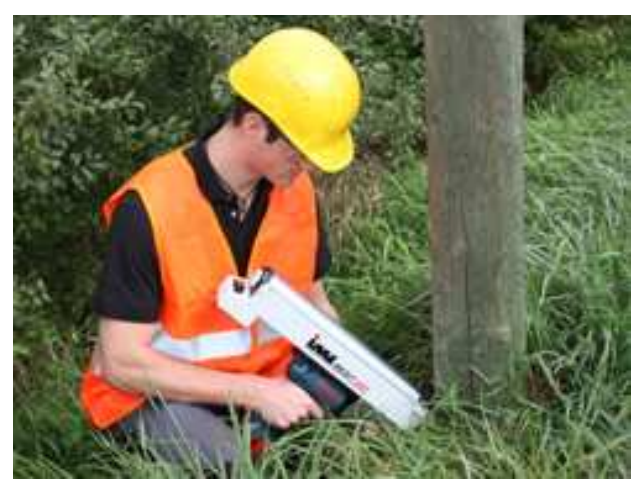

Figura 2.3 - Ensaio de micro-perfuração na zona de afloramento de um poste. Fonte: IML (2008).

A resistência à micro-perfuração pode ser correlacionada com a densidade. Muitos trabalhos relatam resultados obtidos com a correlação da resistência medida no Resistograph com a densidade.

Costello \& Quarles (1999) avaliaram o uso da técnica de micro-perfuração na estimativa da densidade aparente verde das espécies Eucalyptus globulus e Ulmus glabra. Para verificar a possibilidade de empregar uma furadeira comum no ensaio, os autores usaram dois aparelhos Resistograph e mais quatro furadeiras portáteis Dewalt modelo XR2 com baterias de $18 \mathrm{~V}$. A Tabela 2.7 mostra os coeficientes de correlação obtidos entre a resistência à perfuração e a densidade aparente verde.

Costello \& Quarles (1999) concluem que, embora ambos os equipamentos possam ser utilizados na detecção da podridão, o Resistograph mostrou-se mais confiável do que a furadeira portátil.

Ceraldi et al (2001) empregaram a técnica da micro-perfuração para avaliar as características mecânicas de vigas roliças de beech (Fagus sylvatica L) com diâmetro de 210 mm. Os autores observaram um coeficiente de determinação de 0,67 na correlação entre resistência à micro-perfuração e a densidade. 
Tabela 2.7 - Coeficientes de correlação entre a densidade aparente verde e a resistência à perfuração com o Resistograph e com furadeira comum.

\begin{tabular}{|c|c|c|}
\hline \multirow{2}{*}{ Teste } & \multicolumn{2}{|c|}{ Coeficiente de correlação (r) } \\
\hline & Ulmus glabra & Eucalyptus globulus \\
\hline Resistograph 1 & $0,993^{\pi /}$ & $0,982^{\pi / 2}$ \\
\hline Resistograph 2 & $0,975^{* * *}$ & $0,977^{* * *}$ \\
\hline Furadeira 1 & $0,344^{\mathrm{ns}}$ & $0,729^{* * *}$ \\
\hline Furadeira 2 & $0,913^{\star \star *}$ & $0,887^{* * *}$ \\
\hline Furadeira 3 & $0,972^{* * *}$ & $0,930^{* * *}$ \\
\hline Furadeira 4 & $0,926^{* * *}$ & $0,820^{* * *}$ \\
\hline
\end{tabular}

Gantz (2002) avaliou o uso do Resistograph na estimativa da densidade da madeira das espécies Pinus radiata, Pinus caribaea, Eucalyptus globulus e Eucalyptus urophylla. O autor observou coeficiente de determinação variando de 0,30 e 0,78 entre a resistência à micro-perfuração e a densidade. Para Gantz (2002), a correlação com a densidade também deve levar em conta o teor de umidade da madeira.

Feio et al (2005) realizaram um estudo semelhante, porém usando a espécie Castanea sativa Mill, e encontraram para o $\mathrm{R}^{2}$ um valor médio de 0,78 . Os autores salientam que devido à subjetividade dos resultados apresentados pelo Resistograph, o conceito de suas medições precisa ser revisado para reduzir os erros de leitura e melhorar a interpretação dos gráficos obtidos com o aparelho.

A observação de Feio et al (2005) tem fundamento, uma vez que a resistência à microperfuração plotada no gráfico do Resistograph é adimensional e, portanto, tem caráter apenas qualitativo.

Uma das maiores vantagens da técnica de micro-perfuração é a possibilidade de realizar inspeções de elementos estruturais em serviço. Devido a essa característica, essa técnica também vem sendo empregada na avaliação de estruturas de madeira serrada. Vale $e t$ al (2006), por exemplo, empregaram a técnica da micro-perfuração para estimar o estado de deterioração de treliças da cobertura de um laboratório construído em 1772 na Universidade de Coimbra (Figura 2.4).

Os autores observaram que o Resistograph é útil na avaliação da integridade de seções transversais e que por comparação de perfis de diferentes furos na mesma peça pode-se avaliar a extensão da podridão ou confirmar a ocorrência de galerias de insetos. Porém, Vale 
et al (2006) ressaltam que são necessárias mais pesquisas para que se possa relacionar os resultados do Resistograph com os valores de resistência ou densidade da madeira.

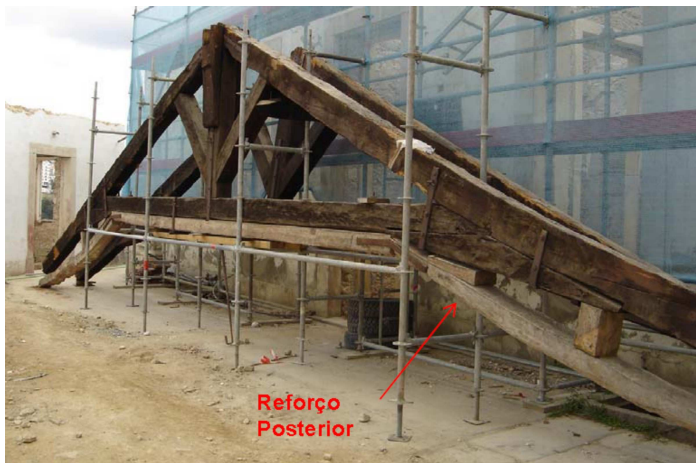

(a)

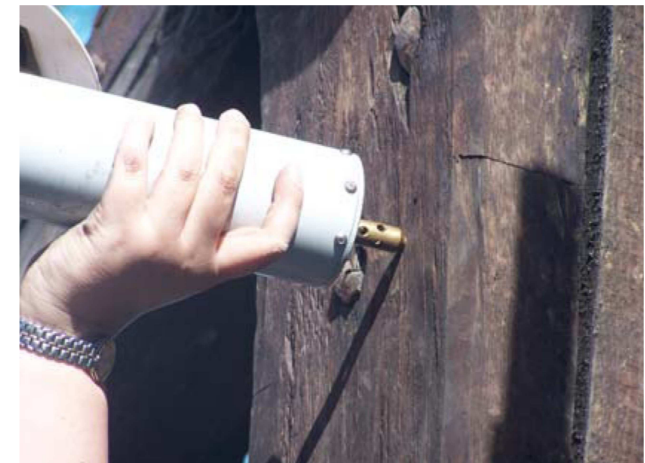

(b)

Figura 2.4 - Ensaio de micro-perfuração em treliça de edificação antiga: a) treliças inspecionadas; b) Ensaio de micro-perfuração.

Fonte: Vale et al (2006).

Tarcísio Lima et al (2007) testaram o Resistograph para a estimativa da densidade básica de sete clones de Eucalyptus sp com 16 anos de idade. Os autores verificaram que a estimativa da densidade básica média resultou em um ajuste significativo pelo modelo de regressão linear para cinco dos sete clones como mostra a Figura 2.5.

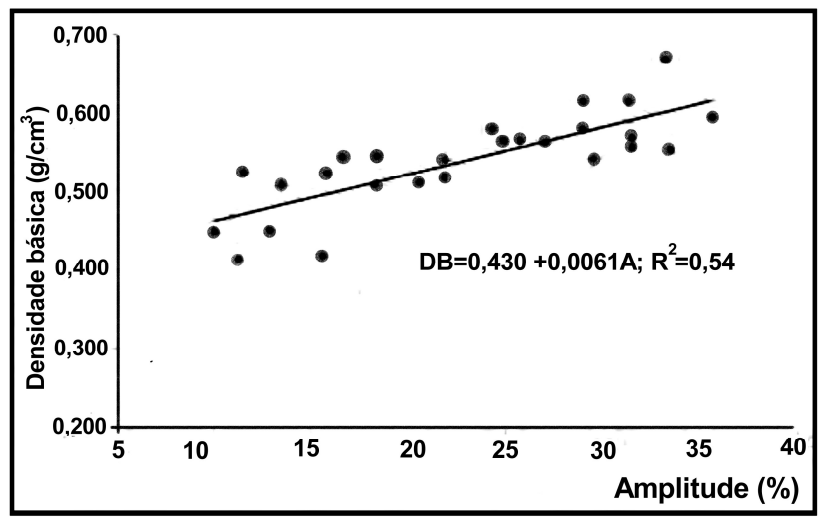

Figura 2.5 - Correlação entre resistência à micro-perfuração e densidade.

Fonte: Tarcísio Lima et al (2007).

Stambaugh et al (2008) investigaram o uso do Resistograph na identificação de podridão e danos causados por incêndios em seções transversais cortadas de troncos da espécie Quercus sp. Ao todo foram cortadas 58 fatias dos troncos sendo, 28 da espécie Quercus alba L, 22 fatias da espécie Quercus velutina Lam e mais 8 fatias da espécie Quercus coccinea Munchh. 
Após a extração, as fatias foram perfuradas com o Resistograph como mostra a Figura 2.6a. A resistência medida pelo aparelho foi confrontada com o estado da madeira em cada disco como mostra a Figura 2.6b.

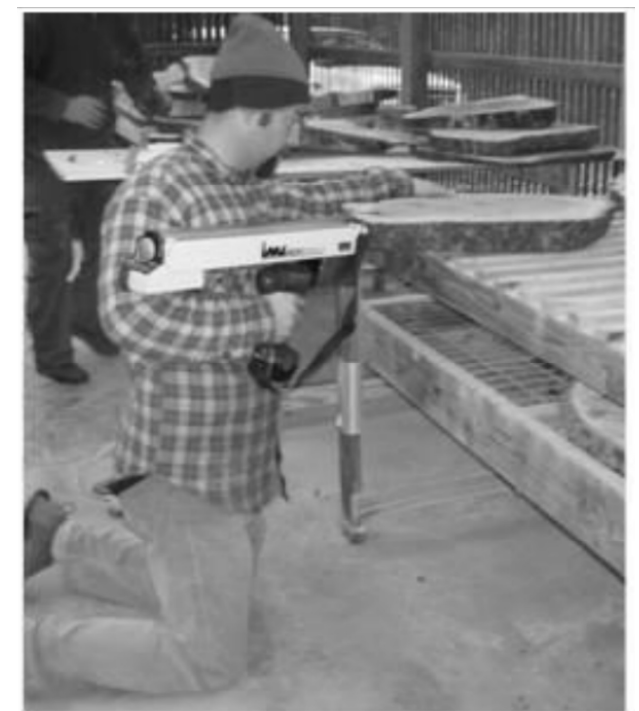

(a)

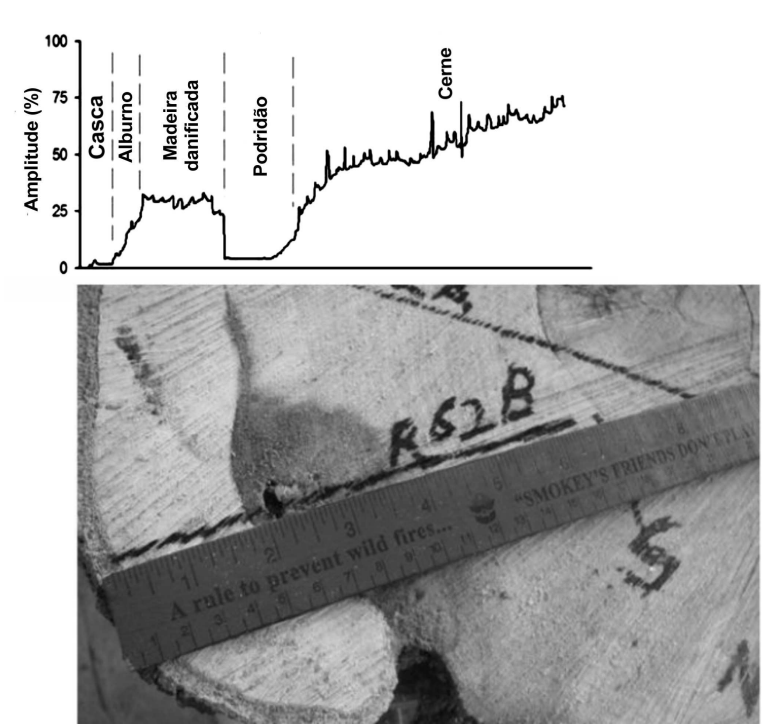

(b)

Figura 2.6 - Ensaio de micro-perfuração na espécie Quercus sp: a) perfuração das seções dos troncos; b) comparação da resistência à perfuração com o estado da madeira.

Fonte: Stambaugh et al (2008).

Stambaugh et al (2008) concluem que o Resistograph permite a identificação de defeitos de forma rápida (menos de 1 minuto por furo), embora não seja capaz de diferenciar entre a podridão e a madeira carbonizada.

\subsubsection{Tomografia}

Tomografia é o nome genérico dado a todo processo de obtenção de uma imagem da seção transversal de um objeto por princípios de transmissão e reflexão de sinais emitidos de diferentes fontes posicionadas em vários ângulos em torno do objeto (KAK \& SLANEY, 2001). A imagem obtida por esses princípios é denominada tomograma.

Os sinais utilizados para a geração do tomograma podem ocupar um amplo espectro de frequências como ultrassom, micro-ondas, raios $\mathrm{X}$, etc.

A obtenção da imagem tomográfica pode ser melhor compreendida quando comparada com geração da imagem em um aparelho convencional de raios $\mathrm{X}$.

A imagem mostrada pelos equipamentos de raio $\mathrm{X}$ é basicamente uma sombra obtida pela iluminação do objeto por uma fonte radioativa. $\mathrm{O}$ alto nível de energia dos raios $\mathrm{X}$ 
permite que os seus feixes passem através da maioria dos materiais como, por exemplo, as partes moles do corpo humano.

Entretanto, as imagens obtidas pelas sombras dão uma visão incompleta da forma do objeto. A Figura 2.7 ilustra o exemplo da projeção de dois cilindros em planos diferentes. Observa-se que a projeção no plano esquerdo não revela a presença do cilindro de menor diâmetro posicionado a frente do cilindro maior.

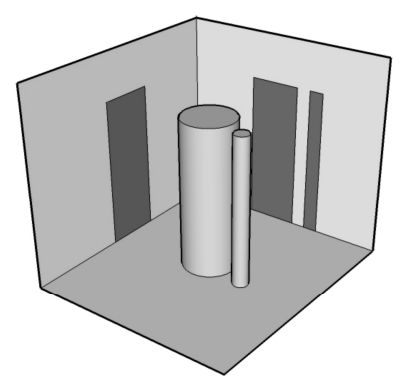

Figura 2.7 - Projeção de objetos em diferentes planos.

A formação de uma imagem tomográfica tem como princípio a construção de uma imagem tridimensional do objeto a partir das imagens das projeções em diversos planos.

Em um tomógrafo usado em exames médicos o feixe de radiação move-se ao redor do paciente, registrando as projeções em centenas de ângulos diferentes. O computador do aparelho utiliza um algoritmo de reconstrução de imagens e a partir dos sinais captados forma uma imagem tridimensional do corpo humano.

O problema de reconstrução de imagens é puramente matemático e o primeiro artigo a tratar desse assunto foi publicado por Radon ${ }^{2}$ (1917) apud Kak \& Slaney (2001).

Segundo Bucur (2005), as três principais técnicas usadas na construção de imagens tomográficas são: técnicas de transformação, técnicas iterativas e técnicas de inversão direta.

Além das aplicações na medicina, a geração de imagens tomográficas também encontrou aplicações no campo da AND, sendo usada, por exemplo, na área de engenharia florestal como uma ferramenta para auxiliar na avaliação das condições das árvores. Assim, a partir da geração das imagens tomográficas, pode-se identificar árvores que estão comprometidas e decidir por sua derrubada.

\footnotetext{
${ }^{2}$ RADON, J. Uber die Bestimmung von Funktionen durch ihre Integralwerte längs gewisser Mannigfaltigkeiten, Ber. Verh. Sächs. Akad. Wiss. Leipzig, Math. Nat. kl. 69, 262-277. 1917.
} 
A avaliação de toras de madeira por imagens tomográficas não é novidade. Os trabalhos de Habermehl et al $^{3}$ (1986) e Wagner et al ${ }^{4}$ (1989) ambos citados por Divós \& Szalal (2002) relatam respectivamente a inspeção de árvores e de toras de madeira empregando a técnica da tomografia computadorizada.

Entretanto, a técnica da tomografia computadorizada é pouco difundida e, segundo Divós \& Szalal (2002), as razões para isso se devem, entre outros, ao receio em trabalhar com raios $\mathrm{X}$ ou raios gama, à necessidade de um bom controle e regulação das fontes radioativas e principalmente ao custo relativamente elevado dos equipamentos.

A técnica da tomografia computadorizada, apesar de pouco utilizada, fornece excelentes informações. Na Figura 2.8 pode ser observada uma imagem obtida com a aplicação da técnica da Tomografia Computadorizada (TC) em uma tora da espécie fir. A resolução da imagem é de $1 \mathrm{~mm}$ permitindo que características importantes na qualidade da madeira como fendas, nós e quantidade de anéis de crescimento sejam perfeitamente visíveis.

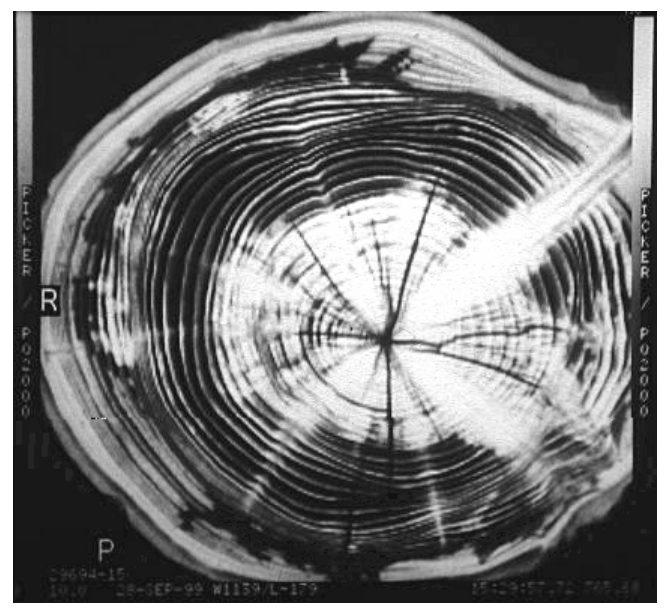

Figura 2.8 - Tomograma de uma tora da espécie fir.

Fonte: Divós \& Szalal (2002)

Entre os principais trabalhos destinados à aplicação da tomografia na AND de toras de madeira podem-se citar:

Socco et al (2000) avaliaram a correlação entre as imagens geradas pelo tomógrafo ultrassônico PUNDIT (Portable Ultrasonic Non-destructive Digital Indicating Testing) com

\footnotetext{
${ }^{3}$ HABERMEHL, A.; RIDDER, H.W.; SCHMIDT, S. Mobiles Computer-Tomographie -Great zur Untersuchung ortsfester Objecte In Atomkernenergia-Kerntechnik, 48 (2), 94-99. 1986.

${ }^{4}$ WAGNER, F.; TAYLOR, F. ; LADD, D. Ultrafast CT scanning of logs for internal defects. In Proc. of the 7th International Nondestructive Testing of Wood Symposium, Pullman WA, USA, 221-229. 1989.
} 
as propriedades mecânicas de seções de toras e observaram que as imagens tomográficas mostraram boa correlação com as propriedades mecânicas da madeira.

Nicolotti et al (2003) testaram as técnicas de tomografia elétrica e ultra-sônica para a detecção de podridão em árvores. Os autores observaram que foi possível detectar defeitos com dimensões da ordem de $5 \mathrm{~cm}$ com o equipamento de ultrassom ajustado para a frequência de $54 \mathrm{kHz}$. Verificaram ainda que a casca da árvore pode atenuar o sinal e atrapalhar o ensaio. Outro ponto observado foi que os furos necessários para a inserção dos eletrodos da tomografia elétrica servem futuramente como caminho para os fungos penetrarem no interior da tora.

Steele \& Cooper (2004) desenvolveram um sistema que permite a geração de imagens tridimensionais de postes de madeira. $\mathrm{O}$ equipamento foi patenteado e é denominado pelos autores de “Through - Log Density Detector - TLDD”. A Figura 2.9 mostra os eletrodos do equipamento.

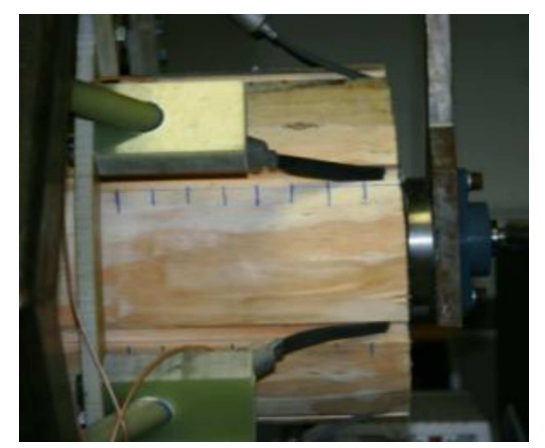

Figura 2.9 - Foto dos eletrodos tipo escova do sistema TLDD.

Fonte: Cooper et al (2008).

Bucur (2005) avaliou a qualidade da madeira de árvores da espécie "beech" com um sistema portátil de tomografia ultrassônica. As medições foram feitas nas alturas de $36 \mathrm{~cm}, 84$ cm e 1,38 m em relação ao nível do solo. A emissão dos pulsos ultrassônicos foi feita em 16 posições em torno da circunferência dos troncos. A Figura 2.10 mostra a imagem tomográfica tridimensional obtida a partir da reconstrução das imagens bidimensionais obtidas nas diferentes alturas. 


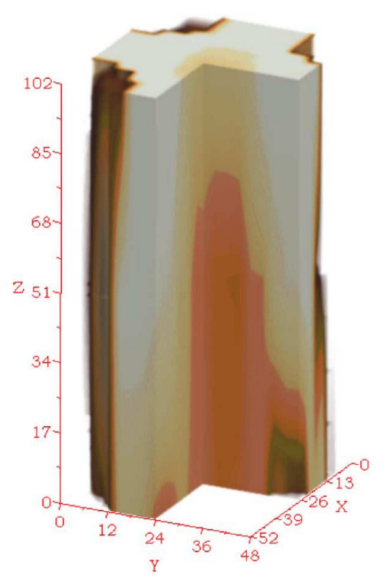

Figura 2.10 - Imagem tomográfica 3D de uma seção do tronco de uma árvore. Fonte: Bucur (2005).

Bucur (2005) conclui que, empregando-se 16 pontos de emissão, a tomografia ultrassônica pode detectar defeitos com dimensões a partir de $4 \mathrm{~cm}$, e afirma que essa resolução é conveniente para a inspeção de árvores em parques, jardins públicos bem como em postes e outros elementos estruturais.

Cooper et al (2008) testaram o sistema TLDD na detecção de madeira juvenil em toras realizando imagens tomográficas a distâncias de $25,4 \mathrm{~cm}$ ao longo do comprimento das toras. Foram empregados 8 sensores. Os autores observaram que as imagens geradas pelo TLDD demonstraram uma estimativa inferior (cerca de 37\%) para a área de madeira juvenil em relação ao método da TC. A Figura 2.11 mostra uma imagem obtida nos ensaios na qual se observa a madeira juvenil (em vermelho) e a presença de nós.

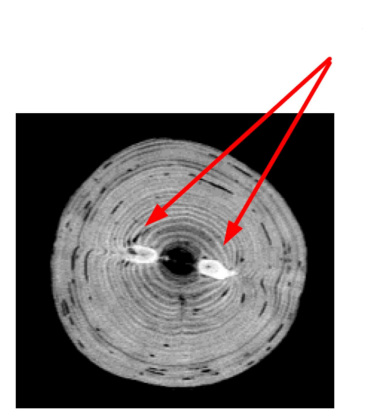

(a)

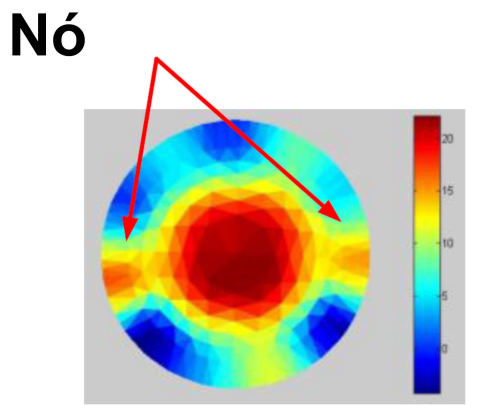

(b)

Figura 2.11 - Imagem tomográfica mostrando nós internos: a) Tomografia Computadorizada;

b) Equipamento TLDD.

Fonte: Cooper et al (2008).

Deflorio et al (2008) investigaram a possibilidade da técnica de tomografia acústica detectar diferentes tipos de podridão nos estágios iniciais em troncos de árvores. Os autores utilizaram o equipamento Picus acoustic tomography. As espécies estudadas foram o Douglas-fir, Beech, Oak e Sycamore. Os autores observaram que o tomograma não identifica 
podridão na superfície das toras, porém é possível observar redução na velocidade do som em regiões acometidas por fungos.

No tomógrafo ultrassônico as imagens são reconstruídas a partir da medição de diferentes parâmetros da onda como: tempo de percurso, amplitude, espectro de frequências, fase, etc (BUCUR, 2004).

A presença de podridão no caminho do sinal entre o transdutor emissor e o transdutor receptor resulta na redução da velocidade de propagação da onda em relação à madeira sã. Partindo desse princípio e realizando múltiplas medições em torno da circunferência da tora é possível formar a imagem 2D de um corte transversal da região da tora comprometida com podridão. A Figura 2.12 mostra como o sinal ultrassônico é desviado quando encontra um defeito em seu caminho.

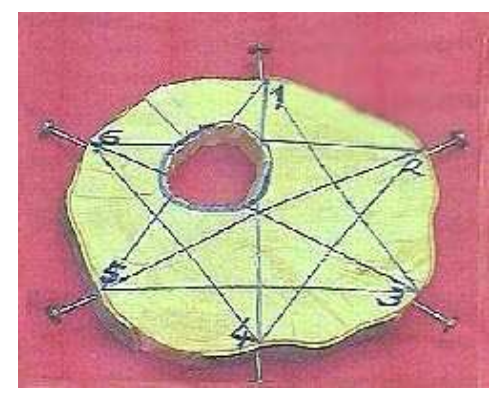

Figura 2.12 - Desvio dos sinais ultrassônicos por um defeito.

Fonte: Fakopp Enterprise (2008).

A empresa Fakopp Enterprise produz um equipamento para a avaliação não-destrutiva de toras in vivo utilizando a técnica da tomografia acústica. $\mathrm{O}$ aparelho denominado Fakopp 2D gera a imagem da seção transversal do tronco da árvore como mostra a Figura 2.13. Para isso, deve-se posicionar os sensores em torno do tronco.

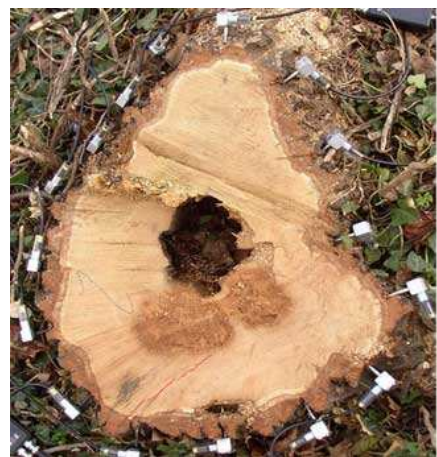

a)

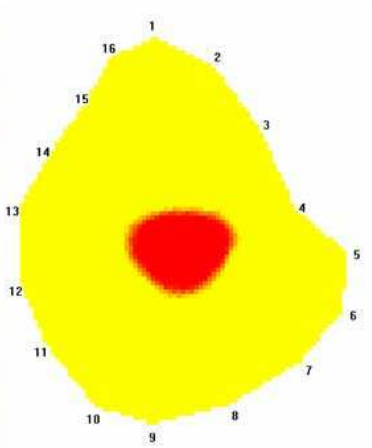

b)

Figura 2.13 - Tomografia ultrassônica de um tronco de Lindentree: a) posicionamento dos sensores; b) imagem gerada pelo Fakopp 2D. 
Quanto maior o número de transdutores melhor será a resolução da imagem. A Tabela 2.8 mostra alguns arranjos possíveis no posicionamento dos transdutores.

Tabela 2.8 - Alguns dos possíveis arranjos no ensaio de tomografia ultrassônica.

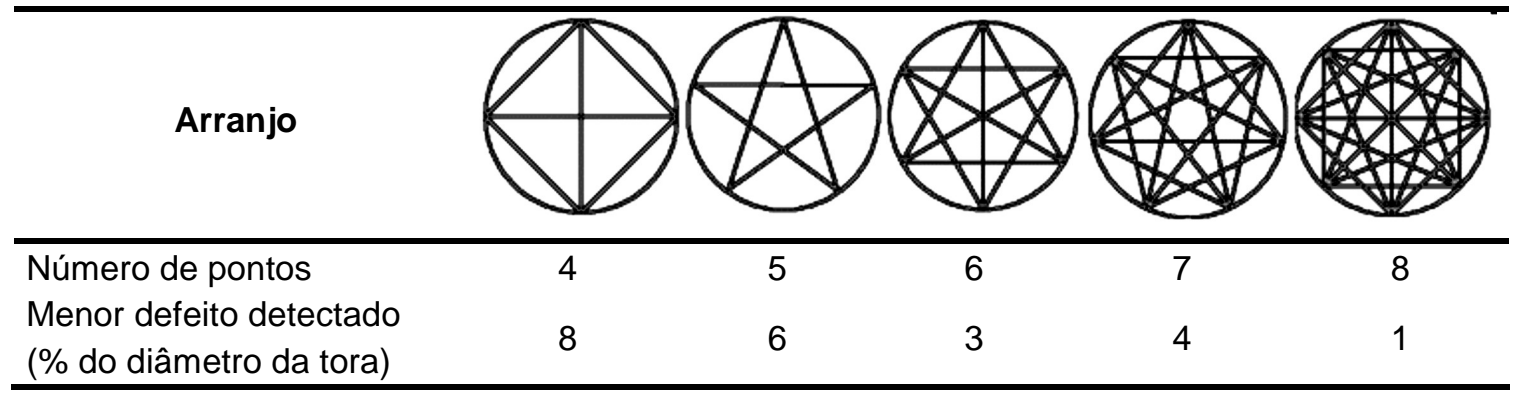

Fonte: Divós \& Szalal (2002)

Outro fator que afeta a resolução da imagem é a frequência do sinal. Imagens de melhor resolução são conseguidas com sinais de frequências maiores. Entretanto, os sinais de alta frequência possuem grande atenuação na madeira (BUCUR, 2005).

De acordo com Bucur (2004), os equipamentos de tomografia para AND de toras de madeira operam com frequências entre $50 \mathrm{kHz}$ a $5 \mathrm{MHz}$.

A Figura 2.14a mostra como os transdutores são posicionados no tronco da árvore e a Figura 2.14b mostra o transdutor do aparelho Fakopp 2D.

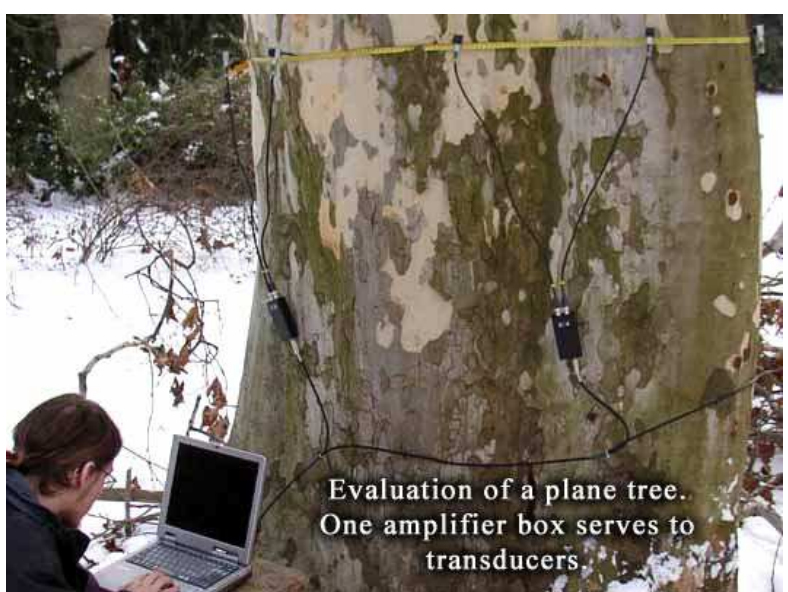

a)

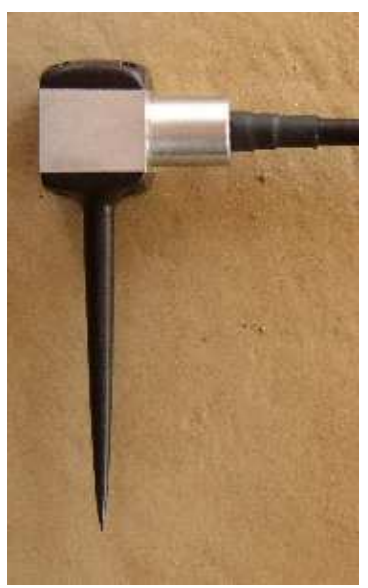

b)

Figura 2.14 - a) Posicionamento dos transdutores ultrassônicos no tronco de uma árvore; b) transdutor ultrassônico do aparelho Fakopp 2D. Fonte: Fakopp Enterprise (2008). 


\subsubsection{Ensaios dinâmicos}

A resposta da madeira a um estímulo dinâmico também pode ser utilizada como indicador da qualidade das toras. A velocidade de propagação de uma onda de choque ou a frequência fundamental de vibração de um elemento estrutural são diretamente relacionadas com a rigidez do elemento e, conhecendo-se uma dessas características, pode-se estimar o módulo de elasticidade das toras de madeira.

Os ensaios dinâmicos mais utilizados na AND de toras de madeira são a emissão ultrassônica, a técnica de ondas de tensão e a vibração transversal.

\section{a. Ensaio de emissão ultrassônica}

De acordo com Gonçalves \& Puccini (2000), o uso da técnica de emissão ultra-sônica na engenharia civil teve início na Europa na década de 50, sendo inicialmente utilizada na avaliação do concreto. Posteriormente, investigadores iniciaram estudos teóricos para a aplicação do ultrassom na madeira encontrando sérias dificuldades em função das peculiaridades anatômicas desse material.

A técnica de inspeção ultrassônica tem sido explorada na detecção de características capazes de reduzir a resistência da madeira tais como nós, inclinação de fibras e apodrecimento (EMERSON et al, 1998).

Wolfe (2000) salienta que o tempo de propagação, a frequência natural e a atenuação da onda são os melhores parâmetros para serem correlacionados com a resistência e a rigidez da madeira.

A presença de imperfeições ou inclusões pode provocar a dispersão das ondas sonoras resultando em ecos e reverberações. A detecção das ondas refletidas e dos ecos permite identificar possíveis defeitos no material. A Figura 2.15 mostra os vários métodos de ensaio que podem ser usados na detecção de defeitos por meio do ultrassom.

O acoplamento entre o transdutor e o espécime em teste deve ser muito bom para evitar atenuações no sinal. Antes de posicionar o transdutor do equipamento ultra-sônico para a realização do ensaio deve-se aplicar um líquido de acoplamento na superfície do espécime. De acordo com Cartz (1996), o líquido de acoplamento tem a função de fornecer um caminho adequado entre o transdutor e o material ensaiado, evitando a presença de ar entre eles. 
Para avaliar a rigidez pela técnica do ultrassom deve-se emitir um pulso de alta frequência (f > $20 \mathrm{KHz}$ ) na direção em que se deseja estudar e medir o tempo necessário para que o pulso atinja a face oposta. Conhecida a distância entre os transdutores emissor e receptor e medindo-se o tempo necessário para a onda percorrer esse caminho, pode-se determinar a velocidade de propagação da onda no interior do material.

O valor do módulo de elasticidade pode ser estimado, por meio da Equação 2.1, usando a velocidade de propagação $C$ e a densidade do material $\rho$.

$$
E_{M, U S}=C^{2} * \rho
$$

Sendo:

$E_{M, U S}=$ Módulo de elasticidade obtido com ultrassom $\left(\mathrm{N} / \mathrm{m}^{2}\right)$;

$C=$ velocidade de propagação da onda $(\mathrm{m} / \mathrm{s})$;

$\rho=$ densidade da madeira $\left(\mathrm{kg} / \mathrm{m}^{3}\right)$.

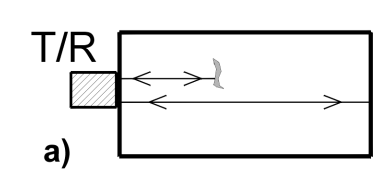

a)

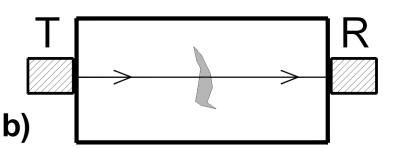

c)

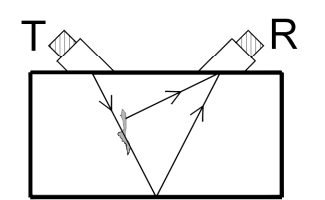

d)

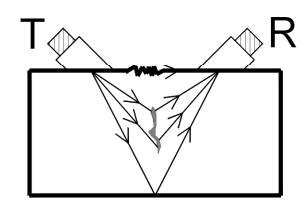

Arranjo experimental
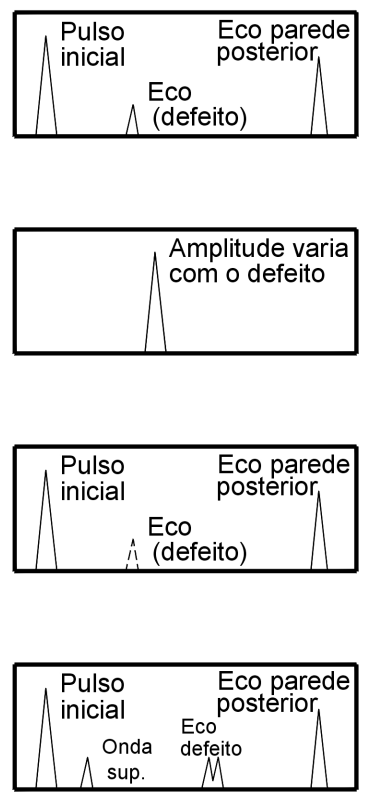

Tela do osciloscópio

Figura 2.15 - Disposições dos transdutores no ensaio ultrassônico.

Fonte: Adaptado de Cartz (1996).

A frequência do sinal dependerá do material que será testado. A Tabela 2.9 mostra as frequências comumente usadas para algumas aplicações. 
Tabela 2.9 - Bandas de frequências do ultrassom para algumas aplicações.

\begin{tabular}{ll}
\hline \multicolumn{1}{c}{ Bandas de frequência } & \multicolumn{1}{c}{ Aplicações } \\
\hline $200 \mathrm{KHz}-1 \mathrm{MHz}$ & $\begin{array}{l}\text { Metais de granulação grossa: Ferro fundido } \\
\text { cinzento, ferro fundido nodular, cobre e aço } \\
\text { inoxidável. }\end{array}$ \\
$\begin{array}{l}\text { Metais de granulação fina: Aço alumínio e } \\
\text { latão. }\end{array}$ \\
$200 \mathrm{KHz}-5 \mathrm{MHz}-2,25 \mathrm{MHz}$ & Plásticos e compósitos com plásticos \\
$1-5 \mathrm{MHz}$ & Produtos laminados: chapas, placas, barras. \\
$2,25-10 \mathrm{MHz}$ & Dobrados e extrudidos: barras, tubos e \\
$1-10 \mathrm{MHz}$ & perfis. \\
$2,25-10 \mathrm{MHz}$ & Forjados. \\
$1-2,25 \mathrm{MHz}$ & Vidros e cerâmicas. \\
$1-10 \mathrm{MHz}$ & Soldas. \\
& Verificação de fadiga e trincas. \\
\hline
\end{tabular}

Fonte: Adaptado de Cartz (1996).

Oliveira (2005) afirma que a velocidade de propagação das ondas na madeira sofre uma grande atenuação para frequências acima de $1 \mathrm{MHz}$ e, por esse motivo, deve-se trabalhar com frequências inferiores a esse valor.

A compreensão dos fatores que afetam a propagação das ondas ultrassônicas pela madeira é de fundamental importância para o emprego correto da técnica.

Segundo Mantilla Carrasco \& Azevedo Júnior (2002), os fatores que influenciam a propagação das ondas ultrassônicas são o teor de umidade e a densidade da madeira, a temperatura ambiente, a estrutura microscópica da madeira e as dimensões dos elementos estruturais.

Santos et al (2002) explicam que o teor de umidade influi diretamente na elasticidade e na densidade da madeira ocasionando significativas variações na leitura do tempo de propagação das ondas; a densidade e a concentração dos anéis de crescimento ocasionam mudança na estrutura da madeira influenciando também a velocidade de propagação de ondas.

Costa \& Gonçalves (2002) ressaltam que a variação da velocidade de propagação das ondas é mais significativa nos trechos com teores de umidade abaixo do ponto de saturação das fibras.

Sales et al (2004), relatam que a velocidade de propagação é maior na direção longitudinal devido à orientação das células nesse eixo as quais propiciam um caminho 
contínuo para as ondas. Oliveira $(2001)^{5}$ e Bucur $(1994)^{6}$ citados por Sales et al (2004) argumentam que quando as ondas se propagam na direção transversal, as mesmas cruzam a lignina mais amorfa e inelástica, e assim estão sujeitas a grandes atenuações.

Segundo Nogueira \& Ballarin (2003), o módulo de elasticidade determinado com a técnica de ultrassom nas direções longitudinal e radial, mostra boas correlações com o módulo de elasticidade medido no ensaio estático. Entretanto, o mesmo não se observa na direção tangencial na qual os autores obtiveram $\mathrm{R}^{2} \approx 42 \%$.

Miná et al (2004) investigaram o uso da técnica ultrassônica para avaliar o módulo de elasticidade dinâmico de 15 postes de 7,5 m de comprimento (diâmetro médio de $21 \mathrm{~cm}$ ) e 35 postes de $9 \mathrm{~m}$ de comprimento (diâmetro médio de 13,5 cm) da espécie Eucalyptus citriodora. O aparelho usado nos ensaios dinâmicos foi o Sylvatest com transdutores de $22 \mathrm{kHz}$. A Figura 2.16 mostra o gráfico da correlação entre o módulo de elasticidade estático e o dinâmico.

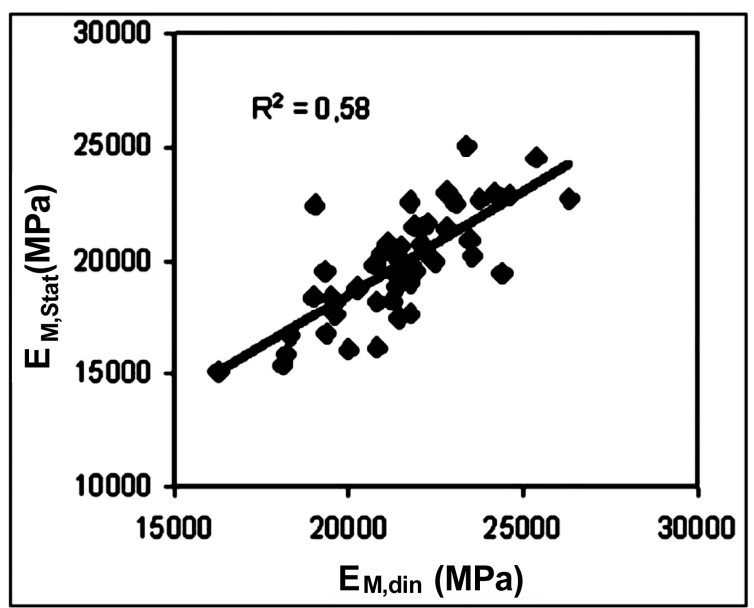

Figura 2.16 - Correlação entre módulo de elasticidade dinâmico $\left(\mathrm{E}_{\mathrm{M}, \mathrm{din}}\right)$ e estático $\left(\mathrm{E}_{\mathrm{M}, \mathrm{Stat}}\right)$ obtido por Miná et al (2004).

Fonte: Adaptado de Miná et al (2004).

A partir da análise dos resultados, os autores concluíram que a técnica do ultrassom pode ser empregada na avaliação da rigidez de postes de madeira.

Sales et al (2004) empregaram a técnica ultrassônica para estudar a propagação das ondas em toras de Eucalyptus citriodora. Foram ensaiados à flexão estática até a ruptura 25 postes de Eucalyptus citriodora. Posteriormente foram extraídas de cada poste duas seções

5 OLIVEIRA, F. G. R. Estudo de propriedades mecânicas de dicotiledôneas por meio de ensaios não destrutivos utilizando equipamento de ultra-som. Dissertação (Mestrado em Engenharia de Materiais). Escola de Engenharia de São Carlos, Universidade de São Paulo. São Carlos,. 2001.

6 BUCUR, V.; BÖHNKE, I. Factors affecting ultrasonic measurements in solid wood. Ultrasonics, v. 32, n. 5, p.385-390. 1994. 
com $50 \mathrm{~cm}$ de comprimento de regiões não afetadas pela ruptura, sendo uma do topo e outra da base dos postes. As seções das toras foram submetidas à emissão ultrassônica nas direções axial e radial como mostra a Figura 2.17.
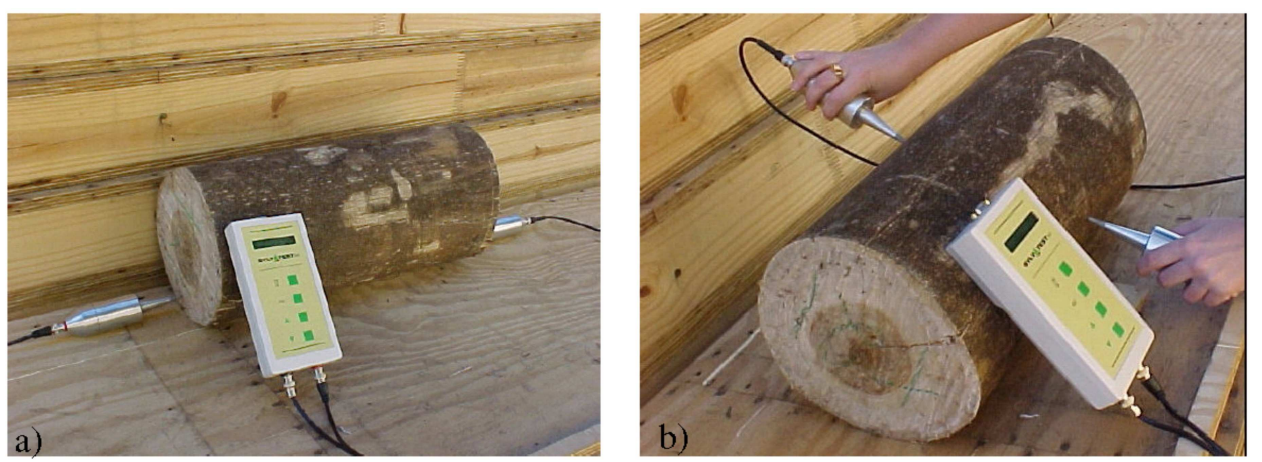

Figura 2.17 - Ensaio de emissão ultrassônica em seções de toras de Eucalyptus citriodora. Fonte: Sales et al (2004).

A Figura 2.18 mostra as correlações entre o módulo de elasticidade dinâmico e o módulo de elasticidade estático e entre o módulo de elasticidade dinâmico e o módulo de ruptura na flexão.
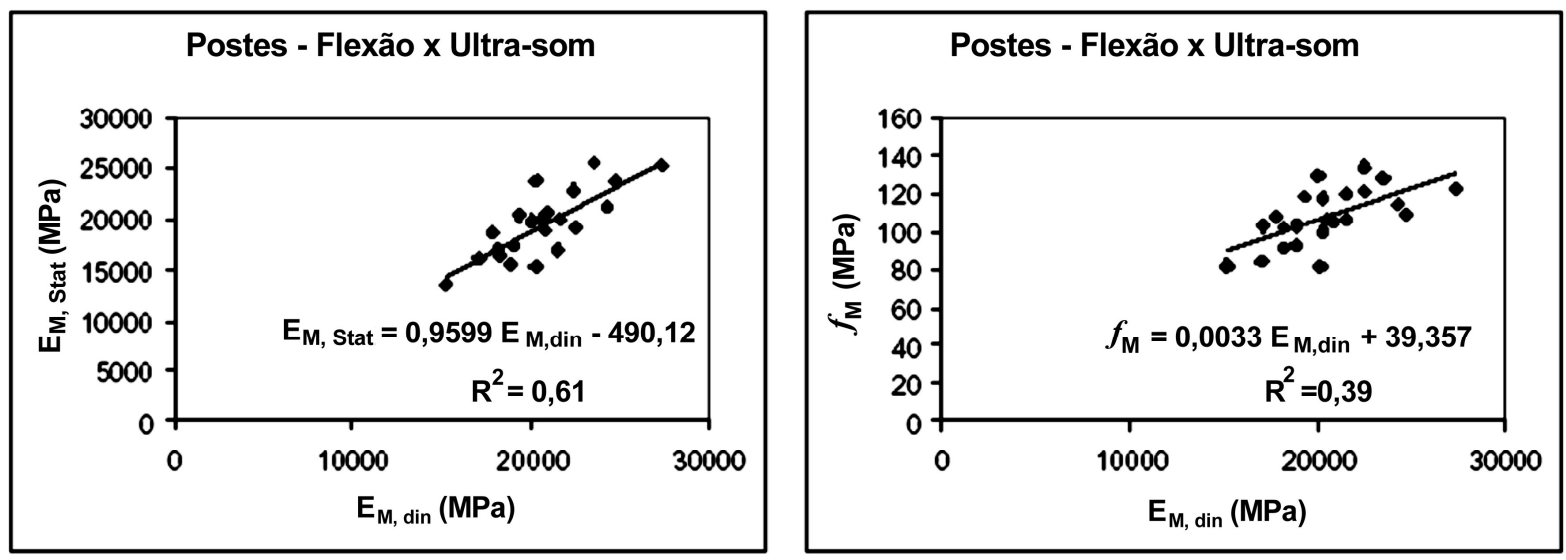

Figura 2.18 - Correlação entre o módulo de elasticidade dinâmico $\left(\mathrm{E}_{\mathrm{M}, \mathrm{din}}\right)$ com o módulo de elasticidade estático ( $\left.\mathrm{E}_{\mathrm{M}, \mathrm{Stat}}\right)$ e com o módulo de ruptura na flexão $\left(f_{\mathrm{M}}\right)$.

Fonte: Adaptado de Sales et al (2004).

Sales et al (2004) concluem que as propriedades determinadas pela emissão ultrassônica e pela flexão estática mostraram boa relação indicando que a técnica ultrassônica pode ser usada para avaliar o módulo de elasticidade à flexão estática de postes de madeira.

Gonçalves et al (2007) avaliaram a variabilidade das propriedades mecânicas de postes novos de madeira e de concreto e definiram uma metodologia de classificação usando a técnica de propagação de ondas ultrassônicas. Os autores mediram as velocidades nas direções longitudinal e radial (Figura 2.19). Nos ensaios com o aparelho de ultrassom foram 
usados transdutores de $25 \mathrm{kHz}$. Foram realizados ensaios estáticos de flexão para avaliar a resposta obtida nos ensaios com o ultrassom.

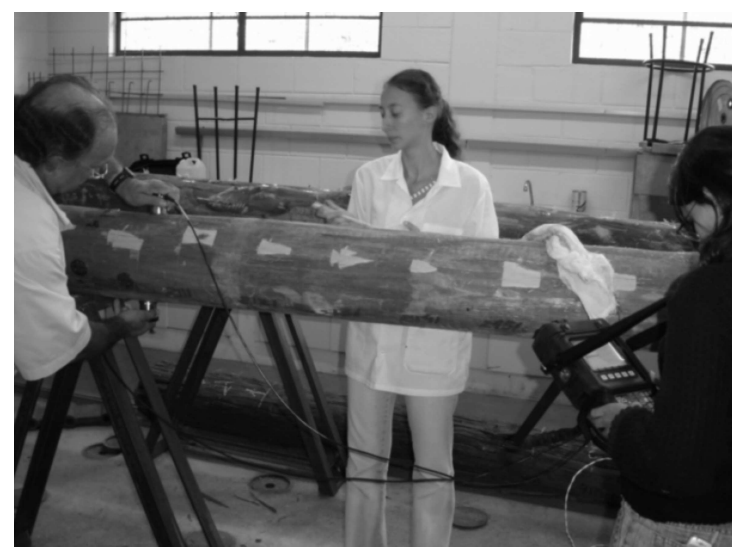

Figura 2.19 - Medição da velocidade de propagação da onda ultrassônica na direção radial de postes de madeira.

Fonte: Gonçalves et al (2007).

Gonçalves et al (2007) concluem que a velocidade das ondas ultrassônicas pode ser usada como uma ferramenta para avaliar as propriedades iniciais de postes de madeira e de concreto.

\section{b. Ondas de tensão}

A técnica de avaliação não-destrutiva por ondas de tensão (stress wave) tem recebido bastante atenção por alguns pesquisadores por ser um método rápido e simples.

Nesse ensaio, uma onda de choque produzida pelo impacto de um martelo em uma das extremidades da peça percorre o material até ser captada por um acelerômetro fixado na outra extremidade (Figura 2.20).

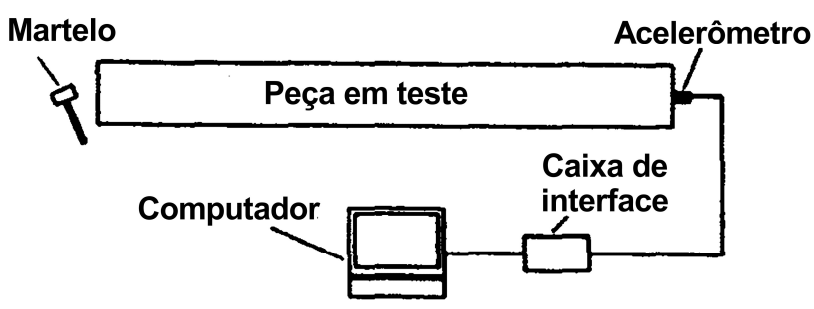

Figura 2.20 - Esquema do ensaio de ondas de tensão. Fonte: Wang et al (2004).

O módulo de elasticidade dinâmico é obtido a partir da velocidade de propagação da onda no material, segundo a Equação 2.1, visto que tal método se baseia no mesmo modelo físico da técnica ultra-sônica. Entretanto, deve-se observar que a Equação 2.1 é válida para 
materiais homogêneos, isotrópicos, elásticos e com a forma de uma barra longa e esbelta (WANG et al, 2004).

Por esse motivo, Wang et al (2004) alertam que sua aplicação em materiais derivados de madeira é afetada por muitos fatores como: ângulo das fibras; teor de umidade; temperatura da madeira e geometria da seção transversal.

Esses fatores podem ter afetado trabalho de Wolfe \& Moseley (2000), os quais encontraram uma fraca correlação $\left(\mathrm{R}^{2}=0,4\right)$ entre o módulo de elasticidade determinado pela técnica de ondas de tensão $\left(\mathrm{E}_{\mathrm{M}, \mathrm{SW}}\right)$ e o módulo de elasticidade medido no ensaio estático de flexão ( $\mathrm{E}_{\mathrm{M} \text {,stat }}$ ). Os autores apontam como possíveis fontes de erro a inexatidão do equipamento, gradientes de umidade, transição brusca da madeira juvenil para a madeira adulta e a interpenetração da onda. Wolfe \& Moseley (2000) afirmam ainda que as medições das ondas de tensão pouco contribuíram com a classificação visual.

Segundo Wolfe \& Moseley (2000), além dos fatores já citados, as estimativas de velocidade da onda no interior da madeira são complicadas pelos seguintes aspectos: as variações naturais na resistência mecânica não são necessariamente relacionadas com as variações na densidade; o teor de umidade pode atenuar e diminuir a velocidade da onda; a onda percorre caminhos que aumentam o seu tempo de percurso.

Wang et al (2001) citam dois estudos anteriores - Wang (1999) ${ }^{7}$ e Wang et al (2000) ${ }^{8}$ nos quais os autores observaram que as ondas de tensão comportaram-se de modo diferente nas toras e nos corpos-de-prova isentos de defeitos. Os autores citados relataram que a parte externa da tora (madeira adulta) pareceu ter um efeito dominante na propagação das ondas. Essa predominância teria resultado em altas velocidades nas ondas de tensão elevando a estimativa do $\mathrm{E}_{\mathrm{M}, \mathrm{SW}}$ obtido por essa técnica.

A técnica de ondas de tensão é sensível ainda às imperfeições geométricas das toras. Wang et al (2001), observaram que toras mais arredondadas e mais retilíneas tendem a desenvolver melhor correlação entre o módulo de elasticidade dinâmico e o módulo de elasticidade estático. Os autores observam também que a relação diâmetro-comprimento (D/L) deve ser levada em conta na regressão.

7 WANG, X. Stress wave-based nondestructive evaluation (NDE) methods for wood quality of standing trees. Ph.D. diss. Michigan Technological Univ., Houghton, MI. 1999.

8 WANG, X; ROSS, R.J.; ERICKSON, J.R.; FORSMAN, J.W.; MCGINNIS, G. D.; DE GROOT, R. C. Nondestructive methods of evaluating quality of wood in preservative treated piles. SDA. Forest Service. Madison, WI. 2000. 
No Brasil, Hellmeister (2003) aplicou a técnica de ondas de tensão para a caracterização mecânica de toras, pranchas e tábuas de Pinus taeda. Os ensaios de ondas de tensão foram realizados com o aparelho Stress wave timer modelo 239A da Metriguard. As toras foram apoiadas em espumas de alta densidade (Figura 2.21).
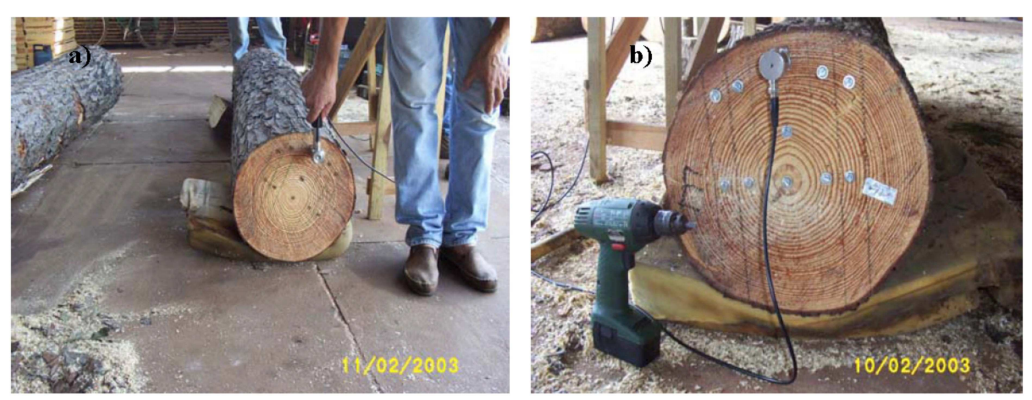

Figura 2.21 - Ensaio de ondas de tensão em toras de Pinus taeda.

Fonte: Hellmeister (2003).

Entre suas principais conclusões, Hellmeister (2003) afirma que as equações de regressão forneceram estimativas pouco precisas da propriedade de rigidez da madeira na umidade de equilíbrio. Os coeficientes de determinação obtidos nos ajustes de regressão variaram de 0,53 a 0,60 .

Wang et al (2004) avaliaram o efeito do diâmetro da tora na estimativa do módulo de elasticidade pelo método de ondas de tensão. O efeito do diâmetro das toras pode ser observado na Figura 2.22 na qual verifica-se que a diferença entre $E_{M \text {,stat }}$ e $E_{M, S w}$ é relacionada com o diâmetro das toras.
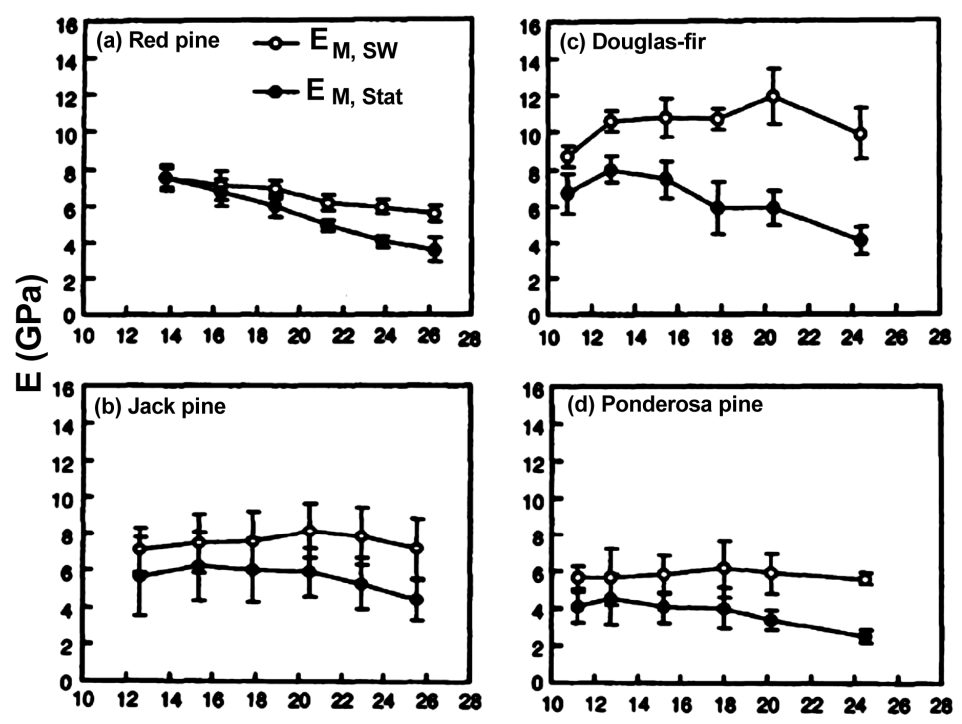

Diâmetro das toras $(\mathrm{cm})$

Figura 2.22 - Efeito do diâmetro das toras no $\mathrm{E}_{\mathrm{M}, \mathrm{Sw}}$.

Fonte: Adaptado de Wang et al (2004). 
Wang et al (2004) observaram que o modelo de regressão exponencial multivariada levando em conta o $\mathrm{E}_{\mathrm{M}, \mathrm{SW}}$, o diâmetro das toras e a densidade da madeira forneceu melhores estimativas do $\mathrm{E}_{\mathrm{M} \text {, stat }}$ do que o modelo de regressão linear simples. A Tabela 2.10 mostra os dois modelos de regressão estudados por Wang et al (2004) e os respectivos coeficientes de determinação.

Os autores concluem que o modelo de regressão multivariada pode permitir o uso da técnica de ondas de tensão para avaliação do $\mathrm{E}_{\mathrm{M} \text {,stat }}$ de toras de madeira.

Tabela 2.10 - Modelos de regressão estudados por Wang et al (2004).

\begin{tabular}{lccccccc}
\hline \multirow{2}{*}{ Espécies } & \multicolumn{3}{c}{ Modelo de regressão 1 } & \multicolumn{4}{c}{ Modelo de regressão 2 } \\
\cline { 2 - 7 } & \multicolumn{3}{c}{$E_{M, S W}=\beta_{0}+\beta_{1}\left(C^{2} \rho\right)$} & \multicolumn{3}{c}{$E_{M, S W}=a\left(C^{2} \rho\right)^{b} D^{c}$} \\
\cline { 2 - 8 } & $\boldsymbol{\beta}_{\mathbf{0}}$ & $\boldsymbol{\beta}_{1}$ & $\mathbf{R}^{2}$ & $\mathbf{A}$ & $\mathbf{b}$ & $\mathbf{C}$ & $\mathbf{R}^{2}$ \\
\hline Red pine & $-4,127$ & 1,4740 & 0,75 & 3,6890 & 0,9078 & $-0,7326$ & 0,92 \\
Jack pine & $-0,444$ & 0,7883 & 0,60 & 1,9725 & 1,1957 & $-0,5060$ & 0,73 \\
Douglas-fir & 3,323 & 0,3313 & 0,07 & 2,9470 & 1,3852 & $-0,8952$ & 0,79 \\
Ponderosa & $-0,362$ & 0,7345 & 0,55 & 3,5858 & 1,0522 & $-0,6459$ & 0,87 \\
pine & &
\end{tabular}

$\mathrm{C}=$ velocidade da onda $(\mathrm{m} / \mathrm{s}) ; \rho=$ densidade aparente $\left(\mathrm{kg} / \mathrm{m}^{3}\right) ; \mathrm{D}=$ diâmetro médio da tora.

Fonte: Adaptado de Wang et al (2004).

Apesar da avaliação por ondas de tensão se mostrar como um meio eficaz para detectar apodrecimento ou outras características capazes de reduzir a resistência de peças estruturais de madeira serrada, os estudos observados até o momento sugerem que é necessário realizar mais pesquisas para o desenvolvimento dessa técnica de forma a obter resultados mais confiáveis na AND de toras.

\section{c. Vibração transversal}

Ballarin et al (2002) explicam que a técnica de vibração transversal tem sido muito empregada na avaliação do módulo de elasticidade especialmente pela forte aderência entre o modelo físico do fenômeno e o correspondente modelo teórico matemático.

$\mathrm{Na}$ AND de peças estruturais de madeira por vibração transversal, a resistência do material é estimada em função do módulo de elasticidade dinâmico que pode ser medido a partir da frequência fundamental. Para tanto, é necessário conhecer de antemão a massa e as dimensões do elemento.

Os fundamentos da técnica de vibração transversal são discutidos com maior profundidade no item 2.2 deste trabalho. 
A técnica de vibração transversal foi trazida ao Brasil há pouco tempo. Os primeiros trabalhos relatando a aplicação desse método em corpos-de-prova de madeira datam de 2002. Todavia, nos Estados Unidos, por exemplo, essa técnica é utilizada desde a década de 60 sendo descrita inicialmente por Pellerin (1965) ${ }^{9}$ apud Ross et al (1991).

O emprego de tal técnica exigiu a elaboração da norma ASTM D6874 (2003) "Standard Test Method for Nondestructive Evaluation of Wood-Based Flexural Members Using Transverse Vibration" que regulamenta o método de ensaio para a avaliação nãodestrutiva de elementos estruturais de madeira serrada por meio da técnica de vibração transversal.

Essa norma padroniza o ensaio com a condição de contorno de viga bi-apoiada e emprega o modelo de Bernoulli, utilizando relação vão/altura superior a 20, para minimizar os efeitos do cisalhamento no módulo de elasticidade. Nessas condições, o módulo de elasticidade na flexão obtido com a técnica de vibração transversal ( $\left.\mathrm{E}_{\mathrm{M}, \mathrm{VT}}\right)$ pode ser determinado pela Equação 2.2.

$$
E_{M, V T}=\frac{f_{1}^{2} * P *\left(L_{\text {apoio }}\right)^{3}}{2,47 * I * g}
$$

Sendo:

$$
\begin{aligned}
& E_{M, V T}=\text { módulo de elasticidade na flexão }(\mathrm{Pa}) ; \\
& f_{l}=\text { frequência natural do } 1^{\circ} \text { modo }(\mathrm{Hz}) ; \\
& P=\text { peso da viga }(\mathrm{N}) ; \\
& L_{\text {apoio }}=\text { distância entre apoios }(\mathrm{m}) ; \\
& I=\text { momento de inércia da seção transversal }\left(\mathrm{m}^{4}\right) ; \\
& g=\text { aceleração da gravidade }\left(9,80665 \mathrm{~m} / \mathrm{s}^{2}\right) .
\end{aligned}
$$

Vários autores relatam bons resultados na aplicação da técnica de vibração transversal para a AND de madeira serrada, dentre os quais pode-se citar:

Ross et al (1991) que estimaram a rigidez à flexão de 30 vigas de Spruce-Pine-Fir com seção transversal de $38 \mathrm{~mm}$ x $89 \mathrm{~mm}$ com comprimento de cerca de 2,7 m empregando a técnica de vibração transversal e observaram uma boa correlação entre as duas propriedades como mostra a Figura 2.23.

\footnotetext{
${ }^{9}$ Pellerin, R.E. A vibrational approach to nondestructive testing of structural lumber. Forest Products Journal 15(3): 93-101. 1965.
} 


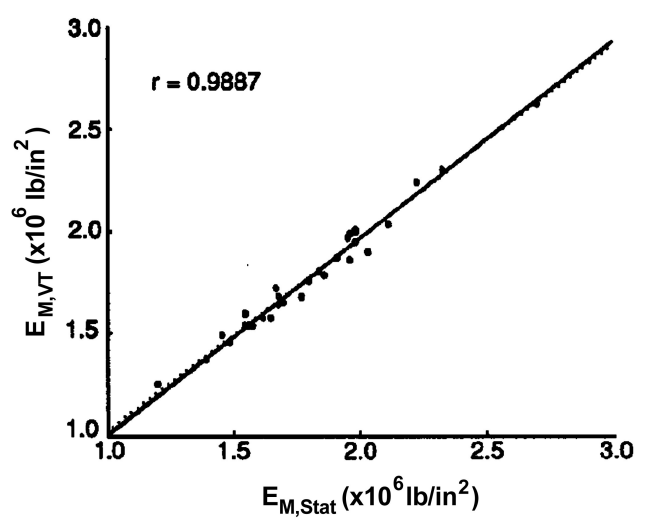

Figura 2.23 - Correlação entre $\mathrm{E}_{\mathrm{M}, \text { Stat }}$ e $\mathrm{E}_{\mathrm{M}, \mathrm{VT}}$.

Fonte: Ross et al (1991).

Ballarin et al (2002) realizaram o teste de vibração transversal e também ensaios de flexão estática em 202 corpos-de-prova com dimensões de $2 \mathrm{~cm}$ x $2 \mathrm{~cm}$ x $46 \mathrm{~cm}$ sendo 48 deles de Pinus taeda, 69 de Eucalyptus citriodora, 57 de Eucalyptus grandis e 28 de Eucalyptus saligna. O equipamento utilizado para o ensaio de vibração transversal foi o BING (Beam Identification by Nondestructive Grading), produzido pelo CIRAD-Forest. Os ensaios foram desenvolvidos com os corpos-de-prova em suspensão livre-livre (Figura 2.24) e a vibração foi introduzida pelo impacto de um martelo. O sinal foi captado por um microfone e digitalizado por uma placa de aquisição ligada a um computador.

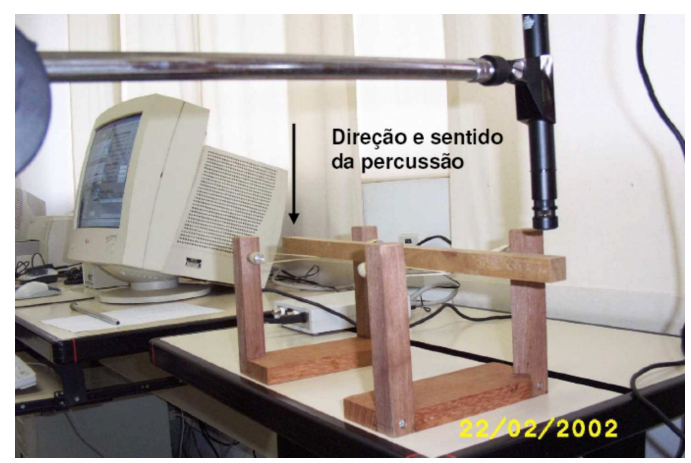

Figura 2.24 - Ensaio de vibração transversal realizado por Ballarin et al (2002).

Fonte: Ballarin et al (2002).

Os coeficientes de correlação encontrados pela análise de regressão dos dados foram 0,98 para o Pinus taeda, 0,87 para o Eucalyptus citriodora, 0,87 para o Eucalyptus grandis e 0,76 para o Eucalyptus saligna. Os autores concluíram que o método da vibração transversal revelou-se uma importante ferramenta para a classificação da madeira e observam que na média, o $\mathrm{E}_{\mathrm{M}, \mathrm{VT}}$ foi superior ao $\mathrm{E}_{\mathrm{M}, \mathrm{stat}}$ em cerca de $12 \%$.

Calil Jr \& Miná (2003) realizaram a AND por vibração transversal em 326 peças estruturais de southern pine, cujas dimensões eram de 3,81 cm x 13,97 cm x 302,26 cm. O 
teor de umidade das peças no momento do ensaio era de $12 \%$. Os autores utilizaram o aparelho E-computer 340 da Metriguard (Figura 2.25). Nesse aparelho, as vigas ficam biapoiadas sobre dois tripés de aço. Um dos tripés contém uma célula de carga que mede a metade do peso e a oscilação na reação de apoio.

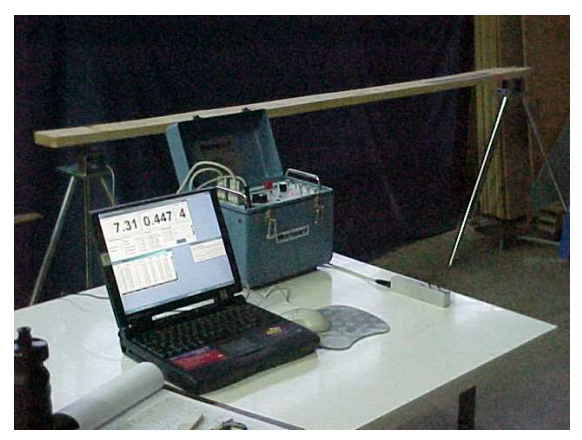

Figura 2.25 - Equipamento E-computer 340 da Metriguard. Fonte: Carreira (2003).

Após o ensaio dinâmico, Calil Jr \& Miná (2003) realizaram o ensaio de flexão estática. As peças foram simplesmente apoiadas e no meio do vão foi aplicada uma força de 44,8 N.

A regressão linear entre $E_{M}$, stat e o $E_{M, V T}$ resultou em um coeficiente de correlação (r) de 0,98 levando os autores a concluírem que a vibração transversal é um método eficiente para classificação de peças estruturais de madeira.

Carreira et al (2003) avaliaram a correlação entre o $\mathrm{E}_{\mathrm{M} \text {,stat }}$ e $\mathrm{E}_{\mathrm{M}, \mathrm{VT}}$. A amostra foi composta por 600 peças estruturais de Pinus sp com dimensões nominais de $3,5 \mathrm{~cm}$ x 12,5 cm x 2,60 m. Os autores verificaram uma forte correlação entre os dados (Figura 2.26) e concluíram que a vibração transversal é um método expedito de elevada confiabilidade para a estimativa do $\mathrm{E}_{\mathrm{M}, \mathrm{Stat}}$.

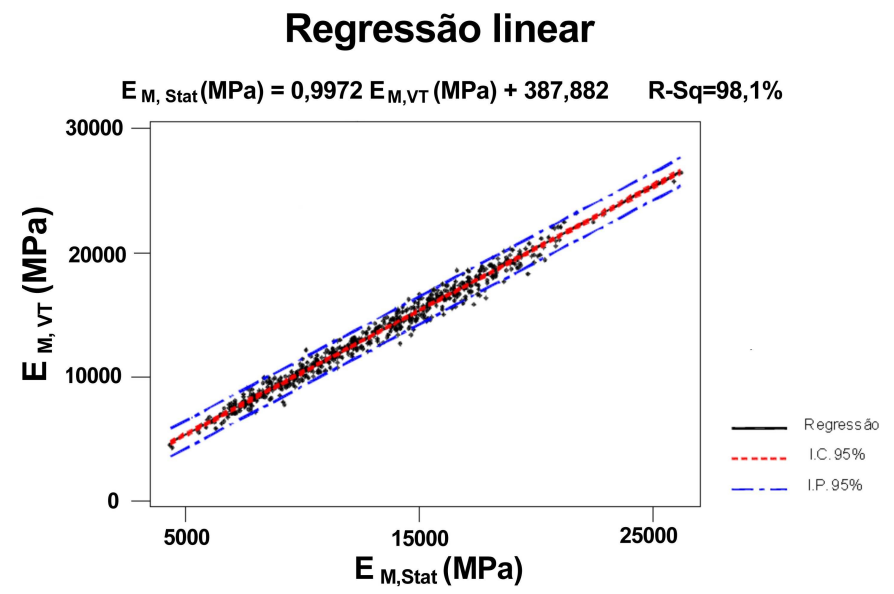

Figura 2.26 - Regressão linear entre $\mathrm{E}_{\mathrm{M}, \mathrm{Stat}}$ e $\mathrm{E}_{\mathrm{M}, \mathrm{VT}}$ obtida por Carreira et al (2003). 
Bartholomeu et al (2004) desenvolveram um ensaio simplificado para a determinação do $\mathrm{E}_{\mathrm{M}, \mathrm{VT}}$. $\mathrm{O}$ sinal da vibração foi captado por um microfone (Figura 2.27) ligado à placa de som de um microcomputador e, para a determinação da frequência de ressonância das peças, os autores empregaram um software usado para afinação de instrumentos musicais. A vibração foi produzida por leves impactos de um martelo de borracha no meio do vão. $\mathrm{O}$ ensaio foi realizado com as vigas bi-apoiadas.

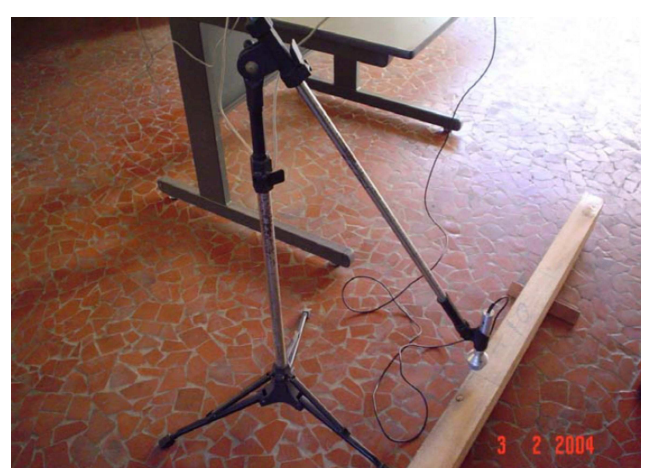

Figura 2.27 - Ensaio de vibração transversal em vigas de Angelim Araroba.

Fonte: Barthlomeu et al (2004).

A amostra foi composta por 91 vigas de Angelim Araroba (Vataireopsis araroba) com dimensões de $6 \mathrm{~cm}$ x $12 \mathrm{~cm}$ x $250 \mathrm{~cm}$. Após o ensaio de vibração transversal foi realizado o ensaio de flexão estática, para o qual foi utilizada a norma ASTM D198 "Standard Methods of Static Test of Timber in Structural Sizes". Os autores encontraram um coeficiente de correlação linear (r) igual a 0,73 e concluíram que o equipamento utilizado, apesar de simples, mostrou-se confiável.

Cho (2007) comparou a eficiência dos métodos de vibração longitudinal e vibração transversal complexa na determinação do módulo de elasticidade de 90 corpos-de-prova com dimensões de $35 \mathrm{~mm}$ x $35 \mathrm{~mm}$ x $600 \mathrm{~mm}$ das espécies Cunninghamia lanceolata, Cryptomerya japonica, Chamaecyparis obtusa var. formosana, Chamaecyparis formosensis e Cinnamomum camphora. As Figuras 2.28 e 2.29 mostram, respectivamente, a configuração dos ensaios de vibração longitudinal e de vibração transversal complexa. 


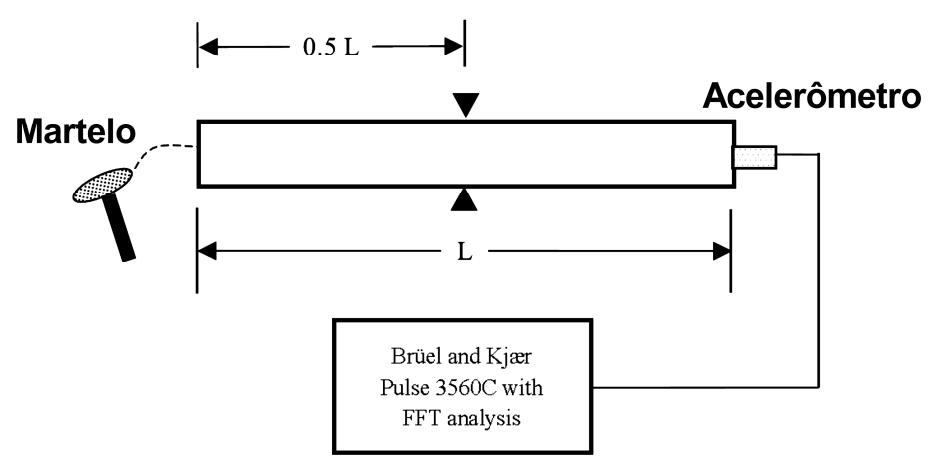

Figura 2.28 - Ensaio de vibração longitudinal.

Fonte: Cho (2007).

No ensaio de vibração longitudinal, a excitação foi produzida pelo impacto de um martelo de borracha em uma das extremidades dos corpos-de-prova. As vibrações resultantes foram captadas por um acelerômetro (Endevco tipo 2250A-10) fixado com cera de abelha na extremidade oposta. Os espécimes foram suspensos por dois prismas de borracha posicionados na metade de seu comprimento.

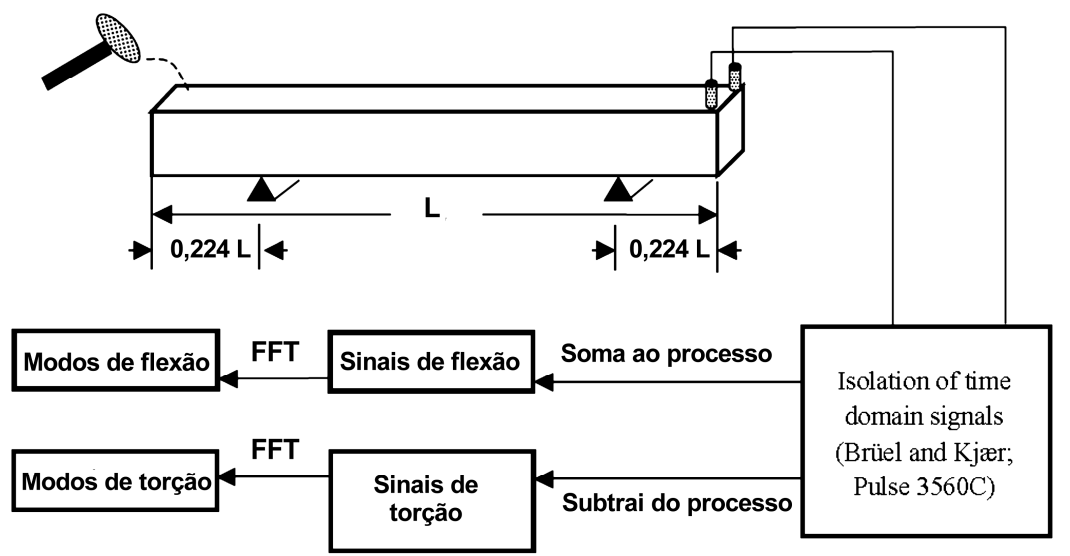

Figura 2.29 - Ensaio de vibração transversal complexa.

Fonte: Cho (2007).

Posteriormente foi feita a Transformada Rápida de Fourier (FFT) dos sinais amostrados para a determinação das frequências naturais.

O ensaio de vibração transversal foi conduzido adotando-se a condição de contorno livre-livre. Para tanto, os corpos-de-prova foram suspensos por dois prismas de espuma muito macia os quais foram posicionados nos pontos nodais do primeiro modo de flexão. Foram empregados dois acelerômetros e o impacto com o martelo de borracha foi desferido contra as bordas da extremidade oposta à dos acelerômetros. Com essa configuração de ensaio, Cho (2007) conseguiu captar tanto os modos de flexão quanto os de torção. Para identificar as 
frequências dos modos de flexão e de torção, foi feito o isolamento dos sinais no domínio do tempo utilizando o método de Sobue $(1986)^{10}$.

Posteriormente foram calculadas as FFT's dos sinais de cada modo. Dessa forma Cho (2007) conseguiu obter tanto $\mathrm{E}_{\mathrm{M}, \mathrm{VT}}$ como o módulo de elasticidade transversal (G).

Os resultados foram comparados com o módulo de elasticidade medido no ensaio estático de flexão e obtendo-se um coeficiente $\mathrm{R}^{2}=0,69$ entre o módulo estático e o dinâmico determinado pelo ensaio de flexão combinada com torção. A Tabela 2.11 mostra os resultados obtidos por Cho (2007).

Tabela 2.11 - Valores médios de E e G obtidos por Cho (2007).

\begin{tabular}{|c|c|c|c|c|c|c|}
\hline \multirow{2}{*}{ Espécies } & \multirow{2}{*}{$\begin{array}{c}\text { Dens. } \\
\left(\mathrm{kg} / \mathrm{m}^{3}\right)\end{array}$} & \multirow{2}{*}{$\begin{array}{c}\text { Umidade } \\
(\%)\end{array}$} & \multicolumn{3}{|c|}{$E$ (GPa) } & \multirow{2}{*}{$\begin{array}{c}\mathrm{G} \\
(\mathrm{GPa})\end{array}$} \\
\hline & & & $\mathrm{E}_{\mathrm{M}, \mathrm{Stat}}{ }^{1}$ & $E_{M, V L}^{2}$ & $E_{M, V T}{ }^{3}$ & \\
\hline Cunninghamia lanceolata & 419 & 13,3 & 8,42 & 11,25 & 9,71 & 0,65 \\
\hline Cryptomerya japonica & 508 & 14,2 & 8,25 & 9,84 & 8,75 & 1,03 \\
\hline $\begin{array}{l}\text { Chamaecyparis obtusa var. } \\
\text { formosana }\end{array}$ & 468 & 11,9 & 8,33 & 9,54 & 8,70 & 1,07 \\
\hline Chamaecyparis formosensis & 452 & 12,1 & 7,46 & 8,29 & 7,60 & 1,01 \\
\hline Cinnamomum camphora & 612 & 13,1 & 7,27 & 9,00 & 8,02 & 0,88 \\
\hline
\end{tabular}

Fonte: Cho (2007).

Cho (2007) observa ainda que o módulo de elasticidade dinâmico tende a ser cerca de $1,2 \%$ maior do que o estático.

Carreira \& Candian (2007) realizaram a avaliação não-destrutiva de 30 vigas de Cupiúba (Goupia glabra) com dimensões nominais de $5 \mathrm{~cm}$ x $10 \mathrm{~cm}$ x $300 \mathrm{~cm}$ empregando dois equipamentos de avaliação não-destrutiva por vibração transversal. Os autores utilizaram o equipamento E-computer modelo 340 da Metriguard e um protótipo desenvolvido pelo autor deste trabalho.

Além dos ensaios dinâmicos foram realizados ensaios de flexão estática para verificar a correlação entre os resultados. A Figura 2.30 mostra a regressão linear entre $\mathrm{E}_{\mathrm{M}, \text { Stat }}$ e $\mathrm{E}_{\mathrm{M}, \mathrm{VT}}$ obtido com o protótipo.

${ }^{10}$ SOBUE N. Instantaneous measurement of elastic constants by analysis of the tape tone of wood. Application to flexural vibration of beams. Mokuzai Gakkaishi 32(4):274-9. 1986. 


\section{Regressão linear simples}

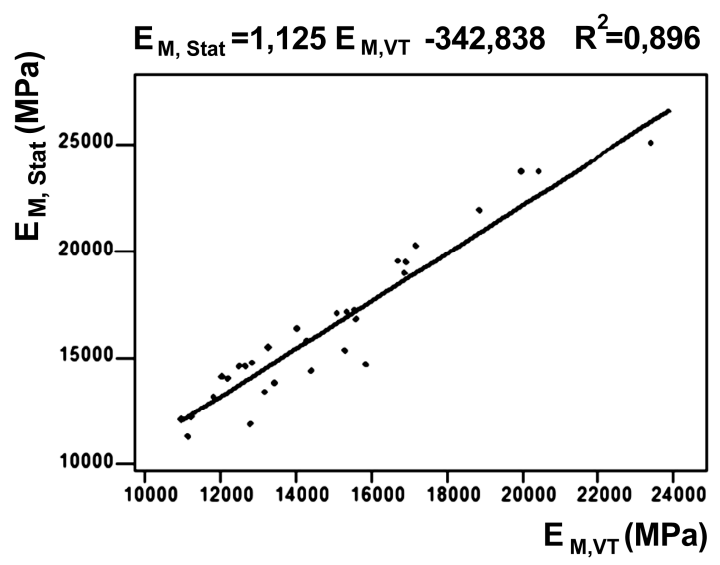

Figura 2.30 - Diagrama de dispersão e reta de regressão entre $E_{M, S t a t}$ e o $E_{M, V T}$ obtido com o equipamento desenvolvido pelo autor para avaliação de madeira serrada.

Fonte: Adaptado de Carreira \& Candian (2007).

As principais conclusões dos autores foram: a técnica de vibração transversal mostrouse rápida e de boa exatidão na avaliação da madeira; o equipamento produzido pelo autor apresentou resultados compatíveis com a versão comercial.

O ensaio de vibração transversal também pode ser aplicado em placas. Gsell et al (2007), por exemplo, empregaram a técnica de vibração transversal para a determinação das constantes elásticas de tabuleiros de madeira com laminação cruzada. Para simular a condição livre, os tabuleiros foram suspensos por fios finos, como mostra a Figura 2.31. A placa foi excitada por meio da percussão de um martelo de impulso e resposta foi captada por um acelerômetro posicionado na face oposta à de impacto. Os autores fizeram a análise modal das placas para a determinação das constantes elásticas. Gsell et al (2007) ainda comparam o módulo de elasticidade determinado no ensaio estático de flexão com o dinâmico e observam que o módulo de elasticidade dinâmico é da ordem de $6 \%$ maior do que o estático.

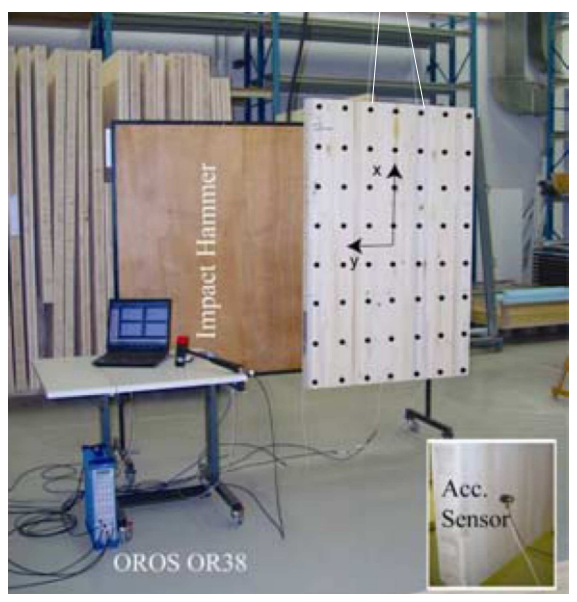

Figura 2.31 - Ensaio de vibração transversal em placa laminada. 
Com os ensaios dinâmicos, além do $\mathrm{E}_{\mathrm{M}, \mathrm{VT}}$, também é possível obter o módulo de elasticidade transversal G.

Hearmon (1958) realizou uma investigação experimental para a determinação da relação $E / G$ e do fator de forma ( $\eta$ ) por meio do ensaio de vibração transversal em vigas de madeira. A partir das frequências naturais de pelo menos dois modos de vibração, da massa, das propriedades geométricas da seção transversal das vigas e utilizando o método de correção de Goens (1931), foi montado um sistema de equações lineares cujas incógnitas eram as propriedades procuradas. Hearmon utilizou o método dos mínimos quadrados para encontrar a solução do sistema de equações.

Um estudo semelhante foi desenvolvido por Chui (1991) que apresentou um método para a avaliação simultânea do módulo de elasticidade longitudinal e transversal (G) de corpos-de-prova de madeira serrada. Tal método é baseado na medição das frequências naturais dos dois primeiros modos de flexão (Figura 2.32). Chui defende a determinação de $\mathrm{G}$ pelo ensaio de vibração transversal ao invés do ensaio estático citando o estudo de Chui \& Smith (1989) ${ }^{11}$ no qual os autores observaram que o efeito do cisalhamento é mais pronunciado no comportamento dinâmico do que no ensaio de flexão estática.

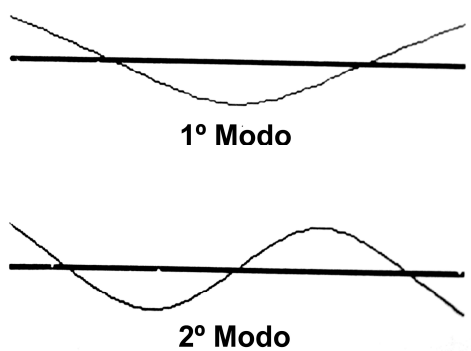

Figura 2.32 - Forma dos dois primeiros modos de flexão de uma viga em suspensão livrelivre.

Fonte: Chui (1991).

Os corpos-de-prova de Eastern canada com dimensões nominais de $40 \mathrm{~mm}$ x $40 \mathrm{~mm}$ x $640 \mathrm{~mm}$ foram suspensos por duas molas flexíveis para simular a condição livre-livre como mostra a Figura 2.33.

\footnotetext{
${ }^{11}$ Chui, Y. H. ; Smith, I. Influence of rotary inertia, shear deformation and support condition on natural frequency of wooden beams. Wood Science Technology. Vol. 24. pp 233-245. 1989.
} 


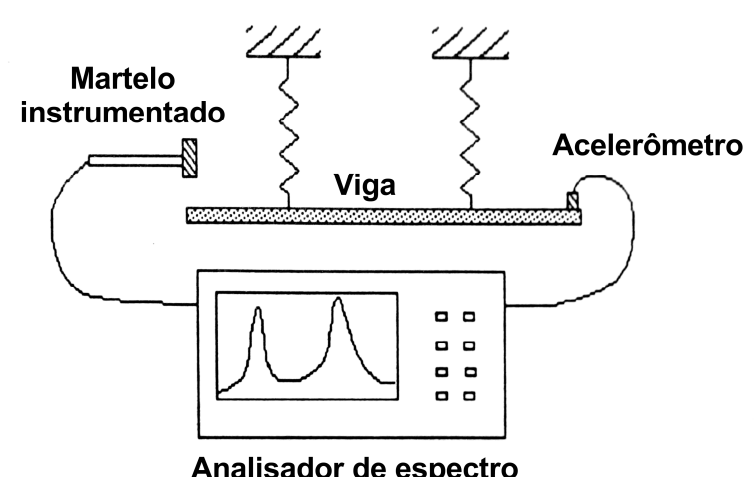

Figura 2.33 - Esquema do ensaio de vibração transversal realizado por Chui (1991).

Fonte: Chui (1991).

As constantes elásticas das vigas de madeira foram obtidas lançando-se os dados do ensaio na equação de Timoshenko (Equação 2.33) e resolvendo-se o sistema de equações resultante.

Chui (1991) avaliou também a influência dos nós na relação E/G e observou que para corpos-de-prova sem nós essa relação é igual a 20. Porém, nos corpos-de-prova com presença de nós o autor verificou grande variabilidade nessa relação não sendo possível definir um valor confiável. Contudo, Chui (1991) salienta que a relação E/G, para vigas com nós, é superior a 20 .

Alguns autores também investigaram a aplicação da técnica de vibração transversal em toras de madeira.

Chui et al (1999) desenvolveram um método para a avaliação do módulo de elasticidade de postes de madeira empregando a técnica da vibração livre. Os postes de red pine tinham comprimento e diâmetro médios respectivamente de 7,6 m e $26 \mathrm{~cm}$. Foram usadas duas molas flexíveis para a suspensão das toras (Figura 2.34).

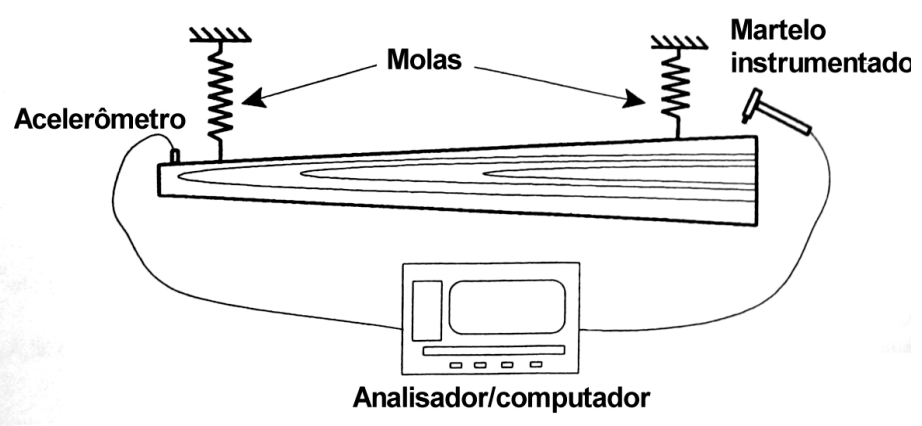

Figura 2.34 - Arranjo do ensaio de vibração livre realizado por Chui et al (1999). Fonte: Adaptado de Chui et al (1999). 
Como a relação entre o comprimento das toras e o diâmetro era superior a 20, Chui et al (1999) utilizam o modelo de vigas de Bernoulli levando em conta a conicidade das toras. O método proposto foi testado comparando-se o módulo de elasticidade dinâmico com o módulo de elasticidade medido no ensaio de flexão estática. Para tanto realizaram ensaios de vibração transversal e de flexão estática em uma amostra composta por dez toras da espécie red pine, cuja densidade aparente média, segundo Alden (1997), é de $0,46 \mathrm{~g} / \mathrm{cm}^{3}$.

A Tabela 2.12 mostra os resultados obtidos por Chui et al (1999)

Tabela 2.12 - Resultados dos testes desenvolvidos por Chui et al (1999).

\begin{tabular}{|c|c|c|c|c|c|c|c|}
\hline \multirow{2}{*}{ Tora } & \multicolumn{2}{|c|}{ Diâmetro (mm) } & \multirow{2}{*}{$\underset{(\mathrm{mm})}{\mathrm{L}}$} & \multirow{2}{*}{$\begin{array}{c}\rho \\
\left(\mathrm{kg} / \mathrm{m}^{3}\right)\end{array}$} & \multirow{2}{*}{$\begin{array}{l}\mathrm{E}_{\mathrm{M}, \mathrm{Stat}} \\
\text { (MPa) }\end{array}$} & \multirow{2}{*}{$\begin{array}{c}\mathbf{f}_{1} \\
(\mathrm{~Hz})\end{array}$} & \multirow{2}{*}{$\begin{array}{c}E_{\mathrm{M}, \mathrm{vT}} \\
(\mathrm{MPa})\end{array}$} \\
\hline & Topo & Base & & & & & \\
\hline 1 & 199 & 262 & 7604 & 612 & 11897 & 14,62 & 10233 \\
\hline 2 & 207 & 259 & 7616 & 641 & 13284 & 15,87 & 12588 \\
\hline 3 & 226 & 267 & 7624 & 654 & 11443 & 14,37 & 9444 \\
\hline 4 & 221 & 261 & 7607 & 653 & 10897 & 14,62 & 10137 \\
\hline 5 & 220 & 258 & 7630 & 676 & 12789 & 15,37 & 11898 \\
\hline 6 & 198 & 260 & 7612 & 576 & 9749 & 13,50 & 8405 \\
\hline 7 & 184 & 259 & 7603 & 661 & 3351 & 13,12 & 9682 \\
\hline 8 & 206 & 259 & 7617 & 644 & 10199 & 13,62 & 9353 \\
\hline 9 & 215 & 265 & 7630 & 577 & 11483 & 16,00 & 10941 \\
\hline 10 & 202 & 270 & 7633 & 777 & 11392 & 13,00 & 9686 \\
\hline
\end{tabular}

Fonte: Adaptado de Chui et al (1999).

$\mathrm{O}$ diagrama de dispersão entre $\mathrm{E}_{\mathrm{M}, \mathrm{Stat}}$ e $\mathrm{E}_{\mathrm{M}, \mathrm{VT}}$ e dinâmico é mostrado na Figura 2.35. Chui et al (1999), observaram que o outlier mostrado no diagrama correspondia a um poste que apresentava rachas anelares as quais afetaram a resistência e a rigidez do mesmo. Excluindo da análise os resultados da tora 7, Chui et al (1999) encontraram $\mathrm{R}^{2}=0,85$ na correlação entre $E_{\mathrm{M}, S t a t}$ e $E_{\mathrm{M}, \mathrm{VT}}$ e concluíram que o método proposto fornece estimativas precisas do módulo de elasticidade embora não seja capaz de identificar postes com avarias que comprometam as propriedades mecânicas.

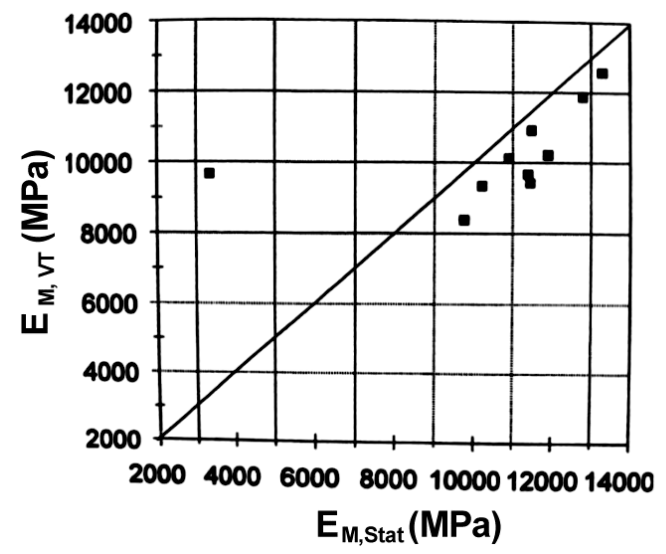

Figura 2.35 - Regressão linear entre $\mathrm{E}_{\mathrm{M}, \mathrm{stat}}$ e $\mathrm{E}_{\mathrm{M}, \mathrm{VT}}$.

Fonte: Adaptado de Chui et al (1999). 
Wang et al (2002) investigaram o uso das técnicas de vibração transversal e ondas de tensão na avaliação do módulo de elasticidade de uma amostra composta por 109 toras da espécie jack pine e 50 toras da espécie red pine. As toras foram cortadas com comprimento de 3,7 m e foram ensaiadas com umidade acima do ponto de saturação. O diâmetro médio das toras variou de $11,9 \mathrm{~cm}$ a $27,9 \mathrm{~cm}$ para o jack pine e de $11,2 \mathrm{~cm}$ a $25,9 \mathrm{~cm}$ para o red pine. Para o ensaio de vibração transversal, um acelerômetro foi colado na face superior na metade do comprimento da tora. A vibração transversal foi induzida com um impacto de um martelo de borracha na metade do comprimento da tora. $\mathrm{O}$ sinal captado pelo acelerômetro foi enviado a um osciloscópio no qual os autores observaram uma série de pulsos com decaimento gradual na amplitude. $\mathrm{O}$ ensaio de vibração transversal foi realizado com as toras na condição bi-apoiada.

As Figuras 2.36 e 2.37 mostram respectivamente os gráficos de correlação entre o $\mathrm{E}_{\mathrm{M}, \mathrm{Stat}}$ e os módulos $\mathrm{E}_{\mathrm{M}, \mathrm{SW}}$ e $\mathrm{E}_{\mathrm{M}, \mathrm{VT}}$.
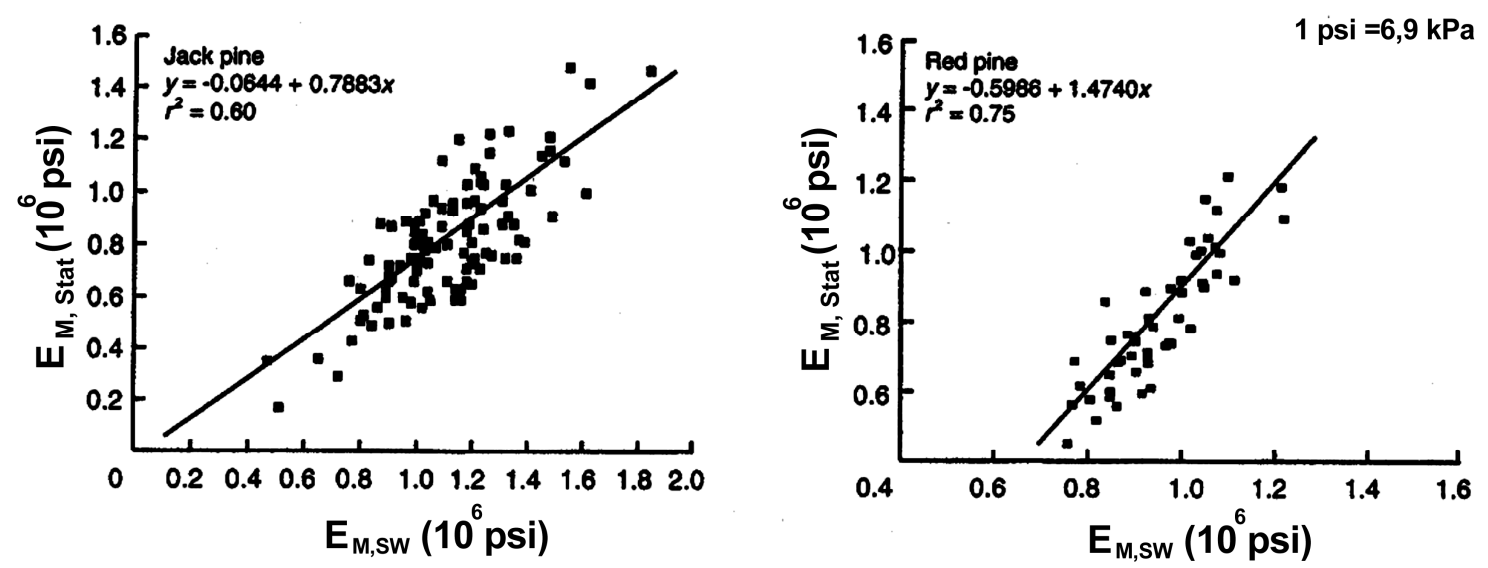

Figura 2.36 - Correlação entre $\mathrm{E}_{\mathrm{M} \text {, Stat }}$ e $\mathrm{E}_{\mathrm{M}, \mathrm{sw}}$.

Fonte: Adaptado de Wang et al (2002).

Os autores concluem que o módulo de elasticidade pode ser avaliado com sucesso pelas técnicas de vibração transversal e ondas de tensão e observam que a técnica de ondas de tensão é sensível às imperfeições geométricas das toras como seção transversal não circular e encurvamento do tronco. 

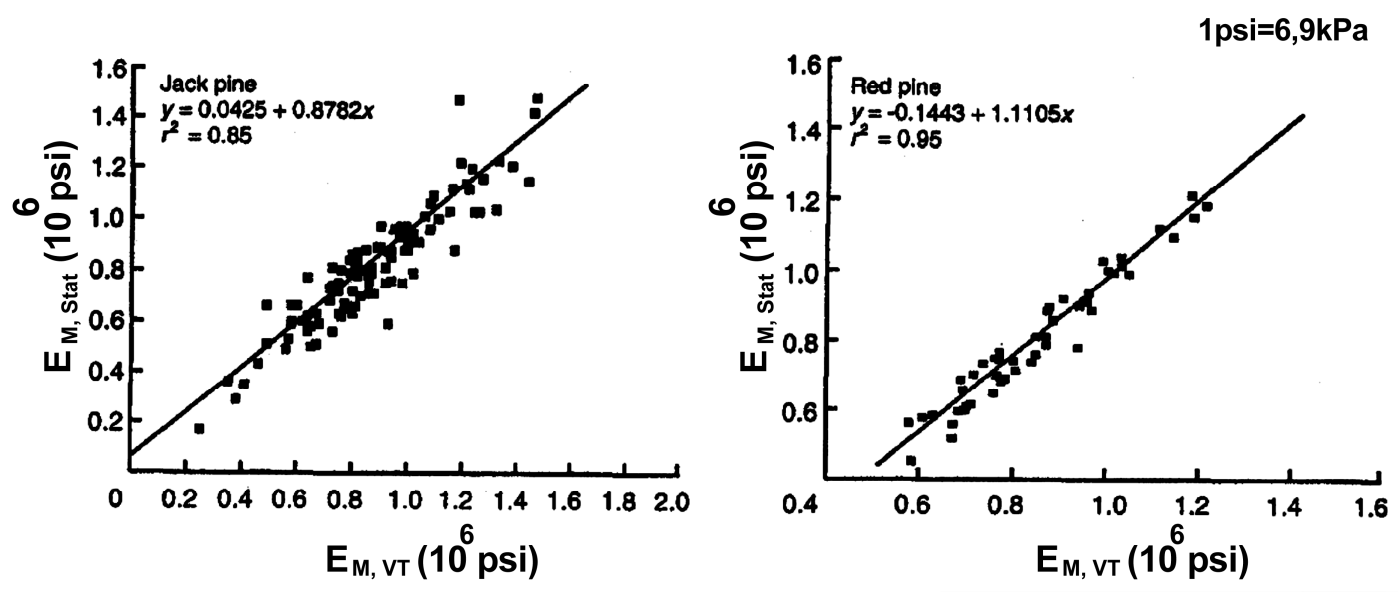

Figura 2.37 - Correlação entre $\mathrm{E}_{\mathrm{M} \text {, Stat }}$ e $\mathrm{E}_{\mathrm{M} \text {, vT. }}$

Fonte: Adaptado de Wang et al (2002).

Green et al (2004) realizaram a classificação de 120 toras de 4,9 m de comprimento, nas quais haviam misturadas as espécies subalpine fir (Albies lasiocarpa) e lodgepole pine (Pinus contorta). Após a seleção da amostra, as toras foram torneadas para ficarem com seção transversal cilíndrica de $230 \mathrm{~mm}$ de diâmetro. Devido à profundidade das fendas de secagem os autores supuseram que o teor de umidade das toras estava abaixo do ponto de saturação. $\mathrm{Na}$ sequência foram realizados os testes de flexão estática e de vibração transversal. O coeficiente de determinação obtido entre os módulos de elasticidade estático e dinâmico foi $\mathrm{R}^{2}=0,95$.

Piao et al (2004) avaliaram o módulo de elasticidade de postes laminados compostos de madeira por meio da vibração transversal livre. Os postes tinham 6,1 m de comprimento e foram ensaiados no esquema estático de viga engastada utilizando uma máquina de ensaio RIVEHLE. O comprimento de engaste na garra da máquina foi de $61 \mathrm{~cm}$. Para medir a frequência de vibração, um extensômetro elétrico de resistência foi colado na superfície do poste e ligado ao sistema StrainSmart System o qual determinou as frequências naturais de vibração dos postes. $\mathrm{O}$ ensaio dinâmico também foi conduzido com os postes engastados. Os resultados dos ensaios dinâmicos foram confrontados com o módulo de elasticidade determinado no ensaio estático de flexão e os autores concluíram que a técnica de vibração transversal livre é uma eficiente alternativa para a determinação das propriedades elásticas de postes e vigas de madeira de grandes dimensões.

Green et al (2006), testaram a técnica da vibração transversal em uma amostra de 225 toras composta por uma mistura das espécies Engelmann spruce-pine e fir-lodgepole pine. As toras foram cortadas com comprimentos entre 4,3 e 4,9 m e torneadas para o diâmetro de 229 mm. O teor de umidade das toras estava abaixo do ponto de saturação. Foram selecionadas 10 
toras para realizar o ensaio de compressão paralela. Inicialmente foi realizado o ensaio de vibração transversal no qual a vibração foi ocasionada por um golpe de um martelo de borracha no meio do comprimento da tora (Figura 2.38). As toras foram ensaiadas na condição bi-apoiada. Nesse ensaio foi determinado o $\mathrm{E}_{\mathrm{M}, \mathrm{VT}}$.

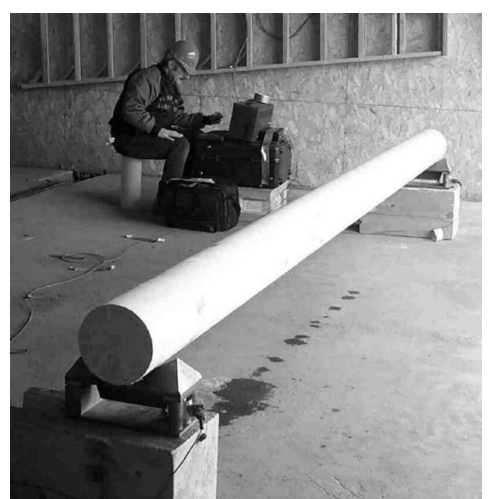

Figura 2.38 - Teste de vibração transversal com toras torneadas.

Fonte: Green et al (2006).

$\mathrm{Na}$ sequência, as toras foram submetidas ao ensaio de flexão estática seguindo os procedimentos da norma ASTM D198. Nesse ensaio foram determinados o módulo de ruptura e o módulo de elasticidade na flexão. Para o desenvolvimento do ensaio de compressão paralela os autores cortaram as toras com comprimento de $2,5 \mathrm{~m}$ a fim de facilitar o manuseio das mesmas. Foi determinado o módulo de elasticidade $\left(\mathrm{E}_{\mathrm{c}, 0}\right)$ e a resistência à compressão paralela $\left(f_{\mathrm{c}, 0}\right)$. Anteriormente a realização do ensaio de compressão foi realizado o ensaio de ondas de tensão (stress wave) para a determinação do módulo de elasticidade $\left(\mathrm{E}_{\mathrm{M}, \mathrm{SW}}\right)$ das toras.

Os resultados das correlações são mostrados na Tabela 2.13 na qual se observa que o $\mathrm{E}_{\mathrm{M}, \mathrm{SW}}$ mostrou fraca correlação com $f_{\mathrm{M}}$. Da mesma forma, $\mathrm{E}_{\mathrm{M}, \mathrm{VT}}$ e $f_{\mathrm{M}}$. exibiram baixo coeficiente de determinação $\left(\mathrm{R}^{2}=0,51\right)$. 
Tabela 2.13 - Estudo de regressão linear entre as propriedades determinadas nos ensaios com toras de $229 \mathrm{~mm}$ de diâmetro.

\begin{tabular}{|c|c|c|c|c|c|}
\hline \multirow{2}{*}{ Propriedade } & \multirow{2}{*}{$x$} & \multirow{2}{*}{$\begin{array}{l}\text { Número } \\
\text { de toras }\end{array}$} & \multicolumn{3}{|c|}{ Propriedade $=a+b x$} \\
\hline & & & $\mathbf{a}$ & b & $\mathbf{R}^{2}$ \\
\hline \multirow{2}{*}{$\mathrm{E}_{\mathrm{M}, \mathrm{Stat}}$} & $\mathrm{E}_{\mathrm{M}, \mathrm{VT}}$ & 60 & $-0,952$ & 1,071 & 0,88 \\
\hline & $\mathrm{E}_{\mathrm{M}, \mathrm{SW}}$ & 56 & 2,710 & 0,543 & 0,67 \\
\hline \multirow{3}{*}{$f_{\mathrm{M}}$} & $\mathrm{E}_{\mathrm{M}, \mathrm{Stat}}$ & 60 & $-13,30$ & 5,902 & 0,61 \\
\hline & $\mathrm{E}_{\mathrm{M}, \mathrm{VT}}$ & 60 & $-17,693$ & 6,174 & 0,51 \\
\hline & $\mathrm{E}_{\mathrm{M}, \mathrm{sw}}$ & 60 & 8,343 & 2,576 & 0,25 \\
\hline \multirow{2}{*}{$\mathrm{E}_{\mathrm{c}, 0}$} & $\mathrm{E}_{\mathrm{M}, \mathrm{VT}}$ & 57 & 0,558 & 0,903 & 0,72 \\
\hline & $\mathrm{E}_{\mathrm{M}, \mathrm{sw}}$ & 57 & 0,579 & 0,799 & 0,76 \\
\hline \multirow{3}{*}{$f_{\mathrm{c}, 0}$} & $\mathrm{E}_{\mathrm{c}, 0}$ & 57 & 4,571 & 2,090 & 0,49 \\
\hline & $\mathrm{E}_{\mathrm{M}, \mathrm{VT}}$ & 57 & 1,234 & 2,422 & 0,60 \\
\hline & $\mathrm{E}_{\mathrm{M}, \mathrm{sw}}$ & 57 & 3,399 & 1,921 & 0,50 \\
\hline
\end{tabular}

Fonte: Adaptado de Green et al (2006).

Carreira \& Dias (2007) investigaram o uso da vibração transversal na avaliação do $\mathrm{E}_{\mathrm{M} \text {,stat }}$ de 18 toras de Eucalyptus citriodora com diâmetros da ordem de $9 \mathrm{~cm}$ e comprimento nominal de 2,40 m. No ensaio de vibração transversal foi utilizado o equipamento protótipo desenvolvido pelo autor deste trabalho (Figura 2.39).

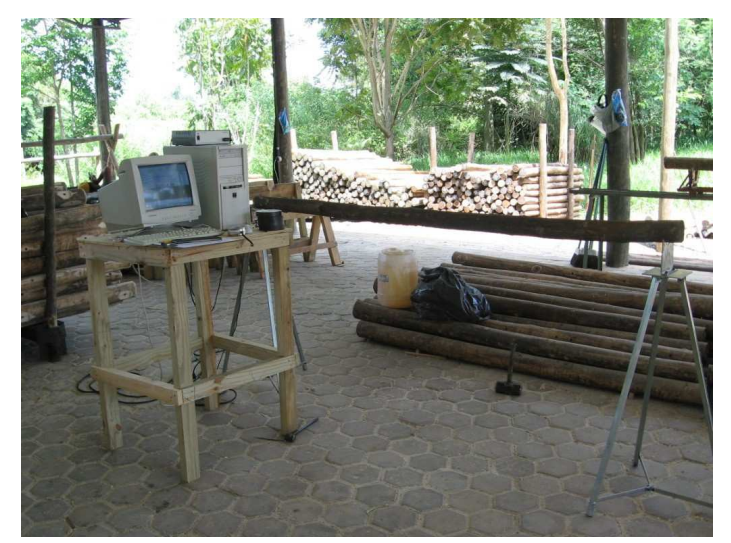

Figura 2.39 - Ensaio de vibração transversal em toras de pequeno diâmetro.

Fonte: Carreira \& Dias (2007).

A vibração foi induzida por um golpe manual na metade do comprimento das toras. Além do ensaio dinâmico foi realizado o ensaio de flexão estática.

A análise dos resultados levou os pesquisadores a concluírem que a metodologia de ensaio empregada mostrou-se inadequada para AND de toras juvenis de Eucalyptus citriodora uma vez que não foi possível estabelecer correlação com o módulo de elasticidade estático. 


\subsection{Fundamentos da Avaliação Não-Destrutiva por Vibração}

\section{Transversal}

Há mais de 300 anos, músicos, físicos e matemáticos têm se interessado pelo fenômeno da vibração livre, que é caracterizado pelo movimento repetitivo e oscilatório de um elemento em torno de sua posição de equilíbrio sem a presença de forças de excitação. Esse movimento ondulatório ocorre pela transferência de energia de um ponto a outro do elemento, por meio da propagação de ondas mecânicas sem transferência de massa. As partículas oscilam em torno da posição de equilíbrio enquanto a energia se propaga no sistema.

A análise do comportamento dinâmico é um meio simples, rápido e eficiente de caracterizar as propriedades de rigidez de uma estrutura.

A técnica de vibração transversal é oriunda da Análise Modal de Estruturas, a qual possui duas formas de abordagem:

- Análise modal teórica: engloba a formulação de modelos teóricos para a determinação de frequências naturais e modos normais e a estimativa das funções de resposta em frequência do sistema;

- Análise modal experimental: consiste na instrumentação do sistema, aquisição e tratamento de sinais, medição das funções de resposta em frequência e identificação dos parâmetros modais.

O comportamento de um sistema dinâmico linear e invariante no tempo pode ser descrito por suas Funções de Transferência, as quais representam matematicamente, no domínio do espaço ou da frequência, a relação entre a entrada e a saída de tal sistema.

$\mathrm{Na}$ análise modal, as Funções de Transferência ou Funções de Resposta em Frequência (FRF's) são relações causa-efeito (Figura 2.40) que descrevem o comportamento de sistemas dinâmicos entre dois pontos de interesse, em função da frequência de excitação (RICHARDSON, 2000).

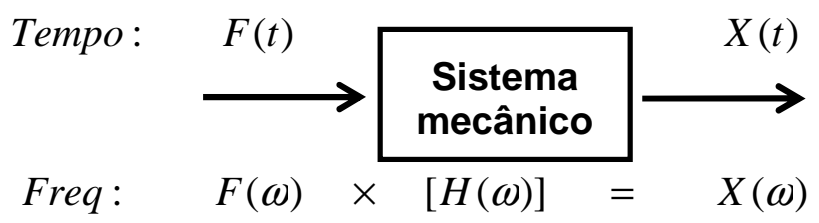

Figura 2.40 - Diagrama de blocos de uma FRF.

Fonte: Adaptado de Richardson (2000). 
$\mathrm{Na}$ análise modal de estruturas, são empregadas três FRF's: receptância (deslocamento/força), mobilidade (velocidade/força) e inertância (aceleração/força).

A Tabela 2.14 mostra as FRF's comuns em análise modal e a relação entre elas.

Tabela 2.14 - Definição das FRF's.

\begin{tabular}{lcl}
\hline \multicolumn{1}{c}{ Resposta } & Definição & Nome \\
\hline Deslocamento & $\mathrm{H}(\omega)=\mathrm{u} / \mathrm{F}$ & Receptância \\
Velocidade & $\mathrm{Y}(\omega)=\mathrm{v} / \mathrm{F}=\mathrm{i} \omega \mathrm{H}(\omega)$ & Mobilidade \\
Aceleração & $\mathrm{A}(\omega)=\mathrm{a} / \mathrm{F}=\mathrm{i} \omega \mathrm{Y}(\omega)$ & Acelerância \\
\hline
\end{tabular}

Fonte: McConnell (1995).

O processamento dos sinais obtidos no ensaio dinâmico permite encontrar as FRF's do sistema dinâmico em estudo e com elas identificar as propriedades que definem os modos de vibração desse sistema.

\subsubsection{Análise modal teórica de vigas retas}

\subsubsection{Modelos discretos}

Todas as estruturas reais possuem um número infinito de graus de liberdade e, a rigor, seriam necessárias infinitas coordenadas para descrever a posição da estrutura num certo instante de tempo. Felizmente, não é necessário considerar todos os modos normais da estrutura, pois muitos deles não são excitados e, caso sejam, eles podem ter amplitudes de deslocamento insignificantes. Além disso, o amortecimento também é maior nos modos superiores. Assim, dependendo da complexidade do problema, o modelo físico do sistema dinâmico pode ser modelado com poucos graus de liberdade, ou até mesmo somente um.

Não é fácil conceber um modelo físico que represente com fidelidade o comportamento de uma estrutura e que seja útil na análise dinâmica, pois a definição dos movimentos estruturais e dos parâmetros do modelo requer grande cuidado.

Entretanto, na modelagem de uma estrutura real, um grande número de simplificações pode ser feito a fim de se obter as informações desejadas de forma rápida e com um nível aceitável de exatidão. Por exemplo, a massa distribuída pode ser considerada concentrada, o efeito do amortecimento pode ser ignorado, uma mola não-linear pode ser considerada como linear dentro de um certo limite de extensão, etc (BEARDS, 1995). 
Uma viga em vibração transversal livre (Figura 2.41) pode, por exemplo, ser modelada como um sistema discreto distribuindo a massa da viga nos pontos nodais dos modos de interesse.

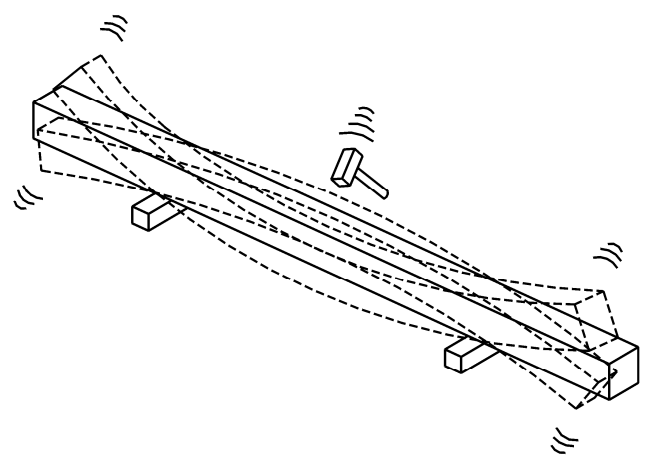

Figura 2.41 - Viga em vibração transversal.

Fonte: Íñiguez Gonzáles et al (2007).

A Figura 2.42 ilustra o exemplo de um sistema discreto com dois graus de liberdade no qual atuam duas forças de excitação $F_{1}(t)$ e $F_{2}(t)$. O sistema consiste de duas massas $\left(m_{1}\right.$ e $\mathrm{m}_{2}$ ) acopladas por uma mola de rigidez $\mathrm{k}_{\mathrm{a}}$ e por um amortecedor com amortecimento $\mathrm{c}_{\mathrm{a}}$. As massas estão vinculadas nas extremidades por meio de molas e amortecedores, cujas rigidezes $\mathrm{k}_{1}$ e $\mathrm{k}_{2}$ e coeficientes de amortecimento $\mathrm{c}_{1}$ e $\mathrm{c}_{2}$, respectivamente, dependem das condições de contorno do problema.

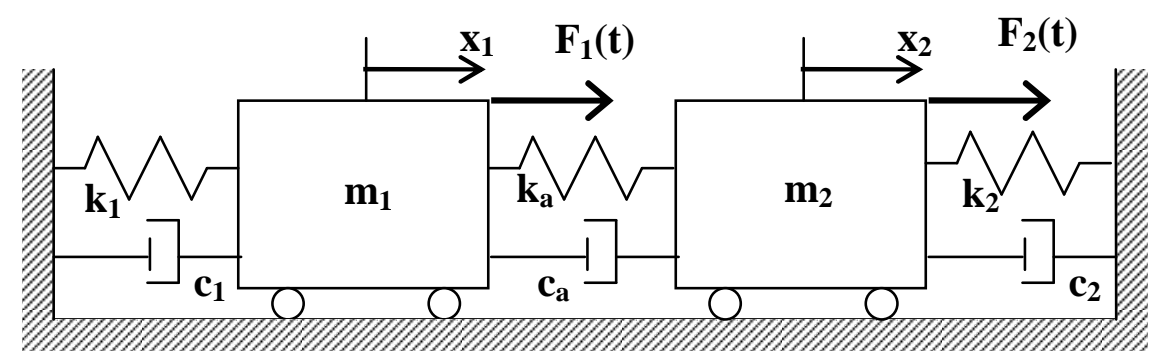

Figura 2.42 - Modelo discreto com dois graus de liberdade.

Supondo amortecimento viscoso e aplicando a segunda Lei de Newton obtém-se a equação de equilíbrio:

$$
\left[\begin{array}{cc}
m_{1} & 0 \\
0 & m_{2}
\end{array}\right]\left\{\begin{array}{l}
\ddot{x}_{1} \\
\ddot{x}_{2}
\end{array}\right\}+\left[\begin{array}{cc}
c_{1}+c_{a} & -c_{a} \\
-c_{a} & c_{2}+c_{a}
\end{array}\right]\left\{\begin{array}{l}
\dot{x}_{1} \\
\dot{x}_{2}
\end{array}\right\}+\left[\begin{array}{cc}
k_{1}+k_{a} & -k_{a} \\
-k_{a} & k_{2}+k_{a}
\end{array}\right]\left\{\begin{array}{l}
x_{1} \\
x_{2}
\end{array}\right\}=\left\{\begin{array}{l}
F_{1}(t) \\
F_{2}(t)
\end{array}\right\}
$$

Ou ainda empregando uma representação mais compacta:

$$
[M]\{\ddot{x}\}+[C]\{\dot{x}\}+[K]\{x\}=\{F(t)\}
$$


Sendo:

$$
\begin{aligned}
& {[M]=\text { matriz de massa; }} \\
& {[C]=\text { matriz de amortecimento; }} \\
& {[K]=\text { matriz de rigidez; }} \\
& \{F(t)\}=\text { vetor das ações dinâmicas; } \\
& \{\ddot{x}\}=\text { vetor das acelerações; } \\
& \{\dot{x}\}=\text { vetor das velocidades; } \\
& \{x\}=\text { vetor dos deslocamentos. }
\end{aligned}
$$

Observa-se que $[M]$ é diagonal de ordem n, o que não ocorre com as matrizes $[K]$ e $[C]$ devido ao acoplamento da mola $\left(k_{a}\right)$ e do amortecedor $\left(c_{a}\right)$. A presença de $c_{a}$ e $k_{a}$ ligando as massas $m_{1}$ e $m_{2}$ acopla os dois sistemas de um grau de liberdade fazendo com que se comportem como um sistema de dois graus de liberdade. $\mathrm{O}$ acoplamento entre as coordenadas $\mathrm{x}_{1}$ e $x_{2}$ acarreta em grande dificuldade de resolução direta do sistema, pois os efeitos são dependentes.

\section{a. Resposta à vibração livre não-amortecida: Método direto}

A solução direta para o caso de vibração livre não-amortecida é obtida admitindo-se que a matriz de amortecimento e o vetor de carga sejam nulos. A equação do movimento fica:

$$
[M]\{\ddot{x}\}+[k]\{x\}=\{0\}
$$

A solução desse problema para sistemas com um grau de liberdade é:

$$
x=A^{*} \operatorname{sen}\left(\theta+\omega_{n} t\right)
$$

Sendo:

$$
\begin{aligned}
& A=\text { amplitude do deslocamento }(\mathrm{m}) ; \\
& \theta=\text { ângulo de fase }(\mathrm{rad}) ; \\
& \omega_{n}=\text { frequência angular natural }(\mathrm{rad} / \mathrm{s}) ; \\
& t=\text { tempo (s). }
\end{aligned}
$$

Substituindo a Equação 2.6 e sua derivada segunda na Equação 2.5 tem-se:

$$
\left[K-\omega_{n}^{2} M\right]\{A\}=\{0\}
$$


A Equação 2.7 é um problema de autovalores e autovetores. Os autovalores $\left(\omega_{\mathrm{n}}\right)$ nãotriviais são obtidos quando o determinante da matriz $\left[K-\omega_{n}^{2} M\right]$ for igual a zero, ou seja:

$$
\left|\begin{array}{cc}
\left(k_{1}+k_{a}\right)-m_{1} \omega_{n}^{2} & -k_{a} \\
-k_{a} & \left(k_{2}+k_{a}\right)-m_{2} \omega_{n}^{2}
\end{array}\right|=0
$$

Calculando o determinante, obtêm-se os valores de $\omega_{n}$. Lançando os autovalores na Equação 2.7 encontram-se os autovetores $\{A\}$. Para o caso com dois graus de liberdade os autovetores são:

$$
A_{1}=\left\{\begin{array}{l}
A_{11} \\
A_{21}
\end{array}\right\} \quad e \quad A_{2}=\left\{\begin{array}{l}
A_{12} \\
A_{22}
\end{array}\right\}
$$

Supondo válidas as condições de ortogonalidade dos modos de vibração, pode-se aplicar a superposição modal e unir $A_{1}$ e $A_{2}$. Logo:

$$
A=\left[\begin{array}{ll}
A_{11} & A_{12} \\
A_{21} & A_{22}
\end{array}\right]
$$

Para encontrar o deslocamento de cada massa no domínio real pode-se expandir a Equação 2.6 para o sistema com dois graus e liberdade e empregar a Equação 2.10, de forma a obter:

$$
\left\{\begin{array}{l}
x_{1} \\
x_{2}
\end{array}\right\}=\left[\begin{array}{l}
A_{11} A_{12} \\
A_{21} A_{22}
\end{array}\right]\left\{\begin{array}{c}
\operatorname{sen}\left(\theta_{1}+\omega_{n 1} t\right) \\
\operatorname{sen}\left(\theta_{2}+\omega_{n 2} t\right)
\end{array}\right\} \text { ou }\{x\}=[A]\{q\}
$$

De acordo com a Equação 2.11, os deslocamentos de cada massa correspondem às somas das contribuições de cada modo. Outra informação importante mostrada é que, nos sistemas com mais de um grau de liberdade, os deslocamentos podem ser obtidos a partir da multiplicação da matriz dos modos normais pelos vetores das soluções para sistemas com um grau de liberdade.

\section{Acoplamento de coordenadas e ortogonalidade dos modos}

Na Equação 2.3, os deslocamentos $x_{1}$ e $x_{2}$ estão acoplados elasticamente devido à presença da mola de rigidez $k_{\mathrm{a}}$. Isso significa que não é possível determinar cada deslocamento separadamente.

Felizmente, os modos normais de vibração têm certas propriedades que permitem o desacoplamento das coordenadas. Estas propriedades são as condições de ortogonalidade que 
podem ser demonstradas pelo teorema de Betti. A dedução detalhada dessas propriedades é mostrada em Clough \& Penzien (1995). A condição de ortogonalidade dos modos em relação a massa é expressa por:

$$
\left\{A_{i}\right\}^{T} \cdot[M] \cdot\left\{A_{j}\right\}=\{0\}
$$

Sendo:

$\left\{A_{i}\right\}^{T}=$ autovetor transposto do modo i;

$[M]=$ matriz de massa do sistema;

$\left\{A_{j}\right\}=$ autovetor do modo j.

e a condição de ortogonalidade em relação à rigidez é dada por:

$$
\left\{A_{i}\right\}^{T} \cdot[K] \cdot\left\{A_{j}\right\}=\{0\}
$$

Sendo:

$$
[K]=\text { matriz de rigidez do sistema. }
$$

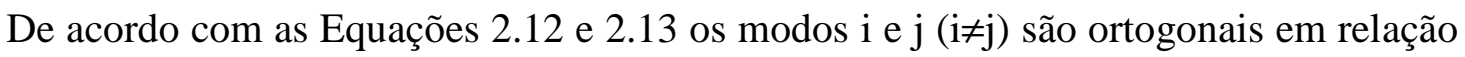
à massa e à rigidez, pois seus produtos escalares são iguais a zero.

\section{b. Resposta à vibração livre não-amortecida: Método modal}

No método modal, a resposta pode ser obtida pela soma das contribuições de cada modo, mediante a transformação das coordenada do domínio modal $\{q\}$ em coordenadas no domínio do espaço $\{x\}$. Essa lei de transformação de coordenadas é mostrada na Equação 2.11 .

Substituindo a Equação 2.11 e sua derivada segunda na Equação 2.5 tem-se:

$$
[M][A]\{\ddot{q}\}+[K][A]\{q\}=\{F(t)\}
$$

Pré-multiplicando a Equação 2.14 por $[\mathrm{A}]^{\mathrm{T}}$ e aplicando as condições de ortogonalidade chega-se a:

$$
\left[M_{m}\right]\{\ddot{q}\}+\left[K_{m}\right]\{q\}=\left\{F_{m}\right\}
$$

Sendo: 


$$
\begin{aligned}
& {\left[M_{m}\right]=[A]^{T}[M][A] \text { (Matriz de massa modal) }} \\
& {\left[K_{m}\right]=[A]^{T}[K][A] \text { (Matriz de rigidez modal) }} \\
& \left\{F_{m}\right\}=[A]^{T}\{F(t)\} \text { (Vetor de carregamento modal) }
\end{aligned}
$$

Na Equação 2.15, as coordenadas $q_{1}$ e $q_{2}$ estão desacopladas, pois as matrizes $\left[K_{m}\right]$ e $\left[M_{m}\right]$ são diagonais. A análise da Equação 2.15 permite concluir que um sistema com $\mathrm{N}$ graus de liberdade no domínio real é equivalente a $\mathrm{N}$ sistemas com um grau de liberdade no domínio modal. Pode-se tirar partido dessa conclusão para aplicar as soluções conhecidas para sistemas com um grau de liberdade na resolução de sistemas com múltiplos graus de liberdade.

\section{c. Amortecimento proporcional}

A introdução do amortecimento na equação de equilíbrio dos sistemas dinâmicos com mais de um grau de liberdade é complexa, pois a matriz de amortecimento é cheia levando ao acoplamento das coordenadas $x_{1}$ e $x_{2}$.

Pode-se tirar partido das condições de ortogonalidade dos modos considerando o amortecimento proporcional à massa e/ou à rigidez. Esse tipo de amortecimento é denominado de amortecimento de Rayleigh (CLOUGH \& PENZIEN, 1995).

A matriz de amortecimento proporcional nesse caso fica:

$$
[C]=a_{0}[M]+a_{1}[K]
$$

Sendo:

$$
\begin{aligned}
& {[C]=\text { matriz de amortecimento; }} \\
& {[M]=\text { matriz de massa; }} \\
& {[K]=\text { matriz de rigidez; }} \\
& a_{o} \text { e } a_{1}=\text { constantes de proporcionalidade. }
\end{aligned}
$$

Devido às condições de ortogonalidade dos modos, a matriz [C] é uma matriz diagonal e, dessa forma, as coordenadas permanecerão desacopladas.

Pode-se ainda escrever o amortecimento adimensional para o n-ésimo modo como: 


$$
\xi_{n}=\frac{a_{0}}{2 \omega_{n}}+\frac{a_{1} \omega_{n}}{2}
$$

Sendo:

$$
\begin{aligned}
& \xi_{\mathrm{n}}=\text { amortecimento adimensional; } \\
& \omega_{n}=\text { frequência natural de vibração do n-ésimo modo. }
\end{aligned}
$$

As constantes $a_{o}$ e $a_{1}$ podem ser determinadas conhecendo-se o valor de $\gamma$ para dois modos diferentes.

Inserindo as Equações 2.11 e 2.19 na Equação 2.4, pré-multiplicando por $[A]^{\mathrm{T}} \mathrm{e}$ aplicando as condições de ortogonalidade chega-se a:

$$
\left[M_{m}\right]\{\ddot{q}\}+a_{0}\left[M_{m}\right]\{\dot{q}\}+a_{1}\left[K_{m}\right]\{\dot{q}\}+\left[K_{m}\right]\{q\}=\left\{F_{m}\right\}
$$

\section{d. Função de Resposta em Frequência}

Se o sistema da Figura 2.41 estiver submetido a uma excitação harmônica do tipo:

$$
\{F(t)\}=\{F\} e^{i \omega t}
$$

O mesmo responderá no domínio modal de acordo com a Equação 2.23.

$$
\{q\}=\{q\} e^{i \omega t}
$$

Substituindo a Equação 2.23 e suas derivadas na Equação 2.21, fazendo as devidas simplificações e escrevendo a resposta no domínio do espaço pode-se obter o vetor de deslocamentos $\{x\}$ por meio da Equação 2.24.

$$
\{x\}=\frac{[A][A]^{T}\{F\}}{\left[K_{m}\right]\left([1]-[\alpha]^{2}+2[\xi][\alpha] i\right)}
$$

Com

Sendo:

$$
\alpha=\frac{\omega}{\omega_{n}}
$$

$$
\begin{aligned}
& \omega=\text { frequência angular do carregamento } \\
& \omega_{n}=\text { frequência angular do n-ésimo modo }
\end{aligned}
$$


Dividindo a entrada $\{F\}$ pela saída do sistema $\{x\}$ encontra-se a FRF receptância, mostrada na Equação 2.26:

$$
[H(\omega)]=\frac{\{x\}}{\{F\}}=\frac{[A][A]^{T}}{\left[K_{m}\right]\left([1]-[\alpha]^{2}+2[\xi][\alpha] i\right)}
$$

\subsubsection{Modelos contínuos}

Os sistemas discretos são simplificações convenientes e práticas para encontrar a resposta dinâmica de estruturas simples. Entretanto, as soluções obtidas são aproximadas, pois os movimentos são representados por um número limitado de deslocamentos. A exatidão dos resultados pode ser refinada aumentando-se o número de graus de liberdade. Contudo, para que haja convergência dos resultados é necessário considerar infinitos graus de liberdade e obviamente essa condição é impossível de ser alcançada na prática.

O procedimento matemático para analisar o comportamento de infinitos pontos conectados com exatidão adequada para a AND faz o uso de equações diferenciais.

Muitos autores propuseram modelos teóricos para descrever o movimento de uma viga em vibração transversal, mas eles esbarravam em problemas matemáticos e metrológicos. De acordo com Brancheriau \& Bailleres (2002), os problemas matemáticos foram resolvidos com avanços nas técnicas matemáticas como séries infinitas e derivadas parciais. Os problemas metrológicos só puderam ser resolvidos com os recentes desenvolvimentos na computação e na eletrônica que forneceram ferramentas para a análise de materiais e de estruturas.

Os principais modelos contínuos para a avaliação não-destrutiva de vigas por vibração transversal são discutidos a seguir.

\section{e. Modelo de Bernoulli}

O modelo teórico de Bernoulli (1748) ${ }^{12}$ apud Brancheriau \& Bailleres (2002), para a vibração transversal de vigas retas (Figura 2.43) é baseado em três hipóteses fundamentais:

- Relação comprimento/altura da seção muito grande;

\footnotetext{
${ }^{12}$ BERNOULLI, D. Réflexion et Eclaircissement sur les Nouvelles Vibrations des Cordes Exposées dans les Mémoires de L'Académie. Riyal Academy of Berlin. 1748.
} 
- A viga é considerada como uma linha fina resultando em esforços cortantes desprezíveis;

- A deformação dos apoios é ignorada.

As propriedades físicas importantes são a rigidez à flexão $\mathrm{EI}(\mathrm{x})$ e a massa por unidade de comprimento $\mathrm{m}(\mathrm{x})$. Ambas podem variar ao longo do comprimento da viga.

No caso de vibração livre, a força de excitação $F(x, t)$ é nula.

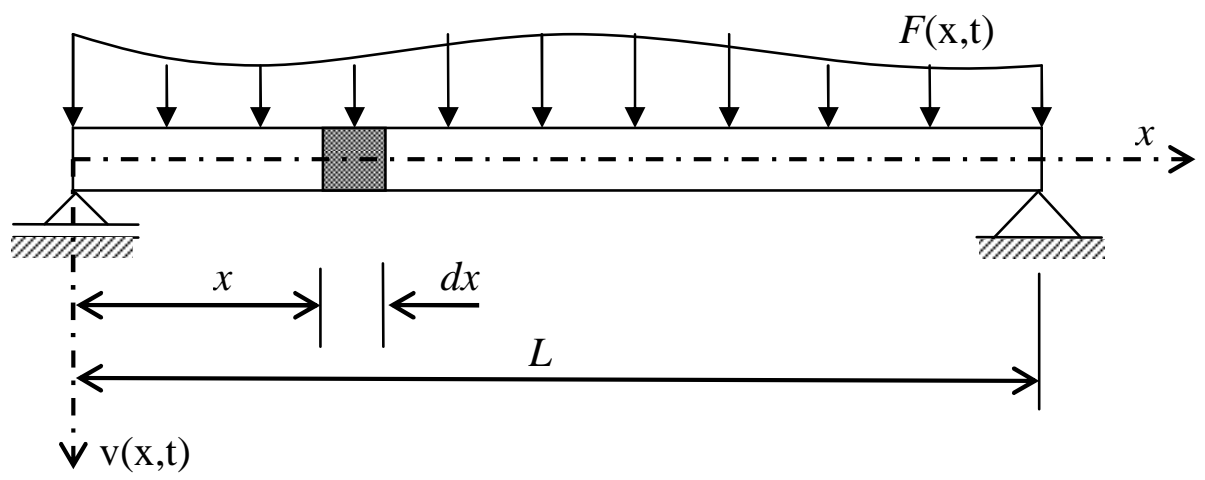

Figura 2.43 - Viga reta em vibração transversal.

Os apoios são arbitrários embora tenham sido desenhados na Figura 2.43 como apoios simples. A equação do movimento pode ser obtida pelo equilíbrio de forças de um elemento infinitesimal $\underline{\mathrm{dx}}$.

Para uma viga em vibração livre tal equação é igual a:

$$
m(x) \frac{\partial^{2} \mathrm{v}(x, t)}{\partial t^{2}}+\frac{\partial^{2}}{\partial x^{2}}\left[E I(x) \frac{\partial^{2} \mathrm{v}(x, t)}{\partial x^{2}}\right]=0
$$

Sendo:

$$
\begin{aligned}
& m(x)=\text { massa por unidade de comprimento; } \\
& \mathrm{v}(x, t)=\text { deslocamento transversal da viga; } \\
& E=\text { módulo de elasticidade do material da viga; } \\
& I(x)=\text { momento de inércia da seção transversal; } \\
& x=\text { coordenada na direção longitudinal da viga; } \\
& t=\text { tempo; }
\end{aligned}
$$

Usando a técnica de separação de variáveis, a solução dessa equação pode ser representada por uma função de duas variáveis: tempo $\underline{t}$ e posição $\underline{x}$ (Equação 2.28). 


$$
\mathrm{v}(x, t)=A(x) q(t)
$$

Sendo:

$$
\begin{aligned}
& A(x)=\text { amplitude do deslocamento ao longo do comprimento (modo); } \\
& q(t)=\text { variação do movimento no tempo. }
\end{aligned}
$$

As funções $A(x)$ e $q(t)$ são respectivamente iguais a:

$$
\begin{gathered}
q(t)=C_{1} \cos \omega t+C_{2} \operatorname{sen} \omega t \\
A(x)=C_{3} \cos \lambda x+C_{4} \operatorname{sen} \lambda x+C_{5} \cosh \lambda x+C_{6} \operatorname{senh} \lambda x
\end{gathered}
$$

Sendo:

$\mathrm{C}_{1}$ a $_{6}=$ constantes;

$\omega=$ frequência natural de vibração;

$\lambda=$ constante de separação.

As constantes $C_{1}$ e $C_{2}$ são obtidas por meio das condições iniciais, enquanto as constantes $C_{3}$ a $C_{6}$ são obtidas pelas condições de contorno.

O lançamento das condições de contorno na Equação 2.30 leva a um sistema homogêneo cujas soluções não-triviais são obtidas fazendo-se o determinante da matriz característica igual a zero. Dessa forma é possível encontrar a constante de separação $\lambda$, os autovalores de cada modo de vibração e as constantes $C_{3}$ a $C_{6}$.

A constante de separação $\lambda$ é relacionada com as frequências naturais (autovalores) pela Equação 2.31.

$$
\lambda^{4}=\frac{\omega^{2} m(x)}{E I}
$$

De posse das constantes $C_{3}$ a $C_{6}$ e da constante de separação $\lambda$, as autofunções que definem a forma dos modos de vibração ficam determinadas pela Equação 2.30.

A Tabela 2.15 mostra os pontos nodais de cada modo (coordenadas $x$ para as quais $A(x)=0$ ), a forma dos modos e também os valores de $\lambda L$ para os primeiros quatro modos normais, para algumas condições de contorno. 
Tabela 2.15 - Frequências naturais e modos normais de algumas vigas prismáticas.

\begin{tabular}{|c|c|c|c|c|c|}
\hline $\begin{array}{l}\text { Condição de } \\
\text { contorno }\end{array}$ & Modo & Forma e pontos nodais & $\begin{array}{l}\text { Condições } \\
\text { de contorno }\end{array}$ & $\begin{array}{l}\text { Equação da } \\
\text { frequência }\end{array}$ & $\lambda \mathrm{L}$ \\
\hline \multirow{4}{*}{$\begin{array}{c}\text { Simplesmente } \\
\text { apoiada }\end{array}$} & 1 & 0.50 & $\mathrm{~A}(0)=0$ & \multirow{4}{*}{$\operatorname{Sen}(\lambda L)=0$} & 3,142 \\
\hline & 2 & 0.333 & $A^{\prime \prime}(0)=0$ & & 6,283 \\
\hline & 3 & 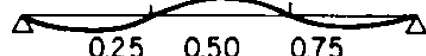 & $\mathrm{A}(\mathrm{L})=0$ & & 9,425 \\
\hline & 4 & & $A^{\prime \prime}(L)=0$ & & 12,566 \\
\hline \multirow{4}{*}{ Bi-engastado } & 1 & $=-$ & $\mathrm{A}(0)=0$ & \multirow{4}{*}{$\begin{array}{c}\operatorname{Cos}(\lambda \mathrm{L}) \\
\operatorname{Cosh}(\lambda \mathrm{L})=1\end{array}$} & 4,730 \\
\hline & 2 & & $\mathrm{~A}^{\prime}(0)=0$ & & 7,853 \\
\hline & 3 & 0.359 & $\mathrm{~A}(\mathrm{~L})=0$ & & 10,966 \\
\hline & 4 & $50 \quad 0.722$ & $\mathrm{~A}^{\prime}(\mathrm{L})=0$ & & 14,137 \\
\hline \multirow{4}{*}{$\begin{array}{l}\text { Engastado } \\
\text { apoiado }\end{array}$} & 1 & $\Delta$ & $\mathrm{A}(0)=0$ & \multirow{4}{*}{$\begin{array}{c}\operatorname{Tan}(\lambda \mathrm{L})=\operatorname{Tanh}( \\
\lambda \mathrm{L})\end{array}$} & 3,927 \\
\hline & 2 & 8 & $\mathrm{~A}^{\prime}(0)=0$ & & 7,069 \\
\hline & 3 & 0.692 & $A(L)=0$ & & 10,210 \\
\hline & 4 & $\frac{1}{2}$ & $A^{\prime \prime}(L)=0$ & & 13,352 \\
\hline \multirow{4}{*}{$\begin{array}{l}\text { Engastado- } \\
\text { livre }\end{array}$} & 1 & 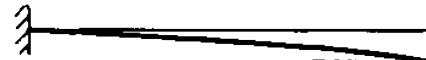 & $\mathrm{A}(0)=0$ & \multirow{4}{*}{$\begin{array}{c}\operatorname{Cos}(\lambda \mathrm{L}) \\
\operatorname{Cosh}(\lambda \mathrm{L})=-1\end{array}$} & 1,875 \\
\hline & 2 & 0.783 & $A^{\prime}(0)=0$ & & 4,694 \\
\hline & 3' & 0.008 & $A^{\prime \prime}(L)=0$ & & 7,855 \\
\hline & 4 & $0.358 \quad 0.644 \quad 0.906$ & $A^{\prime \prime \prime}(L)=0$ & & 10,966 \\
\hline \multirow{4}{*}{ Livre-livre } & 1 & Movimento de corpo rígido & $A^{\prime \prime}(0)=0$ & \multirow{4}{*}{$\begin{array}{c}\operatorname{Cos}(\lambda \mathrm{L}) \\
\operatorname{Cosh}(\lambda \mathrm{L})=1\end{array}$} & 0,000 \\
\hline & 2 & 0.776 & $A^{\prime \prime \prime}(0)=0$ & & 4,730 \\
\hline & 3 & $\begin{array}{lll}0.132 \quad 0.50 & 0.868\end{array}$ & $\mathrm{~A}^{\prime \prime}(\mathrm{L})=0$ & & 7,853 \\
\hline & 4 & $0.094 \quad 0.356 \quad 0.644 \quad 0.906$ & $A^{\prime \prime \prime}(L)=0$ & & 10,966 \\
\hline
\end{tabular}

Fonte: Stokey (2002).

A solução da Equação 2.27 em E para a condição de contorno bi-apoiada é mostrada por vários autores (TIMOSHENKO, 1938; NEWLAND, 1989; MURPHY, 2000; BRANCHERIAU \& BAILLERES, 2002) como:

$$
E_{M, V T}=\frac{4 f_{1}^{2} L^{4} \rho A}{\pi^{2} I}
$$

Sendo:

$E_{M, V T}=$ módulo de Young $(\mathrm{Pa}) ;$

$f_{1}=$ frequência natural de vibração do $1^{\circ}$ modo $(\mathrm{Hz})$;

$\rho=$ densidade do material $\left(\mathrm{Kg} / \mathrm{m}^{3}\right)$;

$A=$ área de seção transversal $\left(\mathrm{m}^{2}\right)$;

$L=$ comprimento da viga $(\mathrm{m})$;

$I=$ momento de inércia da seção transversal $\left(\mathrm{m}^{4}\right)$. 
A clássica teoria de vigas de Bernoulli é inadequada para a análise de vigas curtas e largas e também para os modos superiores. A inadequação surge pelo fato do modelo ignorar o movimento de rotação da seção transversal e as deformações impostas pelo esforço cortante. Ambos efeitos fazem com que as frequências naturais calculadas pelo modelo de Bernoulli sejam inferiores às reais $(\mathrm{CHO}, 2007)$.

\section{f. Modelo de Timoshenko}

O modelo proposto por Timoshenko $(1921)^{13}$ apud Brancheriau \& Bailleres (2002) admite que a razão entre o comprimento e a altura da viga seja relativamente pequena e leva em conta as deformações causadas pelo esforço cortante além de considerar a inércia à rotação da seção transversal. Entretanto, a deformação dos apoios ainda é ignorada.

A cinemática do movimento e as forças envolvidas no equilíbrio de um elemento infinitesimal $d x$ de uma viga de Timoshenko são mostradas na Figura 2.44.

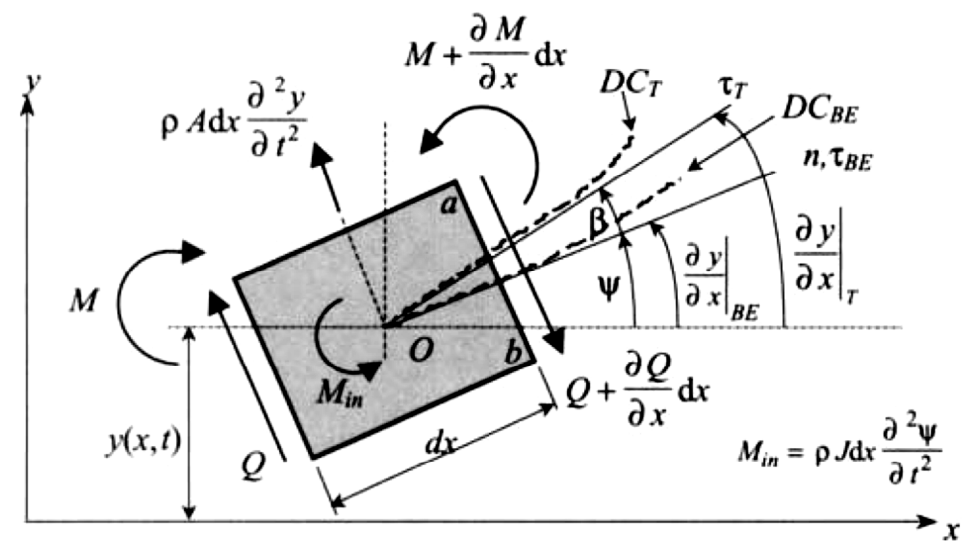

Figura 2.44 - Equilíbrio de um elemento infinitesimal $d x$ em uma viga de Timoshenko.

Fonte: Karnovsky \& Lebed (2001).

A equação de movimento para o elemento $d x$ é obtida pela resolução da Equação 2.33 .

$$
E I\left(\frac{\partial^{4} \mathrm{v}}{\partial x^{4}}\right)-\rho I\left(1+\frac{\eta E}{G}\right) \frac{\partial^{4} \mathrm{v}}{\partial x^{2} \partial t^{2}}+\rho A \frac{\partial \mathrm{v}^{2}}{\partial t^{2}}+\frac{\rho^{2} \eta I}{G} \frac{\partial^{4} \mathrm{v}}{\partial t^{4}}=0
$$

Sendo:

\footnotetext{
${ }^{13}$ TIMOSHENKO S. On the Correction for Shear of the Differential Equation for Transverse Vibrations of Prismatic Bars. Philosophical Magazine and Journal of Science XLI - Sixth Series: 744 - 746. 1921
} 
$E=$ módulo de Young;

$G=$ módulo de elasticidade transversal;

$\mathrm{v}=$ deslocamento perpendicular ao eixo da viga;

$x=$ distância ao longo do comprimento da viga;

$\rho=$ densidade do material;

$A$ = área da seção transversal;

$t=$ tempo;

$I=$ momento de inércia da seção transversal;

$\eta=$ fator de forma da seção transversal.

O desenvolvimento analítico da Equação 2.33 resulta em uma complexa equação transcendental cuja solução só pode ser encontrada por métodos numéricos.

Segundo Íñiguez Gonzáles (2007), a Equação 2.33 tem o inconveniente de ser mais complexa do que a de Bernoulli, exigindo a medição da frequência de pelo menos dois modos de vibração. Além disso, essa equação não tem solução exata e há a necessidade de empregar métodos iterativos para obter uma solução aproximada.

Entre os clássicos métodos aproximados para o cálculo das frequências naturais destacam-se na literatura os de Rayleigh, Rayleigh-Ritz, Bordonné e Goens (NEWLAND, 1989; BEARDS, 1995; STOKEY, 2002; BRANCHERIAU \& BAILLERES, 2002).

Para uma viga bi-apoiada em vibração livre, a frequência natural de um dado modo $\mathrm{j}$ pode ser calculada de forma aproximada com a resolução da Equação 2.34, segundo Newland (1989).

$$
\frac{\eta \rho^{2}}{E G} \omega_{j}^{4}-\left[\frac{\rho}{E}\left(1+\frac{\eta E}{G}\right)\left(j \frac{\pi}{L}\right)^{2}+\frac{\rho A}{E I}\right] \omega_{j}^{2}+\left(j \frac{\pi}{L}\right)^{4}=0
$$

Hijmissen \& Van Horssen (2007) desenvolveram uma expressão aproximada para o cálculo das frequências naturais de uma viga de Timoshenko na posição vertical com uma extremidade engastada. Devido ao efeito da gravidade, uma força de compressão com variação linear atua na viga. Os autores utilizam o método da perturbação e observam que o efeito da gravidade é mais significativo no primeiro modo. 


\section{g. Condições de ortogonalidade dos modos}

Os modos normais dos sistemas contínuos possuem propriedades de ortogonalidade que permitem o cálculo da massa modal e da rigidez modal da mesma forma como foi feito para os sistemas discretos com mais de um grau de liberdade.

As condições de ortogonalidade em relação à massa e a rigidez requerem a integração ao longo do comprimento L como mostram as Equações 2.35 e 2.36.

$$
\begin{gathered}
\int_{0}^{L} m(x) A_{n}(x) A_{p}(x) d x=\left\{\begin{array}{ccc}
0 & \text { para } & n \neq p \\
M_{p} & \text { para } & n=p
\end{array}\right. \\
-\int_{0}^{L} \frac{d^{2}}{d x^{2}}\left[E I \frac{d^{2} A_{p}}{d x^{2}}\right] A_{n}(x) d x=\left\{\begin{array}{ccc}
0 & \text { para } & n \neq p \\
K_{p} & \text { para } & n=p
\end{array}\right.
\end{gathered}
$$

Sendo:

$$
\begin{aligned}
& A_{n}(x)=\text { autofunção do n-ésimo modo; } \\
& A_{p}(x)=\text { autofunção do p-ésimo modo; } \\
& M_{p}=\text { massa modal do p-ésimo modo; } \\
& K_{p}=\text { rigidez modal do p-ésimo modo. }
\end{aligned}
$$

\section{h. Introdução do amortecimento proporcional}

Supondo a atuação de forças de amortecimento em uma viga de Bernoulli e admitindo que o modelo de amortecimento seja o proporcional a massa e a rigidez pode-se escrever a equação de equilíbrio dessa viga como:

$$
m(x) \frac{\partial^{2} u(x, t)}{\partial t^{2}}+C(x) \frac{\partial u(x, t)}{\partial t}+\frac{\partial^{2}}{\partial x^{2}}\left[E I \frac{\partial^{2} u(x, t)}{\partial x^{2}}\right]=F(x, t)
$$

Supondo válidas as condições de ortogonalidade pode-se usar a superposição modal para escrever a resposta do sistema da seguinte forma:

$$
u(x, t)=\sum_{p=1}^{N} A_{p}(x) q_{p}(t)
$$

Sendo:

$$
\begin{aligned}
& p=\text { modo de vibração; } \\
& \mathrm{N}=\text { maior modo de vibração levado em conta na resposta. }
\end{aligned}
$$

Admitindo que o carregamento seja composto por duas funções, uma no tempo e outra no espaço, substituindo a Equação 2.38 e suas derivadas na Equação 2.37 e fazendo as devidas simplificações obtém-se a equação de equilíbrio na forma: 


$$
M_{p} \ddot{q}_{p}+C_{p} \dot{q}_{p}+K_{p} q_{p}=F_{p}
$$

Sendo:

$$
\begin{aligned}
& M_{p}=\text { massa modal no modo } \mathrm{p} ; \\
& K_{p}=\text { rigidez modal no modo } \mathrm{p} ; \\
& C_{p}=\text { amortecimento modal no modo } \mathrm{p} ; \\
& F_{p}=\text { carregamento modal no modo } \mathrm{p} .
\end{aligned}
$$

A massa modal $M_{p}$ pode ser calculada por:

$$
M_{p}=\int_{0}^{L} m(x) A_{p}(x) A_{p}(x) d x
$$

Supondo que e a rigidez EI seja constante ao longo do comprimento, a rigidez modal pode ser calculada por:

$$
K_{p}=E I \int_{0}^{L} \frac{d^{4}}{d x^{4}} A_{P}(x) A_{p}(x) d x
$$

O amortecimento modal é calculado pela Equação 42.

$$
C_{p}=a_{0} M_{p}+a_{1} E I \int_{o}^{L} A_{p}(x) A_{p}(x) d x
$$

O carregamento modal $F_{p}$ é igual a:

$$
F_{p}=P(t) \int_{0}^{L} F(x) A_{p}(x) d x
$$

Sendo:

$$
\begin{aligned}
& P(t)=\text { função de variação do carregamento no tempo; } \\
& F(x)=\text { função de variação do carregamento no espaço. }
\end{aligned}
$$

A Equação 2.43 é muito importante, pois ela mostra a quantidade de força que excita cada modo.

\section{i. Modelos contínuos de FRF's}

Existem dois tipos de FRF's que podem ser geradas com os sistemas contínuos dependendo do tipo de carregamento.

A FRF de ponto $\left(H_{b}\right)$ devido a uma força uniformemente distribuída é igual a: 


$$
H_{b}=\sum_{p=1}^{N} A_{p}(b) H_{p} F_{p}
$$

Sendo $H_{p}$ a Função de Resposta em Frequência modal dada pela Equação 2.45.

$$
H_{p}=\frac{1}{K_{p}\left(1-\alpha_{p}^{2}+2 \xi_{p} \alpha_{p} i\right)}
$$

A FRF no ponto $\underline{b}$ devida a uma carga concentrada aplicada no ponto a é obtida pela Equação 2.46.

$$
H_{b a}=\sum_{p=1}^{N} A_{p}(b) H_{p} A_{p}(a)
$$

\subsubsection{Fatores que afetam o ensaio de vibração transversal}

\subsubsection{Amortecimento}

Nas estruturas de madeira, existem basicamente duas fontes de amortecimento: no material e nas ligações. Obviamente, no caso da AND de toras de madeira, há somente a primeira parcela.

De acordo com Yeh et al (1971), as condições ambientais e o teor de umidade têm maior efeito sobre o coeficiente de amortecimento do que a espécie de madeira. Segundo o mesmo autor, o coeficiente de amortecimento estrutural da madeira varia entre 0,0025 e 0,01.

Contudo, tanto no modelo de Bernoulli como no de Timoshenko, as forças devidas ao amortecimento não foram computadas na dedução da equação diferencial. A consideração de forças de amortecimento viscoso proporcional à velocidade requer a inclusão do termo $c \frac{\partial v(x, t)}{\partial t}$ nas equações dos modelos teóricos. Mas, segundo Beards (1995), na maioria das estruturas o amortecimento é muito pequeno, de forma que a diferença entre as frequências naturais amortecidas e não-amortecidas é insignificante. Só é necessário incluir o amortecimento no modelo teórico se a resposta for procurada em uma frequência próxima à ressonância. 


\subsubsection{Posição dos apoios de vigas simplesmente apoiadas}

Os ensaios de vibração transversal em vigas de madeira na condição bi-apoiada são muito comuns. Com essa configuração a viga nunca fica apoiada exatamente em suas extremidades e, dessa forma, um certo comprimento da viga fica em balanço em cada apoio.

Murphy (1997) investigou o efeito de balanços de mesmo comprimento em ambas as extremidades de uma viga bi-apoiada e encontrou uma solução numérica para a determinação de $E$ levando em conta as extremidades em balanço.

Murphy (1997) observou que, para pequenos balanços $\left(0,85 \leq \mathrm{L}_{\text {apoio }} / \mathrm{L} \leq 1\right)$, a solução numérica converge para a aproximação analítica encontrada por Timoshenko (1974) ${ }^{14}$ e, dessa maneira, o módulo de elasticidade pode ser obtido pela Equação 2.47.

$$
E_{M, V T}=\frac{f_{1}^{2} * \rho^{*} A^{*} L^{*} L_{\text {apoio }}{ }^{3}}{K_{1} * I}
$$

Sendo:

$E_{M, V T}=$ módulo de Young obtido com a técnica de vibração transversal (Pa);

$f_{l}=$ frequência natural do primeiro modo de vibração $(\mathrm{Hz})$;

$L=$ comprimento da viga $(\mathrm{m})$;

$L_{\text {apoio }}=$ distância entre apoios $(\mathrm{m})$;

$\rho=$ densidade do material $\left(\mathrm{kg} / \mathrm{m}^{3}\right)$;

$A$ = área da seção transversal $\left(\mathrm{m}^{2}\right)$;

$I=$ momento de inércia da seção transversal $\left(\mathrm{m}^{4}\right)$;

$K_{1}=\frac{(\lambda L)^{4}}{4 \pi^{2}}=2,476$ (para a condição bi-apoiada com $\left.0,85 \leq \mathrm{L}_{\text {apoio }} / \mathrm{L} \leq 1\right)$;

A Figura 2.45 mostra os valores de $K_{1}$ encontrados por Murphy (1997) e por Timoshenko (1974) em função da relação $\mathrm{L}_{\text {apoio }} / \mathrm{L}$.

14 TIMOSHENKO, S.; YOUNG, D. H.; WEAVER, Jr. W. Vibration Problems in Enginnering. $4^{\text {a }}$ ed. John Wiley \& Sons. New York. 1974. 


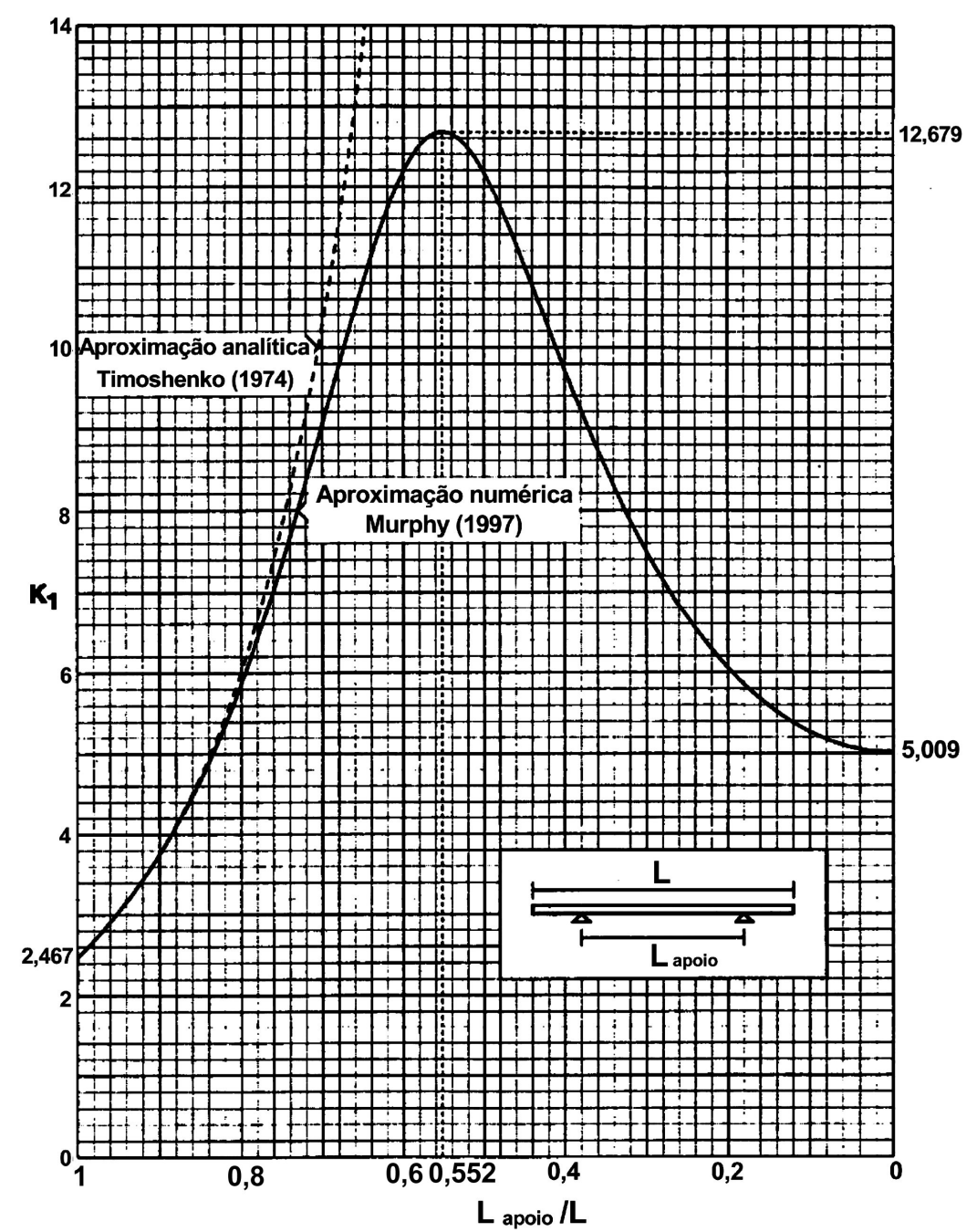

Figura 2.45 - Valores de $\mathrm{K}_{1}$ em função da relação $\mathrm{L}_{\text {apoio }} / \mathrm{L}$.

Fonte: Murphy (1997).

\subsubsection{Influência da inércia a rotação e do esforço cortante}

Para $\mathrm{Hu} \& \mathrm{Hsu}^{15}$ (1996) apud Cho (2007), as tensões de cisalhamento tornam-se insignificantes e seus efeitos podem ser desprezados sem prejuízo para a confiabilidade do ensaio quando o comprimento da viga é superior a 20 vezes a sua altura.

Mas, segundo Zangiácomo (2007), nas toras de madeira, os efeitos das tensões de cisalhamento tornam-se insignificantes para razões entre comprimento e diâmetro maiores que 18.

${ }^{15}$ HU L.J.; HSU, W.E. Implementation of Transverse Simple Beam Vibration Technique to Determine MOE for Wood Based Materials: Accuracy, Comparability, and Limitations. $10^{\text {th }}$ International Symposium on Non-Destructive Testing of Wood, Lausanne, Presses Polytechniques et Universitaires Romandes. pp. 227-235. 1996. 
Alguns autores como Hearmon (1958), Nederveen \& Schwarzl (1964), Brancheriau \& Bailleres (2002) e Kubojima et al (2004) citam o trabalho de Goens (1931) ${ }^{16}$, o qual desenvolveu uma equação transcendental para o cálculo exato do módulo de elasticidade de uma viga computando os efeitos do cisalhamento e da inércia à rotação. A equação de Goens (1931) apud Nederveen \& Schwarzl (1964).

$$
\left(\frac{\tan \frac{1}{2} \beta k}{\tanh \frac{1}{2} \alpha k}+\frac{\beta \varphi}{\alpha \varepsilon}\right)\left(\frac{\tan \frac{1}{2} \beta k}{\tanh \frac{1}{2} \alpha k}-\frac{\alpha \varepsilon}{\beta \varphi}\right)=0
$$

Com:

$$
\begin{aligned}
& \alpha, \beta=\left[\left(B^{2} k^{4}+1\right)^{1 / 2} \pm A k^{2}\right]^{1 / 2} \\
& \mathcal{\varepsilon}, \varphi=\left(B^{2} k^{4}+1\right)^{1 / 2} \pm B k^{2} \\
& A, B=\frac{1}{2} \frac{i^{2}}{L^{2}}\left(\frac{\eta E}{G} \pm 1\right)
\end{aligned}
$$

O módulo de Young é então calculado por:

$$
E=\frac{\omega^{2} L^{4} \rho}{k^{4} i^{2}}
$$

Sendo:

$\omega=$ frequência natural do primeiro modo;

$L=$ comprimento da viga;

$\rho=$ densidade do material;

$k=$ constante obtida pela solução da Equação 2.48;

$i=$ raio de giração da seção transversal.

Goens (1931) apresenta ainda uma aproximação simples para a determinação prática do módulo de elasticidade. Essa aproximação é mostrada na Equação 2.51.

$$
E_{M, G}=E_{M, V T}\left[1+2 A(\lambda L)^{2} \phi^{2}+4(A-2 B)(\lambda L) \phi-\frac{\left(A^{2}-B^{2}\right)(\lambda L)^{4}}{1+2 A(\lambda L)^{2}}\right]
$$

${ }^{16}$ GOENS, E. Uber die Bestimmung des Elastizitätsmoduls von Stäben mit Hilfe von Biegungsschwingungen. Ann D Phys Ser 7 11:649-678. 1931. 
Sendo:

$E_{M, G}=$ módulo de elasticidade na flexão corrigido segundo Goens (1931);

$E_{M, V T}=$ módulo de Young determinado pelo modelo de Bernoulli;

$\phi=0,9825$ ( $1^{\underline{o}}$ modo); 1,0008 ( $2^{\underline{o}}$ modo); 0,99997 ( $3^{\circ}$ modo) e 1,0000 para os demais modos.

$\lambda L=$ para suspensão livre-livre corresponde às raízes da Equação 2.52.

$$
\cos \lambda L \cosh \lambda L=1
$$

Timoshenko (1953) ${ }^{17}$ apud Nederveen \& Schwarzl (1964) sugere a Equação 2.53 para obter o módulo de elasticidade, de forma aproximada, levando em conta os efeitos da inércia à rotação e do esforço cortante.

$$
E_{M, T}=E_{M, V T}\left[1+\frac{i^{2}}{L^{2}}\left(1+\frac{\eta E}{G}\right)(\lambda L)^{2}\right]=E_{M, V T}\left[1+2 A(\lambda L)^{2}\right]
$$

Sendo $\mathrm{E}_{\mathrm{M}, \mathrm{T}} \mathrm{o}$ módulo de elasticidade na flexão corrigido segundo Timoshenko (1953).

Nederveen \& Schwarzl (1964) examinaram o efeito do erro nas aproximações propostas por Goens (1931) e Timoshenko (1953) no coeficiente $\eta$ e concluíram que não há razão para usar uma equação mais complicada do que a simples correção proposta por Timoshenko (1953).

Segundo Goens (1931) apud Hearmon (1958), a frequência teórica de uma viga livrelivre, levando-se em conta os efeitos da inércia à rotação e do esforço cortante, é dada por:

$$
f_{g}=\frac{f_{r}}{\sqrt{T}}
$$

Sendo:

$f_{r}=$ frequência natural de acordo com Bernoulli (Equação 2.55);

$T=$ coeficiente de correção proposto por Goens (1931) (Equação 2.56).

$$
f_{r}=\frac{i(\lambda L)^{2}}{2 \pi L^{2}} \sqrt{\frac{E}{\rho}}
$$

${ }^{17}$ TIMOSHENKO, S. P. Collected Papers. McGraw-Hill. New York. P288-290. 1953. 


$$
\begin{aligned}
& T=1+\frac{i^{2}}{L^{2}}\left[(\lambda L)^{2} F^{2}(\lambda L)+6(\lambda L) F(\lambda L)\right]+\frac{i^{2}}{L^{2}} \frac{\eta E}{G}\left[(\lambda L)^{2} F^{2}(\lambda L)-2(\lambda L) F(\lambda L)\right]- \\
& -\frac{4 \eta \pi^{2} \rho i^{2} f_{g}{ }^{2}}{G}
\end{aligned}
$$

Segundo Hearmon (1958), Goens (1931) encontrou para $F(\lambda L)$ os valores de 0,9825 para o primeiro modo, 1,008 para o segundo modo e 1,000 para os demais modos de uma viga em suspensão livre-livre.

Os valores de $T$ e $f_{\mathrm{g}}$ são encontrados por tentativas.

\subsubsection{Influência da rigidez do sistema de suspensão}

O efeito da rigidez do sistema de suspensão nas frequências naturais de vibração depende da relação entre a rigidez do apoio $(K)$ e a rigidez da viga $\left(E I / L^{3}\right)$, sendo que a frequência de oscilação do sistema aumenta com o acréscimo de $\left(K L^{3}\right) /(E I)$, (MURPHY, 2000).

De acordo com Frýba (1999), o primeiro estudo sobre o efeito de apoios elásticos no comportamento de vigas em vibração transversal foi apresentado por Timoshenko $(1926)^{18}$.

As frequências naturais de uma viga de Bernoulli uniformemente apoiada sobre uma fundação elástica (Figura 2.46) podem ser calculadas pela Equação 2.57, extraída de Clough \& Penzien (1995).

$$
\omega_{n}=\left[(\lambda L)_{n}{ }^{4} \frac{E I}{\rho A L^{4}}+\frac{\bar{K}}{\rho A}\right]
$$

Sendo:

$\omega_{n}=$ frequência natural de vibração do n-ésimo modo;

$\lambda L=$ obtido da Tabela 2.15;

$E$ = módulo de elasticidade da viga;

$I=$ momento de inércia da seção transversal;

$\rho=$ densidade aparente do material da viga;

$L=$ comprimento da viga;

$\bar{K}=$ rigidez do sistema de suspensão por unidade de comprimento.

\footnotetext{
${ }^{18}$ TIMOSHENKO, S. P. Statical and Dynamical Stresses in Rails. In: International Congress of Applied Mechanics. Zurich. p. 407-418. 1926.
} 


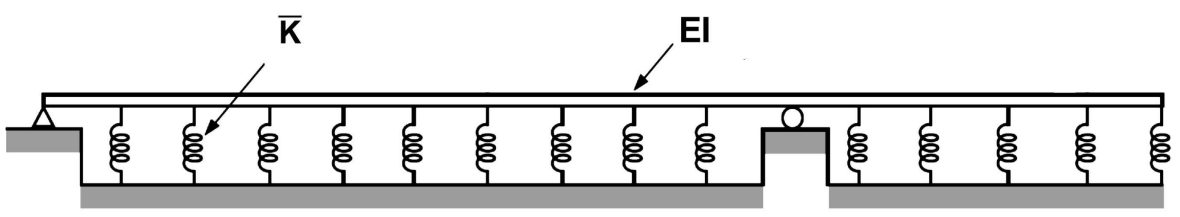

Figura 2.46 - Viga apoiada sobre base elástica.

Fonte: Adaptado de Clough \& Penzien (1995).

Karnovsky \& Lebed (2001) apresentam equações exatas para o cálculo das frequências naturais e dos modos de vibração de vigas de Bernoulli apoiadas em ambas as extremidades por apoios elásticos (Figura 2.47). Essas equações foram extraídas de Anan'ev $(1946)^{19}$ e Gorman $(1975)^{20}$.

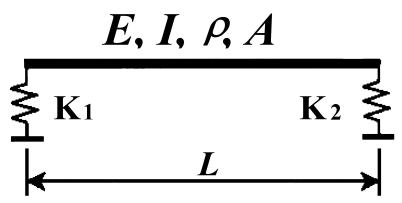

Figura 2.47 - Viga sobre dois apoios elásticos posicionados nas extremidades.

Fonte: Adaptado de Karnovsky \& Lebed (2001).

As frequências naturais de uma viga de Bernoulli, suspensa como mostra a Figura 2.47, podem ser calculadas pela Equação 2.58.

$$
\omega_{n}=\frac{(\lambda L)_{n}{ }^{2}}{L^{2}} \sqrt{\frac{E I}{\rho A}}
$$

Sendo:

$\omega_{n}=$ frequência natural do n-ésimo modo;

$L=$ comprimento da viga;

$E=$ módulo de elasticidade da viga;

$I=$ momento de inércia da seção transversal;

$\rho=$ densidade do material;

$A=$ área da seção transversal;

Os valores de $(\lambda L)_{n}$ correspondem às raízes da Equação 2.59 segundo Gorman (1975) e Anan'ev (1946), citados por Karnovsky \& Lebed (2001).

\footnotetext{
${ }^{19}$ ANAN' EV, I. V. Free Vibration of Elastic System Handbook. Rússia: Gostekhizdat. 1946.

${ }^{20}$ GORMAN, D.J. Free Vibration Analysis of Beams and Shafts. New York: Wiley. 1975.
} 


$$
\begin{aligned}
& \left(K_{1}^{*}\right)^{2}+K_{1}^{*} \frac{(\lambda L)^{3}(1+\psi)[\operatorname{senh}(\lambda L) \cos (\lambda L)-\cosh (\lambda L) \operatorname{sen}(\lambda L)]}{2 \psi \operatorname{sen}(\lambda L) \operatorname{senh}(\lambda L)}+ \\
& +\frac{(\lambda L)^{6}[1-\cos (\lambda L) \cosh (\lambda L)]}{2 \psi \operatorname{sen}(\lambda L) \operatorname{senh}(\lambda L)}=0
\end{aligned}
$$

Sendo:

$$
K_{1}^{*}=\frac{K_{1} L^{3}}{E I}, \quad K_{2}^{*}=\frac{K_{2} L^{3}}{E I} \text { e } \Psi=\frac{K_{2}^{*}}{K_{1}^{*}}
$$

O parâmetro $(\lambda L)_{n}$, em função de $\mathrm{K}_{2}{ }^{*}$ e $\Psi$, pode também ser obtido da Figura 2.48 para os três primeiros modos de uma viga de Bernoulli.

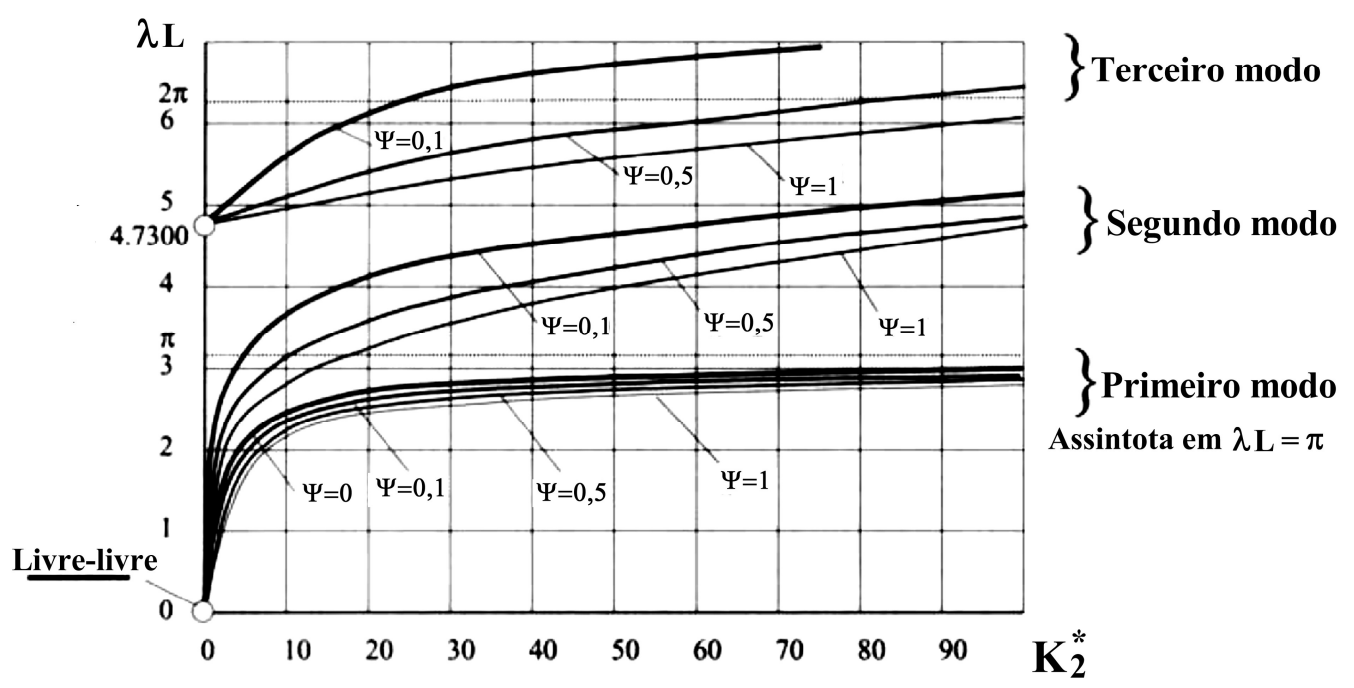

Figura 2.48 - Parâmetros $(\lambda L)_{1},(\lambda L)_{2}$ e $(\lambda L)_{3}$ em função de $K_{2}{ }^{*}$. Fonte: Adaptado de Karnovski \& Lebed (2001).

Blay et al (1971) e posteriormente Richard (1980) fizeram um estudo sobre o efeito da rigidez do sistema de suspensão nas frequências naturais de vigas de Bernoulli. Em ambos os trabalhos, apoios elásticos de mesma rigidez foram considerados nas extremidades da viga.

Blay et al (1971) apresentam um gráfico (Figura 2.48) que demonstra a variação do parâmetro $(\lambda L)^{2}$ para os seis primeiros modos de uma viga de Bernoulli em função da rigidez relativa dos apoios. Tal gráfico pode ser obtido variando-se o valor de $\mathrm{K}^{*}$ na Equação 2.59 e calculando as correspondentes raízes para os seis primeiros modos.

Observa-se nessa figura que se a rigidez $K$ for muito pequena, o parâmetro $(\lambda L)^{2}$ para o terceiro modo tende a $(4,7300)^{2}$, ou seja, a viga se comportaria como em suspensão livrelivre. 
Os dois primeiros modos na Figura 2.49 correspondem respectivamente à translação da viga sobre os apoios e à rotação da mesma em torno de seu centro de gravidade.

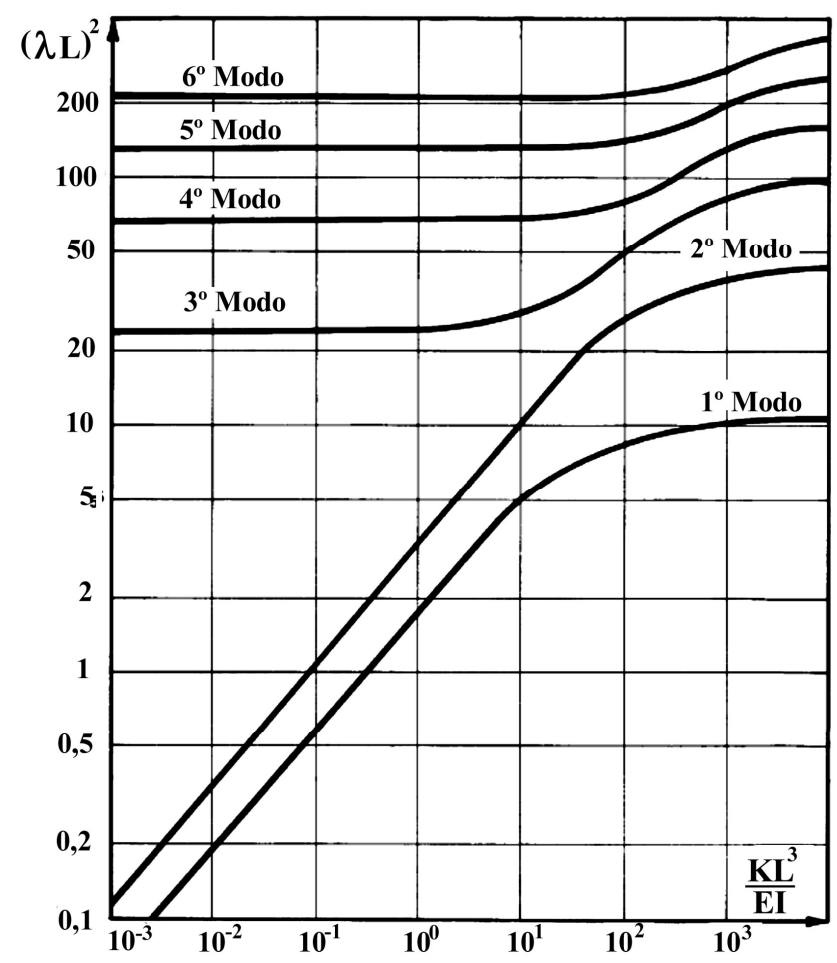

Figura 2.49 - Variação do parâmetro $(\lambda L)^{2}$ para uma viga de Bernoulli em função da rigidez relativa dos apoios elásticos.

Fonte: Adaptado de Blay et al (1971).

A análise do gráfico mostrado na Figura 2.48 leva Blay et al (1971) a concluírem que a viga comporta-se como suspensão livre-livre quando é satisfeita a condição:

$$
\frac{K L^{3}}{E I}<1
$$

E, similarmente, a condição de apoios rígidos seria válida para a determinação das primeiras seis frequências naturais quando:

$$
\frac{K L^{3}}{E I}>10^{5}
$$

Conhecendo-se o parâmetro $\lambda L$ é possível determinar o módulo de elasticidade da viga por meio da Equação 2.63.

$$
E=\frac{f^{2} *(2 \pi)^{2} * \rho^{*} A * L^{4}}{(\lambda L)^{4} * I}
$$


Richard (1980) apresenta um gráfico semelhante (Figura 2.50), porém, relaciona a rigidez relativa com a frequência relativa $f^{*}$ em vez do parâmetro $(\lambda L)^{2}$. A frequência $f^{*}$ é dada por:

$$
f^{*}=\frac{f}{\frac{\pi}{2 L^{2}} \sqrt{\frac{E I}{\rho A}}}
$$

Sendo:

$f=$ frequência da viga sobre apoio elástico;

$L=$ comprimento da viga;

$E=$ módulo de elasticidade da viga;

$I=$ momento de inércia da seção transversal;

$\rho=$ densidade da viga;

$A=$ área da seção transversal.

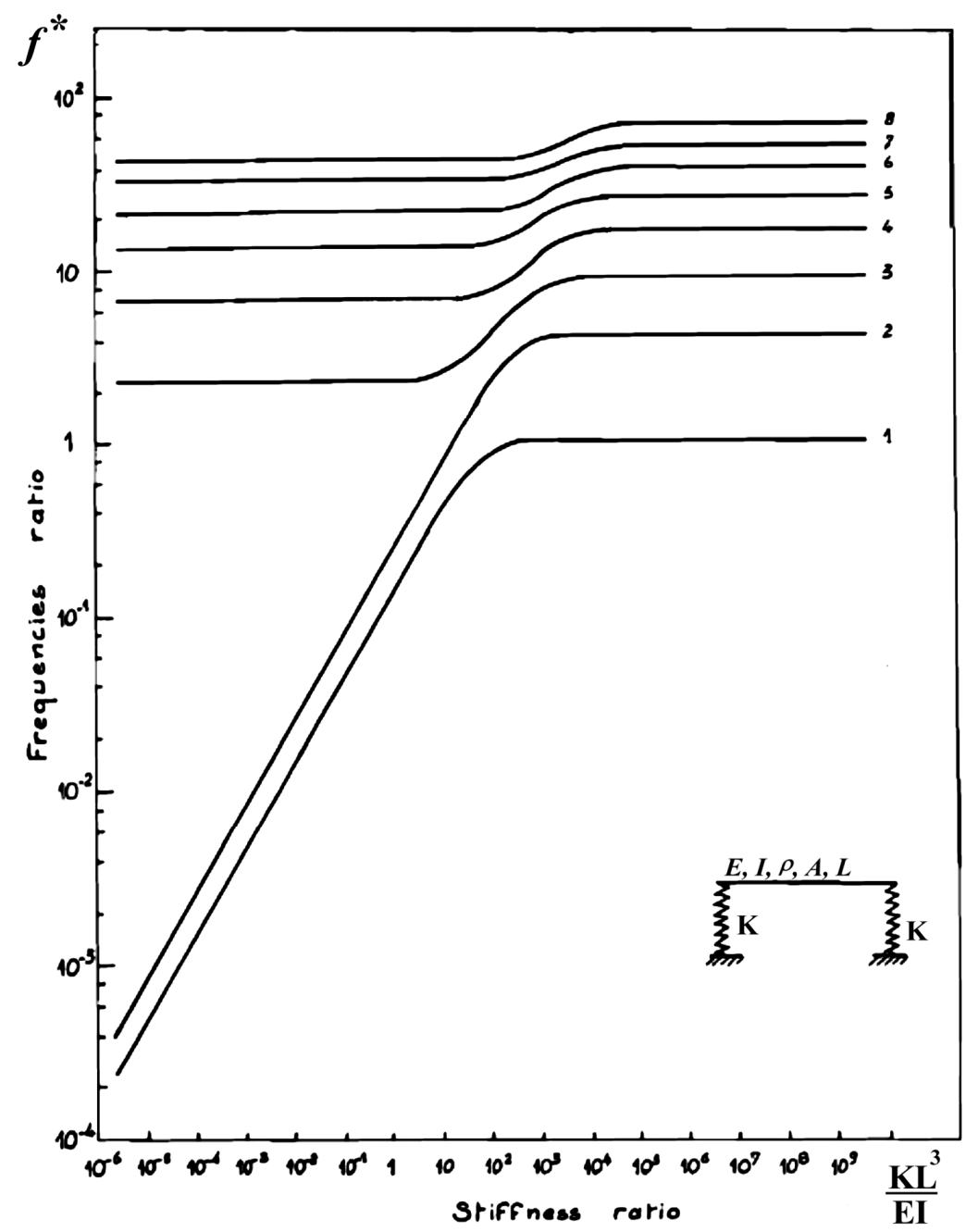

Figura 2.50 - Variação da frequência de uma viga de Bernoulli em função da rigidez relativa dos apoios elásticos. 
Algumas recomendações práticas também podem ser adotadas para a verificação da condição de contorno. Para o caso de suspensão livre-livre, por exemplo, Allemang \& Brown (2002) averiguam se a frequência do modo de corpo rígido é inferior a 1/10 da frequência do primeiro modo de deformação. Satisfeita essa condição, segundo os autores citados, o sistema de suspensão do experimento se aproximará da condição de contorno teórica.

\subsubsection{Outros aspectos que influenciam o ensaio de vibração transversal em toras}

\subsubsection{Variações das propriedades geométricas da seção transversal}

Como a seção transversal das toras varia ao longo do comprimento, a rigor, o módulo de elasticidade à flexão dessas peças não pode ser calculado pelas mesmas equações deduzidas para vigas prismáticas.

As normas NBR 6231 (ABNT, 1980) e ASTM D1036 (ASTM, 2005) consideram o diâmetro calculado de acordo com a Equação 2.65 para a determinação do módulo de elasticidade na flexão com o esquema estático de viga engastada-livre.

$$
\mathrm{D}=\sqrt[4]{\mathrm{D}_{\text {base }}^{3} \mathrm{D}_{\text {topo }}}
$$

Sendo:

$$
\begin{aligned}
& \mathrm{D}_{\text {base }}=\text { diâmetro da base da tora } \\
& \mathrm{D}_{\text {topo }}=\text { diâmetro do topo da tora } .
\end{aligned}
$$

Para efeitos de dimensionamento a norma NBR 7190 (ABNT, 1997) permite considerar as peças de seção transversal circular variável como se fossem de diâmetro uniforme tomado a $1 / 3$ da extremidade mais delgada, não se considerando diâmetro superior a 1,5 o diâmetro dessa extremidade.

Miná (2005) desenvolveu uma equação (Equação 2.66) que permite calcular um "diâmetro equivalente" com o qual se pode determinar o módulo de elasticidade à flexão de toras para o esquema de viga bi-apoiada com força concentrada no meio do vão.

$$
\mathrm{D}_{\text {eq }}=\sqrt[4]{\frac{2 \mathrm{D}_{\text {topo }} \mathrm{D}_{\text {meio }}{ }^{3} \mathrm{D}_{\text {base }}}{\mathrm{D}_{\text {topo }}+\mathrm{D}_{\text {base }}}}
$$


Entretanto, segundo Miná et al (2008), para o ensaio de flexão estática com viga engastada-livre e com carga concentrada na extremidade mais delgada, a rigidez à flexão pode ser calculada a partir do diâmetro tomado na metade do comprimento das toras

No método de avaliação de postes de madeira proposto por Chui et al (1999), as toras são consideradas como vigas tronco-cônicas com variação linear do diâmetro ao longo do comprimento. Os autores utilizam o sistema de coordenadas adimensionais mostrados na Figura 2.51 .

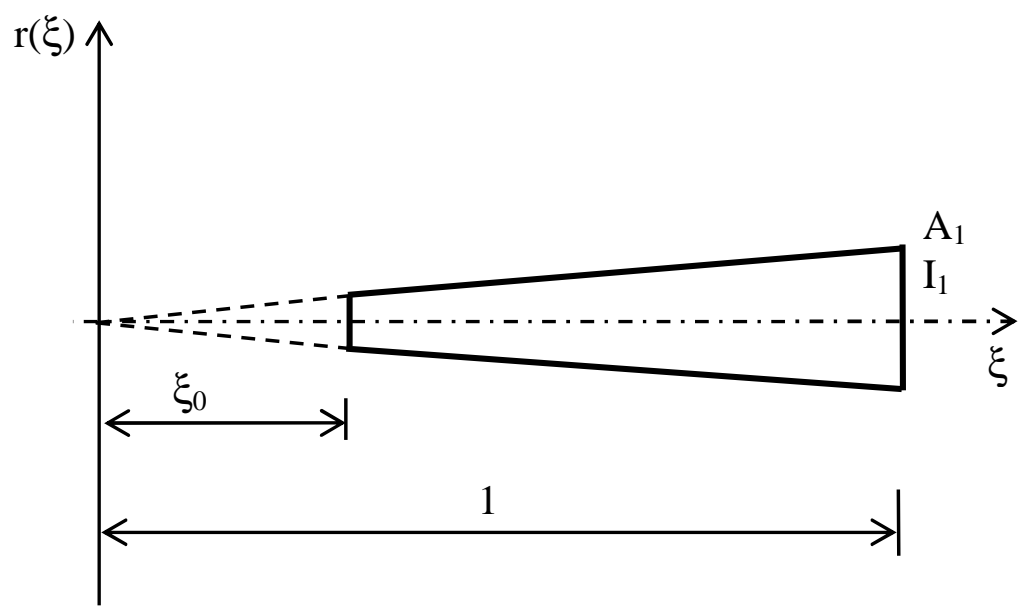

Figura 2.51 - Sistema de coordenadas usado por Chui et al (1999).

Fonte: Chui et al (1999).

Entretanto, para a condição de contorno livre-livre, a inclusão dessas variáveis no modelo teórico torna o problema sem solução analítica. Segundo Chui et al (1999), as frequências naturais para esse modelo são obtidas encontrando-se os valores de $\lambda L$ que satisfazem a Equação 2.67

$$
\left|\begin{array}{cccc}
J_{4}\left(Z_{0}\right) & Y_{4}\left(Z_{0}\right) & I_{4}\left(Z_{0}\right) & K_{4}\left(Z_{0}\right) \\
J_{5}\left(Z_{0}\right) & Y_{5}\left(Z_{0}\right) & -I_{5}\left(Z_{0}\right) & K_{5}\left(Z_{0}\right) \\
J_{4}[2(\lambda L)] & Y_{4}[2(\lambda L)] & I_{4}[2(\lambda L)] & K_{4}[2(\lambda L)] \\
J_{5}[2(\lambda L)] & Y_{5}[2(\lambda L)] & -I_{5}[2(\lambda L)] & K_{5}[2(\lambda L)]
\end{array}\right|=0
$$

Sendo:

$$
Z_{0}=2(\lambda L) \sqrt{\xi_{0}}
$$

$\mathrm{e}$

$\mathrm{J}_{4}$ e $\mathrm{Y}_{4}=$ Funções de Bessel de quarta ordem do primeiro e segundo tipo respectivamente;

$\mathrm{J}_{5}$ e $\mathrm{Y}_{5}=$ Funções de Bessel de quinta ordem do primeiro e segundo tipo respectivamente; 
$\mathrm{I}_{4}$ e $\mathrm{K}_{4}=$ Funções de Bessel modificadas de quarta ordem do primeiro e segundo tipo respectivamente;

$\mathrm{I}_{5}$ e $\mathrm{K}_{5}=$ Funções de Bessel modificadas de quinta ordem do primeiro e segundo tipo respectivamente.

Para realizar esses cálculos, Chui et al (1999) desenvolveram um programa de computador para determinar frequências naturais por método numérico.

Murphy (2000a) desenvolveu uma investigação teórica sobre as frequências naturais de uma viga tronco-cônica bi-apoiada em vibração transversal. A viga foi discretizada em 32 sub-cilindros de raio constante (Figura 2.52). O momento de inércia de cada sub-cilindro foi calculado usando raios tomados em três diferentes posições: metade do comprimento do trecho; coordenada do centróide de cada sub-cilindro e; coordenada na qual o volume de cada sub-cilindro se iguala ao volume do tronco de cone de cada trecho.

Murphy (2000a) avaliou as frequências naturais para cada caso e observou que as diferenças nas frequências naturais são insignificantes.

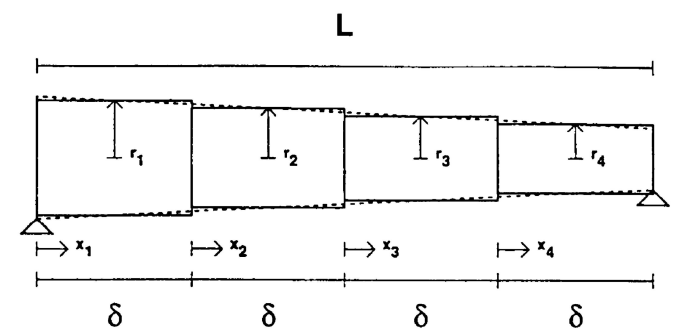

Figura 2.52 - Discretização adotada por Murphy (2000a).

Fonte: Murphy (2000a)

Murphy (2000a) ainda determina módulo de elasticidade da viga tronco-cônica aproximando a mesma a um cilindro de diâmetro igual a média geométrica dos diâmetros das extremidades da viga e compara o resultado obtido com uma simulação computacional. Segundo esse autor, o módulo de elasticidade obtido com essa aproximação resulta em uma avaliação levemente não-conservadora.

Miná et al (2008) desenvolveram uma equação para levar em conta a influência da geometria no cálculo da rigidez à flexão de toras de madeira por meio da aplicação do Princípio dos Trabalhos Virtuais para o esquema estático de viga engastada. A seção transversal da viga, considerada circular, foi dividida em partes iguais. A variação da seção transversal foi considerada linear e a equação deduzida foi utilizada para determinar a rigidez à flexão de 12 estacas de Eucalyptus citriodora. Os autores concluíram que a geometria das 
toras da espécie estudada não teve grande influência na determinação de sua rigidez e observam que a determinação do módulo de elasticidade considerando-se o diâmetro no meio do vão ou o diâmetro a 1/3 da extremidade mais delgada resulta em grande erro.

\subsubsection{Distribuição não-homogênea de densidade}

Kubojima et al (2006) realizaram uma investigação experimental sobre a nãohomogeneidade da densidade e sua relação com o módulo de elasticidade dinâmico de vigas de madeira serrada e observaram que as vigas com distribuição não-homogênea de densidade têm comportamento equivalente ao de vigas uniformes com massas concentradas.

\subsubsection{Teor de umidade}

Há poucas referências na literatura a respeito da influência do teor de umidade na medição do módulo de elasticidade à flexão com o ensaio de vibração transversal.

Para o ensaio em vigas de madeira serrada, a norma ASTM D 6874 (ASTM, 2003) "Standard Test Methods for Nondestructive Evaluation of Wood-Based Flexural Members Using Transverse Vibration" não recomenda a execução do ensaio de vibração transversal em peças com teor de umidade acima de $22 \%$.

Ainda segundo a norma ASTM D 6874 (ASTM, 2003), o módulo de elasticidade dinâmico das peças de madeira serrada com teor de umidade não superior a $22 \%$ podem ser corrigidos empregando os procedimentos da norma ASTM D 2915 (ASTM, 2003) "Practice for Evaluating Allowable Properties for Grades of Structural Lumber".

Barret \& Hong (2009) desenvolveram uma investigação experimental sobre o efeito do teor de umidade na medição do módulo de elasticidade dinâmico simulando a água livre em vigas de madeira serrada com massas (moedas) distribuídas ao longo do comprimento. Os autores observaram que adicionando-se massas para simular teores de umidade acima de 30\% o módulo de elasticidade dinâmico permanece constante. Barret \& Hong (2009) concluíram também que o procedimento da norma ASTM D 1990 (ASTM, 1997) “Standard Practice for Establishing Allowable Properties for Visually-Graded Dimension Lumber from In-Grade Tests of Full-Size Specimens" para correção do módulo de elasticidade em função do teor de umidade pode ser usado para calcular o módulo de elasticidade dinâmico no teor de umidade de $15 \%$. 
Unterwieser \& Schickhofer (2010) estudaram a influência do teor de umidade no módulo de elasticidade dinâmico de vigas de madeira serrada e propuseram as Equações 2.69 e 2.70 para correção do módulo de elasticidade dinâmico da espécie Spruce respectivamente para teores de umidade abaixo e acima do ponto de saturação das fibras.

$$
\begin{array}{cc}
E_{M, V T, 12 \%}=\frac{E_{M, V T, u}}{1-0,0087(u-12)} & u \leq P S \% \\
E_{M, V T, 12 \%}=1,15 E_{M, V T, u} \% & u>P S \%
\end{array}
$$

\subsubsection{Análise modal experimental}

A análise modal experimental corresponde ao processo de determinação, por meio de análise experimental, dos parâmetros modais de um sistema dinâmico, linear e invariante no tempo (ALLEMANG \& BROWN, 2002).

Geralmente, a análise modal experimental é realizada para a verificação ou correção de resultados de um modelo analítico. Segundo Allemang \& Brown (2002), na maior parte das vezes, a análise modal experimental é desenvolvida para elucidar um problema dinâmico (vibração ou acústico) cuja solução não pode ser obtida por intuição, modelos analíticos ou por experiência anterior.

Os parâmetros modais, ou a alteração desses, podem ser empregados na identificação e localização de danos em elementos estruturais. Diversos trabalhos foram desenvolvidos nessa linha como os citados a seguir.

Yang et al (2002) investigaram a detecção de defeitos como nós e fibras inclinadas em vigas de madeira por meio da comparação entre os modos teóricos e modos determinados experimentalmente. Os autores constataram que os modos de vibração obtidos por experimentação apresentaram desvio em relação aos modos teóricos exatamente na região dos nós como mostra a Figura 2.53. 


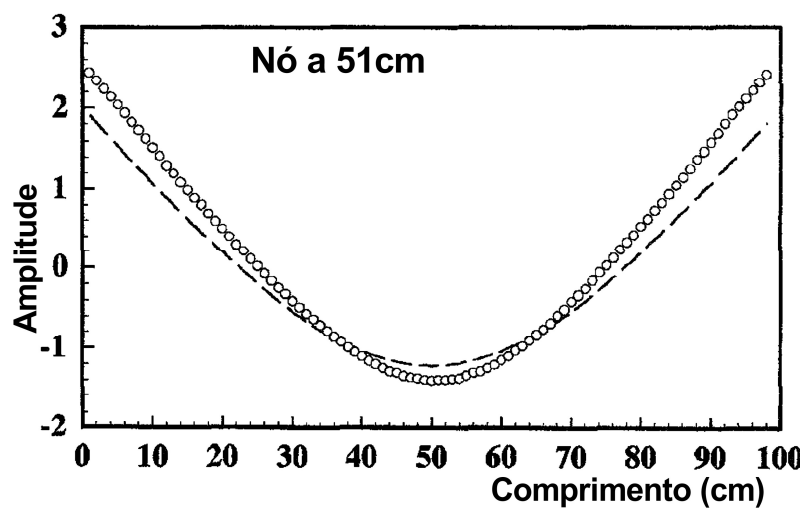

Figura 2.53 - Influência do nó no modo de vibração de uma viga. Linha tracejada: modo teórico; linha com círculos abertos: modo experimental.

Fonte: Yang et al (2002)

Esses desvios são esperados, pois, na região dos nós ocorre tanto a redução da rigidez como a adição de massa, uma vez que os nós são mais densos do que a madeira sã.

Owolabi et al (2003), relatam um método de detecção de trincas em vigas com base na alteração das frequências naturais e na amplitude das FRF's.

Chuanshuang \& Muhammad (2006) propuseram um algoritmo estatístico para a identificação de danos em vigas de madeira baseado na alteração dos modos de vibração após a danificação.

Loya et al (2006) obtiveram as frequências naturais para uma viga de Timoshenko contendo uma trinca. A viga foi modelada como dois segmentos conectados por uma mola de translação e por uma mola de rotação, ambas sem massa. Esse modelo causa descontinuidade à rotação e à translação que são proporcionais ao momento fletor e ao esforço cortante transmitidos pela trinca.

\subsubsection{Hipóteses básicas da análise modal experimental}

De acordo com Allemang \& Brown (2002), a análise modal de qualquer estrutura é fundamentada em quatro hipóteses básicas:

- A estrutura tem comportamento linear: a resposta da estrutura a qualquer combinação de forças, aplicadas simultaneamente, é igual à soma das respostas individuais de cada força atuando isoladamente.

- A estrutura é invariante no tempo: os parâmetros a serem determinados são constantes. Em geral, um sistema que não é invariante no tempo tem suas propriedades como massa, rigidez ou amortecimento dependentes de outros fatores não medidos ou não incluídos no modelo. Por exemplo, algumas propriedades podem ser dependentes da temperatura. 
- A estrutura obedece ao teorema da reciprocidade de Maxwell com relação às medições das FRF's: a FRF entre os pontos $\mathrm{p}$ e q determinada pela excitação em p e medição da resposta em q é igual à FRF obtida pela excitação no ponto q e medição da resposta no ponto $\underline{\mathrm{p}}\left(\mathrm{H}_{\mathrm{pq}}=\mathrm{H}_{\mathrm{qp}}\right)$.

- A estrutura é observável: as medições da entrada e da saída são feitas de modo a obter informações suficientes para gerar um modelo comportamental da estrutura. Estruturas que tem graus de liberdade não medidos não são completamente observáveis.

\subsubsection{Técnicas de análise modal experimental}

\section{j. Condicionamento, conversão e processamento dos sinais do experimento}

Os sinais provenientes da maioria dos transdutores possuem tensões muito baixas e precisam ser amplificados antes de serem convertidos e processados.

Frequentemente, sinais espúrios de considerável intensidade estão presentes no ambiente de ensaio como, por exemplo, o sinal de $60 \mathrm{~Hz}$ da rede, transientes de motores elétricos e outros sinais indesejáveis. No percurso entre o transdutor e o condicionador, os sinais dos transdutores são afetados por esses espúrios.

Dessa forma, os sinais de entrada do equipamento de medição são compostos pela informação registrada pelos transdutores acrescida de ruído.

Para se obter uma medição mais confiável é necessário atenuar o ruído empregando-se filtros.

O processo de amplificação e filtragem dos sinais é denominado condicionamento de sinais.

\section{Condicionamento de sinais}

O circuito eletrônico empregado para a amplificação dos sinais dos transdutores é o amplificador operacional. Existem várias configurações para os amplificadores operacionais, porém uma classe particular denominada amplificador de instrumentação (Figura 2.54a) é a mais indicada para sinais provenientes dos transdutores resistivos como os acelerômetros e as células de carga que fazem uso da ponte de Wheatstone. 


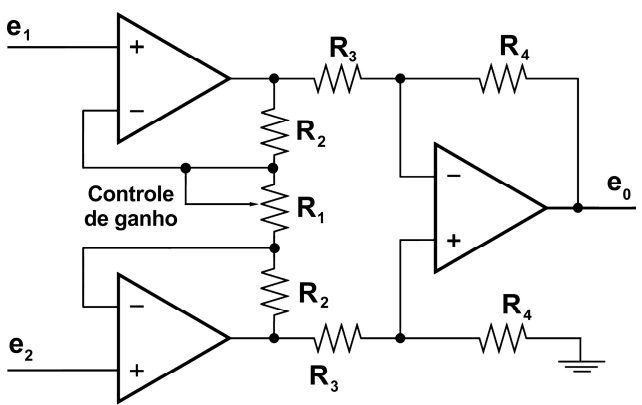

(a)

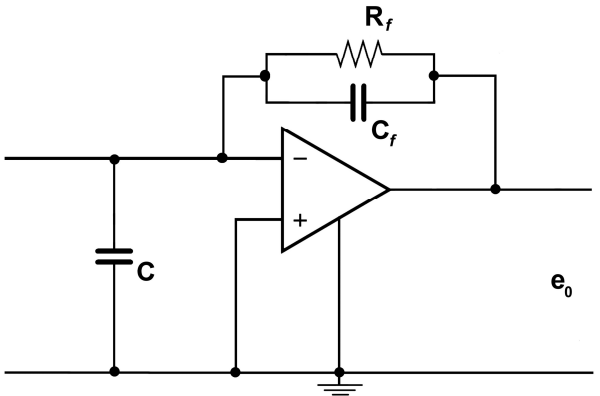

(b)

Figura 2.54 - Amplificadores de sinal: a) Amplificador de instrumentação; b) Amplificador de carga.

Fonte: Doebelin (2004).

Quando empregam-se transdutores piezelétricos, o circuito adequado para amplificar os sinais é o amplificador de carga mostrado na Figura 2.54b.

Após a amplificação, o ruído pode alcançar intensidades elevadas o suficiente para inviabilizar a medição. A correção desse problema é feita com a utilização de filtros capazes de atenuar o ruído permitindo assim uma medição confiável.

Os filtros podem ser implementados eletricamente ou digitalmente. A Figura 2.55 mostra os efeitos dos diversos filtros na aquisição de dados.

A tendência atual é substituir os filtros analógicos por filtros digitais. Além de reproduzirem facilmente as funções de filtragem mostradas na Figura 2.55, esses filtros também são mais precisos e estáveis, podendo ainda serem configurados por software. O filtro digital é um algoritmo no qual o sinal amostrado, representado por uma sequência de números, é transformado em uma segunda sequência de números livre de ruídos (DOEBLIN, 2004).

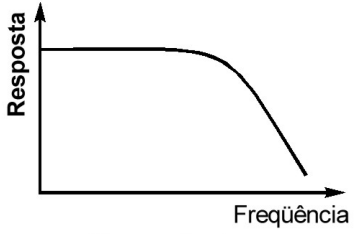

Passa baixa

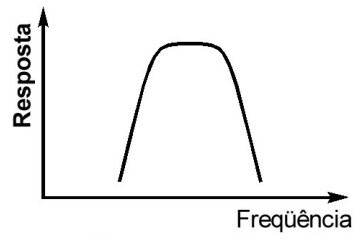

Passa banda

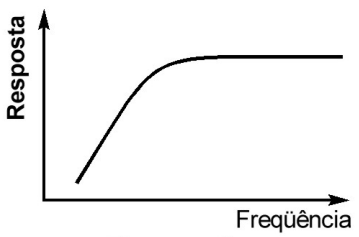

Passa alta

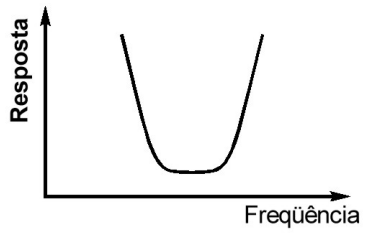

Rejeita banda

Figura 2.55 - Tipos de filtros.

Fonte: Adaptado de Poole (2008). 


\section{Conversão analógico/digital}

Os microcontroladores, controles industriais, computadores e muitos outros circuitos que processam dados obtidos de sensores operam exclusivamente com sinais digitais. Assim, para transferir os sinais de um transdutor analógico a um computador é preciso "convertê-lo" empregando um circuito denominado conversor analógico/digital ou simplesmente "conversor A/D” (BRAGA, 2006).

Esses conversores são largamente empregados em placas de aquisição de dados que realizam a interface dos computadores com os dispositivos de medição.

Um conversor A/D converte uma tensão analógica em um número digital. O número digital representa a tensão de entrada em passos discretos com resolução finita. A Figura 2.56 mostra o comportamento ideal de um conversor A/D de 3 bits com fundo de escada de $5 \mathrm{~V}$.

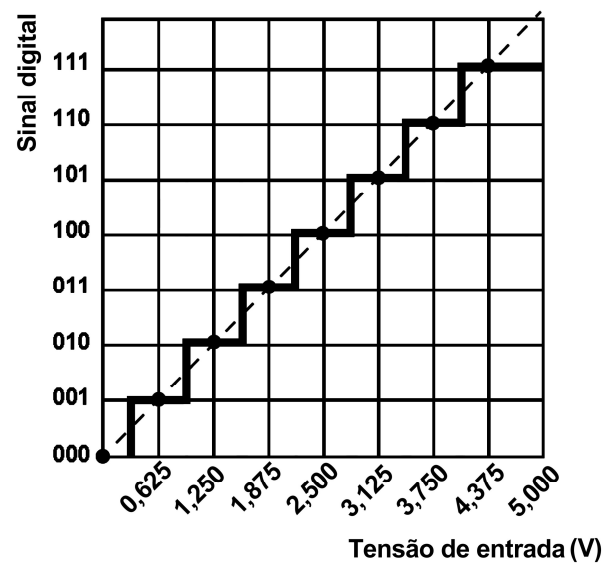

Figura 2.56 - Função de transferência de um conversor A/D de 3 bits.

Fonte: Adaptado de Intersil (1997).

A resolução do conversor $A / D$ é determinada pelo número de bits que representa $o$ número digital. Um conversor A/D de 12 bits, por exemplo, tem uma resolução de 1 parte para $2^{12}$. Para um intervalo de leituras entre 0 e $5 \mathrm{~V}$ esse conversor terá uma resolução de 1,221 mV. Já um conversor de 16 bits, com o mesmo intervalo de leitura, teria resolução de $76,3 \mu \mathrm{V}$.

Segundo Piersol (2002), a conversão dos sinais analógicos em digitais introduz dois erros potenciais que devem ser cuidadosamente suprimidos. Esses erros são o erro de quantização (quantization error) e o aliasing. 


\section{Erro de quantização}

Em qualquer parte do intervalo de leitura de um conversor $\mathrm{A} / \mathrm{D}$, o valor observado na saída não será alterado para uma pequena variação na tensão de entrada. No exemplo da Figura 2.56, se for aplicado $1 \mathrm{~V}$ na entrada do conversor $\mathrm{A} / \mathrm{D}$ ele indicará $1,250 \mathrm{~V}$, pois a faixa de leituras do conversor A/D está discretizada em intervalos de 0,625 V. A diferença entre a tensão aplicada e a indicada pelo conversor é denominada erro de quantização.

O passo da discretização é denominado de intervalo de quantização (q) e corresponde ao menor intervalo de tensão analógica que pode ser medido pelo conversor (INTERSIL, 1997). O intervalo de quantização é calculado pela Equação 2.71.

$$
q=\frac{F E}{2^{n}}
$$

Sendo:

$$
\begin{aligned}
& q=\text { intervalo de quantização; } \\
& F E=\text { fundo de escala do conversor A/D; } \\
& n=\text { número de bits do conversor. }
\end{aligned}
$$

A redução do erro de quantização é feita aumentando-se a resolução do conversor A/D. Atualmente, os fabricantes de placas de aquisição de dados para instrumentação em engenharia produzem placas com resolução entre 10 e 32 bits. O erro de quantização nessas placas é insignificante.

\section{Aliasing}

De acordo com o Teorema da Amostragem de Nyquist, se a maior frequência contida no sinal de um transdutor for igual a $\underline{\mathbf{f}}$, então toda a informação do sinal pode ser capturada se a amostragem for realizada a uma taxa de pelo menos $\underline{2 f}$ (DOEBELIN, 2004; PIERSOL, 2002; OLSHAUSEN, 2000; MCCONNELL, 1995). Essa frequência de amostragem também é denominada frequência de Nyquist.

Entretanto, de acordo com Iotech (1997), na prática, para trabalhar no domínio da frequência é melhor empregar uma taxa de aquisição entre cinco e dez vezes a maior frequência contida no sinal amostrado.

A amostragem em frequências inferiores à de Nyquist é insuficiente para capturar as variações do sinal. O erro gerado é denominado de aliasing. A Figura 2.57 ilustra o exemplo de um sinal de $4 \mathrm{~Hz}$ amostrado a uma taxa de $5 \mathrm{~Hz}$. Devido ao aliasing, o sinal foi reconstruído com frequência de $1 \mathrm{~Hz}$. 


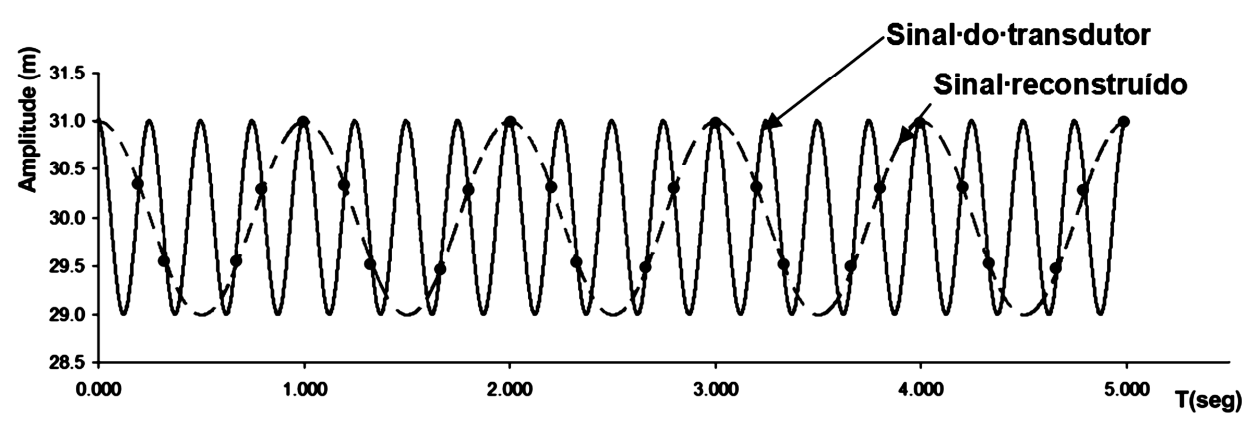

Figura 2.57 - Exemplo de Aliasing.

\section{Processamento dos sinais digitais}

Uma vez convertidos para a forma digital, os sinais são transformados do domínio tempo para o domínio da frequência usando o algoritmo da Transformada Discreta de Fourier ou do inglês Discrete Fourier Transform (DFT).

A Transformada de Fourier decompõe os sinais obtidos dos transdutores em uma combinação de ondas senoidais e co-senoidais, com as respectivas frequências contidas no sinal amostrado, sendo que cada sinal tem somente uma única combinação de senos e cosenos (AGILENT TECHNOLOGIES, 2002; ALLEMANG \& BROWN, 2002).

A DFT é baseada na serie de Fourier. Tal série é conhecida publicamente desde 1822 quando o matemático francês Jean Baptiste Fourier publicou sua Teoria Analítica do Calor (Théorie analytique de la chaleur) na qual Fourier provou que a condução de calor, em corpos sólidos, pode ser analisada por uma série infinita composta pela soma de termos seno e coseno. Posteriormente, tal série recebeu o seu nome.

A série de Fourier pode ser empregada não somente na análise de ondas de calor, mas também em qualquer forma de onda, inclusive as ondas mecânicas. Por esse motivo, a série de Fourier tem grande aplicação na análise modal de estruturas.

A Figura $2.58 \mathrm{~b}$ mostra um gráfico da soma de ondas senoidais. O plano tempoamplitude é familiar para a análise no domínio do tempo. O terceiro eixo, frequência, permite a visualização em separado das ondas senoidais que somadas compõem a onda de forma complexa. 


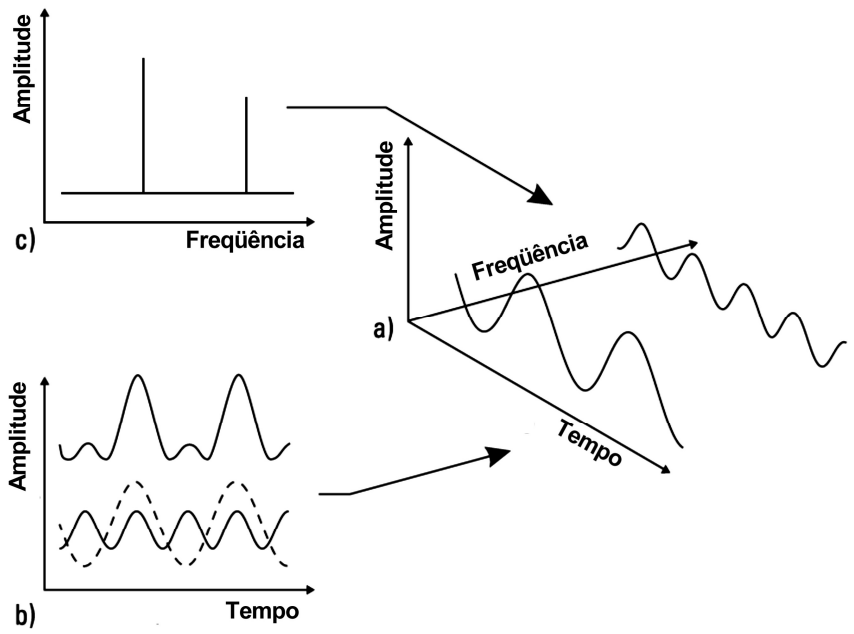

Figura 2.58 - Relação entre os domínios do tempo e da frequência: a) sistema de coordenadas tridimensionais mostrando tempo, frequência e amplitude; b) Observação no domínio do tempo; c) Observação no domínio da frequência.

Fonte: Adaptado de Agilent Technologies (2002).

Se o gráfico da Figura 2.58a for observado do eixo do tempo, será visualizado o gráfico frequência x amplitude denominado de domínio da frequência (Figura 2.58c).

A DFT é uma ferramenta matemática capaz de descrever a amplitude e fase de cada componente para todas as frequências angulares contidas no sinal. Assim, por exemplo, se for calculada a DFT de um sinal como o da Figura 2.58b, a resposta obtida será o gráfico da Figura 2.58c, no qual observam-se as frequências e as respectivas amplitudes de cada componente do sinal.

A Transformada de Fourier de um sinal discreto $f(t)$ é expressa pela Equação 2.72.

$$
F(\omega)=\int_{-\infty}^{+\infty} \mathrm{f}(t) e^{i \omega t} d t
$$

Sendo:

$$
\begin{aligned}
& \mathrm{f}(t)=\text { sinal periódico no domínio do tempo; } \\
& \omega=\text { frequência angular; } \\
& t=\text { tempo; } \\
& i=\text { unidade imaginária }(i=\sqrt{-1}) .
\end{aligned}
$$

A DFT supõe que o sinal seja discreto e periódico. Caso o sinal amostrado não seja periódico, o sinal transformado será afetado por um erro conhecido como leakage. Esse erro e suas implicações são discutidos mais à frente. 
O cálculo da DFT a partir de integrais infinitas como a da Equação 2.72 é muito trabalhoso e lento para fins práticos. Por esse motivo, em 1965 Cooley \& Tukey ${ }^{21}$ apud Smith (1999) apresentaram um algoritmo baseado no cálculo da DFT para números complexos. Tal algoritmo permite o cálculo da DFT em computadores de forma rápida, sendo denominada de Transformada Rápida de Fourier ou do inglês Fast Fourier Transform (FFT).

\section{Leakage}

O algoritmo de cálculo da FFT assume que o sinal seja periódico em cada bloco de dados. Quando o algoritmo calcula a FFT de um sinal não-periódico, o espectro de frequência resultante aparece distorcido. Essa distorção aparece como uma baixa amplitude do sinal fundamental e uma dispersão da energia em um intervalo de frequências mais largo como mostra a Figura 2.59 (LDS TEST AND MEASUREMENT, 2003). A dispersão da energia torna mais difícil a identificação das frequências contidas no sinal amostrado.
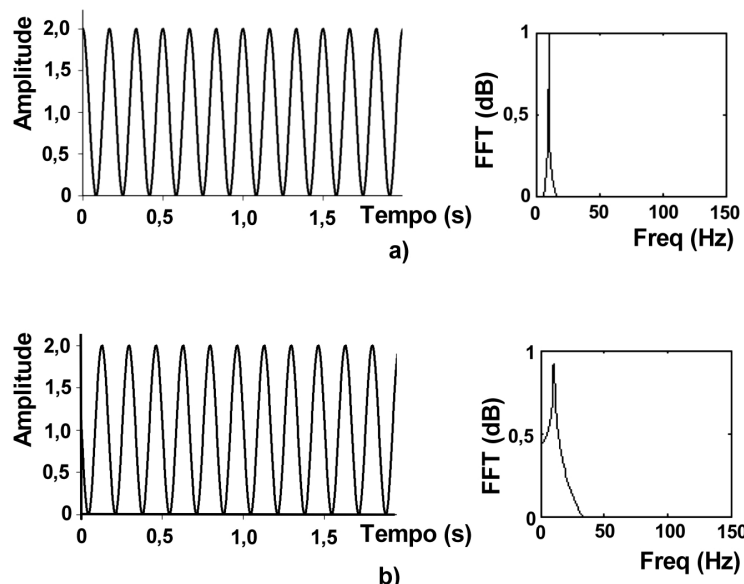

Figura 2.59 - Transformada de Fourier: a) FFT de um sinal periódico; (b) presença de leakage na FFT de um sinal aperiódico.

Fonte: Adaptado de LDS Test and Measurement (2003).

A maioria dos sinais captados nos ensaios dinâmicos é não-periódica e para a redução dos efeitos do leakage na FFT desses sinais empregam-se janelas de aquisição (LDS TEST AND MEASUREMENT, 2003).

Uma janela é uma função de ponderação em relação à qual os dados de aquisição do sinal são multiplicados antes do cálculo da FFT (NOBREGA, 2004). A função janela, em geral, assume o valor zero no início e no fim do período de amostragem.

${ }^{21}$ COOLEY, J. W.; TUKEY, J. W.. An algorithm for the machine calculation of complex Fourier Series. Mathematics Computation. Vol 19. pg 297-301. 1965. 
Muitos tipos de janela foram propostas ao longo do tempo, cada um com sua vantagem e desvantagem. Algumas melhoram a resolução da frequência tornando mais fácil identificar o pico de amplitude. Outras melhoram a exatidão da amplitude. A Tabela 2.16 mostra os tipos de função janela mais comuns.

Tabela 2.16 - Funções janelas mais comuns e suas características.

\begin{tabular}{lcccc}
\hline Janela & $\begin{array}{c}\text { Melhor para o } \\
\text { sinal do tipo }\end{array}$ & $\begin{array}{c}\text { Resolução da } \\
\text { frequência }\end{array}$ & $\begin{array}{c}\text { Leakage no } \\
\text { espectro }\end{array}$ & $\begin{array}{c}\text { Exatidão da } \\
\text { amplitude }\end{array}$ \\
\hline Barlett & Aleatório & Bom & Regular & Regular \\
Blackman & $\begin{array}{c}\text { Aleatório ou } \\
\text { misturado }\end{array}$ & Pobre & Melhor & Bom \\
Flat top & Sinusoides & Pobre & Bom & Melhor \\
Hanning & Aleatório & Bom & Bom & Regular \\
Hamming & Aleatório & Bom & Regular & Regular \\
Kaiser-Bessel & Aleatório & Regular & Bom & Bom \\
Tukey & Aleatório & Bom & Pobre & Pobre \\
Welch & Aleatório & Bom & Bom & Regular \\
\hline
\end{tabular}

Fonte: Adaptado de LDS Test and Measurement (2003).

De acordo com McConnell (1995), as janelas podem ser definidas matematicamente por uma função geral do tipo:

$$
w(t)=a_{0}-a_{1} \cos \left(\omega_{0} t\right)+a_{2} \cos \left(2 \omega_{0} t\right)-a_{3} \cos \left(3 \omega_{0} t\right)+a_{4} \cos \left(4 \omega_{0} t\right)
$$

A função $w(t)$ é válida no intervalo $0<\mathrm{t}<\mathrm{T}$. Para outros valores de $\mathrm{t}, w(t)=0$.

As constantes $\mathrm{a}_{1}$ a $\mathrm{a}_{4}$ são mostradas na Tabela 2.17 .

Tabela 2.17 - Funções janelas mais comuns e suas constantes.

\begin{tabular}{lccccc}
\hline \multirow{2}{*}{ Função } & \multicolumn{6}{c}{ Coeficientes } \\
\cline { 2 - 6 } & $\mathbf{a}_{0}$ & $\mathbf{a}_{1}$ & $\mathbf{a}_{2}$ & $\mathbf{a}_{3}$ & $\mathbf{a}_{4}$ \\
\hline Retangular & 1,000 & - & - & - & - \\
Hanning & 1,000 & 1,000 & - & - & - \\
Kaiser-Bessel & 1,000 & 1,298 & 0,244 & 0,003 & - \\
Flat top & 1,000 & 1,993 & 1,286 & 0,388 & 0,032 \\
\hline
\end{tabular}

Fonte: McConnell (1995).

A Figura 2.60 mostra o formato de algumas funções janela. 


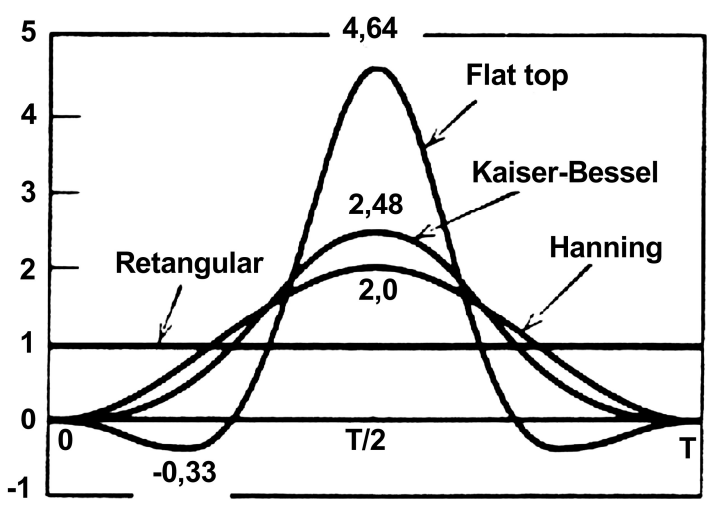

Figura 2.60 - Formato de algumas funções janela observadas no domínio do tempo.

Fonte: McConnell (1995).

Outro tipo de janela, desenvolvida especialmente para análise modal com excitação por impacto, é a janela exponencial. A forma dessa função é mostrada na Figura 2.61.

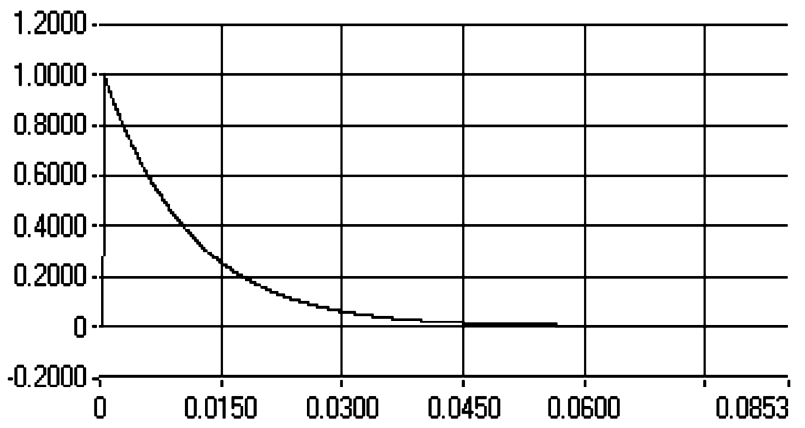

Figura 2.61 - Formato da função janela exponencial.

Fonte: LDS Test and Measurement (2003).

A janela exponencial força os dados da resposta tenderem a zero no fim do período de amostragem, resultando em um sinal periódico.

Deve-se observar que esse tipo de janela afeta o amortecimento e, portanto, sua determinação deve ser feita antes da aplicação da função janela.

Segundo Avitabile (2001a) se for necessário aplicar um grande amortecimento na janela para minimizar os efeitos do leakage, pode-se correr o risco de dois modos vizinhos unirem-se (Figura 2.62). 

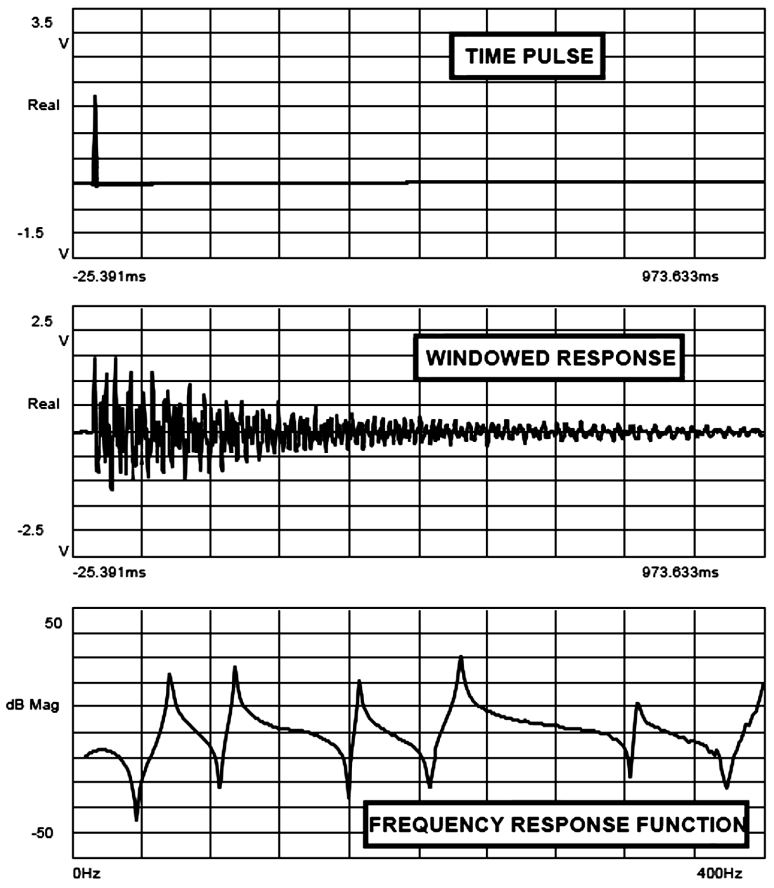

(a)
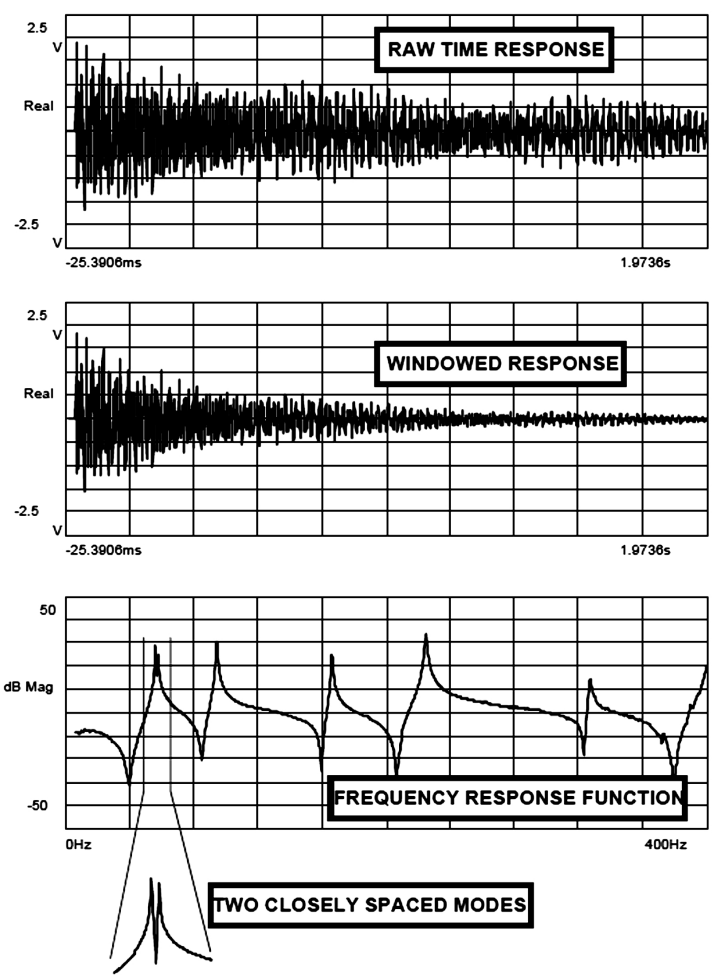

(b)

Figura 2.62 - Efeito da janela exponencial: a) Janela com muito amortecimento; b) Aumento do período de amostragem e uso de pouco amortecimento.

Fonte: Avitabile (2001a).

Avitabile (2001a) sugere observar se o decaimento do sinal é naturalmente atenuado no período de amostragem. Caso não seja, o autor recomenda aumentar o período de amostragem e usar janela exponencial com pouco amortecimento.

Uma das desvantagens do uso de funções janela é que tanto o começo como o fim do sinal são atenuados. Isso significa perda de dados no inicio e no fim do período de amostragem. Para obter uma boa representação estatística do espectro é necessário aumentar o período de amostragem e realizar o cálculo de várias médias do sinal ao longo do período amostrado.

O sinal médio corresponde a uma média aritmética ou ponderada de várias amostragens do sinal.

De acordo com Nóbrega (2004), com esse processo é possível garantir uma confiabilidade mínima do sinal amostrado.

Executar a média também acarreta em trabalhar com um sinal de perfil mais claro, suavizado, além da exclusão de ruídos espúrios.

A maioria dos analisadores de sinais realiza uma sobreposição (overlap) das janelas de aquisição permitindo assim a recuperação dos dados perdidos nas extremidades do período de 
amostragem (LDS TEST AND MEASUREMENT, 2003). A Figura 2.63 mostra como é realizada a operação de sobreposição do sinal.

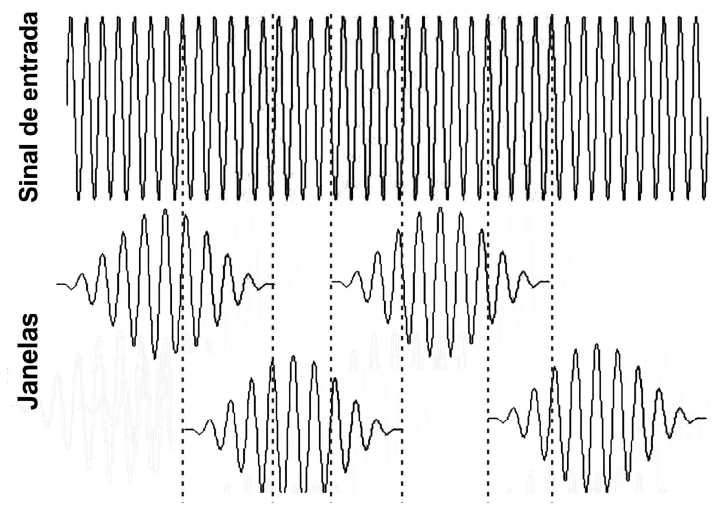

Figura 2.63 - Sobreposição das janelas de aquisição.

Fonte: Adaptado de LDS Test and Measurement (2003).

Nesse caso, para cada janela é calculada uma FFT e posteriormente é calculada uma média aritmética da FFT de todas as janelas. Uma das desvantagens de empregar esse processo, segundo Nóbrega (2004) é que os efeitos não-lineares passam a ser "linearizados".

A Figura 2.64 mostra a redução do ruído de um sinal aleatório estacionário em função do cálculo de médias do sinal.

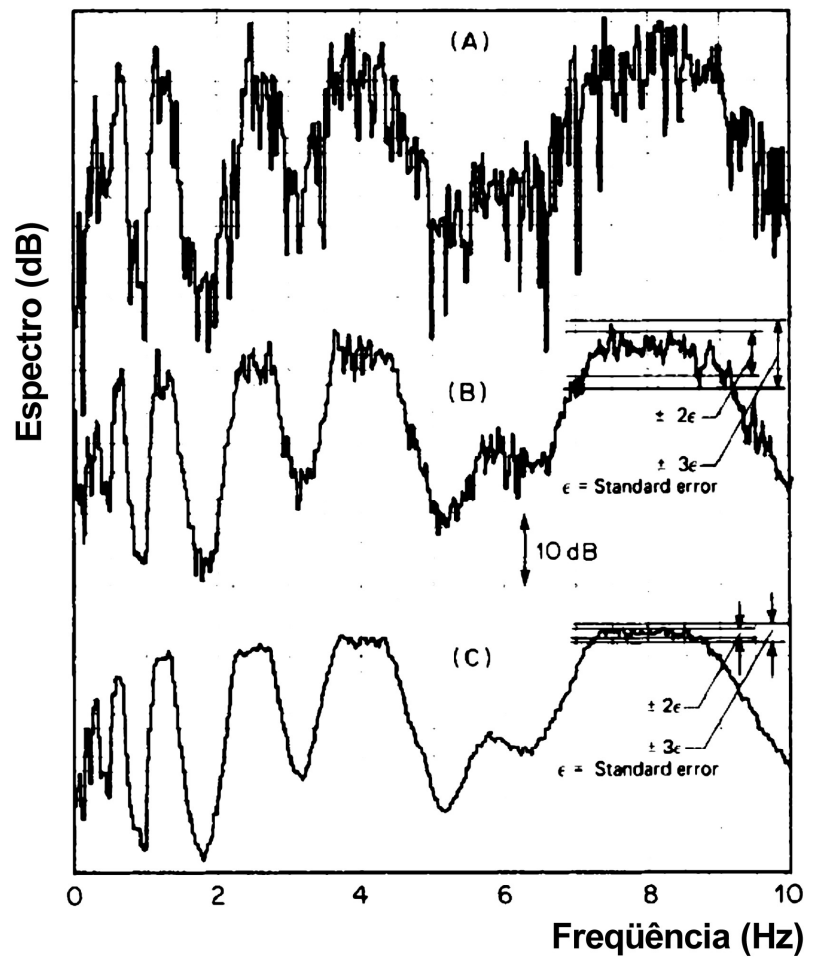

Figura 2.64 - Efeito do cálculo da média: a) espectro instantâneo de um sinal aleatório; b) espectro resultante após 8 médias; c) espectro obtido após 128 médias.

Fonte: Adaptado de Allemang \& Brown (2002). 
Para a medição da Função de Resposta em Frequência é necessário formular um modelo de medição que permita que a FRF seja estimada a partir de dados de entrada e saída, sendo esses medidos na presença de ruídos.

Existem pelo menos quatro configurações de ensaio que podem ser utilizadas no experimento. Essas configurações são:

- $\quad$ Uma entrada e uma saída (Single input/single output - SISO);

- $\quad$ Uma entrada e múltiplas saídas (Single input/multiple output - SIMO);

- $\quad$ Múltiplas entradas e uma saída (Multiple input/single output - MISO);

- Múltiplas entradas e múltiplas saídas (Multiple input/multiple output - MIMO).

A escolha por uma dessas diferentes configurações é norteada basicamente em função do número de canais de aquisição ou fontes de excitação disponíveis para o teste.

Se os dados forem coletados no menor intervalo de tempo possível e, com mínima ou nenhuma, mudança nas condições do teste, a melhor configuração de ensaio será a de múltiplas entradas e múltiplas saídas (Allemang \& Brown, 2002).

A técnica de aproximação mais comum e mais razoável para estimar a Função de Resposta em Frequência a partir dos dados experimentais é aproximação por mínimos quadrados (LS) ou mínimos quadrados totais (TLS). Essas técnicas são clássicas para a estimativa de parâmetros na presença de ruídos. A técnica dos mínimos quadrados minimiza o módulo do erro e assim permite encontrar a melhor estimativa para o módulo da FRF, mas ela tem pouco efeito na fase da FRF. A principal diferença entre os algoritmos usados para estimar a FRF está na consideração de onde o ruído entra no problema de medição. Três algoritmos referenciados como $\mathrm{H}_{1}, \mathrm{H}_{2}$ e $\mathrm{H}_{\mathrm{v}}$ são usualmente empregados para estimar a FRF. A Tabela 2.18 mostra a localização considerada para o ruído em cada algoritmo (ALLEMANG \& BROWN, 2002).

Tabela 2.18 - Localização do ruído em cada algoritmo para estimativa das FRF.

\begin{tabular}{cccc}
\hline Algoritmo & $\begin{array}{c}\text { Método de } \\
\text { solução }\end{array}$ & \multicolumn{2}{c}{ Localização do ruído } \\
& Entrada & Resposta \\
\hline $\mathrm{H}_{1}$ & LS & Sem ruído & Com ruído \\
$\mathrm{H}_{2}$ & LS & Com ruído & Sem ruído \\
$\mathrm{H}_{\mathrm{v}}$ & TLS & Com ruído & Com ruído \\
\hline
\end{tabular}

Fonte: Allemang \& Brown (2002). 
É possível relacionar quão a saída da estrutura em teste está linearmente relacionada com a entrada. Para tanto, pode-se empregar a função coerência conforme Equação 2.74.

$$
\gamma^{2}(\omega)=\frac{H_{1}(\omega)}{H_{2}(\omega)}
$$

A função coerência fornece uma medida da linearidade entre o sinal de saída com o sinal de entrada em cada frequência $\omega$ e seu valor pode variar entre 0 e 1 (MCCONNELL, 1995).

Segundo Trepanier (2009), a coerência pode ser interpretada como uma medida da quantidade de força responsável pela resposta medida, sendo desejável a obtenção de valores iguais ou superiores a 0,9 .

Se o valor da coerência for igual a 1 em uma determinada frequência, significa que a resposta medida é totalmente produzida pela entrada medida. Um valor de coerência menor do que 1 em uma certa frequência indica que a resposta medida é maior do que a produzida pela entrada medida. Nesse caso, algum ruído estranho pode estar contribuindo para a obtenção de uma saída maior do que a esperada. Quando a coerência for zero em certa frequência, significa que, nessa frequência, a saída é totalmente causada por outras fontes e não pela entrada medida. Assim sendo, a coerência pode ser usada como uma medida do grau de contaminação na medição da FRF (ALLEMANG \& BROWN, 2002).

Segundo Mcconnell (1995), a coerência será menor do que 1 se ocorrer uma das seguintes situações:

- Resposta não-linear da estrutura;

- Erro de tendência na resolução do espectro;

- Atraso entre os sinais;

- Ruído não correlacionado nas medições.

\section{k. Fixação dos acelerômetros na estrutura e seus efeitos}

O correto posicionamento e fixação dos acelerômetros na estrutura são muito importantes para evitar erros de medição.

Com relação ao posicionamento, deve-se tomar o cuidado de não fixar os acelerômetros nos pontos nodais dos modos que se deseja medir. Para tanto, é importante realizar a análise modal teórica antes da experimental para verificar a localização dos pontos nodais da estrutura e evitar o posicionamento dos acelerômetros nesses pontos. 
A fixação inadequada dos acelerômetros pode afetar negativamente a medição das vibrações reduzindo a banda de frequências de medição. A principal exigência é garantir o contato mecânico entre a base do acelerômetro e a superfície da estrutura em teste.

Há várias maneiras de fixar os acelerômetros, sendo algumas delas mostradas na Figura 2.65.

Para acelerômetros pequenos pode-se empregar também cera de abelha como meio de fixação, mas esse método é limitado a temperaturas de $40^{\circ} \mathrm{C}$, pois acima desse valor a cera começa a amolecer (BRUEL \& KJÆR, 2008).

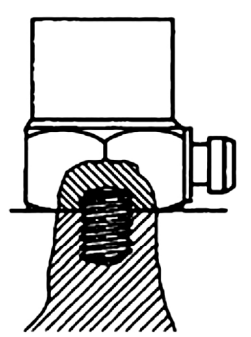

(A)

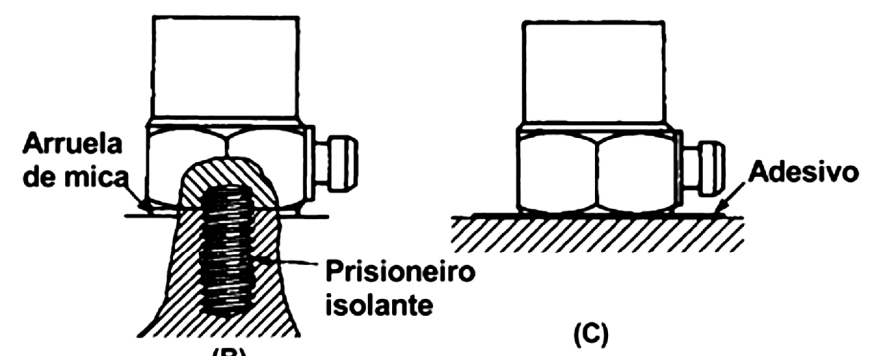

(B)

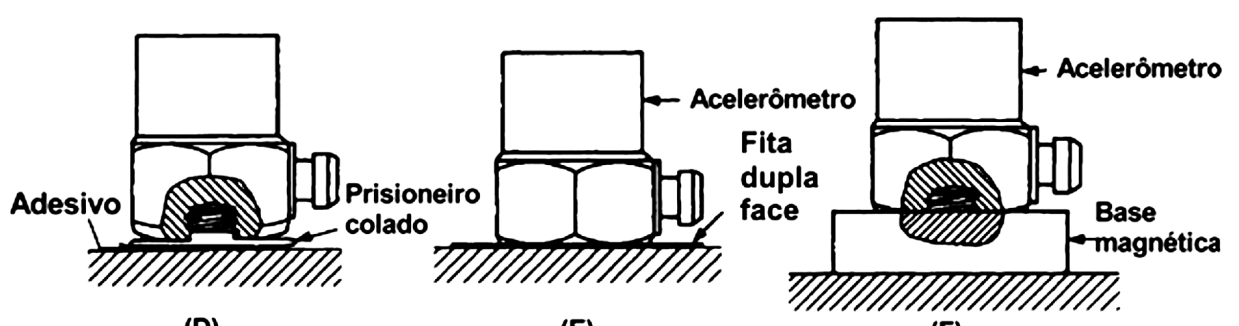

(D)

(F)

Figura 2.65 - Métodos de fixação do acelerômetro na estrutura: A) com prisioneiro de aço; B) fixação isolada eletricamente; C) com adesivo; D) prisioneiro colado; E) com fita dupla face; F) empregando uma base magnética.

Fonte: Adaptado de Harris (2002).

Segundo Harris (2002), a fixação do acelerômetro com prisioneiros de aço é a melhor forma de montagem e deve ser usada sempre que possível pelas seguintes razões:

1. Ela fornece maior frequência de ressonância (até $100 \mathrm{kHz}$ ) do que qualquer outro tipo de fixação e, dessa forma, a maior banda de medição (até $50 \mathrm{kHz}$ );

2. Permite medições em altos níveis de vibração sem o risco do acelerômetro se soltar da estrutura;

3. Não limita as medições a baixas temperaturas como a cera de abelha;

4. Permite medições precisas e repetíveis.

A Figura 2.66 mostra a resposta em frequência para alguns tipos de fixação. 


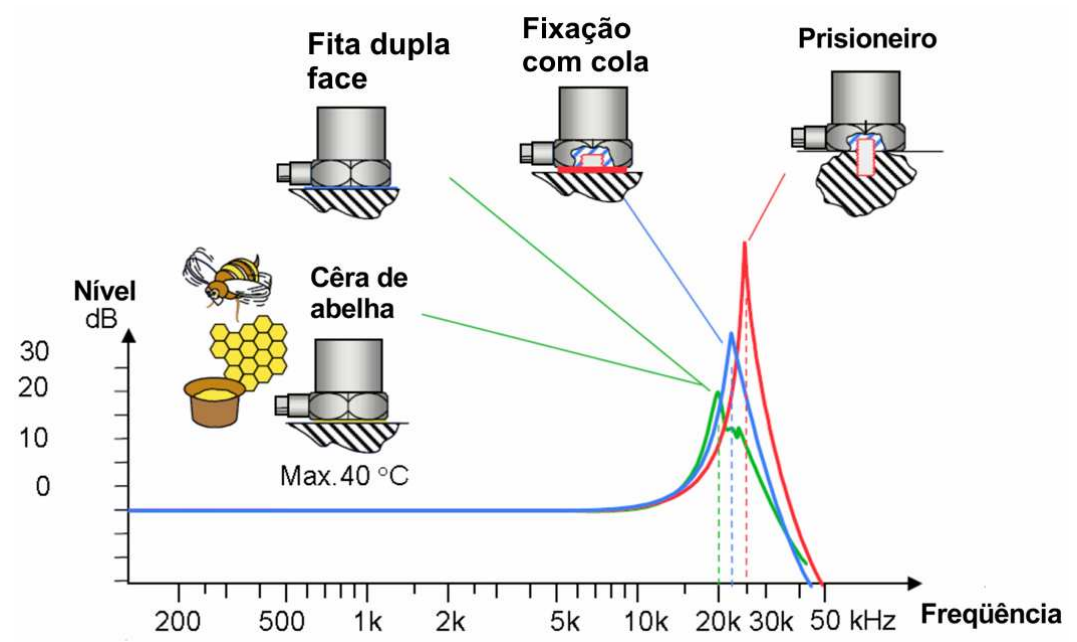

Figura 2.66 - Resposta em frequência de alguns métodos de fixação do acelerômetro.

Fonte: Adaptado de Bruel \& Kjær (2008).

Outro fator importante a ser observado é o acréscimo da massa do acelerômetro na estrutura em teste. Do ponto de vista teórico, as frequências naturais estão relacionadas com a raiz entre a rigidez e a massa. Logo, a adição de massa resulta na redução das frequências naturais.

Se o acelerômetro for fixado a uma estrutura com grande massa como uma ponte ou um edifício, os efeitos são desprezíveis. Porém, para estruturas pequenas e leves, o efeito da massa do acelerômetro pode ser significativo.

A Figura 2.67 mostra o efeito na medição da FRF de um suporte de disco rígido de computador empregando inicialmente um acelerômetro pesado e depois usando um acelerômetro de baixo peso. Essa experiência, relatada em Avitabile (2001), mostra que a massa do acelerômetro afeta a frequência natural dos modos de vibração, sendo que tal efeito é mais pronunciado nos modos superiores.

Para reduzir os erros de medição, Bruel \& Kjær (2008) recomenda que a massa do acelerômetro seja inferior a $10 \%$ da massa em movimento da estrutura em teste. 


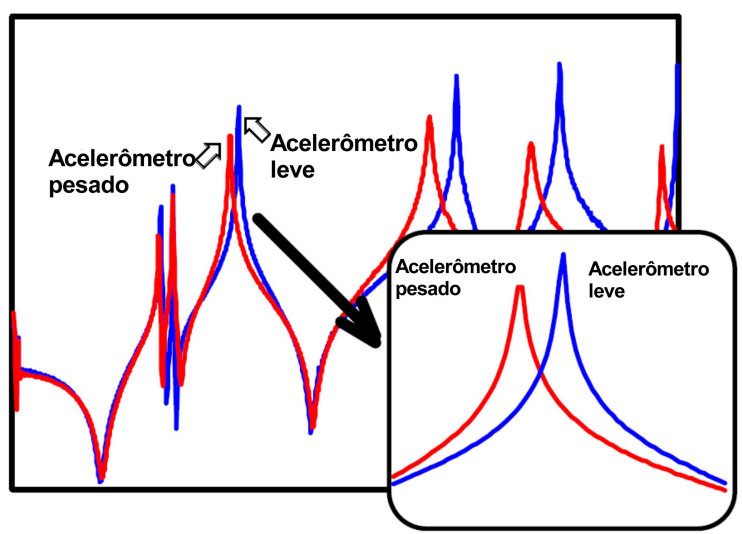

Figura 2.67 - FRF com dois acelerômetros de massas diferentes.

Fonte: Adaptado de Avitabile (2001).

\section{Excitação da estrutura}

Existem diversos dispositivos para excitar os sistemas dinâmicos e a escolha por um ou outro envolve muitas questões, sendo algumas delas abordadas neste trabalho.

Nos ensaios de campo, com estruturas civis de grande porte como pontes, passarelas e barragens, geralmente são empregados equipamentos como shakers servo-hidráulicos, vibradores de massa excêntrica, marretas de impacto ou caminhões vibratórios (Figura 2.68).

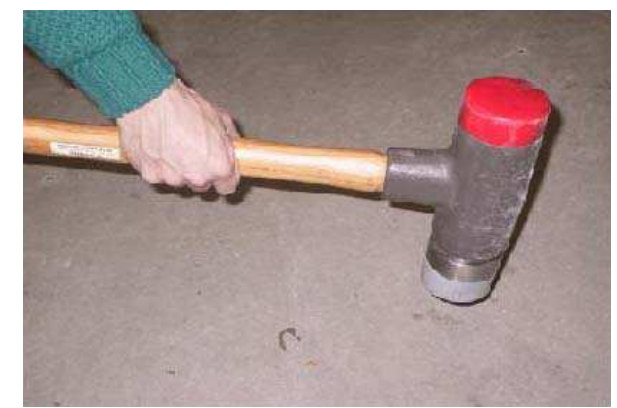

(a)

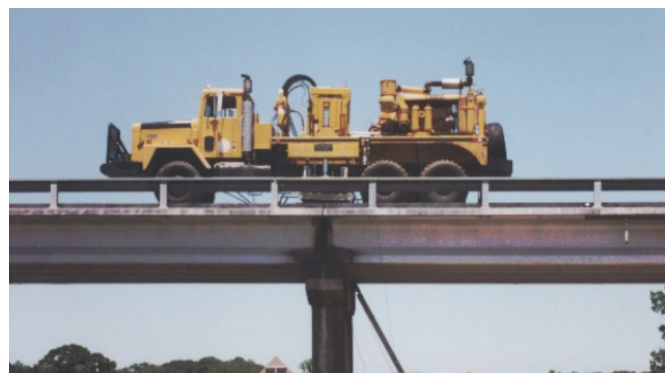

(c)

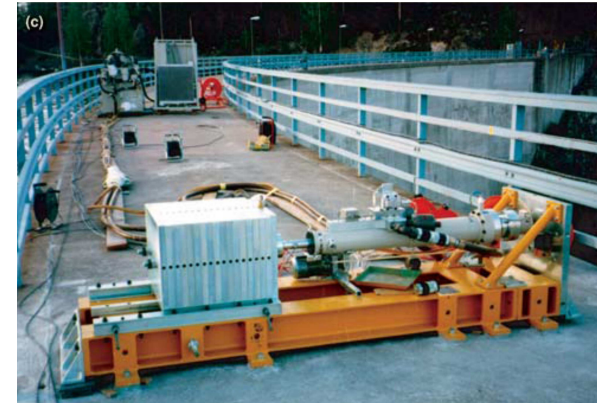

(b)

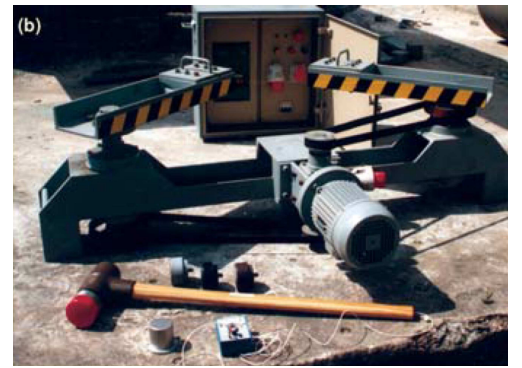

(d)

Figura 2.68 - Excitadores mais comuns para uso em campo: a) marreta de impacto; b) shaker servo-hidráulico; c) caminhão vibratório; d) shaker de massa excêntrica. 
Nos ensaios de laboratório, os dispositivos de excitação comumente empregados são o martelo de impulso e o shaker eletrodinâmico (Figura 2.69).

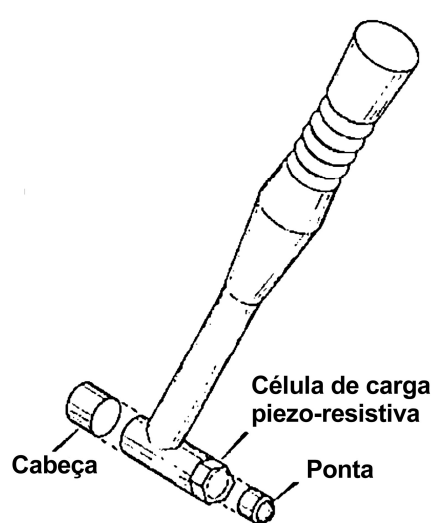

(a)

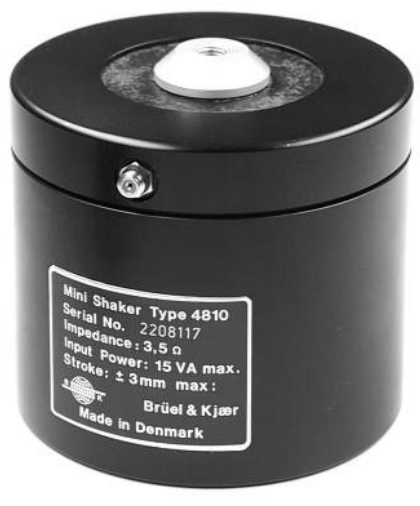

(b)

Figura 2.69 - Excitadores mais comuns usados em laboratório: a) Martelo de impacto; b) Shaker eletrodinâmico.

Fontes: (a) Ewins (1984) e (b) Bruel \& Kjær (2008b).

Tanto o martelo quanto a marreta de impulso possuem rosca na extremidade de impacto para permitir a troca das pontas.

Cada ponta é projetada para ter uma certa quantidade de deformação elástica durante o impacto. O tempo total de duração do impacto da ponta na estrutura está diretamente relacionado com o espectro de frequências excitado (AVITABILE, 2001b). A Figura 2.70 mostra o comportamento de algumas pontas de materiais diferentes.

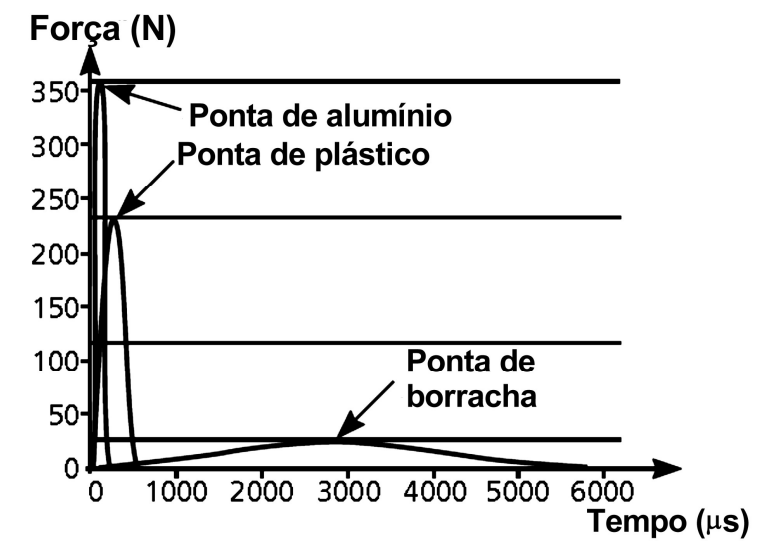

(a)

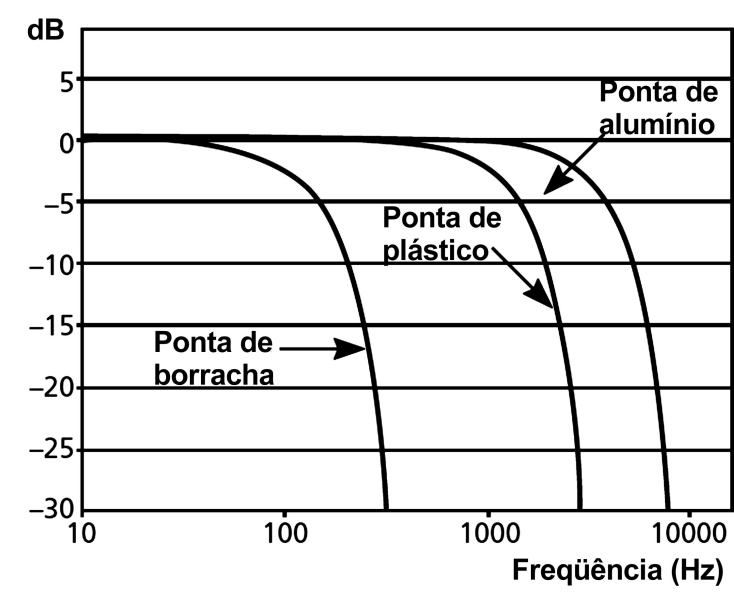

(b)

Figura 2.70 - Exemplo do comportamento de diferentes pontas para o martelo de impulso modelo 8206 do fabricante Bruel \& Kjær: a) Força de excitação; b) espectro de frequências. 
De acordo com Forrest (1995), as pontas macias (plástico ou borracha) produzem picos de força de baixa amplitude com maior tempo de impacto fornecendo boa energia em baixas frequências e baixa energia nas frequências mais altas. Por outro lado, as pontas mais rígidas, como alumínio, produzem picos de força com grande amplitude e pequeno intervalo de tempo fornecendo energia suficiente para os modos de alta frequência mas pouca energia nos modos baixos.

Portanto, a escolha da ponta do martelo deve ser norteada em função da frequência dos modos que se deseja excitar.

A Figura 2.71 mostra o desenvolvimento de um ensaio com o martelo de impacto. Nesse arranjo, o acelerômetro é fixado em um ponto e o impacto com o martelo é feito em vários pontos da estrutura.

Tanto o sinal de excitação como o de reposta são medidos em um único ponto. Essa característica denomina tal configuração de ensaio como SISO, do inglês Single Input Single Output.

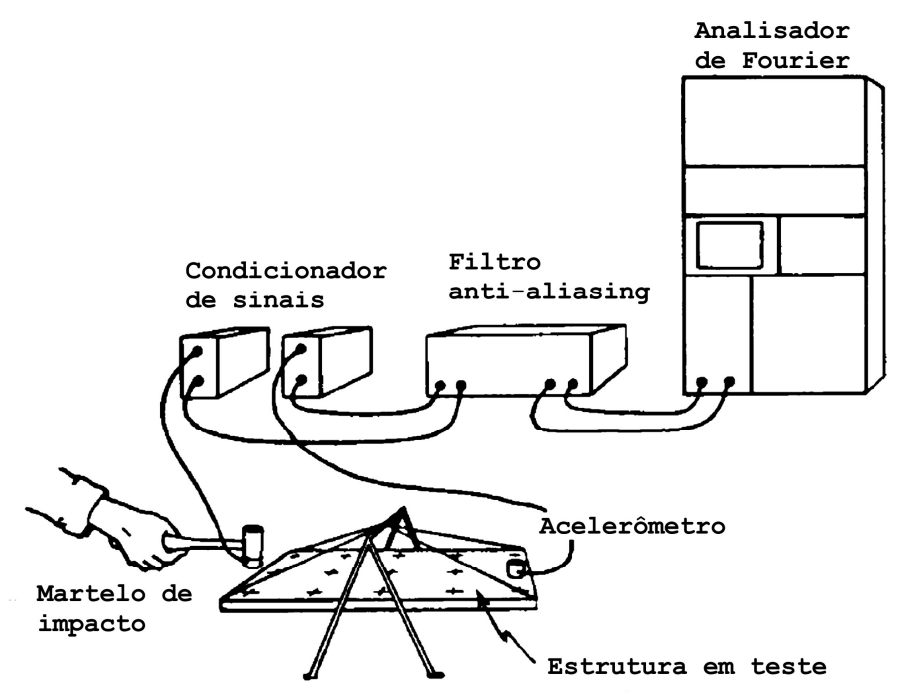

Figura 2.71 - Ensaio dinâmico com saída fixa e excitação por impacto. Fonte: Allemang \& Brown (2002).

O shaker eletrodinâmico é mais versátil do que os antigos sistemas que empregavam a rotação de massas excêntricas, como o mostrado na Figura 2.68d, pois pode aplicar diferentes formas sinal de excitação na estrutura.

A escolha do sinal de entrada depende das características do sistema, dos parâmetros a serem estimados e da utilização esperada dos dados.

O sinal de excitação pode ser aleatório ou determinístico. 
Os sinais aleatórios somente podem ser descritos por meio de suas propriedades estatísticas em certo intervalo de tempo. Qualquer parte do período total é única e nenhuma relação matemática explícita pode ser formulada para descrevê-la. Esses sinais podem ser classificados em estacionários e não-estacionários. Os sinais aleatórios estacionários são aqueles cujas propriedades estatísticas (média e variância) não se alteram ao longo do tempo. (ALLEMANG \& BROWN, 2002).

Já os sinais determinísticos podem ser representados por meio de uma função matemática. Ou seja, podem ser "determinados". Esses sinais são divididos em periódicos e não-periódicos. O sinal periódico determinístico mais comum é o senoidal, enquanto o sinal não-periódico determinístico mais comum é o transiente.

De acordo com Avitabile (1998), os sinais determinísticos, em geral, são empregados para verificar se um sistema é linear enquanto os sinais aleatórios são usados juntamente com o cálculo de médias do sinal amostrado para "linearizar" pequenas não-linearidades no sistema.

Uma das desvantagens do sinal aleatório é que o mesmo não é periódico e, por esse motivo, requer o uso de janelas como a Hanning.

Alguns dos sinais de excitação mais empregados com o shaker são descritos a seguir.

Varredura senoidal (swept sine): Esse sinal corresponde a uma varredura senoidal crescente ou decrescente na banda de frequências.

Step relaxation: É um sinal determinístico transiente produzido pela liberação de uma carga estática. O período de amostragem começa no instante em que a carga é liberada. $\mathrm{O}$ sinal normalmente é gerado pela aplicação de uma força estática por meio de um cabo. O cabo é cortado ou então permite-se a liberação da carga por meio de um pino de cisalhamento. Segundo Varoto $(2008)^{22}$, normalmente esse pino é um parafuso que é detonado por rádiocontrole.

Aleatório puro (pure random): É um sinal aleatório e estacionário com distribuição de probabilidade de Gauss. Em geral, o sinal contém todas as frequências (não somente múltiplos inteiros do incremento de frequência da FFT), mas ele pode ser filtrado para incluir somente a informação na frequência da banda de interesse.

22 Paulo Sérgio Varoto. Professor da disciplina SEM 766 - Análise Modal de Estruturas do Departamento de Engenharia Mecânica da Escola de Engenharia de São Carlos. USP. Comunicação pessoal. 2008. 
Pseudo-aleatório (pseudo-random): É um sinal aleatório e estacionário que consiste somente de múltiplos inteiros do incremento de frequência da FFT. O espectro de frequências desse sinal tem amplitude constante com fase aleatória. Se o tempo de medição for suficiente para qualquer resposta transiente iniciar o decaimento, o histórico de entrada e da resposta serão periódicos em relação ao período amostrado.

Aleatório impulsivo (burst random): Esse sinal contém propriedades do sinal transiente determinístico e do sinal aleatório estacionário. O espectro de frequência desse sinal tem amplitude e distribuição de fase aleatórias e contém energia em todo espectro de freqüências.

A Figura 2.72 mostra uma configuração típica de um ensaio com um shaker, na qual o shaker permanece fixo enquanto o acelerômetro é mudado de posição.

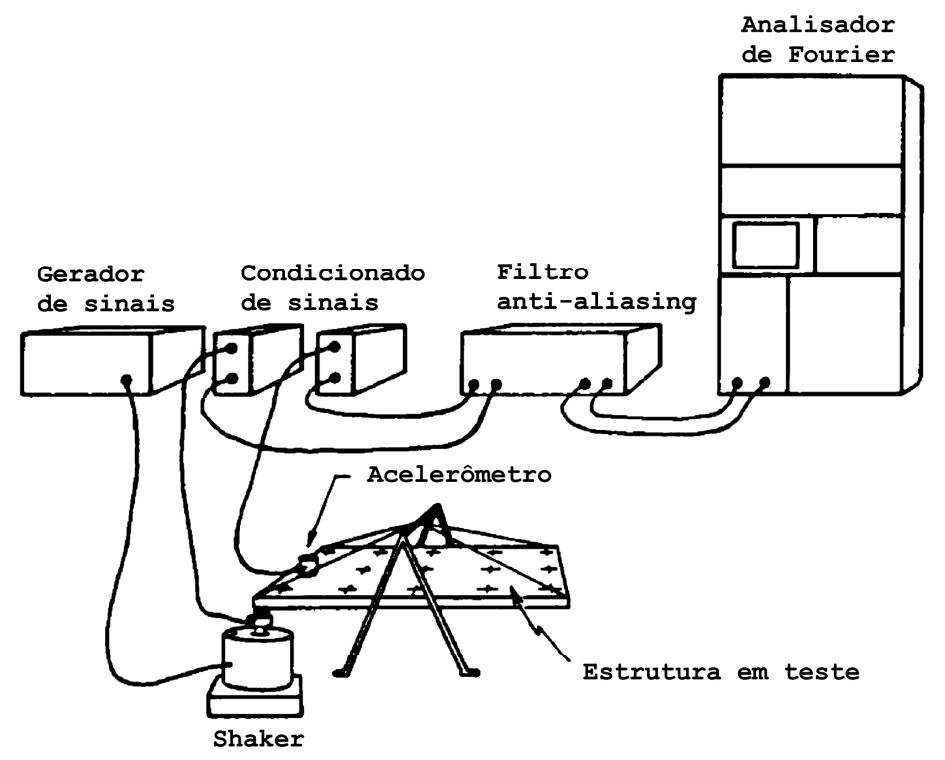

Figura 2.72 - Ensaio dinâmico com entrada fixa e excitação por shaker. Fonte: Allemang \& Brown (2002).

Teoricamente não deveria haver diferença na resposta obtida com o shaker e com o martelo de impulso uma vez que a matriz $[H(\omega)]$ é simétrica e, teoricamente, não haveria diferença entre mudar o ponto de solicitação ou mudar o ponto de medição da resposta. Entretanto, como explica Avitabile (1998a), a resposta obtida refere-se, além da estrutura em teste, aos efeitos do sistema de suspensão da estrutura, à adição da massa dos acelerômetros, à rigidez do stinger e do shaker, entre outros.

Segundo Reynolds \& Pavic (2000), a escolha pelo shaker ou martelo deve ser norteada pelos seguintes aspectos: custo dos equipamentos; tempo e recursos necessários para a 
implementação do ensaio; facilidade de uso das técnicas no local de ensaio e qualidade dos dados obtidos.

Devido à dificuldade de excitar estruturas civis de grande porte, alguns pesquisadores têm utilizado atualmente técnicas de identificação modal baseadas somente na resposta do sistema. Tais métodos são internacionalmente conhecidos como Output-only modal identification (CUNHA \& CAETANO, 2006).

Essa técnica também pode ser empregada na AND de elementos estruturais. A partir dos dados do ensaio (resposta) ajustam-se os parâmetros de um modelo teórico.

Nesses casos não há a necessidade de medir o sinal de entrada do sistema. O leitor pode encontrar maiores detalhes sobre essa técnica em Cunha \& Caetano (2006).

\section{m. Suspensão da estrutura}

A escolha do tipo de suspensão da estrutura é de grande importância, pois deve refletir com fidelidade as condições de contorno assumidas na modelagem teórica.

O sistema de avaliação não-destrutiva por vibração transversal da empresa Norteamericana Metriguard, por exemplo, utiliza a condição de contorno bi-apoiada como mostra a Figura 2.25.

Entretanto, segundo Allemang \& Brown (2002), tradicionalmente os ensaios de análise modal são realizados com a consideração das condições de contorno livre-livre ou engastada.

Com exceção de situações muito especiais, nenhuma das três condições de contorno citadas anteriormente podem ser efetivamente obtidas na prática. Entretanto, segundo Cho (2007), a condição livre-livre é a mais fácil de ser alcançada.

Allemang \& Brown (2002) explicam que, para realizar o teste modal de uma estrutura com condição de contorno livre-livre, é comum suspender a estrutura por meio de cabos bastante flexíveis (Figura 2.73) ou empregando molas pneumáticas (Figura 2.74). 


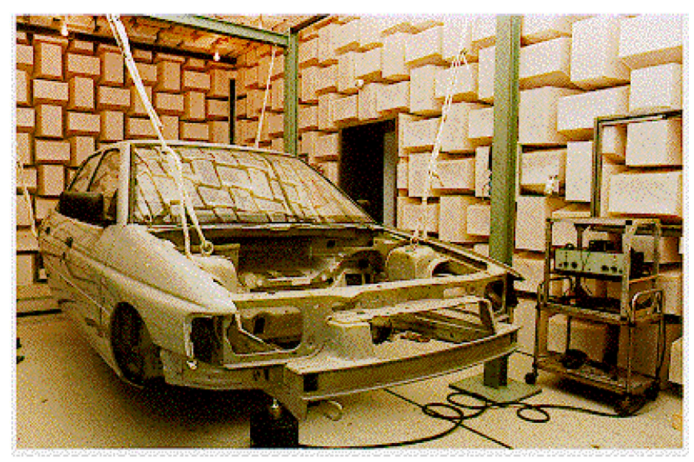

Figura 2.73 - Suspensão da carroceria de um automóvel por cordas de Nylon. Fonte: Sabri (2004).

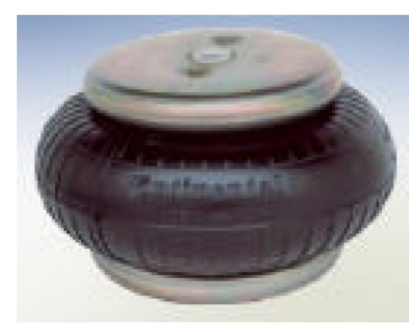

Figura 2.74 - Mola pneumática.

Fonte: Sabri (2004).

A escolha do material de suspensão da estrutura é fundamental para aproximar as condições de contorno do ensaio às do modelo teórico.

Avitabile (2001) verificou a influência do material de suspensão usado para obter a condição livre-livre num suporte de disco rígido de computador. Os materiais empregados para a suspensão foram: espuma grossa, bolsa de ar e, por fim, tiras de borracha. A FRF para cada caso é mostrada na Figura 2.75, na qual se observa alterações tanto na aceleração como na frequência de ressonância.

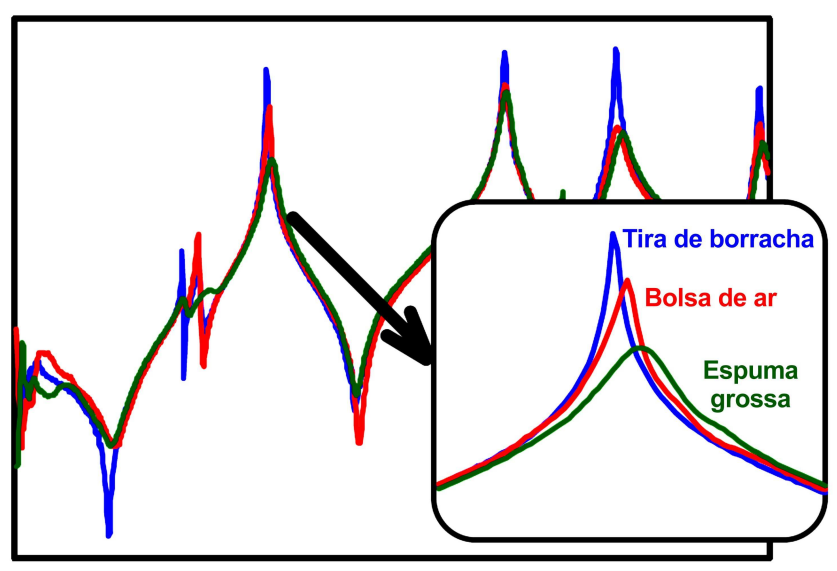

Figura 2.75 - Efeito do material de suspensão na FRF de um suporte de disco rígido Fonte: Adaptado de Avitabile (2001). 


\section{n. Identificação dos parâmetros modais}

A identificação dos parâmetros modais é um caso especial de identificação de sistemas no qual o modelo do sistema é conhecido na forma de seus parâmetros modais como as frequências naturais, os vetores dos deslocamentos modais e os amortecimentos de cada modo.

As técnicas mais comuns de identificação modal tratam as contribuições individuais de cada modo como sistemas de um grau de liberdade que unidos compõem um sistema com múltiplos graus de liberdade (ALLEMANG \& BROWN, 2002). Tal conceito é representado graficamente na Figura 2.76.
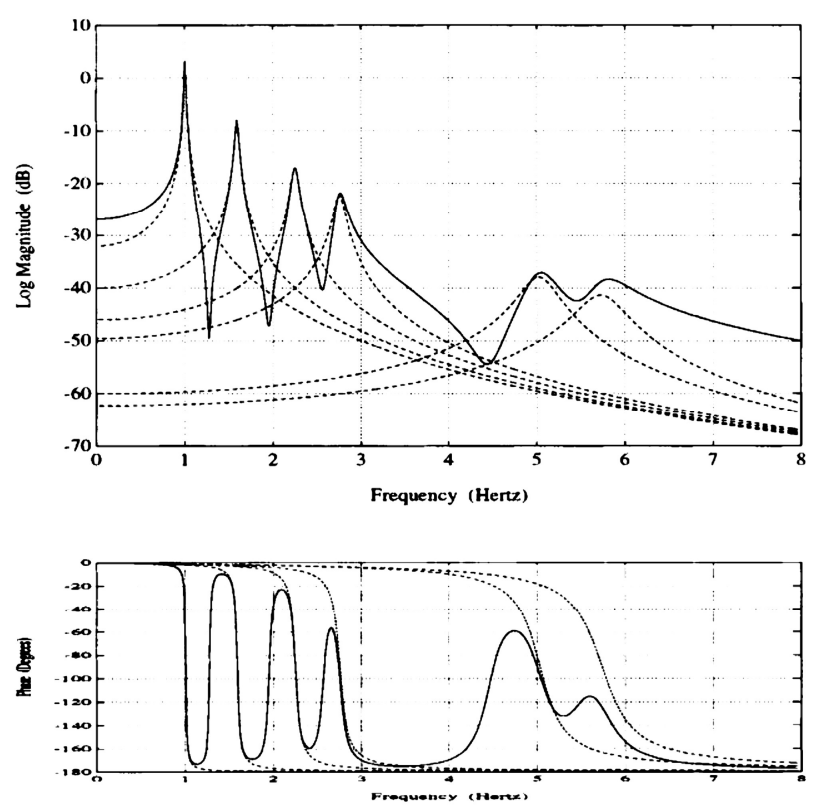

Figura 2.76 - Exemplo de contribuição de diversos modos.

Fonte: Allemang \& Brown (2002).

A identificação dos parâmetros modais pode ser feita tanto no domínio do tempo quanto no domínio da frequência e, em geral, os parâmetros modais são obtidos por meio do ajuste de curvas entre os dados experimentais e o modelo analítico empregando diferentes processos de minimização de erro entre os quais o de mínimos quadrados é o mais comum (HE \& FU, 2001) e (ALLEMANG \& BROWN, 2002).

Os algoritmos de identificação podem ser do tipo modo a modo ou multi-modos. Nos algoritmos modo a modo, cada modo é admitido como um sistema com um grau de liberdade e os parâmetros modais de cada modo são identificados isoladamente. Já nos algoritmos do tipo multimodal, os vários modos contidos em uma banda de frequências são identificados simultaneamente. 
Os primeiros algoritmos de identificação modal foram desenvolvidos no domínio da frequência. Para sistemas com um grau de liberdade podem ser utilizados métodos simples como peak picking, circle fit e inverse FRF os quais são baseados no ajuste de uma FRF teórica de um sistema com um grau de liberdade para os dados da FRF medida. Para tanto, o modo de interesse é tratado como um sistema com um único grau de liberdade, negligenciando a contribuição dos demais modos. Devido a essa abordagem tais métodos são inadequados para a identificação modal de estruturas contendo modos vizinhos.

Nos métodos de identificação multimodal como, por exemplo, rational fraction polynomial (RFP), complex exponential frequency domain (CEFD) e polyreference frequency domain (PRFD) o ajuste entre as FRF's teórica e experimental é feito globalmente para a banda de frequências de interesse.

Os métodos no domínio do tempo tendem a fornecer melhores resultados quando a identificação é feita em uma larga banda de frequências ou o sistema apresenta um grande número de modos. Tais métodos foram desenvolvidos devido a limitações na resolução de frequência e devido aos erros de leakage nas estimativas dos parâmetros modais quando se empregam os algoritmos no domínio da frequência para esses casos (CUNHA \& CAETANO, 2006).

Entre os métodos no domínio do tempo destacam-se complex exponential (CE), leastsquares complex exponential (LSCE), polyreference complex exponential (PRCE), Ibrahim time domain (ITD), eigen system realization algorithm (ERA) e autoregressive movingaverage (ARMA). A Tabela 2.19 mostra alguns métodos de identificação multimodal e suas respectivas siglas.

Tabela 2.19 - Algoritmos para identificação modal.

\begin{tabular}{|c|c|c|}
\hline Domínio & Algoritmo & Sigla \\
\hline \multirow{6}{*}{$\frac{\stackrel{\circ}{\frac{2}{0}}}{\stackrel{0}{!}}$} & Complex exponential algorithm & CEA \\
\hline & Least squares complex exponential & LSCE \\
\hline & Polyreference time domain & PTD \\
\hline & Ibrahim time domain & ITD \\
\hline & Multiple reference Ibrahim time domain & MRITD \\
\hline & Eigensystem realization algorithm & ERA \\
\hline \multirow{6}{*}{ 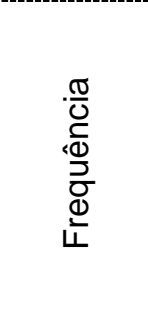 } & Polyreference frequency domain & PFD \\
\hline & Simultaneous frequency domain & SFD \\
\hline & Multireference frequency domain & MRFD \\
\hline & Rational fraction polynomial & RFP \\
\hline & Orthogonal polynomial & OP \\
\hline & Complex mode indication function & CMIF \\
\hline
\end{tabular}

Fonte: Allemang \& Brown (2002). 
No presente trabalho foi empregado o método RFP o qual é abordado com detalhes a seguir.

\section{Método da razão de polinômios (RFP)}

Neste método, a FRF analítica é expressa na forma da razão entre dois polinômios. Uma função erro entre as FRF's analítica e experimental é formulada e equacionada de forma a torná-la um sistema de equações lineares. O erro é então minimizado para a obtenção dos coeficientes dos polinômios. Uma vez encontrados os coeficientes dos polinômios buscam-se as raízes (pólos) do polinômio denominador com as quais se pode determinar as frequências naturais e os amortecimentos modais.

A FRF de receptância $\mathrm{H}_{\mathrm{jk}}$ (deslocamento no ponto i para uma força aplicada no ponto $\underline{\mathrm{k}}$ ) para um sistema linear com $\underline{\mathrm{N}}$ graus de liberdade pode ser modelada como uma equação de frações parciais como mostra a Equação 2.75.

$$
H_{j k}(\omega)=\sum_{r=1}^{N}\left(\frac{A_{j k}^{r}}{\omega_{r} \xi_{r}+i\left(\omega-\omega_{r} \sqrt{1-\xi_{r}^{2}}\right)}+\frac{A_{j k}^{*}}{\omega_{r} \xi_{r}+i\left(\omega+\omega_{r} \sqrt{1-\xi_{r}^{2}}\right)}\right)
$$

Sendo:

$N=$ número de graus de liberdade do sistema;

$A_{j k}=$ resíduo;

$\omega_{r}=$ frequência natural do modo $\underline{\mathrm{r}}$;

$\xi_{\mathrm{r}}=$ amortecimento adimensional do modo $\underline{\mathrm{r}}$;

$i=$ unidade imaginária $(\sqrt{-1})$.

Uma forma mais simples de representar a Equação 2.75 é mostrada na Equação 2.76.

$$
H_{j k}(\omega)=\sum_{r=1}^{N} \frac{A_{r}+i \omega B_{r}}{\omega_{r}^{2}-\omega^{2}+2 \xi_{r} \omega_{r} \omega i}
$$

Sendo:

$$
\begin{aligned}
& A_{r}=\text { constante; } \\
& B_{r}=\text { constante; } \\
& \omega=\text { frequência do sinal de entrada; } \\
& \omega_{r}=\text { frequência natural do modo } \underline{\mathrm{r}} ; \\
& \xi_{\mathrm{r}}=\text { amortecimento adimensional do modo } \underline{\mathrm{r}} ;
\end{aligned}
$$


A Equação 2.76 pode ainda ser expressa na forma de uma razão entre dois polinômios complexos como mostra a Equação 2.77.

$$
H_{j k}(\omega)=\frac{\sum_{k=0}^{m} a_{k}(i \omega)^{k}}{\sum_{k=1}^{n} b_{k}(i \omega)^{k}}
$$

Sendo:

$$
\begin{aligned}
& a_{k}=\text { coeficiente do polinômio numerador; } \\
& b_{k}=\text { coeficiente do polinômio denominador; } \\
& m=\text { ordem do polinômio numerador; } \\
& n=\text { ordem do polinômio denominador. }
\end{aligned}
$$

A obtenção dos coeficientes $a_{k}$ e $b_{k}$ é feita por meio do ajuste de curvas, sendo o Método de Levy (LEVY, 1959) ${ }^{23}$ o mais conhecido. Esse método é descrito a seguir.

A diferença entre a FRF analítica $\mathrm{H}(\omega)$ e a FRF experimental $H_{e}(\omega)$ corresponde à função erro dada por:

$$
e_{j}=\frac{\sum_{k=0}^{m} a_{k}(i \omega)^{k}}{\sum_{k=1}^{n} b_{k}(i \omega)^{k}}-H_{e}\left(\omega_{j}\right)
$$

Da forma como está equacionada, a função erro é não-linear. Para torná-la linear toda a Equação 2.78 deve ser multiplicada pelo denominador da Equação 2.78. Com isso obtém-se:

$$
e_{j}{ }^{\prime}=\sum_{k=0}^{m} a_{k}\left(i \omega_{j}\right)^{k}-H_{e}\left(\omega_{j}\right) \mid \sum_{k=1}^{n} b_{k}\left(i \omega_{j}\right)^{k}
$$

Sendo:

$$
e_{j}{ }^{\prime}=e_{j} \sum_{k=1}^{n} b_{k}\left(i \omega_{j}\right)^{k}
$$

Pode-se definir um vetor erro a partir da Equação 2.80 para todas as $\underline{L}$ frequências medidas como:

\footnotetext{
${ }^{23}$ Levy, E. C. Complex-curve fitting, IEEE Transactions on Automatic Control 4 (1959) (1), pp. 37-44.
} 


$$
\{E\}=\left\{\begin{array}{c}
e_{1}^{\prime} \\
e_{2}^{\prime} \\
\vdots \\
e_{L}^{\prime}
\end{array}\right\}
$$

A Equação 2.81 pode ser expressa na forma matricial como mostra a Equação 2.82.

$$
\{E\}=\left[\begin{array}{ccccc}
1 & \left(i \omega_{1}\right) & \left(i \omega_{1}\right)^{2} & \cdots & \left(i \omega_{1}\right)^{m} \\
1 & \left(i \omega_{2}\right) & \left(i \omega_{2}\right)^{2} & \cdots & \left(i \omega_{2}\right)^{m} \\
\vdots & \vdots & \vdots & \ddots & \vdots \\
1 & \left(i \omega_{L}\right) & \left(i \omega_{L}\right)^{2} & \cdots & \left(i \omega_{L}\right)^{m}
\end{array}\right]\left\{\begin{array}{c}
a_{0} \\
a_{1} \\
\vdots \\
a_{m}
\end{array}\right\}-
$$

$$
-\left[\begin{array}{cccc}
H_{e}\left(\omega_{1}\right) & H_{e}\left(\omega_{1}\right)\left(i \omega_{1}\right) & \cdots & H_{e}\left(\omega_{1}\right)\left(i \omega_{1}\right)^{n-1} \\
H_{e}\left(\omega_{2}\right) & H_{e}\left(\omega_{2}\right)\left(i \omega_{2}\right) & \cdots & H_{e}\left(\omega_{2}\right)\left(i \omega_{2}\right)^{n-1} \\
\vdots & \vdots & \ddots & \vdots \\
H_{e}\left(\omega_{L}\right) & H_{e}\left(\omega_{L}\right)\left(i \omega_{L}\right) & \cdots & H_{e}\left(\omega_{L}\right)\left(i \omega_{L}\right)^{n-1}
\end{array}\right]\left\{\begin{array}{c}
b_{0} \\
b_{1} \\
\vdots \\
b_{n-1}
\end{array}\right\}-\left\{\begin{array}{c}
H_{e}\left(\omega_{1}\right)\left(i \omega_{1}\right)^{n} \\
H_{e}\left(\omega_{2}\right)\left(i \omega_{2}\right)^{n} \\
\vdots \\
H_{e}\left(\omega_{L}\right)\left(i \omega_{L}\right)^{n}
\end{array}\right\}
$$

Ou empregando uma representação mais compacta:

$$
\{E\}_{(\mathrm{Lx} 1)}=[P]_{(\mathrm{Lxm})}\{a\}_{(\mathrm{mx} 1)}-[T]_{(\mathrm{Lx} \mathrm{n})}\{b\}_{(\mathrm{nx} 1)}-\{W\}_{(\mathrm{Lx} 1)}
$$

Sendo:

$$
\begin{aligned}
& {[P]=\left[\begin{array}{ccccc}
1 & \left(i \omega_{1}\right) & \left(i \omega_{1}\right)^{2} & \cdots & \left(i \omega_{1}\right)^{m} \\
1 & \left(i \omega_{2}\right) & \left(i \omega_{2}\right)^{2} & \cdots & \left(i \omega_{2}\right)^{m} \\
\vdots & \vdots & \vdots & \ddots & \vdots \\
1 & \left(i \omega_{L}\right) & \left(i \omega_{L}\right)^{2} & \cdots & \left(i \omega_{L}\right)^{m}
\end{array}\right] \quad(L \times m)} \\
& {[T]=\left[\begin{array}{cccc}
H_{e}\left(\omega_{1}\right) & H_{e}\left(\omega_{1}\right)\left(i \omega_{1}\right) & \cdots & H_{e}\left(\omega_{1}\right)\left(i \omega_{1}\right)^{n-1} \\
H_{e}\left(\omega_{2}\right) & H_{e}\left(\omega_{2}\right)\left(i \omega_{2}\right) & \cdots & H_{e}\left(\omega_{2}\right)\left(i \omega_{2}\right)^{n-1} \\
\vdots & \vdots & \ddots & \vdots \\
H_{e}\left(\omega_{L}\right) & H_{e}\left(\omega_{L}\right)\left(i \omega_{L}\right) & \cdots & H_{e}\left(\omega_{L}\right)\left(i \omega_{L}\right)^{n-1}
\end{array}\right] \quad(L \times n)} \\
& \{a\}=\left\{\begin{array}{c}
a_{0} \\
a_{1} \\
\vdots \\
a^{m}
\end{array}\right\} \quad(m \times 1) \quad\{b\}=\left\{\begin{array}{c}
b_{0} \\
b_{1} \\
\vdots \\
b_{n-1}
\end{array}\right\} \quad(n \times 1) \quad\{W\}=\left\{\begin{array}{c}
H_{e}\left(\omega_{1}\right)\left(i \omega_{1}\right)^{n} \\
H_{e}\left(\omega_{2}\right)\left(i \omega_{2}\right)^{n} \\
\vdots \\
H_{e}\left(\omega_{L}\right)\left(i \omega_{L}\right)^{n}
\end{array}\right\}(L \times 1)
\end{aligned}
$$

A equação a ser minimizada é a do erro quadrado dada por: 


$$
J=\left\{E^{*}\right\}^{T}\{E\}
$$

Na qual o símbolo *indica o conjugado complexo.

Substituindo a Equação 2.82 na Equação 2.86 e fazendo algumas manipulações algébricas obtém-se:

$$
\begin{aligned}
& J=\{a\}^{T} \operatorname{Re}\left(\left[P^{*}\right]^{T}[P]\right)\{a\}+\{b\}^{T} \operatorname{Re}\left(\left[T^{*}\right]^{T}[T]\right\}\{b\}+\left\{W^{*}\right\}^{T}\{W\}- \\
& -2\{a\}^{T} \operatorname{Re}\left(\left[P^{*}\right]^{T}[T]\right)\{b\}-2\{a\}^{T} \operatorname{Re}\left(\left[P^{*}\right]^{T}[W]\right)+2\{b\}^{T} \operatorname{Re}\left(\left[T^{*}\right]^{T}[W]\right)
\end{aligned}
$$

A minimização do erro é feita empregando-se a técnica dos mínimos quadrados na Equação 2.87. Para isso essa equação é derivada em relação a $\{a\}$ e $\{b\}$ e as equações correspondentes são igualadas a zero. Com isso, chega-se ao seguinte sistema de equações:

$$
\begin{aligned}
& \operatorname{Re}\left(\left[P^{*}\right]^{T}[P]\right)\{a\}-\operatorname{Re}\left(\left[P^{*}\right]^{T}[T]\right)\{b\}-\operatorname{Re}\left(\left[P^{*}\right]^{T}\{W\}\right)=\{0\} \\
& \operatorname{Re}\left(\left[T^{*}\right]^{T}[T]\right)\{b\}-\operatorname{Re}\left(\left[T^{*}\right]^{T}[P]\right)\{a\}+\operatorname{Re}\left(\left[T^{*}\right]^{T}\{W\}\right)=\{0\}
\end{aligned}
$$

Que pode ser representado por:

$$
[A]\{x\}=\{b\}
$$

Sendo:

$$
\begin{aligned}
& {[A]=\left[\begin{array}{cc}
{[Y]} & {[X]} \\
{[X]^{T}} & {[Z]}
\end{array}\right]} \\
& \{x\}=\left\{\begin{array}{l}
\{a\} \\
\{b\}
\end{array}\right\} \\
& \{b\}=\left\{\begin{array}{l}
\{G\} \\
\{F\}
\end{array}\right\}
\end{aligned}
$$

Com:

$$
\begin{array}{ll}
{[X]=-\operatorname{Re}\left(\left[P^{*}\right]^{T}[T]\right)} & (m+1 \times n) \\
{[Y]=\operatorname{Re}\left(\left[P^{*}\right]^{T}[P]\right)} & (m+1 \times m+1) \\
{[Z]=\operatorname{Re}\left(\left[T^{*}\right]^{T}[T]\right)} & (n \times n) \\
\{G\}=\operatorname{Re}\left(\left[P^{*}\right]^{T}\{W\}\right) & (m+1) \\
\{F\}=-\operatorname{Re}\left(\left[T^{*}\right]^{T}\{W\}\right) & (n)
\end{array}
$$

Após obter os coeficientes da função racional mostrada na Equação 2.77, pode-se calcular os parâmetros modais. As raízes complexas do polinômio denominador contêm os 
valores das frequências naturais e dos coeficientes de amortecimento. Esses parâmetros podem ser obtidos por:

$$
\begin{aligned}
& f_{n}=\frac{\left|P_{n}\right|}{2 \pi} \\
& \xi_{n}=-\frac{\operatorname{Re}\left(P_{n}\right)}{\left|P_{n}\right|}
\end{aligned}
$$

Sendo $\mathrm{P}_{\mathrm{n}} \mathrm{o}$ n-ésimo pólo (raiz) do polinômio denominador.

Uma das desvantagens do Método de Levy, segundo Varoto $(2008)^{24}$, é que o sistema de equações mostrado na Equação 2.89 pode tornar-se mal condicionado, dependendo da largura da banda de frequências usada no experimento.

\section{o. Correlação modal}

Os ensaios dinâmicos são atualmente muito empregados para estabelecer correlações entre o comportamento dinâmico previsto da estrutura e aquele realmente observado na prática. Algumas vezes esse processo é denominado de "validação do modelo teórico". Entretanto, segundo Ewins (2000), a validação é um processo mais amplo que engloba três fases sendo:

- Comparar, de forma direta e objetiva, as propriedades dinâmicas estimadas com as medidas;

- Quantificar as diferenças entre os dados do modelo e os dados experimentais;

- Fazer ajustes ou modificações no modelo de forma que o comportamento dinâmico do mesmo se aproxime dos dados experimentais.

Segundo Pascual Jimenez (1999) o campo de atualização de modelos foi desenvolvido na década de 70 pela indústria aeronáutica, para a qual o problema de verificação de modelos é uma questão crítica.

No processo de correção de modelos admite-se que os erros envolvidos no processo de coleta de dados experimentais sejam suficientemente pequenos a ponto de serem desprezados. Dessa maneira, considera-se que as diferenças observadas entre as respostas do modelo e as

\footnotetext{
${ }^{24}$ Paulo Sérgio Varoto - comunicação pessoal.
} 
respostas do experimento se devam a falhas no modelo (KLOUTSEY, 2007). Para tanto, é imprescindível que os ensaios dinâmicos sejam desenvolvidos com a máxima cautela possível visando não introduzir erros nas medições.

A Figura 2.77 mostra o algoritmo de atualização de um modelo teórico a partir dos resultados de um ensaio dinâmico.

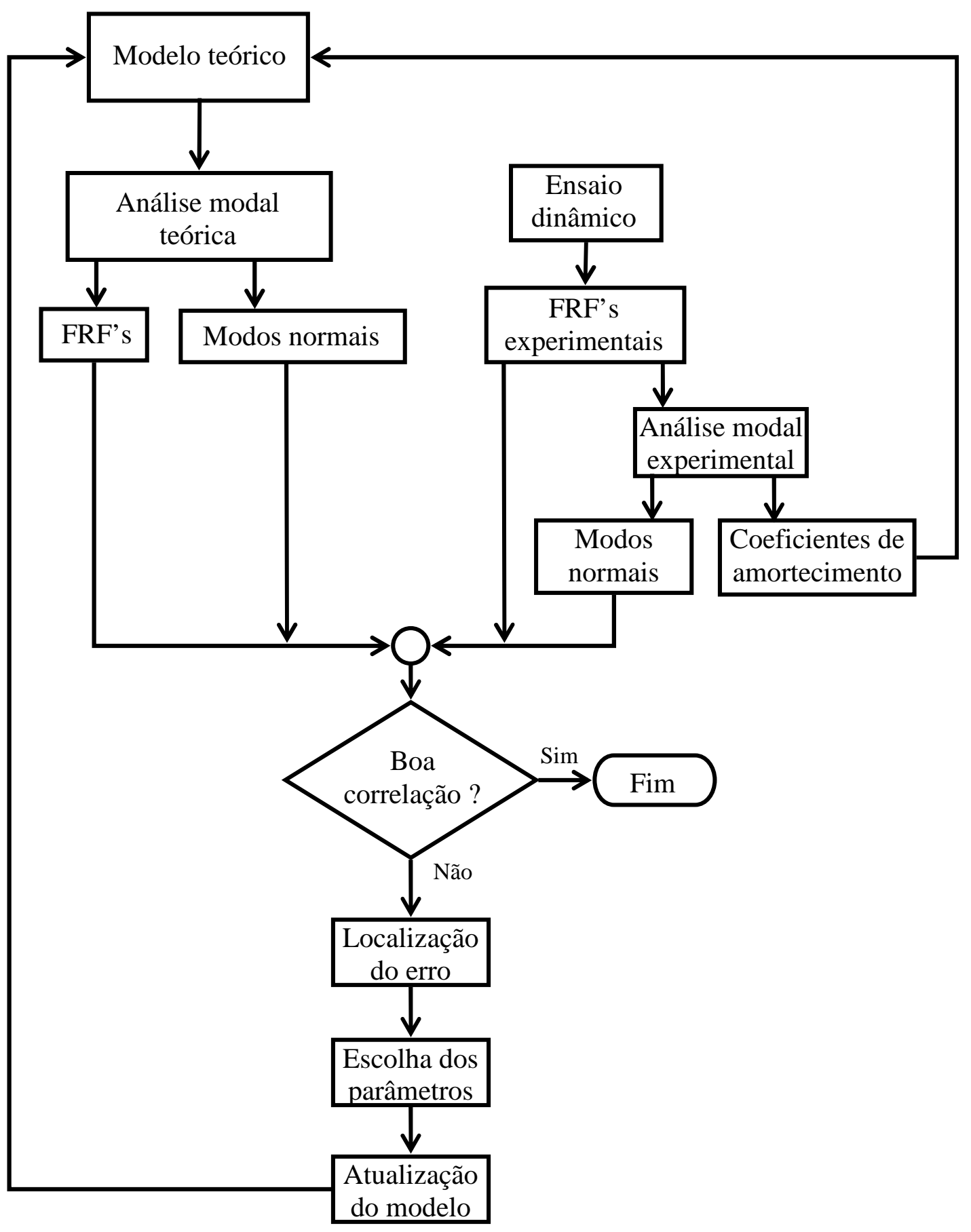

Figura 2.77 - Etapas envolvidas no processo de atualização de modelos.

Fonte: Adaptado de Pascual Jimenez (1999). 
A etapa mais importante nesse processo é a verificação da correlação entre os dados experimentais e teóricos. Segundo Pascual Jimenez (1999), no campo de atualização de modelos essa correlação é entendida como um conjunto de técnicas que permitem medir as diferenças entre as respostas do modelo e da estrutura em teste.

Embora a atualização de um determinado modelo não seja objetivo do presente trabalho, as técnicas de correlação foram úteis para a comparação entre os diferentes métodos de ensaio.

\section{Correlação direta entre as frequências naturais}

A comparação mais simples e óbvia de ser feita é a correlação entre as frequências naturais do modelo teórico e do modelo experimental. Essa comparação pode ser feita tabulando-se os dois conjuntos de dados (modelo e experimento). Entretanto, uma comparação mais útil é obtida quando plota-se em um gráfico os valores experimentais contra os valores estimados de cada uma das frequências naturais dos modos de interesse.

Nessa comparação, ajusta-se uma reta entre os dados empregando-se o método dos mínimos quadrados. Assim, se o coeficiente angular da reta ajustada for igual a 1,0 os dados são perfeitamente correlacionados. Se os pontos se alinham com inclinação muito diferente de $45^{\circ}$ é sinal de que há sérias falhas de modelagem da estrutura e há a necessidade de uma reavaliação do modelo. Se a dispersão dos pontos for muito pequena e os pontos forem aleatoriamente distribuídos em torno de uma linha com inclinação de $45^{\circ}$, então significa que o modelo e o experimento estão bem correlacionados, e os pequenos desvios observados se devem a erros experimentais. (EWINS, 2000).

\section{Correlação no domínio modal}

Uma vantagem importante da correlação no domínio modal é que se reduz a quantidade de informação que deve ser analisada. Uma das desvantagens é que os modos normais são resultados de um processo de identificação modal e, por essa razão, eles contêm implicitamente os erros e as considerações de cada técnica de identificação usada. Outra desvantagem é que, em geral, somente os modos globais podem ser identificados a partir do experimento, visto que os modos locais necessitam de uma grande quantidade de sensores e 
aparecem em médias e altas frequências que podem estar fora da banda de frequências de interesse (PASCUAL JIMENEZ, 1999).

Uma forma similar a utilizada na correlação entre as frequências naturais compreende a plotagem das amplitudes normalizadas dos deslocamentos modais em um gráfico de valores estimados contra valores medidos como mostra a Figura 2.78.

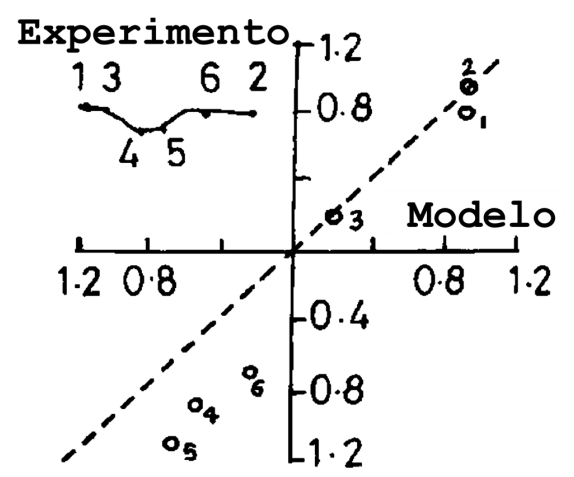

Figura 2.78 - Gráfico dos deslocamentos modais do modelo versus experimento. Fonte: Ewins (2000).

Os pontos individuais do gráfico da Figura 2.78 representam os graus de liberdade do modelo.

\section{Modal Scale Factor (MSF)}

Matematicamente, o MSF fornece a inclinação de uma linha reta que melhor se ajusta entre os pontos do gráfico mostrado na Figura 2.78. O MSF representa o fator de escala entre os modos comparados e é calculado pela Equação 2.93.

$$
M S F=\left(\frac{\sum_{i=1}^{N} A_{\mathrm{mod}, i} \cdot A_{\mathrm{exp}, i}}{\sum_{i=1}^{N} A_{\mathrm{exp}, i} \cdot A_{\mathrm{exp}, i}}\right)^{2}
$$

Sendo:

$i=$ índice do grau de liberdade;

$N$ = número do último grau de liberdade;

$A_{\text {mod }, i}=$ elemento do vetor das amplitudes modais normalizadas do modelo;

$A_{\text {exp }}=$ elemento do vetor das amplitudes modais normalizadas do experimento;

Segundo Ewins (2000) o MSF não fornece nenhuma indicação da qualidade do ajuste entre os pontos, mas apenas a inclinação da reta. 


\section{Modal Assurance Criterion (MAC)}

Segundo Heylen \& Janter (1990), tanto o MAC quanto o MSF foram propostos inicialmente por Allemang $(1980)^{25}$.

O Modal Assurance Criterion (MAC) fornece uma medida do grau de alinhamento entre dois vetores modais e matematicamente corresponde ao desvio dos pontos dos dados em relação à reta de ajuste mostrada na Figura 2.78.

O MAC é a técnica mais usada para verificar os resultados do processo de atualização de modelos, pois fornece uma idéia quantitativa da proximidade global entre duas famílias de modos normais. Seu cálculo é feito pela Equação 2.94.

$$
M A C_{i, j}=\left(\frac{\left\{A_{\mathrm{mod}, i}\right\}^{T} \cdot\left\{A_{\mathrm{exp}, j}\right\}}{\left|A_{\mathrm{mod}, i}\right| \cdot\left|A_{\mathrm{exp}, j}\right|}\right)^{2}
$$

Sendo:

$$
\begin{aligned}
& \left\{A_{\text {mod, } i}\right\}=\text { vetor das amplitudes modais normalizadas do modelo; } \\
& \left\{A_{\text {exp }, j}\right\}=\text { vetor das amplitudes modais normalizadas do experimento; }
\end{aligned}
$$

Os índices $\underline{i}$ e $j$ na Equação 2.94 correspondem aos modos que serão correlacionados que podem ser de mesma ordem no caso de correlação entre experimento e modelo ou de ordens diferentes como no caso da verificação da dependência entre dois modos.

O cálculo da Equação 2.94 resulta em uma matriz com valores que oscilam entre 0 e 1 . O valor unitário representa uma perfeita correlação. Mas em geral essa situação dificilmente ocorre e na prática admite-se que valores entre 0,8 e 0,9 sejam aceitáveis. Nesse caso diz-se que os dois modos normais têm alto grau de correlação (PASCUAL JIMENEZ, 1999).

\section{Coordinate Modal Assurance Criterion (COMAC)}

O Coordinate Modal Assurance Criterion (COMAC) foi proposto por Lieven \& Ewins $(1988)^{26}$ como uma extensão do MAC para o nível local de correlação (ALLEMANG, 2003).

\footnotetext{
25 ALLEMANG, R. Investigation of Some Multiple Input/Output Frequency Response Experimental Modal Analysis Techniques. Tese de Doutorado. Mechanical Engineering Department. University of Cincinnati. Ohio. 1980.

${ }^{26}$ LIEVEN, N. A. J., EWINS, D. J., "Spatial Correlation of Mode Shapes, The Coordinate Modal Assurance Criterion (COMAC)," Proceedings, International Modal Analysis Conference. p. 690-695, 1988.
} 
O COMAC permite identificar quais graus de liberdade contribuíram para a obtenção de um baixo valor de MAC e mede a correlação entre vários modos normais num mesmo grau de liberdade.

A comparação pode ser feita entre experimento versus experimento, modelo versus modelo ou modelo versus experimento. Para a verificação da correlação entre o modelo e o experimento, o COMAC é calculado de acordo com a Equação 2.95.

$$
\operatorname{COMAC}_{i}=\left(\frac{\left\{A_{\mathrm{mod}, i, n}\right\}^{T} \cdot\left\{A_{\mathrm{exp}, i, n}\right\}}{\left|A_{\mathrm{mod}, i, n}\right| \cdot\left|A_{\mathrm{exp}, i, n}\right|}\right)^{2}
$$

Sendo:

$i=$ índice do grau de liberdade;

$n=$ número de modos considerados;

$\left\{A_{\text {mod,i,n }}\right\}=$ vetor das amplitudes modais normalizadas do modelo, no grau de liberdade $\underline{\mathrm{i}}$, com $\underline{\mathrm{n}}$ modos;

$\left\{A_{\text {exp }, i, n}\right\}=$ vetor das amplitudes modais normalizadas do experimento, no grau de liberdade i, com $\underline{\mathrm{n}}$ modos;

Assim como o MAC, o COMAC varia de 0 a 1 . Um valor de COMAC igual a 1 indica que, para o grau de liberdade analisado, os modos normais são altamente correlacionados.

\section{Correlação no domínio da frequência}

\section{Frequency Domain Assurance Criterion (FDAC)}

O Frequency Domain Assurance Criterion (FDAC) mede a correlação entre duas FRF's de maneira similar ao MAC e, segundo Pascual Jimenez (1999) foi proposto inicialmente por Nefske \& Sung $(1996)^{27}$ com a formulação apresentada na Equação 2.96.

$$
\operatorname{FDAC}\left(\omega_{i}, \omega_{j}\right)=\frac{\left(\left\{H_{\text {mod }}\left(\omega_{i}\right)\right\}^{T} \cdot\left\{H_{\text {exp }}\left(\omega_{j}\right)\right\}\right)^{2}}{\left(\left\{H_{\text {mod }}\left(\omega_{i}\right)\right\}^{T} \cdot\left\{H_{\text {mod }}\left(\omega_{i}\right)\right\}\right) \cdot\left(\left\{H_{\text {exp }}\left(\omega_{j}\right)\right\}^{T} \cdot\left\{H_{\text {exp }}\left(\omega_{j}\right)\right\}\right)}
$$

\footnotetext{
${ }^{27}$ NEFSKE, D. J.; SUNG, S. H. Correlation of a coarse-mesh finite element model using structural system identification and a frequency domain response criterion. In XIV International Modal Analysis Conference. p. 596-602, 1996.
} 
O FDAC varia entre 0 e 1, sendo que FDAC igual a zero indica que não há correspondência entre as duas FRF's analisadas e um valor unitário significa que há perfeita correlação.

Entretanto, como observa Pascual Jimenez (1999), a formulação proposta por Nefske \& Sung não é sensível às diferenças de fase entre as duas FRF's. Assim sendo, é possível obter FDAC igual a 1,0 mesmo no caso de uma defasagem de $180^{\circ}$ entre as FRF's.

Para solucionar esse problema Pascual Jimenez (1999) sugere para o FDAC a formulação mostrada na Equação 2.97.

$$
\operatorname{FDAC}\left(\omega_{i}, \omega_{j}\right)=\frac{\left\{H_{\mathrm{mod}}\left(\omega_{i}\right)\right\}^{T} \cdot\left\{H_{\mathrm{exp}}\left(\omega_{j}\right)\right\}}{\left|H_{\text {mod }}\right| \cdot\left|H_{\text {exp }}\right|}
$$

Com essa formulação o FDAC passa a variar de $-1 \mathrm{a}+1 \mathrm{e}$, um valor de FDAC $>0$ indica que as FRF's estão em fase.

Assim como o MAC, o resultado do cálculo do FDAC resulta em uma matriz. Porém, como a ordem da matriz é muito grande, é comum representar o FDAC por meio de um gráfico com escala de cores como mostra a Figura 2.79.

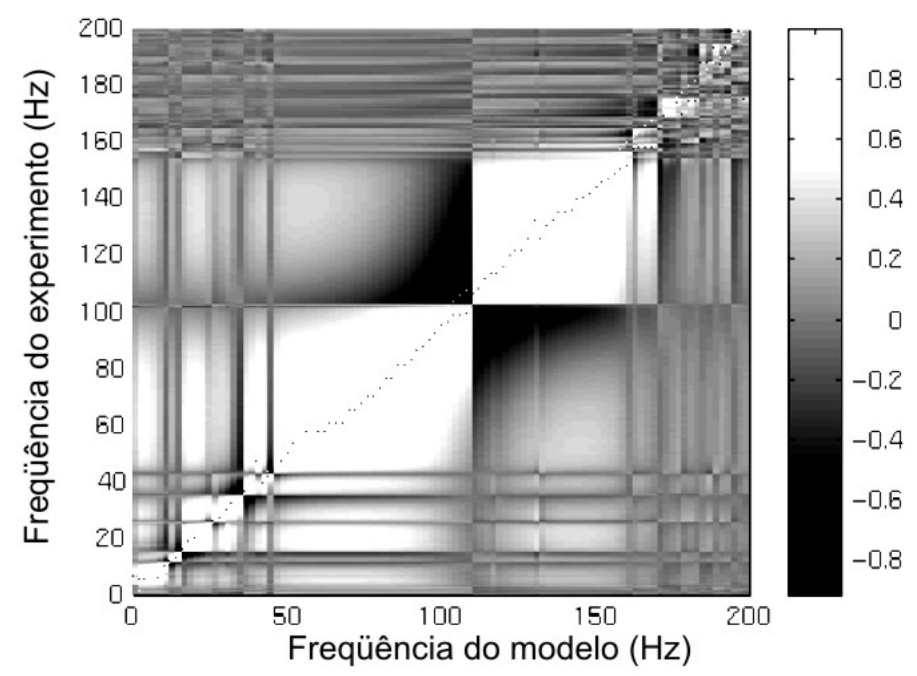

Figura 2.79 - Gráfico dos deslocamentos modais do modelo versus experimento. Fonte: Pascual et al (1997).

Na verificação da correlação entre modelo e experimento, as FRF's são comparadas na mesma frequência e, nesse caso, interessam apenas os valores na diagonal da matriz de FDAC. 


\section{Frequency Response Assurance Criterion (FRAC)}

Duas FRF's representando a mesma relação de entrada e saída podem ser comparadas usando uma técnica conhecida como Frequency Response Assurance Criterion (FRAC). O FRAC é calculado pela Equação 2.98.

$$
\operatorname{FRAC}(j, k)=\frac{\left(\left\{H_{\mathrm{mod}, j k}(\omega)\right\}^{T} \cdot\left\{H_{\mathrm{exp}, j k}(\omega)\right\}\right\}^{2}}{\left(\left\{H_{\mathrm{mod}, j k}(\omega)\right\}^{T} \cdot\left\{H_{\mathrm{mod}, j k}(\omega)\right\}\right) \cdot\left(\left\{H_{\mathrm{exp}, j k}(\omega)\right\}^{T} \cdot\left\{H_{\text {exp }, j k}(\omega)\right\}\right)}
$$

Sendo $H_{\text {mod,jk }}$ a FRF analítica da resposta no grau de liberdade $j$ devido a uma excitação no grau de liberdade $\underline{k}$ e $H_{\text {exp }, j k}$ a correspondente FRF experimental.

O FRAC, que retorna um valor entre 0 e 1 para indicar nenhuma ou total correlação, é análogo ao COMAC, pois contém informações específicas sobre a medição da resposta em um determinado ponto com excitação em um dado ponto.

De acordo com Fotsch \& Ewins (2000) como as FRF's contém informações sobre as respostas simultâneas de muitos modos da estrutura, uma significativa diferença nas frequências naturais entre o modelo analítico e o experimento pode resultar em baixos valores de FRAC.

\section{Frequency Response Scale Factor (FRSF)}

O FRAC assim como o FDAC são insensíveis à existência de um fator de escala entre as FRF's teórica e experimental. Para comparar as amplitudes das FRF's, pode-se calcular o Frequency Response Scale Factor (FRSF) que pode ser definido como:

$$
\operatorname{FRSF}(\omega)_{j}=\frac{\left\{H_{\mathrm{mod}}(\omega)\right\}_{j}^{T} \cdot\left\{H_{\mathrm{mod}}(\omega)\right\}_{j}}{\left\{H_{\exp }(\omega)\right\}_{j}^{T} \cdot\left\{H_{\exp }(\omega)\right\}_{j}}
$$

Sendo:

$$
\begin{aligned}
& \omega=\text { frequência; } \\
& j=\text { coluna da matriz }[H] .
\end{aligned}
$$

Para um modelo perfeitamente ajustado com o experimento, todas as componentes do FRSF devem ser iguais a 1,0. Entretanto, como em geral o amortecimento não é levado em conta no modelo teórico, é comum encontrar valores de FRSF maiores do que 1,0 nas zonas próximas às ressonâncias, (PASCUAL JIMENEZ, 1999). 


\subsection{CONCLUSÕES DA REVISÃO DE LITERATURA}

As toras de madeira apresentam vantagens em relação à madeira serrada como, por exemplo, a continuidade das fibras e o confinamento dos nós. Tais características conferem a esses elementos menor variabilidade e maior resistência mecânica fazendo das toras materiais interessantes para aplicações estruturais. Para essa finalidade, é preciso conhecer as propriedades mecânicas das toras para saber se as mesmas podem suportar os esforços resultantes do carregamento de serviço da estrutura.

As técnicas de AND de toras fornecem informações a respeito da qualidade da madeira e permitem uma estimativa da resistência mecânica. As principais técnicas de AND para toras são: inspeção visual; ensaio de flexão estática; micro-perfuração; tomografia; ultrassom; ondas de tensão e vibração transversal.

A inspeção visual pode não detectar alguns defeitos internos. Contudo, deve ser ressaltado que essa técnica fornece um bom indicativo da qualidade da superfície externa que, para os efeitos de flexão, é a região de maior importância. Assim, para a classificação estrutural das toras devem ser utilizados ensaios mecânicos para mensuração da rigidez, juntamente com a inspeção visual.

É possível realizar uma avaliação qualitativa das toras por meio de outras técnicas não-destrutivas como, por exemplo, a micro-perfuração e tomografia. Embora alguns autores tenham encontrado fraca correlação entre a resistência à micro-perfuração e a resistência à compressão, com essa técnica é possível verificar a presença de podridão no interior das toras e estimar a densidade da madeira. A tomografia computadorizada permite obter excelentes informações a respeito do estado interno das toras, sendo possível a visualização de nós, anéis de crescimento e a diferenciação entre madeira juvenil de adulta. Entretanto, o elevado custo desse equipamento inviabiliza o emprego de tal técnica de AND na inspeção de toras de madeira.

Um processo mais eficiente para classificar as toras de madeira consiste na medição direta de uma propriedade mecânica como, por exemplo, o módulo de elasticidade ou o módulo de ruptura na flexão.

A rigidez e o módulo de ruptura na flexão das toras de madeira podem ser medidos diretamente pelo ensaio de flexão estática com o esquema de viga engastada-livre, como padronizam as normas NBR 6231 (ABTN, 1980) e ASTM D1036 (ASTM, 2005). Contudo, a 
condição ideal de engaste é difícil de ser alcançada e, na prática, os resultados obtidos são pouco precisos.

O módulo de elasticidade na flexão pode também ser estimado por meio de ensaios dinâmicos como, por exemplo, o ultrassom, ondas de tensão e a vibração transversal.

No caso do ultrassom, o modelo matemático usado nas avaliações precisa levar em conta os fatores que interferem na velocidade de propagação da onda, tais como as dimensões da peça, a frequência de excitação, o teor de umidade e a direção das fibras.

Do mesmo modo, as avaliações do módulo de elasticidade pela técnica das ondas de tensão são dependentes da geometria da seção transversal e, por esse motivo, o modelo de regressão exponencial levando em conta o diâmetro das toras fornece melhores estimativas de

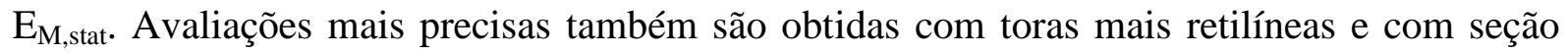
transversal mais próxima da circular.

Vários autores relatam a obtenção de boas estimativas da rigidez à flexão de peças de madeira serrada empregando a técnica de vibração transversal. Vale ressaltar que, na maior parte desses trabalhos, foi adotado o modelo teórico de Bernoulli idealizado para uma viga prismática composta por material isotrópico e homogêneo.

Embora o modelo de viga de Timoshenko seja mais completo do que o de Bernoulli suas soluções só podem ser obtidas por método numérico, o que reduz significativamente a velocidade de ensaio, tornando tal modelo inconveniente para aplicações práticas. Alternativamente, pode-se obter $\mathrm{E}_{\mathrm{M}, \mathrm{VT}}$ pelo modelo de Bernoulli e incluir o efeito do cisalhamento usando as expressões de Goens (1931) ou Timoshenko (1953).

Se a água livre na madeira for simulada com a adição de massas distribuídas ao longo do comprimento da viga, segundo Barret \& Hong (2009), o módulo de elasticidade dinâmico permanece constante e igual ao obtido no ponto de saturação para teores de umidade igual ou superiores a $30 \%$.

Vale ressaltar que é preciso verificar se a equação definida no item 6.2.1 da norma NBR 7190 (ABNT, 1997) fornece boas estimativas para o módulo de elasticidade dinâmico no teor de umidade de $12 \%$. 
Supondo válidas as condições de ortogonalidade dos modos de vibração, pode-se afirmar que, teoricamente, a rigidez do sistema de suspensão não afetará a frequência do primeiro modo de flexão de uma tora na condição de contorno livre-livre desde que a mesma seja apoiada nos pontos nodais desse modo.

Para o caso de viga suspensa por apoios elásticos presos às suas extremidades, as frequências naturais da mesma ficam dependentes da rigidez relativa $\mathrm{K}^{*}$, que é a razão entre a rigidez axial do apoio e a rigidez à flexão da viga. Para minimizar tal influência, deve-se evitar que $10^{-1} \leq \mathrm{K}^{*} \leq 10^{4}$, pois do contrário, as frequências naturais das vigas ficam dependentes da rigidez relativa $K^{*}$. Pode-se deduzir então que, para vigas de elevada rigidez à flexão, deve-se utilizar um sistema de suspensão bastante deformável e para vigas de baixa rigidez deve-se utilizar um sistema de apoios rígidos.

Até o presente momento, a maioria dos trabalhos publicados sobre o emprego da técnica de vibração transversal na AND de toras de madeira relata estudos superficiais e casos particulares como: Wang et al (2002), que não consideraram os efeitos do cisalhamento e da variação da inércia; Green et al (2004) e Green et al (2006) que testaram a técnica de vibração transversal em toras torneadas com L/D >18; e Chui et al (1999) que, apesar de levarem em conta a variação do momento de inércia e da área da seção transversal no modelo teórico, testaram toras nas quais os efeitos do cisalhamento e da inércia à rotação eram desprezíveis. 


\section{DETERMINAÇÃO DO DIÂMETRO EQUIVALENTE PARA O CÁlCULO DO MÓDULO DE ELASTICIDADE E ESTUDO DA INFLUÊNCIA DO ESFORÇO CORTANTE NO ENSAIO DINÂMICO}

No método proposto por Chui (1999), a inclusão da conicidade das toras na solução do modelo de Bernoulli para uma viga em vibração livre levou a resolução de um determinante com funções de Bessel de $4^{\mathrm{a}}$ e $5^{\mathrm{a}}$ ordem tornando a obtenção do módulo de elasticidade uma tarefa trabalhosa.

Para simplificar o cálculo do módulo de elasticidade pode-se admitir a tora como um cilindro com um "diâmetro equivalente" $\left(D_{\text {eq }}\right)$ que resulte na melhor estimativa da rigidez à flexão, tanto no ensaio de flexão estática quanto no de vibração transversal. Assim, neste capítulo foi desenvolvido um estudo para verificar a melhor forma de considerá-lo.

$\mathrm{Na}$ revisão de literatura verificou-se que os efeitos do esforço cortante passam a ser desprezíveis no ensaio de flexão estática em toras para valores de $\mathrm{L} / \mathrm{D}_{\text {meio }}$ superiores a 18 .

Como não foi encontrada alguma referência sobre um valor limite de $L / \mathrm{D}_{\text {meio }}$ a partir do qual o efeito do esforço cortante possa ser desprezado no ensaio de vibração transversal com toras foi desenvolvido um estudo teórico a fim de encontrá-lo.

\subsection{Determinação de um diâmetro equivalente para o cálculo do módulo de elasticidade nos ensaios de flexão estática e vibração transversal}

Foram feitas simulações numéricas no programa de modelagem por elementos finitos Abaqus 6.3, nas quais o ensaio de vibração transversal foi modelado com a condição de contorno livre-livre, e o ensaio de flexão estática foi modelado para duas condições: engastado-livre e bi-apoiado. As vigas foram modeladas como sólidos tridimensionais com comprimento de $3 \mathrm{~m}$, conicidade variando de $0,2 \%$ a $1,8 \%$ e relação $\mathrm{L} / \mathrm{D}_{\text {meio }}$ variando de $10 \mathrm{a}$ 26 , totalizando 45 vigas analisadas. 
O intervalo de conicidade anteriormente mencionado foi definido a partir da observação da variação das conicidades das toras de Eucalyptus citriodora utilizadas por Miná (2005) e Zangiácomo (2007).

A malha de elementos finitos foi gerada usando o elemento Hex com dimensão máxima de $10 \mathrm{~mm}$. Foram adotados os seguintes valores para as propriedades físicas do material das vigas: $\mathrm{E}=18,0 \mathrm{GPa} ; \mathrm{G}=1,125 \mathrm{GPa}, v=0,23$ e $\rho=800 \mathrm{~kg} / \mathrm{m}^{3}$.

Para o cálculo do módulo de elasticidade dinâmico levando em conta os efeitos da inércia à rotação e do esforço cortante foi utilizada a Equação 3.1, na qual o diâmetro equivalente adotado no cálculo é função de uma coordenada relativa $x$,' conforme sistema de referência mostrado na Figura 3.1.

$$
\begin{aligned}
& E_{M, V T}=E_{M, V T, a p} * T \\
& E_{M, V T, a p}=\frac{1,607 * f^{2} * M * L^{3}}{D_{e q}{ }^{4}} \quad T=1+43,193 A+18,589(A-2 B)-\frac{500,547\left(A^{2}-B^{2}\right)}{1+44,746 A} \\
& A=\frac{D_{e q}{ }^{2}}{32 L^{2}}\left(\frac{\eta E}{G}+1\right) B=\frac{D_{e q}{ }^{2}}{32 L^{2}}\left(\frac{\eta E}{G}-1\right) \quad D_{\text {eq }}=D_{\text {topo }}+\left(\frac{D_{\text {base }}-D_{\text {topo }}}{L}\right) * x \quad x^{\prime}=\frac{x}{L}
\end{aligned}
$$

Sendo:

$E_{M, V T}=$ módulo de elasticidade da tora $(\mathrm{Pa})$;

$E_{M, V T, a p}=$ módulo de elasticidade aparente $(\mathrm{Pa})$;

$f=$ frequência do primeiro modo de flexão $(\mathrm{Hz})$;

$M=$ massa da viga $(\mathrm{kg})$;

$L=$ comprimento $(\mathrm{m})$;

$\eta=$ fator de forma da seção transversal $(\eta=1,11$ para seção circular);

$E / G=$ constante admitida igual 16 .

Na Equação 3.1 x' é a coordenada relativa do diâmetro equivalente a partir do topo da tora. A Figura 3.1 mostra ao sistema de coordenadas adotado.

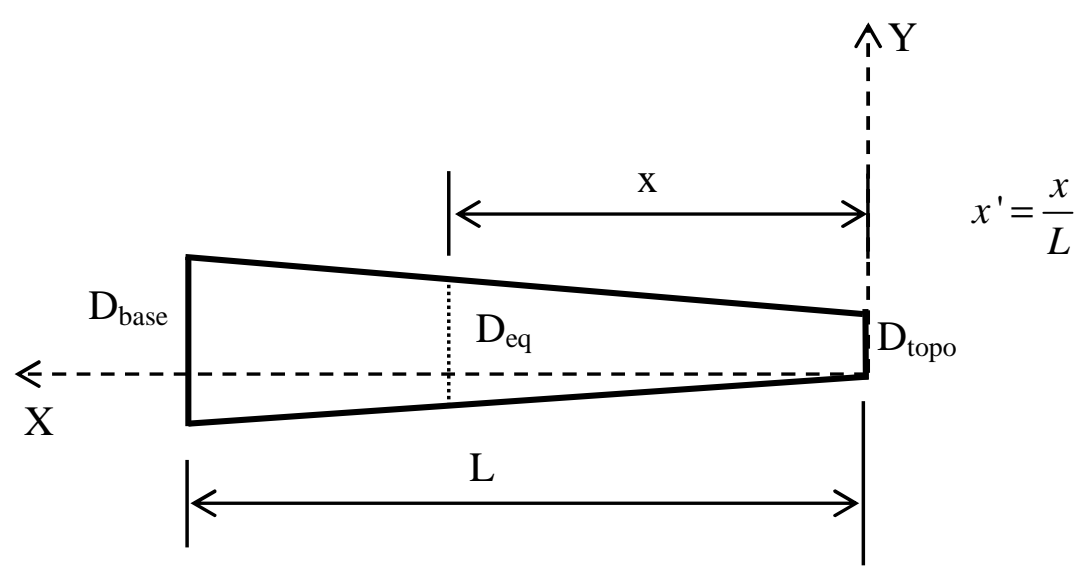

Figura 3.1 - Coordenadas utilizadas no cálculo de $x$ '. 
Para avaliar a exatidão das estimativas foi definida uma função erro (Equação 3.2) entre o módulo de elasticidade adotado nas modelagens (18,0 GPa) e o módulo de elasticidade calculado com a Equação 3.1.

$$
\exists(\%)=\left|\frac{E_{M, V T}-18 * 10^{9}}{18 * 10^{9}}\right| * 100
$$

Sendo:

$$
\exists \text { = erro de estimativa do módulo de elasticidade; }
$$

Para o ensaio de flexão estática, foi realizada uma análise estática das mesmas vigas para as condições de contorno engastada-livre e bi-apoiada. Na condição engastada-livre a extremidade de maior diâmetro foi engastada e na extremidade livre foi aplicada uma força concentrada tal que o deslocamento nessa extremidade fosse igual a 1/200 do comprimento da viga, segundo equações da estática clássica.

$\mathrm{O}$ valor do deslocamento na extremidade livre foi determinado com o Abaqus 6.3 e o erro de estimativa do módulo de elasticidade estático foi calculado pela Equação 3.3.

$$
\begin{aligned}
& \exists(\%)=\left|\frac{\left(\frac{64 * \Delta F * L^{3}}{3 \pi * \Delta v * D_{e q}{ }^{4}}+\frac{64 * \eta * \Delta F * L}{\pi * \Delta v * D_{e q}{ }^{2}}\right)-18 * 10^{9}}{18 * 10^{9}}\right| * 100 \\
& D_{e q}=D_{\text {topo }}+\left(D_{\text {base }}-D_{\text {topo }}\right) * x^{\prime} \quad x^{\prime}=\frac{x}{L}
\end{aligned}
$$

Sendo:

$\exists=$ erro no valor do módulo de elasticidade estático;

$\Delta F=$ força necessária para produzir um deslocamento na extremidade livre igual a $1 / 200$ do comprimento da viga $(\mathrm{N})$;

$L=$ comprimento da viga $(\mathrm{m})$;

$D_{e q}=$ diâmetro equivalente $(\mathrm{m})$;

$\eta=$ fator de forma da seção transversal ( $\eta=1,11$ para seção circular);

$G=$ módulo de elasticidade transversal $(\mathrm{Pa})$;

$\Delta v=$ deslocamento vertical da extremidade em balanço $(\mathrm{m})$.

Analogamente, para a condição bi-apoiada, foi aplicada uma força concentrada na metade do comprimento da viga. A intensidade da força foi determinada fixando o deslocamento vertical no ponto de aplicação da força a L/200. 
O erro na determinação do módulo de elasticidade estático foi calculado pela Equação 3.4 .

$$
\begin{aligned}
& \exists(\%)=\left|\frac{\left(\frac{4 * \Delta F * L^{3}}{3 \pi * \Delta v * D_{e q}{ }^{4}}+\frac{16 * \eta * \Delta F * L}{\pi * \Delta v * D_{e q}{ }^{2}}\right)-18 * 10^{9}}{18 * 10^{9}}\right| * 100 \\
& D_{e q}=D_{\text {topo }}+\left(D_{\text {base }}-D_{\text {topo }}\right) * x^{\prime} \quad x^{\prime}=\frac{x}{L}
\end{aligned}
$$

Sendo:

$\exists=$ erro no valor do módulo de elasticidade estático;

$\Delta F=$ força necessária para produzir um deslocamento não igual a 1/200 do vão da viga $(\mathrm{N})$;

$L=$ comprimento da viga $(\mathrm{m})$;

$D_{e q}=$ diâmetro equivalente $(\mathrm{m})$;

$\eta=$ fator de forma da seção transversal $(\eta=1,11$ para seção circular);

$G=$ módulo de elasticidade transversal $(\mathrm{Pa})$;

$\Delta v=$ deslocamento vertical da extremidade em balanço $(\mathrm{m})$.

A coordenada relativa $x^{\prime}$ para a qual o erro total é mínimo foi denominada de $x^{\prime}{ }_{\text {ótimo, }}$, sendo determinada por meio da minimização da função objetivo mostrada na Equação 3.5.

$$
F_{o b j}=\sum_{i=1}^{45} \exists_{i}
$$

Sendo:

$\exists_{\mathrm{i}}=$ erro de estimativa do módulo de elasticidade para a i-ésima viga.

O problema de otimização foi resolvido empregando-se a ferramenta Solver do Microsoft Excel para o intervalo de pesquisa $0,001 \leq x^{\prime} \leq 1,0$.

\subsubsection{Resultados}

A Tabela 3.1 mostra o resultado da determinação de $x^{\prime}{ }_{\text {ótimo }}$ para o ensaio de vibração transversal na condição de contorno livre-livre. 
Tabela 3.1 - Determinação de $x^{\prime}{ }_{\text {ótimo }}$ para o ensaio de vibração transversal.

\begin{tabular}{|c|c|c|c|c|c|c|c|c|c|c|c|c|}
\hline Viga & $\begin{array}{c}\text { Viga } \\
\mathbf{N}^{\circ}\end{array}$ & $\begin{array}{c}\text { C } \\
(\%)\end{array}$ & $\begin{array}{c}\mathrm{L} \\
(\mathrm{m})\end{array}$ & $L / D_{\text {meio }}$ & $\begin{array}{c}D_{\text {base }} \\
(\mathrm{m})\end{array}$ & $\begin{array}{c}D_{\text {meio }} \\
(\mathrm{m})\end{array}$ & $\begin{array}{l}D_{\text {topo }} \\
\text { (m) }\end{array}$ & $\begin{array}{c}\text { Massa } \\
(\mathrm{kg})\end{array}$ & $\begin{array}{c}\mathbf{f}_{10 \text { modo }} \\
(\mathrm{Hz})\end{array}$ & $\begin{array}{l}D_{\text {eq }}{ }^{1} \\
(\mathrm{~m})\end{array}$ & $\begin{array}{c}E_{M, V T} \\
(G P a)\end{array}$ & $\begin{array}{c}\exists_{i} \\
(\%)\end{array}$ \\
\hline $02-10$ & 1 & & & 10 & 0,303 & 0,300 & 0,297 & 169,65 & 130,098 & 0,300 & 17,9 & $0,5 \%$ \\
\hline $02-12$ & 2 & & & 12 & 0,253 & 0,250 & 0,247 & 117,82 & 110,845 & 0,250 & 17,9 & $0,5 \%$ \\
\hline $02-14$ & 3 & & & 14 & 0,217 & 0,214 & 0,211 & 86,56 & 96,243 & 0,214 & 17,9 & $0,6 \%$ \\
\hline $02-16$ & 4 & & & 16 & 0,191 & 0,188 & 0,185 & 66,27 & 85,098 & 0,188 & 17,9 & $0,4 \%$ \\
\hline $02-18$ & 5 & $0,2 \%$ & 3,00 & 18 & 0,170 & 0,167 & 0,164 & 52,37 & 76,272 & 0,167 & 18,0 & $0,0 \%$ \\
\hline $02-20$ & 6 & & & 20 & 0,153 & 0,150 & 0,147 & 42,42 & 68,822 & 0,150 & 17,9 & $0,4 \%$ \\
\hline $02-22$ & 7 & & & 22 & 0,139 & 0,136 & 0,133 & 35,06 & 62,607 & 0,136 & 17,8 & $1,0 \%$ \\
\hline $02-24$ & 8 & & & 24 & 0,128 & 0,125 & 0,122 & 29,46 & 57,676 & 0,125 & 17,9 & $0,6 \%$ \\
\hline $02-26$ & 9 & & & 26 & 0,118 & 0,115 & 0,112 & 25,10 & 53,169 & 0,115 & 17,8 & $1,2 \%$ \\
\hline $06-10$ & 10 & & & 10 & 0,309 & 0,300 & 0,291 & 169,70 & 130,109 & 0,300 & 17,9 & $0,6 \%$ \\
\hline $06-12$ & 11 & & & 12 & 0,259 & 0,250 & 0,241 & 117,86 & 110,864 & 0,250 & 17,9 & $0,5 \%$ \\
\hline $06-14$ & 12 & & & 14 & 0,223 & 0,214 & 0,205 & 86,60 & 96,265 & 0,214 & 17,9 & $0,7 \%$ \\
\hline $06-16$ & 13 & & & 16 & 0,197 & 0,188 & 0,179 & 66,32 & 85,124 & 0,188 & 17,9 & $0,4 \%$ \\
\hline $06-18$ & 14 & $0,6 \%$ & 3,00 & 18 & 0,176 & 0,167 & 0,158 & 52,41 & 76,302 & 0,167 & 18,0 & $0,0 \%$ \\
\hline $06-20$ & 15 & & & 20 & 0,159 & 0,150 & 0,141 & 42,46 & 68,859 & 0,150 & 17,9 & $0,4 \%$ \\
\hline $06-22$ & 16 & & & 22 & 0,145 & 0,136 & 0,127 & 35,10 & 62,648 & 0,136 & 17,8 & $0,9 \%$ \\
\hline $06-24$ & 17 & & & 24 & 0,134 & 0,125 & 0,116 & 29,50 & 57,722 & 0,125 & 17,9 & $0,4 \%$ \\
\hline $06-26$ & 18 & & & 26 & 0,124 & 0,115 & 0,106 & 25,15 & 53,220 & 0,115 & 17,8 & $1,1 \%$ \\
\hline $10-10$ & 19 & & & 10 & 0,315 & 0,300 & 0,285 & 169,79 & 130,152 & 0,300 & 17,9 & $0,5 \%$ \\
\hline $10-12$ & 20 & & & 12 & 0,265 & 0,250 & 0,235 & 117,95 & 110,898 & 0,250 & 17,9 & $0,4 \%$ \\
\hline $10-14$ & 21 & & & 14 & 0,229 & 0,214 & 0,199 & 86,70 & 96,305 & 0,214 & 17,9 & $0,6 \%$ \\
\hline $10-16$ & 22 & & & 16 & 0,203 & 0,188 & 0,173 & 66,41 & 85,172 & 0,188 & 18,0 & $0,3 \%$ \\
\hline $10-18$ & 23 & $1,0 \%$ & 3,00 & 18 & 0,182 & 0,167 & 0,152 & 52,50 & 76,359 & 0,167 & 18,0 & $0,2 \%$ \\
\hline $10-20$ & 24 & & & 20 & 0,165 & 0,150 & 0,135 & 42,55 & 68,923 & 0,150 & 18,0 & $0,1 \%$ \\
\hline $10-22$ & 25 & & & 22 & 0,151 & 0,136 & 0,121 & 35,19 & 62,721 & 0,137 & 17,9 & $0,6 \%$ \\
\hline $10-24$ & 26 & & & 24 & 0,140 & 0,125 & 0,110 & 29,59 & 57,803 & 0,125 & 18,0 & $0,0 \%$ \\
\hline $10-26$ & 27 & & & 26 & 0,130 & 0,115 & 0,100 & 25,24 & 53,309 & 0,116 & 17,9 & $0,6 \%$ \\
\hline $14-10$ & 28 & & & 10 & 0,321 & 0,300 & 0,279 & 169,92 & 130,171 & 0,300 & 17,9 & $0,5 \%$ \\
\hline $14-12$ & 29 & & & 12 & 0,271 & 0,250 & 0,229 & 118,09 & 110,943 & 0,250 & 17,9 & $0,3 \%$ \\
\hline $14-14$ & 30 & & & 14 & 0,235 & 0,214 & 0,193 & 86,83 & 96,364 & 0,214 & 17,9 & $0,4 \%$ \\
\hline $14-16$ & 31 & & & 16 & 0,209 & 0,188 & 0,167 & 66,55 & 85,243 & 0,188 & 18,0 & $0,0 \%$ \\
\hline $14-18$ & 32 & $1,4 \%$ & 3,00 & 18 & 0,188 & 0,167 & 0,146 & 52,64 & 76,441 & 0,167 & 18,1 & $0,5 \%$ \\
\hline $14-20$ & 33 & & & 20 & 0,171 & 0,150 & 0,129 & 42,69 & 69,018 & 0,150 & 18,1 & $0,3 \%$ \\
\hline $14-22$ & 34 & & & 22 & 0,157 & 0,136 & 0,115 & 35,33 & 62,828 & 0,137 & 18,0 & $0,0 \%$ \\
\hline $14-24$ & 35 & & & 24 & 0,146 & 0,125 & 0,104 & 29,73 & 57,923 & 0,125 & 18,1 & $0,7 \%$ \\
\hline $14-26$ & 36 & & & 26 & 0,136 & 0,115 & 0,094 & 25,37 & 53,441 & 0,116 & 18,0 & $0,3 \%$ \\
\hline $18-10$ & 37 & & & 10 & 0,327 & 0,300 & 0,273 & 170,10 & 130,243 & 0,300 & 17,9 & $0,3 \%$ \\
\hline $18-12$ & 38 & & & 12 & 0,277 & 0,250 & 0,223 & 118,27 & 111,007 & 0,250 & 18,0 & $0,1 \%$ \\
\hline $18-14$ & 39 & & & 14 & 0,241 & 0,214 & 0,187 & 87,01 & 96,443 & 0,215 & 18,0 & $0,1 \%$ \\
\hline $18-16$ & 40 & & & 16 & 0,215 & 0,188 & 0,161 & 66,73 & 85,338 & 0,188 & 18,1 & $0,4 \%$ \\
\hline $18-18$ & 41 & $1,8 \%$ & 3,00 & 18 & 0,194 & 0,167 & 0,140 & 52,82 & 76,548 & 0,167 & 18,2 & $1,0 \%$ \\
\hline $18-20$ & 42 & & & 20 & 0,177 & 0,150 & 0,123 & 42,87 & 69,151 & 0,150 & 18,2 & $1,0 \%$ \\
\hline $18-22$ & 43 & & & 22 & 0,163 & 0,136 & 0,109 & 35,51 & 62,974 & 0,137 & 18,1 & $0,8 \%$ \\
\hline $18-24$ & 44 & & & 24 & 0,152 & 0,125 & 0,098 & 29,91 & 58,086 & 0,125 & 18,3 & $1,7 \%$ \\
\hline \multirow[t]{4}{*}{$18-26$} & 45 & & & 26 & 0,142 & 0,115 & 0,088 & 25,55 & 53,623 & 0,116 & 18,3 & $1,5 \%$ \\
\hline & & & & & & & $\mathrm{X}_{\text {ótimo }}^{\prime}=$ & 0,50 & & Mínimo & 17,8 & $0,0 \%$ \\
\hline & & & & & & & $\Sigma \exists_{i}=$ & $23,3 \%$ & & Média & 18,0 & $0,5 \%$ \\
\hline & & & & & & & & & & Máximo & 18,3 & $1,7 \%$ \\
\hline
\end{tabular}

1. Diâmetro equivalente para resíduo mínimo.

As Tabelas 3.2 e 3.3 mostram os resultados da determinação de $x^{\prime}{ }_{\text {ótimo }}$ para o ensaio de flexão estática respectivamente com as condições de contorno engastada-livre e bi-apoiada. 
Tabela 3.2 - Determinação de $x^{\prime}{ }_{\text {ótimo }}$ para o ensaio de flexão estática na condição de contorno engastado-livre.

\begin{tabular}{|c|c|c|c|c|c|c|c|c|c|c|c|}
\hline $\begin{array}{l}\text { Viga } \\
\mathbf{N}^{\circ}\end{array}$ & C (\%) & $L(m)$ & $L / D_{\text {meio }}$ & $\begin{array}{c}D_{\text {base }} \\
(\mathrm{m})\end{array}$ & $\begin{array}{c}D_{\text {meio }} \\
(\mathrm{m})\end{array}$ & $\begin{array}{l}D_{\text {topo }} \\
\text { (m) }\end{array}$ & $\begin{array}{l}\Delta \mathrm{F} \\
(\mathrm{N})\end{array}$ & $\begin{array}{c}\Delta \mathbf{v} \\
(\mathrm{m})\end{array}$ & $\begin{array}{l}D_{\text {eq }} \\
(m)\end{array}$ & $\begin{array}{l}E_{\mathrm{M}, \text { Stat }} \\
(\mathrm{GPa})\end{array}$ & $\begin{array}{c}\exists_{\mathrm{i}} \\
(\%)\end{array}$ \\
\hline 1 & & & 10 & 0,303 & $\overline{0,300}$ & $\overline{0,297}$ & 11928 & 0,015 & 0,301 & 18,0 & $0,1 \%$ \\
\hline 2 & & & 12 & 0,253 & 0,250 & 0,247 & 5752 & 0,015 & 0,251 & 17,9 & $0,3 \%$ \\
\hline 3 & & & 14 & 0,217 & 0,214 & 0,211 & 3105 & 0,015 & 0,215 & 17,8 & $1,1 \%$ \\
\hline 4 & & & 16 & 0,191 & 0,188 & 0,185 & 1820 & 0,015 & 0,189 & 18,0 & $0,2 \%$ \\
\hline 5 & $0,2 \%$ & 3,00 & 18 & 0,170 & 0,167 & 0,164 & 1136 & 0,015 & 0,168 & 18,0 & $0,2 \%$ \\
\hline 6 & & & 20 & 0,153 & 0,150 & 0,147 & 745 & 0,015 & 0,151 & 17,7 & $1,5 \%$ \\
\hline 7 & & & 22 & 0,139 & 0,136 & 0,133 & 470 & 0,015 & 0,138 & 16,0 & $11,0 \%$ \\
\hline 8 & & & 24 & 0,128 & 0,125 & 0,122 & 350 & 0,016 & 0,126 & 16,4 & $9,0 \%$ \\
\hline 9 & & & 26 & 0,118 & 0,115 & 0,112 & 240 & 0,015 & 0,117 & 16,3 & $9,3 \%$ \\
\hline 10 & & & 10 & 0,309 & 0,300 & 0,291 & 11928 & 0,015 & 0,304 & 18,1 & $0,5 \%$ \\
\hline 11 & & & 12 & 0,259 & 0,250 & 0,241 & 5752 & 0,014 & 0,254 & 18,1 & $0,5 \%$ \\
\hline 12 & & & 14 & 0,223 & 0,214 & 0,205 & 3105 & 0,014 & 0,218 & 18,0 & $0,2 \%$ \\
\hline 13 & & & 16 & 0,197 & 0,188 & 0,179 & 1820 & 0,014 & 0,191 & 18,2 & $1,3 \%$ \\
\hline 14 & $0,6 \%$ & 3,00 & 18 & 0,176 & 0,167 & 0,158 & 1136 & 0,014 & 0,170 & 18,1 & $0,8 \%$ \\
\hline 15 & & & 20 & 0,159 & 0,150 & 0,141 & 745 & 0,014 & 0,154 & 18,0 & $0,2 \%$ \\
\hline 16 & & & 22 & 0,145 & 0,136 & 0,127 & 470 & 0,014 & 0,140 & 16,3 & $9,7 \%$ \\
\hline 17 & & & 24 & 0,134 & 0,125 & 0,116 & 350 & 0,014 & 0,129 & 16,6 & $7,5 \%$ \\
\hline 18 & & & 26 & 0,124 & 0,115 & 0,106 & 240 & 0,013 & 0,119 & 16,6 & $8,0 \%$ \\
\hline 19 & & & 10 & 0,315 & 0,300 & 0,285 & 11928 & 0,014 & 0,306 & 18,2 & $1,0 \%$ \\
\hline 20 & & & 12 & 0,265 & 0,250 & 0,235 & 5752 & 0,014 & 0,256 & 18,2 & $1,0 \%$ \\
\hline 21 & & & 14 & 0,229 & 0,214 & 0,199 & 3105 & 0,014 & 0,220 & 18,1 & $0,4 \%$ \\
\hline 22 & & & 16 & 0,203 & 0,188 & 0,173 & 1820 & 0,013 & 0,194 & 18,3 & $1,8 \%$ \\
\hline 23 & $1,0 \%$ & 3,00 & 18 & 0,182 & 0,167 & 0,152 & 1136 & 0,013 & 0,173 & 18,3 & $1,5 \%$ \\
\hline 24 & & & 20 & 0,165 & 0,150 & 0,135 & 745 & 0,013 & 0,156 & 18,1 & $0,3 \%$ \\
\hline 25 & & & 22 & 0,151 & 0,136 & 0,121 & 470 & 0,013 & 0,142 & 16,3 & $9,2 \%$ \\
\hline 26 & & & 24 & 0,140 & 0,125 & 0,110 & 350 & 0,013 & 0,131 & 16,7 & $7,3 \%$ \\
\hline 27 & & & 26 & 0,130 & 0,115 & 0,100 & 240 & 0,012 & 0,121 & 16,7 & $7,5 \%$ \\
\hline 28 & & & 10 & 0,321 & 0,300 & 0,279 & 11928 & 0,014 & 0,308 & 18,2 & $1,4 \%$ \\
\hline 29 & & & 12 & 0,271 & 0,250 & 0,229 & 5752 & 0,013 & 0,258 & 18,3 & $1,4 \%$ \\
\hline 30 & & & 14 & 0,235 & 0,214 & 0,193 & 3105 & 0,013 & 0,223 & 18,1 & $0,8 \%$ \\
\hline 31 & & & 16 & 0,209 & 0,188 & 0,167 & 1820 & 0,012 & 0,196 & 18,4 & $2,2 \%$ \\
\hline 32 & $1,4 \%$ & 3,00 & 18 & 0,188 & 0,167 & 0,146 & 1136 & 0,012 & 0,175 & 18,3 & $1,6 \%$ \\
\hline 33 & & & 20 & 0,171 & 0,150 & 0,129 & 745 & 0,012 & 0,158 & 18,1 & $0,5 \%$ \\
\hline 34 & & & 22 & 0,157 & 0,136 & 0,115 & 470 & 0,012 & 0,145 & 16,4 & $9,0 \%$ \\
\hline 35 & & & 24 & 0,146 & 0,125 & 0,104 & 350 & 0,012 & 0,133 & 16,7 & $7,2 \%$ \\
\hline 36 & & & 26 & 0,136 & 0,115 & 0,094 & 240 & 0,011 & 0,124 & 16,6 & $7,8 \%$ \\
\hline 37 & & & 10 & 0,327 & 0,300 & 0,273 & 11928 & 0,013 & 0,311 & 18,3 & $1,6 \%$ \\
\hline 38 & & & 12 & 0,277 & 0,250 & 0,223 & 5752 & 0,013 & 0,261 & 18,3 & $1,5 \%$ \\
\hline 39 & & & 14 & 0,241 & 0,214 & 0,187 & 3105 & 0,012 & 0,225 & 18,7 & $3,8 \%$ \\
\hline 40 & & & 16 & 0,215 & 0,188 & 0,161 & 1820 & 0,012 & 0,198 & 18,4 & $2,0 \%$ \\
\hline 41 & $1,8 \%$ & 3,00 & 18 & 0,194 & 0,167 & 0,140 & 1136 & 0,012 & 0,178 & 18,2 & $1,3 \%$ \\
\hline 42 & & & 20 & 0,177 & 0,150 & 0,123 & 745 & 0,011 & 0,161 & 18,0 & $0,0 \%$ \\
\hline 43 & & & 22 & 0,163 & 0,136 & 0,109 & 470 & 0,011 & 0,147 & 16,3 & $9,5 \%$ \\
\hline 44 & & & 24 & 0,152 & 0,125 & 0,098 & 350 & 0,011 & 0,136 & 16,6 & $8,0 \%$ \\
\hline \multirow[t]{3}{*}{45} & & & 26 & 0,142 & 0,115 & 0,088 & 240 & 0,011 & 0,126 & 16,4 & $8,7 \%$ \\
\hline & & & & & & $\mathrm{X}_{\text {ótimo }}^{\prime}=$ & 0,70 & & Mínimo & 16,0 & $0,0 \%$ \\
\hline & & & & & & $\Sigma \exists i=$ & $159,6 \%$ & & $\begin{array}{l}\text { Média } \\
\text { Máximo }\end{array}$ & $\begin{array}{l}17,6 \\
18.7\end{array}$ & $\begin{array}{c}3,5 \% \\
11,0 \%\end{array}$ \\
\hline
\end{tabular}


Tabela 3.3 - Determinação de $x^{\prime}{ }_{\text {ótimo }}$ para o ensaio de flexão estática na condição de contorno bi-apoiado.

\begin{tabular}{|c|c|c|c|c|c|c|c|c|c|c|}
\hline $\begin{array}{c}\text { Viga } \\
\mathrm{N}^{\circ}\end{array}$ & $C(\%) L(m)$ & $L / D_{\text {meio }}$ & $\begin{array}{c}D_{\text {base }} \\
(\mathrm{m})\end{array}$ & $\begin{array}{c}D_{\text {meio }} \\
(\mathrm{m})\end{array}$ & $\begin{array}{c}D_{\text {topo }} \\
\text { (m) }\end{array}$ & $\begin{array}{l}\Delta \mathrm{F} \\
(\mathrm{N})\end{array}$ & $\begin{array}{l}\Delta v \\
(\mathrm{~m})\end{array}$ & $\begin{array}{l}D_{\text {eq }} \\
(m)\end{array}$ & $\begin{array}{l}\mathrm{E}_{\mathrm{M}, \mathrm{Stat}} \\
(\mathrm{GPa})\end{array}$ & $\begin{array}{c}\exists_{i} \\
(\%)\end{array}$ \\
\hline 1 & & 10 & 0,303 & 0,300 & 0,297 & 121160 & 0,011 & 0,300 & 17,9 & $0,3 \%$ \\
\hline 2 & & 12 & 0,253 & 0,250 & 0,247 & 64363 & 0,012 & 0,250 & 17,9 & $0,5 \%$ \\
\hline 3 & & 14 & 0,217 & 0,214 & 0,211 & 37007 & 0,012 & 0,214 & 17,8 & $1,4 \%$ \\
\hline 4 & & 16 & 0,191 & 0,188 & 0,185 & 22652 & 0,012 & 0,187 & 18,0 & $0,1 \%$ \\
\hline 5 & $0,2 \% \quad 3,00$ & 18 & 0,170 & 0,167 & 0,164 & 14583 & 0,013 & 0,166 & 17,9 & $0,4 \%$ \\
\hline 6 & & 20 & 0,153 & 0,150 & 0,147 & 9787 & 0,013 & 0,150 & 17,7 & $1,8 \%$ \\
\hline 7 & & 22 & 0,139 & 0,136 & 0,133 & 6800 & 0,013 & 0,136 & 17,7 & $1,4 \%$ \\
\hline 8 & & 24 & 0,128 & 0,125 & 0,122 & 4865 & 0,014 & 0,125 & 16,8 & $6,7 \%$ \\
\hline 9 & & 26 & 0,118 & 0,115 & 0,112 & 3569 & 0,013 & 0,115 & 17,7 & $1,7 \%$ \\
\hline 10 & & 10 & 0,309 & 0,300 & 0,291 & 121160 & 0,011 & 0,299 & 18,0 & $0,2 \%$ \\
\hline 11 & & 12 & 0,259 & 0,250 & 0,241 & 64363 & 0,012 & 0,249 & 18,0 & $0,0 \%$ \\
\hline 12 & & 14 & 0,223 & 0,214 & 0,205 & 37007 & 0,012 & 0,214 & 17,9 & $0,7 \%$ \\
\hline 13 & & 16 & 0,197 & 0,188 & 0,179 & 22652 & 0,012 & 0,187 & 18,1 & $0,7 \%$ \\
\hline 14 & $0,6 \% \quad 3,00$ & 18 & 0,176 & 0,167 & 0,158 & 14583 & 0,013 & 0,166 & 18,0 & $0,2 \%$ \\
\hline 15 & & 20 & 0,159 & 0,150 & 0,141 & 9787 & 0,013 & 0,149 & 17,9 & $0,8 \%$ \\
\hline 16 & & 22 & 0,145 & 0,136 & 0,127 & 6800 & 0,013 & 0,136 & 17,9 & $0,5 \%$ \\
\hline 17 & & 24 & 0,134 & 0,125 & 0,116 & 4865 & 0,013 & 0,124 & 18,1 & $0,5 \%$ \\
\hline 18 & & 26 & 0,124 & 0,115 & 0,106 & 3569 & 0,013 & 0,115 & 17,9 & $0,8 \%$ \\
\hline 19 & & 10 & 0,315 & 0,300 & 0,285 & 121160 & 0,011 & 0,299 & 18,1 & $0,4 \%$ \\
\hline 20 & & 12 & 0,265 & 0,250 & 0,235 & 64363 & 0,012 & 0,249 & 18,1 & $0,3 \%$ \\
\hline 21 & & 14 & 0,229 & 0,214 & 0,199 & 37007 & 0,012 & 0,213 & 17,9 & $0,3 \%$ \\
\hline 22 & & 16 & 0,203 & 0,188 & 0,173 & 22652 & 0,012 & 0,187 & 18,2 & $1,1 \%$ \\
\hline 23 & $1,0 \% \quad 3,00$ & 18 & 0,182 & 0,167 & 0,152 & 14583 & 0,013 & 0,166 & 18,1 & $0,7 \%$ \\
\hline 24 & & 20 & 0,165 & 0,150 & 0,135 & 9787 & 0,013 & 0,149 & 17,9 & $0,4 \%$ \\
\hline 25 & & 22 & 0,151 & 0,136 & 0,121 & 6800 & 0,013 & 0,135 & 18,0 & $0,0 \%$ \\
\hline 26 & & 24 & 0,140 & 0,125 & 0,110 & 4865 & 0,013 & 0,124 & 18,2 & $0,9 \%$ \\
\hline 27 & & 26 & 0,130 & 0,115 & 0,100 & 3569 & 0,014 & 0,114 & 17,9 & $0,5 \%$ \\
\hline 28 & & 10 & 0,321 & 0,300 & 0,279 & 121160 & 0,011 & 0,299 & 18,1 & $0,7 \%$ \\
\hline 29 & & 12 & 0,271 & 0,250 & 0,229 & 64363 & 0,012 & 0,249 & 18,1 & $0,6 \%$ \\
\hline 30 & & 14 & 0,235 & 0,214 & 0,193 & 37007 & 0,012 & 0,213 & 18,0 & $0,0 \%$ \\
\hline 31 & & 16 & 0,209 & 0,188 & 0,167 & 22652 & 0,012 & 0,186 & 18,3 & $1,4 \%$ \\
\hline 32 & $1,4 \% \quad 3,00$ & 18 & 0,188 & 0,167 & 0,146 & 14583 & 0,013 & 0,165 & 18,2 & $0,9 \%$ \\
\hline 33 & & 20 & 0,171 & 0,150 & 0,129 & 9787 & 0,013 & 0,149 & 18,0 & $0,1 \%$ \\
\hline 34 & & 22 & 0,157 & 0,136 & 0,115 & 6800 & 0,013 & 0,135 & 18,0 & $0,2 \%$ \\
\hline 35 & & 24 & 0,146 & 0,125 & 0,104 & 4865 & 0,013 & 0,124 & 18,1 & $0,7 \%$ \\
\hline 36 & & 26 & 0,136 & 0,115 & 0,094 & 3569 & 0,014 & 0,114 & 17,9 & $0,8 \%$ \\
\hline 37 & & 10 & 0,327 & 0,300 & 0,273 & 121160 & 0,011 & 0,298 & 18,2 & $0,9 \%$ \\
\hline 38 & & 12 & 0,277 & 0,250 & 0,223 & 64363 & 0,011 & 0,248 & 19,0 & $5,3 \%$ \\
\hline 39 & & 14 & 0,241 & 0,214 & 0,187 & 37007 & 0,012 & 0,213 & 18,0 & $0,0 \%$ \\
\hline 40 & & 16 & 0,215 & 0,188 & 0,161 & 22652 & 0,013 & 0,186 & 18,2 & $1,4 \%$ \\
\hline 41 & $1,8 \% 3,00$ & 18 & 0,194 & 0,167 & 0,140 & 14583 & 0,013 & 0,165 & 18,1 & $0,7 \%$ \\
\hline 42 & & 20 & 0,177 & 0,150 & 0,123 & 9787 & 0,013 & 0,148 & 17,9 & $0,4 \%$ \\
\hline 43 & & 22 & 0,163 & 0,136 & 0,109 & 6800 & 0,014 & 0,135 & 17,9 & $0,6 \%$ \\
\hline 44 & & 24 & 0,152 & 0,125 & 0,098 & 4865 & 0,014 & 0,123 & 18,0 & $0,1 \%$ \\
\hline \multirow[t]{4}{*}{45} & & 26 & 0,142 & 0,115 & 0,088 & 3569 & 0,014 & 0,114 & 17,7 & $1,7 \%$ \\
\hline & & & & & $x_{\text {ótimo }}^{\prime}=$ & 0,47 & & Mínimo & 16,8 & $0,0 \%$ \\
\hline & & & & & $\Sigma \exists_{i}=$ & $40,1 \%$ & & Média & 18,0 & $0,9 \%$ \\
\hline & & & & & & & & Máximo & 19,0 & $6,7 \%$ \\
\hline
\end{tabular}

\subsubsection{Análise dos resultados}

$\mathrm{Na}$ Tabela 3.1, pode ser observado que o menor erro total para a estimativa do módulo de elasticidade dinâmico no ensaio de vibração transversal com as toras em suspensão livre- 
livre é obtido para $x^{\prime}{ }_{\text {ótimo }}=0,50$. Com o diâmetro calculado nessa coordenada, o módulo de elasticidade variou de 17,8 a 18,3 GPa, sendo que o valor médio de 18,0 GPa coincide com o módulo de elasticidade adotado na modelagem numérica.

Para o ensaio estático na condição engastado-livre com força concentrada na extremidade livre foi encontrado $x^{\prime}{ }_{\text {ótimo }}=0,70$.

$\mathrm{Na}$ modelagem com as vigas bi-apoiadas com força concentrada na metade do comprimento foi encontrado $x^{\prime}{ }_{\text {ótimo }}=0,47$.

A Tabela 3.4 mostra uma comparação entre os módulos de elasticidade calculados com diâmetro equivalente para $x^{\prime}{ }_{\text {ótimo }}=0,70$ e o adotado pelas normas NBR 6231(ABNT, 1980) e ASTM D 1036 (ASTM, 2005) para o ensaio de flexão estática na condição de contorno engastada-livre.

Observa-se que ambas as formas de calcular o diâmetro equivalente levam a estimativas muito próximas do módulo de elasticidade. Assim sendo, foi feito o seguinte teste de hipótese (ver Apêndice D):

$$
\left\{\begin{array}{l}
H_{0}: E_{M, \text { Stat }}\left(x_{\text {otimo }}^{\prime}\right)=E_{M, \text { Stat }}\left(x^{\prime}{ }_{N B R 6231}\right) \\
H_{1}: E_{M, \text { Stat }}\left(x_{\text {ótimo }}^{\prime}\right) \neq E_{M, \text { Stat }}\left(x_{N B R 6231}^{\prime}\right)
\end{array}\right.
$$

Como se pode observar no Apêndice D, os diâmetros obtidos com $x^{\prime}{ }_{\text {ótimo }}$ e $\mathrm{D}_{\text {eq }}$ dado segundo as normas NBR 6231 (ABNT, 1980) e ASTM D1036 (ASTM, 2005) produzem resultados diferentes para o módulo de elasticidade à flexão no ensaio de flexão estática com a condição de contorno engastada-livre. Contudo, a diferença encontrada foi considerada insignificante conforme se observa no teste de Tukey.

A Tabela 3.5 mostra uma comparação entre os módulos de elasticidade calculados com diâmetro equivalente para $x^{\prime}=0,47$ e o diâmetro medido na metade do comprimento da tora $\left(x^{\prime}=0,50\right)$ para o ensaio de flexão estática na condição de contorno bi-apoiada.

Como os valores encontrados para o módulo de elasticidade calculado com os diâmetros anteriormente citados foram diferentes foi realizado o seguinte teste de hipótese (ver Apêndice D):

$$
\left\{\begin{array}{l}
H_{0}: E_{M, \text { Stat }}\left(x^{\prime}=0,47\right)=E_{M, \text { Stat }}\left(x^{\prime}=0,50\right) \\
H_{1}: E_{M, \text { Stat }}\left(x^{\prime}=0,47\right) \neq E_{M, \text { Stat }}\left(x^{\prime}=0,50\right)
\end{array}\right.
$$


Observou-se que os diâmetros obtidos com $x^{\prime}=0,47$ e $x^{\prime}=0,50$ produzem resultados significativamente diferentes para o módulo de elasticidade à flexão no ensaio de flexão estática com a condição de contorno bi-apoiada.

Tabela 3.4 - Comparação entre os módulos de elasticidade calculados com $\mathrm{D}_{\text {eq }}$ para $x^{\prime}{ }_{\text {ótimo }}=$ 0,70 e $\mathrm{D}_{\text {eq }}$ adotado pelas normas NBR 6231 (ABNT, 1980) e ASTM D 1036 (ASTM, 2005) para o ensaio de flexão estática na condição de contorno engastada-livre.

\begin{tabular}{|c|c|c|c|c|c|c|c|}
\hline \multirow{2}{*}{$\begin{array}{l}\text { Viga } \\
\mathbf{N}^{\circ}\end{array}$} & \multirow{2}{*}{ C (\%) } & \multirow{2}{*}{$L(m)$} & \multirow{2}{*}{$L / D_{\text {meio }}$} & \multicolumn{2}{|c|}{$\mathrm{E}_{\mathrm{M}, \text { Stat }} \quad(\mathrm{GPa})$} & \multicolumn{2}{|c|}{$\exists_{i}(\%)$} \\
\hline & & & & Ótimo & NBR 6231 & Ótimo & NBR 6231 \\
\hline 1 & & & 10 & 18,0 & 17,9 & $0,1 \%$ & $0,5 \%$ \\
\hline 2 & & & 12 & 17,9 & 17,9 & $0,3 \%$ & $0,7 \%$ \\
\hline 3 & & & 14 & 17,8 & 17,7 & $1,1 \%$ & $1,6 \%$ \\
\hline 4 & & & 16 & 18,0 & 17,9 & $0,2 \%$ & $0,3 \%$ \\
\hline 5 & $0,2 \%$ & 3,00 & 18 & 18,0 & 17,9 & $0,2 \%$ & $0,8 \%$ \\
\hline 6 & & & 20 & 17,7 & 17,6 & $1,5 \%$ & $2,2 \%$ \\
\hline 7 & & & 22 & 16,0 & 15,9 & $11,0 \%$ & $11,7 \%$ \\
\hline 8 & & & 24 & 16,4 & 16,3 & $9,0 \%$ & $9,7 \%$ \\
\hline 9 & & & 26 & 16,3 & 16,2 & $9,3 \%$ & $10,1 \%$ \\
\hline 10 & & & 10 & 18,1 & 17,9 & $0,5 \%$ & $0,5 \%$ \\
\hline 11 & & & 12 & 18,1 & 17,9 & $0,5 \%$ & $0,7 \%$ \\
\hline 12 & & & 14 & 18,0 & 17,7 & $0,2 \%$ & $1,5 \%$ \\
\hline 13 & & & 16 & 18,2 & 18,0 & $1,3 \%$ & $0,2 \%$ \\
\hline 14 & $0,6 \%$ & 3,00 & 18 & 18,1 & 17,9 & $0,8 \%$ & $0,8 \%$ \\
\hline 15 & & & 20 & 18,0 & 17,7 & $0,2 \%$ & $1,9 \%$ \\
\hline 16 & & & 22 & 16,3 & 16,0 & $9,7 \%$ & $11,3 \%$ \\
\hline 17 & & & 24 & 16,6 & 16,3 & $7,5 \%$ & $9,3 \%$ \\
\hline 18 & & & 26 & 16,6 & 16,2 & $8,0 \%$ & $9,8 \%$ \\
\hline 19 & & & 10 & 18,2 & 17,9 & $1,0 \%$ & $0,5 \%$ \\
\hline 20 & & & 12 & 18,2 & 17,9 & $1,0 \%$ & $0,7 \%$ \\
\hline 21 & & & 14 & 18,1 & 17,7 & $0,4 \%$ & $1,5 \%$ \\
\hline 22 & & & 16 & 18,3 & 18,0 & $1,8 \%$ & $0,2 \%$ \\
\hline 23 & $1,0 \%$ & 3,00 & 18 & 18,3 & 17,9 & $1,5 \%$ & $0,6 \%$ \\
\hline 24 & & & 20 & 18,1 & 17,7 & $0,3 \%$ & $1,9 \%$ \\
\hline 25 & & & 22 & 16,3 & 16,0 & $9,2 \%$ & $11,2 \%$ \\
\hline 26 & & & 24 & 16,7 & 16,3 & $7,3 \%$ & $9,3 \%$ \\
\hline 27 & & & 26 & 16,7 & 16,3 & $7,5 \%$ & $9,5 \%$ \\
\hline 28 & & & 10 & 18,2 & 17,9 & $1,4 \%$ & $0,5 \%$ \\
\hline 29 & & & 12 & 18,3 & 17,9 & $1,4 \%$ & $0,7 \%$ \\
\hline 30 & & & 14 & 18,1 & 17,8 & $0,8 \%$ & $1,4 \%$ \\
\hline 31 & & & 16 & 18,4 & 18,0 & $2,2 \%$ & $0,1 \%$ \\
\hline 32 & $1,4 \%$ & 3,00 & 18 & 18,3 & 17,9 & $1,6 \%$ & $0,7 \%$ \\
\hline 33 & & & 20 & 18,1 & 17,7 & $0,5 \%$ & $1,6 \%$ \\
\hline 34 & & & 22 & 16,4 & 16,0 & $9,0 \%$ & $10,9 \%$ \\
\hline 35 & & & 24 & 16,7 & 16,4 & $7,2 \%$ & $9,0 \%$ \\
\hline 36 & & & 26 & 16,6 & 16,3 & $7,8 \%$ & $9,3 \%$ \\
\hline 37 & & & 10 & 18,3 & 17,9 & $1,6 \%$ & $0,5 \%$ \\
\hline 38 & & & 12 & 18,3 & 17,9 & $1,5 \%$ & $0,7 \%$ \\
\hline 39 & & & 14 & 18,7 & 18,3 & $3,8 \%$ & $1,5 \%$ \\
\hline 40 & & & 16 & 18,4 & 18,0 & $2,0 \%$ & $0,2 \%$ \\
\hline 41 & $1,8 \%$ & 3,00 & 18 & 18,2 & 17,9 & $1,3 \%$ & $0,7 \%$ \\
\hline 42 & & & 20 & 18,0 & 17,7 & $0,0 \%$ & $1,7 \%$ \\
\hline 43 & & & 22 & 16,3 & 16,1 & $9,5 \%$ & $10,7 \%$ \\
\hline 44 & & & 24 & 16,6 & 16,4 & $8,0 \%$ & $8,8 \%$ \\
\hline \multirow[t]{4}{*}{45} & & & 26 & 16,4 & 16,4 & $8,7 \%$ & $8,9 \%$ \\
\hline & & & Mínimo & 16,0 & 15,9 & $0,0 \%$ & $0,1 \%$ \\
\hline & & & Média & 17,6 & 17,3 & $3,5 \%$ & $3,9 \%$ \\
\hline & & & Máximo & 18,7 & 18,3 & $11,0 \%$ & $11,7 \%$ \\
\hline
\end{tabular}


Tabela 3.5 - Comparação entre os módulos de elasticidade calculados com $\mathrm{D}_{\text {eq }}$ para $x^{\prime}{ }_{\text {ótimo }}=0,47$ e o diâmetro medido na metade do comprimento das toras para o ensaio de flexão estática na condição de contorno bi-apoiada.

\begin{tabular}{|c|c|c|c|c|c|c|}
\hline \multirow{2}{*}{$\begin{array}{l}\text { Viga } \\
\mathbf{N}^{\circ}\end{array}$} & \multirow{2}{*}{ C (\%) L (m) } & \multirow{2}{*}{$\mathrm{L} / \mathrm{D}_{\text {meio }}$} & \multicolumn{2}{|c|}{$\mathrm{E}_{\mathrm{M}, \mathrm{Stat}}(\mathrm{GPa})$} & \multicolumn{2}{|c|}{$\exists_{i}(\%)$} \\
\hline & & & $\mathrm{D}_{\mathrm{eq}}$ & $D_{\text {meio }}$ & $D_{e q}$ & $D_{\text {meio }}$ \\
\hline 1 & & 10 & 17,9 & 17,9 & $0,3 \%$ & $0,5 \%$ \\
\hline 2 & & 12 & 17,9 & 17,8 & $0,5 \%$ & $0,8 \%$ \\
\hline 3 & & 14 & 17,8 & 17,7 & $1,4 \%$ & $1,7 \%$ \\
\hline 4 & & 16 & 18,0 & 17,9 & $0,1 \%$ & $0,5 \%$ \\
\hline 5 & $0,2 \% \quad 3,00$ & 18 & 17,9 & 17,8 & $0,4 \%$ & $0,9 \%$ \\
\hline 6 & & 20 & 17,7 & 17,6 & $1,8 \%$ & $2,3 \%$ \\
\hline 7 & & 22 & 17,7 & 17,6 & $1,4 \%$ & $2,0 \%$ \\
\hline 8 & & 24 & 16,8 & 16,7 & $6,7 \%$ & $7,3 \%$ \\
\hline 9 & & 26 & 17,7 & 17,6 & $1,7 \%$ & $2,3 \%$ \\
\hline 10 & & 10 & 18,0 & 17,9 & $0,2 \%$ & $0,6 \%$ \\
\hline 11 & & 12 & 18,0 & 17,8 & $0,0 \%$ & $0,9 \%$ \\
\hline 12 & & 14 & 17,9 & 17,7 & $0,7 \%$ & $1,7 \%$ \\
\hline 13 & & 16 & 18,1 & 17,9 & $0,7 \%$ & $0,5 \%$ \\
\hline 14 & $0,6 \% \quad 3,00$ & 18 & 18,0 & 17,8 & $0,2 \%$ & $1,2 \%$ \\
\hline 15 & & 20 & 17,9 & 17,6 & $0,8 \%$ & $2,3 \%$ \\
\hline 16 & & 22 & 17,9 & 17,6 & $0,5 \%$ & $2,2 \%$ \\
\hline 17 & & 24 & 18,1 & 17,8 & $0,5 \%$ & $1,3 \%$ \\
\hline 18 & & 26 & 17,9 & 17,5 & $0,8 \%$ & $2,8 \%$ \\
\hline 19 & & 10 & 18,1 & 17,9 & $0,4 \%$ & $0,8 \%$ \\
\hline 20 & & 12 & 18,1 & 17,8 & $0,3 \%$ & $1,2 \%$ \\
\hline 21 & & 14 & 17,9 & 17,6 & $0,3 \%$ & $2,1 \%$ \\
\hline 22 & & 16 & 18,2 & 17,8 & $1,1 \%$ & $0,9 \%$ \\
\hline 23 & $1,0 \% \quad 3,00$ & 18 & 18,1 & 17,7 & $0,7 \%$ & $1,5 \%$ \\
\hline 24 & & 20 & 17,9 & 17,5 & $0,4 \%$ & $2,9 \%$ \\
\hline 25 & & 22 & 18,0 & 17,5 & $0,0 \%$ & $2,8 \%$ \\
\hline 26 & & 24 & 18,2 & 17,6 & $0,9 \%$ & $2,2 \%$ \\
\hline 27 & & 26 & 17,9 & 17,3 & $0,5 \%$ & $3,8 \%$ \\
\hline 28 & & 10 & 18,1 & 17,8 & $0,7 \%$ & $1,0 \%$ \\
\hline 29 & & 12 & 18,1 & 17,7 & $0,6 \%$ & $1,4 \%$ \\
\hline 30 & & 14 & 18,0 & 17,6 & $0,0 \%$ & $2,4 \%$ \\
\hline 31 & & 16 & 18,3 & 17,7 & $1,4 \%$ & $1,4 \%$ \\
\hline 32 & $1,4 \% \quad 3,00$ & 18 & 18,2 & 17,6 & $0,9 \%$ & $2,3 \%$ \\
\hline 33 & & 20 & 18,0 & 17,3 & $0,1 \%$ & $3,6 \%$ \\
\hline 34 & & 22 & 18,0 & 17,3 & $0,2 \%$ & $4,0 \%$ \\
\hline 35 & & 24 & 18,1 & 17,4 & $0,7 \%$ & $3,5 \%$ \\
\hline 36 & & 26 & 17,9 & 17,0 & $0,8 \%$ & $5,3 \%$ \\
\hline 37 & & 10 & 18,2 & 17,8 & $0,9 \%$ & $1,3 \%$ \\
\hline 38 & & 12 & 19,0 & 18,5 & $5,3 \%$ & $2,5 \%$ \\
\hline 39 & & 14 & 18,0 & 17,4 & $0,0 \%$ & $3,1 \%$ \\
\hline 40 & & 16 & 18,2 & 17,6 & $1,4 \%$ & $2,2 \%$ \\
\hline 41 & $1,8 \% \quad 3,00$ & 18 & 18,1 & 17,4 & $0,7 \%$ & $3,3 \%$ \\
\hline 42 & & 20 & 17,9 & 17,1 & $0,4 \%$ & $4,9 \%$ \\
\hline 43 & & 22 & 17,9 & 17,0 & $0,6 \%$ & $5,5 \%$ \\
\hline 44 & & 24 & 18,0 & 17,0 & $0,1 \%$ & $5,3 \%$ \\
\hline \multirow[t]{4}{*}{45} & & 26 & 17,7 & 16,7 & $1,7 \%$ & $7,4 \%$ \\
\hline & & Mínimo & 16,8 & 16,7 & $0,0 \%$ & $0,5 \%$ \\
\hline & & Média & 18,0 & 17,6 & $0,9 \%$ & $2,5 \%$ \\
\hline & & Máximo & 19,0 & 18,5 & $6,7 \%$ & $7,4 \%$ \\
\hline
\end{tabular}




\subsubsection{Conclusões}

Para o ensaio de vibração transversal com as toras em suspensão livre-livre, o módulo de elasticidade deve ser calculado com o diâmetro medido na metade do comprimento.

No ensaio de flexão estática com a base da tora engastada o cálculo do módulo de elasticidade pode ser feito empregando-se o diâmetro adotado pelas normas NBR 6231 (ABNT, 1980) e ASTM D 1036 (ASTM, 2005) ou, para uma maior acurácia, o diâmetro medido a $0,70 \mathrm{~L}$ a partir da extremidade mais delgada da tora.

No ensaio de flexão estática com a tora simplesmente apoiada, o módulo de elasticidade apresentará menor erro quanto calculado com o diâmetro medido a 0,47 L a partir da extremidade mais delgada. Entretanto, por uma questão de simplicidade, recomenda-se calcular o módulo de elasticidade com o diâmetro médio, pois os erros obtidos no cálculo do módulo de elasticidade para esse diâmetro são na maioria das observações inferiores a 5\%, além desse procedimento ser a favor da segurança.

\subsection{Estudo da influência do esforço cortante no módulo de elasticidade dinâmico}

Foi realizado um estudo teórico, por meio de simulações numéricas com as vigas modeladas no item 3.1, para avaliar o erro de estimativa do módulo de elasticidade dinâmico das toras ao desprezar o efeito do esforço cortante.

Com exceção do $\mathrm{G}$, cujo valor foi alterado de forma a obter quatro grupos de vigas com relações E/G iguais a 16, 18, 20 e 22, os demais dados das vigas modeladas no item 3.1 não foram alterados.

Utilizando o programa Abaqus 6.3 foi realizada a análise modal teórica das vigas por meio de elementos finitos. Com o valor da frequência do primeiro modo de flexão, o módulo de elasticidade dinâmico aparente ( $\left.\mathrm{E}_{\mathrm{M}, \mathrm{VT}, \mathrm{ap}}\right)$ foi calculado conforme Equação 3.8.

$$
E_{M, V T, a p}=\frac{1,607 * f^{2} * M * L^{3}}{D_{\text {meio }} 4}
$$

Sendo:

$E_{M, V T, a p}=$ módulo de elasticidade aparente $(\mathrm{Pa})$;

$f=$ frequência do primeiro modo de flexão $(\mathrm{Hz})$;

$M=$ massa da viga $(\mathrm{kg})$; 


$$
\begin{aligned}
& L=\text { comprimento }(\mathrm{m}) ; \\
& D_{\text {meio }}=\text { diâmetro na metade do comprimento da tora. }
\end{aligned}
$$

Foi calculado o erro de estimativa no módulo de elasticidade empregando a Equação 3.2.

\subsubsection{Resultados}

As Tabelas 3.6 e 3.7 mostram o resultado do cálculo do erro de estimativa no módulo de elasticidade dinâmico para diferentes valores de conicidade e das relações $E / G$ e L/Dmeio.

Tabela 3.6 - Cálculo do erro no módulo de elasticidade dinâmico para relações E/G iguais a

\begin{tabular}{|c|c|c|c|c|c|c|c|c|c|c|}
\hline \multirow{2}{*}{ Viga $\mathbf{N}^{\circ}$} & \multirow{2}{*}{$\begin{array}{c}\text { C } \\
(\%)\end{array}$} & \multirow{2}{*}{$\begin{array}{c}\mathrm{L} \\
(\mathrm{m})\end{array}$} & \multirow{2}{*}{$L / D_{\text {meio }}$} & \multirow{2}{*}{$\begin{array}{c}\text { Massa } \\
(\mathbf{k g})\end{array}$} & \multicolumn{3}{|c|}{$E / G=16$} & \multicolumn{3}{|c|}{$E / G=18$} \\
\hline & & & & & $f(\mathrm{~Hz})$ & $E_{M, V T}$ & $\exists_{i}$ & $f(\mathrm{~Hz})$ & $E_{M, V T}$ & $\exists_{\mathrm{i}}$ \\
\hline 1 & & & 10 & 169,65 & 130,10 & 17,91 & $14,6 \%$ & 129,03 & 17,87 & $16,0 \%$ \\
\hline 2 & & & 12 & 117,82 & 110,85 & 17,92 & $10,7 \%$ & 110,11 & 17,87 & $11,9 \%$ \\
\hline 3 & & & 14 & 86,56 & 96,24 & 17,89 & $8,4 \%$ & 95,65 & 17,81 & $9,5 \%$ \\
\hline 4 & & & 16 & 66,27 & 85,10 & 17,94 & $6,4 \%$ & 84,81 & 17,93 & $7,1 \%$ \\
\hline 5 & $0,2 \%$ & 3,00 & 18 & 52,37 & 76,27 & 18,01 & $4,8 \%$ & 75,84 & 17,89 & $5,9 \%$ \\
\hline 6 & & & 20 & 42,42 & 68,82 & 17,93 & $4,4 \%$ & 68,39 & 17,78 & $5,6 \%$ \\
\hline 7 & & & 22 & 35,06 & 62,61 & 17,83 & $4,2 \%$ & 62,50 & 17,83 & $4,6 \%$ \\
\hline 8 & & & 24 & 29,46 & 57,68 & 17,92 & $3,3 \%$ & 57,59 & 17,91 & $3,6 \%$ \\
\hline 9 & & & 26 & 25,10 & 53,17 & 17,80 & $3,5 \%$ & 53,10 & 17,79 & $3,8 \%$ \\
\hline 10 & & & 10 & 169,70 & 130,11 & 17,92 & $14,5 \%$ & 129,05 & 17,88 & $15,9 \%$ \\
\hline 11 & & & 12 & 117,86 & 110,86 & 17,94 & $10,6 \%$ & 110,14 & 17,89 & $11,8 \%$ \\
\hline 12 & & & 14 & 86,60 & 96,27 & 17,91 & $8,3 \%$ & 95,69 & 17,84 & $9,3 \%$ \\
\hline 13 & & & 16 & 66,32 & 85,12 & 17,96 & $6,3 \%$ & 84,86 & 17,96 & $6,9 \%$ \\
\hline 14 & $0,6 \%$ & 3,00 & 18 & 52,41 & 76,30 & 18,04 & $4,7 \%$ & 75,87 & 17,92 & $5,8 \%$ \\
\hline 15 & & & 20 & 42,46 & 68,86 & 17,97 & $4,1 \%$ & 68,47 & 17,84 & $5,2 \%$ \\
\hline 16 & & & 22 & 35,10 & 62,65 & 17,88 & $4,0 \%$ & 62,54 & 17,88 & $4,3 \%$ \\
\hline 17 & & & 24 & 29,50 & 57,72 & 17,97 & $3,0 \%$ & 57,64 & 17,97 & $3,2 \%$ \\
\hline 18 & & & 26 & 25,15 & 53,22 & 17,86 & $3,2 \%$ & 53,15 & 17,86 & $3,4 \%$ \\
\hline 19 & & & 10 & 169,79 & 130,15 & 17,94 & $14,4 \%$ & 129,08 & 17,90 & $15,8 \%$ \\
\hline 20 & & & 12 & 117,95 & 110,90 & 17,96 & $10,5 \%$ & 110,17 & 17,91 & $11,7 \%$ \\
\hline 21 & & & 14 & 86,70 & 96,31 & 17,94 & $8,1 \%$ & 95,76 & 17,88 & $9,1 \%$ \\
\hline 22 & & & 16 & 66,41 & 85,17 & 18,01 & $6,1 \%$ & 84,91 & 18,01 & $6,6 \%$ \\
\hline 23 & $1,0 \%$ & 3,00 & 18 & 52,50 & 76,36 & 18,10 & $4,4 \%$ & 75,96 & 17,99 & $5,4 \%$ \\
\hline 24 & & & 20 & 42,55 & 68,92 & 18,04 & $3,8 \%$ & 68,53 & 17,91 & $4,9 \%$ \\
\hline 25 & & & 22 & 35,19 & 62,72 & 17,97 & $3,5 \%$ & 62,61 & 17,97 & $3,8 \%$ \\
\hline 26 & & & 24 & 29,59 & 57,80 & 18,08 & $2,4 \%$ & 57,72 & 18,08 & $2,7 \%$ \\
\hline 27 & & & 26 & 25,24 & 53,31 & 17,99 & $2,5 \%$ & 53,24 & 17,98 & $2,7 \%$ \\
\hline 28 & & & 10 & 169,92 & 130,17 & 17,96 & $14,3 \%$ & 129,11 & 17,92 & $15,7 \%$ \\
\hline 29 & & & 12 & 118,09 & 110,94 & 18,00 & $10,3 \%$ & 110,23 & 17,95 & $11,5 \%$ \\
\hline 30 & & & 14 & 86,83 & 96,36 & 17,99 & $7,8 \%$ & 95,81 & 17,93 & $8,9 \%$ \\
\hline 31 & & & 16 & 66,55 & 85,24 & 18,07 & $5,7 \%$ & 85,00 & 18,08 & $6,2 \%$ \\
\hline 32 & $1,4 \%$ & 3,00 & 18 & 52,64 & 76,44 & 18,18 & $3,9 \%$ & 76,03 & 18,08 & $5,0 \%$ \\
\hline 33 & & & 20 & 42,69 & 69,02 & 18,15 & $3,2 \%$ & 68,66 & 18,04 & $4,2 \%$ \\
\hline 34 & & & 22 & 35,33 & 62,83 & 18,10 & $2,8 \%$ & 62,72 & 18,10 & $3,1 \%$ \\
\hline 35 & & & 24 & 29,73 & 57,92 & 18,24 & $1,5 \%$ & 57,84 & 18,23 & $1,8 \%$ \\
\hline 36 & & & 26 & 25,37 & 53,44 & 18,17 & $1,5 \%$ & 53,37 & 18,17 & $1,7 \%$ \\
\hline 37 & & & 10 & 170,10 & 130,24 & 18,00 & $14,1 \%$ & 129,16 & 17,96 & $15,6 \%$ \\
\hline 38 & & & 12 & 118,27 & 111,01 & 18,04 & $10,1 \%$ & 110,29 & 18,00 & $11,2 \%$ \\
\hline 39 & & & 14 & 87,01 & 96,44 & 18,06 & $7,5 \%$ & 95,82 & 17,97 & $8,7 \%$ \\
\hline 40 & & & 16 & 66,73 & 85,34 & 18,16 & $5,2 \%$ & 85,09 & 18,17 & $5,8 \%$ \\
\hline 41 & $1,8 \%$ & 3,00 & 18 & 52,82 & 76,55 & 18,29 & $3,3 \%$ & 76,14 & 18,19 & $4,4 \%$ \\
\hline 42 & & & 20 & 42,87 & 69,15 & 18,30 & $2,4 \%$ & 68,78 & 18,18 & $3,5 \%$ \\
\hline 43 & & & 22 & 35,51 & 62,97 & 18,28 & $1,8 \%$ & 62,86 & 18,27 & $2,2 \%$ \\
\hline 44 & & & 24 & 29,91 & 58,09 & 18,45 & $0,4 \%$ & 58,00 & 18,45 & $0,7 \%$ \\
\hline 45 & & & 26 & 25,55 & 53,62 & 18,43 & $0,1 \%$ & 53,55 & 18,42 & $0,4 \%$ \\
\hline
\end{tabular}
16 e 18. 
Tabela 3.7 - Cálculo do erro no módulo de elasticidade dinâmico para relações E/G iguais a 20 e 22.

\begin{tabular}{|c|c|c|c|c|c|c|c|c|c|c|}
\hline \multirow{2}{*}{ Viga $\mathbf{N}^{\circ}$} & \multirow{2}{*}{$\begin{array}{c}\text { C } \\
(\%)\end{array}$} & \multirow{2}{*}{$\begin{array}{l}\mathrm{L} \\
(\mathrm{m})\end{array}$} & \multirow{2}{*}{$L / D_{\text {meio }}$} & \multirow{2}{*}{$\begin{array}{c}\text { Massa } \\
(\mathrm{kg})\end{array}$} & \multicolumn{3}{|c|}{$E / G=20$} & \multicolumn{3}{|c|}{$E / G=22$} \\
\hline & & & & & $f(\mathrm{~Hz})$ & $E_{M, V T}$ & $\exists_{\mathrm{i}}$ & $f(\mathrm{~Hz})$ & $E_{M, V T}$ & $\exists_{\mathrm{i}}$ \\
\hline 1 & & & 10 & 169,65 & 128,09 & 17,86 & $17,2 \%$ & 127,17 & 17,86 & $18,4 \%$ \\
\hline 2 & & & 12 & 117,82 & 109,52 & 17,86 & $12,8 \%$ & 108,94 & 17,86 & $13,7 \%$ \\
\hline 3 & & & 14 & 86,56 & 95,26 & 17,81 & $10,2 \%$ & 94,88 & 17,80 & $10,9 \%$ \\
\hline 4 & & & 16 & 66,27 & 84,54 & 17,92 & $7,6 \%$ & 84,27 & 17,92 & $8,2 \%$ \\
\hline 5 & $0,2 \%$ & 3,00 & 18 & 52,37 & 75,65 & 17,89 & $6,4 \%$ & 75,46 & 17,89 & $6,9 \%$ \\
\hline 6 & & & 20 & 42,42 & 68,25 & 17,78 & $6,0 \%$ & 68,10 & 17,78 & $6,3 \%$ \\
\hline 7 & & & 22 & 35,06 & 62,39 & 17,83 & $4,9 \%$ & 62,28 & 17,83 & $5,2 \%$ \\
\hline 8 & & & 24 & 29,46 & 57,51 & 17,91 & $3,8 \%$ & 57,42 & 17,91 & $4,1 \%$ \\
\hline 9 & & & 26 & 25,10 & 53,04 & 17,79 & $4,0 \%$ & 52,97 & 17,79 & $4,2 \%$ \\
\hline 10 & & & 10 & 169,70 & 128,12 & 17,88 & $17,1 \%$ & 127,20 & 17,87 & $18,3 \%$ \\
\hline 11 & & & 12 & 117,86 & 109,55 & 17,88 & $12,7 \%$ & 108,97 & 17,87 & $13,7 \%$ \\
\hline 12 & & & 14 & 86,60 & 95,31 & 17,83 & $10,1 \%$ & 94,92 & 17,83 & $10,8 \%$ \\
\hline 13 & & & 16 & 66,32 & 84,59 & 17,96 & $7,5 \%$ & 84,32 & 17,95 & $8,1 \%$ \\
\hline 14 & $0,6 \%$ & 3,00 & 18 & 52,41 & 75,67 & 17,92 & $6,3 \%$ & 75,48 & 17,91 & $6,7 \%$ \\
\hline 15 & & & 20 & 42,46 & 68,33 & 17,84 & $5,6 \%$ & 68,19 & 17,84 & $6,0 \%$ \\
\hline 16 & & & 22 & 35,10 & 62,43 & 17,88 & $4,6 \%$ & 62,32 & 17,87 & $5,0 \%$ \\
\hline 17 & & & 24 & 29,50 & 57,55 & 17,97 & $3,5 \%$ & 57,46 & 17,97 & $3,8 \%$ \\
\hline 18 & & & 26 & 25,15 & 53,08 & 17,86 & $3,7 \%$ & 53,02 & 17,86 & $3,9 \%$ \\
\hline 19 & & & 10 & 169,79 & 128,14 & 17,89 & $17,0 \%$ & 127,21 & 17,88 & $18,2 \%$ \\
\hline 20 & & & 12 & 117,95 & 109,58 & 17,90 & $12,6 \%$ & 109,00 & 17,90 & $13,5 \%$ \\
\hline 21 & & & 14 & 86,70 & 95,34 & 17,87 & $9,9 \%$ & 94,96 & 17,86 & $10,6 \%$ \\
\hline 22 & & & 16 & 66,41 & 84,63 & 18,00 & $7,2 \%$ & 84,36 & 18,00 & $7,8 \%$ \\
\hline 23 & $1,0 \%$ & 3,00 & 18 & 52,50 & 75,76 & 17,99 & $5,9 \%$ & 75,57 & 17,99 & $6,4 \%$ \\
\hline 24 & & & 20 & 42,55 & 68,38 & 17,91 & $5,3 \%$ & 68,24 & 17,91 & $5,7 \%$ \\
\hline 25 & & & 22 & 35,19 & 62,50 & 17,96 & $4,2 \%$ & 62,39 & 17,96 & $4,5 \%$ \\
\hline 26 & & & 24 & 29,59 & 57,63 & 18,07 & $3,0 \%$ & 57,54 & 18,07 & $3,3 \%$ \\
\hline 27 & & & 26 & 25,24 & 53,17 & 17,98 & $3,0 \%$ & 53,11 & 17,98 & $3,2 \%$ \\
\hline 28 & & & 10 & 169,92 & 128,17 & 17,92 & $16,9 \%$ & 127,24 & 17,90 & $18,1 \%$ \\
\hline 29 & & & 12 & 118,09 & 109,64 & 17,94 & $12,4 \%$ & 109,05 & 17,94 & $13,4 \%$ \\
\hline 30 & & & 14 & 86,83 & 95,42 & 17,92 & $9,6 \%$ & 95,03 & 17,92 & $10,4 \%$ \\
\hline 31 & & & 16 & 66,55 & 84,73 & 18,08 & $6,8 \%$ & 84,46 & 18,07 & $7,4 \%$ \\
\hline 32 & $1,4 \%$ & 3,00 & 18 & 52,64 & 75,84 & 18,07 & $5,4 \%$ & 75,64 & 18,07 & $5,9 \%$ \\
\hline 33 & & & 20 & 42,69 & 68,52 & 18,03 & $4,6 \%$ & 68,37 & 18,03 & $5,0 \%$ \\
\hline 34 & & & 22 & 35,33 & 62,61 & 18,09 & $3,5 \%$ & 62,50 & 18,09 & $3,8 \%$ \\
\hline 35 & & & 24 & 29,73 & 57,75 & 18,23 & $2,1 \%$ & 57,66 & 18,23 & $2,4 \%$ \\
\hline 36 & & & 26 & 25 & -0 & & $2,0 \%$ & 53,24 & 18,17 & $2,2 \%$ \\
\hline 37 & & & 10 & 170,10 & 128,22 & 17,95 & $16,8 \%$ & 127,30 & 17,94 & $18,0 \%$ \\
\hline 38 & & & 12 & 118,27 & 109,70 & 17,99 & $12,2 \%$ & 109,11 & 17,98 & $13,1 \%$ \\
\hline 39 & & & 14 & 87,01 & 95,49 & 17,99 & $9,3 \%$ & 95,10 & 17,98 & $10,0 \%$ \\
\hline 40 & & & 16 & 66,73 & 84,82 & 18,16 & $6,4 \%$ & 84,54 & 18,16 & $7,0 \%$ \\
\hline 41 & $1,8 \%$ & 3,00 & 18 & 52,82 & 75,94 & 18,19 & $4,9 \%$ & 75,75 & 18,18 & $5,3 \%$ \\
\hline 42 & & & 20 & 42,87 & 68,64 & 18,17 & $3,9 \%$ & 68,49 & 18,17 & $4,3 \%$ \\
\hline 43 & & & 22 & 35,51 & 62,75 & 18,27 & $2,5 \%$ & 62,64 & 18,27 & $2,9 \%$ \\
\hline 44 & & & 24 & 29,9 & 57,91 & 18,45 & $1,0 \%$ & 57,82 & 18,44 & $1,3 \%$ \\
\hline 45 & & & 26 & 25,55 & 53,48 & 18,42 & $0,6 \%$ & 53,41 & 18,42 & $0,9 \%$ \\
\hline
\end{tabular}

As Figuras 3.2 a 3.5 mostram, para cada grupo de vigas, a variação do erro na estimativa do módulo de elasticidade dinâmico em função da relação $L / \mathrm{D}_{\text {meio }} \mathrm{e}$ da conicidade das toras. 


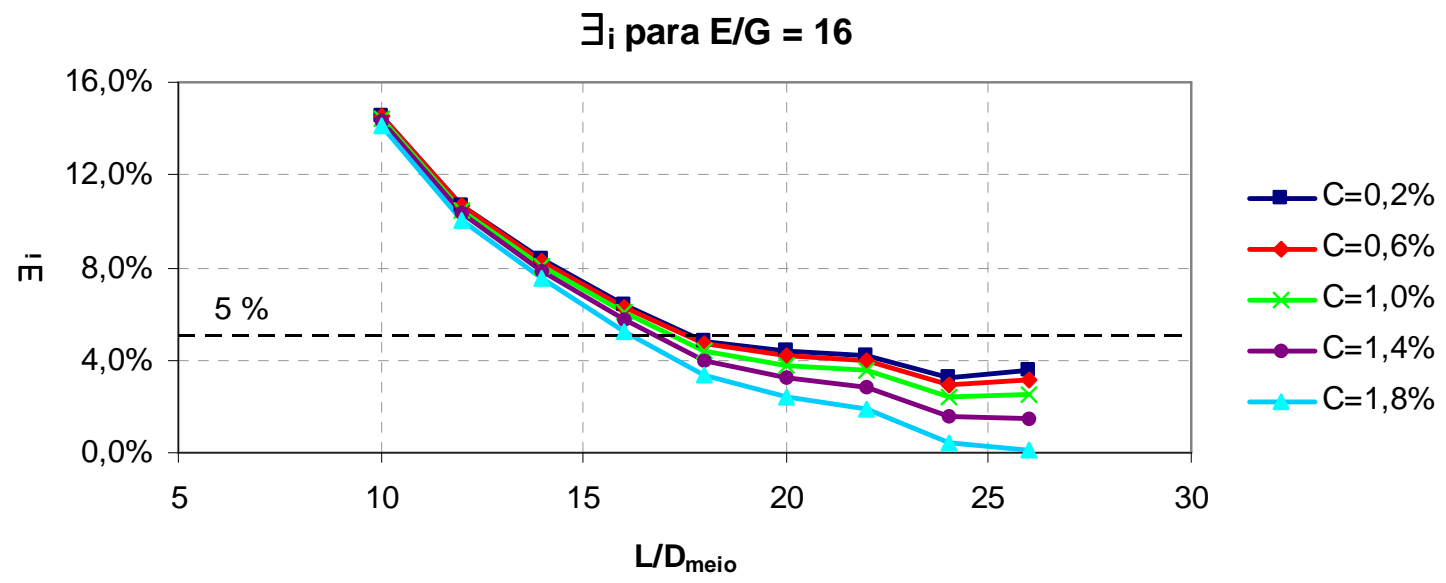

Figura 3.2 - Erro na estimativa do módulo de elasticidade para $\mathrm{E} / \mathrm{G}=16$.

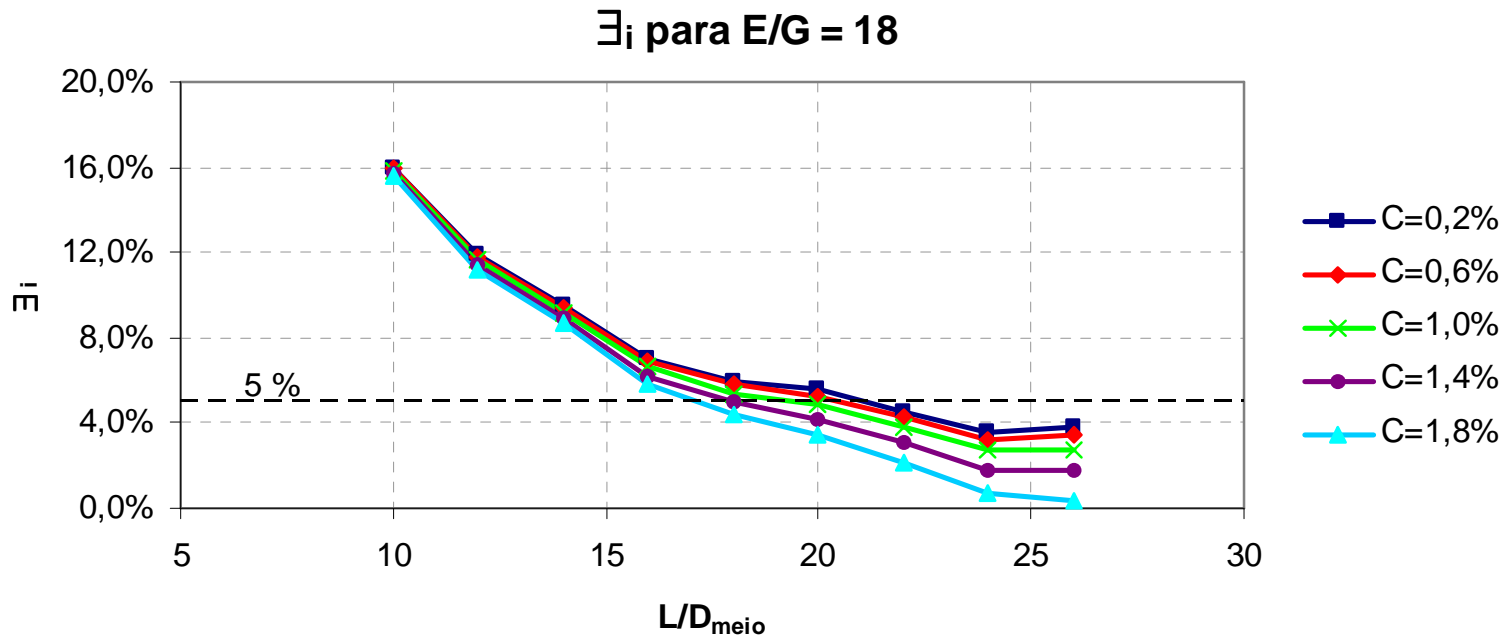

Figura 3.3 - Erro na estimativa do módulo de elasticidade para E/G = 18 .

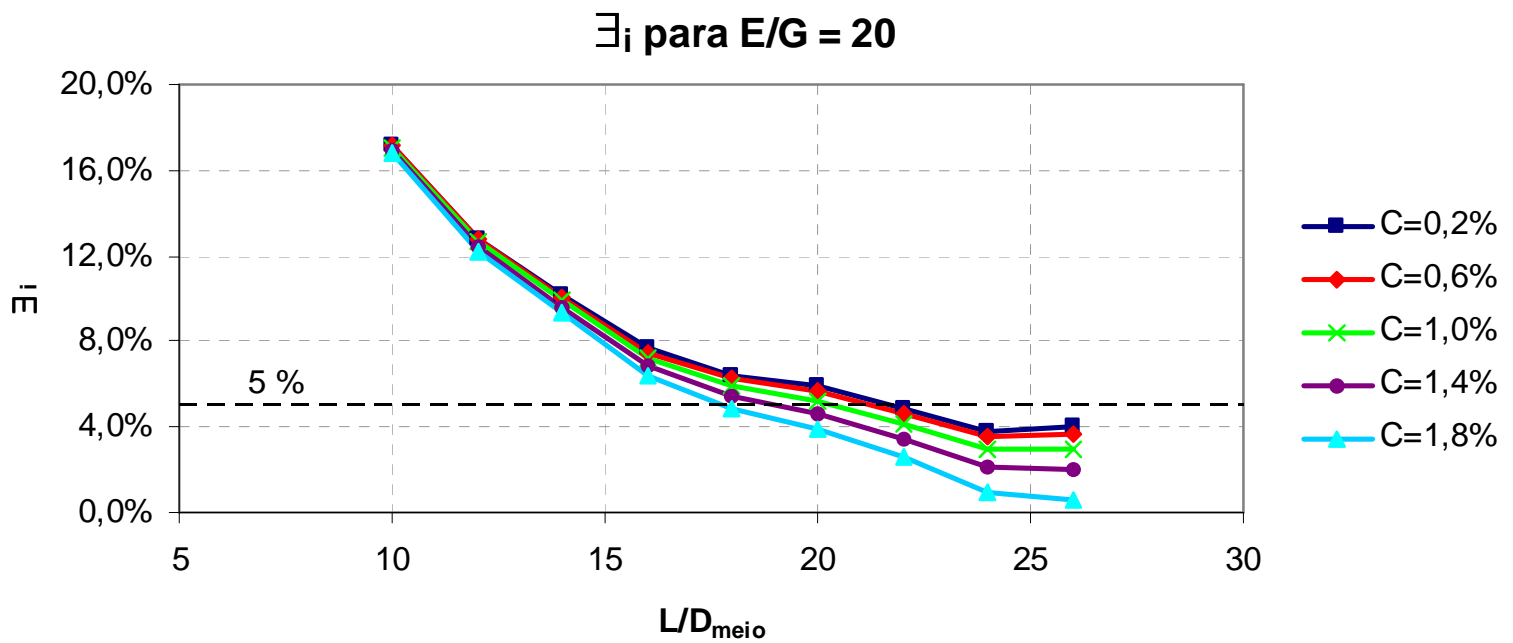

Figura 3.4 - Erro na estimativa do módulo de elasticidade para $\mathrm{E} / \mathrm{G}=20$. 


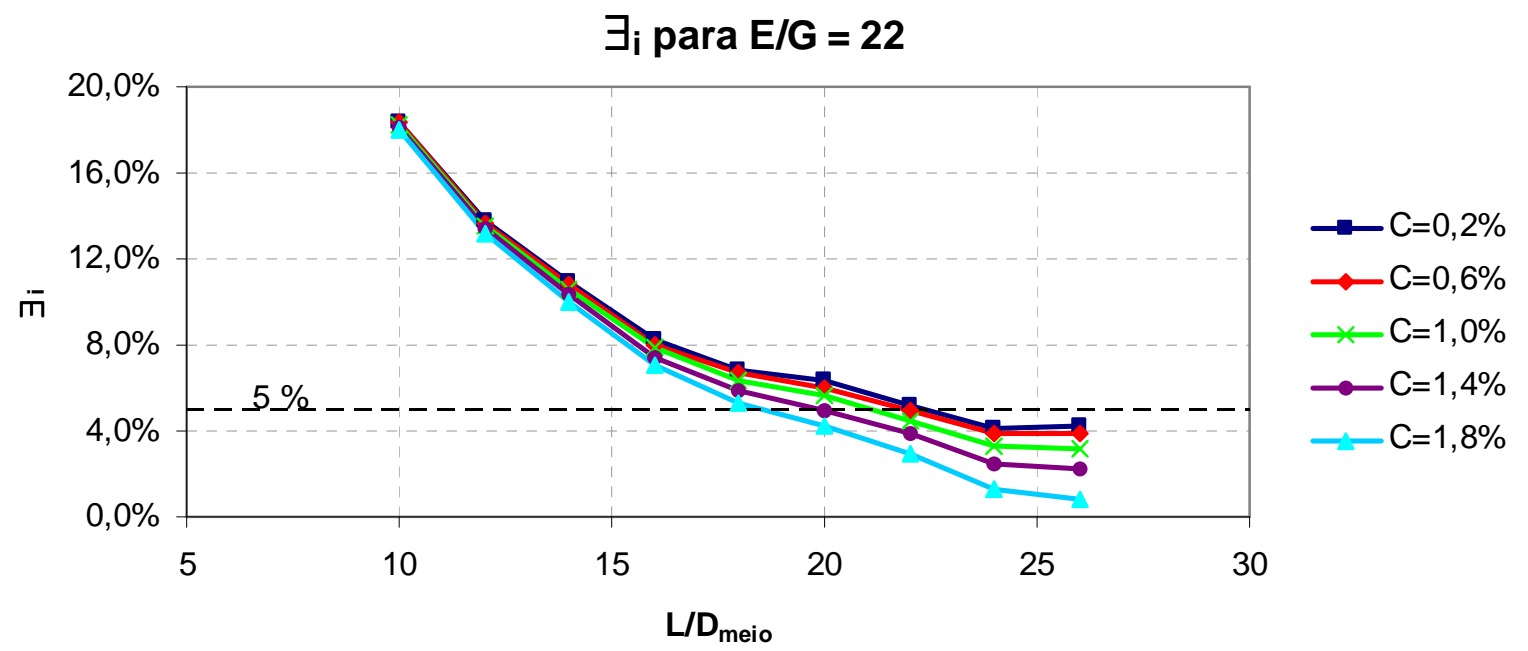

Figura 3.5 - Erro na estimativa do módulo de elasticidade para $E / G=22$.

\subsubsection{Análise dos Resultados}

Observa-se que o erro na determinação do módulo de elasticidade varia inversamente com a relação $\mathrm{L} / \mathrm{D}_{\text {meio }}$ e diretamente com a relação $\mathrm{E} / \mathrm{G}$.

Verifica-se também que o aumento na conicidade leva a uma pequena elevação na massa e na frequência das toras resultando em maiores valores para o módulo de elasticidade dinâmico.

Para as relações $\mathrm{L} / \mathrm{D}_{\text {meio }}$ de 10 a 26 , o erro na estimativa do módulo de elasticidade pode variar de $18,4 \%$ a $0,1 \%$ respectivamente.

Admitindo-se como insignificantes erros iguais ou inferiores a 5\% e considerando uma interpolação linear entre os pontos mostrados nas Figuras 3.2 a 3.5, para a conicidade de 0,2\% (situação mais crítica), pode-se definir os limites de $\mathrm{L} / \mathrm{D}_{\text {meio }}$ indicados na Tabela 3.8 .

Tabela 3.8 - Limites de $\mathrm{L} / \mathrm{D}_{\text {meio }}$ para os quais o esforço cortante pode ser ignorado.

\begin{tabular}{cc}
\hline $\mathbf{E} / \mathbf{G}$ & $\mathbf{L} / \mathbf{D}_{\text {meio }}$ (Limite) \\
\hline 16 & 17,8 \\
18 & 21,2 \\
20 & 21,8 \\
22 & 22,4 \\
\hline
\end{tabular}


Para $E / G=20$, conforme recomendação da norma NBR 7190 (ABNT, 1997), verificase que o o limite da relação $\mathrm{L} / \mathrm{D}_{\text {meio }}$, para a qual o esforço cortante pode ser desprezado no cálculo do módulo de elasticidade dinâmico, é igual a 21,8. Como o valor encontrado é muito próximo do limite de L/h (21) para o qual o esforço cortante pode ser desprezado em vigas de seção retangular sugere-se que seja utilizado também 21 para o caso de toras.

\subsubsection{Conclusão}

O esforço cortante pode ser desprezado no cálculo do módulo de elasticidade dinâmico pelo ensaio de vibração transversal para valores de $L / \mathrm{D}_{\text {meio }}$ iguais ou maiores do que 21 . 


\section{ENSAIOS COM AS TORAS DA AMOSTRA PILOTO}

Neste capítulo da tese foram realizados ensaios preliminares em uma amostra piloto com os seguintes objetivos: testar o método de ensaio de vibração transversal pré-definido a partir da revisão de literatura; avaliar a influência da direção da excitação nos resultados do ensaio; verificar a necessidade de excitar as toras em vários planos e em diferentes pontos ao longo do comprimento; comparar os valores do módulo de elasticidade na flexão medidos nos ensaios de vibração transversal e flexão estática e verificar a correlação entre a rigidez à flexão e as propriedades físicas e dimensionais das toras.

\subsection{Materiais}

A amostra piloto continha 10 toras de Eucalyptus citriodora com comprimento médio de 4,5 m e diâmetro na metade do comprimento da ordem de $16 \mathrm{~cm}$. Essas toras foram adquiridas em uma indústria de postes da cidade de São Carlos, estado de São Paulo, e eram provenientes do estado do Mato Grosso do Sul.

\subsection{Métodos}

\subsubsection{Propriedades dimensionais e de densidade aparente}

Nos ensaios de vibração transversal e flexão estática as toras foram fletidas em quatro planos. Para auxiliar a orientação das toras durante a execução dos ensaios, foram desenhadas, nas extremidades das mesmas, 8 linhas radiais de referência com ângulos de $45^{\circ}$ entre si tomando a posição da medula como a interseção dessas linhas (Figura 4.1). 


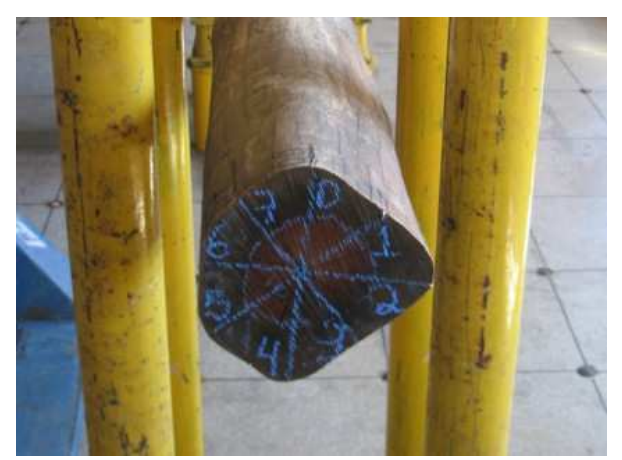

Figura 4.1 - Linhas radiais na base das toras.

As linhas radiais mostradas na Figura 4.1 foram transferidas para a superfície das toras de forma semelhante à geratriz de um cone.

Após a marcação foi feita a medição do comprimento das circunferências em 11 seções ao longo do comprimento da tora, sendo essas seções distanciadas entre si de $0,1 \mathrm{~L}$ (L é o comprimento) a partir da base da tora. Foi medido ainda o máximo encurvamento e a massa das toras. Para a medição do comprimento foi empregada uma trena metálica com resolução de $1 \mathrm{~mm}$ e para a medição das circunferências foi empregada uma fita métrica de fibra de vidro com resolução de $1 \mathrm{~mm}$.

Para a determinação da densidade aparente, a massa das toras foi medida com uma balança digital Toledo modelo 2098, com resolução de 50 g, e o volume foi calculado considerando-as como sólido tronco-cônico (Equação 4.1).

$$
\text { Vol }=\frac{\pi L}{12}\left(D_{\text {topo }}^{2}+D_{\text {topo }} D_{\text {base }}+D_{\text {base }}^{2}\right)
$$

Sendo:

$V o l=$ volume de madeira da tora;

$D_{\text {base }}=$ diâmetro da base;

$D_{\text {topo }}=$ diâmetro no topo;

$L=$ comprimento da tora.

O encurvamento máximo da tora, como mostra a figura 4.2, foi medido com o auxílio de uma linha de nylon usando trena metálica com resolução de $1 \mathrm{~mm}$.

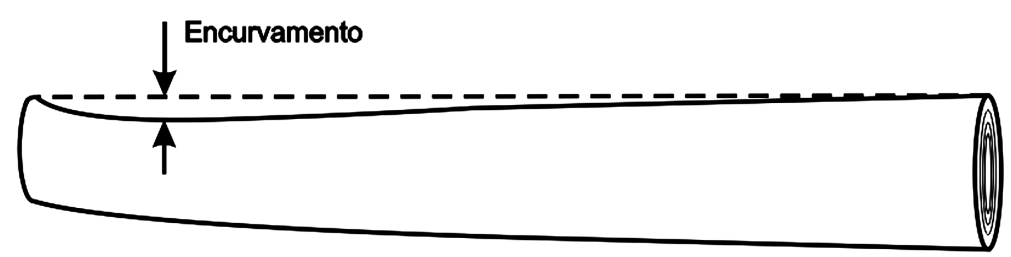

Figura 4.2 - Esquema de medição do encurvamento. 
Para relacionar as possíveis divergências entre os módulos de elasticidade obtidos a partir dos ensaios estático e dinâmico com as variações nas dimensões das toras, foram definidos alguns indicadores para expressar propriedades dimensionais das mesmas. Esses indicadores são listados a seguir:

a) Desvio da forma da seção transversal das extremidades em relação à geometria $\operatorname{circular}\left(\Delta_{\text {circ }}\right)$

Esse indicador expressa o quanto a geometria da seção transversal das extremidades difere do circulo e foi calculado por meio da Equação 4.2:

$$
\Delta_{\text {circ }}(\%)=\frac{\left|\left(\frac{C}{D_{m}}\right)-\pi\right|}{\pi} * 100 \quad \text { com } \quad D_{m}=\sqrt[4]{D_{04} * D_{15} * D_{26} * D_{37}}
$$

Sendo:

$$
\begin{aligned}
& \Delta_{\text {circ }}=\text { Índice de desvio da seção circular } \\
& C=\text { perímetro da tora na extremidade em que } \Delta_{\text {circ }} \text { é calculado; } \\
& D_{m}=\text { média dos diâmetros na extremidade da tora; } \\
& D_{i j}=\text { diâmetro medido na linha diametral i-j. }
\end{aligned}
$$

\section{b) Coeficiente de variação do perímetro $(\Delta D)$}

O coeficiente de variação dos perímetros medidos nas doze seções transversais das toras pode ser empregado como uma forma de representar a regularidade do diâmetro ao longo do comprimento da tora, admitindo a seção como circular, foi calculado de acordo com a Equação 4.3.

$$
\Delta D=\frac{\text { desv.pad }\left(C_{0}, C_{1}, \cdots, C_{11}\right)}{\text { média }\left(C_{0}, C_{1}, \cdots, C_{11}\right)}
$$

Sendo:

$$
\begin{aligned}
& \Delta D=\text { coeficiente de variação do perímetro; } \\
& C_{i}=\text { perímetro da tora na seção i assumindo-o como circular. }
\end{aligned}
$$

\subsubsection{Ensaio de vibração transversal}

Nos ensaios dinâmicos foi empregada a suspensão livre-livre, pois essa condição de contorno é a mais fácil de ser efetivamente alcançada em vigas de elevada rigidez, conforme se observou no item 2.3 . 
Essa condição de apoio pode ser alcançada com o arranjo mostrado na Figura 4.3, no caso de excitação no plano vertical, posicionando os apoios (com baixa rigidez axial) nos pontos nodais do primeiro modo de vibração por flexão.

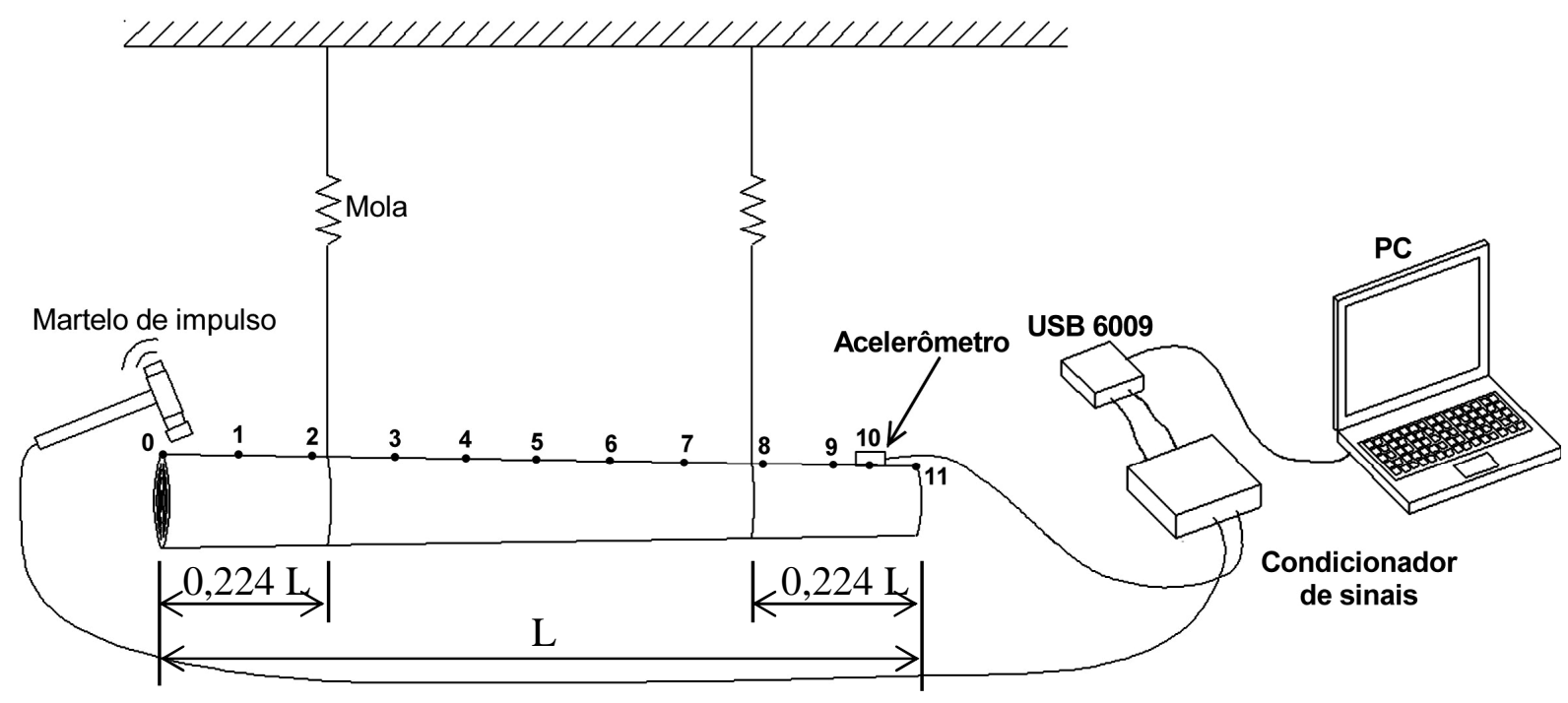

Figura 4.3 - Esquema do ensaio dinâmico.

É importante ressaltar que melhores resultados devem ser obtidos para a excitação no plano horizontal, para o qual se reduz a influência dos apoios, que foi a condição preferencial neste trabalho.

Os pontos numerados de 1 a 11 na Figura 4.3 referem-se às seções transversais nas quais a circunferência das toras foi medida. À exceção do ponto 10 que está distante do ponto 9 de $0,05 \mathrm{~L}$, todos os demais pontos estão distanciados entre si de $0,1 \mathrm{~L}$ (sendo L o comprimento da tora).

As toras foram suspensas por cordas de Nylon com 1/4" $(6,3 \mathrm{~mm})$ de diâmetro presas à molas de baixa rigidez as quais foram fixadas a um pórtico metálico como mostra a Figura 4.4. As cordas foram posicionadas nos pontos nodais do primeiro modo de flexão (ver Tabela 2.15) considerando-se a tora como uma viga prismática em suspensão livre-livre. 


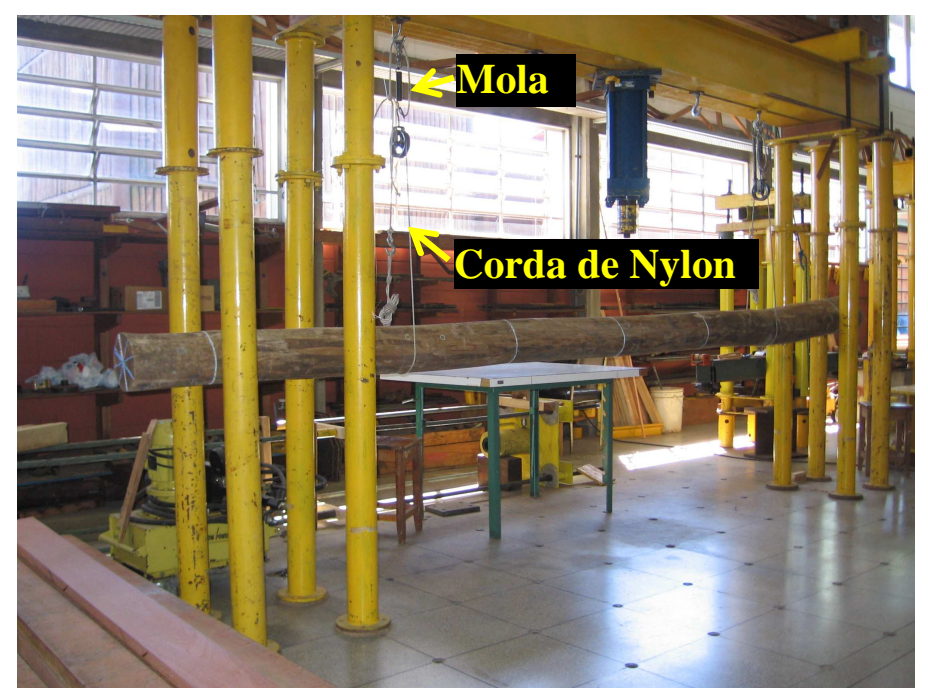

Figura 4.4 - Suspensão das toras com cordas de Nylon.

O acelerômetro foi fixado com parafusos a uma distância de 0,05 L medida a partir da extremidade mais delgada (ponto 10 na Figura 4.3). A Figura 4.5 mostra o acelerômetro fixado em uma das toras, no caso da excitação feita no plano horizontal.

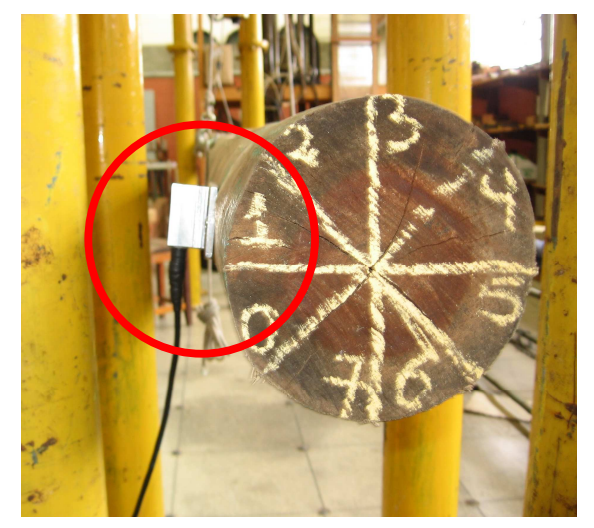

Figura 4.5 - Acelerômetro fixado em uma das toras.

No desenvolvimento do ensaio, o acelerômetro permaneceu fixo no ponto 10 e foram desferidos impactos com o martelo de impulso nos pontos $0,1,3,5,7,9$ e 11 para a medição das FRF's.

Todas as toras foram excitadas com impacto desferido na direção horizontal, ou seja, perpendicularmente ao sistema de suspensão.

Após a excitação da extremidade mais delgada (ponto 11) no plano 0-4, as toras foram rotacionadas em $45^{\circ}$ em torno de seu eixo longitudinal e o ensaio foi então realizado excitando-se a tora no plano 1-5 conforme linhas radias mostradas na Figura $4.1 \mathrm{e}$ assim sucessivamente até a tora completar uma volta em torno de seu eixo longitudinal. 
Os ensaios dinâmicos nas toras 1 a 4 foram repetidos com excitação e medição da aceleração na direção vertical com a finalidade de avaliar o efeito da direção da medição da FRF em relação ao sistema de suspensão.

Em todos os ensaios, para garantir que a força de excitação fosse aplicada sempre no mesmo ponto, foi fixado um pino no ponto de aplicação do impacto. $\mathrm{O}$ pino de aço teve a parte superior revestida com borracha rígida para não danificar a ponta do martelo de impulso (Figura 4.6).

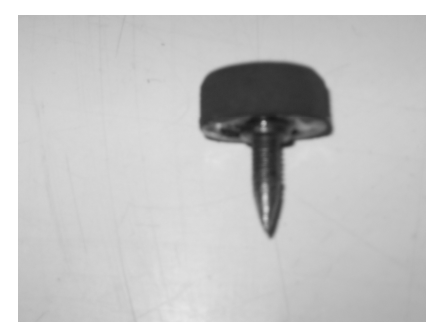

Figura 4.6 - Pino de impacto com a cabeça revestida de borracha.

Foram testadas todas as pontas do martelo modelo 2303 da Endevco e observou-se que a ponta mais macia (verde) resultava em FRF com menor intensidade de ruído na banda de frequências de 0 a $500 \mathrm{~Hz}$. A força aplicada pelo martelo de impulso variou entre 1,7 a 3,0 kN resultando em acelerações da ordem de 1,7 a $3 \mathrm{~g}$, sendo $\mathrm{g}=9,80665 \mathrm{~m} / \mathrm{s}^{2}$.

Com o limite superior da banda de frequências fixado em $500 \mathrm{~Hz}$ foi possível identificar as frequências naturais até o $3^{0}$ modo de flexão.

Foi utilizado o algoritmo $\mathrm{H}_{1}$ para a estimativa da FRF por ser o que apresentou FRF com menor intensidade de ruído.

A Tabela 4.1 mostra as configurações do programa de aquisição de dados. O sistema de análise modal utilizado nos ensaios foi desenvolvido pelo autor dessa tese e está descrito com detalhes no Apêndice A.

Tabela 4.1 - Configurações do programa Impact nos ensaios dinâmicos com as toras.

\begin{tabular}{lc}
\hline \multicolumn{1}{c}{ Configurações do programa de aquisição de dados } \\
\hline Taxa de amostragem & $5 \mathrm{kHz}$ \\
Número de amostras & 8192 \\
Resolução da FRF & $0,610 \mathrm{~Hz}$ \\
Nível de disparo do trigger & $0,2 \mathrm{volts}$ \\
Número de amostras pré-trigger & 100 \\
Número de médias & 10 \\
Janela exponencial & Valor final 0,1 \\
Banda de frequências & 0 a $500 \mathrm{~Hz}$ \\
Algoritmo para determinação da FRF & $\mathrm{H}_{1}$ \\
\hline
\end{tabular}


A Figura 4.7 mostra os equipamentos utilizados no ensaio dinâmico.

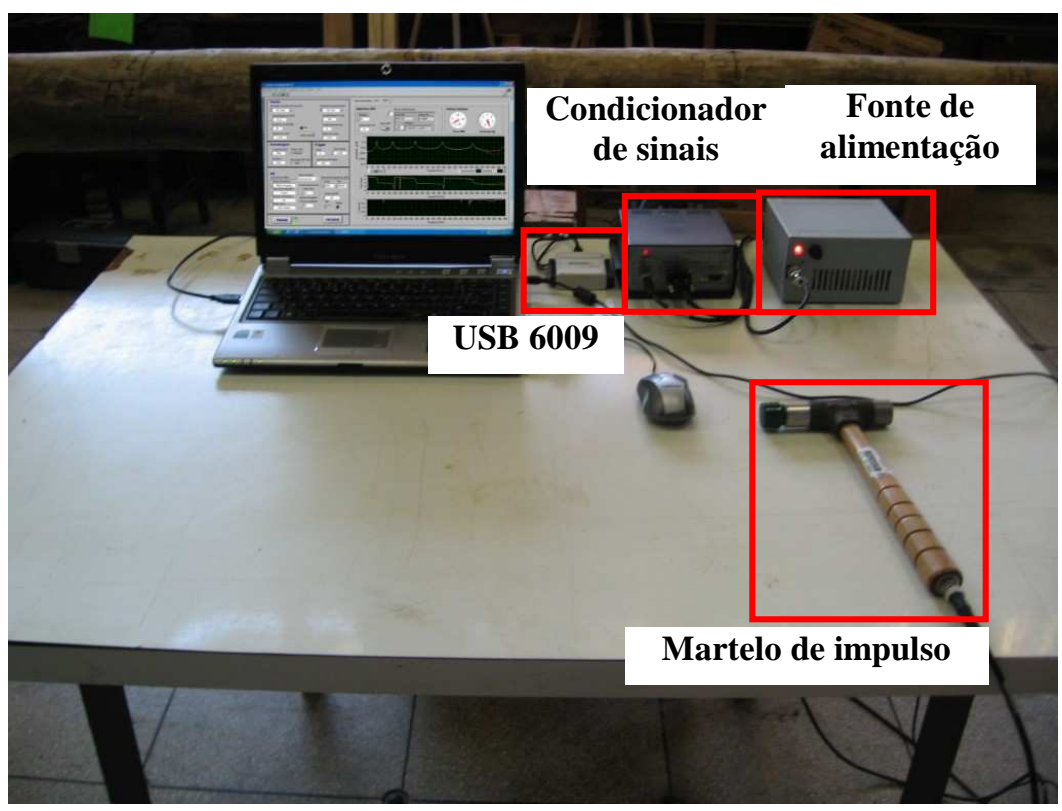

Figura 4.7 - Equipamentos empregados no ensaio dinâmico com as toras.

Posteriormente, as toras foram submetidas ao ensaio de flexão estática e, ao fim desse ensaio, foi extraída uma seção de $20 \mathrm{~cm}$ de comprimento da metade do comprimento das toras para determinação do teor de umidade e da densidade.

A metade mais espessa de cada tora recebeu a denominação tora-base (abreviada por TB) e a metade mais delgada recebeu a denominação tora-topo (abreviada por TT) como mostra a Figura 4.8.

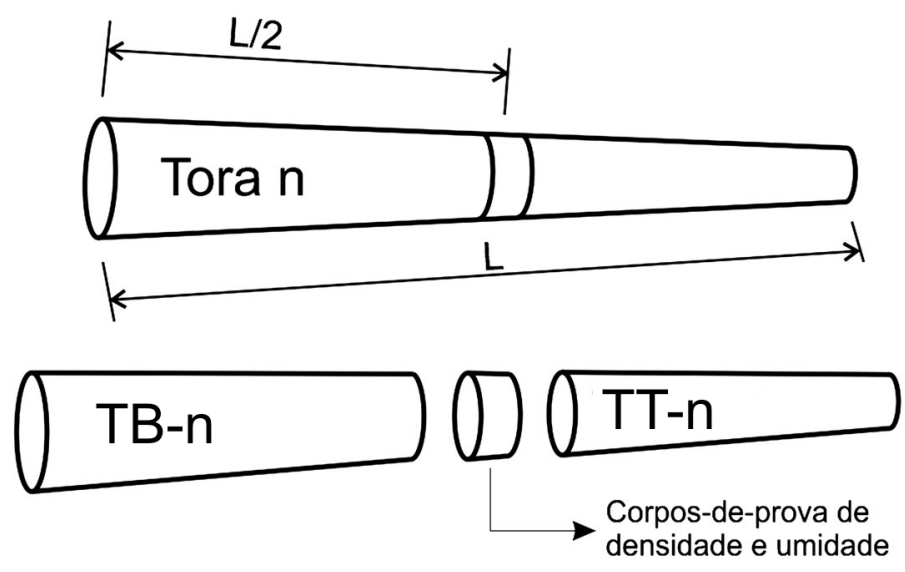

Figura 4.8 - Esquema de corte das toras. 
Na sequência, as toras-topo e toras-base também foram submetidas aos ensaios de flexão estática e vibração transversal (no plano horizontal), com o objetivo de avaliar a influência do esforço cortante.

Nas toras TT e TB as acelerações foram medidas na coordenada a 0,05 L a partir da extremidade de menor diâmetro (ponto 12 nas toras TB e ponto 10 nas toras TT) como mostra a Figura 4.9.
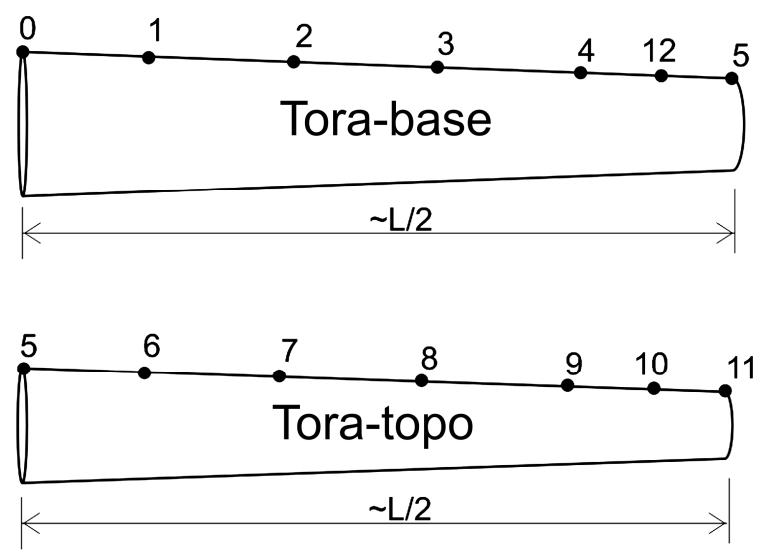

Figura 4.9 - Toras-base e toras-topo.

A excitação dessas toras foi feita nos pontos 0,2 e 3 para as toras TB e nos pontos 5, 7 e 8 para as toras TT.

Nos ensaios com as toras-topo e toras-base foi utilizada uma corda de Nylon com 1/8" $(3,2 \mathrm{~mm})$ de diâmetro e foi empregada uma mola de menor rigidez do que a utilizada no ensaio com as toras inteiras. A Figura 4.10 mostra como as toras foram suspensas.

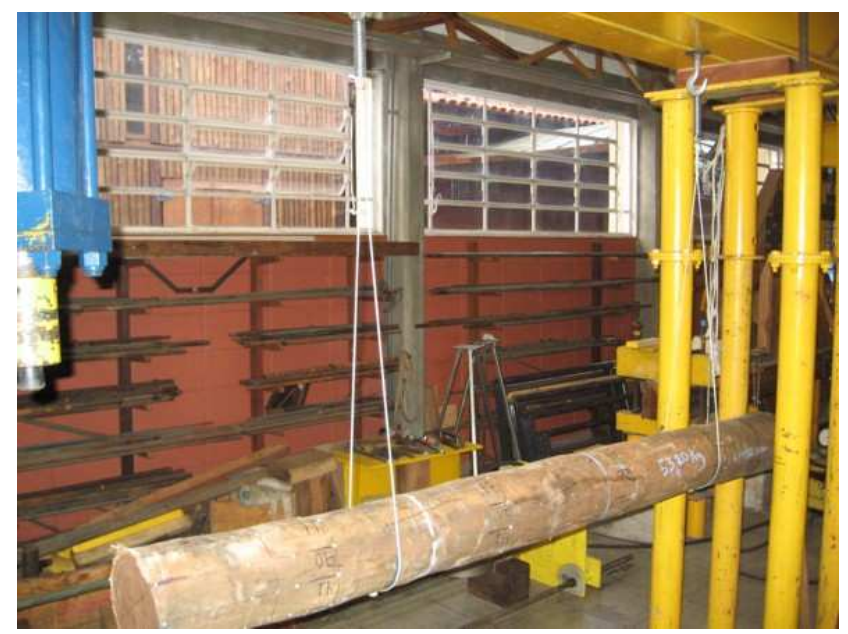

Figura 4.10 - Suspensão das toras TT e TB.

Como as toras TT e TB tinham cerca de metade da massa da tora inteira, a força de impacto foi reduzida para cerca de 0,5 a $1,5 \mathrm{kN}$ de forma a não saturar o acelerômetro. 
O limite superior da banda de frequências foi alterado para $1000 \mathrm{~Hz}$ e para medir frequências maiores foi necessário trocar a ponta do martelo de impulso, pois a ponta mais macia (verde) não tinha rigidez suficiente para excitar frequências maiores do que $300 \mathrm{~Hz}$ com boa quantidade de energia. Assim sendo, foi utilizada uma ponta de maior rigidez (vermelha). O pino de impacto também teve de ser confeccionado com material mais rígido para permitir a excitação de frequências superiores a $300 \mathrm{~Hz}$. Para tanto foi utilizado um pino de aço com cabeça de alumínio (Figura 4.11).

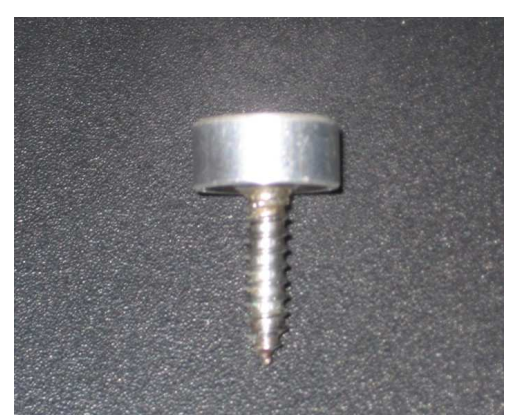

Figura 4.11 - Pino de impacto com cabeça de alumínio empregado nos ensaios com as toras mais curtas.

Como a vibração das toras cessava em uma fração de segundos, o período de amostragem foi reduzido pela metade $(800 \mathrm{~ms})$ para evitar aquisição de ruído. A taxa de aquisição também foi alterada para $20 \mathrm{kHz}$.

A Tabela 4.2 mostra as configurações do programa de aquisição de dados usadas nos ensaios com as toras de menor comprimento.

Tabela 4.2 - Configurações do programa Impact nos ensaios com as toras de menor comprimento.

\begin{tabular}{lc}
\hline \multicolumn{1}{c}{ Configurações do programa de aquisição de dados } \\
\hline Taxa de amostragem & $20 \mathrm{kHz}$ \\
Número de amostras & 16384 \\
Resolução da FRF & $1,221 \mathrm{~Hz}$ \\
Nível de disparo do trigger & 0,2 volts \\
Número de amostras pré-trigger & 200 \\
Número de médias & 10 \\
Janela exponencial & Valor final 0,2 \\
Banda de frequências & 0 a $1000 \mathrm{~Hz}$ \\
Algoritmo para determinação da FRF & $\mathrm{H}_{1}$ \\
\hline
\end{tabular}

A identificação dos parâmetros modais foi feita com o algoritmo RFP (Rational Fraction Polynomial) o qual foi implementado no programa Modal-Id (Figura 4.12) que foi 
desenvolvido pelo autor durante o curso da Disciplina SEM 5766 - Análise Modal de Estruturas. A implementação do programa Modal-Id é descrita no Apêndice C deste trabalho.

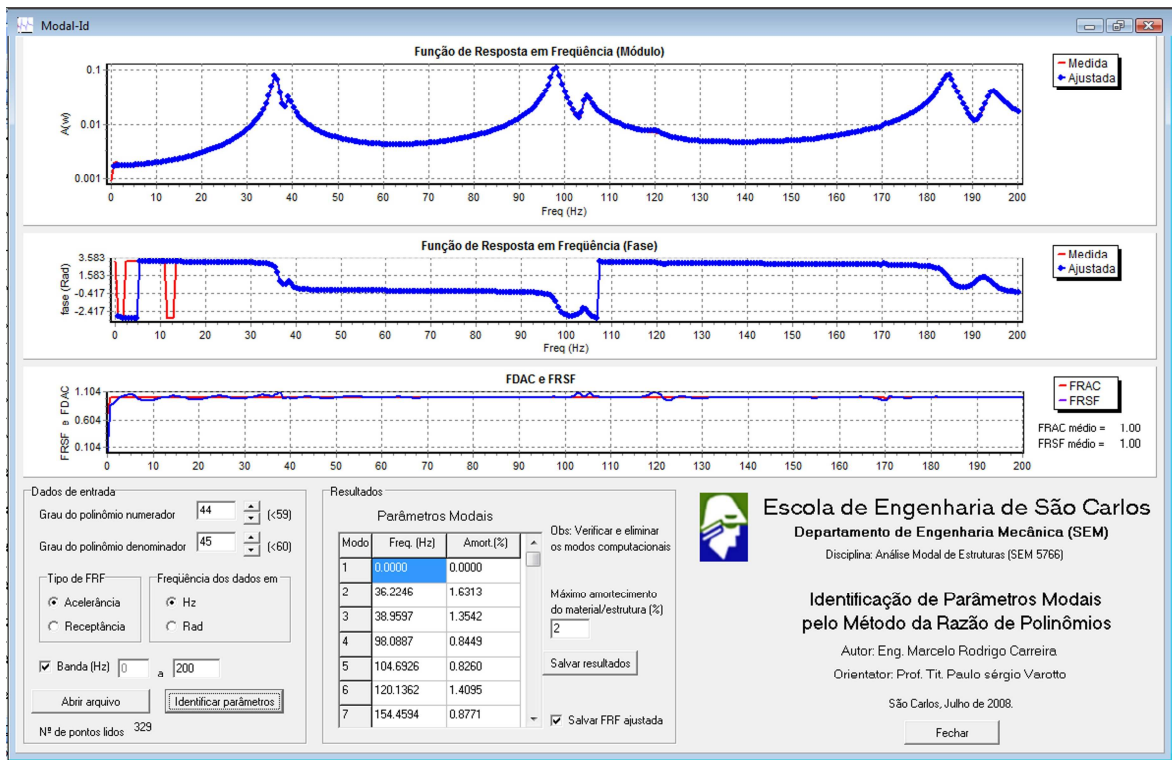

Figura 4.12 - Identificação dos parâmetros modais com o programa Modal-Id.

O módulo de elasticidade dinâmico segundo Bernoulli, e aqui denominado de aparente, foi calculado com a Equação 4.4.

$$
E_{M, V T, a p}=\frac{f^{2} *(2 \pi)^{2} * M * L^{3}}{(4,73)^{4} * I} \quad I=\frac{\pi * D_{\text {meio }}{ }^{4}}{64}
$$

Sendo:

$E_{M, V T, a p}=$ módulo de elasticidade aparente $(\mathrm{Pa}) ;$

$f=$ frequência do primeiro modo de flexão $(\mathrm{Hz})$;

$M=$ massa $(\mathrm{kg})$;

$L=$ comprimento $(\mathrm{m})$;

$D_{\text {meio }}=$ diâmetro medido na metade do comprimento das toras (m).

Os efeitos da inércia à rotação e do esforço cortante foram levados em conta aplicando-se a correção proposta por Goens (1931) conforme Equação 4.5.

$$
\begin{aligned}
& E_{M, V T}=E_{M, V T, a p} * T \\
& T=\left[1+43,193 A+18,589(A-2 B)-\frac{500,547\left(A^{2}-B^{2}\right)}{1+44,746 A}\right] \\
& A, B=\frac{1}{2} * \frac{i^{2}}{L^{2}}\left(\frac{\eta * E}{G} \pm 1\right)
\end{aligned}
$$


Sendo:

$E_{M, V T}=$ módulo de elasticidade da tora $(\mathrm{Pa})$

$E_{M, V T, a p}=$ módulo de elasticidade aparente $(\mathrm{Pa})$;

$T=$ fator de correção proposto por Goens (1931);

$i=$ raio de giração da seção transversal para $\mathrm{D}_{\text {meio }}(\mathrm{m})$;

$L=$ comprimento (m);

$\eta=$ fator de forma da seção transversal ( $\eta=1,11$ para seção circular);

$E / G=$ constante admitida igual 20 conforme NBR 7190 (ABNT, 1997).

\subsubsection{Ensaio de flexão estática}

Imediatamente após a realização dos ensaios dinâmicos, as toras foram submetidas ao ensaio de flexão estática de acordo com o método de ensaio da norma ASTM D 198 (ASTM, 2008) "Standard Test Methods of Static Tests of Lumber in Structural Sizes". As Figuras 4.13a e 4.13b mostram, respectivamente, o esquema estático e uma visão geral do ensaio. A distância entre apoios $\left(\mathrm{L}_{\text {apoio }}\right)$ foi fixada em $0,9 \mathrm{~L}$, para todos casos.

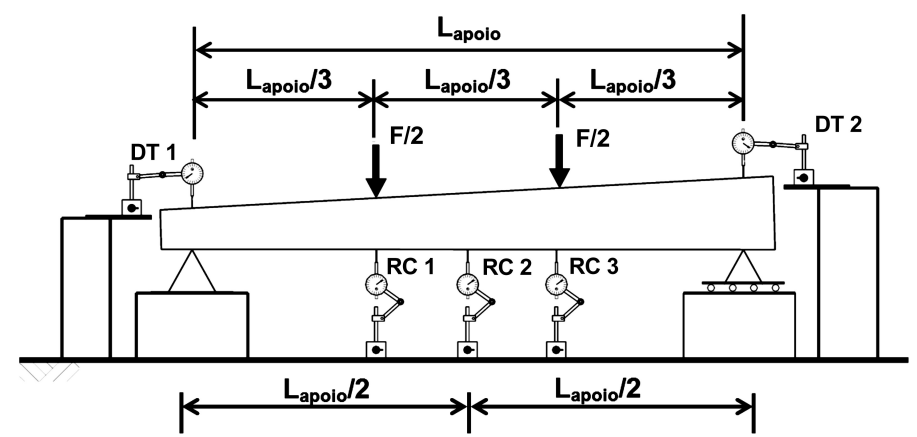

(a)

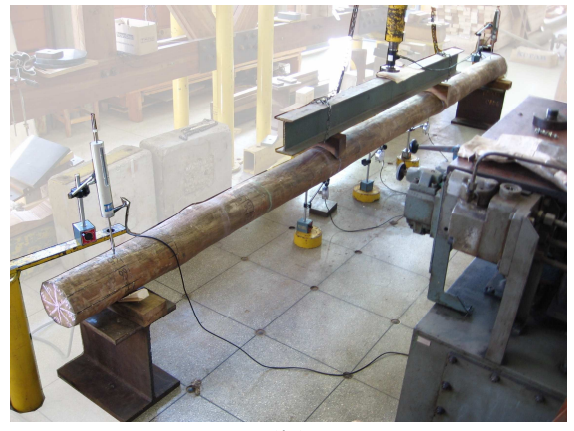

(b)

Figura 4.13 - Ensaio de flexão estática: a) esquema estático; b) visão geral do ensaio.

A força foi medida com uma célula de carga de compressão com capacidade de $50 \mathrm{kN}$. Foi aplicada uma força crescente até que o deslocamento vertical no meio do vão fosse cerca de $\mathrm{L}_{\text {apoio }} / 200$.

Os deslocamentos verticais foram medidos nos apoios (usando transdutores de deslocamento modelo DT-100A - Kyowa), no meio do vão e nos pontos de aplicação da força (usando três relógios comparadores elétricos modelo DT-20D - Kyowa).

A leitura e o registro dos dados dos ensaios foram feitos usando um sistema de aquisição de dados modelo 5100 do fabricante Vishay Measurement Group, com uma taxa de amostragem de $4 \mathrm{~Hz}$. 
As toras foram submetidas à flexão nos planos 0-4, 1-5, 2-6, 3-7, 4-0, 5-1, 6-2 e 7-3 definidos pelas linhas radias desenhadas em suas extremidades (Figura 4.1) totalizando 8 ensaios de flexão por tora. Foram calculados o módulo de elasticidade em cada ensaio e o módulo de elasticidade médio de cada tora.

De acordo a norma ASTM D198 (ASTM, 2008), o módulo de elasticidade aparente, isto é, não considerando as deformações devidas ao esforço cortante, pode ser obtido pela Equação 4.6.

$$
E_{M, S t a t, a p}=\frac{23 * \Delta F * L_{a p o i o}{ }^{3}}{1296 * \Delta v * I}
$$

Sendo:

$E_{M, \text { Stat, ap }}=$ módulo de elasticidade aparente $(\mathrm{Pa})$

$\Delta F=$ incremento de força aplicada $(\mathrm{N})$;

$L_{\text {apoio }}=$ distância entre apoios $(\mathrm{m})$;

$\Delta v=$ incremento no deslocamento vertical medido na metade do comprimento da tora $(\mathrm{m})$;

$I=$ momento de inércia da seção transversal calculado com o diâmetro medido na metade do comprimento da tora $\left(\mathrm{m}^{4}\right)$.

Foi calculado também, por meio da Equação 4.7, o módulo de elasticidade que a norma ASTM D198 (ASTM, 2008) denomina como "módulo de elasticidade verdadeiro", ou seja, a partir do deslocamento vertical no centro, devido à deformação por flexão apenas no trecho central, que não tem esforço cortante.

$$
E_{M, \text { Stat }, v}=\frac{\Delta F * L_{\text {apoio }} * L_{b}^{2}}{48 * \Delta_{L b} * I}
$$

Sendo:

$E_{M, S t a t, v}=$ módulo de elasticidade verdadeiro $(\mathrm{Pa})$

$\Delta F=$ incremento de força aplicada $(\mathrm{N})$;

$L_{\text {apoio }}=$ distância entre apoios $(\mathrm{m})$;

$L_{b}=$ distância entre os dois pontos de aplicação de força $(\mathrm{m})$;

$\Delta_{L b}=$ incremento no deslocamento vertical medido na metade do vão da tora, descontando-se os deslocamentos nos pontos de aplicação da força (m);

$I=$ momento de inércia da seção transversal calculado com o diâmetro medido na metade do comprimento da tora $\left(\mathrm{m}^{4}\right)$. 
Alternativamente o módulo de elasticidade "verdadeiro" das toras também foi avaliado acrescentando-se a parcela do esforço cortante na Equação 4.6, obtendo-se a Equação 4.8.

$$
E_{M, \text { Stat }, v}{ }^{*}=\frac{23 * \Delta F * L_{\text {apoio }}{ }^{3}}{1296 * \Delta v * I}+\frac{\eta * \beta * \Delta F * L_{\text {apoio }}}{6 * \Delta v * A} \quad \beta=\frac{E}{G}
$$

Sendo:

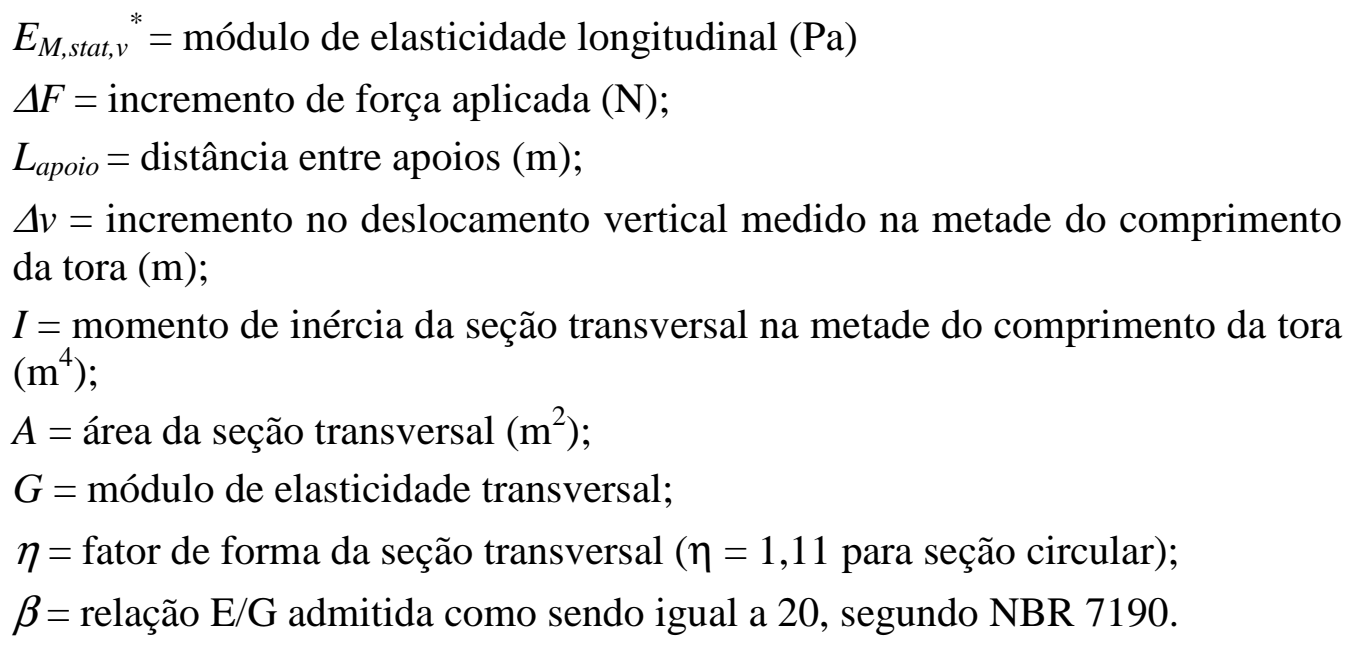

$\mathrm{O}$ módulo de elasticidade estático foi calculado a partir do diagrama força $\mathrm{x}$ deslocamento ajustando-se uma reta, pela técnica dos mínimos quadrados, entre os pontos de leitura de força iguais a $20 \%$ e $80 \%$ da máxima força aplicada no teste.

\subsubsection{Determinação do teor de umidade das toras}

Logo após a execução dos ensaios estáticos e dinâmicos nas toras inteiras, o teor de umidade nas extremidades e na metade do comprimento das toras foi medido utilizando um medidor elétrico modelo DL 2000 do fabricante Digisystem. A partir das três medições foi calculado o teor de umidade médio na superfície das toras.

Ao término desses ensaios, na metade do comprimento de cada tora foi extraída uma seção de $20 \mathrm{~cm}$ de comprimento, da qual foram retirados de 3 a 5 corpos-de-prova para determinação do teor de umidade segundo a norma NBR 7190 (ABNT, 1997).

Os corpos-de-prova foram retirados seguindo-se uma linha radial como mostra a Figura 4.14, sendo que o corpo-de-prova 1 foi extraído da região onde o teor de umidade foi estimado com o medidor elétrico. 


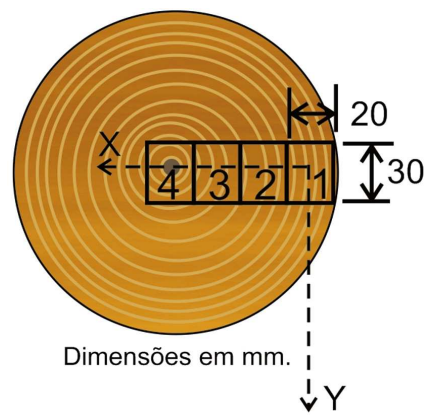

Figura 4.14 - Esquema de extração de corpos-de-prova para determinação do teor de umidade.

\subsection{Resultados}

\subsubsection{Propriedades dimensionais e densidade aparente das toras}

A Tabela 4.3 mostra os resultados obtidos na determinação da densidade aparente e das propriedades geométricas das toras da amostra piloto.

Tabela 4.3 - Características físicas das toras da amostra piloto.

\begin{tabular}{|c|c|c|c|c|c|c|c|c|c|}
\hline \multirow{2}{*}{ Tora } & \multirow{2}{*}{$\begin{array}{c}\mathrm{L} \\
(\mathrm{cm})\end{array}$} & \multirow{2}{*}{$\begin{array}{l}D_{\text {meio }} \\
(\mathrm{cm})\end{array}$} & \multirow{2}{*}{$L / D_{\text {meio }}$} & \multicolumn{2}{|c|}{$\overline{\Delta_{\text {circ }}}$} & \multirow{2}{*}{$c^{1}$} & \multirow{2}{*}{$\Delta \mathrm{D}$} & \multirow{2}{*}{$\rho\left(\mathrm{kg} / \mathrm{m}^{3}\right)$} & \multirow{2}{*}{$\begin{array}{l}\text { Enc. }^{2} \\
(\mathrm{~mm})\end{array}$} \\
\hline & & & & Base & Topo & & & & \\
\hline 1 & 428,0 & 16,3 & 26,2 & $0,1 \%$ & $1,1 \%$ & $1,1 \%$ & $8,1 \%$ & 930 & 50 \\
\hline 2 & 446,0 & 16,4 & 27,3 & $2,1 \%$ & $1,0 \%$ & $0,6 \%$ & $5,2 \%$ & 933 & 30 \\
\hline 3 & 450,5 & 17,1 & 26,4 & $0,6 \%$ & $1,7 \%$ & $0,8 \%$ & $6,0 \%$ & 935 & 37 \\
\hline 4 & 436,5 & 15,7 & 27,8 & $2,5 \%$ & $1,3 \%$ & $0,9 \%$ & $7,6 \%$ & 880 & 35 \\
\hline 5 & 445,5 & 16,0 & 27,8 & $7,1 \%$ & $1,8 \%$ & $1,2 \%$ & $11,1 \%$ & 764 & 35 \\
\hline 6 & 464,3 & 16,4 & 28,4 & $3,0 \%$ & $0,5 \%$ & $0,9 \%$ & $8,2 \%$ & 846 & 33 \\
\hline 7 & 439,5 & 15,9 & 27,6 & $2,3 \%$ & $1,4 \%$ & $0,9 \%$ & $7,4 \%$ & 786 & 50 \\
\hline 8 & 441,5 & 15,9 & 27,7 & $3,6 \%$ & $0,7 \%$ & $0,9 \%$ & $7,8 \%$ & 914 & 24 \\
\hline 9 & 446,3 & 16,7 & 26,8 & $3,3 \%$ & $0,2 \%$ & $0,8 \%$ & $6,9 \%$ & 911 & 29 \\
\hline 10 & 452,3 & 15,9 & 28,4 & $0,3 \%$ & $1,1 \%$ & $1,0 \%$ & $8,3 \%$ & 818 & 31 \\
\hline Mínimo & 428,0 & 15,7 & 26,2 & $0,1 \%$ & $0,2 \%$ & $0,6 \%$ & $5,2 \%$ & 764 & 24,0 \\
\hline Máximo & 464,3 & 17,1 & 28,4 & $7,1 \%$ & $1,8 \%$ & $1,2 \%$ & $11,1 \%$ & 935 & 50,0 \\
\hline Média & 445,0 & 16,2 & 27,4 & $2,5 \%$ & $1,1 \%$ & $0,9 \%$ & $7,7 \%$ & 872 & 35,4 \\
\hline Coef. Var. ${ }^{3}$ & $2,2 \%$ & $2,6 \%$ & $2,8 \%$ & $82,2 \%$ & $46,4 \%$ & $17,6 \%$ & $20,6 \%$ & $7,4 \%$ & $24,1 \%$ \\
\hline
\end{tabular}

1) $\mathrm{C}=$ conicidade; 2) Enc. = encurvamento; 3) Coef. Var.= coeficiente de variação

As Tabelas 4.4 e 4.5 mostram respectivamente as propriedades físicas das toras-topo e toras-base. 
Tabela 4.4 - Características físicas das toras-topo.

\begin{tabular}{|c|c|c|c|c|c|c|c|}
\hline \multirow{2}{*}{ Tora } & \multirow{2}{*}{$\begin{array}{c}\mathrm{L} \\
(\mathrm{cm})\end{array}$} & \multirow{2}{*}{$\mathrm{D}_{\text {meio }}(\mathrm{cm})$} & \multirow{2}{*}{$L / D_{\text {meio }}$} & \multicolumn{2}{|c|}{$\Delta_{\text {circ }}$} & \multirow{2}{*}{$c^{1}$} & \multirow{2}{*}{$\Delta \mathrm{D}$} \\
\hline & & & & Base & Topo & & \\
\hline TT -1 & 202,5 & 15,5 & 13,0 & $2,1 \%$ & $1,1 \%$ & $0,2 \%$ & $2,0 \%$ \\
\hline TT -2 & 210,5 & 15,7 & 13,4 & $2,3 \%$ & $1,0 \%$ & $0,3 \%$ & $2,1 \%$ \\
\hline TT -3 & 215,5 & 16,4 & 13,1 & $8,8 \%$ & $1,7 \%$ & $0,0 \%$ & $3,2 \%$ \\
\hline TT -4 & 207,0 & 14,6 & 14,1 & $1,2 \%$ & $1,3 \%$ & $0,5 \%$ & $2,7 \%$ \\
\hline TT -5 & 211,5 & 15,2 & 13,9 & $1,9 \%$ & $1,8 \%$ & $0,7 \%$ & $3,2 \%$ \\
\hline TT -6 & 220,0 & 15,6 & 14,1 & $0,7 \%$ & $0,5 \%$ & $0,3 \%$ & $1,9 \%$ \\
\hline TT -7 & 207,0 & 15,1 & 13,7 & $1,3 \%$ & $1,4 \%$ & $0,5 \%$ & $2,4 \%$ \\
\hline TT -8 & 211,7 & 15,6 & 13,5 & $1,7 \%$ & $0,7 \%$ & $0,4 \%$ & $2,6 \%$ \\
\hline TT -9 & 212,0 & 15,9 & 13,4 & $0,5 \%$ & $0,2 \%$ & $0,6 \%$ & $3,1 \%$ \\
\hline TT -10 & 216,2 & 15,2 & 14,2 & $2,2 \%$ & $1,1 \%$ & $0,5 \%$ & $3,1 \%$ \\
\hline Mínimo & 202,5 & 14,6 & 13,0 & $0,5 \%$ & $0,2 \%$ & $0,0 \%$ & $1,9 \%$ \\
\hline Máximo & 220,0 & 16,4 & 14,2 & $8,8 \%$ & $1,8 \%$ & $0,7 \%$ & $3,2 \%$ \\
\hline Média & 211,4 & 15,5 & 13,7 & $2,3 \%$ & $1,1 \%$ & $0,4 \%$ & $2,6 \%$ \\
\hline Coef. Var. ${ }^{2}$ & $2,4 \%$ & $3,2 \%$ & $3,1 \%$ & $104,5 \%$ & $46,4 \%$ & $44,7 \%$ & $18,6 \%$ \\
\hline
\end{tabular}

Tabela 4.5 - Características físicas das toras-base.

\begin{tabular}{|c|c|c|c|c|c|c|c|}
\hline \multirow{2}{*}{ Tora } & \multirow{2}{*}{$\begin{array}{c}\mathrm{L} \\
(\mathrm{cm})\end{array}$} & \multirow{2}{*}{$D_{\text {meio }}(\mathrm{cm})$} & \multirow{2}{*}{$L / D_{\text {meio }}$} & \multicolumn{2}{|c|}{$\overline{\Delta_{\text {circ }}}$} & \multirow{2}{*}{$c^{1}$} & \multirow{2}{*}{$\Delta \mathrm{D}$} \\
\hline & & & & Base & Topo & & \\
\hline TB - 1 & 201,5 & 17,0 & 11,9 & $0,1 \%$ & $1,5 \%$ & $1,8 \%$ & $7,2 \%$ \\
\hline TB - 2 & 214,0 & 16,5 & 13,0 & $2,1 \%$ & $2,6 \%$ & $1,0 \%$ & $4,3 \%$ \\
\hline TB - 3 & 215,0 & 17,6 & 12,2 & $0,6 \%$ & $1,4 \%$ & $1,1 \%$ & $4,7 \%$ \\
\hline TB - 4 & 207,0 & 16,2 & 12,8 & $2,5 \%$ & $3,4 \%$ & $1,5 \%$ & $6,7 \%$ \\
\hline TB - 5 & 211,0 & 17,1 & 12,3 & $7,1 \%$ & $3,1 \%$ & $1,9 \%$ & $10,1 \%$ \\
\hline TB - 6 & 221,5 & 17,1 & 13,0 & $3,0 \%$ & $0,6 \%$ & $1,4 \%$ & $7,7 \%$ \\
\hline TB - 7 & 211,0 & 16,3 & 12,9 & $2,3 \%$ & $1,7 \%$ & $1,3 \%$ & $6,8 \%$ \\
\hline TB - 8 & 209,0 & 17,1 & 12,2 & $3,6 \%$ & $0,3 \%$ & $1,2 \%$ & $7,0 \%$ \\
\hline TB -9 & 212,5 & 17,4 & 12,2 & $3,3 \%$ & $2,0 \%$ & $1,2 \%$ & $5,5 \%$ \\
\hline TB - 10 & 215,3 & 16,9 & 12,8 & $0,3 \%$ & $2,0 \%$ & $1,6 \%$ & $7,0 \%$ \\
\hline Mínimo & 201,5 & 16,2 & 11,9 & $0,1 \%$ & $0,3 \%$ & $1,0 \%$ & $4,3 \%$ \\
\hline Máximo & 221,5 & 17,6 & 13,0 & $7,1 \%$ & $3,4 \%$ & $1,9 \%$ & $10,1 \%$ \\
\hline Média & 211,8 & 16,9 & 12,5 & $2,5 \%$ & $1,9 \%$ & $1,4 \%$ & $6,7 \%$ \\
\hline Coef. Var. ${ }^{2}$ & $2,5 \%$ & $2,7 \%$ & $3,2 \%$ & $82,2 \%$ & $52,6 \%$ & $21,3 \%$ & $24,5 \%$ \\
\hline
\end{tabular}

1) $\mathrm{C}=$ conicidade; 2) Coef. Var.= coeficiente de variação.

\subsubsection{Ensaio de vibração transversal}

Devido ao grande número de FRF's obtidas nos ensaios dinâmicos, apenas algumas das FRF's são mostradas neste item, a título de ilustração. A Figura 4.15 mostra um exemplo de FRF obtida nos ensaios. 

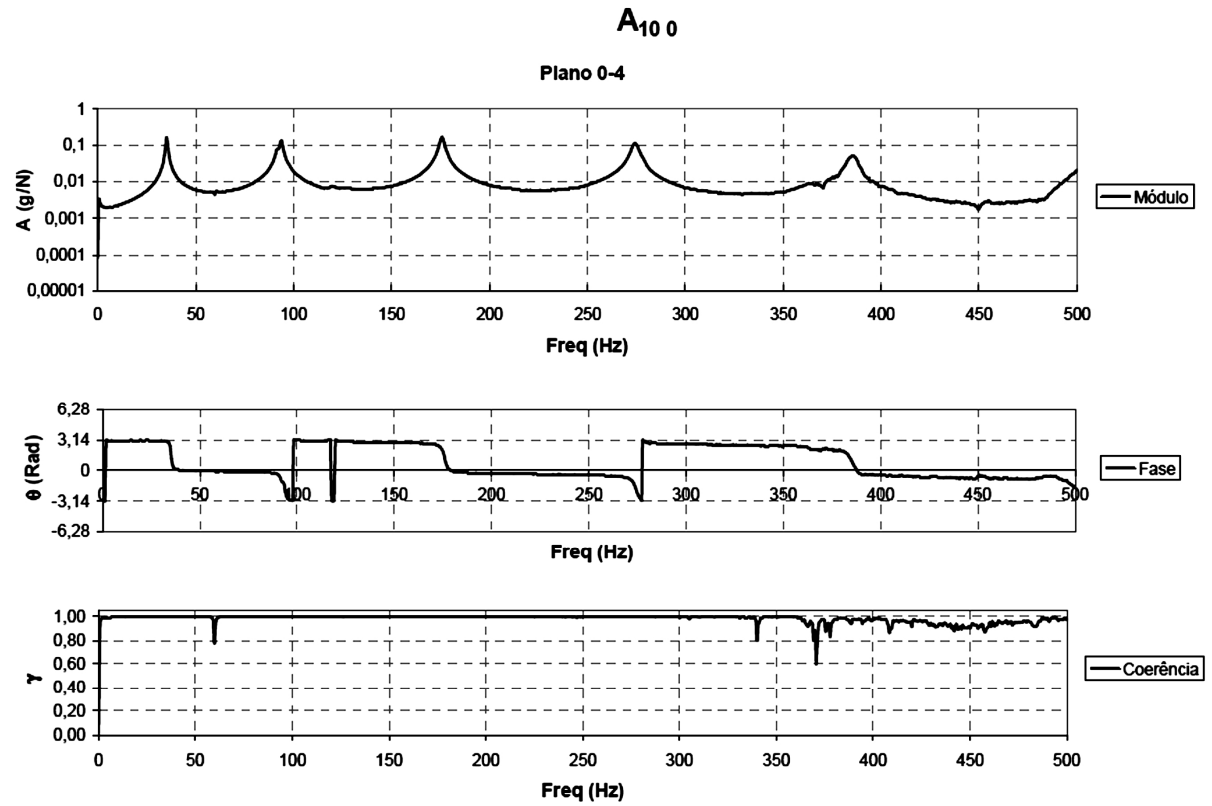

Figura 4.15 - FRF de acelerância $\left(\mathrm{A}_{10}\right)$ obtida para a tora 2.

Várias FRF's apresentaram picos de frequência duplicados na região de ressonância como mostram as Figuras 4.16 a 4.18.
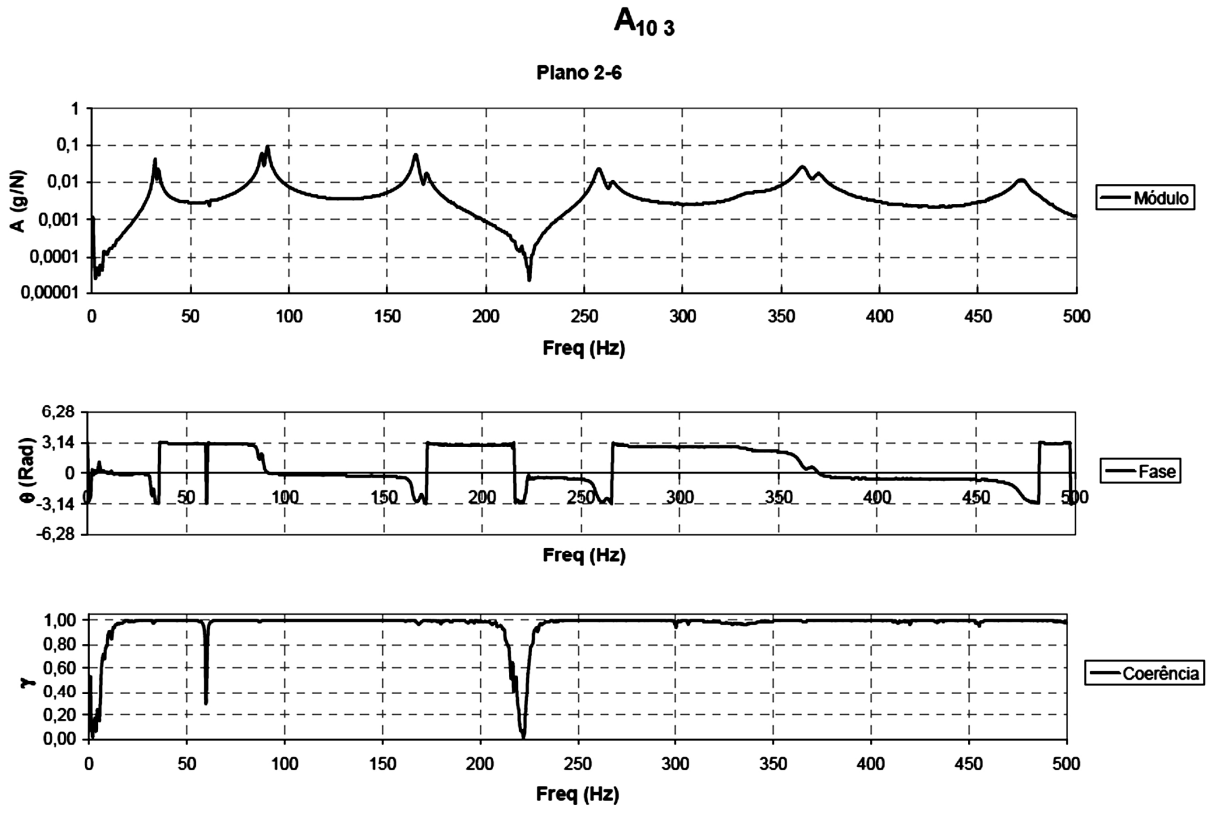

Figura 4.16 - Picos duplicados na FRF de acelerância $\left(\mathrm{A}_{103}\right)$ da tora 6. 

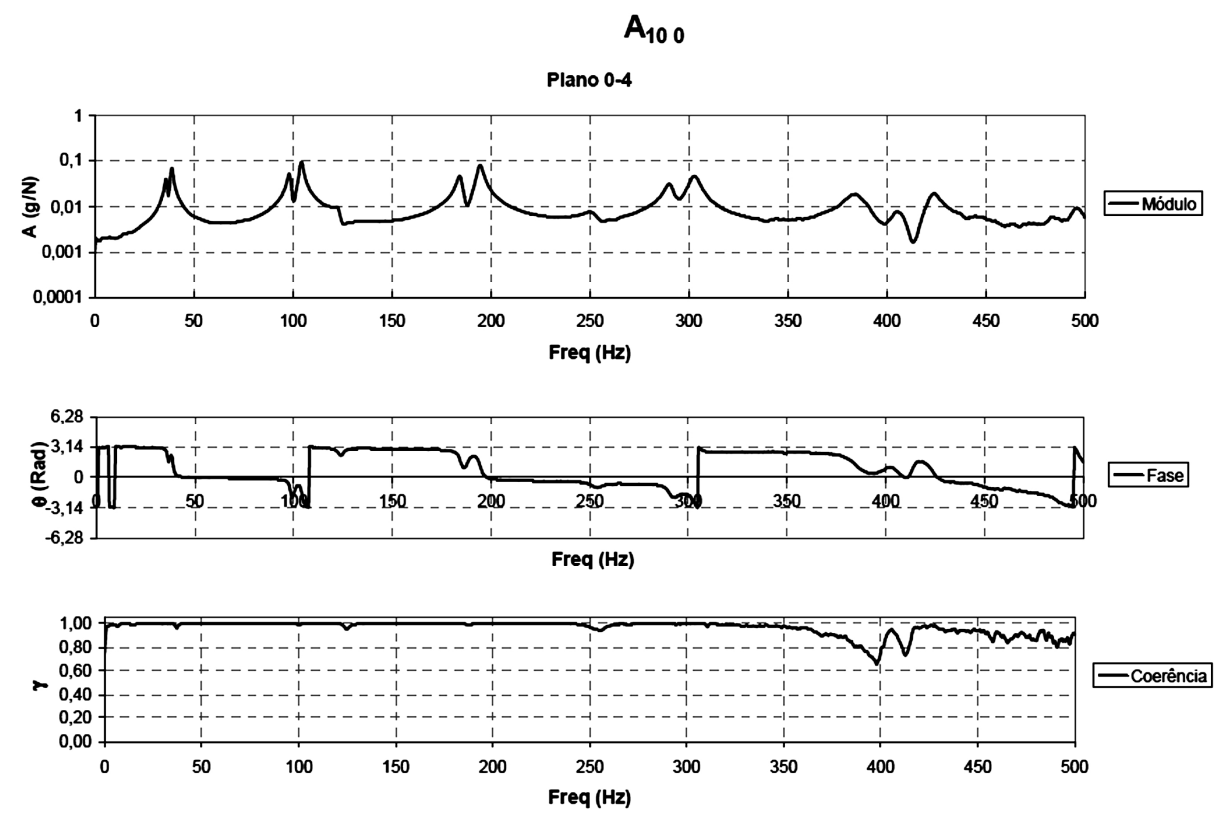

Figura 4.17 - Picos duplicados na FRF de acelerância $\left(\mathrm{A}_{10} 0_{0}\right)$ da tora 1.
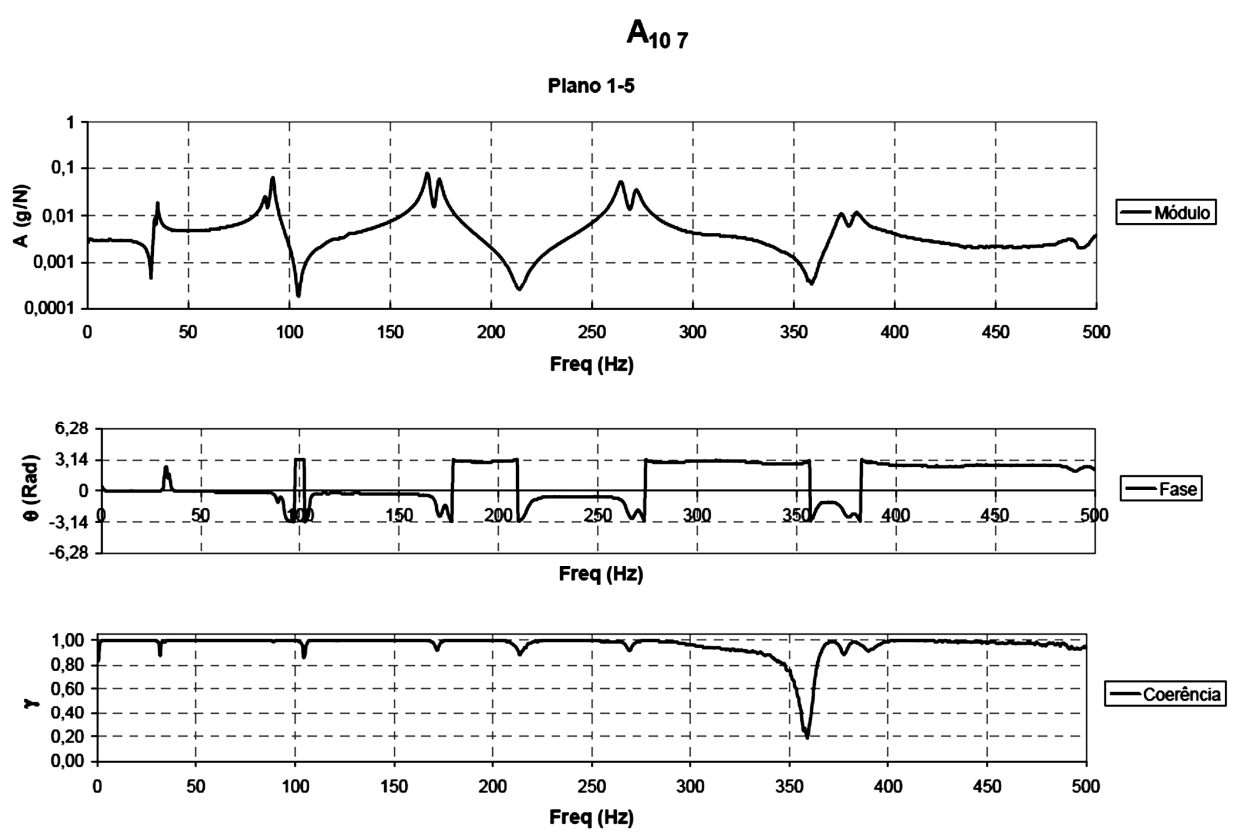

Figura 4.18 - Picos duplicados na FRF de acelerância $\left(\mathrm{A}_{107}\right)$ da tora 7.

Várias FRF's das toras-topo e toras-base também exibiram picos duplos de acelerância nas frequências dos modos de flexão. Como exemplo, a Figura 4.19 mostra a FRF $A_{12} 0$ medida na tora TB-1. 

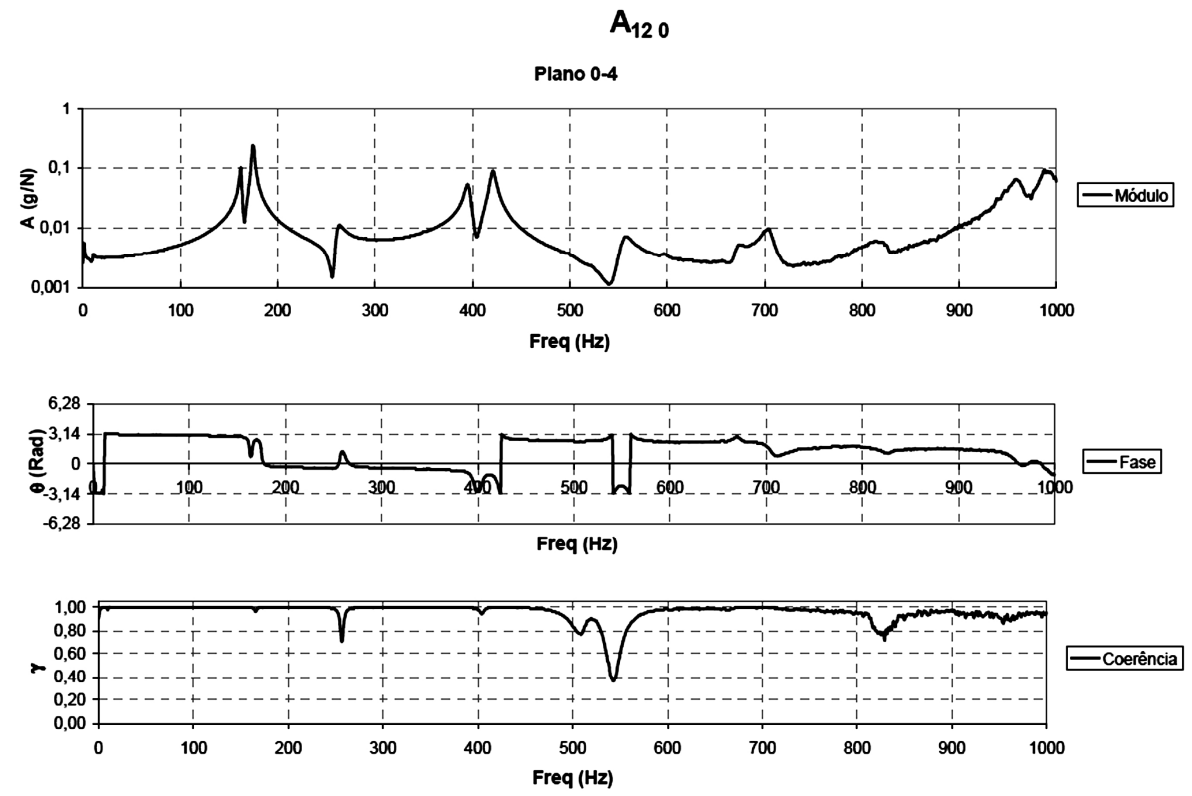

Figura 4.19 - FRF A 120 medida na tora TB-1.

A Figura 4.20 mostra um exemplo da qualidade do ajuste alcançada com o programa Modal-Id. A linha azul é a FRF ajustada enquanto a linha vermelha é a experimental.

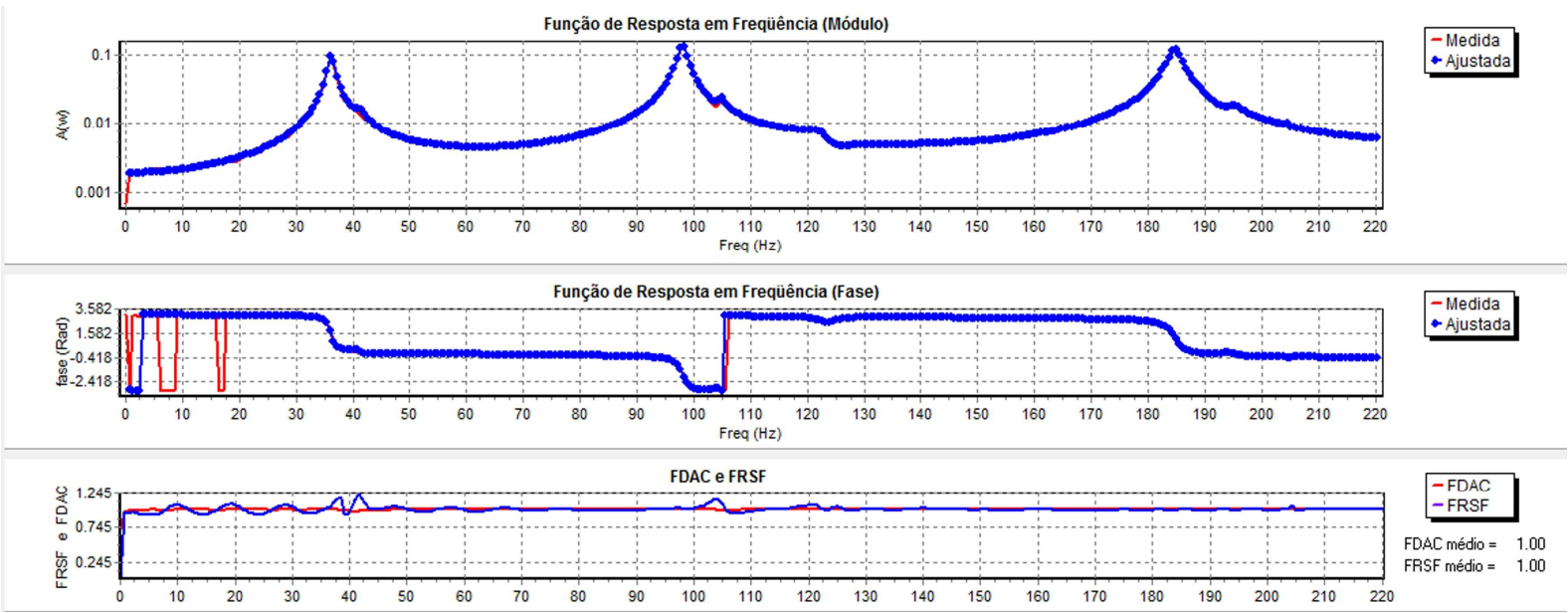

Figura 4.20 - Ajuste para a FRF $A_{10} 0$ medida na Tora 1 para o ensaio realizado no plano 5-1.

A Figura 4.21 mostra o ajuste de curvas para uma FRF com picos de frequência duplicados. 

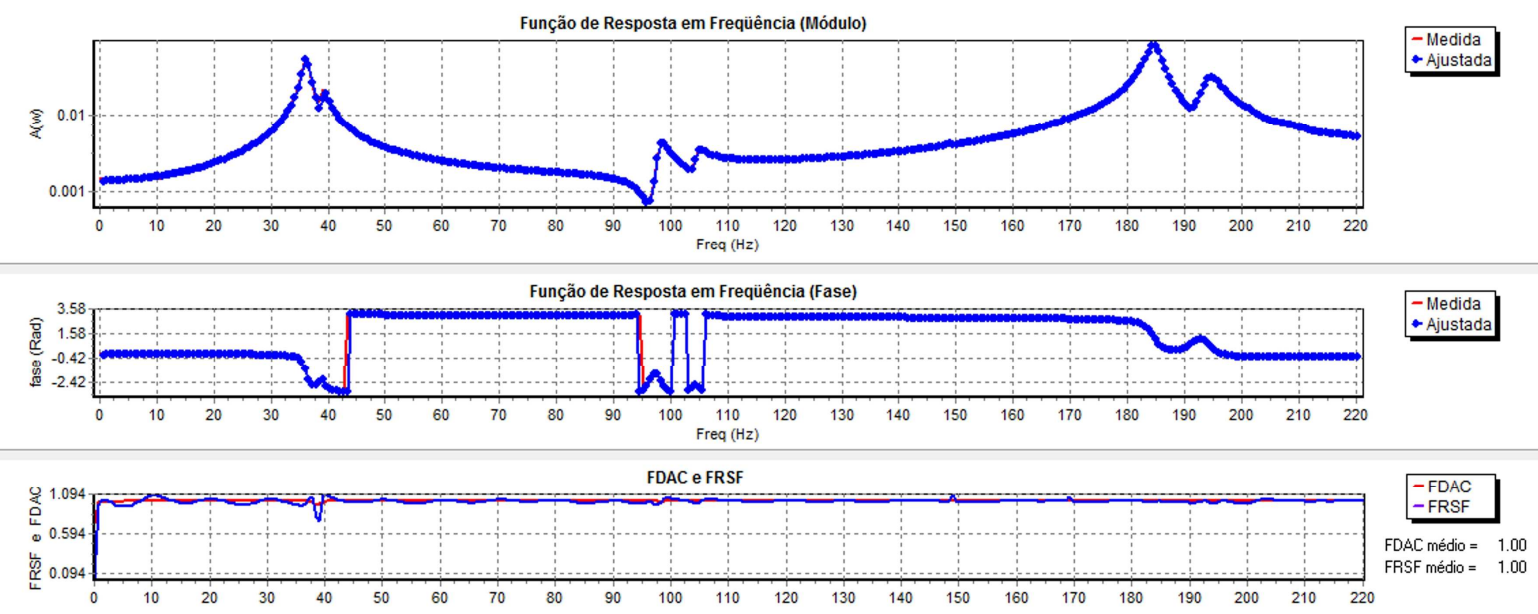

Figura 4.21 - Ajuste para a FRF $\mathrm{A}_{10}{ }_{5}$ medida na Tora 1 para o ensaio realizado no plano 2-6.

Algumas FRF's apresentaram ainda três picos de frequências nas regiões de ressonância como mostra a Figura 4.22.

Devido ao grande volume de informações obtidas na identificação dos parâmetros modais da amostra piloto, esses resultados foram agrupados no Apêndice E.
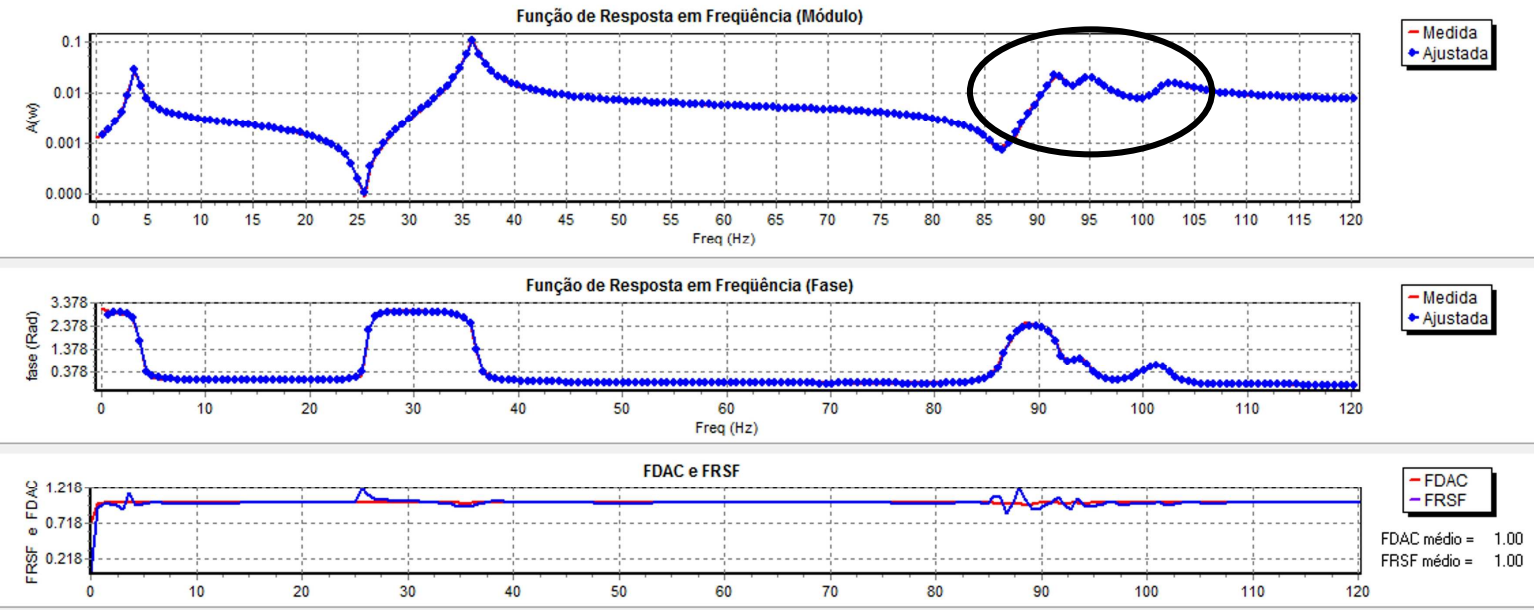

Figura 4.22 - Exemplo de FRF com três picos de frequência (FRF $A_{10} 9$ plano 2-6 Tora 2).

As Tabelas 4.6 a 4.13 mostram as frequências naturais do primeiro modo de flexão das toras e os respectivos coeficientes de variação nas medições das frequências. 
Tabela 4.6 - Frequências do $1^{\circ}$ modo de flexão das toras 1 e 2 para excitação nos planos horizontal e vertical.

\begin{tabular}{|c|c|c|c|c|c|c|c|c|c|}
\hline \multirow{3}{*}{ Plano } & \multirow{3}{*}{ FRF } & \multicolumn{6}{|c|}{ Tora 1} & \multicolumn{2}{|c|}{ Tora 2} \\
\hline & & \multicolumn{3}{|c|}{ Horizontal } & \multicolumn{3}{|c|}{ Vertical } & & \\
\hline & & $1^{\circ}$ pico & $2^{\circ}$ pico & média & $1^{\circ}$ pico & $2^{\circ}$ pico & média & nonla. & vert. \\
\hline \multirow{7}{*}{$0-4$} & $A_{100}$ & 36,23 & 38,88 & 37,55 & 36,23 & 38,87 & 37,55 & 35,29 & 35,33 \\
\hline & $\mathrm{A}_{101}$ & 36,20 & 38,90 & 37,55 & 36,25 & 38,87 & 37,56 & 35,29 & 35,32 \\
\hline & $\mathrm{A}_{103}$ & 36,20 & 38,90 & 37,55 & 36,22 & 38,89 & 37,55 & 35,25 & 35,35 \\
\hline & $A_{105}$ & 36,23 & 38,88 & 37,56 & 36,20 & 38,88 & 37,54 & 35,29 & 35,28 \\
\hline & $A_{107}$ & & 38,83 & 38,83 & 36,28 & 38,87 & 37,58 & 35,29 & 35,30 \\
\hline & $\mathrm{A}_{109}$ & & 38,95 & 38,95 & 36,12 & 38,90 & 37,51 & 35,31 & 35,33 \\
\hline & $\mathrm{A}_{1011}$ & 36,18 & 38,89 & 37,53 & 36,21 & 38,87 & 37,54 & 35,29 & 35,28 \\
\hline \multirow{7}{*}{$1-5$} & $A_{100}$ & 36,26 & 38,90 & 37,58 & 36,20 & & 36,20 & 35,42 & 35,42 \\
\hline & $A_{101}$ & 36,23 & & 36,23 & 36,17 & & 36,17 & 35,44 & 35,45 \\
\hline & $\mathrm{A}_{103}$ & 36,22 & & 36,22 & 36,25 & & 36,25 & 35,46 & 35,39 \\
\hline & $A_{105}$ & 36,25 & 38,94 & 37,59 & 36,21 & 38,91 & 37,56 & 35,47 & 35,41 \\
\hline & $A_{107}$ & 36,25 & 39,30 & 37,77 & 36,13 & 39,19 & 37,66 & 35,45 & 35,48 \\
\hline & $A_{109}$ & 36,16 & & 36,16 & 36,22 & 38,81 & 37,51 & 35,44 & 35,54 \\
\hline & $\mathrm{A}_{1011}$ & 36,18 & & 36,18 & 36,20 & 38,87 & 37,54 & 35,44 & 35,52 \\
\hline \multirow{7}{*}{$2-6$} & $A_{100}$ & 36,21 & 38,91 & 37,56 & 36,20 & 38,87 & 37,54 & 35,94 & 35,91 \\
\hline & $\mathrm{A}_{101}$ & 36,16 & 39,29 & 37,73 & 36,21 & 38,88 & 37,54 & 35,93 & 35,96 \\
\hline & $\mathrm{A}_{103}$ & 36,12 & 39,43 & 37,78 & 36,03 & 39,15 & 37,59 & 35,93 & 35,98 \\
\hline & $A_{105}$ & 36,26 & 39,06 & 37,66 & 36,22 & 38,84 & 37,53 & 35,92 & 35,95 \\
\hline & $A_{107}$ & 36,22 & 38,71 & 37,47 & 36,12 & 39,03 & 37,58 & 35,93 & 35,97 \\
\hline & $\mathrm{A}_{109}$ & 36,16 & 38,97 & 37,56 & 36,12 & 39,19 & 37,65 & 35,93 & 35,92 \\
\hline & $\mathrm{A}_{1011}$ & 36,23 & & 36,23 & 36,20 & 38,86 & 37,53 & 35,92 & 35,94 \\
\hline \multirow{7}{*}{ 3-7 } & $A_{100}$ & & 38,89 & 38,89 & & 38,88 & 38,88 & 35,82 & 35,32 \\
\hline & $\mathrm{A}_{101}$ & & 38,98 & 38,98 & & 38,73 & 38,73 & 35,75 & 35,42 \\
\hline & $\mathrm{A}_{103}$ & & 38,89 & 38,89 & & 39,06 & 39,06 & 35,85 & 35,28 \\
\hline & $A_{105}$ & & 39,00 & 39,00 & & 38,87 & 38,87 & 35,79 & 35,29 \\
\hline & $\mathrm{A}_{107}$ & & 38,93 & 38,93 & & 38,91 & 38,91 & 35,78 & 35,94 \\
\hline & $\mathrm{A}_{109}$ & & 38,88 & 38,88 & & 38,93 & 38,93 & 35,83 & 35,43 \\
\hline & $\mathrm{A}_{1011}$ & & 38,88 & 38,88 & 35,17 & 38,87 & 37,02 & 35,80 & 35,47 \\
\hline \multirow{7}{*}{$4-0$} & $A_{100}$ & 36,04 & 38,97 & 37,51 & 36,20 & 38,89 & 37,55 & 35,36 & 35,35 \\
\hline & $\mathrm{A}_{101}$ & 36,15 & 38,91 & 37,53 & 36,16 & 38,90 & 37,53 & 35,35 & 35,34 \\
\hline & $\mathrm{A}_{103}$ & 36,10 & 38,92 & 37,51 & 36,24 & 38,89 & 37,56 & 35,34 & 35,37 \\
\hline & $\mathrm{A}_{105}$ & 36,18 & 38,88 & 37,53 & 36,13 & 38,93 & 37,53 & 35,34 & 35,32 \\
\hline & $A_{107}$ & & 39,00 & 39,00 & 36,26 & 38,87 & 37,56 & 35,33 & 35,30 \\
\hline & $A_{109}$ & 36,41 & 38,91 & 37,66 & 36,21 & 38,92 & 37,57 & 35,34 & 35,32 \\
\hline & $\mathrm{A}_{1011}$ & 36,70 & 38,93 & 37,81 & 35,97 & 38,97 & 37,47 & 35,34 & 35,36 \\
\hline \multirow{7}{*}{ 5-1 } & $A_{100}$ & 36,19 & & 36,19 & 36,08 & & 36,08 & 35,34 & 35,43 \\
\hline & $\mathrm{A}_{101}$ & 36,23 & & 36,23 & 36,14 & & 36,14 & 35,38 & 35,41 \\
\hline & $\mathrm{A}_{103}$ & 36,41 & & 36,41 & 36,22 & & 36,22 & 35,33 & 35,43 \\
\hline & $A_{105}$ & 36,14 & & 36,14 & 36,22 & & 36,22 & 35,37 & 35,38 \\
\hline & $A_{107}$ & 36,32 & & 36,32 & 36,21 & & 36,21 & 35,39 & 35,43 \\
\hline & $A_{109}$ & 36,23 & & 36,23 & 36,23 & & 36,23 & 35,38 & 35,24 \\
\hline & $\mathrm{A}_{1011}$ & 36,22 & & 36,22 & 36,23 & & 36,23 & 35,37 & 35,31 \\
\hline \multirow{7}{*}{$6-2$} & $A_{100}$ & 36,25 & 38,80 & 37,52 & 36,13 & 39,06 & 37,59 & 35,89 & 35,92 \\
\hline & $\mathrm{A}_{101}$ & 36,18 & 39,06 & 37,62 & 36,20 & 38,92 & 37,56 & 35,92 & 35,93 \\
\hline & $\mathrm{A}_{103}$ & 36,13 & & 36,13 & 36,23 & 38,88 & 37,55 & 35,96 & 35,96 \\
\hline & $\mathrm{A}_{105}$ & 36,29 & 38,65 & 37,47 & 36,20 & 38,90 & 37,55 & 35,93 & 35,93 \\
\hline & $A_{107}$ & 36,25 & & 36,25 & 36,21 & 38,92 & 37,56 & 35,90 & 35,91 \\
\hline & $\mathrm{A}_{109}$ & 35,97 & 38,88 & 37,43 & 36,27 & 38,75 & 37,51 & 35,91 & 35,86 \\
\hline & $\mathrm{A}_{1011}$ & 36,22 & 38,82 & 37,52 & 36,20 & 38,89 & 37,55 & 35,97 & 35,91 \\
\hline \multirow{7}{*}{$7-3$} & $A_{100}$ & & 38,92 & 38,92 & 36,18 & 38,89 & 37,54 & 35,86 & 35,82 \\
\hline & $\mathrm{A}_{101}$ & & 38,93 & 38,93 & 36,19 & 38,89 & 37,54 & 35,81 & 35,83 \\
\hline & $\mathrm{A}_{103}$ & & 38,98 & 38,98 & 36,37 & 38,90 & 37,64 & 35,84 & 35,80 \\
\hline & $A_{105}$ & 36,80 & 39,02 & 37,91 & 36,21 & 38,89 & 37,55 & 35,78 & 35,88 \\
\hline & $A_{107}$ & 35,51 & 38,98 & 37,25 & 36,10 & 38,90 & 37,50 & 35,85 & 35,77 \\
\hline & $\mathrm{A}_{109}$ & & 39,22 & 39,22 & 36,20 & 38,89 & 37,55 & 35,82 & 35,33 \\
\hline & $\mathrm{A}_{1011}$ & & 38,81 & 38,81 & 36,48 & 38,89 & 37,68 & 35,84 & 35,82 \\
\hline & & 36,22 & 38,95 & 37,61 & 36,18 & 38,91 & 37,45 & 35,62 & 35,57 \\
\hline $\begin{array}{l}\text { Desvio } \\
\text { Coef. V }\end{array}$ & $\begin{array}{l}\text { adrão } \\
\text { iação }\end{array}$ & $\begin{array}{c}0,18 \\
0,5 \%\end{array}$ & $\begin{array}{l}0,14 \\
0,4 \%\end{array}$ & $\begin{array}{l}0,99 \\
2,6 \%\end{array}$ & $\begin{array}{c}0,16 \\
0,5 \%\end{array}$ & $\begin{array}{l}0,09 \\
0,2 \%\end{array}$ & $\begin{array}{c}0,73 \\
1,9 \%\end{array}$ & $\begin{array}{l}0,27 \\
0,7 \%\end{array}$ & $\begin{array}{c}0,27 \\
0,8 \%\end{array}$ \\
\hline
\end{tabular}


Tabela 4.7 - Frequências do $1^{\circ}$ modo de flexão das toras 3 e 4 para excitação nos planos horizontal e vertical.

\begin{tabular}{|c|c|c|c|c|c|c|c|c|c|c|c|c|c|}
\hline \multirow{3}{*}{ Plano } & \multirow{3}{*}{ FRF } & \multicolumn{6}{|c|}{ Tora 3} & \multicolumn{6}{|c|}{ Tora 4} \\
\hline & & \multicolumn{3}{|c|}{ Horizontal } & \multicolumn{3}{|c|}{ Vertical } & \multicolumn{3}{|c|}{ Horizontal } & \multicolumn{3}{|c|}{ Vertical } \\
\hline & & $1^{\circ}$ pico & $2^{\circ}$ pico & média & $1^{\circ}$ pico & $2^{\circ}$ pico & média & $1^{\circ}$ pico & $2^{\circ}$ pico & média & $1^{\circ}$ pico & $2^{\circ}$ pico & médie \\
\hline \multirow{7}{*}{$0-4$} & $A_{100}$ & 33,46 & 34,69 & 34,07 & 33,34 & 34,65 & 34,00 & 31,88 & 32,73 & 32,30 & 31,96 & 32,74 & 32,35 \\
\hline & $A_{101}$ & 33,35 & 34,61 & 33,98 & 33,33 & 34,58 & 33,95 & 31,99 & 32,81 & 32,40 & 32,04 & 32,75 & 32,39 \\
\hline & $A_{103}$ & 33,34 & & 33,34 & 33,34 & 34,65 & 33,99 & 31,97 & 32,76 & 32,37 & 31,95 & 32,78 & 32,36 \\
\hline & $A_{105}$ & 33,39 & 34,67 & 34,03 & 33,34 & 34,62 & 33,98 & 31,96 & 32,76 & 32,36 & 31,96 & 32,75 & 32,36 \\
\hline & $A_{107}$ & 33,34 & 34,61 & 33,98 & 33,34 & 34,64 & 33,99 & 31,96 & 32,77 & 32,37 & 31,95 & 32,76 & 32,36 \\
\hline & $A_{109}$ & 33,23 & & 33,23 & 33,31 & 34,64 & 33,98 & 31,96 & 32,76 & 32,36 & 31,87 & 32,83 & 32,35 \\
\hline & $\mathrm{A}_{1011}$ & 33,34 & 34,58 & 33,96 & 33,34 & 34,61 & 33,97 & 31,99 & 32,70 & 32,35 & 31,95 & 32,71 & 32,33 \\
\hline \multirow{7}{*}{$1-5$} & $A_{100}$ & 33,41 & & 33,41 & 33,40 & & 33,40 & & 32,75 & 32,75 & 32,77 & & 32,77 \\
\hline & $A_{101}$ & 33,40 & & 33,40 & 33,40 & & 33,40 & & 32,76 & 32,76 & 32,77 & & 32,77 \\
\hline & $\mathrm{A}_{103}$ & 33,40 & & 33,40 & 33,42 & & 33,42 & & 32,76 & 32,76 & 32,77 & & 32,77 \\
\hline & $A_{105}$ & 33,40 & & 33,40 & 33,39 & & 33,39 & & 32,76 & 32,76 & 32,77 & & 32,77 \\
\hline & $A_{107}$ & 33,40 & & 33,40 & 33,40 & & 33,40 & & 32,77 & 32,77 & 32,77 & & 32,77 \\
\hline & $A_{109}$ & 33,40 & & 33,40 & 33,40 & & 33,40 & & 32,77 & 32,77 & 32,77 & & 32,77 \\
\hline & $\mathrm{A}_{1011}$ & 33,39 & & 33,39 & 33,40 & & 33,40 & & 32,71 & 32,71 & 32,75 & & 32,75 \\
\hline \multirow{7}{*}{$2-6$} & $A_{100}$ & 33,37 & 34,75 & 34,06 & 33,38 & 34,72 & 34,05 & & 32,82 & 32,82 & 32,06 & 32,91 & 32,49 \\
\hline & $A_{101}$ & 33,59 & 34,64 & 34,12 & 33,31 & 34,78 & 34,05 & & 32,48 & 32,48 & 32,05 & 32,93 & 32,49 \\
\hline & $\mathrm{A}_{103}$ & 33,38 & 34,71 & 34,04 & 33,33 & 34,82 & 34,08 & & 32,53 & 32,53 & 32,08 & 32,89 & 32,48 \\
\hline & $\mathrm{A}_{105}$ & 33,45 & 34,61 & 34,03 & 33,37 & 34,72 & 34,05 & 31,06 & 32,76 & 31,91 & 32,07 & 32,95 & 32,51 \\
\hline & $A_{107}$ & & 34,46 & 34,46 & 33,36 & 34,71 & 34,04 & & 32,66 & 32,66 & 32,22 & 32,82 & 32,52 \\
\hline & $\mathrm{A}_{109}$ & 33,32 & 34,71 & 34,02 & 33,47 & 34,68 & 34,07 & & 32,58 & 32,58 & 32,06 & 32,94 & 32,50 \\
\hline & $\mathrm{A}_{1011}$ & & 34,25 & 34,25 & 33,10 & 34,89 & 34,00 & & 32,54 & 32,54 & 31,98 & 32,93 & 32,46 \\
\hline & $A_{100}$ & & 34,69 & 34,69 & & 34,69 & 34,69 & & 32,11 & 32,11 & 32,11 & & 32,11 \\
\hline & $\mathrm{A}_{101}$ & & 34,68 & 34,68 & & 34,70 & 34,70 & & 32,13 & 32,13 & 32,14 & & 32,14 \\
\hline & $\mathrm{A}_{103}$ & & 34,73 & 34,73 & & 34,71 & 34,71 & & 32,10 & 32,10 & 32,12 & & 32,12 \\
\hline 3-7 & $\mathrm{A}_{105}$ & & 34,68 & 34,68 & & 34,67 & 34,67 & & 32,12 & 32,12 & 32,11 & & 32,11 \\
\hline & $\mathrm{A}_{107}$ & & 34,68 & 34,68 & & 34,67 & 34,67 & & 32,12 & 32,12 & 32,12 & & 32,12 \\
\hline & $\mathrm{A}_{109}$ & & 34,68 & 34,68 & & 34,68 & 34,68 & & 32,13 & 32,13 & 32,12 & & 32,12 \\
\hline & $\mathrm{A}_{1011}$ & & 34,66 & 34,66 & & 34,66 & 34,66 & & 32,12 & 32,12 & 32,11 & & 32,11 \\
\hline & $\mathrm{A}_{100}$ & & 34,06 & 34,06 & 33,41 & 34,65 & 34,03 & & 32,61 & 32,61 & 32,13 & & 32,13 \\
\hline & $\mathrm{A}_{101}$ & 33,31 & 35,34 & 34,32 & 33,42 & 34,60 & 34,01 & & 32,30 & 32,30 & 32,17 & 32,94 & 32,56 \\
\hline & $\mathrm{A}_{103}$ & 33,38 & & 33,38 & 33,46 & 34,57 & 34,02 & & 32,47 & 32,47 & 31,89 & 32,96 & 32,43 \\
\hline $4-0$ & $A_{105}$ & 33,64 & 34,69 & 34,16 & 33,37 & 34,78 & 34,08 & & 32,43 & 32,43 & 31,90 & 32,99 & 32,44 \\
\hline & $\mathrm{A}_{107}$ & 33,31 & & 33,31 & 33,35 & 34,55 & 33,95 & & 32,50 & 32,50 & 32,13 & 32,91 & 32,52 \\
\hline & $A_{109}$ & 33,50 & & 33,50 & 33,37 & 34,78 & 34,07 & & 32,42 & 32,42 & 32,11 & 32,94 & 32,53 \\
\hline & $\mathrm{A}_{1011}$ & 33,39 & & 33,39 & & & & & 32,45 & 32,45 & 31,87 & 32,93 & 32,40 \\
\hline & $A_{100}$ & 33,40 & & 33,40 & 33,39 & & 33,39 & & 32,88 & 32,88 & & 32,86 & 32,86 \\
\hline & $A_{101}$ & 33,42 & & 33,42 & 33,41 & & 33,41 & & 32,87 & 32,87 & & 32,87 & 32,87 \\
\hline & $\mathrm{A}_{103}$ & 33,40 & & 33,40 & 33,41 & & 33,41 & & 32,87 & 32,87 & & 32,87 & 32,87 \\
\hline $5-1$ & $\mathrm{~A}_{105}$ & 33,55 & & 33,55 & 33,40 & & 33,40 & & 32,87 & 32,87 & & 32,86 & 32,86 \\
\hline & $\mathrm{A}_{107}$ & 33,41 & & 33,41 & 33,41 & & 33,41 & & 32,89 & 32,89 & & 32,81 & 32,81 \\
\hline & $A_{109}$ & 33,41 & & 33,41 & 33,41 & & 33,41 & & 32,89 & 32,89 & & 32,86 & 32,86 \\
\hline & $\mathrm{A}_{1011}$ & 33,40 & & 33,40 & 33,35 & & 33,35 & & 32,89 & 32,89 & & 32,86 & 32,86 \\
\hline & $A_{100}$ & & 34,19 & 34,19 & & 34,78 & 34,78 & & 32,58 & 32,58 & 32,07 & 32,89 & 32,48 \\
\hline & $\mathrm{A}_{101}$ & 33,44 & 34,92 & 34,18 & 33,39 & 34,70 & 34,04 & & 32,72 & 32,72 & 32,07 & 32,89 & 32,48 \\
\hline & $\mathrm{A}_{103}$ & 33,43 & 34,74 & 34,09 & 33,25 & 34,75 & 34,00 & & 32,49 & 32,49 & 32,09 & 32,89 & 32,49 \\
\hline $6-2$ & $\mathrm{~A}_{105}$ & 33,42 & 34,85 & 34,13 & 33,40 & 34,68 & 34,04 & & 32,57 & 32,57 & 32,11 & 32,89 & 32,50 \\
\hline & $A_{107}$ & 33,85 & 34,70 & 34,28 & 33,40 & 34,66 & 34,03 & & 32,63 & 32,63 & 32,17 & 32,87 & 32,52 \\
\hline & $\mathrm{A}_{109}$ & 33,55 & 34,69 & 34,12 & 33,40 & 34,68 & 34,04 & & 32,59 & 32,59 & 32,09 & 32,90 & 32,50 \\
\hline & $\mathrm{A}_{1011}$ & & 34,47 & 34,47 & 33,40 & 34,68 & 34,04 & & 32,69 & 32,69 & 32,23 & 32,81 & 32,52 \\
\hline & $\mathrm{A}_{100}$ & & 34,68 & 34,68 & & 34,62 & 34,62 & & 32,09 & 32,09 & 32,08 & & 32,08 \\
\hline & $A_{101}$ & & 34,68 & 34,68 & & 34,68 & 34,68 & & 32,09 & 32,09 & 32,09 & & 32,09 \\
\hline & $\mathrm{A}_{103}$ & & 34,67 & 34,67 & & 34,72 & 34,72 & & 32,10 & 32,10 & 32,08 & & 32,08 \\
\hline $7-3$ & $\mathrm{~A}_{105}$ & & 34,68 & 34,68 & & 34,68 & 34,68 & & 32,09 & 32,09 & 32,09 & & 32,09 \\
\hline & $A_{107}$ & & 34,67 & 34,67 & & 34,65 & 34,65 & & 32,10 & 32,10 & 32,25 & & 32,25 \\
\hline & $\mathrm{A}_{109}$ & & 34,70 & 34,70 & & 34,69 & 34,69 & & 32,09 & 32,09 & 32,10 & & 32,10 \\
\hline & $\mathrm{A}_{1011}$ & & 34,67 & 34,67 & & 34,67 & 34,67 & & 32,11 & 32,11 & 32,08 & & 32,08 \\
\hline & & 33,42 & 34,65 & 34,01 & 33,37 & 34,68 & 34,04 & 31,84 & 32,54 & 32,47 & 32,17 & 32,87 & 32,45 \\
\hline Desvio & badrão & 0,11 & 0,20 & 0,52 & 0,06 & 0,07 & 0,47 & 0,321 & 0,283 & 0,28 & 0,261 & 0,070 & 0,26 \\
\hline Coef. V & iação & $0,3 \%$ & $0,6 \%$ & $1,5 \%$ & $0,2 \%$ & $0,2 \%$ & $1,4 \%$ & $1,0 \%$ & $0,9 \%$ & $0,9 \%$ & $0,8 \%$ & $0,2 \%$ & $0,8 \%$ \\
\hline
\end{tabular}


Tabela 4.8 - Frequências do $1^{\circ}$ modo de flexão das toras 5, 6 e 7 para excitação no plano horizontal.

\begin{tabular}{|c|c|c|c|c|c|c|c|c|}
\hline \multirow[b]{2}{*}{ Plano } & \multirow[b]{2}{*}{ FRF } & \multirow[b]{2}{*}{ Tora 5} & \multicolumn{3}{|c|}{ Tora 6} & \multicolumn{3}{|c|}{ Tora 7} \\
\hline & & & $1^{\circ}$ pico & $2^{\circ}$ pico & média & $1^{\circ}$ pico & $2^{\circ}$ pico & média \\
\hline \multirow{7}{*}{$0-4$} & $A_{100}$ & 33,33 & 32,19 & 33,89 & 33,04 & 33,32 & & 33,32 \\
\hline & $\mathrm{A}_{101}$ & 33,29 & 32,06 & 33,92 & 32,99 & 33,24 & & 33,24 \\
\hline & $\mathrm{A}_{103}$ & 33,37 & 32,30 & 33,69 & 33,00 & 33,36 & & 33,36 \\
\hline & $A_{105}$ & 33,29 & 32,40 & 33,89 & 33,14 & 33,36 & & 33,36 \\
\hline & $A_{107}$ & 33,30 & 32,17 & 33,72 & 32,94 & 33,37 & & 33,37 \\
\hline & $A_{109}$ & 33,31 & 32,11 & 33,76 & 32,93 & 33,32 & & 33,32 \\
\hline & $A_{1011}$ & 33,29 & 32,02 & 33,79 & 32,90 & 33,36 & & 33,36 \\
\hline \multirow{7}{*}{$1-5$} & $A_{100}$ & 32,30 & 32,17 & & 32,17 & 33,48 & 36,70 & 35,09 \\
\hline & $\mathrm{A}_{101}$ & 32,42 & 32,19 & & 32,19 & 33,64 & 36,65 & 35,15 \\
\hline & $\mathrm{A}_{103}$ & 32,30 & 32,18 & & 32,18 & 33,37 & 36,75 & 35,06 \\
\hline & $\mathrm{A}_{105}$ & 32,28 & 32,18 & & 32,18 & 33,39 & 36,84 & 35,11 \\
\hline & $A_{107}$ & 32,36 & 32,22 & & 32,22 & 33,31 & 36,75 & 35,03 \\
\hline & $A_{109}$ & 32,34 & 32,19 & & 32,19 & 33,13 & 36,74 & 34,93 \\
\hline & $\mathrm{A}_{1011}$ & 32,27 & 32,16 & & 32,16 & 33,27 & 36,73 & 35,00 \\
\hline \multirow{7}{*}{$2-6$} & $\mathrm{~A}_{100}$ & 32,41 & 32,23 & & 32,23 & 33,31 & 36,75 & 35,03 \\
\hline & $A_{101}$ & 32,40 & 32,25 & 33,48 & 32,86 & & 36,79 & 36,79 \\
\hline & $\mathrm{A}_{103}$ & 32,31 & 32,17 & 33,70 & 32,94 & & 36,65 & 36,65 \\
\hline & $A_{105}$ & 32,42 & 32,18 & 33,72 & 32,95 & 33,23 & 36,73 & 34,98 \\
\hline & $A_{107}$ & 32,36 & 32,21 & 33,59 & 32,90 & & 36,77 & 36,77 \\
\hline & $A_{109}$ & 32,43 & 32,18 & 33,64 & 32,91 & 33,57 & 36,71 & 35,14 \\
\hline & $\mathrm{A}_{1011}$ & 32,36 & 32,34 & & 32,34 & & 36,67 & 36,67 \\
\hline \multirow{7}{*}{$3-7$} & $\mathrm{~A}_{100}$ & 33,35 & & 33,60 & 33,60 & 33,36 & 36,63 & 35,00 \\
\hline & $\mathrm{A}_{101}$ & 33,19 & & 33,72 & 33,72 & 33,38 & 36,66 & 35,02 \\
\hline & $\mathrm{A}_{103}$ & 33,23 & & 33,75 & 33,75 & 33,32 & 36,74 & 35,03 \\
\hline & $\mathrm{A}_{105}$ & 33,27 & & 33,70 & 33,70 & 33,37 & 36,84 & 35,10 \\
\hline & $\mathrm{A}_{107}$ & 33,22 & & 33,73 & 33,73 & 33,33 & 36,72 & 35,03 \\
\hline & $\mathrm{A}_{109}$ & 33,27 & & 33,69 & 33,69 & 33,35 & 36,70 & 35,03 \\
\hline & $\mathrm{A}_{1011}$ & 33,25 & & 33,69 & 33,69 & 33,41 & 36,55 & 34,98 \\
\hline \multirow{7}{*}{$4-0$} & $A_{100}$ & 33,35 & 32,25 & 33,71 & 32,98 & 33,29 & & 33,29 \\
\hline & $\mathrm{A}_{101}$ & 33,23 & 32,22 & 33,68 & 32,95 & 33,34 & & 33,34 \\
\hline & $\mathrm{A}_{103}$ & 33,25 & & 33,72 & 33,72 & 33,31 & & 33,31 \\
\hline & $\mathrm{A}_{105}$ & 33,31 & 32,26 & 33,70 & 32,98 & 33,35 & & 33,35 \\
\hline & $\mathrm{A}_{107}$ & 33,31 & & 33,54 & 33,54 & 33,37 & & 33,37 \\
\hline & $\mathrm{A}_{109}$ & 33,36 & 32,15 & 33,73 & 32,94 & 33,33 & & 33,33 \\
\hline & $\mathrm{A}_{1011}$ & 33,31 & 32,24 & 33,68 & & 33,39 & & 33,39 \\
\hline \multirow{7}{*}{$5-1$} & $\mathrm{~A}_{100}$ & 32,35 & 32,14 & & 32,14 & 33,37 & 36,83 & 35,10 \\
\hline & $\mathrm{A}_{101}$ & 32,25 & 32,13 & & 32,13 & 33,66 & 36,79 & 35,22 \\
\hline & $\mathrm{A}_{103}$ & 32,18 & 32,19 & & 32,19 & 33,49 & 36,79 & 35,14 \\
\hline & $\mathrm{A}_{105}$ & 32,46 & 32,18 & & 32,18 & 33,52 & 36,81 & 35,16 \\
\hline & $\mathrm{A}_{107}$ & 32,40 & 32,18 & & 32,18 & & 36,53 & 36,53 \\
\hline & $\mathrm{A}_{109}$ & 32,39 & 32,15 & & 32,15 & 33,50 & 36,80 & 35,15 \\
\hline & $\mathrm{A}_{1011}$ & 32,39 & 32,17 & & 32,17 & & & \\
\hline \multirow{7}{*}{$6-2$} & $\mathrm{~A}_{100}$ & 32,29 & 32,21 & & 32,21 & 33,53 & 36,79 & 35,16 \\
\hline & $\mathrm{A}_{101}$ & 32,26 & 32,15 & 33,71 & 32,93 & & 36,83 & 36,83 \\
\hline & $\mathrm{A}_{103}$ & 32,34 & 32,13 & 33,81 & 32,97 & & 36,77 & 36,77 \\
\hline & $\mathrm{A}_{105}$ & 32,26 & 32,14 & & 32,14 & & 36,84 & 36,84 \\
\hline & $\mathrm{A}_{107}$ & 32,27 & 32,16 & 33,73 & 32,95 & & 36,80 & 36,80 \\
\hline & $A_{109}$ & 32,29 & 32,21 & 33,48 & 32,85 & & 36,78 & 36,78 \\
\hline & $\mathrm{A}_{1011}$ & 32,31 & 32,14 & 33,66 & 32,90 & & 36,82 & 36,82 \\
\hline \multirow{7}{*}{$7-3$} & $A_{100}$ & 33,37 & & 33,76 & 33,76 & 33,44 & 36,99 & 35,21 \\
\hline & $\mathrm{A}_{101}$ & 33,34 & & 33,69 & 33,69 & 33,43 & 36,82 & 35,12 \\
\hline & $\mathrm{A}_{103}$ & 33,39 & & 33,77 & 33,77 & 33,42 & 37,08 & 35,25 \\
\hline & $\mathrm{A}_{105}$ & 33,36 & & 33,71 & 33,71 & 33,46 & 37,37 & 35,42 \\
\hline & $\mathrm{A}_{107}$ & 33,32 & & 33,70 & 33,70 & 33,46 & 36,85 & 35,15 \\
\hline & $\mathrm{A}_{109}$ & 33,36 & & 33,74 & 33,74 & 33,42 & 37,16 & 35,29 \\
\hline & $A_{1011}$ & 33,36 & & 33,73 & 33,73 & 33,44 & 36,95 & 35,19 \\
\hline \multicolumn{2}{|c|}{ Média } & 32,82 & 32,19 & 33,71 & 32,92 & 33,39 & 36,79 & 34,99 \\
\hline \multicolumn{2}{|c|}{$\begin{array}{l}\text { Desvio padrão } \\
\text { Coef. Variação }\end{array}$} & $\begin{array}{l}0,49 \\
1,5 \%\end{array}$ & $\begin{array}{l}0,07 \\
0,2 \%\end{array}$ & $\begin{array}{l}0,09 \\
0,3 \%\end{array}$ & $\begin{array}{l}0,60 \\
1,8 \%\end{array}$ & $\begin{array}{l}0,10 \\
0,3 \%\end{array}$ & $\begin{array}{l}0,15 \\
0,4 \%\end{array}$ & $\begin{array}{r}1,16 \\
3,3 \%\end{array}$ \\
\hline
\end{tabular}


Tabela 4.9 - Frequências do $1^{\circ}$ modo de flexão das toras 8,9 e 10 para excitação no plano horizontal.

\begin{tabular}{|c|c|c|c|c|c|c|c|c|}
\hline \multirow{2}{*}{ Plano } & \multirow[b]{2}{*}{ FRF } & \multicolumn{3}{|c|}{ Tora 8} & \multicolumn{3}{|c|}{ Tora 9} & \multirow{2}{*}{ Tora 10} \\
\hline & & $1^{\circ}$ pico & $2^{\circ}$ pico & média & $1^{\circ}$ pico & $2^{\circ}$ pico & média & \\
\hline \multirow{7}{*}{$0-4$} & $A_{100}$ & & 35,70 & 35,70 & 32,05 & 33,72 & 32,88 & 34,03 \\
\hline & $A_{101}$ & & 35,75 & 35,75 & 32,06 & 33,73 & 32,89 & 34,13 \\
\hline & $\mathrm{A}_{103}$ & & 35,79 & 35,79 & 32,00 & 33,83 & 32,92 & 34,17 \\
\hline & $A_{105}$ & & 35,68 & 35,68 & 32,06 & 33,72 & 32,89 & 34,16 \\
\hline & $A_{107}$ & & 35,71 & 35,71 & 32,07 & 33,69 & 32,88 & 34,15 \\
\hline & $A_{109}$ & & 35,68 & 35,68 & 32,07 & 33,71 & 32,89 & 34,15 \\
\hline & $\mathrm{A}_{1011}$ & & 35,72 & 35,72 & & & & \\
\hline \multirow{6}{*}{$1-5$} & $A_{100}$ & 34,34 & 35,67 & 35,00 & & 33,70 & 33,70 & 33,83 \\
\hline & $A_{101}$ & 34,23 & 35,70 & 34,97 & & 33,70 & 33,70 & 33,84 \\
\hline & $\mathrm{A}_{103}$ & 34,22 & 35,69 & 34,96 & & 33,75 & 33,75 & 33,86 \\
\hline & $A_{105}$ & & 35,61 & 35,61 & & 33,74 & 33,74 & 33,85 \\
\hline & $A_{107}$ & & 35,62 & 35,62 & & 33,72 & 33,72 & 33,87 \\
\hline & $\begin{array}{l}A_{109} \\
A_{1011}\end{array}$ & & 35,98 & 35,98 & & 33,71 & 33,71 & 33,85 \\
\hline \multirow{7}{*}{$2-6$} & $A_{100}$ & 34,15 & 35,78 & 34,97 & 32,13 & 33,70 & 32,92 & 34,04 \\
\hline & $A_{101}$ & 34,12 & 35,93 & 35,02 & 32,10 & 33,73 & 32,91 & 33,95 \\
\hline & $\mathrm{A}_{103}$ & 34,17 & 35,65 & 34,91 & 32,15 & 33,68 & 32,91 & 34,03 \\
\hline & $A_{105}$ & 34,15 & 35,73 & 34,94 & 32,05 & 33,73 & 32,89 & 33,98 \\
\hline & $A_{107}$ & 34,16 & 35,74 & 34,95 & 32,12 & 33,71 & 32,91 & 34,05 \\
\hline & $A_{109}$ & 34,20 & & 34,20 & 31,96 & 33,84 & 32,90 & 33,98 \\
\hline & $A_{1011}$ & 34,16 & 35,77 & 34,96 & & & & \\
\hline \multirow{7}{*}{$3-7$} & $A_{100}$ & 34,15 & 35,75 & 34,95 & 32,05 & & 32,05 & 34,31 \\
\hline & $A_{101}$ & 34,23 & 35,81 & 35,02 & 32,03 & & 32,03 & 34,27 \\
\hline & $\mathrm{A}_{103}$ & 34,15 & 35,73 & 34,94 & 32,11 & & 32,11 & 34,30 \\
\hline & $\mathrm{A}_{105}$ & 34,15 & 35,72 & 34,93 & 32,06 & & 32,06 & 34,28 \\
\hline & $A_{107}$ & 34,12 & 35,88 & 35,00 & 32,06 & & 32,06 & 34,28 \\
\hline & $A_{109}$ & 34,15 & 35,74 & 34,95 & 32,05 & & 32,05 & 34,28 \\
\hline & $A_{1011}$ & 34,21 & 35,54 & 34,88 & & & & \\
\hline \multirow{7}{*}{$4-0$} & $\mathrm{~A}_{100}$ & 34,17 & 35,71 & 34,94 & 32,03 & 33,73 & 32,88 & 34,09 \\
\hline & $A_{101}$ & 34,15 & 35,71 & 34,93 & 32,08 & 33,68 & 32,88 & 34,13 \\
\hline & $\mathrm{A}_{103}$ & 34,13 & 35,72 & 34,93 & 32,07 & 33,57 & 32,82 & 34,25 \\
\hline & $\mathrm{A}_{105}$ & 34,14 & 35,72 & 34,93 & 32,07 & 33,79 & 32,93 & 34,15 \\
\hline & $A_{107}$ & 34,09 & 35,73 & 34,91 & 32,04 & 33,72 & 32,88 & 34,23 \\
\hline & $A_{109}$ & 34,17 & 35,71 & 34,94 & 31,98 & 34,02 & 33,00 & 34,19 \\
\hline & $A_{1011}$ & 34,09 & 35,71 & & & & & \\
\hline \multirow{7}{*}{$5-1$} & $\mathrm{~A}_{100}$ & 34,31 & 35,46 & 34,89 & & 33,73 & 33,73 & 33,95 \\
\hline & $A_{101}$ & 34,14 & 35,71 & 34,93 & & 33,73 & 33,73 & 33,97 \\
\hline & $\mathrm{A}_{103}$ & 34,19 & 35,77 & 34,98 & & 33,80 & 33,80 & 33,92 \\
\hline & $A_{105}$ & 35,68 & & 35,68 & & 33,72 & 33,72 & 33,95 \\
\hline & $\mathrm{A}_{107}$ & 35,81 & & 35,81 & & 33,72 & 33,72 & 33,94 \\
\hline & $A_{109}$ & 33,84 & 35,77 & 34,81 & & 33,71 & 33,71 & 33,95 \\
\hline & $\mathrm{A}_{1011}$ & 34,17 & 35,70 & 34,93 & & & & \\
\hline \multirow{7}{*}{$6-2$} & $A_{100}$ & 34,15 & 35,72 & 34,93 & 32,09 & 33,70 & 32,90 & 34,03 \\
\hline & $A_{101}$ & 34,15 & 35,79 & 34,97 & 32,06 & 33,72 & 32,89 & 34,02 \\
\hline & $\mathrm{A}_{103}$ & 34,15 & 35,82 & 34,98 & 31,99 & 33,76 & 32,88 & 34,10 \\
\hline & $\mathrm{A}_{105}$ & 34,13 & 35,77 & 34,95 & 32,06 & 33,69 & 32,88 & 34,04 \\
\hline & $\mathrm{A}_{107}$ & 34,16 & 35,73 & 34,94 & 31,98 & 33,73 & 32,86 & 34,05 \\
\hline & $A_{109}$ & 34,16 & 35,70 & 34,93 & 31,94 & 33,76 & 32,85 & 34,05 \\
\hline & $\mathrm{A}_{1011}$ & 34,16 & 35,70 & 34,93 & & & & \\
\hline \multirow{7}{*}{$7-3$} & $\mathrm{~A}_{100}$ & 34,17 & 35,62 & 34,90 & 32,09 & & 32,09 & 34,37 \\
\hline & $A_{101}$ & 34,14 & 35,76 & 34,95 & 32,05 & & 32,05 & 34,34 \\
\hline & $\mathrm{A}_{103}$ & 34,17 & 35,63 & 34,90 & 32,06 & & 32,06 & 34,39 \\
\hline & $A_{105}$ & 34,16 & 35,66 & 34,91 & 32,05 & & 32,05 & 34,34 \\
\hline & $\mathrm{A}_{107}$ & 34,15 & 35,79 & 34,97 & 32,06 & & 32,06 & 34,35 \\
\hline & $A_{109}$ & 34,16 & 35,75 & 34,95 & 32,04 & & 32,04 & 34,34 \\
\hline & $\mathrm{A}_{1011}$ & 34,16 & 35,66 & 34,91 & & & & \\
\hline \multirow{3}{*}{\multicolumn{2}{|c|}{$\begin{array}{l}\text { Média } \\
\text { vio padrão } \\
\text { f. Variação }\end{array}$}} & 34,23 & 35,72 & 35,10 & 32,05 & 33,73 & 32,89 & 34,10 \\
\hline & & 0,338 & 0,083 & 0,36 & 0,045 & 0,067 & 0,60 & 0,165 \\
\hline & & $1,0 \%$ & $0,2 \%$ & $1,0 \%$ & $0,1 \%$ & $0,2 \%$ & $1,8 \%$ & $0,5 \%$ \\
\hline
\end{tabular}


Tabela 4.10 - Frequências naturais das toras TB-1 a TB-5 obtidas com excitação no plano horizontal.

\begin{tabular}{|c|c|c|c|c|c|c|c|c|c|c|c|c|c|c|c|c|}
\hline \multirow{3}{*}{ Plano } & \multirow{3}{*}{ FRF } & \multicolumn{3}{|c|}{ TB-1 } & \multicolumn{3}{|c|}{ TB-2 } & \multicolumn{3}{|c|}{ TB-3 } & \multicolumn{3}{|c|}{ TB-4 } & \multicolumn{3}{|c|}{ TB-5 } \\
\hline & & \multicolumn{2}{|c|}{ Pico } & \multirow{2}{*}{ Média } & \multicolumn{2}{|c|}{ Pico } & \multirow{2}{*}{ Média } & \multicolumn{2}{|c|}{ Pico } & \multirow{2}{*}{ Média } & \multicolumn{2}{|c|}{ Pico } & \multirow{2}{*}{ Média } & \multicolumn{2}{|c|}{ Pico } & \multirow{2}{*}{ Média } \\
\hline & & $1^{\circ}$ & $2^{\circ}$ & & $1^{\circ}$ & $2^{\circ}$ & & $1^{\circ}$ & $2^{\circ}$ & & $1^{\circ}$ & $2^{\circ}$ & & $1^{\circ}$ & $2^{\circ}$ & \\
\hline \multirow{3}{*}{$0-4$} & $A_{120}$ & 162,65 & $\begin{array}{l}5174,97 \\
\end{array}$ & 168,81 & 147,42 & & 147,42 & 143,96 & 1477,49 & 145,72 & 143,40 & 149,54 & 146,47 & & 150,45 & 150,45 \\
\hline & $A_{122}$ & 162,48 & \begin{tabular}{l|l}
3 & 175,07
\end{tabular} & 168,78 & 147,48 & & 147,48 & 143,82 & 147,81 & 145,81 & 143,48 & & 143,48 & & 150,39 & 150,39 \\
\hline & $A_{123}$ & 162,46 & $\begin{array}{ll}175,08 \\
\end{array}$ & 168,77 & 147,45 & & 147,45 & 143,72 & 147,72 & 145,72 & 143,46 & & 143,46 & & 150,47 & 150,47 \\
\hline \multirow{3}{*}{$1-5$} & $A_{120}$ & 162,34 & \begin{tabular}{|l|l}
175,14 \\
\end{tabular} & 168,74 & \begin{tabular}{|l}
147,44 \\
\end{tabular} & 154,27 & 150,86 & 143,88 & & \begin{tabular}{|l|}
143,88 \\
\end{tabular} & 143,70 & 149,27 & \begin{tabular}{|l|}
146,48 \\
\end{tabular} & 143,44 & 150,47 & 146,96 \\
\hline & $A_{122}$ & 162,41 & 175,05 & 168,73 & 147,58 & 154,21 & 150,90 & 143,85 & & 143,85 & 143,35 & \begin{tabular}{|l|}
149,37 \\
\end{tabular} & 146,36 & 143,70 & 150,36 & 147,03 \\
\hline & $A_{123}$ & 162,29 & 175,19 & 168,74 & 147,46 & 154,35 & 150,91 & 143,86 & & 143,86 & 143,39 & 149,36 & 146,38 & 143,62 & 150,40 & 47,01 \\
\hline \multirow{3}{*}{$2-6$} & $A_{120}$ & 162,26 & 175,10 & 168,68 & & 154,27 & 154,27 & 143,86 & & 143,86 & 142,37 & & 142,37 & 143,52 & & 143,52 \\
\hline & 122 & 162,35 & 175,02 & 168,68 & & 154,36 & 154,36 & 143,90 & 147,82 & 145,86 & & 149,25 & 149,25 & 143,54 & & 143,54 \\
\hline & $A_{123}$ & 162,37 & 174,98 & 168,67 & & 154,31 & 154,31 & 143,93 & 148,09 & 146,01 & & 149,25 & 149,25 & 143,55 & & 143,55 \\
\hline \multirow{3}{*}{ 3-7 } & $A_{120}$ & 162,39 & 174,82 & 168,60 & 147,28 & 154,44 & 150,86 & 147,69 & & 147,69 & 143,33 & 149,98 & 146,66 & 143,68 & 150,28 & 146,98 \\
\hline & $A_{122}$ & 162,23 & 174,85 & 168,54 & 147,49 & 154,30 & 150,89 & 147,73 & & 147,73 & 143,29 & 149,31 & 146,30 & 143,56 & 150,57 & 147,07 \\
\hline & $A_{123}$ & 162,16 & 174,86 & 168,51 & 147,29 & 154,44 & 150,87 & 147,71 & & 147,71 & 143,32 & 149,21 & 146,26 & 143,58 & 150,62 & 147,10 \\
\hline \multirow{3}{*}{ 4-0 } & $A_{120}$ & 161,96 & 174,87 & 168,41 & 147,20 & & 147,20 & 143,96 & 147,46 & 145,71 & 143,25 & & 143,25 & & 150,44 & 150,44 \\
\hline & $A_{122}$ & 162,17 & 174,79 & 168,48 & 147,26 & & 147,26 & 143,93 & 147,72 & 145,83 & 143,27 & & 143,27 & & 150,41 & 150,41 \\
\hline & $A_{123}$ & 162,00 & 174,89 & 168,44 & 147,25 & & 147,25 & 143,93 & 147,66 & 145,80 & 143,28 & & 143,28 & & 150,47 & 150,47 \\
\hline \multirow{3}{*}{$5-1$} & $A_{120}$ & 162,21 & 174,44 & 168,32 & 147,18 & 154,00 & 150,59 & 143,79 & & 143,79 & 143,09 & & 143,09 & 143,42 & 150,60 & 147,01 \\
\hline & $A_{122}$ & 162,19 & 175,20 & 168,69 & 146,64 & 154,72 & 150,68 & 143,81 & & 143,81 & 143,39 & & 143,39 & 143,24 & 150,97 & 147,10 \\
\hline & $A_{123}$ & 162,18 & 175,05 & 168,61 & \begin{tabular}{|l|}
147,21 \\
\end{tabular} & 154,11 & 150,66 & 143,88 & & 143,88 & 142,93 & & 142,93 & 143,53 & 150,56 & \begin{tabular}{|l|}
147,05 \\
\end{tabular} \\
\hline \multirow{3}{*}{ 6-2 } & $A_{120}$ & 162,17 & 174,89 & 168,53 & & 154,08 & 154,08 & 143,93 & 147,67 & 145,80 & & 149,13 & 149,13 & 143,56 & & 143,56 \\
\hline & $A_{122}$ & 162,26 & 174,38 & 16 & & 154,11 & 154,11 & 143,76 & 147,71 & 145,74 & & \begin{tabular}{|l}
149,07 \\
\end{tabular} & 149,07 & 143,59 & & 143,59 \\
\hline & $A_{123}$ & 162,21 & 175,20 & 168,70 & & 154,12 & 154,12 & 143,69 & 147,81 & 145,75 & & 149,21 & 149,21 & 143,60 & & 143,60 \\
\hline \multirow{3}{*}{$7-3$} & $A_{120}$ & 161,84 & 174,83 & 168,33 & 147,12 & 154,04 & 150,58 & & 147,63 & 147,63 & 143,20 & 149,06 & 146,13 & 143,52 & 150,40 & 146,96 \\
\hline & $A_{122}$ & 162,21 & 174,82 & 168,52 & 147,07 & 154,14 & 150,61 & & 147,65 & 147,65 & 143,13 & 149,30 & 146,22 & 143,49 & 150,46 & 146,98 \\
\hline & $A_{123}$ & 162,78 & 174,01 & 168,39 & 147,11 & 154,12 & 150,61 & & 147,65 & 147,65 & 143,28 & 149,07 & 146,17 & 143,52 & 150,46 & 146,99 \\
\hline \multirow{2}{*}{\multicolumn{2}{|c|}{$\begin{array}{c}\text { Média } \\
\text { Desvio padrão } \\
\text { Coef. Variacão }\end{array}$}} & 162,27 & 174,90 & 168,58 & 147,27 & 154,24 & 150 & 14 & 147,71 & 145,70 & 143,26 & 149,29 & 145,74 & 143,54 & 150,49 & 147,01 \\
\hline & & & 0,2 & 01 & 0,2 & 0,18 & & 1,38 & 015 & 1,44 & 0,27 & 0,23 & 2,32 & 0,10 & 0,15 & $\begin{array}{l}2,48 \\
170\end{array}$ \\
\hline
\end{tabular}

Tabela 4.11 - Frequências naturais das toras TB-6 a TB-10 obtidas com excitação no plano horizontal.

\begin{tabular}{|c|c|c|c|c|c|c|c|c|c|c|c|c|c|c|c|c|}
\hline \multirow{3}{*}{ Plano } & \multirow{3}{*}{ FRF } & \multicolumn{3}{|c|}{ TB-6 } & \multicolumn{3}{|c|}{ TB-7 } & \multicolumn{3}{|c|}{ TB-8 } & \multicolumn{3}{|c|}{ TB-9 } & \multicolumn{3}{|c|}{ TB-10 } \\
\hline & & \multicolumn{2}{|c|}{ Pico } & \multirow{2}{*}{ Média } & \multicolumn{2}{|c|}{ Pico } & \multirow{2}{*}{ Média } & \multicolumn{2}{|c|}{ Pico } & \multirow{2}{*}{ Média } & \multicolumn{2}{|c|}{ Pico } & \multirow{2}{*}{ Média } & \multicolumn{2}{|c|}{ Pico } & \multirow{2}{*}{ Média } \\
\hline & & $1^{\circ}$ & $2^{\circ}$ & & $1^{\circ}$ & $2^{\circ}$ & & $1^{\circ}$ & $2^{\circ}$ & & $1^{\circ}$ & $2^{\circ}$ & & $1^{\circ}$ & $2^{\circ}$ & \\
\hline \multirow{3}{*}{$0-4$} & 20 & & 146,58 & 146,58 & 140,68 & & 140,68 & & 157,01 & 157,01 & 139,17 & 146,55 & 142,86 & 146,74 & 152,90 & $149, \varepsilon$ \\
\hline & $A_{122}$ & & $146,61 \mid$ & 146,61 & 140,70 & & 140,70 & & 157,00 & 157,00 & 138,86 & 146,65 & 142,76 & 147,07 & 152,47 & 149,77 \\
\hline & $A_{123}$ & & 146,64 & 146,64 & 140,70 & & 140,70 & & 157,03 & 157,03 & 138,60 & 146,75 & 142,68 & 147,22 & 152,21 & 49,72 \\
\hline \multirow{3}{*}{$1-5$} & $A_{120}$ & $\overline{1,18}$ & $\mid 146,71$ & 143,94 & 140,60 & 158,08 & 149,34 & 150,12 & 156,92 & 153,52 & & 146,66 & 146,66 & & 152,38 & 152,38 \\
\hline & $A_{122}$ & ,14 & 146,80 & 143,97 & 0,64 & 158,10 & 9,37 & 150,14 & 156,93 & 153,54 & & 146,68 & 146,68 & & 152,37 & 152,37 \\
\hline & $A_{123}$ & 0,97 & 146,83 & 143,90 & 0,65 & 158,14 & 149,39 & 150,05 & 157,00 & 153,53 & & 146,67 & $\mid$\begin{tabular}{|l|}
146,67 \\
\end{tabular} & & 152,39 & 152,3 \\
\hline \multirow{3}{*}{$2-6$} & $A_{120}$ & 141,32 & & 141,32 & & 158,06 & 158,06 & 150,04 & & 150,04 & 138,83 & 146,76 & 142,79 & 146,70 & 152,29 & 149,5 \\
\hline & $A_{122}$ & 141,33 & & 141,33 & & 158,17 & 158,17 & 150,09 & & 150,09 & 138,87 & 146,63 & 142,75 & 147,02 & 152,16 & 149 \\
\hline & $A_{123}$ & 141,31 & & 141,31 & & 158,13 & 158,13 & 150,08 & & 150,08 & 138,88 & 146,65 & 142,77 & 146,81 & 152,35 & 149,58 \\
\hline \multirow{3}{*}{$3-7$} & $A_{120}$ & 141,32 & 146,58 & 143,95 & 140,75 & 157,95 & 149,35 & 149,98 & 157,01 & 153,50 & 138,84 & & 138,84 & 147,01 & & 147,01 \\
\hline & $A_{122}$ & 1,29 & 146,60 & 143,94 & 140,72 & 158,07 & 149,40 & 150,04 & 157,01 & 153,52 & 138,84 & & 138,84 & 147,04 & & 47,04 \\
\hline & $A_{123}$ & 0,91 & 147,05 & 143,98 & 0,75 & 158,06 & 149,40 & 150,08 & 156,93 & 153,51 & 138,89 & & 138,89 & 147,01 & & 47,0 \\
\hline \multirow{3}{*}{$4-0$} & $A_{120}$ & & 146,59 & 146,59 & 10,69 & & 140,69 & & 157,02 & 157,02 & 138,54 & 146,98 & 142,76 & 146,78 & 152,56 & 149,6 \\
\hline & $A_{122}$ & & 146,62 & 146,62 & 140,69 & & 140,69 & & 157,01 & 157,01 & 139,04 & 146,28 & 142,66 & 147,03 & 152,38 & 149,7 \\
\hline & $A_{123}$ & & 146,62 & 146,62 & 140,69 & & 140,69 & & 157,03 & 157,03 & 138,83 & 146,66 & 142,75 & 147,01 & 152,41 & 149,7 \\
\hline \multirow{3}{*}{ 5-1 } & $\mathrm{A}_{120}$ & 1,41 & 146,52 & 143,97 & 140,54 & 158,10 & 149,32 & 150,04 & 156,85 & 153,45 & & 146,63 & 146,63 & & 152,43 & 152,43 \\
\hline & $A_{122}$ & 141,59 & $|146,37|$ & 143,98 & 140,65 & 158,02 & 149,33 & 150,13 & 156,82 & 153,48 & & 146,59 & 146,59 & & 152,34 & 152,34 \\
\hline & $A_{123}$ & 141,46 & 146,54 & 144,00 & 0,55 & 158,13 & 149,34 & 150,05 & 156,89 & 153,47 & & 146,57 & 146,57 & & 152,55 & 152,5 \\
\hline \multirow{3}{*}{ 6-2 } & $A_{120}$ & 141,39 & & 141,39 & & 158,06 & 158,06 & 150,12 & & 150,12 & 138,81 & 146,61 & 142,71 & 146,67 & 152,46 & 149,5 \\
\hline & & 1,36 & & 141,36 & & 158,07 & 158,07 & 150,10 & & 150,10 & 138,76 & 146,78 & 142,77 & 146,98 & 152,27 & 149,63 \\
\hline & $A_{123}$ & 141,37 & & 141,37 & & 158,14 & 158,14 & 150,09 & & 150,09 & 138,89 & 146,54 & 142,71 & 147,03 & 152,24 & 149,6 \\
\hline \multirow{3}{*}{$7-3$} & $A_{120}$ & 11,04 & 146,47 & 143,75 & 0,67 & 158,05 & 149,36 & 150,18 & 156,85 & 153,51 & 138,83 & & 138,83 & 146,94 & & $146, \subseteq$ \\
\hline & $A_{122}$ & 141,47 & 146,35 & 143,91 & 140,66 & 158,11 & 149,38 & 150,14 & 156,96 & 153,55 & 138,90 & 146,32 & 142,61 & 147,07 & & 147,0 \\
\hline & $A_{123}$ & 141,39 & 146,35 & 143,87 & 140,80 & 158,11 & 149,46 & 150,13 & 157,02 & 153,57 & 138,81 & 147,84 & 143,32 & 147,12 & & 147, \\
\hline \multirow{2}{*}{\multicolumn{2}{|c|}{$\begin{array}{l}\text { Desvio padrão } \\
\text { Coef. Variacão }\end{array}$}} & 141,29 & 146,60 & 143,95 & 140,67 & 158,09 & 149,38 & 150,09 & 156,96 & 153,53 & 138,85 & 146,69 & 143,09 & 146,96 & 152,40 & 149,69 \\
\hline & & & 0 & 1 & & $00 \%$ & & $0.0 \%$ & & & & & & & 0,16 & 10 \\
\hline
\end{tabular}


Tabela 4.12 - Frequências naturais das toras TT-1 a TT-5 obtidas com excitação no plano horizontal.

\begin{tabular}{|c|c|c|c|c|c|c|c|c|c|c|c|c|c|c|c|c|}
\hline \multirow{3}{*}{ Plano } & \multirow{3}{*}{ FRF } & \multicolumn{3}{|c|}{ TT-1 } & \multicolumn{3}{|c|}{ TT-2 } & \multicolumn{3}{|c|}{ TT-3 } & \multicolumn{3}{|c|}{ TT-4 } & \multicolumn{3}{|c|}{ TT-5 } \\
\hline & & \multicolumn{2}{|c|}{ Pico } & \multirow{2}{*}{ Média } & \multicolumn{2}{|c|}{ Pico } & \multirow{2}{*}{ Média } & \multicolumn{2}{|c|}{ Pico } & \multirow{2}{*}{ Média } & \multicolumn{2}{|c|}{ Pico } & \multirow{2}{*}{ Média } & \multicolumn{2}{|c|}{ Pico } & \multirow{2}{*}{ Média } \\
\hline & & $1^{\circ}$ & $2^{\circ}$ & & $1^{\circ}$ & $2^{\circ}$ & & $1^{\circ}$ & $2^{\circ}$ & & $1^{\circ}$ & $2^{\circ}$ & & $1^{\circ}$ & $2^{\circ}$ & \\
\hline \multirow{3}{*}{$0-4$} & $A_{105}$ & 158,79 & 165,57 & 162,18 & 149,45 & 156,48 & 152,96 & 140,60 & \begin{tabular}{|l|l}
146,84 \\
\end{tabular} & 143,72 & 136,76 & 139,19 & 137,97 & & 140,27 & 140,27 \\
\hline & $A_{107}$ & 158,84 & 165,63 & 162,23 & 149,52 & 156,57 & 153,05 & 140,56 & 147,04 & 143,80 & 136,88 & 139,25 & 138,06 & & 139,85 & 139,85 \\
\hline & $A_{108}$ & 158,84 & 165,64 & 162,24 & 149,53 & 156,57 & 153,05 & 140,73 & 146,77 & 143,75 & 136,98 & 139,29 & 138,13 & & 139,90 & 139,90 \\
\hline \multirow{3}{*}{$1-5$} & $A_{105}$ & 158,74 & 165,97 & 162,36 & 149,51 & 156,92 & 153,21 & 140,71 & & 140,71 & & 139,21 & 139,21 & 135,82 & 139,79 & 137,80 \\
\hline & $A_{107}$ & 158,80 & 165,60 & 162,20 & 149,67 & & 149,67 & 140,76 & & 140,76 & & 139,24 & 139,24 & 135,76 & 139,78 & 137,77 \\
\hline & $A_{108}$ & 158,78 & 165,63 & 162,20 & 149,56 & 156,55 & 153,06 & 140,75 & & 140,75 & & 139,20 & 139,20 & 135,72 & 140,05 & 137,89 \\
\hline \multirow{3}{*}{$2-6$} & $A_{105}$ & 158,70 & 165,48 & 162,09 & 149,72 & 156,37 & 153,04 & 140,36 & 146,73 & 143,54 & 136,72 & 139,32 & 138,02 & 135,54 & & 135,54 \\
\hline & $A_{107}$ & 158,82 & 165,52 & 162,17 & 149,58 & 156,49 & 153,03 & 140,53 & 146,73 & 143,63 & 137,17 & 139,18 & 138,17 & 135,82 & & 135,82 \\
\hline & $A_{108}$ & 158,76 & 165,66 & 162,21 & 149,66 & 156,48 & 153,07 & 140,73 & 146,57 & 143,65 & 137,30 & 139,34 & 138,32 & 135,90 & & 135,90 \\
\hline \multirow{3}{*}{ 3-7 } & $A_{105}$ & 159,60 & 165,53 & 162,57 & & 156,28 & 156,28 & & 147,09 & 147,09 & 136,90 & 139,63 & 138,26 & 135,58 & 139,88 & 137,73 \\
\hline & $A_{107}$ & & 165,59 & 165,59 & 150,50 & 156,35 & 153,43 & & 147,14 & 147,14 & 136,98 & & 136,98 & 135,72 & 139,91 & 137,81 \\
\hline & $\mathrm{A}_{108}$ & 158,75 & 165,63 & 162,19 & & 156,45 & 156,45 & & 147,13 & 147,13 & 136,96 & & 136,96 & 135,70 & 139,74 & 137,72 \\
\hline \multirow{3}{*}{ 4-0 } & $A_{105}$ & 158,57 & 165,67 & 162,12 & 149,58 & 156,23 & 152,90 & 140,94 & 147,12 & 144,03 & 137,03 & 139,23 & 138,13 & & 139,90 & 139,90 \\
\hline & $A_{107}$ & 158,81 & 165,63 & 162,22 & 149,52 & 156,53 & 153,02 & 141,09 & 147,05 & 144,07 & 136,84 & 139,30 & 138,07 & & 139,90 & 139,90 \\
\hline & $A_{108}$ & 158,76 & 165,64 & 162,20 & 149,60 & 156,31 & 152,95 & 140,99 & 147,16 & 144,08 & 137,02 & 139,40 & 138,21 & & 139,91 & 139,91 \\
\hline \multirow{3}{*}{ 5-1 } & $A_{105}$ & 158,63 & & 158,63 & 149,24 & & 149,24 & 141,06 & & 141,06 & & 139,06 & 139,06 & 135,56 & 139,94 & 137,75 \\
\hline & $A_{107}$ & 158,63 & & 158,63 & 149,61 & & 149,61 & 141,11 & & 141,11 & & 139,12 & 139,12 & 136,00 & 139,74 & 137,87 \\
\hline & $A_{108}$ & 158,78 & & 158,78 & 149,65 & 156,14 & 152,89 & 141,11 & & 141,11 & & 139,10 & 139,10 & 135,86 & 140,06 & 137,96 \\
\hline \multirow{3}{*}{ 6-2 } & $A_{105}$ & 158,74 & 165,46 & 162,10 & 149,42 & 156,23 & 152,83 & 141,07 & 146,96 & 144,02 & 136,63 & 138,95 & 137,79 & 135,72 & & 135,72 \\
\hline & $A_{107}$ & 158,78 & 165,58 & 162,18 & 149,46 & 156,29 & 152,88 & 141,18 & 146,99 & 144,08 & 136,78 & 139,31 & 138,04 & 135,77 & & 135,77 \\
\hline & $A_{108}$ & 158,74 & 165,64 & 162,19 & 149,21 & 156,38 & 152,80 & 141,10 & 147,04 & 144,07 & 136,85 & 139,04 & 137,94 & 135,73 & & 135,73 \\
\hline \multirow{3}{*}{$7-3$} & $A_{105}$ & 158,33 & 165,62 & 161,97 & 149,69 & 156,33 & 153,01 & & 147,00 & 147,00 & 137,01 & & 137,01 & & 140,02 & 140,02 \\
\hline & $A_{107}$ & 158,80 & 165,55 & 162,18 & & 156,29 & 156,29 & & 147,07 & 147,07 & 136,97 & & 136,97 & 135,87 & 139,95 & 137,91 \\
\hline & $A_{108}$ & 158,30 & 165,60 & 161,95 & 149,33 & 156,42 & 152,88 & & 147,04 & 147,04 & 137,00 & & 137,00 & 136,25 & 139,90 & 138,08 \\
\hline \multirow{2}{*}{\multicolumn{2}{|c|}{$\begin{array}{l}\text { Desvio padrão } \\
\text { Coef. Variação }\end{array}$}} & 158,75 & 165,61 & 161,89 & 149,57 & 156,41 & 152,98 & 140,85 & 146,97 & 143,93 & 136,93 & 139,23 & 138,12 & 135,78 & 139,92 & 137,94 \\
\hline & & $\begin{array}{l}0,23 \\
0,1 \%\end{array}$ & $\begin{array}{l}0,10 \\
0,1 \%\end{array}$ & $\begin{array}{r}1,42 \\
0,9 \%\end{array}$ & $\begin{array}{l}0,25 \\
0,2 \%\end{array}$ & $\begin{array}{l}0,17 \\
0,1 \%\end{array}$ & $\begin{array}{l}1,75 \\
1,1 \%\end{array}$ & $\begin{array}{l}0,25 \\
0,2 \%\end{array}$ & $\begin{array}{l}0,17 \\
0,1 \%\end{array}$ & $\begin{array}{l}2,23 \\
1,6 \%\end{array}$ & $\begin{array}{l}0,16 \\
0.1 \%\end{array}$ & $\begin{array}{l}0,15 \\
0,1 \%\end{array}$ & $\begin{array}{l}0,76 \\
0,5 \%\end{array}$ & 0,17 & 0,13 & 1,59 \\
\hline
\end{tabular}

Tabela 4.13 - Frequências naturais das toras TT-6 a TT-10 obtidas com excitação no plano horizontal.

\begin{tabular}{|c|c|c|c|c|c|c|c|c|c|c|c|c|c|c|c|c|}
\hline \multirow{3}{*}{ Plano } & \multirow{3}{*}{ FRF } & \multicolumn{3}{|c|}{ TT-6 } & \multicolumn{3}{|c|}{ TT-7 } & \multicolumn{3}{|c|}{ TT-8 } & \multicolumn{3}{|c|}{ TT-9 } & \multicolumn{3}{|c|}{ TT-10 } \\
\hline & & \multicolumn{2}{|c|}{ Pico } & \multirow{2}{*}{ lédia } & \multicolumn{2}{|c|}{ Pico } & \multirow{2}{*}{ Média } & \multicolumn{2}{|c|}{ Pico } & \multirow{2}{*}{ Média } & \multicolumn{2}{|c|}{ Pico } & \multirow{2}{*}{ Média } & \multicolumn{2}{|c|}{ Pico } & \multirow{2}{*}{ Média } \\
\hline & & $1^{\circ}$ & $2^{\circ}$ & & $1^{\circ}$ & $2^{\circ}$ & & $1^{\circ}$ & $2^{\circ}$ & & $1^{\circ}$ & $2^{\circ}$ & & $1^{\circ}$ & $2^{\circ}$ & \\
\hline \multirow{3}{*}{$0-4$} & 05 & 37,07 & 142,89 & 139,98 & 146,81 & & 146,81 & & 149,28 & 149,28 & 137,17 & 143,51 & 140,34 & 141,47 & 147,19 & 144,33 \\
\hline & 107 & 137,07 & 142,94 & 140,00 & 146,79 & & 46,79 & & 149,23 & 149,23 & 137,43 & 143,42 & 140,43 & 141,51 & 147,23 & 144,37 \\
\hline & $A_{108}$ & 137,00 & 143,03 & 140,02 & 146,85 & & 146,85 & & 148,12 & 148,12 & 137,24 & 143,48 & 140,36 & 141,43 & 147,31 & 144,37 \\
\hline \multirow{3}{*}{$1-5$} & $A_{105}$ & 37,10 & & 137,10 & 146,68 & 154,62 & 150,65 & 144,32 & 149,25 & 146,78 & & 143,59 & 143,59 & 141,53 & & 141,53 \\
\hline & $A_{107}$ & 136,92 & & 136,92 & 146,72 & 154,59 & 150,66 & 144,14 & 149,27 & 146,70 & & 143,74 & 143,74 & 141,48 & & 141,48 \\
\hline & $A_{108}$ & 37,19 & & 137,19 & 146,74 & 154,56 & 150,65 & 144,10 & 149,31 & 146,70 & & 143,61 & 143,61 & 141,47 & & 141,47 \\
\hline \multirow{3}{*}{$2-6$} & $\mathrm{~A}_{105}$ & 37,11 & 142,81 & 139,96 & 145,01 & 154,59 & 149,80 & 143,80 & & 143,80 & 137,21 & 143,64 & 140,43 & 141,30 & 147,24 & 144,27 \\
\hline & $A_{107}$ & 37,13 & 142,83 & 139,98 & & 154,63 & 154,63 & 144,12 & & 144,12 & 137,19 & 143,74 & 140,46 & 141,40 & 147,24 & 144,32 \\
\hline & $A_{108}$ & 7,02 & 142,92 & 139,97 & & 154,71 & 154,71 & 144,17 & & 144,17 & 137,29 & 143,59 & 140,44 & 141,46 & 147,19 & 144,33 \\
\hline \multirow{3}{*}{$3-7$} & & & 35 & & & 154,48 & & 144,23 & 27 & 75 & 137,31 & & & 141,04 & 147,19 & \\
\hline & $A_{107}$ & & 142,89 & & 146 & 154,64 & 63 & 144,09 & 149,52 & 146,81 & 137,34 & & 34 & & 147,01 & 147,01 \\
\hline & $A_{108}$ & & 142,86 & 86 & 146,67 & 154,56 &, 62 & 144,00 & 149,75 & 146,88 & 137,34 & & 34 & & 147,10 & 147,10 \\
\hline \multirow{3}{*}{$4-0$} & $A_{105}$ & 7,12 & 142,68 & 139,90 & 146,75 & & 146,75 & 144,44 & 149,27 & 146,86 & 137,33 & 143,56 & 140,44 & 141,39 & 147,14 & 144,27 \\
\hline & $A_{107}$ & 37,09 & 142,80 & 139,95 & 146,79 & & 146,79 & 144,07 & 149,29 & 146,68 & 138,38 & 144,51 & 141,44 & 141,56 & 146,93 & 144,24 \\
\hline & $A_{108}$ & 37,03 & 142,84 & 139,93 & 146,77 & & 146,77 & 144,06 & 149,28 & 146,67 & 137,14 & 143,81 & 140,47 & 141,47 & 147,12 & 144,29 \\
\hline \multirow{3}{*}{$5-1$} & $A_{105}$ & 37,12 & & 137,12 & 146,69 & 154,49 & 150,59 & 143,77 & 149,18 & 146,47 & & 143,56 & 143,56 & 141,49 & & 141,49 \\
\hline & $A_{107}$ & 37,14 & & 137,14 & 146,65 & 154,59 & 150,62 & 144,18 & 149,21 & 146,69 & & 143,59 & 143,59 & 141,50 & & 141,50 \\
\hline & $\mathrm{A}_{108}$ & 37,13 & & 137,13 & 146,54 & 154,73 & 150,63 & 144,13 & 149,18 & 146,65 & & 143,59 & 143,59 & 141,51 & & 141,51 \\
\hline \multirow{3}{*}{$6-2$} & $A_{105}$ & 37,05 & 142,79 & 139,92 & & 154,61 & 154,61 & 144,28 & 148,06 & 146,17 & 137,10 & 143,65 & 140,38 & 141,30 & 147,18 & 144,24 \\
\hline & $A_{107}$ & 137,08 & 142,82 & 139,95 & & 154,67 & 154,67 & 144,22 & 149,36 & 146,79 & 137,39 & 143,48 & 140,44 & 141,34 & 147,21 & 144,28 \\
\hline & $A_{108}$ & 137,04 & 142,85 & 139,95 & & 154,64 & 154,64 & 144,19 & 149,42 & 146,80 & 137,33 & 143,53 & 140,43 & 141,50 & 147,00 & 144,25 \\
\hline \multirow{3}{*}{$7-3$} & $A_{105}$ & 142,92 & & 142,92 & 146,72 & 154,54 & 150,63 & 144,10 & 148,58 & 146,34 & 137,29 & & 137,29 & & 147,10 & 147,10 \\
\hline & $A_{107}$ & 142,82 & & 142,82 & 146,81 & 154,53 & 150,67 & 144,04 & 149,13 & 146,58 & 137,33 & & 137,33 & & 147,08 & 147,08 \\
\hline & $A_{108}$ & & 142,85 & 142,85 & 146,74 & 154,73 & 150,74 & 144,03 & 148,91 & 146,47 & 137,32 & & 137,32 & & 147,08 & 147,08 \\
\hline \multirow{3}{*}{\multicolumn{2}{|c|}{$\begin{array}{l}\text { Média } \\
\text { vio padrão } \\
\text { f. Variação }\end{array}$}} & 37,66 & 142,85 & 139,97 & 146,63 & 154,61 & 150,48 & 144,12 & 149,14 & 146,61 & 137,34 & 143,64 & 140,49 & 141,43 & 147,14 & 144,17 \\
\hline & & 1,78 & 0,07 & 2,08 & 0,40 & 0,07 & 2,71 & 0,15 & 0,41 & 1,27 & 0,27 & 0,24 & 2,28 & 0,12 & 0,10 & 1,93 \\
\hline & & $1,3 \%$ & $0,1 \%$ & $1,5 \%$ & $0,3 \%$ & $0,0 \%$ & $1,8 \%$ & $0,1 \%$ & $0,3 \%$ & $0,9 \%$ & $0,2 \%$ & $0,2 \%$ & $1,6 \%$ & $0,1 \%$ & $0,1 \%$ & $1,3 \%$ \\
\hline
\end{tabular}


As Tabelas 4.14 e 4.15 mostram os valores do módulo de elasticidade dinâmico aparente $\left(\mathrm{E}_{\mathrm{M}, \mathrm{VT}, \mathrm{ap}}\right)$ e considerando o esforço cortante $\left(\mathrm{E}_{\mathrm{M}, \mathrm{VT}}\right)$, respectivamente para os ensaios com excitação no plano horizontal e vertical. Em todos os casos o módulo de elasticidade foi calculado com a média aritmética das frequências naturais do primeiro modo de flexão mostradas nas Tabelas 4.6 a 4.13 .

Tabela 4.14 - Módulo de elasticidade dinâmico das toras da amostra piloto para excitação horizontal.

\begin{tabular}{|c|c|c|c|c|c|c|}
\hline \multirow{2}{*}{ Tora } & \multicolumn{3}{|c|}{$\mathrm{E}_{\mathrm{M}, \mathrm{VT} \text {,ap }}(\mathrm{GPa})$} & \multicolumn{3}{|c|}{$\mathrm{E}_{\mathrm{M}, \mathrm{VT}}(\mathrm{GPa})$} \\
\hline & $1^{\circ}$ pico & $2^{\circ}$ pico & Média & $1^{\circ}$ pico & $2^{\circ}$ pico & Média \\
\hline 1 & 23,04 & 26,65 & 24,81 & 23,71 & 27,43 & 25,54 \\
\hline 2 & 23,22 & - & 23,22 & 23,85 & - & 23,85 \\
\hline 3 & 19,99 & 21,49 & 20,73 & 20,57 & 22,11 & 21,33 \\
\hline 4 & 18,68 & 19,50 & 19,09 & 19,17 & 20,01 & 19,59 \\
\hline 5 & 20,08 & - & 20,08 & 20,60 & - & 20,60 \\
\hline 6 & 22,76 & 24,96 & 23,85 & 23,33 & 25,58 & 24,44 \\
\hline 7 & 18,26 & 22,18 & 20,17 & 18,74 & 22,76 & 20,70 \\
\hline 8 & 23,28 & 25,36 & 24,31 & 23,89 & 26,02 & 24,94 \\
\hline 9 & 18,34 & 20,31 & 19,32 & 18,86 & 20,88 & 19,86 \\
\hline 10 & 22,46 & - & 22,46 & 23,02 & - & 23,02 \\
\hline Média & 21,01 & 22,92 & 21,80 & 21,57 & 23,54 & 22,39 \\
\hline TB-1 & 19,60 & 22,77 & 21,16 & 22,38 & 26,00 & 24,16 \\
\hline TB-2 & 21,55 & 23,64 & 22,58 & 24,12 & 26,45 & 25,27 \\
\hline TB-3 & 18,51 & 19,37 & 18,94 & 20,99 & 21,96 & 21,47 \\
\hline TB-4 & 18,29 & 19,87 & 19,07 & 20,54 & 22,30 & 21,41 \\
\hline TB-5 & 17,01 & 18,69 & 17,84 & 19,23 & 21,14 & 20,17 \\
\hline TB-6 & 21,44 & 23,08 & 22,25 & 23,98 & 25,81 & 24,89 \\
\hline TB-7 & 17,03 & 21,51 & 19,20 & 19,06 & 24,07 & 21,49 \\
\hline TB-8 & 18,78 & 20,54 & 19,65 & 21,30 & 23,30 & 22,29 \\
\hline TB-9 & 16,53 & 18,45 & 17,48 & 18,74 & 20,92 & 19,82 \\
\hline TB-10 & 19,37 & 20,83 & 20,09 & 21,74 & 23,38 & 22,55 \\
\hline Média & 18,81 & 20,88 & 19,83 & 21,21 & 23,53 & 22,35 \\
\hline TT-1 & 22,08 & 24,03 & 23,05 & 24,67 & 26,85 & 25,75 \\
\hline TT-2 & 21,60 & 23,63 & 22,60 & 24,01 & 26,26 & 25,12 \\
\hline TT-3 & 19,51 & 21,24 & 20,36 & 21,77 & 23,70 & 22,72 \\
\hline TT-4 & 20,01 & 20,69 & 20,35 & 22,01 & 22,76 & 22,38 \\
\hline TT-5 & 18,10 & 19,22 & 18,66 & 19,97 & 21,20 & 20,58 \\
\hline TT-6 & 22,14 & 23,84 & 22,98 & 24,37 & 26,24 & 25,30 \\
\hline TT-7 & 19,21 & 21,35 & 20,26 & 21,25 & 23,62 & 22,42 \\
\hline TT-8 & 20,72 & 22,18 & 21,44 & 22,97 & 24,60 & 23,78 \\
\hline TT-9 & 18,58 & 20,32 & 19,44 & 20,65 & 22,59 & 21,61 \\
\hline TT-10 & 21,09 & 22,83 & 21,95 & 23,18 & 25,09 & 24,13 \\
\hline Média & 20,30 & 21,93 & 21,11 & 22,49 & 24,29 & 23,38 \\
\hline
\end{tabular}


Tabela 4.15 - Módulo de elasticidade dinâmico das toras da amostra piloto para excitação vertical.

\begin{tabular}{ccccccc}
\hline \multirow{2}{*}{ Tora } & \multicolumn{3}{c}{$\mathrm{E}_{\mathrm{M}, \mathrm{VT}, \mathrm{ap}}(\mathrm{GPa})$} & \multicolumn{3}{c}{$\mathrm{E}_{\mathrm{M}, \mathrm{VT}}(\mathrm{GPa})$} \\
& $\mathbf{1}^{\mathbf{0}}$ pico & $\mathbf{2}^{\mathbf{0}}$ pico & Média & $\mathbf{1}^{\mathbf{0}}$ pico & $\mathbf{2}^{\mathbf{0}}$ pico & Média \\
\hline 1 & 22,99 & 26,60 & 24,76 & 23,66 & 27,38 & 25,49 \\
2 & 23,16 & - & 23,16 & 23,79 & - & 23,79 \\
3 & 19,93 & 21,53 & 20,72 & 20,51 & 22,15 & 21,32 \\
4 & 19,06 & 19,90 & 19,48 & 19,56 & 20,42 & 19,99 \\
\hline
\end{tabular}

\subsubsection{Ensaio de flexão estática}

A seguir são apresentados os resultados da determinação do módulo de elasticidade estático no teor de umidade do ensaio.

A Tabela 4.16 mostra os valores do módulo de elasticidade aparente das toras determinado de acordo com a Equação 4.6.

Tabela 4.16 - Módulo de elasticidade aparente das toras da amostra piloto.

\begin{tabular}{|c|c|c|c|c|c|c|c|c|c|c|c|}
\hline \multirow{3}{*}{ Tora } & \multicolumn{8}{|c|}{$\mathrm{E}_{\mathrm{M}, \text { Stat,ap }}(\mathrm{GPa})$} & \multirow{3}{*}{$\begin{array}{l}\text { Média } \\
\text { (GPa) }\end{array}$} & \multirow{3}{*}{$\begin{array}{c}\text { Desv. } \\
\text { Pad }\end{array}$} & \multirow{3}{*}{ Coef. Var. } \\
\hline & & \multicolumn{7}{|c|}{ Plano } & & & \\
\hline & $0-4$ & $1-5$ & $2-6$ & $3-7$ & $4-0$ & $5-1$ & $6-2$ & $7-3$ & & & \\
\hline 1 & 23,05 & 21,58 & 22,08 & 24,17 & 22,73 & 21,87 & 22,94 & 26,19 & 23,08 & 1,50 & $6,5 \%$ \\
\hline 2 & 22,31 & 23,67 & 23,94 & 22,29 & 22,84 & 23,88 & 23,57 & 22,66 & 23,15 & 0,70 & $3,0 \%$ \\
\hline 3 & 20,00 & 19,30 & 20,47 & 21,35 & 20,15 & 19,74 & 20,49 & 21,62 & 20,39 & 0,78 & $3,8 \%$ \\
\hline 4 & 19,50 & 19,91 & 19,65 & 18,43 & 18,44 & 18,91 & 18,18 & 18,83 & 18,98 & 0,64 & $3,4 \%$ \\
\hline 5 & 20,31 & 19,65 & 18,67 & 20,56 & 20,15 & 20,39 & 19,41 & 20,63 & 19,97 & 0,68 & $3,4 \%$ \\
\hline 6 & 25,07 & 22,96 & 24,48 & 25,69 & 24,07 & 22,76 & 22,81 & 24,61 & 24,06 & 1,11 & $4,6 \%$ \\
\hline 7 & 18,92 & 21,53 & 22,15 & 20,52 & 19,36 & 22,25 & 22,67 & 20,07 & 20,93 & 1,42 & $6,8 \%$ \\
\hline 8 & 25,82 & 25,22 & 23,68 & 24,05 & 25,47 & 25,06 & 24,81 & 23,56 & 24,71 & 0,85 & $3,4 \%$ \\
\hline 9 & 19,41 & 20,35 & 20,00 & 18,54 & 19,36 & 20,66 & 19,63 & 18,80 & 19,60 & 0,73 & $3,7 \%$ \\
\hline 10 & 21,51 & 22,03 & 22,25 & 22,99 & 21,93 & 21,70 & 22,28 & 22,05 & 22,09 & 0,45 & $2,0 \%$ \\
\hline
\end{tabular}

A Tabela 4.17 mostra o "módulo de elasticidade verdadeiro" calculado de acordo com a Equação 4.7.

Tabela 4.17 - Módulo de elasticidade verdadeiro das toras da amostra piloto.

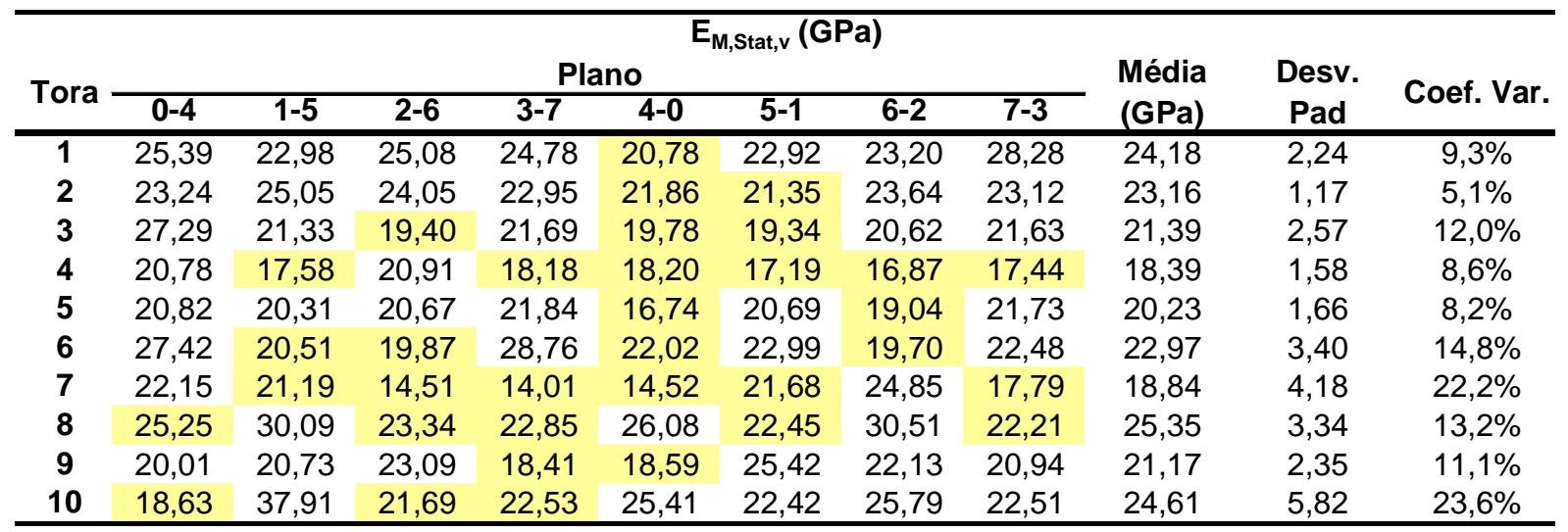


Os valores realçados em amarelo na Tabela 4.17 indicam resultados inesperados nos quais obteve-se $\mathrm{E}_{\mathrm{M}, \mathrm{Stat}, \mathrm{v}}$ inferior a $\mathrm{E}_{\mathrm{M}, \mathrm{Stat}, \mathrm{ap}}$.

A Tabela 4.18 mostra os resultados do módulo de elasticidade levando em conta o efeito do esforço cortante, calculados de acordo com Equação 4.8.

Tabela 4.18 - Módulo de elasticidade das toras da amostra piloto levando em conta o efeito do esforço cortante.

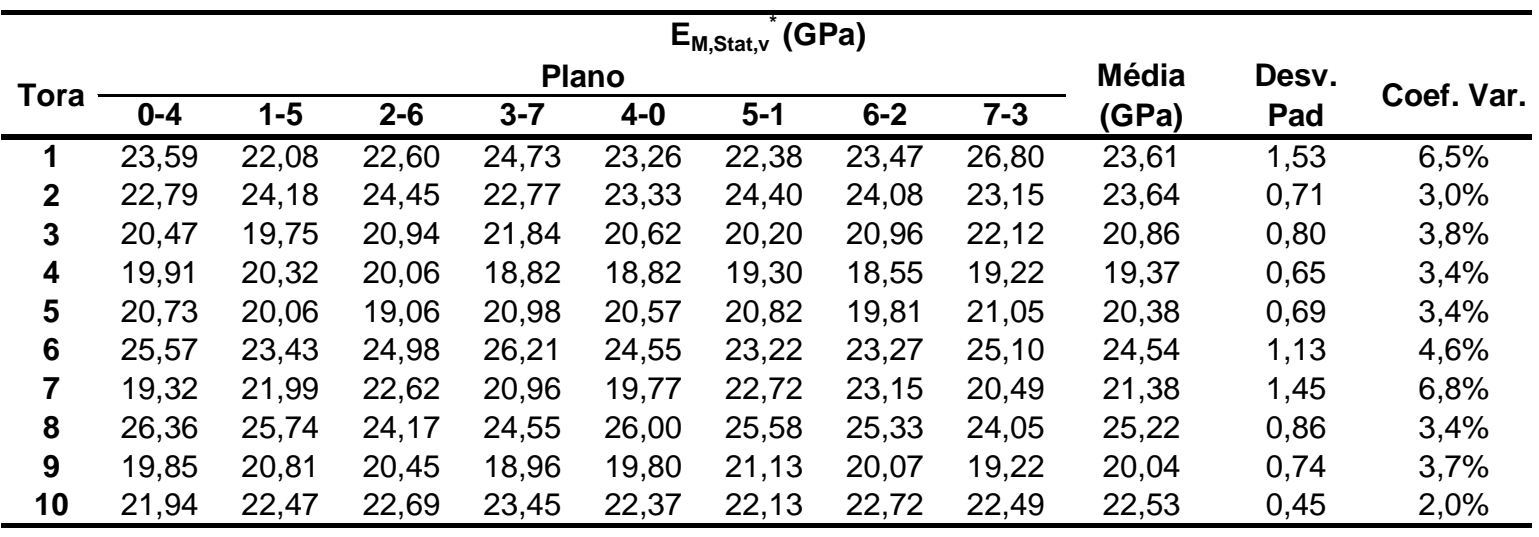

As Tabelas 4.19 e 4.20 mostram respectivamente os módulos de elasticidade aparente das toras-base e toras-topo obtidos com a Equação 4.6.

Tabela 4.19 - Módulo de elasticidade aparente das toras-base.

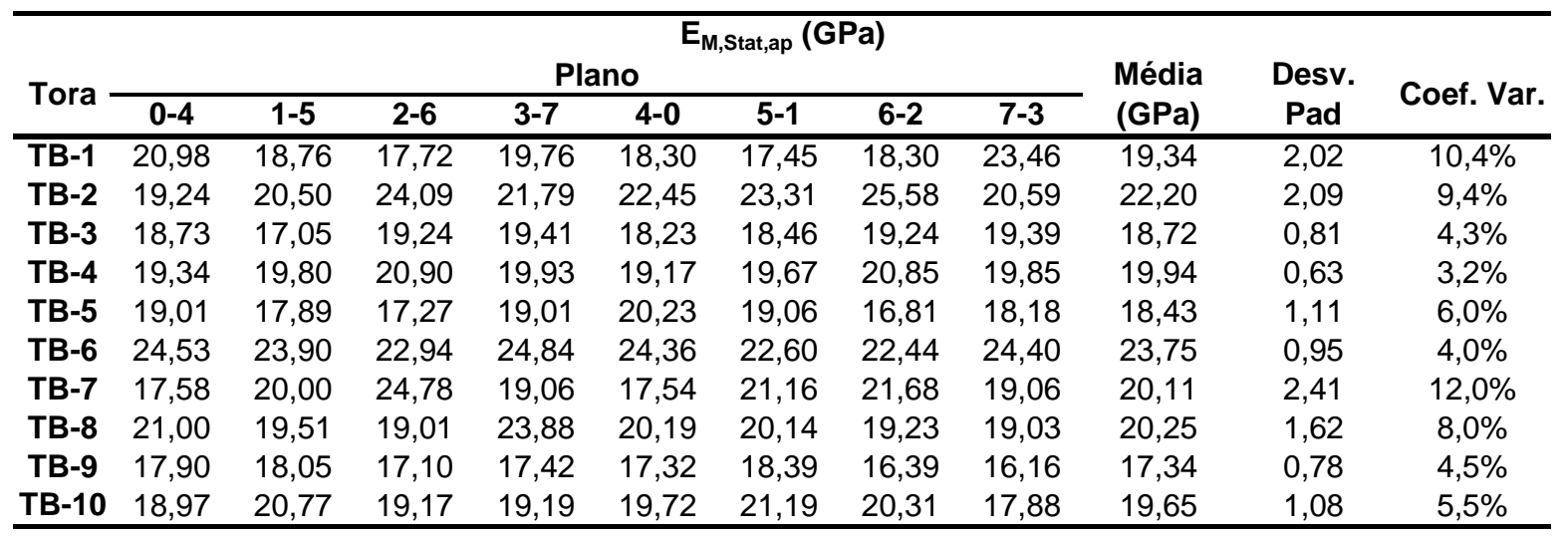

Tabela 4.20 - Módulo de elasticidade aparente das toras-topo.

\begin{tabular}{|c|c|c|c|c|c|c|c|c|c|c|c|}
\hline \multirow[b]{3}{*}{ Tora } & \multicolumn{8}{|c|}{$\mathrm{E}_{\mathrm{M}, \text { Stat,ap }}(\mathrm{GPa})$} & \multirow{3}{*}{$\begin{array}{l}\text { Média } \\
(\mathrm{GPa})\end{array}$} & \multirow{3}{*}{$\begin{array}{c}\text { Desv. Pad } \\
(\mathrm{GPa})\end{array}$} & \multirow{3}{*}{ Coef. Var. } \\
\hline & \multicolumn{8}{|c|}{ Plano } & & & \\
\hline & $0-4$ & $1-5$ & $2-6$ & $3-7$ & $4-0$ & $5-1$ & $6-2$ & $7-3$ & & & \\
\hline TT-1 & 21,92 & 21,41 & 22,92 & 24,01 & 21,75 & 20,31 & 22,01 & 25,00 & 22,42 & 1,50 & $6,7 \%$ \\
\hline TT-2 & 21,76 & 22,40 & 21,77 & 20,45 & 22,37 & 22,48 & 22,87 & 21,52 & 21,95 & 0,76 & $3,4 \%$ \\
\hline TT-3 & 20,02 & 18,97 & 19,29 & 19,92 & 19,68 & 18,67 & 19,82 & 20,34 & 19,59 & 0,56 & $2,9 \%$ \\
\hline TT-4 & 21,76 & 22,09 & 21,17 & 21,49 & 20,38 & 21,65 & 21,08 & 20,70 & 21,29 & 0,57 & $2,7 \%$ \\
\hline TT-5 & 19,61 & 18,78 & 19,06 & 18,99 & 18,55 & 19,40 & 17,30 & 19,56 & 18,91 & 0,75 & $4,0 \%$ \\
\hline TT-6 & 21,98 & 23,23 & 24,06 & 25,03 & 23,77 & 22,43 & 23,13 & 22,80 & 23,30 & 0,97 & $4,2 \%$ \\
\hline TT-7 & 20,39 & 19,95 & 21,71 & 20,95 & 20,40 & 20,92 & 20,94 & 20,70 & 20,74 & 0,52 & $2,5 \%$ \\
\hline TT-8 & 21,38 & 21,43 & 21,17 & 21,47 & 22,58 & 22,57 & 21,02 & 20,86 & 21,56 & 0,66 & $3,1 \%$ \\
\hline TT-9 & 19,98 & 19,94 & 19,77 & 19,30 & 20,20 & 20,80 & 19,07 & 18,12 & 19,65 & 0,81 & $4,1 \%$ \\
\hline TT-10 & 22,23 & 21,87 & 23,03 & 23,29 & 21,73 & 20,87 & 22,85 & 23,30 & 22,40 & 0,87 & $3,9 \%$ \\
\hline
\end{tabular}


Os valores do módulo de elasticidade verdadeiro das toras-topo e toras-base são mostrados respectivamente nas Tabelas 4.21 e 4.22 nas quais os valores realçados em amarelo indicam $\mathrm{E}_{\mathrm{M}, \text { stat, } \mathrm{v}}$ inferior ao módulo de elasticidade aparente.

Tabela 4.21 - Módulo de elasticidade verdadeiro das toras-base.

\begin{tabular}{|c|c|c|c|c|c|c|c|c|c|c|c|}
\hline \multirow{3}{*}{ Tora } & \multicolumn{8}{|c|}{$\mathrm{E}_{\mathrm{M}, \mathrm{Stat}, \mathrm{v}}(\mathrm{GPa})$} & \multirow{3}{*}{$\begin{array}{l}\text { Média } \\
\text { (GPa) }\end{array}$} & \multirow{3}{*}{$\begin{array}{c}\text { Desv. } \\
\text { Pad }\end{array}$} & \multirow{3}{*}{ Coef. Var. } \\
\hline & \multicolumn{8}{|c|}{ Plano } & & & \\
\hline & $0-4$ & $1-5$ & $2-6$ & 3-7 & $4-0$ & 5-1 & $6-2$ & $7-3$ & & & \\
\hline TB-1 & 21,86 & 17,48 & 15,20 & 18,09 & $\overline{12,94}$ & 15,93 & 16,16 & 23,03 & 17,58 & 3,39 & $19,3 \%$ \\
\hline TB-2 & 17,69 & 16,52 & 28,01 & 22,55 & 21,82 & 24,16 & 20,63 & 24,86 & 22,03 & 3,78 & $17,1 \%$ \\
\hline TB-3 & 17,29 & 16,08 & 27,34 & 19,68 & 19,66 & 19,61 & 17,96 & 22,20 & 19,98 & 3,50 & $17,5 \%$ \\
\hline TB-4 & 19,73 & 23,81 & 19,86 & 21,34 & 19,77 & 22,27 & 19,50 & 17,33 & 20,45 & 1,98 & $9,7 \%$ \\
\hline TB-5 & 20,13 & 17,24 & 16,69 & 19,15 & 25,44 & 14,98 & 15,03 & 18,26 & 18,37 & 3,39 & $18,5 \%$ \\
\hline TB-6 & 28,04 & 23,73 & 23,91 & 28,91 & 27,54 & 21,35 & 21,42 & 29,63 & 25,57 & 3,35 & $13,1 \%$ \\
\hline TB-7 & 16,86 & 13,91 & 21,26 & 21,71 & 15,81 & 21,60 & 21,96 & 24,93 & 19,76 & 3,77 & $19,1 \%$ \\
\hline TB-8 & 20,86 & 21,00 & 19,38 & 28,61 & 18,79 & 22,73 & 22,51 & 22,49 & 22,05 & 3,03 & $13,7 \%$ \\
\hline TB-9 & 18,72 & 20,46 & 14,13 & 17,82 & 17,78 & 19,48 & 17,02 & 20,69 & 18,26 & 2,12 & $11,6 \%$ \\
\hline TB-10 & 17,22 & 22,37 & 15,50 & 21,16 & 24,90 & 21,49 & 23,29 & 24,53 & 21,31 & 3,36 & $15,7 \%$ \\
\hline
\end{tabular}

Tabela 4.22 - Módulo de elasticidade verdadeiro das toras-topo.

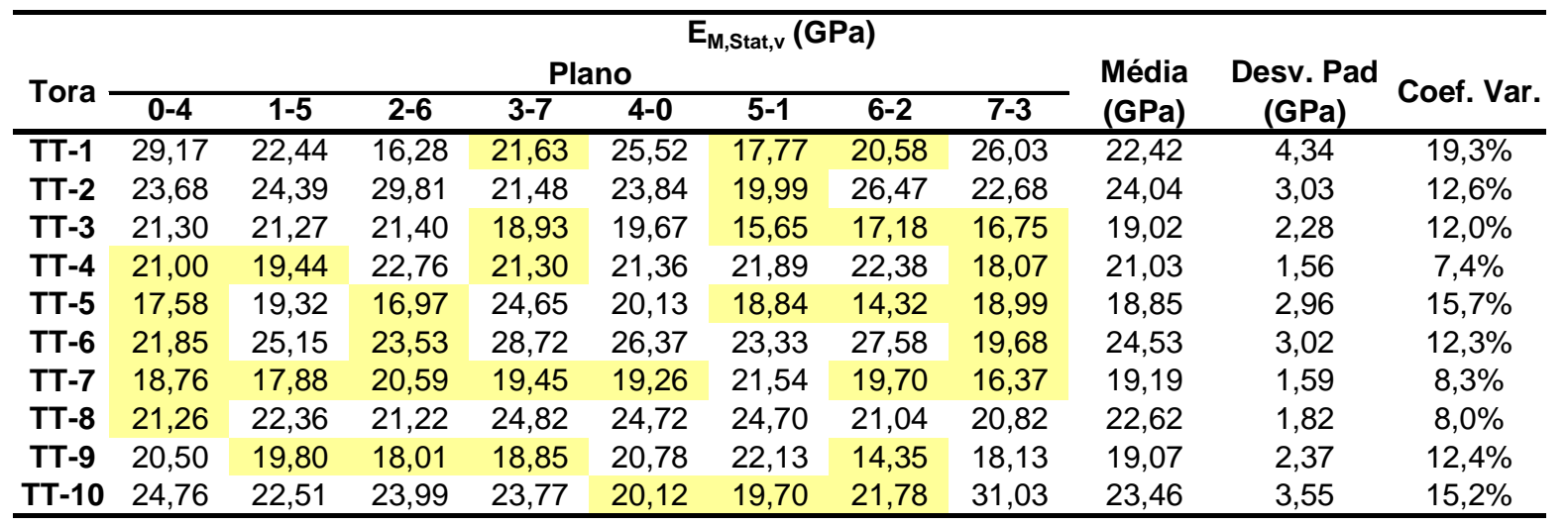

As Tabelas 4.23 e 4.24 mostram os valores do módulo de elasticidade calculado pela Equação 4.8, respectivamente para as toras-base e toras-topo.

Tabela 4.23 - Módulo de elasticidade das toras-base levando em conta o efeito do esforço cortante.

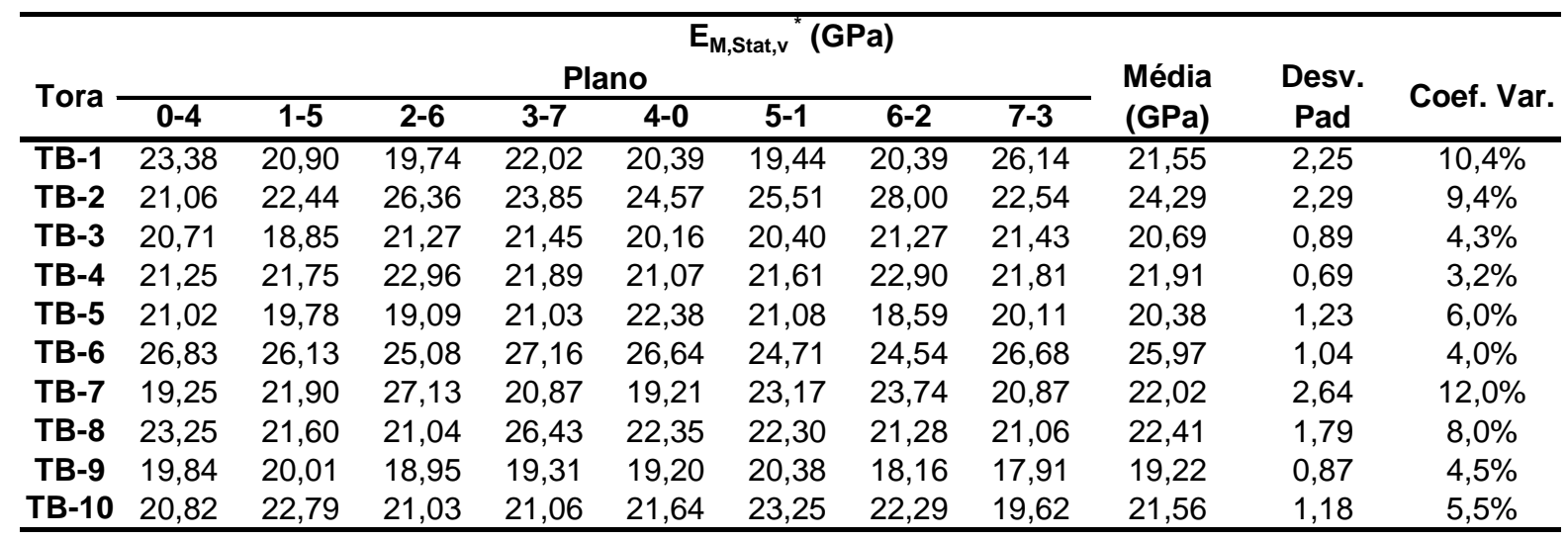


Tabela 4.24 - Módulo de elasticidade das toras-topo levando em conta o efeito do esforço cortante.

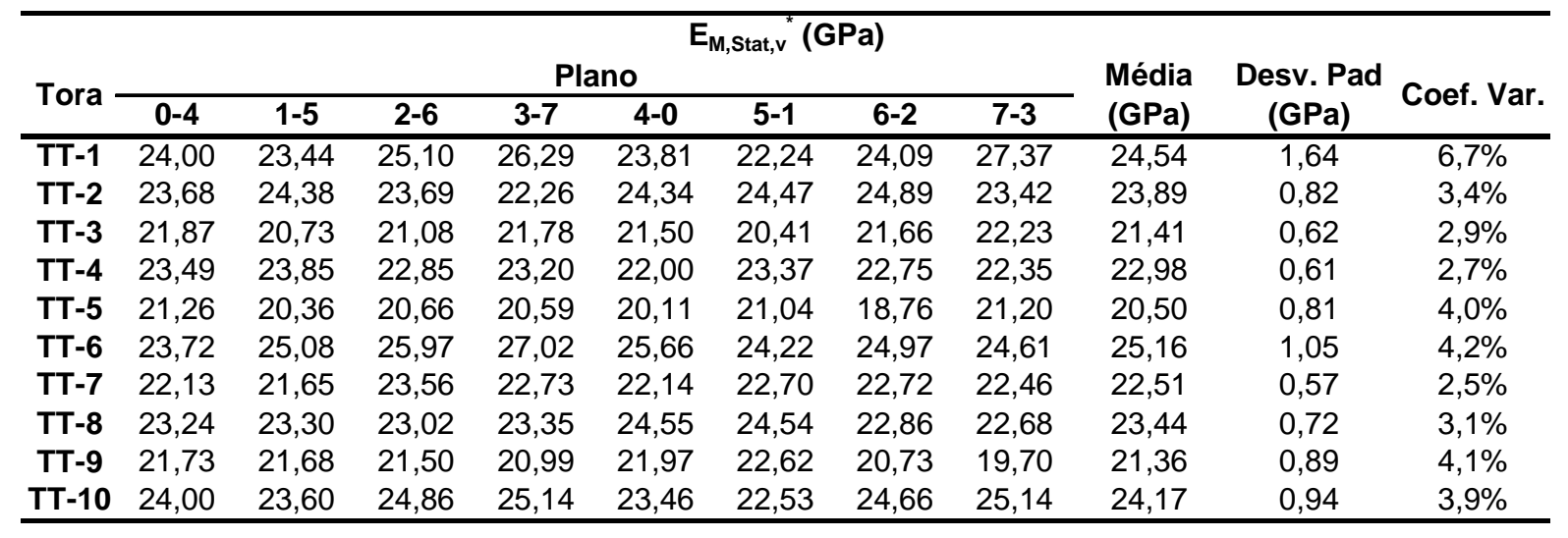

\subsubsection{Teor de umidade}

A Tabela 4.25 mostra o resultado da medição do teor de umidade das toras com o medidor elétrico DL 2000.

Tabela 4.25 - Teor de umidade obtido com o medidor elétrico.

\begin{tabular}{ccccc}
\hline \multirow{2}{*}{ Tora } & \multicolumn{4}{c}{ Umidade (\%) } \\
\cline { 2 - 5 } & Base & Topo & $\begin{array}{c}\text { Metade do } \\
\text { comprimento }\end{array}$ & Média \\
\hline 1 & 18,0 & 17,2 & 20,4 & 18,5 \\
2 & 24,0 & 21,2 & 28,3 & 24,5 \\
3 & 23,2 & 23,4 & 25,8 & 24,1 \\
4 & 22,0 & 18,5 & 19,6 & 20,0 \\
5 & 24,7 & 21,3 & 24,0 & 23,3 \\
6 & 16,3 & 16,0 & 16,5 & 16,3 \\
7 & 21,6 & 14,5 & 22,5 & 19,5 \\
8 & 17,7 & 20,2 & 22,8 & 20,2 \\
9 & 20,7 & 17,8 & 22,2 & 20,2 \\
10 & 14,2 & 15,6 & 15,1 & 15,0 \\
\hline Mínimo & 14,2 & 14,5 & 15,1 & 15,0 \\
Máximo & 24,7 & 23,4 & 28,3 & 24,5 \\
Média & 20,2 & 18,6 & 21,7 & 20,2 \\
Coef. Var. ${ }^{1}$ & $17,4 \%$ & $15,5 \%$ & $18,4 \%$ & $15,7 \%$ \\
\hline Coef. Var. = Coeficiente de variação & \multicolumn{3}{c}{}
\end{tabular}

A Tabela 4.26 mostra o resultado do ensaio para a determinação do teor de umidade conforme norma NBR 7190 (ABNT, 1997). 
Tabela 4.26 - Teor de umidade obtido pelo ensaio da norma NBR 7190 (ABNT, 1997).

\begin{tabular}{|c|c|c|c|c|c|}
\hline \multirow{2}{*}{ Tora } & \multicolumn{4}{|c|}{ Corpo-de-prova } & \multirow{2}{*}{$U_{\text {média }}(\%)$} \\
\hline & 1 & 2 & 3 & 4 & \\
\hline 1 & 25,5 & 38,8 & 47,7 & 48,9 & $\overline{40,2}$ \\
\hline 2 & 28,0 & 29,4 & 40,2 & 46,5 & 36,0 \\
\hline 3 & 31,0 & 51,3 & 55,6 & & 46,0 \\
\hline 4 & 26,3 & 40,3 & 44,0 & & 36,9 \\
\hline 5 & 25,7 & 34,6 & 47,3 & & 35,9 \\
\hline 6 & 19,5 & 25,6 & 39,0 & 50,0 & 33,5 \\
\hline 7 & 25,2 & 29,8 & 43,2 & 43,4 & 35,4 \\
\hline 8 & 19,2 & 25,3 & 44,6 & 48,1 & 34,3 \\
\hline 9 & 25,0 & 38,4 & 52,7 & 54,3 & 42,6 \\
\hline 10 & 18,4 & 21,5 & 27,8 & 32,6 & 25,1 \\
\hline Média & & & & & 36,6 \\
\hline
\end{tabular}

\subsection{Análise dos resultados}

\subsubsection{Propriedades dimensionais e densidade aparente das toras}

Observa-se na Tabela 4.3 que as toras inicialmente tinham $L / \mathrm{D}_{\text {meio }}>22$, o que torna insignificante o efeito do esforço cortante nos ensaios mecânicos.

Verifica-se também que a geometria da base das toras apresentou maior variação em relação à geometria circular $\left(\Delta_{\text {circ }}\right)$ do que o topo; provavelmente em função da proximidade da raiz. O maior valor de $\Delta_{\text {circ }}$ foi observado na tora $5(7,1 \%)$ e o menor valor na tora 1 $(0,1 \%)$. A Figura 4.23 mostra as fotos das bases dessas duas toras a título de comparação.

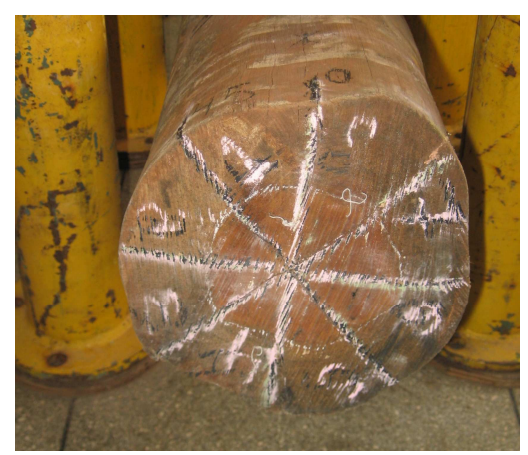

(a)

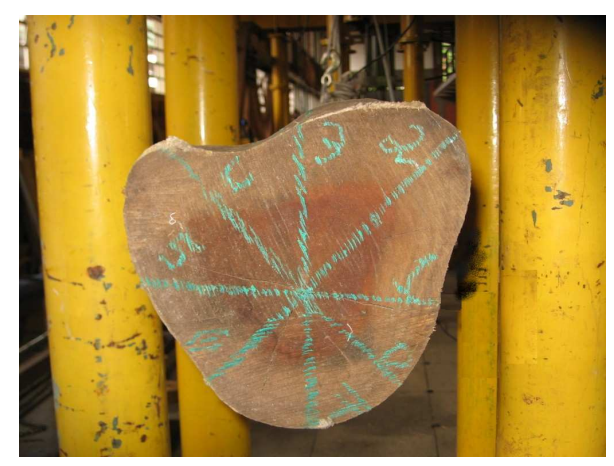

(b)

Figura 4.23 - Variação da geometria da base das toras integras: a) Tora $1\left(\Delta_{\text {circ }}=0,1 \%\right)$. b)

$$
\text { tora } 5\left(\Delta_{\text {circ }}=7,1 \%\right) \text {. }
$$

A conicidade das toras da amostra piloto variou de 0,6 a 1,2\%. Esses valores são coerentes com os observados nas amostras de Eucalyptus citriodora estudadas por Miná 
(2005) e por Zangiácomo (2007) os quais encontraram respectivamente variações entre 0,3\% a $1,5 \%$ e $0,2 \%$ a $1,2 \%$.

Observa-se ainda que o desvio padrão dos diâmetros foi, em média, cerca de 7,7\%, sendo o valor máximo observado na tora $5\left(\Delta_{\mathrm{D}}=11,1 \%\right)$ e o valor mínimo observado na tora 2 $\left(\Delta_{\mathrm{D}}=5,2 \%\right)$

A densidade aparente média, no teor de umidade do ensaio, encontrada para a amostra foi de $872 \mathrm{~kg} / \mathrm{m}^{3}$. Esse valor é um pouco inferior a $999 \mathrm{~kg} / \mathrm{m}^{3}$, mostrado no Anexo B da norma NBR 7190 (ABNT, 1997) para o teor de umidade de $12 \%$.

O valor médio encontrado para a relação $L / D_{\text {meio }}$ das toras-topo foi de 13,7 enquanto para as toras-base foi de 12,5 .

A conicidade variou de $0 \%$ a $0,7 \%$ para as toras-topo e de $1 \%$ a $1,9 \%$ para as torasbase.

Observa-se também que o coeficiente de variação do diâmetro $\left(\Delta_{\mathrm{D}}\right)$ foi menor para as toras-topo, indicando que a maior variação do diâmetro ocorre na porção inferior das toras.

\subsubsection{Ensaio de vibração transversal}

De forma geral, foram obtidas FRF's com baixa intensidade de ruído até a frequência de $350 \mathrm{~Hz}$ permitindo a identificação das frequências naturais até o terceiro modo de flexão.

A maioria das FRF's apresentou coerência igual a 1,0 para as frequências até $300 \mathrm{~Hz}$ indicando que a magnitude da resposta medida nessa banda de frequências se deve apenas à força de excitação do martelo.

Durante a execução dos ensaios observou-se que muitas das FRF's medidas apresentaram picos de frequências vizinhos na região das ressonâncias. Essa característica foi mais comum em toras nas quais a seção transversal da base da tora assumia uma geometria muito irregular (como a tora 5), nos casos em que devido à superfície irregular da tora o acelerômetro ficava desalinhado com o ponto de aplicação do impacto (Figura 4.24) e, principalmente, nas toras com grandes encurvamento, como as toras 1 e 7 . 


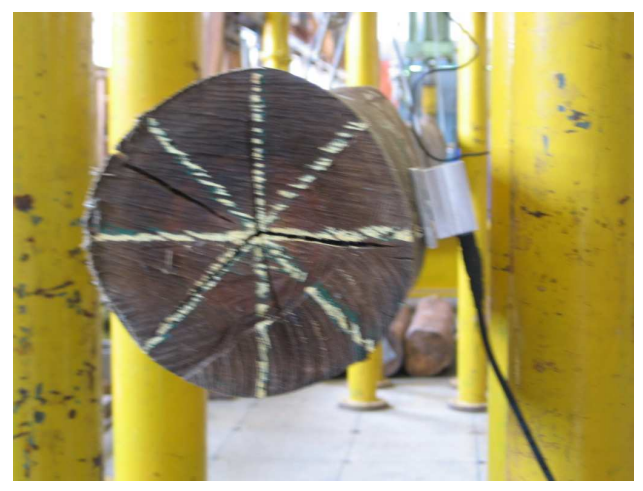

Figura 4.24 - Desalinhamento do acelerômetro na tora 6 devido à irregularidade na superfície.

Nos ensaios realizados com impacto aplicado na direção vertical, ou seja, paralelamente ao sistema de suspensão, a frequência do modo de corpo rígido foi da ordem de $3,0 \mathrm{~Hz}$ e, em todas as toras, foi inferior a $1 / 10$ da frequência do primeiro modo de flexão. Nos ensaios realizados com excitação no plano horizontal, a frequência do modo de corpo rígido foi da ordem de $0,6 \mathrm{~Hz}$, sendo que em algumas toras não foi detectada pelo sistema de aquisição de dados como se pode observar nas Figuras 4.17 e 4.18.

Foram obtidos bons ajustes para todas as toras, inclusive para aquelas que apresentaram picos de frequência múltiplos na região da ressonância como se observou nas Figuras 4.21 e 4.22 .

Como pode ser observado nas Tabelas 4.6 a 4.13 o coeficiente de variação das frequências do primeiro modo de flexão medidas nos vários planos e pontos ao longo do comprimento oscilou, na maior parte das toras, entre 0,1 a $0,5 \%$. Como a variabilidade nas frequências naturais é insignificante, acredita-se que tenha resultado da própria resolução do sistema de medição empregado.

O módulo de elasticidade dinâmico encontrado para o Eucalyptus citriodora variou entre 20 e $25 \mathrm{GPa}$ (conforme Tabelas 4.14 e 4.15), valores esses compatíveis com os encontrados por Miná et al (2004).

Confrontando-se os dados das toras 1 a 4 nas Tabelas 4.14 e 4.15 verifica-se que os valores encontrados para o módulo de elasticidade à flexão das toras 1 a 4 não sofreram alterações significativas com a mudança do plano de excitação. 


\subsubsection{Ensaio de flexão estática}

$\mathrm{Na}$ Tabela 4.16 verifica-se que, com exceção das toras 1 e 7, o coeficiente de variação observado no módulo de elasticidade à flexão de uma mesma tora, para os diferentes planos nos quais as mesmas foram testadas, é inferior a $5 \%$.

Como as toras que mostraram maior variação no módulo de elasticidade também apresentaram maiores encurvamentos há um indício de que essas características possam estar relacionadas.

Os valores realçados em amarelo nas Tabelas 4.17, 4.21 e 4.22 indicam resultados nos quais obteve-se $E_{M, S t a t, v}$ inferior a $E_{M, S t a t, a p}$. Obviamente esses resultados estão incorretos uma vez que o módulo de elasticidade medido no trecho central, sem esforço cortante, deveria ser maior. Outro ponto que chama a atenção é o fato do coeficiente de variação de $\mathrm{E}_{\mathrm{M}, \text { Stat,v }}$ ser

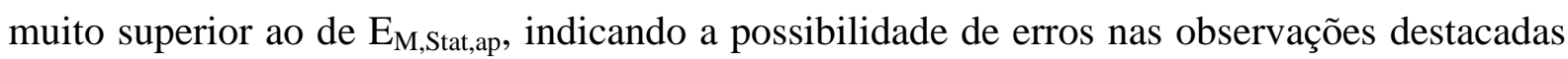
nessas tabelas.

Analisando-se as Tabelas 4.18, 4.23 e 4.24, verifica-se que o emprego da Equação 4.8 para o cálculo do módulo de elasticidade levando em conta o efeito do esforço cortante resulta

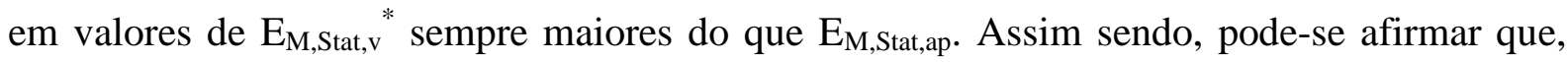
para avaliação do módulo de elasticidade na flexão de toras de madeira, a Equação 4.8 conduz a resultados mais coerentes de $\mathrm{E}_{\mathrm{M}, \mathrm{Stat}, \mathrm{v}}{ }^{*}$ do que a Equação 4.7 proposta pela ASTM D198 (ASTM, 2008).

\subsubsection{Teor de umidade}

A Tabela 4.25 mostra que, na maioria das toras, o teor de umidade medido na metade do comprimento foi superior ao medido nas extremidades das mesmas.

Observa-se na Tabela 4.26 que, no momento dos ensaios, o teor de umidade variou entre 18 e $31 \%$ na superfície (corpos-de-prova 1) e de 30 a $50 \%$ no cerne das toras (corposde-prova 3 ou 4).

A Tabela 4.27 mostra uma comparação entre os resultados obtidos na medição do teor de umidade da superfície das toras com o ensaio da norma NBR 7190 (ABNT, 1997) e com o medidor elétrico. Pode-se afirmar que o medidor elétrico tem a tendência de subestimar o teor de umidade medido na superfície das toras. Essa constatação coincide com as conclusões de Calonego et al (2006). 
Tabela 4.27 - Comparação entre os resultados obtidos com o ensaio da norma NBR 7190 (ABNT, 1997) e com o medidor elétrico.

\begin{tabular}{rcc}
\hline \multirow{2}{*}{ Tora } & \multicolumn{2}{c}{ Teor de umidade (\%) } \\
& $\mathbf{U}_{\mathrm{NBR7190}}$ & $\mathbf{U}_{\mathrm{EL}}$ \\
\hline 1 & 25,5 & 20,4 \\
2 & 28,0 & 28,3 \\
3 & 31,0 & 25,8 \\
4 & 26,3 & 19,6 \\
5 & 25,7 & 24,0 \\
6 & 19,5 & 16,5 \\
7 & 25,2 & 22,5 \\
8 & 19,2 & 22,8 \\
9 & 25,0 & 22,2 \\
10 & 18,4 & 15,1 \\
\hline
\end{tabular}

\subsubsection{Avaliação da influência da direção do impacto em relação ao sistema de suspensão}

A avaliação do efeito da direção do impacto nas FRF's medidas com excitação no mesmo ponto foi feita por meio da análise da variação das frequências naturais e também dos parâmetros de correlação globais FRAC e GSF (Global Scale Factor) e locais FDAC e FRSF. O parâmetro GSF foi definido pelo autor como se verá adiante.

A diferença entre as frequências naturais foi calculada por meio da Equação 4.9.

$$
\Delta \mathrm{f}_{\mathrm{n}}=1-\frac{\mathrm{f}_{\mathrm{n}, \mathrm{H}}}{\mathrm{f}_{\mathrm{n}, \mathrm{V}}}
$$

Sendo:

$$
\begin{aligned}
& \Delta \mathrm{f}_{\mathrm{n}}=\text { diferença na frequência do } \mathrm{n} \text {-ésimo modo; } \\
& \mathrm{f}_{\mathrm{n}, \mathrm{H}}=\text { frequência do n-ésimo modo medida no ensaio horizontal; } \\
& \mathrm{f}_{\mathrm{n}, \mathrm{V}}=\text { frequência do n-ésimo modo medida no ensaio vertical. }
\end{aligned}
$$

A Tabela 4.28 mostra os valores de $\Delta \mathrm{f}_{\mathrm{n}}$, sendo que os valores positivos indicam que a frequência medida no ensaio com excitação vertical foi superior a medida no ensaio com excitação horizontal. 
Tabela 4.28 - Diferença entre as frequências medidas nos ensaios vertical e horizontal.

\begin{tabular}{|c|c|c|c|c|c|c|c|}
\hline \multirow{2}{*}{ 윰 } & \multirow{2}{*}{ FRF } & \multicolumn{2}{|c|}{$1^{\circ}$ Modo } & \multicolumn{2}{|c|}{$2^{\circ}$ Modo } & \multicolumn{2}{|c|}{$3^{\circ}$ Modo } \\
\hline & & $1^{\circ}$ Pico & $2^{\circ}$ Pico & $1^{\circ}$ Pico & $2^{\circ}$ Pico & $1^{\circ}$ Pico & $2^{\circ}$ Pico \\
\hline \multirow{7}{*}{1} & $A_{100}$ & $0,0 \%$ & $0,0 \%$ & $-0,3 \%$ & $0,2 \%$ & $0,1 \%$ & $-0,1 \%$ \\
\hline & $\mathrm{A}_{101}$ & $0,1 \%$ & $-0,1 \%$ & $-0,3 \%$ & $0,2 \%$ & $0,1 \%$ & $-0,1 \%$ \\
\hline & $\mathrm{A}_{103}$ & $0,0 \%$ & $0,0 \%$ & $-0,2 \%$ & $0,2 \%$ & $0,1 \%$ & $-0,1 \%$ \\
\hline & $A_{105}$ & $-0,1 \%$ & $0,0 \%$ & & & $0,1 \%$ & $-0,1 \%$ \\
\hline & $A_{107}$ & & $0,1 \%$ & $0,0 \%$ & $0,2 \%$ & $0,1 \%$ & $-0,1 \%$ \\
\hline & $A_{109}$ & & $-0,1 \%$ & $0,8 \%$ & $0,2 \%$ & & \\
\hline & $A_{1011}$ & $0,1 \%$ & $-0,1 \%$ & $-0,2 \%$ & $0,2 \%$ & $0,1 \%$ & $-0,1 \%$ \\
\hline \multirow{7}{*}{2} & $A_{100}$ & $0,1 \%$ & & $-1,4 \%$ & $7,3 \%$ & $0,3 \%$ & \\
\hline & $A_{101}$ & $0,1 \%$ & & $-1,2 \%$ & & $0,3 \%$ & \\
\hline & $\mathrm{A}_{103}$ & $0,3 \%$ & & $-2,2 \%$ & $7,5 \%$ & $0,3 \%$ & \\
\hline & $A_{105}$ & $0,0 \%$ & & & $9,0 \%$ & $0,3 \%$ & \\
\hline & $A_{107}$ & $0,0 \%$ & & $-2,2 \%$ & $7,6 \%$ & $0,3 \%$ & \\
\hline & $A_{109}$ & $0,1 \%$ & & $-0,2 \%$ & $8,3 \%$ & $0,7 \%$ & \\
\hline & $A_{1011}$ & $0,0 \%$ & & $-1,5 \%$ & $7,3 \%$ & $0,2 \%$ & \\
\hline \multirow{7}{*}{3} & $A_{100}$ & $-0,4 \%$ & $-0,1 \%$ & $-3,4 \%$ & & $-0,1 \%$ & $0,1 \%$ \\
\hline & $\mathrm{A}_{101}$ & $-0,1 \%$ & $-0,1 \%$ & $-3,1 \%$ & & $0,1 \%$ & $-0,2 \%$ \\
\hline & $\mathrm{A}_{103}$ & $0,0 \%$ & & $-2,9 \%$ & & $0,1 \%$ & $-0,2 \%$ \\
\hline & $A_{105}$ & $-0,2 \%$ & $-0,1 \%$ & & & $0,0 \%$ & $0,0 \%$ \\
\hline & $A_{107}$ & $0,0 \%$ & $0,1 \%$ & $-1,5 \%$ & & $0,1 \%$ & $-0,1 \%$ \\
\hline & $A_{109}$ & $0,3 \%$ & & $-1,1 \%$ & & & \\
\hline & $\mathrm{A}_{1011}$ & $0,0 \%$ & $0,1 \%$ & $-1,6 \%$ & & $0,1 \%$ & $0,3 \%$ \\
\hline \multirow{7}{*}{4} & $A_{100}$ & $0,3 \%$ & $0,0 \%$ & $-1,9 \%$ & & $0,4 \%$ & $-0,2 \%$ \\
\hline & $A_{101}$ & $0,1 \%$ & $-0,2 \%$ & $-1,3 \%$ & & $0,4 \%$ & \\
\hline & $\mathrm{A}_{103}$ & $-0,1 \%$ & $0,1 \%$ & $-1,5 \%$ & $14,8 \%$ & $0,4 \%$ & $0,0 \%$ \\
\hline & $A_{105}$ & $0,0 \%$ & $0,0 \%$ & & $16,0 \%$ & $0,4 \%$ & $-0,2 \%$ \\
\hline & $A_{107}$ & $0,0 \%$ & $0,0 \%$ & $-1,5 \%$ & $15,6 \%$ & $0,3 \%$ & $0,1 \%$ \\
\hline & $\mathrm{A}_{109}$ & $-0,3 \%$ & $0,2 \%$ & $-1,6 \%$ & & & \\
\hline & $\mathrm{A}_{1011}$ & $-0,1 \%$ & $0,0 \%$ & $-2,2 \%$ & & $0,4 \%$ & \\
\hline \multirow{3}{*}{\multicolumn{2}{|c|}{$\begin{array}{l}\text { Máximo } \\
\text { Média } \\
\text { Mínimo }\end{array}$}} & $0,3 \%$ & $0,2 \%$ & $0,8 \%$ & $16,0 \%$ & $0,7 \%$ & $0,3 \%$ \\
\hline & & $0,0 \%$ & $0,0 \%$ & $-1,4 \%$ & $6,3 \%$ & $0,2 \%$ & $-0,1 \%$ \\
\hline & & $-0,4 \%$ & $-0,2 \%$ & $-3,4 \%$ & $0,2 \%$ & $-0,1 \%$ & $-0,2 \%$ \\
\hline
\end{tabular}

Verifica-se que nos dois picos de ressonância na frequência do primeiro modo de flexão a diferença das frequências é insignificante.

O GSF expressa um fator de escala global entre as FRF's. Seu cálculo foi efetuado com a Equação 4.10.

$$
\mathrm{GSF}=\sqrt{\frac{\left\{A_{\text {hor }}(\omega)\right\}^{T} \cdot\left\{A_{\text {hor }}(\omega)\right\}}{\left\{A_{v e r}(\omega)\right\}^{T} \cdot\left\{A_{v e r}(\omega)\right\}}}=\frac{\left|\left\{A_{h o r}(\omega)\right\}\right|}{\left|\left\{A_{v e r}(\omega)\right\}\right|}
$$

Sendo:

$$
\begin{aligned}
& A_{h o r}(\omega)=\text { acelerância obtida com excitação horizontal; } \\
& A_{v e r}(\omega)=\text { acelerância obtida com excitação vertical. }
\end{aligned}
$$


Foram obtidos 224 gráficos de correlação como o mostrado na Figura 4.25 e, devido à grande quantidade de informação, somente os valores de FDAC e FRSF obtidos nos picos de frequência do primeiro modo de flexão são mostrados neste capítulo.
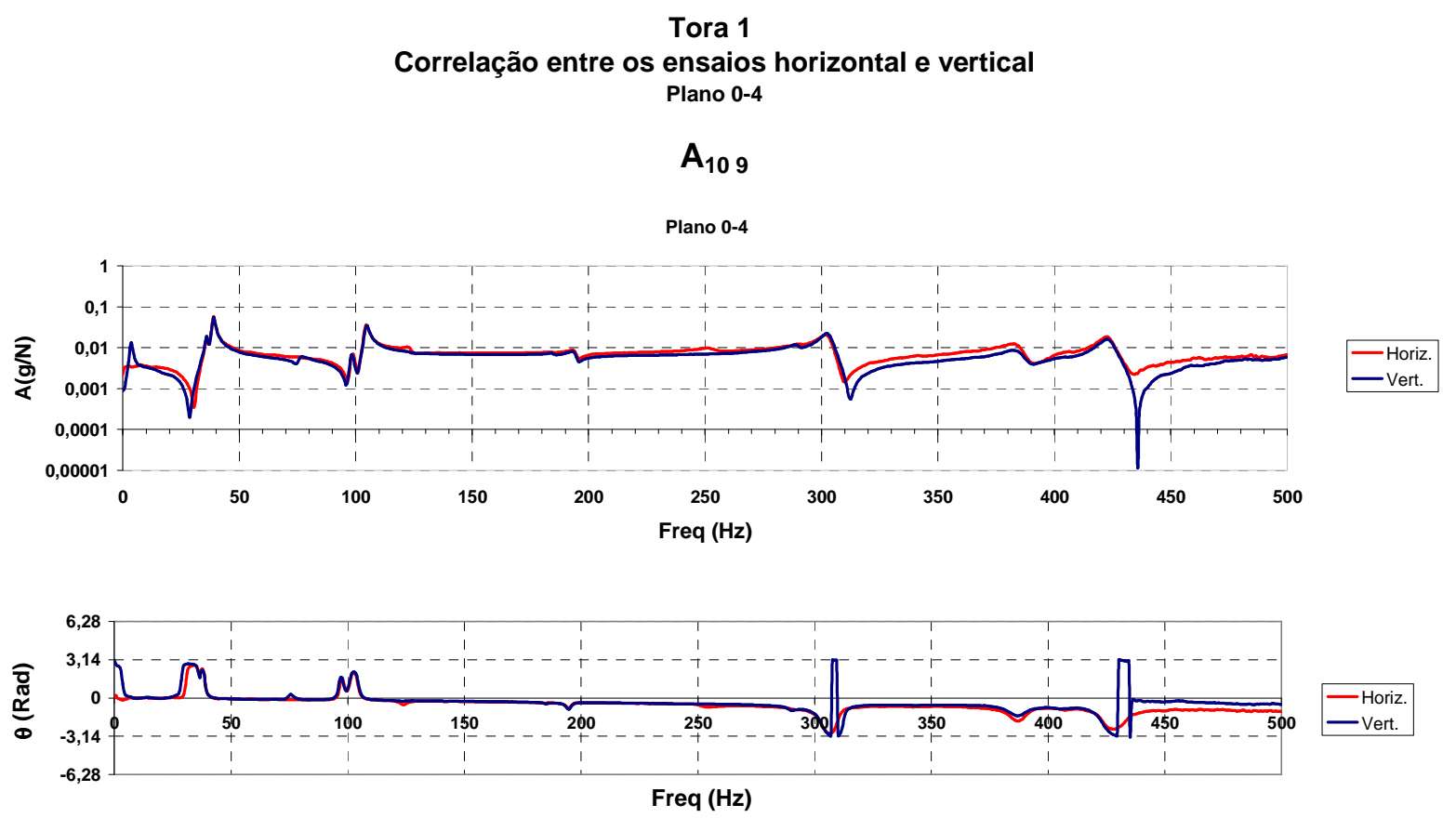

Correlação entre os ensaios

Frequency Domain Assurance Criterion (FDAC)

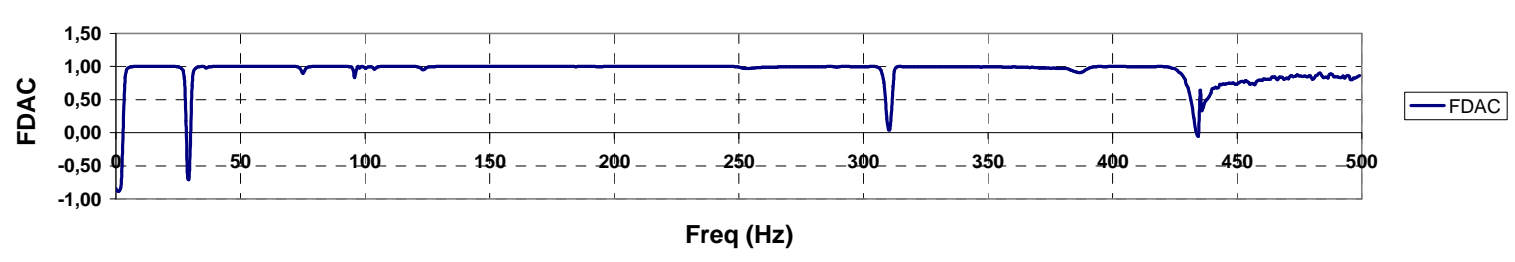

Frequency Response Scale Factor (FRSF)

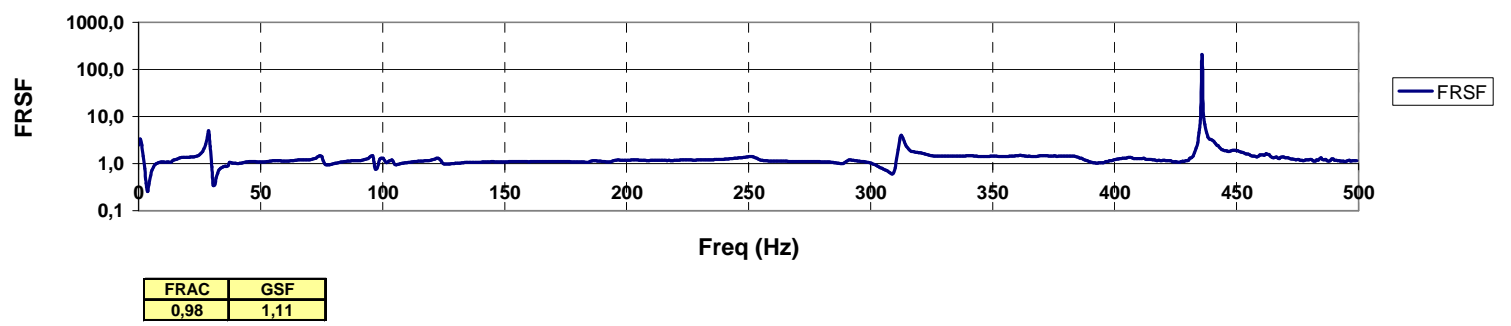

Figura 4.25 - Correlação entre as FRF's $\mathrm{A}_{10} 9$ da tora 1 para os ensaios com excitação horizontal e vertical no plano 0-4.

Inicialmente foi verificada a correlação global (em toda a banda de frequências) entre as FRF's. Para tanto, os valores de FRAC e GSF obtidos nas correlações foram tabelados obtendo-se a Tabela 4.29. 
Tabela 4.29 - Parâmetros FRAC e GSF obtidos nos picos de frequência do primeiro modo de flexão na correlação entre os ensaios com excitação vertical e horizontal.

\begin{tabular}{|c|c|c|c|c|c|c|c|c|c|}
\hline \multirow{2}{*}{ Plano } & \multirow{2}{*}{ FRF } & \multicolumn{2}{|c|}{ Tora 1} & \multicolumn{2}{|c|}{ Tora 2} & \multicolumn{2}{|c|}{ Tora 3} & \multicolumn{2}{|c|}{ Tora 4} \\
\hline & & FRAC & GSF & FRAC & GSF & FRAC & GSF & FRAC & GSF \\
\hline \multirow{7}{*}{$0-4$} & $\mathrm{~A}_{100}$ & 0.98 & 1.02 & 0.90 & 1.17 & 0.90 & 1.09 & 0.86 & 1.01 \\
\hline & $A_{101}$ & 0.98 & 1.04 & 0.95 & 1.14 & 0.95 & 0.99 & 0.93 & 1.01 \\
\hline & $A_{103}$ & 0.99 & 1.04 & 0.82 & 1.18 & 0.83 & 1.18 & 0.79 & 1.06 \\
\hline & $A_{105}$ & 0.99 & 1.07 & 0.98 & 1.11 & 0.99 & 0.96 & 0.96 & 1.09 \\
\hline & $A_{107}$ & 0.99 & 1.02 & 0.83 & 1.18 & 0.76 & 1.15 & 0.79 & 1.06 \\
\hline & $A_{109}$ & 0.98 & 1.11 & 0.94 & 1.13 & 0.94 & 1.01 & 0.94 & 0.96 \\
\hline & $\mathrm{A}_{1011}$ & 0.99 & 1.10 & 0.90 & 1.02 & 0.87 & 1.14 & 0.91 & 1.02 \\
\hline \multirow{7}{*}{$1-5$} & $A_{100}$ & 0.95 & 1.09 & 0.81 & 1.09 & 0.90 & 1.13 & 0.85 & 1.02 \\
\hline & $A_{101}$ & 0.97 & 0.95 & 0.88 & 0.91 & 0.96 & 1.06 & 0.95 & 1.04 \\
\hline & $A_{103}$ & 0.99 & 1.03 & 0.72 & 1.01 & 0.83 & 1.17 & 0.77 & 1.10 \\
\hline & $A_{105}$ & 0.99 & 0.98 & 0.98 & 0.94 & 0.98 & 1.01 & 0.97 & 0.98 \\
\hline & $A_{107}$ & 0.98 & 1.05 & 0.76 & 1.05 & 0.83 & 1.16 & 0.76 & 1.15 \\
\hline & $A_{109}$ & 0.98 & 1.05 & 0.92 & 1.04 & 0.94 & 1.08 & 0.95 & 1.01 \\
\hline & $A_{1011}$ & 0.98 & 1.04 & 0.85 & 0.97 & 0.90 & 1.10 & 0.88 & 1.02 \\
\hline \multirow{7}{*}{$2-6$} & $A_{100}$ & 0.99 & 1.00 & 0.81 & 1.04 & 0.84 & 1.10 & 0.80 & 1.10 \\
\hline & $A_{101}$ & 0.98 & 1.08 & 0.89 & 0.92 & 0.90 & 1.05 & 0.87 & 1.10 \\
\hline & $A_{103}$ & 0.99 & 1.04 & 0.69 & 1.07 & 0.75 & 1.13 & 0.66 & 1.20 \\
\hline & $A_{105}$ & 1.00 & 1.01 & 0.98 & 0.92 & 0.89 & 0.97 & 0.98 & 0.97 \\
\hline & $A_{107}$ & 0.98 & 1.04 & 0.71 & 1.19 & 0.72 & 1.13 & 0.65 & 1.18 \\
\hline & $A_{109}$ & 0.98 & 1.10 & 0.87 & 1.20 & 0.88 & 0.97 & 0.93 & 1.04 \\
\hline & $A_{1011}$ & 0.95 & 1.15 & 0.86 & 1.04 & 0.69 & 1.02 & 0.86 & 1.15 \\
\hline \multirow{7}{*}{$3-7$} & $A_{100}$ & 0.98 & 1.09 & 0.76 & 0.87 & 0.86 & 1.10 & 0.88 & 1.02 \\
\hline & $A_{101}$ & 0.99 & 1.01 & 0.91 & 1.00 & 0.95 & 1.05 & 0.95 & 1.10 \\
\hline & $\mathrm{A}_{103}$ & 0.98 & 1.00 & 0.62 & 1.08 & 0.76 & 1.16 & 0.80 & 1.07 \\
\hline & $A_{105}$ & 0.99 & 1.03 & 0.99 & 1.00 & 0.98 & 1.00 & 0.96 & 1.02 \\
\hline & $A_{107}$ & 0.97 & 1.00 & 0.67 & 1.16 & 0.74 & 1.17 & 0.79 & 1.08 \\
\hline & $A_{109}$ & 0.99 & 1.04 & 0.90 & 0.99 & 0.92 & 1.09 & 0.95 & 1.02 \\
\hline & $A_{1011}$ & 0.98 & 1.00 & 0.84 & 1.06 & 0.87 & 1.02 & 0.62 & 0.98 \\
\hline \multirow{7}{*}{$4-0$} & $A_{100}$ & 0.98 & 1.04 & 0.86 & 0.98 & 0.71 & 1.82 & 0.87 & 1.05 \\
\hline & $A_{101}$ & 0.95 & 1.10 & 0.92 & 0.97 & 0.95 & 0.99 & 0.95 & 1.01 \\
\hline & $\mathrm{A}_{103}$ & 0.95 & 1.06 & 0.75 & 1.07 & 0.80 & 1.02 & 0.78 & 1.15 \\
\hline & $A_{105}$ & 0.98 & 1.04 & 0.97 & 1.01 & 0.99 & 1.02 & 0.97 & 1.05 \\
\hline & $A_{107}$ & 0.98 & 1.03 & 0.76 & 1.12 & 0.82 & 1.03 & 0.79 & 1.15 \\
\hline & $A_{109}$ & 0.97 & 1.03 & 0.92 & 1.01 & 0.95 & 0.92 & 0.96 & 1.00 \\
\hline & $A_{1011}$ & 0.97 & 1.10 & 0.89 & 0.99 & * & * & 0.91 & 1.08 \\
\hline \multirow{7}{*}{ 5-1 } & $A_{100}$ & 0.99 & 0.98 & 0.83 & 0.99 & 0.88 & 1.11 & 0.85 & 1.09 \\
\hline & $A_{101}$ & 0.99 & 1.04 & 0.91 & 0.92 & 0.93 & 1.03 & 0.94 & 1.04 \\
\hline & $A_{103}$ & 0.98 & 0.99 & 0.72 & 0.99 & 0.81 & 1.13 & 0.72 & 1.23 \\
\hline & $A_{105}$ & 1.00 & 0.99 & 0.98 & 0.92 & 0.98 & 1.04 & 0.97 & 0.99 \\
\hline & $A_{107}$ & 0.98 & 0.99 & 0.75 & 1,06 & 0.80 & 1.10 & 0.71 & 1.21 \\
\hline & $A_{109}$ & 0.98 & 1.03 & 0.94 & 0.95 & 0.94 & 0.99 & 0.94 & 1.02 \\
\hline & $A_{1011}$ & 0.99 & 1.07 & 0.87 & 1.05 & 0.89 & 1.02 & 0.89 & 1.03 \\
\hline \multirow{7}{*}{$6-2$} & $A_{100}$ & 0.99 & 1.06 & 0.82 & 0.96 & 0.87 & 1.11 & 0.80 & 1.12 \\
\hline & $A_{101}$ & 0.99 & 1.03 & 0.89 & 0.94 & 0.93 & 0.91 & 0.89 & 1.12 \\
\hline & $A_{103}$ & 0.98 & 1.04 & 0.73 & 1.03 & 0.79 & 1.11 & 0.65 & 1.13 \\
\hline & $A_{105}$ & 1.00 & 1.03 & 0.97 & 0.91 & 0.98 & 0.99 & 0.98 & 1.01 \\
\hline & $A_{107}$ & 0.98 & 1.06 & 0.72 & 1.05 & 0.79 & 1.16 & 0.68 & 1.24 \\
\hline & $A_{109}$ & 0.98 & 1.00 & 0.92 & 0.99 & 0.94 & 0.99 & 0.94 & 1.04 \\
\hline & $A_{1011}$ & 0.99 & 1.05 & 0.84 & 1.04 & 0.87 & 1.01 & 0.97 & 0.92 \\
\hline \multirow{7}{*}{ 7-3 } & $A_{100}$ & 0.98 & 1.00 & 0.81 & 1.08 & 0.81 & 1.16 & 0.89 & 1.00 \\
\hline & $A_{101}$ & 0.99 & 1.00 & 0.90 & 1.05 & 0.93 & 1.05 & 0.94 & 1.03 \\
\hline & $A_{103}$ & 0.99 & 0.98 & 0.72 & 1.23 & 0.69 & 1.28 & 0.81 & 1.05 \\
\hline & $A_{105}$ & 1.00 & 1.00 & 0.97 & 1.05 & 0.98 & 1.01 & 0.95 & 0.99 \\
\hline & $A_{107}$ & 0.99 & 0.95 & 0.73 & 1.15 & 0.68 & 1.26 & 0.79 & 1.04 \\
\hline & $A_{109}$ & 0.98 & 1.03 & 0.91 & 1.12 & 0.93 & 1.00 & 0.95 & 1.00 \\
\hline & $A_{1011}$ & 0.94 & 1.13 & 0.85 & 1.09 & 0.84 & 1.07 & 0.90 & 0.99 \\
\hline \multicolumn{2}{|l|}{ Média } & 0.98 & 1.04 & 0.85 & 1.04 & 0.87 & 1.08 & 0.86 & 1.06 \\
\hline
\end{tabular}


Os valores médios de FRAC maiores que 0,80 indicam que, em geral, foram obtidas boas correlações entre as FRF's medidas com excitação horizontal e vertical para as toras 1 a 4.

A tora 1 apresentou melhor correlação entre os ensaios do que as demais. Tal resultado pode ser consequência de ter sido usada, somente para esta tora, uma corda com o dobro do comprimento das usadas nas toras 2, 3 e 4 como mostra a Figura 4.26.

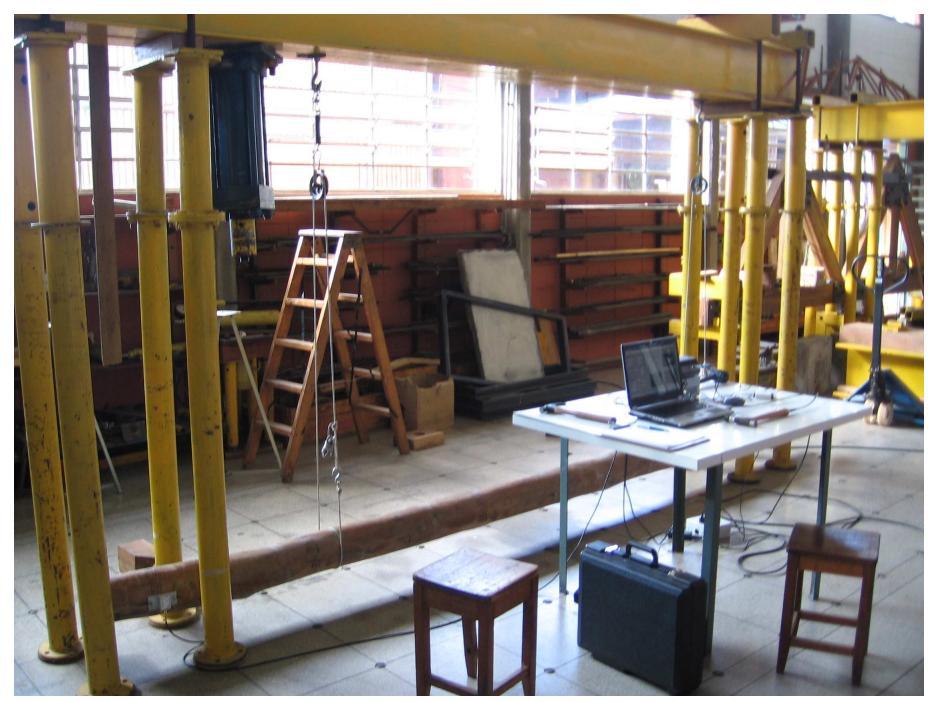

(a)

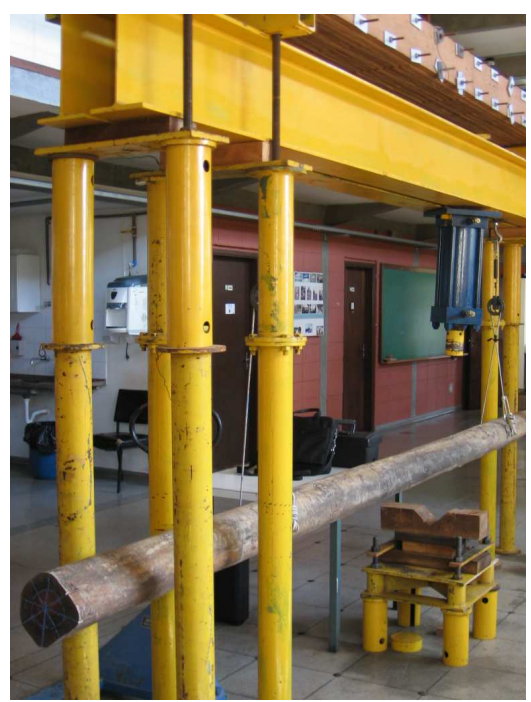

(b)

Figura 4.26 - Ensaio dinâmico: a) Tora 1; b) demais toras.

Na maior parte das correlações obteve-se GSF maiores do que 1,00, sendo que há várias observações maiores do que 1,10. Em todos esses casos as FRF's medidas com excitação horizontal apresentaram magnitude maior do que as medidas com excitação vertical. As FRF's medidas com excitação no plano vertical apresentaram menor magnitude, pois nesses ensaios, uma parcela maior da energia introduzida no sistema pelo martelo de impulso foi absorvida pelo sistema de suspensão. Assim sendo, pode-se dizer que o sistema de suspensão teve menor influência no comportamento à vibração no plano horizontal.

A Tabela 4.30 mostra os valores dos parâmetros FDAC e FRSF obtidos nas correlações entre os ensaios com excitação vertical e horizontal das toras 1 a 4 . 
Tabela 4.30 - Parâmetros FDAC e FRSF obtidos nos picos de frequência do primeiro modo de flexão na correlação entre os ensaios com excitação vertical e horizontal.

\begin{tabular}{|c|c|c|c|c|c|c|c|c|c|c|c|c|c|c|c|}
\hline \multirow{3}{*}{ Plano } & \multirow{3}{*}{ FRF } & \multicolumn{4}{|c|}{$\begin{array}{ll} & \text { Tora } 1 \\
\end{array}$} & \multirow{2}{*}{\multicolumn{2}{|c|}{ Tora 2}} & \multicolumn{4}{|c|}{ Tora 3} & \multicolumn{4}{|c|}{ Tora 4} \\
\hline & & \multirow{2}{*}{\multicolumn{4}{|c|}{$\begin{array}{cc}\text { FDAC } & \text { FRSF } \\
1^{\circ} \text { pico } 2^{\circ} \text { pico } 1^{\circ} \text { pico } 2^{\circ} \text { pico }\end{array}$}} & & & \multicolumn{2}{|c|}{ FDAC } & \multicolumn{2}{|c|}{ FRSF } & & AC & FR & SF \\
\hline & & & & & & FDAC & FRSF & $1^{\circ}$ pico & $2^{\circ}$ pico & $1^{\circ}$ pico & $2^{\circ}$ pico & $1^{\circ}$ pico & $2^{\circ}$ pico & $1^{\circ}$ pico & $2^{\circ}$ pico \\
\hline & $A_{100}$ & 1,00 & 1,00 & 1,04 & 0,98 & 0,98 & 1,58 & 1,00 & 1,00 & 0,98 & 1,04 & 1,00 & 1,00 & 1,08 & 0,96 \\
\hline & $\mathrm{A}_{101}$ & 1,00 & 1,00 & 1,07 & 1,00 & 0,98 & 1,58 & 1,00 & 1,00 & 0,98 & 1,01 & 0,99 & 1,00 & 1,12 & 0,98 \\
\hline & $\mathrm{A}_{103}$ & 0,99 & 1,00 & 0,97 & 0,99 & 0,98 & 1,55 & 1,00 & 1,00 & 1,00 & 1,00 & 0,98 & 1,00 & 1,12 & 0,96 \\
\hline $0-4$ & $A_{105}$ & 0,99 & 1,00 & 0,96 & 1,02 & 0,98 & 1,57 & 0,98 & 1,00 & 0,91 & 1,08 & 0,98 & 1,00 & 1,10 & 0,91 \\
\hline & $A_{107}$ & & 1,00 & & 1,01 & 0,97 & 1,59 & 0,99 & 1,00 & 0,94 & 1,11 & 1,00 & 1,00 & 0,99 & 1,01 \\
\hline & $A_{109}$ & 0,98 & 1,00 & 0,87 & 1,03 & 0,98 & 1,56 & 0,99 & 1,00 & 0,93 & 1,05 & 1,00 & 1,00 & 1,02 & 1,00 \\
\hline & $A_{1011}$ & 0,99 & 1,00 & 0,93 & 1,08 & 1,00 & 1,02 & 0,99 & 1,00 & 0,96 & 1,11 & 0,99 & 1,00 & 1,07 & 0,98 \\
\hline & $A_{100}$ & 1,00 & & 0,96 & & 1,00 & 1,02 & 1,00 & & 1,02 & & & 1,00 & & 1,00 \\
\hline & $\mathrm{A}_{101}$ & 1,00 & & 0,98 & & 1,00 & 1,03 & 1,00 & & 0,99 & & & 1,00 & & 1,05 \\
\hline & $\mathrm{A}_{103}$ & 1,00 & & 1,02 & & 1,00 & 1,03 & 1,00 & & 1,03 & & & 1,00 & & 1,05 \\
\hline $1-5$ & $A_{105}$ & 1,00 & 1,00 & 0,94 & 1,11 & 1,00 & 0,98 & 1,00 & & 1,00 & & & 1,00 & & 1,00 \\
\hline & $A_{107}$ & 1,00 & 1,00 & 0,94 & 1,08 & 1,00 & 1,06 & 1,00 & & 0,95 & & & 1,00 & & 1,04 \\
\hline & $\mathrm{A}_{109}$ & 1,00 & & 0,98 & & 1,00 & 1,00 & 1,00 & & 1,01 & & & 1,00 & & 0,99 \\
\hline & $A_{1011}$ & 1,00 & & 1,03 & & 1,00 & 0,79 & 1,00 & & 1,01 & & & 1,00 & & 1,03 \\
\hline & $\mathrm{A}_{100}$ & 1,00 & 1,00 & 0,98 & 1,03 & 1,00 & 1,01 & 0,99 & 1,00 & 1,22 & 0,98 & & 1,00 & & 1,08 \\
\hline & $\mathrm{A}_{101}$ & 1,00 & 1,00 & 1,03 & 0,91 & 1,00 & 0,96 & 0,99 & 1,00 & 1,26 & 0,97 & & 1,00 & & 1,13 \\
\hline & $\mathrm{A}_{103}$ & 1,00 & 1,00 & 0,97 & 0,98 & 1,00 & 0,94 & 1,00 & 1,00 & 1,08 & 0,94 & & 1,00 & & 1,06 \\
\hline $2-6$ & $A_{105}$ & 1,00 & 1,00 & 1,03 & 0,97 & 1,00 & 0,92 & 0,99 & 1,00 & 1,16 & 0,94 & 1,00 & 1,00 & 1,03 & 1,08 \\
\hline & $A_{107}$ & 1,00 & 1,00 & 1,02 & 0,87 & 1,00 & 0,93 & 0,97 & 1,00 & 1,02 & 0,84 & & 1,00 & & 1,01 \\
\hline & $A_{109}$ & 1,00 & 1,00 & 1,08 & 0,94 & 1,00 & 0,95 & 1,00 & 1,00 & 1,02 & 1,01 & & 1,00 & & 1,02 \\
\hline & $A_{1011}$ & 1,00 & & 1,04 & & 1,00 & 0,97 & 1,00 & 1,00 & 1,06 & 0,94 & & 1,00 & & 1,02 \\
\hline & $\mathrm{A}_{100}$ & 1,00 & & 1,01 & & 1,00 & 1,07 & 1,00 & & 1,03 & & & 1,00 & & 1,04 \\
\hline & $\mathrm{A}_{101}$ & 1,00 & & 1,04 & & 1,00 & 1,04 & 1,00 & & 1,05 & & & 1,00 & & 1,00 \\
\hline & $\mathrm{A}_{103}$ & 1,00 & & 0,99 & & 1,00 & 1,02 & 1,00 & & 0,98 & & & 1,00 & & 1,03 \\
\hline $3-7$ & $\mathrm{~A}_{105}$ & 1,00 & & 1,00 & & 1,00 & 1,04 & 1,00 & & 1,03 & & & 1,00 & & 1,02 \\
\hline & $A_{107}$ & 1,00 & & 0,97 & & 1,00 & 1,06 & 1,00 & & 1,02 & & & 1,00 & & 1,04 \\
\hline & $A_{109}$ & 1,00 & & 1,00 & & 1,00 & 1,08 & 1,00 & & 0,99 & & & 1,00 & & 0,98 \\
\hline & $A_{1011}$ & 1,00 & & 0,96 & & 1,00 & 1,06 & 1,00 & & 1,00 & & & 1,00 & & 0,99 \\
\hline & $A_{100}$ & 1,00 & 1,00 & 1,11 & 1,07 & 0,99 & 0,92 & & 1,00 & & 1,95 & & & & \\
\hline & $\mathrm{A}_{101}$ & 1,00 & 1,00 & 1,02 & 1,04 & 1,00 & 0,99 & 0,93 & 1,00 & 0,84 & 1,23 & & 1,00 & & 0,91 \\
\hline & $\mathrm{A}_{103}$ & 1,00 & 1,00 & 0,90 & 1,05 & 1,00 & 0,92 & 0,95 & 1,00 & 0,87 & 1,17 & & 1,00 & & 1,13 \\
\hline $4-0$ & $\mathrm{~A}_{105}$ & 1,00 & 1,00 & 1,03 & 1,03 & 1,00 & 0,96 & 1,00 & 1,00 & 0,98 & 1,07 & & 1,00 & & 1,14 \\
\hline & $\mathrm{A}_{107}$ & & 1,00 & & 1,09 & 1,00 & 0,92 & 0,99 & 1,00 & 0,97 & 1,13 & & 1,00 & & 0,94 \\
\hline & $A_{109}$ & 0,97 & 1,00 & 1,14 & 1,10 & 0,99 & 1,50 & 1,00 & 1,00 & 0,95 & 1,03 & & 1,00 & & 0,97 \\
\hline & $A_{1011}$ & 1,00 & 1,00 & 1,01 & 1,01 & 1,00 & 0,97 & & & & & & 1,00 & & 0,99 \\
\hline & $A_{100}$ & 1,00 & & 0,99 & & 1,00 & 1,04 & 1,00 & & 1,04 & & & 1,00 & & 1,02 \\
\hline & $\mathrm{A}_{101}$ & 1,00 & & 1,03 & & 1,00 & 1,01 & 1,00 & & 1,03 & & & 1,00 & & 1,03 \\
\hline & $\mathrm{A}_{103}$ & 1,00 & & 0,96 & & 0,99 & 1,03 & 1,00 & & 1,03 & & & 1,00 & & 1,02 \\
\hline $5-1$ & $\mathrm{~A}_{105}$ & 1,00 & & 1,00 & & 1,00 & 1,01 & 1,00 & & 1,02 & & & 1,00 & & 1,03 \\
\hline & $A_{107}$ & 1,00 & & 0,96 & & 1,00 & 0,99 & 1,00 & & 1,07 & & & 1,00 & & 1,06 \\
\hline & $\mathrm{A}_{109}$ & 1,00 & & 1,04 & & 1,00 & 1,06 & 1,00 & & 1,04 & & & 1,00 & & 0,98 \\
\hline & $A_{1011}$ & 1,00 & & 1,03 & & 1,00 & 1,05 & 1,00 & & 1,04 & & & 1,00 & & 1,05 \\
\hline & $\mathrm{A}_{100}$ & 1,00 & 1,00 & 1,06 & 0,91 & 1,00 & 0,95 & & 0,99 & & 1,16 & & 1,00 & & 1,08 \\
\hline & $\mathrm{A}_{101}$ & 1,00 & 1,00 & 1,04 & 0,99 & 1,00 & 1,00 & 0,66 & 0,99 & 0,99 & 1,67 & & 1,00 & & 1,05 \\
\hline & $\mathrm{A}_{103}$ & 1,00 & & 1,05 & & 0,99 & 1,76 & 0,99 & 1,00 & 1,22 & 0,97 & & 1,00 & & 1,04 \\
\hline $6-2$ & $A_{105}$ & 1,00 & 1,00 & 1,06 & 0,84 & 1,00 & 0,99 & 1,00 & 1,00 & 0,97 & 1,03 & & 1,00 & & 1,09 \\
\hline & $A_{107}$ & 1,00 & & 1,04 & & 1,00 & 0,98 & 1,00 & 1,00 & 1,12 & 0,97 & & 1,00 & & 1,01 \\
\hline & $A_{109}$ & 1,00 & 1,00 & 0,98 & 1,04 & 1,00 & 0,99 & 1,00 & 1,00 & 0,93 & 1,11 & & 1,00 & & 1,09 \\
\hline & $A_{1011}$ & 1,00 & 1,00 & 1,05 & 0,96 & 1,00 & 1,02 & 0,99 & 1,00 & 1,11 & 0,92 & & 1,00 & & 1,08 \\
\hline & $\mathrm{A}_{100}$ & & 1,00 & & 1,01 & 1,00 & 1,05 & & 1,00 & & 1,01 & & 1,00 & & 1,03 \\
\hline & $\mathrm{A}_{101}$ & & 1,00 & & 0,97 & 1,00 & 0,99 & & 1,00 & & 1,00 & & 1,00 & & 0,99 \\
\hline & $\mathrm{A}_{103}$ & & 1,00 & & 0,94 & 1,00 & 1,09 & & 1,00 & & 1,05 & & 1,00 & & 0,98 \\
\hline $7-3$ & $\mathrm{~A}_{105}$ & 0,99 & 1,00 & 1,06 & 1,01 & 1,00 & 1,01 & & 1,00 & & 1,01 & & 1,00 & & 0,98 \\
\hline & $\mathrm{A}_{107}$ & 0,99 & 1,00 & 1,02 & 0,92 & 1,00 & 1,04 & & 1,00 & & 1,05 & & 1,00 & & 0,95 \\
\hline & $A_{109}$ & & 1,00 & & 0,95 & 1,00 & 1,04 & & 1,00 & & 0,95 & & 1,00 & & 1,04 \\
\hline & $A_{1011}$ & & 0,98 & & 2,63 & 1,00 & 1,06 & & 1,00 & & 0,99 & & 1,00 & & 1,04 \\
\hline & & 1,00 & 1,00 & 1,01 & 1,05 & 1,00 & 1,08 & 0,99 & 1,00 & 1,02 & 1,07 & 0,99 & 1,00 & 1,06 & 1,02 \\
\hline
\end{tabular}


A partir da análise da Tabela 4.30 verifica-se que:

a) Em apenas uma observação o valor de FDAC calculado nos picos de ressonância do primeiro modo de flexão foi inferior a 0,90 indicando que para as demais observações obteve-se uma boa correlação entre os ensaios nessas frequências;

b) Embora o parâmetro FRSF tenha apresentado muitos valores próximos de 1,00, observam-se em algumas correlações valores superiores a 1,10 para esse parâmetro como mostra, por exemplo, a Figura 4.27.

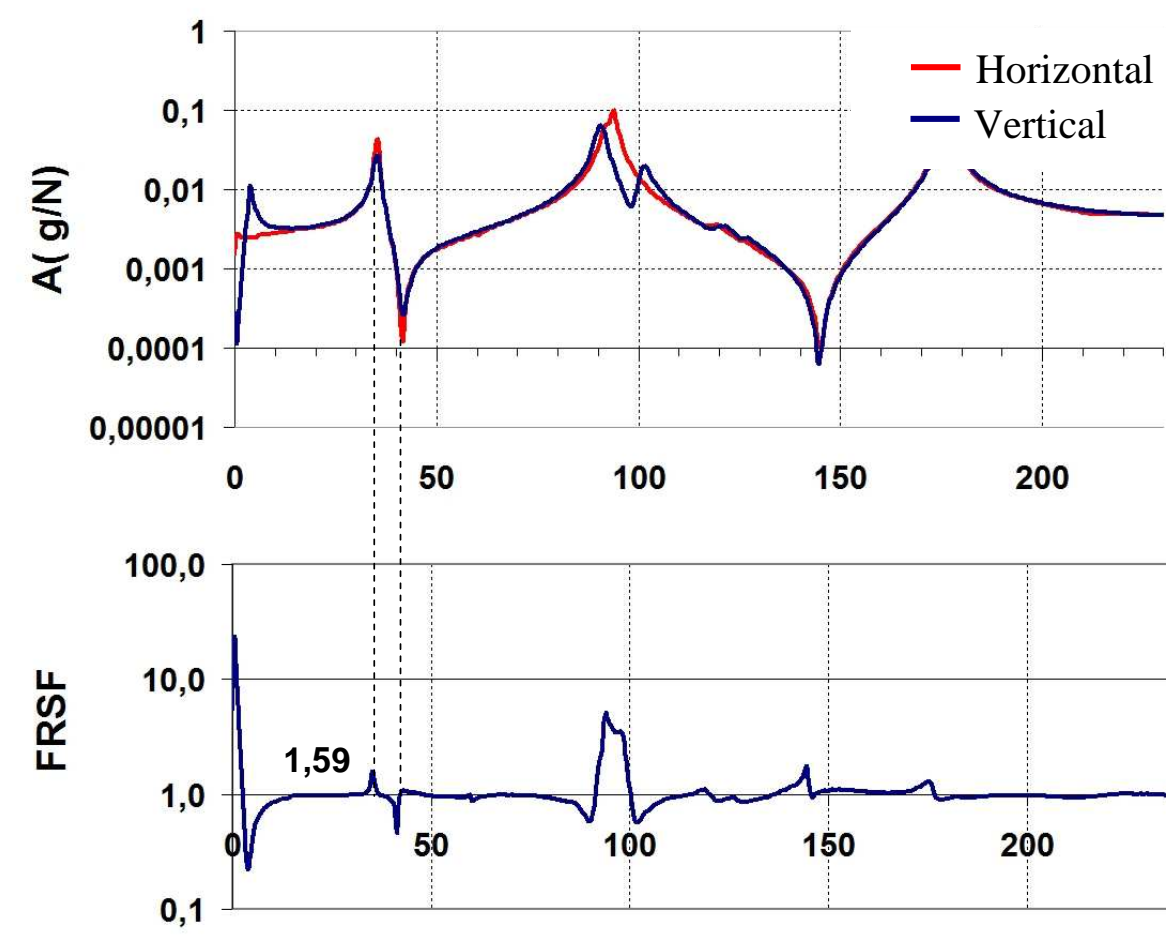

Figura 4.27 - Exemplo de atenuação da intensidade da acelerância no primeiro modo para o ensaio com excitação vertical ( $\mathrm{A}_{10} 7$ tora 2 - plano $\left.0-4\right)$.

Conforme já mencionado no item 4.4.2, o fato do modo de corpo rígido não ter aparecido em várias das FRF's medidas com excitação horizontal (Figura 4.28, por exemplo) indica que a frequência desse modo foi inferior à resolução da FRF $(0,61 \mathrm{~Hz})$. A baixa frequência do modo de corpo rígido indica que a rigidez do sistema de suspensão na direção horizontal é muito pequena. Assim sendo pode-se comprovar que o ensaio com excitação horizontal aproximou-se mais da condição livre-livre do que o ensaio com excitação vertical. 


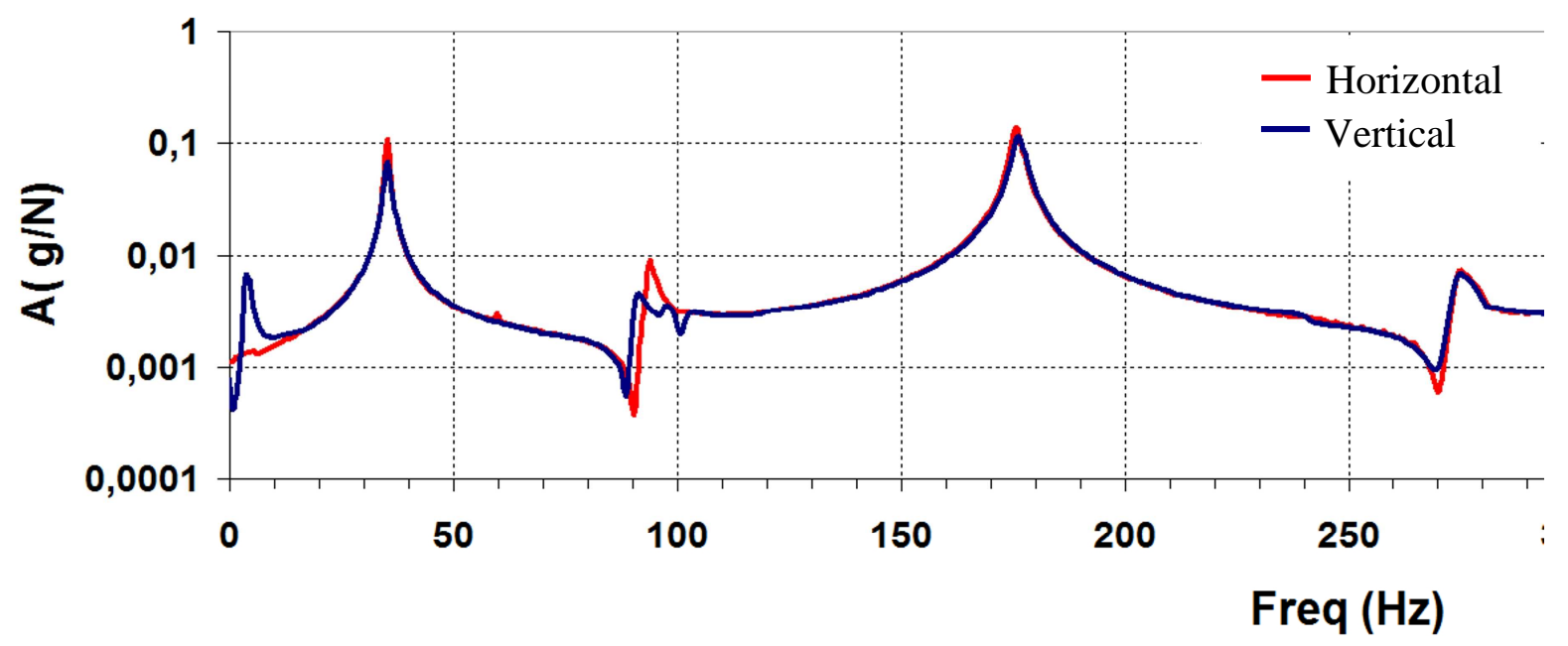

Figura 4.28 - Exemplo de ausência do modo de corpo rígido na FRF medida com excitação horizontal ( $\mathrm{A}_{105}$ tora 2$)$.

Portanto, observa-se que o sistema de suspensão pode interferir na amplitude da acelerância para o primeiro modo de flexão, ainda que a frequência natural do modo de corpo rígido seja inferior a $1 / 10$ da frequência do primeiro modo de flexão.

Deve-se ter em mente que possivelmente as condições de ensaio em campo não permitam obter um sistema de suspensão de baixa rigidez como o utilizado nesses ensaios de forma que a interferência do mesmo nos parâmetros modais das toras pode ser muito maior do que o observado nos experimentos desenvolvidos neste trabalho. Nesses casos, é mais interessante que o ensaio dinâmico seja realizado com excitação horizontal para atenuar ao máximo a influência do sistema de suspensão na avaliação do módulo de elasticidade das toras.

\subsubsection{Comparação entre os módulos de elasticidade estático e dinâmico}

Nas análises apresentadas nesse item, o módulo de elasticidade estático corresponde à média aritmética dos módulos obtidos nos oito planos em que as toras foram ensaiadas. Da mesma forma, o módulo de elasticidade dinâmico é o valor calculado com a média aritmética dos dois picos de frequência observados para o primeiro modo de flexão.

A Figura 4.29 mostra o gráfico de correlação entre os módulos de elasticidade à flexão estático e dinâmico, ambos sem levar em conta o efeito do esforço cortante. 


\section{$E_{M, V T, a p} \times E_{M, S t a t, a p}$}

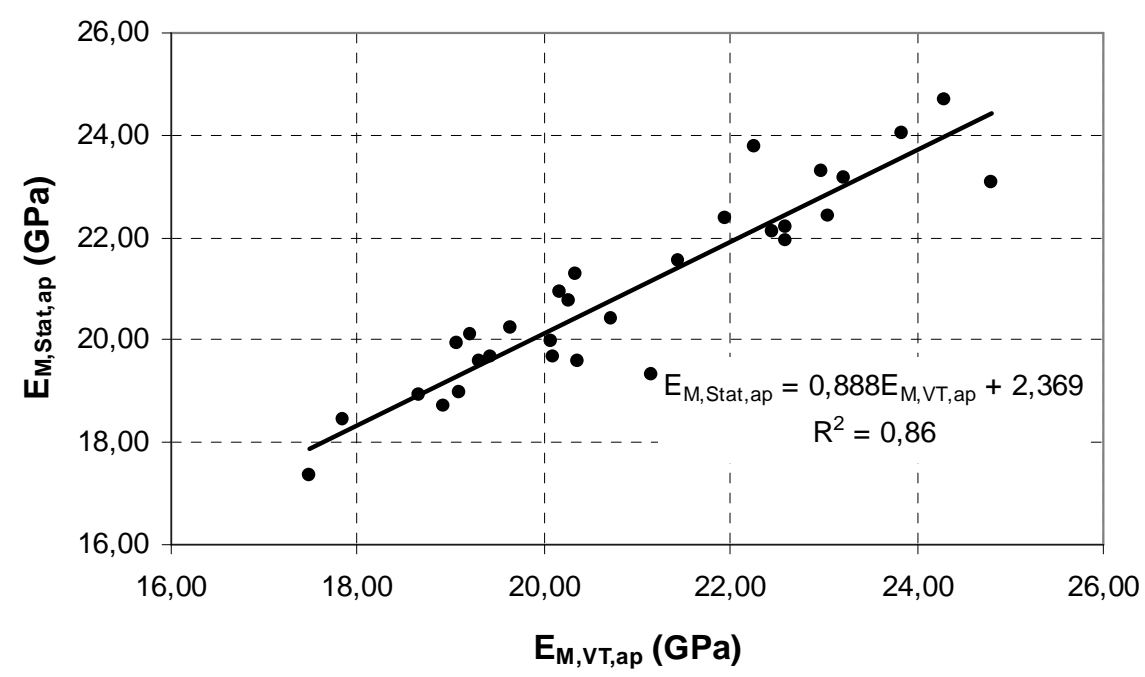

Figura 4.29 - Gráfico de correlação entre $\mathrm{E}_{\mathrm{M}, \mathrm{Stat,ap}}$ e $\mathrm{E}_{\mathrm{M}, \mathrm{VT} \text {,ap }}$.

Verifica-se na Figura 4.29 uma boa correlação entre os resultados sendo que o valor do coeficiente de determinação encontrado $\left(\mathrm{R}^{2}=0,86\right)$ é comparável aos obtidos por Wang et al (2002), Chui et al (1999) e por Green et al (2006). Entretanto, os valores dos módulos de elasticidade das toras TT e TB necessitam de correção para levar em conta o efeito do esforço cortante.

A Figura 4.30 mostra a correlação entre os módulos de elasticidade estático e dinâmico, ambos levando em conta o efeito do esforço cortante, sendo que o módulo de elasticidade estático foi calculado pela Equação 4.7.

\section{$E_{M, V T} \times E_{M, S t a t, v}$}

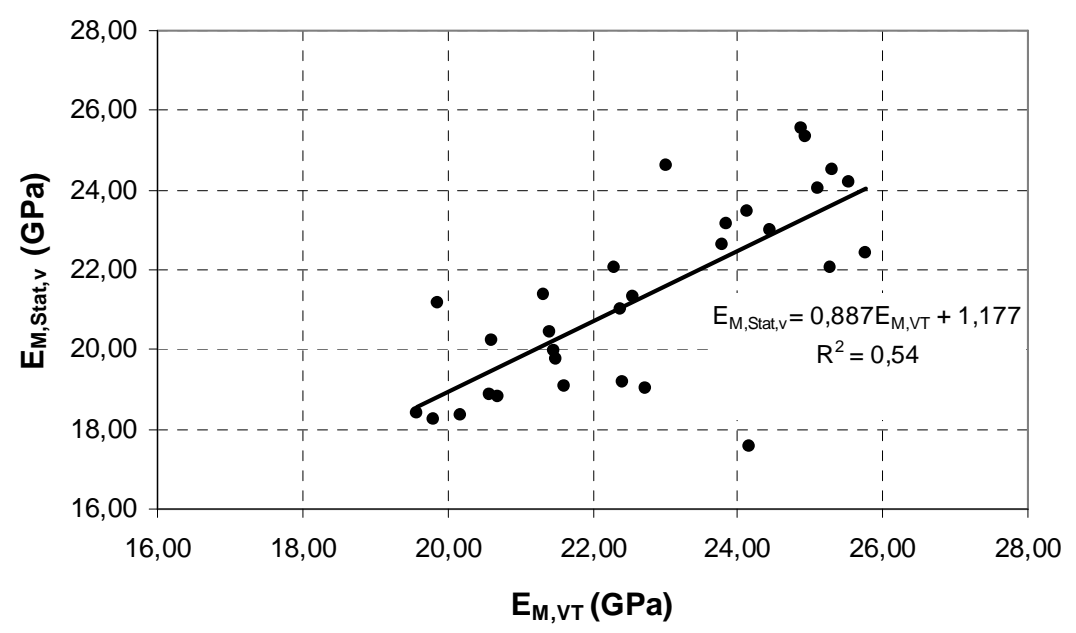

Figura 4.30 - Gráfico de correlação entre $\mathrm{E}_{\mathrm{M}, \mathrm{VT}}$ e $\mathrm{E}_{\mathrm{M}, \text { Stat,v. }}$ 
Observa-se que os pontos ficaram mais dispersos em relação a Figura 4.29 resultando em $R^{2}=0,54$. Esse resultado pode ser atribuído aos valores estranhos obtidos para $E_{M, s t a t, v}$.

A Figura 4.31 mostra o gráfico de correlação entre $\mathrm{E}_{\mathrm{M}, \mathrm{VT}}$ e $\mathrm{E}_{\mathrm{M}, \mathrm{Stat}, \mathrm{v}}{ }^{*}$ no qual observa-se que, embora os pontos tenham sofrido uma pequena dispersão em relação à Figura 4.29, a correlação entre $\mathrm{E}_{\mathrm{M}, \mathrm{VT}}$ e $\mathrm{E}_{\mathrm{M}, \mathrm{Stat}, \mathrm{v}^{*}}$ é mais forte do que o gráfico mostrado na Figura 4.30.

\section{$E_{M, v T} \times E_{M, \text { Stat,v }}$}

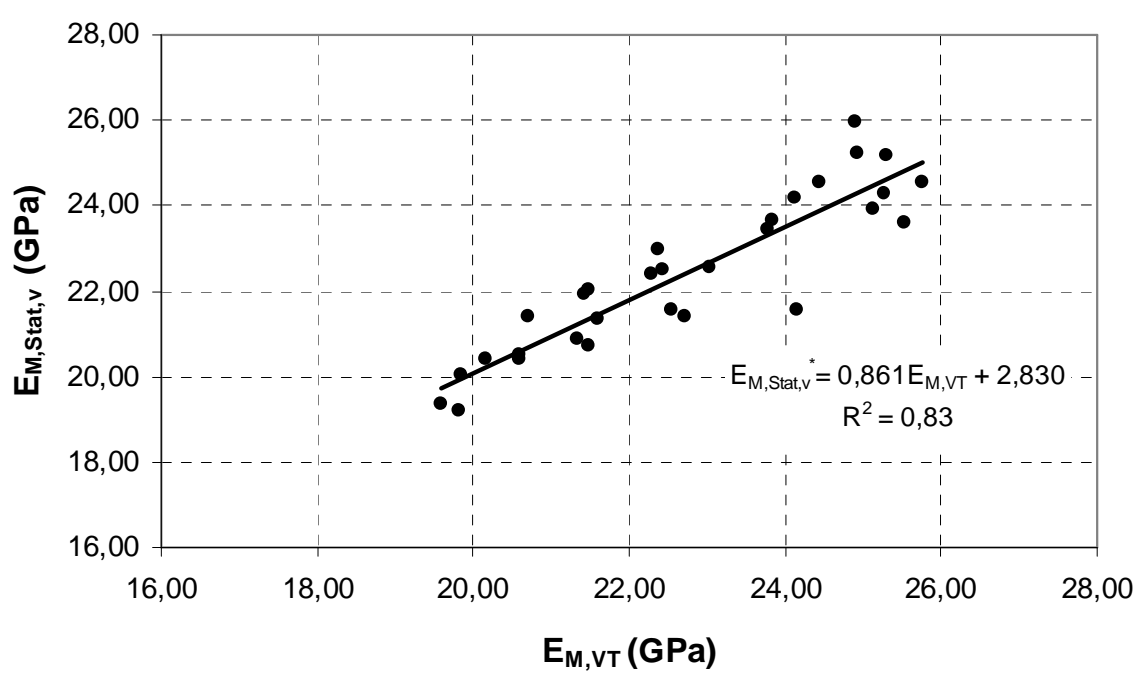

Figura 4.31 - Gráfico de dispersão entre $\mathrm{E}_{\mathrm{M}, \mathrm{VT}}$ e $\mathrm{E}_{\mathrm{M}, \mathrm{Stat}, \mathrm{v}^{*}}$ calculado pela Equação 4.6.

O maior resíduo observado nas estimativas do módulo de elasticidade à flexão com o modelo de regressão mostrado na Figura 4.31 foi de $2 \mathrm{GPa}$, sendo que 27 das 30 observações apresentaram resíduo inferior a $1 \mathrm{GPa}$.

A título de comparação, a Figura 4.32 mostra o gráfico de correlação entre $\mathrm{E}_{\mathrm{M}, \mathrm{VT}} \mathrm{e}$ $\mathrm{E}_{\mathrm{M}, \mathrm{Stat}, \mathrm{v}^{*}}$ com $\mathrm{E}_{\mathrm{M}, \mathrm{VT}}$ calculado com a frequência do primeiro pico em vez da média aritmética das frequências dos dois primeiros picos. 


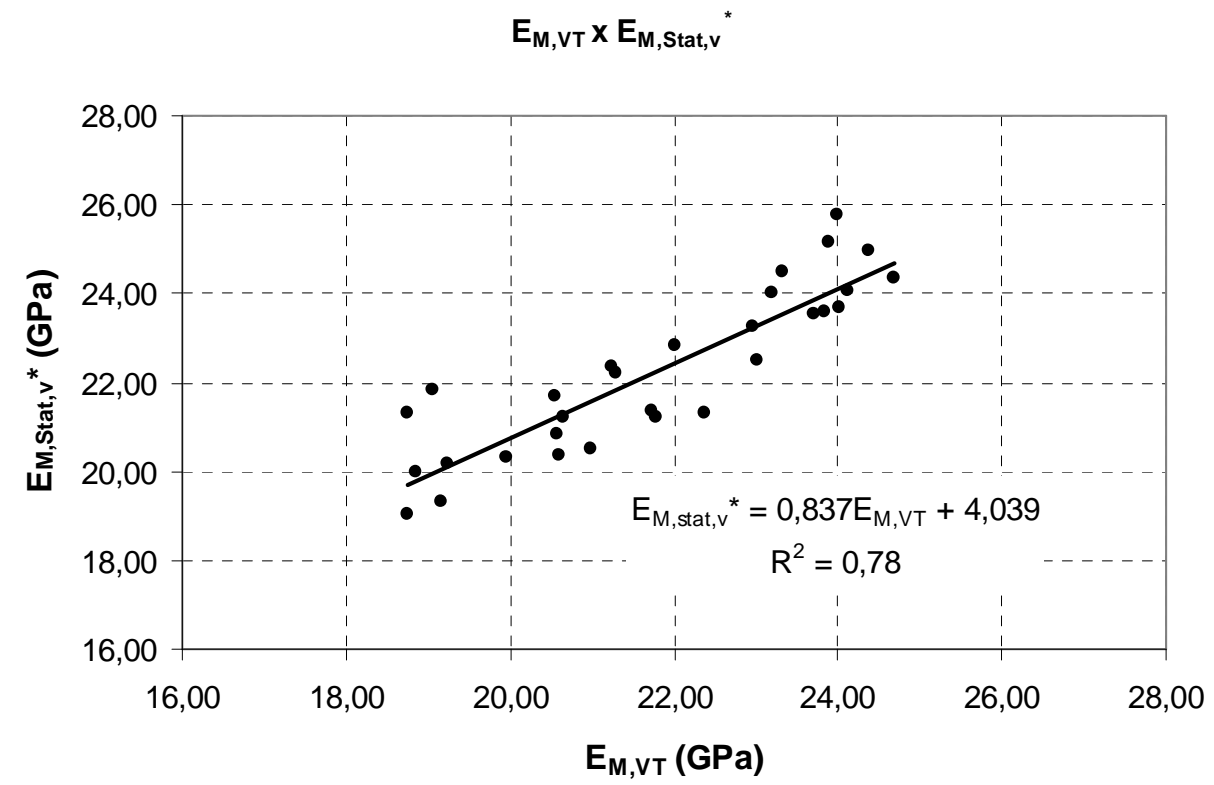

Figura 4.32 - Gráfico de dispersão entre $\mathrm{E}_{\mathrm{M}, \mathrm{VT}}$ e $\mathrm{E}_{\mathrm{M}, \mathrm{Stat,v}}{ }^{*}$ para o primeiro pico de frequência.

Verifica-se na Figura 4.32 uma maior dispersão dos pontos em relação ao gráfico mostrado na Figura 4.31.

\subsubsection{Correlações entre as propriedades das toras}

Foi realizada a análise de correlação entre os resultados obtidos nos testes mecânicos e as propriedades físicas e dimensionais das dez toras no teor de umidade dos ensaios como mostra a Tabela 4.31.

Tabela 4.31 - Coeficientes de correlação de Pearson entre as propriedades da toras da amostra piloto.

\begin{tabular}{|c|c|c|c|c|c|c|c|c|c|c|}
\hline Variáveis & $\mathrm{E}_{\mathrm{M}, \text { Stat, } \mathrm{v}^{*}}$ & $\mathrm{E}_{\mathrm{M}, \mathrm{VT}}$ & $\rho$ & $\mathrm{U}_{\mathrm{EL}}$ & $\mathrm{L} / \mathrm{D}_{\text {meio }}$ & $\Delta_{\text {circ }}($ Base) & $\begin{array}{c}\Delta_{\text {circ }} \\
(\text { Topo) }\end{array}$ & C & $\Delta_{\mathrm{D}}$ & Encurv \\
\hline$E_{M, S t a t, v^{*}}$ & 1,00 & 0,95 & 0,19 & $-0,29$ & $-0,33$ & $-0,20$ & $-0,40$ & $-0,10$ & $-0,11$ & $-0,17$ \\
\hline $\mathrm{E}_{\mathrm{M}, \mathrm{VT}}$ & & 1,00 & 0,25 & $-0,29$ & $-0,34$ & $-0,33$ & $-0,30$ & 0,02 & $-0,07$ & $-0,04$ \\
\hline$\rho$ & & & 1,00 & 0,46 & $-0,69$ & $-0,21$ & $-0,33$ & $-0,54$ & $-0,60$ & $-0,34$ \\
\hline$U_{\mathrm{EL}}$ & & & & 1,00 & $-0,33$ & 0,33 & 0,43 & $-0,34$ & $-0,28$ & $-0,08$ \\
\hline $\mathrm{L} / \mathrm{D}_{\text {meio }}$ & & & & & 1,00 & 0,08 & 0,16 & 0,13 & 0,26 & 0,14 \\
\hline$\Delta_{\text {circ }}($ Base $)$ & & & & & & 1,00 & 0,06 & 0,30 & 0,60 & $-0,32$ \\
\hline$\Delta_{\text {circ }}$ (Topo) & & & & & & & 1,00 & 0,36 & 0,26 & 0,44 \\
\hline C & & & & & & & & 1,00 & 0,92 & 0,35 \\
\hline$\Delta_{\mathrm{D}}$ & & & & & & & & & 1,00 & 0,09 \\
\hline Encurv. & & & & & & & & & & 1,00 \\
\hline
\end{tabular}

Verifica-se uma forte correlação entre o módulo de elasticidade estático $\left(\mathrm{E}_{\mathrm{M}, \mathrm{Stat}, \mathrm{v}^{*}}\right)$ e o módulo de elasticidade dinâmico $\left(\mathrm{E}_{\mathrm{M}, \mathrm{VT}}\right)$. 
O coeficiente de variação do diâmetro, a conicidade, a relação $L / \mathrm{D}_{\text {meio }}$ e a umidade mostram correlação moderada com a densidade aparente no teor de umidade do ensaio.

A fraca correlação entre o teor de umidade e a rigidez à flexão também foi observada por Ranta Maunus (1999) o qual obteve $r=0,06$ para uma amostra composta por toras de White pine, Spruce e Larch.

Observou-se também uma fraca correlação entre a densidade aparente e a rigidez à flexão.

As propriedades dimensionais verificadas durante a inspeção das toras como $\Delta_{\text {circ }}, \Delta_{\mathrm{D}}$, conicidade e o encurvamento apresentaram fraca correlação com a rigidez à flexão.

\subsection{Conclusões}

\subsubsection{Ensaios dinâmicos com as toras}

Acredita-se que a origem dos picos de frequência duplicados se deva principalmente a encurvamentos e desalinhamento entre o acelerômetro e o ponto de aplicação do impacto causados pela irregularidade da superfície das toras. Ainda com relação aos picos duplicados, a princípio acredita-se que a frequência de maior amplitude (maior energia) corresponda à direção na qual o impacto foi desferido. Para o primeiro modo de flexão observou-se uma diferença entre as frequências dos picos vizinhos da ordem de 2 a $5 \%$.

Verifica-se que não há necessidade de realizar o ensaio de vibração transversal excitando as toras em diferentes pontos ao longo do comprimento e com excitação em diferentes planos, pois o coeficiente de variação da frequência do primeiro modo de flexão é inferior a $1 \%$, para a maioria das toras.

\subsubsection{Ensaios estáticos}

A pequena variação no módulo de elasticidade estático de uma mesma tora em relação a vários ângulos em que os ensaios foram desenvolvidos (na maior parte inferior a 5\%) mostra ser desnecessário realizar o ensaio de flexão estática em diferentes planos. 
O emprego da Equação 4.7 para calcular o módulo de elasticidade considerando-se a influência do esforço cortante resultou, na maioria dos casos, em valores incorretos. Diante desses resultados, fica evidente que não é recomendável empregar a Equação 4.7 para estimar o módulo de elasticidade de toras e em substituição a essa equação sugere-se o emprego da Equação 4.8.

Os valores obtidos para o módulo de elasticidade à flexão das toras foram compatíveis com os registrados na literatura.

\subsubsection{Avaliação do teor de umidade}

O medidor elétrico tende a subestimar o teor de umidade das toras e serve apenas como uma avaliação qualitativa. Assim sendo, para uma maior exatidão na determinação do teor de umidade deve-se empregar o ensaio gravimétrico conforme NBR 7190 (ABNT, 1997).

\subsubsection{Avaliação da influência da direção do impacto em relação ao sistema de suspensão}

Embora nos ensaios realizados a diferença entre a frequência do primeiro modo das toras tenha sido insignificante, está claro que o ensaio com excitação horizontal é mais indicado para avaliação da rigidez à flexão das toras de madeira.

\subsubsection{Comparação entre os módulos de elasticidade estático e dinâmico}

A fraca correlação observada entre $\mathrm{E}_{\mathrm{M}, \mathrm{Stat,v}}$ e $\mathrm{E}_{\mathrm{M}, \mathrm{VT}}$ indica que o módulo de elasticidade estático levando em conta o efeito do esforço cortante deve ser calculado pela Equação 4.8 em vez da Equação 4.7 uma vez que esta conduz a uma maior dispersão entre os pontos como se observou na Figura 4.30.

Os gráficos de dispersão entre $\mathrm{E}_{\mathrm{M}, \mathrm{Stat}, \mathrm{ap}}$ e $\mathrm{E}_{\mathrm{M}, \mathrm{VT}, \mathrm{ap}}$ e entre $\mathrm{E}_{\mathrm{M}, \mathrm{Stat}, \mathrm{v}}{ }^{*}$ e $\mathrm{E}_{\mathrm{M}, \mathrm{VT}}$ evidenciaram boa correlação entre os resultados. Logo, pode-se afirmar que a Equação 4.5 fornece boas estimativas do módulo de elasticidade à flexão para o ensaio de vibração transversal.

Uma vez que o módulo de elasticidade estático da tora foi admitido como a média aritmética dos módulos de elasticidade medidos nos diversos planos e que os picos múltiplos de frequência representam modos de vibrar em mais de um plano, já era de se esperar que o cálculo de $\mathrm{E}_{\mathrm{M}, \mathrm{VT}}$ com a média aritmética dos dois picos de frequências observados para $\mathrm{o}$ 
primeiro modo leva a uma correlação mais forte entre $\mathrm{E}_{\mathrm{M}, \mathrm{Stat}, \mathrm{V}}{ }^{*}$ e $\mathrm{E}_{\mathrm{M}, \mathrm{VT}}$ do que o $\mathrm{E}_{\mathrm{M}, \mathrm{VT}}$ calculado com a frequência do primeiro pico.

Contudo, no caso dos ensaios serem realizados em somente um plano de excitação, deve-se calcular o módulo de elasticidade dinâmico com a frequência com maior intensidade de acelerância.

\subsubsection{Correlações entre as propriedades das toras}

As propriedades dimensionais das toras não mostraram boa correlação com a rigidez à flexão e, assim sendo, não podem ser utilizadas como estimadores da rigidez.

Observou-se fraca correlação entre a densidade aparente e a rigidez à flexão. 


\section{ESTUDO DA INFLUÊNCIA DO TEOR DE UMIDADE}

Como se sabe, no processo de secagem da madeira até o ponto de saturação das fibras o módulo de elasticidade estático não sofre alteração significativa, podendo ser admitido como constante.

Este capítulo apresenta uma investigação sobre a influência do teor de umidade na determinação do módulo de elasticidade pelo ensaio de vibração transversal. Neste estudo observou-se como o módulo de elasticidade dinâmico é afetado pelo teor de umidade e verificou-se a viabilidade do emprego dos métodos proposto por Unterwieser \& Schickhofer (2010) e recomendado pela norma NBR 7190 (ABNT, 1997) para a correção do módulo de elasticidade dinâmico em função do teor de umidade.

Neste estudo optou-se por utilizar vigas de madeira serrada a fim de ter maior exatidão na medição de algumas variáveis como o teor de umidade médio das peças e as dimensões da seção transversal.

Inicialmente, o teor de umidade foi estimado a partir de corpos-de-prova extraídos das peças e, posteriormente, a massa das vigas foi medida diariamente, estimando-se um teor de umidade preliminar.

Quando, na secagem natural, a variação do teor de umidade foi igual ou superior a 5\%, foram realizadas medições das dimensões, módulo de elasticidade estático e frequências naturais. As medições foram feitas até as vigas atingirem a umidade de equilíbrio com o ambiente. Então, foi obtida a massa seca das vigas, com a qual foram calculados os teores de umidade efetivos em cada medição.

\subsection{Materiais}

Foram utilizadas 20 vigas de madeira serrada de Pinus sp com dimensões nominais de $5 \mathrm{~cm} \times 10 \mathrm{~cm} \times 200 \mathrm{~cm}$. As vigas foram extraídas de toras recém abatidas e foram 
condicionadas em uma sala fechada cuja temperatura e umidade relativa do ar variaram, respectivamente, de 21,4 a $24,6{ }^{\circ} \mathrm{C}$ e de 55 a $65 \%$.

\subsection{Métodos}

\subsubsection{Ensaio de flexão estática}

O ensaio de flexão estática foi realizado com o esquema de viga simplesmente apoiada com força concentrada na metade do comprimento da viga. As vigas foram fletidas em relação ao eixo de menor inércia, com um vão de $185 \mathrm{~cm}$. A relação vão/altura foi igual a 37 e, por essa razão, o efeito do esforço cortante foi desprezado no cálculo dos módulos de elasticidade estático e dinâmico.

A força aplicada foi medida com um anel dinamométrico com capacidade de $4,7 \mathrm{kN}$ e os deslocamentos verticais na metade do comprimento das vigas foram medidos com um relógio comparador Mitutoyo com resolução de 0,01 mm.

Foi aplicada uma força crescente tendo sido anotadas as forças necessárias para provocar deslocamentos verticais de $4 \mathrm{~mm}$ e de $8 \mathrm{~mm}$. O módulo de elasticidade foi calculado a partir desses valores.

\subsubsection{Ensaio de vibração transversal}

O ensaio de vibração transversal foi realizado com excitação no plano vertical devido à dificuldade de manter o eixo de menor inércia da peça na posição vertical. As vigas foram suspensas por duas linhas de Nylon, com diâmetro igual a $0,7 \mathrm{~mm}$, posicionadas nas coordenadas $0,224 \mathrm{~L}$ e $0,776 \mathrm{~L}$ pelas razões já apontadas anteriormente no capítulo 4. A Figura 5.1a mostra uma visão geral do ensaio.

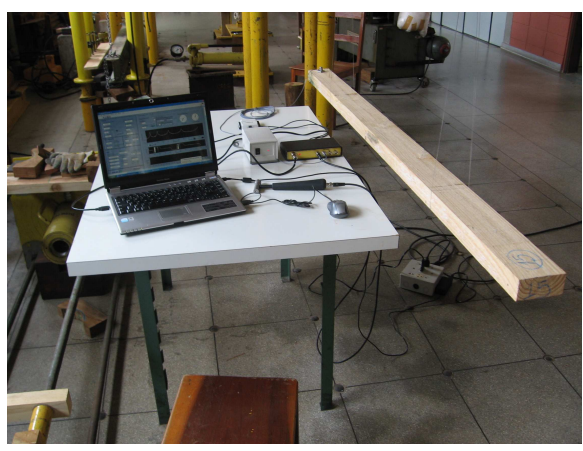

(a)

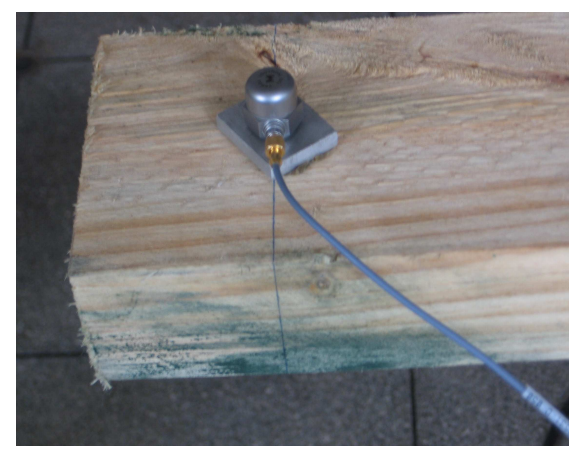

(b)

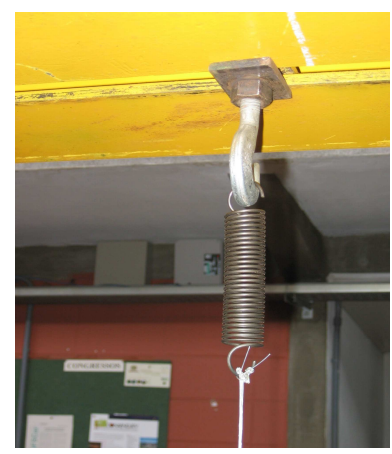

(c)

Figura 5.1 - Ensaio de vibração transversal nas vigas serradas de Pinus sp: a) vista geral do ensaio; b) acelerômetro fixado na extremidade da viga; c) mola empregada para suspensão. 
As linhas foram amarradas em molas de baixa rigidez (Figura 5.1c) de forma que a frequência do modo de corpo rígido fosse inferior a $10 \%$ da frequência natural do primeiro modo de flexão. Dessa maneira pode-se admitir que as vigas comportaram-se como em suspensão livre-livre.

As acelerações foram medidas com um acelerômetro Endevco modelo 7254A-100 o qual foi fixado em uma das extremidades da viga empregando-se cera de abelha (Figura 5.1b). A excitação foi produzida com um martelo de impulso B \& K modelo 8206-002.

Os sinais do martelo e do acelerômetro foram enviados a um condicionador de sinais desenvolvido pelo autor e então foram convertidos em sinais digitais por uma placa USB 6009 da National Instruments. Os sinais foram adquiridos e analisados pelo programa Impact, sendo que a Função de Resposta em Frequência foi calculada com a média de 10 espectros. A identificação dos parâmetros modais foi feita com o programa Modal-Id.

A Tabela 5.1 mostra as configurações do programa Impact.

Tabela 5.1 - Configurações do programa Impact no ensaio com vigas serradas de Pinus sp.

\begin{tabular}{lc}
\hline \multicolumn{1}{c}{ Parâmetro } & Valor \\
\hline Taxa de amostragem $(\mathrm{Hz})$ & 5000 \\
Número de amostras & 32768 \\
Resolução FRF $(\mathrm{Hz})$ & 0,15 \\
Tempo de amostragem (s) & 6,55 \\
\hline
\end{tabular}

\subsubsection{Determinação do teor de umidade final e correção das umidades dos ensaios}

Ao fim dos ensaios foram extraídos de cada viga 15 corpos-de-prova com dimensões de 3 × 2 x $5 \mathrm{~cm}$ conforme esquema mostrado na Figura 5.2 para a determinação do teor de umidade médio de acordo com a norma NBR 7190 (ABNT, 1997).

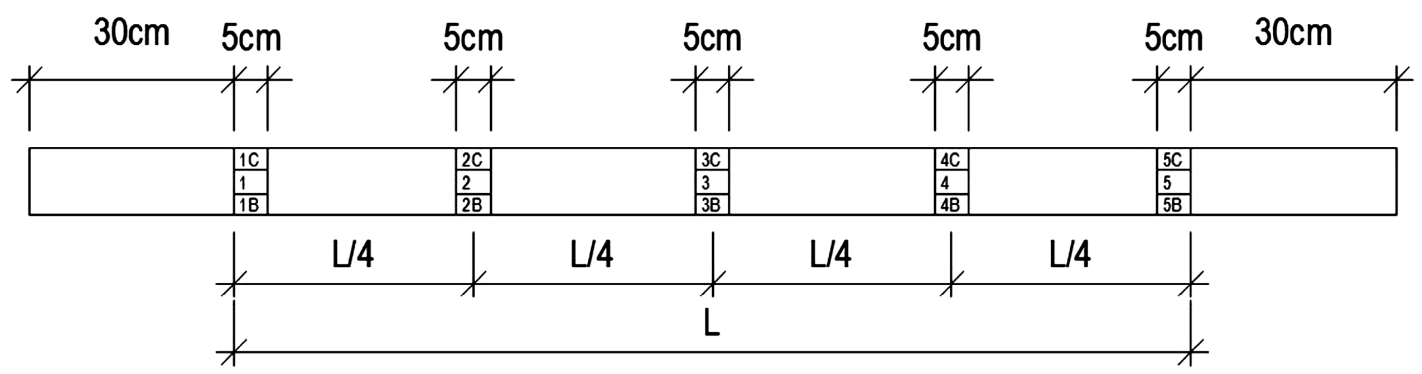

Figura 5.2 - Esquema de extração de corpos-de-prova para determinação do teor de umidade das vigas de madeira serrada de Pinus sp. 
A partir do teor de umidade médio foi estimada a massa seca das vigas e então, para cada medição, o teor de umidade no momento do ensaio foi calculado empregando-se a Equação 5.1.

$$
U(\%)=\frac{M_{U}-M_{S}}{M_{S}} * 100
$$

Sendo:

$$
\begin{aligned}
& M_{U}=\text { massa úmida }(\mathrm{g}) ; \\
& M_{S}=\text { massa seca }(\mathrm{g}) .
\end{aligned}
$$

\subsection{Resultados}

As Tabelas 5.2 a 5.21 mostram os resultados dos ensaios de flexão estática e vibração

\begin{tabular}{|c|c|c|c|c|c|c|c|c|c|c|c|}
\hline Medição & Data & $\begin{array}{c}\text { Massa } \\
(\mathrm{kg})\end{array}$ & U (\%) & $\begin{array}{c}b_{m} \\
(m m)\end{array}$ & $\begin{array}{c}\mathrm{h}_{\mathrm{m}} \\
(\mathrm{mm})\end{array}$ & $L(\mathrm{~cm})$ & $\begin{array}{c}F_{1}(N) \\
(\delta=4 \mathrm{~mm})\end{array}$ & $\begin{array}{c}F_{2}(\mathrm{~N}) \\
(\delta=8 \mathrm{~mm})\end{array}$ & $\begin{array}{l}\mathrm{Fr}_{1} \\
(\mathrm{~Hz})\end{array}$ & $\begin{array}{l}\mathrm{E}_{\mathrm{M}, \text { Stat }} \\
(\mathrm{GPa})\end{array}$ & $\begin{array}{l}E_{M, V T} \\
(\mathrm{GPa})\end{array}$ \\
\hline 1 & $10 / 03 / 10$ & 7,95 & $65,73 \%$ & 100,66 & 50,74 & 197,5 & 211,80 & 416,54 & 38,58 & 6,04 & 6,56 \\
\hline 2 & $16 / 03 / 10$ & 7,35 & $53,22 \%$ & 100,61 & 50,72 & 197,5 & 215,33 & 423,60 & 40,35 & 6,16 & 6,65 \\
\hline 3 & $21 / 03 / 10$ & 6,85 & $42,80 \%$ & 100,54 & 50,70 & 197,5 & 206,51 & 413,01 & 41,76 & 6,12 & 6,65 \\
\hline 4 & $26 / 03 / 10$ & 6,25 & $30,29 \%$ & 100,50 & 50,68 & 197,4 & 215,33 & 423,60 & 44,00 & 6,18 & 6,73 \\
\hline 5 & $31 / 03 / 10$ & 6,10 & $27,16 \%$ & 100,23 & 50,14 & 197,4 & 215,33 & 427,13 & 44,51 & 6,51 & 6,96 \\
\hline 6 & $07 / 04 / 10$ & 5,95 & $24,04 \%$ & 100,25 & 50,46 & 197,4 & 211,80 & 423,60 & 45,63 & 6,38 & 7,00 \\
\hline 7 & $13 / 04 / 10$ & 5,85 & $21,95 \%$ & 100,03 & 50,29 & 197,4 & 211,80 & 427,13 & 46,24 & 6,57 & 7,16 \\
\hline 8 & $19 / 04 / 10$ & 5,75 & $19,87 \%$ & 99,71 & 50,12 & 197,4 & 218,86 & 437,72 & 46,58 & 6,77 & 7,23 \\
\hline 9 & $26 / 04 / 10$ & 5,70 & $18,82 \%$ & 99,59 & 49,93 & 197,4 & 225,92 & 444,78 & 46,91 & 6,85 & 7,37 \\
\hline 10 & $05 / 05 / 10$ & 5,65 & $17,78 \%$ & 99,24 & 49,87 & 197,3 & 218,86 & 444,78 & 47,67 & 7,12 & 7,58 \\
\hline 11 & $13 / 05 / 10$ & 5,60 & $16,74 \%$ & 99,05 & 49,78 & 197,2 & 227,69 & 465,96 & 48,41 & 7,57 & 7,80 \\
\hline 12 & $23 / 05 / 10$ & 5,55 & $15,70 \%$ & 98,90 & 49,43 & 197,2 & 225,92 & 458,90 & 48,44 & 7,57 & 7,91 \\
\hline 13 & $14 / 06 / 10$ & 5,50 & $14,65 \%$ & 98,73 & 49,35 & 197,2 & 240,04 & 476,55 & 49,08 & 7,73 & 8,10 \\
\hline 14 & $19 / 07 / 10$ & 5,40 & $12,57 \%$ & 98,37 & 49,48 & 197,2 & 243,57 & 487,14 & 49,68 & 7,93 & 8,12 \\
\hline 15 & 02/08/10 & 5,35 & $11,53 \%$ & 98,24 & 48,92 & 197,1 & 243,57 & 473,02 & 50,48 & 7,74 & 8,59 \\
\hline 16 & $01 / 09 / 10$ & 5,30 & $10,49 \%$ & 97,47 & 48,46 & 196,9 & 261,22 & 504,79 & 51,31 & 8,52 & 9,09 \\
\hline 17 & $15 / 09 / 10$ & 5,25 & $9,44 \%$ & 97,32 & 48,43 & 197,2 & 211,80 & 441,25 & 51,33 & 8,05 & 9,08 \\
\hline 18 & 05/10/10 & 5,40 & $12,57 \%$ & 97,68 & 48,77 & 197,3 & 236,51 & 462,43 & 49,73 & 7,74 & 8,57 \\
\hline
\end{tabular}
transversal respectivamente nas vigas 1 a 20 para o teor de umidade corrigido.

Tabela 5.2 - Resultados dos ensaios na viga 1. 
Tabela 5.3 - Resultados dos ensaios na viga 2.

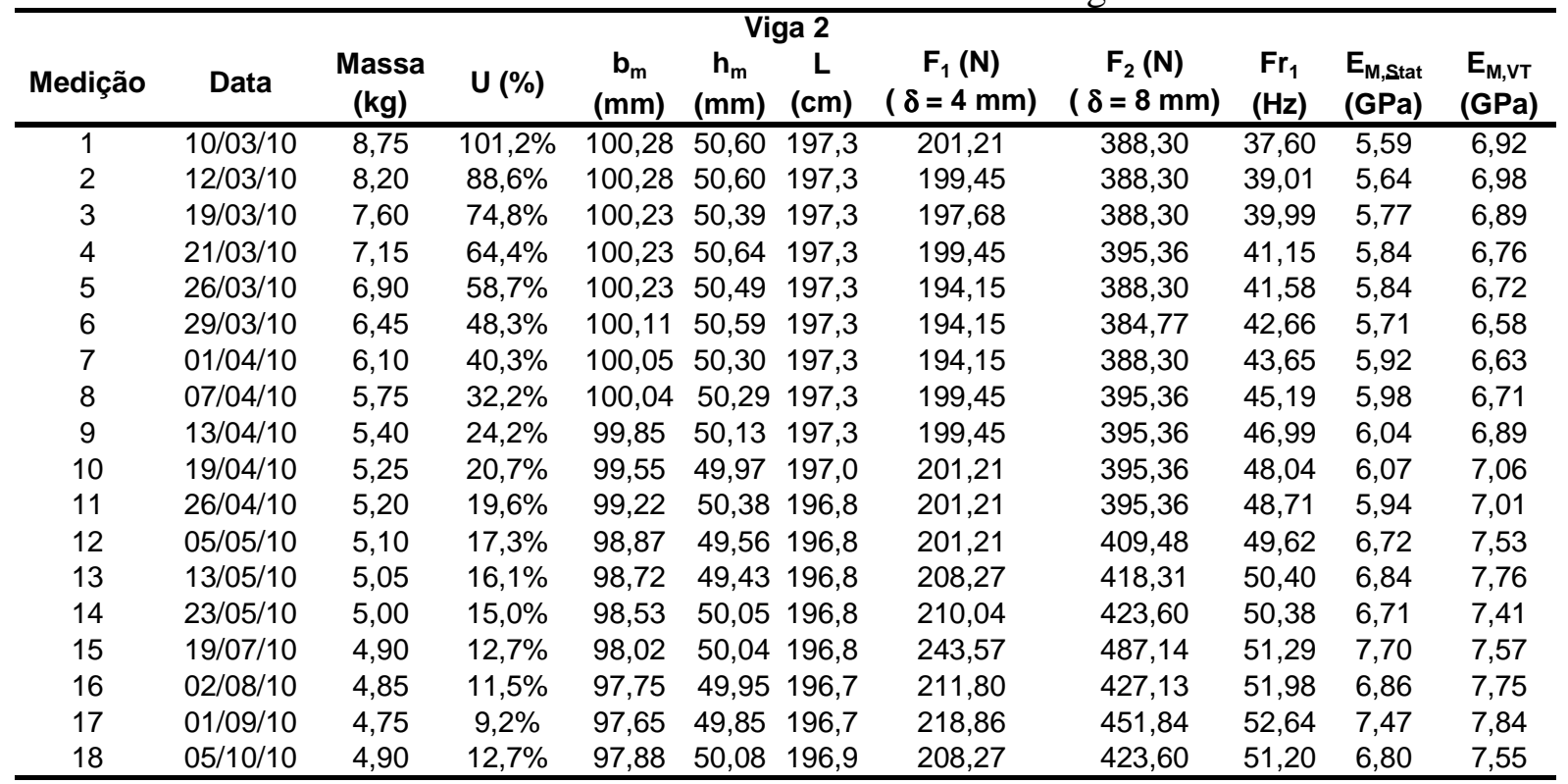

Tabela 5.4 - Resultados dos ensaios na viga 3.

\begin{tabular}{|c|c|c|c|c|c|c|c|c|c|c|c|}
\hline \multirow[b]{2}{*}{ Medição } & \multirow[b]{2}{*}{ Data } & \multicolumn{7}{|c|}{ Viga 3} & \multirow[b]{2}{*}{$\begin{array}{l}\mathrm{Fr}_{1} \\
(\mathrm{~Hz})\end{array}$} & \multirow[b]{2}{*}{$\begin{array}{l}\mathrm{E}_{\mathrm{M}, \mathrm{Stat}} \\
(\mathrm{GPa})\end{array}$} & \multirow[b]{2}{*}{$\begin{array}{l}\mathrm{E}_{\mathrm{M}, \mathrm{VT}} \\
(\mathrm{GPa})\end{array}$} \\
\hline & & $\begin{array}{c}\text { Massa } \\
(\mathrm{kg})\end{array}$ & U (\%) & $\begin{array}{c}b_{m} \\
(\mathrm{~mm})\end{array}$ & $\begin{array}{c}\mathrm{h}_{\mathrm{m}} \\
(\mathrm{mm})\end{array}$ & $\begin{array}{c}\mathrm{L} \\
(\mathrm{cm})\end{array}$ & $\begin{array}{c}F_{1}(\mathrm{~N}) \\
(\delta=4 \mathrm{~mm})\end{array}$ & $\begin{array}{c}F_{2}(\mathbf{N}) \\
(\delta=8 \mathrm{~mm})\end{array}$ & & & \\
\hline$\overline{1}$ & $10 / 03 / 10$ & 9,20 & $114,8 \%$ & 100,28 & 50,23 & 197,6 & 250,63 & 487,14 & 38,76 & 7,22 & 7,94 \\
\hline 2 & $12 / 03 / 10$ & 8,50 & $98,4 \%$ & 100,12 & 50,23 & 197,6 & 247,10 & 480,08 & 40,33 & 7,13 & 7,96 \\
\hline 3 & $19 / 03 / 10$ & 7,65 & $78,6 \%$ & 100,36 & 50,31 & 197,5 & 215,33 & 441,25 & 42,57 & 6,86 & 7,91 \\
\hline 4 & $21 / 03 / 10$ & 7,00 & $63,4 \%$ & 100,16 & 50,56 & 197,5 & 247,10 & 487,14 & 44,24 & 7,20 & 7,72 \\
\hline 5 & $26 / 03 / 10$ & 6,65 & $55,2 \%$ & 100,26 & 50,62 & 197,5 & 238,28 & 476,55 & 45,08 & 7,11 & 7,58 \\
\hline 6 & $29 / 03 / 10$ & 6,20 & $44,7 \%$ & 100,19 & 50,20 & 197,5 & 240,04 & 480,08 & 46,67 & 7,35 & 7,77 \\
\hline 7 & $01 / 04 / 10$ & 5,85 & $36,6 \%$ & 100,14 & 50,55 & 197,5 & 236,51 & 473,02 & 47,88 & 7,10 & 7,56 \\
\hline 8 & $06 / 04 / 10$ & 5,55 & $29,6 \%$ & 100,07 & 50,48 & 197,5 & 240,04 & 476,55 & 49,42 & 7,13 & 7,68 \\
\hline 9 & $12 / 04 / 10$ & 5,35 & $24,9 \%$ & 99,84 & 50,13 & 197,5 & 236,51 & 476,55 & 50,58 & 7,41 & 7,93 \\
\hline 10 & $19 / 04 / 10$ & 5,20 & $21,4 \%$ & 99,32 & 50,15 & 197,4 & 240,04 & 476,55 & 51,67 & 7,33 & 8,07 \\
\hline 11 & $26 / 04 / 10$ & 5,15 & $20,2 \%$ & 99,25 & 50,00 & 197,3 & 243,57 & 487,14 & 52,29 & 7,62 & 8,25 \\
\hline 12 & $05 / 05 / 10$ & 5,05 & $17,9 \%$ & 98,87 & 49,88 & 197,3 & 243,57 & 494,20 & 52,80 & 7,93 & 8,34 \\
\hline 13 & $13 / 05 / 10$ & 5,00 & $16,7 \%$ & 98,50 & 49,83 & 197,2 & 243,57 & 497,73 & 53,45 & 8,09 & 8,51 \\
\hline 14 & $23 / 05 / 10$ & 5,00 & $16,7 \%$ & 98,50 & 49,65 & 197,2 & 247,10 & 504,79 & 53,61 & 8,30 & 8,65 \\
\hline 15 & $19 / 07 / 10$ & 4,85 & $13,2 \%$ & 97,97 & 49,32 & 197,2 & 254,16 & 515,38 & 54,51 & 8,63 & 8,90 \\
\hline 16 & $02 / 08 / 10$ & 4,80 & $12,1 \%$ & 97,67 & 49,44 & 197,0 & 254,16 & 508,32 & 55,05 & 8,36 & 8,92 \\
\hline 17 & $01 / 09 / 10$ & 4,75 & $10,9 \%$ & 97,32 & 48,76 & 197,0 & 264,75 & 529,50 & 55,576 & 9,11 & 9,41 \\
\hline 18 & $15 / 09 / 10$ & 4,70 & $9,7 \%$ & 97,42 & 48,72 & 197,5 & 229,45 & 494,20 & 55,736 & 9,12 & 9,45 \\
\hline 19 & $05 / 10 / 10$ & 4,85 & $13,2 \%$ & 97,37 & 49,02 & 197,2 & 247,10 & 501,26 & 54,399 & 8,60 & 9,08 \\
\hline
\end{tabular}


Tabela 5.5 - Resultados dos ensaios na viga 4.

\begin{tabular}{|c|c|c|c|c|c|c|c|c|c|c|c|}
\hline \multirow[b]{2}{*}{ Medição } & \multirow[b]{2}{*}{ Data } & \multicolumn{7}{|c|}{ Viga 4} & \multirow[b]{2}{*}{$\begin{array}{c}\mathrm{Fr}_{1} \\
(\mathrm{~Hz})\end{array}$} & \multirow[b]{2}{*}{$\begin{array}{l}\mathrm{E}_{\mathrm{M}, \text { Stat }} \\
(\mathrm{GPa})\end{array}$} & \multirow[b]{2}{*}{$\begin{array}{l}E_{M, V T} \\
(G P a) \\
\end{array}$} \\
\hline & & $\begin{array}{c}\text { Massa } \\
(\mathrm{kg})\end{array}$ & U (\%) & $\begin{array}{c}b_{m} \\
(m m)\end{array}$ & $\begin{array}{c}\mathrm{h}_{\mathrm{m}} \\
(\mathrm{mm})\end{array}$ & $\begin{array}{c}\mathrm{L} \\
(\mathrm{cm})\end{array}$ & $\begin{array}{c}F_{1}(\mathrm{~N}) \\
(\delta=4 \mathrm{~mm})\end{array}$ & $\begin{array}{c}F_{2}(\mathrm{~N}) \\
(\delta=8 \mathrm{~mm})\end{array}$ & & & \\
\hline 1 & $10 / 03 / 10$ & 7,45 & $52,4 \%$ & 100,43 & $\overline{50,86}$ & 197,7 & 384,77 & 762,48 & 54,91 & 11,09 & 12,43 \\
\hline 2 & $11 / 03 / 10$ & 7,05 & $44,2 \%$ & 100,67 & 50,70 & 197,7 & 391,83 & 780,13 & 56,68 & 11,49 & 12,63 \\
\hline 3 & $14 / 03 / 10$ & 6,70 & $37,0 \%$ & 100,51 & 50,53 & 197,7 & 381,24 & 766,01 & 57,77 & 11,51 & 12,61 \\
\hline 4 & $17 / 03 / 10$ & 6,55 & $34,0 \%$ & 100,71 & 50,40 & 197,7 & 386,54 & 767,78 & 58,27 & 11,47 & 12,61 \\
\hline 5 & $21 / 03 / 10$ & 6,15 & $25,8 \%$ & 100,00 & 50,48 & 197,6 & 384,77 & 766,01 & 59,99 & 11,50 & 12,56 \\
\hline 6 & $26 / 03 / 10$ & 6,10 & $24,8 \%$ & 100,22 & 50,25 & 197,7 & 388,30 & 769,54 & 60,06 & 11,63 & 12,66 \\
\hline 7 & $31 / 03 / 10$ & 5,95 & $21,7 \%$ & 99,54 & 49,80 & 197,6 & 383,01 & 762,48 & 60,78 & 11,98 & 13,05 \\
\hline 8 & $05 / 04 / 10$ & 5,90 & $20,7 \%$ & 99,82 & 49,99 & 197,6 & 390,07 & 773,07 & 60,92 & 11,92 & 12,82 \\
\hline 9 & $12 / 04 / 10$ & 5,90 & $20,7 \%$ & 99,51 & 49,84 & 197,6 & 381,24 & 758,95 & 61,48 & 11,90 & 13,22 \\
\hline 10 & $19 / 04 / 10$ & 5,80 & $18,6 \%$ & 99,31 & 50,15 & 197,6 & 374,18 & 748,36 & 61,83 & 11,59 & 12,92 \\
\hline 11 & $26 / 04 / 10$ & 5,75 & $17,6 \%$ & 99,04 & 49,56 & 197,6 & 379,48 & 762,48 & 61,93 & 12,33 & 13,36 \\
\hline 12 & $05 / 05 / 10$ & 5,70 & $16,6 \%$ & 98,96 & 49,38 & 197,6 & 384,77 & 771,31 & 62,39 & 12,59 & 13,60 \\
\hline 13 & $13 / 05 / 10$ & 5,65 & $15,6 \%$ & 98,46 & 49,23 & 197,6 & 388,30 & 776,60 & 62,91 & 12,83 & 13,90 \\
\hline 14 & $23 / 05 / 10$ & 5,60 & $14,5 \%$ & 98,27 & 49,17 & 197,6 & 388,30 & 780,13 & 62,97 & 13,02 & 13,88 \\
\hline 15 & $19 / 07 / 10$ & 5,50 & $12,5 \%$ & 97,67 & 48,85 & 197,6 & 409,48 & 811,90 & 63,79 & 13,72 & 14,35 \\
\hline 16 & 02/08/10 & 5,45 & $11,5 \%$ & 97,69 & 49,53 & 197,5 & 405,95 & 808,37 & 64,24 & 13,16 & 13,81 \\
\hline 17 & $01 / 09 / 10$ & 5,35 & $9,4 \%$ & 97,33 & 49,36 & 197,5 & 402,42 & 811,90 & 64,62 & 13,58 & 13,91 \\
\hline 18 & 05/10/10 & 5,45 & $11,5 \%$ & 97,68 & 49,40 & 197,6 & 388,30 & 773,07 & 63,65 & 12,68 & 13,69 \\
\hline 19 & $07 / 02 / 11$ & 5,50 & $12,5 \%$ & 97,89 & 49,37 & 197,7 & 413,01 & 818,96 & 63,62 & 13,37 & 13,821 \\
\hline
\end{tabular}

Tabela 5.6 - Resultados dos ensaios na viga 5.

\begin{tabular}{|c|c|c|c|c|c|c|c|c|c|c|c|}
\hline \multirow[b]{2}{*}{ Medição } & \multirow[b]{2}{*}{ Data } & \multirow[b]{2}{*}{$\begin{array}{c}\text { Massa } \\
(\mathrm{kg})\end{array}$} & \multirow[b]{2}{*}{ U (\%) } & \multicolumn{4}{|c|}{ Viga 5} & \multirow[b]{2}{*}{$\begin{array}{c}F_{2}(N) \\
(\delta=8 \mathrm{~mm})\end{array}$} & \multirow[b]{2}{*}{$\begin{array}{l}\mathrm{Fr}_{1} \\
(\mathrm{~Hz})\end{array}$} & \multirow[b]{2}{*}{$\begin{array}{l}\mathrm{E}_{\mathrm{M}, \text { Stat }} \\
(\mathrm{GPa})\end{array}$} & \multirow[b]{2}{*}{$\begin{array}{l}\mathrm{E}_{\mathrm{M}, \mathrm{VT}} \\
(\mathrm{GPa})\end{array}$} \\
\hline & & & & $\begin{array}{c}b_{m} \\
(m m)\end{array}$ & $\begin{array}{c}\mathrm{h}_{\mathrm{m}} \\
(\mathrm{mm})\end{array}$ & $\mathrm{L}(\mathrm{cm})$ & $\begin{array}{c}F_{1}(\mathrm{~N}) \\
(\delta=4 \mathrm{~mm})\end{array}$ & & & & \\
\hline 1 & $10 / 03 / 10$ & 8,95 & $83,2 \%$ & 100,29 & 50,71 & 196,8 & 268,28 & 529,50 & 42,40 & 7,75 & 8,88 \\
\hline 2 & $16 / 03 / 10$ & 8,25 & $68,9 \%$ & 100,37 & 50,79 & 196,8 & 271,81 & 533,03 & 44,19 & 7,71 & 8,84 \\
\hline 3 & $21 / 03 / 10$ & 7,25 & $48,4 \%$ & 100,32 & 50,52 & 196,8 & 278,87 & 547,15 & 46,66 & 8,05 & 8,80 \\
\hline 4 & $26 / 03 / 10$ & 6,75 & $38,2 \%$ & 100,28 & 50,71 & 196,8 & 264,75 & 529,50 & 48,05 & 7,86 & 8,60 \\
\hline 5 & $29 / 03 / 10$ & 6,45 & $32,0 \%$ & 100,24 & 50,41 & 196,8 & 266,52 & 531,27 & 49,04 & 8,00 & 8,72 \\
\hline 6 & $31 / 03 / 10$ & 6,30 & $28,9 \%$ & 99,89 & 50,46 & 196,8 & 268,28 & 536,56 & 49,84 & 8,11 & 8,80 \\
\hline 7 & 05/04/10 & 6,05 & $23,8 \%$ & 100,01 & 50,58 & 196,8 & 264,75 & 533,03 & 50,84 & 8,04 & 8,72 \\
\hline 8 & $12 / 04 / 10$ & 5,95 & $21,8 \%$ & 99,81 & 50,17 & 196,8 & 271,81 & 540,09 & 51,65 & 8,26 & 9,09 \\
\hline 9 & $19 / 04 / 10$ & 5,85 & $19,7 \%$ & 99,50 & 50,45 & 196,7 & 268,28 & 541,86 & 52,32 & 8,31 & 9,03 \\
\hline 10 & $26 / 04 / 10$ & 5,85 & $19,7 \%$ & 99,41 & 49,91 & 196,7 & 275,34 & 550,68 & 52,51 & 8,65 & 9,40 \\
\hline 11 & 05/05/10 & 5,75 & $17,7 \%$ & 99,09 & 50,25 & 196,6 & 282,40 & 566,57 & 53,02 & 8,77 & 9,25 \\
\hline 12 & $13 / 05 / 10$ & 5,70 & $16,7 \%$ & 98,89 & 49,59 & 196,6 & 285,93 & 568,33 & 53,73 & 9,09 & 9,81 \\
\hline 13 & $23 / 05 / 10$ & 5,70 & $16,7 \%$ & 98,84 & 50,18 & 196,6 & 277,11 & 559,51 & 53,75 & 8,78 & 9,48 \\
\hline 14 & 03/06/10 & 5,65 & $15,6 \%$ & 98,68 & 49,45 & 197,0 & 278,87 & 561,27 & 53,98 & 9,18 & 9,98 \\
\hline 15 & $19 / 07 / 10$ & 5,55 & $13,6 \%$ & 98,23 & 49,16 & 197,0 & 300,05 & 596,57 & 54,61 & 9,86 & 10,26 \\
\hline 16 & 02/08/10 & 5,45 & $11,5 \%$ & 98,15 & 49,85 & 196,5 & 294,76 & 589,51 & 55,15 & 9,41 & 9,79 \\
\hline 17 & 01/09/10 & 5,40 & $10,5 \%$ & 97,96 & 49,64 & 196,5 & 282,40 & 568,33 & 55,60 & 9,26 & 10,00 \\
\hline 18 & $15 / 09 / 10$ & 5,35 & $9,5 \%$ & 98,04 & 48,52 & 196,4 & 268,28 & 564,80 & 55,80 & 10,28 & 10,67 \\
\hline 19 & $05 / 10 / 10$ & 5,50 & $12,6 \%$ & 98,18 & 49,73 & 196,6 & 289,46 & 568,33 & 54,61 & 8,96 & 9,77 \\
\hline
\end{tabular}


Tabela 5.7 - Resultados dos ensaios na viga 6.

\begin{tabular}{|c|c|c|c|c|c|c|c|c|c|c|c|}
\hline \multirow[b]{2}{*}{ Medição } & \multicolumn{8}{|c|}{ Viga 6} & \multirow[b]{2}{*}{$\begin{array}{l}\mathrm{Fr}_{1} \\
(\mathrm{~Hz})\end{array}$} & \multirow[b]{2}{*}{$\begin{array}{l}\mathrm{E}_{\mathrm{M}, \mathrm{Stat}} \\
(\mathrm{GPa})\end{array}$} & \multirow[b]{2}{*}{$\begin{array}{c}E_{M, V T} \\
(G P a)\end{array}$} \\
\hline & Data & $\begin{array}{c}\text { Massa } \\
(\mathrm{kg})\end{array}$ & U (\%) & $\begin{array}{c}b_{m} \\
(m m)\end{array}$ & $\begin{array}{c}\mathrm{h}_{\mathrm{m}} \\
(\mathrm{mm})\end{array}$ & $\begin{array}{c}\mathrm{L} \\
(\mathrm{cm})\end{array}$ & $\begin{array}{c}F_{1}(\mathrm{~N}) \\
(\delta=4 \mathrm{~mm})\end{array}$ & $\begin{array}{c}F_{2}(\mathrm{~N}) \\
(\delta=8 \mathrm{~mm})\end{array}$ & & & \\
\hline 1 & $09 / 03 / 10$ & 9,70 & $93,8 \%$ & 100,77 & 50,72 & $\overline{197,3}$ & 243,57 & 473,02 & 39,03 & 6,77 & 8,17 \\
\hline 2 & $11 / 03 / 10$ & 9,40 & $87,8 \%$ & 100,67 & 50,49 & 197,3 & 243,57 & 473,02 & 39,75 & 6,87 & 8,33 \\
\hline 3 & $14 / 03 / 10$ & 8,95 & $78,8 \%$ & 100,67 & 50,49 & 197,3 & 240,04 & 476,55 & 40,56 & 7,08 & 8,26 \\
\hline 4 & $17 / 03 / 10$ & 8,70 & $73,8 \%$ & 100,66 & 50,76 & 197,3 & 240,04 & 480,08 & 41,19 & 7,08 & 8,15 \\
\hline 5 & $21 / 03 / 10$ & 8,15 & $62,8 \%$ & 100,66 & 50,77 & 197,2 & 236,51 & 469,49 & 42,34 & 6,86 & 8,05 \\
\hline 6 & $29 / 03 / 10$ & 7,60 & $51,9 \%$ & 100,58 & 50,45 & 197,2 & 236,51 & 473,02 & 43,74 & 7,11 & 8,17 \\
\hline 7 & $31 / 03 / 10$ & 7,35 & $46,9 \%$ & 100,35 & 50,29 & 197,2 & 240,04 & 476,55 & 44,44 & 7,19 & 8,26 \\
\hline 8 & $05 / 04 / 10$ & 6,90 & $37,9 \%$ & 100,57 & 50,72 & 197,2 & 241,81 & 480,08 & 45,92 & 7,05 & 8,05 \\
\hline 9 & $12 / 04 / 10$ & 6,40 & $27,9 \%$ & 100,49 & 50,29 & 197,2 & 245,34 & 487,14 & 47,86 & 7,34 & 8,32 \\
\hline 10 & $19 / 04 / 10$ & 6,15 & $22,9 \%$ & 100,40 & 50,11 & 197,2 & 252,40 & 497,73 & 49,12 & 7,54 & 8,52 \\
\hline 11 & $26 / 04 / 10$ & 6,00 & $19,9 \%$ & 100,14 & 50,22 & 197,1 & 254,16 & 504,79 & 49,99 & 7,67 & 8,57 \\
\hline 12 & $05 / 05 / 10$ & 5,90 & $17,9 \%$ & 99,99 & 49,99 & 197,1 & 247,10 & 497,73 & 50,63 & 7,79 & 8,78 \\
\hline 13 & $13 / 05 / 10$ & 5,85 & $16,9 \%$ & 99,73 & 49,87 & 197,1 & 261,22 & 518,91 & 51,34 & 8,08 & 9,03 \\
\hline 14 & $23 / 05 / 10$ & 5,80 & $15,9 \%$ & 99,62 & 49,34 & 197,0 & 261,22 & 522,44 & 51,65 & 8,47 & 9,36 \\
\hline 15 & $03 / 06 / 10$ & 5,75 & $14,9 \%$ & 99,50 & 49,64 & 197,0 & 261,22 & 518,91 & 51,79 & 8,22 & 9,17 \\
\hline 16 & $19 / 07 / 10$ & 5,65 & $12,9 \%$ & 99,27 & 49,02 & 197,0 & 268,28 & 543,62 & 52,32 & 9,14 & 9,57 \\
\hline 17 & $02 / 08 / 10$ & 5,60 & $11,9 \%$ & 99,14 & 48,83 & 196,9 & 271,81 & 536,56 & 52,88 & 8,90 & 9,80 \\
\hline 18 & $01 / 09 / 10$ & 5,50 & $9,9 \%$ & 98,59 & 48,72 & 196,9 & 271,81 & 547,15 & 53,35 & 9,37 & 9,92 \\
\hline 19 & $05 / 10 / 10$ & 5,60 & $11,9 \%$ & 98,88 & 49,09 & 197,1 & 264,75 & 522,44 & 52,37 & 8,55 & 9,51 \\
\hline 20 & $07 / 02 / 11$ & 5,65 & $12,9 \%$ & 98,82 & 49,60 & 197,1 & 282,40 & 547,15 & 52,342 & 8,52 & 9,30 \\
\hline
\end{tabular}

Tabela 5.8 - Resultados dos ensaios na viga 7.

\begin{tabular}{|c|c|c|c|c|c|c|c|c|c|c|c|}
\hline \multirow[b]{2}{*}{ Medição } & \multirow[b]{2}{*}{ Data } & \multirow[b]{2}{*}{$\begin{array}{c}\text { Massa } \\
(\mathrm{kg})\end{array}$} & \multirow[b]{2}{*}{ U (\%) } & \multirow[b]{2}{*}{$\begin{array}{c}\mathbf{b}_{\mathrm{m}} \\
(\mathrm{mm})\end{array}$} & \multicolumn{2}{|c|}{ Viga 7} & \multirow[b]{2}{*}{$\begin{array}{c}F_{1}(\mathrm{~N}) \\
(\delta=4 \mathrm{~mm})\end{array}$} & \multirow[b]{2}{*}{$\begin{array}{c}F_{2}(\mathrm{~N}) \\
(\delta=8 \mathrm{~mm})\end{array}$} & \multirow[b]{2}{*}{$\begin{array}{l}\mathrm{Fr}_{1} \\
(\mathrm{~Hz})\end{array}$} & \multirow[b]{2}{*}{$\begin{array}{l}\mathrm{E}_{\mathrm{M}, \text { Stat }} \\
(\mathrm{GPa})\end{array}$} & \multirow[b]{2}{*}{$\begin{array}{l}\mathrm{E}_{\mathrm{M}, \mathrm{VT}} \\
(\mathrm{GPa})\end{array}$} \\
\hline & & & & & $\begin{array}{c}\mathbf{h}_{\mathrm{m}} \\
(\mathrm{mm})\end{array}$ & $\begin{array}{c}\mathrm{L} \\
(\mathrm{cm})\end{array}$ & & & & & \\
\hline 1 & $09 / 03 / 10$ & 10,05 & $120,0 \%$ & 100,19 & 50,53 & 197,6 & 303,58 & 554,21 & 38,97 & 7,52 & 8,62 \\
\hline 2 & $16 / 03 / 10$ & 9,45 & $106,9 \%$ & 100,09 & 50,62 & 197,6 & 266,52 & 529,50 & 40,89 & 7,86 & 8,89 \\
\hline 3 & $21 / 03 / 10$ & 8,75 & $91,6 \%$ & 100,02 & 50,38 & 197,6 & 250,63 & 501,26 & 42,36 & 7,60 & 8,96 \\
\hline 4 & $26 / 03 / 10$ & 7,55 & $65,3 \%$ & 100,02 & 50,38 & 197,6 & 254,16 & 511,85 & 45,04 & 7,82 & 8,74 \\
\hline 5 & $01 / 04 / 10$ & 7,00 & $53,3 \%$ & 100,02 & 50,38 & 197,6 & 261,22 & 518,91 & 46,31 & 7,82 & 8,57 \\
\hline 6 & $07 / 04 / 10$ & 6,40 & $40,1 \%$ & 99,94 & 50,46 & 197,6 & 264,75 & 525,97 & 48,33 & 7,89 & 8,50 \\
\hline 7 & $13 / 04 / 10$ & 5,80 & $27,0 \%$ & 99,67 & 50,22 & 197,6 & 264,75 & 525,97 & 50,87 & 8,03 & 8,68 \\
\hline 8 & $19 / 04 / 10$ & 5,55 & $21,5 \%$ & 99,51 & 49,97 & 197,5 & 268,28 & 536,56 & 52,10 & 8,39 & 8,85 \\
\hline 9 & $26 / 04 / 10$ & 5,45 & $19,3 \%$ & 98,68 & 49,62 & 197,4 & 271,81 & 543,62 & 52,94 & 8,75 & 9,22 \\
\hline 10 & $05 / 05 / 10$ & 5,40 & $18,2 \%$ & 98,44 & 49,43 & 197,5 & 275,34 & 550,68 & 53,35 & 8,99 & 9,43 \\
\hline 11 & $13 / 05 / 10$ & 5,35 & $17,1 \%$ & 98,26 & 49,33 & 197,4 & 292,99 & 571,86 & 54,04 & 9,18 & 9,64 \\
\hline 12 & $23 / 05 / 10$ & 5,30 & $16,0 \%$ & 98,14 & 49,18 & 197,4 & 280,64 & 561,27 & 54,05 & 9,33 & 9,66 \\
\hline 13 & $19 / 07 / 10$ & 5,20 & $13,9 \%$ & 97,66 & 48,51 & 197,4 & 285,93 & 568,33 & 54,86 & 9,83 & 10,22 \\
\hline 14 & $02 / 08 / 10$ & 5,15 & $12,8 \%$ & 97,41 & 49,44 & 197,3 & 300,05 & 582,45 & 55,45 & 9,31 & 9,78 \\
\hline 15 & $08 / 09 / 10$ & 5,10 & $11,7 \%$ & 97,35 & 49,5 & 197,3 & 289,46 & 582,45 & 55,75 & 9,63 & 9,76 \\
\hline 16 & 01/09/10 & 5,05 & $10,6 \%$ & 96,05 & 48,31 & 197,3 & 285,93 & 582,45 & 55,99 & 10,63 & 10,63 \\
\hline 17 & $15 / 09 / 10$ & 5,00 & $9,5 \%$ & 95,91 & 48,18 & 197,3 & 257,69 & 557,74 & 56,11 & 10,86 & 10,67 \\
\hline 18 & $05 / 10 / 10$ & 5,15 & $12,8 \%$ & 96,53 & 48,53 & 197,4 & 285,93 & 568,33 & 54,76 & 9,93 & 10,19 \\
\hline
\end{tabular}


Tabela 5.9 - Resultados dos ensaios na viga 8 .

\begin{tabular}{|c|c|c|c|c|c|c|c|c|c|c|c|}
\hline \multirow[b]{2}{*}{ Medição } & \multirow[b]{2}{*}{ Data } & \multirow[b]{2}{*}{$\begin{array}{c}\text { Massa } \\
(\mathrm{kg})\end{array}$} & \multirow[b]{2}{*}{ U (\%) } & \multirow[b]{2}{*}{$\begin{array}{c}b_{m} \\
(\mathrm{~mm})\end{array}$} & \multicolumn{2}{|c|}{ Viga 8} & \multirow[b]{2}{*}{$\begin{array}{c}F_{1}(\mathrm{~N}) \\
(\delta=4 \mathrm{~mm})\end{array}$} & \multirow[b]{2}{*}{$\begin{array}{c}F_{2}(\mathrm{~N}) \\
(\delta=8 \mathrm{~mm})\end{array}$} & \multirow[b]{2}{*}{$\begin{array}{c}\mathrm{Fr}_{1} \\
(\mathrm{~Hz})\end{array}$} & \multirow[b]{2}{*}{$\begin{array}{l}\mathrm{E}_{\mathrm{M}, \mathrm{Stat}} \\
(\mathrm{GPa})\end{array}$} & \multirow[b]{2}{*}{$\begin{array}{l}\mathrm{E}_{\mathrm{M}, \mathrm{VT}} \\
(\mathrm{GPa})\end{array}$} \\
\hline & & & & & $\begin{array}{c}\mathrm{h}_{\mathrm{m}} \\
(\mathrm{mm})\end{array}$ & $\begin{array}{c}\mathrm{L} \\
(\mathrm{cm})\end{array}$ & & & & & \\
\hline 1 & $09 / 03 / 10$ & 10,30 & $126,6 \%$ & 100,41 & 50,89 & 196,7 & 292,99 & 578,92 & 42,33 & 8,38 & 10,05 \\
\hline 2 & $16 / 03 / 10$ & 8,95 & $96,9 \%$ & 100,63 & 50,99 & 196,7 & 292,99 & 582,45 & 44,65 & 8,42 & 9,63 \\
\hline 3 & $21 / 03 / 10$ & 8,30 & $82,6 \%$ & 100,64 & 50,92 & 196,7 & 270,05 & 547,15 & 45,91 & 8,09 & 9,48 \\
\hline 4 & $26 / 03 / 10$ & 7,35 & $61,7 \%$ & 100,55 & 50,87 & 196,7 & 282,40 & 564,80 & 48,43 & 8,28 & 9,38 \\
\hline 5 & $30 / 03 / 10$ & 7,15 & $57,3 \%$ & 100,64 & 50,86 & 196,7 & 282,40 & 564,80 & 49,05 & 8,28 & 9,36 \\
\hline 6 & $06 / 04 / 10$ & 6,40 & $40,8 \%$ & 100,66 & 50,89 & 196,7 & 289,46 & 578,92 & 51,76 & 8,47 & 9,31 \\
\hline 7 & $12 / 04 / 10$ & 5,80 & $27,6 \%$ & 100,20 & 50,76 & 196,7 & 289,46 & 578,92 & 54,37 & 8,57 & 9,42 \\
\hline 8 & $19 / 04 / 10$ & 5,60 & $23,2 \%$ & 99,61 & 50,51 & 196,7 & 303,58 & 607,16 & 55,46 & 9,18 & 9,66 \\
\hline 9 & $26 / 04 / 10$ & 5,50 & $21,0 \%$ & 99,20 & 50,34 & 196,7 & 296,52 & 600,10 & 56,12 & 9,31 & 9,86 \\
\hline 10 & $05 / 05 / 10$ & 5,40 & $18,8 \%$ & 98,67 & 50,16 & 196,7 & 310,64 & 617,75 & 56,75 & 9,57 & 10,06 \\
\hline 11 & $13 / 05 / 10$ & 5,35 & $17,7 \%$ & 98,49 & 49,95 & 196,7 & 314,17 & 626,58 & 57,51 & 9,88 & 10,39 \\
\hline 12 & $23 / 05 / 10$ & 5,35 & $17,7 \%$ & 98,15 & 49,91 & 196,6 & 307,11 & 624,81 & 57,51 & 10,10 & 10,43 \\
\hline 13 & 03/06/10 & 5,30 & $16,6 \%$ & 98,04 & 49,82 & 196,6 & 314,17 & 631,87 & 57,54 & 10,17 & 10,41 \\
\hline 14 & $19 / 07 / 10$ & 5,20 & $14,4 \%$ & 97,47 & 49,57 & 196,6 & 331,82 & 656,58 & 58,21 & 10,62 & 10,67 \\
\hline 15 & $02 / 08 / 10$ & 5,15 & $13,3 \%$ & 97,17 & 49,49 & 196,6 & 328,29 & 653,05 & 58,76 & 10,70 & 10,86 \\
\hline 16 & $01 / 09 / 10$ & 5,05 & $11,1 \%$ & 95,98 & 48,74 & 196,5 & 331,82 & 667,17 & 59,41 & 11,71 & 11,52 \\
\hline 17 & $15 / 09 / 10$ & 5,00 & $10,0 \%$ & 95,92 & 48,86 & 196,5 & 278,87 & 593,04 & 59,48 & 10,90 & 11,35 \\
\hline 18 & $05 / 10 / 10$ & 5,15 & $13,3 \%$ & 96,53 & 49,31 & 196,7 & 310,64 & 635,40 & 58,09 & 10,89 & 10,82 \\
\hline
\end{tabular}

Tabela 5.10 - Resultados dos ensaios na viga 9.

\begin{tabular}{|c|c|c|c|c|c|c|c|c|c|c|c|}
\hline Medição & Data & $\begin{array}{c}\text { Massa } \\
(\mathbf{k g})\end{array}$ & U (\%) & $\begin{array}{c}\mathbf{b}_{\mathrm{m}} \\
(\mathrm{mm})\end{array}$ & $\begin{array}{c}\mathbf{h}_{\mathrm{m}} \\
(\mathrm{mm})\end{array}$ & $\begin{array}{c}\text { Viga } 9 \\
\text { L } \\
(\mathrm{cm})\end{array}$ & $\begin{array}{c}F_{1}(\mathrm{~N}) \\
(\delta=4 \mathrm{~mm})\end{array}$ & $\begin{array}{c}F_{2}(\mathrm{~N}) \\
(\delta=8 \mathrm{~mm})\end{array}$ & $\begin{array}{c}\mathrm{Fr}_{1} \\
(\mathrm{~Hz})\end{array}$ & $\begin{array}{l}E_{M, \text { Stat }} \\
(\mathrm{GPa})\end{array}$ & $\begin{array}{l}E_{M, V T} \\
(G P a)\end{array}$ \\
\hline 1 & $09 / 03 / 10$ & 9,00 & $89,6 \%$ & 100,11 & 50,48 & 197,7 & 243,57 & 476,55 & 40,19 & 7,02 & 8,25 \\
\hline 2 & $16 / 03 / 10$ & 8,45 & $78,1 \%$ & 100,11 & 50,53 & 197,7 & 241,81 & 473,02 & 41,99 & 6,95 & 8,44 \\
\hline 3 & $21 / 03 / 10$ & 8,00 & $68,6 \%$ & 100,07 & 50,96 & 197,7 & 232,98 & 465,96 & 42,87 & 6,83 & 8,12 \\
\hline 4 & $26 / 03 / 10$ & 6,85 & $44,3 \%$ & 100,07 & 50,52 & 197,7 & 229,45 & 458,90 & 45,79 & 6,90 & 8,14 \\
\hline 5 & $30 / 03 / 10$ & 6,75 & $42,2 \%$ & 100,07 & 50,67 & 197,7 & 236,51 & 465,96 & 46,01 & 6,84 & 8,03 \\
\hline 6 & $06 / 04 / 10$ & 6,40 & $34,9 \%$ & 100,06 & 50,51 & 197,6 & 240,04 & 476,55 & 47,20 & 7,12 & 8,07 \\
\hline 7 & $13 / 04 / 10$ & 6,05 & $27,5 \%$ & 99,92 & 50,58 & 197,6 & 234,75 & 469,49 & 48,62 & 7,05 & 8,08 \\
\hline 8 & $19 / 04 / 10$ & 5,80 & $22,2 \%$ & 99,63 & 50,18 & 197,6 & 236,51 & 473,02 & 49,45 & 7,29 & 8,23 \\
\hline 9 & $26 / 04 / 10$ & 5,70 & $20,1 \%$ & 99,27 & 50,32 & 197,5 & 240,04 & 476,55 & 50,03 & 7,26 & 8,22 \\
\hline 10 & $05 / 05 / 10$ & 5,60 & $18,0 \%$ & 98,95 & 50,06 & 197,5 & 238,28 & 478,32 & 50,80 & 7,50 & 8,49 \\
\hline 11 & $13 / 05 / 10$ & 5,50 & $15,9 \%$ & 98,60 & 50,05 & 197,3 & 243,57 & 490,67 & 51,66 & 7,76 & 8,63 \\
\hline 12 & $23 / 05 / 10$ & 5,50 & $15,9 \%$ & 98,28 & 49,95 & 197,3 & 243,57 & 487,14 & 51,63 & 7,72 & 8,70 \\
\hline 13 & 03/06/10 & 5,45 & $14,8 \%$ & 98,41 & 49,26 & 197,3 & 250,63 & 494,20 & 51,87 & 8,04 & 9,06 \\
\hline 14 & $19 / 07 / 10$ & 5,35 & $12,7 \%$ & 97,91 & 49,75 & 197,2 & 250,63 & 501,26 & 52,70 & 8,07 & 8,94 \\
\hline 15 & $02 / 08 / 10$ & 5,30 & $11,7 \%$ & 97,72 & 49,64 & 197,0 & 257,69 & 511,85 & 53,35 & 8,25 & 9,13 \\
\hline 16 & 01/09/10 & 5,20 & $9,6 \%$ & 97,35 & 48,19 & 196,9 & 250,63 & 511,85 & 54,23 & 9,30 & 10,14 \\
\hline 17 & $15 / 09 / 10$ & 5,15 & $8,5 \%$ & 97,33 & 48,21 & 197,1 & 236,51 & 494,20 & 54,20 & 9,17 & 10,05 \\
\hline 18 & $05 / 10 / 10$ & 5,30 & $11,7 \%$ & 97,57 & 48,55 & 197,2 & 243,57 & 487,14 & 52,75 & 8,47 & 9,59 \\
\hline 19 & $07 / 02 / 11$ & 5,35 & $12,7 \%$ & 98,06 & 49,42 & 197,6 & 264,75 & 522,44 & 52,58 & 8,45 & 9,12 \\
\hline
\end{tabular}


Tabela 5.11 - Resultados dos ensaios na viga 10.

\begin{tabular}{|c|c|c|c|c|c|c|c|c|c|c|c|}
\hline \multirow[b]{2}{*}{ Medição } & \multicolumn{8}{|c|}{ Viga 10} & \multirow[b]{2}{*}{$\begin{array}{c}\mathrm{Fr}_{1} \\
(\mathrm{~Hz})\end{array}$} & \multirow[b]{2}{*}{$\begin{array}{l}E_{M, \text { Stat }} \\
(\mathrm{GPa})\end{array}$} & \multirow[b]{2}{*}{$\begin{array}{l}\mathrm{E}_{\mathrm{M}, \mathrm{VT}} \\
(\mathrm{GPa})\end{array}$} \\
\hline & Data & $\begin{array}{c}\text { Massa } \\
(\mathrm{kg})\end{array}$ & U (\%) & $\begin{array}{c}b_{m} \\
(\mathrm{~mm})\end{array}$ & $\begin{array}{c}h_{m} \\
(\mathrm{~mm})\end{array}$ & $(\mathrm{cm})$ & $\begin{array}{c}F_{1}(\mathrm{~N}) \\
(\delta=4 \mathrm{~mm})\end{array}$ & $\begin{array}{c}F_{2}(\mathrm{~N}) \\
(\delta=8 \mathrm{~mm})\end{array}$ & & & \\
\hline 1 & $10 / 03 / 10$ & 8,45 & $96,7 \%$ & 100,31 & 50,36 & 197,6 & 247,10 & 480,08 & 40,92 & 7,06 & 8,07 \\
\hline 2 & $16 / 03 / 10$ & 7,20 & $67,6 \%$ & 100,31 & 50,40 & 197,6 & 243,57 & 476,55 & 44,11 & 7,04 & 7,96 \\
\hline 3 & $21 / 03 / 10$ & 6,05 & $40,8 \%$ & 100,25 & 50,28 & 197,6 & 240,04 & 476,55 & 47,47 & 7,20 & 7,81 \\
\hline 4 & $26 / 03 / 10$ & 5,55 & $29,2 \%$ & 100,21 & 50,59 & 197,6 & 240,04 & 476,55 & 49,22 & 7,07 & 7,57 \\
\hline 5 & $29 / 03 / 10$ & 5,35 & $24,6 \%$ & 100,1 & 50,47 & 197,6 & 232,98 & 469,49 & 50,14 & 7,13 & 7,63 \\
\hline 6 & $31 / 03 / 10$ & 5,30 & $23,4 \%$ & 99,81 & 50,07 & 197,6 & 240,04 & 476,55 & 50,42 & 7,33 & 7,85 \\
\hline 7 & $05 / 04 / 10$ & 5,25 & $22,2 \%$ & 99,91 & 50,25 & 197,6 & 240,04 & 476,55 & 50,85 & 7,24 & 7,82 \\
\hline 8 & $12 / 04 / 10$ & 5,20 & $21,1 \%$ & 99,69 & 50,10 & 197,6 & 232,98 & 471,26 & 51,67 & 7,38 & 8,09 \\
\hline 9 & $19 / 04 / 10$ & 5,10 & $18,7 \%$ & 99,36 & 49,89 & 197,6 & 240,04 & 480,08 & 52,25 & 7,55 & 8,24 \\
\hline 10 & $26 / 04 / 10$ & 5,05 & $17,6 \%$ & 99,45 & 49,96 & 197,6 & 240,04 & 487,14 & 52,59 & 7,73 & 8,22 \\
\hline 11 & $05 / 05 / 10$ & 5,00 & $16,4 \%$ & 99,18 & 49,49 & 197,5 & 243,57 & 490,67 & 53,12 & 7,98 & 8,56 \\
\hline 12 & $13 / 05 / 10$ & 4,95 & $15,2 \%$ & 98,98 & 49,83 & 197,3 & 247,10 & 501,26 & 53,68 & 8,05 & 8,47 \\
\hline 13 & $23 / 05 / 10$ & 4,95 & $15,2 \%$ & 98,91 & 49,77 & 197,3 & 240,04 & 476,55 & 53,71 & 7,53 & 8,51 \\
\hline 14 & $25 / 06 / 10$ & 4,90 & $14,1 \%$ & 98,91 & 49,77 & 197,3 & 257,69 & 511,85 & 53,96 & 8,09 & 8,50 \\
\hline 15 & $10 / 07 / 10$ & 4,85 & $12,9 \%$ & 98,57 & 49,65 & 197,3 & 243,57 & 501,26 & 54,47 & 8,29 & 8,67 \\
\hline 16 & $02 / 08 / 10$ & 4,80 & $11,7 \%$ & 97,38 & 48,88 & 197,1 & 254,16 & 511,85 & 55,06 & 8,79 & 9,27 \\
\hline 17 & $01 / 09 / 10$ & 4,70 & $9,4 \%$ & 98,38 & 48,46 & 197,1 & 257,69 & 525,97 & 55,51 & 9,30 & 9,38 \\
\hline 18 & $05 / 10 / 10$ & 4,85 & $12,9 \%$ & 98,75 & 49,18 & 197,2 & 250,63 & 497,73 & 54,28 & 8,16 & 8,83 \\
\hline
\end{tabular}

Tabela 5.12 - Resultados dos ensaios na viga 11 .

\begin{tabular}{|c|c|c|c|c|c|c|c|c|c|c|c|}
\hline \multirow[b]{2}{*}{ Medição } & \multirow[b]{2}{*}{ Data } & \multirow[b]{2}{*}{$\begin{array}{l}\text { Massa } \\
(\mathrm{kg})\end{array}$} & \multirow[b]{2}{*}{ U (\%) } & \multicolumn{4}{|c|}{ Viga 11 } & \multirow[b]{2}{*}{$\begin{array}{c}F_{2}(\mathrm{~N}) \\
(\delta=8 \mathrm{~mm})\end{array}$} & \multirow[b]{2}{*}{$\begin{array}{l}\mathrm{Fr}_{1} \\
(\mathrm{~Hz})\end{array}$} & \multirow[b]{2}{*}{$\begin{array}{l}E_{M, \text { stat }} \\
(\mathrm{GPa})\end{array}$} & \multirow[b]{2}{*}{$\begin{array}{l}\mathrm{E}_{\mathrm{M}, \mathrm{VT}} \\
(\mathrm{GPa})\end{array}$} \\
\hline & & & & $\begin{array}{c}b_{m} \\
(m m)\end{array}$ & $\begin{array}{c}\mathrm{h}_{\mathrm{m}} \\
(\mathrm{mm})\end{array}$ & $\begin{array}{l}\mathrm{L} \\
(\mathrm{cm})\end{array}$ & $\begin{array}{c}F_{1}(\mathrm{~N}) \\
(\delta=4 \mathrm{~mm})\end{array}$ & & & & \\
\hline 1 & $09 / 03 / 10$ & 7,35 & $65,5 \%$ & 100,25 & 50,77 & 197,5 & 303,58 & 600,10 & 48,90 & 8,77 & 9,77 \\
\hline 2 & $11 / 03 / 10$ & 7,10 & $59,9 \%$ & 100,25 & 50,77 & 197,5 & 307,11 & 610,69 & 49,90 & 8,98 & 9,83 \\
\hline 3 & $14 / 03 / 10$ & 6,75 & $52,0 \%$ & 100,25 & 50,77 & 197,5 & 300,05 & 596,57 & 51,18 & 8,77 & 9,83 \\
\hline 4 & $17 / 03 / 10$ & 6,40 & $44,1 \%$ & 100,24 & 50,77 & 197,5 & 303,58 & 600,10 & 52,65 & 8,77 & 9,86 \\
\hline 5 & $21 / 03 / 10$ & 6,10 & $37,4 \%$ & 100,12 & 50,71 & 197,5 & 294,76 & 584,22 & 53,58 & 8,60 & 9,78 \\
\hline 6 & $29 / 03 / 10$ & 5,60 & $26,1 \%$ & 99,94 & 50,71 & 197,5 & 300,05 & 600,10 & 55,71 & 8,93 & 9,72 \\
\hline 7 & $31 / 03 / 10$ & 5,55 & $25,0 \%$ & 99,73 & 50,50 & 197,5 & 300,05 & 596,57 & 55,99 & 8,96 & 9,88 \\
\hline 8 & $05 / 04 / 10$ & 5,50 & $23,8 \%$ & 99,89 & 50,43 & 197,5 & 296,52 & 593,04 & 56,11 & 8,98 & 9,86 \\
\hline 9 & $13 / 04 / 10$ & 5,45 & $22,7 \%$ & 99,64 & 50,59 & 197,5 & 289,46 & 582,45 & 56,82 & 8,81 & 9,94 \\
\hline 10 & 19/04/10 & 5,35 & $20,5 \%$ & 99,49 & 50,02 & 197,5 & 292,99 & 585,98 & 57,20 & 9,13 & 10,25 \\
\hline 11 & $26 / 04 / 10$ & 5,30 & $19,3 \%$ & 99,42 & 50,40 & 197,4 & 296,52 & 593,04 & 57,60 & 9,04 & 10,06 \\
\hline 12 & $05 / 05 / 10$ & 5,25 & $18,2 \%$ & 99,02 & 49,58 & 197,4 & 307,11 & 610,69 & 58,03 & 9,76 & 10,67 \\
\hline 13 & $13 / 05 / 10$ & 5,15 & $16,0 \%$ & 98,68 & 50,16 & 197,4 & 307,11 & 617,75 & 58,77 & 9,68 & 10,40 \\
\hline 14 & $23 / 05 / 10$ & 5,15 & $16,0 \%$ & 98,49 & 50,21 & 197,4 & 303,58 & 614,22 & 58,69 & 9,67 & 10,36 \\
\hline 15 & $14 / 06 / 10$ & 5,10 & $14,8 \%$ & 98,49 & 49,95 & 197,4 & 317,70 & 635,40 & 59,09 & 10,04 & 10,56 \\
\hline 16 & $19 / 07 / 10$ & 5,05 & $13,7 \%$ & 98,41 & 49,84 & 197,4 & 317,70 & 642,46 & 59,48 & 10,34 & 10,68 \\
\hline 17 & $02 / 08 / 10$ & 4,95 & $11,5 \%$ & 97,88 & 49,73 & 197,2 & 317,70 & 631,87 & 59,91 & 10,13 & 10,71 \\
\hline 18 & $01 / 09 / 10$ & 4,90 & $10,3 \%$ & 97,63 & 47,93 & 197,3 & 310,64 & 631,87 & 60,271 & 11,60 & 12,04 \\
\hline 19 & $15 / 09 / 10$ & 4,85 & $9,2 \%$ & 97,48 & 47,77 & 197,3 & 285,93 & 603,63 & 60,485 & 11,60 & 12,14 \\
\hline 20 & $05 / 10 / 10$ & 5,00 & $12,6 \%$ & 97,92 & 48,19 & 197,4 & 303,58 & 617,75 & 59,354 & 11,13 & 11,70 \\
\hline
\end{tabular}


Tabela 5.13 - Resultados dos ensaios na viga 12 .

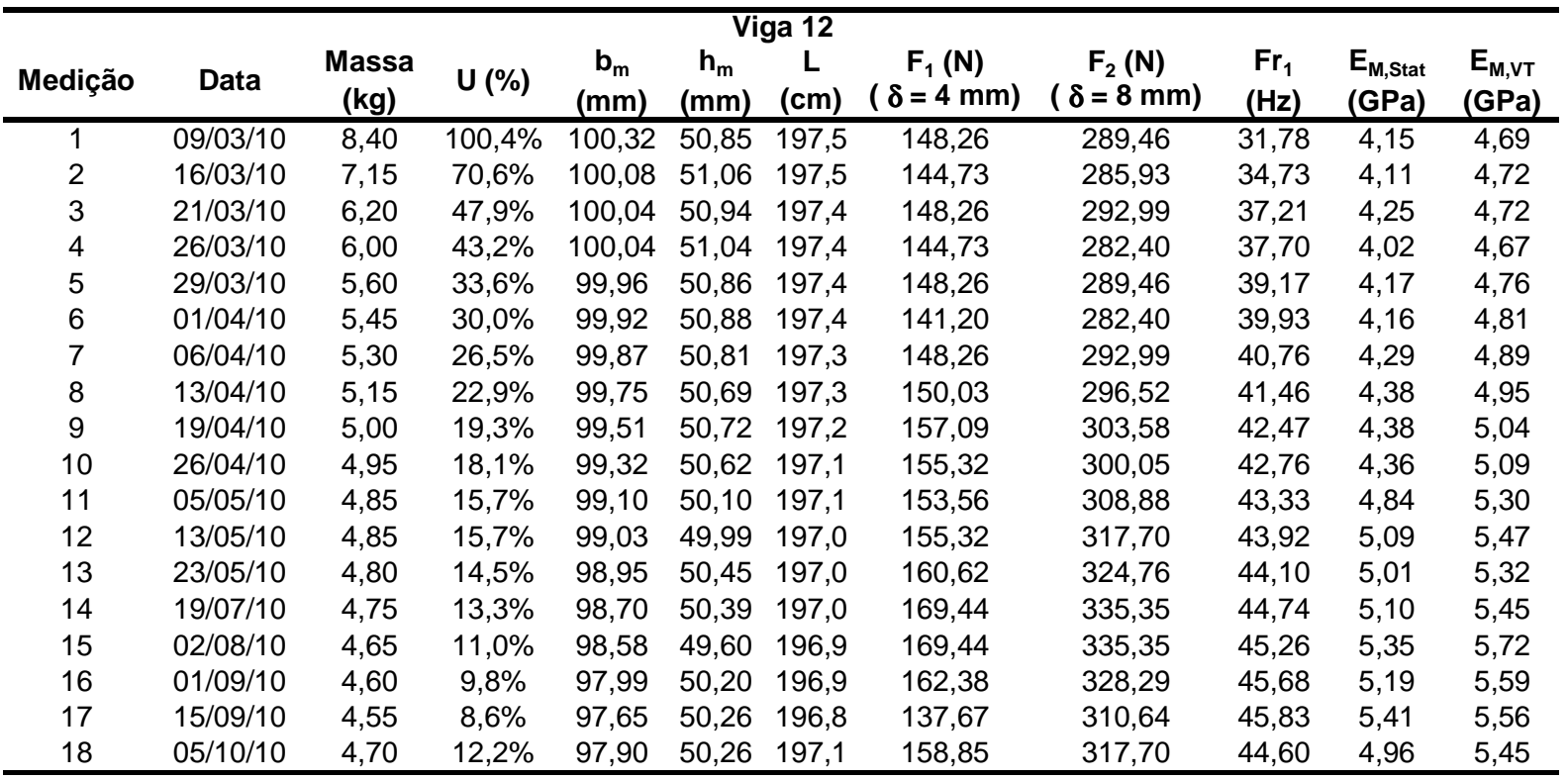

Tabela 5.14 - Resultados dos ensaios na viga 13.

\begin{tabular}{|c|c|c|c|c|c|c|c|c|c|c|c|}
\hline \multirow[b]{2}{*}{ Medição } & \multirow[b]{2}{*}{ Data } & \multirow[b]{2}{*}{$\begin{array}{c}\text { Massa } \\
(\mathrm{kg})\end{array}$} & \multirow[b]{2}{*}{$\mathbf{U}_{\text {est. }}(\%)$} & \multirow[b]{2}{*}{$\begin{array}{c}\mathbf{b}_{\mathrm{m}} \\
(\mathrm{mm})\end{array}$} & \multicolumn{3}{|c|}{ Viga 13} & \multirow[b]{2}{*}{$\begin{array}{c}F_{2}(\mathrm{~N}) \\
(\delta=8 \mathrm{~mm})\end{array}$} & \multirow[b]{2}{*}{$\begin{array}{l}\mathrm{Fr}_{1} \\
(\mathrm{~Hz})\end{array}$} & \multirow[b]{2}{*}{$\begin{array}{l}E_{M, \text { Stat }} \\
(\mathrm{GPa})\end{array}$} & \multirow[b]{2}{*}{$\begin{array}{l}\mathrm{E}_{\mathrm{M}, \mathrm{VT}} \\
(\mathrm{GPa})\end{array}$} \\
\hline & & & & & $\begin{array}{c}\mathrm{h}_{\mathrm{m}} \\
(\mathrm{mm})\end{array}$ & $\begin{array}{l}\mathrm{L} \\
(\mathrm{cm})\end{array}$ & $\begin{array}{c}F_{1}(N) \\
(\delta=4 \mathrm{~mm})\end{array}$ & & & & \\
\hline 1 & $09 / 03 / 10$ & 9,85 & $116,3 \%$ & 100,89 & 50,31 & 197,5 & 222,39 & 434,19 & 35,83 & 6,40 & 7,17 \\
\hline 2 & $16 / 03 / 10$ & 8,55 & $87,8 \%$ & 100,65 & 50,49 & 197,5 & 215,33 & 430,66 & 38,45 & 6,45 & 7,12 \\
\hline 3 & $21 / 03 / 10$ & 7,50 & $64,7 \%$ & 100,56 & 50,28 & 197,4 & 218,86 & 434,19 & 40,69 & 6,54 & 7,07 \\
\hline 4 & $26 / 03 / 10$ & 7,20 & $58,1 \%$ & 100,56 & 50,38 & 197,4 & 215,33 & 430,66 & 41,45 & 6,50 & 7,00 \\
\hline 5 & $29 / 03 / 10$ & 6,70 & $47,1 \%$ & 100,51 & 50,29 & 197,4 & 218,86 & 435,96 & 42,95 & 6,59 & 7,04 \\
\hline 6 & $01 / 04 / 10$ & 6,45 & $41,6 \%$ & 100,54 & 50,37 & 197,4 & 218,86 & 437,72 & 43,99 & 6,61 & 7,07 \\
\hline 7 & $06 / 04 / 10$ & 6,20 & $36,1 \%$ & 100,51 & 50,36 & 197,4 & 218,86 & 437,72 & 44,99 & 6,62 & 7,12 \\
\hline 8 & $13 / 04 / 10$ & 5,80 & $27,4 \%$ & 100,37 & 50,24 & 197,4 & 222,39 & 441,25 & 46,59 & 6,67 & 7,20 \\
\hline 9 & $19 / 04 / 10$ & 5,60 & $23,0 \%$ & 100,00 & 50,10 & 197,2 & 220,63 & 435,96 & 47,78 & 6,65 & 7,38 \\
\hline 10 & $26 / 04 / 10$ & 5,45 & $19,7 \%$ & 99,73 & 49,76 & 197,2 & 222,39 & 444,78 & 48,51 & 7,02 & 7,58 \\
\hline 11 & $05 / 05 / 10$ & 5,40 & $18,6 \%$ & 99,42 & 49,63 & 197,2 & 222,39 & 451,84 & 49,01 & 7,33 & 7,75 \\
\hline 12 & $13 / 05 / 10$ & 5,35 & $17,5 \%$ & 99,26 & 49,58 & 196,9 & 229,45 & 458,90 & 49,58 & 7,36 & 7,85 \\
\hline 13 & $23 / 05 / 10$ & 5,35 & $17,5 \%$ & 99,16 & 49,57 & 196,9 & 222,39 & 451,84 & 49,52 & 7,37 & 7,85 \\
\hline 14 & 03/06/10 & 5,30 & $16,4 \%$ & 99,13 & 49,58 & 196,9 & 215,33 & 437,72 & 49,66 & 7,14 & 7,82 \\
\hline 15 & $19 / 07 / 10$ & 5,20 & $14,2 \%$ & 98,79 & 49,45 & 196,9 & 236,51 & 473,02 & 50,07 & 7,68 & 7,88 \\
\hline 16 & $02 / 08 / 10$ & 5,15 & $13,1 \%$ & 98,58 & 49,18 & 196,8 & 243,57 & 476,55 & 50,52 & 7,71 & 8,09 \\
\hline 17 & $01 / 09 / 10$ & 5,05 & $10,9 \%$ & 98,28 & 48,79 & 196,6 & 261,22 & 497,73 & 51,06 & 8,04 & 8,30 \\
\hline 18 & $05 / 10 / 10$ & 5,15 & $13,1 \%$ & 98,71 & 49,10 & 196,9 & 218,86 & 444,78 & 49,93 & 7,50 & 7,94 \\
\hline
\end{tabular}


Tabela 5.15 - Resultados dos ensaios na viga 14.

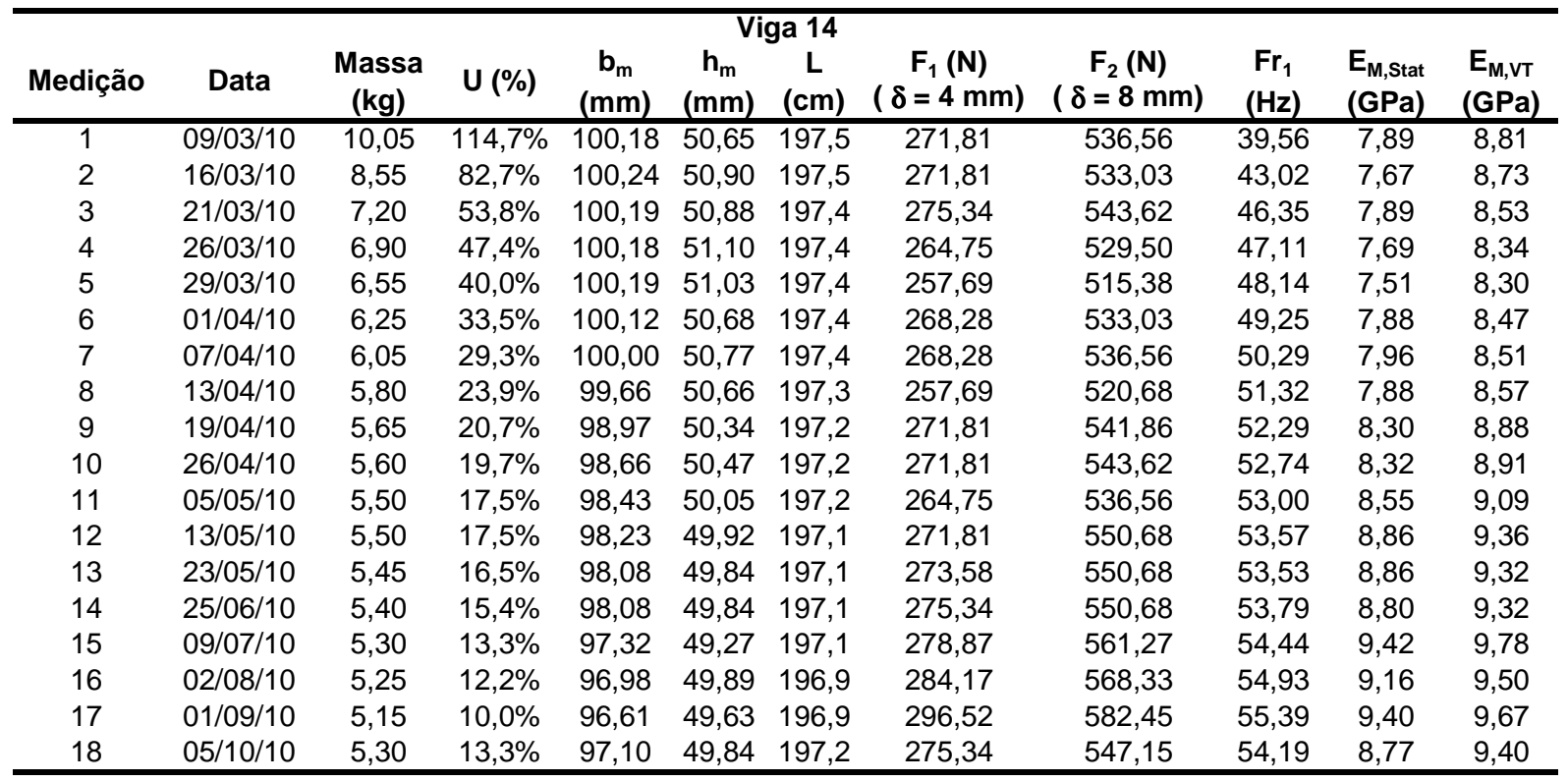

Tabela 5.16 - Resultados dos ensaios na viga 15 .

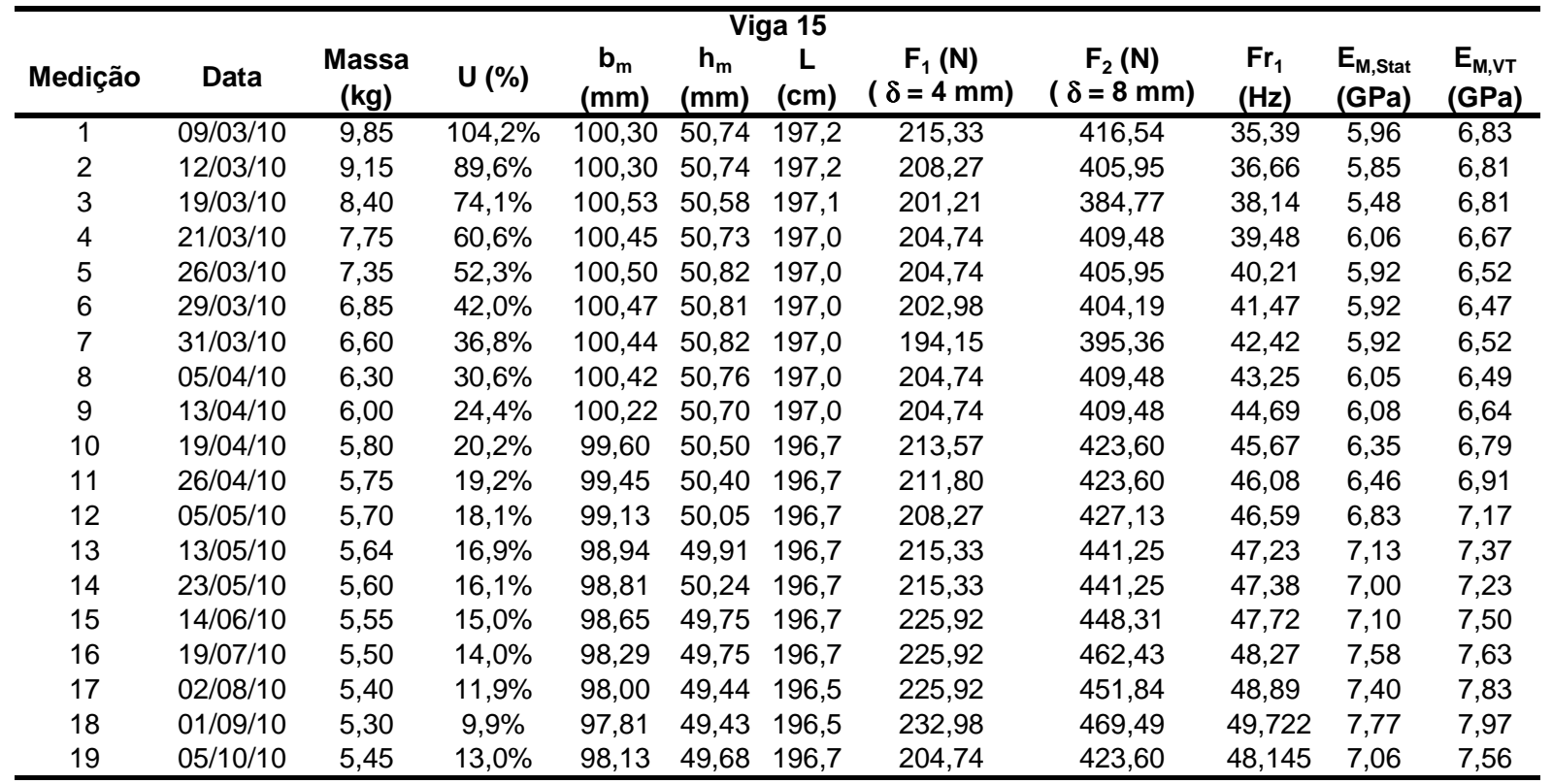


Tabela 5.17 - Resultados dos ensaios na viga 16.

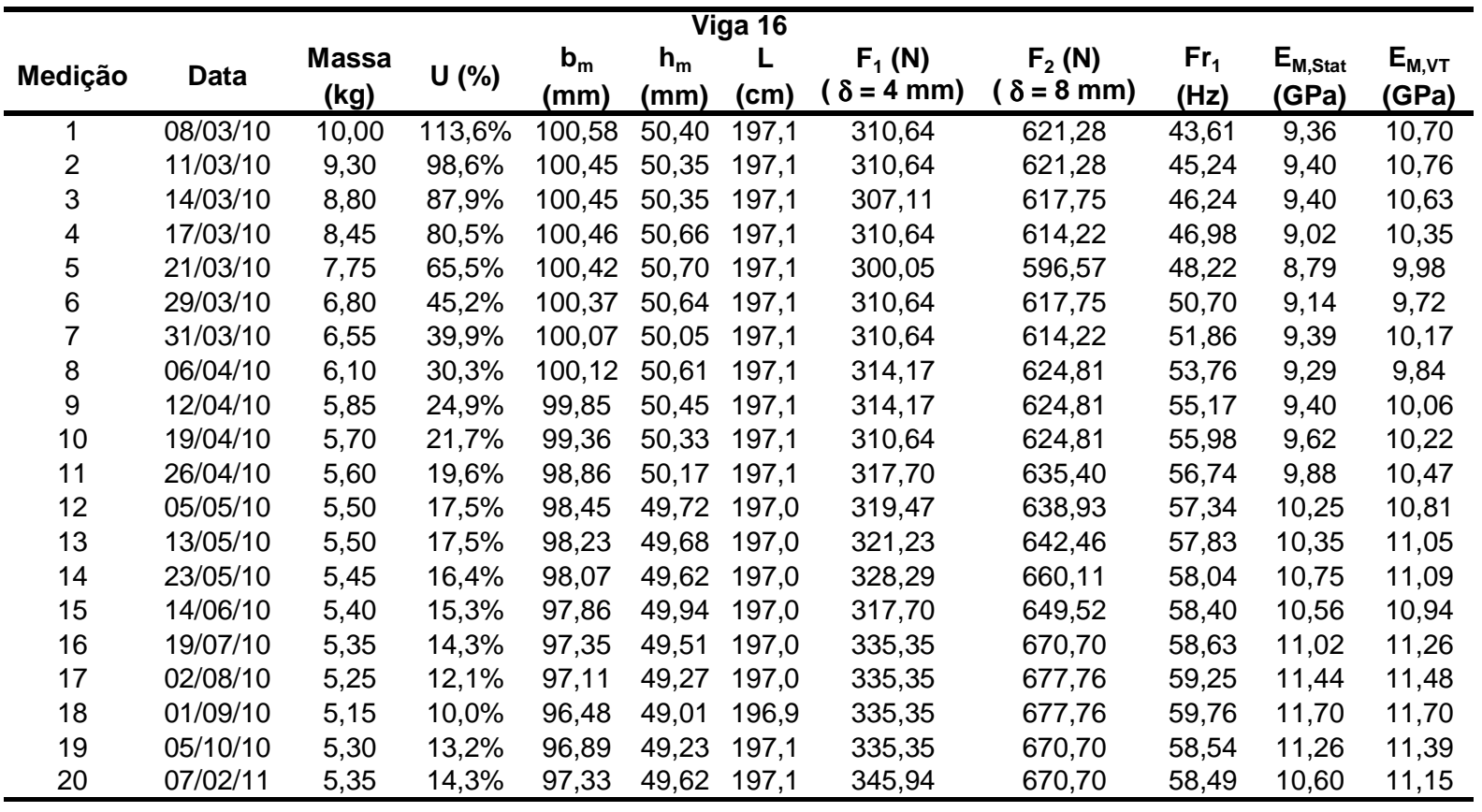

Tabela 5.18 - Resultados dos ensaios na viga 17.

\begin{tabular}{|c|c|c|c|c|c|c|c|c|c|c|c|}
\hline \multirow[b]{2}{*}{ Medição } & \multirow[b]{2}{*}{ Data } & \multirow[b]{2}{*}{$\begin{array}{c}\text { Massa } \\
(\mathrm{kg})\end{array}$} & \multirow[b]{2}{*}{ U (\%) } & \multicolumn{4}{|c|}{ Viga 17} & \multirow[b]{2}{*}{$\begin{array}{c}F_{2}(\mathrm{~N}) \\
(\delta=8 \mathrm{~mm})\end{array}$} & \multirow[b]{2}{*}{$\begin{array}{c}\mathrm{Fr}_{1} \\
(\mathrm{~Hz})\end{array}$} & \multirow[b]{2}{*}{$\begin{array}{l}\mathrm{E}_{\mathrm{M}, \mathrm{Stat}} \\
(\mathrm{GPa})\end{array}$} & \multirow[b]{2}{*}{$\begin{array}{l}\mathrm{E}_{\mathrm{M}, \mathrm{VT}} \\
(\mathrm{GPa})\end{array}$} \\
\hline & & & & $\begin{array}{c}\mathbf{b}_{\mathrm{m}} \\
(\mathrm{mm})\end{array}$ & $\begin{array}{c}\mathbf{h}_{\mathrm{m}} \\
(\mathrm{mm})\end{array}$ & $\begin{array}{c}\mathrm{L} \\
(\mathrm{cm})\end{array}$ & $\begin{array}{c}F_{1}(\mathrm{~N}) \\
(\delta=4 \mathrm{~mm})\end{array}$ & & & & \\
\hline 1 & $08 / 03 / 10$ & 8,85 & $74,5 \%$ & 100,25 & 50,55 & 197,7 & 155,32 & 303,58 & 32,31 & 4,44 & 5,22 \\
\hline 2 & $11 / 03 / 10$ & 8,40 & $65,6 \%$ & 100,25 & 50,49 & 197,6 & 155,32 & 303,58 & 33,45 & 4,46 & 5,32 \\
\hline 3 & $14 / 03 / 10$ & 8,10 & $59,7 \%$ & 100,25 & 50,49 & 197,6 & 155,32 & 303,58 & 33,79 & 4,46 & 5,23 \\
\hline 4 & $17 / 03 / 10$ & 7,80 & $53,8 \%$ & 100,23 & 50,76 & 197,6 & 155,32 & 307,11 & 34,61 & 4,49 & 5,21 \\
\hline 5 & $21 / 03 / 10$ & 7,35 & $44,9 \%$ & 100,19 & 50,80 & 197,6 & 155,32 & 300,05 & 35,24 & 4,28 & 5,08 \\
\hline 6 & $29 / 03 / 10$ & 6,65 & $31,1 \%$ & 100,15 & 50,70 & 197,6 & 158,85 & 303,58 & 36,75 & 4,30 & 5,02 \\
\hline 7 & $31 / 03 / 10$ & 6,55 & $29,2 \%$ & 99,92 & 50,30 & 197,5 & 155,32 & 307,11 & 37,05 & 4,63 & 5,16 \\
\hline 8 & $05 / 04 / 10$ & 6,40 & $26,2 \%$ & 99,93 & 50,52 & 197,5 & 155,32 & 300,05 & 37,77 & 4,36 & 5,17 \\
\hline 9 & $13 / 04 / 10$ & 6,25 & $23,3 \%$ & 99,60 & 50,31 & 197,5 & 158,85 & 314,17 & 38,60 & 4,75 & 5,35 \\
\hline 10 & $19 / 04 / 10$ & 6,15 & $21,3 \%$ & 99,33 & 50,11 & 197,4 & 160,62 & 314,17 & 39,07 & 4,77 & 5,47 \\
\hline 11 & $26 / 04 / 10$ & 6,10 & $20,3 \%$ & 99,12 & 50,07 & 197,4 & 162,38 & 317,70 & 39,55 & 4,84 & 5,58 \\
\hline 12 & 05/05/10 & 6,00 & $18,3 \%$ & 98,91 & 49,76 & 197,4 & 165,91 & 328,29 & 40,26 & 5,17 & 5,81 \\
\hline 13 & $13 / 05 / 10$ & 5,95 & $17,3 \%$ & 98,61 & 49,61 & 197,2 & 165,91 & 335,35 & 41,40 & 5,46 & 6,15 \\
\hline 14 & $23 / 05 / 10$ & 5,95 & $17,3 \%$ & 98,48 & 49,80 & 197,2 & 164,15 & 335,35 & 41,55 & 5,46 & 6,13 \\
\hline 15 & 03/06/10 & 5,90 & $16,3 \%$ & 98,41 & 49,76 & 197,2 & 176,50 & 349,47 & 41,81 & 5,54 & 6,17 \\
\hline 16 & $19 / 07 / 10$ & 5,80 & $14,4 \%$ & 98,01 & 49,21 & 197,2 & 180,03 & 360,06 & 43,29 & 5,98 & 6,75 \\
\hline 17 & 02/08/10 & 5,70 & $12,4 \%$ & 97,87 & 49,08 & 197,0 & 180,03 & 356,53 & 44,42 & 5,92 & 7,03 \\
\hline 18 & 01/09/10 & 5,65 & $11,4 \%$ & 97,27 & 49,36 & 197,3 & 176,50 & 353,00 & 45,69 & 5,86 & 7,33 \\
\hline 19 & $15 / 09 / 10$ & 5,60 & $10,4 \%$ & 97,15 & 48,37 & 196,9 & 144,73 & 324,76 & 45,99 & 6,35 & 7,78 \\
\hline 20 & $05 / 10 / 10$ & 5,70 & $12,4 \%$ & 97,45 & 48,63 & 197,1 & 165,91 & 328,29 & 43,81 & 5,62 & 7,07 \\
\hline 21 & $07 / 02 / 11$ & 5,75 & $13,4 \%$ & 97,68 & 48,49 & 197,1 & 183,56 & 360,06 & 43,34 & 6,15 & 7,03 \\
\hline
\end{tabular}


Tabela 5.19 - Resultados dos ensaios na viga 18.

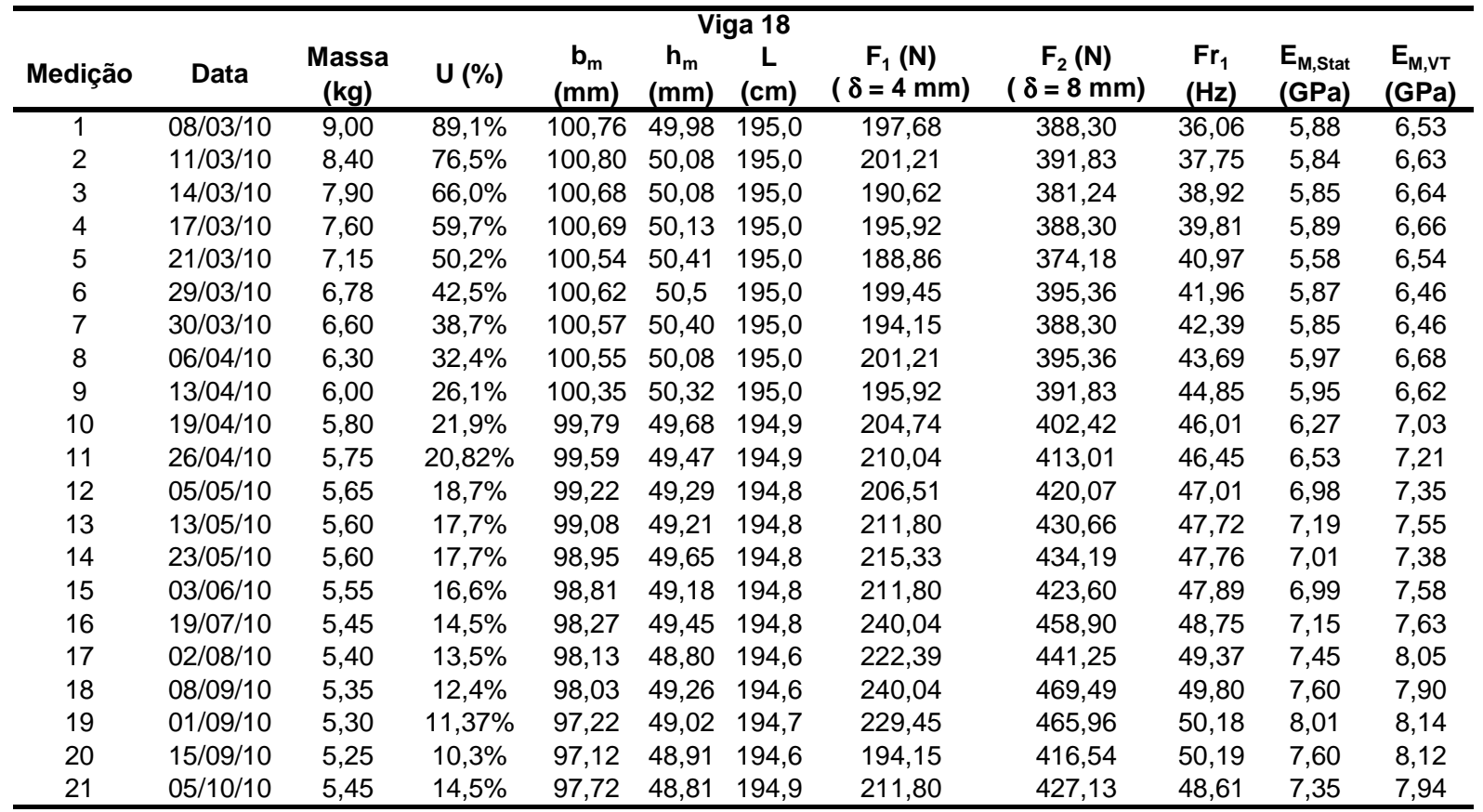

Tabela 5.20 - Resultados dos ensaios na viga 19.

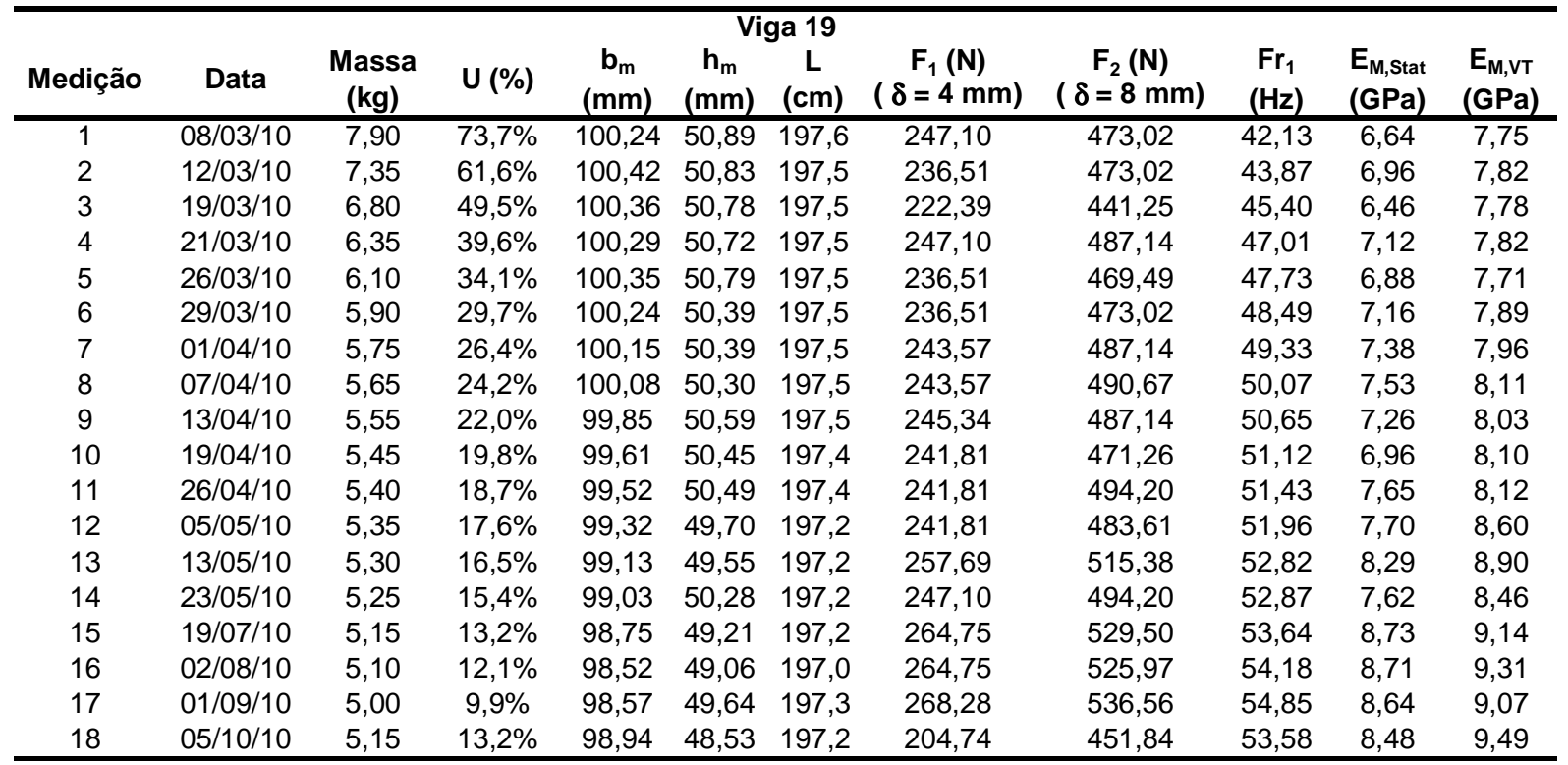


Tabela 5.21 - Resultados dos ensaios na viga 20.

\begin{tabular}{|c|c|c|c|c|c|c|c|c|c|c|c|}
\hline \multirow[b]{2}{*}{ Medição } & \multirow[b]{2}{*}{ Data } & \multirow[b]{2}{*}{$\begin{array}{c}\text { Massa } \\
(\mathrm{kg})\end{array}$} & \multirow[b]{2}{*}{ U (\%) } & \multirow[b]{2}{*}{$\begin{array}{c}b_{m} \\
(m m)\end{array}$} & \multicolumn{2}{|c|}{ Viga 20} & \multirow[b]{2}{*}{$\begin{array}{c}F_{1}(\mathrm{~N}) \\
(\delta=4 \mathrm{~mm})\end{array}$} & \multirow[b]{2}{*}{$\begin{array}{c}F_{2}(\mathrm{~N}) \\
(\delta=8 \mathrm{~mm})\end{array}$} & \multirow[b]{2}{*}{$\begin{array}{c}\mathrm{Fr}_{1} \\
(\mathrm{~Hz})\end{array}$} & \multirow[b]{2}{*}{$\begin{array}{l}E_{M, S t a t} \\
(\mathrm{GPa})\end{array}$} & \multirow[b]{2}{*}{$\begin{array}{l}\mathrm{E}_{\mathrm{M}, \mathrm{VT}} \\
(\mathrm{GPa})\end{array}$} \\
\hline & & & & & $\begin{array}{c}h_{m} \\
(\mathrm{~mm})\end{array}$ & $\underset{(\mathrm{cm})}{\mathrm{L}}$ & & & & & \\
\hline 2 & $11 / 03 / 10$ & 9,50 & $96,8 \%$ & 100,21 & 50,74 & 196,9 & 342,41 & 688,35 & 45,67 & 10,26 & 10,93 \\
\hline 3 & $14 / 03 / 10$ & 9,05 & $87,4 \%$ & 100,21 & 50,74 & 196,9 & 338,88 & 677,76 & 46,43 & 10,05 & 10,77 \\
\hline 4 & $17 / 03 / 10$ & 8,70 & $80,2 \%$ & 100,40 & 50,86 & 196,9 & 338,88 & 677,76 & 47,23 & 9,96 & 10,62 \\
\hline 5 & $21 / 03 / 10$ & 7,90 & $63,6 \%$ & 100,48 & 50,58 & 196,9 & 328,29 & 653,05 & 49,07 & 9,69 & 10,57 \\
\hline 6 & $28 / 03 / 10$ & 7,20 & $49,1 \%$ & 100,38 & 50,87 & 196,9 & 335,35 & 663,64 & 51,24 & 9,64 & 10,34 \\
\hline 7 & $29 / 03 / 10$ & 7,10 & $47,0 \%$ & 100,36 & 50,86 & 196,9 & 335,35 & 663,64 & 51,58 & 9,65 & 10,34 \\
\hline 8 & $30 / 03 / 10$ & 6,90 & $42,9 \%$ & 100,27 & 50,64 & 196,8 & 331,82 & 660,11 & 52,41 & 9,78 & 10,50 \\
\hline 9 & $06 / 04 / 10$ & 6,50 & $34,6 \%$ & 100,36 & 50,75 & 196,8 & 335,35 & 670,70 & 54,52 & 9,92 & 10,63 \\
\hline 10 & $13 / 04 / 10$ & 6,05 & $25,3 \%$ & 100,14 & 50,47 & 196,8 & 331,82 & 663,64 & 56,88 & 10,00 & 10,97 \\
\hline 11 & $19 / 04 / 10$ & 5,90 & $22,2 \%$ & 99,74 & 50,63 & 196,8 & 335,35 & 674,23 & 57,84 & 10,16 & 11,00 \\
\hline 12 & $26 / 04 / 10$ & 5,85 & $21,2 \%$ & 99,49 & 50,60 & 196,8 & 342,41 & 684,82 & 58,41 & 10,31 & 11,17 \\
\hline 13 & $05 / 05 / 10$ & 5,75 & $19,1 \%$ & 99,08 & 49,94 & 196,8 & 335,35 & 674,23 & 58,95 & 10,66 & 11,68 \\
\hline 14 & $13 / 05 / 10$ & 5,65 & $17,0 \%$ & 98,76 & 50,38 & 196,8 & 338,88 & 684,82 & 59,76 & 10,63 & 11,53 \\
\hline 15 & $23 / 05 / 10$ & 5,60 & $16,0 \%$ & 98,50 & 50,13 & 196,7 & 349,47 & 698,94 & 59,92 & 10,93 & 11,67 \\
\hline 16 & $19 / 07 / 10$ & 5,50 & $13,9 \%$ & 97,99 & 49,99 & 196,7 & 356,53 & 713,06 & 60,59 & 11,30 & 11,88 \\
\hline 17 & $02 / 08 / 10$ & 5,40 & $11,8 \%$ & 97,70 & 49,24 & 196,7 & 353,00 & 702,47 & 61,15 & 11,63 & 12,47 \\
\hline 18 & $01 / 09 / 10$ & 5,35 & $10,8 \%$ & 97,51 & 49,52 & 196,7 & 353,00 & 706,00 & 61,39 & 11,57 & 12,26 \\
\hline 19 & $15 / 09 / 10$ & 5,30 & $9,8 \%$ & 97,22 & 48,69 & 196,7 & 317,70 & 674,23 & 61,57 & 12,33 & 12,90 \\
\hline 20 & $05 / 10 / 10$ & 5,45 & $12,9 \%$ & 97,76 & 49,64 & 196,8 & 345,94 & 688,35 & 60,44 & 11,11 & 12,01 \\
\hline 21 & $07 / 02 / 11$ & 5,50 & $13,9 \%$ & 98,01 & 48,92 & 196,9 & 370,65 & 716,59 & 60,46 & 11,70 & 12,66 \\
\hline
\end{tabular}

\subsection{Análise dos resultados}

\subsubsection{Influência do teor de umidade}

Para permitir o agrupamento de todos os resultados dos ensaios dinâmicos com as vigas de Pinus $s p$ em um único gráfico, foi calculado o módulo de elasticidade adimensional no teor de umidade do ensaio (u\%) conforme mostra a Equação 5.2.

$$
E_{M, r e l, u \%}=\frac{E_{M, u \%}}{E_{M, S t a t, 12 \%}}
$$

Sendo:

$E_{M, r e l, u \%}=$ módulo de elasticidade relativo (adimensional);

$E_{M, u \%}=$ módulo de elasticidade no teor de umidade u\%;

$E_{M, \text { stat }, 12 \%}=$ módulo de elasticidade estático a $12 \%$ de umidade.

O módulo de elasticidade estático de cada viga no teor de umidade de $12 \%$ foi calculado conforme item 6.2.1 da norma NBR 7190 (ABNT, 1997), considerando-se os valores de $\mathrm{E}_{\mathrm{M}, \mathrm{Stat}}$ medidos para teores de umidade abaixo de $20 \%$.

As Figuras 5.3 e 5.4 mostram respectivamente os gráficos dos valores dos módulos de elasticidade estático e dinâmico contra o teor de umidade. 


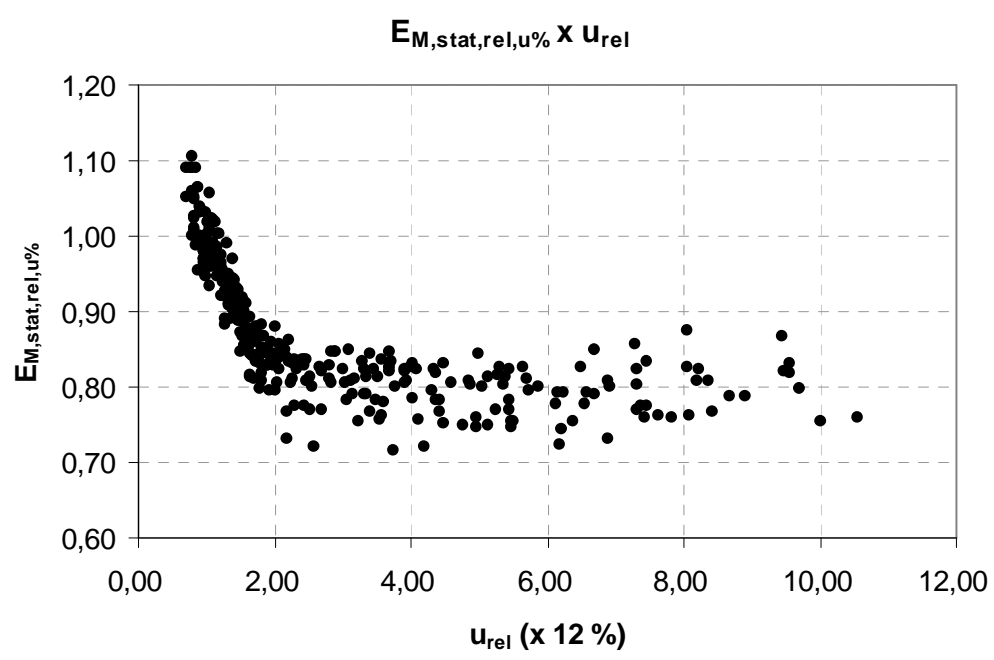

Figura 5.3 - Associação do módulo de elasticidade estático com o teor de umidade.

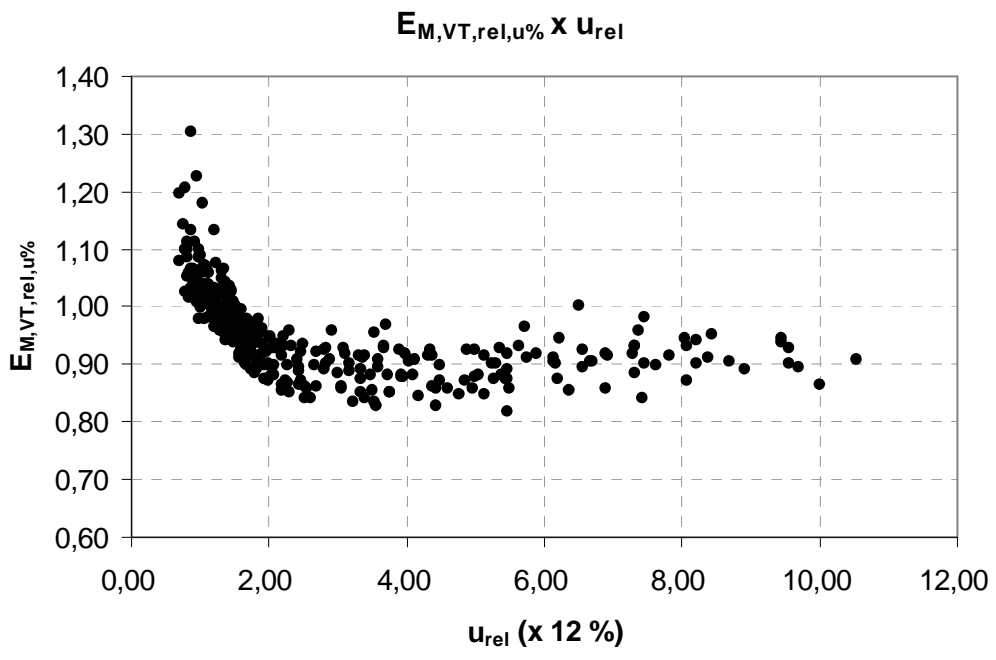

Figura 5.4 - Associação do módulo de elasticidade dinâmico com o teor de umidade.

Analisando o gráfico da Figura 5.4 observa-se que o módulo de elasticidade dinâmico permanece praticamente constante para teores de umidade acima de $25 \%$. Para teores de umidade inferiores a 25\%, o módulo de elasticidade dinâmico aumenta com a perda de água de impregnação.

A Figura 5.5 mostra a função ajustada por mínimos quadrados para os valores de $\mathrm{E}_{\mathrm{M}, \mathrm{VT}, \mathrm{rel}, \mathrm{u} \%}$ nos teores de umidade abaixo de $25 \%$. 


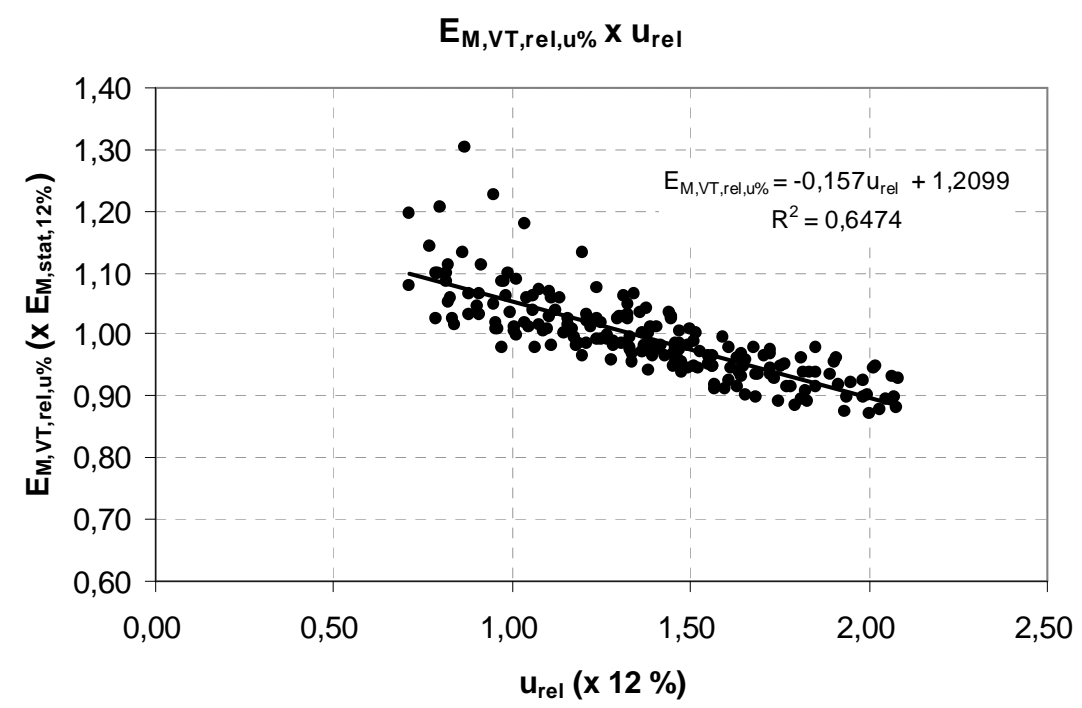

Figura 5.5 - Regressão linear entre $\mathrm{E}_{\mathrm{M}, \mathrm{VT}, \mathrm{rel}, \mathrm{u} \%}$ e $\mathrm{u}_{\text {rel }}$ para $\mathrm{u} \leq 25 \%$.

Observa-se uma moderada correlação linear negativa entre $\mathrm{E}_{\mathrm{M}, \mathrm{VT} \text {,rel, } \mathrm{u} \%}$ e $\mathrm{u}_{\text {rel }}$ com a presença de 5 outliers. Esses pontos foram identificados com sendo da viga 17. Os dados da viga 17 foram então descartados e a Figura 5.6 mostra o novo diagrama de dispersão obtido.

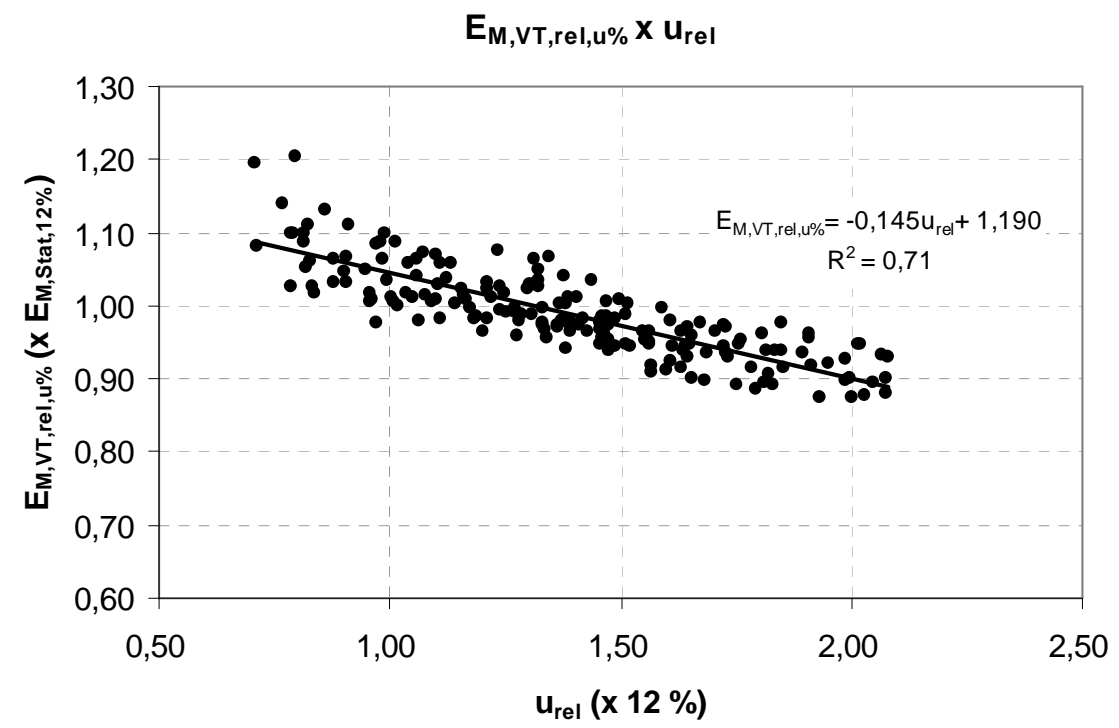

Figura 5.6 - Regressão linear entre $\mathrm{E}_{\mathrm{M}, \mathrm{VT}, \text { rel, } \mathrm{u} \%} \mathrm{e} \mathrm{u}_{\text {rel }}$ para $\mathrm{u} \leq 25 \%$ sem os dados da viga 17.

Como as suposições do modelo de regressão linear não foram atendidas pelos dados, o modelo de regressão linear da Figura 5.6 não pode ser validado, como mostrado no Apêndice D. Assim, foi feita a transformação de Box-Cox (1964) para a validação da equação de regressão. A Figura 5.7 mostra o diagrama de dispersão dos dados transformados. 


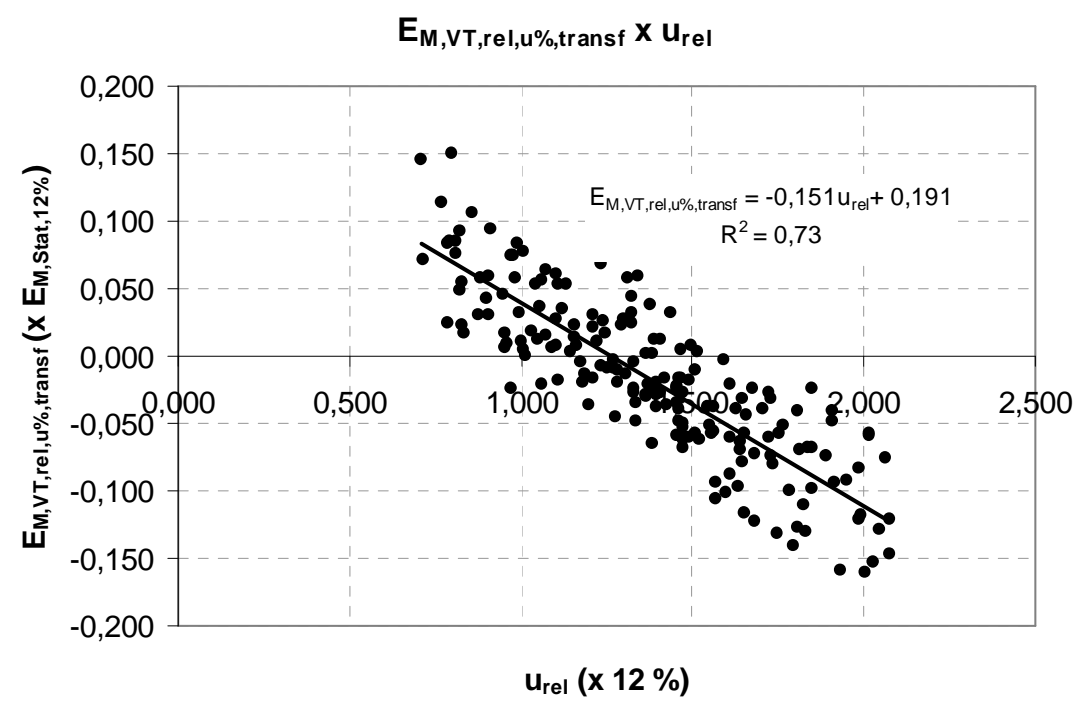

Figura 5.7 - Regressão linear entre $\mathrm{E}_{\mathrm{M}, \mathrm{VT}, \mathrm{rel}, \mathrm{u} \% \text {,transf }}$ e $\mathrm{u}_{\mathrm{rel}}$ para $\mathrm{u}<25 \%$.

Obviamente os dados transformados não têm significado físico e por esse motivo aparecem valores negativos para o módulo de elasticidade.

Para obter uma relação com os dados originais foi aplicada uma transformação inversa com a qual se obteve a Equação 5.3

$$
E_{M, V T, r e l, u}=\frac{1}{\sqrt[2,371]{0,3673 u_{r e l}+0,5476}}
$$

A Figura 5.8 mostra a função ajustada por mínimos quadrados para os valores de $\mathrm{E}_{\mathrm{M}, \mathrm{VT}, \mathrm{rel}, \mathrm{u} \%}$ nos teores de umidade acima de $25 \%$.

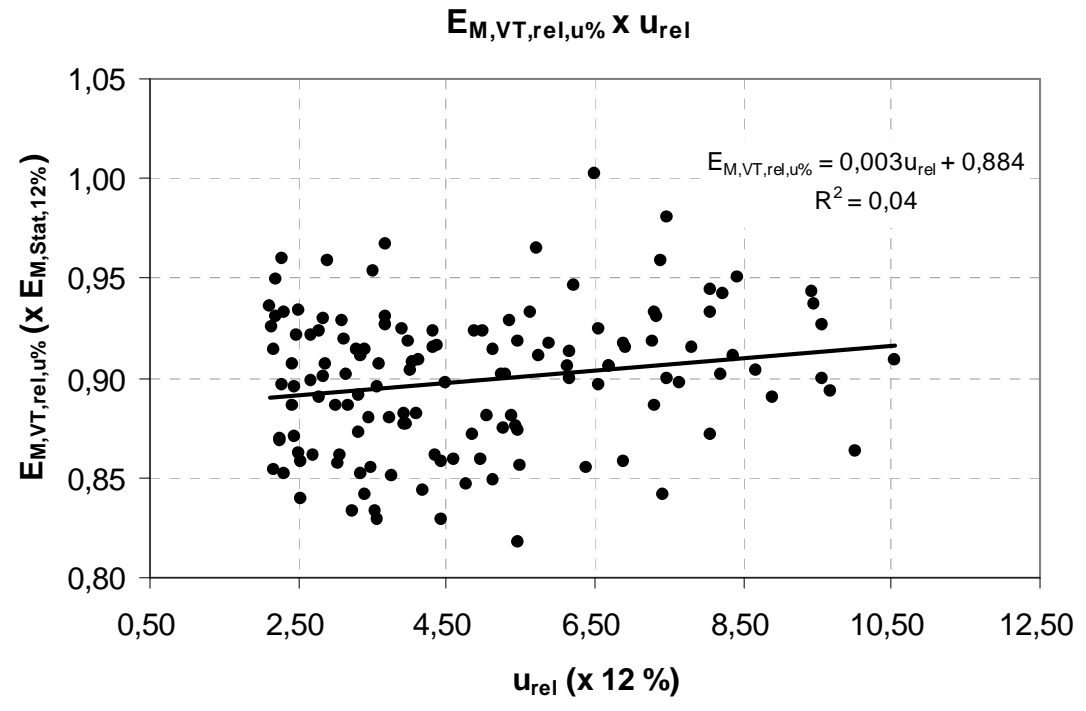

Figura 5.8 - Regressão linear entre $\mathrm{E}_{\mathrm{M}, \mathrm{VT}, \mathrm{rel}, \mathrm{u} \%}$ e $\mathrm{u}_{\mathrm{rel}}$ para $\mathrm{u}>25 \%$. 
Como se vê na Figura 5.8, não foi encontrada uma correlação significativa entre o módulo de elasticidade dinâmico e o teor de umidade. Observa-se que o módulo de elasticidade dinâmico aparentemente permanece constante para $\mathrm{u}>25 \%$.

Usando a solução do modelo de Bernoulli para uma viga em suspensão livre-livre, foi calculada a frequência teórica para teores de umidade acima de 25\%, admitindo-se que o módulo de elasticidade, o comprimento e as dimensões da seção transversal permanecem constante e iguais aos valores medidos no teor de umidade de $25 \%$ (Equação 5.4).

$$
f_{\text {teórica }}=\sqrt{\frac{12,679 * E_{M, V T, 25 \%} * I}{M * L^{3}}}
$$

Sendo:

$f_{\text {teórica }}=$ frequência teórica do primeiro modo de flexão;

$E_{M, V T, 25 \%}=$ módulo de elasticidade dinâmico a $25 \%$ de umidade

$I=$ momento de inércia no teor de umidade de $25 \%\left(\mathrm{~m}^{4}\right)$

$M=$ massa da viga $(\mathrm{kg})$;

$L=$ comprimento no teor de umidade de $25 \%(\mathrm{~m})$.

Foi feita uma comparação entre a frequência medida experimentalmente e a frequência estimada por meio da Equação 5.4 e o resultado é mostrado na Tabela 5.22. 
Tabela 5.22 - Comparação entre a frequência teórica e experimental para u > 25\%.

\begin{tabular}{|c|c|c|c|c|c|c|c|c|}
\hline \multirow{2}{*}{ Viga } & \multirow{2}{*}{ U (\%) } & \multirow{2}{*}{$\begin{array}{c}\text { Massa } \\
(\mathrm{kg})\end{array}$} & \multirow{2}{*}{$\begin{array}{c}E_{M, V T} \\
(G P a)\end{array}$} & \multirow{2}{*}{$I\left(m^{4}\right)$} & \multirow{2}{*}{$L(\mathrm{~cm})$} & \multicolumn{2}{|c|}{$f(\mathrm{~Hz})$} & \multirow{2}{*}{$\begin{array}{l}\mathbf{f}_{\text {teórica }} \\
\mathbf{f}_{\text {medida }}\end{array}$} \\
\hline & & & & & & Teórica & Medida & \\
\hline \multirow{5}{*}{1} & $65,73 \%$ & 7,95 & \multirow{5}{*}{6,96} & \multirow{5}{*}{ 1,05E-06 } & \multirow{5}{*}{197,40} & 38,99 & 38,58 & $\overline{1,01}$ \\
\hline & $53,22 \%$ & 7,35 & & & & 40,55 & 40,35 & 1,00 \\
\hline & $42,80 \%$ & 6,85 & & & & 42,01 & 41,76 & 1,01 \\
\hline & $30,29 \%$ & 6,25 & & & & 43,98 & 44,00 & 1,00 \\
\hline & $27,16 \%$ & 6,10 & & & & 44,51 & 44,51 & 1,00 \\
\hline \multirow{8}{*}{2} & $101,21 \%$ & 8,75 & \multirow{8}{*}{6,71} & \multirow{8}{*}{ 1,06E-06 } & \multirow{8}{*}{197,30} & 36,63 & 37,60 & 0,97 \\
\hline & $88,57 \%$ & 8,20 & & & & 37,84 & 39,01 & 0,97 \\
\hline & $74,77 \%$ & 7,60 & & & & 39,30 & 39,99 & 0,98 \\
\hline & $64,42 \%$ & 7,15 & & & & 40,52 & 41,15 & 0,98 \\
\hline & $58,67 \%$ & 6,90 & & & & 41,25 & 41,58 & 0,99 \\
\hline & $48,32 \%$ & 6,45 & & & & 42,66 & 42,66 & 1,00 \\
\hline & $40,28 \%$ & 6,10 & & & & 43,87 & 43,65 & 1,01 \\
\hline & $32,23 \%$ & 5,75 & & & & 45,19 & 45,19 & 1,00 \\
\hline & $114,77 \%$ & 9,20 & & & & 38,38 & 38,76 & 0,99 \\
\hline & $98,43 \%$ & 8,50 & & & & 39,93 & 40,33 & 0,99 \\
\hline & $78,58 \%$ & 7,65 & & & & 42,09 & 42,57 & 0,99 \\
\hline 3 & $63,41 \%$ & 7,00 & & & & 44,00 & 44,24 & 0,99 \\
\hline 3 & $55,24 \%$ & 6,65 & 7,68 & I,U/E-Ub & 191,50 & 45,15 & 45,08 & 1,00 \\
\hline & $44,73 \%$ & 6,20 & & & & 46,76 & 46,67 & 1,00 \\
\hline & $36,56 \%$ & 5,85 & & & & 48,14 & 47,88 & 1,01 \\
\hline & $29,56 \%$ & 5,55 & & & & 49,42 & 49,42 & 1,00 \\
\hline & $52,39 \%$ & 7,45 & & & & 54,51 & 54,91 & 0,99 \\
\hline & $44,20 \%$ & 7,05 & & & & 56,03 & 56,68 & 0,99 \\
\hline 4 & $37,05 \%$ & 6,70 & 12,56 & 1,07E-06 & 197,60 & 57,48 & 57,77 & 0,99 \\
\hline & $33,98 \%$ & 6,55 & & & & 58,13 & 58,27 & 1,00 \\
\hline & $25,80 \%$ & 6,15 & & & & 59,99 & 59,99 & 1,00 \\
\hline & $83,18 \%$ & 8,95 & & & & 41,83 & 42,40 & 0,99 \\
\hline & $68,86 \%$ & 8,25 & & & & 43,57 & 44,19 & 0,99 \\
\hline & $48,39 \%$ & 7,25 & & & & 46,48 & 46,66 & 1,00 \\
\hline 5 & $38,15 \%$ & 6,75 & 8,80 & 1,0/E-06 & 196,80 & 48,17 & 48,05 & 1,00 \\
\hline & $32,01 \%$ & 6,45 & & & & 49,26 & 49,04 & 1,00 \\
\hline & $28,94 \%$ & 6,30 & & & & 49,84 & 49,84 & 1,00 \\
\hline & $93,81 \%$ & 9,70 & & & & 38,88 & 39,03 & 1,00 \\
\hline & $87,82 \%$ & 9,40 & & & & 39,49 & 39,75 & 0,99 \\
\hline & $78,83 \%$ & 8,95 & & & & 40,47 & 40,56 & 1,00 \\
\hline & $73,83 \%$ & 8,70 & & & & 41,05 & 41,19 & 1,00 \\
\hline 6 & $62,84 \%$ & 8,15 & 8,32 & 1,07E-06 & 197,20 & 42,41 & 42,34 & 1,00 \\
\hline & $51,85 \%$ & 7,60 & & & & 43,92 & 43,74 & 1,00 \\
\hline & $46,86 \%$ & 7,35 & & & & 44,66 & 44,44 & 1,00 \\
\hline & $37,87 \%$ & 6,90 & & & & 46,09 & 45,92 & 1,00 \\
\hline & $27,88 \%$ & 6,40 & & & & 47,86 & 47,86 & 1,00 \\
\hline & $120,05 \%$ & 10,05 & & & & 38,65 & 38,97 & 0,99 \\
\hline & $106,91 \%$ & 9,45 & & & & 39,85 & 40,89 & 0,97 \\
\hline 7 & $91,58 \%$ & 8,75 & & & & 41,42 & 42,36 & 0,98 \\
\hline 7 & $65,31 \%$ & 7,55 & 8,68 & 1,05E-06 & 197,60 & 44,59 & 45,04 & 0,99 \\
\hline & $53,27 \%$ & 7,00 & & & & 46,31 & 46,31 & 1,00 \\
\hline & $40,13 \%$ & 6,40 & & & & 48,43 & 48,33 & 1,00 \\
\hline & $26,99 \%$ & 5,80 & & & & 50,87 & 50,87 & 1,00 \\
\hline & $126,60 \%$ & 10,30 & & & & 40,80 & 42,33 & 0,96 \\
\hline & $96,90 \%$ & 8,95 & & & & 43,76 & 44,65 & 0,98 \\
\hline & $82,60 \%$ & 8,30 & & & & 45,45 & 45,91 & 0,99 \\
\hline 8 & $61,70 \%$ & 7,35 & 9,42 & 1,09E-06 & 196,70 & 48,29 & 48,43 & 1,00 \\
\hline & $57,30 \%$ & 7,15 & & & & 48,96 & 49,05 & 1,00 \\
\hline & $40,80 \%$ & 6,40 & & & & 51,75 & 51,76 & 1,00 \\
\hline & $27,60 \%$ & 5,80 & & & & 54,37 & 54,37 & 1,00 \\
\hline
\end{tabular}


Continuação da Tabela 5.22.

\begin{tabular}{|c|c|c|c|c|c|c|c|c|}
\hline \multirow{2}{*}{ Viga } & \multirow{2}{*}{ U (\%) } & \multirow{2}{*}{$\begin{array}{c}\text { Massa } \\
(\mathrm{kg})\end{array}$} & \multirow{2}{*}{$\begin{array}{l}E_{M, V T} \\
(G P a) \\
\end{array}$} & \multirow{2}{*}{$I\left(m^{4}\right)$} & \multirow{2}{*}{$\mathrm{L}(\mathrm{cm})$} & \multicolumn{2}{|c|}{$f(\mathrm{~Hz})$} & \multirow{2}{*}{$\begin{array}{l}f_{\text {teórica }} \\
\mathbf{f}_{\text {medida }}\end{array}$} \\
\hline & & & & & & Teórica & Medida & \\
\hline \multirow{7}{*}{9} & $89,64 \%$ & 9,00 & \multirow{7}{*}{8,08} & \multirow{7}{*}{ 1,08E-06 } & \multirow{7}{*}{197,60} & 39,86 & 40,19 & 0,99 \\
\hline & $78,05 \%$ & 8,45 & & & & 41,14 & 41,99 & 0,98 \\
\hline & $68,57 \%$ & 8,00 & & & & 42,28 & 42,87 & 0,99 \\
\hline & $44,34 \%$ & 6,85 & & & & 45,69 & 45,79 & 1,00 \\
\hline & $42,23 \%$ & 6,75 & & & & 46,03 & 46,01 & 1,00 \\
\hline & $34,85 \%$ & 6,40 & & & & 47,27 & 47,20 & 1,00 \\
\hline & $27,48 \%$ & 6,05 & & & & 48,62 & 48,62 & 1,00 \\
\hline \multirow{4}{*}{10} & $96,72 \%$ & 8,45 & \multirow{4}{*}{7,57} & \multirow{4}{*}{ 1,08E-06 } & \multirow{4}{*}{197,60} & 39,89 & 40,92 & 0,97 \\
\hline & $67,62 \%$ & 7,20 & & & & 43,22 & 44,11 & 0,98 \\
\hline & $40,85 \%$ & 6,05 & & & & 47,15 & 47,47 & 0,99 \\
\hline & $29,21 \%$ & 5,55 & & & & 49,22 & 49,22 & 1,00 \\
\hline & $65,51 \%$ & 7,35 & & & & 48,63 & 48,90 & 0,99 \\
\hline & $59,88 \%$ & 7,10 & & & & 49,48 & 49,90 & 0,99 \\
\hline 11 & $52,00 \%$ & 6,75 & 972 & $109 F-06$ & 19750 & 50,74 & 51,18 & 0,99 \\
\hline & $44,12 \%$ & 6,40 & 9,12 & I,UYᄃ-UD & ט, & 52,11 & 52,65 & 0,99 \\
\hline & $37,36 \%$ & 6,10 & & & & 53,38 & 53,58 & 1,00 \\
\hline & $26,10 \%$ & 5,60 & & & & 55,71 & 55,71 & 1,00 \\
\hline & $100,44 \%$ & 8,40 & & & & 32,38 & 31,78 & 1,02 \\
\hline & $70,61 \%$ & 7,15 & & & & 35,10 & 34,73 & 1,01 \\
\hline & $47,94 \%$ & 6,20 & & & & 37,69 & 37,21 & 1,01 \\
\hline 12 & $43,17 \%$ & 6,00 & 4,89 & $1,09 E-06$ & 197,30 & 38,31 & 37,70 & 1,02 \\
\hline & $33,63 \%$ & 5,60 & & & & 39,66 & 39,17 & 1,01 \\
\hline & $30,05 \%$ & 5,45 & & & & 40,20 & 39,93 & 1,01 \\
\hline & $26,47 \%$ & 5,30 & & & & 40,76 & 40,76 & 1,00 \\
\hline & $116,30 \%$ & 9,85 & & & & 35,75 & 35,83 & 1,00 \\
\hline & $87,75 \%$ & 8,55 & & & & 38,37 & 38,45 & 1,00 \\
\hline & $64,69 \%$ & 7,50 & & & & 40,97 & 40,69 & 1,01 \\
\hline & $58,11 \%$ & 7,20 & & & & 41,81 & 41,45 & 1,01 \\
\hline 13 & $47,13 \%$ & 6,70 & 7,20 & 1,U6t-Ub & 197,40 & 43,35 & 42,95 & 1,01 \\
\hline & $41,64 \%$ & 6,45 & & & & 44,18 & 43,99 & 1,00 \\
\hline & $36,15 \%$ & 6,20 & & & & 45,06 & 44,99 & 1,00 \\
\hline & $27,36 \%$ & 5,80 & & & & 46,59 & 46,59 & 1,00 \\
\hline & $114,75 \%$ & 10,05 & & & & 39,02 & 39,56 & 0,99 \\
\hline & $82,70 \%$ & 8,55 & & & & 42,30 & 43,02 & 0,98 \\
\hline & $53,85 \%$ & 7,20 & & & & 46,10 & 46,35 & 0,99 \\
\hline 14 & $47,44 \%$ & 6,90 & 8,51 & $1,09 E-06$ & 197,40 & 47,09 & 47,11 & 1,00 \\
\hline & $39,96 \%$ & 6,55 & & & & 48,33 & 48,14 & 1,00 \\
\hline & $33,55 \%$ & 6,25 & & & & 49,48 & 49,25 & 1,00 \\
\hline & $29,28 \%$ & 6,05 & & & & 50,29 & 50,29 & 1,00 \\
\hline & $104,16 \%$ & 9,85 & & & & 34,59 & 35,39 & 0,98 \\
\hline & $89,65 \%$ & 9,15 & & & & 35,89 & 36,66 & 0,98 \\
\hline & $74,10 \%$ & 8,40 & & & & 37,46 & 38,14 & 0,98 \\
\hline 15 & $60,63 \%$ & 7,75 & 6.49 & & & 39,00 & 39,48 & 0,99 \\
\hline 10 & $52,34 \%$ & 7,35 & 0,49 & I,UYE-Ub & 191,00 & 40,05 & 40,21 & 1,00 \\
\hline & $41,98 \%$ & 6,85 & & & & 41,48 & 41,47 & 1,00 \\
\hline & $36,80 \%$ & 6,60 & & & & 42,26 & 42,42 & 1,00 \\
\hline & $30,58 \%$ & 6,30 & & & & 43,25 & 43,25 & 1,00 \\
\hline & $113,55 \%$ & 10,00 & & & & 41,99 & 43,61 & 0,96 \\
\hline & $98,60 \%$ & 9,30 & & & & 43,54 & 45,24 & 0,96 \\
\hline & $87,93 \%$ & 8,80 & & & & 44,76 & 46,24 & 0,97 \\
\hline & $80,45 \%$ & 8,45 & & & & 45,68 & 46,98 & 0,97 \\
\hline 10 & $65,50 \%$ & 7,75 & 9,84 & 1,UరЕ-Ub & 197,10 & 47,70 & 48,22 & 0,99 \\
\hline & $45,21 \%$ & 6,80 & & & & 50,92 & 50,70 & 1,00 \\
\hline & $39,88 \%$ & 6,55 & & & & 51,88 & 51,86 & 1,00 \\
\hline & $30,27 \%$ & 6,10 & & & & 53,76 & 53,76 & 1,00 \\
\hline
\end{tabular}


Continuação da Tabela 5.22.

\begin{tabular}{|c|c|c|c|c|c|c|c|c|}
\hline \multirow{2}{*}{ Viga } & \multirow{2}{*}{ U (\%) } & \multirow{2}{*}{$\begin{array}{c}\text { Massa } \\
(\mathrm{kg}) \\
\end{array}$} & \multirow{2}{*}{$\begin{array}{c}E_{M, V T} \\
(G P a) \\
\end{array}$} & \multirow{2}{*}{$I\left(m^{4}\right)$} & \multirow{2}{*}{$\mathrm{L}(\mathrm{cm})$} & \multicolumn{2}{|c|}{$f(\mathbf{H z})$} & \multirow{2}{*}{$\begin{array}{l}\mathbf{f}_{\text {teórica }} / \\
\mathbf{f}_{\text {medida }}\end{array}$} \\
\hline & & & & & & Teórica & Medida & \\
\hline \multirow{8}{*}{17} & $74,52 \%$ & 8,85 & \multirow{8}{*}{5,17} & \multirow{8}{*}{ 1,06E-06 } & \multirow{8}{*}{197,50} & 31,91 & 32,31 & 0,99 \\
\hline & $65,65 \%$ & 8,40 & & & & 32,75 & 33,45 & 0,98 \\
\hline & $59,73 \%$ & 8,10 & & & & 33,35 & 33,79 & 0,99 \\
\hline & $53,82 \%$ & 7,80 & & & & 33,99 & 34,61 & 0,98 \\
\hline & $44,94 \%$ & 7,35 & & & & 35,01 & 35,24 & 0,99 \\
\hline & $31,14 \%$ & 6,65 & & & & 36,81 & 36,75 & 1,00 \\
\hline & $29,17 \%$ & 6,55 & & & & 37,33 & 37,05 & 1,01 \\
\hline & $26,21 \%$ & 6,40 & & & & 37,77 & 37,77 & 1,00 \\
\hline \multirow{9}{*}{18} & $89,12 \%$ & 9,00 & \multirow{9}{*}{6,62} & \multirow{9}{*}{ 1,07E-06 } & \multirow{9}{*}{195,00} & 36,62 & 36,06 & 1,02 \\
\hline & $76,51 \%$ & 8,40 & & & & 37,91 & 37,75 & 1,00 \\
\hline & $66,00 \%$ & 7,90 & & & & 39,09 & 38,92 & 1,00 \\
\hline & $59,70 \%$ & 7,60 & & & & 39,85 & 39,81 & 1,00 \\
\hline & $50,24 \%$ & 7,15 & & & & 41,09 & 40,97 & 1,00 \\
\hline & $42,47 \%$ & 6,78 & & & & 42,19 & 41,96 & 1,01 \\
\hline & $38,68 \%$ & 6,60 & & & & 42,76 & 42,39 & 1,01 \\
\hline & $32,38 \%$ & 6,30 & & & & 43,77 & 43,69 & 1,00 \\
\hline & $26,08 \%$ & 6,00 & & & & 44,85 & 44,85 & 1,00 \\
\hline \multirow{7}{*}{19} & $73,69 \%$ & 7,90 & \multirow{7}{*}{7,96} & \multirow{7}{*}{ 1,07E-06 } & \multirow{7}{*}{197,50} & 42,10 & 42,13 & 1,00 \\
\hline & $61,60 \%$ & 7,35 & & & & 43,65 & 43,87 & 0,99 \\
\hline & $49,51 \%$ & 6,80 & & & & 45,38 & 45,40 & 1,00 \\
\hline & $39,61 \%$ & 6,35 & & & & 46,96 & 47,01 & 1,00 \\
\hline & $34,12 \%$ & 6,10 & & & & 47,91 & 47,73 & 1,00 \\
\hline & $29,72 \%$ & 5,90 & & & & 48,70 & 48,49 & 1,00 \\
\hline & $26,42 \%$ & 5,75 & & & & 49,33 & 49,33 & 1,00 \\
\hline \multirow{10}{*}{20} & $113,32 \%$ & 10,30 & \multirow{10}{*}{10,97} & \multirow{10}{*}{ 1,07E-06 } & \multirow{10}{*}{196,80} & 43,59 & 44,07 & 0,99 \\
\hline & $96,75 \%$ & 9,50 & & & & 45,39 & 45,67 & 0,99 \\
\hline & $87,43 \%$ & 9,05 & & & & 46,51 & 46,43 & 1,00 \\
\hline & $80,18 \%$ & 8,70 & & & & 47,43 & 47,23 & 1,00 \\
\hline & $63,62 \%$ & 7,90 & & & & 49,78 & 49,07 & 1,01 \\
\hline & $49,12 \%$ & 7,20 & & & & 52,14 & 51,24 & 1,02 \\
\hline & $47,05 \%$ & 7,10 & & & & 52,51 & 51,58 & 1,02 \\
\hline & $42,91 \%$ & 6,90 & & & & 53,26 & 52,41 & 1,02 \\
\hline & $34,62 \%$ & 6,50 & & & & 54,88 & 54,52 & 1,01 \\
\hline & $25,30 \%$ & 6,05 & & & & 56,88 & 56,88 & 1,00 \\
\hline
\end{tabular}

A Figura 5.9 mostra o diagrama de dispersão entre as frequências experimental e teórica na qual observa-se uma forte correlação entre os dados.

Analisando a Tabela 5.22 e a Figura 5.9 pode-se constatar que o módulo de elasticidade na flexão bem como as dimensões das vigas não sofrem alterações significativas para teores de umidade acima do ponto de saturação podendo ser admitidos como constantes para teores de umidade acima de $25 \%$. 


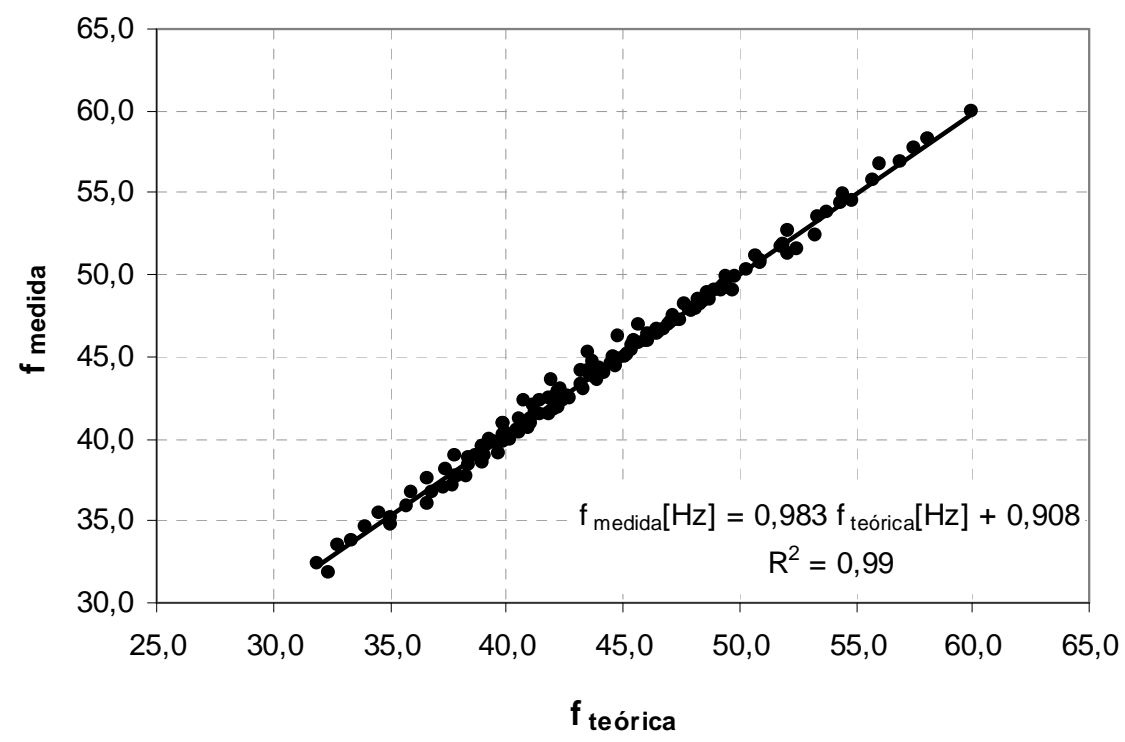

Figura 5.9 - Diagrama de dispersão entre $\mathrm{f}_{\text {teórica }}$ e $\mathrm{f}_{\text {medida }}$ para $\mathrm{u}>25 \%$.

Pode-se chegar à mesma conclusão de outra forma. O módulo de elasticidade na flexão das vigas de Pinus $s p$ pode ser determinado pela Equação 5.5

$$
E_{M, V T}=\frac{f^{2} * M * L^{3}}{12,679 * I}
$$

Sendo

$$
\begin{aligned}
& f=\text { frequência do primeiro modo de flexão }(\mathrm{Hz}) \\
& M=\text { massa da viga }(\mathrm{kg}) \\
& L=\text { comprimento }(\mathrm{m}) \\
& I=\text { momento de inércia }(\mathrm{I})
\end{aligned}
$$

Admitindo-se desprezível a variação das dimensões e o módulo de elasticidade para teores de umidade superiores a $25 \%$, pode-se escrever $f^{2} M=k^{\prime}$, sendo $k^{\prime}$ uma constante dada pela Equação 5.6.

$$
k^{\prime}=\frac{12,679 * E_{M, V T} * I}{L^{3}}
$$

Analisando os dados dos ensaios observa-se que, de fato, para teores de umidade acima de $25 \%$ a relação $f^{2} M$ permanece aproximadamente constante, ou seja, apesar da frequência aumentar a massa decresce rapidamente pela perda da água livre. O fato de $f^{2} M$ ficar constante indica que as três propriedades envolvidas no cálculo de $k$ ' permaneceram constantes, ou seja, o módulo de elasticidade bem como as dimensões das vigas não se alteraram significativamente para teores de umidade acima de $25 \%$. 


\subsubsection{Determinação do módulo de elasticidade dinâmico a $12 \%$ de umidade}

Foram testados dois métodos de correção do módulo de elasticidade sendo: equação dada pela norma NBR 7190 (ABNT, 1997) no item 6.2.1 e o modelo de Unterwieser \& Schickhofer (2010). A Tabela 5.23 mostra o cálculo do módulo de elasticidade dinâmico das vigas de Pinus sp no teor de umidade de $12 \%\left(\mathrm{E}_{\mathrm{M}, \mathrm{VT}, 12 \%}\right)$. Foi calculada ainda a diferença percentual (resíduo) entre $\mathrm{E}_{\mathrm{M}, \mathrm{VT}, 12 \%}$ e $\mathrm{E}_{\mathrm{M}, \mathrm{Stat}, 12 \% \text {. }}$

Tabela 5.23 - Estimativa de $\mathrm{E}_{\mathrm{M}, \mathrm{VT}, 12 \% \text {. }}$

\begin{tabular}{|c|c|c|c|c|c|c|c|}
\hline \multirow[b]{2}{*}{ Viga } & \multirow[b]{2}{*}{$\begin{array}{c}\mathrm{E}_{\mathrm{M}, \mathrm{Stat}, \mathbf{1 2} \%} \\
\text { (GPa) }\end{array}$} & \multirow[b]{2}{*}{$\mathbf{U}$} & \multirow[b]{2}{*}{$\begin{array}{c}\mathrm{E}_{\mathrm{M}, \mathrm{vT}, \mathrm{u} \%} \\
(\mathrm{GPa})\end{array}$} & \multicolumn{2}{|c|}{$\mathrm{E}_{\mathrm{M}, \mathrm{VT}, 12 \%}(\mathrm{GPa})$} & \multicolumn{2}{|c|}{ Resíduo } \\
\hline & & & & $\begin{array}{c}\text { Unterwieser \& } \\
\text { Schickhofer } \\
\text { (2010) }\end{array}$ & $\begin{array}{c}\text { NBR } 7190 \\
(1997)\end{array}$ & $\begin{array}{c}\text { Unterwieser \& } \\
\text { Schickhofer } \\
\text { (2010) }\end{array}$ & $\begin{array}{l}\text { NBR } 7190 \\
\quad(1997)\end{array}$ \\
\hline \multirow{16}{*}{1} & \multirow{16}{*}{8,02} & $65,7 \%$ & 6,56 & 7,55 & 7,61 & $-5,9 \%$ & $-5,1 \%$ \\
\hline & & $53,2 \%$ & 6,65 & 7,64 & 7,71 & $-4,7 \%$ & $-3,9 \%$ \\
\hline & & $42,8 \%$ & 6,65 & 7,64 & 7,71 & $-4,7 \%$ & $-3,9 \%$ \\
\hline & & $30,3 \%$ & 6,73 & 7,74 & 7,81 & $-3,4 \%$ & $-2,6 \%$ \\
\hline & & $27,2 \%$ & 6,96 & 8,01 & 8,08 & $-0,1 \%$ & $0,7 \%$ \\
\hline & & $24,0 \%$ & 7,00 & 7,01 & 8,12 & $-12,6 \%$ & $1,3 \%$ \\
\hline & & $22,0 \%$ & 7,16 & 7,16 & 8,30 & $-10,7 \%$ & $3,5 \%$ \\
\hline & & $19,9 \%$ & 7,23 & 7,24 & 8,37 & $-9,7 \%$ & $4,4 \%$ \\
\hline & & $18,8 \%$ & 7,37 & 7,37 & 8,37 & $-8,1 \%$ & $4,4 \%$ \\
\hline & & $17,8 \%$ & 7,58 & 7,59 & 8,46 & $-5,4 \%$ & $5,5 \%$ \\
\hline & & $16,7 \%$ & 7,80 & 7,80 & 8,54 & $-2,7 \%$ & $6,4 \%$ \\
\hline & & $15,7 \%$ & 7,91 & 7,92 & 8,50 & $-1,3 \%$ & $6,0 \%$ \\
\hline & & $14,7 \%$ & 8,10 & 8,10 & 8,53 & $1,0 \%$ & $6,4 \%$ \\
\hline & & $12,6 \%$ & 8,12 & 8,12 & 8,21 & $1,2 \%$ & $2,4 \%$ \\
\hline & & $11,5 \%$ & 8,59 & 8,59 & 8,51 & $7,1 \%$ & $6,1 \%$ \\
\hline & & $10,5 \%$ & 9,09 & 9,09 & 8,81 & $13,3 \%$ & $9,9 \%$ \\
\hline \multirow{16}{*}{2} & \multirow{16}{*}{7,28} & $101,2 \%$ & 6,92 & 7,96 & 8,03 & $9,3 \%$ & $10,3 \%$ \\
\hline & & $88,6 \%$ & 6,98 & 8,03 & 8,10 & $10,3 \%$ & $11,2 \%$ \\
\hline & & $74,8 \%$ & 6,89 & 7,92 & 7,99 & $8,8 \%$ & $9,8 \%$ \\
\hline & & $64,4 \%$ & 6,76 & 7,78 & 7,84 & $6,8 \%$ & $7,8 \%$ \\
\hline & & $58,7 \%$ & 6,72 & 7,73 & 7,80 & $6,2 \%$ & $7,1 \%$ \\
\hline & & $48,3 \%$ & 6,58 & 7,57 & 7,64 & $4,0 \%$ & $4,9 \%$ \\
\hline & & $40,3 \%$ & 6,63 & 7,63 & 7,70 & $4,8 \%$ & $5,7 \%$ \\
\hline & & $32,2 \%$ & 6,71 & 7,71 & 7,78 & $5,9 \%$ & $6,9 \%$ \\
\hline & & $24,2 \%$ & 6,89 & 6,90 & 7,99 & $-5,3 \%$ & $9,8 \%$ \\
\hline & & $20,7 \%$ & 7,06 & 7,06 & 8,19 & $-3,0 \%$ & $12,5 \%$ \\
\hline & & $19,6 \%$ & 7,01 & 7,02 & 8,08 & $-3,6 \%$ & $11,0 \%$ \\
\hline & & $17,3 \%$ & 7,53 & 7,53 & 8,32 & $3,5 \%$ & $14,3 \%$ \\
\hline & & $16,1 \%$ & 7,76 & 7,77 & 8,40 & $6,7 \%$ & $15,4 \%$ \\
\hline & & $15,0 \%$ & 7,41 & 7,41 & 7,85 & $1,8 \%$ & $7,9 \%$ \\
\hline & & $12,7 \%$ & 7,57 & 7,57 & 7,67 & $4,0 \%$ & $5,4 \%$ \\
\hline & & $11,5 \%$ & 7,75 & 7,75 & 7,68 & $6,4 \%$ & $5,4 \%$ \\
\hline
\end{tabular}

Continua na próxima página. 
Continuação da Tabela 5.23.

\begin{tabular}{|c|c|c|c|c|c|c|c|}
\hline \multirow[b]{2}{*}{ Viga } & \multirow[b]{2}{*}{$\begin{array}{c}\mathrm{E}_{\mathrm{M}, \mathrm{Stat}, \mathbf{1 2} \%} \\
\text { (GPa) }\end{array}$} & \multirow[b]{2}{*}{$\mathbf{U}$} & \multirow[b]{2}{*}{$\begin{array}{c}E_{M, V T, u \%} \\
\text { (GPa) }\end{array}$} & \multicolumn{2}{|c|}{$E_{M, V T, 12 \%}(G P a)$} & \multicolumn{2}{|c|}{ Resíduo } \\
\hline & & & & $\begin{array}{c}\text { Unterwieser \& } \\
\text { Schickhofer } \\
(2010)\end{array}$ & $\begin{array}{c}\text { NBR } 7190 \\
(1997)\end{array}$ & $\begin{array}{c}\text { Unterwieser \& } \\
\text { Schickhofer } \\
(2010)\end{array}$ & $\begin{array}{c}\text { NBR } 7190 \\
(1997)\end{array}$ \\
\hline \multirow{17}{*}{3} & \multirow{17}{*}{8,82} & $114,8 \%$ & 7,94 & 9,13 & 9,21 & $3,5 \%$ & $4,4 \%$ \\
\hline & & $98,4 \%$ & 7,96 & 9,15 & 9,23 & $3,7 \%$ & $4,6 \%$ \\
\hline & & $78,6 \%$ & 7,91 & 9,09 & 9,17 & $3,1 \%$ & $4,0 \%$ \\
\hline & & $63,4 \%$ & 7,72 & 8,87 & 8,95 & $0,6 \%$ & $1,5 \%$ \\
\hline & & $55,2 \%$ & 7,58 & 8,71 & 8,79 & $-1,2 \%$ & $-0,3 \%$ \\
\hline & & $44,7 \%$ & 7,77 & 8,93 & 9,01 & $1,3 \%$ & $2,2 \%$ \\
\hline & & $36,6 \%$ & 7,56 & 8,70 & 8,77 & $-1,4 \%$ & $-0,6 \%$ \\
\hline & & $29,6 \%$ & 7,68 & 8,83 & 8,91 & $0,1 \%$ & $1,0 \%$ \\
\hline & & $24,9 \%$ & 7,93 & 7,94 & 9,20 & $-9,9 \%$ & $4,3 \%$ \\
\hline & & $21,4 \%$ & 8,07 & 8,07 & 9,36 & $-8,5 \%$ & $6,1 \%$ \\
\hline & & $20,2 \%$ & 8,25 & 8,26 & 9,57 & $-6,4 \%$ & $8,5 \%$ \\
\hline & & $17,9 \%$ & 8,34 & 8,34 & 9,32 & $-5,4 \%$ & $5,7 \%$ \\
\hline & & $16,7 \%$ & 8,51 & 8,51 & 9,31 & $-3,5 \%$ & $5,6 \%$ \\
\hline & & $16,7 \%$ & 8,65 & 8,66 & 9,47 & $-1,9 \%$ & $7,4 \%$ \\
\hline & & $13,2 \%$ & 8,90 & 8,90 & 9,12 & $0,9 \%$ & $3,3 \%$ \\
\hline & & $12,1 \%$ & 8,92 & 8,92 & 8,93 & $1,1 \%$ & $1,2 \%$ \\
\hline & & $10,9 \%$ & 9,41 & 9,41 & 9,20 & $6,7 \%$ & $4,3 \%$ \\
\hline \multirow{17}{*}{4} & \multirow{17}{*}{13,57} & $52,4 \%$ & 12,43 & 14,30 & 14,42 & $5,4 \%$ & $6,3 \%$ \\
\hline & & $44,2 \%$ & 12,63 & 14,52 & 14,65 & $7,0 \%$ & $7,9 \%$ \\
\hline & & $37,0 \%$ & 12,61 & 14,50 & 14,63 & $6,9 \%$ & $7,8 \%$ \\
\hline & & $34,0 \%$ & 12,61 & 14,51 & 14,63 & $6,9 \%$ & $7,8 \%$ \\
\hline & & $25,8 \%$ & 12,56 & 14,45 & 14,58 & $6,5 \%$ & $7,4 \%$ \\
\hline & & $24,8 \%$ & 12,66 & 12,67 & 14,68 & $-6,6 \%$ & $8,2 \%$ \\
\hline & & $21,7 \%$ & 13,05 & 13,07 & 15,14 & $-3,7 \%$ & $11,6 \%$ \\
\hline & & $20,7 \%$ & 12,82 & 12,83 & 14,88 & $-5,4 \%$ & $9,6 \%$ \\
\hline & & $20,7 \%$ & 13,22 & 13,23 & 15,33 & $-2,5 \%$ & $13,0 \%$ \\
\hline & & $18,6 \%$ & 12,92 & 12,93 & 14,64 & $-4,7 \%$ & $7,9 \%$ \\
\hline & & $17,6 \%$ & 13,36 & 13,36 & 14,86 & $-1,5 \%$ & $9,5 \%$ \\
\hline & & $16,6 \%$ & 13,60 & 13,60 & 14,85 & $0,2 \%$ & $9,4 \%$ \\
\hline & & $15,6 \%$ & 13,90 & 13,90 & 14,89 & $2,5 \%$ & $9,7 \%$ \\
\hline & & $14,5 \%$ & 13,88 & 13,88 & 14,59 & $2,3 \%$ & $7,5 \%$ \\
\hline & & $12,5 \%$ & 14,35 & 14,35 & 14,50 & $5,8 \%$ & $6,8 \%$ \\
\hline & & $11,5 \%$ & 13,81 & 13,81 & 13,67 & $1,8 \%$ & $0,7 \%$ \\
\hline & & $9,4 \%$ & 13,91 & 13,91 & 13,20 & $2,5 \%$ & $-2,7 \%$ \\
\hline \multirow{17}{*}{5} & \multirow{17}{*}{9,70} & $83,2 \%$ & 8,88 & 10,21 & 10,30 & $5,2 \%$ & $6,1 \%$ \\
\hline & & $68,9 \%$ & 8,84 & 10,16 & 10,25 & $4,8 \%$ & $5,7 \%$ \\
\hline & & $48,4 \%$ & 8,80 & 10,12 & 10,21 & $4,3 \%$ & $5,3 \%$ \\
\hline & & $38,2 \%$ & 8,60 & 9,89 & 9,97 & $1,9 \%$ & $2,8 \%$ \\
\hline & & $32,0 \%$ & 8,72 & 10,02 & 10,11 & $3,3 \%$ & $4,2 \%$ \\
\hline & & $28,9 \%$ & 8,80 & 10,12 & 10,21 & $4,3 \%$ & $5,2 \%$ \\
\hline & & $23,8 \%$ & 8,72 & 8,72 & 10,11 & $-10,1 \%$ & $4,2 \%$ \\
\hline & & $21,8 \%$ & 9,09 & 9,09 & 10,54 & $-6,2 \%$ & $8,7 \%$ \\
\hline & & $19,7 \%$ & 9,03 & 9,03 & 10,42 & $-6,9 \%$ & $7,5 \%$ \\
\hline & & $19,7 \%$ & 9,40 & 9,41 & 10,85 & $-3,0 \%$ & $11,9 \%$ \\
\hline & & $17,7 \%$ & 9,25 & 9,25 & 10,30 & $-4,6 \%$ & $6,2 \%$ \\
\hline & & $16,7 \%$ & 9,81 & 9,82 & 10,73 & $1,2 \%$ & $10,6 \%$ \\
\hline & & $16,7 \%$ & 9,48 & 9,49 & 10,37 & $-2,2 \%$ & $6,9 \%$ \\
\hline & & $15,6 \%$ & 9,98 & 9,99 & 10,71 & $2,9 \%$ & $10,4 \%$ \\
\hline & & $13,6 \%$ & 10,26 & 10,26 & 10,59 & $5,8 \%$ & $9,1 \%$ \\
\hline & & $11,5 \%$ & 9,79 & 9,79 & 9,70 & $0,9 \%$ & $0,0 \%$ \\
\hline & & $10,5 \%$ & 10,00 & 10,00 & 9,71 & $3,1 \%$ & $0,1 \%$ \\
\hline
\end{tabular}


Continuação da Tabela 5.23.

\begin{tabular}{|c|c|c|c|c|c|c|c|}
\hline \multirow[b]{2}{*}{ Viga } & \multirow[b]{2}{*}{$\begin{array}{c}\mathrm{E}_{\mathrm{M}, \mathrm{Stat}, 12 \%} \\
\text { (GPa) }\end{array}$} & \multirow[b]{2}{*}{$\mathbf{U}$} & \multirow[b]{2}{*}{$\begin{array}{c}\mathrm{E}_{\mathrm{M}, \mathrm{VT}, \mathrm{u} \%} \\
\text { (GPa) }\end{array}$} & \multicolumn{2}{|c|}{$E_{M, V T, 12 \%}(G P a)$} & \multicolumn{2}{|c|}{ Resíduo } \\
\hline & & & & $\begin{array}{c}\text { Unterwieser \& } \\
\text { Schickhofer } \\
\text { (2010) }\end{array}$ & $\begin{array}{c}\text { NBR } 7190 \\
(1997)\end{array}$ & $\begin{array}{c}\text { Unterwieser \& } \\
\text { Schickhofer } \\
\text { (2010) }\end{array}$ & $\begin{array}{c}\text { NBR } 7190 \\
(1997)\end{array}$ \\
\hline \multirow{17}{*}{6} & \multirow{17}{*}{8,93} & $93,8 \%$ & 8,17 & 9,39 & 9,47 & $5,2 \%$ & $6,1 \%$ \\
\hline & & $87,8 \%$ & 8,33 & 9,58 & 9,66 & $7,3 \%$ & $8,2 \%$ \\
\hline & & $78,8 \%$ & 8,26 & 9,50 & 9,58 & $6,4 \%$ & $7,3 \%$ \\
\hline & & $73,8 \%$ & 8,15 & 9,37 & 9,45 & $5,0 \%$ & $5,9 \%$ \\
\hline & & $62,8 \%$ & 8,05 & 9,26 & 9,34 & $3,7 \%$ & $4,6 \%$ \\
\hline & & $51,9 \%$ & 8,17 & 9,40 & 9,48 & $5,2 \%$ & $6,1 \%$ \\
\hline & & $46,9 \%$ & 8,26 & 9,49 & 9,58 & $6,3 \%$ & $7,2 \%$ \\
\hline & & $37,9 \%$ & 8,05 & 9,25 & 9,33 & $3,6 \%$ & $4,5 \%$ \\
\hline & & $27,9 \%$ & 8,32 & 9,57 & 9,66 & $7,2 \%$ & $8,1 \%$ \\
\hline & & $22,9 \%$ & 8,52 & 8,53 & 9,89 & $-4,4 \%$ & $10,7 \%$ \\
\hline & & $19,9 \%$ & 8,57 & 8,57 & 9,92 & $-4,0 \%$ & $11,1 \%$ \\
\hline & & $17,9 \%$ & 8,78 & 8,78 & 9,81 & $-1,7 \%$ & $9,8 \%$ \\
\hline & & $16,9 \%$ & 9,03 & 9,04 & 9,92 & $1,2 \%$ & $11,1 \%$ \\
\hline & & $15,9 \%$ & 9,36 & 9,36 & 10,08 & $4,8 \%$ & $12,9 \%$ \\
\hline & & $14,9 \%$ & 9,17 & 9,17 & 9,70 & $2,7 \%$ & $8,6 \%$ \\
\hline & & $12,9 \%$ & 9,57 & 9,57 & 9,74 & $7,2 \%$ & $9,1 \%$ \\
\hline & & $11,9 \%$ & 9,80 & 9,80 & 9,78 & $9,8 \%$ & $9,5 \%$ \\
\hline \multirow{16}{*}{7} & \multirow{16}{*}{9,98} & $120,0 \%$ & 8,62 & 9,92 & 10,00 & $-0,6 \%$ & $0,2 \%$ \\
\hline & & $106,9 \%$ & 8,89 & 10,22 & 10,31 & $2,4 \%$ & $3,3 \%$ \\
\hline & & $91,6 \%$ & 8,96 & 10,31 & 10,40 & $3,3 \%$ & $4,2 \%$ \\
\hline & & $65,3 \%$ & 8,74 & 10,05 & 10,14 & $0,7 \%$ & $1,6 \%$ \\
\hline & & $53,3 \%$ & 8,57 & 9,86 & 9,94 & $-1,2 \%$ & $-0,4 \%$ \\
\hline & & $40,1 \%$ & 8,50 & 9,78 & 9,86 & $-2,1 \%$ & $-1,2 \%$ \\
\hline & & $27,0 \%$ & 8,68 & 9,98 & 10,07 & $0,0 \%$ & $0,9 \%$ \\
\hline & & $21,5 \%$ & 8,85 & 8,85 & 10,26 & $-11,3 \%$ & $2,8 \%$ \\
\hline & & $19,3 \%$ & 9,22 & 9,23 & 10,57 & $-7,5 \%$ & $5,9 \%$ \\
\hline & & $18,2 \%$ & 9,43 & 9,43 & 10,60 & $-5,5 \%$ & $6,2 \%$ \\
\hline & & $17,1 \%$ & 9,64 & 9,65 & 10,63 & $-3,3 \%$ & $6,5 \%$ \\
\hline & & $16,0 \%$ & 9,66 & 9,66 & 10,44 & $-3,2 \%$ & $4,6 \%$ \\
\hline & & $13,9 \%$ & 10,22 & 10,22 & 10,60 & $2,4 \%$ & $6,2 \%$ \\
\hline & & $12,8 \%$ & 9,78 & 9,78 & 9,93 & $-2,0 \%$ & $-0,5 \%$ \\
\hline & & $11,7 \%$ & 9,76 & 9,76 & 9,69 & $-2,2 \%$ & $-2,9 \%$ \\
\hline & & $10,6 \%$ & 10,63 & 10,63 & 10,32 & $6,5 \%$ & $3,4 \%$ \\
\hline \multirow{17}{*}{8} & \multirow{17}{*}{11,06} & $126,6 \%$ & 10,05 & 11,55 & 11,66 & $4,5 \%$ & $5,4 \%$ \\
\hline & & $96,9 \%$ & 9,63 & 11,08 & 11,18 & $0,2 \%$ & $1,0 \%$ \\
\hline & & $82,6 \%$ & 9,48 & 10,91 & 11,00 & $-1,4 \%$ & $-0,5 \%$ \\
\hline & & $61,7 \%$ & 9,38 & 10,79 & 10,88 & $-2,5 \%$ & $-1,6 \%$ \\
\hline & & $57,3 \%$ & 9,36 & 10,76 & 10,85 & $-2,7 \%$ & $-1,9 \%$ \\
\hline & & $40,8 \%$ & 9,31 & 10,71 & 10,80 & $-3,2 \%$ & $-2,4 \%$ \\
\hline & & $27,6 \%$ & 9,42 & 10,84 & 10,93 & $-2,0 \%$ & $-1,2 \%$ \\
\hline & & $23,2 \%$ & 9,66 & 9,67 & 11,21 & $-12,5 \%$ & $1,4 \%$ \\
\hline & & $21,0 \%$ & 9,86 & 9,87 & 11,44 & $-10,8 \%$ & $3,4 \%$ \\
\hline & & $18,8 \%$ & 10,06 & 10,07 & 11,43 & $-9,0 \%$ & $3,3 \%$ \\
\hline & & $17,7 \%$ & 10,39 & 10,39 & 11,57 & $-6,1 \%$ & $4,6 \%$ \\
\hline & & $17,7 \%$ & 10,43 & 10,43 & 11,62 & $-5,7 \%$ & $5,0 \%$ \\
\hline & & $16,6 \%$ & 10,41 & 10,42 & 11,37 & $-5,8 \%$ & $2,8 \%$ \\
\hline & & $14,4 \%$ & 10,67 & 10,68 & 11,19 & $-3,5 \%$ & $1,1 \%$ \\
\hline & & $13,3 \%$ & 10,86 & 10,86 & 11,14 & $-1,8 \%$ & $0,7 \%$ \\
\hline & & $11,1 \%$ & 11,52 & 11,52 & 11,31 & $4,1 \%$ & $2,3 \%$ \\
\hline & & $10,0 \%$ & 11,35 & 11,35 & 10,90 & $2,6 \%$ & $-1,5 \%$ \\
\hline
\end{tabular}


Continuação da Tabela 5.23.

\begin{tabular}{|c|c|c|c|c|c|c|c|}
\hline \multirow[b]{2}{*}{ Viga } & \multirow[b]{2}{*}{$\begin{array}{c}\mathrm{E}_{\mathrm{M}, \mathrm{Stat}, \mathbf{1 2} \%} \\
\text { (GPa) }\end{array}$} & \multirow[b]{2}{*}{$\mathbf{U}$} & \multirow[b]{2}{*}{$\begin{array}{c}\mathrm{E}_{\mathrm{M}, \mathrm{VT}, \mathrm{u} \%} \\
\text { (GPa) }\end{array}$} & \multicolumn{2}{|c|}{$\mathrm{E}_{\mathrm{M}, \mathrm{VT}, 12 \%}(\mathrm{GPa})$} & \multicolumn{2}{|c|}{ Resíduo } \\
\hline & & & & $\begin{array}{c}\text { Unterwieser \& } \\
\text { Schickhofer } \\
\text { (2010) }\end{array}$ & $\begin{array}{c}\text { NBR } 7190 \\
(1997)\end{array}$ & $\begin{array}{c}\text { Unterwieser \& } \\
\text { Schickhofer } \\
(2010)\end{array}$ & $\begin{array}{c}\text { NBR } 7190 \\
(1997)\end{array}$ \\
\hline \multirow{15}{*}{9} & \multirow{15}{*}{8,42} & $89,6 \%$ & 8,25 & 9,49 & 9,57 & $12,7 \%$ & $13,7 \%$ \\
\hline & & $78,1 \%$ & 8,44 & 9,70 & 9,79 & $15,2 \%$ & $16,2 \%$ \\
\hline & & $68,6 \%$ & 8,12 & 9,34 & 9,42 & $10,9 \%$ & $11,9 \%$ \\
\hline & & $44,3 \%$ & 8,14 & 9,36 & 9,44 & $11,2 \%$ & $12,2 \%$ \\
\hline & & $42,2 \%$ & 8,03 & 9,23 & 9,31 & $9,6 \%$ & $10,6 \%$ \\
\hline & & $34,9 \%$ & 8,07 & 9,28 & 9,37 & $10,3 \%$ & $11,2 \%$ \\
\hline & & $27,5 \%$ & 8,08 & 9,29 & 9,37 & $10,3 \%$ & $11,3 \%$ \\
\hline & & $22,2 \%$ & 8,23 & 8,23 & 9,54 & $-2,2 \%$ & $13,3 \%$ \\
\hline & & $20,1 \%$ & 8,22 & 8,23 & 9,54 & $-2,3 \%$ & $13,3 \%$ \\
\hline & & $18,0 \%$ & 8,49 & 8,49 & 9,51 & $0,9 \%$ & $12,9 \%$ \\
\hline & & $15,9 \%$ & 8,63 & 8,63 & 9,30 & $2,5 \%$ & $10,5 \%$ \\
\hline & & $15,9 \%$ & 8,70 & 8,70 & 9,38 & $3,4 \%$ & $11,4 \%$ \\
\hline & & $14,8 \%$ & 9,06 & 9,06 & 9,58 & $7,7 \%$ & $13,7 \%$ \\
\hline & & $12,7 \%$ & 8,94 & 8,95 & 9,08 & $6,2 \%$ & $7,8 \%$ \\
\hline & & $11,7 \%$ & 9,13 & 9,13 & 9,07 & $8,4 \%$ & $7,7 \%$ \\
\hline \multirow{16}{*}{10} & \multirow{16}{*}{8,54} & $96,7 \%$ & 8,07 & 9,28 & 9,36 & $8,6 \%$ & $9,6 \%$ \\
\hline & & $67,6 \%$ & 7,96 & 9,16 & 9,24 & $7,3 \%$ & $8,2 \%$ \\
\hline & & $40,8 \%$ & 7,81 & 8,98 & 9,06 & $5,2 \%$ & $6,1 \%$ \\
\hline & & $29,2 \%$ & 7,57 & 8,70 & 8,78 & $1,9 \%$ & $2,8 \%$ \\
\hline & & $24,6 \%$ & 7,63 & 7,64 & 8,85 & $-10,5 \%$ & $3,7 \%$ \\
\hline & & $23,4 \%$ & 7,85 & 7,86 & 9,11 & $-7,9 \%$ & $6,7 \%$ \\
\hline & & $22,2 \%$ & 7,82 & 7,83 & 9,07 & $-8,4 \%$ & $6,2 \%$ \\
\hline & & $21,1 \%$ & 8,09 & 8,09 & 9,38 & $-5,2 \%$ & $9,8 \%$ \\
\hline & & $18,7 \%$ & 8,24 & 8,24 & 9,35 & $-3,5 \%$ & $9,5 \%$ \\
\hline & & $17,6 \%$ & 8,22 & 8,23 & 9,14 & $-3,7 \%$ & $7,0 \%$ \\
\hline & & $16,4 \%$ & 8,56 & 8,56 & 9,31 & $0,2 \%$ & $9,0 \%$ \\
\hline & & $15,2 \%$ & 8,47 & 8,47 & 9,01 & $-0,8 \%$ & $5,6 \%$ \\
\hline & & $15,2 \%$ & 8,51 & 8,51 & 9,06 & $-0,3 \%$ & $6,1 \%$ \\
\hline & & $14,1 \%$ & 8,50 & 8,51 & 8,86 & $-0,4 \%$ & $3,7 \%$ \\
\hline & & $12,9 \%$ & 8,67 & 8,67 & 8,83 & $1,5 \%$ & $3,4 \%$ \\
\hline & & $11,7 \%$ & 9,27 & 9,27 & 9,23 & $8,6 \%$ & $8,0 \%$ \\
\hline \multirow{20}{*}{11} & \multirow{20}{*}{10,64} & $65,5 \%$ & 9,77 & 11,23 & 11,33 & $5,6 \%$ & $6,5 \%$ \\
\hline & & $59,9 \%$ & 9,83 & 11,30 & 11,40 & $6,2 \%$ & $7,1 \%$ \\
\hline & & $52,0 \%$ & 9,83 & 11,30 & 11,40 & $6,2 \%$ & $7,1 \%$ \\
\hline & & $44,1 \%$ & 9,86 & 11,34 & 11,44 & $6,6 \%$ & $7,5 \%$ \\
\hline & & $37,4 \%$ & 9,78 & 11,25 & 11,34 & $5,7 \%$ & $6,6 \%$ \\
\hline & & $26,1 \%$ & 9,72 & 11,18 & 11,28 & $5,1 \%$ & $6,0 \%$ \\
\hline & & $25,0 \%$ & 9,88 & 9,89 & 11,46 & $-7,1 \%$ & $7,7 \%$ \\
\hline & & $23,8 \%$ & 9,86 & 9,87 & 11,43 & $-7,3 \%$ & $7,5 \%$ \\
\hline & & $22,7 \%$ & 9,94 & 9,95 & 11,53 & $-6,5 \%$ & $8,4 \%$ \\
\hline & & $20,5 \%$ & 10,25 & 10,26 & 11,89 & $-3,6 \%$ & $11,7 \%$ \\
\hline & & $19,3 \%$ & 10,06 & 10,06 & 11,53 & $-5,4 \%$ & $8,4 \%$ \\
\hline & & $18,2 \%$ & 10,67 & 10,67 & 11,99 & $0,3 \%$ & $12,7 \%$ \\
\hline & & $16,0 \%$ & 10,40 & 10,40 & 11,22 & $-2,3 \%$ & $5,5 \%$ \\
\hline & & $16,0 \%$ & 10,36 & 10,36 & 11,18 & $-2,6 \%$ & $5,1 \%$ \\
\hline & & $14,8 \%$ & 10,56 & 10,56 & 11,16 & $-0,7 \%$ & $4,9 \%$ \\
\hline & & $13,7 \%$ & 10,68 & 10,68 & 11,04 & $0,4 \%$ & $3,8 \%$ \\
\hline & & $11,5 \%$ & 10,71 & 10,71 & 10,60 & $0,7 \%$ & $-0,4 \%$ \\
\hline & & $10,3 \%$ & 12,04 & 12,03 & 11,64 & $13,1 \%$ & $9,4 \%$ \\
\hline & & $9,2 \%$ & 12,14 & 12,13 & 11,46 & $14,0 \%$ & $7,7 \%$ \\
\hline & & $12,6 \%$ & 11,70 & 11,70 & 11,84 & $10,0 \%$ & $11,3 \%$ \\
\hline
\end{tabular}


Continuação da Tabela 5.23.

\begin{tabular}{|c|c|c|c|c|c|c|c|}
\hline \multirow[b]{2}{*}{ Viga } & \multirow[b]{2}{*}{$\begin{array}{c}\mathrm{E}_{\mathrm{M}, \mathrm{Stat}, 12 \%} \\
(\mathrm{GPa})\end{array}$} & \multirow[b]{2}{*}{$\mathbf{U}$} & \multirow[b]{2}{*}{$\begin{array}{c}\mathrm{E}_{\mathrm{M}, \mathrm{VT}, \mathrm{u} \%} \\
\text { (GPa) }\end{array}$} & \multicolumn{2}{|c|}{$E_{M, V T, 12 \%}(G P a)$} & \multicolumn{2}{|c|}{ Resíduo } \\
\hline & & & & $\begin{array}{c}\text { Unterwieser \& } \\
\text { Schickhofer } \\
\text { (2010) }\end{array}$ & $\begin{array}{c}\text { NBR } 7190 \\
(1997)\end{array}$ & $\begin{array}{c}\text { Unterwieser \& } \\
\text { Schickhofer } \\
(2010)\end{array}$ & $\begin{array}{c}\text { NBR } 7190 \\
(1997)\end{array}$ \\
\hline \multirow{16}{*}{12} & \multirow{16}{*}{5,15} & $100,4 \%$ & 4,69 & 5,39 & 5,44 & $4,7 \%$ & $5,6 \%$ \\
\hline & & $70,6 \%$ & 4,72 & 5,43 & 5,47 & $5,4 \%$ & $6,3 \%$ \\
\hline & & $47,9 \%$ & 4,72 & 5,43 & 5,48 & $5,5 \%$ & $6,4 \%$ \\
\hline & & $43,2 \%$ & 4,67 & 5,37 & 5,41 & $4,2 \%$ & $5,1 \%$ \\
\hline & & $33,6 \%$ & 4,76 & 5,47 & 5,52 & $6,2 \%$ & $7,1 \%$ \\
\hline & & $30,0 \%$ & 4,81 & 5,53 & 5,58 & $7,3 \%$ & $8,3 \%$ \\
\hline & & $26,5 \%$ & 4,89 & 5,62 & 5,67 & $9,1 \%$ & $10,1 \%$ \\
\hline & & $22,9 \%$ & 4,95 & 4,96 & 5,75 & $-3,7 \%$ & $11,6 \%$ \\
\hline & & $19,3 \%$ & 5,04 & 5,04 & 5,78 & $-2,1 \%$ & $12,2 \%$ \\
\hline & & $18,1 \%$ & 5,09 & 5,10 & 5,72 & $-1,1 \%$ & $11,0 \%$ \\
\hline & & $15,7 \%$ & 5,30 & 5,30 & 5,69 & $2,9 \%$ & $10,5 \%$ \\
\hline & & $15,7 \%$ & 5,47 & 5,47 & 5,88 & $6,3 \%$ & $14,2 \%$ \\
\hline & & $14,5 \%$ & 5,32 & 5,32 & 5,59 & $3,3 \%$ & $8,5 \%$ \\
\hline & & $13,3 \%$ & 5,45 & 5,45 & 5,59 & $5,8 \%$ & $8,6 \%$ \\
\hline & & $11,0 \%$ & 5,72 & 5,72 & 5,60 & $11,1 \%$ & $8,8 \%$ \\
\hline & & $9,8 \%$ & 5,59 & 5,59 & 5,34 & $8,6 \%$ & $3,8 \%$ \\
\hline \multirow{17}{*}{13} & \multirow{17}{*}{8,03} & $116,3 \%$ & 7,17 & 8,25 & 8,32 & $2,8 \%$ & $3,6 \%$ \\
\hline & & $87,8 \%$ & 7,12 & 8,18 & 8,25 & $1,9 \%$ & $2,8 \%$ \\
\hline & & $64,7 \%$ & 7,07 & 8,13 & 8,20 & $1,3 \%$ & $2,2 \%$ \\
\hline & & $58,1 \%$ & 7,00 & 8,06 & 8,13 & $0,3 \%$ & $1,2 \%$ \\
\hline & & $47,1 \%$ & 7,04 & 8,10 & 8,17 & $0,8 \%$ & $1,7 \%$ \\
\hline & & $41,6 \%$ & 7,07 & 8,13 & 8,20 & $1,3 \%$ & $2,2 \%$ \\
\hline & & $36,1 \%$ & 7,12 & 8,19 & 8,26 & $1,9 \%$ & $2,8 \%$ \\
\hline & & $27,4 \%$ & 7,20 & 8,28 & 8,35 & $3,1 \%$ & $4,0 \%$ \\
\hline & & $23,0 \%$ & 7,38 & 7,39 & 8,56 & $-8,0 \%$ & $6,6 \%$ \\
\hline & & $19,7 \%$ & 7,58 & 7,58 & 8,74 & $-5,6 \%$ & $8,8 \%$ \\
\hline & & $18,6 \%$ & 7,75 & 7,75 & 8,77 & $-3,5 \%$ & $9,2 \%$ \\
\hline & & $17,5 \%$ & 7,85 & 7,86 & 8,72 & $-2,1 \%$ & $8,5 \%$ \\
\hline & & $17,5 \%$ & 7,85 & 7,85 & 8,71 & $-2,2 \%$ & $8,5 \%$ \\
\hline & & $16,4 \%$ & 7,82 & 7,82 & 8,50 & $-2,6 \%$ & $5,9 \%$ \\
\hline & & $14,2 \%$ & 7,88 & 7,89 & 8,23 & $-1,8 \%$ & $2,5 \%$ \\
\hline & & $13,1 \%$ & 8,09 & 8,09 & 8,26 & $0,7 \%$ & $2,9 \%$ \\
\hline & & $10,9 \%$ & 8,30 & 8,29 & 8,11 & $3,3 \%$ & $1,0 \%$ \\
\hline \multirow{17}{*}{14} & \multirow{17}{*}{9,51} & $114,7 \%$ & 8,81 & 10,13 & 10,22 & $6,5 \%$ & $7,5 \%$ \\
\hline & & $82,7 \%$ & 8,73 & 10,03 & 10,12 & $5,5 \%$ & $6,4 \%$ \\
\hline & & $53,8 \%$ & 8,53 & 9,81 & 9,90 & $3,2 \%$ & $4,1 \%$ \\
\hline & & $47,4 \%$ & 8,34 & 9,59 & 9,68 & $0,9 \%$ & $1,7 \%$ \\
\hline & & $40,0 \%$ & 8,30 & 9,54 & 9,63 & $0,4 \%$ & $1,2 \%$ \\
\hline & & $33,5 \%$ & 8,47 & 9,74 & 9,82 & $2,4 \%$ & $3,3 \%$ \\
\hline & & $29,3 \%$ & 8,51 & 9,79 & 9,87 & $2,9 \%$ & $3,8 \%$ \\
\hline & & $23,9 \%$ & 8,57 & 8,58 & 9,94 & $-9,8 \%$ & $4,5 \%$ \\
\hline & & $20,7 \%$ & 8,88 & 8,89 & 10,30 & $-6,5 \%$ & $8,3 \%$ \\
\hline & & $19,7 \%$ & 8,91 & 8,92 & 10,28 & $-6,2 \%$ & $8,1 \%$ \\
\hline & & $17,5 \%$ & 9,09 & 9,09 & 10,09 & $-4,4 \%$ & $6,1 \%$ \\
\hline & & $17,5 \%$ & 9,36 & 9,36 & 10,39 & $-1,5 \%$ & $9,3 \%$ \\
\hline & & $16,5 \%$ & 9,32 & 9,32 & 10,15 & $-2,0 \%$ & $6,7 \%$ \\
\hline & & $15,4 \%$ & 9,32 & 9,33 & 9,95 & $-1,9 \%$ & $4,7 \%$ \\
\hline & & $13,3 \%$ & 9,78 & 9,78 & 10,03 & $2,9 \%$ & $5,4 \%$ \\
\hline & & $12,2 \%$ & 9,50 & 9,50 & 9,54 & $-0,1 \%$ & $0,3 \%$ \\
\hline & & $10,0 \%$ & 9,67 & 9,67 & 9,29 & $1,6 \%$ & $-2,3 \%$ \\
\hline
\end{tabular}


Continuação da Tabela 5.23.

\begin{tabular}{|c|c|c|c|c|c|c|c|}
\hline \multirow[b]{2}{*}{ Viga } & \multirow[b]{2}{*}{$\begin{array}{c}\mathrm{E}_{\mathrm{M}, \mathrm{Stat}, 12 \%} \\
(\mathrm{GPa})\end{array}$} & \multirow[b]{2}{*}{$\mathbf{U}$} & \multirow[b]{2}{*}{$\begin{array}{c}\mathrm{E}_{\mathrm{M}, \mathrm{VT}, \mathrm{u} \%} \\
\text { (GPa) }\end{array}$} & \multicolumn{2}{|c|}{$E_{M, V T, 12 \%}(G P a)$} & \multicolumn{2}{|c|}{ Resíduo } \\
\hline & & & & $\begin{array}{c}\text { Unterwieser \& } \\
\text { Schickhofer } \\
(2010)\end{array}$ & $\begin{array}{c}\text { NBR } 7190 \\
(1997)\end{array}$ & $\begin{array}{c}\text { Unterwieser \& } \\
\text { Schickhofer } \\
\text { (2010) }\end{array}$ & $\begin{array}{c}\text { NBR } 7190 \\
(1997)\end{array}$ \\
\hline \multirow{18}{*}{15} & \multirow{18}{*}{7,57} & $104,2 \%$ & 6,83 & 7,86 & 7,93 & $3,8 \%$ & $4,7 \%$ \\
\hline & & $89,6 \%$ & 6,81 & 7,83 & 7,90 & $3,5 \%$ & $4,4 \%$ \\
\hline & & $74,1 \%$ & 6,81 & 7,83 & 7,90 & $3,4 \%$ & $4,3 \%$ \\
\hline & & $60,6 \%$ & 6,67 & 7,67 & 7,73 & $1,3 \%$ & $2,1 \%$ \\
\hline & & $52,3 \%$ & 6,52 & 7,50 & 7,56 & $-1,0 \%$ & $-0,1 \%$ \\
\hline & & $42,0 \%$ & 6,47 & 7,44 & 7,50 & $-1,7 \%$ & $-0,9 \%$ \\
\hline & & $36,8 \%$ & 6,52 & 7,50 & 7,56 & $-1,0 \%$ & $-0,1 \%$ \\
\hline & & $30,6 \%$ & 6,49 & 7,47 & 7,53 & $-1,3 \%$ & $-0,5 \%$ \\
\hline & & $24,4 \%$ & 6,64 & 6,65 & 7,70 & $-12,2 \%$ & $1,7 \%$ \\
\hline & & $20,2 \%$ & 6,79 & 6,80 & 7,88 & $-10,2 \%$ & $4,1 \%$ \\
\hline & & $19,2 \%$ & 6,91 & 6,91 & 7,90 & $-8,7 \%$ & $4,3 \%$ \\
\hline & & $18,1 \%$ & 7,17 & 7,17 & 8,05 & $-5,2 \%$ & $6,4 \%$ \\
\hline & & $16,9 \%$ & 7,37 & 7,37 & 8,09 & $-2,7 \%$ & $6,8 \%$ \\
\hline & & $16,1 \%$ & 7,23 & 7,23 & 7,82 & $-4,5 \%$ & $3,2 \%$ \\
\hline & & $15,0 \%$ & 7,50 & 7,50 & 7,95 & $-1,0 \%$ & $5,0 \%$ \\
\hline & & $14,0 \%$ & 7,63 & 7,63 & 7,93 & $0,8 \%$ & $4,8 \%$ \\
\hline & & $11,9 \%$ & 7,83 & 7,83 & 7,81 & $3,4 \%$ & $3,2 \%$ \\
\hline & & $9,9 \%$ & 7,97 & 7,96 & 7,62 & $5,2 \%$ & $0,7 \%$ \\
\hline \multirow{17}{*}{16} & \multirow{17}{*}{11,42} & $113,6 \%$ & 10,70 & 12,31 & 12,42 & $7,8 \%$ & $8,7 \%$ \\
\hline & & $98,6 \%$ & 10,76 & 12,37 & 12,48 & $8,3 \%$ & $9,3 \%$ \\
\hline & & $87,9 \%$ & 10,63 & 12,23 & 12,33 & $7,1 \%$ & $8,0 \%$ \\
\hline & & $80,5 \%$ & 10,35 & 11,90 & 12,00 & $4,2 \%$ & $5,1 \%$ \\
\hline & & $65,5 \%$ & 9,98 & 11,47 & 11,57 & $0,5 \%$ & $1,3 \%$ \\
\hline & & $45,2 \%$ & 9,72 & 11,17 & 11,27 & $-2,2 \%$ & $-1,3 \%$ \\
\hline & & $39,9 \%$ & 10,17 & 11,70 & 11,80 & $2,5 \%$ & $3,4 \%$ \\
\hline & & $30,3 \%$ & 9,84 & 11,32 & 11,42 & $-0,9 \%$ & $0,0 \%$ \\
\hline & & $24,9 \%$ & 10,06 & 10,07 & 11,67 & $-11,8 \%$ & $2,2 \%$ \\
\hline & & $21,7 \%$ & 10,22 & 10,23 & 11,85 & $-10,5 \%$ & $3,8 \%$ \\
\hline & & $19,6 \%$ & 10,47 & 10,47 & 12,05 & $-8,3 \%$ & $5,5 \%$ \\
\hline & & $17,5 \%$ & 10,81 & 10,82 & 11,99 & $-5,3 \%$ & $5,0 \%$ \\
\hline & & $17,5 \%$ & 11,05 & 11,06 & 12,26 & $-3,2 \%$ & $7,3 \%$ \\
\hline & & $16,4 \%$ & 11,09 & 11,09 & 12,06 & $-2,9 \%$ & $5,6 \%$ \\
\hline & & $15,3 \%$ & 10,94 & 10,94 & 11,66 & $-4,2 \%$ & $2,1 \%$ \\
\hline & & $14,3 \%$ & 11,26 & 11,27 & 11,77 & $-1,3 \%$ & $3,1 \%$ \\
\hline & & $12,1 \%$ & 11,48 & 11,48 & 11,51 & $0,5 \%$ & $0,8 \%$ \\
\hline \multirow{18}{*}{17} & \multirow{18}{*}{5,97} & $74,5 \%$ & 5,22 & 6,00 & 6,05 & $0,5 \%$ & $1,4 \%$ \\
\hline & & $65,6 \%$ & 5,32 & 6,12 & 6,17 & $2,4 \%$ & $3,3 \%$ \\
\hline & & $59,7 \%$ & 5,23 & 6,02 & 6,07 & $0,8 \%$ & $1,7 \%$ \\
\hline & & $53,8 \%$ & 5,21 & 5,99 & 6,04 & $0,3 \%$ & $1,1 \%$ \\
\hline & & $44,9 \%$ & 5,08 & 5,84 & 5,89 & $-2,2 \%$ & $-1,4 \%$ \\
\hline & & $31,1 \%$ & 5,02 & 5,78 & 5,83 & $-3,2 \%$ & $-2,4 \%$ \\
\hline & & $29,2 \%$ & 5,16 & 5,93 & 5,98 & $-0,7 \%$ & $0,2 \%$ \\
\hline & & $26,2 \%$ & 5,17 & 5,94 & 5,99 & $-0,5 \%$ & $0,4 \%$ \\
\hline & & $23,3 \%$ & 5,35 & 5,36 & 6,21 & $-10,2 \%$ & $4,0 \%$ \\
\hline & & $21,3 \%$ & 5,47 & 5,47 & 6,34 & $-8,3 \%$ & $6,3 \%$ \\
\hline & & $20,3 \%$ & 5,58 & 5,59 & 6,48 & $-6,4 \%$ & $8,5 \%$ \\
\hline & & $18,3 \%$ & 5,81 & 5,81 & 6,54 & $-2,6 \%$ & $9,6 \%$ \\
\hline & & $17,3 \%$ & 6,15 & 6,15 & 6,80 & $3,0 \%$ & $14,0 \%$ \\
\hline & & $17,3 \%$ & 6,13 & 6,13 & 6,78 & $2,7 \%$ & $13,6 \%$ \\
\hline & & $16,3 \%$ & 6,17 & 6,18 & 6,71 & $3,5 \%$ & $12,4 \%$ \\
\hline & & $14,4 \%$ & 6,75 & 6,75 & 7,07 & $13,1 \%$ & $18,5 \%$ \\
\hline & & $12,4 \%$ & 7,03 & 7,03 & 7,09 & $17,8 \%$ & $18,8 \%$ \\
\hline & & $11,4 \%$ & 7,33 & 7,33 & 7,24 & $22,8 \%$ & $21,3 \%$ \\
\hline
\end{tabular}

Continua na próxima página. 
Continuação da Tabela 5.23.

\begin{tabular}{|c|c|c|c|c|c|c|c|}
\hline \multirow[b]{2}{*}{ Viga } & \multirow[b]{2}{*}{$\begin{array}{c}\mathrm{E}_{\mathrm{M}, \mathrm{Stat}, 12 \%} \\
\text { (GPa) }\end{array}$} & \multirow[b]{2}{*}{$\mathbf{U}$} & \multirow[b]{2}{*}{$\begin{array}{c}\mathrm{E}_{\mathrm{M}, \mathrm{VT}, \mathrm{u} \%} \\
(\mathrm{GPa})\end{array}$} & \multicolumn{2}{|c|}{$E_{M, V T, 12 \%}(G P a)$} & \multicolumn{2}{|c|}{ Resíduo } \\
\hline & & & & $\begin{array}{c}\text { Unterwieser \& } \\
\text { Schickhofer } \\
(2010)\end{array}$ & $\begin{array}{c}\text { NBR } 7190 \\
(1997)\end{array}$ & $\begin{array}{c}\text { Unterwieser \& } \\
\text { Schickhofer } \\
(2010)\end{array}$ & $\begin{array}{c}\text { NBR } 7190 \\
(1997)\end{array}$ \\
\hline \multirow{20}{*}{18} & \multirow{20}{*}{7,76} & $89,1 \%$ & 6,53 & 7,51 & 7,57 & $-3,3 \%$ & $-2,4 \%$ \\
\hline & & $76,5 \%$ & 6,63 & 7,63 & 7,70 & $-1,7 \%$ & $-0,8 \%$ \\
\hline & & $66,0 \%$ & 6,64 & 7,64 & 7,71 & $-1,6 \%$ & $-0,7 \%$ \\
\hline & & $59,7 \%$ & 6,66 & 7,66 & 7,73 & $-1,3 \%$ & $-0,4 \%$ \\
\hline & & $50,2 \%$ & 6,54 & 7,52 & 7,59 & $-3,1 \%$ & $-2,2 \%$ \\
\hline & & $42,5 \%$ & 6,46 & 7,43 & 7,50 & $-4,2 \%$ & $-3,4 \%$ \\
\hline & & $38,7 \%$ & 6,46 & 7,43 & 7,50 & $-4,2 \%$ & $-3,4 \%$ \\
\hline & & $32,4 \%$ & 6,68 & 7,69 & 7,75 & $-1,0 \%$ & $-0,1 \%$ \\
\hline & & $26,1 \%$ & 6,62 & 7,62 & 7,68 & $-1,8 \%$ & $-1,0 \%$ \\
\hline & & $21,9 \%$ & 7,03 & 7,04 & 8,15 & $-9,3 \%$ & $5,1 \%$ \\
\hline & & $20,8 \%$ & 7,21 & 7,21 & 8,36 & $-7,0 \%$ & $7,8 \%$ \\
\hline & & $18,7 \%$ & 7,35 & 7,36 & 8,34 & $-5,2 \%$ & $7,5 \%$ \\
\hline & & $17,7 \%$ & 7,55 & 7,56 & 8,41 & $-2,6 \%$ & $8,4 \%$ \\
\hline & & $17,7 \%$ & 7,38 & 7,38 & 8,22 & $-4,9 \%$ & $5,9 \%$ \\
\hline & & $16,6 \%$ & 7,58 & 7,58 & 8,28 & $-2,3 \%$ & $6,7 \%$ \\
\hline & & $14,5 \%$ & 7,63 & 7,63 & 8,01 & $-1,7 \%$ & $3,2 \%$ \\
\hline & & $13,5 \%$ & 8,05 & 8,05 & 8,29 & $3,7 \%$ & $6,8 \%$ \\
\hline & & $12,4 \%$ & 7,90 & 7,90 & 7,96 & $1,8 \%$ & $2,6 \%$ \\
\hline & & $11,4 \%$ & 8,14 & 8,14 & 8,04 & $4,9 \%$ & $3,6 \%$ \\
\hline & & $10,3 \%$ & 8,12 & 8,11 & 7,84 & $4,6 \%$ & $1,1 \%$ \\
\hline \multirow{17}{*}{19} & \multirow{17}{*}{8,55} & $73,7 \%$ & 7,75 & 8,91 & 8,99 & $4,2 \%$ & $5,1 \%$ \\
\hline & & $61,6 \%$ & 7,82 & 8,99 & 9,07 & $5,2 \%$ & $6,1 \%$ \\
\hline & & $49,5 \%$ & 7,78 & 8,94 & 9,02 & $4,6 \%$ & $5,5 \%$ \\
\hline & & $39,6 \%$ & 7,82 & 8,99 & 9,07 & $5,2 \%$ & $6,1 \%$ \\
\hline & & $34,1 \%$ & 7,71 & 8,86 & 8,94 & $3,6 \%$ & $4,5 \%$ \\
\hline & & $29,7 \%$ & 7,89 & 9,07 & 9,15 & $6,1 \%$ & $7,0 \%$ \\
\hline & & $26,4 \%$ & 7,96 & 9,16 & 9,23 & $7,1 \%$ & $8,0 \%$ \\
\hline & & $24,2 \%$ & 8,11 & 8,12 & 9,41 & $-5,1 \%$ & $10,0 \%$ \\
\hline & & $22,0 \%$ & 8,03 & 8,04 & 9,31 & $-6,0 \%$ & $8,9 \%$ \\
\hline & & $19,8 \%$ & 8,10 & 8,11 & 9,37 & $-5,1 \%$ & $9,6 \%$ \\
\hline & & $18,7 \%$ & 8,12 & 8,12 & 9,21 & $-5,0 \%$ & $7,7 \%$ \\
\hline & & $17,6 \%$ & 8,60 & 8,60 & 9,57 & $0,6 \%$ & $11,9 \%$ \\
\hline & & $16,5 \%$ & 8,90 & 8,90 & 9,71 & $4,1 \%$ & $13,5 \%$ \\
\hline & & $15,4 \%$ & 8,46 & 8,47 & 9,04 & $-1,0 \%$ & $5,8 \%$ \\
\hline & & $13,2 \%$ & 9,14 & 9,14 & 9,36 & $6,9 \%$ & $9,5 \%$ \\
\hline & & $12,1 \%$ & 9,31 & 9,31 & 9,34 & $8,9 \%$ & $9,2 \%$ \\
\hline & & $9,9 \%$ & 9,07 & 9,07 & 8,69 & $6,0 \%$ & $1,7 \%$ \\
\hline \multirow{18}{*}{20} & \multirow{18}{*}{11,72} & $96,8 \%$ & 10,93 & 12,57 & 12,68 & $7,3 \%$ & $8,2 \%$ \\
\hline & & $87,4 \%$ & 10,77 & 12,38 & 12,49 & $5,7 \%$ & $6,6 \%$ \\
\hline & & $80,2 \%$ & 10,62 & 12,21 & 12,32 & $4,2 \%$ & $5,1 \%$ \\
\hline & & $63,6 \%$ & 10,57 & 12,15 & 12,26 & $3,7 \%$ & $4,6 \%$ \\
\hline & & $49,1 \%$ & 10,34 & 11,89 & 11,99 & $1,4 \%$ & $2,3 \%$ \\
\hline & & $47,0 \%$ & 10,34 & 11,89 & 11,99 & $1,4 \%$ & $2,3 \%$ \\
\hline & & $42,9 \%$ & 10,50 & 12,07 & 12,18 & $3,0 \%$ & $3,9 \%$ \\
\hline & & $34,6 \%$ & 10,63 & 12,22 & 12,33 & $4,3 \%$ & $5,2 \%$ \\
\hline & & $25,3 \%$ & 10,97 & 12,61 & 12,72 & $7,6 \%$ & $8,6 \%$ \\
\hline & & $22,2 \%$ & 11,00 & 11,01 & 12,76 & $-6,1 \%$ & $8,9 \%$ \\
\hline & & $21,2 \%$ & 11,17 & 11,18 & 12,96 & $-4,6 \%$ & $10,6 \%$ \\
\hline & & $19,1 \%$ & 11,68 & 11,69 & 13,34 & $-0,3 \%$ & $13,8 \%$ \\
\hline & & $17,0 \%$ & 11,53 & 11,53 & 12,68 & $-1,6 \%$ & $8,2 \%$ \\
\hline & & $16,0 \%$ & 11,67 & 11,68 & 12,60 & $-0,4 \%$ & $7,5 \%$ \\
\hline & & $13,9 \%$ & 11,8798 & 11,88 & 12,33 & $1,4 \%$ & $5,2 \%$ \\
\hline & & $11,8 \%$ & 12,47 & 12,47 & 12,43 & $6,4 \%$ & $6,0 \%$ \\
\hline & & $10,8 \%$ & 12,26 & 12,26 & 11,97 & $4,6 \%$ & $2,1 \%$ \\
\hline & & $9,8 \%$ & 12,90 & 12,89 & 12,32 & $10,0 \%$ & $5,1 \%$ \\
\hline
\end{tabular}


As Figuras 5.10 e 5.11 mostram os gráficos dos resíduos obtidos entre $\mathrm{E}_{\mathrm{M}, \mathrm{Stat}, 12 \%} \mathrm{e}$ $\mathrm{E}_{\mathrm{M}, \mathrm{VT}, 12 \%}$ respectivamente para $\mathrm{u} \leq 25 \%$ e para $\mathrm{u}>25 \%$.

\section{Resíduos para $\mathrm{u} \leq \mathbf{2 5 \%}$}

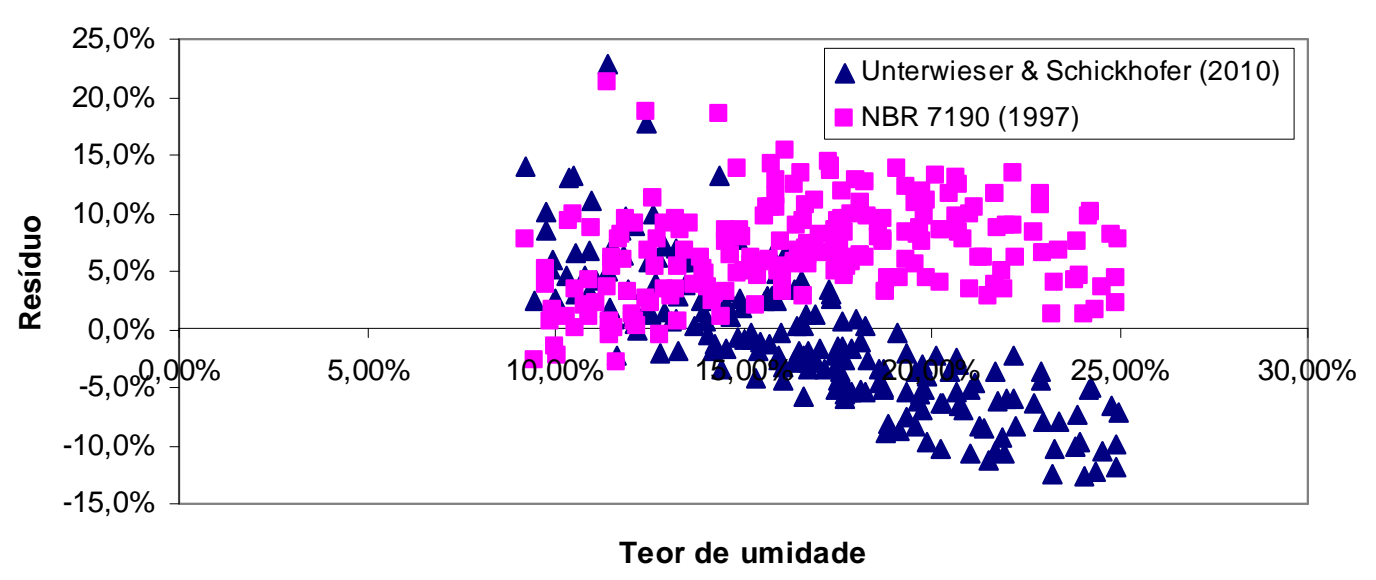

Figura 5.10 - Resíduo obtidos na estimativa de $\mathrm{E}_{\mathrm{M}, \text { Stat, } 12 \%}$ para $\mathrm{u} \leq 25 \%$.

\section{Resíduos para u > 25\%}

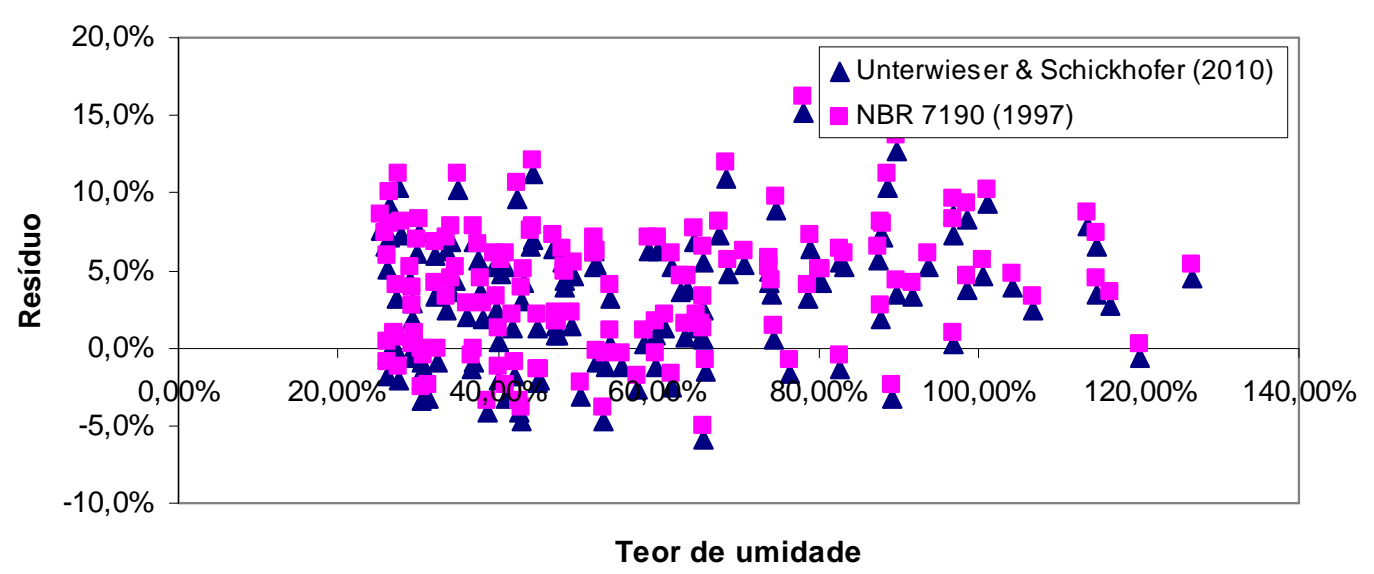

Figura 5.11 - Resíduo obtidos na estimativa de $\mathrm{E}_{\mathrm{M}, \mathrm{Stat}, 12 \%}$ para $\mathrm{u}>25 \%$.

Para teores de umidade inferiores a $25 \%$ observa-se que os dois métodos de correção levam a resíduos de mesma ordem de grandeza, porém a equação proposta por Unterwieser \& Schickhofer (2010) resulta em valores de $\mathrm{E}_{\mathrm{M}, \mathrm{VT}, 12 \%}$ inferiores a $\mathrm{E}_{\mathrm{M}, \mathrm{Stat}, 12 \%}$, sendo dessa maneira a favor da segurança. Para teores de umidade maiores que $25 \%$ os resíduos obtidos pelos dois métodos de correção são equivalentes, embora a correção proposta por Unterwieser \& Schickhofer (2010) ainda resulte em valores mais conservadores para $\mathrm{E}_{\mathrm{M}, \mathrm{VT}, 12 \% .}$ 
A Figura 5.12 mostra o diagrama de dispersão entre $\mathrm{E}_{\mathrm{M}, \mathrm{Stat}}$ e $\mathrm{E}_{\mathrm{M}, \mathrm{VT}}$ no teor de umidade do ensaio. Verifica-se nessa figura uma forte correlação entre os dados.

\section{$E_{M, V T, u \%} \times E_{M, S t a t, u \%}$}

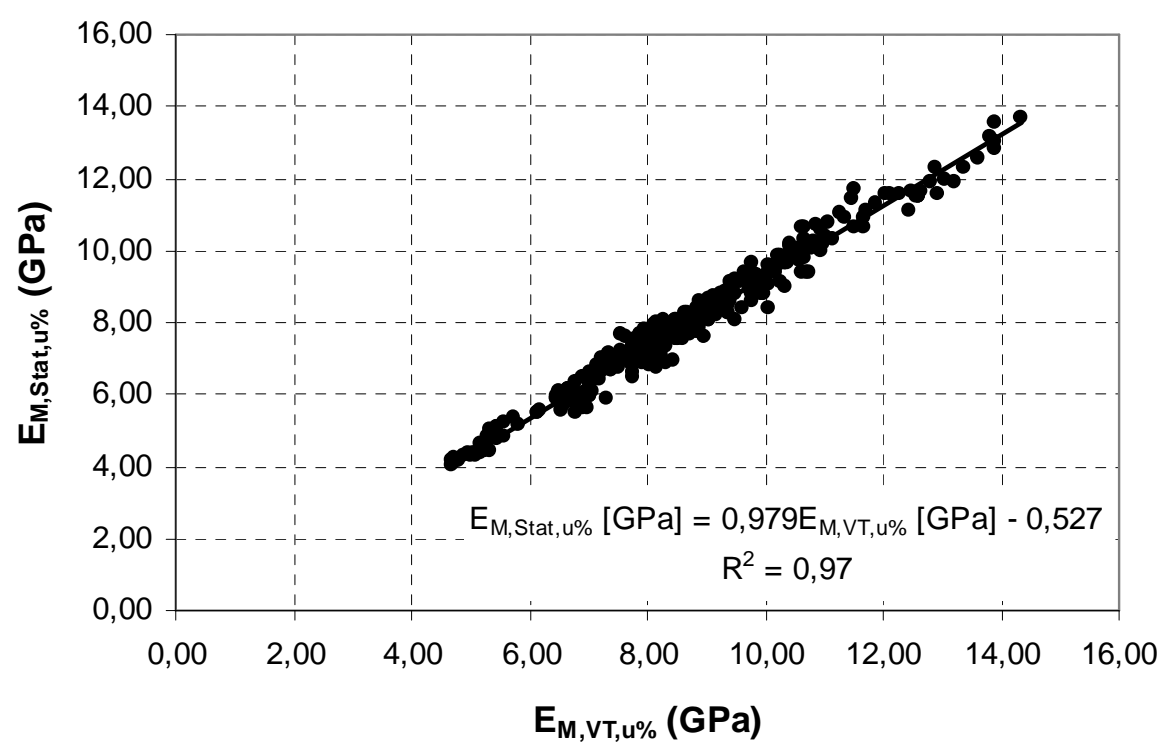

Figura 5.12 - Correlação entre $\mathrm{E}_{\mathrm{M}, \text { Stat }}$ e $\mathrm{E}_{\mathrm{M}, \mathrm{VT}}$ no teor de umidade do ensaio.

A Figura 5.13 mostra o diagrama de dispersão entre $\mathrm{E}_{\mathrm{M} \text {,stat, }}$ e $\mathrm{E}_{\mathrm{M}, \mathrm{VT}}$ no teor de umidade de 12\% sendo o módulo de elasticidade estático corrigido segundo NBR 7190 (ABNT, 1997) e o módulo de elasticidade dinâmico corrigido segundo Unterwieser \& Schickhofer (2010). Em comparação com o gráfico mostrado na Figura 5.12 observa-se que a correção proposta por Unterwieser \& Schickhofer (2010) leva a uma maior dispersão dos pontos enfraquecendo a correlação

Corrigindo-se ambos os módulos de elasticidade segundo a norma NBR 7190 (ABNT, 1997) verifica-se uma correlação mais forte entre os dados do que empregando-se a correção sugerida por Unterwieser \& Schickhofer (2010), conforme se observa na Figura 5.14. 


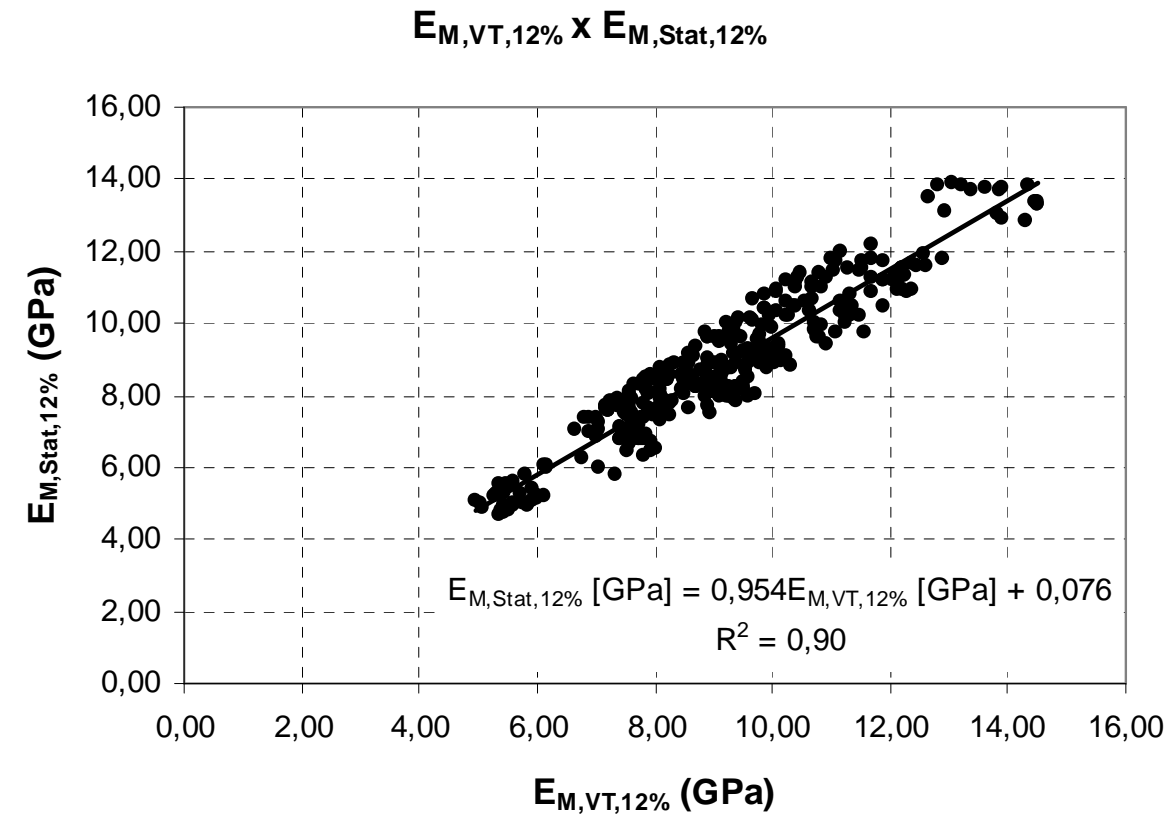

Figura 5.13 - Correlação entre $\mathrm{E}_{\mathrm{M}, \mathrm{Stat}}$, $\mathrm{E}_{\mathrm{M}, \mathrm{VT}}$ a $12 \%$ de umidade.

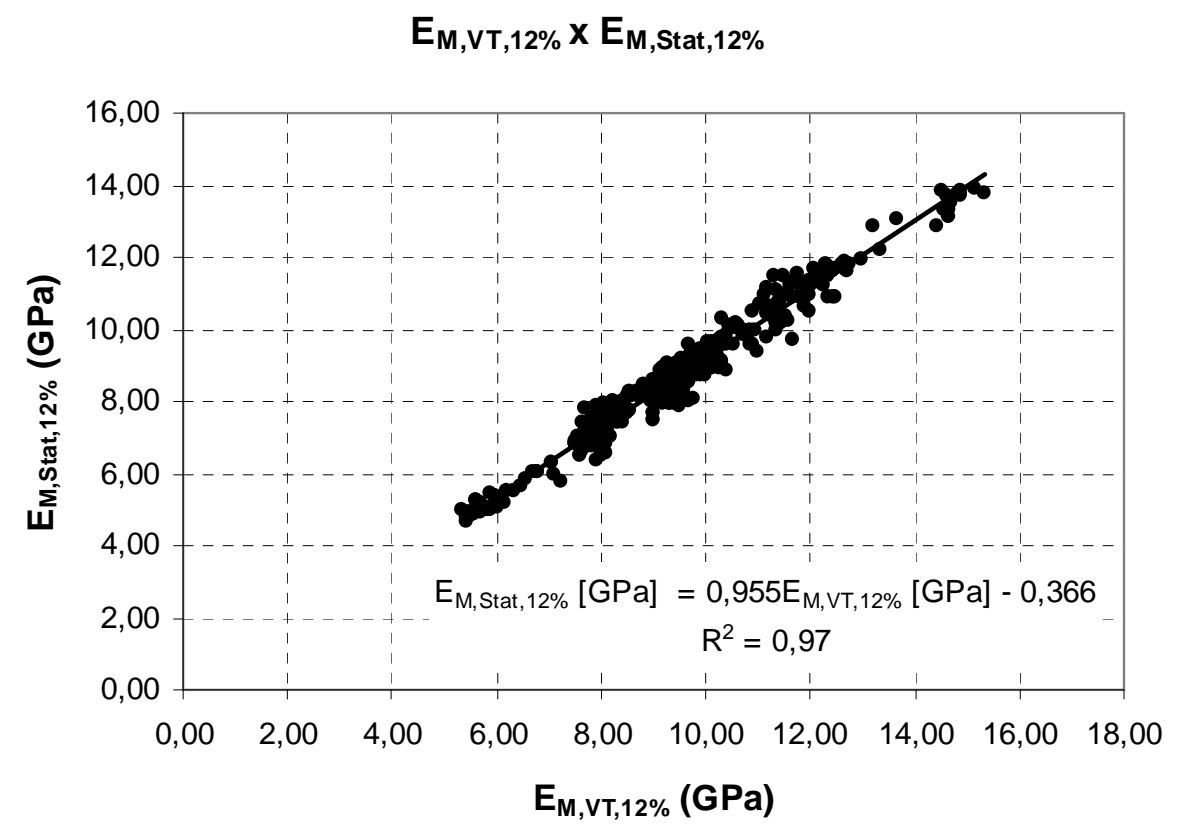

Figura 5.14 - Correlação entre $\mathrm{E}_{\mathrm{M}, \mathrm{Stat}}$ e $\mathrm{E}_{\mathrm{M}, \mathrm{VT}}$ a $12 \%$ de umidade.

Tendo em vista as correlações obtidas e as análises de resíduos feitas, pode-se concluir que é mais interessante utilização a equação recomendada pela norma NBR 7190 (ABNT, 1997) para a correção do módulo de elasticidade dinâmico em função do teor de umidade, 
para as finalidades de comparação entre os ensaios estáticos e dinâmicos e classificação estrutural.

\subsection{Conclusões}

Para teores de umidade abaixo de 25\%, o módulo de elasticidade dinâmico aumenta com a perda da água de impregnação, podendo ser estimado de acordo com a Equação 5.3. Para teores de umidade superiores, pode-se admitir que o módulo de elasticidade dinâmico permanece constante e igual ao valor obtido para o teor de umidade de $25 \%$.

Para a finalidade de classificação das toras o módulo de elasticidade obtido no ensaio de vibração transversal no teor de umidade do ensaio pode ser corrigido para o teor de umidade de 12\% utilizando-se a equação recomendada pela norma NBR 7190 (ABNT, 1997). 


\section{PROPOSTA DE UM MÉTODO DE ENSAIO PARA AVALIAR A RIGIDEZ À FLEXÃO DE TORAS DE MADEIRA POR MEIO DE VIBRAÇÃO TRANSVERSAL LIVRE}

A partir das conclusões obtidas na Revisão de Literatura bem como na análise dos resultados dos ensaios na amostra piloto e do estudo da influência da umidade foi definido um método para determinar o módulo de elasticidade à flexão de toras de madeira por meio de vibração transversal.

Assim sendo, o desenvolvimento deste trabalho acrescentou as seguintes contribuições:

- O módulo de elasticidade pode ser calculado com o diâmetro medido na metade do comprimento da tora eliminando a necessidade a resolução de um determinante com funções de Bessel para a obtenção do módulo de elasticidade;

- Para toras com $\mathrm{L} / \mathrm{D}_{\text {meio }}$ menor do que 21 foi incluído um fator de correção para levar em conta os efeitos do esforço cortante e da inércia à rotação;

- O ensaio deve ser realizado preferencialmente com excitação e medição da aceleração no plano horizontal, pois verificou-se que nessa direção há uma menor interferência do sistema de suspensão;

- Considerando a imprecisão do medidor elétrico, e ressaltando que a finalidade do método é a classificação estrutural das toras, sugere-se a realização dos ensaios com as toras na condição saturada com posterior correção do módulo de elasticidade para o teor de umidade de $12 \%$;

- Verificou-se que o módulo de elasticidade dinâmico pode ser corrigido para o teor de umidade de $12 \%$ conforme procedimento da norma NBR 7190 (ABNT, 1997);

- Observou-se a presença de picos múltiplos de acelerância na região da ressonância em várias toras e verificou-se que, nesses casos, o módulo de elasticidade deve ser calculado com a frequência de maior amplitude de acelerância;

- Foram definidas as características necessárias do sistema de aquisição de dados para se obter uma correta medição das frequências naturais. 


\subsection{MÉTODO DE ENSAIO}

O método de ensaio proposto neste capítulo destina-se a determinação do módulo de elasticidade à flexão de toras de madeira por meio do ensaio de vibração transversal livre.

A determinação do módulo de elasticidade deve ser precedida de uma inspeção visual com a finalidade descartar as peças com presença de podridão, encurvamentos e rachaduras excessivas, furos de insetos ou algum outro defeito que possa comprometer o seu desempenho estrutural.

\subsubsection{Resumo do método de ensaio}

A tora deve ser mantida na posição horizontal sendo excitada por meio de impactos desferidos na base da tora, na direção transversal ao seu comprimento e, preferencialmente, no plano horizontal. No caso da excitação ser realizada no plano vertical, a tora deve ser suspensa como mostra a Figura 6.1 utilizando uma mola com rigidez igual ou inferior a 1/10 da rigidez à flexão da tora.

O módulo de elasticidade dinâmico é determinado de acordo com as Equações 6.1 e 6.2, a partir da frequência do primeiro modo de flexão.

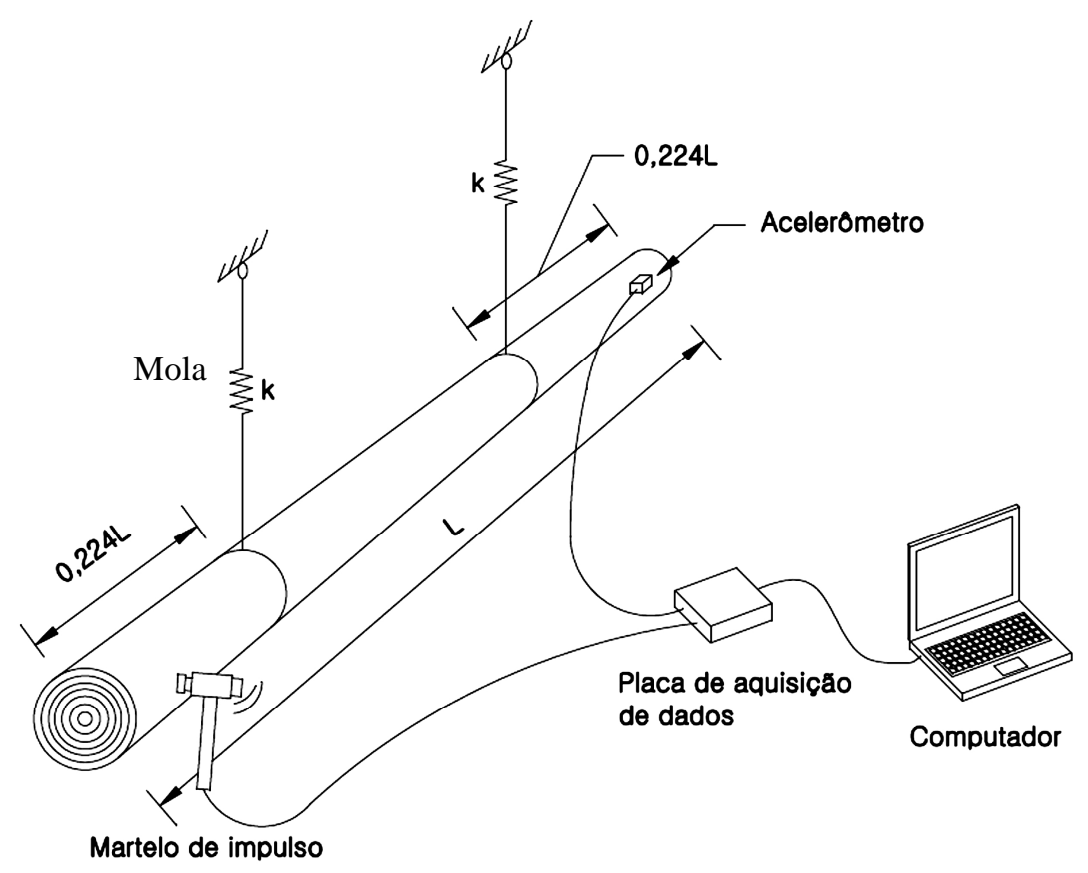

Figura 6.1 - Esquema do ensaio de vibração transversal em toras de madeira. 


\subsubsection{Generalidades}

O módulo de elasticidade dinâmico determinado pelo método de ensaio proposto pode ser correlacionado com o módulo de elasticidade medido no ensaio de flexão estática.

A facilidade de execução do ensaio dinâmico e sua curta duração favorecem a substituição do ensaio de flexão estática pelo ensaio de vibração transversal.

O módulo de elasticidade dinâmico pode ser utilizado como um parâmetro para agrupar as toras em classes de rigidez.

\subsubsection{Equipamentos}

O aparato de ensaio deve ser constituído de quatro elementos fundamentais:

- Sistema de suspensão;

- Dispositivo de excitação;

- Transdutor de aceleração;

- Sistema de aquisição de dados para ensaios dinâmicos.

6.1.3.1. Sistema de suspensão - A tora deve ser suspensa por meio de cordas, molas, ou algum outro dispositivo cuja rigidez axial seja inferior a rigidez à flexão da tora. A frequência do modo de deslocamento de corpo rígido deve ser inferior a $1 / 10$ da frequência do primeiro modo de flexão da tora.

6.1.3.2. Posicionamento do sistema de suspensão - O sistema de suspensão deve ser posicionado nos pontos nodais do primeiro modo de flexão de uma viga prismática com condição de contorno livre-livre. Esses pontos são localizados a 0,224 L a partir das extremidades (sendo L o comprimento da tora).

6.1.3.3. Dispositivo de excitação - A excitação deve ser produzida por meio de impactos horizontais com um martelo de impulso.

6.1.3.4. Massa e sensibilidade do martelo de impulso - Deve-se escolher um martelo de impulso com massa modal suficiente para excitar o primeiro modo de flexão das toras. A sensibilidade do martelo de impulso deve ser compatível com o nível de força aplicado e com o fundo de escala da placa de aquisição de dados.

Observação 1 - Para toras de Eucalyptus citriodora com comprimento de 4,5m e diâmetro na metade do comprimento de $17 \mathrm{~cm}$, pode-se usar um martelo com massa modal de 0,45 $\mathrm{kg}$ e sensibilidade da ordem de $0,23 \mathrm{mV} / \mathrm{N}$. 
6.1.3.5. Seleção da ponta da cabeça do martelo de impulso - Para excitar a frequência do primeiro modo de flexão com boa quantidade de energia é necessário escolher adequadamente a ponta do martelo de impulso. A dureza da ponta está relacionada com a frequência que se deseja excitar. Em geral, para madeira, as frequências do primeiro modo são baixas e, por esse motivo pode-se testar as pontas macias e de dureza média.

6.1.3.6. Transdutor de aceleração - O transdutor de aceleração, ou acelerômetro, deve ter sensibilidade suficiente para produzir um sinal de boa intensidade, porém não elevada o suficiente para causar a saturação da placa de aquisição de dados.

6.1.3.7. Fundo de escala do acelerômetro - $\mathrm{O}$ fundo de escala do acelerômetro deve ser dimensionado de acordo com a massa das toras e com a força aplicada pelo martelo de impulso.

Observação 2 - Para toras com massa da ordem de 90 a $120 \mathrm{~kg}$, excitadas com um martelo de impulso com as características do citado na observação 1 , as acelerações podem variar de 2 a $10 \mathrm{~g}$, sendo $\mathrm{g}=9,80665 \mathrm{~m} / \mathrm{s}^{2}$, dependendo da força aplicada.

6.1.3.8. Massa do acelerômetro - A massa do acelerômetro deve ser inferior a 1/10 da massa da tora.

6.1.3.9. Sistema de aquisição de dados - O sistema de aquisição de dados é composto por uma placa de aquisição e digitalização dos sinais do martelo e do acelerômetro e por um programa capaz de analisar os sinais. A frequência de amostragem da placa de aquisição de dados deve ser igual ou superior a 10 vezes o valor da frequência do primeiro modo de flexão das toras. O ganho dos canais do sistema de aquisição de dados deve ser compatível com as sensibilidades do martelo de impulso e do acelerômetro.

6.1.3.10. Programa de análise de sinais - O programa deve permitir a aplicação da janela exponencial quando o sinal não for completamente atenuado na janela de amostragem. As frequências naturais devem ser determinadas por meio de identificação modal de um espectro resultante da média de 10 amostragens.

\subsubsection{Espécimes para teste}

6.1.4.1. As toras devem ser submetidas a uma inspeção visual previamente ao ensaio de vibração transversal a fim de descartar peças com encurvamento ou fendilhamento excessivos, podridão ou algum outro defeito capaz de inutilizá-las para aplicação estrutural. 
6.1.4.2. Para fins de correção do módulo de elasticidade dinâmico para o teor de umidade padrão (12\%) é preferível realizar a medição do módulo de elasticidade com as toras na condição saturada, ou seja, com teor de umidade acima de $30 \%$.

\subsubsection{Procedimento}

6.1.5.1. Calibração - O martelo de impulso e o acelerômetro devem ser calibrados periodicamente.

6.1.5.2. Fixação do acelerômetro - O acelerômetro pode ser fixado na tora por meio de parafusos, cola ou mesmo cera de abelha desde que a temperatura da tora seja inferior a $40{ }^{\circ} \mathrm{C}$. $\mathrm{O}$ acelerômetro deve ser fixado na extremidade mais delgada da tora como mostra a Figura 6.1.

6.1.5.3. Excitação - A tora deve ser excitada com impactos desferidos na extremidade de maior diâmetro das toras por meio de um martelo de impulso. Os impactos devem ser desferidos na direção transversal à tora, no plano horizontal, ou seja, perpendicularmente ao sistema de suspensão. A identificação da frequência do primeiro modo de flexão deve ser realizada no espectro resultante de 10 médias.

6.1.5.4. O ensaio pode ser realizado com excitação e medição de aceleração no plano vertical, desde que se garanta que a rigidez axial do sistema de suspensão nessa direção seja inferior a 1/10 da rigidez à flexão da tora.

6.1.5.5. Cálculo do módulo de elasticidade - Para toras cujo comprimento for superior a 21 vezes o diâmetro tomado na metade do comprimento, o efeito do esforço cortante pode ser desprezado, e o módulo de elasticidade dinâmico pode ser calculado pela Equação 6.1.

$$
E_{M, \operatorname{din}}=\frac{156,54 * f^{2} * M * L^{3}}{C^{4}}
$$

Sendo:

$E_{M, d i n}=$ módulo de elasticidade dinâmico $(\mathrm{Pa})$;

$f=$ frequência do primeiro modo de flexão $(\mathrm{Hz})$;

$M=\operatorname{massa}(\mathrm{kg})$;

$L=$ comprimento (m);

$C=$ perímetro medido na metade do comprimento da tora. 
Os efeitos da inércia à rotação e do esforço cortante devem ser considerados para as toras cujo comprimento for inferior a 21 vezes o diâmetro na metade do comprimento, multiplicando-se o módulo de elasticidade dinâmico pelo coeficiente $T$, como mostrado na Equação 6.2.

$$
\begin{aligned}
& E_{M, d i n}=\left(\frac{156,54 * f^{2} * M * L^{3}}{C^{4}}\right) * T \\
& T=1+\frac{2,02 C^{2}}{L^{2}}-\frac{0,40 * \frac{C^{4}}{L^{4}}}{1+3,27 * \frac{C^{2}}{L^{2}}}
\end{aligned}
$$

Sendo:

$E_{M, d i n}=$ módulo de elasticidade dinâmico $(\mathrm{Pa})$;

$C=$ perímetro medido na metade do comprimento da tora;

$L=$ comprimento $(\mathrm{m})$.

6.1.5.6. Nas toras em que o primeiro modo de flexão apresenta picos de frequência múltiplos (Figura 6.2), o módulo de elasticidade deve ser calculado com a frequência cuja acelerância tenha maior amplitude.

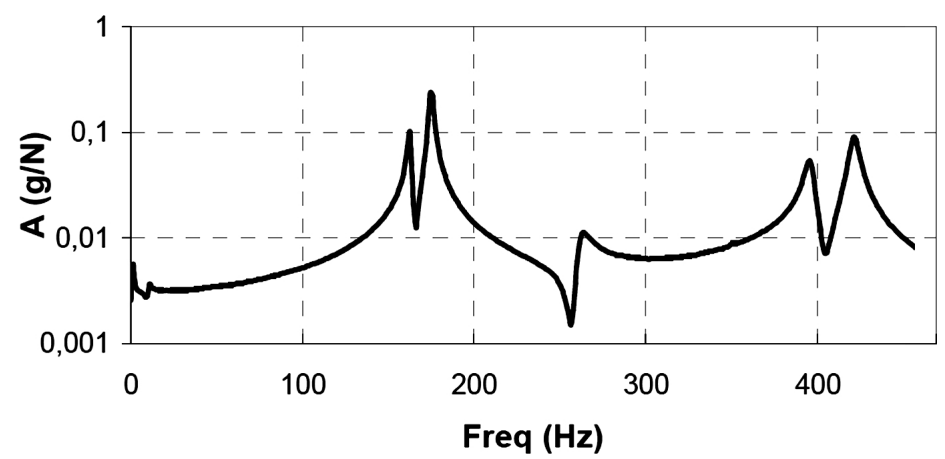

Figura 6.2 - Exemplo de Função de Resposta em Frequência com mais de um pico para o primeiro modo de flexão.

6.1.5.7. A correção do módulo de elasticidade para o valor relativo ao teor de umidade padrão (12\%) pode ser feita usando a equação recomendada no item 6.2.1 da norma NBR 7190 (ABNT, 1997). 


\section{VALIDAÇÃO DO MÉTODO DE ENSAIO}

Os ensaios e análises apresentados neste capítulo tiveram por objetivo a comprovação da eficácia do método proposto no Capítulo 6, em uma amostra com maior número de exemplares, comparando os resultados dos testes de vibração transversal e de flexão estática. Essa amostra também foi submetida a uma inspeção visual para verificar outras características importantes para utilização das toras, tais como encurvamento, presença de furos de insetos, fendas, etc.

\subsection{Materiais}

A amostra usada na validação do método de ensaio foi composta por 40 toras de Eucalyptus citriodora. A média do diâmetro na metade do comprimento foi igual a $16,5 \mathrm{~cm}$, e a média do comprimento igual a 4,2 $\mathrm{m}$.

\subsection{Métodos}

\subsubsection{Inspeção visual das toras}

A inspeção visual das toras foi feita conforme a norma ANSI O5.1 (ANSI, 2002), cujos critérios são resumidos no Anexo A. Cabe lembrar que essa norma não define classes de qualidade estrutural e que seus critérios de classificação definem as características mínimas aceitáveis para utilização de toras como postes em linhas de transmissão de energia.

Foi examinada toda a superfície e as duas extremidades das toras, analisando-se os seguintes aspectos: presença de furos de insetos, nós, encurvamento, fendas, inclusões contendo casca, madeira comprimida, fibras torcidas e diâmetros das extremidades.

Ao término da classificação visual, a massa das toras foi medida usando uma balança digital Toledo modelo 2098, com resolução de 50 g. Foi feita também a medição das 
seguintes dimensões das toras: diâmetros nas extremidades, comprimento e circunferências em seções transversais a cada $0,1 \mathrm{~L}$ ao longo do comprimento.

A Figura 7.1 mostra alguns exemplos de características avaliadas.

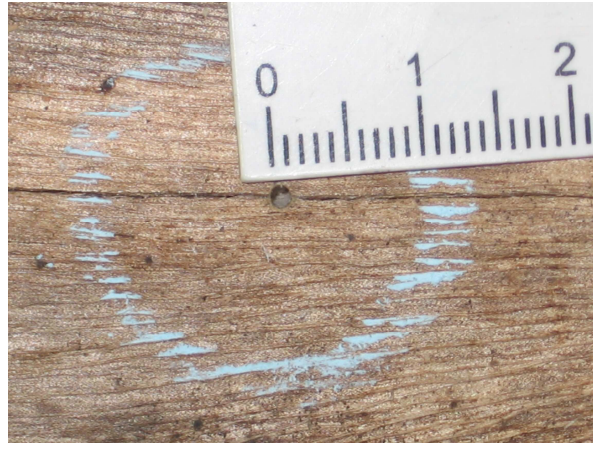

a) Furo de insetos

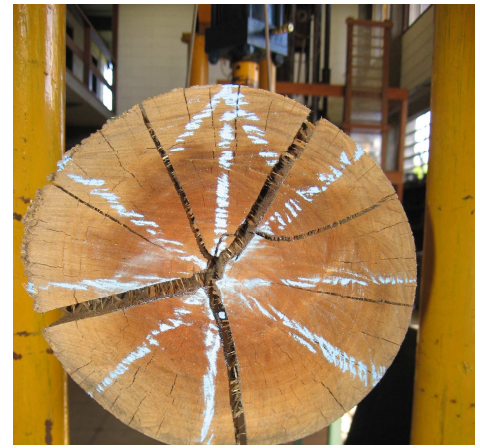

c) Fendas

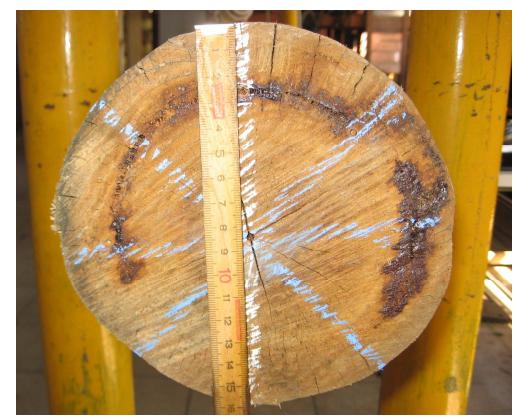

e) Bolsa de resina.

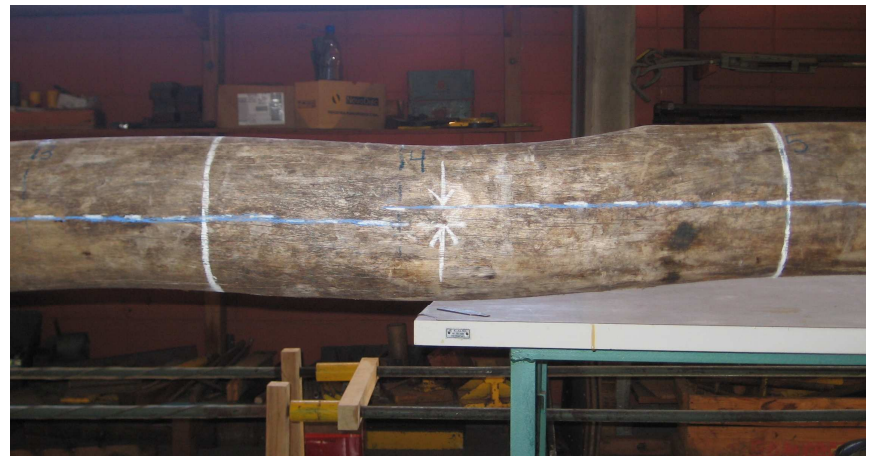

b) Curvatura curta

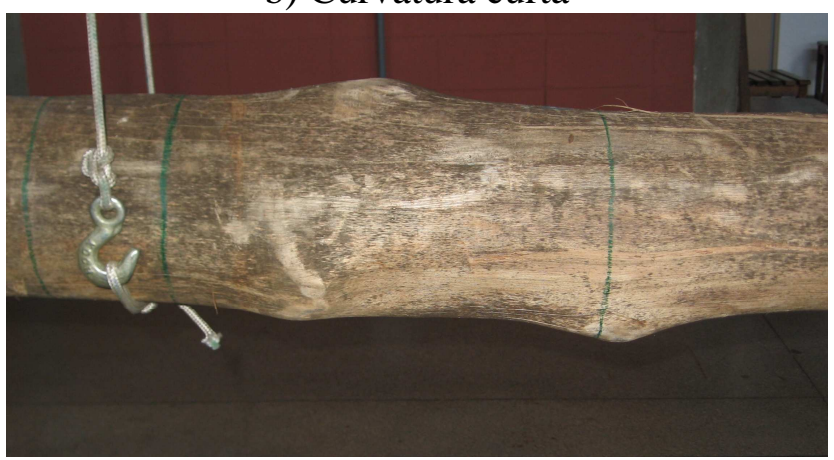

d) Nós.

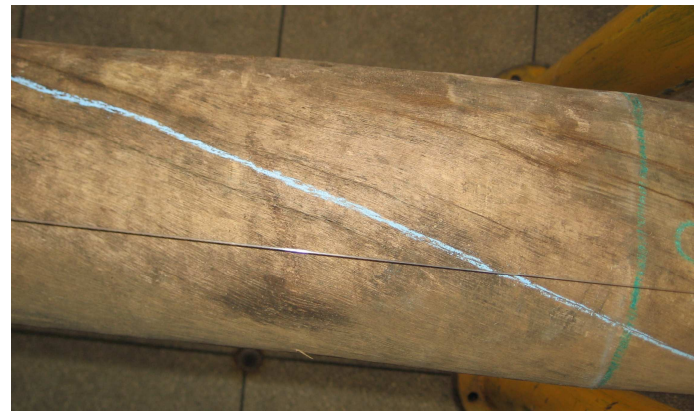

f) Fibra torcida.

Figura 7.1 - Exemplo de características observadas na inspeção visual das toras.

O Apêndice F mostra os dados das toras da amostra de validação.

\subsubsection{Ensaio de vibração transversal}

O ensaio de vibração transversal foi conduzido de acordo com o método proposto no Capítulo 6. O sistema de aquisição de dados foi configurado com os parâmetros mostrados na Tabela. 7.1. 
Tabela 7.1 - Configurações do programa Impact nos ensaios com as toras da amostra de validação

\begin{tabular}{lc}
\hline \multicolumn{1}{c}{ Configurações do programa de aquisição de dados } \\
\hline Taxa de amostragem & $5 \mathrm{kHz}$ \\
Número de amostras & 32768 \\
Resolução da FRF & $0,1526 \mathrm{~Hz}$ \\
Nível de disparo do trigger & 0,2 volts \\
Número de amostras pré-trigger & 200 \\
Número de médias & 10 \\
Janela exponencial & Valor final 0,2 \\
Banda de frequências & 0 a $500 \mathrm{~Hz}$ \\
Algoritmo para determinação da FRF & $\mathrm{H}_{1}$ \\
\hline
\end{tabular}

A Figura 7.2 mostra uma visão geral do ensaio.

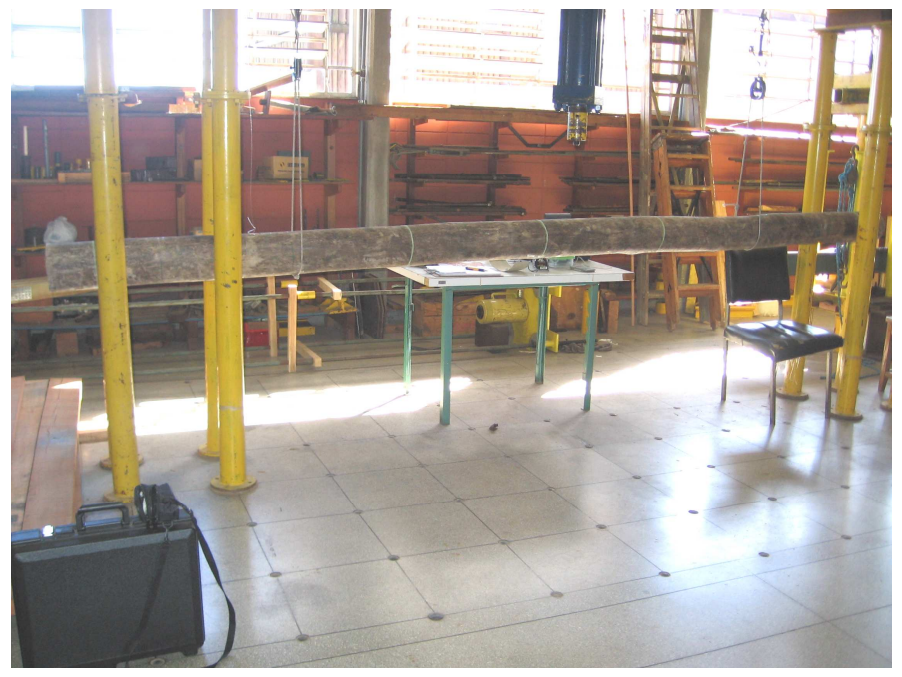

Figura 7.2 - Ensaio de vibração transversal na segunda amostra.

Com o programa Modal-Id foram identificadas as frequências de vibração até o terceiro modo de flexão, sendo o módulo de elasticidade dinâmico calculado de acordo com a Equação 6.2. O módulo de elasticidade dinâmico foi corrigido para o teor de umidade de $12 \%$ conforme norma NBR 7190 (ABNT, 1997). Para tanto, o teor de umidade do ensaio foi considerado como sendo a média aritmética dos teores de umidade medidos no cerne e no alburno das toras.

As toras foram flexionadas em um único plano e, para garantir que fossem flexionadas no mesmo plano tanto no ensaio dinâmico quanto no ensaio estático, foi desenhada uma seta nas extremidades das toras indicando o plano de aplicação do carregamento (Figura 7.3). 


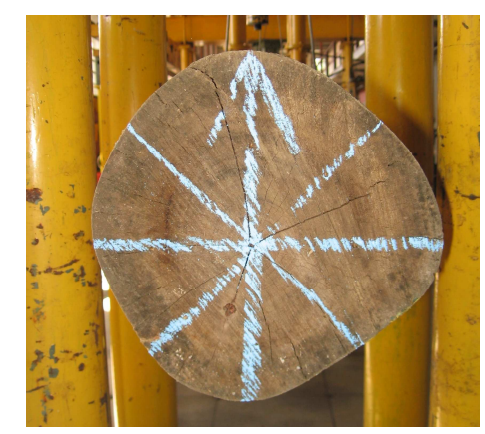

Figura 7.3 - Indicação do plano de carregamento.

\subsubsection{Ensaio de flexão estática}

Assim como na amostra piloto, esse ensaio foi conduzido em conformidade com a norma ASTM D 198 (ASTM, 2008).

As toras foram fletidas com vão de $3,75 \mathrm{~m}$ e os deslocamentos foram medidos até que a flecha na metade do comprimento atingisse $15 \mathrm{~mm}$. O ensaio teve duração média de 14 minutos.

Foram utilizados os mesmos equipamentos empregados nos ensaios com a amostra piloto, com exceção da célula de carga que foi substituída por outra com fundo de escala de $200 \mathrm{kN}$.

O módulo de elasticidade estático foi corrigido para o teor de umidade de $12 \%$ conforme norma NBR 7190 (ABNT, 1997).

\subsubsection{Determinação do teor de umidade e da densidade aparente}

Foram extraídos dois corpos-de-prova do cerne e dois do alburno nas seções transversais a $0,1 \mathrm{~L}, 0,4 \mathrm{~L}$ e a $0,9 \mathrm{~L}$ medidas a partir da base das toras. Esses corpos-de-prova foram submetidos ao ensaio para determinação do teor de umidade conforme a norma NBR 7190 (ABNT, 1997).

Alternativamente, o teor de umidade foi medido nas duas extremidades e na metade do comprimento das toras com um medidor elétrico modelo DL 2000 da Digisystem.

Para a correção do módulo de elasticidade medido nos ensaios de flexão estática e vibração transversal, o teor de umidade das toras foi calculado admitindo-se proporções iguais de cerne e alburno. 
O teor de umidade das toras foi utilizado para a correção das propriedades mecânicas e da densidade aparente para o teor de umidade de $12 \%$. A correção da densidade aparente foi feita empregando-se o gráfico de Kollman (1968).

A densidade aparente das toras no teor de umidade do ensaio foi calculada a partir da massa da tora e considerando o volume da madeira admitindo-se a tora como um tronco de cone, medindo-se os diâmetros das extremidades.

\subsection{Resultados}

Os itens a seguir apresentam os resultados obtidos na validação do método de Avaliação Não-Destrutiva de toras de madeira por vibração transversal.

\subsubsection{Inspeção visual das toras}

A Tabela 7.2 mostra o resultado da inspeção visual das toras segundo norma ANSI O5.1 (ANSI, 2002).

Tabela 7.2 - Resultado da inspeção visual das toras.

\begin{tabular}{cccccc}
\hline Tora & $\begin{array}{c}\text { Resultado da } \\
\text { inspeção visual }\end{array}$ & Defeitos & Tora & $\begin{array}{c}\text { Resultado da } \\
\text { inspeção visual }\end{array}$ & Defeitos \\
\hline 1 & Aprovada & - & 21 & Aprovada & - \\
2 & Aprovada & - & 22 & Aprovada & - \\
3 & Aprovada & - & 23 & Aprovada & - \\
4 & Reprovada & Encurvamento & 24 & Aprovada & - \\
5 & Aprovada & - & 25 & Aprovada & - \\
6 & Reprovada & Fenda topo & 26 & Aprovada & - \\
7 & Reprovada & Encurvamento & 27 & Reprovada & Fenda topo \\
8 & Reprovada & Encurvamento & 28 & Reprovada & Fibra torcida \\
9 & Aprovada & - & 29 & Aprovada & - \\
10 & Aprovada & - & 30 & Reprovada & Nó, encurvamento \\
11 & Reprovada & Nó & 31 & Aprovada & - \\
12 & Reprovada & Madeira comprimida & 32 & Aprovada & - \\
13 & Aprovada & - & 33 & Reprovada & Nó \\
14 & Aprovada & - & 34 & Aprovada & - \\
15 & Reprovada & Encurvamento & 35 & Reprovada & Encurvamento \\
16 & Reprovada & Nó, fibra torcida & 36 & Reprovada & Fenda topo \\
17 & Reprovada & Fenda base & 37 & Aprovada & - \\
18 & Reprovada & Encurvamento & 38 & Aprovada & - \\
19 & Aprovada & - & 39 & Aprovada & - \\
20 & Reprovada & Nó & 40 & Aprovada & - \\
\hline
\end{tabular}

A Tabela 7.3 mostra os defeitos e o respectivo número de toras reprovadas. 
Tabela 7.3 - Número de defeitos encontrados.

\begin{tabular}{lc}
\hline \multicolumn{1}{c}{ Defeitos } & Toras reprovadas \\
\hline Encurvamento & 7 \\
Nó & 5 \\
Fenda & 4 \\
Fibra torcida & 2 \\
Madeira comprimida & 1 \\
\hline
\end{tabular}

\subsubsection{Ensaio de vibração transversal}

A frequência do modo de corpo rígido variou de 0,6 a 3,2 Hz, sendo sempre inferior a $1 / 10$ da frequência do $1^{\underline{o}}$ modo de flexão.

Em algumas toras foram observados picos múltiplos de frequência como mostra a Figura 7.4 na qual observa-se dois picos de frequência para o primeiro modo e quatro para o segundo modo.
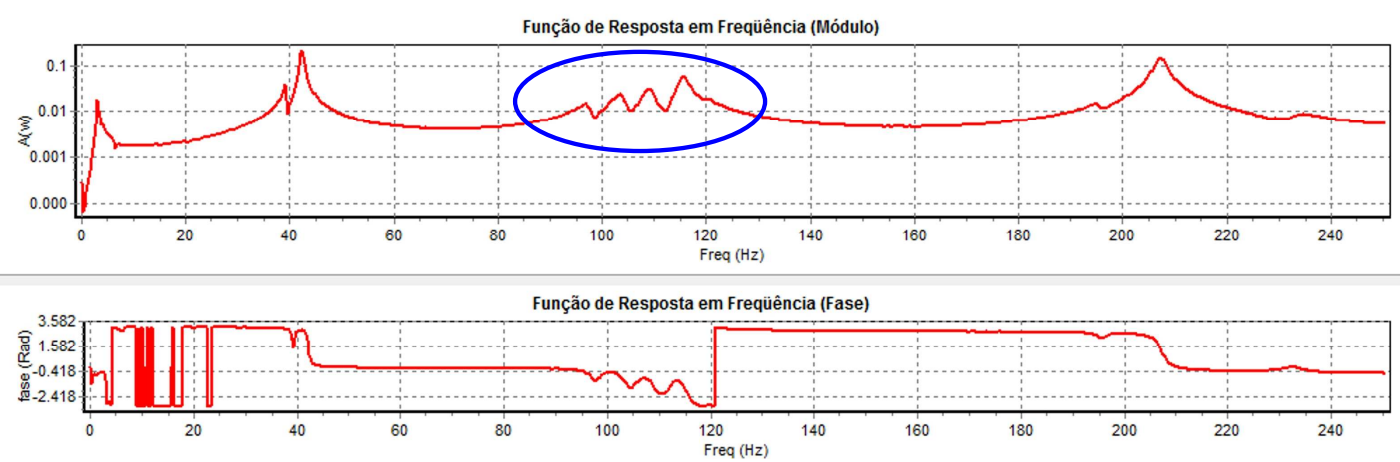

Figura 7.4 - FRF $A_{10} 0$ medida na tora 2 evidenciando 4 picos para o segundo modo.

A Tabela 7.4 mostra as frequências encontradas para o primeiro modo de flexão das toras. 
Tabela 7.4 - Frequências do primeiro modo de flexão.

\begin{tabular}{|c|c|c|c|c|c|c|c|}
\hline \multirow[b]{2}{*}{ Tora } & \multicolumn{3}{|c|}{ Freqüência do 10 modo. (Hz) } & \multirow[b]{2}{*}{ Tora } & \multicolumn{3}{|c|}{ Freqüência do 10 modo. (Hz) } \\
\hline & $1^{\circ}$ pico & $2^{\circ}$ pico & Média & & $1^{\circ}$ pico & $2^{\circ}$ pico & Média \\
\hline 1 & 44,72 & & 44,72 & 21 & 38,10 & 40,89 & 39,49 \\
\hline 2 & 39,07 & 42,30 & 40,69 & 22 & 31,67 & & 31,67 \\
\hline 3 & 45,58 & & 45,58 & 23 & 37,94 & & 37,94 \\
\hline 4 & 35,47 & & 35,47 & 24 & 41,49 & 43,98 & 42,74 \\
\hline 5 & 40,41 & & 40,41 & 25 & 38,47 & 40,11 & 39,29 \\
\hline 6 & 46,30 & 47,88 & 47,09 & 26 & 37,23 & & 37,23 \\
\hline 7 & 39,14 & & 39,14 & 27 & 38,81 & & 38,81 \\
\hline 8 & 43,34 & & 43,34 & 28 & 33,32 & & 33,32 \\
\hline 9 & 35,38 & 39,06 & 37,22 & 29 & 47,70 & & 47,70 \\
\hline 10 & 45,61 & 47,64 & 46,62 & 30 & 36,09 & & 36,09 \\
\hline 11 & 44,81 & 46,67 & 45,74 & 31 & 43,45 & & 43,45 \\
\hline 12 & 46,49 & & 46,49 & 32 & 39,56 & 40,64 & 40,10 \\
\hline 13 & 38,38 & 42,28 & 40,33 & 33 & 37,70 & & 37,70 \\
\hline 14 & 34,28 & & 34,28 & 34 & 38,71 & & 38,71 \\
\hline 15 & 39,96 & 42,21 & 41,09 & 35 & 49,92 & 52,41 & 51,16 \\
\hline 16 & 38,91 & 44,28 & 41,60 & 36 & 36,23 & 39,90 & 38,07 \\
\hline 17 & 43,30 & 47,98 & 45,64 & 37 & 35,25 & & 35,25 \\
\hline 18 & 40,66 & 42,61 & 41,63 & 38 & 41,78 & & 41,78 \\
\hline 19 & 34,74 & 37,78 & 36,26 & 39 & 37,91 & 41,09 & 39,50 \\
\hline 20 & 40,22 & 42,25 & 41,24 & 40 & 36,75 & & 36,75 \\
\hline
\end{tabular}

A Tabela 7.5 mostra o módulo de elasticidade dinâmico no teor de umidade do ensaio e corrigido para o teor de umidade de 12\% de acordo com a norma NBR 7190 (ABNT, 1997).

Os valores em negrito indicam as frequências com maior amplitude de acelerância.

O módulo de elasticidade foi calculado para a média aritmética das frequências dos dois picos e para a frequência de maior amplitude de acelerância. 
Tabela 7.5 - Cálculo do módulo de elasticidade dinâmico das toras.

\begin{tabular}{|c|c|c|c|c|c|c|c|c|c|c|}
\hline \multirow{2}{*}{ Tora } & $\mathbf{L}$ & $\mathbf{D}_{\text {meio }}$ & Massa & \multicolumn{3}{|c|}{$f(\mathrm{~Hz})$} & \multicolumn{2}{|c|}{$\mathrm{E}_{\mathrm{M}, \mathrm{VT}, \mathrm{u} \%}(\mathrm{GPa})$} & \multicolumn{2}{|c|}{$\mathrm{E}_{\mathrm{M}, \mathrm{VT}, 12 \%}(\mathrm{GPa})$} \\
\hline & $(\mathrm{m})$ & (m) & $(\mathrm{kg})$ & $1^{\circ}$ pico & $2^{\circ}$ pico & Média & $f_{\text {média }}$ & $f_{\text {maior pico }}$ & $f_{\text {média }}$ & $f_{\text {maior pico }}$ \\
\hline 1 & 4,10 & 0,172 & 95,8 & 44,72 & & 44,72 & 24,95 & 24,95 & 28,94 & 28,94 \\
\hline 2 & 4,26 & 0,173 & 104,40 & 39,07 & 42,30 & 40,69 & 24,57 & 26,55 & 28,50 & 30,80 \\
\hline 3 & 4,17 & 0,186 & 118,45 & 45,58 & & 45,58 & 25,03 & 25,03 & 29,04 & 29,04 \\
\hline 4 & 4,30 & 0,179 & 122,80 & 35,47 & & 35,47 & 19,75 & 19,75 & 22,91 & 22,91 \\
\hline 5 & 4,12 & 0,159 & 75,80 & 40,41 & & 40,41 & 22,35 & 22,35 & 25,92 & 25,93 \\
\hline 6 & 4,12 & 0,181 & 108,80 & 46,30 & 47,88 & 47,09 & 25,98 & 26,85 & 30,13 & 31,15 \\
\hline 7 & 4,28 & 0,164 & 90,60 & 39,14 & & 39,14 & 24,86 & 24,86 & 28,83 & 28,84 \\
\hline 8 & 4,12 & 0,169 & 93,60 & 43,34 & & 43,34 & 25,15 & 25,14 & 29,17 & 29,16 \\
\hline 9 & 4,28 & 0,158 & 87,55 & 35,38 & 39,06 & 37,22 & 25,06 & 27,60 & 29,07 & 32,02 \\
\hline 10 & 3,97 & 0,175 & 97,35 & 45,61 & 47,64 & 46,62 & 23,51 & 22,51 & 27,28 & 26,11 \\
\hline 11 & 4,10 & 0,200 & 118,80 & 44,81 & 46,67 & 45,74 & 18,22 & 18,97 & 21,13 & 22,00 \\
\hline 12 & 4,03 & 0,185 & 115,60 & 46,49 & & 46,49 & 23,15 & 23,35 & 26,85 & 27,08 \\
\hline 13 & 4,09 & 0,164 & 87,20 & 38,38 & 42,28 & 40,33 & 22,33 & 24,55 & 25,91 & 28,48 \\
\hline 14 & 4,38 & 0,166 & 96,45 & 34,28 & & 34,28 & 20,96 & 20,95 & 24,31 & 24,31 \\
\hline 15 & 4,05 & 0,156 & 81,65 & 39,96 & 42,21 & 41,09 & 25,74 & 24,35 & 29,74 & 28,13 \\
\hline 16 & 4,02 & 0,158 & 66,85 & 38,91 & 44,28 & 41,60 & 19,80 & 17,33 & 22,97 & 20,10 \\
\hline 17 & 4,09 & 0,178 & 101,65 & 43,30 & 47,98 & 45,64 & 24,19 & 21,78 & 28,06 & 25,26 \\
\hline 18 & 4,13 & 0,173 & 95,50 & 40,66 & 42,61 & 41,63 & 21,71 & 20,70 & 25,18 & 24,02 \\
\hline 19 & 4,26 & 0,151 & 78,30 & 34,74 & 37,78 & 36,26 & 25,29 & 23,21 & 29,33 & 26,92 \\
\hline 20 & 4,12 & 0,154 & 80,55 & 40,22 & 42,25 & 41,24 & 27,85 & 26,49 & 32,30 & 30,73 \\
\hline 21 & 4,09 & 0,154 & 75,40 & 38,10 & 40,89 & 39,49 & 23,33 & 25,01 & 27,07 & 29,01 \\
\hline 22 & 4,16 & 0,137 & 60,35 & 31,67 & & 31,67 & 20,30 & 20,30 & 23,55 & 23,54 \\
\hline 23 & 3,97 & 0,140 & 63,60 & 37,94 & & 37,94 & 24,81 & 24,80 & 28,78 & 28,77 \\
\hline 24 & 4,05 & 0,165 & 85,70 & 41,49 & 43,98 & 42,74 & 23,40 & 22,05 & 27,14 & 25,58 \\
\hline 25 & 4,00 & 0,142 & 64,00 & 38,47 & 40,11 & 39,29 & 25,53 & 26,60 & 29,61 & 30,86 \\
\hline 26 & 4,26 & 0,181 & 110,30 & 37,23 & & 37,23 & 18,49 & 18,49 & 21,45 & 21,44 \\
\hline 27 & 4,24 & 0,165 & 92,25 & 38,81 & & 38,81 & 23,59 & 23,60 & 27,37 & 27,37 \\
\hline 28 & 4,18 & 0,136 & 64,35 & 33,32 & & 33,32 & 25,06 & 25,07 & 29,07 & 29,08 \\
\hline 29 & 4,01 & 0,183 & 101,40 & 47,70 & & 47,70 & 22,13 & 22,12 & 25,67 & 25,66 \\
\hline 30 & 4,25 & 0,167 & 76,35 & 36,09 & & 36,09 & 16,05 & 18,80 & 18,62 & 21,81 \\
\hline 31 & 4,31 & 0,157 & 82,90 & 43,45 & & 43,45 & 34,10 & 33,95 & 39,56 & 39,38 \\
\hline 32 & 4,41 & 0,177 & 118,85 & 39,56 & 40,64 & 40,10 & 27,48 & 26,75 & 31,88 & 31,02 \\
\hline 33 & 4,13 & 0,165 & 85,40 & 37,70 & & 37,70 & 19,10 & 19,11 & 22,16 & 22,17 \\
\hline 34 & 4,09 & 0,156 & 84,95 & 38,71 & & 38,71 & 24,32 & 24,32 & 28,21 & 28,21 \\
\hline 35 & 4,05 & 0,184 & 109,95 & 49,92 & 52,41 & 51,16 & 27,89 & 29,27 & 32,36 & 33,95 \\
\hline 36 & 4,00 & 0,140 & 61,70 & 36,23 & 39,90 & 38,07 & 24,69 & 27,13 & 28,65 & 31,47 \\
\hline 37 & 4,24 & 0,177 & 112,15 & 35,25 & & 35,25 & 18,16 & 18,16 & 21,06 & 21,06 \\
\hline 38 & 4,06 & 0,166 & 94,90 & 41,78 & & 41,78 & 24,39 & 24,40 & 28,30 & 28,30 \\
\hline 39 & 4,00 & 0,143 & 64,20 & 37,91 & 41,09 & 39,50 & 25,37 & 23,37 & 29,43 & 27,11 \\
\hline 40 & 4,31 & 0,157 & 82,90 & 36,75 & & 36,75 & 24,40 & 24,40 & 28,31 & 28,30 \\
\hline
\end{tabular}

\subsubsection{Ensaio de flexão estática}

A Tabela 7.6 mostra o módulo de elasticidade estático e o módulo de ruptura das toras para o teor de umidade do ensaio e para o teor de umidade de $12 \%$ conforme NBR 7190 (ABNT, 1997). 
Tabela 7.6 - Resultados do ensaio de flexão estática.

\begin{tabular}{ccc}
\hline Tora & $\begin{array}{c}\mathbf{E}_{\mathbf{M}, \text { Stat }, v^{*}, \mathrm{u}^{*} \%} \\
(\mathbf{G P a})\end{array}$ & $\begin{array}{c}\mathbf{E}_{\mathbf{M}, \mathbf{S t a t}, \mathbf{v}^{*}, \mathbf{1 2} \%} \\
(\mathbf{G P a})\end{array}$ \\
\hline 1 & 24,99 & 28,99 \\
2 & 25,89 & 30,03 \\
3 & 24,75 & 28,71 \\
4 & 18,80 & 21,81 \\
5 & 21,11 & 24,49 \\
6 & 26,77 & 31,05 \\
7 & 22,52 & 26,12 \\
8 & 23,88 & 27,70 \\
9 & 25,23 & 29,27 \\
10 & 22,90 & 26,56 \\
11 & 18,31 & 21,24 \\
12 & 21,76 & 25,24 \\
13 & 21,84 & 25,33 \\
14 & 20,99 & 24,35 \\
15 & 24,44 & 28,24 \\
16 & 17,22 & 19,98 \\
17 & 20,75 & 24,07 \\
18 & 20,06 & 23,27 \\
19 & 24,04 & 27,89 \\
20 & 25,20 & 29,23 \\
21 & 24,23 & 28,11 \\
22 & 18,77 & 21,77 \\
23 & 22,78 & 26,42 \\
24 & 22,39 & 25,97 \\
25 & 24,70 & 28,65 \\
26 & 17,44 & 20,23 \\
27 & 22,35 & 25,93 \\
28 & 24,83 & 28,80 \\
29 & 21,79 & 25,28 \\
30 & 15,01 & 17,41 \\
31 & 45,86 & 53,20 \\
32 & 26,55 & 30,80 \\
33 & 18,02 & 20,90 \\
34 & 22,22 & 25,78 \\
35 & 27,81 & 32,26 \\
36 & 26,07 & 30,24 \\
37 & 17,91 & 20,78 \\
38 & 23,54 & 27,31 \\
39 & 21,52 & 24,96 \\
40 & 24,08 & 27,93 \\
\hline & &
\end{tabular}




\subsubsection{Determinação do teor de umidade e densidade aparente}

A Tabela 7.7 mostra os resultados dos ensaios para determinação do teor de umidade.

Tabela 7.7 - Resultados dos ensaios para determinação do teor de umidade.

\begin{tabular}{|c|c|c|c|c|c|c|c|c|c|c|c|}
\hline \multirow[b]{2}{*}{ Tora } & \multicolumn{4}{|c|}{ Medidor elétrico $\left(\mathrm{U}_{\mathrm{el}}\right)$} & \multicolumn{7}{|c|}{ Ensaio NBR $7190\left(\mathrm{U}_{\mathrm{gr}}\right)$} \\
\hline & Base & Meio & Topo & Média & $\begin{array}{r}\text { Se } \\
\text { Cerne }\end{array}$ & $\begin{array}{l}\text { ção } 1 \\
\text { Alburno }\end{array}$ & $\begin{array}{r}\text { Se } \\
\text { Cerne }\end{array}$ & $\begin{array}{l}\text { ção } 4 \\
\text { Alburno }\end{array}$ & $\begin{array}{l}\text { Se } \\
\text { Cerne }\end{array}$ & $\begin{array}{l}\text { ão } 10 \\
\text { Alburno }\end{array}$ & $\begin{array}{c}\text { Média geral } \\
(\%)\end{array}$ \\
\hline 1 & 22,5 & 24,1 & 20,2 & 22,3 & 39,8 & * & 39,7 & * & 37,4 & * & 39,0 \\
\hline 2 & 32,3 & 31,5 & 29,5 & 31,1 & 43,5 & * & 38,7 & * & 38,7 & * & 40,3 \\
\hline 3 & 16,6 & 14,5 & 18,2 & 16,4 & 38,0 & * & 33,3 & * & 33,3 & * & 34,9 \\
\hline 4 & 25,5 & 20,0 & 22,2 & 22,6 & 47,0 & * & 40,9 & * & 38,8 & * & 42,2 \\
\hline 5 & 26,1 & 28,0 & 26,2 & 26,8 & 39,6 & 26,8 & 33,7 & 23,0 & 33,2 & 23,8 & 30,0 \\
\hline 6 & 22,8 & 25,0 & 23,7 & 23,8 & 34,9 & 24,3 & 36,9 & 25,1 & 31,7 & 28,2 & 30,2 \\
\hline 7 & 21,3 & 24,7 & 20,5 & 22,2 & 30,3 & 22,7 & 33,7 & 23,0 & 35,6 & 23,7 & 28,1 \\
\hline 8 & 19,8 & 22,5 & 17,4 & 19,9 & 29,7 & 21,0 & 35,1 & 21,9 & 35,8 & 20,4 & 27,3 \\
\hline 9 & 25,6 & 28,8 & 22,5 & 25,6 & 26,7 & 28,4 & 38,2 & 23,2 & 36,7 & 21,9 & 29,2 \\
\hline 10 & 22,7 & 21,8 & 21,7 & 22,1 & 38,0 & 19,7 & 36,3 & 31,4 & 36,2 & 19,8 & 30,2 \\
\hline 11 & 23,0 & 22,2 & 19,6 & 21,6 & 33,5 & 20,7 & 30,4 & 19,9 & 26,2 & 25,4 & 26,0 \\
\hline 12 & 27,0 & 27,5 & 25,3 & 26,6 & 33,0 & 20,6 & 30,5 & 21,7 & 30,5 & 22,0 & 26,4 \\
\hline 13 & 18,8 & 16,3 & 16,5 & 17,2 & 25,9 & 19,2 & 26,5 & 19,4 & 26,3 & 18,5 & 22,6 \\
\hline 14 & 18,8 & 18,6 & 16,4 & 17,9 & 31,7 & 20,5 & 27,5 & 21,5 & 25,4 & 19,6 & 24,3 \\
\hline 15 & 12,8 & 14,2 & 14,7 & 13,9 & 21,2 & 17,5 & 22,0 & 19,7 & 21,0 & 17,4 & 19,8 \\
\hline 16 & 16,6 & 18,4 & 15,2 & 16,7 & 28,6 & 17,8 & 25,0 & 17,9 & 25,9 & 18,2 & 22,2 \\
\hline 17 & 17,8 & 22,3 & 23,1 & 21,1 & 28,0 & 19,3 & 35,5 & 19,5 & 32,1 & 17,8 & 25,3 \\
\hline 18 & 15,9 & 22,4 & 19,6 & 19,3 & 39,9 & 18,7 & 23,8 & 10,7 & 28,5 & 19,1 & 23,4 \\
\hline 19 & 20,7 & 19,3 & 17,1 & 19,0 & 25,2 & 21,3 & 26,0 & 23,1 & 33,3 & 20,0 & 24,8 \\
\hline 20 & 18,1 & 17,5 & 20,8 & 18,8 & 32,2 & 23,5 & 29,9 & 21,7 & 31,1 & 19,9 & 26,4 \\
\hline 21 & 17,8 & 17,4 & 17,3 & 17,5 & 37,5 & 18,8 & 30,2 & 20,5 & 31,0 & 18,2 & 26,0 \\
\hline 22 & 17,0 & 15,5 & 18,0 & 16,8 & 36,0 & 18,1 & 22,2 & 18,5 & 28,8 & 20,0 & 23,9 \\
\hline 23 & 14,3 & 14,7 & 13,0 & 14,0 & 29,0 & 19,4 & 27,7 & 20,7 & 27,7 & 18,2 & 23,8 \\
\hline 24 & 15,4 & 17,0 & 18,1 & 16,8 & 35,3 & 20,9 & 33,3 & 23,8 & 28,2 & 19,9 & 26,9 \\
\hline 25 & 12,1 & 12,8 & 12,5 & 12,5 & 27,3 & 19,5 & 28,1 & 23,5 & 28,5 & * & 21,1 \\
\hline 26 & 11,5 & 14,5 & 16,3 & 14,1 & 28,5 & 15,8 & 34,1 & 16,6 & 27,4 & 16,0 & 23,1 \\
\hline 27 & 15,8 & 11,4 & 15,1 & 14,1 & 33,6 & 17,2 & 28,9 & 17,8 & 29,4 & 17,2 & 24,0 \\
\hline 28 & 16,4 & 17,8 & 14,9 & 16,4 & 32,4 & 16,3 & 24,5 & 17,5 & 31,3 & 15,1 & 22,8 \\
\hline 29 & 21,7 & 16,3 & 18,6 & 18,9 & 47,1 & 21,0 & 34,4 & 17,6 & 28,9 & 16,7 & 27,6 \\
\hline 30 & 13,4 & 12,0 & 12,6 & 12,7 & 31,7 & 18,8 & 27,8 & 15,6 & 32,5 & 18,2 & 24,1 \\
\hline 31 & 17,4 & 17,5 & 15,4 & 16,8 & 39,5 & 18,2 & 36,5 & 19,1 & 37,8 & 16,7 & 27,9 \\
\hline 32 & 15,1 & 16,2 & 14,3 & 15,2 & 31,1 & 17,8 & 36,5 & 20,3 & 30,0 & 19,9 & 25,9 \\
\hline 33 & 14,5 & 15,5 & 15,5 & 15,2 & 31,5 & 16,5 & 25,7 & 15,0 & 29,9 & 15,0 & 22,3 \\
\hline 34 & 14,3 & 16,5 & 15,7 & 15,5 & 26,4 & 14,8 & 30,9 & 15,5 & 29,7 & 14,5 & 21,9 \\
\hline 35 & 14,7 & 13,8 & 15,2 & 14,6 & 43,8 & 19,4 & 40,2 & 21,3 & 35,2 & 20,3 & 30,0 \\
\hline 36 & 16,0 & 15,0 & 15,5 & 15,5 & 43,1 & 16,4 & 36,8 & 16,6 & 32,9 & 16,6 & 27,0 \\
\hline 37 & 15,0 & 13,5 & 15,6 & 14,7 & 42,1 & 15,5 & 32,4 & 15,5 & 34,0 & 14,3 & 25,6 \\
\hline 38 & 10,9 & 11,3 & 11,2 & 11,1 & 29,0 & 17,7 & 19,7 & 24,9 & 28,1 & 17,2 & 22,7 \\
\hline 39 & 10,8 & 11,3 & 11,5 & 11,2 & 36,2 & 16,0 & 28,3 & 14,8 & 29,2 & 15,9 & 23,4 \\
\hline 40 & 10,9 & 11,1 & 10,8 & 10,9 & 27,4 & 16,4 & 32,0 & 17,9 & 24,3 & 14,7 & 22,1 \\
\hline
\end{tabular}

A Tabela 7.8 mostra os resultados do ensaio para determinação da densidade aparente no teor de umidade do ensaio e a $12 \%$ de umidade. 
Tabela 7.8 - Resultados dos ensaios para determinação da densidade aparente.

\begin{tabular}{|c|c|c|c|c|c|c|c|}
\hline Tora & $U_{g r}(\%)$ & $\begin{array}{c}\text { Massa } \\
(\mathrm{kg})\end{array}$ & $\begin{array}{l}D_{\text {base }} \\
(\mathrm{cm})\end{array}$ & $\begin{array}{l}D_{\text {topo }} \\
(\mathrm{cm})\end{array}$ & $\mathrm{L}(\mathrm{cm})$ & $\begin{array}{c}\rho_{\mathrm{u} \%} \\
\left(\mathrm{~kg} / \mathrm{m}^{3}\right)\end{array}$ & $\begin{array}{c}\rho_{12 \%} \\
\left(\mathrm{~kg} / \mathrm{m}^{3}\right)\end{array}$ \\
\hline 1 & 39,0 & 95,80 & 18,13 & 16,91 & 409,8 & 969 & 810 \\
\hline 2 & 40,3 & 104,40 & 21,85 & 16,45 & 425,5 & 846 & 760 \\
\hline 3 & 34,9 & 118,45 & 19,21 & 17,40 & 417,4 & 1078 & 925 \\
\hline 4 & 42,2 & 122,80 & 22,14 & 16,16 & 429,6 & 984 & 870 \\
\hline 5 & 30,0 & 75,80 & 17,82 & 14,57 & 412,3 & 889 & 830 \\
\hline 6 & 30,2 & 108,80 & 19,19 & 16,70 & 411,8 & 1043 & 1010 \\
\hline 7 & 28,1 & 90,60 & 17,16 & 14,68 & 427,5 & 1062 & 1020 \\
\hline 8 & 27,3 & 93,60 & 17,67 & 15,32 & 411,6 & 1062 & 1025 \\
\hline 9 & 29,2 & 87,55 & 17,51 & 14,47 & 428,0 & 1015 & 960 \\
\hline 10 & 30,2 & 97,35 & 19,77 & 16,70 & 397,0 & 937 & 820 \\
\hline 11 & 26,0 & 118,40 & 19,87 & 18,21 & 410,4 & 1013 & 975 \\
\hline 12 & 26,4 & 115,60 & 20,27 & 17,77 & 402,5 & 1009 & 970 \\
\hline 13 & 22,6 & 87,20 & 17,78 & 14,68 & 409,2 & 1027 & 985 \\
\hline 14 & 24,3 & 96,45 & 17,95 & 14,95 & 437,8 & 1034 & 1010 \\
\hline 15 & 19,8 & 81,65 & 16,45 & 14,77 & 404,8 & 1053 & 1050 \\
\hline 16 & 22,2 & 66,85 & 15,77 & 13,79 & 401,5 & 969 & 935 \\
\hline 17 & 25,3 & 101,65 & 18,84 & 17,14 & 408,5 & 978 & 955 \\
\hline 18 & 23,4 & 95,50 & 20,16 & 16,61 & 412,7 & 869 & 835 \\
\hline 19 & 24,8 & 78,30 & 16,02 & 14,67 & 426,0 & 993 & 965 \\
\hline 20 & 26,4 & 80,55 & 16,67 & 14,42 & 412,0 & 1028 & 1010 \\
\hline 21 & 26,0 & 75,40 & 18,05 & 14,15 & 408,6 & 902 & 865 \\
\hline 22 & 23,9 & 60,35 & 16,71 & 12,41 & 415,5 & 866 & 830 \\
\hline 23 & 23,8 & 63,60 & 15,49 & 13,95 & 397,2 & 940 & 920 \\
\hline 24 & 26,9 & 85,70 & 19,38 & 14,69 & 405,3 & 922 & 880 \\
\hline 25 & 21,1 & 64,00 & 14,72 & 13,99 & 399,5 & 989 & 970 \\
\hline 26 & 23,1 & 110,30 & 21,47 & 16,84 & 425,6 & 895 & 860 \\
\hline 27 & 24,0 & 92,25 & 17,97 & 15,02 & 424,3 & 1014 & 990 \\
\hline 28 & 22,8 & 64,35 & 14,69 & 12,79 & 417,8 & 1037 & 1020 \\
\hline 29 & 27,6 & 101,40 & 19,99 & 16,29 & 400,5 & 976 & 950 \\
\hline 30 & 24,1 & 76,35 & 16,20 & 14,97 & 424,5 & 943 & 920 \\
\hline 31 & 27,9 & 82,90 & 17,72 & 14,45 & 431,0 & 943 & 910 \\
\hline 32 & 25,9 & 118,85 & 19,02 & 17,00 & 440,8 & 1057 & 1045 \\
\hline 33 & 22,3 & 85,40 & 17,19 & 14,22 & 412,5 & 1065 & 1050 \\
\hline 34 & 21,9 & 84,95 & 18,64 & 14,75 & 409,0 & 944 & 925 \\
\hline 35 & 30,0 & 109,95 & 20,67 & 17,79 & 404,9 & 933 & 880 \\
\hline 36 & 27,0 & 61,70 & 17,29 & 13,02 & 399,8 & 850 & 805 \\
\hline 37 & 25,6 & 112,15 & 18,67 & 16,59 & 424,3 & 1082 & 1070 \\
\hline 38 & 22,7 & 94,90 & 17,57 & 15,82 & 406,2 & 1066 & 1060 \\
\hline 39 & 23,4 & 64,20 & 16,14 & 12,92 & 400,2 & 963 & 935 \\
\hline 40 & 22,1 & 82,90 & 17,72 & 14,45 & 431,0 & 943 & 925 \\
\hline Média & 26,6 & 90,2 & 18,14 & 15,31 & 414,4 & 980 & 938 \\
\hline
\end{tabular}




\subsection{Análise dos resultados}

\subsubsection{Inspeção visual das toras}

Obteve-se um índice elevado de reprovação das toras na inspeção visual segundo a norma ANSI O5.1 (ANSI, 2002).

Verificou-se que $17(42,5 \%)$ das 40 toras foram reprovadas na inspeção visual e não poderiam ser utilizadas como postes.

As maiores causas de reprovação foram encurvamentos excessivos seguidos de nós de grandes dimensões.

Segundo a norma ANSI O5.1 (2002), para todas as espécies, com exceção para a Northern White Cedar, o limite para aceitável para o encurvamento das toras é 0,8\%. Para a espécie Northern White Cedar (Thuja occidentalis L.) esse limite é estendido para 1,6\%.

Utilizando-se o critério definido para todas as espécies, segundo a norma ANSI O5.1 (2002), obteve-se um índice de reprovação de 17,5\% em função do encurvamento.

\subsubsection{Correlação entre os módulos de elasticidade estático e dinâmico}

A Figura 7.5 mostra o gráfico de dispersão entre os módulos de elasticidade estático e dinâmico calculado com a frequência de maior amplitude, ambos corrigidos para o teor de umidade de 12\% conforme NBR 7190 (ABNT, 1997).

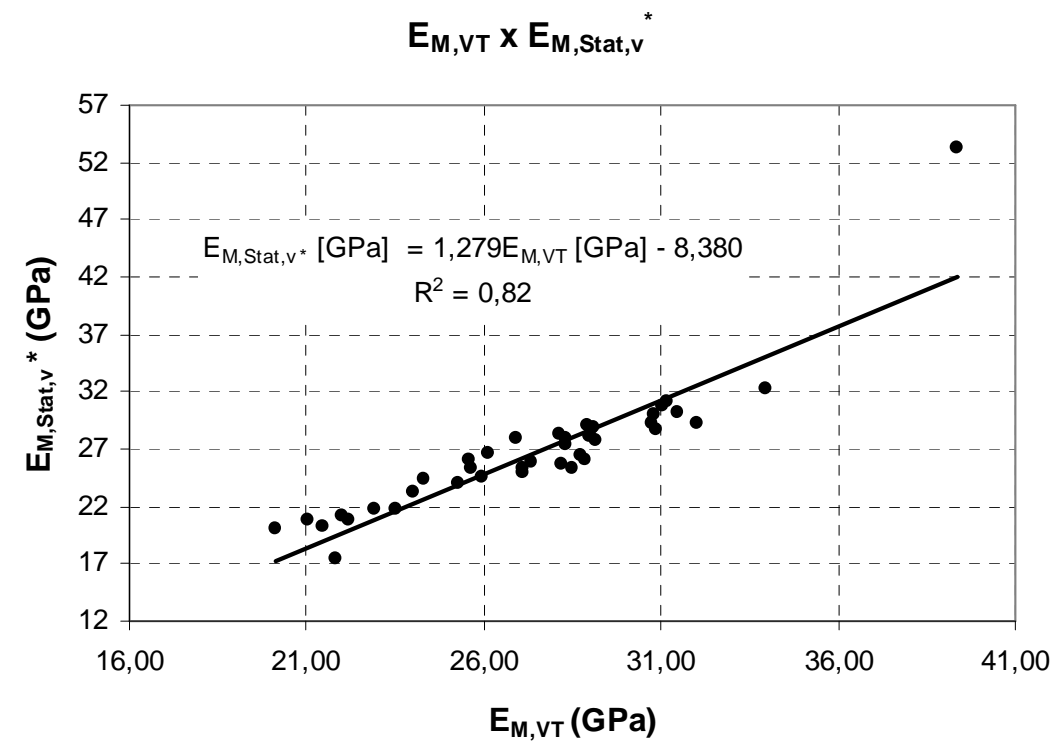

Figura 7.5 - Gráfico de dispersão entre $\mathrm{E}_{\mathrm{M}, \mathrm{VT}}$ e $\mathrm{E}_{\mathrm{M}, \mathrm{Stat}, \mathrm{v}}{ }^{*}$. 
Observa-se na Figura 7.5 a presença de uma observação extrema (outlier) para a tora 31. Eliminando o outlier do grupo de dados, tem-se o diagrama de dispersão mostrado na Figuras 7.6, notando-se uma forte correlação entre os módulos de elasticidade estático e dinâmico com $\mathrm{R}^{2}=0,90$. Verifica-se, ainda, que o coeficiente angular da equação de regressão é próximo de 1,00, e que o termo independente dessa equação é inferior a $1 \mathrm{GPa}$. Como resultado, obtém-se resíduos de pequena magnitude nas estimativas de $\mathrm{E}_{\mathrm{M}, S t a t, v^{*}}$ a partir de $\mathrm{E}_{\mathrm{M}, \mathrm{VT}}$.

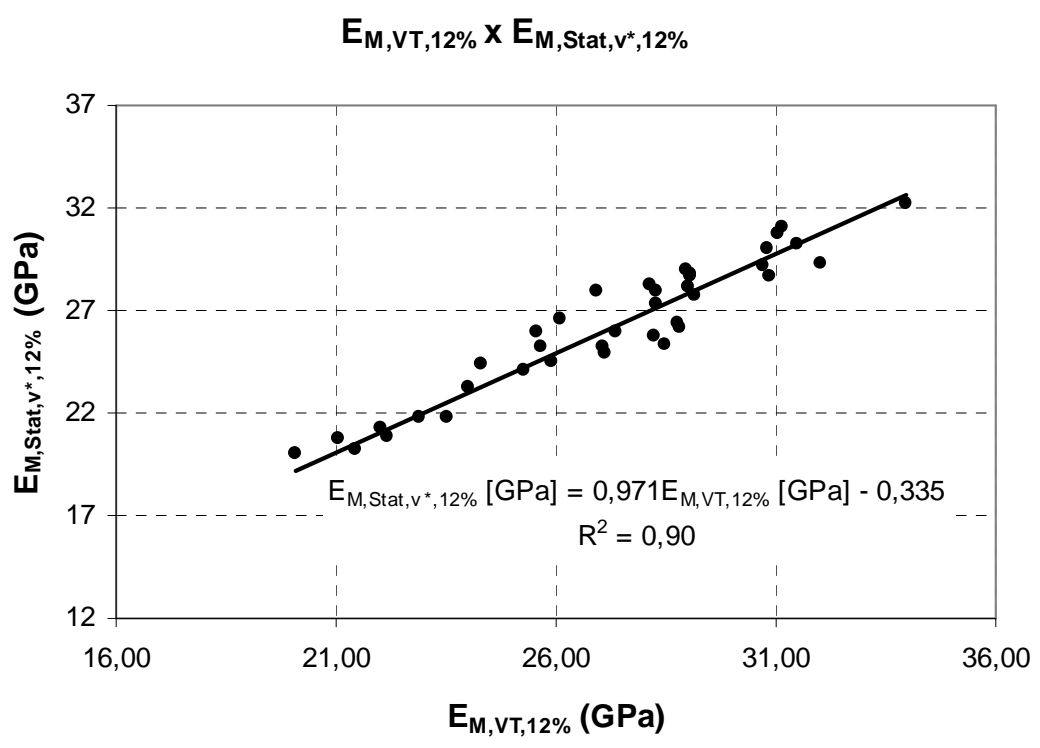

Figura 7.6 - Gráfico de dispersão entre $\mathrm{E}_{\mathrm{M}, \mathrm{VT}, 12 \%}$ e $\mathrm{E}_{\mathrm{M}, \mathrm{Stat}, \mathrm{v}^{*}, 12 \%}$ após eliminação do outlier.

A equação de regressão mostrada na Figura 7.6 (Equação 7.1) foi validada, como se observa no Apêndice D, e foi usada para calibrar o aparelho de vibração transversal para estimativas de $\mathrm{E}_{\mathrm{M}, \mathrm{Stat,v}}{ }^{*}$ a partir de $\mathrm{E}_{\mathrm{M}, \mathrm{VT}}$ para a amostra em questão.

$$
\mathrm{E}_{\mathrm{M}, \mathrm{Stat}, \mathrm{v}^{*}, 12 \%}[\mathrm{GPa}]=0,971 \mathrm{E}_{\mathrm{M}, \mathrm{VT}, 12 \%}[\mathrm{GPa}]-0,335
$$

As Figuras 7.7 e 7.8 mostram os gráficos de dispersão entre os valores do módulo de elasticidade estático e dinâmico exclusivamente para as toras que apresentaram picos de acelerância duplicados para o primeiro modo de flexão. Os valores do módulo de elasticidade dinâmico mostrados na Figura 7.7, foram calculados com a média aritmética das frequências observadas para o primeiro modo de flexão enquanto os da Figura 7.8 foram calculados com a frequência de maior amplitude de acelerância. 


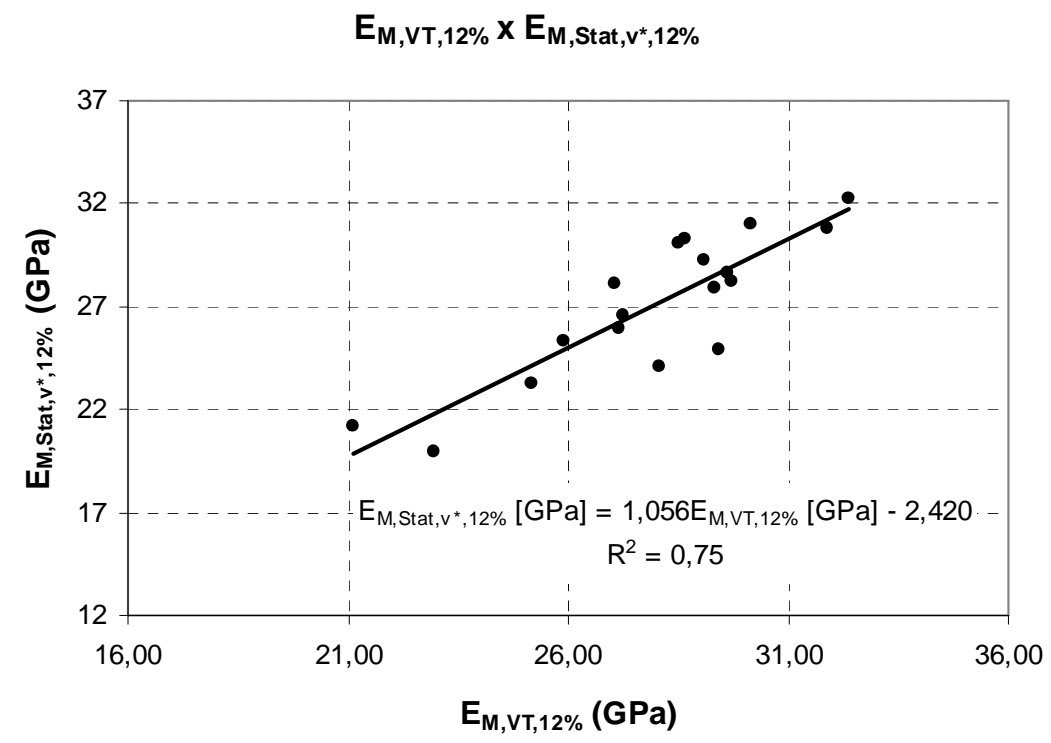

Figura 7.7 - Gráfico de dispersão entre $\mathrm{E}_{\mathrm{M}, \mathrm{VT}}$ e $\mathrm{E}_{\mathrm{M}, \mathrm{Stat}, \mathrm{v}}{ }^{*}$ para as toras com picos de frequência duplicados sendo $\mathrm{E}_{\mathrm{M}, \mathrm{VT}}$ calculado com a média aritmética das frequências.

\section{$E_{M, V T, 12 \%} \times E_{M, S t a t, v^{*}, 12 \%}$}

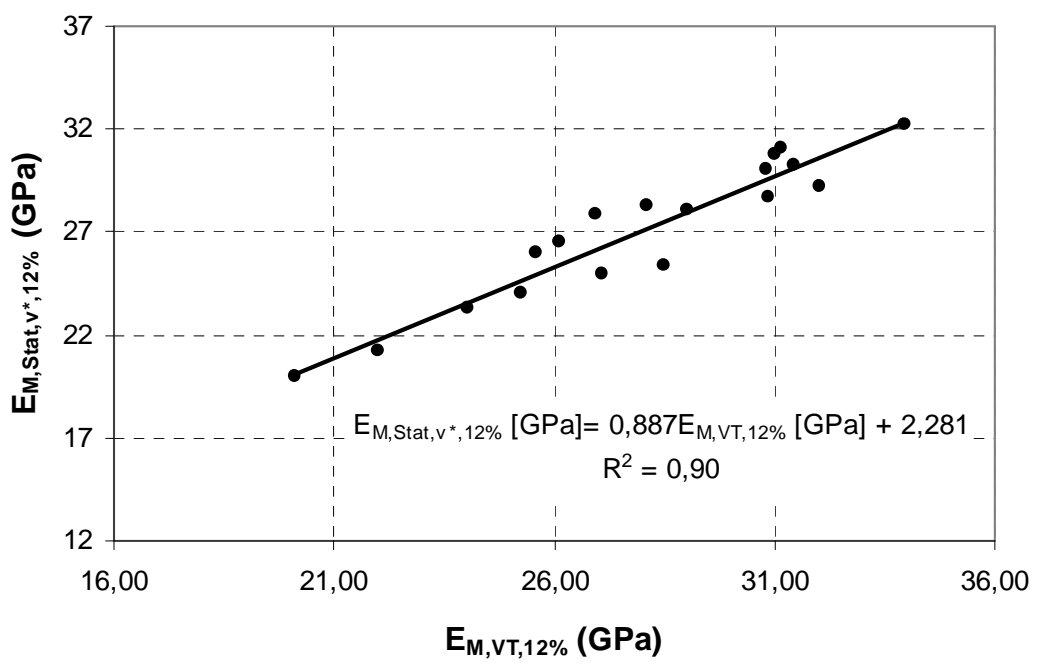

Figura 7.8 - Gráfico de dispersão entre $\mathrm{E}_{\mathrm{M}, \mathrm{VT}}$ e $\mathrm{E}_{\mathrm{M}, \mathrm{Stat,v}}{ }^{*}$ para as toras com picos de frequência duplicados sendo $\mathrm{E}_{\mathrm{M}, \mathrm{VT}}$ calculado com a frequência de maior pico de acelerância.

Embora se observe menor dispersão nos pontos da Figura 7.8 ( $\mathrm{E}_{\mathrm{M}, \mathrm{VT}}$ calculado com a frequência de maior acelerância) o teste de Tukey mostrado na Tabela 7.9 revelou que não há diferença estatisticamente significativa entre os módulos de elasticidade dinâmico calculados com as duas formas de considerar a frequência do primeiro modo das toras. 
Tabela 7.9 - Teste de Tukey.

\begin{tabular}{lcc}
\hline \multicolumn{1}{c}{ Comparação } & Diferença & $\begin{array}{c}\text { Diferença } \\
\text { padronizada }\end{array}$ \\
\hline $\mathrm{E}_{\mathrm{M}, \mathrm{VT}, 12 \%}$ (maior pico) vs $\mathrm{E}_{\mathrm{M}, \mathrm{Stat}, 12 \%}$ & 0,893 & 0,800 \\
$\mathrm{E}_{\mathrm{M}, \mathrm{VT}, 12 \%}$ (maior pico) vs $\mathrm{E}_{\mathrm{M}, \mathrm{VT}, 12 \%}$ (média) & 0,032 & 0,028 \\
$\mathrm{E}_{\mathrm{M}, \mathrm{VT}, 12 \% \text { (média) vs } \mathrm{E}_{\mathrm{M}, \mathrm{Stat}, 12 \%}}$ & 0,862 & 0,772 \\
\hline & & d.m.s. $=3,415$
\end{tabular}

\subsubsection{Determinação do teor de umidade e densidade aparente}

O medidor elétrico tende a subestimar o teor de umidade da madeira. Recomenda-se o emprego desse aparelho para avaliações qualitativas.

Observa-se na Tabela 7.7 uma diferença significativa entre os teores de umidade medidos no cerne e no alburno. Verifica-se também, ainda que menos acentuada, a variação do teor de umidade ao longo do comprimento.

Assim sendo, a determinação de um teor de umidade representativo para a tora requer a medição em vários pontos, principalmente no cerne, o que torna complicada a avaliação do teor de umidade. Por esse motivo, é preferível realizar a avaliação do módulo de elasticidade com as toras saturadas. Essa condição é favorável tanto para a estimativa do módulo de elasticidade a $12 \%$ de umidade quanto para sua identificação pelo medidor elétrico.

Observou-se que todas as toras tinham teor de umidade médio superior a $12 \%$ no momento dos ensaios.

A densidade aparente média a $12 \%$ de umidade foi de $938 \mathrm{~kg} / \mathrm{m}^{3}$, sendo compatível com o valor apresentado no Anexo E da norma NBR 7190 (ABNT, 1997).

\subsubsection{Classificação das toras}

Para avaliar a utilidade do ensaio de vibração transversal na classificação de toras foram definidas três classes de qualidade em função do módulo de elasticidade estático no teor de umidade do ensaio conforme mostra a Tabela 7.10.

Tabela 7.10 - Classes definidas para as toras de Eucalyptus citriodora.

\begin{tabular}{cc}
\hline Classe & Faixa de $\mathbf{E}_{\mathbf{M}, \text { Stat, } \mathbf{u}}(\mathbf{G P a})$ \\
\hline 1 & $28,00-24,01$ \\
2 & $24,00-20,01$ \\
3 & $20,00-16,00$ \\
\hline
\end{tabular}


Para tanto, foi necessário estabelecer a correlação entre os módulos de elasticidade estático e dinâmico na condição saturada para a calibração do equipamento de vibração transversal. A Figura 7.9 mostra o gráfico de dispersão entre os módulos de elasticidade estático e dinâmico no teor de umidade de ensaio.

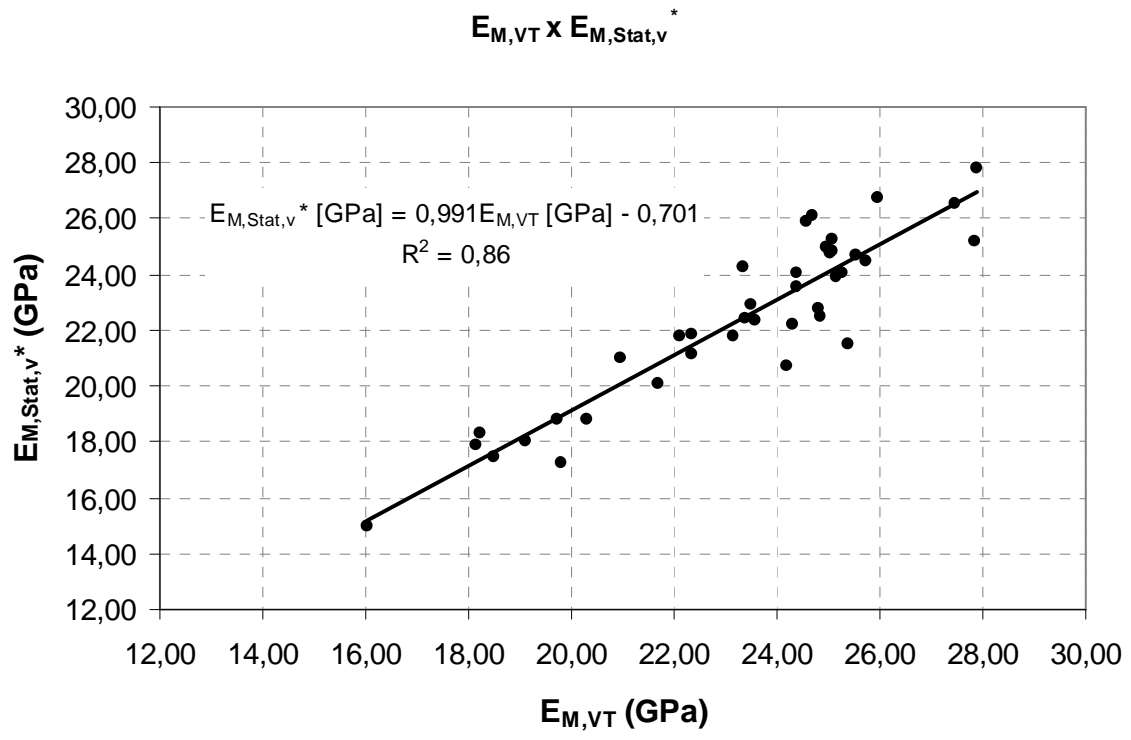

Figura 7.1 - Gráfico de dispersão entre $\mathrm{E}_{\mathrm{M}, \mathrm{VT}}$ e $\mathrm{E}_{\mathrm{M}, \mathrm{Stat}, \mathrm{v}}{ }^{*}$ no teor de umidade de ensaio, sendo $\mathrm{E}_{\mathrm{M}, \mathrm{VT}}$ calculado com a frequência de maior pico de acelerância.

As suposições do modelo de regressão linear foram confirmadas (ver Apêndice D), de forma que a Equação 7.2 pode ser utilizada para estimativas de $\mathrm{E}_{\mathrm{M}, \mathrm{Stat}, \mathrm{v}}{ }^{*}$ a partir de $\mathrm{E}_{\mathrm{M}, \mathrm{VT}}$, no teor de umidade do ensaio.

$$
\mathrm{E}_{\mathrm{M}, \mathrm{Stat},{ }^{*}}[\mathrm{GPa}]=0,991 \mathrm{E}_{\mathrm{M}, \mathrm{VT}}[\mathrm{GPa}]-0,701
$$

Foram classificadas apenas as toras aprovadas na inspeção visual. A Tabela 7.11 mostra o resultado da classificação das toras.

A tora 31 apresentou um valor extremamente elevado para os módulos de elasticidade estático e dinâmico e por esse motivo não foi classificada, sendo descartada da análise. 
Tabela 7.11 - Classificação das toras em função do módulo de elasticidade na flexão.

\begin{tabular}{ccc}
\hline Tora & \multicolumn{2}{c}{ Classificação } \\
$\begin{array}{c}\text { Vibração } \\
\text { transversal }\end{array}$ & $\begin{array}{c}\text { Flexão } \\
\text { estática }\end{array}$ \\
\hline 1 & 1 & 1 \\
2 & 1 & 1 \\
3 & 1 & 1 \\
5 & 2 & 2 \\
9 & 1 & 1 \\
10 & 2 & 2 \\
13 & 2 & 2 \\
14 & 2 & 2 \\
19 & 2 & 1 \\
21 & 1 & 1 \\
22 & 3 & 3 \\
23 & 2 & 2 \\
24 & 2 & 2 \\
25 & 1 & 1 \\
26 & 3 & 3 \\
29 & 2 & 2 \\
31 & $\mathrm{nc}$ & $\mathrm{nc}$ \\
32 & 1 & 1 \\
34 & 2 & 2 \\
37 & 3 & 3 \\
38 & 2 & 2 \\
39 & 2 & 2 \\
40 & 2 & 1 \\
\hline
\end{tabular}

$\mathrm{nc}=$ não classificada

A avaliação do desempenho do método de classificação foi feita com o auxílio da matriz de confusão mostrada na Tabela 7.12.

Tabela 7.12 - Matriz de confusão para a classificação das toras pelo ensaio de vibração transversal.

\begin{tabular}{|c|c|c|c|c|c|c|}
\hline \multirow{2}{*}{\multicolumn{2}{|c|}{ Classe }} & \multicolumn{3}{|c|}{ Vibração transversal } & \multirow{3}{*}{$\begin{array}{c}\begin{array}{c}\text { Precisão na } \\
\text { classe }\end{array} \\
78 \% \\
\end{array}$} & \multirow{3}{*}{$\begin{array}{c}\begin{array}{c}\text { Precisão } \\
\text { total }\end{array} \\
91 \%\end{array}$} \\
\hline & & 1 & 2 & 3 & & \\
\hline \multirow{3}{*}{ 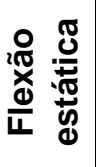 } & 1 & 7 & 2 & 0 & & \\
\hline & 2 & 0 & 10 & 0 & $100 \%$ & \\
\hline & 3 & 0 & 0 & 3 & $100 \%$ & \\
\hline
\end{tabular}

Observa-se que houve concordância na classificação pelos dois métodos de ensaio em $20(91 \%)$ das 22 toras aprovadas na inspeção visual. As duas toras em que houve divergência foram classificadas pelo ensaio de vibração transversal na classe de qualidade 2 em vez da 1 , ficando dessa maneira a favor da segurança. 


\subsubsection{Correlação entre as propriedades físicas e mecânicas}

Foi feito o teste de correlação linear entre as propriedades dimensionais, físicas e mecânica das toras da amostra de validação. Como resultado obteve-se a Tabela 7.13 na qual observa-se o coeficiente de determinação encontrado para as correlações entre as propriedades físicas e mecânicas das toras.

A análise da Tabela 7.13 permite observar que:

- A densidade aparente não mostrou boa correlação com alguma outra propriedade física ou mecânica;

- O teor de umidade obtido com o medidor elétrico $\left(\mathrm{U}_{\mathrm{el}}\right)$ apresentou fraca correlação $\left(\mathrm{R}^{2}=0,42\right)$ com o teor de umidade médio medido conforme ensaio da norma NBR 7190 (ABNT, 1997) (U $\left.U_{\text {gr }}\right)$.

- As características de crescimento das toras como encurvamento (Enc.), fibras torcidas (F.T.), diâmetro dos nós ( $\left.\mathrm{D}_{\text {nó }}\right)$, desvio da seção circular $\left(\Delta_{\text {circ }}\right)$, fendas, conicidade $(\mathrm{C})$ e coeficiente de variação do diâmetro $\left(\Delta_{\mathrm{D}}\right)$ não apresentaram correlação significativa com a rigidez à flexão;

- A diferença entre $E_{M, V T}$ e $E_{M, s t a t}$ não apresentou correlação com nenhuma propriedade das toras;

- Foi encontrada uma forte correlação entre o módulo de elasticidade medido com o ensaio de vibração transversal e o ensaio de flexão estática;

Tabela 7.13 - Coeficiente de determinação $\left(\mathrm{R}^{2}\right)$ entre as propriedades físicas e mecânicas.

\begin{tabular}{|c|c|c|c|c|c|c|c|c|c|c|c|c|c|c|c|c|c|}
\hline \multirow{2}{*}{\multicolumn{2}{|c|}{ Variáveis }} & \multirow{2}{*}{$\rho_{\mathrm{ap}}$} & \multirow{2}{*}{$\mathrm{U}_{\mathrm{el}}$} & \multirow{2}{*}{$U_{g r}$} & \multicolumn{2}{|c|}{ Fenda } & \multirow{2}{*}{ Enc. } & \multirow{2}{*}{ F.T. } & \multirow{2}{*}{$D_{\text {nó }}$} & \multicolumn{2}{|c|}{$\Delta_{\text {circ }}$} & \multirow{2}{*}{$\mathrm{L} / \mathrm{D}_{\text {meio }}$} & \multirow{2}{*}{ C } & \multirow{2}{*}{$\Delta_{\mathrm{D}}$} & \multirow{2}{*}{$\mathrm{E}_{\mathrm{M}, \text { stat }}$} & \multirow{2}{*}{$\mathrm{E}_{\mathrm{M}, \mathrm{VT}}$} & \multirow{2}{*}{$\begin{array}{l}\mathrm{E}_{\mathrm{M}, \mathrm{VT} \mathrm{T}^{-}} \\
\mathrm{E}_{\mathrm{M}, \mathrm{stat}}\end{array}$} \\
\hline & & & & & Topo & Base & & & & Topo & Base & & & & & & \\
\hline$\rho_{\mathrm{ap}}$ & & 1,00 & 0,10 & 0,23 & 0,03 & 0,15 & 0,03 & 0,00 & 0,04 & 0,14 & 0,04 & 0,00 & 0,32 & 0,19 & 0,00 & 0,00 & 0,00 \\
\hline$U_{\mathrm{el}}$ & & & 1,00 & 0,42 & 0,00 & 0,04 & 0,08 & 0,06 & 0,01 & 0,00 & 0,04 & 0,11 & 0,05 & 0,01 & 0,02 & 0,01 & 0,01 \\
\hline$U_{\mathrm{gr}}$ & & & & 1,00 & 0,01 & 0,02 & 0,00 & 0,02 & 0,02 & 0,00 & 0,00 & 0,14 & 0,10 & 0,06 & 0,06 & 0,04 & 0,03 \\
\hline \multirow{2}{*}{ Fenda } & Topo & & & & 1,00 & 0,20 & 0,04 & 0,33 & 0,02 & 0,03 & 0,01 & 0,04 & 0,02 & 0,11 & 0,06 & 0,06 & 0,00 \\
\hline & Base & & & & & 1,00 & 0,03 & 0,03 & 0,00 & 0,13 & 0,01 & 0,00 & 0,01 & 0,04 & 2 & 2 & 0,00 \\
\hline \multirow{2}{*}{\multicolumn{2}{|c|}{$\begin{array}{l}\text { Encurv. } \\
\text { F. T. }\end{array}$}} & & & & & & 1,00 & 0,00 & 0,00 & 0,00 & 0,03 & 0,01 & 0,00 & 0,01 & 0,00 & 0,00 & 0,02 \\
\hline & & & & & & & & 1,00 & 0,00 & 0,01 & 0,00 & 0,07 & 0,00 & 0,05 & 0,01 & 0,00 & 0,03 \\
\hline \multicolumn{2}{|l|}{$D_{\text {nó }}$} & & & & & & & & 1,00 & 0,00 & 0,00 & 0,01 & 0,02 & 0,01 & 0,11 & 0,11 & 0,00 \\
\hline & Topo & & & & & & & & & 1,00 & 0,02 & 0,08 & 0,04 & 0,00 & 0,03 & 0,03 & 0,00 \\
\hline & Base & & & & & & & & & & 1,00 & 0,00 & 0,02 & 0,04 & 0,01 & 0,01 & 0,00 \\
\hline \multicolumn{2}{|l|}{$L / D_{\text {meio }}$} & & & & & & & & & & & 1,00 & 0,00 & 0,05 & 0,02 & 0,03 & 0,03 \\
\hline \multicolumn{2}{|l|}{$C$} & & & & & & & & & & & & 1,00 & 0,49 & 0,01 & 0,01 & 0,00 \\
\hline \multicolumn{2}{|l|}{$\Delta_{\mathrm{D}}$} & & & & & & & & & & & & & 1,00 & 0,00 & 0,00 & 0,03 \\
\hline \multicolumn{2}{|l|}{$\mathrm{E}_{\mathrm{M} \text {,stat }}$} & & & & & & & & & & & & & & 1,00 & 0,90 & 0,05 \\
\hline \multicolumn{2}{|l|}{$\mathrm{E}_{\mathrm{M}, \mathrm{VT}}$} & & & & & & & & & & & & & & & 1,00 & 0,01 \\
\hline \multicolumn{2}{|c|}{$E_{M, V T}-E_{M, \text { stat }}$} & & & & & & & & & & & & & & & & 1,00 \\
\hline
\end{tabular}




\subsection{Conclusões}

\subsubsection{Inspeção visual das toras}

A inspeção visual das toras pela norma ANSI O5.1 (ANSI, 2002) resultou na reprovação de $17(42,5 \%)$ toras.

Defeitos como encurvamentos excessivos e nós de grande diâmetro foram os responsáveis pela reprovação de 12 toras. Esses defeitos poderiam ser controlados por meio do manejo da floresta resultando em índice de aprovação maior na amostra.

\subsubsection{Correlação entre os módulos de elasticidade estático e dinâmico}

Após a eliminação da observação extrema (tora 31) foi obtida uma forte correlação entre os módulos de elasticidade medidos com a técnica de vibração transversal e com o ensaio de flexão estática.

A equação de regressão linear entre os módulos de elasticidade estático e dinâmico mostrada na Figura 7.6 apresentou coeficiente angular próximo de 1,00 e com constante muito próximo de zero, denotando uma forte correlação entre os dados. Esse resultado demonstra que o método de ensaio proposto pode ser empregado para avaliação da rigidez à flexão de toras de madeira com boa exatidão.

Observou-se que não há diferença estatisticamente significativa entre os módulos de elasticidade dinâmicos calculados com a frequência de maior pico de acelerância ou com a média das frequências do primeiro modo de flexão.

\subsubsection{Determinação do teor de umidade e densidade aparente}

A determinação do módulo de elasticidade das toras seja pelo ensaio de vibração transversal ou de flexão estática deve ser feita preferencialmente com as toras na condição saturada.

O valor encontrado para a densidade aparente a $12 \%$ é compatível com a espécie Eucalyptus citriodora.

\subsubsection{Classificação das toras}

O alto índice de concordância de resultados na classificação das toras entre os ensaios de flexão estática e vibração transversal indicam que o método de ensaio de vibração 
transversal proposto no Capítulo 6 mostrou-se eficiente para a classificação estrutural de toras de madeira.

\subsubsection{Correlação entre as propriedades físicas e mecânicas}

Como era esperado a densidade aparente e o teor de umidade não mostraram boa correlação com as propriedades mecânicas pelo fato do teor de umidade das toras estar acima do ponto de saturação das fibras.

As propriedades dimensionais e os defeitos não mostraram significativa correlação com a rigidez. Assim sendo, pode-se supor que a continuidade das fibras e o confinamento dos nós contribuem para a transmissão de tensões minimizando a interferência dos defeitos localizados no módulo de elasticidade. 


\section{CONCLUSÕES FINAIS}

Este trabalho teve por objetivo propor um método de ensaio para estimar o módulo de elasticidade na flexão de toras de madeira por meio de vibração transversal. Para tanto foram realizados diversos estudos com os quais foram obtidas várias conclusões. Neste capítulo são destacadas as principais conclusões obtidas em cada etapa do trabalho.

- Para o ensaio de vibração transversal com as toras em suspensão livre-livre, o módulo de elasticidade deve ser calculado com o diâmetro medido na metade do comprimento;

- No ensaio de flexão estática com a base da tora engastada, o módulo de elasticidade pode ser calculado empregando-se o diâmetro adotado pelas normas NBR 6231 (ABNT, 1980) e ASTM D 1036 (ASTM, 2005) ou o diâmetro medido a 0,70L de distância a partir da extremidade mais delgada da tora;

- No ensaio de flexão estática com a tora simplesmente apoiada, o módulo de elasticidade pode ser calculado com o diâmetro medido na metade do comprimento;

- O esforço cortante pode ser desprezado no cálculo do módulo de elasticidade dinâmico pelo ensaio de vibração transversal para valores de $L / D_{\text {meio }}$ igual ou maiores do que 21

- O ensaio de vibração transversal pode ser realizado com excitação em uma extremidade e medição da aceleração na outra extremidade da tora;

- Observou-se que a conicidade, a forma da seção transversal ( $\left.\Delta_{\text {circ }}\right)$ e o encurvamento não apresentaram correlação com o módulo de elasticidade dinâmico das toras. Assim sendo não devem ser utilizados como estimador dessa propriedade;

- O emprego da Equação 4.7 para calcular o módulo de elasticidade considerando-se a influência do esforço cortante resultou, na maioria dos casos, em valores 
incorretos. Diante desses resultados, fica evidente que não é recomendável empregar essa equação para estimar o módulo de elasticidade de toras e em substituição a essa equação sugere-se o emprego da Equação 4.8;

- O medidor de umidade elétrico tende a subestimar o teor de umidade das toras servindo apenas para uma avaliação qualitativa;

- É recomendável realizar a determinação do módulo de elasticidade das toras, seja qual for o ensaio, com as mesmas na condição saturada;

- No ensaio de vibração transversal com excitação horizontal uma parcela menor da energia de excitação foi absorvida pelo sistema de suspensão resultando em maiores amplitudes de acelerância em relação ao ensaio com excitação vertical. Assim sendo, verificou-se que o ensaio com excitação horizontal é mais indicado para avaliação da rigidez à flexão das toras de madeira;

- O módulo de elasticidade dinâmico das toras pode ser calculado pela Equação 4.5.

- Na existência de picos múltiplos de acelerância para o primeiro modo de flexão, é recomendável calcular o módulo de elasticidade dinâmico com a frequência correspondente ao pico de maior amplitude;

- O módulo de elasticidade dinâmico permanece constante para teores de umidade acima do ponto de saturação das fibras;

- Para teores de umidade acima do ponto de saturação das fibras, pode-se admitir que o módulo de elasticidade dinâmico permanece constante e igual ao valor obtido no ponto de saturação;

- O módulo de elasticidade obtido no ensaio de vibração transversal no teor de umidade do ensaio pode ser corrigido para o teor de umidade de $12 \%$ utilizando-se a equação recomendada pela norma NBR 7190 (ABNT, 1997);

- A partir das conclusões citadas anteriormente foi elaborado o método de ensaio apresentado no Capítulo 6 o qual foi validado como mostrado no Capítulo 7 e verificou-se que o método de ensaio proposto aliado ao sistema de avaliação nãodestrutiva desenvolvido pelo autor possibilitou obter estimativas precisas do módulo de elasticidade das toras de madeira de forma rápida, simples e eficaz sendo de grande utilidade para a classificação estrutural de toras de madeira. 


\section{REFERÊNCIAS}

AGILENT TECHNOLOGIES. Fundamentals of Signal Analysis. Série: Introduction to Time, Frequency and Modal Domains. Application Note 1405-1. 5988-6765EN Estados Unidos. 2002.

ALDEN, H. A. Softwoods of North America. Gen. Tech. Rep. FPL-GTR-102.. Madison, WI: U.S. Department of Agriculture, Forest Service, Forest Products Laboratory.1997. $151 \mathrm{p}$.

ALLEMANG, R.J.; BROWN, D. L. Experimental Modal Analysis. In: HARRIS, C.M.; PIERSOL, A.G. Harris' shock and vibration handbook. 5 ed. New York: McGraw-Hill, 2002. Capítulo 21, p. 21.1-21.72.

ALLEMANG, R.J. The Modal Assurance Criterion-Twenty Years of Use and Abuse. Sound and vibration. Agosto de 2003.

ALLEMANG, R. Vibration III: Course notes. University of Cincinnati. Structural Dynamics Research Labs. Cincinnati. 2008. Disponível em http://www.sdrl.uc.edu/academic-course-info/vibrations-iii-20-263-663. Acesso em: 03 jul. 2008.

AMERICAN NATIONAL STANDARD INSTITUTE. ANSI O5.1. American national standard for wood poles: specification and dimensions. Washington, DC. 2002.

AMERICAN SOCIETY OF TESTING AND MATERIAL. ASTM D 1036 Standard Test Methods of Static Tests of Wood Poles. Philadelphia, PA. 2005.

AMERICAN SOCIETY OF TESTING AND MATERIAL. ASTM D 198 - Standard Test Methods of Static Tests of Lumber in Structural Sizes. Philadelphia, PA. 2008.

AMERICAN SOCIETY OF TESTING AND MATERIAL. ASTM D1990. Standard Practice for Establishing Allowable Properties for Visually Graded Dimension Lumber From In-Grade Test of Full-Size Specimens. Philadelphia, PA. 1997.

AMERICAN SOCIETY OF TESTING AND MATERIAL. ASTM D 25 - Standard Specification for Round Timber Piles. Philadelphia, PA. 1998.

AMERICAN SOCIETY OF TESTING AND MATERIAL. ASTM D 3957 Establishing Stress Grades for Structural Members in Log Buildings. Philadelphia, PA. 1990. 
AMERICAN SOCIETY OF TESTING AND MATERIAL. ASTM D 6874 Standard Test Method for nondestructive Evaluation of Wood-Based Flexural Members Using Transverse Vibration. Philadelphia, PA. 2003.

ASSOCIAÇÃO BRASILEIRA DE NORMAS TÉCNICAS - ABNT. NBR 7190 Projeto de Estruturas de Madeira. Rio de Janeiro. 1997.

ASSOCIAÇÃO BRASILEIRA DE NORMAS TÉCNICAS - ABNT. NBR 6231 Postes de madeira - resistência à flexão. Rio de Janeiro. 1980.

ASSOCIAÇÃO BRASILEIRA DOS PRODUTORES DE FLORESTAS PLANTADAS - ABRAF - Anuário Estatístico da ABRAF: Brasília: 2011. 130p.

AVITABILE, P. Which Shaker excitation is best? Is there any difference?. Modal space in our own little world. SEM experimental Techniques. 1998. 2 p.

Is there any difference between a modal test with a shaker excitation or impact excitation?. Modal space in our own little world. SEM experimental Techniques. 1998a. 2 p.

Can the test setup have an effect on the modal data?. Modal space in our own little world. SEM experimental Techniques. 2001. 2 p.

When impact testing, can the use of an exponential windows cause any problems ?. Modal space in our own little world. SEM experimental Techniques. 2001a. 2 p.

What are some of the most important things to consider when impact testing?. Modal space in our own little world. SEM experimental Techniques. 2001b. 2 p.

BALLARIN, A. W. NOGUEIRA, M. Caracterização elástica da madeira de Eucalyptus citriodora. Cerne. Vol 9. $\mathrm{N}^{\mathrm{o}}$ 1. p. 66-80. 2003.

BALLARIN, A. W. TARGA, L. A.; PALMA, H. A. L. Ensaios não-destrutivos de vibração transversal na avaliação do módulo de elasticidade de madeiras de reflorestamento. In: ENCONTRO BRASILEIRO EM MADEIRAS E ESTRUTURAS DE MADEIRA, 8. 2002. Uberlândia-MG.

BARRET, J. D.; HONG, J. P. Moisture content adjustments for dynamic modulus of elasticity of wood members. In: Wood Science and Technology. v.44; $\mathrm{N}^{\mathrm{o}}$. 3, p 485495. 2010.

BARTHOLOMEU, A. ; GONÇALVES, R. ; GUIMARAES, I. ; CAMARGO, J. I. Metodologia simplificada para o ensaio de vibração transversal em vigas estruturais de Angelim Araroba. In: ENCONTRO BRASILEIRO EM MADEIRAS E ESTRUTURAS DE MADEIRA, 9. 2004. Cuiabá-MT.

BEARDS, C. F. Engineering Vibration Analysis with Application to Control Systems. ISBN 034063183 X. Londres: Edward Arnold. 1995426 p. 
BLAY, D.; BOURGAIN, L.; SAMSON, G. Application of Electro-Acoustical Techniques to the Determination of the Modulus of Elasticity by a NonDestructive Process. Technical Review to Advance Techniques in Acoustical, Electrical and Mechanical Measurement. Bruel \& Kjaer. Dinamarca. v. 4, p. 13-19, 1971.

BOX, G. E. P. ; COX, D. R. An Analysis of Transformations. In: Journal of the Royal Statistical Society. Series B (Methodological), Vol. 26, N ${ }^{\mathrm{o}}$. 2, p. 211-243. 1964.

BOYCE, W. E.; DIPRIMA, R. C. Elementary Differential Equation and Boundary Value Problems. 7 ed. John Wiley \& Sons. New York. 2001

BRAGA, N. C. Como funcionam os conversores A/D - Parte I. Revista Saber Eletrônica. Editora Saber. Ano 42, Número 402. Julho de 2006.

BRANCHERIAU, L.; BAILLERES, H. Natural vibration analysis of clear wood beams: a theoretical review. Wood Science and Technology. Vol 36. . p 347-365. 2002.

BRÜEL \& KJÆR. Vibration transducers and signal conditioning. Sound and Vibration Measurement A/S. Disponível em: www.bksv.com/lectures/BA767512.pdf. Acesso em: 16 out. 2008.

BRÜEL \& KJÆR. 8206 Impact Hammer. Disponível em: http://www.bksv.com/products/transducersconditioning/vibrationtransducers/impactha mmers/8206.aspx. Acesso em: 28 out. 2008a.

BRÜEL \& KJÆR. Product data - Mini shaker 4810. Disponível em: http://www.bksv.com/doc/bp0232.pdf. Acesso em: 28 out. 2008 b.

BUCUR, B. Techniques for High Resolution Imaging of Wood Structure. In: 16th WCNDT 2004 - World Conference on NDT. CD-ROM Proceedings. Montreal, Canadá. 2004. Disponível em: http://www.ndt.net/abstract/wcndt2004/585.htm. Acesso em: 25 set. 2008

BUCUR, V. Ultrasonic Techniques for Nondestructive Testing of Standing Trees. Ultrasonics. Vol. 43, n. 4, p. 237-239, 2005.

CALIL JR., C ; MINÁ, A. J. S. Vibração transversal: Um método eficiente para classificação de peças estruturais de madeira. Revista Brasileira de Engenharia Agrícola e Ambiental, Campina Grande, v.7, n.2. p.335-338. 2003

CALONEGO, F. W. ; BATISTA, W. R. ; SEVERO, E. T. D.; SANTOS, J. E. G.; RIBAS, C. Avaliação do teor de umidade da madeira de Eucalyptus grandis por medidores elétricos resistivos. Revista do Instituto Florestal. São Paulo, v. 18, n. único, p. 71-78, dez. 2006.

CARREIRA, M. R.; CHEUNG, A. B.; OLIVEIRA, F. G. R.; DIAS, A. A.; CALIL JR, C.; SAlES, A. STAMATO, G. C. Avaliação de Técnicas Não-Destrutivas Aplicadas à Madeira de Pinus sp. In: PAN AMERICAN CONFERENCE FOR NONDESTRUCTIVE TESTING - PANND, 3. 2003. Rio de Janeiro - RJ. 
CARREIRA, M. R. ; CANDIAN, M. Teste de um Equipamento Para Classificação de Peças Estruturais de Madeira Pela Técnica da Vibração Transversal. Semina: Ciências Exatas e Tecnológicas, Universidade Estadual de Londrina. Londrina. No prelo. 2007

CARREIRA, M. R. ; DIAS, A. A. Relatório de ensaio de vibração transversal em toras pequeno diâmetro de Eucalyptus citriodora. Material não publicado. São Carlos. 2007.

CARTZ, L. Nondestructive Testing: Radiography, Ultrasonics, Liquid Penetrant, Magnetic Particle, Eddy Current. ASM International. ISBN 0871705176, 9780871705174, 1996. 229 p.

CERALDI, C.; MORMONE, V.; RUSSO ERMOLLI, E. Resistographic inspection of ancient timber structures for the evaluation of mechanical characteristics. Materials and Structures. v. 34, Janeiro-Fevereiro. p. 59-64. 2001

CHO, C.L. Comparison of Three Methods for Determining Young's Modulus of Wood. Taiwan Journal of Forest Science. v.22, n. 3. p. 297-306. 2007.

CHUANSHUANG, H.; MUHAMMAD, T. A. A statistical algorithm for comparing mode shapes of vibration testing before and after damage in timbers. Journal of Wood Science. v. 54. p. 348-352. 2006.

CHUI, Y. H.; BARCLAY, D. W.; COOPER, P. A. Evaluation of Wood Poles Using a Free Vibration Technique. Journal of Testing and Evaluation. v. 27, n. 3. p. 191195. 1999.

CHUI, Y. H. Simultaneous evaluation of bending and shear moduli of wood and the influence of knots on these parameters. Wood Science and Technology. v. 25, n. 2. p. 125-134. 1991.

CLOUGH, R. W.; PENZIEN, J. Dynamics of Structures. $3^{\text {a }}$ ed. Berkeley: Computers \& Structures. 1995.

COOPER, J. E.; STEELE, P.H.; MITCHELL, B.K.; BODEN, C.; LIONHEART, W. R. B. Detecting Juvenile Wood in Southern Pine Logs with Brush Electrodes. In: International Electrical Impedance Conference, 9. 2008. New Hampshire.

COSTA, O. L.; GONÇALVES, R. Influência da umidade na velocidade de propagação de ondas de ultra-som na madeira de Pinus sp, nas direções radial, tangencial e longitudinal. In: ENCONTRO BRASILEIRO EM MADEIRAS E ESTRUTURAS DE MADEIRA, 8. 2002. Uberlândia-MG.

COSTELLO, L.R.; QUARLES, S. L. Detection of Wood Decay in Blue Gum and Elm: An Evaluation of The Resistograph ${ }^{\circledR}$ and The Portable Drill. Journal of Arboriculture. v. 25, n. 6. p. 311-318. 1999.

CUNHA, A.; CAETANO, E. Experimental Modal Analysis of Civil Engineering Structures. Sound and Vibration. v. 6, n. 40. p. 12-20. 2006. 
DEFLORIO. G. ; SIEGFRIED, F.; SCHWARZWE, F. W. M. R. Detection of incipient decay in tree stems with sonic tomography after wounding and fungal inoculation. Wood Science Technology. v. 42. p. 117-132. 2008.

DIVÓS, F.; SZALAL, L. Tree Evaluation by Acoustic Tomography. In: INTERNATIONAL SYMPOSIUM ON NDT OF WOOD, 13. 2002. Berkeley.

DOEBELIN, E. O. Measurement Systems: application and design. $5^{\mathrm{a}}$ ed. New York: MCGraw-Hill. 2004.

EMERSON, N. R. ; POLLOCK, D. G. ; KAINZ, J. A. ; FRIDLEY, K. J. ; MCLEAN, D. L. ; ROSS, R. J. Nondestructive Evaluation Techniques for Timber Bridges. In: World Conference on Timber Engineering, 5. 1998. Montreux, Suiça.

EWINS, D. J. Modal Testing: Theory and Practice. Inglaterra: John Wiley \& Sons. 1984.

EWINS, D. J. Model validation: Correlation for updating. Sädhanã. Vol. 25. Part 3. p. 221-234. 2000.

FAKOPP ENTERPRISE. FAKOPP 2D - Acoustic tomography for tree evaluation. Disponível em: http://www.fakopp.com/fakopp2d/fakopp2d.htm. Acesso em: 25 set. 2008.

FEIO, A. O.; MACHADO, J. S.; LOURENÇO, P. B. Compressive behavior and NDT correlations for chestnut wood (Castanea sativa Mill.). In: International Seminar on Structural Analysis of Historical Constructions, 4. Padova. 2005.

FORREST, D. Careful Planning Improves Impact Testing. Realtime Update. Spring 1995. Hewlett-Packard. 1995.

FOTSCH, D. ; EWINS, D. J. Application of MAC in the frequency domain. In: International modal analysis conference No18. XVIII IMAC. Vol. 4062 (2). p. 12251231. 7-10 Fevereiro de 2000. 1996. San Antonio-TX.

FRÝBA, L. Vibration of solids and structures under moving loads. Praga: Thomas Telford. 1999.

GANTZ C. H. Evaluating the Efficiency of the Resistograph To Estimate genetic Parameters For Wood Density in Two Softwood and Two Hardwood Species. Dissertação de mestrado. Faculty of North Carolina State University. Department of Forestry. 2002.

GONÇALVES, R.; GRAZIANO MAGALHÃES, P. S.; HERRERA, S.; BARTHOLOMEU, A. Using Ultrasonic Wave Propagation to Grading New Wooden and Concrete Poles. E-Journal of Nondestructive Testing and Ultrasonics, v. 12. 5 p. 2007.

GONÇALVES, R.; PUCCINI, C. T. Utilização do ultra-som na avaliação de aspectos de qualidade da madeira. In: ENCONTRO BRASILEIRO EM MADEIRAS E ESTRUTURAS DE MADEIRA, 7. 2000. São Carlos-SP. 
GREEN, D. W.; GORMAN, T. M.; EVANS, J. W.; MURPHY, J.F. Improved grading system for structural logs for log homes. Forest Products Journal. Madison: v. 54, n. 9. 2004.

GREEN, D. W. ; GORMAN, T. M. ; EVANS, J. W.; MURPHY, J. F. Mechanical Grading of Round Timber Beams. Journal of Materials in Civil Engineering. Edição de Janeiro/Fevereiro. American Society of Civil Engineers. 2006.

GSELL, D.; FELTRIN, G.; SCHUBERT, S.; STEIGER, R.; MOTAVALLI, M. CrossLaminated Plates: Evaluation and Verification of Homogenized Elastic Properties. Journal of Structural Engineering. v. 133, n. 1. p. 132-138. 2007.

HARRIS, C. M. Measurement Techniques. In: HARRIS, C.M.; PIERSOL, A.G. Harris' shock and vibration handbook. 5 ed. New York: McGraw-Hill, 2002. Capítulo 15, p. 15.1-15.23.

HEARMON, R. F. S. The influence of shear and rotary inertia on the free flexural vibration of wooden beams. British Journal of Applied Physics. n. 9. p. 381-388. 1958.

HE, J.; FU, Z. F. Modal analysis. Estados Unidos: Butterworth-Heinemann. 2001.

HELlMEISTER, L. A. V. Aplicação do método das ondas de tensão na caracterização mecânica de toras, pranchas e tábuas de pinus taeda L. 2003. 107 p. Tese (Doutorado em agronomia). Faculdade de Ciências Agronômicas, Campus de Botucatu, Universidade Estadual Paulista. Botucatu. 2003.

HEYLEN, W.; JANTER, T. Extensions of the Modal Assurance Criterion. Journal of Vibration and Acoustics. Vol. 112. p. 468-472. 1990.

HIJMISSEN, J.W.; VAN HORSSEN, W. T. On transverse vibrations of a vertical Timoshenko beam. Journal of Sound and Vibration. V. 314, n. 2. p. 161-179. 2007.

INSTITUTO BRASILEIRO DE GEOGRAFIA E ESTATÍSTICA. Produção da Extração Vegetal e da Silvicultura 2010. Disponível em : http://www.ibge.gov.br/home/estatistica/economia/pevs/2010/pevs2010.pdf. Acesso em: 20/03/2012.

IML. IML Resistograph F-Series. Disponível em : http://www.imlusa.com/html/iml_resistograph.html. Acesso em: 29 set. 2008.

ÍNIIGUEZ GONZÁLES, G.; ARRIAGA MARTITEGUI, F.; ESTEBAN HERRERO, M. Los Métodos de Vibración Como Herramienta No Destructiva Para La Estimación de las Propiedades Resistentes de la Madera Aserrada Estructural. Informes de la Construcción.v. 59, n. 506. p. 97-105. ISSN: 0020-0883. 2007.

INTERSIL. Principles of Data Acquisition and Conversion. Application Note. AN 002. Intersil Corporation. Melbourne, FL. 1997.

IOTECH. Signal Conditioning \& Pc-Based Data Acquisition Handbook. Iotech, Inc. ISBN: 0-9656789-0-3. 1997. 
KAK, A.; SLANEY, M. Principles of Computerized Tomographic Imaging. Society of Industrial and Applied Mathematics. 327 pg. ISBN-13: 978-0-89871494-4 / ISBN-10: 0-89871-494-X. Philadelphia, PA. 2001.

KARNOVSKY, I. A. LEBED, O. I. Formulas for Structural Dynamics: Tables, Graphs and Solutions. ISBN 0-07-136712-8. Canadá: McGraw-Hill. 2001.

KAWAMOTO, S. ; WILLIAMS, R. S. Acoustic Emissions and Acousto-Ultrasonic Techniques for Wood and Wood-Based Composites - A Review. . FPL-GTR-104. Madison, WI: United States Departament of Agriculture. Forest Products Laboratory. 2002. 16 p.

KLOUTSEY, A. E. H. Correção de modelos elementos finitos - Estudo de um conjunto rotor-gerador. 2007. 105 p. Dissertação (Mestrado em Ciências Mecânicas). Departamento de Engenharia Mecânica. Faculdade de Tecnologia. Universidade de Brasília. Brasília. 2007.

KOLlmAN, F. F. P.; W. A. CÔTE J.R. Principles of Wood Science and Technology I. Solid Wood. New York, Springer Vellag, 1968. 592 p.

KUBOJIMA, Y.; OHTANI, T.; YOSHIHARA, H. Effects of Shear deflection on vibrational properties of compressed wood. Wood Science Technology. v. 38, n. 3. p 237-244. 2004.

KUBOJIMA, Y.; TONOSAKI, M.; YOSHIHARA, H. Young's modulus obtained by flexural vibration test of a wooden beam with inhomogeneity of density. Journal of Wood Science. v. 52, n. 1. p 20 -24. 2006.

LDS TEST AND MEASUREMENT. Understanding FFT Windows. Application note AN014.USA. 2003.

LEVAN, S. Program on Small-Diameter and Underutilized Forest Material. Forest Products Laboratory. 2 p. Madison-WI. 2003. Disponível em: http://www.fpl.fs.fed.us/tmu/resources/documents/sdu_program.pdf. Acesso em: out 2006.

LIMA, J. T., SARTÓRIO, R. C. ; TRUGILHO, P. F.; DA CRUZ, C. R.; VIEIRA, R. D. S. Uso do resistógrafo para estimar a densidade básica e a resistência à perfuração da madeira de Eucalyptus. Scientia Forestalis. n. 75, set. p. 85-93. 2007.

LOPES, W. Variação da aceleração da gravidade com a latitude e altitude. Cad. Bras. Ens. Fís. v. 25, n. 3: p. 561-568, dez. 2008.

LOYA, J. A.; RUBIO, L.; FERNÁNDEZ-SÁEZ, J. Natural frequencies for bending vibrations of Timoshenko cracked beams. Journal of Sound and vibration. v. 290. p. 640-653. 2006.

MAIA, N. M. M.; SILVA, J. M. M. Modal analysis identification techniques. Philosophical Transactions: Mathematical, Physical and Engineering Sciences. No 359. p. 29-40. 2001. 
MANTILLA CARRASCO, E. V; AZEVEDO JUNIOR, A.P. Princípios gerais de propagação de ondas ultra-sônicas em madeiras. In: ENCONTRO BRASILEIRO EM MADEIRAS E ESTRUTURAS DE MADEIRA, 8. 2002. Uberlândia-MG.

MCCONNELL, K. G. Vibration Testing. Theory and Practice. United States: John Wiley \& Sons. 1995.

MINÁ, A. J. S.; OLIVEIRA, F. G. R.; CALIL JR, C.; DIAS, A. A.; SALES, A. Avaliação não-destrutiva de postes de madeira por ultra-som. Scientia forestalis. $n$. 65. pg 188-196. 2004.

MINÁ, A. J. S. (2005). Estudo de estacas de madeira para fundações de pontes de madeira. 177p. Tese (Doutorado) - Escola de Engenharia de São Carlos, Universidade de São Paulo, São Carlos, 2005.

MINÁ, A. J. S.; DIAS, A. A.; CALIL JR, C. Determinação da rigidez à flexão de peças roliças de madeira por meio do PTV. In: In: ENCONTRO BRASILEIRO EM MADEIRAS E ESTRUTURAS DE MADEIRA, 11. 2008. Londrina-PR.

MURPHY, J. F. Transverse Vibration of a Simply Supported Beam with Symmetric Overhang of Arbitrary Length. Journal of Testing and Evaluation. v. 25, n. 5. p. 522-524. 1997.

Commentary on factors affecting transverse vibration using an idealized theoretical equation. FPL-RN-0276. Madison, WI: United States Departament of Agriculture. Forest Products Laboratory. 2000. 4 p.

Transverse Vibration of a Simply Supported Frustum of a Right Circular Cone. Journal of Testing and Evaluation. v. 8, n. 5. p. 415-419. 2000a.

NEDERVEEN, C. J. ; SCHWARZL, F. R. Corrections for shear and rotary inertia on flexural vibration of beams. British Journal of Applied Physics. v. 15. p. 323-225. 1964.

NEWLAND, D. E. Mechanical Vibration: Analysis and Computation. Inglaterra: Longman Scientific \& Technical. 1989.

NICOLOTTI, G.; SOCCO, L. V.; MARTINIS, R. GODIO, A. SAMBUELLI, L. Application and Comparison of Three Tomographic Techniques for Detection of Decay in Trees. Journal of Arboriculture. v.29, n. 2. p. 66-78. 2003.

NÓBREGA, P. G. B. Análise dinâmica de estruturas de concreto: estudo experimental e numérico das condições de contorno de estruturas pré-moldadas. 2004. 265 p.Tese (Doutorado em Engenharia de Estruturas). Escola de Engenharia de São Carlos, Universidade de São Paulo. São Carlos, 2004.

NOGUEIRA, M.; BALLARIN, A. W. Sensibilidade dos ensaios de ultra-som à ortotropia elástica da madeira. In: PAN AMERICAN CONFERENCE FOR NONDESTRUCTIVE TESTING - PANND, 3. 2003. Rio de Janeiro - RJ.

OLIVEIRA, F. G. R. Contribuição ao estabelecimento de parâmetros para ensaios não-destrutivos em madeira serrada por meio de ultra-som. 2005. Tese 
(Doutorado em Ciência e Engenharia de Materiais). Escola de Engenharia de São Carlos, Universidade de São Paulo. São Carlos, 2005.

OLIVEIRA GALVÃO, C.; SILVA VALENÇA, M. J. S. Sistemas inteligentes: aplicações a recursos hídricos e sistemas ambientais. Ed. Universidade, Universidade Federal do Rio Grande do Sul, Associação Brasileira de Recursos Hídricos, 1999.

OLSHAUSEN, B. A. Aliasing. PSC 129 - Sensory Processes. Lecture notes. 2000. University of California. Berkeley. Disponível em: https://redwood.berkeley.edu/bruno/psc129/handouts/aliasing.pdf. Acesso em: 8 out. 2008.

OLSON, L. D. Dynamic Bridge Substructure Evaluation and Monitoring. Publication No. FHWA-RD-03-089. U.S. Department of Transportation. McLean, VA. 2005.

OWOLABI, G. M.; SWAMIDAS, A. S. J.; SESHADRI, R. Crack detection in beams using changes in frequencies and amplitudes of frequency response functions. Journal of Sound and Vibration. v. 265, n. 1. p.1-22. 2003.

PASCUAL, R.; GOLINVAL, J. C. ; RAZETO, M. A frequency domain correlation technique for model correlation and updating. In: XV International Modal Analysis conference. XV IMAC. p. 587-592. 1997.

PASCUAL JIMENEZ, R. Model Based Structural Damage Assessment Using Vibration Measurements. 1999. 159 p. Tese (Doutorado em Ciências Aplicadas). Faculte dês Sciences Appliquees. Universite de Liege. Liege. Belgian. Liege. 1999.

PIAO, C.; SHUPE, T. F. ; CHUNG, Y. H.; TANG, R. C. Nondestructive Evaluation of Young's Moduli of Full-Size Wood Laminated Composite Poles. In: Pacific Rim Bio-Based Composites Symposium, 7. 2004. Nanjing Forestry University. China.

PIERSOL, A. G. Concepts in Vibration Data Analysis. In: HARRIS, C.M.; PIERSOL, A.G. Harris' shock and vibration handbook. 5 ed. New York: McGraw-Hill, 2002. Capítulo 22, p. 22.1-22.28.

PleSSEY TELECOMMUNICATIONS. Computermatic MK PIVa Timber Stress Grading Machine. New Soult Wates, Austrália. 1973.

POOLE, I. RF filter basics tutorial. Radio-Electronics.Com. 2008. Disponível em: http://www.radio-electronics.com/info/rf-technology-design/rf-filters/rf-filter-basicstutorial.php. Acesso em 06 out. 2008.

RAJ, B.; JAYAKUMAR; THAVASIMUTHU, M. Practical Non-Destructive Testing. Metalurgy and Materials Group. Indira Gandhi Centre of Atomic Research. Kalpakkam, India. 2002.

RANTA MAUNUS, A. Round small-diameter timber for construction. Relatório final do projeto FAIR CT 95-0091. Tecnhical Research Centre of Finland, VTT Publications 383.191 p. Espoo. 1999. 
REYNOLDS, P.; PAVIC, S. Impulse Hammer versus Shaker Excitation for the Modal Testing of Building Floor. Structural Testing Series. Parte 7. Maio/Junho. p. 39-44. 2000.

RIBEIRO DA SILVA, R. R. Medindo a aceleração da gravidade através de um pêndulo.

RICHARD, J. Natural Frequencies of Bernoulli-Euler Beams Resting on Two Elastic Supports: Application to Railway Vehicles. Vehicle System Dynamics. v. 9, n. 6. p. 309-326. 1980.

RICHARDSON, M. H. Structural Dynamics Measurements. Structural Dynamics @ 2000: Current Status and Future Directions. Inglaterra. Research Studies Press, Ltd. p.341. 2000.

ROSS, R. J.; GESKE, E. A.; LARSON, G. R.; MURPHY, J. Transverse vibration nondestructive testing using a personal computer. Res. Pap. FPL RP-502. Madison, WI: U.S. Department of Agriculture, Forest Service, Forest Products Laboratory. 17 p. 1991.

SABRI, S. Experimental Determination of Transfer Functions For a Car BodyIn-White. 2004. 134 p. Dissertação (Mestrado em engenharia mecânica). The Graduate School of Natural and Applied Sciences. The Middle East Technical University. Pleinlaan. 2004.

SALES, A.; PELIZAN, T. R.; OLIVEIRA, F. G. R.; CANDIAN, M.;LUCCHETTE, F.F; SALGON, J. L.; MILLER, K. P. Avaliação de propriedades mecânicas de peças roliças de eucalipto por meio de ultra-som. In: In: ENCONTRO BRASILEIRO EM MADEIRAS E ESTRUTURAS DE MADEIRA, 9. 2004. CuiabáMT.

SANTOS, A. C. ; SZÜCS, C. A.; DÍAZ, A. D; TELES, C. D. M. Influência do ângulo de inclinação das fibras da madeira na propagação do ultra-som. . In: In: ENCONTRO BRASILEIRO EM MADEIRAS E ESTRUTURAS DE MADEIRA, 8. 2002. Uberlândia-MG.

SHEPARD, K. Log Home Basics. $2007 . \quad$ Disponível em: http://activerain.com/blogsview/61822/-LOG-HOME-BASICS.htm. Acesso em: 19 set. 2008.

SMITH, S. W. The Scientist and Engineer's Guide to Digital Signal Processing. $2^{\mathrm{a}}$ ed. ISBN 0-9660176-6-8. San Diego. California: California Technical Publishing. 1999.

SOCCO, L. V.; SAMBUELLI, L.; NICOLOTTI, G. Ultrasonic Tomography for Non Destructive Testing of Living Trees. Atti del $19^{\circ}$ Convegno Nazionale. Gruppo Nazionale di Geofisica della Terra Solida. Consiglio Nazionale delle Ricerche. Istituto Nazionale di Oceanografia e di Geofisica Sperimentale. Itália. 2000.

SOLTIS, L. A. Structural Analysis Equations. In: Forest Products Laboratory. Wood handbook-Wood as an engineering. Madison, WI: U.S. Department of Agriculture, Forest Service, Forest Products Laboratory, 1999. Capítulo 8, p. 8-1-8.12. 
STAMBAUGH, M.; McMURRY, E. R. ; MASCHALL, J. M.; GUYETTE, R. Use and calibration of the Resistograph for analysis of oak (Quercus sp.) decay and callus formation associated with fire scars. Relatório de pesquisa. University of Missouri. Department of Forestry. Columbia Missouri. 2008.

STMICROELECTRONICS. LIS3L02AS4-MEMS INERTIAL SENSOR 3 axis\$2g/士6g LINEAR ACCELEROMETER. Datasheet. 2005.

STEELE, P. H.; COOPER, J. E. Through-Log Density Detector. Patente Norte Americana $\mathrm{n}^{\circ}$ US 6784672. 2004.

STOKEY, W. F. Vibration of systems having distributed mass and elasticity. In: HARRIS, C.M.; PIERSOL, A.G. Harris' shock and vibration handbook. 5 ed. New York: McGraw-Hill, 2002. Capítulo 7, p. 7.1-7.50.

TIMBER PRODUCTS INSPECTION - TPI . Log homes grading rules. Conyers. Ga. 1997.

TIMOSHENKO, S. Vibration problems in engineering. $2^{\text {a }}$ ed. New York: John Wiley \& Sons. 1938.

TREPANIER, R. (2009). Good Modal Analysis Practices. Training Course. Toronto. Canadá. Brüel \& Kjær. Curso ministrado por video-conferência em 04/09/2009.

UNTERWIESER, H.; SCHICKHOFER, G. Influence of moisture content of wood on sound velocity and dynamic MOE of natural frequency- and ultrasonic runtime measurement. In: European Journal of Wood and Wood Products. $\mathrm{N}^{\mathrm{o}}$ 2. v. 69, p. 171-181. 2010.

VALE, A.; BRITES, R. D.; LOURENÇO, P. B. Uso da Perfuração Controlada na Avaliação de Degradação da Madeira em Edificações Antigas - Estudo de Caso. In: ENCONTRO BRASILEIRO EM MADEIRAS E ESTRUTURAS DE MADEIRA, 10. 2006. São Pedro-SP.

VAROTO, P. S. (2008). Técnicas de identificação modal. Notas de aula da disciplina SEM 766 - Análise Modal de Estruturas do Departamento de Engenharia Mecânica da Escola de Engenharia de São Carlos da Universidade de São Paulo. São Carlos-SP.

WANG, X; ROSS, R.J.; MATTSON, J. A. ; ERICKSON, J.R.; FORSMAN, J.W.; GESKE, E. A. ; WEHR, M. A. Several Nondestructive Evaluation Techniques for Assessing Stiffnes and MOE. Paper FPL-PR-600. WI: United States Department of Agriculture. Forest Products Laboratory. 12 p. 2001.

WANG, X; ROSS, R. J.; MATTSON, J. A. ; ERICKSON, J. R.; FORSMAN, J. W.; GESKE, E. A. ; WEHR, M. A. Nondestructive evaluation techniques for assessing modulus of elasticity and stiffness of small-diameter logs. Forest Products Journal. v. 52, n. 2. p. 79-85. 2002.

WANG, X; ROSS, R J.; BRASHAW, B. K. ; PUNCHES, J.; ERICKSON, J. R.; FORSMAN, J. W.; PELLERIN, R. E. Diameter effect on stress-wave evaluation of modulus of elasticity of logs. Wood and Fiber Science. v. 36, n. 3. p.368-377. 2004. 
WANG, X.; WIEDENBECK, J.; ROSS, R. J.; FORSMAN, J. W.; ERICKSON, J. R.; PILON, C.; BRASHAW; B. K. Nondestructive evaluation of incipient decay in hardwood logs. FPL-GTR-162. Madison, WI: U.S. Department of Agriculture, Forest Service, Forest Products Laboratory. 11p. 2005.

WOLFE, R. ; HERNANDEZ, H. Trussed assemblies form small-diameter round timbers. In: Pacific Timber Engineering Conference. 1999. p. 251-256. New Zealand.

WOLFE, R.; MOSELEY, C. Small-Diameter Log Evaluation for Value-Added Structural Applications. Forest Products Journal. v. 50, n. 10. p. 49-58. 2000.

WOLFE, R. Research challenges for structural use of small-diameter round timbers. Forest Products Journal. v. 50, n. 2. p. 21-29. 2000.

YANG, X.; ISHIMARU, Y.; IDA, I.; URAKMI, H. Application of modal analysis by transfer function to nondestructive testing of wood I: determination of localized defects in wood by mode shape of the flexural vibration wave. Journal of Wood Science. v. 48, n. 4. p. 283-288. 2002.

YEH, C. T.; HARTZ, B. J.; BROWN, C. B. Damping Sources in Wood Structures. Journal of Sound and Vibration. v. 19, n. 4. p. 411- 419. 1971.

ZANGIÁCOMO, A. L. Estudo de elementos roliços de madeira. 2007. 142 p. Tese (Doutorado em Engenharia de Estruturas). Escola de Engenharia de São Carlos, Universidade de São Paulo. São Carlos, 2007. 


\section{APÊNDICE A - DESENVOLVIMENTO E CALIBRAÇÃO DO SISTEMA DE ANÁLISE MODAL EXPERIMENTAL UTILIZADO NOS ENSAIOS COM AS TORAS}

O sistema de AND por vibração transversal foi composto por um dispositivo para excitar a vibração, um acelerômetro, uma placa de aquisição de dados, uma placa condicionadora de sinais e um programa de computador.

Para a digitalização dos sinais analógicos optou-se por utilizar a placa de aquisição de dados de baixo custo modelo USB 6009 produzida pela National Instruments (Figura A.1).

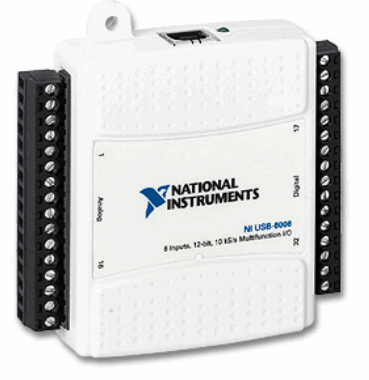

Figura A.1 - Placa de aquisição de dados modelo USB 6009.

Fonte: National Instruments (2009).

Essa placa tem oito entradas analógicas com 14 bits de resolução as quais, no modo single-ended, medem tensões no intervalo de $-10 \mathrm{~V}$ a $+10 \mathrm{~V}$. Assim, o erro de quantização é de $1,22 \mathrm{mV}$ que é relativamente elevado para os transdutores usualmente empregados em ensaios dinâmicos. Por esse motivo foi necessário amplificar os sinais dos transdutores para então aplicá-los na placa de aquisição.

Para excitar a vibração nas toras foi empregado o martelo de impulso modelo 2303 da Endevco (Figura A.2). 


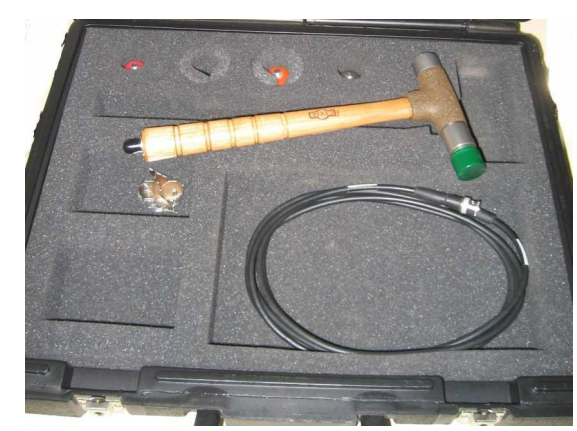

Figura A.2 - Martelo de impulso modelo 2303 da Endevco.

A célula de carga do martelo de impulso é do tipo IEPE (Integrated Electronics Piezo Electric). Esse tipo de transdutor possui internamente um cristal piezelétrico e uma placa condicionadora de sinais. Ao ser deformado, o cristal cria uma carga elétrica que é convertida em tensão pelo circuito condicionador. O sinal do martelo tem baixa intensidade e, para ser medido necessita ser amplificado.

A resposta dinâmica das toras foi captada por um acelerômetro com tecnologia $M E M S$ (Micro Electro-Mechanical Systems). Em função do baixo custo e pela facilidade de obtenção no mercado nacional foi utilizado o acelerômetro LIS3L02AS4 (Figura A.3), fabricado pela ST Microelectronics.

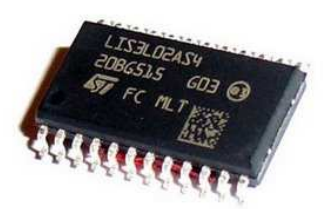

Figura A.3 - Chip do acelerômetro LIS3L02AS4.

O acelerômetro LIS3L02AS4 é capaz de medir acelerações de até $58,84 \mathrm{~m} / \mathrm{s}^{2}$ em três direções com limite superior da banda de freqüências de $1500 \mathrm{~Hz}$. Esse acelerômetro possui internamente um circuito amplificador de carga (Figura A.4) que fornece nos terminais de saída uma tensão diretamente proporcional à aceleração aplicada. A sensibilidade nominal é da ordem de $v_{d d} / 15 / g$, sendo $v_{d d}$ a tensão de alimentação e $g=9,80665 \mathrm{~m} / \mathrm{s}^{2}$. Esse acelerômetro suporta acelerações de até $10000 \mathrm{~g}$ durante 0,1 segundo. Para a banda de freqüências de $100 \mathrm{~Hz}$ a resolução do LIS3L02AS4 é de 0,5 mg. 


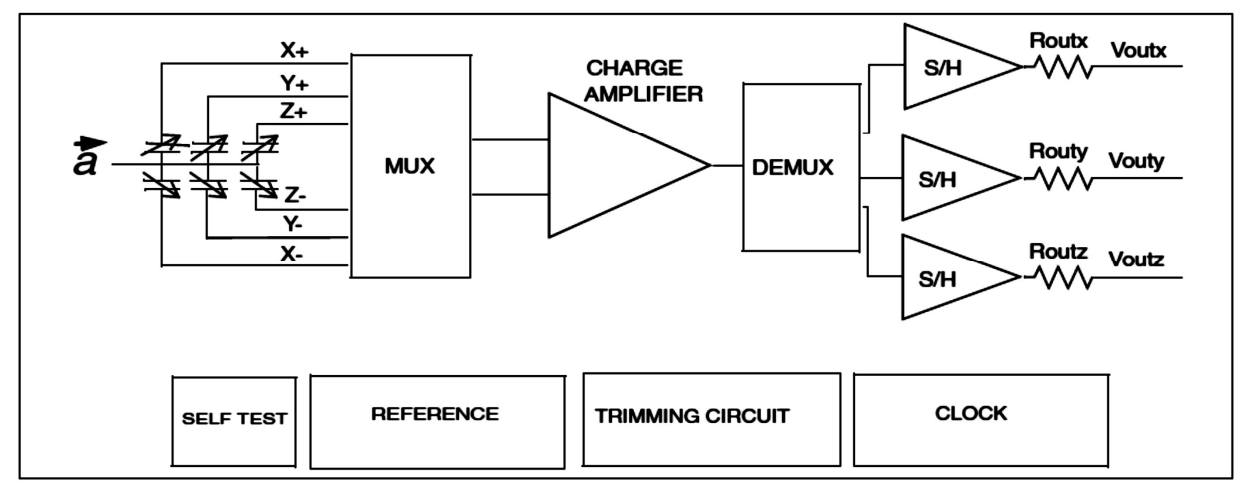

Figura A.4 - Diagrama de blocos do acelerômetro LIS3L02AS4.

Fonte: STMicroelectronics (2005),

Para que os sinais do acelerômetro e do martelo pudessem ser medidos pela placa USB 6009 foi preciso construir um condicionador de sinais. No condicionador também foi incluída uma fonte de alimentação para os transdutores.

\section{A.1.1. Construção da placa do acelerômetro}

Foram preparados dois acelerômetros de forma a manter um de reserva. Para a utilização do acelerômetro LIS3L02AS4, foi necessário construir o circuito mostrado na Figura A.5 o qual foi acondicionado no interior da caixa do acelerômetro Esse circuito foi obtido da folha de dados (datasheet) do acelerômetro. Os capacitores C1 a C3 formam um filtro passa-baixa em cada canal de saída cuja frequência de corte está sintonizada em 1450 Hz.

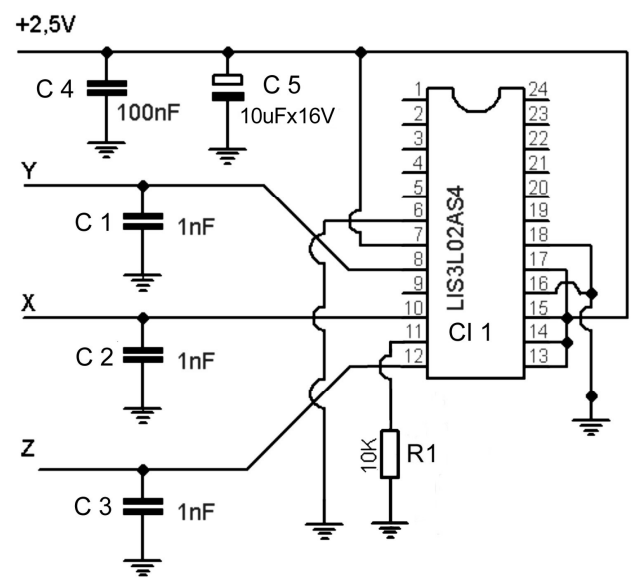

Figura A.5 - Circuito elétrico da placa do acelerômetro LIS3L02AS4.

A Figura A.6a mostra o layout da placa de circuito impresso. 
Para proteção do chip, a placa do mesmo foi acondicionada em uma caixa usinada em alumínio naval (Figura A.6b). A caixa foi fechada com selante de silicone para impedir a penetração de umidade no seu interior.

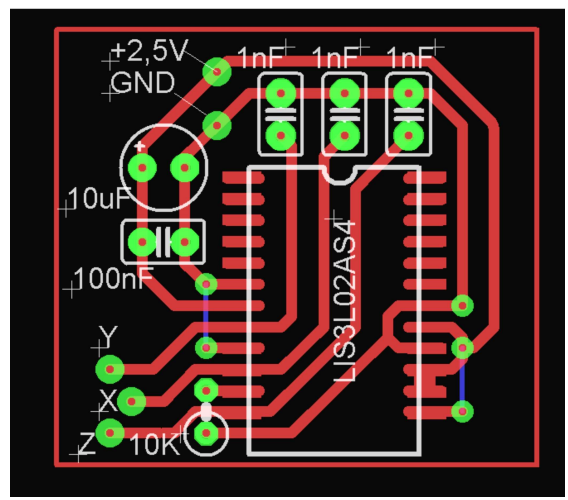

(a)

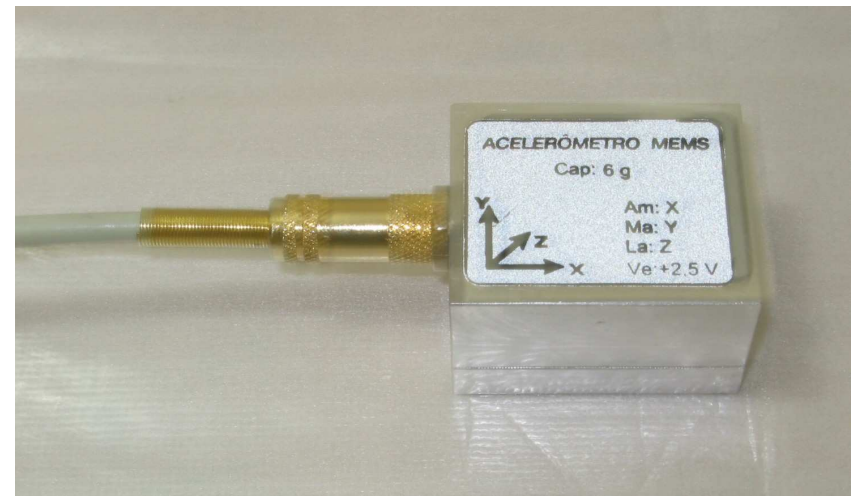

(b)

Figura A.6 - Acelerômetro LIS3L02AS4: a) Layout da placa de circuito impresso; b) Acelerômetro acondicionado em caixa de alumínio naval.

\section{A.1.2. Construção do condicionador de sinais}

As Figuras A.7 e A.8 mostram respectivamente os circuitos condicionadores do acelerômetro MEMS e do martelo de impulso. O circuito da Figura A.7 foi desenvolvido pelo autor e o circuito da Figura A.8 foi desenvolvido com o auxílio do Engenheiro Eletrônico Jorge Nicolau dos Santos, técnico do Laboratório de Engenharia Térmica e Fluidos do Departamento e Engenharia Mecânica da Escola de Engenharia de São Carlos da Universidade de São Paulo.

Para a fabricação do circuito condicionador de sinais foram usados resistores com tolerância de $5 \%$. 


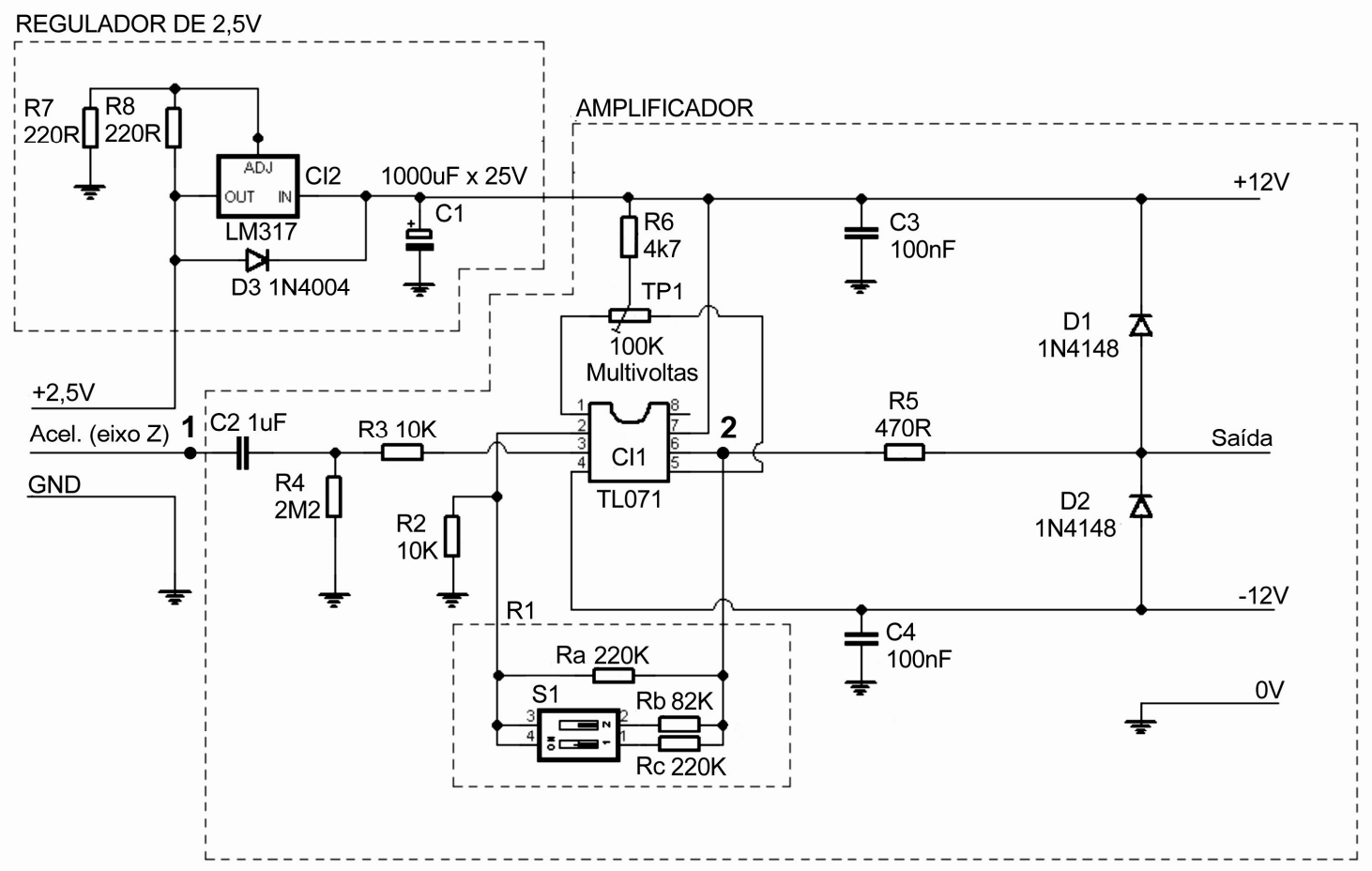

Figura A.7 - Circuito condicionador do acelerômetro MEMS.

O ganho dos amplificadores operacionais TL071 e TL072 mostrados nas Figuras A.7 e A.8 é calculado pela Equação A.1

$$
\text { Ganho }=\frac{R 1}{R 2}+1
$$

Sendo:

$\mathrm{R} 1$ e $\mathrm{R} 2$ = resistências dos resistores 1 e 2 , respectivamente (ohms).

No circuito da Figura A.7 foi incluído um Dip Switch (S1) para permitir a alteração do ganho do amplificador do acelerômetro. Assim sendo, o circuito amplificador dos acelerômetros tem os ganhos teóricos mostrados na Tabela A.1, enquanto o amplificador do martelo de impulso tem ganho teórico igual a 11. Entretanto, deve-se ressaltar que esses valores podem sofrer uma pequena variação em função da tolerância dos resistores e das características dos amplificadores operacionais. Logo, para maior exatidão das medições, o ganho real dos amplificadores foi medido conforme mostrado adiante. 


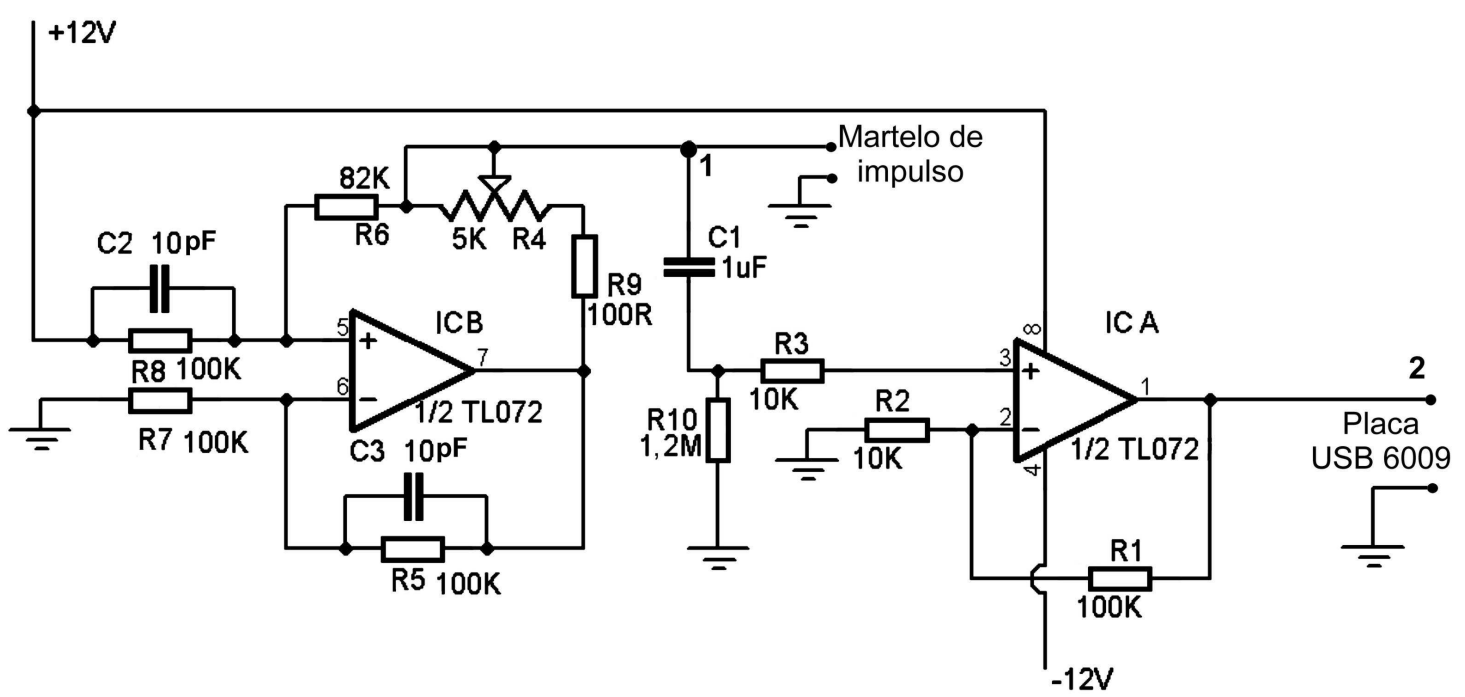

Figura A.8- Circuito condicionador do martelo de impulso.

Tabela A.1 - Ganhos teóricos dos amplificadores dos acelerômetros MEMS.

\begin{tabular}{ccc}
\hline \multicolumn{2}{c}{ Dip-Switch } & Ganho teórico \\
Chave S1 & Chave S2 & \\
\hline OFF & OFF & 23,00 \\
ON & OFF & 12,00 \\
OFF & ON & 6,97 \\
ON & ON & 5,70 \\
\hline
\end{tabular}

A Figura A.9 mostra o aspecto final do condicionador de sinais.

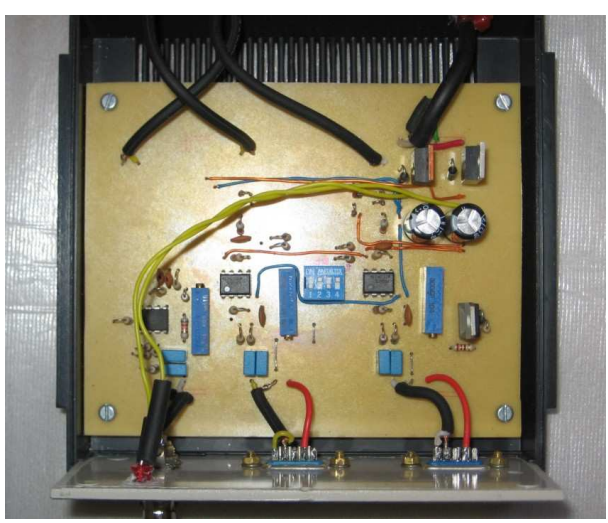

(a)

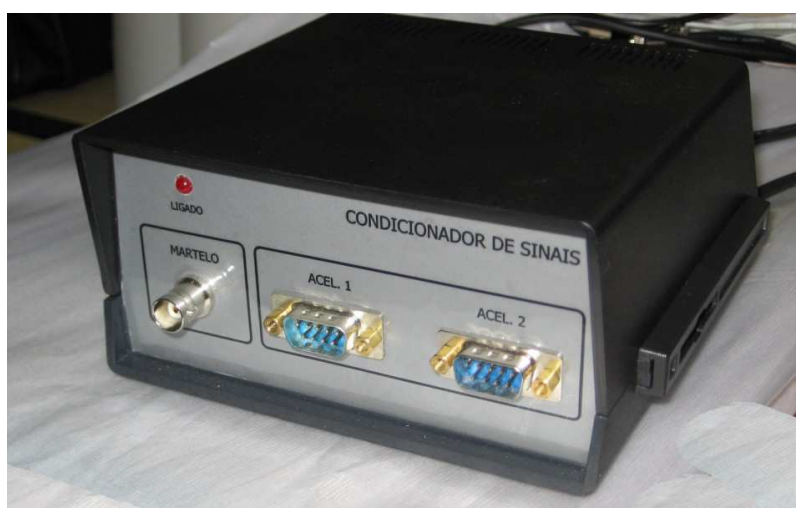

(b)

Figura A.9 - Aspecto final do condicionador de sinais: a) vista interna; b) vista externa. 
A alimentação do circuito foi feita com uma fonte chaveada ATX extraída de computador. Essa fonte recebeu uma etapa de filtragem adicional para atenuar os ruídos oriundos do circuito de chaveamento.

\section{A.1.3. Determinação dos ganhos reais dos canais do condicionador de sinais}

Para a determinação do ganho dos canais dos acelerômetros foi aplicada uma tensão senoidal de $200 \mathrm{~Hz}$ com intensidade de $72 \mathrm{mV}$ na entrada do circuito amplificador (ponto 1 do circuito da Figura A.7) e foi medida a tensão de saída do amplificador (ponto 2 da Figura A.7).

Foram medidas as tensões na entrada e na saída dos amplificadores e o ganho foi determinado dividindo-se a tensão de saída pela de entrada.

O sinal senoidal foi gerado utilizando o programa Realtime Analyzer versão 2.0.0.1 produzido pela Yoshimasa Electronic inc. o qual juntamente com a placa de som do microcomputador permite a geração de diversos sinais na faixa de áudio (20 Hz a $20 \mathrm{kHz}$ ).

A intensidade dos sinais de entrada e saída foi medida com um osciloscópio duplotraço de $25 \mathrm{MHz}$ modelo MO-2025 produzido pela Minipa.

A determinação do ganho do canal do martelo foi feita de forma semelhante, porém, em vez de injetar uma tensão conhecida, foi utilizado o sinal do martelo de impulso. Utilizando-se o osciloscópio de dois canais foram medidas as tensões de entrada e de saída do amplificador respectivamente nos pontos 1 e 2 do circuito mostrado na Figura A.8. Para tanto foram desferidos 5 impactos com o martelo e foi calculado o ganho médio.

\section{A.1.4. Determinação da sensibilidade real dos acelerômetros}

Para a determinação da sensibilidade dos acelerômetros, foram medidas as tensões nos terminais de saída dos mesmos em função da aceleração da gravidade na cidade de São Carlos, Estado de São Paulo.

A cidade de São Carlos está situada na latitude 22 01'03'” e tem uma altitude média de 856 m. Portanto, de acordo com Lopes (2008) a aceleração da gravidade local é $\mathrm{g}^{*}=$ $9,7849 \mathrm{~m} / \mathrm{s}^{2}$. 
Os acelerômetros foram dispostos em uma superfície plana nas posições mostradas nas Figuras A.10a, A.10b e A.10c as quais submetem respectivamente os acelerômetros às acelerações de $+\mathrm{g}^{*}, 0 \mathrm{~g}^{*} \mathrm{e}-\mathrm{g}^{*}$ em relação ao eixo $\mathrm{Z}$ do acelerômetro.

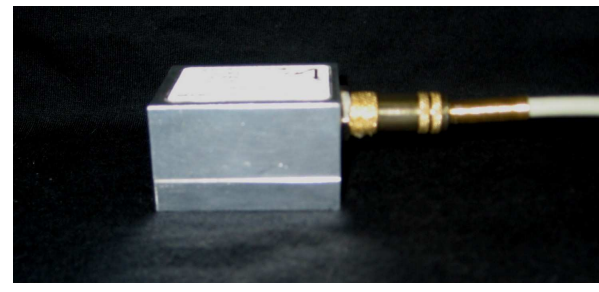

(a)

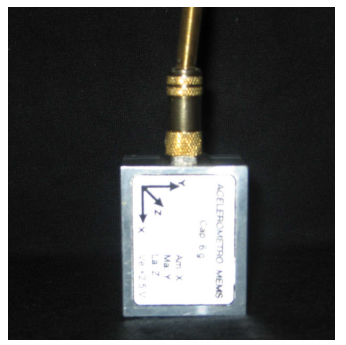

(b)

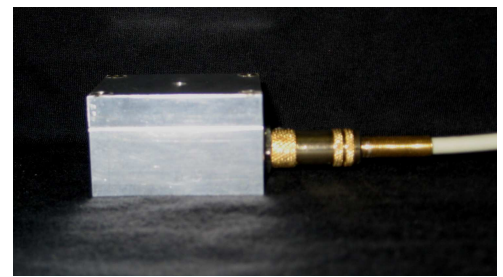

(c)

Figura A.10 - Posições dos acelerômetros na determinação da sensibilidade real: a) +g; b) 0g; c) $-\mathrm{g}$.

Para cada posição mostrada na Figura A.10 foi medida a tensão na saída dos acelerômetros utilizado um multímetro digital modelo MD-380 produzido pela Instrutherm.

Posteriormente foi feita a regressão linear entre a aceleração aplicada e a tensão medida.

\section{A.1.5. Desenvolvimento do programa de aquisição e análise de sinais de ensaios} dinâmicos

Foi desenvolvido um programa de computador para aquisição, processamento dos sinais dos transdutores e identificação dos parâmetros modais. O programa denominado de Impact foi desenvolvido com a versão de avaliação do software LabVIEW $8.6^{\circledR}$ da National Instruments o qual pode ser baixado gratuitamente na página da internet www.ni.com.

Para a identificação dos parâmetros modais foi utilizada a ferramenta Modal Parameter Extraction e as toolkits Advanced Signal Processing e System identification sendo todas elas versões de avaliação também disponíveis no site www.ni.com. A Figura A.11 mostra o fluxograma do programa.

O programa faz a aquisição contínua de dados de dois canais da placa USB 6009 a uma taxa definida pelo usuário que pode variar desde $1 \mathrm{~Hz}$ até $24 \mathrm{KHz}$ por canal. Os canais podem ser escolhidos pelo usuário.

A etapa de processamento dos sinais é disparada por um trigger (gatilho) no qual o usuário tem a possibilidade de definir em qual canal o trigger será aplicado, podendo ajustar a 
sensibilidade, e ainda especificar o número de amostras (pré-trigger) a serem coletadas antes do disparo. O programa permite também que o usuário defina o número de amostras coletadas para o processamento.

$\mathrm{Na}$ etapa de janelamento dos sinais foram inseridas três opções sendo: janela exponencial, janela retangular e nenhuma janela. Essa última opção foi incluída para o caso do sinal ser totalmente atenuado no período de amostragem.

Após o janelamento o programa calcula a FRF do sistema a partir de um número de médias estipulado pelo usuário e apresenta como resultado dois gráficos sendo um com o módulo e outro com a fase da FRF.

Para a identificação dos parâmetros modais foi implementado o método LSCE (Least Squares Complex Exponential ) empregando-se ferramenta Modal Parameter Extraction.

Após a identificação dos parâmetros modais o programa grava no disco rígido do computador um arquivo de texto com extensão .txt contendo as FRF's medida e ajustada e as frequências naturais bem como os coeficientes de amortecimento dos 10 primeiros modos identificados. 


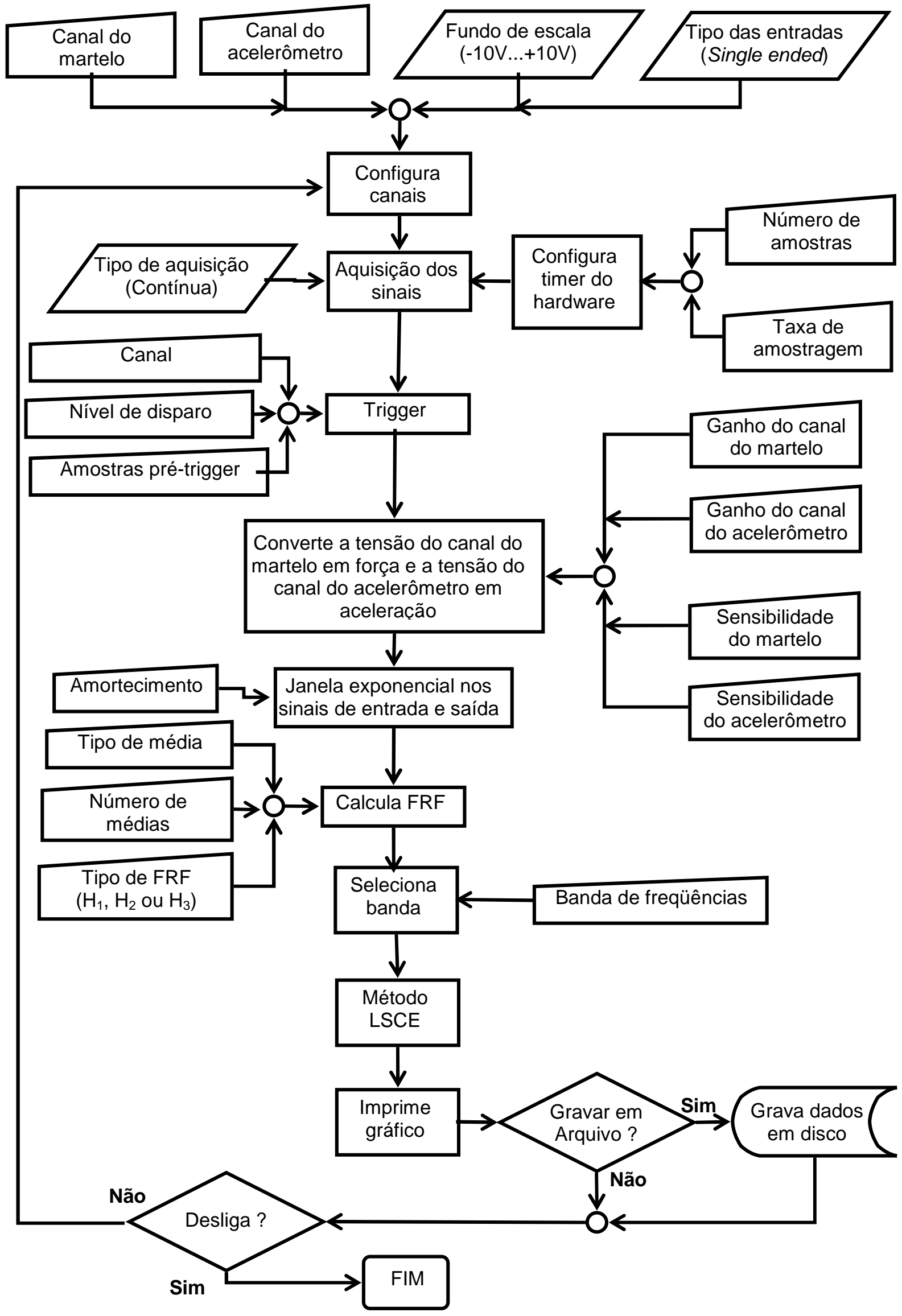

Figura A.11 - Fluxograma do programa Impact. 
A Figura A.12 mostra a tela principal do programa.

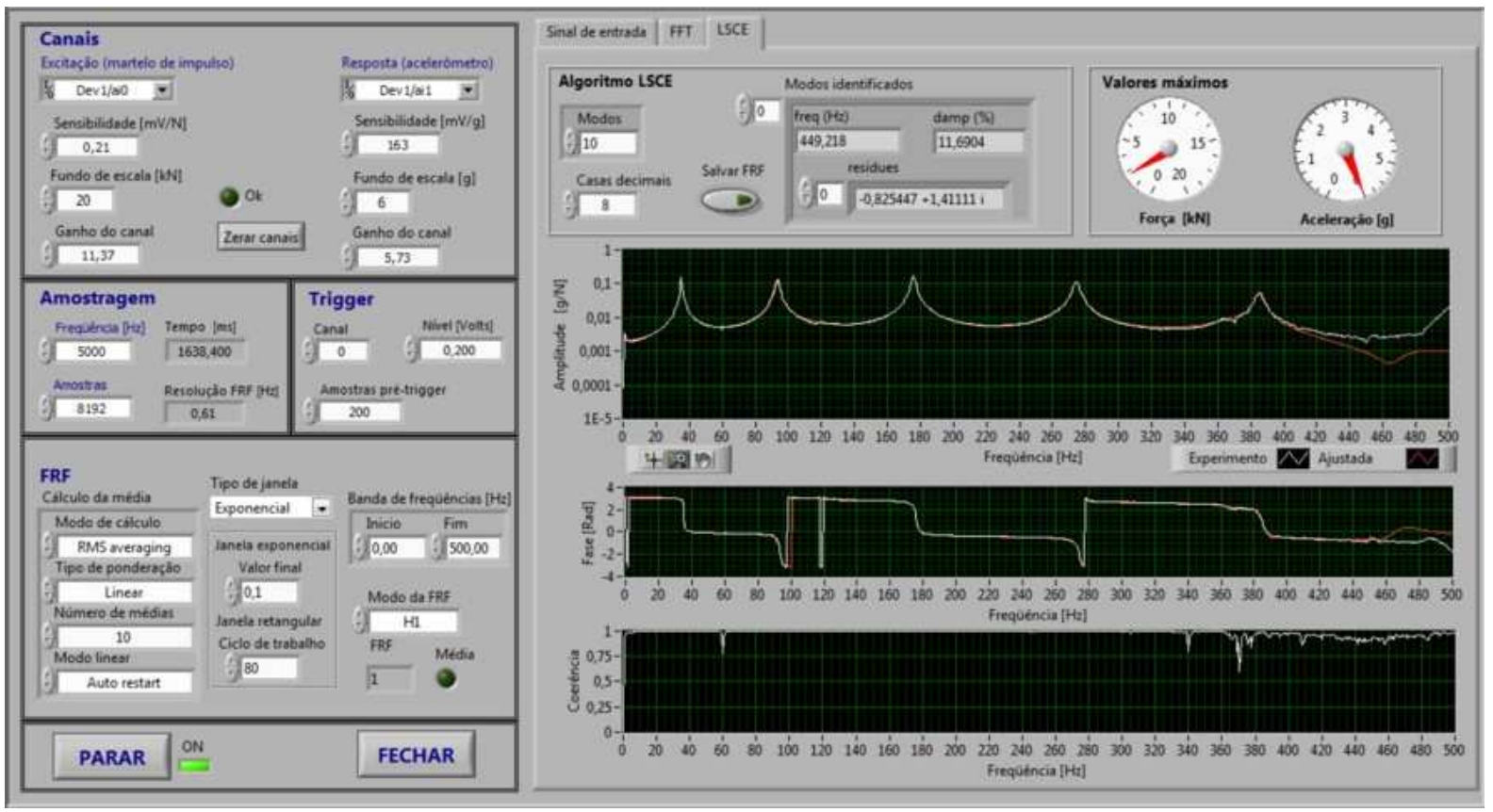

Figura A.12- Tela principal do programa Impact.

A interface gráfica foi desenhada de forma que do lado esquerdo da tela o usuário tenha acesso aos parâmetros de configuração do ensaio e do lado direito ele possa visualizar os resultados do ensaio.

Do lado direito da tela o programa contém uma paleta com as janelas "sinal de entrada", "FFT" e "LSCE". A janela "sinal de entrada" mostra ao usuário os sinais de entrada no domínio do tempo enquanto a janela "FFT" mostra os sinais no domínio da freqüência. $\mathrm{Na}$ janela LSCE o usuário pode visualizar a qualidade do ajuste e os parâmetros modais estimados.

A Tabela A.2 mostra o resultado obtido na determinação dos ganhos dos canais dos acelerômetros.

Tabela A.2 - Ganhos reais dos canais dos acelerômetros.

\begin{tabular}{|c|c|c|c|c|c|c|c|c|c|}
\hline \multirow{3}{*}{ S1 } & \multirow{3}{*}{ S2 } & \multicolumn{2}{|l|}{ Canal 1} & \multirow{3}{*}{ Ganho } & \multicolumn{5}{|c|}{ Canal 2} \\
\hline & & Tensõ & s (V) & & s1 & s2 & Tens & s (V) & Ganho \\
\hline & & Entrada & Saída & & & & Entrada & Saída & \\
\hline Deslig. & Deslig. & 0,072 & 0,408 & 5,67 & Deslig. & Deslig. & 0,072 & 0,400 & 5,56 \\
\hline Ligada & Deslig. & 0,072 & 0,504 & 7,00 & Ligada & Deslig. & 0,072 & 0,480 & 6,67 \\
\hline Deslig. & Ligada & 0,072 & 0,864 & 12,00 & Deslig. & Ligada & 0,072 & 0,832 & 11,56 \\
\hline Ligada & Ligada & 0,072 & 1,640 & 22,78 & Ligada & Ligada & 0,072 & 1,600 & 22,22 \\
\hline
\end{tabular}

Observa-se na Tabela A.2 que houve pequena diferença nos ganhos dos canais 1 e 2 . do condicionador de sinais, sendo que o canal 2 apresentou ganhos sensivelmente menores. 
Essa pequena diferença pode ser explicada pela tolerância de 5\% dos resistores R1 e R2 do circuito da Figura A.7. O canal 1 apresentou valores muito próximos dos ganhos teóricos.

Observa-se que o valor do ganho real do canal do martelo de impulso é muito próximo do teórico $(11,00)$.

A Tabela A.3 mostra os resultados obtidos na medição do ganho do amplificador do martelo de impulso.

Tabela A.3 - Determinação do ganho real do canal do martelo de impulso.

\begin{tabular}{ccc}
\hline Leitura & $\begin{array}{c}\text { Entrada } \\
\text { (Volts) }\end{array}$ & $\begin{array}{c}\text { Saida } \\
\text { (Volts) }\end{array}$ \\
\hline 1 & 0,79 & 9,16 \\
2 & 0,79 & 8,47 \\
3 & 0,89 & 10,15 \\
4 & 0,74 & 8,81 \\
5 & 0,80 & 9,09 \\
\hline Média & 0,80 & 9,14 \\
\hline Ganho real & \multicolumn{2}{c}{11,37} \\
\hline
\end{tabular}

A Tabela A.4 mostra as tensões medidas na saída dos acelerômetros em função da aceleração.

Tabela A.4 - Tensões medidas na calibração dos acelerômetros.

\begin{tabular}{ccc}
\hline Aceleração $\left(\mathbf{m} / \mathbf{s}^{2}\right)$ & \multicolumn{2}{c}{ Tensão (Volts) } \\
& Acelerômetro 1 & Acelerômetro 2 \\
\hline 9,7849 & 1,090 & 1,109 \\
0,0000 & 1,256 & 1,270 \\
$-9,7849$ & 1,421 & 1,436 \\
\hline
\end{tabular}

As Figuras A.13 e A.14 mostram respectivamente as retas de regressão ajustadas para os acelerômetros 1 e 2 .

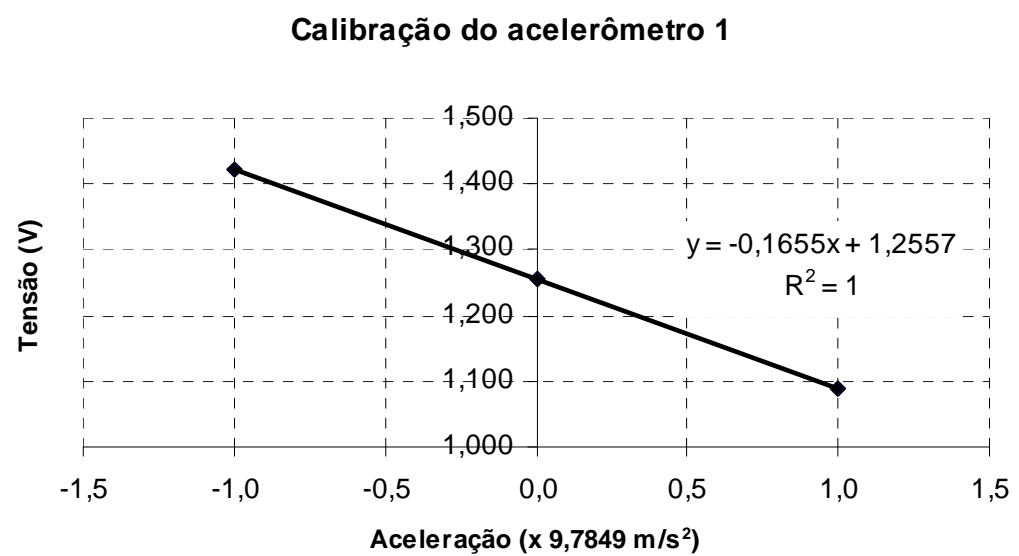

Figura A.13- Calibração do acelerômetro 1. 


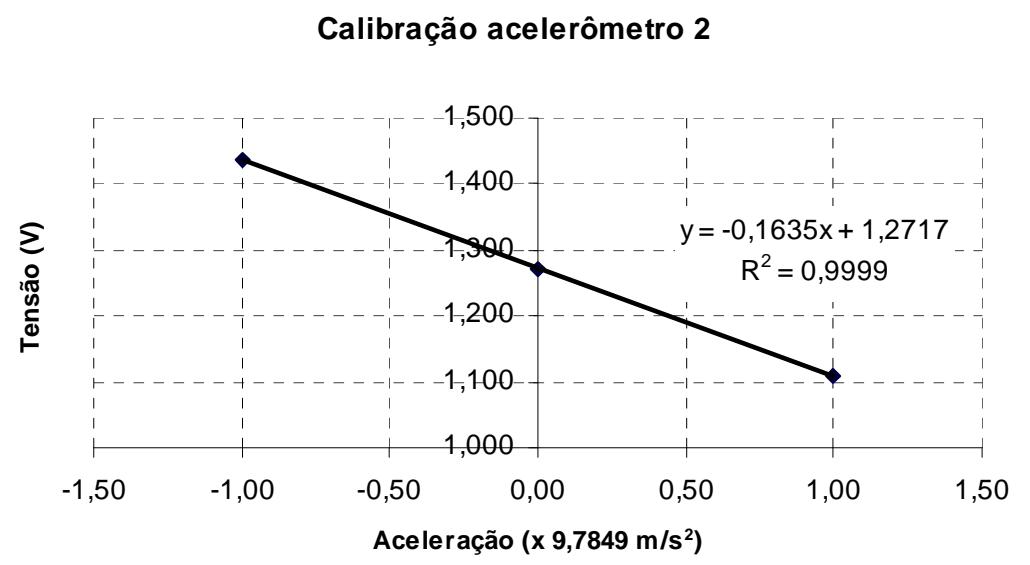

Figura A.14 - Calibração do acelerômetro 2.

Nas Figuras A.13 e A.14 verifica-se que a tensão de saída dos acelerômetros varia linearmente com a aceleração aplicada.

O termo independente das equações de regressão mostradas nas Figuras A.13 e A.14 corresponde ao nível DC do sinal do acelerômetro. Como essa tensão é eliminada pelo capacitor C2 mostrado no circuito da Figura A.7, para a aceleração da gravidade local, as sensibilidades de ambos os acelerômetros correspondem unicamente ao coeficiente angular de cada reta ajustada.

Corrigindo-se os valores das sensibilidades para a aceleração da gravidade adotada na folha de dados do acelerômetro LIS3L02AS4 $\left(\mathrm{g}=9,80665 \mathrm{~m} / \mathrm{s}^{2}\right)$ têm-se os valores mostrados na Tabela A.5.

Tabela A.5 - Sensibilidade dos acelerômetros.

\begin{tabular}{cc}
\hline Acelerômetro & Sensibilidade $\left(\mathbf{m V} / \mathbf{g}^{*}\right)$ \\
\hline 1 & 166 \\
2 & 164 \\
\hline *obs: $\mathrm{g}=9,80665 \mathrm{~m} / \mathrm{s}^{2}$
\end{tabular}

De acordo com o STMicroelectronics (2005), quando alimentado com 2,5V a sensibilidade nominal do acelerômetro LIS3L02AS4 é de $166 \mathrm{mV} / \mathrm{g}$, sendo $\mathrm{g}=9,80665 \mathrm{~m} / \mathrm{s}^{2}$. Observa-se então que a constante do acelerômetro 1 coincide com o valor nominal enquanto a constante do acelerômetro 2 tem $1 \%$ de diferença em relação ao valor nominal.

Os ensaios dinâmicos foram realizados com o acelerômetro 1 sendo que o acelerômetro 2 foi mantido de reserva.

As características do acelerômetro LIS3L02AS4 associadas ao seu baixo custo o tornam interessante para análise experimental de estruturas. O fato de possuir internamente 
um amplificador facilita sua utilização, dispensando a aquisição de amplificadores de carga. $\mathrm{O}$ custo final de cada acelerômetro ficou em R \$ 142,65, ou seja, cerca de 1/30 a 1/8 do custo de um acelerômetro comercial com as mesmas características.

Os ganhos medidos nos amplificadores do condicionador de sinais foram muito próximos dos valores teóricos sendo que a pequena diferença observada no canal 2 provavelmente se deve à tolerância dos resistores empregados na construção da placa do condicionador.

O custo do condicionador de sinais também ficou muito inferior aos comerciais tornando viável sua construção. Os componentes empregados são facilmente encontrados no mercado e o circuito pode ser montado com facilidade por um técnico em eletrônica.

Com relação à calibração dos acelerômetros, observou-se que as constantes não sofreram variação significativa em relação à constante nominal. 


\section{APÊNDICE B - DADOS DAS TORAS DA AMOSTRA PILOTO}

Tabela B.1 - Dados da tora 1.

\begin{tabular}{|c|c|c|c|c|c|c|c|c|c|c|c|c|c|}
\hline Data: 15/09/2009 & \multicolumn{13}{|c|}{ Espécie: Eucalyptus citriodora } \\
\hline \multicolumn{3}{|c|}{ Dados gerais } & & & & & & & & & & & \\
\hline Comprimento $(\mathrm{cm})$ & & 428 & & & & & & & & & & & \\
\hline Massa $(\mathrm{kg})$ & & 99,15 & & & & & & & & & & & \\
\hline Densidade $\left(\mathrm{kg} / \mathrm{m}^{3}\right)$ & & 930 & & & & & & & & & & & \\
\hline \begin{tabular}{|l|} 
Encurvamento $(\mathrm{mm})$ \\
\end{tabular} & & 50 & & & & & & & & & & & \\
\hline \multirow{4}{*}{$\begin{array}{c}\text { Características da seção } \\
\text { transversal }\end{array}$} & \multirow{4}{*}{ Direção } & \multicolumn{12}{|c|}{ Seção } \\
\hline & & $\begin{array}{c}0 \\
0,00 \mathrm{~L}\end{array}$ & $\begin{array}{c}1 \\
0,10 \mathrm{~L}\end{array}$ & $\begin{array}{c}2 \\
0,20 \mathrm{~L}\end{array}$ & $\begin{array}{c}3 \\
0,30 \mathrm{~L}\end{array}$ & $\begin{array}{c}4 \\
0,40 \mathrm{~L}\end{array}$ & $\begin{array}{c}5 \\
0,50 \mathrm{~L}\end{array}$ & $\begin{array}{c}6 \\
0,60 \mathrm{~L}\end{array}$ & $\begin{array}{c}7 \\
0,70 \mathrm{~L}\end{array}$ & $\begin{array}{c}8 \\
0,80 \mathrm{~L}\end{array}$ & $\begin{array}{c}9 \\
0,90 \mathrm{~L}\end{array}$ & $\begin{array}{c}11 \\
1,00 \mathrm{~L}\end{array}$ & $\begin{array}{c}10 \\
0,95 \mathrm{~L}\end{array}$ \\
\hline & & & & & & & Dist & (cm) & & & & & \\
\hline & & 0,0 & 42,8 & 85,6 & 128,4 & 171,2 & 214,0 & 256,8 & 299,6 & 342,4 & 385,2 & 428,0 & 406,6 \\
\hline \multirow{4}{*}{ Diâmetros $(\mathrm{cm})$} & $0-4$ & 20,2 & & & & & & & & & & 15,5 & \\
\hline & $1-5$ & 19,5 & & & & & & & & & & 15,5 & \\
\hline & $2-6$ & 19,5 & & & & & & & & & & 15,1 & \\
\hline & $3-7$ & 20,7 & & & & & & & & & & 15,5 & \\
\hline \multicolumn{2}{|l|}{ Teor de umidade (\%) } & 18,0 & & & & & 20,4 & & & & & 17,2 & \\
\hline \multicolumn{2}{|l|}{ Perímetro $(\mathrm{cm})$} & 62,7 & 59,6 & 55,1 & 53,8 & 53,9 & 51,3 & 51,5 & 49,9 & 49,7 & 51,2 & 48,9 & \\
\hline \multicolumn{2}{|l|}{$\mathrm{D}(\mathrm{cm})$} & 19,96 & 18,97 & 17,54 & 17,13 & 17,16 & 16,33 & 16,39 & 15,88 & 15,82 & 16,30 & 15,57 & - \\
\hline \multicolumn{2}{|l|}{$\mathrm{D}_{\mathrm{m}}(\mathrm{cm})$} & 19,97 & & & & & & & & & & 15,40 & - \\
\hline \multicolumn{2}{|l|}{$\Delta_{\text {circ }}$} & $0,1 \%$ & & & & & & & & & & $1,1 \%$ & - \\
\hline \multicolumn{2}{|l|}{$L / D_{\text {meio }}$} & \multicolumn{12}{|c|}{26,21} \\
\hline \multirow{2}{*}{\multicolumn{2}{|c|}{\begin{tabular}{|l|}
$\mathrm{C}$ \\
$\Delta \mathrm{D}$
\end{tabular}}} & \multicolumn{12}{|c|}{$1,1 \%$} \\
\hline & & \multicolumn{12}{|c|}{$8,1 \%$} \\
\hline
\end{tabular}

Tabela B.2 - Dados da tora TB-1.

Data: $25 / 09 / 2009$

Espécie: Eucalyptus citriodora

\begin{tabular}{|c|c|c|c|c|c|c|c|c|}
\hline \multicolumn{3}{|c|}{ Dados gerais } & & & & & & \\
\hline Comprimento $(\mathrm{cm})$ & & 201,5 & & & & & & \\
\hline Massa $(\mathrm{kg})$ & & 47,30 & & & & & & \\
\hline Densidade $\left(\mathrm{kg} / \mathrm{m}^{3}\right)$ & & 891 & & & & & & \\
\hline \multirow{5}{*}{$\begin{array}{c}\text { Características da seção } \\
\text { transversal }\end{array}$} & \multirow{5}{*}{ Direção } & \multicolumn{7}{|c|}{ Seção } \\
\hline & & 0 & 1 & 2 & 3 & 4 & 5 & 12 \\
\hline & & $0,00 \mathrm{~L}$ & $0,203 \mathrm{~L}$ & $0,417 \mathrm{~L}$ & $0,630 \mathrm{~L}$ & $0,844 \mathrm{~L}$ & $1 \mathrm{~L}$ & $0,896 \mathrm{~L}$ \\
\hline & & & & & ist. (cm & & & \\
\hline & & 0,0 & 41,0 & 84,0 & 127,0 & 170,0 & 201,5 & 180,5 \\
\hline \multirow{4}{*}{ Diâmetros (cm) } & $0-4$ & 20,2 & & & & & 16,6 & \\
\hline & $1-5$ & 19,5 & & & & & 15,6 & \\
\hline & $2-6$ & 19,5 & & & & & 16,5 & \\
\hline & $3-7$ & 20,7 & & & & & 16,8 & \\
\hline \multicolumn{2}{|l|}{ Perímetro (cm) } & 62,7 & 59,6 & 55,1 & 53,8 & 53,9 & 52,2 & \\
\hline \multicolumn{2}{|l|}{ Peímetro L/2 (cm) } & \multicolumn{7}{|c|}{53,4} \\
\hline \multicolumn{2}{|l|}{$\mathrm{D}(\mathrm{cm})$} & 19,96 & 18,97 & 17,54 & 17,13 & 17,16 & 16,62 & - \\
\hline \multicolumn{2}{|l|}{$D_{m}(\mathrm{~cm})$} & 19,97 & & & & & 16,37 & - \\
\hline \multicolumn{2}{|l|}{$\Delta_{\text {circ }}$} & $0,1 \%$ & & & & & $1,5 \%$ & - \\
\hline \multicolumn{2}{|l|}{$D_{\text {meio }}(\mathrm{cm})$} & \multicolumn{7}{|c|}{17,00} \\
\hline \multicolumn{2}{|l|}{$L / D_{\text {meio }}$} & \multicolumn{7}{|c|}{11,85} \\
\hline \multicolumn{2}{|l|}{$\mathrm{C}$} & \multicolumn{7}{|c|}{$1,8 \%$} \\
\hline \multicolumn{2}{|l|}{$\Delta \mathrm{D}$} & \multicolumn{7}{|c|}{$7,2 \%$} \\
\hline
\end{tabular}


Tabela B.3 - Dados da tora TT-1.

Data: $23 / 09 / 2009$ Espécie: Eucalyptus citriodora

\begin{tabular}{|c|c|c|c|c|c|c|c|c|}
\hline \multicolumn{3}{|c|}{ Dados gerais } & & & & & & \\
\hline \multirow{3}{*}{\begin{tabular}{|l} 
Comprimento $(\mathrm{cm})$ \\
Massa $(\mathrm{kg})$ \\
Densidade $\left(\mathrm{kg} / \mathrm{m}^{3}\right)$ \\
\end{tabular}} & \multirow{2}{*}{\multicolumn{2}{|c|}{$\frac{202,5}{38,20}$}} & & & & & & \\
\hline & & & & & & & & \\
\hline & \multicolumn{2}{|r|}{950} & & & & & & \\
\hline \multirow{5}{*}{$\begin{array}{c}\text { Características da seção } \\
\text { transversal }\end{array}$} & \multirow{5}{*}{ Direção } & \multicolumn{7}{|c|}{ Seção } \\
\hline & & 5 & 6 & 7 & 8 & 9 & 11 & 10 \\
\hline & & $0,00 \mathrm{~L}$ & $0,158 \mathrm{~L}$ & $0,368 \mathrm{~L}$ & $0,574 \mathrm{~L}$ & $0,790 \mathrm{~L}$ & $1 \mathrm{~L}$ & $0,894 \mathrm{~L}$ \\
\hline & & & & & Jist. (cn & & & \\
\hline & & $\overline{0,0}$ & 32,0 & 74,5 & 116,5 & 160,0 & 202,5 & 181,0 \\
\hline \multirow{4}{*}{ Diâmetros $(\mathrm{cm})$} & $0-4$ & 16,0 & & & & & 15,5 & \\
\hline & $1-5$ & 15,5 & & & & & 15,5 & \\
\hline & $2-6$ & 16,6 & & & & & 15,1 & \\
\hline & $3-7$ & 15,5 & & & & & 15,5 & \\
\hline \multicolumn{2}{|l|}{ Perímetro $(\mathrm{cm})$} & 51 & 51,5 & 49,9 & 49,7 & 51,2 & 48,9 & \\
\hline \multicolumn{2}{|l|}{ Peímetro L/2 (cm) } & \multicolumn{7}{|c|}{48,8} \\
\hline \multicolumn{2}{|l|}{$\overline{D(\mathrm{~cm})}$} & 16,23 & 16,39 & 15,88 & 15,82 & 16,30 & 15,57 & - \\
\hline \multicolumn{2}{|l|}{$D_{m}(\mathrm{~cm})$} & 15,89 & & & & & 15,40 & - \\
\hline \multicolumn{2}{|l|}{$\Delta_{\text {circ }}$} & $2,1 \%$ & & & & & $1,1 \%$ & - \\
\hline \multicolumn{2}{|l|}{$\mathrm{D}_{\text {meio }}(\mathrm{cm})$} & \multicolumn{7}{|c|}{15,53} \\
\hline \multicolumn{2}{|l|}{$\mathrm{L} / \mathrm{D}_{\text {meio }}$} & \multicolumn{7}{|c|}{13,04} \\
\hline \multicolumn{2}{|l|}{$\mathrm{C}$} & \multicolumn{7}{|c|}{$0,2 \%$} \\
\hline \multicolumn{2}{|l|}{$\Delta \mathrm{D}$} & \multicolumn{7}{|c|}{$2,0 \%$} \\
\hline
\end{tabular}

Tabela B.4 - Dados da tora 2.

Data: 01/09/2009 Espécie: Eucalyptus citriodora

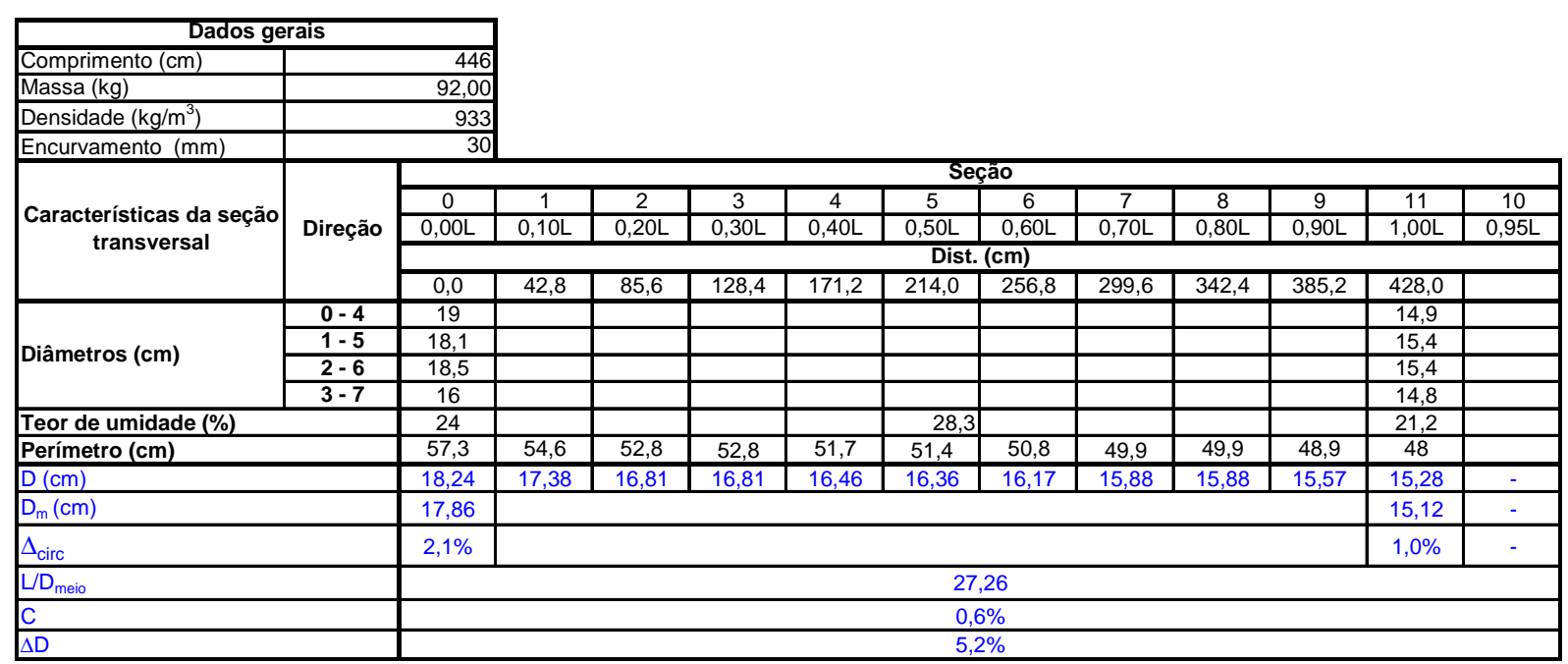


Tabela B.5 - Dados da tora TB-2.

Data: $27 / 09 / 2009$

Espécie: Eucalyptus citriodora

\begin{tabular}{|c|c|c|c|c|c|c|c|c|}
\hline \multicolumn{3}{|c|}{ Dados gerais } & & & & & & \\
\hline \multirow{3}{*}{$\begin{array}{l}\text { Comprimento }(\mathrm{cm}) \\
\text { Massa }(\mathrm{kg}) \\
\text { Densidade }\left(\mathrm{kg} / \mathrm{m}^{3}\right)\end{array}$} & \multirow{2}{*}{\multicolumn{2}{|c|}{$\begin{array}{r}214 \\
47.00\end{array}$}} & & & & & & \\
\hline & & & & & & & & \\
\hline & \multicolumn{2}{|r|}{940} & & & & & & \\
\hline \multirow{5}{*}{$\begin{array}{c}\text { Características da seção } \\
\text { transversal }\end{array}$} & \multirow{5}{*}{ Direção } & \multicolumn{7}{|c|}{ Seção } \\
\hline & & $\overline{0}$ & 1 & 2 & $\overline{3}$ & $\overline{4}$ & 5 & 12 \\
\hline & & $0,00 \mathrm{~L}$ & $0,210 \mathrm{~L}$ & $0,417 \mathrm{~L}$ & $0,630 \mathrm{~L}$ & $0,841 \mathrm{~L}$ & $1 \mathrm{~L}$ & $0,894 \mathrm{~L}$ \\
\hline & & & & & )ist. (cm & & & \\
\hline & & $\overline{0,0}$ & 45,0 & $\overline{90,0}$ & 135,0 & 180,0 & 214,0 & 191,5 \\
\hline \multirow{4}{*}{ Diâmetros (cm) } & $0-4$ & 19,0 & & & & & 16,0 & \\
\hline & $1-5$ & $\overline{18,1}$ & & & & & 15,5 & \\
\hline & $2-6$ & 18,5 & & & & & 16,0 & \\
\hline & $3-7$ & 16,0 & & & & & 15,8 & \\
\hline \multicolumn{2}{|l|}{ Perímetro $(\mathrm{cm})$} & 57,3 & 54,6 & 52,8 & 52,8 & 51,7 & 51 & \\
\hline \multicolumn{2}{|l|}{ Peímetro $\mathrm{L} / 2(\mathrm{~cm})$} & \multicolumn{7}{|c|}{51,9} \\
\hline \multicolumn{2}{|l|}{$\overline{D(c m)}$} & 18,24 & 17,38 & 16,81 & 16,81 & 16,46 & 16,23 & - \\
\hline \multicolumn{2}{|l|}{$D_{m}(\mathrm{~cm})$} & 17,86 & & & & & 15,82 & - \\
\hline \multicolumn{2}{|l|}{$\Delta_{\text {circ }}$} & $2,1 \%$ & & & & & $2,6 \%$ & - \\
\hline \multicolumn{2}{|l|}{$\mathrm{D}_{\text {meio }}(\mathrm{cm})$} & \multicolumn{7}{|c|}{16,52} \\
\hline \multicolumn{2}{|l|}{$\mathrm{L} / \mathrm{D}_{\text {meio }}$} & \multicolumn{7}{|c|}{12,95} \\
\hline \multirow{2}{*}{\multicolumn{2}{|c|}{$\frac{C}{\Delta D}$}} & \multicolumn{7}{|c|}{$1,0 \%$} \\
\hline & & \multicolumn{7}{|c|}{$4,3 \%$} \\
\hline
\end{tabular}

Tabela B.6 - Dados da tora TT-2.

Data: 22/09/2009

Espécie: Eucalyptus citriodora

\begin{tabular}{|c|c|c|c|c|c|c|c|c|}
\hline \multicolumn{3}{|c|}{ Dados gerais } & & & & & & \\
\hline \multirow{3}{*}{$\begin{array}{l}\text { Comprimento }(\mathrm{cm}) \\
\text { Massa }(\mathrm{kg}) \\
\text { Densidade }\left(\mathrm{kg} / \mathrm{m}^{3}\right)\end{array}$} & \multicolumn{2}{|r|}{210,5} & & & & & & \\
\hline & \multirow{2}{*}{\multicolumn{2}{|c|}{$\begin{array}{r}39,35 \\
966\end{array}$}} & & & & & & \\
\hline & & & & & & & & \\
\hline \multirow{5}{*}{$\begin{array}{c}\text { Características da seção } \\
\text { transversal }\end{array}$} & \multirow{5}{*}{ Direção } & \multicolumn{7}{|c|}{ Seção } \\
\hline & & 5 & 6 & 7 & 8 & 9 & 11 & 10 \\
\hline & & $0,00 \mathrm{~L}$ & $0,151 \mathrm{~L}$ & $0,361 \mathrm{~L}$ & $0,571 \mathrm{~L}$ & $0,780 \mathrm{~L}$ & $1 \mathrm{~L}$ & $\overline{0,884 \mathrm{~L}}$ \\
\hline & & & & & Dist. (cm & & & \\
\hline & & 0,0 & 33,9 & 78,0 & 122,8 & 166,8 & 210,5 & 188,0 \\
\hline \multirow{4}{*}{ Diâmetros (cm) } & $0-4$ & 15,5 & & & & & 14,9 & \\
\hline & $1-5$ & 16 & & & & & 15,4 & \\
\hline & $2-6$ & 16 & & & & & 15,4 & \\
\hline & $3-7$ & 15,5 & & & & & 14,8 & \\
\hline \multicolumn{2}{|l|}{ Perímetro $(\mathrm{cm})$} & 50,6 & 50,8 & 49,9 & 49,9 & 48,9 & 48 & \\
\hline \multicolumn{2}{|l|}{ Peímetro $\mathrm{L} / 2(\mathrm{~cm})$} & \multicolumn{7}{|c|}{49,4} \\
\hline \multicolumn{2}{|l|}{$\mathrm{D}(\mathrm{cm})$} & 16,11 & 16,17 & 15,88 & 15,88 & 15,57 & 15,28 & - \\
\hline \multicolumn{2}{|l|}{$D_{m}(\mathrm{~cm})$} & 15,75 & & & & & 15,12 & - \\
\hline \multicolumn{2}{|l|}{$\Delta_{\text {circ }}$} & $2,3 \%$ & & & & & $1,0 \%$ & - \\
\hline \multicolumn{2}{|l|}{$D_{\text {meio }}(\mathrm{cm})$} & \multicolumn{7}{|c|}{15,72} \\
\hline \multicolumn{2}{|l|}{$L / D_{\text {meio }}$} & \multicolumn{7}{|c|}{13,39} \\
\hline \multirow{2}{*}{\multicolumn{2}{|c|}{$\frac{\mathrm{C}}{\mathrm{An}}$}} & \multicolumn{7}{|c|}{$0,3 \%$} \\
\hline & $\Delta \mathrm{D}$ & \multicolumn{7}{|c|}{$2,1 \%$} \\
\hline
\end{tabular}


Tabela B.7 - Dados da tora 3.

Data: 10/09/2009 Espécie: Eucalyptus citriodora

\begin{tabular}{|c|c|c|c|c|c|c|c|c|c|c|c|c|c|}
\hline \multicolumn{3}{|c|}{ Dados gerais } & & & & & & & & & & & \\
\hline Comprimento $(\mathrm{cm})$ & & 450,5 & & & & & & & & & & & \\
\hline Massa $(\mathrm{kg})$ & & 104,00 & & & & & & & & & & & \\
\hline Densidade $\left(\mathrm{kg} / \mathrm{m}^{3}\right)$ & & 935 & & & & & & & & & & & \\
\hline Encurvamento $(\mathrm{mm})$ & & 37 & & & & & & & & & & & \\
\hline \multirow{5}{*}{$\begin{array}{c}\text { Características da seção } \\
\text { transversal }\end{array}$} & \multirow{5}{*}{ Direção } & \multicolumn{12}{|c|}{ Seção } \\
\hline & & 0 & 1 & 2 & 3 & 4 & 5 & 6 & 7 & 8 & 9 & 11 & 10 \\
\hline & & $0,00 \mathrm{~L}$ & $0,10 \mathrm{~L}$ & $0,20 \mathrm{~L}$ & $0,30 \mathrm{~L}$ & $0,40 \mathrm{~L}$ & $0,50 \mathrm{~L}$ & $0,60 \mathrm{~L}$ & $0,70 \mathrm{~L}$ & $0,80 \mathrm{~L}$ & $0,90 \mathrm{~L}$ & $1,00 \mathrm{~L}$ & $0,95 \mathrm{~L}$ \\
\hline & & & & & & & Dist. & cm) & & & & & \\
\hline & & 0,0 & 45,0 & 90,0 & 135,0 & 180,0 & 225,0 & 270,0 & 315,0 & 360,0 & 405,0 & 450,5 & \\
\hline \multirow{4}{*}{ Diâmetros (cm) } & $0-4$ & 19,7 & & & & & & & & & & 15,7 & \\
\hline & $1-5$ & 18,8 & & & & & & & & & & 15 & \\
\hline & $2-6$ & 20,1 & & & & & & & & & & 15,7 & \\
\hline & $3-7$ & 19,0 & & & & & & & & & & 16,1 & \\
\hline \multicolumn{2}{|l|}{ Teor de umidade (\%) } & 23,2 & & & & & 25,8 & & & & & 23,4 & \\
\hline \multicolumn{2}{|l|}{ Perímetro $(\mathrm{cm})$} & 61,3 & 57,1 & 56 & 55,1 & 54,7 & 53,7 & 52,5 & 53,6 & 51,9 & 50,1 & 49,9 & \\
\hline \multicolumn{2}{|l|}{$\mathrm{D}(\mathrm{cm})$} & 19,51 & 18,18 & 17,83 & 17,54 & 17,41 & 17,09 & 16,71 & 17,06 & 16,52 & 15,95 & 15,88 & - \\
\hline \multicolumn{2}{|l|}{$D_{m}(\mathrm{~cm})$} & 19,39 & & & & & & & & & & 15,62 & - \\
\hline \multicolumn{2}{|l|}{$\Delta_{\text {circ }}$} & $0,6 \%$ & & & & & & & & & & $1,7 \%$ & - \\
\hline \multicolumn{2}{|l|}{$L / D_{\text {meio }}$} & \multicolumn{12}{|c|}{26,36} \\
\hline \multirow{2}{*}{\multicolumn{2}{|c|}{\begin{tabular}{|l|}
$\mathrm{C}$ \\
$\Delta \mathrm{D}$
\end{tabular}}} & \multirow{2}{*}{\multicolumn{12}{|c|}{$0,8 \%$}} \\
\hline & & & \multicolumn{11}{|c|}{$6,0 \%$} \\
\hline
\end{tabular}

Tabela B.8 - Dados da tora TB-3.

Data: 17/09/2009 Espécie: Eucalyptus citriodora

\begin{tabular}{|c|c|c|c|c|c|c|c|c|}
\hline \multicolumn{3}{|c|}{ Dados gerais } & & & & & & \\
\hline \multirow{3}{*}{\begin{tabular}{|l|} 
Comprimento $(\mathrm{cm})$ \\
Massa $(\mathrm{kg})$ \\
Densidade $\left(\mathrm{kg} / \mathrm{m}^{3}\right)$
\end{tabular}} & \multirow{2}{*}{\multicolumn{2}{|c|}{$\frac{215}{53.70}$}} & & & & & & \\
\hline & & & & & & & & \\
\hline & \multicolumn{2}{|r|}{945} & & & & & & \\
\hline \multirow{5}{*}{$\begin{array}{c}\text { Características da seção } \\
\text { transversal }\end{array}$} & \multirow{5}{*}{ Direção } & \multicolumn{7}{|c|}{ Seção } \\
\hline & & 0 & 1 & 2 & 3 & 4 & 5 & 12 \\
\hline & & $0,00 \mathrm{~L}$ & $0,209 \mathrm{~L}$ & $0,418 \mathrm{~L}$ & $0,628 \mathrm{~L}$ & $0,837 \mathrm{~L}$ & $1 \mathrm{~L}$ & $0,897 \mathrm{~L}$ \\
\hline & & & & & ist. (cm & & & \\
\hline & & $\overline{0,0}$ & 45,0 & 90,0 & 135,0 & 180,0 & 215,0 & 193,0 \\
\hline \multirow{4}{*}{ Diâmetros (cm) } & $0-4$ & 19,7 & & & & & 16,6 & \\
\hline & $1-5$ & 18,8 & & & & & 16,5 & \\
\hline & $2-6$ & 20,1 & & & & & 17,3 & \\
\hline & $3-7$ & 19,0 & & & & & 17,3 & \\
\hline \multicolumn{2}{|l|}{ Perímetro $(\mathrm{cm})$} & 61,3 & $\overline{57,1}$ & 56 & $\overline{55,1}$ & 54,7 & 53,9 & \\
\hline \multicolumn{2}{|l|}{ Peímetro L/2 (cm) } & \multicolumn{7}{|c|}{55,4} \\
\hline \multicolumn{2}{|l|}{$\mathrm{D}(\mathrm{cm})$} & 19,51 & 18,18 & 17,83 & 17,54 & 17,41 & 17,16 & - \\
\hline \multicolumn{2}{|l|}{$D_{m}(\mathrm{~cm})$} & 19,39 & & & & & 16,92 & - \\
\hline \multicolumn{2}{|l|}{$\Delta_{\text {circ }}$} & $0,6 \%$ & & & & & $1,4 \%$ & e \\
\hline \multicolumn{2}{|l|}{$D_{\text {meio }}(\mathrm{cm})$} & \multicolumn{7}{|c|}{17,63} \\
\hline \multicolumn{2}{|l|}{$L / D_{\text {meio }}$} & \multicolumn{7}{|c|}{12,19} \\
\hline \multicolumn{2}{|l|}{ C } & \multicolumn{7}{|c|}{$1,1 \%$} \\
\hline \multicolumn{2}{|l|}{$\Delta \mathrm{D}$} & \multicolumn{7}{|c|}{$4,7 \%$} \\
\hline
\end{tabular}


Tabela B.9 - Dados da tora TT-3.

Data: 14/09/2009

Espécie: Eucalyptus citriodora

\begin{tabular}{|c|c|c|c|c|c|c|c|c|}
\hline \multicolumn{3}{|c|}{ Dados gerais } & & & & & & \\
\hline \multirow{3}{*}{$\begin{array}{l}\text { Comprimento }(\mathrm{cm}) \\
\text { Massa }(\mathrm{kg}) \\
\text { Densidade }\left(\mathrm{kg} / \mathrm{m}^{3}\right)\end{array}$} & \multirow{2}{*}{\multicolumn{2}{|c|}{$\frac{215,5}{44,45}$}} & & & & & & \\
\hline & & & & & & & & \\
\hline & \multicolumn{2}{|r|}{966} & & & & & & \\
\hline \multirow{5}{*}{$\begin{array}{c}\text { Características da seção } \\
\text { transversal }\end{array}$} & \multirow{5}{*}{ Direção } & \multicolumn{7}{|c|}{ Seção } \\
\hline & & 5 & 6 & 7 & 8 & 9 & 11 & 10 \\
\hline & & $0,00 \mathrm{~L}$ & $0,151 \mathrm{~L}$ & $0,361 \mathrm{~L}$ & $0,571 \mathrm{~L}$ & $0,780 \mathrm{~L}$ & $1 \mathrm{~L}$ & $0,884 \mathrm{~L}$ \\
\hline & & & & & jist. (cm & & & \\
\hline & & $\overline{0,0}$ & 32,7 & $\overline{77,7}$ & 122,7 & 167,8 & 215,5 & 192,5 \\
\hline \multirow{4}{*}{ Diâmetros (cm) } & $0-4$ & 16,7 & & & & & 15,7 & \\
\hline & $1-5$ & $\overline{17,4}$ & & & & & 15 & \\
\hline & $2-6$ & 17,5 & & & & & 15,7 & \\
\hline & $3-7$ & 12,0 & & & & & 16,1 & \\
\hline \multicolumn{2}{|l|}{ Perímetro $(\mathrm{cm})$} & 53,7 & 52,5 & 53,6 & 51,9 & 50,1 & 49,9 & \\
\hline \multicolumn{2}{|l|}{ Peímetro L/2 (cm) } & \multicolumn{7}{|c|}{51,6} \\
\hline \multicolumn{2}{|l|}{$\overline{D(c m)}$} & 17,09 & 16,71 & 17,06 & 16,52 & 15,95 & 15,88 & - \\
\hline \multicolumn{2}{|l|}{$D_{m}(\mathrm{~cm})$} & 15,72 & & & & & 15,62 & - \\
\hline \multicolumn{2}{|l|}{$\Delta_{\text {circ }}$} & $8,8 \%$ & & & & & $1,7 \%$ & - \\
\hline \multicolumn{2}{|l|}{$\mathrm{D}_{\text {meio }}(\mathrm{cm})$} & \multicolumn{7}{|c|}{16,42} \\
\hline \multicolumn{2}{|l|}{$\mathrm{L} / \mathrm{D}_{\text {meio }}$} & \multicolumn{7}{|c|}{13,12} \\
\hline \multicolumn{2}{|l|}{$\mathrm{C}$} & \multicolumn{7}{|c|}{$0,0 \%$} \\
\hline \multicolumn{2}{|l|}{$\Delta \mathrm{D}$} & \multicolumn{7}{|c|}{$3,2 \%$} \\
\hline
\end{tabular}

Tabela B.10 - Dados da tora 4.

Data: 29/09/2009 Espécie: Eucalyptus citriodora

\begin{tabular}{|c|c|c|c|c|c|c|c|c|c|c|c|c|c|}
\hline \multicolumn{3}{|c|}{ Dados gerais } & & & & & & & & & & & \\
\hline Comprimento $(\mathrm{cm})$ & & 436,5 & & & & & & & & & & & \\
\hline Massa $(\mathrm{kg})$ & & 83,55 & & & & & & & & & & & \\
\hline Densidade $\left(\mathrm{kg} / \mathrm{m}^{3}\right)$ & & 880 & & & & & & & & & & & \\
\hline Encurvamento $(\mathrm{mm})$ & & 35 & & & & & & & & & & & \\
\hline \multirow{5}{*}{$\begin{array}{c}\text { Características da seção } \\
\text { transversal }\end{array}$} & \multirow{5}{*}{ Direção } & \multicolumn{12}{|c|}{ Seção } \\
\hline & & $\overline{0}$ & 1 & 2 & $\overline{3}$ & $\overline{4}$ & 5 & 6 & 7 & 8 & $\overline{9}$ & 11 & 10 \\
\hline & & $0,00 \mathrm{~L}$ & $0,10 \mathrm{~L}$ & $0,20 \mathrm{~L}$ & $0,30 \mathrm{~L}$ & $0,40 \mathrm{~L}$ & $0,50 \mathrm{~L}$ & $0,60 \mathrm{~L}$ & $0,70 \mathrm{~L}$ & $0,80 \mathrm{~L}$ & $0,90 \mathrm{~L}$ & $1,00 \mathrm{~L}$ & $0,95 \mathrm{~L}$ \\
\hline & & & & & & & Dist & $\mathrm{cm})$ & & & & & \\
\hline & & 0,0 & 43,6 & 86,3 & 131,0 & 174,6 & 218,3 & 261,9 & 305,5 & 349,2 & 392,9 & 436,5 & \\
\hline \multirow{4}{*}{ Diâmetros (cm) } & $0-4$ & 17,7 & & & & & & & & & & 14,1 & \\
\hline & $1-5$ & 18,8 & & & & & & & & & & 15,3 & \\
\hline & $2-6$ & 19,2 & & & & & & & & & & 13,7 & \\
\hline & $3-7$ & 17,5 & & & & & & & & & & 14 & \\
\hline \multicolumn{2}{|l|}{ Teor de umidade (\%) } & 22 & & & & & 19,6 & & & & & 18,5 & \\
\hline \multicolumn{2}{|l|}{ Perímetro $(\mathrm{cm})$} & 58,9 & 54,5 & 52,2 & 51,1 & 49,8 & 49,3 & 48,5 & 47,4 & 46,8 & 48,8 & 45,4 & \\
\hline \multicolumn{2}{|l|}{$\mathrm{D}(\mathrm{cm})$} & 18,75 & 17,35 & 16,62 & 16,27 & 15,85 & 15,69 & 15,44 & 15,09 & 14,90 & 15,53 & 14,45 & - \\
\hline \multicolumn{2}{|l|}{$\mathrm{D}_{\mathrm{m}}(\mathrm{cm})$} & 18,29 & & & & & & & & & & 14,26 & - \\
\hline \multicolumn{2}{|l|}{$\Delta_{\text {circ }}$} & $2,5 \%$ & & & & & & & & & & $1,3 \%$ & - \\
\hline \multicolumn{2}{|l|}{$L / D_{\text {meio }}$} & \multicolumn{12}{|c|}{27,82} \\
\hline \multirow{2}{*}{\multicolumn{2}{|c|}{$\frac{C}{C D}$}} & \multirow{2}{*}{\multicolumn{12}{|c|}{$0,9 \%$}} \\
\hline & & \multicolumn{10}{|c|}{$7,6 \%$} & & \\
\hline
\end{tabular}


Tabela B.11 - Dados da tora TB-4.

Data: $17 / 09 / 2009$

Espécie: Eucalyptus citriodora

\begin{tabular}{|c|c|c|c|c|c|c|c|c|}
\hline \multicolumn{3}{|c|}{ Dados gerais } & & & & & & \\
\hline \multirow{3}{*}{\begin{tabular}{|l} 
Comprimento $(\mathrm{cm})$ \\
Massa $(\mathrm{kg})$ \\
Densidade $\left(\mathrm{kg} / \mathrm{m}^{3}\right)$ \\
\end{tabular}} & \multirow{2}{*}{\multicolumn{2}{|c|}{$\begin{array}{r}207 \\
43,40\end{array}$}} & & & & & & \\
\hline & & & & & & & & \\
\hline & \multicolumn{2}{|r|}{895} & & & & & & \\
\hline \multirow{5}{*}{$\begin{array}{c}\text { Características da seção } \\
\text { transversal }\end{array}$} & \multirow{5}{*}{ Direção } & \multicolumn{7}{|c|}{ Seção } \\
\hline & & 0 & 1 & 2 & 3 & 4 & 5 & 12 \\
\hline & & $0,00 \mathrm{~L}$ & $0,207 \mathrm{~L}$ & $0,422 \mathrm{~L}$ & $0,628 \mathrm{~L}$ & $0,843 \mathrm{~L}$ & $1 \mathrm{~L}$ & $0,936 \mathrm{~L}$ \\
\hline & & & & & ist. $(\mathrm{cm}$ & & & \\
\hline & & 0,0 & 42,8 & 87,0 & 130,0 & 174,7 & 207,0 & 193,7 \\
\hline \multirow{4}{*}{ Diâmetros (cm) } & $0-4$ & 17,7 & & & & & 15,5 & \\
\hline & $1-5$ & 18,8 & & & & & 16,0 & \\
\hline & $2-6$ & 19,2 & & & & & 14,5 & \\
\hline & $3-7$ & 17,5 & & & & & 15,0 & \\
\hline Perímetro $(\mathrm{cm})$ & & 58,9 & 54,5 & 52,2 & 51,1 & 49,8 & 49,5 & \\
\hline Peímetro L/2 (cm) & & & & & 51 & & & \\
\hline \multicolumn{2}{|l|}{$\mathrm{D}(\mathrm{cm})$} & 18,75 & 17,35 & 16,62 & 16,27 & 15,85 & 15,76 & - \\
\hline \multicolumn{2}{|l|}{$D_{m}(\mathrm{~cm})$} & 18,29 & & & & & 15,24 & - \\
\hline \multicolumn{2}{|l|}{$\Delta_{\text {circ }}$} & $2,5 \%$ & & & & & $3,4 \%$ & - \\
\hline \multicolumn{2}{|l|}{$D_{\text {meio }}(\mathrm{cm})$} & \multicolumn{7}{|c|}{16,23} \\
\hline \multicolumn{2}{|l|}{$L / D_{\text {meio }}$} & \multicolumn{7}{|c|}{12,75} \\
\hline \multicolumn{2}{|l|}{ C } & \multicolumn{7}{|c|}{$1,5 \%$} \\
\hline \multicolumn{2}{|l|}{$\Delta \mathrm{D}$} & \multicolumn{7}{|c|}{$6,7 \%$} \\
\hline
\end{tabular}

Tabela B.12 - Dados da tora TT-4.

Data: 14/09/2009 Espécie: Eucalyptus citriodora

\begin{tabular}{|c|c|c|c|c|c|c|c|c|}
\hline \multicolumn{3}{|c|}{ Dados gerais } & & & & & & \\
\hline \multirow{3}{*}{\begin{tabular}{|l|} 
Comprimento $(\mathrm{cm})$ \\
Massa $(\mathrm{kg})$ \\
Densidade $\left(\mathrm{kg} / \mathrm{m}^{3}\right)$ \\
\end{tabular}} & \multirow{2}{*}{\multicolumn{2}{|c|}{$\begin{array}{r}207 \\
34,40\end{array}$}} & & & & & & \\
\hline & & & & & & & & \\
\hline & \multicolumn{2}{|r|}{$\begin{array}{r}0,40 \\
951\end{array}$} & & & & & & \\
\hline \multirow{5}{*}{$\begin{array}{c}\text { Características da seção } \\
\text { transversal }\end{array}$} & \multirow{5}{*}{ Direção } & \multicolumn{7}{|c|}{ Seção } \\
\hline & & 5 & 6 & 7 & 8 & $\overline{9}$ & 11 & 10 \\
\hline & & $0,00 \mathrm{~L}$ & $0,157 \mathrm{~L}$ & $0,367 \mathrm{~L}$ & $\overline{0,577 \mathrm{~L}}$ & $0,778 \mathrm{~L}$ & $1 \mathrm{~L}$ & $\overline{0,896 \mathrm{~L}}$ \\
\hline & & & & & )ist. (cn & & & \\
\hline & & 0,0 & 32,5 & $\overline{76,0}$ & 119,5 & 161,0 & 207,0 & 185,5 \\
\hline \multirow{4}{*}{ Diâmetros (cm) } & $0-4$ & 15,3 & & & & & 14,1 & \\
\hline & $1-5$ & 15,2 & & & & & 15,3 & \\
\hline & $2-6$ & 15,0 & & & & & 13,7 & \\
\hline & $3-7$ & 15,3 & & & & & 14,0 & \\
\hline \multicolumn{2}{|l|}{ Perímetro $(\mathrm{cm})$} & 48,3 & 48,5 & 47,4 & 46,8 & 48,8 & 45,4 & \\
\hline \multicolumn{2}{|l|}{ Peímetro L/2 $(\mathrm{cm})$} & \multicolumn{7}{|c|}{46} \\
\hline \multicolumn{2}{|l|}{$\mathrm{D}(\mathrm{cm})$} & 15,37 & 15,44 & 15,09 & 14,90 & 15,53 & 14,45 & - \\
\hline \multicolumn{2}{|l|}{$\mathrm{D}_{\mathrm{m}}(\mathrm{cm})$} & 15,20 & & & & & 14,26 & - \\
\hline \multicolumn{2}{|l|}{$\Delta_{\text {circ }}$} & $1,2 \%$ & & & & & $1,3 \%$ & - \\
\hline \multicolumn{2}{|l|}{$\mathrm{D}_{\text {meio }}(\mathrm{cm})$} & \multicolumn{7}{|c|}{14,64} \\
\hline \multicolumn{2}{|l|}{$L / D_{\text {meio }}$} & \multicolumn{7}{|c|}{14,14} \\
\hline \multicolumn{2}{|l|}{ C } & \multicolumn{7}{|c|}{$0,5 \%$} \\
\hline \multicolumn{2}{|l|}{$\Delta \mathrm{D}$} & \multicolumn{7}{|c|}{$2,7 \%$} \\
\hline
\end{tabular}


Tabela B.13 - Dados da tora 5.

\begin{tabular}{|c|c|c|c|c|c|c|c|c|c|c|c|c|c|}
\hline Data: 9/11/2009 & \multicolumn{13}{|c|}{ Espécie: Eucalyptus citriodora } \\
\hline \multicolumn{3}{|c|}{ Dados gerais } & & & & & & & & & & & \\
\hline Comprimento $(\mathrm{cm})$ & & 445,5 & & & & & & & & & & & \\
\hline Massa $(\mathrm{kg})$ & & 86,20 & & & & & & & & & & & \\
\hline Densidade $\left(\mathrm{kg} / \mathrm{m}^{3}\right)$ & & 764 & & & & & & & & & & & \\
\hline Encurvamento (mm) & & 35 & & & & & & & & & & & \\
\hline \multirow{5}{*}{$\begin{array}{c}\text { Características da seção } \\
\text { transversal }\end{array}$} & \multirow{5}{*}{ Direção } & \multicolumn{12}{|c|}{ Seção } \\
\hline & & 0 & 1 & 2 & 3 & 4 & 5 & 6 & 7 & 8 & 9 & 11 & 10 \\
\hline & & $0,00 \mathrm{~L}$ & $0,10 \mathrm{~L}$ & $0,20 \mathrm{~L}$ & $0,30 \mathrm{~L}$ & $0,40 \mathrm{~L}$ & $0,50 \mathrm{~L}$ & $0,60 \mathrm{~L}$ & $0,70 \mathrm{~L}$ & $0,80 \mathrm{~L}$ & $0,90 \mathrm{~L}$ & $1,00 \mathrm{~L}$ & $0,95 \mathrm{~L}$ \\
\hline & & & & & & & Dist & cm) & & & & & \\
\hline & & 0,0 & 44,6 & 89,1 & 133,7 & 178,2 & 222,8 & 267,3 & 311,9 & 356,4 & 401,0 & 445,5 & 423,2 \\
\hline \multirow{4}{*}{ Diâmetros (cm) } & $0-4$ & 20,5 & & & & & & & & & & 14,5 & \\
\hline & $1-5$ & 18 & & & & & & & & & & 14 & \\
\hline & $2-6$ & 21,5 & & & & & & & & & & 14,4 & \\
\hline & $3-7$ & 19,0 & & & & & & & & & & 14,5 & \\
\hline \multicolumn{2}{|l|}{ Teor de umidade (\%) } & 24,7 & & & & & 24 & & & & & 21,3 & \\
\hline \multicolumn{2}{|l|}{ Perímetro $(\mathrm{cm})$} & 66,3 & 57,6 & 55,3 & 52,9 & 51,9 & 50,3 & 49 & 48,5 & 47,5 & 49 & 45,9 & \\
\hline \multicolumn{2}{|l|}{$\mathrm{D}(\mathrm{cm})$} & 21,10 & 18,33 & 17,60 & 16,84 & 16,52 & 16,01 & 15,60 & 15,44 & 15,12 & 15,60 & 14,61 & - \\
\hline \multicolumn{2}{|l|}{$D_{m}(\mathrm{~cm})$} & 19,70 & & & & & & & & & & 14,35 & - \\
\hline \multicolumn{2}{|l|}{$\Delta_{\text {circ }}$} & $7,1 \%$ & & & & & & & & & & $1,8 \%$ & - \\
\hline \multicolumn{2}{|l|}{$L / D_{\text {meio }}$} & \multicolumn{12}{|c|}{27,82} \\
\hline \multicolumn{2}{|l|}{$\mathrm{C}$} & \\
\hline \multicolumn{2}{|l|}{$\Delta \mathrm{D}$} & \multicolumn{12}{|c|}{$11,1 \%$} \\
\hline
\end{tabular}

Tabela B.14 - Dados da tora TB-5.

Data: 11/11/2009 Espécie: Eucalyptus citriodora

\begin{tabular}{|c|c|c|c|c|c|c|c|c|}
\hline \multicolumn{3}{|c|}{ Dados gerais } & & & & & & \\
\hline \multirow{3}{*}{$\begin{array}{l}\text { Comprimento }(\mathrm{cm}) \\
\text { Massa }(\mathrm{kg}) \\
\text { Densidade }\left(\mathrm{kg} / \mathrm{m}^{3}\right)\end{array}$} & \multirow{2}{*}{\multicolumn{2}{|c|}{$\begin{array}{r}211 \\
46.65\end{array}$}} & & & & & & \\
\hline & & & & & & & & \\
\hline & \multicolumn{2}{|c|}{$\begin{array}{r}40,05 \\
803\end{array}$} & & & & & & \\
\hline \multirow{5}{*}{$\begin{array}{c}\text { Características da seção } \\
\text { transversal }\end{array}$} & \multirow{5}{*}{ Direção } & \multicolumn{7}{|c|}{ Seção } \\
\hline & & 0 & 1 & 2 & 3 & 4 & 5 & 12 \\
\hline & & 0 & $0,211 \mathrm{~L}$ & $0,422 \mathrm{~L}$ & $0,632 \mathrm{~L}$ & $0,844 \mathrm{~L}$ & $\mathrm{~L}$ & $0,893 \mathrm{~L}$ \\
\hline & & & & & ist. $(\mathrm{cm}$ & & & \\
\hline & & $\overline{0,0}$ & 44,5 & 89,0 & 133,5 & 178,0 & 211,0 & 188,5 \\
\hline \multirow{4}{*}{ Diâmetros $(\mathrm{cm})$} & $0-4$ & 20,5 & & & & & 15,5 & \\
\hline & $1-5$ & 18,0 & & & & & 15,5 & \\
\hline & $2-6$ & 21,5 & & & & & 15,5 & \\
\hline & $3-7$ & 19,0 & & & & & 16,5 & \\
\hline \multicolumn{2}{|l|}{ Perímetro $(\mathrm{cm})$} & 66,3 & 57,6 & 55,3 & 52,9 & 51,9 & 51,0 & \\
\hline \multicolumn{2}{|l|}{ Peímetro L/2 $(\mathrm{cm})$} & \multicolumn{7}{|c|}{53,7} \\
\hline \multicolumn{2}{|l|}{$\mathrm{D}(\mathrm{cm})$} & 21,10 & 18,33 & 17,60 & 16,84 & 16,52 & 16,23 & - \\
\hline \multicolumn{2}{|l|}{$D_{m}(\mathrm{~cm})$} & 19,70 & & & & & 15,74 & - \\
\hline \multicolumn{2}{|l|}{$\Delta_{\text {circ }}$} & $7,1 \%$ & & & & & $3,1 \%$ & - \\
\hline \multicolumn{2}{|l|}{$D_{\text {meio }}(\mathrm{cm})$} & \multicolumn{7}{|c|}{17,09} \\
\hline \multicolumn{2}{|l|}{$L / D_{\text {meio }}$} & \multicolumn{7}{|c|}{12,34} \\
\hline \multicolumn{2}{|l|}{ C } & \multicolumn{7}{|c|}{$1,9 \%$} \\
\hline \multicolumn{2}{|l|}{$\Delta \mathrm{D}$} & \multicolumn{7}{|c|}{$10,1 \%$} \\
\hline
\end{tabular}


Tabela B.15 - Dados da tora TT-5.

Data: 11/11/2009 Espécie: Eucalyptus citriodora

\begin{tabular}{|c|c|c|c|c|c|c|c|c|}
\hline \multicolumn{3}{|c|}{ Dados gerais } & & & & & & \\
\hline Comprimento $(\mathrm{cm})$ & & 211,5 & & & & & & \\
\hline Massa (kg) & & 34,30 & & & & & & \\
\hline Densidade $\left(\mathrm{kg} / \mathrm{m}^{3}\right)$ & & 878 & & & & & & \\
\hline \multirow{5}{*}{$\begin{array}{c}\text { Características da seção } \\
\text { transversal }\end{array}$} & \multirow{5}{*}{ Direção } & \multicolumn{7}{|c|}{ Seção } \\
\hline & & 5 & 6 & 7 & 8 & 9 & 11 & 10 \\
\hline & & 0 & $0,156 \mathrm{~L}$ & $0,369 \mathrm{~L}$ & $0,581 \mathrm{~L}$ & $0,791 \mathrm{~L}$ & $\mathrm{~L}$ & $0,898 \mathrm{~L}$ \\
\hline & & & & & ist. (cm & & & \\
\hline & & 0,0 & 33,0 & 77,8 & 122,5 & 167,0 & 211,5 & 189,0 \\
\hline \multirow{4}{*}{ Diâmetros (cm) } & $0-4$ & 15,5 & & & & & 14,5 & \\
\hline & $1-5$ & 15,0 & & & & & 14,0 & \\
\hline & $2-6$ & 16,5 & & & & & 14,4 & \\
\hline & $3-7$ & 16,0 & & & & & 14,5 & \\
\hline \multicolumn{2}{|l|}{ Perímetro (cm) } & 50,4 & 49 & 48,5 & 47,5 & 49 & 45,9 & \\
\hline \multicolumn{2}{|l|}{ Peímetro L/2 (cm) } & \multicolumn{7}{|c|}{47,7} \\
\hline \multicolumn{2}{|l|}{$\mathrm{D}(\mathrm{cm})$} & 16,04 & 15,60 & 15,44 & 15,12 & 15,60 & 14,61 & - \\
\hline \multicolumn{2}{|l|}{$\mathrm{D}_{\mathrm{m}}(\mathrm{cm})$} & 15,74 & & & & & 14,35 & - \\
\hline \multicolumn{2}{|l|}{$\Delta_{\text {circ }}$} & $1,9 \%$ & & & & & $1,8 \%$ & - \\
\hline \multicolumn{2}{|l|}{$\mathrm{D}_{\text {meio }}(\mathrm{cm})$} & \multicolumn{7}{|c|}{15,18} \\
\hline \multicolumn{2}{|l|}{$L / D_{\text {meio }}$} & \multicolumn{7}{|c|}{13,93} \\
\hline \multicolumn{2}{|l|}{$\mathrm{C}$} & \multicolumn{7}{|c|}{$0,7 \%$} \\
\hline \multicolumn{2}{|l|}{$\Delta \mathrm{D}$} & \multicolumn{7}{|c|}{$3,2 \%$} \\
\hline
\end{tabular}

Tabela B.16 - Dados da tora 6.

Data: 20/11/2009 Espécie: Eucalyptus citriodora

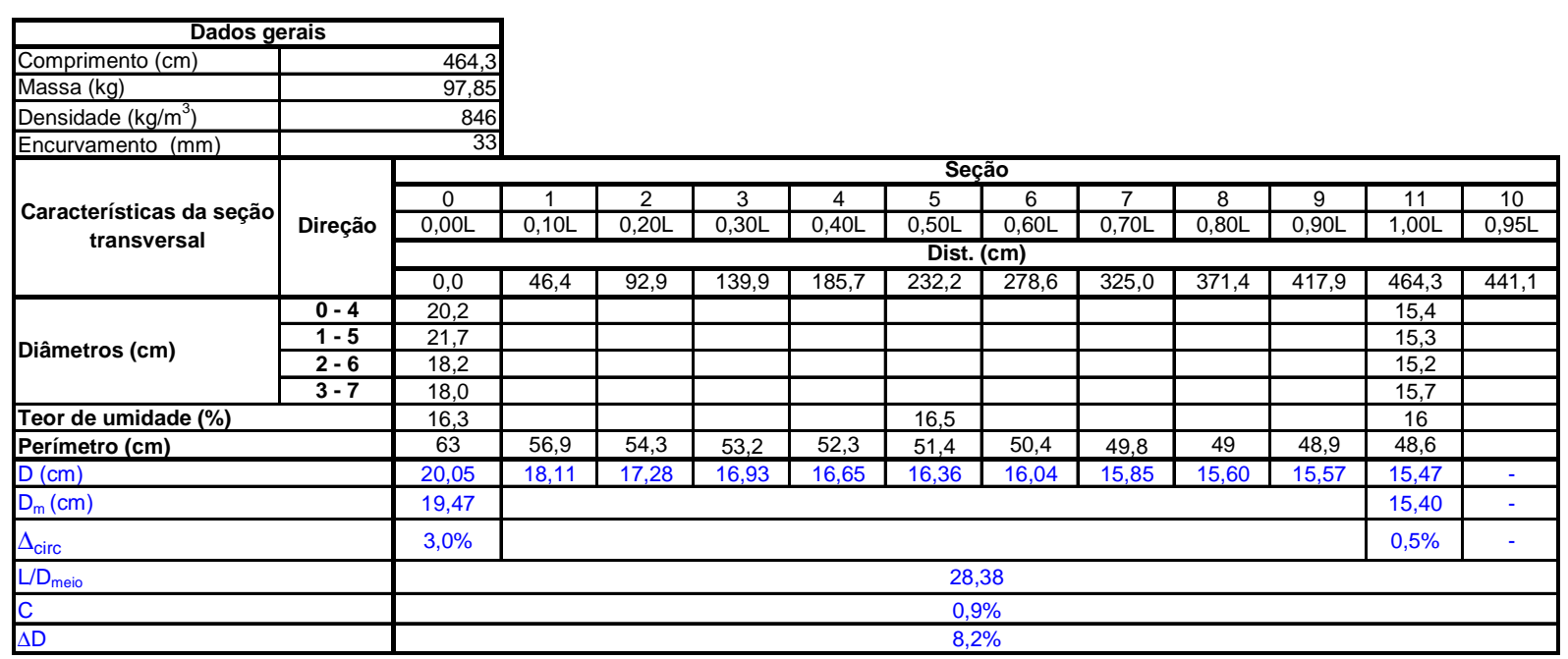


Tabela B.17 - Dados da tora TB-6.

Data: $11 / 11 / 2009$

Espécie: Eucalyptus citriodora

\begin{tabular}{|c|c|c|c|c|c|c|c|c|}
\hline \multicolumn{3}{|c|}{ Dados gerais } & & & & & & \\
\hline \multirow{3}{*}{$\begin{array}{l}\text { Comprimento }(\mathrm{cm}) \\
\text { Massa }(\mathrm{kg}) \\
\text { Densidade }\left(\mathrm{kg} / \mathrm{m}^{3}\right) \\
\end{array}$} & \multirow{2}{*}{\multicolumn{2}{|c|}{$\frac{221,5}{52,10}$}} & & & & & & \\
\hline & & & & & & & & \\
\hline & \multicolumn{2}{|r|}{897} & & & & & & \\
\hline \multirow{5}{*}{$\begin{array}{c}\text { Características da seção } \\
\text { transversal }\end{array}$} & \multirow{5}{*}{ Direção } & \multicolumn{7}{|c|}{ Seção } \\
\hline & & 0 & 1 & 2 & 3 & 4 & 5 & 12 \\
\hline & & 0 & $\overline{0,212 \mathrm{~L}}$ & $0,424 \mathrm{~L}$ & $0,636 \mathrm{~L}$ & $0,842 \mathrm{~L}$ & $0,900 \mathrm{~L}$ & $\bar{L}$ \\
\hline & & & & & ist. $(\mathbf{c m})$ & & & \\
\hline & & $\overline{0,0}$ & 47,0 & $\overline{94,0}$ & 141,0 & 186,5 & 199,5 & 221,5 \\
\hline \multirow{4}{*}{ Diâmetros $(\mathrm{cm})$} & $0-4$ & 20,2 & & & & & 16,5 & \\
\hline & $1-5$ & 21,7 & & & & & 16,2 & \\
\hline & $2-6$ & 18,2 & & & & & 16 & \\
\hline & $3-7$ & 18,0 & & & & & 16,6 & \\
\hline \multicolumn{2}{|l|}{ Perímetro $(\mathrm{cm})$} & 63 & 56,9 & 54,3 & 53,2 & 52,3 & 51,6 & \\
\hline \multicolumn{2}{|l|}{ Peímetro L/2 (cm) } & \multicolumn{7}{|c|}{53,6} \\
\hline \multicolumn{2}{|l|}{$\mathrm{D}(\mathrm{cm})$} & 20,05 & 18,11 & 17,28 & 16,93 & 16,65 & 16,42 & - \\
\hline \multicolumn{2}{|l|}{$D_{m}(\mathrm{~cm})$} & 19,47 & & & & & 16,32 & - \\
\hline \multicolumn{2}{|l|}{$\Delta_{\text {circ }}$} & $3,0 \%$ & & & & & $0,6 \%$ & - \\
\hline \multicolumn{2}{|l|}{$D_{\text {meio }}(\mathrm{cm})$} & \multicolumn{7}{|c|}{17,06} \\
\hline \multicolumn{2}{|l|}{$L / D_{\text {meio }}$} & \multicolumn{7}{|c|}{12,98} \\
\hline \multicolumn{2}{|l|}{$\mathrm{C}$} & \multicolumn{7}{|c|}{$1,4 \%$} \\
\hline \multicolumn{2}{|l|}{$\Delta \mathrm{D}$} & \multicolumn{7}{|c|}{$7,7 \%$} \\
\hline
\end{tabular}

Tabela B.18 - Dados da tora TT-6.

Data: $11 / 11 / 2009$

Espécie: Eucalyptus citriodora

\begin{tabular}{|c|c|c|c|c|c|c|c|c|}
\hline \multicolumn{3}{|l|}{ Dados gerais } & & & & & & \\
\hline \multirow{3}{*}{$\begin{array}{l}\text { Comprimento }(\mathrm{cm}) \\
\text { Massa }(\mathrm{kg}) \\
\text { Densidade }\left(\mathrm{kg} / \mathrm{m}^{3}\right)\end{array}$} & \multirow{2}{*}{\multicolumn{2}{|c|}{$\begin{array}{r}220 \\
40,75\end{array}$}} & & & & & & \\
\hline & & & & & & & & \\
\hline & \multicolumn{2}{|r|}{938} & & & & & & \\
\hline \multirow{5}{*}{$\begin{array}{c}\text { Características da seção } \\
\text { transversal }\end{array}$} & \multirow{5}{*}{ Direção } & \multicolumn{7}{|c|}{ Seção } \\
\hline & & 5 & 6 & 7 & 8 & $\overline{9}$ & 11 & 10 \\
\hline & & 0 & $0,159 \mathrm{~L}$ & $0,370 \mathrm{~L}$ & $0,583 \mathrm{~L}$ & $0,795 \mathrm{~L}$ & $\mathrm{~L}$ & $0,889 \mathrm{~L}$ \\
\hline & & & & & Dist. $(\mathrm{cm})$ & & & \\
\hline & & $\overline{0,0}$ & 35,0 & 81,5 & 128,3 & 175,0 & 220,0 & 195,7 \\
\hline \multirow{4}{*}{ Diâmetros (cm) } & $0-4$ & $\overline{16,3}$ & & & & & 15,4 & \\
\hline & $1-5$ & 15,7 & & & & & 15,3 & \\
\hline & $2-6$ & 16,0 & & & & & 15,2 & \\
\hline & $3-7$ & 16,5 & & & & & 15,7 & \\
\hline \multicolumn{2}{|l|}{ Perímetro $(\mathrm{cm})$} & 51 & 50,4 & 49,8 & 49 & 48,9 & 48,6 & \\
\hline \multicolumn{2}{|l|}{ Peímetro L/2 $(\mathrm{cm})$} & \multicolumn{7}{|c|}{49,1} \\
\hline \multicolumn{2}{|l|}{$\mathrm{D}(\mathrm{cm})$} & 16,23 & 16,04 & 15,85 & 15,60 & 15,57 & 15,47 & - \\
\hline \multicolumn{2}{|l|}{$D_{m}(\mathrm{~cm})$} & 16,12 & & & & & 15,40 & - \\
\hline \multicolumn{2}{|l|}{$\Delta_{\text {circ }}$} & $0,7 \%$ & & & & & $0,5 \%$ & - \\
\hline \multicolumn{2}{|l|}{$\mathrm{D}_{\text {meio }}(\mathrm{cm})$} & \multicolumn{7}{|c|}{15,63} \\
\hline \multicolumn{2}{|l|}{$L / D_{\text {meio }}$} & \multicolumn{7}{|c|}{14,08} \\
\hline \multicolumn{2}{|l|}{ C } & \multicolumn{7}{|c|}{$0,3 \%$} \\
\hline \multicolumn{2}{|l|}{$\Delta \mathrm{D}$} & \multicolumn{7}{|c|}{$1,9 \%$} \\
\hline
\end{tabular}


Tabela B.19 - Dados da tora 7.

Data: 30/11/2009 Espécie: Eucalyptus citriodora

\begin{tabular}{|c|c|c|c|c|c|c|c|c|c|c|c|c|c|}
\hline \multicolumn{3}{|c|}{ Dados gerais } & & & & & & & & & & & \\
\hline \multirow{2}{*}{\begin{tabular}{|l} 
Comprimento $(\mathrm{cm})$ \\
Massa $(\mathrm{kg})$
\end{tabular}} & \multirow{2}{*}{\multicolumn{2}{|c|}{$\begin{array}{l}439,5 \\
77,15\end{array}$}} & & & & & & & & & & & \\
\hline & & & & & & & & & & & & & \\
\hline \multirow{2}{*}{\begin{tabular}{|l|} 
Densidade $\left(\mathrm{kg} / \mathrm{m}^{3}\right)$ \\
Encurvamento $(\mathrm{mm})$
\end{tabular}} & & & & & & & & & & & & \\
\hline & \multicolumn{2}{|r|}{$\begin{array}{r}786 \\
50\end{array}$} & & & & & & & & & & & \\
\hline \multirow{5}{*}{$\begin{array}{c}\text { Características da seção } \\
\text { transversal }\end{array}$} & \multirow{5}{*}{ Direção } & \multicolumn{12}{|c|}{ Seção } \\
\hline & & 0 & $\overline{1}$ & $\overline{2}$ & $\overline{3}$ & $\overline{4}$ & 5 & $\overline{6}$ & 7 & $\overline{8}$ & $\overline{9}$ & 11 & $\overline{10}$ \\
\hline & & $0,00 \mathrm{~L}$ & $0,10 \mathrm{~L}$ & $0,20 \mathrm{~L}$ & $0,30 \mathrm{~L}$ & $0,40 \mathrm{~L}$ & $0,50 \mathrm{~L}$ & $0,60 \mathrm{~L}$ & $0,70 \mathrm{~L}$ & $0,80 \mathrm{~L}$ & $0,90 \mathrm{~L}$ & $1,00 \mathrm{~L}$ & $0,95 \mathrm{~L}$ \\
\hline & & & & & & & Dist. & m) & & & & & \\
\hline & & 0,0 & 44,0 & 87,9 & 131,9 & 175,8 & 219,8 & 263,7 & 307,7 & 351,6 & 395,6 & 439,5 & 417,5 \\
\hline \multirow{4}{*}{ Diâmetros (cm) } & $0-4$ & 15,6 & & & & & & & & & & 14,5 & \\
\hline & $1-5$ & 18,7 & & & & & & & & & & 14,5 & \\
\hline & $2-6$ & 21,5 & & & & & & & & & & 15,0 & \\
\hline & $3-7$ & 18,5 & & & & & & & & & & 14,3 & \\
\hline \multicolumn{2}{|l|}{ Teor de umidade (\%) } & 21,6 & & & & & 22,5 & & & & & 14,5 & \\
\hline \multicolumn{2}{|l|}{ Perímetro (cm) } & 59,3 & 54,4 & 51,6 & 50,8 & 50,3 & 50 & 48,8 & 48 & 47 & 47,7 & 46,4 & \\
\hline \multicolumn{2}{|l|}{$\mathrm{D}(\mathrm{cm})$} & 18,88 & 17,32 & 16,42 & 16,17 & 16,01 & 15,92 & 15,53 & 15,28 & 14,96 & 15,18 & 14,77 & - \\
\hline \multicolumn{2}{|l|}{$D_{m}(\mathrm{~cm})$} & 18,46 & & & & & & & & & & 14,57 & - \\
\hline \multicolumn{2}{|l|}{$\Delta_{\text {circ }}$} & $2,3 \%$ & & & & & & & & & & $1,4 \%$ & - \\
\hline \multicolumn{2}{|l|}{$L / D_{\text {meio }}$} & \multicolumn{12}{|c|}{27,61} \\
\hline \multicolumn{2}{|l|}{$\mathrm{C}$} & \multicolumn{12}{|c|}{$0,9 \%$} \\
\hline \multicolumn{2}{|l|}{$\Delta \mathrm{D}$} & \multicolumn{12}{|c|}{$7,4 \%$} \\
\hline
\end{tabular}

Tabela B.20 - Dados da tora TB-7.

Data: 02/12/2009 Espécie: Eucalyptus citriodora

\begin{tabular}{|c|c|c|c|c|c|c|c|c|}
\hline \multicolumn{3}{|c|}{ Dados gerais } & & & & & & \\
\hline \multirow{3}{*}{\begin{tabular}{|l|} 
Comprimento $(\mathrm{cm})$ \\
Massa $(\mathrm{kg})$ \\
Densidade $\left(\mathrm{kg} / \mathrm{m}^{3}\right)$ \\
\end{tabular}} & \multirow{2}{*}{\multicolumn{2}{|c|}{$\begin{array}{r}211 \\
40,25\end{array}$}} & & & & & & \\
\hline & & & & & & & & \\
\hline & \multicolumn{2}{|r|}{802} & & & & & & \\
\hline \multirow{5}{*}{$\begin{array}{c}\text { Características da seção } \\
\text { transversal }\end{array}$} & \multirow{5}{*}{ Direção } & \multicolumn{7}{|c|}{ Seção } \\
\hline & & 0 & 1 & 2 & 3 & 4 & 5 & 12 \\
\hline & & 0 & $0,209 \mathrm{~L}$ & $0,417 \mathrm{~L}$ & $0,626 \mathrm{~L}$ & $0,834 \mathrm{~L}$ & $\mathrm{~L}$ & $0,896 \mathrm{~L}$ \\
\hline & & \multicolumn{7}{|c|}{ Dist. (cm) } \\
\hline & & $\overline{0,0}$ & 44,2 & 88,0 & 132,0 & 176,0 & 211,0 & 189,0 \\
\hline \multirow{4}{*}{ Diâmetros (cm) } & $0-4$ & 15,6 & & & & & 15,2 & \\
\hline & $1-5$ & 18,7 & & & & & 16,3 & \\
\hline & $2-6$ & 21,5 & & & & & 16,2 & \\
\hline & $3-7$ & 18,5 & & & & & 14,8 & \\
\hline Perímetro $(\mathrm{cm})$ & & 59,3 & 54,4 & 51,6 & 50,8 & 50,3 & 49,9 & \\
\hline Peímetro L/2 (cm) & & \multicolumn{7}{|c|}{51,2} \\
\hline \multicolumn{2}{|l|}{$\mathrm{D}(\mathrm{cm})$} & 18,88 & 17,32 & 16,42 & 16,17 & 16,01 & 15,88 & - \\
\hline \multicolumn{2}{|l|}{$D_{m}(\mathrm{~cm})$} & 18,46 & & & & & 15,61 & - \\
\hline \multicolumn{2}{|l|}{$\Delta_{\text {circ }}$} & $2,3 \%$ & & & & & $1,7 \%$ & - \\
\hline \multicolumn{2}{|l|}{$\mathrm{D}_{\text {meio }}(\mathrm{cm})$} & \multicolumn{7}{|c|}{16,30} \\
\hline \multicolumn{2}{|l|}{$\mathrm{L} / \mathrm{D}_{\text {meio }}$} & \multicolumn{7}{|c|}{12,95} \\
\hline \multicolumn{2}{|l|}{ C } & \multicolumn{7}{|c|}{$1,3 \%$} \\
\hline \multicolumn{2}{|l|}{$\Delta \mathrm{D}$} & \multicolumn{7}{|c|}{$6,8 \%$} \\
\hline
\end{tabular}


Tabela B.23 - Dados da tora TB-8.

Data: 08/12/2009

Espécie: Eucalyptus citriodora

\begin{tabular}{|c|c|c|c|c|c|c|c|c|}
\hline \multicolumn{3}{|c|}{ Dados gerais } & & & & & & \\
\hline \multirow{3}{*}{\begin{tabular}{|l} 
Comprimento $(\mathrm{cm})$ \\
Massa $(\mathrm{kg})$ \\
Densidade $\left(\mathrm{kg} / \mathrm{m}^{3}\right)$ \\
\end{tabular}} & \multirow{2}{*}{\multicolumn{2}{|c|}{$\frac{209}{48,95}$}} & & & & & & \\
\hline & & & & & & & & \\
\hline & \multicolumn{2}{|r|}{955} & & & & & & \\
\hline \multirow{5}{*}{$\begin{array}{c}\text { Características da seção } \\
\text { transversal }\end{array}$} & \multirow{5}{*}{ Direção } & \multicolumn{7}{|c|}{ Seção } \\
\hline & & 0 & 1 & 2 & 3 & 4 & 5 & 12 \\
\hline & & 0 & $0,213 \mathrm{~L}$ & $0,424 \mathrm{~L}$ & $0,635 \mathrm{~L}$ & $0,847 \mathrm{~L}$ & $\mathrm{~L}$ & $0,903 \mathrm{~L}$ \\
\hline & & & & & ist. $(\mathrm{cm})$ & & & \\
\hline & & 0,0 & 44,5 & 88,7 & 132,8 & 177,0 & 209,0 & 188,8 \\
\hline \multirow{4}{*}{ Diâmetros (cm) } & $0-4$ & 19,5 & & & & & 16,4 & \\
\hline & $1-5$ & 18,6 & & & & & 16,3 & \\
\hline & $2-6$ & 17,6 & & & & & 15,7 & \\
\hline & $3-7$ & 18,6 & & & & & 15,7 & \\
\hline \multicolumn{2}{|l|}{ Perímetro $(\mathrm{cm})$} & 60,4 & 56,0 & 53,4 & 51,8 & 51,0 & 50,5 & \\
\hline \multicolumn{2}{|l|}{ Peímetro L/2 $(\mathrm{cm})$} & \multicolumn{7}{|c|}{53,8} \\
\hline \multicolumn{2}{|l|}{$D(\mathrm{~cm})$} & 19,23 & 17,83 & 17,00 & 16,49 & 16,23 & 16,07 & - \\
\hline \multicolumn{2}{|l|}{$D_{m}(\mathrm{~cm})$} & 18,56 & & & & & 16,02 & - \\
\hline \multicolumn{2}{|l|}{$\Delta_{\text {circ }}$} & $3,6 \%$ & & & & & $0,3 \%$ & - \\
\hline \multicolumn{2}{|l|}{$D_{\text {meio }}(\mathrm{cm})$} & \multicolumn{7}{|c|}{17,13} \\
\hline \multicolumn{2}{|l|}{$L / D_{\text {meio }}$} & \multicolumn{7}{|c|}{12,20} \\
\hline \multicolumn{2}{|l|}{ C } & \multicolumn{7}{|c|}{$1,2 \%$} \\
\hline \multicolumn{2}{|l|}{$\Delta \mathrm{D}$} & \multicolumn{7}{|c|}{$7,0 \%$} \\
\hline
\end{tabular}

Tabela B.24 - Dados da tora TT-8.

Data: 02/12/2009

Espécie: Eucalyptus citriodora

\begin{tabular}{|c|c|c|c|c|c|c|c|c|}
\hline \multicolumn{3}{|c|}{ Dados gerais } & & & & & & \\
\hline \multirow{3}{*}{\begin{tabular}{|l} 
Comprimento $(\mathrm{cm})$ \\
Massa $(\mathrm{kg})$ \\
Densidade $\left(\mathrm{kg} / \mathrm{m}^{3}\right)$ \\
\end{tabular}} & \multirow{2}{*}{\multicolumn{2}{|c|}{$\begin{array}{l}211,7 \\
39,05\end{array}$}} & & & & & & \\
\hline & & & & & & & & \\
\hline & \multicolumn{2}{|r|}{997} & & & & & & \\
\hline \multirow{5}{*}{$\begin{array}{c}\text { Características da seção } \\
\text { transversal }\end{array}$} & \multirow{5}{*}{ Direção } & \multicolumn{7}{|c|}{ Secão } \\
\hline & & 5 & $\overline{6}$ & 7 & 8 & $\overline{9}$ & $\overline{11}$ & 10 \\
\hline & & 0 & $0,162 \mathrm{~L}$ & $0,371 \mathrm{~L}$ & $0,580 \mathrm{~L}$ & $0,789 \mathrm{~L}$ & $\mathrm{~L}$ & $0,902 \mathrm{~L}$ \\
\hline & & & & & Dist. (cm & & & \\
\hline & & $\overline{0,0}$ & 34,4 & 78,5 & 122,8 & 167,0 & 211,7 & 191,0 \\
\hline \multirow{4}{*}{ Diâmetros (cm) } & $0-4$ & 16,0 & & & & & 15,0 & \\
\hline & $1-5$ & 15,6 & & & & & 14,5 & \\
\hline & $2-6$ & 15,6 & & & & & 14,5 & \\
\hline & $3-7$ & 15,3 & & & & & 14,8 & \\
\hline \multicolumn{2}{|l|}{ Perímetro (cm) } & 49,9 & 49,3 & 49,6 & 48,7 & 48,0 & 46,5 & \\
\hline \multicolumn{2}{|l|}{ Peímetro L/2 (cm) } & \multicolumn{7}{|c|}{49,1} \\
\hline \multicolumn{2}{|l|}{$\mathrm{D}(\mathrm{cm})$} & 15,88 & 15,69 & 15,79 & 15,50 & 15,28 & 14,80 & - \\
\hline \multicolumn{2}{|l|}{$D_{m}(\mathrm{~cm})$} & 15,62 & & & & & 14,70 & - \\
\hline \multicolumn{2}{|l|}{$\Delta_{\text {circ }}$} & $1,7 \%$ & & & & & $0,7 \%$ & - \\
\hline \multicolumn{2}{|l|}{$D_{\text {meio }}(\mathrm{cm})$} & \multicolumn{7}{|c|}{15,63} \\
\hline \multicolumn{2}{|l|}{$L / D_{\text {meio }}$} & \multicolumn{7}{|c|}{13,55} \\
\hline \multicolumn{2}{|l|}{ C } & \multicolumn{7}{|c|}{$0,4 \%$} \\
\hline \multicolumn{2}{|l|}{$\Delta \mathrm{D}$} & \multicolumn{7}{|c|}{$2,6 \%$} \\
\hline
\end{tabular}


Tabela B.25 - Dados da tora 9.

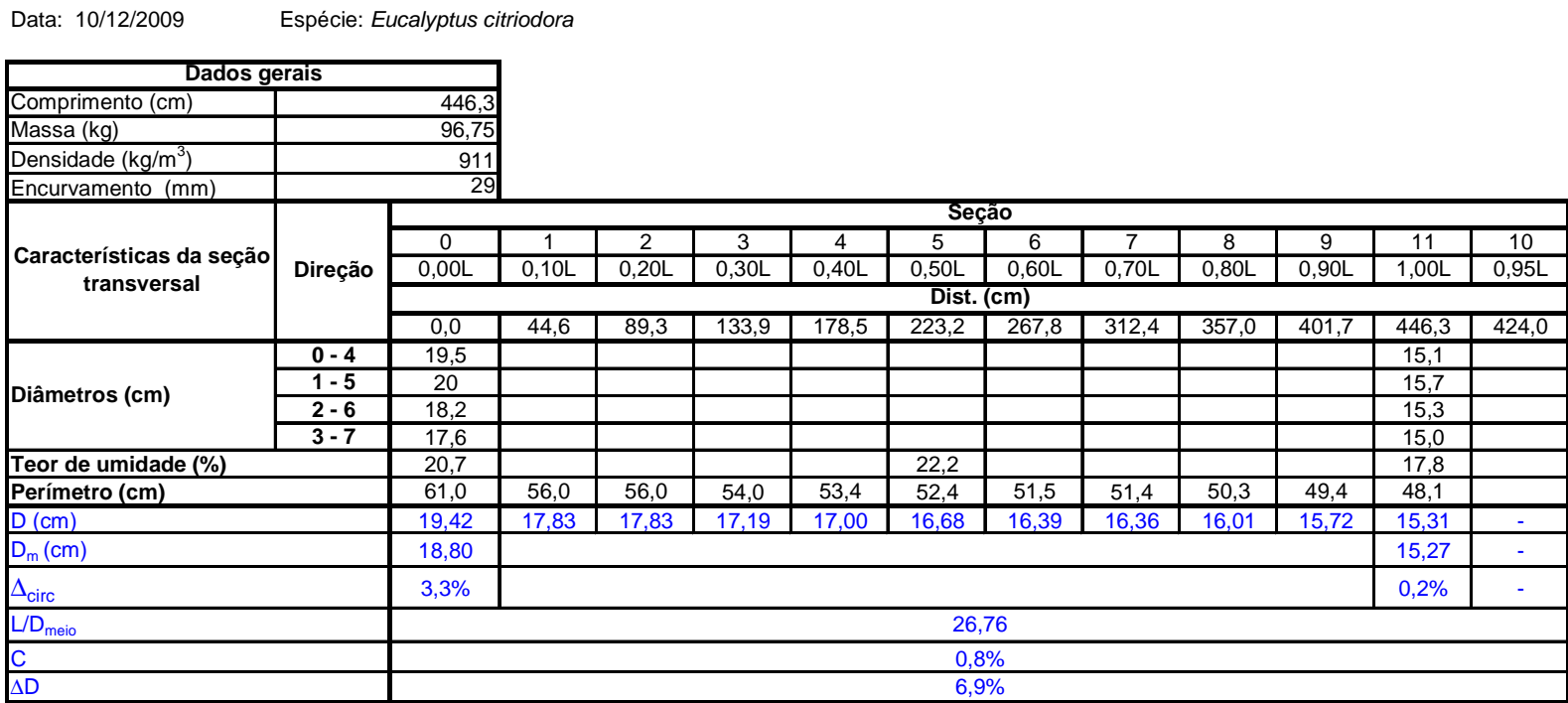

Tabela B.26 - Dados da tora TB-9.

Data: 15/12/2009 Espécie: Eucalyptus citriodora

\begin{tabular}{|c|c|c|c|c|c|c|c|c|}
\hline \multicolumn{3}{|c|}{ Dados gerais } & & & & & & \\
\hline \multirow{3}{*}{$\begin{array}{l}\text { Comprimento }(\mathrm{cm}) \\
\text { Massa }(\mathrm{kg}) \\
\text { Densidade }\left(\mathrm{kg} / \mathrm{m}^{3}\right) \\
\end{array}$} & \multirow{2}{*}{\multicolumn{2}{|c|}{$\frac{212,5}{51,10}$}} & & & & & & \\
\hline & & & & & & & & \\
\hline & \multicolumn{2}{|r|}{938} & & & & & & \\
\hline \multirow{5}{*}{$\begin{array}{c}\text { Características da seção } \\
\text { transversal }\end{array}$} & \multirow{5}{*}{ Direção } & \multicolumn{7}{|c|}{ Seção } \\
\hline & & 0 & 1 & 2 & 3 & 4 & 5 & 12 \\
\hline & & 0 & $0,210 \mathrm{~L}$ & $0,420 \mathrm{~L}$ & $0,630 \mathrm{~L}$ & $0,840 \mathrm{~L}$ & $\bar{L}$ & $0,883 \mathrm{~L}$ \\
\hline & & & & & ist. $(\mathbf{c m})$ & & & \\
\hline & & $\overline{0,0}$ & 44,6 & $\overline{89,3}$ & 133,9 & 178,5 & 212,5 & 187,7 \\
\hline \multirow{4}{*}{ Diâmetros $(\mathrm{cm})$} & $0-4$ & 19,5 & & & & & 16,1 & \\
\hline & $1-5$ & 20 & & & & & 16,6 & \\
\hline & $2-6$ & 18,2 & & & & & 17,5 & \\
\hline & $3-7$ & 17,6 & & & & & 15,3 & \\
\hline \multicolumn{2}{|l|}{ Perímetro $(\mathrm{cm})$} & 61,0 & 56,0 & 56,0 & 54,0 & 53,4 & 52,4 & \\
\hline \multicolumn{2}{|l|}{ Peímetro L/2 (cm) } & \multicolumn{7}{|c|}{54,7} \\
\hline \multicolumn{2}{|l|}{$\mathrm{D}(\mathrm{cm})$} & 19,42 & 17,83 & 17,83 & 17,19 & 17,00 & 16,68 & - \\
\hline \multicolumn{2}{|l|}{$D_{m}(\mathrm{~cm})$} & 18,80 & & & & & 16,36 & - \\
\hline \multicolumn{2}{|l|}{$\Delta_{\text {circ }}$} & $3,3 \%$ & & & & & $2,0 \%$ & - \\
\hline \multicolumn{2}{|l|}{$D_{\text {meio }}(\mathrm{cm})$} & \multicolumn{7}{|c|}{17,41} \\
\hline \multicolumn{2}{|l|}{$L / D_{\text {meio }}$} & \multicolumn{7}{|c|}{12,20} \\
\hline \multicolumn{2}{|l|}{$\mathrm{C}$} & \multicolumn{7}{|c|}{$1,2 \%$} \\
\hline \multicolumn{2}{|l|}{$\Delta \mathrm{D}$} & \multicolumn{7}{|c|}{$5,5 \%$} \\
\hline
\end{tabular}


Tabela B.27 - Dados da tora TT-9.

Data: 15/12/2009

Espécie: Eucalyptus citriodora

\begin{tabular}{|c|c|c|c|c|c|c|c|c|}
\hline \multicolumn{3}{|c|}{ Dados gerais } & & & & & & \\
\hline \multirow{3}{*}{\begin{tabular}{|l|} 
Comprimento $(\mathrm{cm})$ \\
Massa $(\mathrm{kg})$ \\
Densidade $\left(\mathrm{kg} / \mathrm{m}^{3}\right)$ \\
\end{tabular}} & \multirow{2}{*}{\multicolumn{2}{|c|}{$\begin{array}{r}212 \\
40,60\end{array}$}} & & & & & & \\
\hline & & & & & & & & \\
\hline & \multicolumn{2}{|r|}{954} & & & & & & \\
\hline \multirow{5}{*}{$\begin{array}{c}\text { Características da seção } \\
\text { transversal }\end{array}$} & \multirow{5}{*}{ Direção } & \multicolumn{7}{|c|}{ Seção } \\
\hline & & 5 & 6 & 7 & 8 & $\overline{9}$ & 11 & 10 \\
\hline & & 0 & $0,156 \mathrm{~L}$ & $0,369 \mathrm{~L}$ & $0,580 \mathrm{~L}$ & $0,790 \mathrm{~L}$ & $\mathrm{~L}$ & $0,894 \mathrm{~L}$ \\
\hline & & & & & Dist. (cn & & & \\
\hline & & $\overline{0,0}$ & 33,0 & $\overline{78,3}$ & 123,0 & 167,5 & 212,0 & 189,5 \\
\hline \multirow{4}{*}{ Diâmetros (cm) } & $0-4$ & 17,8 & & & & & 15,1 & \\
\hline & $1-5$ & 16,0 & & & & & 15,7 & \\
\hline & $2-6$ & 16,0 & & & & & 15,3 & \\
\hline & $3-7$ & 16,5 & & & & & 15,0 & \\
\hline \multicolumn{2}{|l|}{ Perímetro (cm) } & 52,3 & 51,5 & 51,4 & 50,3 & 49,4 & 48,1 & \\
\hline \multicolumn{2}{|l|}{ Peímetro L/2 (cm) } & \multicolumn{7}{|c|}{49,8} \\
\hline \multicolumn{2}{|l|}{$\mathrm{D}(\mathrm{cm})$} & 16,65 & 16,39 & 16,36 & 16,01 & 15,72 & 15,31 & - \\
\hline \multicolumn{2}{|l|}{$D_{m}(\mathrm{~cm})$} & 16,56 & & & & & 15,27 & - \\
\hline \multicolumn{2}{|l|}{$\Delta_{\text {circ }}$} & $0,5 \%$ & & & & & $0,2 \%$ & - \\
\hline \multicolumn{2}{|l|}{$D_{\text {meio }}(\mathrm{cm})$} & \multicolumn{7}{|c|}{15,85} \\
\hline \multicolumn{2}{|l|}{$L / D_{\text {meio }}$} & \multicolumn{7}{|c|}{13,37} \\
\hline \multicolumn{2}{|l|}{$\mathrm{C}$} & \multicolumn{7}{|c|}{$0,6 \%$} \\
\hline \multicolumn{2}{|l|}{$\Delta \mathrm{D}$} & \multicolumn{7}{|c|}{$3,1 \%$} \\
\hline
\end{tabular}

Tabela B.28 - Dados da tora 10.

Data: 04/01/2010 Espécie: Eucalyptus citriodora

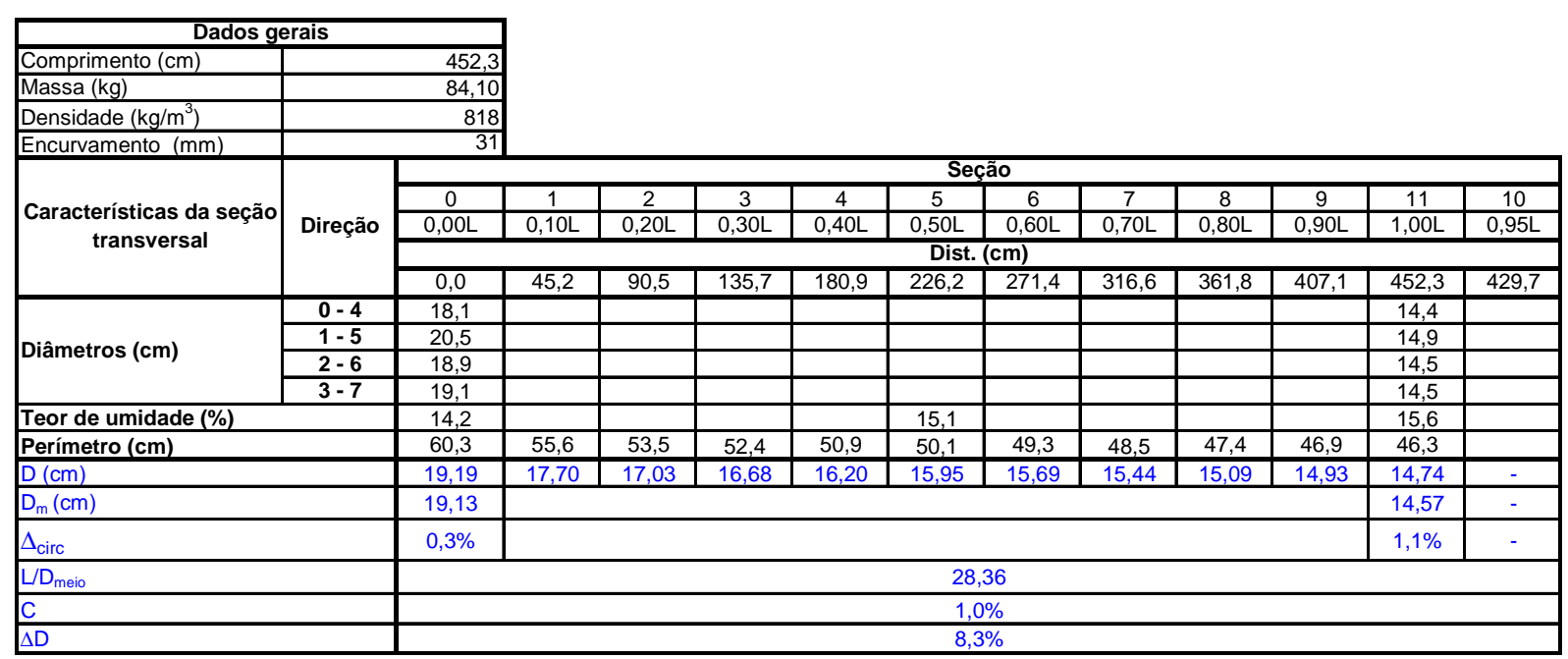


Tabela B.29 - Dados da tora TB-10.

Data: $15 / 12 / 2010$

Espécie: Eucalyptus citriodora

\begin{tabular}{|c|c|c|c|c|c|c|c|c|}
\hline \multicolumn{3}{|c|}{ Dados gerais } & & & & & & \\
\hline \multirow{3}{*}{$\begin{array}{l}\text { Comprimento }(\mathrm{cm}) \\
\text { Massa }(\mathrm{kg}) \\
\text { Densidade }\left(\mathrm{kg} / \mathrm{m}^{3}\right)\end{array}$} & \multirow{2}{*}{\multicolumn{2}{|c|}{$\frac{215,3}{45,30}$}} & & & & & & \\
\hline & \multirow{2}{*}{\multicolumn{2}{|c|}{$\begin{array}{r}45,30 \\
867\end{array}$}} & & & & & & \\
\hline & & & & & & & & \\
\hline \multirow{5}{*}{$\begin{array}{c}\text { Características da seção } \\
\text { transversal }\end{array}$} & \multirow{5}{*}{ Direção } & \multicolumn{7}{|c|}{ Seção } \\
\hline & & $\overline{0}$ & $\overline{1}$ & $\overline{2}$ & 3 & $\overline{4}$ & 5 & $\overline{12}$ \\
\hline & & 0 & $0,210 \mathrm{~L}$ & $\overline{0,420 \mathrm{~L}}$ & $0,630 \mathrm{~L}$ & $\overline{0,840 \mathrm{~L}}$ & $\bar{L}$ & $0,882 \mathrm{~L}$ \\
\hline & & & & & ist. $(\mathrm{cm})$ & & & \\
\hline & & $\overline{0,0}$ & $\overline{45,2}$ & 90,5 & 135,7 & 180,9 & 212,3 & 189,8 \\
\hline \multirow{4}{*}{ Diâmetros (cm) } & $0-4$ & 18,1 & & & & & 15,3 & \\
\hline & $1-5$ & 20,5 & & & & & 15,5 & \\
\hline & $2-6$ & 18,9 & & & & & 15,6 & \\
\hline & $3-7$ & 19,1 & & & & & 16,0 & \\
\hline \multicolumn{2}{|l|}{ Perímetro $(\mathrm{cm})$} & 60,3 & 55,6 & 53,5 & 52,4 & 50,9 & 50,0 & \\
\hline \multicolumn{2}{|l|}{ Peímetro L/2 $(\mathrm{cm})$} & \multicolumn{7}{|c|}{53} \\
\hline \multicolumn{2}{|l|}{$\mathrm{D}(\mathrm{cm})$} & 19,19 & 17,70 & 17,03 & 16,68 & 16,20 & 15,92 & - \\
\hline \multicolumn{2}{|l|}{$D_{m}(\mathrm{~cm})$} & 19,13 & & & & & 15,60 & - \\
\hline \multicolumn{2}{|l|}{$\Delta_{\text {circ }}$} & $0,3 \%$ & & & & & $2,0 \%$ & - \\
\hline \multicolumn{2}{|l|}{$\mathrm{D}_{\text {meio }}(\mathrm{cm})$} & \multicolumn{7}{|c|}{16,87} \\
\hline \multicolumn{2}{|l|}{$L / D_{\text {meio }}$} & \multicolumn{7}{|c|}{12,76} \\
\hline \multicolumn{2}{|l|}{ C } & \multicolumn{7}{|c|}{$1,6 \%$} \\
\hline \multicolumn{2}{|l|}{$\Delta \mathrm{D}$} & \multicolumn{7}{|c|}{$7,0 \%$} \\
\hline
\end{tabular}

Tabela B.30 - Dados da tora TT-10.

Data: $15 / 12 / 2010$

Espécie: Eucalyptus citriodora

\begin{tabular}{|c|c|c|c|c|c|c|c|c|}
\hline \multicolumn{3}{|c|}{ Dados gerais } & & & & & & \\
\hline \multirow{3}{*}{\begin{tabular}{|l|} 
Comprimento $(\mathrm{cm})$ \\
Massa $(\mathrm{kg})$ \\
Densidade $\left(\mathrm{kg} / \mathrm{m}^{3}\right)$ \\
\end{tabular}} & \multirow{2}{*}{\multicolumn{2}{|c|}{$\frac{216,2}{34,85}$}} & & & & & & \\
\hline & & & & & & & & \\
\hline & \multicolumn{2}{|c|}{871} & & & & & & \\
\hline \multirow{5}{*}{$\begin{array}{c}\text { Características da seção } \\
\text { transversal }\end{array}$} & \multirow{5}{*}{ Direção } & \multicolumn{7}{|c|}{ Seção } \\
\hline & & 5 & 6 & $\overline{7}$ & 8 & $\overline{9}$ & 11 & 10 \\
\hline & & $\overline{0}$ & $0,162 \mathrm{~L}$ & $\overline{0,372 \mathrm{~L}}$ & $0,580 \mathrm{~L}$ & $\overline{0,790 \mathrm{~L}}$ & $\mathrm{~L}$ & $\overline{0,894 \mathrm{~L}}$ \\
\hline & & & & & ist. $(\mathbf{c m}$ & & & \\
\hline & & $\overline{0,0}$ & 35,0 & 80,5 & 125,5 & 170,8 & 216,2 & 193,3 \\
\hline \multirow{4}{*}{ Diâmetros $(\mathrm{cm})$} & $0-4$ & 15,3 & & & & & 14,4 & \\
\hline & $1-5$ & 15,6 & & & & & 14,9 & \\
\hline & $2-6$ & 15,5 & & & & & 14,5 & \\
\hline & $3-7$ & 16,0 & & & & & 14,5 & \\
\hline \multicolumn{2}{|l|}{ Perímetro $(\mathrm{cm})$} & 50,1 & 49,3 & 48,5 & 47,4 & 46,9 & 46,3 & \\
\hline \multicolumn{2}{|l|}{ Peímetro L/2 (cm) } & \multicolumn{7}{|c|}{47,8} \\
\hline \multicolumn{2}{|l|}{$\mathrm{D}(\mathrm{cm})$} & 15,95 & 15,69 & 15,44 & 15,09 & 14,93 & 14,74 & - \\
\hline \multicolumn{2}{|l|}{$D_{m}(\mathrm{~cm})$} & 15,60 & & & & & 14,57 & - \\
\hline \multicolumn{2}{|l|}{$\Delta_{\text {circ }}$} & $2,2 \%$ & & & & & $1,1 \%$ & - \\
\hline \multicolumn{2}{|l|}{$\mathrm{D}_{\text {meio }}(\mathrm{cm})$} & \multicolumn{7}{|c|}{15,22} \\
\hline \multicolumn{2}{|l|}{$\mathrm{L} / \mathrm{D}_{\text {meio }}$} & \multicolumn{7}{|c|}{14,21} \\
\hline \multirow{2}{*}{\multicolumn{2}{|c|}{$\frac{C}{\Delta D}$}} & \multirow{2}{*}{\multicolumn{7}{|c|}{$0,5 \%$}} \\
\hline & & \multicolumn{5}{|c|}{$3,1 \%$} & & \\
\hline
\end{tabular}




\section{APÊNDICE C - IMPLEMENTAÇÃO DE UM PROGRAMA DE COMPUTADOR PARA IDENTIFICAÇẪO DE PARÂMETROS MODAIS PELO MÉTODO DA RAZÃO DE POLINÔMIOS}

Durante o curso da Disciplina SEM 5766 - Análise Modal de Estruturas, ministrada pelo Professor Titular Paulo Sérgio Varoto no ano de 2008, foi implementado um programa em linguagem $\mathrm{C}$ para a identificação de parâmetros modais pelo método da razão de polinômios. Como resultado, obteve-se um programa de identificação modal com o qual se obtêm bons ajustes entre as FRF's experimentais e teóricas.

Este Apêndice fornece uma breve descrição sobre a implementação desse programa.

O programa de identificação modal, denominado de Modal-Id, foi implementado em linguagem $\mathrm{C}$.

A entrada de dados do programa se faz por um arquivo texto padrão ASCII contendo a FRF medida. Para tornar o programa Modal-Id compatível com o programa Impact, o arquivo de entrada de dados foi padronizado com a formatação do arquivo de resultados do programa Impact. A Figura C.1 mostra um exemplo de um arquivo de entrada de dados para o programa Modal-Id. O programa descarta o início do arquivo que contém as frequências e os amortecimentos modais e lê somente as três primeiras colunas do arquivo de texto sendo as frequências, o módulo e a fase da FRF medida. 


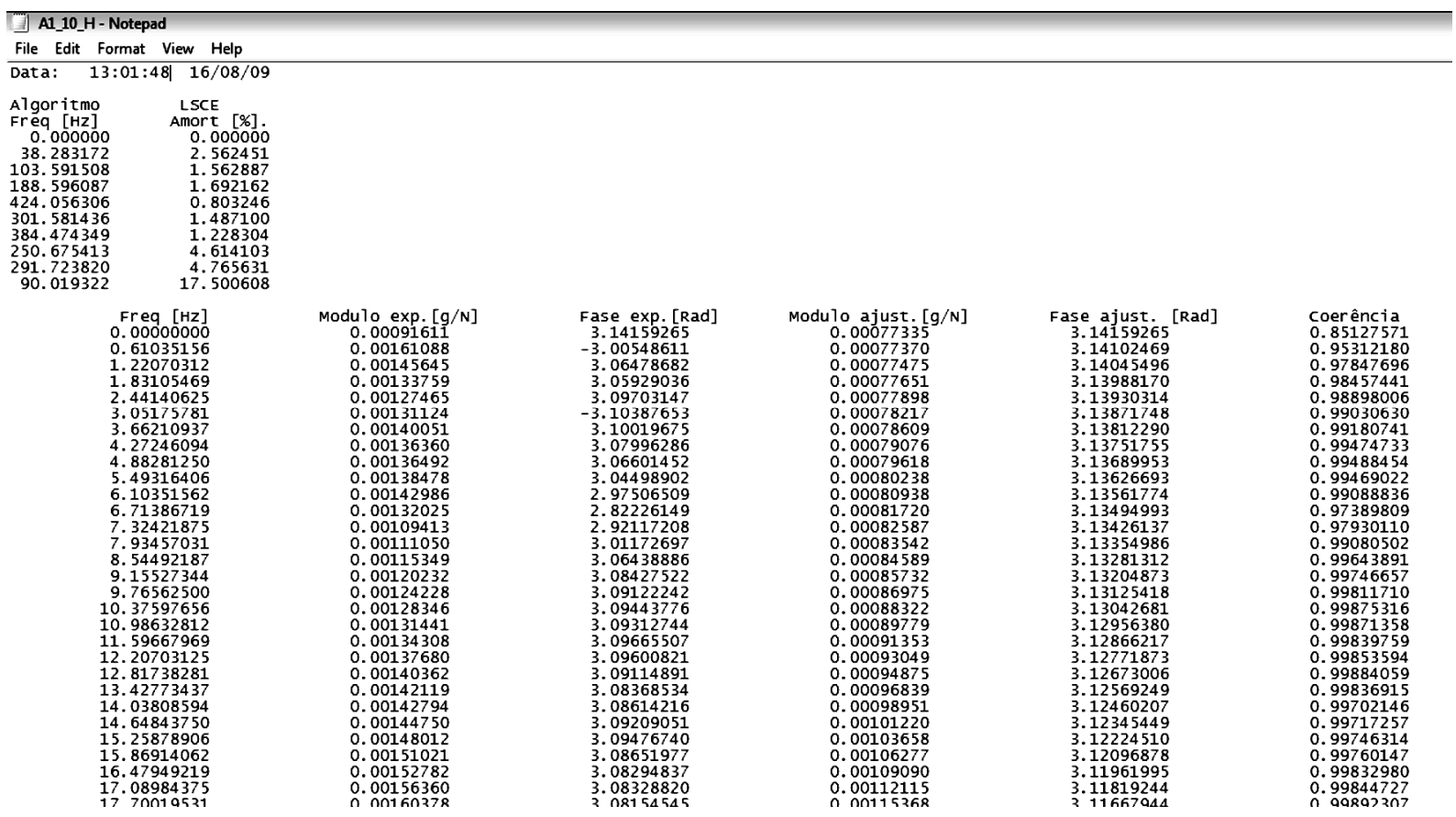

Figura C.1 - Exemplo de arquivo de entrada de dados do programa Modal-Id.

Como já foi mencionado anteriormente, o algoritmo de identificação implementado foi o da razão de polinômios sendo que os coeficientes dos polinômios são encontrados pelo método de Levy (1959).

A Figura C.2 mostra o fluxograma do programa.

Pensando em utilizar o programa para trabalhos futuros, optou-se por deixar o número de graus de liberdade livre permitindo que o usuário informe em uma caixa de texto o grau dos polinômios numerador e denominador.

Foi implementada também a possibilidade de importar frequência em $\mathrm{Hz}$ ou $\mathrm{Rad}$ e FRF acelerância ou receptância.

A Figura C.3 mostra a tela principal do programa Moda-Id. O primeiro gráfico, de cima para baixo, mostra o módulo da FRF, o segundo gráfico mostra a fase e o terceiro gráfico mostra o FRAC (Frequency Response Assurance Criterion) e o FRSF (Frequency Response Scale Factor) entre a FRF experimental e a FRF ajustada. 


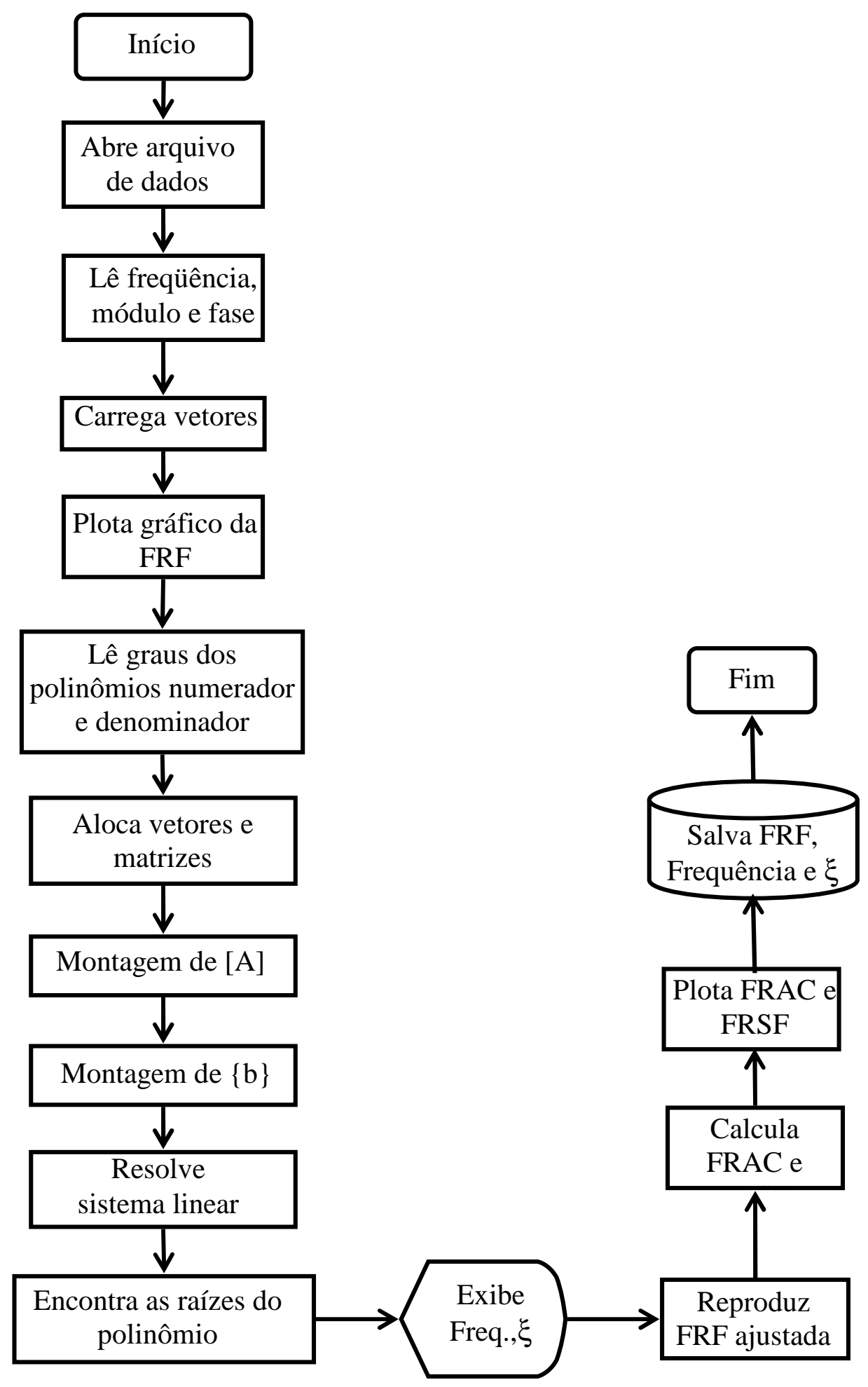

Figura C.2 - Fluxograma do programa Modal-Id. 
O botão "Abrir arquivo" faz a leitura de um arquivo com extensão *.txt contendo três colunas de dados, sendo a primeira coluna a frequência, a segunda o módulo da FRF e a terceira a fase da FRF. O arquivo texto deve ter a forma apresentada na Figura C.1. Se os dados estiverem em radianos, o usuário deverá selecionar esta opção antes de abrir o arquivo.

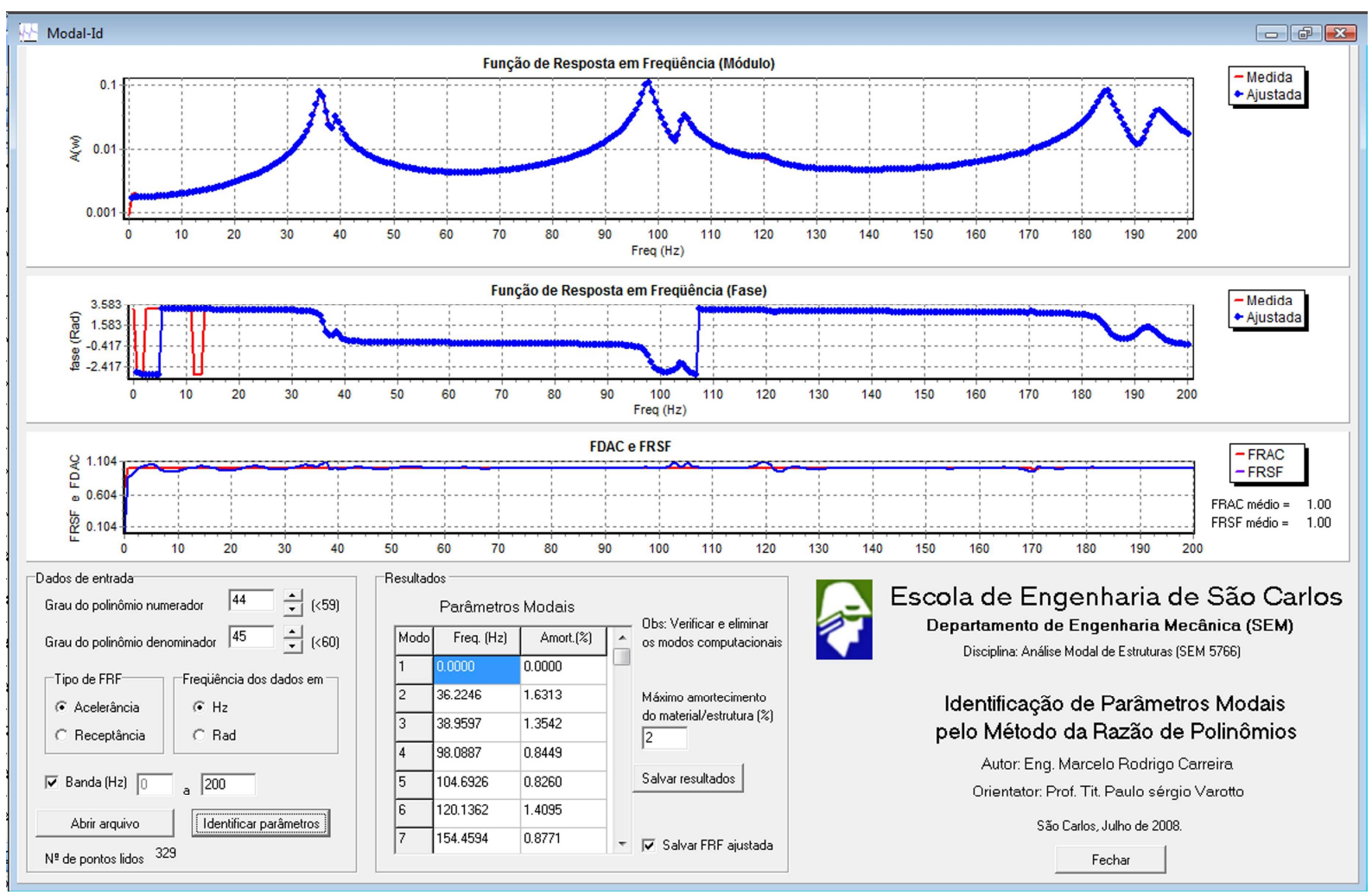

Figura C.3 - Tela principal do programa Modal-Id.

O programa plota na tela os dados importados e mostra o número de linhas lidas no arquivo de entrada, já descontando a linha do cabeçalho. É importante notar que não deve haver linhas em branco no arquivo texto, pois do contrário, o programa irá travar.

Os dados importados são armazenados em vetores. Caso os dados importados estejam em Hz, o programa irá convertê-los em radianos antes de realizar os cálculos, pois é preferível realizar o ajuste com a frequência em radianos.

O botão "identificar parâmetros" realiza os cálculos para a obtenção dos parâmetros modais.

Inicialmente, o número de graus dos polinômios é copiado das caixas de textos e armazenado nas variáveis $\underline{\mathrm{n}}$ e $\underline{\mathrm{m}}$. Essas variáveis são usadas para a alocação das matrizes e vetores envolvidos nos cálculos. Vale lembrar que o grau do polinômio numerador sempre deve ser menor do que o grau do polinômio denominador. De posse dos dados experimentais 
e com os graus dos polinômios, o programa calcula todos os termos da Matriz [A] da Equação 2.89. Na seqüência, são calculados os coeficientes do vetor $\{b\}$ da mesma equação.

O programa calcula os termos do vetor $\{\mathrm{x}\}$ utilizando uma função para a resolução de sistemas lineares denominada "SIS_LIN". Essa função busca a solução de um sistema linear por fatoração direta. Os termos dessa solução correspondem aos coeficientes dos polinômios da Equação 2.77. Os parâmetros de entrada da função "SIS_LIN" são: a matriz [A], o vetor $\{b\}$, a ordem da matriz, a matriz $[Z]$ e o vetor $\{w\}$. Estes dois últimos parâmetros são auxiliares nos cálculos. A matriz [A] é quadrada de ordem m+1+n.

Com os coeficientes do polinômio denominador da Equação 2.77, o programa calcula as raízes ou pólos do polinômio usando a função "CNEWTON". Esta função emprega o método de Newton para a obtenção das raízes complexas do polinômio. Os parâmetros de entrada são: o grau do polinômio (n) e os coeficientes do polinômio $\left(b_{k}\right)$.

A partir das raízes do polinômio denominador, o programa Modal-Id calcula o amortecimento modal e as frequências naturais utilizando a Equação 2.92. O programa desenha também o gráfico da FRF ajustada para a verificação visual da qualidade do ajuste. Para tanto, o programa resolve a Equação 2.77 para cada valor de frequência do arquivo de entrada.

Para auxiliar o usuário na verificação da qualidade do ajuste da FRF foi implementado o cálculo do FDAC e do FRSF, respectivamente conforme Equações 2.96 e 2.99.

No botão "Salvar resultados" foi implementada a gravação dos resultados em um arquivo texto como mostra a Figura C.4.

Vale destacar que não foi implementada nenhuma estratégia de eliminação dos modos computacionais dos resultados. Portanto, cabe ao usuário verificar e descartar esses modos. Entretanto, para facilitar a eliminação dos modos computacionais, foi inserida logo abaixo do botão "Salvar resultados" uma caixa de texto na qual o usuário deverá informar qual é o máximo amortecimento esperado para o sistema dinâmico testado. O programa irá ler esse valor e eliminará todos os modos com amortecimentos superiores. O valor padrão adotado para o amortecimento máximo foi de $2 \%$. 


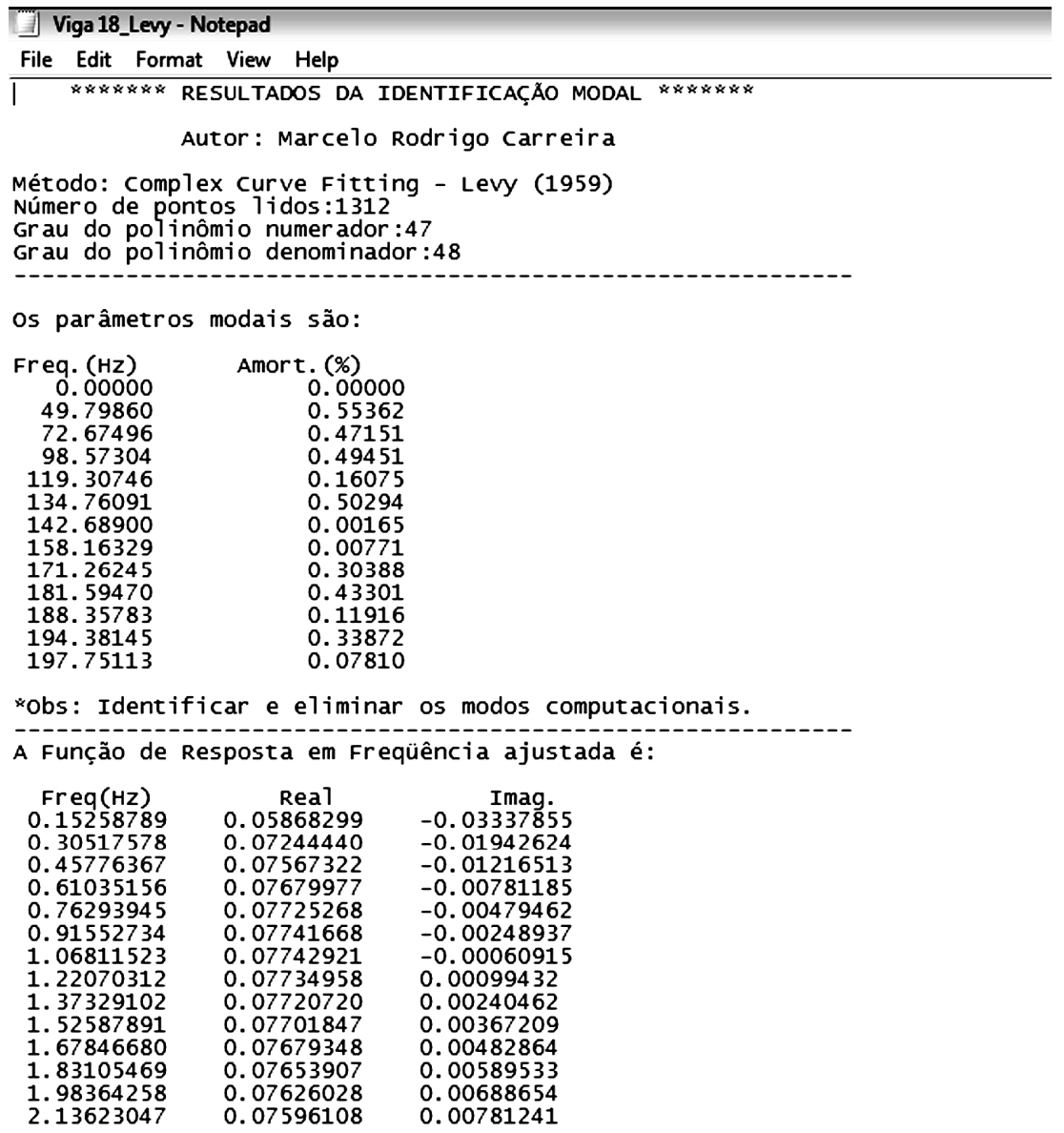

Figura C.4 - Formato do arquivo de resultados. 


\section{APÊNDICE D - TESTES ESTATÍSTICOS E VERIFICAÇÃO DA VALIDADE DOS MODELOS DE REGRESSÃO LINEAR APRESENTADOS NA TESE}

\section{D.1. Testes estatísticos realizados no item 3.1.2}

\section{Primeiro teste de hipótese}

$$
\left\{\begin{array}{l}
H_{0}: E_{M, \text { Stat }}\left(x_{\text {otimo }}^{\prime}\right)=E_{M, \text { Stat }}\left(x^{\prime}{ }_{\text {NBR } 6231}\right) \\
H_{1}: E_{M, \text { Stat }}\left(x_{\text {ottimo }}^{\prime}\right) \neq E_{M, \text { Stat }}\left(x^{\prime}{ }_{\text {NBR 6231 }}\right)
\end{array}\right.
$$

Assim, para um nível de significância $\alpha=0,05$. A hipótese $\mathrm{H}_{0}$ deve ser rejeitada se $\mathrm{F}_{\mathrm{cal}}$ $>\mathrm{F}_{\text {tab. }}$.

A Tabela D.1 mostra a análise de variância para o teste em questão.

Tabela D.1 - Análise de variância.

\begin{tabular}{lcccc}
\hline Fonte de variação & GL & SQ & QM & F \\
\hline Modelo & 1 & 1,702 & 1,702 & 2,571 \\
Erro & 88 & 58,253 & 0,662 & \\
Total & 89 & 59,954 & & \\
\hline
\end{tabular}

Da tabela de distribuição $F$ tem-se que $F_{0,05 ; 1 ; 88}=3,95$. Como $F_{\text {cal }}<3,95$ aceita-se a hipótese $\mathrm{H}_{0}$ ao nível de significância $\alpha=0,05$, ou seja, os diâmetros obtidos com $x^{\prime}{ }_{\text {ótimo }}$ e $\mathrm{D}_{\mathrm{eq}}$ dado pelas normas NBR 6231 (ABNT, 1980) e ASTM D 1036 (ASTM, 2005) produzem resultados semelhantes para o módulo de elasticidade à flexão no ensaio de flexão estática na condição de contorno engastada-livre.

\section{Segundo teste de hipótese}

$$
\left\{\begin{array}{l}
H_{0}: E_{M, \text { Stat }}\left(x^{\prime}=0,47\right)=E_{M, \text { Stat }}\left(x^{\prime}=0,50\right) \\
H_{1}: E_{M, \text { Stat }}\left(x^{\prime}=0,47\right) \neq E_{M, \text { Stat }}\left(x^{\prime}=0,50\right)
\end{array}\right.
$$

Assim, para um nível de significância $\alpha=0,05$. A hipótese $\mathrm{H}_{0}$ deve ser rejeitada se $\mathrm{F}_{\text {cal }}$ $>\mathrm{F}_{\text {tab }}$. 
A Tabela D.2 mostra a análise de variância para o teste em questão.

Tabela D.2 - Análise de variância.

\begin{tabular}{lcccc}
\hline Fonte de variacão & GL & SQ & QM & F \\
\hline Modelo & 1 & 3,678 & 3,678 & 39,317 \\
Erro & 88 & 8,233 & 0,094 & \\
Total & 89 & 11,911 & & \\
\hline
\end{tabular}

Da tabela de distribuição $F$ tem-se que $F_{0,05 ; 1 ; 88}=3,95$. Como $F_{c a l}>3,95$ rejeita-se a hipótese $\mathrm{H}_{0}$ ao nível de significância $\alpha=0,05$, ou seja, os valores obtidos para o módulo de elasticidade com os diâmetros tomados a $x^{\prime}=0,47$ e $x^{\prime}=0,50$ no ensaio de flexão estática na condição de contorno bi-apoiada são estatisticamente diferentes.

Foi realizado o teste de Tukey para avaliar se a diferença entre os tratamentos é significativa como mostra a Tabela D.3.

Tabela D.3 - Teste de Tukey.

\begin{tabular}{ccc}
\hline Comparação & Diferença & $\begin{array}{c}\text { Diferença } \\
\text { padronizada }\end{array}$ \\
\hline$x^{\prime}=0,47$ vs $x^{\prime}=0,50$ & 0,404 & 6,270 \\
\hline & d.m.s. $=$ & 2,810
\end{tabular}

Como a diferença padronizada é superior à diferença mínima significativa (d.m.s) pode-se concluir a um nível de significância $\alpha=0,05$ que a diferença entre os tratamentos é significativa.

\section{D.2. Modelos de regressão linear apresentados no item 4.4.6}

A Figura D.1 mostra o gráfico dos resíduos contra os valores estimados para a regressão entre $\mathrm{E}_{\mathrm{M}, \mathrm{VT}, \text { ap }}$ e $\mathrm{E}_{\mathrm{M}, \mathrm{Stat}, \mathrm{ap}}$ no qual observa-se que a variância é constante. 
Resíduos contra valores estimados

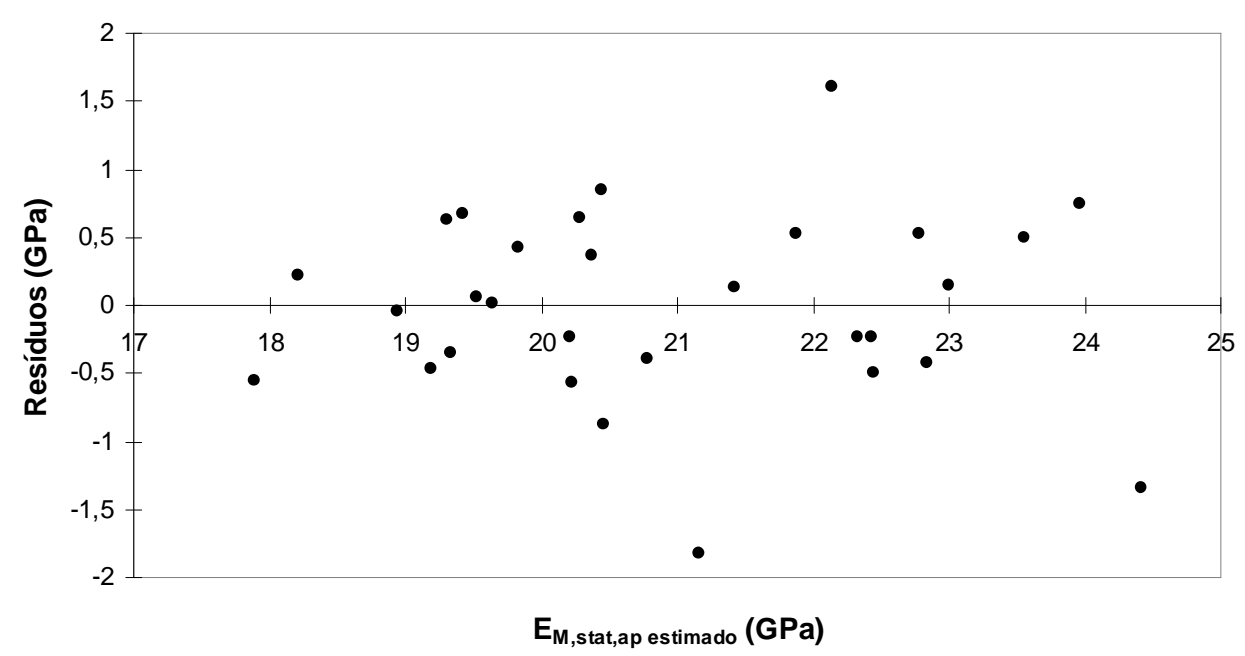

Figura D.1 - Resíduos contra valores estimados para regressão entre $E_{M, V T, a p}$ e $E_{M, S t a t, a p}$.

A Figura D.2 mostra o teste de normalidade dos resíduos no qual verifica-se que a suposição de normalidade dos resíduos é confirmada uma vez que o valor-p é maior do que 0,05 .

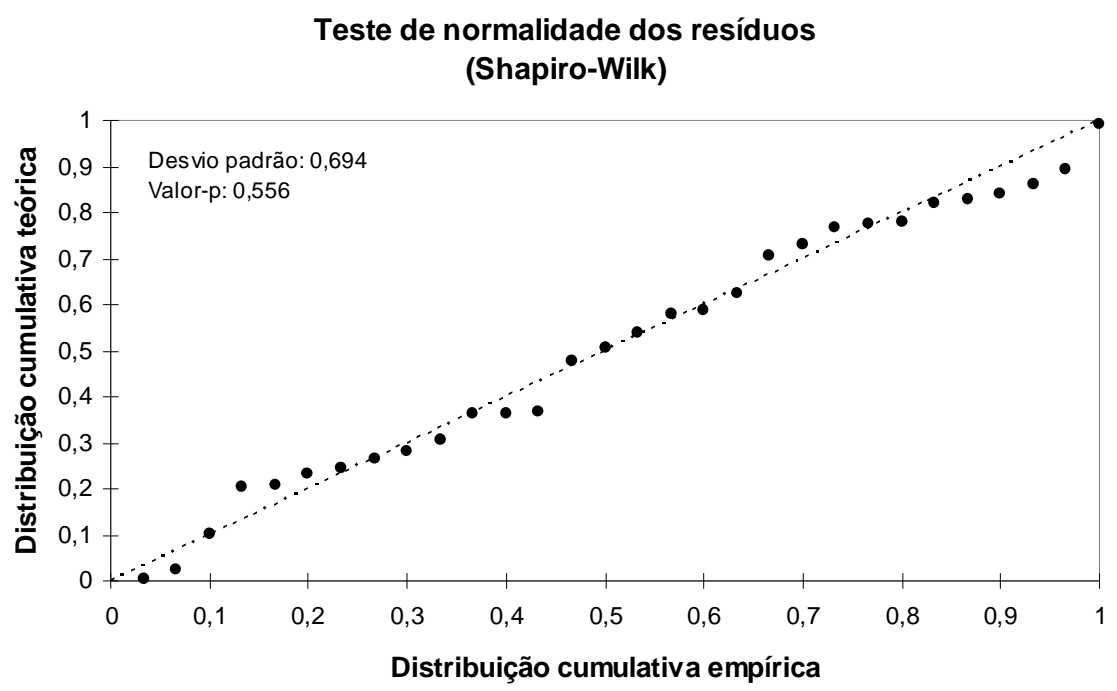

Figura D.2 - Teste de normalidade dos resíduos para regressão entre $\mathrm{E}_{\mathrm{M}, \mathrm{VT} \text {,ap }}$ e $\mathrm{E}_{\mathrm{M}, \mathrm{Stat}, \mathrm{ap}}$.

Com as suposições do modelo de regressão linear confirmadas foi feita a análise de variância como mostra a Tabela D.4.

Tabela D.4 - Análise de variância para o modelo de regressão entre $\mathrm{E}_{\mathrm{M}, \mathrm{VT} \text {,ap }}$ e $\mathrm{E}_{\mathrm{M}, \mathrm{Stat}, \mathrm{ap}}$.

\begin{tabular}{lcccc}
\hline Fonte de variação & $\mathrm{GL}$ & $\mathrm{SQ}$ & $\mathrm{QM}$ & $\mathrm{F}_{\text {cal }}$ \\
\hline Modelo & 1 & 86,740 & 86,740 & 174,068 \\
Erro & 28 & 13,953 & 0,498 & \\
Total & 29 & 100,693 & & \\
\hline
\end{tabular}


Da tabela $F$, tem-se que $F_{0,05 ; 1 ; 28}=4,20$. Logo, como $F_{\text {cal }}>F_{0,05 ; 1 ; 28}$ pode-se afirmar, a um nível de significância $\alpha=0,05$, que a proporção da variância total explicada pela equação $\mathrm{E}_{\mathrm{M}, \text { Stat,ap }}[\mathrm{GPa}]=0,888 \mathrm{E}_{\mathrm{M}, \mathrm{VT} \text {,ap }}[\mathrm{GPa}]+2,369$ é altamente significativa de forma que essa equação pode ser empregada para se fazer inferências de $E_{M, S t a t, a p}$ a partir de $E_{M, V T, a p}$.

A Figura D.3 mostra o gráfico dos resíduos contra valores estimados para a regressão entre $\mathrm{E}_{\mathrm{M}, \mathrm{VT}}$ e $\mathrm{E}_{\mathrm{M}, \mathrm{Stat,v}}$ e no qual observa-se que a variância é aproximadamente constante.

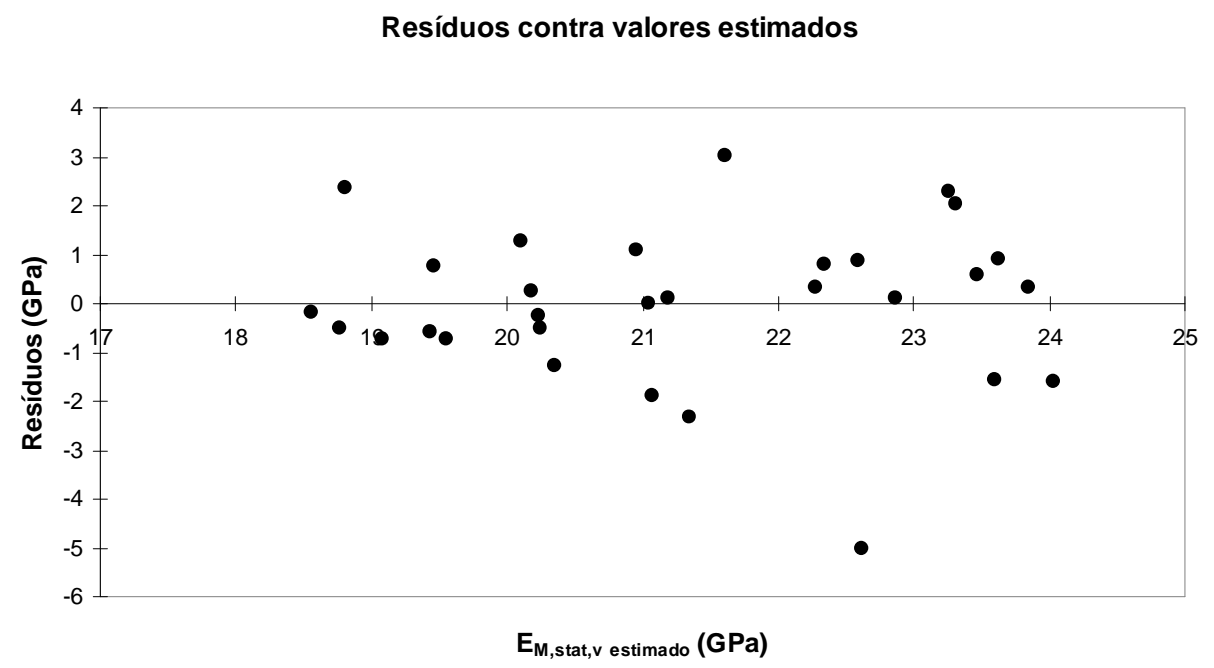

Figura D.3 - Resíduos contra valores estimados para regressão entre $\mathrm{E}_{\mathrm{M}, \mathrm{VT}}$ e $\mathrm{E}_{\mathrm{M}, \mathrm{Stat}, \mathrm{v}}$.

A distribuição normal dos resíduos foi confirmada pelo teste de normalidade mostrados na Figura D.4.

Teste de normalidade dos resíduos

(Shapiro-Wilk)

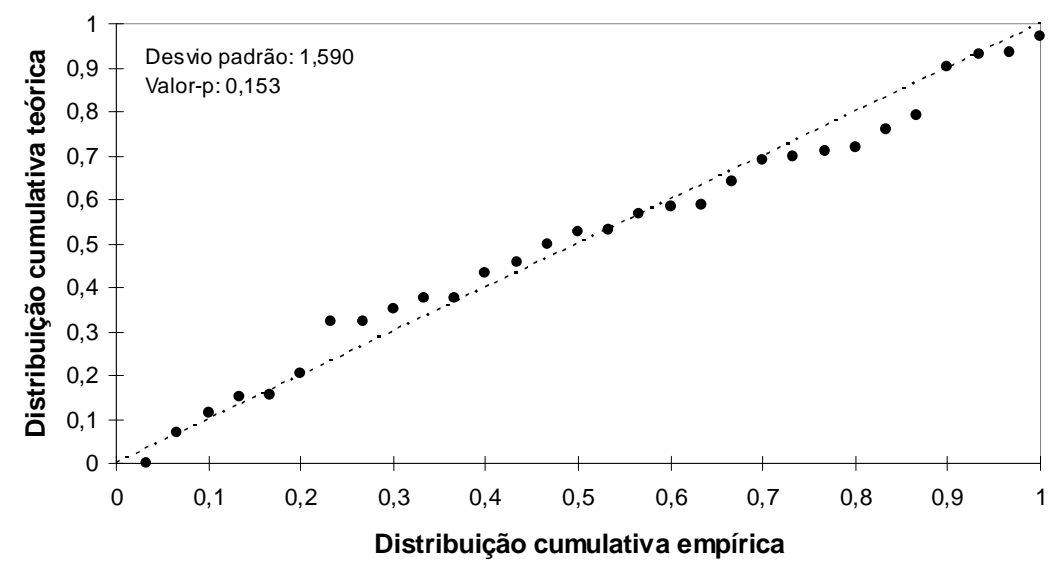

Figura D.4 - Teste de normalidade dos resíduos para regressão entre $\mathrm{E}_{\mathrm{M}, \mathrm{VT}}$ e $\mathrm{E}_{\mathrm{M}, \mathrm{Stat}, \mathrm{v}}$.

A Tabela D.5 mostra a análise de variância para a regressão em questão. 
Tabela D.5 - Análise de variância para o modelo de regressão entre $\mathrm{E}_{\mathrm{M}, \mathrm{VT}}$ e $\mathrm{E}_{\mathrm{M}, \mathrm{Stat}, \mathrm{v}}$.

\begin{tabular}{lcccc}
\hline Fonte de variação & $\mathrm{GL}$ & $\mathrm{SQ}$ & $\mathrm{QM}$ & $\mathrm{F}_{\text {cal }}$ \\
\hline Modelo & 1 & 86,325 & 86,325 & 32,980 \\
Erro & 28 & 73,291 & 2,618 & \\
Total & 29 & 159,616 & & \\
\hline
\end{tabular}

Da tabela $F$, tem-se que $F_{0,05 ; 1 ; 28}=4,20$. Logo, como $F_{\text {cal }}>F_{0,05 ; 1 ; 28}$ pode-se afirmar, a um nível de significância $\alpha=0,05$, que a proporção da variância total explicada pela equação $\mathrm{E}_{\mathrm{M}, \mathrm{Stat}, \mathrm{v}}[\mathrm{GPa}]=0,887 \mathrm{E}_{\mathrm{M}, \mathrm{VT}}[\mathrm{GPa}]+1,177$ é altamente significativa de forma que essa equação pode ser empregada para se fazer inferências de $\mathrm{E}_{\mathrm{M}, \mathrm{Stat,v}}$ a partir de $\mathrm{E}_{\mathrm{M}, \mathrm{VT}}$.

A Figura D.5 mostra o gráfico dos resíduos contra os valores estimados para a regressão entre $\mathrm{E}_{\mathrm{M}, \mathrm{Stat}, \mathrm{v}^{*}} \mathrm{e} \mathrm{E}_{\mathrm{M}, \mathrm{VT}}$ mostrada na Figura 4.31.

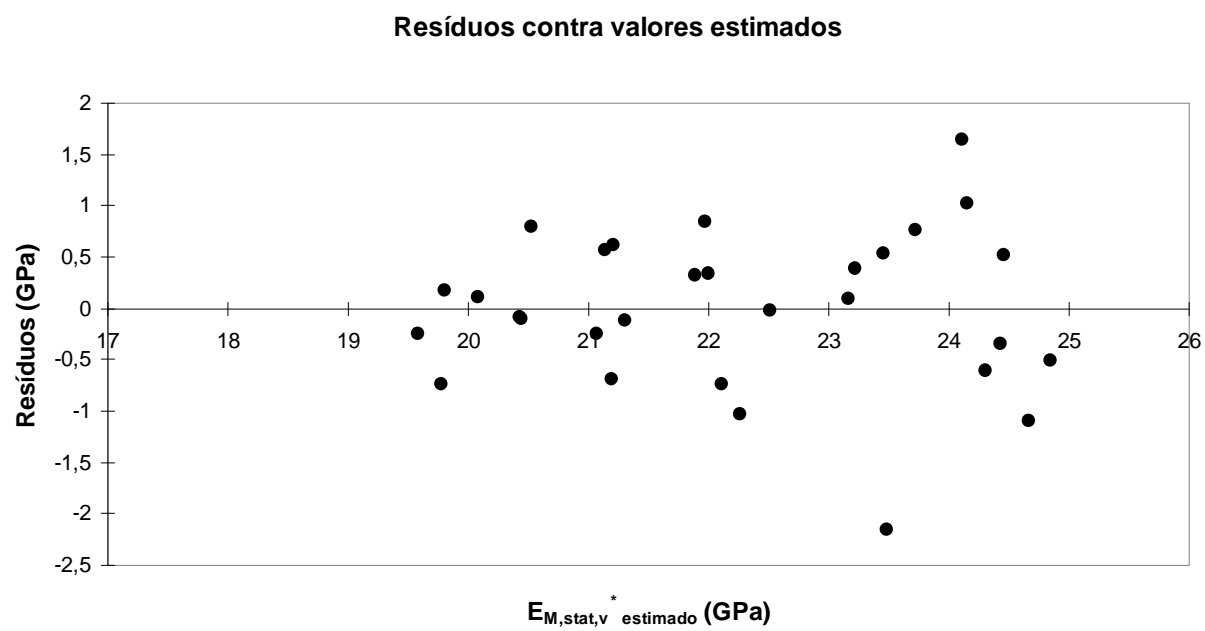

Figura D.5 - Resíduos contra valores estimados para regressão entre $\mathrm{E}_{\mathrm{M}, \mathrm{VT}}$ e $\mathrm{E}_{\mathrm{M}, \mathrm{Stat}, \mathrm{V}^{*} \text {. }}$

A Figura D.6 mostra o gráfico do teste de normalidade dos resíduos

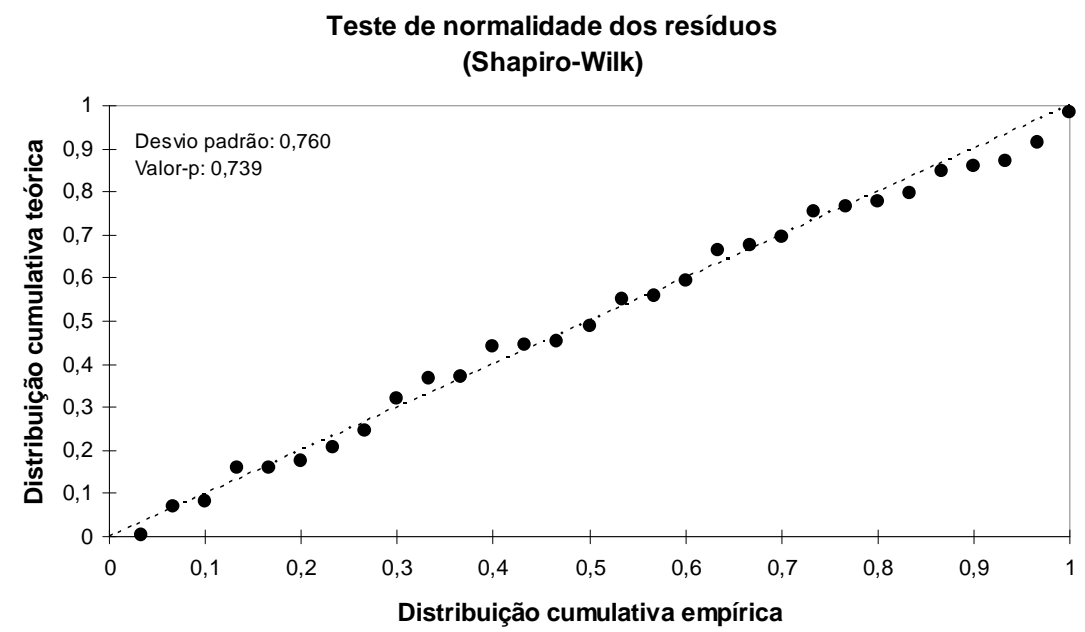

Figura D.6 - Teste de normalidade dos resíduos para a regressão entre $\mathrm{E}_{\mathrm{M}, \mathrm{vT}}$ e $\mathrm{E}_{\mathrm{M}, \mathrm{Stat}, \mathrm{v}^{*} \text {. }}$ 


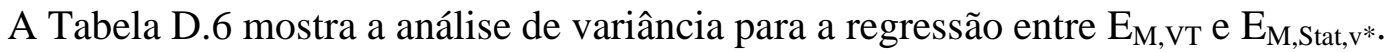

Tabela D.6 - Análise de variância para o modelo de regressão entre $\mathrm{E}_{\mathrm{M}, \mathrm{VT}}$ e $\mathrm{E}_{\mathrm{M}, \mathrm{Stat}, \mathrm{V}^{*}}$.

\begin{tabular}{lcccc}
\hline Fonte de variação & $\mathrm{GL}$ & $\mathrm{SQ}$ & $\mathrm{QM}$ & $\mathrm{F}_{\text {cal }}$ \\
\hline Modelo & 1 & 79,946 & 79,946 & 133,494 \\
Erro & 28 & 16,769 & 0,599 & \\
Total & 29 & 96,715 & & \\
\hline
\end{tabular}

Da tabela $F$, tem-se que $F_{0,05 ; 1 ; 28}=4,20$. Logo, como $F_{\text {cal }}>F_{0,05 ; 1 ; 28}$ pode-se afirmar, a um nível de significância $\alpha=0,05$, que a proporção da variância total explicada pela equação $\mathrm{E}_{\mathrm{M}, \mathrm{sta}, \mathrm{v}^{*}}[\mathrm{GPa}]=0,861 \mathrm{E}_{\mathrm{M}, \mathrm{VT}}[\mathrm{GPa}]+2,830$ é altamente significativa de forma que essa equação pode ser empregada para se fazer inferências de $\mathrm{E}_{\mathrm{M}, \mathrm{Stat}, \mathrm{v}^{*}}$ a partir de $\mathrm{E}_{\mathrm{M}, \mathrm{VT}}$.

A Figura D.7 mostra o gráfico dos resíduos contra os valores estimados para o gráfico de correlação mostrado na Figura 4.32. Observa-se nessa figura que a suposição de variância constante foi atendida.

Resíduos contra valores estimados

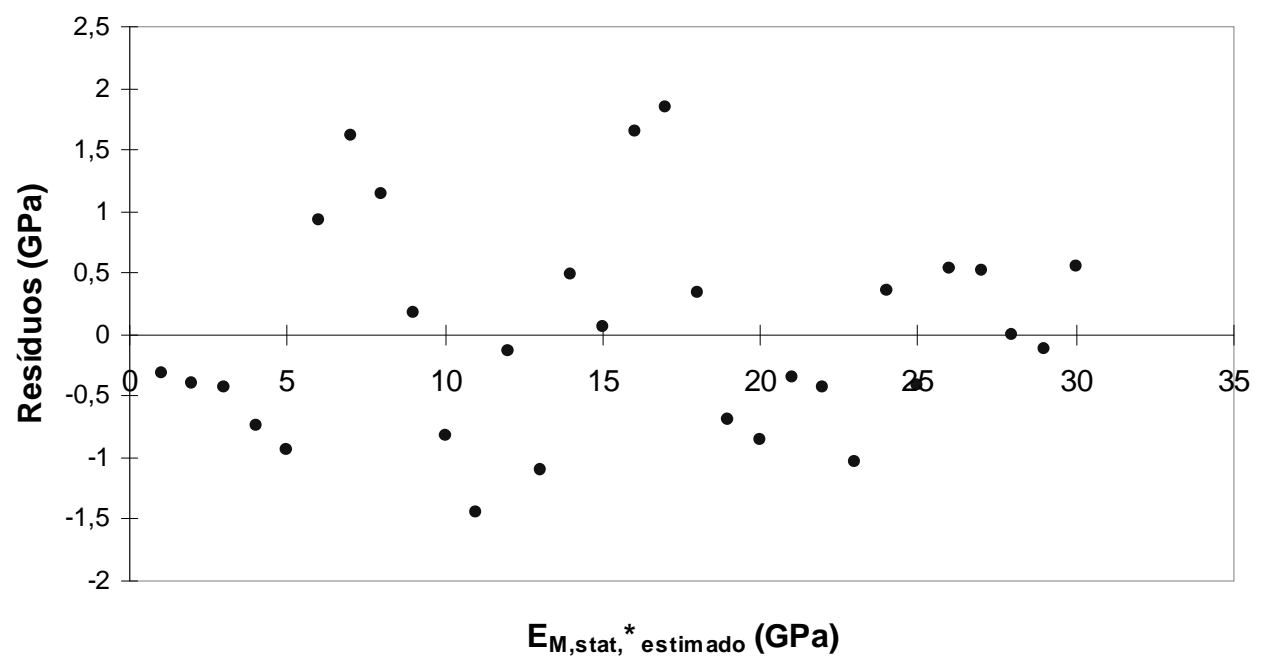

Figura D.7 - Resíduos contra valores estimados para regressão entre $\mathrm{E}_{\mathrm{M}, \mathrm{VT}}$ e $\mathrm{E}_{\mathrm{M}, \mathrm{Stat}, \mathrm{v}^{*} \text {. }}$

Os resíduos seguem uma distribuição normal como mostra o gráfico da Figura D.8. 
Teste de normalidade dos resíduos

(Shapiro-Wilk)

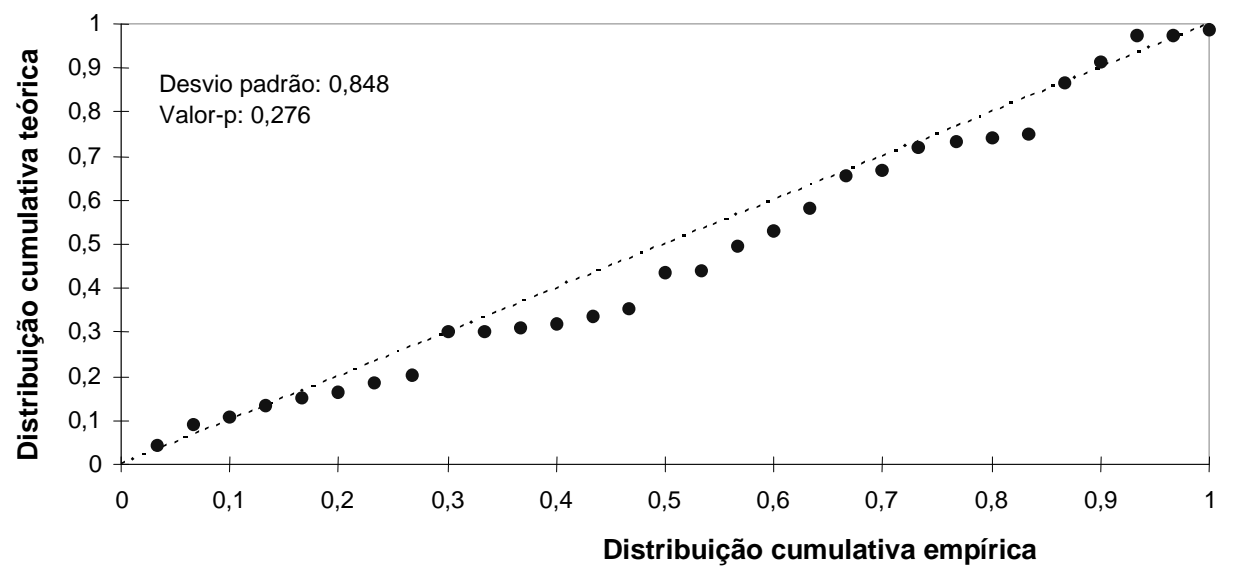

Figura D.8 - Teste de normalidade dos resíduos para a regressão entre $\mathrm{E}_{\mathrm{M}, \mathrm{VT}}$ e $\mathrm{E}_{\mathrm{M}, \mathrm{Stat}, \mathrm{v}^{*}}$.

Logo pode-se usar a Tabela D.7 para avaliar o modelo ajustado.

Tabela D.7 - Análise de variância para o modelo de regressão entre $\mathrm{E}_{\mathrm{M}, \mathrm{VT}}$ e $\mathrm{E}_{\mathrm{M}, \mathrm{Stat}, \mathrm{v}^{*} \text {. }}$

\begin{tabular}{lcccc}
\hline Fonte de variação & $\mathrm{GL}$ & $\mathrm{SQ}$ & $\mathrm{QM}$ & $\mathrm{F}_{\text {cal }}$ \\
\hline Modelo & 1 & 75,846 & 75,846 & 101,766 \\
Erro & 28 & 20,868 & 0,745 & \\
Total & 29 & 96,715 & & \\
\hline
\end{tabular}

Da tabela $\mathrm{F}$, tem-se que $\mathrm{F}_{0,05 ; 1 ; 28}=4,20$. Logo, como $\mathrm{F}_{\text {cal }}>\mathrm{F}_{0,05 ; 1 ; 28}$ pode-se afirmar, a um nível de significância $\alpha=0,05$, que a proporção da variância total explicada pela equação $\mathrm{E}_{\mathrm{M}, \mathrm{Stat}, \mathrm{v}^{*}}[\mathrm{GPa}]=0,837 \mathrm{E}_{\mathrm{M}, \mathrm{VT}}[\mathrm{GPa}]+4,039$ é altamente significativa de forma que essa equação pode ser empregada para se fazer inferências de $\mathrm{E}_{\mathrm{M}, \mathrm{Stat}, \mathrm{v}^{*}}$ a partir de $\mathrm{E}_{\mathrm{M}, \mathrm{VT}}$.

\section{D.3. Modelos de regressão linear apresentados no item 5.4.1}

As análises a seguir referem-se aos dados e ao modelo de regressão linear mostrado na Figura 5.6.

A Figura D.9 mostra o gráfico dos resíduos contra os valores estimados no qual observa-se que a variância é aproximadamente constante. 


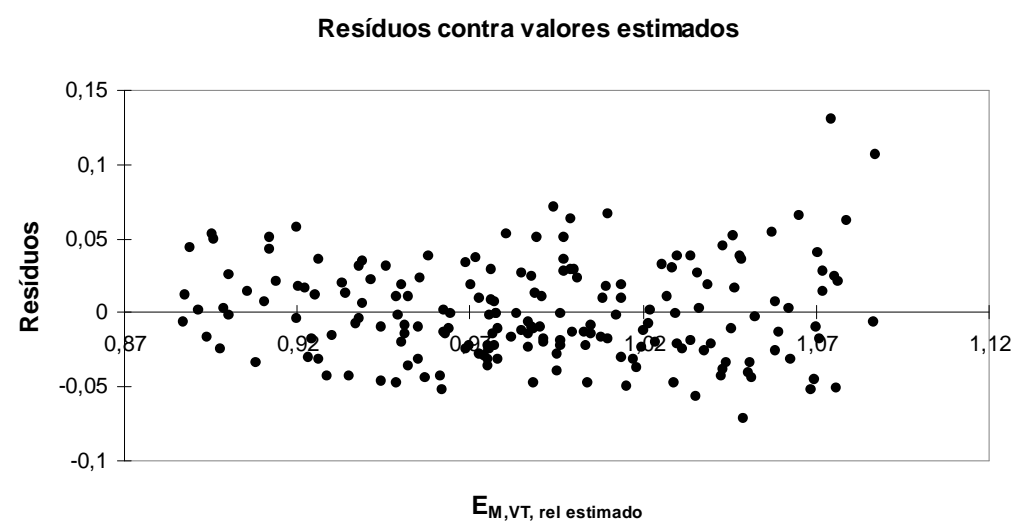

Figura D.9 - Resíduos contra valores estimados para regressão entre $\mathrm{E}_{\mathrm{M}, \mathrm{VT} \text {,rel }}$ e $\mathrm{u}_{\mathrm{rel}}$.

Na Figura D.10 verifica-se que a suposição de normalidade dos resíduos não foi atendida.

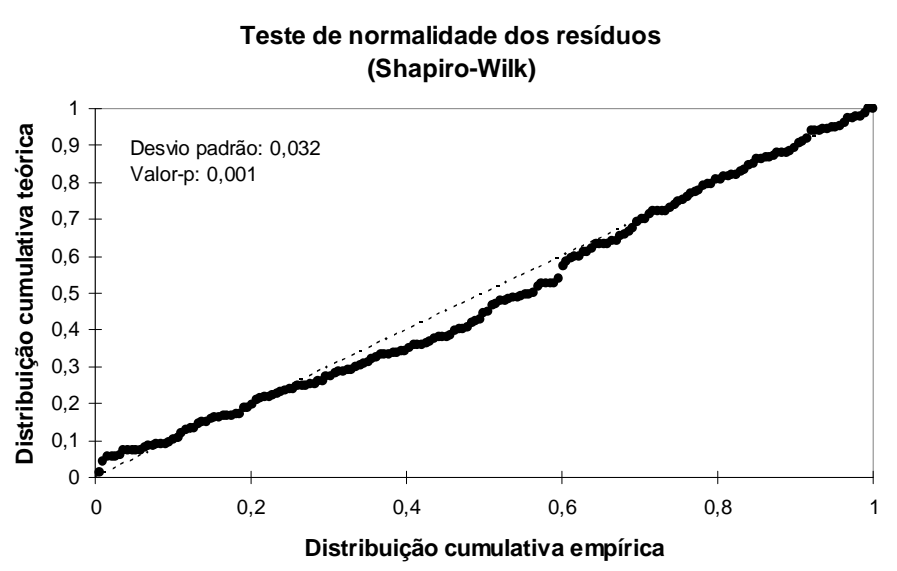

Figura D.10 - Teste de normalidade dos resíduos para regressão entre $\mathrm{E}_{\mathrm{M}, \mathrm{VT} \text {,rel }} \mathrm{e} \mathrm{u}_{\mathrm{rel}}$.

Assim sendo, foi aplicada a transformação de Box-Cox (1964) aos dados de $\mathrm{E}_{\mathrm{M}, \mathrm{VT} \text {,rel }}$ de modo a normalizá-los. Esse método aplica uma transformação exponencial nos dados, de forma a aproximá-los de uma distribuição normal. Para situações em que a variável dependente $y$ é conhecida e positiva, as seguintes transformações podem ser usadas:

$$
T\left(y_{i}\right)= \begin{cases}\left(\frac{y_{i}^{\lambda}-1}{\lambda}\right) & \text { quando } \lambda \neq 0 \quad(a) \\ \ln \left(y_{i}\right) & \text { quando } \lambda=0 \quad(b)\end{cases}
$$

Foi encontrado $\lambda_{\text {ótimo }}=-2,371$ que resulta nos valores transformados mostrados na Tabela D.8. 
Tabela D.8 - Valores de $\mathrm{E}_{\mathrm{M}, \mathrm{VT} \text {,rel }}$ transformados pela Equação D.3.

\begin{tabular}{|c|c|c|c|c|c|c|c|}
\hline $\mathbf{u}_{\text {rel }}$ & $\begin{array}{c}\mathbf{E}_{\mathrm{M}, \mathrm{VT}, \text { rel }} \\
\text { transf. }\end{array}$ & $\mathbf{u}_{\text {rel }}$ & $\begin{array}{c}\mathbf{E}_{\mathrm{M}, \mathrm{VT}, \mathrm{rel}} \\
\text { transf. }\end{array}$ & $\mathbf{u}_{\text {rel }}$ & $\begin{array}{c}\mathbf{E}_{\mathrm{M}, \mathrm{VT}, \text { rel }} \\
\text { transf. }\end{array}$ & $\mathbf{u}_{\text {rel }}$ & $\begin{array}{c}\mathbf{E}_{\mathrm{M}, \mathrm{VT}, \text { rel }} \\
\text { transf. }\end{array}$ \\
\hline 0,710 & 0,145 & 1,108 & $-0,019$ & 1,385 & $-0,024$ & 1,638 & $-0,070$ \\
\hline 0,714 & 0,071 & 1,112 & 0,053 & 1,389 & 0,012 & 1,640 & $-0,063$ \\
\hline 0,768 & 0,113 & 1,122 & 0,036 & 1,389 & $-0,023$ & 1,644 & $-0,078$ \\
\hline 0,785 & 0,084 & 1,133 & 0,053 & 1,393 & $-0,038$ & 1,644 & $-0,032$ \\
\hline 0,786 & 0,024 & 1,143 & 0,003 & 1,393 & $-0,020$ & 1,652 & $-0,058$ \\
\hline 0,792 & 0,085 & 1,155 & 0,023 & 1,395 & $-0,029$ & 1,656 & $-0,117$ \\
\hline 0,797 & 0,151 & 1,159 & 0,013 & 1,407 & 0,012 & 1,657 & $-0,044$ \\
\hline 0,814 & 0,076 & 1,166 & 0,008 & 1,408 & $-0,028$ & 1,675 & $-0,024$ \\
\hline 0,814 & 0,085 & 1,173 & $-0,004$ & 1,418 & $-0,017$ & 1,685 & $-0,123$ \\
\hline 0,821 & 0,048 & 1,182 & $-0,019$ & 1,428 & $-0,036$ & 1,685 & $-0,073$ \\
\hline 0,824 & 0,093 & 1,188 & $-0,014$ & 1,440 & 0,032 & 1,706 & $-0,039$ \\
\hline 0,828 & 0,054 & 1,200 & $-0,037$ & 1,454 & $-0,058$ & 1,723 & $-0,061$ \\
\hline 0,832 & 0,023 & 1,210 & $-0,017$ & 1,454 & $-0,034$ & 1,723 & $-0,027$ \\
\hline 0,837 & 0,016 & 1,211 & 0,031 & 1,457 & $-0,023$ & 1,727 & $-0,033$ \\
\hline 0,862 & 0,107 & 1,212 & 0,022 & 1,457 & $-0,024$ & 1,727 & $-0,074$ \\
\hline 0,877 & 0,030 & 1,221 & 0,010 & 1,460 & $-0,048$ & 1,735 & $-0,080$ \\
\hline 0,881 & 0,058 & 1,236 & 0,068 & 1,460 & $-0,016$ & 1,750 & $-0,131$ \\
\hline 0,900 & 0,043 & 1,237 & $-0,008$ & 1,464 & $-0,040$ & 1,755 & $-0,058$ \\
\hline 0,907 & 0,060 & 1,241 & 0,025 & 1,468 & $-0,016$ & 1,763 & $-0,051$ \\
\hline 0,908 & 0,031 & 1,248 & 0,017 & 1,469 & 0,005 & 1,783 & $-0,100$ \\
\hline 0,913 & 0,094 & 1,253 & $-0,009$ & 1,473 & $-0,027$ & 1,793 & $-0,140$ \\
\hline 0,947 & 0,046 & 1,270 & $-0,009$ & 1,473 & $-0,053$ & 1,809 & $-0,041$ \\
\hline 0,955 & 0,007 & 1,270 & $-0,003$ & 1,474 & $-0,050$ & 1,810 & $-0,128$ \\
\hline 0,956 & 0,017 & 1,276 & $-0,046$ & 1,475 & $-0,068$ & 1,815 & $-0,070$ \\
\hline 0,962 & 0,010 & 1,282 & $-0,020$ & 1,475 & $-0,063$ & 1,823 & $-0,111$ \\
\hline 0,972 & $-0,023$ & 1,286 & $-0,011$ & 1,482 & $-0,060$ & 1,829 & $-0,131$ \\
\hline 0,973 & 0,074 & 1,297 & 0,023 & 1,490 & $-0,018$ & 1,835 & $-0,068$ \\
\hline 0,979 & 0,075 & 1,303 & 0,028 & 1,491 & $-0,060$ & 1,850 & $-0,069$ \\
\hline 0,987 & 0,057 & 1,308 & $-0,014$ & 1,500 & 0,008 & 1,851 & $-0,024$ \\
\hline 0,991 & 0,084 & 1,311 & 0,027 & 1,510 & $-0,011$ & 1,852 & $-0,098$ \\
\hline 0,994 & 0,032 & 1,311 & 0,057 & 1,512 & $-0,057$ & 1,894 & $-0,074$ \\
\hline 1,004 & 0,011 & 1,324 & 0,044 & 1,518 & 0,002 & 1,907 & $-0,049$ \\
\hline 1,010 & 0,005 & 1,324 & 0,024 & 1,519 & $-0,062$ & 1,907 & $-0,040$ \\
\hline 1,011 & 0,077 & 1,324 & 0,032 & 1,548 & $-0,038$ & 1,914 & $-0,094$ \\
\hline 1,015 & 0,000 & 1,331 & $-0,024$ & 1,553 & $-0,052$ & 1,933 & $-0,159$ \\
\hline 1,035 & 0,018 & 1,331 & $-0,028$ & 1,560 & $-0,057$ & 1,949 & $-0,093$ \\
\hline 1,042 & 0,052 & 1,332 & $-0,004$ & 1,561 & $-0,056$ & 1,986 & $-0,121$ \\
\hline 1,048 & 0,012 & 1,337 & $-0,035$ & 1,561 & $-0,037$ & 1,987 & $-0,084$ \\
\hline 1,057 & 0,037 & 1,339 & $-0,048$ & 1,567 & $-0,106$ & 1,994 & $-0,118$ \\
\hline 1,061 & 0,056 & 1,344 & 0,059 & 1,569 & $-0,094$ & 2,003 & $-0,161$ \\
\hline 1,063 & $-0,021$ & 1,365 & $-0,028$ & 1,591 & $-0,004$ & 2,015 & $-0,059$ \\
\hline 1,074 & 0,064 & 1,365 & $-0,031$ & 1,598 & $-0,102$ & 2,019 & $-0,057$ \\
\hline 1,076 & 0,015 & 1,367 & 0,002 & 1,609 & $-0,022$ & 2,030 & $-0,153$ \\
\hline 1,091 & 0,006 & 1,371 & $-0,020$ & 1,611 & $-0,087$ & 2,046 & $-0,129$ \\
\hline 1,102 & 0,008 & 1,377 & 0,038 & 1,612 & $-0,060$ & 2,064 & $-0,076$ \\
\hline 1,103 & 0,061 & 1,383 & 0,002 & 1,632 & $-0,039$ & 2,074 & $-0,121$ \\
\hline 1,104 & 0,027 & 1,383 & $-0,065$ & 1,632 & $-0,097$ & 2,077 & $-0,148$ \\
\hline
\end{tabular}

A Figura D.11 mostra o diagrama de dispersão dos dados transformados e a equação de regressão ajustada por mínimos quadrados. 


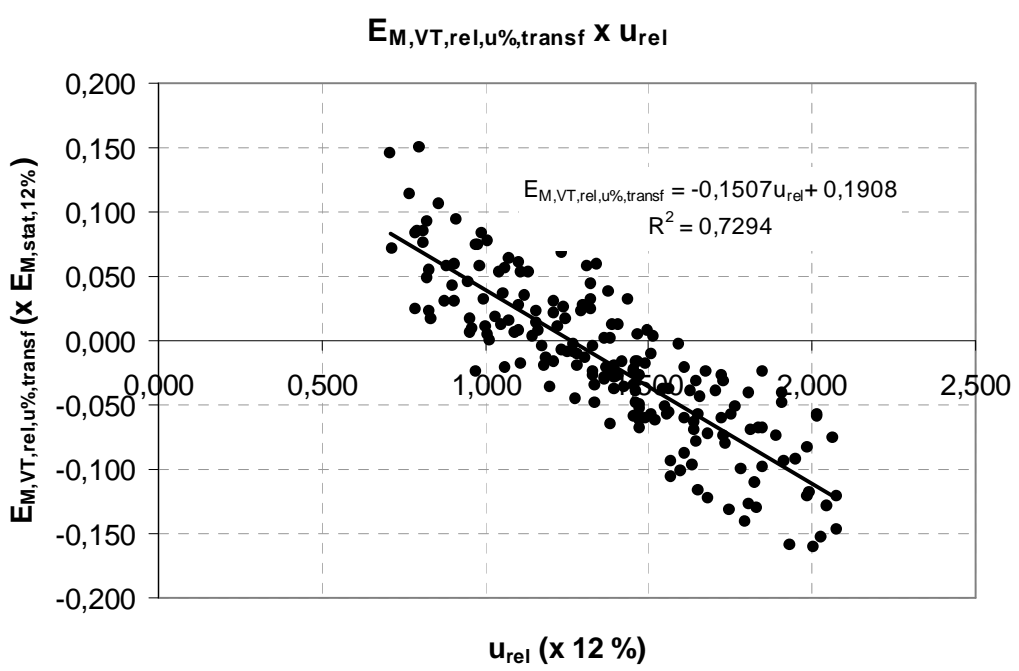

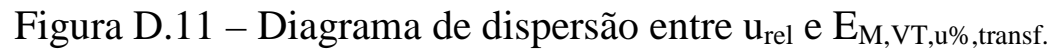

As Figuras D.12 e D.13 mostram respectivamente os gráficos dos resíduos contra os valores estimados e o teste de normalidade dos resíduos para os dados transformados nos quais observa-se que, após a transformação dos dados, as suposições do modelo foram atendidas.

Resíduos contra valores estimados

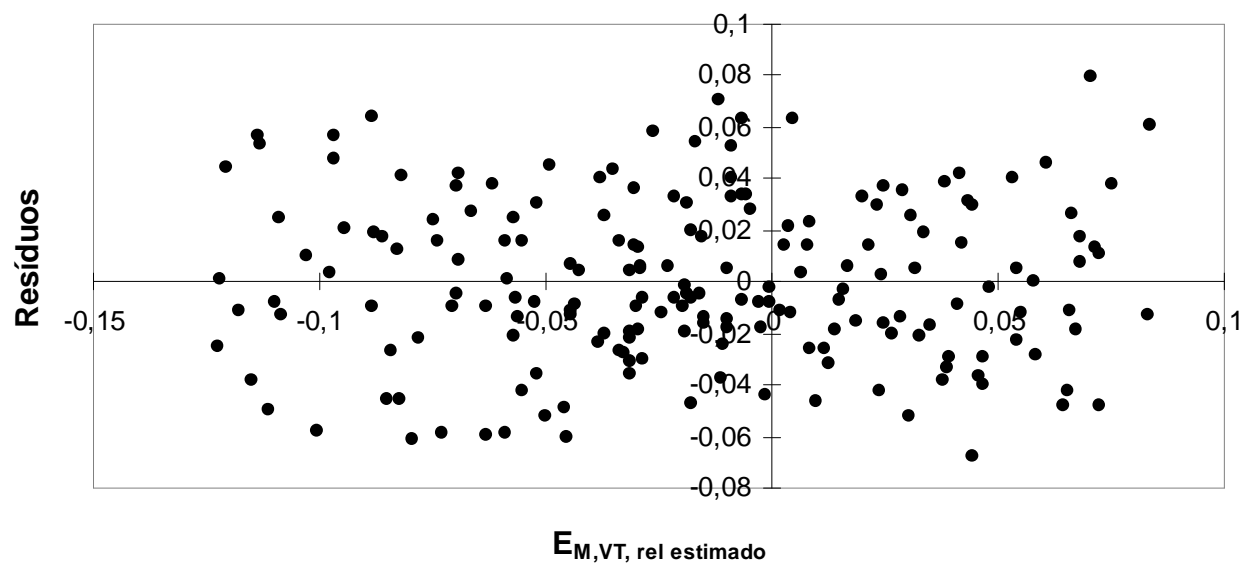

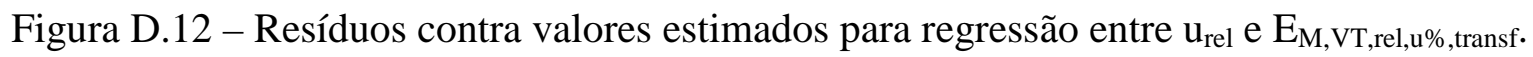




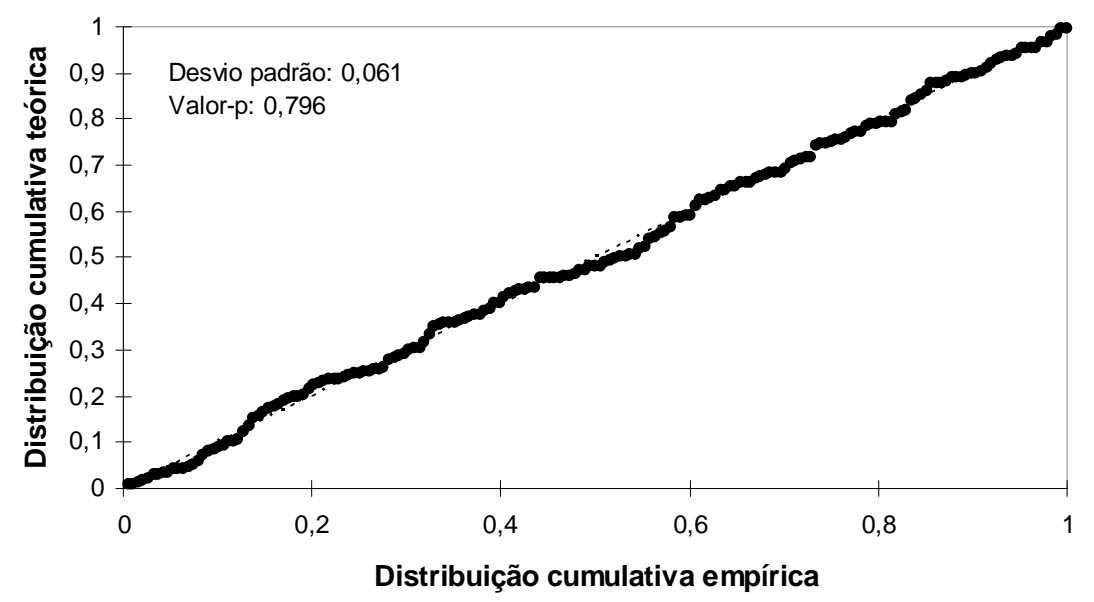

Figura D.13 - Teste de normalidade dos resíduos para regressão entre $\mathrm{u}_{\mathrm{rel}}$ e $\mathrm{E}_{\mathrm{M}, \mathrm{VT}, \mathrm{rel}, \mathrm{u} \% \text {,transf. }}$

Com as suposições do modelo de regressão linear confirmadas foi feita a análise de variância como mostra a Tabela D.9.

Tabela D.9- Análise de variância para o modelo de regressão entre $\mathrm{E}_{\mathrm{M}, \mathrm{VT}, \mathrm{ap}}$ e $\mathrm{E}_{\mathrm{M}, \text { Stat,ap} \text {. }}$

\begin{tabular}{lcccc}
\hline Fonte de variação & GL & $\mathbf{S Q}$ & $\mathbf{Q M}$ & $\mathbf{F}_{\text {cal }}$ \\
\hline Modelo & 1 & 0,501 & 0,501 & 501,425 \\
Erro & 186 & 0,186 & 0,001 & \\
Total & 187 & 0,687 & & \\
\hline
\end{tabular}

Da tabela $\mathrm{F}$, tem-se que $\mathrm{F}_{0,05 ; 1 ; 186}=3,89$. Logo, como $\mathrm{F}_{\text {cal }}>\mathrm{F}_{0,05 ; 1 ; 186}$ pode-se afirmar, a um nível de significância $\alpha=0,05$, que a proporção da variância total explicada pela equação $E_{M, V T, r e l, u \%, t r a n s f}=-0,15075 u_{\text {rel }}+0,1908$ é altamente significativa de forma que essa equação pode ser empregada para se fazer inferências de $E_{M, V T, r e l, u} \%$,transf a partir de $u_{\text {rel }}$. Entretanto, como interessa saber a relação entre os dados originais, ou seja, sem transformação, foi aplicada na equação de regressão a transformação inversa e obteve-se a Equação D.4.

$$
E_{M, V T, r e l, u}=\frac{1}{\sqrt[2,371]{0,3673 u_{r e l}+0,5476}}
$$

\section{D.4. Modelo de regressão linear da Figura 7.6 apresentada no item 7.4.2}

A Figura D.14 mostra o gráfico dos resíduos contra os valores estimados para a regressão entre $E_{M, V T}$ e $E_{M, S t a t, v^{*}}$ no qual observa-se que a variância é aproximadamente constante. 
Resíduos contra valores estimados

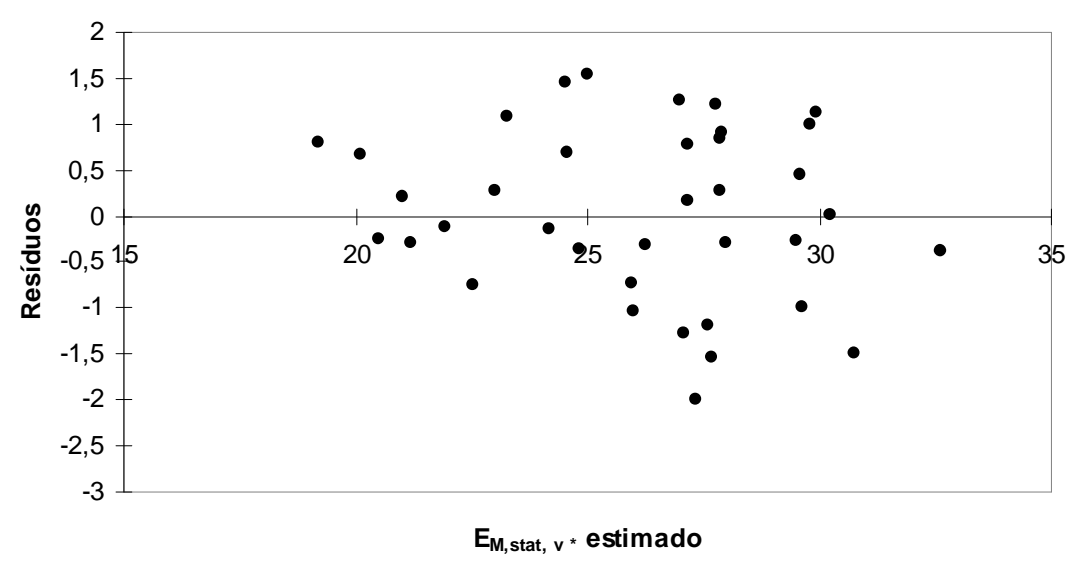

Figura D.14 - Resíduos contra valores estimados para regressão entre $\mathrm{E}_{\mathrm{M}, \mathrm{VT}}$ e $\mathrm{E}_{\mathrm{M}, \mathrm{Stat}, \mathrm{v}^{*} \text {. }}$

A Figura D.15 mostra o teste de normalidade dos resíduos no qual verifica-se que a suposição de normalidade dos resíduos é confirmada uma vez que o valor-p é maior do que 0,05 .

\section{Teste de normalidade dos resíduos Shapiro-Wilk}

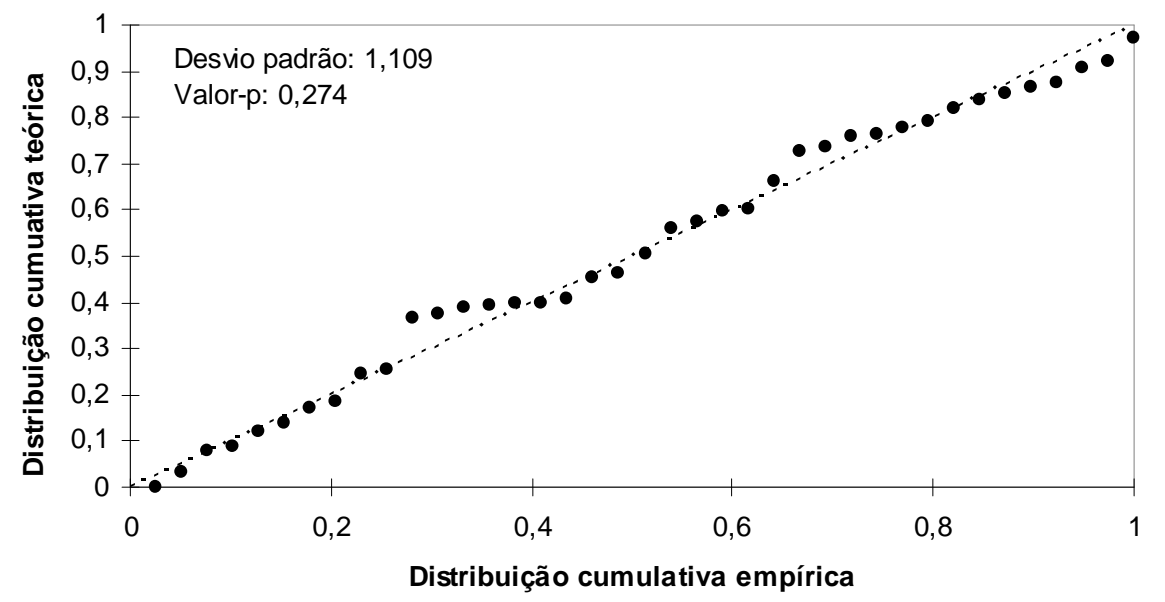

Figura D.15 - Teste de normalidade dos resíduos para regressão entre $\mathrm{E}_{\mathrm{M}, \mathrm{VT}}$ e $\mathrm{E}_{\mathrm{M}, \mathrm{stat}, \mathrm{v}^{*} \text {. }}$

Com as suposições do modelo de regressão linear confirmadas foi feita a análise de variância como mostra a Tabela D.10.

Tabela D.10 - Análise de variância para o modelo de regressão entre $\mathrm{E}_{\mathrm{M}, \mathrm{VT}}$ e $\mathrm{E}_{\mathrm{M}, \mathrm{Stat}, \mathrm{v}^{*} \text {. }}$

\begin{tabular}{lcccc}
\hline Fonte de variação & $\mathrm{GL}$ & $\mathrm{SQ}$ & $\mathrm{QM}$ & $\mathrm{F}_{\text {cal }}$ \\
\hline Modelo & 1 & 422,889 & 422,889 & 334,789 \\
Erro & 37 & 46,737 & 1,263 & \\
Total & 38 & 469,625 & & \\
\hline
\end{tabular}


Da tabela $F$, tem-se que $F_{0,05 ; 1 ; 37}=4,10$. Logo, como $F_{\text {cal }}>F_{0,05 ; 1 ; 37}$ pode-se afirmar, a um nível de significância $\alpha=0,05$, que a proporção da variância total explicada pela equação $\mathrm{E}_{\mathrm{M}, \mathrm{Stat},{ }^{v}}[\mathrm{GPa}]=0,971 \mathrm{E}_{\mathrm{M}, \mathrm{VT}}[\mathrm{GPa}]-0,335$ é altamente significativa de forma que essa equação

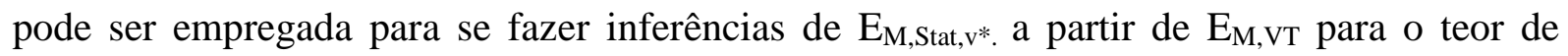
umidade de $12 \%$.

\section{D.5. Modelo de regressão linear da Figura 7.9 apresentada no item 7.4.4}

A Figura D.16 mostra o gráfico dos resíduos contra os valores estimados para a regressão entre $E_{M, V T}$ e $E_{M, S t a t, v^{*}}$ no qual observa-se que a variância é aproximadamente constante.

Resíduos contra valores estimados

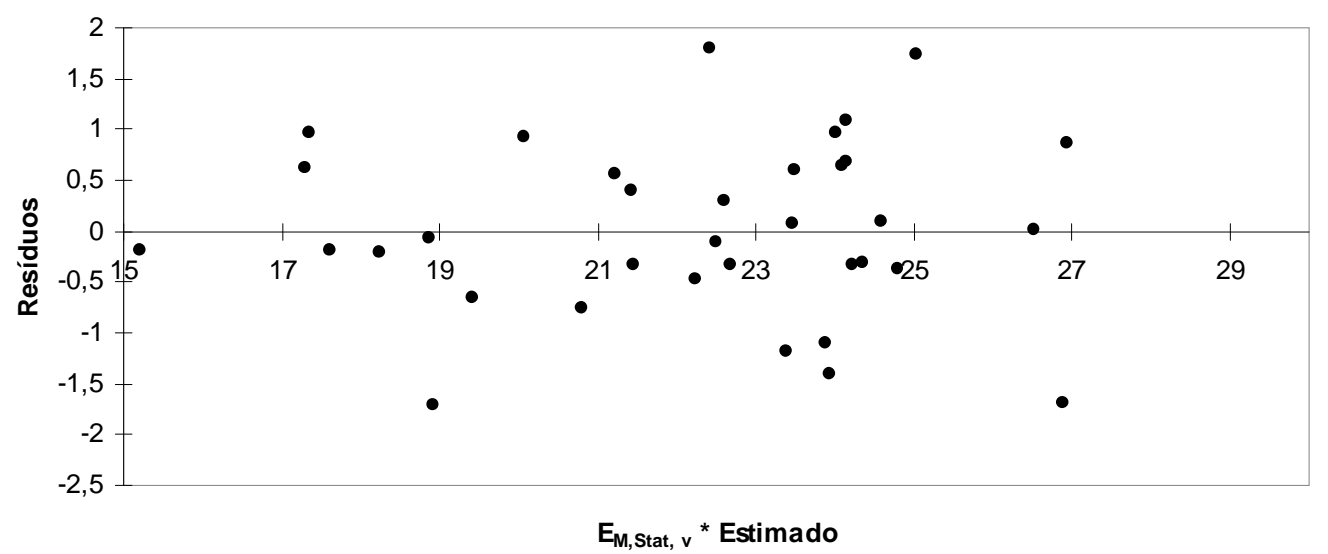

Figura D.16 - Resíduos contra valores estimados para regressão entre $\mathrm{E}_{\mathrm{M}, \mathrm{VT}}$ e $\mathrm{E}_{\mathrm{M}, \mathrm{Stat, \textrm {v }}}$

A Figura D.17 mostra o teste de normalidade dos resíduos no qual verifica-se que a suposição de normalidade dos resíduos é confirmada uma vez que o valor-p é maior do que 0,05 . 
Teste de normalidade dos resíduos

Shapiro-Wilk

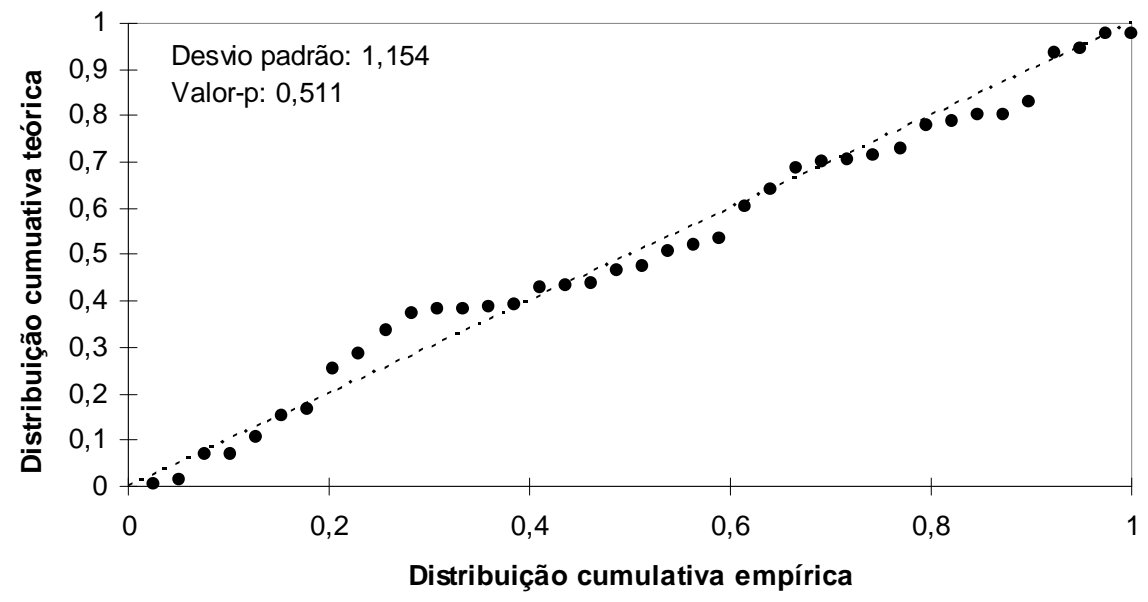

Figura D.17 - Teste de normalidade dos resíduos para regressão entre $\mathrm{E}_{\mathrm{M}, \mathrm{VT}}$ e $\mathrm{E}_{\mathrm{M}, \mathrm{stat}, \mathrm{v}^{*} \text {. }}$

Com as suposições do modelo de regressão linear confirmadas foi feita a análise de variância como mostra a Tabela D.11.

Tabela D.11 - Análise de variância para o modelo de regressão entre $\mathrm{E}_{\mathrm{M}, \mathrm{VT}}$ e $\mathrm{E}_{\mathrm{M}, \mathrm{Stat}, \mathrm{v}^{*} \text {. }}$

\begin{tabular}{lcccc}
\hline Fonte de variação & $\mathrm{GL}$ & $\mathrm{SQ}$ & $\mathrm{QM}$ & $\mathrm{F}$ \\
\hline Modelo & 1 & 298,809 & 298,809 & 218,351 \\
Erro & 37 & 50,634 & 1,368 & \\
Total & 38 & 349,442 & & \\
\hline
\end{tabular}

Da tabela $F$, tem-se que $F_{0,05 ; 1 ; 37}=4,10$. Logo, como $F_{\text {cal }}>F_{0,05 ; 1 ; 37}$ pode-se afirmar, a um nível de significância $\alpha=0,05$, que a proporção da variância total explicada pela equação $\mathrm{E}_{\mathrm{M}, \mathrm{Stat}, \mathrm{v}}{ }^{*}[\mathrm{GPa}]=0,991 \mathrm{E}_{\mathrm{M}, \mathrm{VT}}[\mathrm{GPa}]-0,701$ é altamente significativa de forma que essa equação

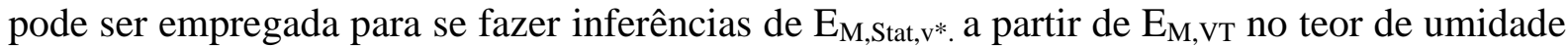
do ensaio. 


\section{APÊNDICE E - RESULTADOS DA IDENTIFICAÇÃO DOS PARÂMETROS MODAIS DAS TORAS DA AMOSTRA PILOTOO}

As Tabelas E.1 a E.34 mostram os resultados da identificação dos parâmetros modais das toras da amostra piloto. 
Tabela E.1 - Parâmetros modais da Tora 1 para o ensaio com excitação horizontal.

\begin{tabular}{|c|c|c|c|c|c|c|c|c|c|c|c|c|c|}
\hline \multirow[b]{2}{*}{ Plano } & \multirow[b]{2}{*}{ FRF } & \multicolumn{4}{|c|}{$1^{\circ}$ Modo } & \multicolumn{4}{|c|}{$2^{\circ}$ Modo } & \multicolumn{4}{|c|}{$3^{\circ}$ Modo } \\
\hline & & $\begin{array}{l}\text { Freq. } \\
(\mathrm{Hz})\end{array}$ & $\begin{array}{c}\text { Amort. } \\
(\%)\end{array}$ & $\begin{array}{l}\text { Freq. } \\
(\mathrm{Hz})\end{array}$ & $\begin{array}{c}\text { Amort. } \\
(\%)\end{array}$ & $\begin{array}{l}\text { Freq. } \\
(\mathrm{Hz})\end{array}$ & $\begin{array}{c}\text { Amort. } \\
(\%)\end{array}$ & $\begin{array}{l}\text { Freq. } \\
(\mathrm{Hz})\end{array}$ & $\begin{array}{c}\text { Amort. } \\
(\%)\end{array}$ & $\begin{array}{l}\text { Freq. } \\
(\mathrm{Hz})\end{array}$ & $\begin{array}{c}\text { Amort. } \\
(\%)\end{array}$ & $\begin{array}{l}\text { Freq. } \\
(\mathrm{Hz})\end{array}$ & $\begin{array}{c}\text { Amort. } \\
(\%)\end{array}$ \\
\hline \multirow{7}{*}{$0-4$} & $\mathrm{~A}_{100}$ & 36,23 & 1,54 & 38,88 & 1,51 & 98,40 & 0,74 & 104,34 & 0,91 & 184,63 & 0,71 & 194,56 & 0,72 \\
\hline & $A_{101}$ & 36,20 & 1,56 & 38,90 & 1,51 & 98,41 & 0,77 & 104,36 & 0,90 & 184,65 & 0,73 & 194,60 & 0,73 \\
\hline & $A_{103}$ & 36,20 & 1,53 & 38,90 & 1,51 & 98,50 & 0,91 & 104,28 & 0,84 & 184,74 & 0,73 & 194,56 & 0,71 \\
\hline & $A_{105}$ & 36,23 & 1,64 & 38,88 & 1,48 & 98,93 & 0,50 & & & 184,64 & 0,68 & 194,56 & 0,71 \\
\hline & $\mathrm{A}_{107}$ & & & 38,83 & 1,70 & 98,33 & 0,85 & 104,33 & 0,84 & 184,60 & 0,71 & 194,57 & 0,70 \\
\hline & $A_{109}$ & & & 38,95 & 0,91 & 97,37 & 1,18 & 104,37 & 0,78 & & & & \\
\hline & $A_{1011}$ & 36,18 & 1,55 & 38,89 & 1,52 & 98,31 & 0,90 & 104,31 & 0,83 & 184,62 & 0,72 & 194,53 & 0,72 \\
\hline \multirow{7}{*}{$1-5$} & $A_{100}$ & 36,26 & 1,68 & 38,90 & 0,98 & 98,12 & 0,86 & 104,53 & 0,84 & 184,73 & 0,73 & 194,29 & 0,68 \\
\hline & $A_{101}$ & 36,23 & 1,49 & & & 98,17 & 0,85 & 104,35 & 0,96 & 184,79 & 0,73 & 194,31 & 0,27 \\
\hline & $\mathrm{A}_{103}$ & 36,22 & 1,63 & & & 98,11 & 0,84 & 104,94 & 0,73 & 184,74 & 0,73 & 194,30 & 0,66 \\
\hline & $A_{105}$ & 36,25 & 1,61 & 38,94 & 1,34 & & & & & 184,74 & 0,73 & 194,32 & 0,71 \\
\hline & $A_{107}$ & 36,25 & 1,61 & 39,30 & 1,67 & 98,12 & 0,86 & 104,59 & 0,83 & 184,74 & 0,72 & 194,33 & 0,72 \\
\hline & $A_{109}$ & 36,16 & 1,79 & & & 98,25 & 1,04 & & & & & & \\
\hline & $A_{1011}$ & 36,18 & 1,42 & & & 98,10 & 0,88 & 104,58 & 0,61 & 184,70 & 0,73 & 194,12 & 0,77 \\
\hline \multirow{7}{*}{$2-6$} & $A_{100}$ & 36,21 & 1,56 & 38,91 & 1,70 & 98,10 & 0,84 & 104,65 & 0,91 & 184,76 & 0,68 & 194,29 & 0,82 \\
\hline & $A_{101}$ & 36,16 & 1,65 & 39,29 & 1,71 & 98,05 & 0,79 & 105,25 & 0,94 & 184,81 & 0,73 & 194,49 & 1,05 \\
\hline & $\mathrm{A}_{103}$ & 36,12 & 1,73 & 39,43 & 2,00 & 98,11 & 0,85 & 104,58 & 0,85 & 184,76 & 0,70 & 194,24 & 0,80 \\
\hline & $A_{105}$ & 36,26 & 1,65 & 39,06 & 1,37 & 98,10 & 0,59 & 104,96 & 1,56 & 184,78 & 0,67 & 194,38 & 0,85 \\
\hline & $A_{107}$ & 36,22 & 1,46 & 38,71 & 1,88 & 98,10 & 0,85 & 104,63 & 0,84 & 184,77 & 0,70 & 194,28 & 0,79 \\
\hline & $A_{109}$ & 36,16 & 1,47 & 38,97 & 1,92 & 98,15 & 0,88 & 104,14 & 0,86 & & & & \\
\hline & $A_{1011}$ & 36,23 & 1,79 & & & 98,10 & 0,88 & 104,52 & 0,71 & 184,74 & 0,70 & 194,19 & 0,79 \\
\hline \multirow{7}{*}{$3-7$} & $\mathrm{~A}_{100}$ & & & 38,89 & 1,83 & 98,23 & 1,36 & 104,22 & 0,84 & 185,46 & 0,59 & 194,64 & 0,69 \\
\hline & $A_{101}$ & & & 38,98 & 1,80 & & & 104,34 & 0,76 & & & 194,67 & 0,71 \\
\hline & $A_{103}$ & & & 38,89 & 1,64 & 98,57 & 0,82 & 104,23 & 0,88 & 184,54 & 0,77 & 194,67 & 0,69 \\
\hline & $A_{105}$ & & & 39,00 & 1,64 & & & & & 184,34 & 0,69 & 194,68 & 0,70 \\
\hline & $A_{107}$ & & & 38,93 & 1,69 & 98,30 & 0,72 & 104,25 & 0,86 & 184,47 & 0,73 & 194,67 & 0,70 \\
\hline & $A_{109}$ & & & 38,88 & 1,60 & & & 104,25 & 1,02 & & & 194,70 & 0,67 \\
\hline & $A_{1011}$ & & & 38,88 & 1,70 & 98,54 & 1,06 & 104,23 & 0,83 & 184,78 & 0,90 & 194,63 & 0,69 \\
\hline \multirow{7}{*}{$4-0$} & $A_{100}$ & 36,04 & 1,14 & 38,97 & 1,62 & 98,42 & 0,89 & 104,30 & 0,86 & 184,60 & 0,73 & 194,66 & 0,77 \\
\hline & $A_{101}$ & 36,15 & 1,30 & 38,91 & 1,58 & 98,74 & 0,92 & 104,24 & 0,87 & 184,61 & 0,66 & 194,69 & 0,77 \\
\hline & $\mathrm{A}_{103}$ & 36,10 & 1,05 & 38,92 & 1,89 & 98,47 & 0,82 & 104,31 & 0,88 & 184,60 & 0,73 & 194,64 & 0,78 \\
\hline & $A_{105}$ & 36,18 & 1,50 & 38,88 & 1,64 & 99,00 & 0,53 & & & 184,54 & 0,73 & 194,67 & 0,77 \\
\hline & $A_{107}$ & & & 39,00 & 1,27 & 98,69 & 0,85 & 104,12 & 0,95 & 184,60 & 0,71 & 194,67 & 0,78 \\
\hline & $A_{109}$ & 36,41 & 1,56 & 38,91 & 1,45 & 98,76 & 0,94 & 104,22 & 0,91 & & & 193,69 & 1,05 \\
\hline & $A_{1011}$ & 36,70 & 1,04 & 38,93 & 1,53 & 98,79 & 1,14 & 104,24 & 0,87 & 184,57 & 0,69 & 194,73 & 0,81 \\
\hline \multirow{7}{*}{$5-1$} & $A_{100}$ & 36,19 & 1,44 & & & 98,07 & 0,84 & 104,66 & 1,93 & 184,79 & 0,71 & 194,22 & 0,76 \\
\hline & $A_{101}$ & 36,23 & 1,52 & & & 98,13 & 0,85 & 104,16 & 1,18 & 184,82 & 0,69 & 194,13 & 0,68 \\
\hline & $\mathrm{A}_{103}$ & 36,41 & 1,79 & & & 98,08 & 0,86 & 104,49 & 0,89 & 184,78 & 0,70 & 194,30 & 0,74 \\
\hline & $A_{105}$ & 36,14 & 1,57 & & & & & & & 184,77 & 0,71 & 194,34 & 0,75 \\
\hline & $A_{107}$ & 36,32 & 1,80 & & & 97,91 & 0,92 & & & 184,79 & 0,70 & 194,33 & 0,75 \\
\hline & $A_{109}$ & 36,23 & 1,70 & & & 98,10 & 0,79 & & & & & & \\
\hline & $A_{1011}$ & 36,22 & 1,72 & & & 98,06 & 0,88 & 104,73 & 0,67 & 184,74 & 0,70 & 194,26 & 0,75 \\
\hline \multirow{7}{*}{$6-2$} & $A_{100}$ & 36,25 & 1,54 & 38,80 & 1,63 & 98,08 & 0,87 & 104,46 & 0,86 & 184,79 & 0,70 & 194,49 & 0,70 \\
\hline & $A_{101}$ & 36,18 & 1,66 & 39,06 & 1,58 & 98,11 & 0,83 & 104,55 & 1,00 & 184,78 & 0,68 & 194,58 & 0,69 \\
\hline & $A_{103}$ & 36,13 & 1,45 & & & 98,09 & 0,83 & 104,64 & 0,99 & 184,82 & 0,71 & 194,51 & 0,73 \\
\hline & $A_{105}$ & 36,29 & 1,73 & 38,65 & 1,04 & & & & & 184,80 & 0,71 & 194,44 & 0,69 \\
\hline & $A_{107}$ & 36,25 & 1,76 & & & 98,08 & 0,84 & 104,58 & 0,89 & 184,81 & 0,70 & 194,50 & 0,71 \\
\hline & $A_{109}$ & 35,97 & 1,35 & 38,88 & 1,80 & 98,19 & 0,94 & 103,72 & 0,62 & & & & \\
\hline & $A_{1011}$ & 36,22 & 1,60 & 38,82 & 1,27 & 98,07 & 0,86 & 104,50 & 0,84 & 184,78 & 0,70 & 194,48 & 0,71 \\
\hline & $A_{100}$ & & & 38,92 & 1,98 & 98,47 & 0,54 & 104,30 & 0,90 & 184,84 & 0,72 & 194,62 & 0,70 \\
\hline & $A_{101}$ & & & 38,93 & 1,66 & 98,74 & 0,98 & 104,17 & 0,91 & 184,57 & 0,56 & 194,66 & 0,71 \\
\hline & $\mathrm{A}_{103}$ & & & 38,98 & 1,90 & 98,65 & 0,77 & 104,21 & 0,90 & 184,80 & 0,74 & 194,64 & 0,71 \\
\hline $7-3$ & $A_{105}$ & 36,80 & 1,55 & 39,02 & 1,33 & & & & & 184,87 & 0,71 & 194,60 & 0,70 \\
\hline & $\mathrm{A}_{107}$ & 35,51 & 0,87 & 38,98 & 1,84 & 98,49 & 0,90 & 104,21 & 0,87 & 184,86 & 0,71 & 194,66 & 0,70 \\
\hline & $A_{109}$ & & & 39,22 & 0,74 & 98,67 & 0,94 & 104,28 & 0,82 & & & & \\
\hline & $A_{1011}$ & & & 38,81 & 1,64 & 98,11 & 0,80 & 104,32 & 0,88 & 184,70 & 0,72 & 194,61 & 0,69 \\
\hline & & 36,22 & 1,54 & 38,95 & 1,57 & 98,29 & 0,86 & 104,41 & 0,90 & 184,73 & 0,71 & 194,47 & 0,73 \\
\hline $\begin{array}{l}\text { Desvio } \\
\text { Coef. V }\end{array}$ & $\begin{array}{l}\text { adrão } \\
\text { riação }\end{array}$ & $\begin{array}{c}0,182 \\
0,5 \%\end{array}$ & $\begin{array}{c}0,211 \\
13,7 \% \\
\end{array}$ & $\begin{array}{c}0,145 \\
0,4 \%\end{array}$ & $\begin{array}{c}0,283 \\
18,0 \% \\
\end{array}$ & $\begin{array}{c}0,303 \\
0,3 \%\end{array}$ & $\begin{array}{r}0,147 \\
17,0 \% \\
\end{array}$ & $\begin{array}{c}0,258 \\
0,2 \% \\
\end{array}$ & $\begin{array}{c}0,211 \\
23,4 \% \\
\end{array}$ & $\begin{array}{c}0,156 \\
0,1 \% \\
\end{array}$ & $\begin{array}{l}0,044 \\
6,2 \%\end{array}$ & $\begin{array}{c}0,208 \\
0,1 \% \\
\end{array}$ & $\begin{array}{r}0,100 \\
13,7 \%\end{array}$ \\
\hline
\end{tabular}


Tabela E.2 - Parâmetros modais da Tora 1 para o ensaio com excitação vertical.

\begin{tabular}{|c|c|c|c|c|c|c|c|c|c|c|c|c|c|}
\hline \multirow[b]{2}{*}{ Plano } & \multirow[b]{2}{*}{ FRF } & \multicolumn{4}{|c|}{$1^{\circ}$ Modo } & \multicolumn{4}{|c|}{$2^{\circ}$ Modo } & \multicolumn{4}{|c|}{$3^{\circ}$ Modo } \\
\hline & & $\begin{array}{l}\text { Freq. } \\
(\mathrm{Hz})\end{array}$ & $\begin{array}{c}\text { Amort. } \\
(\%)\end{array}$ & $\begin{array}{l}\text { Freq. } \\
(\mathrm{Hz})\end{array}$ & $\begin{array}{c}\text { Amort. } \\
(\%)\end{array}$ & $\begin{array}{l}\text { Freq. } \\
(\mathrm{Hz})\end{array}$ & $\begin{array}{c}\text { Amort. } \\
(\%)\end{array}$ & $\begin{array}{c}\text { Freq. } \\
(\mathrm{Hz})\end{array}$ & $\begin{array}{c}\text { Amort. } \\
(\%)\end{array}$ & $\begin{array}{c}\text { Freq. } \\
(\mathrm{Hz})\end{array}$ & $\begin{array}{c}\text { Amort. } \\
(\%)\end{array}$ & $\begin{array}{c}\text { Freq. } \\
(\mathrm{Hz})\end{array}$ & $\begin{array}{c}\text { Amort. } \\
(\%)\end{array}$ \\
\hline \multirow{7}{*}{$0-4$} & $\overline{A_{100}}$ & 36,23 & 1,44 & 38,87 & 1,56 & 98,15 & 0,85 & 104,58 & 0,79 & 184,80 & 0,71 & 194,32 & 0,72 \\
\hline & $A_{101}$ & 36,25 & 1,53 & 38,87 & 1,53 & 98,16 & 0,87 & 104,57 & 0,87 & 184,93 & 0,74 & 194,32 & 0,72 \\
\hline & $\mathrm{A}_{103}$ & 36,22 & 1,55 & 38,89 & 1,52 & 98,26 & 0,76 & 104,54 & 0,91 & 184,84 & 0,71 & 194,29 & 0,74 \\
\hline & $A_{105}$ & 36,20 & 1,58 & 38,88 & 1,52 & & & & & 184,81 & 0,71 & 194,31 & 0,74 \\
\hline & $A_{107}$ & 36,28 & 1,66 & 38,87 & 1,53 & 98,29 & 0,82 & 104,55 & 0,94 & 184,83 & 0,70 & 194,33 & 0,73 \\
\hline & $A_{109}$ & 36,12 & 1,45 & 38,90 & 1,56 & 98,13 & 0,86 & 104,57 & 0,86 & & & & \\
\hline & $A_{1011}$ & 36,21 & 1,62 & 38,87 & 1,51 & 98,12 & 0,85 & 104,54 & 0,86 & 184,82 & 0,71 & 194,28 & 0,74 \\
\hline \multirow{7}{*}{$1-5$} & $A_{100}$ & 36,20 & 1,75 & & & 98,48 & 0,86 & 104,36 & 0,90 & 184,68 & 0,72 & 194,55 & 0,72 \\
\hline & $A_{101}$ & 36,17 & 1,89 & & & 98,52 & 0,85 & 104,40 & 0,96 & 184,72 & 0,72 & 194,63 & 0,73 \\
\hline & $\mathrm{A}_{103}$ & 36,25 & 1,30 & & & 98,53 & 0,88 & & & 184,71 & 0,73 & 194,57 & 0,67 \\
\hline & $A_{105}$ & 36,21 & 1,55 & 38,91 & 1,69 & 98,48 & 0,87 & 104,27 & 0,81 & 184,66 & 0,73 & 194,54 & 0,71 \\
\hline & $A_{107}$ & 36,13 & 1,82 & 39,19 & 0,81 & 98,45 & 0,86 & 104,32 & 0,88 & 184,64 & 0,73 & 194,54 & 0,71 \\
\hline & $A_{109}$ & 36,22 & 1,48 & 38,81 & 1,98 & 98,48 & 0,86 & 104,37 & 0,88 & & & & \\
\hline & $A_{1011}$ & 36,20 & 1,59 & 38,87 & 1,49 & 98,44 & 0,85 & 104,25 & 0,89 & 184,64 & 0,73 & 194,46 & 0,76 \\
\hline \multirow{7}{*}{$2-6$} & $A_{100}$ & 36,20 & 1,65 & 38,87 & 1,48 & 98,49 & 0,87 & 104,28 & 0,85 & 184,65 & 0,75 & 194,49 & 0,75 \\
\hline & $A_{101}$ & 36,21 & 1,64 & 38,88 & 1,30 & 98,50 & 0,87 & 104,32 & 0,88 & 184,62 & 0,74 & 194,43 & 0,77 \\
\hline & $\mathrm{A}_{103}$ & 36,03 & 1,20 & 39,15 & 1,95 & 98,50 & 0,87 & 104,31 & 0,86 & 184,63 & 0,75 & 194,52 & 0,73 \\
\hline & $A_{105}$ & 36,22 & 1,77 & 38,84 & 1,16 & 98,53 & 0,86 & 104,34 & 0,86 & 184,61 & 0,73 & 194,49 & 0,73 \\
\hline & $A_{107}$ & 36,12 & 1,60 & 39,03 & 1,60 & 98,49 & 0,87 & 104,26 & 0,87 & 184,64 & 0,73 & 194,53 & 0,74 \\
\hline & $A_{109}$ & 36,12 & 1,60 & 39,19 & 1,60 & 98,51 & 0,85 & 104,54 & 0,81 & & & & \\
\hline & $A_{1011}$ & 36,20 & 1,67 & 38,86 & 1,23 & 98,47 & 0,88 & 104,28 & 0,84 & 184,58 & 0,73 & 194,46 & 0,76 \\
\hline \multirow{7}{*}{ 3-7 } & $A_{100}$ & & & 38,88 & 1,60 & & & 104,76 & 0,84 & & & 194,33 & 0,74 \\
\hline & $A_{101}$ & & & 38,73 & 1,61 & & & 104,76 & 0,83 & & & 194,36 & 0,73 \\
\hline & $\mathrm{A}_{103}$ & & & 39,06 & 1,72 & & & 104,56 & 0,88 & & & 194,34 & 0,73 \\
\hline & $A_{105}$ & & & 38,87 & 1,50 & & & 104,86 & 0,92 & & & 194,24 & 0,74 \\
\hline & $A_{107}$ & & & 38,91 & 1,89 & & & 104,74 & 0,87 & & & 194,26 & 0,73 \\
\hline & $A_{109}$ & & & 38,93 & 1,41 & & & 104,65 & 0,86 & & & & \\
\hline & $A_{1011}$ & 35,17 & 1,54 & 38,87 & 1,66 & 98,08 & 0,84 & 104,65 & 0,87 & 184,76 & 0,68 & 194,12 & 0,74 \\
\hline \multirow{7}{*}{ 4-0 } & $A_{100}$ & 36,20 & 1,59 & 38,89 & 1,51 & 94,97 & 1,83 & 104,53 & 0,87 & 184,79 & 0,75 & 194,40 & 0,93 \\
\hline & $A_{101}$ & 36,16 & 1,76 & 38,90 & 1,47 & 98,21 & 0,88 & 104,55 & 0,86 & 184,97 & 0,68 & 194,36 & 0,81 \\
\hline & $\mathrm{A}_{103}$ & 36,24 & 1,58 & 38,89 & 1,52 & 98,16 & 0,86 & 104,53 & 0,87 & 184,84 & 0,70 & 194,36 & 0,83 \\
\hline & $A_{105}$ & 36,13 & 1,55 & 38,93 & 1,50 & & & & & 184,79 & 0,70 & 194,43 & 0,81 \\
\hline & $A_{107}$ & 36,26 & 1,49 & 38,87 & 1,52 & 98,14 & 0,85 & 104,54 & 0,88 & 184,80 & 0,71 & 194,52 & 0,88 \\
\hline & $A_{109}$ & 36,21 & 1,86 & 38,92 & 1,48 & 98,15 & 0,84 & 104,55 & 0,86 & & & & \\
\hline & $A_{1011}$ & 35,97 & 1,23 & 38,97 & 1,55 & 98,13 & 0,86 & 104,53 & 0,87 & 184,73 & 0,71 & 194,47 & 0,74 \\
\hline \multirow{7}{*}{$5-1$} & $A_{100}$ & 36,08 & 1,71 & & & 98,44 & 0,86 & & & 184,80 & 0,71 & & \\
\hline & $A_{101}$ & 36,14 & 1,97 & & & 98,60 & 0,85 & & & 184,85 & 0,70 & & \\
\hline & $\mathrm{A}_{103}$ & 36,22 & 1,75 & & & 98,53 & 0,82 & & & 184,82 & 0,70 & & \\
\hline & $A_{105}$ & 36,22 & 1,76 & & & & & & & 184,80 & 0,71 & & \\
\hline & $A_{107}$ & 36,21 & 1,59 & & & 98,64 & 0,77 & & & 184,81 & 0,70 & & \\
\hline & $A_{109}$ & 36,23 & 1,76 & & & 98,51 & 0,82 & & & & & & \\
\hline & $A_{1011}$ & 36,23 & 1,86 & & & 98,51 & 0,87 & & & 184,78 & 0,71 & & \\
\hline \multirow{7}{*}{ 6-2 } & $A_{100}$ & 36,13 & 1,54 & 39,06 & 1,06 & 98,42 & 0,87 & 104,24 & 0,86 & 184,84 & 0,71 & 194,66 & 0,70 \\
\hline & $A_{101}$ & 36,20 & 1,52 & 38,92 & 1,40 & 98,44 & 0,86 & 104,26 & 0,86 & 184,88 & 0,71 & 194,74 & 0,71 \\
\hline & $\mathrm{A}_{103}$ & 36,23 & 1,53 & 38,88 & 1,81 & 98,42 & 0,86 & 104,22 & 0,85 & 184,87 & 0,70 & 194,72 & 0,70 \\
\hline & $A_{105}$ & 36,20 & 1,61 & 38,90 & 1,47 & 98,50 & 0,87 & 104,37 & 0,93 & 184,84 & 0,70 & 194,69 & 0,70 \\
\hline & $A_{107}$ & 36,21 & 1,59 & 38,92 & 1,49 & 98,42 & 0,84 & 104,37 & 0,92 & 184,86 & 0,71 & 194,04 & 0,95 \\
\hline & $A_{109}$ & 36,27 & 1,56 & 38,75 & 1,70 & 98,44 & 0,87 & 104,26 & 0,88 & & & & \\
\hline & $A_{1011}$ & 36,20 & 1,61 & 38,89 & 1,53 & 98,41 & 0,88 & 104,25 & 0,91 & 184,82 & 0,71 & 194,67 & 0,72 \\
\hline & $A_{100}$ & 36,18 & 1,51 & 38,89 & 1,51 & 98,37 & 1,54 & 104,56 & 0,84 & 184,71 & 0,71 & 194,71 & 0,71 \\
\hline & $A_{101}$ & 36,19 & 1,62 & 38,89 & 1,50 & 98,03 & 0,91 & 104,59 & 0,85 & 184,92 & 0,66 & 194,73 & 0,73 \\
\hline & $\mathrm{A}_{103}$ & 36,37 & 1,09 & 38,90 & 1,57 & 98,18 & 0,84 & 104,58 & 0,85 & 184,84 & 0,71 & 194,74 & 0,71 \\
\hline $7-3$ & $A_{105}$ & 36,21 & 1,57 & 38,89 & 1,52 & & & & & 184,85 & 0,73 & 194,75 & 0,73 \\
\hline & $A_{107}$ & 36,10 & 1,68 & 38,90 & 1,48 & 98,29 & 1,02 & 104,54 & 0,86 & 184,84 & 0,71 & 194,75 & 0,72 \\
\hline & $A_{109}$ & 36,20 & 1,63 & 38,89 & 1,51 & 98,05 & 0,89 & 104,59 & 0,85 & & & & \\
\hline & $A_{1011}$ & 36,48 & 0,90 & 38,89 & 1,52 & 98,04 & 0,83 & 104,57 & 0,84 & 184,81 & 0,72 & 194,70 & 0,72 \\
\hline $\mathbf{I V I}$ & & 36,18 & 1,59 & 38,91 & 1,52 & 98,28 & 0,89 & 104,47 & 0,87 & 184,78 & 0,71 & 194,48 & 0,75 \\
\hline & adrão & 0,164 & 0,193 & 0,091 & 0,199 & 0,528 & 0,177 & 0,166 & 0,033 & 0,095 & 0,018 & 0,182 & 0,057 \\
\hline oef. & riação & $0,5 \%$ & $12,2 \%$ & $0,2 \%$ & $13,1 \%$ & $0,5 \%$ & $19,8 \%$ & $0,2 \%$ & $3,8 \%$ & $0,1 \%$ & $2,5 \%$ & $0,1 \%$ & $7,7 \%$ \\
\hline
\end{tabular}


Tabela E.3 - Parâmetros modais da Tora 2 para o ensaio com excitação horizontal.

\begin{tabular}{|c|c|c|c|c|c|c|c|c|c|c|c|c|c|}
\hline \multirow[b]{2}{*}{ Plano } & \multirow[b]{2}{*}{ FRF } & \multicolumn{2}{|c|}{$1^{\circ}$ Modo } & \multirow[b]{2}{*}{$\begin{array}{l}\text { Freq. } \\
(\mathrm{Hz})\end{array}$} & \multicolumn{3}{|c|}{$2^{\circ}$ Modo } & \multirow[b]{2}{*}{$\begin{array}{l}\text { Freq. } \\
(\mathrm{Hz})\end{array}$} & \multirow[b]{2}{*}{$\begin{array}{c}\text { Amort. } \\
(\%)\end{array}$} & \multicolumn{4}{|c|}{$3^{\circ}$ Modo } \\
\hline & & $\begin{array}{c}\text { Freq. } \\
(\mathrm{Hz})\end{array}$ & $\begin{array}{c}\text { Amort. } \\
(\%)\end{array}$ & & $\begin{array}{c}\text { Amort. } \\
(\%)\end{array}$ & $\begin{array}{l}\text { Freq. } \\
(\mathrm{Hz})\end{array}$ & $\begin{array}{c}\text { Amort. } \\
(\%)\end{array}$ & & & $\begin{array}{c}\text { Freq. } \\
(\mathrm{Hz})\end{array}$ & $\begin{array}{c}\text { Amort. } \\
(\%)\end{array}$ & $\begin{array}{l}\text { Freq. } \\
(\mathrm{Hz})\end{array}$ & $\begin{array}{c}\text { Amort. } \\
(\%)\end{array}$ \\
\hline \multirow{7}{*}{$0-4$} & $A_{100}$ & 35,29 & 1,07 & 91,88 & 0,92 & 93,72 & 0,78 & & & 175,82 & 0,61 & & \\
\hline & $\mathrm{A}_{101}$ & 35,29 & 1,06 & 91,70 & 0,47 & 93,33 & 0,97 & & & 175,88 & 0,59 & & \\
\hline & $\mathrm{A}_{103}$ & 35,25 & 1,02 & 92,57 & 0,84 & 93,36 & 1,14 & & & 175,86 & 0,63 & & \\
\hline & $A_{105}$ & 35,29 & 1,03 & & & 93,64 & 0,81 & & & 175,81 & 0,64 & & \\
\hline & $A_{107}$ & 35,29 & 1,08 & 92,65 & 0,32 & 93,45 & 0,86 & & & 175,81 & 0,64 & & \\
\hline & $A_{109}$ & 35,31 & 1,08 & 90,85 & 1,17 & 93,46 & 0,99 & & & 175,23 & 0,68 & & \\
\hline & $\mathrm{A}_{1011}$ & 35,29 & 1,09 & 91,96 & 1,42 & 93,71 & 0,71 & & & 175,84 & 0,62 & & \\
\hline \multirow{7}{*}{$1-5$} & $A_{100}$ & 35,42 & 1,12 & & & 93,44 & 0,78 & & & 176,43 & 0,57 & 180,51 & 0,67 \\
\hline & $A_{101}$ & 35,44 & 1,19 & & & 93,41 & 0,84 & & & 176,49 & 0,58 & & \\
\hline & $\mathrm{A}_{103}$ & 35,46 & 1,17 & & & 93,40 & 0,91 & & & 176,51 & 0,58 & 180,40 & 0,62 \\
\hline & $A_{105}$ & 35,47 & 1,24 & & & 93,46 & 0,88 & & & 176,45 & 0,58 & 180,48 & 0,58 \\
\hline & $A_{107}$ & 35,45 & 1,20 & & & 93,46 & 0,81 & & & 176,44 & 0,57 & 180,48 & 0,64 \\
\hline & $A_{109}$ & 35,44 & 1,18 & & & 93,39 & 0,93 & & & & & & \\
\hline & $A_{1011}$ & 35,44 & 1,11 & & & 93,38 & 0,85 & & & 176,43 & 0,55 & 180,40 & 0,63 \\
\hline \multirow{7}{*}{$2-6$} & $A_{100}$ & 35,94 & 1,07 & & & & & 96,25 & 0,73 & 176,48 & 1,03 & 180,01 & 0,67 \\
\hline & $\mathrm{A}_{101}$ & 35,93 & 1,10 & & & & & 96,25 & 0,73 & & & 180,07 & 0,58 \\
\hline & $\mathrm{A}_{103}$ & 35,93 & 1,14 & & & & & 96,23 & 0,77 & 175,95 & 0,02 & 180,07 & 0,62 \\
\hline & $A_{105}$ & 35,92 & 1,09 & & & & & 96,47 & 0,85 & & & 180,24 & 0,62 \\
\hline & $A_{107}$ & 35,93 & 1,08 & & & & & 96,07 & 1,18 & & & 180,03 & 0,64 \\
\hline & $A_{109}$ & 35,93 & 1,12 & & & & & 96,17 & 0,79 & & & 179,93 & 0,68 \\
\hline & $\mathrm{A}_{1011}$ & 35,92 & 1,11 & & & & & 96,21 & 0,83 & & & 179,91 & 0,64 \\
\hline \multirow{7}{*}{ 3-7 } & $\mathrm{A}_{100}$ & 35,82 & 1,21 & & & & & 96,18 & 0,80 & 176,13 & 0,65 & 179,98 & 0,60 \\
\hline & $\mathrm{A}_{101}$ & 35,75 & 1,25 & 91,39 & 0,74 & & & 96,20 & 0,76 & 176,12 & 0,58 & 180,03 & 0,64 \\
\hline & $\mathrm{A}_{103}$ & 35,85 & 1,12 & & & & & 96,19 & 0,85 & 176,16 & 0,63 & 179,99 & 0,61 \\
\hline & $\mathrm{A}_{105}$ & 35,79 & 1,24 & & & & & 96,14 & 0,66 & 176,20 & 0,64 & 179,96 & 0,60 \\
\hline & $\mathrm{A}_{107}$ & 35,78 & 1,24 & 91,20 & 0,20 & & & 96,21 & 0,81 & 176,13 & 0,63 & 180,01 & 0,62 \\
\hline & $\mathrm{A}_{109}$ & 35,83 & 1,23 & & & & & 96,31 & 0,79 & & & & \\
\hline & $\mathrm{A}_{1011}$ & 35,80 & 1,24 & 90,93 & 0,34 & & & 96,20 & 0,81 & 176,09 & 0,63 & 179,97 & 0,61 \\
\hline & $A_{100}$ & 35,36 & 1,22 & & & 93,87 & 0,87 & & & 175,92 & 0,60 & & \\
\hline & $A_{101}$ & 35,35 & 1,13 & & & 94,08 & 0,93 & & & 175,93 & 0,58 & & \\
\hline & $\mathrm{A}_{103}$ & 35,34 & 1,15 & & & 93,94 & 0,59 & & & 175,94 & 0,59 & & \\
\hline 4-0 & $A_{105}$ & 35,34 & 1,13 & & & 94,13 & 0,80 & & & 175,94 & 0,59 & 180,07 & 0,04 \\
\hline & $A_{107}$ & 35,33 & 1,11 & & & 93,98 & 0,79 & & & 175,94 & 0,58 & 180,55 & 0,55 \\
\hline & $A_{109}$ & 35,34 & 1,13 & & & 93,50 & 0,88 & & & 175,88 & 0,72 & & \\
\hline & $\mathrm{A}_{1011}$ & 35,34 & 1,12 & 91,02 & 1,50 & 94,07 & 0,97 & & & 175,90 & 0,58 & & \\
\hline & $\mathrm{A}_{100}$ & 35,34 & 1,20 & 91,73 & 1,31 & 94,05 & 0,76 & & & 176,09 & 0,63 & 179,88 & 0,66 \\
\hline & $\mathrm{A}_{101}$ & 35,38 & 1,23 & & & 94,16 & 0,64 & & & 176,14 & 0,62 & 179,82 & 0,75 \\
\hline & $\mathrm{A}_{103}$ & 35,33 & 1,18 & & & 94,47 & 0,87 & & & 176,09 & 0,65 & 180,00 & 0,57 \\
\hline $5-1$ & $A_{105}$ & 35,37 & 1,22 & 92,83 & 1,32 & & & & & 176,08 & 0,63 & 179,97 & 0,63 \\
\hline & $A_{107}$ & 35,39 & 1,28 & 91,94 & 0,37 & 93,95 & 0,87 & & & 176,09 & 0,64 & 179,96 & 0,61 \\
\hline & $A_{109}$ & 35,38 & 1,22 & & & 94,37 & 0,55 & & & & & 180,17 & 0,48 \\
\hline & $\mathrm{A}_{1011}$ & 35,37 & 1,19 & & & 94,19 & 0,70 & & & 176,09 & 0,64 & 179,88 & 0,61 \\
\hline & $A_{100}$ & 35,89 & 1,15 & & & & & 96,31 & 0,76 & & & 179,83 & 0,59 \\
\hline & $A_{101}$ & 35,92 & 1,05 & & & & & 96,34 & 0,84 & & & 179,96 & 0,60 \\
\hline & $\mathrm{A}_{103}$ & 35,96 & 1,02 & & & & & 96,10 & 1,08 & & & 179,89 & 0,59 \\
\hline $6-2$ & $A_{105}$ & 35,93 & 0,97 & & & & & & & & & 179,89 & 0,59 \\
\hline & $\mathrm{A}_{107}$ & 35,90 & 1,10 & & & & & 96,27 & 0,94 & & & 179,89 & 0,59 \\
\hline & $A_{109}$ & 35,91 & 1,14 & & & & & 96,10 & 0,85 & & & 179,45 & 1,08 \\
\hline & $\mathrm{A}_{1011}$ & 35,97 & 1,11 & & & & & 96,28 & 0,72 & & & 179,83 & 0,59 \\
\hline & $A_{100}$ & 35,86 & 1,12 & & & & & 96,27 & 1,29 & 176,53 & 0,30 & 180,08 & 0,79 \\
\hline & $A_{101}$ & 35,81 & 1,22 & & & & & 96,39 & 1,10 & 176,65 & 0,49 & 180,01 & 0,64 \\
\hline & $\mathrm{A}_{103}$ & 35,84 & 1,73 & & & & & 96,26 & 1,15 & 176,49 & 0,59 & 180,12 & 0,62 \\
\hline $7-3$ & $A_{105}$ & 35,78 & 1,24 & & & & & 96,43 & 1,20 & 176,51 & 0,65 & 180,05 & 0,57 \\
\hline & $A_{107}$ & 35,85 & 1,05 & & & & & 96,43 & 0,93 & 176,52 & 0,61 & 180,06 & 0,61 \\
\hline & $A_{109}$ & 35,82 & 1,23 & & & & & 96,53 & 1,17 & & & & \\
\hline & $A_{1011}$ & 35,84 & 1,11 & & & & & 96,38 & 1,06 & 176,39 & 0,61 & 180,11 & 0,61 \\
\hline & & 35,62 & 1,15 & 91,74 & 0,84 & 93,75 & 0,83 & 96,27 & 0,91 & 176,13 & 0,60 & 180,05 & 0,62 \\
\hline Desvi & adrão & 0,265 & 0,106 & 0,657 & 0,468 & 0,351 & 0,126 & 0,117 & 0,178 & 0,294 & 0,131 & 0,219 & 0,128 \\
\hline Coef. & riação & $0,7 \%$ & $9,2 \%$ & $0,7 \%$ & $55,8 \%$ & $0,4 \%$ & $15,1 \%$ & $0,1 \%$ & $19,6 \%$ & $0,2 \%$ & $21,9 \%$ & $0,1 \%$ & $20,8 \%$ \\
\hline
\end{tabular}


Tabela E.4 - Parâmetros modais da Tora 2 para o ensaio com excitação vertical.

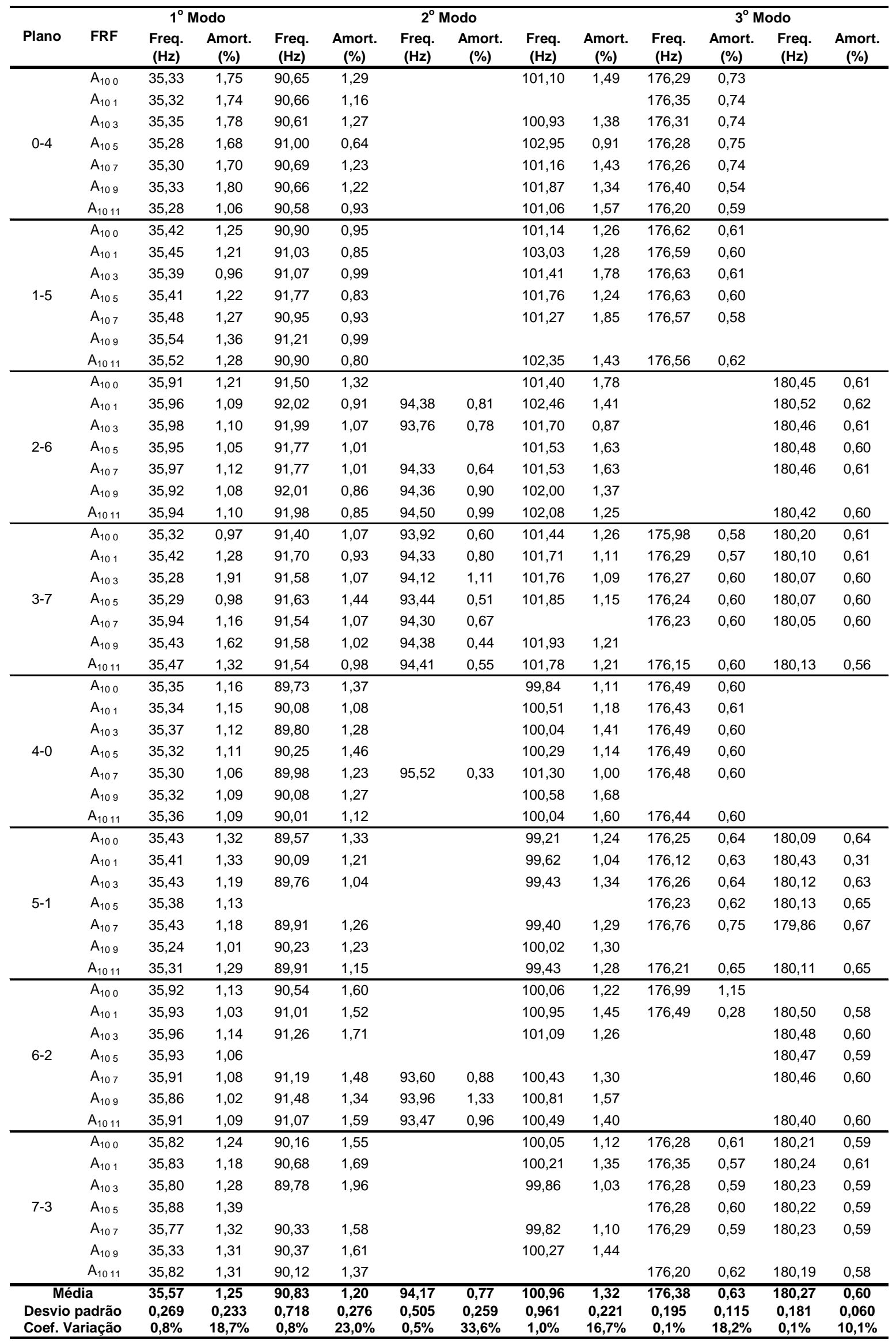


Tabela E.5 - Parâmetros modais da Tora 3 para o ensaio com excitação horizontal.

\begin{tabular}{|c|c|c|c|c|c|c|c|c|c|c|c|c|c|}
\hline \multirow[b]{2}{*}{ Plano } & \multirow[b]{2}{*}{ FRF } & \multicolumn{4}{|c|}{$1^{\circ}$ Modo } & \multicolumn{4}{|c|}{$2^{\circ}$ Modo } & \multicolumn{4}{|c|}{$3^{\circ}$ Modo } \\
\hline & & $\begin{array}{c}\text { Freq. } \\
(\mathrm{Hz})\end{array}$ & $\begin{array}{c}\text { Amort. } \\
(\%)\end{array}$ & $\begin{array}{l}\text { Freq. } \\
(\mathrm{Hz})\end{array}$ & $\begin{array}{c}\text { Amort. } \\
(\%)\end{array}$ & $\begin{array}{l}\text { Freq. } \\
(\mathrm{Hz})\end{array}$ & $\begin{array}{c}\text { Amort. } \\
(\%)\end{array}$ & $\begin{array}{l}\text { Freq. } \\
(\mathrm{Hz})\end{array}$ & $\begin{array}{c}\text { Amort. } \\
(\%)\end{array}$ & $\begin{array}{l}\text { Freq. } \\
(\mathrm{Hz})\end{array}$ & $\begin{array}{c}\text { Amort. } \\
(\%)\end{array}$ & $\begin{array}{l}\text { Freq. } \\
(\mathrm{Hz})\end{array}$ & $\begin{array}{c}\text { Amort. } \\
(\%)\end{array}$ \\
\hline \multirow{7}{*}{$0-4$} & $A_{100}$ & 33,46 & 1,26 & 34,69 & 0,42 & 88,59 & 0,73 & 91,44 & 0,77 & 168,23 & 0,72 & 173,79 & 0,58 \\
\hline & $\mathrm{A}_{101}$ & 33,35 & 1,02 & 34,61 & 1,00 & 88,81 & 0,70 & 91,44 & 0,79 & 168,21 & 0,66 & 173,90 & 0,59 \\
\hline & $\mathrm{A}_{103}$ & 33,34 & 1,05 & & & 88,65 & 0,73 & 91,50 & 0,73 & 168,18 & 0,68 & 173,90 & 0,60 \\
\hline & $A_{105}$ & 33,39 & 1,13 & 34,67 & 0,63 & & & & & 168,21 & 0,70 & 173,87 & 0,62 \\
\hline & $\mathrm{A}_{107}$ & 33,34 & 0,99 & 34,61 & 1,06 & 88,66 & 0,76 & 91,47 & 0,70 & 168,22 & 0,68 & 173,90 & 0,60 \\
\hline & $\mathrm{A}_{109}$ & 33,23 & 1,33 & & & 88,68 & 0,84 & 91,55 & 0,74 & 168,27 & 0,60 & 173,88 & 0,62 \\
\hline & $\mathrm{A}_{1011}$ & 33,34 & 0,91 & 34,58 & 1,05 & 88,71 & 0,79 & 91,46 & 0,67 & 168,20 & 0,67 & 173,85 & 0,59 \\
\hline \multirow{7}{*}{$1-5$} & $A_{100}$ & 33,41 & 1,04 & & & 88,32 & 1,43 & & & 168,43 & 0,58 & & \\
\hline & $\mathrm{A}_{101}$ & 33,40 & 1,03 & & & 89,58 & 0,59 & & & 168,43 & 0,57 & & \\
\hline & $\mathrm{A}_{103}$ & 33,40 & 1,01 & & & 89,57 & 0,67 & & & 168,43 & 0,58 & & \\
\hline & $\mathrm{A}_{105}$ & 33,40 & 1,02 & & & 89,70 & 0,79 & & & 168,44 & 0,58 & & \\
\hline & $A_{107}$ & 33,40 & 1,05 & & & 89,54 & 0,69 & & & 168,44 & 0,58 & & \\
\hline & $A_{109}$ & 33,40 & 1,05 & & & 89,56 & 0,67 & & & 168,45 & 0,60 & & \\
\hline & $\mathrm{A}_{1011}$ & 33,39 & 1,03 & & & 89,54 & 0,67 & & & 168,41 & 0,58 & & \\
\hline \multirow{7}{*}{$2-6$} & $\mathrm{~A}_{100}$ & 33,37 & 1,33 & 34,75 & 0,84 & 88,19 & 1,71 & 91,80 & 0,71 & 168,61 & 0,64 & 174,32 & 0,57 \\
\hline & $\mathrm{A}_{101}$ & 33,59 & 1,05 & 34,64 & 0,87 & 88,21 & 1,08 & 91,86 & 0,74 & 168,35 & 0,67 & 174,58 & 0,54 \\
\hline & $\mathrm{A}_{103}$ & 33,38 & 0,93 & 34,71 & 1,07 & 87,84 & 1,02 & 91,83 & 0,72 & 168,59 & 0,67 & 174,37 & 0,52 \\
\hline & $\mathrm{A}_{105}$ & 33,45 & 1,51 & 34,61 & 0,60 & & & & & 168,38 & 0,66 & 174,40 & 0,39 \\
\hline & $\mathrm{A}_{107}$ & & & 34,46 & 1,67 & 87,72 & 0,84 & 91,84 & 0,73 & 168,59 & 0,66 & 174,28 & 0,53 \\
\hline & $\mathrm{A}_{109}$ & 33,32 & 0,84 & 34,71 & 1,12 & & & 91,88 & 0,73 & & & & \\
\hline & $\mathrm{A}_{1011}$ & & & 34,25 & 1,91 & 88,14 & 0,57 & 91,78 & 0,73 & 168,53 & 0,63 & 174,19 & 0,42 \\
\hline \multirow{7}{*}{$3-7$} & $A_{100}$ & & & 34,69 & 1,03 & & & 92,41 & 0,64 & & & 174,13 & 0,56 \\
\hline & $\mathrm{A}_{101}$ & & & 34,68 & 0,99 & & & 92,42 & 0,63 & & & 174,19 & 0,57 \\
\hline & $\mathrm{A}_{103}$ & & & 34,73 & 1,12 & & & 92,41 & 0,64 & & & 174,16 & 0,57 \\
\hline & $\mathrm{A}_{105}$ & & & 34,68 & 1,01 & & & 92,44 & 0,58 & & & 174,12 & 0,57 \\
\hline & $\mathrm{A}_{107}$ & & & 34,68 & 1,01 & & & 92,41 & 0,64 & & & 174,15 & 0,57 \\
\hline & $\mathrm{A}_{109}$ & & & 34,68 & 1,31 & & & 92,45 & 0,63 & & & 174,11 & 0,57 \\
\hline & $\mathrm{A}_{1011}$ & & & 34,66 & 1,03 & & & 92,40 & 0,64 & & & 174,09 & 0,56 \\
\hline \multirow{7}{*}{$4-0$} & $A_{100}$ & & & 34,06 & 1,48 & 88,93 & 0,62 & 91,23 & 0,76 & 168,54 & 0,57 & 174,39 & 0,55 \\
\hline & $\mathrm{A}_{101}$ & 33,31 & 1,64 & 35,34 & 1,74 & 88,66 & 0,78 & 91,52 & 0,97 & 168,57 & 0,56 & 174,44 & 0,55 \\
\hline & $\mathrm{A}_{103}$ & 33,38 & 1,63 & & & 88,72 & 0,63 & 91,34 & 0,85 & 168,56 & 0,56 & 174,44 & 0,56 \\
\hline & $\mathrm{A}_{105}$ & 33,64 & 1,25 & 34,69 & 1,49 & & & & & 168,54 & 0,56 & 174,41 & 0,58 \\
\hline & $\mathrm{A}_{107}$ & 33,31 & 0,61 & & & 88,62 & 0,86 & 91,41 & 0,83 & 168,53 & 0,57 & 174,44 & 0,54 \\
\hline & $\mathrm{A}_{109}$ & 33,50 & 1,43 & & & 88,83 & 0,56 & 91,38 & 1,04 & & & & \\
\hline & $\mathrm{A}_{1011}$ & 33,39 & 1,48 & & & 89,04 & 1,22 & 91,42 & 0,61 & 168,49 & 0,56 & 174,41 & 0,55 \\
\hline \multirow{7}{*}{$5-1$} & $\mathrm{~A}_{100}$ & 33,40 & 1,05 & & & 89,57 & 0,64 & & & 168,38 & 0,55 & & \\
\hline & $\mathrm{A}_{101}$ & 33,42 & 1,05 & & & 89,60 & 0,65 & & & 168,41 & 0,54 & & \\
\hline & $\mathrm{A}_{103}$ & 33,40 & 1,04 & & & 89,58 & 0,65 & & & 168,41 & 0,56 & & \\
\hline & $\mathrm{A}_{105}$ & 33,55 & 1,32 & & & 89,54 & 0,15 & & & 164,34 & 0,58 & & \\
\hline & $\mathrm{A}_{107}$ & 33,41 & 1,07 & & & 89,61 & 0,58 & & & 168,40 & 0,55 & & \\
\hline & $A_{109}$ & 33,41 & 1,05 & & & 89,61 & 0,64 & & & & & & \\
\hline & $\mathrm{A}_{1011}$ & 33,40 & 1,02 & & & 89,56 & 0,65 & & & 168,35 & 0,56 & & \\
\hline \multirow{7}{*}{$6-2$} & $A_{100}$ & & & 34,19 & 1,66 & 88,33 & 0,87 & 91,94 & 0,64 & 168,71 & 0,56 & & \\
\hline & $\mathrm{A}_{101}$ & 33,44 & 0,96 & 34,92 & 0,95 & 88,54 & 0,66 & 91,95 & 0,68 & 168,83 & 0,54 & 174,39 & 0,57 \\
\hline & $\mathrm{A}_{103}$ & 33,43 & 0,90 & 34,74 & 0,75 & 88,36 & 0,67 & 91,96 & 0,67 & 168,78 & 0,56 & 174,37 & 0,56 \\
\hline & $\mathrm{A}_{105}$ & 33,42 & 1,31 & 34,85 & 1,00 & & & 91,94 & 0,70 & 168,78 & 0,57 & 174,05 & 0,92 \\
\hline & $A_{107}$ & 33,85 & 0,50 & 34,70 & 0,34 & 88,44 & 0,69 & 91,93 & 0,67 & 168,77 & 0,56 & 174,36 & 0,56 \\
\hline & $A_{109}$ & 33,55 & 1,16 & 34,69 & 0,47 & 88,53 & 0,82 & 91,96 & 0,64 & & & & \\
\hline & $\mathrm{A}_{1011}$ & & & 34,47 & 1,17 & 88,33 & 0,76 & 91,92 & 0,65 & 168,74 & 0,56 & 174,34 & 0,57 \\
\hline & $A_{100}$ & & & 34,68 & 0,98 & & & 92,43 & 0,64 & & & 174,11 & 0,58 \\
\hline & $\mathrm{A}_{101}$ & & & 34,68 & 1,03 & & & 92,45 & 0,64 & & & 174,18 & 0,54 \\
\hline & $\mathrm{A}_{103}$ & & & 34,67 & 1,01 & & & 92,43 & 0,64 & & & 174,15 & 0,58 \\
\hline $7-3$ & $\mathrm{~A}_{105}$ & & & 34,68 & 1,05 & & & 92,39 & 0,56 & & & 174,15 & 0,59 \\
\hline & $A_{107}$ & & & 34,67 & 0,99 & & & 92,44 & 0,67 & & & 174,13 & 0,57 \\
\hline & $A_{109}$ & & & 34,70 & 1,04 & & & 92,47 & 0,65 & & & 174,16 & 0,54 \\
\hline & $A_{1011}$ & & & 34,67 & 1,04 & & & 92,42 & 0,64 & & & 174,06 & 0,58 \\
\hline & & 33,42 & 1,11 & 34,65 & 1,05 & 88,88 & 0,77 & 91,94 & 0,70 & 168,36 & 0,60 & 174,19 & 0,57 \\
\hline Desvic & padrão & 0,107 & 0,241 & 0,203 & 0,349 & 0,586 & 0,260 & 0,417 & 0,095 & 0,693 & 0,052 & 0,202 & 0,073 \\
\hline Coef. & riação & $0,3 \%$ & $21,7 \%$ & $0,6 \%$ & $33,2 \%$ & $0,7 \%$ & $33,9 \%$ & $0,5 \%$ & $13,6 \%$ & $0,4 \%$ & $8,7 \%$ & $0,1 \%$ & $12,8 \%$ \\
\hline
\end{tabular}


Tabela E.6 - Parâmetros modais da Tora 3 para o ensaio com excitação vertical.

\begin{tabular}{|c|c|c|c|c|c|c|c|c|c|c|c|c|c|c|c|}
\hline \multirow[b]{2}{*}{ Plano } & \multirow[b]{2}{*}{ FRF } & \multicolumn{4}{|c|}{$1^{\circ}$ Modo } & \multicolumn{6}{|c|}{$2^{\circ}$ Modo } & \multicolumn{4}{|c|}{$3^{\circ}$ Modo } \\
\hline & & $\begin{array}{c}\text { Freq. } \\
(\mathrm{Hz})\end{array}$ & $\begin{array}{c}\text { Amort. } \\
(\%)\end{array}$ & $\begin{array}{c}\text { Freq. } \\
(\mathrm{Hz})\end{array}$ & $\begin{array}{c}\text { Amort. } \\
(\%)\end{array}$ & $\begin{array}{c}\text { Freq. } \\
(\mathrm{Hz})\end{array}$ & $\begin{array}{c}\text { Amort. } \\
(\%)\end{array}$ & $\begin{array}{l}\text { Freq. } \\
(\mathrm{Hz})\end{array}$ & $\begin{array}{c}\text { Amort. } \\
(\%)\end{array}$ & $\begin{array}{c}\text { Freq. } \\
(\mathrm{Hz})\end{array}$ & $\begin{array}{c}\text { Amort. } \\
(\%)\end{array}$ & $\begin{array}{c}\text { Freq. } \\
(\mathrm{Hz})\end{array}$ & $\begin{array}{c}\text { Amort. } \\
(\%)\end{array}$ & $\begin{array}{l}\text { Freq. } \\
(\mathrm{Hz})\end{array}$ & $\begin{array}{c}\text { Amort. } \\
(\%)\end{array}$ \\
\hline \multirow{7}{*}{$0-4$} & $A_{100}$ & 33,34 & 0,98 & 34,65 & 1,07 & 85,64 & 1,07 & & & & & 168,14 & 0,68 & 173,93 & 0,76 \\
\hline & $A_{101}$ & 33,33 & 0,97 & 34,58 & 1,06 & 86,13 & 1,51 & 91,98 & 0,56 & & & 168,33 & 0,60 & 173,55 & 0,79 \\
\hline & $\mathrm{A}_{103}$ & 33,34 & 1,01 & 34,65 & 1,11 & 86,13 & 1,51 & 91,98 & 0,56 & & & 168,33 & 0,60 & 173,55 & 0,79 \\
\hline & $A_{105}$ & 33,34 & 1,01 & 34,62 & 0,99 & 87,98 & 1,48 & 91,76 & 0,54 & & & 168,24 & 0,57 & 173,84 & 0,63 \\
\hline & $A_{107}$ & 33,34 & 1,04 & 34,64 & 0,96 & 87,32 & 1,76 & 91,29 & 0,43 & & & 168,36 & 0,61 & 173,80 & 0,61 \\
\hline & $A_{109}$ & 33,31 & 1,01 & 34,64 & 1,10 & 87,73 & 1,31 & & & & & & & & \\
\hline & $\mathrm{A}_{1011}$ & 33,34 & 1,03 & 34,61 & 0,96 & 87,30 & 1,73 & & & & & 168,31 & 0,68 & 174,29 & 0,61 \\
\hline \multirow{7}{*}{$1-5$} & $A_{100}$ & 33,40 & 1,08 & & & 87,83 & 1,12 & & & & & 168,90 & 0,60 & & \\
\hline & $A_{101}$ & 33,40 & 1,04 & & & 87,73 & 1,40 & & & & & 168,91 & 0,59 & & \\
\hline & $\mathrm{A}_{103}$ & 33,42 & 0,91 & & & 87,71 & 0,97 & & & & & 168,90 & 0,59 & & \\
\hline & $A_{105}$ & 33,39 & 1,04 & & & 87,86 & 1,28 & & & & & 168,89 & 0,58 & & \\
\hline & $A_{107}$ & 33,40 & 1,04 & & & 87,61 & 1,26 & & & & & 168,90 & 0,58 & & \\
\hline & $A_{109}$ & 33,40 & 1,02 & & & 88,05 & 1,65 & & & & & & & & \\
\hline & $\mathrm{A}_{1011}$ & 33,40 & 1,03 & & & 87,71 & 1,25 & & & & & 168,86 & 0,58 & & \\
\hline \multirow{7}{*}{$2-6$} & $A_{100}$ & 33,38 & 1,25 & 34,72 & 0,87 & 88,65 & 0,89 & 91,03 & 0,75 & & & 168,48 & 0,58 & 174,39 & 0,57 \\
\hline & $A_{101}$ & 33,31 & 1,99 & 34,78 & 0,94 & 88,76 & 0,86 & 91,56 & 0,83 & & & & & 174,54 & 0,56 \\
\hline & $A_{103}$ & 33,33 & 1,61 & 34,82 & 0,88 & 88,71 & 0,84 & 91,10 & 0,80 & & & 168,52 & 0,61 & 174,49 & 0,57 \\
\hline & $A_{105}$ & 33,37 & 1,08 & 34,72 & 1,03 & 88,67 & 0,89 & 91,95 & 0,65 & & & 168,58 & 0,64 & 174,45 & 0,60 \\
\hline & $\mathrm{A}_{107}$ & 33,36 & 0,64 & 34,71 & 1,18 & 88,69 & 0,81 & 91,14 & 1,02 & 99,88 & 1,47 & 168,52 & 0,59 & 174,47 & 0,59 \\
\hline & $A_{109}$ & 33,47 & 0,67 & 34,68 & 1,12 & 88,74 & 0,87 & 91,46 & 0,84 & & & & & & \\
\hline & $\mathrm{A}_{1011}$ & 33,10 & 1,61 & 34,89 & 1,27 & 88,68 & 0,83 & 91,19 & 1,20 & & & 168,56 & 0,96 & 174,38 & 0,59 \\
\hline \multirow{7}{*}{$3-7$} & $A_{100}$ & & & 34,69 & 0,96 & & & 90,04 & 1,34 & 100,53 & 1,67 & & & 174,63 & 0,56 \\
\hline & $A_{101}$ & & & 34,70 & 1,03 & & & 90,46 & 0,90 & & & & & 174,68 & 0,59 \\
\hline & $\mathrm{A}_{103}$ & & & 34,71 & 0,99 & & & 90,32 & 0,91 & 100,70 & 1,95 & & & 174,67 & 0,56 \\
\hline & $A_{105}$ & & & 34,67 & 1,05 & & & 90,55 & 0,79 & & & & & 174,64 & 0,56 \\
\hline & $A_{107}$ & & & 34,67 & 1,06 & & & 90,26 & 0,99 & 100,77 & 1,65 & 169,98 & 1,13 & 174,64 & 0,57 \\
\hline & $A_{109}$ & & & 34,68 & 1,02 & & & 90,38 & 1,03 & & & & & & \\
\hline & $\mathrm{A}_{1011}$ & & & 34,66 & 1,11 & & & 90,24 & 0,99 & 101,75 & 1,40 & & & 174,59 & 0,57 \\
\hline \multirow{7}{*}{$4-0$} & $A_{100}$ & 33,41 & 1,02 & 34,65 & 0,98 & 88,35 & 0,73 & & & 100,61 & 1,51 & 168,67 & 0,55 & 174,26 & 0,59 \\
\hline & $\mathrm{A}_{101}$ & 33,42 & 0,97 & 34,60 & 1,06 & 88,41 & 0,77 & 92,15 & 0,49 & & & 168,72 & 0,60 & 174,34 & 0,55 \\
\hline & $\mathrm{A}_{103}$ & 33,46 & 1,05 & 34,57 & 0,72 & 88,32 & 0,76 & 92,00 & 0,26 & & & & & & \\
\hline & $\mathrm{A}_{105}$ & 33,37 & 1,15 & 34,78 & 0,92 & 88,44 & 0,83 & 92,17 & 0,79 & 100,99 & 1,20 & 168,68 & 0,59 & 174,32 & 0,56 \\
\hline & $A_{107}$ & 33,35 & 0,70 & 34,55 & 1,21 & 88,35 & 0,74 & 91,83 & 0,68 & 101,35 & 1,40 & 168,70 & 0,57 & 174,35 & 0,58 \\
\hline & $A_{109}$ & 33,37 & 1,03 & 34,78 & 1,20 & 88,46 & 0,76 & 91,85 & 0,73 & & & & & & \\
\hline & $\mathrm{A}_{1011}$ & & & & & & & & & & & & & & \\
\hline \multirow{7}{*}{ 5-1 } & $A_{100}$ & 33,39 & 1,06 & & & 88,14 & 0,72 & & & & & 168,85 & 0,63 & & \\
\hline & $\mathrm{A}_{101}$ & 33,41 & 1,07 & & & 88,23 & 0,74 & & & & & 168,86 & 0,64 & & \\
\hline & $\mathrm{A}_{103}$ & 33,41 & 1,15 & & & 88,17 & 0,73 & & & & & 168,84 & 0,64 & & \\
\hline & $\mathrm{A}_{105}$ & 33,40 & 1,10 & & & 88,20 & 0,65 & & & & & 168,88 & 0,62 & & \\
\hline & $\mathrm{A}_{107}$ & 33,41 & 1,11 & & & 88,15 & 0,72 & & & & & 168,85 & 0,65 & & \\
\hline & $A_{109}$ & 33,41 & 1,06 & & & 88,33 & 0,85 & & & & & 168,77 & 0,67 & & \\
\hline & $\mathrm{A}_{1011}$ & 33,35 & 1,17 & & & 88,13 & 0,75 & & & & & 168,78 & 0,61 & & \\
\hline & $A_{100}$ & & & 34,78 & 0,99 & 88,86 & 0,71 & 91,65 & 0,64 & & & 168,39 & 0,62 & 174,22 & 0,59 \\
\hline & $\mathrm{A}_{101}$ & 33,39 & 1,13 & 34,70 & 1,00 & 88,92 & 0,70 & 91,67 & 0,70 & & & 168,44 & 0,56 & 174,31 & 0,59 \\
\hline & $\mathrm{A}_{103}$ & 33,25 & 1,12 & 34,75 & 1,01 & 88,89 & 0,73 & 91,62 & 0,65 & & & 168,46 & 0,60 & 174,25 & 0,59 \\
\hline $6-2$ & $\mathrm{~A}_{105}$ & 33,40 & 1,04 & 34,68 & 0,99 & 88,41 & 0,75 & 91,95 & 0,65 & & & 168,77 & 0,56 & 174,37 & 0,56 \\
\hline & $A_{107}$ & 33,40 & 0,64 & 34,66 & 1,16 & 88,90 & 0,71 & 91,63 & 0,67 & & & 168,50 & 0,59 & 174,26 & 0,60 \\
\hline & $\mathrm{A}_{109}$ & 33,40 & 0,94 & 34,68 & 1,01 & 88,91 & 0,70 & 91,74 & 0,67 & & & & & & \\
\hline & $\mathrm{A}_{1011}$ & 33,40 & 1,23 & 34,68 & 0,92 & 88,87 & 0,71 & 91,65 & 0,61 & & & 168,46 & 0,59 & 174,22 & 0,58 \\
\hline & $A_{100}$ & & & 34,62 & 1,27 & 88,94 & 1,58 & & & & & & & 174,61 & 0,57 \\
\hline & $\mathrm{A}_{101}$ & & & 34,68 & 1,01 & 89,54 & 1,44 & & & 98,80 & 1,23 & 167,91 & 0,82 & 174,67 & 0,58 \\
\hline & $\mathrm{A}_{103}$ & & & 34,72 & 1,01 & 88,68 & 1,21 & & & & & 168,10 & 0,65 & & \\
\hline $7-3$ & $A_{105}$ & & & 34,68 & 1,02 & 89,90 & 1,40 & & & & & & & 174,64 & 0,56 \\
\hline & $\mathrm{A}_{107}$ & & & 34,65 & 1,06 & 88,55 & 1,35 & & & 97,76 & 1,91 & 168,74 & 0,58 & 174,66 & 0,57 \\
\hline & $A_{109}$ & & & 34,69 & 0,99 & 89,38 & 1,34 & & & & & & & 174,70 & 0,55 \\
\hline & $A_{1011}$ & & & 34,67 & 1,02 & 89,00 & 1,62 & & & 97,40 & 1,50 & & & 174,60 & 0,57 \\
\hline & & 33,37 & 1,07 & 34,68 & 1,03 & 88,27 & 1,04 & 91,35 & 0,76 & 100,05 & 1,53 & 168,63 & 0,63 & 174,36 & 0,60 \\
\hline Desvic & adrão & 0,060 & 0,242 & 0,067 & 0,106 & 0,807 & 0,345 & 0,652 & 0,226 & 1,442 & 0,244 & 0,342 & 0,110 & 0,311 & 0,060 \\
\hline Coef. & riação & $0,2 \%$ & $22,6 \%$ & $0,2 \%$ & $10,3 \%$ & $0,9 \%$ & $33,1 \%$ & $0,7 \%$ & $29,9 \%$ & $1,4 \%$ & $15,9 \%$ & $0,2 \%$ & $17,4 \%$ & $0,2 \%$ & $10,1 \%$ \\
\hline
\end{tabular}


Tabela E.7 - Parâmetros modais da Tora 4 para o ensaio com excitação horizontal.

\begin{tabular}{|c|c|c|c|c|c|c|c|c|c|c|c|c|c|}
\hline \multirow[b]{2}{*}{ Plano } & \multirow[b]{2}{*}{ FRF } & \multicolumn{4}{|c|}{$1^{\circ}$ Modo } & \multicolumn{4}{|c|}{$2^{\circ}$ Modo } & \multicolumn{4}{|c|}{$3^{\circ}$ Modo } \\
\hline & & $\begin{array}{c}\text { Freq. } \\
(\mathrm{Hz})\end{array}$ & $\begin{array}{c}\text { Amort. } \\
(\%)\end{array}$ & $\begin{array}{l}\text { Freq. } \\
(\mathrm{Hz})\end{array}$ & $\begin{array}{c}\text { Amort. } \\
(\%)\end{array}$ & $\begin{array}{l}\text { Freq. } \\
(\mathrm{Hz})\end{array}$ & $\begin{array}{c}\text { Amort. } \\
(\%)\end{array}$ & $\begin{array}{l}\text { Freq. } \\
(\mathrm{Hz})\end{array}$ & $\begin{array}{c}\text { Amort. } \\
(\%)\end{array}$ & $\begin{array}{l}\text { Freq. } \\
(\mathrm{Hz})\end{array}$ & $\begin{array}{c}\text { Amort. } \\
(\%)\end{array}$ & $\begin{array}{c}\text { Freq. } \\
(\mathrm{Hz})\end{array}$ & $\begin{array}{c}\text { Amort. } \\
(\%)\end{array}$ \\
\hline \multirow{7}{*}{$0-4$} & $A_{100}$ & 31,88 & 0,74 & 32,73 & 1,33 & 86,47 & 0,45 & 87,06 & 0,40 & 163,42 & 0,58 & 167,34 & 0,69 \\
\hline & $\mathrm{A}_{101}$ & 31,99 & 1,04 & 32,81 & 0,66 & 86,13 & 0,68 & 87,22 & 0,70 & 163,45 & 0,58 & & \\
\hline & $\mathrm{A}_{103}$ & 31,97 & 0,93 & 32,76 & 0,81 & 86,19 & 0,70 & 87,15 & 0,58 & 163,45 & 0,59 & 167,31 & 0,63 \\
\hline & $A_{105}$ & 31,96 & 0,89 & 32,76 & 0,88 & & & 87,14 & 0,70 & 163,43 & 0,59 & 167,31 & 0,60 \\
\hline & $\mathrm{A}_{107}$ & 31,96 & 0,90 & 32,77 & 0,89 & 86,24 & 0,55 & 87,09 & 0,52 & 163,45 & 0,59 & 167,21 & 0,60 \\
\hline & $\mathrm{A}_{109}$ & 31,96 & 0,88 & 32,76 & 0,91 & 86,74 & 0,97 & & & 163,90 & 0,57 & & \\
\hline & $A_{1011}$ & 31,99 & 0,94 & 32,70 & 0,77 & 86,76 & 0,89 & & & 163,41 & 0,66 & & \\
\hline \multirow{7}{*}{$1-5$} & $\mathrm{~A}_{100}$ & & & 32,75 & 0,88 & & & 88,55 & 0,59 & & & 166,97 & 0,61 \\
\hline & $\mathrm{A}_{101}$ & & & 32,76 & 0,88 & & & 88,72 & 0,70 & & & 167,10 & 0,61 \\
\hline & $\mathrm{A}_{103}$ & & & 32,76 & 0,86 & & & 88,75 & 0,68 & & & 166,55 & 0,46 \\
\hline & $\mathrm{A}_{105}$ & & & 32,76 & 0,88 & & & 88,79 & 0,63 & & & 166,83 & 0,52 \\
\hline & $A_{107}$ & & & 32,77 & 0,89 & & & 88,66 & 0,62 & 164,37 & 0,31 & 166,91 & 0,74 \\
\hline & $\mathrm{A}_{109}$ & & & 32,77 & 0,91 & & & 88,71 & 0,77 & & & & \\
\hline & $A_{1011}$ & & & 32,71 & 0,70 & & & 88,72 & 0,57 & & & 167,25 & 0,80 \\
\hline \multirow{7}{*}{$2-6$} & $A_{100}$ & & & 32,82 & 1,50 & & & 89,11 & 0,61 & 164,91 & 0,67 & 168,13 & 0,55 \\
\hline & $A_{101}$ & & & 32,48 & 1,33 & & & 89,12 & 0,65 & 165,18 & 0,51 & 167,76 & 0,61 \\
\hline & $\mathrm{A}_{103}$ & & & 32,53 & 1,53 & & & 89,08 & 0,59 & 164,75 & 0,57 & 168,21 & 0,62 \\
\hline & $\mathrm{A}_{105}$ & 31,06 & 1,89 & 32,76 & 1,26 & & & & & 165,09 & 0,62 & 168,13 & 0,58 \\
\hline & $\mathrm{A}_{107}$ & & & 32,66 & 1,50 & & & 89,04 & 0,57 & 164,98 & 0,56 & 168,11 & 0,60 \\
\hline & $\mathrm{A}_{109}$ & & & 32,58 & 1,46 & & & 89,10 & 0,68 & & & 167,86 & 0,90 \\
\hline & $A_{1011}$ & & & 32,54 & 1,44 & & & 89,03 & 0,67 & 164,76 & 0,48 & 168,13 & 0,63 \\
\hline \multirow{7}{*}{$3-7$} & $\mathrm{~A}_{100}$ & & & 32,11 & 0,85 & 85,92 & 0,89 & 88,05 & 0,89 & 164,46 & 0,56 & & \\
\hline & $\mathrm{A}_{101}$ & & & 32,13 & 0,78 & 86,23 & 0,53 & 87,94 & 0,80 & 164,55 & 0,55 & & \\
\hline & $\mathrm{A}_{103}$ & & & 32,10 & 0,87 & 86,54 & 0,61 & 87,83 & 0,58 & 164,48 & 0,57 & & \\
\hline & $\mathrm{A}_{105}$ & & & 32,12 & 0,92 & 86,14 & 0,70 & & & 164,48 & 0,55 & 168,46 & 0,75 \\
\hline & $\mathrm{A}_{107}$ & & & 32,12 & 0,90 & 86,33 & 0,53 & 87,86 & 0,72 & 164,48 & 0,55 & & \\
\hline & $\mathrm{A}_{109}$ & & & 32,13 & 0,85 & & & 87,44 & 1,08 & & & & \\
\hline & $A_{1011}$ & & & 32,12 & 0,88 & & & 87,91 & 0,69 & 164,41 & 0,54 & 168,82 & 0,70 \\
\hline \multirow{7}{*}{$4-0$} & $\mathrm{~A}_{100}$ & & & 32,61 & 1,35 & 86,73 & 1,19 & 88,06 & 0,38 & 164,67 & 0,59 & 168,55 & 0,51 \\
\hline & $\mathrm{A}_{101}$ & & & 32,30 & 1,28 & & & 88,01 & 1,18 & 164,68 & 0,59 & 168,43 & 0,57 \\
\hline & $\mathrm{A}_{103}$ & & & 32,47 & 1,36 & 86,39 & 0,59 & 87,85 & 0,67 & 164,71 & 0,55 & 168,41 & 0,69 \\
\hline & $\mathrm{A}_{105}$ & & & 32,43 & 1,25 & & & 87,82 & 0,52 & 164,71 & 0,56 & 168,37 & 0,63 \\
\hline & $A_{107}$ & & & 32,50 & 1,40 & & & 87,72 & 0,60 & 164,71 & 0,57 & 168,41 & 0,61 \\
\hline & $\mathrm{A}_{109}$ & & & 32,42 & 1,53 & & & 87,48 & 1,04 & 164,77 & 0,54 & & \\
\hline & $A_{1011}$ & & & 32,45 & 1,44 & & & 87,62 & 1,24 & 164,65 & 0,57 & 168,46 & 0,52 \\
\hline \multirow{7}{*}{$5-1$} & $A_{100}$ & & & 32,88 & 0,86 & & & 88,79 & 0,70 & 164,57 & 0,32 & 167,92 & 0,64 \\
\hline & $\mathrm{A}_{101}$ & & & 32,87 & 0,88 & & & 88,78 & 0,65 & & & 168,05 & 0,70 \\
\hline & $\mathrm{A}_{103}$ & & & 32,87 & 0,92 & & & 88,85 & 0,54 & & & 167,97 & 0,60 \\
\hline & $\mathrm{A}_{105}$ & & & 32,87 & 0,89 & & & 88,93 & 0,53 & & & 167,91 & 0,57 \\
\hline & $\mathrm{A}_{107}$ & & & 32,89 & 0,87 & & & 88,77 & 0,62 & & & 167,76 & 0,64 \\
\hline & $A_{109}$ & & & 32,89 & 0,88 & & & 88,79 & 0,64 & & & & \\
\hline & $A_{1011}$ & & & 32,89 & 0,82 & & & 88,84 & 0,79 & & & 167,86 & 0,67 \\
\hline \multirow{7}{*}{$6-2$} & $\mathrm{~A}_{100}$ & & & 32,58 & 1,46 & & & 88,92 & 0,61 & 164,88 & 0,49 & 167,99 & 0,64 \\
\hline & $\mathrm{A}_{101}$ & & & 32,72 & 1,00 & & & 88,95 & 0,64 & 164,76 & 0,544 & 168,045 & 0,623 \\
\hline & $\mathrm{A}_{103}$ & & & 32,49 & 1,42 & & & 89,23 & 1,33 & & & 167,91 & 0,62 \\
\hline & $\mathrm{A}_{105}$ & & & 32,57 & 1,57 & & & 88,51 & 1,05 & 164,68 & 0,56 & 168,15 & 0,62 \\
\hline & $A_{107}$ & & & 32,63 & 1,36 & & & 88,90 & 0,63 & 164,94 & 0,58 & 167,98 & 0,59 \\
\hline & $A_{109}$ & & & 32,59 & 1,34 & & & 88,97 & 0,67 & & & & \\
\hline & $A_{1011}$ & & & 32,69 & 1,09 & & & 88,89 & 0,63 & 164,92 & 0,54 & 167,96 & 0,58 \\
\hline & $A_{100}$ & & & 32,09 & 0,94 & & & 87,14 & 1,17 & 163,97 & 0,62 & & \\
\hline & $\mathrm{A}_{101}$ & & & 32,09 & 0,94 & 85,68 & 0,82 & 87,58 & 0,83 & 163,99 & 0,62 & & \\
\hline & $\mathrm{A}_{103}$ & & & 32,10 & 0,90 & 86,24 & 0,51 & 87,64 & 0,68 & 163,96 & 0,62 & & \\
\hline $7-3$ & $\mathrm{~A}_{105}$ & & & 32,09 & 0,91 & 86,33 & 0,57 & & & 164,00 & 0,62 & 167,76 & 0,64 \\
\hline & $A_{107}$ & & & 32,10 & 0,92 & 85,94 & 1,05 & 87,80 & 0,76 & 163,99 & 0,64 & & \\
\hline & $\mathrm{A}_{109}$ & & & 32,09 & 0,90 & & & 87,47 & 0,83 & & & & \\
\hline & $A_{1011}$ & & & 32,11 & 0,74 & & & 87,98 & 0,71 & 163,96 & 0,64 & & \\
\hline & & 31,84 & 1,03 & 32,54 & 1,06 & 86,29 & 0,72 & 88,28 & 0,72 & 164,38 & 0,56 & 167,85 & 0,63 \\
\hline $\begin{array}{l}\text { Desvi } \\
\text { Coef. }\end{array}$ & $\begin{array}{l}\text { adrão } \\
\text { riação }\end{array}$ & $\begin{array}{l}0,321 \\
1,0 \%\end{array}$ & $\begin{array}{c}0,360 \\
35,1 \%\end{array}$ & $\begin{array}{c}0,283 \\
0,9 \%\end{array}$ & $\begin{array}{l}0,270 \\
25,4 \%\end{array}$ & $\begin{array}{c}0,297 \\
0,3 \%\end{array}$ & $\begin{array}{c}0,214 \\
29,7 \%\end{array}$ & $\begin{array}{c}0,682 \\
0,8 \%\end{array}$ & $\begin{array}{c}0,204 \\
28,5 \%\end{array}$ & $\begin{array}{c}0,527 \\
0,3 \%\end{array}$ & $\begin{array}{c}0,072 \\
12,8 \%\end{array}$ & $\begin{array}{c}0,538 \\
0,3 \%\end{array}$ & $\begin{array}{c}0,081 \\
12,9 \%\end{array}$ \\
\hline
\end{tabular}


Tabela E.8 - Parâmetros modais da Tora 4 para o ensaio com excitação vertical.

\begin{tabular}{|c|c|c|c|c|c|c|c|c|c|c|c|c|c|}
\hline \multirow[b]{2}{*}{ Plano } & \multirow[b]{2}{*}{ FRF } & \multicolumn{4}{|c|}{$1^{\circ}$ Modo } & \multicolumn{4}{|c|}{$2^{\circ}$ Modo } & \multicolumn{4}{|c|}{$3^{\circ}$ Modo } \\
\hline & & $\begin{array}{l}\text { Freq. } \\
(\mathrm{Hz})\end{array}$ & $\begin{array}{c}\text { Amort. } \\
(\%)\end{array}$ & $\begin{array}{l}\text { Freq. } \\
(\mathrm{Hz})\end{array}$ & $\begin{array}{c}\text { Amort. } \\
(\%)\end{array}$ & $\begin{array}{l}\text { Freq. } \\
(\mathrm{Hz})\end{array}$ & $\begin{array}{c}\text { Amort. } \\
(\%)\end{array}$ & $\begin{array}{l}\text { Freq. } \\
(\mathrm{Hz})\end{array}$ & $\begin{array}{c}\text { Amort. } \\
(\%)\end{array}$ & $\begin{array}{l}\text { Freq. } \\
(\mathrm{Hz})\end{array}$ & $\begin{array}{c}\text { Amort. } \\
(\%)\end{array}$ & $\begin{array}{l}\text { Freq. } \\
(\mathrm{Hz})\end{array}$ & $\begin{array}{c}\text { Amort. } \\
(\%)\end{array}$ \\
\hline \multirow{7}{*}{$0-4$} & $\mathrm{~A}_{100}$ & 31,96 & 0,82 & 32,74 & 0,96 & 84,83 & 0,73 & & & 164,16 & 0,61 & 167,04 & 0,56 \\
\hline & $\mathrm{A}_{101}$ & 32,04 & 1,08 & 32,75 & 0,52 & 85,02 & 0,72 & & & 164,13 & 0,63 & 167,02 & 0,60 \\
\hline & $\mathrm{A}_{103}$ & 31,95 & 0,93 & 32,78 & 0,93 & 84,94 & 0,71 & 102,31 & 0,88 & 164,03 & 0,66 & 167,28 & 0,52 \\
\hline & $\mathrm{A}_{105}$ & 31,96 & 0,94 & 32,75 & 0,88 & 85,13 & 0,62 & 103,78 & 0,68 & 164,13 & 0,65 & 166,90 & 0,56 \\
\hline & $\mathrm{A}_{107}$ & 31,95 & 0,87 & 32,76 & 0,98 & 84,96 & 0,71 & 103,15 & 0,69 & 163,93 & 0,65 & 167,44 & 0,57 \\
\hline & $\mathrm{A}_{109}$ & 31,87 & 1,09 & 32,83 & 1,42 & 85,34 & 0,80 & & & & & & \\
\hline & $A_{1011}$ & 31,95 & 0,82 & 32,71 & 1,02 & 84,91 & 0,67 & 103,03 & 0,96 & 164,00 & 0,63 & 167,14 & 0,55 \\
\hline \multirow{7}{*}{$1-5$} & $\mathrm{~A}_{100}$ & 32,77 & 0,94 & & & 85,93 & 0,79 & 100,87 & 1,35 & 164,60 & 0,48 & 167,53 & 0,62 \\
\hline & $\mathrm{A}_{101}$ & 32,77 & 0,90 & & & 85,97 & 0,73 & 100,09 & 1,63 & & & 167,66 & 0,61 \\
\hline & $\mathrm{A}_{103}$ & 32,77 & 0,93 & & & 85,98 & 0,74 & 101,11 & 0,87 & & & 167,60 & 0,59 \\
\hline & $A_{105}$ & 32,77 & 0,92 & & & 86,25 & 0,67 & 101,29 & 0,93 & & & 167,65 & 0,58 \\
\hline & $A_{107}$ & 32,77 & 0,93 & & & 85,94 & 0,68 & 100,93 & 1,15 & 164,03 & 0,56 & 167,60 & 0,62 \\
\hline & $A_{109}$ & 32,77 & 0,93 & & & 85,82 & 0,88 & & & & & & \\
\hline & $A_{1011}$ & 32,75 & 0,87 & & & 85,95 & 0,85 & 101,27 & 0,92 & 163,41 & 0,62 & 167,59 & 0,59 \\
\hline \multirow{7}{*}{$2-6$} & $A_{100}$ & 32,06 & 0,81 & 32,91 & 1,10 & 86,32 & 0,80 & 101,72 & 1,15 & 164,61 & 0,55 & 168,41 & 0,60 \\
\hline & $A_{101}$ & 32,05 & 0,85 & 32,93 & 1,05 & 86,32 & 0,85 & 100,99 & 1,26 & 164,73 & 0,43 & 168,45 & 0,63 \\
\hline & $\mathrm{A}_{103}$ & 32,08 & 0,51 & 32,89 & 1,18 & 86,43 & 0,69 & 101,43 & 1,30 & 164,71 & 0,78 & 168,47 & 0,52 \\
\hline & $\mathrm{A}_{105}$ & 32,07 & 1,01 & 32,95 & 0,94 & 86,76 & 0,34 & 101,78 & 1,08 & 164,70 & 0,60 & 168,43 & 0,58 \\
\hline & $A_{107}$ & 32,22 & 0,48 & 32,82 & 1,00 & 86,63 & 1,39 & 101,84 & 1,01 & 164,73 & 0,62 & 168,43 & 0,58 \\
\hline & $\mathrm{A}_{109}$ & 32,06 & 0,92 & 32,94 & 1,05 & 86,48 & 0,74 & 102,04 & 1,00 & & & & \\
\hline & $A_{1011}$ & 31,98 & 0,74 & 32,93 & 1,22 & 86,26 & 0,81 & 101,98 & 1,10 & 164,46 & 0,59 & 168,43 & 0,58 \\
\hline \multirow{7}{*}{$3-7$} & $A_{100}$ & 32,11 & 0,92 & & & 85,21 & 0,83 & & & 165,19 & 0,58 & & \\
\hline & $\mathrm{A}_{101}$ & 32,14 & 0,95 & & & 85,41 & 0,97 & & & 165,25 & 0,58 & & \\
\hline & $\mathrm{A}_{103}$ & 32,12 & 0,90 & & & 85,18 & 0,81 & & & 165,19 & 0,56 & & \\
\hline & $\mathrm{A}_{105}$ & 32,11 & 0,94 & & & 85,21 & 0,72 & & & 165,17 & 0,56 & & \\
\hline & $\mathrm{A}_{107}$ & 32,12 & 0,95 & & & 85,27 & 0,94 & 100,75 & 1,03 & 164,91 & 0,56 & & \\
\hline & $\mathrm{A}_{109}$ & 32,12 & 0,95 & & & 85,27 & 0,94 & 100,75 & 1,03 & 164,91 & 0,56 & & \\
\hline & $A_{1011}$ & 32,11 & 0,90 & & & 85,19 & 0,98 & 101,21 & 1,74 & 165,16 & 0,57 & & \\
\hline \multirow{7}{*}{$4-0$} & $\mathrm{~A}_{100}$ & 32,13 & 1,10 & & & 85,17 & 1,12 & & & 164,90 & 0,61 & 168,24 & 0,58 \\
\hline & $A_{101}$ & 32,17 & 1,06 & 32,94 & 0,69 & 85,38 & 1,46 & & & 164,84 & 0,66 & 168,31 & 0,56 \\
\hline & $\mathrm{A}_{103}$ & 31,89 & 0,97 & 32,96 & 1,51 & 85,39 & 1,07 & & & 165,00 & 0,66 & 168,20 & 0,52 \\
\hline & $\mathrm{A}_{105}$ & 31,90 & 1,33 & 32,99 & 1,47 & 84,89 & 1,84 & & & 164,77 & 0,68 & 168,49 & 0,43 \\
\hline & $\mathrm{A}_{107}$ & 32,13 & 0,97 & 32,91 & 0,85 & 85,47 & 1,02 & & & 164,86 & 0,69 & 168,40 & 0,56 \\
\hline & $\mathrm{A}_{109}$ & 32,11 & 1,04 & 32,94 & 0,81 & 85,90 & 1,48 & & & & & & \\
\hline & $A_{1011}$ & 31,87 & 1,04 & 32,93 & 1,41 & 85,31 & 1,22 & & & 164,83 & 0,68 & 168,39 & 0,58 \\
\hline \multirow{7}{*}{$5-1$} & $A_{100}$ & & & 32,86 & 0,92 & 85,84 & 1,47 & 99,65 & 0,61 & & & 168,53 & 0,65 \\
\hline & $A_{101}$ & & & 32,87 & 0,89 & 86,13 & 1,26 & & & & & 168,47 & 0,59 \\
\hline & $\mathrm{A}_{103}$ & & & 32,87 & 0,91 & 86,10 & 1,37 & & & & & 168,48 & 0,59 \\
\hline & $\mathrm{A}_{105}$ & & & 32,86 & 0,89 & & & & & & & 168,53 & 0,57 \\
\hline & $A_{107}$ & & & 32,81 & 1,03 & 86,17 & 1,11 & & & & & 168,48 & 0,60 \\
\hline & $A_{109}$ & & & 32,86 & 0,90 & 86,22 & 0,73 & & & & & & \\
\hline & $A_{1011}$ & & & 32,86 & 0,93 & 86,32 & 1,36 & & & 164,18 & 0,56 & 168,47 & 0,57 \\
\hline \multirow{7}{*}{$6-2$} & $A_{100}$ & 32,07 & 0,95 & 32,89 & 0,91 & 86,16 & 1,22 & 99,15 & 1,17 & 168,31 & 0,61 & 174,78 & 0,14 \\
\hline & $A_{101}$ & 32,07 & 0,84 & 32,89 & 0,94 & 86,20 & 1,09 & & & 164,70 & 0,93 & 168,17 & 0,45 \\
\hline & $\mathrm{A}_{103}$ & 32,09 & 0,93 & 32,89 & 0,88 & 85,86 & 1,76 & & & 164,88 & 0,52 & 168,25 & 0,63 \\
\hline & $\mathrm{A}_{105}$ & 32,11 & 1,02 & 32,89 & 0,77 & & & & & 164,97 & 0,43 & 168,23 & 0,63 \\
\hline & $A_{107}$ & 32,17 & 1,05 & 32,87 & 0,70 & 86,11 & 1,23 & 98,43 & 1,43 & 163,90 & 0,76 & 168,47 & 0,61 \\
\hline & $A_{109}$ & 32,09 & 1,02 & 32,90 & 0,88 & 85,96 & 1,04 & & & & & & \\
\hline & $\mathrm{A}_{1011}$ & 32,23 & 0,94 & 32,81 & 0,65 & 85,84 & 1,42 & & & 164,06 & 0,63 & 168,38 & 0,64 \\
\hline & $\mathrm{A}_{100}$ & 32,08 & 0,90 & & & 85,49 & 0,65 & & & 164,67 & 0,52 & & \\
\hline & $A_{101}$ & 32,09 & 0,92 & & & 85,52 & 0,76 & & & 164,90 & 0,66 & & \\
\hline & $\mathrm{A}_{103}$ & 32,08 & 0,98 & & & 85,54 & 0,79 & & & 164,72 & 0,60 & & \\
\hline $7-3$ & $\mathrm{~A}_{105}$ & 32,09 & 0,94 & & & & & & & 164,77 & 0,57 & & \\
\hline & $A_{107}$ & 32,25 & 0,75 & & & 85,54 & 0,59 & & & 164,77 & 0,64 & & \\
\hline & $\mathrm{A}_{109}$ & 32,10 & 0,89 & & & 85,52 & 0,77 & & & & & & \\
\hline & $A_{1011}$ & 32,08 & 0,92 & & & 85,58 & 0,69 & & & 164,69 & 0,63 & & \\
\hline & & 32,17 & 0,93 & 32,87 & 0,98 & 85,71 & 0,96 & 101,29 & 1,09 & 164,70 & 0,61 & 168,23 & 0,57 \\
\hline $\begin{array}{l}\text { Desvi } \\
\text { Coef. }\end{array}$ & $\begin{array}{l}\text { adrão } \\
\text { riação }\end{array}$ & $\begin{array}{r}0,261 \\
0,8 \%\end{array}$ & $\begin{array}{c}0,132 \\
14,3 \%\end{array}$ & $\begin{array}{l}0,070 \\
0,2 \%\end{array}$ & $\begin{array}{r}0,225 \\
23,1 \% \\
\end{array}$ & $\begin{array}{c}0,505 \\
0,6 \%\end{array}$ & $\begin{array}{r}0,315 \\
33,0 \%\end{array}$ & $\begin{array}{l}1,233 \\
1,2 \% \\
\end{array}$ & $\begin{array}{r}0,280 \\
25,8 \%\end{array}$ & $\begin{array}{c}0,718 \\
0,4 \% \\
\end{array}$ & $\begin{array}{c}0,088 \\
14,4 \% \\
\end{array}$ & $\begin{array}{l}1,236 \\
0,7 \%\end{array}$ & $\begin{array}{l}0,087 \\
15,3 \%\end{array}$ \\
\hline
\end{tabular}


Tabela E.9 - Parâmetros modais da Tora 5 para o ensaio com excitação horizontal.

\begin{tabular}{|c|c|c|c|c|c|c|c|c|c|c|c|}
\hline \multirow[b]{2}{*}{ Plano } & \multirow[b]{2}{*}{ FRF } & \multicolumn{2}{|c|}{$1^{\circ}$ Modo } & \multicolumn{4}{|c|}{$2^{\circ}$ Modo } & \multicolumn{4}{|c|}{$3^{\circ}$ Modo } \\
\hline & & $\begin{array}{l}\text { Freq. } \\
(\mathrm{Hz})\end{array}$ & $\begin{array}{c}\text { Amort. } \\
(\%)\end{array}$ & $\begin{array}{l}\text { Freq. } \\
(\mathrm{Hz})\end{array}$ & $\begin{array}{c}\text { Amort. } \\
(\%)\end{array}$ & $\begin{array}{l}\text { Freq. } \\
(\mathrm{Hz})\end{array}$ & $\begin{array}{c}\text { Amort. } \\
(\%)\end{array}$ & $\begin{array}{c}\text { Freq. } \\
(\mathrm{Hz})\end{array}$ & $\begin{array}{c}\text { Amort. } \\
(\%)\end{array}$ & $\begin{array}{l}\text { Freq. } \\
(\mathrm{Hz})\end{array}$ & $\begin{array}{c}\text { Amort. } \\
(\%)\end{array}$ \\
\hline \multirow{7}{*}{$0-4$} & $A_{100}$ & 33,33 & 1,09 & & & 90,29 & 0,61 & & & 169,54 & 0,61 \\
\hline & $\mathrm{A}_{101}$ & 33,29 & 1,19 & & & 90,30 & 0,62 & & & 169,69 & 0,65 \\
\hline & $\mathrm{A}_{103}$ & 33,37 & 1,16 & & & 90,29 & 0,62 & & & 169,58 & 0,60 \\
\hline & $A_{105}$ & 33,29 & 1,26 & & & 90,08 & 0,86 & & & 169,50 & 0,56 \\
\hline & $\mathrm{A}_{107}$ & 33,30 & 1,09 & & & 90,27 & 0,61 & & & 169,58 & 0,63 \\
\hline & $\mathrm{A}_{109}$ & 33,31 & 1,09 & & & 90,29 & 0,61 & & & 169,64 & 0,61 \\
\hline & $A_{1011}$ & 33,29 & 1,17 & & & 90,26 & 0,61 & & & 169,59 & 0,61 \\
\hline \multirow{7}{*}{$1-5$} & $A_{100}$ & 32,30 & 1,26 & 85,87 & 1,09 & 89,01 & 0,61831 & 164,71 & 0,59 & 170,02 & 0,61 \\
\hline & $A_{101}$ & 32,42 & 1,16 & 86,02 & 1,22 & 89,14 & 0,67 & 164,75 & 0,60 & & \\
\hline & $\mathrm{A}_{103}$ & 32,30 & 1,10 & 86,17 & 0,91 & 88,96 & 0,65 & 164,80 & 0,61 & 170,08 & 0,59 \\
\hline & $A_{105}$ & 32,28 & 1,03 & & & & & 164,66 & 0,60 & 170,13 & 0,62 \\
\hline & $A_{107}$ & 32,36 & 0,84 & 85,93 & 0,89 & 89,02 & 0,67 & 164,30 & 0,67 & 170,04 & 0,62 \\
\hline & $\mathrm{A}_{109}$ & 32,34 & 1,10 & 85,99 & 1,04 & 89,09 & 0,65 & & & 170,03 & 0,58 \\
\hline & $A_{1011}$ & 32,27 & 1,04 & 86,20 & 0,72 & 88,88 & 0,71 & 164,63 & 0,65 & 169,98 & 0,53 \\
\hline \multirow{7}{*}{$2-6$} & $A_{100}$ & 32,41 & 1,46 & 87,14 & 0,68 & & & 164,56 & 0,57 & & \\
\hline & $\mathrm{A}_{101}$ & 32,40 & 1,37 & 87,15 & 0,68 & & & 164,68 & 0,58 & & \\
\hline & $\mathrm{A}_{103}$ & 32,31 & 1,43 & 87,14 & 0,704 & & & 164,58 & 0,58 & & \\
\hline & $\mathrm{A}_{105}$ & 32,42 & 1,47 & & & & & 164,53 & 0,59 & & \\
\hline & $A_{107}$ & 32,36 & 1,20 & 87,13 & 0,70 & & & 164,57 & 0,59 & & \\
\hline & $A_{109}$ & 32,43 & 1,32 & 87,12 & 0,69 & & & & & & \\
\hline & $\mathrm{A}_{1011}$ & 32,36 & 1,01 & 87,10 & 0,68 & & & 164,51 & 0,57 & & \\
\hline \multirow{7}{*}{$3-7$} & $A_{100}$ & 33,35 & 1,41 & 86,54 & 0,66 & 89,24 & 0,81 & 164,95 & 0,56 & 169,95 & 0,60 \\
\hline & $\mathrm{A}_{101}$ & 33,19 & 1,46 & 86,15 & 0,23 & 89,38 & 0,79 & 164,94 & 0,57 & 169,95 & 0,60 \\
\hline & $\mathrm{A}_{103}$ & 33,23 & 1,36 & 85,81 & 1,23 & 89,37 & 0,62 & 165,00 & 0,59 & 169,86 & 0,56 \\
\hline & $\mathrm{A}_{105}$ & 33,27 & 1,54 & & & 89,49 & 1,06 & 164,91 & 0,58 & 169,94 & 0,58 \\
\hline & $A_{107}$ & 33,22 & 1,26 & 86,26 & 0,80 & 89,24 & 0,71 & & & & \\
\hline & $A_{109}$ & 33,27 & 1,22 & & & 89,42 & 0,62 & & & 170,02 & 0,37 \\
\hline & $A_{1011}$ & 33,25 & 1,26 & 85,81 & 0,53 & 89,31 & 0,74 & 164,88 & 0,58 & 169,84 & 0,60 \\
\hline \multirow{7}{*}{ 4-0 } & $A_{100}$ & 33,35 & 1,16 & & & 90,25 & 0,67 & & & 169,56 & 0,60 \\
\hline & $A_{101}$ & 33,23 & 1,18 & & & 90,27 & 0,73 & & & 170,29 & 0,40 \\
\hline & $\mathrm{A}_{103}$ & 33,25 & 1,01 & & & 90,25 & 0,67 & & & 169,70 & 0,65 \\
\hline & $\mathrm{A}_{105}$ & 33,31 & 1,17 & & & & & & & 169,76 & 0,63 \\
\hline & $A_{107}$ & 33,31 & 1,04 & & & 90,24 & 0,66 & & & 169,72 & 0,61 \\
\hline & $A_{109}$ & 33,36 & 1,07 & & & 90,26 & 0,65 & & & 169,71 & 0,58 \\
\hline & $A_{1011}$ & 33,31 & 1,18 & & & 90,24 & 0,66 & & & 169,68 & 0,59 \\
\hline \multirow{7}{*}{$5-1$} & $A_{100}$ & 32,35 & 1,08 & 85,13 & 0,68 & 88,63 & 0,93 & 164,79 & 0,73 & 170,10 & 0,61 \\
\hline & $A_{101}$ & 32,25 & 1,08 & 85,78 & 0,78 & 88,91 & 0,86 & 164,84 & 0,72 & 170,14 & 0,47 \\
\hline & $\mathrm{A}_{103}$ & 32,18 & 1,26 & & & 88,87 & 1,05 & 164,53 & 0,66 & 170,22 & 0,62 \\
\hline & $\mathrm{A}_{105}$ & 32,46 & 1,21 & & & & & 164,76 & 0,71 & 170,16 & 0,60 \\
\hline & $\mathrm{A}_{107}$ & 32,40 & 1,22 & 85,14 & 0,25 & 88,85 & 0,93 & 164,90 & 0,73 & 170,16 & 0,61 \\
\hline & $\mathrm{A}_{109}$ & 32,39 & 1,22 & & & 88,95 & 0,86 & & & & \\
\hline & $A_{1011}$ & 32,39 & 1,30 & 85,04 & 1,00 & 88,86 & 0,86 & 164,57 & 0,67 & 170,12 & 0,60 \\
\hline \multirow{7}{*}{$6-2$} & $A_{100}$ & 32,29 & 0,88 & 87,12 & 0,69 & & & 164,53 & 0,577 & & \\
\hline & $A_{101}$ & 32,26 & 0,85 & 86,98 & 0,63 & & & & & & \\
\hline & $\mathrm{A}_{103}$ & 32,34 & 0,81 & 87,14 & 0,72 & & & 164,52 & 0,59 & & \\
\hline & $\mathrm{A}_{105}$ & 32,26 & 1,09 & 87,19 & 0,58 & & & 164,53 & 0,57 & & \\
\hline & $A_{107}$ & 32,27 & 0,86 & 87,10 & 0,68 & & & 164,54 & 0,58 & & \\
\hline & $A_{109}$ & 32,29 & 0,90 & 87,08 & 0,67 & & & & & & \\
\hline & $A_{1011}$ & 32,31 & 0,82 & 87,10 & 0,63 & & & 164,48 & 0,57 & & \\
\hline \multirow{7}{*}{$7-3$} & $A_{100}$ & 33,37 & 0,94 & & & 89,74 & 0,98 & 164,66 & 0,91 & 169,85 & 0,62 \\
\hline & $\mathrm{A}_{101}$ & 33,34 & 0,67 & & & 89,74 & 0,60 & 164,75 & 0,66 & 169,82 & 0,64 \\
\hline & $\mathrm{A}_{103}$ & 33,39 & 0,93 & & & 89,64 & 0,55 & 163,91 & 0,97 & 169,86 & 0,65 \\
\hline & $\mathrm{A}_{105}$ & 33,36 & 0,89 & & & 89,42 & 0,47 & 164,98 & 0,86 & 169,69 & 0,70 \\
\hline & $A_{107}$ & 33,32 & 0,91 & & & 89,52 & 0,69 & 164,81 & 0,83 & 169,83 & 0,62 \\
\hline & $A_{109}$ & 33,36 & 0,89 & & & 89,66 & 0,67 & & & & \\
\hline & $A_{1011}$ & 33,36 & 0,97 & & & 89,56 & 0,65 & 164,75 & 0,77 & 169,74 & 0,60 \\
\hline & & 32,82 & 1,12 & 86,44 & 0,74 & 89,57 & 0,72 & 164,67 & 0,65 & 169,87 & 0,59 \\
\hline Desvi & adrão & 0,494 & 0,194 & 0,714 & 0,232 & 0,554 & 0,136 & 0,217 & 0,106 & 0,218 & 0,061 \\
\hline Coef. & riação & $1,5 \%$ & $17,3 \%$ & $0,8 \%$ & $31,3 \%$ & $0,6 \%$ & $19,0 \%$ & $0,1 \%$ & $16,2 \%$ & $0,1 \%$ & $10,3 \%$ \\
\hline
\end{tabular}


Tabela E.10 - Parâmetros modais da Tora 6 para o ensaio com excitação horizontal.

\begin{tabular}{|c|c|c|c|c|c|c|c|c|c|c|c|c|c|}
\hline \multirow[b]{2}{*}{ Plano } & \multirow[b]{2}{*}{ FRF } & \multicolumn{4}{|c|}{$1^{\circ}$ Modo } & \multicolumn{4}{|c|}{$2^{\circ}$ Modo } & \multicolumn{4}{|c|}{$3^{\circ}$ Modo } \\
\hline & & $\begin{array}{l}\text { Freq. } \\
(\mathrm{Hz})\end{array}$ & $\begin{array}{c}\text { Amort. } \\
(\%)\end{array}$ & $\begin{array}{l}\text { Freq. } \\
(\mathrm{Hz})\end{array}$ & $\begin{array}{c}\text { Amort. } \\
(\%)\end{array}$ & $\begin{array}{l}\text { Freq. } \\
(\mathrm{Hz})\end{array}$ & $\begin{array}{c}\text { Amort. } \\
(\%)\end{array}$ & $\begin{array}{c}\text { Freq. } \\
(\mathrm{Hz})\end{array}$ & $\begin{array}{c}\text { Amort. } \\
(\%)\end{array}$ & $\begin{array}{c}\text { Freq. } \\
(\mathrm{Hz})\end{array}$ & $\begin{array}{c}\text { Amort. } \\
(\%)\end{array}$ & $\begin{array}{l}\text { Freq. } \\
(\mathrm{Hz})\end{array}$ & $\begin{array}{c}\text { Amort. } \\
(\%)\end{array}$ \\
\hline \multirow{7}{*}{$0-4$} & $A_{100}$ & 32,19 & 0,04 & 33,89 & 1,14 & & & 89,17 & 0,84 & 164,90 & 0,56 & 169,33 & 0,57 \\
\hline & $A_{101}$ & 32,06 & 1,23 & 33,92 & 1,00 & & & 89,51 & 0,61 & 164,94 & 0,57 & 169,37 & 0,57 \\
\hline & $\mathrm{A}_{103}$ & 32,30 & 1,51 & 33,69 & 0,38 & & & 89,37 & 0,62 & 164,99 & 0,50 & 169,39 & 0,55 \\
\hline & $\mathrm{A}_{105}$ & 32,40 & 1,12 & 33,89 & 0,63 & & & 89,43 & 0,82 & 164,90 & 0,56 & 169,35 & 0,56 \\
\hline & $A_{107}$ & 32,17 & 0,81 & 33,72 & 0,84 & & & 89,30 & 0,63 & 164,92 & 0,55 & 169,36 & 0,58 \\
\hline & $\mathrm{A}_{109}$ & 32,11 & 0,97 & 33,76 & 0,78 & 85,66 & 0,62 & 89,44 & 0,64 & & & & \\
\hline & $A_{1011}$ & 32,02 & 1,42 & 33,79 & 0,68 & & & 89,39 & 0,65 & 164,92 & 0,53 & 169,34 & 0,58 \\
\hline \multirow{7}{*}{$1-5$} & $A_{100}$ & 32,17 & 1,06 & & & 87,34 & 0,91 & & & 164,46 & 0,56 & & \\
\hline & $\mathrm{A}_{101}$ & 32,19 & 0,92 & & & 87,19 & 0,91 & & & 164,51 & 0,54 & & \\
\hline & $\mathrm{A}_{103}$ & 32,18 & 0,88 & & & 87,79 & 0,89 & & & 164,50 & 0,55 & & \\
\hline & $\mathrm{A}_{105}$ & 32,18 & 0,77 & & & 86,90 & 0,71 & & & 164,49 & 0,55 & & \\
\hline & $\mathrm{A}_{107}$ & 32,22 & 1,08 & & & 87,24 & 0,91 & & & 164,49 & 0,56 & & \\
\hline & $A_{109}$ & 32,19 & 0,94 & & & 86,93 & 1,17 & & & & & & \\
\hline & $A_{1011}$ & 32,16 & 1,02 & & & 86,71 & 0,77 & & & 164,46 & 0,55 & & \\
\hline \multirow{7}{*}{$2-6$} & $A_{100}$ & 32,23 & 0,98 & & & 86,57 & 0,62 & 89,04 & 0,67 & 164,55 & 0,55 & 169,65 & 0,55 \\
\hline & $\mathrm{A}_{101}$ & 32,25 & 0,77 & 33,48 & 0,86 & 86,53 & 0,77 & 89,28 & 0,59 & 164,57 & 0,58 & 169,60 & 0,48 \\
\hline & $\mathrm{A}_{103}$ & 32,17 & 0,72 & 33,70 & 1,00 & 86,52 & 0,67 & 89,10 & 0,65 & 164,53 & 0,53 & 169,69 & 0,57 \\
\hline & $\mathrm{A}_{105}$ & 32,18 & 0,81 & 33,72 & 0,98 & & & & & 164,68 & 0,52 & 169,62 & 0,53 \\
\hline & $\mathrm{A}_{107}$ & 32,21 & 0,96 & 33,59 & 0,62 & 86,49 & 0,61 & 89,07 & 0,70 & 164,57 & 0,56 & 169,62 & 0,58 \\
\hline & $\mathrm{A}_{109}$ & 32,18 & 0,44 & 33,64 & 1,27 & 86,47 & 0,59 & 89,18 & 0,67 & & & & \\
\hline & $A_{1011}$ & 32,34 & 1,25 & & & 86,13 & 0,59 & 88,86 & 0,73 & 164,50 & 0,52 & 169,84 & 0,22 \\
\hline \multirow{7}{*}{$3-7$} & $A_{100}$ & & & 33,60 & 1,14 & & & 90,00 & 0,68 & 165,15 & 0,65 & 169,17 & 0,55 \\
\hline & $\mathrm{A}_{101}$ & & & 33,72 & 0,89 & & & 89,92 & 0,61 & 165,52 & 0,53 & 169,15 & 0,57 \\
\hline & $\mathrm{A}_{103}$ & & & 33,75 & 0,88 & & & 90,02 & 0,65 & 164,96 & 0,40 & 169,24 & 0,58 \\
\hline & $\mathrm{A}_{105}$ & & & 33,70 & 0,92 & & & 89,92 & 0,64 & 165,06 & 0,57 & 169,20 & 0,56 \\
\hline & $\mathrm{A}_{107}$ & & & 33,73 & 0,92 & & & 90,00 & 0,69 & 165,05 & 0,47 & 169,21 & 0,58 \\
\hline & $\mathrm{A}_{109}$ & & & 33,69 & 0,83 & & & 89,97 & 0,62 & & & & \\
\hline & $A_{1011}$ & & & 33,69 & 1,03 & & & 89,97 & 0,72 & 164,87 & 0,42 & 169,19 & 0,61 \\
\hline \multirow{7}{*}{$4-0$} & $A_{100}$ & 32,25 & 1,12 & 33,71 & 0,72 & 85,89 & 0,71 & 89,63 & 0,60 & 164,81 & 0,56 & 169,23 & 0,58 \\
\hline & $\mathrm{A}_{101}$ & 32,22 & 0,77 & 33,68 & 0,86 & 85,96 & 0,84 & 89,66 & 0,59 & 164,89 & 0,60 & 169,23 & 0,56 \\
\hline & $\mathrm{A}_{103}$ & & & 33,72 & 1,07 & 85,86 & 0,69 & 89,64 & 0,60 & 164,79 & 0,53 & 169,30 & 0,60 \\
\hline & $\mathrm{A}_{105}$ & 32,26 & 1,19 & 33,70 & 0,68 & & & & & 164,89 & 0,58 & 169,23 & 0,59 \\
\hline & $\mathrm{A}_{107}$ & & & 33,54 & 1,25 & 85,00 & 0,65 & 89,65 & 0,63 & 164,87 & 0,49 & 169,35 & 0,53 \\
\hline & $A_{109}$ & 32,15 & 1,18 & 33,73 & 0,75 & 85,79 & 0,67 & 89,66 & 0,60 & & & & \\
\hline & $A_{1011}$ & 32,24 & 1,07 & 33,68 & 0,73 & 85,85 & 0,73 & 89,63 & 0,61 & 164,97 & 0,58 & 169,19 & 0,57 \\
\hline \multirow{7}{*}{$5-1$} & $A_{100}$ & 32,14 & 0,96 & & & 87,05 & 0,80 & & & 164,44 & 0,56 & 169,73 & 0,53 \\
\hline & $A_{101}$ & 32,13 & 0,88 & & & 86,89 & 0,74 & & & 164,52 & 0,55 & & \\
\hline & $\mathrm{A}_{103}$ & 32,19 & 0,77 & & & 87,63 & 0,84 & & & 164,47 & 0,54 & 169,92 & 0,32 \\
\hline & $\mathrm{A}_{105}$ & 32,18 & 0,92 & & & 86,97 & 0,43 & & & 164,46 & 0,55 & 169,74 & 0,56 \\
\hline & $\mathrm{A}_{107}$ & 32,18 & 0,91 & & & 86,92 & 0,70 & & & 164,47 & 0,55 & & \\
\hline & $\mathrm{A}_{109}$ & 32,15 & 0,83 & & & 87,02 & 0,64 & & & & & & \\
\hline & $A_{1011}$ & 32,17 & 0,92 & & & 86,86 & 0,57 & & & 164,42 & 0,55 & & \\
\hline \multirow{7}{*}{$6-2$} & $A_{100}$ & 32,21 & 0,88 & & & 86,51 & 0,64 & 89,04 & 0,61 & 164,55 & 0,59 & 169,40 & 0,57 \\
\hline & $\mathrm{A}_{101}$ & 32,15 & 0,82 & 33,71 & 0,90 & 86,55 & 0,65 & 89,12 & 0,63 & 164,53 & 0,63 & 169,48 & 0,50 \\
\hline & $\mathrm{A}_{103}$ & 32,13 & 1,03 & 33,81 & 0,44 & 86,54 & 0,65 & 89,02 & 0,61 & 164,60 & 0,58 & 169,49 & 0,63 \\
\hline & $\mathrm{A}_{105}$ & 32,14 & 1,13 & & & & & 88,93 & 1,04 & 164,57 & 0,58 & 169,47 & 0,60 \\
\hline & $\mathrm{A}_{107}$ & 32,16 & 0,90 & 33,73 & 0,52 & 86,50 & 0,61 & 89,08 & 0,64 & 164,57 & 0,58 & 169,49 & 0,55 \\
\hline & $\mathrm{A}_{109}$ & 32,21 & 0,65 & 33,48 & 1,36 & 86,56 & 0,65 & 89,08 & 0,64 & & & & \\
\hline & $A_{1011}$ & 32,14 & 0,86 & 33,66 & 0,53 & 86,52 & 0,62 & 89,07 & 0,64 & 164,53 & 0,56 & 169,59 & 0,61 \\
\hline & $A_{100}$ & & & 33,76 & 0,79 & 89,83 & 0,61 & & & 164,69 & 0,49 & 169,03 & 0,53 \\
\hline & $\mathrm{A}_{101}$ & & & 33,69 & 0,90 & 89,83 & 0,60 & & & 164,70 & 0,10 & 169,29 & 0,55 \\
\hline & $\mathrm{A}_{103}$ & & & 33,77 & 0,78 & 89,87 & 0,60 & & & 164,77 & 0,61 & 169,06 & 0,57 \\
\hline $7-3$ & $\mathrm{~A}_{105}$ & & & 33,71 & 0,89 & 89,81 & 0,56 & & & 164,90 & 0,56 & 169,06 & 0,57 \\
\hline & $\mathrm{A}_{107}$ & & & 33,70 & 0,79 & 89,84 & 0,59 & & & 164,66 & 0,61 & 169,06 & 0,56 \\
\hline & $\mathrm{A}_{109}$ & & & 33,74 & 1,00 & 89,86 & 0,61 & & & & & & \\
\hline & $A_{1011}$ & & & 33,73 & 0,97 & 89,85 & 0,58 & & & 165,25 & 0,59 & 169,02 & 0,62 \\
\hline & & 32,19 & 0,94 & 33,71 & 0,86 & 87,16 & 0,69 & 89,43 & 0,66 & 164,73 & 0,54 & 169,38 & 0,55 \\
\hline $\begin{array}{l}\text { Desvio } \\
\text { Coef. }\end{array}$ & $\begin{array}{l}\text { adrão } \\
\text { riação }\end{array}$ & $\begin{array}{c}0,066 \\
0,2 \%\end{array}$ & $\begin{array}{l}0,249 \\
26,6 \%\end{array}$ & $\begin{array}{l}0,091 \\
0,3 \%\end{array}$ & $\begin{array}{l}0,219 \\
25,4 \%\end{array}$ & $\begin{array}{l}1,362 \\
1,6 \%\end{array}$ & $\begin{array}{c}0,134 \\
19,3 \%\end{array}$ & $\begin{array}{c}0,365 \\
0,4 \%\end{array}$ & $\begin{array}{r}0,089 \\
13,5 \%\end{array}$ & $\begin{array}{c}0,250 \\
0,2 \%\end{array}$ & $\begin{array}{c}0,078 \\
14,4 \%\end{array}$ & $\begin{array}{c}0,234 \\
0,1 \%\end{array}$ & $\begin{array}{r}0,074 \\
13,5 \%\end{array}$ \\
\hline
\end{tabular}


Tabela E.11 - Parâmetros modais da Tora 7 para o ensaio com excitação horizontal.

\begin{tabular}{|c|c|c|c|c|c|c|c|c|c|c|c|c|c|}
\hline \multirow[b]{2}{*}{ Plano } & \multirow[b]{2}{*}{ FRF } & \multicolumn{4}{|c|}{$1^{\circ}$ Modo } & \multicolumn{4}{|c|}{$2^{\circ}$ Modo } & \multicolumn{4}{|c|}{$3^{\circ}$ Modo } \\
\hline & & $\begin{array}{c}\text { Freq. } \\
(\mathrm{Hz})\end{array}$ & $\begin{array}{c}\text { Amort. } \\
(\%)\end{array}$ & $\begin{array}{l}\text { Freq. } \\
(\mathrm{Hz})\end{array}$ & $\begin{array}{c}\text { Amort. } \\
(\%)\end{array}$ & $\begin{array}{l}\text { Freq. } \\
(\mathrm{Hz})\end{array}$ & $\begin{array}{c}\text { Amort. } \\
(\%)\end{array}$ & $\begin{array}{l}\text { Freq. } \\
(\mathrm{Hz})\end{array}$ & $\begin{array}{c}\text { Amort. } \\
(\%)\end{array}$ & $\begin{array}{l}\text { Freq. } \\
(\mathrm{Hz})\end{array}$ & $\begin{array}{c}\text { Amort. } \\
(\%)\end{array}$ & $\begin{array}{l}\text { Freq. } \\
(\mathrm{Hz})\end{array}$ & $\begin{array}{c}\text { Amort. } \\
(\%)\end{array}$ \\
\hline \multirow{7}{*}{$0-4$} & $A_{100}$ & 33,32 & 0,83 & & & & & 89,71 & 1,19 & 169,19 & 0,59 & & \\
\hline & $\mathrm{A}_{101}$ & 33,24 & 1,01 & & & & & 89,98 & 1,07 & 169,19 & 0,58 & & \\
\hline & $\mathrm{A}_{103}$ & 33,36 & 0,99 & & & & & 89,78 & 1,01 & 169,19 & 0,57 & & \\
\hline & $\mathrm{A}_{105}$ & 33,36 & 0,92 & & & & & 90,29 & 1,12 & 169,17 & 0,58 & & \\
\hline & $\mathrm{A}_{107}$ & 33,37 & 1,04 & & & & & 90,19 & 1,05 & 169,19 & 0,58 & & \\
\hline & $\mathrm{A}_{109}$ & 33,32 & 1,22 & & & & & 90,02 & 1,10 & 169,25 & 0,54 & & \\
\hline & $A_{1011}$ & 33,36 & 0,88 & & & & & 90,96 & 0,95 & 169,16 & 0,58 & & \\
\hline \multirow{7}{*}{$1-5$} & $A_{100}$ & 33,48 & 0,79 & 36,70 & 0,84 & 87,60 & 0,88 & 94,11 & 1,45 & 169,51 & 0,59 & 183,81 & 0,58 \\
\hline & $\mathrm{A}_{101}$ & 33,64 & 0,18 & 36,65 & 1,19 & & & & & 169,63 & 0,57 & 183,86 & 0,57 \\
\hline & $\mathrm{A}_{103}$ & 33,37 & 0,65 & 36,75 & 0,85 & & & & & 169,57 & 0,58 & 183,86 & 0,57 \\
\hline & $\mathrm{A}_{105}$ & 33,39 & 1,21 & 36,84 & 0,68 & & & & & 169,58 & 0,59 & 183,86 & 0,58 \\
\hline & $A_{107}$ & 33,31 & 0,93 & 36,75 & 0,78 & 87,32 & 1,12 & 94,04 & 1,46 & 169,57 & 0,60 & 183,85 & 0,57 \\
\hline & $\mathrm{A}_{109}$ & 33,13 & 0,79 & 36,74 & 0,67 & & & 94,26 & 1,61 & & & & \\
\hline & $A_{1011}$ & 33,27 & 0,58 & 36,73 & 0,75 & 87,01 & 0,72 & 94,41 & 1,38 & 169,55 & 0,60 & 183,94 & 0,58 \\
\hline \multirow{7}{*}{$2-6$} & $A_{100}$ & 33,31 & 0,20 & 36,75 & 0,85 & 87,01 & 1,01 & 95,93 & 0,79 & 169,72 & 0,72 & 183,63 & 0,55 \\
\hline & $\mathrm{A}_{101}$ & & & 36,79 & 1,25 & & & 95,97 & 0,77 & 169,31 & 0,80 & 183,63 & 0,58 \\
\hline & $\mathrm{A}_{103}$ & & & 36,65 & 1,00 & & & 95,98 & 0,64 & & & 183,62 & 0,57 \\
\hline & $\mathrm{A}_{105}$ & 33,23 & 1,56 & 36,73 & 0,76 & & & & & 169,83 & 0,63 & 183,63 & 0,58 \\
\hline & $\mathrm{A}_{107}$ & & & 36,77 & 0,74 & 86,48 & 0,82 & 95,91 & 0,75 & 169,80 & 0,64 & 183,62 & 0,57 \\
\hline & $\mathrm{A}_{109}$ & 33,57 & 1,34 & 36,71 & 0,85 & & & 95,98 & 0,74 & & & & \\
\hline & $A_{1011}$ & & & 36,67 & 0,79 & & & 95,89 & 0,79 & 169,99 & 0,45 & 183,57 & 0,56 \\
\hline \multirow{7}{*}{$3-7$} & $\mathrm{~A}_{100}$ & 33,36 & 0,81 & 36,63 & 0,92 & 87,08 & 1,13 & 91,64 & 1,24 & 169,38 & 0,55 & 183,85 & 0,60 \\
\hline & $\mathrm{A}_{101}$ & 33,38 & 1,03 & 36,66 & 0,61 & 87,78 & 1,42 & 91,78 & 1,01 & 169,37 & 0,58 & 183,95 & 0,58 \\
\hline & $\mathrm{A}_{103}$ & 33,32 & 0,80 & 36,74 & 0,83 & 86,55 & 0,89 & 95,06 & 1,16 & 169,35 & 0,58 & 183,99 & 0,58 \\
\hline & $\mathrm{A}_{105}$ & 33,37 & 0,79 & 36,84 & 0,98 & & & 91,72 & 1,70 & 169,36 & 0,56 & 184,00 & 0,61 \\
\hline & $\mathrm{A}_{107}$ & 33,33 & 0,82 & 36,72 & 0,79 & 86,80 & 0,85 & 94,27 & 0,36 & 169,34 & 0,58 & 183,95 & 0,58 \\
\hline & $\mathrm{A}_{109}$ & 33,35 & 0,82 & 36,70 & 0,87 & 87,72 & 0,97 & 91,70 & 1,32 & & & & \\
\hline & $A_{1011}$ & 33,41 & 0,81 & 36,55 & 0,99 & 87,43 & 1,24 & 91,38 & 1,39 & 169,34 & 0,59 & 183,92 & 0,64 \\
\hline \multirow{7}{*}{$4-0$} & $\mathrm{~A}_{100}$ & 33,29 & 0,97 & & & 89,94 & 0,70 & & & 169,16 & 0,57 & & \\
\hline & $\mathrm{A}_{101}$ & 33,34 & 0,83 & & & 90,03 & 0,73 & & & 169,19 & 0,59 & & \\
\hline & $\mathrm{A}_{103}$ & 33,31 & 0,83 & & & 89,96 & 0,72 & & & 169,23 & 0,60 & & \\
\hline & $\mathrm{A}_{105}$ & 33,35 & 0,90 & & & 90,13 & 0,69 & & & 169,16 & 0,55 & & \\
\hline & $\mathrm{A}_{107}$ & 33,37 & 0,86 & & & 89,94 & 0,71 & & & 169,18 & 0,57 & & \\
\hline & $\mathrm{A}_{109}$ & 33,33 & 0,89 & & & 89,97 & 0,68 & & & & & & \\
\hline & $A_{1011}$ & 33,39 & 0,94 & & & 90,06 & 0,75 & & & 169,14 & 0,58 & & \\
\hline \multirow{7}{*}{$5-1$} & $A_{100}$ & 33,37 & 0,56 & 36,83 & 0,79 & 88,41 & 0,73 & 95,08 & 1,08 & 170,08 & 0,63 & 184,07 & 0,62 \\
\hline & $A_{101}$ & 33,66 & 1,36 & 36,79 & 0,71 & 88,32 & 0,86 & 95,04 & 1,15 & 170,15 & 0,61 & 184,09 & 0,63 \\
\hline & $\mathrm{A}_{103}$ & 33,49 & 0,95 & 36,79 & 0,79 & 88,20 & 0,75 & 94,94 & 1,05 & 170,15 & 0,59 & 184,11 & 0,63 \\
\hline & $\mathrm{A}_{105}$ & 33,52 & 0,64 & 36,81 & 0,75 & & & & & 170,13 & 0,59 & 184,10 & 0,62 \\
\hline & $\mathrm{A}_{107}$ & & & 36,53 & 1,76 & 87,63 & 0,84 & 95,97 & 1,28 & 170,15 & 0,60 & 184,10 & 0,62 \\
\hline & $\mathrm{A}_{109}$ & 33,50 & 0,81 & 36,80 & 0,81 & 88,32 & 0,68 & 96,76 & 1,41 & & & & \\
\hline & $A_{1011}$ & & & & & & & & & & & & \\
\hline \multirow{7}{*}{$6-2$} & $\mathrm{~A}_{100}$ & 33,53 & 1,28 & 36,79 & 0,77 & & & 95,72 & 0,94 & & & 184,17 & 0,56 \\
\hline & $\mathrm{A}_{101}$ & & & 36,83 & 0,75 & & & 95,81 & 1,05 & & & 184,17 & 0,56 \\
\hline & $\mathrm{A}_{103}$ & & & 36,77 & 1,06 & & & 95,54 & 1,00 & & & 184,10 & 0,57 \\
\hline & $\mathrm{A}_{105}$ & & & 36,84 & 0,90 & & & & & & & 184,11 & 0,57 \\
\hline & $\mathrm{A}_{107}$ & & & 36,80 & 0,83 & & & 95,53 & 0,49 & & & 184,13 & 0,58 \\
\hline & $\mathrm{A}_{109}$ & & & 36,78 & 0,65 & & & 95,51 & 0,94 & & & & \\
\hline & $A_{1011}$ & & & 36,82 & 0,74 & & & 95,74 & 1,09 & & & 184,09 & 0,57 \\
\hline & $A_{100}$ & 33,44 & 0,73 & 36,99 & 0,91 & 88,59 & 1,23 & 92,07 & 0,91 & 169,84 & 0,57 & 184,61 & 0,53 \\
\hline & $\mathrm{A}_{101}$ & 33,43 & 0,80 & 36,82 & 0,67 & 89,05 & 1,05 & 92,27 & 1,18 & 169,86 & 0,63 & 184,78 & 0,59 \\
\hline & $\mathrm{A}_{103}$ & 33,42 & 0,66 & 37,08 & 1,27 & 89,18 & 0,58 & 92,04 & 0,94 & 169,85 & 0,55 & 184,62 & 0,57 \\
\hline $7-3$ & $\mathrm{~A}_{105}$ & 33,46 & 0,84 & 37,37 & 0,94 & & & & & 169,84 & 0,56 & 184,66 & 0,56 \\
\hline & $A_{107}$ & 33,46 & 0,81 & 36,85 & 0,65 & 87,76 & 1,12 & 92,35 & 1,15 & 169,83 & 0,50 & 184,78 & 0,57 \\
\hline & $A_{109}$ & 33,42 & 0,73 & 37,16 & 1,48 & 89,02 & 1,01 & 92,23 & 1,25 & & & & \\
\hline & $A_{1011}$ & 33,44 & 0,84 & 36,95 & 0,31 & 89,17 & 0,94 & 91,89 & 0,87 & 169,89 & 0,55 & 184,62 & 0,58 \\
\hline & & 33,39 & 0,87 & 36,79 & 0,87 & 88,36 & 0,89 & 93,55 & 1,07 & 169,55 & 0,59 & 184,05 & 0,58 \\
\hline Desvic & ladrão & 0,102 & 0,255 & 0,150 & 0,246 & 1,194 & 0,206 & 2,241 & 0,280 & 0,341 & 0,053 & 0,338 & 0,024 \\
\hline Coef. & riação & $0,3 \%$ & $29,3 \%$ & $0,4 \%$ & $28,4 \%$ & $1,4 \%$ & $23,1 \%$ & $2,4 \%$ & $26,2 \%$ & $0,2 \%$ & $9,0 \%$ & $0,2 \%$ & $4,1 \%$ \\
\hline
\end{tabular}


Tabela E.12 - Parâmetros modais da Tora 8 para o ensaio com excitação horizontal.

\begin{tabular}{|c|c|c|c|c|c|c|c|c|c|c|c|c|c|c|c|}
\hline \multirow[b]{2}{*}{ Plano } & \multirow[b]{2}{*}{ FRF } & \multicolumn{4}{|c|}{$1^{\circ}$ Modo } & \multicolumn{6}{|c|}{$2^{\circ}$ Modo } & \multicolumn{4}{|c|}{$3^{\circ}$ Modo } \\
\hline & & $\begin{array}{c}\text { Freq. } \\
(\mathrm{Hz})\end{array}$ & $\begin{array}{c}\text { Amort. } \\
(\%)\end{array}$ & $\begin{array}{c}\text { Freq. } \\
(\mathrm{Hz})\end{array}$ & $\begin{array}{c}\text { Amort. } \\
(\%)\end{array}$ & $\begin{array}{c}\text { Freq. } \\
(\mathrm{Hz})\end{array}$ & $\begin{array}{c}\text { Amort. } \\
(\%)\end{array}$ & $\begin{array}{c}\text { Freq. } \\
(\mathrm{Hz})\end{array}$ & $\begin{array}{c}\text { Amort. } \\
(\%)\end{array}$ & $\begin{array}{c}\text { Freq. } \\
(\mathrm{Hz})\end{array}$ & $\begin{array}{c}\text { Amort. } \\
(\%)\end{array}$ & $\begin{array}{c}\text { Freq. } \\
(\mathrm{Hz})\end{array}$ & $\begin{array}{c}\text { Amort. } \\
(\%)\end{array}$ & $\begin{array}{c}\text { Freq. } \\
(\mathrm{Hz})\end{array}$ & $\begin{array}{c}\text { Amort. } \\
(\%)\end{array}$ \\
\hline \multirow{7}{*}{$0-4$} & $A_{100}$ & & & 35,70 & 1,02 & & & & & 95,48 & 0,63 & & & 179,70 & 0,55 \\
\hline & $\mathrm{A}_{101}$ & & & 35,75 & 1,00 & & & & & 95,56 & 0,53 & & & 179,68 & 0,55 \\
\hline & $\mathrm{A}_{103}$ & & & 35,79 & 1,33 & & & & & 95,63 & 0,50 & & & 179,80 & 0,53 \\
\hline & $\mathrm{A}_{105}$ & & & 35,68 & 0,91 & & & & & 95,53 & 0,71 & & & 179,71 & 0,55 \\
\hline & $A_{107}$ & & & 35,71 & 0,81 & & & & & 95,55 & 0,58 & & & 179,71 & 0,54 \\
\hline & $A_{109}$ & & & 35,68 & 0,98 & & & & & 95,55 & 0,54 & & & 179,76 & 0,55 \\
\hline & $\mathrm{A}_{1011}$ & & & 35,72 & 0,73 & & & & & 95,58 & 0,60 & & & 179,74 & 0,55 \\
\hline \multirow{7}{*}{$1-5$} & $A_{100}$ & 34,34 & 0,84 & 35,67 & 0,70 & 89,97 & 0,72 & & & 95,03 & 0,69 & 173,52 & 0,52 & 179,85 & 0,53 \\
\hline & $A_{101}$ & 34,23 & 0,69 & 35,70 & 0,85 & 90,03 & 0,56 & & & 95,15 & 0,62 & 173,61 & 0,56 & 179,77 & 0,53 \\
\hline & $\mathrm{A}_{103}$ & 34,22 & 0,67 & 35,69 & 0,87 & 90,02 & 0,68 & & & 95,19 & 0,63 & 173,60 & 0,56 & 179,78 & 0,54 \\
\hline & $\mathrm{A}_{105}$ & & & 35,61 & 1,11 & & & & & 95,22 & 0,75 & 173,63 & 0,56 & 179,76 & 0,55 \\
\hline & $A_{107}$ & & & 35,62 & 1,10 & & & & & 95,12 & 0,63 & 173,63 & 0,56 & 179,79 & 0,54 \\
\hline & $A_{109}$ & & & 35,98 & 1,83 & & & & & 95,47 & 0,62 & 172,84 & 1,35 & 179,66 & 0,52 \\
\hline & $A_{1011}$ & & & & & & & & & & & & & & \\
\hline \multirow{7}{*}{$2-6$} & $A_{100}$ & 34,15 & 0,71 & 35,78 & 0,90 & 91,41 & 0,64 & 92,97 & 0,89 & & & 172,62 & 0,55 & & \\
\hline & $A_{101}$ & 34,12 & 0,75 & 35,93 & 1,25 & 91,38 & 0,55 & 93,10 & 0,96 & & & 172,66 & 0,55 & & \\
\hline & $\mathrm{A}_{103}$ & 34,17 & 0,83 & 35,65 & 0,63 & 91,48 & 0,64 & 92,91 & 0,77 & & & 172,51 & 0,77 & 179,98 & 0,75 \\
\hline & $\mathrm{A}_{105}$ & 34,15 & 0,89 & 35,73 & 0,46 & 91,39 & 0,51 & 93,23 & 1,10 & & & 172,96 & 0,72 & 179,99 & 0,56 \\
\hline & $A_{107}$ & 34,16 & 0,82 & 35,74 & 0,69 & 91,20 & 0,44 & 92,76 & 1,03 & & & 172,50 & 0,83 & & \\
\hline & $A_{109}$ & 34,20 & 1,03 & & & 91,93 & 0,90 & 93,38 & 1,09 & & & 172,69 & 0,67 & & \\
\hline & $\mathrm{A}_{1011}$ & 34,16 & 0,82 & 35,77 & 0,66 & 91,49 & 0,66 & 92,91 & 0,76 & & & 173,22 & 0,68 & & \\
\hline \multirow{7}{*}{ 3-7 } & $A_{100}$ & 34,15 & 0,77 & 35,75 & 0,97 & 91,21 & 0,70 & 93,14 & 0,65 & & & 173,11 & 0,52 & 179,82 & 0,59 \\
\hline & $A_{101}$ & 34,23 & 0,91 & 35,81 & 0,34 & 91,03 & 0,62 & 93,27 & 0,74 & & & 173,09 & 0,56 & 179,72 & 0,53 \\
\hline & $\mathrm{A}_{103}$ & 34,15 & 0,78 & 35,73 & 0,96 & 91,28 & 1,33 & 93,27 & 0,67 & & & 173,06 & 0,55 & 179,55 & 0,47 \\
\hline & $\mathrm{A}_{105}$ & 34,15 & 0,82 & 35,72 & 0,78 & 90,94 & 0,63 & 93,31 & 0,66 & & & 173,11 & 0,53 & 179,82 & 0,52 \\
\hline & $\mathrm{A}_{107}$ & 34,12 & 0,87 & 35,88 & 0,89 & 90,98 & 0,65 & 93,27 & 0,69 & & & 173,14 & 0,54 & 179,75 & 0,54 \\
\hline & $\mathrm{A}_{109}$ & 34,15 & 1,03 & 35,74 & 0,60 & 91,01 & 0,76 & 93,26 & 0,61 & & & 173,12 & 0,53 & 179,84 & 0,52 \\
\hline & $\mathrm{A}_{1011}$ & 34,21 & 0,77 & 35,54 & 0,90 & 91,00 & 0,74 & 93,24 & 0,65 & & & 173,19 & 0,55 & 179,59 & 0,78 \\
\hline \multirow{7}{*}{$4-0$} & $A_{100}$ & 34,17 & 0,63 & 35,71 & 0,81 & & & & & 95,23 & 0,57 & 173,48 & 0,55 & 179,41 & 0,53 \\
\hline & $\mathrm{A}_{101}$ & 34,15 & 0,90 & 35,71 & 0,77 & & & & & 95,25 & 0,56 & & & 179,43 & 0,56 \\
\hline & $\mathrm{A}_{103}$ & 34,13 & 0,98 & 35,72 & 0,74 & & & & & 95,26 & 0,57 & 173,39 & 0,62 & 179,41 & 0,52 \\
\hline & $\mathrm{A}_{105}$ & 34,14 & 0,95 & 35,72 & 0,74 & & & & & 95,26 & 0,57 & 173,58 & 0,56 & 179,40 & 0,54 \\
\hline & $A_{107}$ & 34,09 & 0,78 & 35,73 & 0,79 & & & & & 95,24 & 0,56 & 173,34 & 0,48 & 179,43 & 0,51 \\
\hline & $A_{109}$ & 34,17 & 1,01 & 35,71 & 0,73 & & & & & 95,26 & 0,58 & & & 179,49 & 0,52 \\
\hline & $\mathrm{A}_{1011}$ & 34,09 & 0,85 & 35,71 & 0,79 & & & & & 95,24 & 0,60 & 173,58 & 0,57 & 179,38 & 0,53 \\
\hline \multirow{7}{*}{$5-1$} & $A_{100}$ & 34,31 & 0,79 & 35,46 & 0,57 & 89,99 & 0,66 & & & 95,03 & 0,59 & 173,35 & 0,57 & 179,51 & 0,55 \\
\hline & $\mathrm{A}_{101}$ & 34,14 & 0,68 & 35,71 & 0,87 & 90,04 & 0,77 & & & 95,02 & 0,59 & 173,39 & 0,48 & 179,61 & 0,53 \\
\hline & $\mathrm{A}_{103}$ & 34,19 & 1,61 & 35,77 & 0,75 & 90,00 & 0,60 & & & 95,03 & 0,60 & 173,42 & 0,54 & 179,57 & 0,55 \\
\hline & $\mathrm{A}_{105}$ & 35,68 & 0,95 & & & & & & & 95,11 & 0,77 & 173,38 & 0,55 & 179,54 & 0,54 \\
\hline & $A_{107}$ & 35,81 & 1,02 & & & & & & & 95,02 & 0,71 & 173,57 & 0,57 & 179,53 & 0,54 \\
\hline & $A_{109}$ & 33,84 & 1,89 & 35,77 & 0,80 & 89,88 & 0,49 & & & 95,06 & 0,57 & & & 179,60 & 0,54 \\
\hline & $\mathrm{A}_{1011}$ & 34,17 & 1,07 & 35,70 & 0,75 & 90,12 & 0,75 & & & 95,01 & 0,62 & 173,36 & 0,56 & 179,55 & 0,53 \\
\hline & $\mathrm{A}_{100}$ & 34,15 & 0,80 & 35,72 & 0,86 & 91,20 & 0,58 & 93,02 & 0,74 & & & 173,09 & 0,56 & 179,66 & 0,59 \\
\hline & $A_{101}$ & 34,15 & 0,84 & 35,79 & 0,64 & 91,17 & 0,67 & 93,11 & 0,66 & & & 173,12 & 0,55 & & \\
\hline & $\mathrm{A}_{103}$ & 34,15 & 0,85 & 35,82 & 0,62 & 91,22 & 0,75 & 93,13 & 0,66 & & & 173,09 & 0,58 & 179,63 & 0,69 \\
\hline $6-2$ & $\mathrm{~A}_{105}$ & 34,13 & 0,74 & 35,77 & 1,12 & & & & & & & 173,07 & 0,55 & 179,92 & 0,56 \\
\hline & $A_{107}$ & 34,16 & 0,82 & 35,73 & 0,75 & 91,23 & 0,51 & 93,09 & 0,85 & & & 173,10 & 0,55 & 179,88 & 0,65 \\
\hline & $A_{109}$ & 34,16 & 0,80 & 35,70 & 0,73 & 91,07 & 0,68 & 93,21 & 0,71 & & & 173,05 & 0,65 & 179,10 & 0,57 \\
\hline & $\mathrm{A}_{1011}$ & 34,16 & 0,79 & 35,70 & 0,88 & 91,18 & 0,68 & 93,11 & 0,70 & & & 173,08 & 0,55 & 179,85 & 0,54 \\
\hline & $A_{100}$ & 34,17 & 0,83 & 35,62 & 0,71 & 91,21 & 0,66 & 93,56 & 0,74 & & & 173,29 & 0,55 & 179,80 & 0,85 \\
\hline & $\mathrm{A}_{101}$ & 34,14 & 0,78 & 35,76 & 0,83 & 91,19 & 0,65 & 93,62 & 0,73 & & & 173,25 & 0,55 & 179,79 & 0,70 \\
\hline & $\mathrm{A}_{103}$ & 34,17 & 0,78 & 35,63 & 1,06 & 91,15 & 0,70 & 93,65 & 0,71 & & & 173,30 & 0,55 & 179,71 & 0,83 \\
\hline $7-3$ & $\mathrm{~A}_{105}$ & 34,16 & 0,78 & 35,66 & 0,95 & 91,29 & 0,55 & 93,64 & 0,73 & & & 173,32 & 0,56 & 179,63 & 0,87 \\
\hline & $\mathrm{A}_{107}$ & 34,15 & 0,80 & 35,79 & 1,01 & 91,26 & 0,71 & 93,59 & 0,70 & & & 173,28 & 0,55 & 179,72 & 0,71 \\
\hline & $A_{109}$ & 34,16 & 0,79 & 35,75 & 0,98 & 91,37 & 0,61 & 93,55 & 0,75 & & & 173,32 & 0,56 & 179,45 & 0,68 \\
\hline & $\mathrm{A}_{1011}$ & 34,16 & 0,82 & 35,66 & 0,85 & 91,20 & 0,64 & 93,62 & 0,75 & & & 173,30 & 0,55 & 179,73 & 0,90 \\
\hline & & 34,23 & 0,87 & 35,72 & 0,85 & 90,96 & 0,67 & 93,26 & 0,77 & 95,26 & 0,61 & 173,21 & 0,59 & 179,66 & 0,59 \\
\hline $\begin{array}{l}\text { Desvio } \\
\text { Coef. }\end{array}$ & $\begin{array}{l}\text { sadrão } \\
\text { riação }\end{array}$ & $\begin{array}{l}0,338 \\
1,0 \%\end{array}$ & $\begin{array}{l}0,218 \\
25,0 \%\end{array}$ & $\begin{array}{c}0,083 \\
0,2 \%\end{array}$ & $\begin{array}{r}0,230 \\
26,9 \%\end{array}$ & $\begin{array}{c}0,555 \\
0,6 \%\end{array}$ & $\begin{array}{c}0,147 \\
22,0 \%\end{array}$ & $\begin{array}{l}0,250 \\
0,3 \%\end{array}$ & $\begin{array}{c}0,134 \\
17,5 \%\end{array}$ & $\begin{array}{l}0,206 \\
0,2 \%\end{array}$ & $\begin{array}{c}0,066 \\
10,8 \%\end{array}$ & $\begin{array}{c}0,293 \\
0,2 \%\end{array}$ & $\begin{array}{c}0,134 \\
22,7 \%\end{array}$ & $\begin{array}{c}0,177 \\
0,1 \%\end{array}$ & $\begin{array}{c}0,104 \\
17,6 \%\end{array}$ \\
\hline
\end{tabular}


Tabela E.13 - Parâmetros modais da Tora 9 para o ensaio com excitação horizontal.

\begin{tabular}{|c|c|c|c|c|c|c|c|c|c|c|c|c|c|}
\hline \multirow[b]{2}{*}{ Plano } & \multirow[b]{2}{*}{ FRF } & \multicolumn{4}{|c|}{$1^{\circ}$ Modo } & \multicolumn{4}{|c|}{$2^{\circ}$ Modo } & \multicolumn{4}{|c|}{$3^{\circ}$ Modo } \\
\hline & & Freq. $(\mathrm{Hz})$ & $\begin{array}{c}\text { Amort. } \\
(\%)\end{array}$ & Freq. (Hz) & $\begin{array}{c}\text { Amort. } \\
(\%)\end{array}$ & Freq. (Hz) & $\begin{array}{c}\text { Amort. } \\
(\%)\end{array}$ & Freq. (Hz) & $\begin{array}{c}\text { Amort. } \\
(\%)\end{array}$ & Freq. $(\mathrm{Hz})$ & $\begin{array}{c}\text { Amort. } \\
(\%)\end{array}$ & Freq. (Hz) & $\begin{array}{c}\text { Amort. } \\
(\%)\end{array}$ \\
\hline \multirow{7}{*}{$0-4$} & $\mathrm{~A}_{100}$ & 32,05 & 0,94 & 33,72 & 0,87 & 85,67 & 0,71 & 89,36 & 0,72 & 161,91 & 0,61 & 171,73 & 0,63 \\
\hline & $\mathrm{A}_{101}$ & 32,06 & 0,99 & 33,73 & 0,72 & 85,71 & 0,71 & 89,35 & 0,72 & 161,96 & 0,61 & 171,79 & 0,65 \\
\hline & $\mathrm{A}_{103}$ & 32,00 & 0,86 & 33,83 & 1,20 & 85,70 & 0,72 & 89,33 & 0,72 & 161,90 & 0,54 & 171,83 & 0,61 \\
\hline & $\mathrm{A}_{105}$ & 32,06 & 0,95 & 33,72 & 0,87 & 85,33 & 0,59 & 89,31 & 0,71 & 161,92 & 0,62 & 171,75 & 0,63 \\
\hline & $A_{107}$ & 32,07 & 0,89 & 33,69 & 0,93 & 85,59 & 0,71 & 89,34 & 0,72 & 161,90 & 0,60 & 171,75 & 0,62 \\
\hline & $\mathrm{A}_{109}$ & 32,07 & 1,56 & 33,71 & 0,11 & 85,80 & 0,71 & 89,32 & 0,76 & & & & \\
\hline & $A_{1011}$ & & & & & & & & & & & & \\
\hline \multirow{7}{*}{$1-5$} & $A_{100}$ & & & 33,70 & 0,89 & & & 89,99 & 0,69 & & & 171,35 & 0,62 \\
\hline & $\mathrm{A}_{101}$ & & & 33,70 & 0,93 & & & 90,04 & 0,69 & & & 171,44 & 0,71 \\
\hline & $\mathrm{A}_{103}$ & & & 33,75 & 0,91 & & & 90,00 & 0,68 & & & 171,34 & 0,62 \\
\hline & $\mathrm{A}_{105}$ & & & 33,74 & 0,98 & & & 89,72 & 0,65 & & & 171,36 & 0,61 \\
\hline & $\mathrm{A}_{107}$ & & & 33,72 & 0,93 & & & 89,99 & 0,67 & & & 171,36 & 0,61 \\
\hline & $\mathrm{A}_{109}$ & & & 33,71 & 1,03 & & & 89,99 & 0,70 & & & 171,53 & 0,83 \\
\hline & $A_{1011}$ & & & & & & & & & & & & \\
\hline \multirow{7}{*}{$2-6$} & $\mathrm{~A}_{100}$ & 32,13 & 1,18 & 33,70 & 1,02 & 85,97 & 0,68 & 89,32 & 0,71 & 161,96 & 0,61 & 171,50 & 0,62 \\
\hline & $\mathrm{A}_{101}$ & 32,10 & 1,15 & 33,73 & 0,73 & 86,00 & 0,74 & 89,36 & 0,64 & 161,93 & 0,70 & 171,40 & 0,58 \\
\hline & $\mathrm{A}_{103}$ & 32,15 & 0,76 & 33,68 & 0,99 & 85,99 & 0,71 & 89,31 & 0,69 & 161,98 & 0,61 & 171,53 & 0,63 \\
\hline & $\mathrm{A}_{105}$ & 32,05 & 0,87 & 33,73 & 0,95 & & & & & 161,97 & 0,61 & 171,51 & 0,62 \\
\hline & $\mathrm{A}_{107}$ & 32,12 & 0,79 & 33,71 & 0,93 & 85,98 & 0,68 & 89,30 & 0,70 & 161,99 & 0,62 & 171,52 & 0,63 \\
\hline & $\mathrm{A}_{109}$ & 31,96 & 1,97 & 33,84 & 0,65 & 85,99 & 0,67 & 89,36 & 0,70 & & & & \\
\hline & $\mathrm{A}_{1011}$ & & & & & & & & & & & & \\
\hline \multirow{7}{*}{$3-7$} & $A_{100}$ & 32,05 & 1,09 & & & 86,65 & 0,62 & & & 161,67 & 0,64 & & \\
\hline & $\mathrm{A}_{101}$ & 32,03 & 1,00 & & & 86,65 & 0,64 & & & 161,64 & 0,61 & & \\
\hline & $\mathrm{A}_{103}$ & 32,11 & 0,97 & & & 86,65 & 0,69 & & & 161,74 & 0,60 & & \\
\hline & $\mathrm{A}_{105}$ & 32,06 & 0,96 & & & 86,72 & 0,63 & & & 161,72 & 0,61 & & \\
\hline & $\mathrm{A}_{107}$ & 32,06 & 0,95 & & & 86,74 & 0,66 & & & 161,72 & 0,61 & & \\
\hline & $\mathrm{A}_{109}$ & 32,05 & 1,04 & & & 86,70 & 0,64 & & & & & & \\
\hline & $A_{1011}$ & & & & & & & & & & & & \\
\hline \multirow{7}{*}{ 4-0 } & $\mathrm{A}_{100}$ & 32,03 & 0,84 & 33,73 & 1,23 & 85,26 & 0,97 & 89,19 & 0,78 & 161,96 & 0,60 & 171,71 & 0,53 \\
\hline & $\mathrm{A}_{101}$ & 32,08 & 0,56 & 33,68 & 1,51 & 85,55 & 1,05 & 89,23 & 0,82 & 162,01 & 0,59 & 171,77 & 0,63 \\
\hline & $\mathrm{A}_{103}$ & 32,07 & 0,73 & 33,57 & 1,60 & 85,41 & 1,01 & 89,21 & 0,73 & 161,98 & 0,60 & 171,70 & 0,62 \\
\hline & $\mathrm{A}_{105}$ & 32,07 & 0,95 & 33,79 & 0,91 & & & 89,16 & 0,95 & 161,98 & 0,60 & 171,70 & 0,60 \\
\hline & $\mathrm{A}_{107}$ & 32,04 & 0,91 & 33,72 & 1,02 & 85,23 & 1,02 & 89,18 & 0,80 & 161,96 & 0,59 & 171,71 & 0,60 \\
\hline & $\mathrm{A}_{109}$ & 31,98 & 1,01 & 34,02 & 1,01 & 85,61 & 1,20 & 89,29 & 0,84 & & & & \\
\hline & $A_{1011}$ & & & & & & & & & & & & \\
\hline \multirow{7}{*}{ 5-1 } & $\mathrm{A}_{100}$ & & & 33,73 & 0,90 & & & 89,91 & 0,67 & & & 171,34 & 0,61 \\
\hline & $\mathrm{A}_{101}$ & & & 33,73 & 1,01 & & & 89,92 & 0,67 & & & 171,35 & 0,66 \\
\hline & $\mathrm{A}_{103}$ & & & 33,80 & 1,10 & & & 89,90 & 0,67 & & & 171,37 & 0,62 \\
\hline & $\mathrm{A}_{105}$ & & & 33,72 & 0,96 & & & 90,01 & 0,72 & & & 171,36 & 0,62 \\
\hline & $\mathrm{A}_{107}$ & & & 33,72 & 0,94 & & & 89,92 & 0,66 & & & 171,40 & 0,63 \\
\hline & $\mathrm{A}_{109}$ & & & 33,71 & 0,98 & & & 89,94 & 0,67 & & & 171,44 & 0,50 \\
\hline & $A_{1011}$ & & & & & & & & & & & & \\
\hline \multirow{7}{*}{ 6-2 } & $\mathrm{A}_{100}$ & 32,09 & 1,15 & 33,70 & 0,79 & 85,81 & 0,84 & 88,80 & 0,77 & 162,08 & 0,61 & 171,64 & 0,62 \\
\hline & $\mathrm{A}_{101}$ & 32,06 & 1,05 & 33,72 & 0,88 & 85,98 & 0,92 & 88,99 & 0,76 & 162,00 & 0,57 & 171,64 & 0,57 \\
\hline & $\mathrm{A}_{103}$ & 31,99 & 0,82 & 33,76 & 1,02 & 85,82 & 0,81 & 88,82 & 0,82 & 162,10 & 0,60 & 171,64 & 0,62 \\
\hline & $\mathrm{A}_{105}$ & 32,06 & 0,99 & 33,69 & 0,90 & 86,12 & 0,87 & 89,01 & 0,85 & 162,11 & 0,61 & 171,67 & 0,63 \\
\hline & $\mathrm{A}_{107}$ & 31,98 & 1,04 & 33,73 & 0,87 & 85,74 & 0,77 & 88,82 & 0,83 & 162,10 & 0,62 & 171,65 & 0,64 \\
\hline & $\mathrm{A}_{109}$ & 31,94 & 1,29 & 33,76 & 0,88 & 85,97 & 0,79 & 88,96 & 0,82 & & & & \\
\hline & $A_{1011}$ & & & & & & & & & & & & \\
\hline & $\mathrm{A}_{100}$ & 32,09 & 1,00 & & & 86,56 & 0,76 & & & 161,68 & 0,59 & & \\
\hline & $\mathrm{A}_{101}$ & 32,05 & 1,08 & & & 86,57 & 0,71 & & & 161,67 & 0,61 & & \\
\hline & $\mathrm{A}_{103}$ & 32,06 & 1,03 & & & 86,61 & 0,77 & & & 161,68 & 0,60 & & \\
\hline $7-3$ & $\mathrm{~A}_{105}$ & 32,05 & 1,07 & & & 86,78 & 0,95 & & & 161,67 & 0,60 & & \\
\hline & $\mathrm{A}_{107}$ & 32,06 & 1,03 & & & 86,52 & 0,78 & & & 161,68 & 0,60 & & \\
\hline & $\mathrm{A}_{109}$ & 32,04 & 1,08 & & & 86,55 & 0,71 & & & & & & \\
\hline & $A_{1011}$ & & & & & & & & & & & & \\
\hline & & 32,05 & 1,02 & 33,73 & 0,95 & 86,06 & 0,78 & 89,45 & 0,73 & 161,89 & 0,61 & 171,55 & 0,62 \\
\hline Desvic & ladrão & 0,045 & 0,235 & 0,067 & 0,233 & 0,488 & 0,143 & 0,397 & 0,070 & 0,153 & 0,024 & 0,163 & 0,051 \\
\hline Coef. & riação & $0,1 \%$ & $23,2 \%$ & $0,2 \%$ & $24,5 \%$ & $0,6 \%$ & $18,4 \%$ & $0,4 \%$ & $9,5 \%$ & $0,1 \%$ & $3,9 \%$ & $0,1 \%$ & $8,3 \%$ \\
\hline
\end{tabular}


Tabela E.14 - Parâmetros modais da Tora 10 para o ensaio com excitação horizontal.

\begin{tabular}{|c|c|c|c|c|c|c|c|}
\hline \multirow{2}{*}{ Plano } & \multirow{2}{*}{ FRF } & \multicolumn{2}{|c|}{$1^{\circ}$ Modo } & \multicolumn{2}{|c|}{$2^{\circ}$ Modo } & \multicolumn{2}{|c|}{$3^{\circ}$ Modo } \\
\hline & & Freq. (Hz) & Amort. (\%) & Freq. (Hz) & Amort. (\%) & Freq. (Hz) & Amort. (\%) \\
\hline \multirow{7}{*}{$0-4$} & $A_{100}$ & 34,03 & 0,91 & 91,04 & 0,58 & 172,55 & 0,49 \\
\hline & $\mathrm{A}_{101}$ & 34,13 & 1,07 & 91,07 & 0,60 & 172,53 & 0,43 \\
\hline & $\mathrm{A}_{103}$ & 34,17 & 1,02 & 91,06 & 0,60 & 172,53 & 0,55 \\
\hline & $\mathrm{A}_{105}$ & 34,16 & 0,98 & 91,04 & 0,69 & 172,67 & 0,51 \\
\hline & $\mathrm{A}_{107}$ & 34,15 & 1,07 & 91,07 & 0,59 & 172,55 & 0,60 \\
\hline & $\mathrm{A}_{109}$ & 34,15 & 1,02 & 91,06 & 0,64 & 172,74 & 0,54 \\
\hline & $A_{1011}$ & & & & & & \\
\hline \multirow{7}{*}{$1-5$} & $A_{100}$ & 33,83 & 0,76 & 91,79 & 0,62 & 172,30 & 0,60 \\
\hline & $A_{101}$ & 33,84 & 0,93 & 91,84 & 0,61 & 172,15 & 0,52 \\
\hline & $A_{103}$ & 33,86 & 1,16 & 91,86 & 0,64 & 172,32 & 0,59 \\
\hline & $A_{105}$ & 33,85 & 0,90 & 91,57 & 0,20 & 172,28 & 0,56 \\
\hline & $A_{107}$ & 33,87 & 0,83 & 91,80 & 0,63 & 172,28 & 0,55 \\
\hline & $\mathrm{A}_{109}$ & 33,85 & 0,81 & 91,81 & 0,69 & & \\
\hline & $A_{1011}$ & & & & & & \\
\hline \multirow{7}{*}{$2-6$} & $\mathrm{~A}_{100}$ & 34,04 & 0,96 & 91,94 & 0,60 & 172,63 & 0,59 \\
\hline & $A_{101}$ & 33,95 & 1,11 & 91,96 & 0,55 & 172,76 & 0,70 \\
\hline & $\mathrm{A}_{103}$ & 34,03 & 0,90 & 91,94 & 0,58 & 172,24 & 0,78 \\
\hline & $A_{105}$ & 33,98 & 1,05 & 91,86 & 0,34 & 172,27 & 0,40 \\
\hline & $\mathrm{A}_{107}$ & 34,05 & 1,06 & 91,93 & 0,61 & 172,60 & 0,86 \\
\hline & $\mathrm{A}_{109}$ & 33,98 & 1,01 & 91,93 & 0,54 & & \\
\hline & $A_{1011}$ & & & & & & \\
\hline \multirow{7}{*}{$3-7$} & $A_{100}$ & 34,31 & 0,69 & 91,34 & 0,95 & 172,21 & 1,26 \\
\hline & $A_{101}$ & 34,27 & 0,78 & 91,30 & 0,70 & 173,73 & 0,72 \\
\hline & $A_{103}$ & 34,30 & 0,81 & 91,28 & 0,57 & 173,96 & 0,58 \\
\hline & $A_{105}$ & 34,28 & 0,81 & 91,24 & 0,74 & 173,80 & 0,18 \\
\hline & $\mathrm{A}_{107}$ & 34,28 & 0,82 & 91,31 & 0,79 & 173,89 & 0,53 \\
\hline & $A_{109}$ & 34,28 & 0,83 & 91,36 & 0,61 & & \\
\hline & $A_{1011}$ & & & & & & \\
\hline \multirow{7}{*}{$4-0$} & $A_{100}$ & 34,09 & 0,99 & 91,06 & 0,75 & 172,52 & 0,59 \\
\hline & $A_{101}$ & 34,13 & 1,01 & 91,16 & 0,71 & 172,55 & 0,61 \\
\hline & $\mathrm{A}_{103}$ & 34,25 & 1,10 & 91,30 & 0,66 & 173,09 & 0,53 \\
\hline & $A_{105}$ & 34,15 & 1,03 & 91,26 & 0,59 & 172,98 & 0,52 \\
\hline & $A_{107}$ & 34,23 & 0,88 & 91,24 & 0,69 & 173,18 & 0,52 \\
\hline & $A_{109}$ & 34,19 & 1,11 & 91,33 & 0,71 & & \\
\hline & $A_{1011}$ & & & & & & \\
\hline \multirow{7}{*}{$5-1$} & $A_{100}$ & 33,95 & 0,79 & 92,02 & 0,59 & 172,99 & 0,57 \\
\hline & $A_{101}$ & 33,97 & 0,81 & 92,03 & 0,68 & 173,17 & 0,65 \\
\hline & $A_{103}$ & 33,92 & 0,98 & 92,04 & 0,62 & 173,19 & 0,57 \\
\hline & $\mathrm{A}_{105}$ & 33,95 & 0,85 & 92,00 & 0,61 & 173,06 & 0,58 \\
\hline & $A_{107}$ & 33,94 & 0,82 & 91,97 & 0,58 & 173,00 & 0,57 \\
\hline & $\mathrm{A}_{109}$ & 33,95 & 0,87 & 91,96 & 0,57 & & \\
\hline & $A_{1011}$ & & & & & & \\
\hline \multirow{7}{*}{$6-2$} & $A_{100}$ & 34,03 & 1,06 & 92,25 & 0,59 & 173,56 & 0,68 \\
\hline & $A_{101}$ & 34,02 & 1,00 & 92,27 & 0,59 & 173,30 & 0,48 \\
\hline & $\mathrm{A}_{103}$ & 34,10 & 1,00 & 92,27 & 0,59 & 173,24 & 0,54 \\
\hline & $A_{105}$ & 34,04 & 1,06 & 92,26 & 0,52 & 173,17 & 0,58 \\
\hline & $A_{107}$ & 34,05 & 1,02 & 92,24 & 0,57 & 173,23 & 0,58 \\
\hline & $A_{109}$ & 34,05 & 1,00 & 92,27 & 0,58 & 173,22 & 0,62 \\
\hline & $A_{1011}$ & & & & & & \\
\hline \multirow{7}{*}{$7-3$} & $\mathrm{~A}_{100}$ & 34,37 & 0,79 & 91,65 & 0,59 & 174,84 & 0,55 \\
\hline & $\mathrm{A}_{101}$ & 34,34 & 0,83 & 91,65 & 0,61 & 174,84 & 0,57 \\
\hline & $\mathrm{A}_{103}$ & 34,39 & 0,89 & 91,63 & 0,60 & 174,81 & 0,55 \\
\hline & $A_{105}$ & 34,34 & 0,86 & 91,65 & 0,60 & 174,82 & 0,55 \\
\hline & $A_{107}$ & 34,35 & 0,84 & 91,63 & 0,59 & 174,80 & 0,54 \\
\hline & $\mathrm{A}_{109}$ & 34,34 & 0,82 & 91,64 & 0,59 & & \\
\hline & $A_{1011}$ & & & & & & \\
\hline \multicolumn{2}{|c|}{ Média } & 34,10 & 0,93 & 91,65 & 0,61 & 173,11 & 0,58 \\
\hline \multicolumn{2}{|c|}{$\begin{array}{l}\text { Desvio padrão } \\
\text { Coef. Variação }\end{array}$} & $\begin{array}{l}0,165 \\
0,5 \%\end{array}$ & $\begin{array}{r}0,115 \\
12,4 \% \\
\end{array}$ & $\begin{array}{l}0,402 \\
0,4 \% \\
\end{array}$ & $\begin{array}{c}0,104 \\
16,9 \% \\
\end{array}$ & $\begin{array}{l}0,796 \\
0,5 \% \\
\end{array}$ & $\begin{array}{r}0,148 \\
25,3 \% \\
\end{array}$ \\
\hline
\end{tabular}


Tabela E.15 - Parâmetros modais da Tora TB-1 para o ensaio com excitação horizontal.

\begin{tabular}{|c|c|c|c|c|c|c|c|c|c|}
\hline \multirow[b]{2}{*}{ Plano } & \multirow[b]{2}{*}{ FRF } & \multicolumn{4}{|c|}{$1^{\circ}$ Modo } & \multicolumn{4}{|c|}{$2^{\circ}$ Modo } \\
\hline & & Freq. (Hz) & $\begin{array}{c}\text { Amort. } \\
(\%)\end{array}$ & Freq. (Hz) & $\begin{array}{c}\text { Amort. } \\
(\%)\end{array}$ & Freq. (Hz) & $\begin{array}{c}\text { Amort. } \\
(\%)\end{array}$ & Freq. (Hz) & $\begin{array}{c}\text { Amort. } \\
(\%)\end{array}$ \\
\hline \multirow{3}{*}{$0-4$} & $\overline{A_{120}}$ & 162,65 & 0,57 & 174,97 & 0,61 & 395,58 & 0,64 & 421,12 & 0,63 \\
\hline & $A_{122}$ & 162,48 & 0,54 & 175,07 & 0,61 & 395,80 & 0,70 & 421,17 & 0,66 \\
\hline & $A_{123}$ & 162,46 & 0,59 & 175,08 & 0,59 & 396,24 & 0,68 & 421,33 & 0,66 \\
\hline \multirow{3}{*}{$1-5$} & $A_{120}$ & 162,34 & 0,58 & 175,14 & 0,61 & 395,38 & 0,64 & 420,51 & 0,61 \\
\hline & $A_{122}$ & 162,41 & 0,56 & 175,05 & 0,87 & 395,56 & 0,65 & 421,68 & 0,71 \\
\hline & $A_{123}$ & 162,29 & 0,60 & 175,19 & 0,53 & 395,32 & 0,63 & 420,83 & 0,70 \\
\hline \multirow{3}{*}{$2-6$} & $A_{120}$ & 162,26 & 0,61 & 175,10 & 0,57 & 395,30 & 0,65 & 420,88 & 0,68 \\
\hline & $A_{122}$ & 162,35 & 0,56 & 175,02 & 0,80 & 395,38 & 0,64 & 421,93 & 0,68 \\
\hline & $A_{123}$ & 162,37 & 0,61 & 174,98 & 0,65 & 395,74 & 0,66 & 421,57 & 0,67 \\
\hline \multirow{3}{*}{$3-7$} & $A_{120}$ & 162,39 & 0,47 & 174,82 & 0,64 & 398,99 & 0,70 & 420,38 & 0,66 \\
\hline & $A_{122}$ & 162,23 & 0,62 & 174,85 & 0,60 & 395,84 & 0,64 & 420,43 & 0,65 \\
\hline & $A_{123}$ & 162,16 & 0,73 & 174,86 & 0,59 & 394,94 & 0,75 & 420,46 & 0,69 \\
\hline \multirow{3}{*}{$4-0$} & $A_{120}$ & 161,96 & 0,60 & 174,87 & 0,58 & 395,56 & 1,28 & 420,54 & 0,78 \\
\hline & $A_{122}$ & 162,17 & 0,60 & 174,79 & 0,62 & 395,06 & 0,67 & 420,61 & 0,67 \\
\hline & $A_{123}$ & 162,00 & 0,58 & 174,89 & 0,61 & 395,07 & 0,88 & 420,62 & 0,64 \\
\hline \multirow{3}{*}{$5-1$} & $A_{120}$ & 162,21 & 0,64 & 174,44 & 0,35 & 394,71 & 0,65 & 420,27 & 0,55 \\
\hline & $A_{122}$ & 162,19 & 0,58 & 175,20 & 0,88 & 394,80 & 0,64 & 420,56 & 0,63 \\
\hline & $A_{123}$ & 162,18 & 0,61 & 175,05 & 0,40 & 394,75 & 0,64 & 423,19 & 1,40 \\
\hline \multirow{3}{*}{$6-2$} & $A_{120}$ & 162,17 & 0,60 & 174,89 & 0,54 & 394,93 & 0,65 & 420,02 & 0,81 \\
\hline & $A_{122}$ & 162,26 & 0,60 & 174,38 & 0,63 & 395,06 & 0,65 & 421,18 & 0,79 \\
\hline & $A_{123}$ & 162,21 & 0,56 & 175,20 & 0,91 & 395,03 & 0,70 & 421,03 & 0,68 \\
\hline \multirow{3}{*}{$7-3$} & $A_{120}$ & 161,84 & 0,59 & 174,83 & 0,57 & 394,90 & 0,60 & 420,15 & 0,67 \\
\hline & $A_{122}$ & 162,21 & 0,67 & 174,82 & 0,59 & 395,17 & 0,64 & 420,32 & 0,66 \\
\hline & $A_{123}$ & 162,78 & 0,68 & 174,01 & 0,60 & 394,70 & 0,94 & 420,38 & 0,64 \\
\hline \multicolumn{2}{|c|}{ Média } & 162,27 & 0,60 & 174,90 & 0,62 & 395,41 & 0,70 & 420,88 & 0,71 \\
\hline \multicolumn{2}{|c|}{$\begin{array}{l}\text { Desvio padrão } \\
\text { Coef. Variacão }\end{array}$} & 0,203 & 0,050 & 0,280 & 0,131 & 0,863 & 0,145 & 0,703 & 0,159 \\
\hline
\end{tabular}


Tabela E.16 - Parâmetros modais da Tora TB-2 para o ensaio com excitação horizontal.

\begin{tabular}{|c|c|c|c|c|c|c|c|c|c|}
\hline \multirow[b]{2}{*}{ Plano } & \multirow[b]{2}{*}{ FRF } & \multicolumn{4}{|c|}{$1^{\circ}$ Modo } & \multicolumn{4}{|c|}{$2^{\circ}$ Modo } \\
\hline & & $\begin{array}{l}\text { Freq. } \\
(\mathrm{Hz})\end{array}$ & $\begin{array}{c}\text { Amort. } \\
(\%)\end{array}$ & $\begin{array}{l}\text { Freq. } \\
(\mathrm{Hz})\end{array}$ & $\begin{array}{l}\text { Amort. } \\
(\%)\end{array}$ & $\begin{array}{l}\text { Freq. } \\
(\mathrm{Hz})\end{array}$ & $\begin{array}{c}\text { Amort. } \\
(\%)\end{array}$ & $\begin{array}{l}\text { Freq. } \\
(\mathrm{Hz})\end{array}$ & $\begin{array}{c}\text { Amort. } \\
(\%)\end{array}$ \\
\hline \multirow{3}{*}{$0-4$} & $\mathrm{~A}_{120}$ & 147,42 & 0,61 & & & 362,35 & 0,66 & & \\
\hline & $A_{122}$ & 147,48 & 0,63 & & & 362,53 & 0,63 & & \\
\hline & $A_{123}$ & 147,45 & 0,65 & & & 362,57 & 0,65 & & \\
\hline \multirow{3}{*}{$1-5$} & $A_{120}$ & 147,44 & 0,62 & 154,27 & 0,63 & 363,01 & 0,68 & 372,36 & 0,63 \\
\hline & $A_{122}$ & 147,58 & 0,58 & 154,21 & 0,67 & 363,22 & 0,60 & 372,60 & 0,69 \\
\hline & $\mathrm{A}_{123}$ & 147,46 & 0,63 & 154,35 & 0,61 & 363,14 & 0,64 & 372,04 & 0,67 \\
\hline \multirow{3}{*}{$2-6$} & $A_{120}$ & & & 154,27 & 0,73 & & & 372,46 & 0,63 \\
\hline & $A_{122}$ & & & 154,36 & 0,72 & & & 372,56 & 0,64 \\
\hline & $\mathrm{A}_{123}$ & & & 154,31 & 0,64 & & & 372,53 & 0,65 \\
\hline \multirow{3}{*}{$3-7$} & $A_{120}$ & 147,28 & 0,51 & 154,44 & 0,72 & 362,20 & 0,51 & 373,06 & 0,79 \\
\hline & $A_{122}$ & 147,49 & 0,66 & 154,30 & 0,57 & 362,67 & 0,77 & 371,82 & 0,42 \\
\hline & $A_{123}$ & 147,29 & 0,65 & 154,44 & 0,58 & 362,59 & 0,63 & 372,75 & 0,63 \\
\hline \multirow{3}{*}{$4-0$} & $A_{120}$ & 147,20 & 0,59 & & & 361,75 & 0,63 & & \\
\hline & $A_{122}$ & 147,26 & 0,61 & & & 361,85 & 0,64 & & \\
\hline & $\mathrm{A}_{123}$ & 147,25 & 0,33 & & & 361,85 & 0,63 & & \\
\hline \multirow{3}{*}{$5-1$} & $A_{120}$ & 147,18 & 0,61 & 154,00 & 0,64 & 362,01 & 0,65 & 371,80 & 0,66 \\
\hline & $A_{122}$ & 146,64 & 0,45 & 154,72 & 0,82 & 361,31 & 1,00 & 372,99 & 0,38 \\
\hline & $A_{123}$ & 147,21 & 0,63 & 154,11 & 0,60 & 362,16 & 0,62 & 371,91 & 0,66 \\
\hline \multirow{3}{*}{$6-2$} & $A_{120}$ & & & 154,08 & 0,62 & & & 371,71 & 0,65 \\
\hline & $A_{122}$ & & & 154,11 & 0,62 & & & 371,88 & 0,66 \\
\hline & $A_{123}$ & & & 154,12 & 0,61 & & & 371,78 & 0,67 \\
\hline \multirow{3}{*}{$7-3$} & $A_{120}$ & 147,12 & 0,63 & 154,04 & 0,63 & 361,77 & 0,64 & 371,84 & 0,67 \\
\hline & $A_{122}$ & 147,07 & 0,64 & 154,14 & 0,61 & 362,03 & 0,63 & 372,03 & 0,67 \\
\hline & $A_{123}$ & 147,11 & 0,67 & 154,12 & 0,59 & 361,96 & 0,62 & 372,00 & 0,68 \\
\hline \multirow{3}{*}{\multicolumn{2}{|c|}{$\begin{array}{l}\text { Desvio padrão } \\
\text { Coef. Variação }\end{array}$}} & 147,27 & 0,59 & 154,24 & 0,64 & 362,28 & 0,66 & 372,23 & 0,64 \\
\hline & & 0,219 & 0,084 & 0,178 & 0,065 & 0,524 & 0,097 & 0,440 & 0,092 \\
\hline & & $0,1 \%$ & $14,1 \%$ & $0,1 \%$ & $10,1 \%$ & $0,1 \%$ & $14,8 \%$ & $0,1 \%$ & $14,5 \%$ \\
\hline
\end{tabular}


Tabela E.17 - Parâmetros modais da Tora TB-3 para o ensaio com excitação horizontal.

\begin{tabular}{|c|c|c|c|c|c|c|c|}
\hline \multirow[b]{2}{*}{ Plano } & \multirow[b]{2}{*}{ FRF } & \multicolumn{4}{|c|}{$1^{\circ}$ Modo } & \multicolumn{2}{|c|}{$2^{\circ}$ Modo } \\
\hline & & $\begin{array}{c}\text { Freq. } \\
(\mathrm{Hz})\end{array}$ & $\begin{array}{c}\text { Amort. } \\
(\%)\end{array}$ & $\begin{array}{l}\text { Freq. } \\
(\mathrm{Hz})\end{array}$ & $\begin{array}{c}\text { Amort. } \\
(\%)\end{array}$ & $\begin{array}{c}\text { Freq. } \\
(\mathrm{Hz})\end{array}$ & $\begin{array}{c}\text { Amort. } \\
(\%)\end{array}$ \\
\hline \multirow{3}{*}{$0-4$} & $\mathrm{~A}_{120}$ & 143,96 & 0,78 & 147,49 & 0,43 & 359,10 & 0,69 \\
\hline & $\mathrm{A}_{122}$ & 143,82 & 0,77 & 147,81 & 0,65 & 359,14 & 0,65 \\
\hline & $A_{123}$ & 143,72 & 0,69 & 147,72 & 0,79 & 358,80 & 0,64 \\
\hline \multirow{3}{*}{$1-5$} & $A_{120}$ & 143,88 & 0,67 & & & 358,77 & 0,62 \\
\hline & $A_{122}$ & 143,85 & 0,71 & & & 358,94 & 0,65 \\
\hline & $\mathrm{A}_{123}$ & 143,86 & 0,71 & & & 358,89 & 0,65 \\
\hline \multirow{3}{*}{$2-6$} & $A_{120}$ & 143,86 & 0,54 & & & 359,79 & 0,68 \\
\hline & $A_{122}$ & 143,90 & 0,60 & 147,82 & 0,75 & 358,98 & 0,64 \\
\hline & $A_{123}$ & 143,93 & 0,69 & 148,09 & 0,49 & 359,61 & 0,66 \\
\hline \multirow{3}{*}{$3-7$} & $A_{120}$ & 147,69 & 0,61 & & & 360,70 & 0,62 \\
\hline & $\mathrm{A}_{122}$ & 147,73 & 0,61 & & & 360,81 & 0,61 \\
\hline & $A_{123}$ & 147,71 & 0,62 & & & 360,75 & 0,63 \\
\hline \multirow{3}{*}{$4-0$} & $\mathrm{~A}_{120}$ & 143,96 & 0,54 & 147,46 & 0,66 & 359,22 & 0,66 \\
\hline & $A_{122}$ & 143,93 & 0,63 & 147,72 & 0,59 & 359,21 & 0,63 \\
\hline & $A_{123}$ & 143,93 & 0,58 & 147,66 & 0,65 & 358,95 & 0,66 \\
\hline \multirow{3}{*}{$5-1$} & $A_{120}$ & 143,79 & 0,61 & & & 358,87 & 0,61 \\
\hline & $A_{122}$ & 143,81 & 0,61 & & & 358,91 & 0,61 \\
\hline & $A_{123}$ & 143,88 & 0,64 & & & 358,90 & 0,61 \\
\hline \multirow{3}{*}{$6-2$} & $A_{120}$ & 143,93 & 0,71 & 147,67 & 0,55 & 359,60 & 0,76 \\
\hline & $A_{122}$ & 143,76 & 0,53 & 147,71 & 0,66 & 359,73 & 0,57 \\
\hline & $A_{123}$ & 143,69 & 0,77 & 147,81 & 0,57 & 359,47 & 0,56 \\
\hline \multirow{3}{*}{$7-3$} & $A_{120}$ & & & 147,63 & 0,61 & 360,49 & 0,62 \\
\hline & $A_{122}$ & & & 147,65 & 0,63 & 360,66 & 0,62 \\
\hline & $A_{123}$ & & & 147,65 & 0,64 & 360,70 & 0,57 \\
\hline \multirow{3}{*}{\multicolumn{2}{|c|}{$\begin{array}{l}\text { Desvio padrão } \\
\text { Coef. Variação }\end{array}$}} & 144,41 & 0,65 & 147,71 & 0,62 & 359,54 & 0,63 \\
\hline & & 1,384 & 0,076 & 0,153 & 0,092 & 0,737 & 0,042 \\
\hline & & $1,0 \%$ & $11,7 \%$ & $0,1 \%$ & $14,9 \%$ & $0,2 \%$ & $6,5 \%$ \\
\hline
\end{tabular}


Tabela E.18 - Parâmetros modais da Tora TB-4 para o ensaio com excitação horizontal.

\begin{tabular}{|c|c|c|c|c|c|c|c|c|c|}
\hline \multirow[b]{2}{*}{ Plano } & \multirow[b]{2}{*}{ FRF } & \multicolumn{4}{|c|}{$1^{\circ}$ Modo } & \multicolumn{4}{|c|}{$2^{\circ}$ Modo } \\
\hline & & $\begin{array}{l}\text { Freq. } \\
(\mathrm{Hz})\end{array}$ & $\begin{array}{c}\text { Amort. } \\
(\%)\end{array}$ & $\begin{array}{l}\text { Freq. } \\
(\mathrm{Hz})\end{array}$ & $\begin{array}{c}\text { Amort. } \\
(\%)\end{array}$ & $\begin{array}{c}\text { Freq. } \\
(\mathrm{Hz})\end{array}$ & $\begin{array}{c}\text { Amort. } \\
(\%)\end{array}$ & $\begin{array}{c}\text { Freq. } \\
(\mathrm{Hz})\end{array}$ & $\begin{array}{c}\text { Amort } \\
(\%)\end{array}$ \\
\hline \multirow{3}{*}{$0-4$} & $\mathrm{~A}_{120}$ & 143,40 & 0,65 & 149,54 & 0,35 & 356,38 & 0,66 & & \\
\hline & $A_{122}$ & 143,48 & 0,68 & & & 356,70 & 0,64 & & \\
\hline & $A_{123}$ & 143,46 & 0,68 & & & 356,41 & 0,65 & & \\
\hline \multirow{3}{*}{$1-5$} & $A_{120}$ & 143,70 & 0,69 & 149,27 & 0,61 & 357,60 & 0,77 & 364,80 & 0,64 \\
\hline & $A_{122}$ & 143,35 & 0,59 & 149,37 & 0,66 & 356,00 & 0,83 & 365,06 & 0,65 \\
\hline & $\mathrm{A}_{123}$ & 143,39 & 0,58 & 149,36 & 0,66 & 357,36 & 0,70 & 365,00 & 0,66 \\
\hline \multirow{3}{*}{$2-6$} & $A_{120}$ & 142,37 & 0,72 & & & 357,14 & 0,81 & & \\
\hline & $A_{122}$ & & & 149,25 & 0,68 & & & 364,67 & 0,70 \\
\hline & $A_{123}$ & & & 149,25 & 0,65 & & & 364,54 & 0,65 \\
\hline \multirow{3}{*}{$3-7$} & $A_{120}$ & 143,33 & 0,62 & 149,98 & 0,85 & 356,25 & 0,66 & 364,32 & 0,68 \\
\hline & $A_{122}$ & 143,29 & 0,65 & 149,31 & 0,72 & 356,28 & 0,64 & 364,66 & 0,78 \\
\hline & $A_{123}$ & 143,32 & 0,66 & 149,21 & 0,63 & 356,23 & 0,65 & 364,25 & 0,73 \\
\hline \multirow{3}{*}{$4-0$} & $A_{120}$ & 143,25 & 0,65 & & & 356,02 & 0,62 & & \\
\hline & $A_{122}$ & 143,27 & 0,67 & & & 355,97 & 0,66 & & \\
\hline & $A_{123}$ & 143,28 & 0,66 & & & 355,93 & 0,66 & & \\
\hline \multirow{3}{*}{$5-1$} & $A_{120}$ & 143,09 & 0,53 & & & 356,42 & 0,68 & & \\
\hline & $A_{122}$ & 143,39 & 0,67 & & & 356,67 & 0,69 & & \\
\hline & $A_{123}$ & 142,93 & 0,57 & & & 356,47 & 0,64 & & \\
\hline \multirow{3}{*}{$6-2$} & $A_{120}$ & & & 149,13 & 0,75 & & & 364,31 & 0,69 \\
\hline & $A_{122}$ & & & 149,07 & 0,68 & & & 364,36 & 0,66 \\
\hline & $A_{123}$ & & & 149,21 & 0,63 & & & 364,42 & 0,66 \\
\hline \multirow{3}{*}{$7-3$} & $A_{120}$ & 143,20 & 0,67 & 149,06 & 0,62 & 356,55 & 0,71 & 363,22 & 0,64 \\
\hline & $A_{122}$ & 143,13 & 0,68 & 149,30 & 0,66 & 356,29 & 0,68 & 364,83 & 0,69 \\
\hline & $A_{123}$ & 143,28 & 0,66 & 149,07 & 0,63 & 356,63 & 0,69 & & \\
\hline \multicolumn{2}{|c|}{$\begin{array}{c}\text { Média } \\
\text { Desvio padrão } \\
\text { Coef. Variação }\end{array}$} & $\begin{array}{c}143,26 \\
0,268\end{array}$ & $\begin{array}{l}0,65 \\
0,047\end{array}$ & $\begin{array}{c}149,29 \\
0,231\end{array}$ & $\begin{array}{c}0,65 \\
0,103 \\
158 \%\end{array}$ & $\begin{array}{c}356,49 \\
0,459\end{array}$ & $\begin{array}{l}0,69 \\
0,058\end{array}$ & $\begin{array}{c}364,49 \\
0,467\end{array}$ & $\begin{array}{l}0,68 \\
0,042\end{array}$ \\
\hline
\end{tabular}


Tabela E.19 - Parâmetros modais da Tora TB-5 para o ensaio com excitação horizontal.

\begin{tabular}{|c|c|c|c|c|c|c|c|c|c|}
\hline \multirow[b]{2}{*}{ Plano } & \multirow[b]{2}{*}{ FRF } & \multicolumn{4}{|c|}{$1^{\circ}$ Modo } & \multicolumn{4}{|c|}{$2^{\circ}$ Modo } \\
\hline & & $\begin{array}{c}\text { Freq. } \\
(\mathrm{Hz})\end{array}$ & $\begin{array}{c}\text { Amort. } \\
(\%)\end{array}$ & $\begin{array}{c}\text { Freq. } \\
(\mathrm{Hz})\end{array}$ & $\begin{array}{c}\text { Amort. } \\
(\%)\end{array}$ & $\begin{array}{c}\text { Freq. } \\
(\mathrm{Hz})\end{array}$ & $\begin{array}{c}\text { Amort. } \\
(\%) \\
\end{array}$ & $\begin{array}{c}\text { Freq. } \\
(\mathrm{Hz})\end{array}$ & $\begin{array}{c}\text { Amort. } \\
(\%)\end{array}$ \\
\hline \multirow{3}{*}{$0-4$} & $A_{120}$ & & & 150,45 & 0,68 & & & 366,11 & 0,73 \\
\hline & $A_{122}$ & & & 150,39 & 0,66 & & & 366,17 & 0,72 \\
\hline & $A_{123}$ & & & 150,47 & 0,66 & & & 366,12 & 0,69 \\
\hline \multirow{3}{*}{$1-5$} & $A_{120}$ & 143,44 & 0,57 & 150,47 & 0,78 & 355,52 & 0,76 & 366,00 & 0,68 \\
\hline & $A_{122}$ & 143,70 & 0,72 & 150,36 & 0,62 & 355,95 & 0,75 & 366,27 & 0,67 \\
\hline & $\mathrm{A}_{123}$ & 143,62 & 0,61 & 150,40 & 0,73 & 355,77 & 0,72 & 366,77 & 0,69 \\
\hline \multirow{3}{*}{$2-6$} & $A_{120}$ & 143,52 & 0,67 & & & 354,95 & 0,68 & & \\
\hline & $A_{122}$ & 143,54 & 0,68 & & & 355,31 & 0,64 & & \\
\hline & $\mathrm{A}_{123}$ & 143,55 & 0,73 & & & 355,31 & 0,68 & & \\
\hline \multirow{3}{*}{$3-7$} & $A_{120}$ & 143,68 & 0,62 & 150,28 & 0,72 & 356,02 & 0,70 & 366,31 & 0,80 \\
\hline & $A_{122}$ & 143,56 & 0,71 & 150,57 & 0,62 & 355,67 & 0,80 & 366,05 & 0,49 \\
\hline & $\mathrm{A}_{123}$ & 143,58 & 0,73 & 150,62 & 0,55 & 356,11 & 0,71 & 366,21 & 0,80 \\
\hline \multirow{3}{*}{$4-0$} & $A_{120}$ & & & 150,44 & 0,67 & & & 365,96 & 0,71 \\
\hline & $A_{122}$ & & & 150,41 & 0,72 & & & 366,17 & 0,68 \\
\hline & $\mathrm{A}_{123}$ & & & 150,47 & 0,67 & & & 366,08 & 0,69 \\
\hline \multirow{3}{*}{$5-1$} & $A_{120}$ & 143,42 & 0,72 & 150,60 & 0,48 & 355,60 & 0,70 & 366,66 & 0,80 \\
\hline & $A_{122}$ & 143,24 & 0,68 & 150,97 & 0,66 & 355,85 & 0,71 & 366,53 & 0,72 \\
\hline & $\mathrm{A}_{123}$ & 143,53 & 0,69 & 150,56 & 0,64 & 355,69 & 0,70 & 366,48 & 0,70 \\
\hline \multirow{3}{*}{$6-2$} & $A_{120}$ & 143,56 & 0,67 & & & 355,20 & 0,68 & & \\
\hline & $A_{122}$ & 143,59 & 0,65 & & & 355,27 & 0,72 & & \\
\hline & $\mathrm{A}_{123}$ & 143,60 & 0,67 & & & 355,17 & 0,72 & & \\
\hline \multirow{3}{*}{$7-3$} & $A_{120}$ & 143,52 & 0,67 & 150,40 & 0,67 & 356,56 & 0,64 & 366,19 & 0,72 \\
\hline & $A_{122}$ & 143,49 & 0,66 & 150,46 & 0,69 & 356,46 & 0,75 & 366,42 & 0,72 \\
\hline & $A_{123}$ & 143,52 & 0,68 & 150,46 & 0,66 & 356,51 & 0,82 & 366,49 & 0,68 \\
\hline \multirow{3}{*}{\multicolumn{2}{|c|}{$\begin{array}{c}\text { Média } \\
\text { Desvio padrão } \\
\text { Coef. Variação }\end{array}$}} & 143,54 & 0,67 & 150,49 & 0,66 & 355,72 & 0,72 & 366,28 & 0,70 \\
\hline & & 0,103 & 0,043 & 0,147 & 0,068 & 0,483 & 0,047 & 0,234 & 0,068 \\
\hline & & $0,1 \%$ & $6,4 \%$ & $0,1 \%$ & $10,3 \%$ & $0,1 \%$ & $6,6 \%$ & $0,1 \%$ & $9,7 \%$ \\
\hline
\end{tabular}


Tabela E.20 - Parâmetros modais da Tora TB-6 para o ensaio com excitação horizontal.

\begin{tabular}{|c|c|c|c|c|c|c|c|c|c|}
\hline \multirow[b]{2}{*}{ Plano } & \multirow[b]{2}{*}{ FRF } & \multicolumn{4}{|c|}{$1^{\circ}$ Modo } & \multicolumn{4}{|c|}{$2^{\circ}$ Modo } \\
\hline & & $\begin{array}{c}\text { Freq. } \\
(\mathrm{Hz})\end{array}$ & $\begin{array}{c}\text { Amort. } \\
(\%)\end{array}$ & $\begin{array}{c}\text { Freq. } \\
(\mathrm{Hz})\end{array}$ & $\begin{array}{c}\text { Amort. } \\
(\%)\end{array}$ & $\begin{array}{c}\text { Freq. } \\
(\mathrm{Hz})\end{array}$ & $\begin{array}{c}\text { Amort. } \\
(\%)\end{array}$ & $\begin{array}{l}\text { Freq. } \\
(\mathrm{Hz})\end{array}$ & $\begin{array}{c}\text { Amort. } \\
(\%)\end{array}$ \\
\hline \multirow{3}{*}{$0-4$} & $A_{120}$ & & & 146,58 & 0,64 & & & 355,61 & 0,70 \\
\hline & $A_{122}$ & & & 146,61 & 0,65 & & & 355,59 & 0,69 \\
\hline & $A_{123}$ & & & 146,64 & 0,67 & & & 355,58 & 0,67 \\
\hline \multirow{3}{*}{$1-5$} & $A_{120}$ & 141,18 & 0,87 & 146,71 & 0,69 & 343,61 & 0,58 & 356,14 & 0,59 \\
\hline & $A_{122}$ & 141,14 & 0,88 & 146,80 & 0,76 & 343,99 & 0,66 & 355,47 & 0,97 \\
\hline & $A_{123}$ & 140,97 & 0,84 & 146,83 & 0,79 & 343,74 & 0,67 & 356,11 & 0,81 \\
\hline \multirow{3}{*}{$2-6$} & $A_{120}$ & 141,32 & 0,62 & & & 343,94 & 0,66 & & \\
\hline & $A_{122}$ & 141,33 & 0,62 & & & 344,05 & 0,65 & & \\
\hline & $A_{123}$ & 141,31 & 0,63 & & & 344,02 & 0,66 & & \\
\hline \multirow{3}{*}{$3-7$} & $A_{120}$ & 141,32 & 0,70 & 146,58 & 0,58 & 343,44 & 0,72 & 355,65 & 0,69 \\
\hline & $A_{122}$ & 141,29 & 0,57 & 146,60 & 0,69 & 343,73 & 0,71 & 356,18 & 0,71 \\
\hline & $A_{123}$ & 140,91 & 0,19 & 147,05 & 0,97 & 343,82 & 0,59 & 356,28 & 0,50 \\
\hline \multirow{3}{*}{$4-0$} & $A_{120}$ & & & 146,59 & 0,62 & & & 355,55 & 0,74 \\
\hline & $A_{122}$ & & & 146,62 & 0,62 & & & 355,78 & 0,69 \\
\hline & $A_{123}$ & & & 146,62 & 0,62 & & & 355,36 & 0,70 \\
\hline \multirow{3}{*}{$5-1$} & $A_{120}$ & 141,41 & 0,60 & 146,52 & 0,65 & 343,97 & 0,65 & 356,60 & 0,34 \\
\hline & $A_{122}$ & 141,59 & 0,80 & 146,37 & 0,44 & 344,42 & 0,68 & 356,83 & 0,75 \\
\hline & $A_{123}$ & 141,46 & 0,67 & 146,54 & 0,57 & 343,48 & 0,60 & 356,77 & 0,80 \\
\hline \multirow{3}{*}{$6-2$} & $A_{120}$ & 141,39 & & & & 344,05 & 0,66 & & \\
\hline & $A_{122}$ & 141,36 & 0,63 & & & 344,06 & 0,66 & & \\
\hline & $A_{123}$ & 141,37 & 0,63 & & & 344,07 & 0,67 & & \\
\hline \multirow{3}{*}{$7-3$} & $A_{120}$ & 141,04 & 0,55 & 146,47 & 0,73 & 343,52 & 0,66 & 356,25 & 0,83 \\
\hline & $A_{122}$ & 141,47 & 0,58 & 146,35 & 0,66 & 343,61 & 0,69 & 356,37 & 0,65 \\
\hline & $A_{123}$ & 141,39 & 0,62 & 146,35 & 0,62 & 343,85 & 0,94 & 356,23 & 0,70 \\
\hline \multirow{3}{*}{\multicolumn{2}{|c|}{$\begin{array}{c}\text { Média } \\
\text { Desvio padrão } \\
\text { Coef. Variação }\end{array}$}} & 141,29 & 0,65 & 146,60 & 0,67 & 343,85 & 0,67 & 356,02 & 0,70 \\
\hline & & 0,179 & 0,158 & 0,173 & 0,108 & 0,256 & 0,076 & 0,460 & 0,134 \\
\hline & & $0,1 \%$ & $24,4 \%$ & $0,1 \%$ & $16,3 \%$ & $0,1 \%$ & $11,3 \%$ & $0,1 \%$ & $19,3 \%$ \\
\hline
\end{tabular}


Tabela E.21 - Parâmetros modais da Tora TB-7 para o ensaio com excitação horizontal.

\begin{tabular}{|c|c|c|c|c|c|c|c|c|c|}
\hline \multirow[b]{2}{*}{ Plano } & \multirow[b]{2}{*}{ FRF } & \multicolumn{4}{|c|}{$1^{\circ}$ Modo } & \multicolumn{4}{|c|}{$2^{\circ}$ Modo } \\
\hline & & $\begin{array}{c}\text { Freq. } \\
(\mathrm{Hz})\end{array}$ & $\begin{array}{c}\text { Amort. } \\
(\%)\end{array}$ & $\begin{array}{c}\text { Freq. } \\
(\mathrm{Hz})\end{array}$ & $\begin{array}{c}\text { Amort. } \\
(\%)\end{array}$ & $\begin{array}{c}\text { Freq. } \\
(\mathrm{Hz})\end{array}$ & $\begin{array}{c}\text { Amort. } \\
(\%)\end{array}$ & $\begin{array}{l}\text { Freq. } \\
(\mathrm{Hz})\end{array}$ & $\begin{array}{c}\text { Amort. } \\
(\%)\end{array}$ \\
\hline \multirow{3}{*}{$0-4$} & $A_{120}$ & 140,68 & 0,63 & & & 348,12 & 0,70 & & \\
\hline & $A_{122}$ & 140,70 & 0,63 & & & 348,22 & 0,70 & & \\
\hline & $A_{123}$ & 140,70 & 0,60 & & & 348,16 & 0,67 & & \\
\hline \multirow{3}{*}{$1-5$} & $A_{120}$ & 140,60 & 0,66 & 158,08 & 0,61 & 348,39 & 1,53 & 384,94 & 0,71 \\
\hline & $A_{122}$ & 140,64 & 0,66 & 158,10 & 0,65 & 348,31 & 0,83 & 382,40 & 0,70 \\
\hline & $A_{123}$ & 140,65 & 0,63 & 158,14 & 0,6 & 345,69 & 0,67 & 382,38 & 0,69 \\
\hline \multirow{3}{*}{$2-6$} & $A_{120}$ & & & 158,06 & 0,64 & & & 382,12 & 0,68 \\
\hline & $A_{122}$ & & & 158,17 & 0,63 & & & 382,29 & 0,69 \\
\hline & $A_{123}$ & & & 158,13 & 0,64 & & & 382,22 & 0,70 \\
\hline \multirow{3}{*}{$3-7$} & $A_{120}$ & 140,75 & 0,65 & 157,95 & 0,67 & 348,15 & 0,80 & 382,55 & 0,79 \\
\hline & $A_{122}$ & 140,72 & 0,63 & 158,07 & 0,64 & 347,59 & 0,72 & 382,58 & 0,80 \\
\hline & $A_{123}$ & 140,75 & 0,64 & 158,06 & 0,66 & 347,77 & 0,75 & 382,51 & 0,67 \\
\hline \multirow{3}{*}{$4-0$} & $A_{120}$ & 140,69 & 0,64 & & & 348,18 & 0,70 & & \\
\hline & $A_{122}$ & 140,69 & 0,65 & & & 348,11 & 0,70 & & \\
\hline & $A_{123}$ & 140,69 & 0,63 & & & 348,17 & 0,70 & & \\
\hline \multirow{3}{*}{$5-1$} & $A_{120}$ & 140,54 & 0,64 & 158,10 & 0,63 & 349,99 & 0,66 & 382,18 & 0,70 \\
\hline & $A_{122}$ & 140,65 & 0,65 & 158,02 & 0,65 & 350,31 & 0,53 & 382,23 & 0,70 \\
\hline & $A_{123}$ & 140,55 & 0,65 & 158,13 & 0,63 & 350,44 & 0,52 & 382,20 & 0,70 \\
\hline \multirow{3}{*}{$6-2$} & $A_{120}$ & & & 158,06 & 0,64 & & & 382,11 & 0,70 \\
\hline & $A_{122}$ & & & 158,07 & 0,63 & & & 382,18 & 0,69 \\
\hline & $A_{123}$ & & & 158,14 & 0,62 & & & 382,16 & 0,70 \\
\hline \multirow{3}{*}{$7-3$} & $A_{120}$ & 140,67 & 0,64 & 158,05 & 0,66 & 349,36 & 0,88 & 382,63 & 0,71 \\
\hline & $A_{122}$ & 140,66 & 0,63 & 158,11 & 0,64 & 348,61 & 0,75 & 382,00 & 0,91 \\
\hline & $A_{123}$ & 140,80 & 0,53 & 158,11 & 0,77 & 347,51 & 0,74 & 382,62 & 0,70 \\
\hline \multirow{3}{*}{\multicolumn{2}{|c|}{$\begin{array}{c}\text { Média } \\
\text { Desvio padrão } \\
\text { Coef. Variação }\end{array}$}} & 140,67 & 0,63 & 158,09 & 0,65 & 348,39 & 0,75 & 382,46 & $\overline{0,72}$ \\
\hline & & 0,064 & 0,029 & 0,050 & 0,034 & 1,108 & 0,213 & 0,648 & 0,059 \\
\hline & & $0,0 \%$ & $4,6 \%$ & $0,0 \%$ & $5,2 \%$ & $0,3 \%$ & $28,3 \%$ & $0,2 \%$ & $8,2 \%$ \\
\hline
\end{tabular}


Tabela E.22 - Parâmetros modais da Tora TB-8 para o ensaio com excitação horizontal.

\begin{tabular}{|c|c|c|c|c|c|c|c|c|c|}
\hline \multirow[b]{2}{*}{ Plano } & \multirow[b]{2}{*}{ FRF } & \multicolumn{4}{|c|}{$1^{\circ}$ Modo } & \multicolumn{4}{|c|}{$2^{\circ}$ Modo } \\
\hline & & $\begin{array}{c}\text { Freq. } \\
(\mathrm{Hz})\end{array}$ & $\begin{array}{c}\text { Amort. } \\
(\%)\end{array}$ & $\begin{array}{c}\text { Freq. } \\
(\mathrm{Hz})\end{array}$ & $\begin{array}{c}\text { Amort. } \\
(\%)\end{array}$ & $\begin{array}{c}\text { Freq. } \\
(\mathrm{Hz})\end{array}$ & $\begin{array}{c}\text { Amort. } \\
(\%)\end{array}$ & $\begin{array}{c}\text { Freq. } \\
(\mathrm{Hz})\end{array}$ & $\begin{array}{c}\text { Amort } \\
(\%)\end{array}$ \\
\hline \multirow{3}{*}{$0-4$} & $A_{120}$ & & & 157,01 & 0,59 & & & 377,64 & 0,64 \\
\hline & $A_{122}$ & & & 157,00 & 0,59 & & & 377,74 & 0,63 \\
\hline & $A_{123}$ & & & 157,03 & 0,60 & & & 377,67 & 0,64 \\
\hline \multirow{3}{*}{$1-5$} & $A_{120}$ & 150,12 & 0,56 & 156,92 & 0,63 & 368,87 & 0,55 & 377,79 & 0,73 \\
\hline & $A_{122}$ & 150,14 & 0,60 & 156,93 & 0,60 & 368,72 & 0,62 & 377,81 & 0,70 \\
\hline & $\mathrm{A}_{123}$ & 150,05 & 0,58 & 157,00 & 0,62 & 369,03 & 0,50 & 377,89 & 0,74 \\
\hline \multirow{3}{*}{$2-6$} & $A_{120}$ & 150,04 & 0,63 & & & 368,30 & 0,62 & & \\
\hline & $A_{122}$ & 150,09 & 0,58 & & & 368,34 & 0,62 & & \\
\hline & $\mathrm{A}_{123}$ & 150,08 & 0,60 & & & 368,33 & 0,62 & & \\
\hline \multirow{3}{*}{$3-7$} & $A_{120}$ & 149,98 & 0,64 & 157,01 & 0,55 & 368,28 & 0,65 & 377,97 & 0,71 \\
\hline & $A_{122}$ & 150,04 & 0,58 & 157,01 & 0,65 & 368,29 & 0,71 & 377,63 & 0,63 \\
\hline & $\mathrm{A}_{123}$ & 150,08 & 0,62 & 156,93 & 0,59 & 368,22 & 0,64 & 377,62 & 0,59 \\
\hline \multirow{3}{*}{$4-0$} & $A_{120}$ & & & 157,02 & 0,63 & & & 377,55 & 0,67 \\
\hline & $A_{122}$ & & & 157,01 & 0,60 & & & 377,63 & 0,66 \\
\hline & $A_{123}$ & & & 157,03 & 0,59 & & & 377,63 & 0,66 \\
\hline \multirow{3}{*}{$5-1$} & $A_{120}$ & 150,04 & 0,67 & 156,85 & 0,58 & 368,61 & 0,62 & 377,62 & 0,63 \\
\hline & $A_{122}$ & 150,13 & 0,59 & 156,82 & 0,64 & 368,66 & 0,62 & 377,69 & 0,63 \\
\hline & $\mathrm{A}_{123}$ & 150,05 & 0,58 & 156,89 & 0,64 & 368,64 & 0,62 & 377,66 & 0,63 \\
\hline \multirow{3}{*}{$6-2$} & $A_{120}$ & 150,12 & 0,58 & & & 368,29 & 0,64 & & \\
\hline & $A_{122}$ & 150,10 & 0,60 & & & 368,38 & 0,63 & & \\
\hline & $A_{123}$ & 150,09 & 0,78 & & & 368,36 & 0,62 & & \\
\hline \multirow{3}{*}{$7-3$} & $A_{120}$ & 150,18 & 0,60 & 156,85 & 0,67 & 368,32 & 0,61 & 378,02 & 0,52 \\
\hline & $A_{122}$ & 150,14 & 0,64 & 156,96 & 0,60 & 368,43 & 0,62 & 378,00 & 0,64 \\
\hline & $A_{123}$ & 150,13 & 0,60 & 157,02 & 0,65 & 368,33 & 0,61 & 378,43 & 0,60 \\
\hline \multirow{2}{*}{\multicolumn{2}{|c|}{$\begin{array}{l}\text { Média } \\
\text { vio padrão } \\
\text { ef. Variação }\end{array}$}} & 150,09 & 0,61 & 156,96 & 0,61 & 368,47 & 0,62 & 377,78 & 0,65 \\
\hline & & 0,049 & 0,049 & 0,069 & 0,032 & 0,232 & 0,042 & 0,217 & 0,052 \\
\hline
\end{tabular}


Tabela E.23 - Parâmetros modais da Tora TB-9 para o ensaio com excitação horizontal.

\begin{tabular}{|c|c|c|c|c|c|c|c|c|c|}
\hline \multirow[b]{2}{*}{ Plano } & \multirow[b]{2}{*}{ FRF } & \multicolumn{4}{|c|}{$1^{\circ}$ Modo } & \multicolumn{4}{|c|}{$2^{\circ}$ Modo } \\
\hline & & $\begin{array}{c}\text { Freq. } \\
(\mathrm{Hz})\end{array}$ & $\begin{array}{c}\text { Amort. } \\
(\%)\end{array}$ & $\begin{array}{c}\text { Freq. } \\
(\mathrm{Hz})\end{array}$ & $\begin{array}{c}\text { Amort. } \\
(\%)\end{array}$ & $\begin{array}{l}\text { Freq. } \\
(\mathrm{Hz})\end{array}$ & $\begin{array}{c}\text { Amort. } \\
(\%)\end{array}$ & $\begin{array}{c}\text { Freq. } \\
(\mathrm{Hz})\end{array}$ & $\begin{array}{c}\text { Amort. } \\
(\%)\end{array}$ \\
\hline \multirow{3}{*}{$0-4$} & $A_{120}$ & 139,17 & 0,86 & 146,55 & 0,64 & 346,49 & 0,80 & 359,51 & 0,80 \\
\hline & $A_{122}$ & 138,86 & 0,70 & 146,65 & 0,69 & 346,92 & 0,73 & 358,90 & 0,78 \\
\hline & $A_{123}$ & 138,60 & 0,60 & 146,75 & 0,72 & 346,46 & 0,76 & 359,64 & 0,78 \\
\hline \multirow{3}{*}{$1-5$} & $A_{120}$ & & & 146,66 & 0,69 & & & 358,48 & 0,68 \\
\hline & $A_{122}$ & & & 146,68 & 0,70 & & & 358,46 & 0,68 \\
\hline & $\mathrm{A}_{123}$ & & & 146,67 & 0,68 & & & 358,43 & 0,68 \\
\hline \multirow{3}{*}{$2-6$} & $A_{120}$ & 138,83 & 0,68 & 146,76 & 0,84 & 346,22 & 0,76 & 359,15 & 0,84 \\
\hline & $A_{122}$ & 138,87 & 0,69 & 146,63 & 0,75 & 346,58 & 0,76 & 358,84 & 0,85 \\
\hline & $A_{123}$ & 138,88 & 0,69 & 146,65 & 0,71 & 346,05 & 0,94 & 359,27 & 0,71 \\
\hline \multirow{3}{*}{$3-7$} & $A_{120}$ & 138,84 & 0,73 & & & 346,88 & 0,63 & & \\
\hline & $A_{122}$ & 138,84 & 0,70 & & & 346,82 & 0,67 & & \\
\hline & $A_{123}$ & 138,89 & 0,71 & & & 346,85 & 0,68 & & \\
\hline \multirow{3}{*}{ 4-0 } & $A_{120}$ & 138,54 & 0,60 & 146,98 & 0,82 & 346,59 & 1,27 & 359,43 & 0,33 \\
\hline & $A_{122}$ & 139,04 & 0,64 & 146,28 & 0,83 & 347,45 & 0,35 & 358,23 & 0,63 \\
\hline & $A_{123}$ & 138,83 & 0,72 & 146,66 & 0,70 & 346,58 & 0,70 & 359,07 & 0,68 \\
\hline \multirow{3}{*}{$5-1$} & $A_{120}$ & & & 146,63 & 0,69 & & & 358,41 & 0,70 \\
\hline & $A_{122}$ & & & 146,59 & 0,67 & & & 358,46 & 0,67 \\
\hline & $A_{123}$ & & & 146,57 & 0,71 & & & 358,24 & 0,58 \\
\hline \multirow{3}{*}{$6-2$} & $A_{120}$ & 138,81 & 0,71 & 146,61 & 0,68 & 346,25 & 0,71 & 358,50 & 0,74 \\
\hline & $A_{122}$ & 138,76 & 0,69 & 146,78 & 0,66 & 346,13 & 0,89 & 358,69 & 0,73 \\
\hline & $A_{123}$ & 138,89 & 0,73 & 146,54 & 0,66 & 345,94 & 0,85 & 358,80 & 0,72 \\
\hline \multirow{3}{*}{$7-3$} & $A_{120}$ & 138,83 & 0,70 & & & 346,78 & 0,68 & & \\
\hline & $A_{122}$ & 138,90 & 0,70 & 146,32 & 0,80 & 346,88 & 0,67 & & \\
\hline & $A_{123}$ & 138,81 & 0,70 & 147,84 & 0,32 & 346,83 & 0,67 & & \\
\hline \multirow{3}{*}{\multicolumn{2}{|c|}{$\begin{array}{l}\text { Média } \\
\text { svio padrão } \\
\text { ef. Variação }\end{array}$}} & 138,85 & 0,70 & 146,69 & 0,70 & 346,60 & 0,75 & 358,80 & 0,70 \\
\hline & & 0,137 & 0,055 & 0,308 & 0,108 & 0,379 & 0,179 & 0,448 & 0,115 \\
\hline & & $0,1 \%$ & $7,9 \%$ & $0,2 \%$ & $15,4 \%$ & $0,1 \%$ & $23,8 \%$ & $0,1 \%$ & $16,5 \%$ \\
\hline
\end{tabular}


Tabela E.24 - Parâmetros modais da Tora TB-10 para o ensaio com excitação horizontal.

\begin{tabular}{|c|c|c|c|c|c|c|c|c|c|}
\hline \multirow[b]{2}{*}{ Plano } & \multirow[b]{2}{*}{ FRF } & \multicolumn{4}{|c|}{$1^{\circ}$ Modo } & \multicolumn{4}{|c|}{$2^{\circ}$ Modo } \\
\hline & & $\begin{array}{c}\text { Freq. } \\
(\mathrm{Hz})\end{array}$ & $\begin{array}{c}\text { Amort. } \\
(\%)\end{array}$ & $\begin{array}{c}\text { Freq. } \\
(\mathrm{Hz})\end{array}$ & $\begin{array}{c}\text { Amort. } \\
(\%)\end{array}$ & $\begin{array}{l}\text { Freq. } \\
(\mathrm{Hz})\end{array}$ & $\begin{array}{c}\text { Amort. } \\
(\%)\end{array}$ & $\begin{array}{c}\text { Freq. } \\
(\mathrm{Hz})\end{array}$ & $\begin{array}{c}\text { Amort } \\
(\%)\end{array}$ \\
\hline \multirow{3}{*}{$0-4$} & $A_{120}$ & 146,74 & 0,69 & 152,90 & 0,55 & 363,31 & 0,64 & & \\
\hline & $A_{122}$ & 147,07 & 0,62 & 152,47 & 0,63 & 363,25 & 0,66 & & \\
\hline & $A_{123}$ & 147,22 & 0,59 & 152,21 & 0,66 & 363,33 & 0,64 & & \\
\hline \multirow{3}{*}{$1-5$} & $A_{120}$ & & & 152,38 & 0,63 & & & 370,78 & 0,67 \\
\hline & $A_{122}$ & & & 152,37 & 0,62 & & & 370,85 & 0,66 \\
\hline & $A_{123}$ & & & 152,39 & 0,62 & & & 370,81 & 0,65 \\
\hline \multirow{3}{*}{$2-6$} & $\mathrm{~A}_{120}$ & 146,70 & 0,48 & 152,29 & 0,85 & 363,88 & 0,69 & 370,73 & 0,63 \\
\hline & $A_{122}$ & 147,02 & 0,58 & 152,16 & 0,67 & 363,72 & 0,59 & 370,83 & 0,66 \\
\hline & $A_{123}$ & 146,81 & 0,61 & 152,35 & 0,67 & 363,67 & 0,65 & 370,82 & 0,66 \\
\hline \multirow{3}{*}{$3-7$} & $A_{120}$ & 147,01 & 0,62 & & & 363,33 & 0,59 & & \\
\hline & $A_{122}$ & 147,04 & 0,63 & & & 363,26 & 0,64 & & \\
\hline & $\mathrm{A}_{123}$ & 147,01 & 0,62 & & & 363,30 & 0,64 & & \\
\hline \multirow{3}{*}{$4-0$} & $A_{120}$ & 146,78 & 0,70 & 152,56 & 0,59 & 362,89 & 0,79 & 371,22 & 0,66 \\
\hline & $A_{122}$ & 147,03 & 0,61 & 152,38 & 0,64 & 363,03 & 0,83 & 370,68 & 0,54 \\
\hline & $A_{123}$ & 147,01 & 0,64 & 152,41 & 0,62 & 362,95 & 0,77 & 371,11 & 0,71 \\
\hline \multirow{3}{*}{$5-1$} & $A_{120}$ & & & 152,43 & 0,63 & 363,51 & 0,64 & 370,87 & 0,66 \\
\hline & $A_{122}$ & & & 152,34 & 0,67 & 363,94 & 0,66 & 370,80 & 0,66 \\
\hline & $A_{123}$ & & & 152,55 & 0,62 & 363,72 & 0,64 & 370,87 & 0,66 \\
\hline \multirow{3}{*}{$6-2$} & $\mathrm{~A}_{120}$ & 146,67 & 0,58 & 152,46 & 0,70 & 363,56 & 0,62 & 370,90 & 0,67 \\
\hline & $A_{122}$ & 146,98 & 0,64 & 152,27 & 0,62 & 363,61 & 0,66 & 370,97 & 0,67 \\
\hline & $A_{123}$ & 147,03 & 0,61 & 152,24 & 0,62 & 363,69 & 0,64 & 370,93 & 0,66 \\
\hline \multirow{3}{*}{$7-3$} & $\mathrm{~A}_{120}$ & 146,94 & 0,58 & & & 363,25 & 0,64 & 371,37 & 0,75 \\
\hline & $A_{122}$ & 147,07 & 0,63 & & & 363,35 & 0,66 & 371,36 & 0,65 \\
\hline & $A_{123}$ & 147,12 & 0,70 & & & 363,35 & 0,66 & 371,33 & 0,64 \\
\hline \multirow{2}{*}{\multicolumn{2}{|c|}{$\begin{array}{c}\text { Média } \\
\text { Desvio padrão } \\
\text { Coef. Variação }\end{array}$}} & 146,96 & 0,62 & 152,40 & 0,65 & 363,42 & 0,66 & 370,96 & 0,66 \\
\hline & & $\begin{array}{c}0,155 \\
0,1 \%\end{array}$ & $\begin{array}{r}0,051 \\
8,3 \%\end{array}$ & $\begin{array}{c}0,164 \\
0,1 \%\end{array}$ & $\begin{array}{c}0,061 \\
9,5 \%\end{array}$ & $\begin{array}{c}0,286 \\
0,1 \%\end{array}$ & $\begin{array}{c}0,061 \\
9,2 \%\end{array}$ & $\begin{array}{c}0,220 \\
0,1 \%\end{array}$ & $\begin{array}{c}0,039 \\
5,9 \%\end{array}$ \\
\hline
\end{tabular}


Tabela E.25 - Parâmetros modais da Tora TT-1 para o ensaio com excitação horizontal.

\begin{tabular}{|c|c|c|c|c|c|c|c|c|c|}
\hline \multirow[b]{2}{*}{ Plano } & \multirow[b]{2}{*}{ FRF } & \multicolumn{4}{|c|}{$1^{\circ}$ Modo } & \multicolumn{4}{|c|}{$2^{\circ}$ Modo } \\
\hline & & $\begin{array}{l}\text { Freq. } \\
(\mathrm{Hz})\end{array}$ & $\begin{array}{c}\text { Amort. } \\
(\%)\end{array}$ & $\begin{array}{c}\text { Freq. } \\
(\mathrm{Hz})\end{array}$ & $\begin{array}{c}\text { Amort. } \\
(\%)\end{array}$ & $\begin{array}{l}\text { Freq. } \\
(\mathrm{Hz})\end{array}$ & $\begin{array}{c}\text { Amort. } \\
(\%)\end{array}$ & $\begin{array}{c}\text { Freq. } \\
(\mathrm{Hz})\end{array}$ & $\begin{array}{c}\text { Amort. } \\
(\%)\end{array}$ \\
\hline \multirow{3}{*}{$0-4$} & $A_{105}$ & 158,79 & 0,63 & 165,57 & 0,58 & 391,83 & 1,06 & 405,90 & 0,64 \\
\hline & $A_{107}$ & 158,84 & 0,59 & 165,63 & 0,61 & 391,50 & 0,45 & 405,28 & 0,54 \\
\hline & $A_{108}$ & 158,84 & 0,60 & 165,64 & 0,60 & 390,89 & 0,84 & 405,40 & 0,65 \\
\hline \multirow{3}{*}{$1-5$} & $A_{105}$ & 158,74 & 0,58 & 165,97 & 0,90 & 390,48 & 0,63 & 405,53 & 0,67 \\
\hline & $A_{107}$ & 158,80 & 0,58 & 165,60 & 0,84 & 390,54 & 0,65 & 404,88 & 0,76 \\
\hline & $A_{108}$ & 158,78 & 0,58 & 165,63 & 1,43 & 390,59 & 0,65 & 405,75 & 0,76 \\
\hline \multirow{3}{*}{$2-6$} & $A_{105}$ & 158,70 & 0,55 & 165,48 & 0,74 & 389,96 & 0,66 & 403,09 & 0,92 \\
\hline & $A_{107}$ & 158,82 & 0,62 & 165,52 & 0,55 & 390,27 & 0,63 & 405,21 & 1,23 \\
\hline & $A_{108}$ & 158,76 & 0,59 & 165,66 & 0,64 & 390,39 & 0,64 & 405,65 & 0,70 \\
\hline \multirow{3}{*}{$3-7$} & $A_{105}$ & 159,60 & 0,22 & 165,53 & 0,61 & 390,58 & 0,77 & 405,36 & 0,67 \\
\hline & $A_{107}$ & & & 165,59 & 0,56 & & & 405,80 & 0,71 \\
\hline & $A_{108}$ & 158,75 & 0,80 & 165,63 & 0,59 & 390,67 & 1,22 & 405,84 & 0,71 \\
\hline \multirow{3}{*}{$4-0$} & $A_{105}$ & 158,57 & 0,54 & 165,67 & 0,64 & 390,29 & 0,81 & 405,80 & 0,65 \\
\hline & $A_{107}$ & 158,81 & 0,66 & 165,63 & 0,56 & 390,72 & 0,90 & 405,74 & 0,66 \\
\hline & $A_{108}$ & 158,76 & 0,59 & 165,64 & 0,61 & 390,89 & 0,74 & 406,44 & 0,72 \\
\hline \multirow{3}{*}{$5-1$} & $A_{105}$ & 158,63 & 0,61 & & & 389,63 & 0,70 & & \\
\hline & $A_{107}$ & 158,63 & 0,62 & & & 390,00 & 0,67 & 405,77 & 0,75 \\
\hline & $A_{108}$ & 158,78 & 0,60 & & & 390,08 & 0,67 & 406,60 & 0,64 \\
\hline \multirow{3}{*}{$6-2$} & $A_{105}$ & 158,74 & 0,56 & 165,46 & 0,70 & 390,70 & 0,70 & 405,53 & 0,32 \\
\hline & $A_{107}$ & 158,78 & 0,59 & 165,58 & 0,63 & 390,52 & 0,68 & 406,01 & 0,54 \\
\hline & $A_{108}$ & 158,74 & 0,62 & 165,64 & 0,55 & 390,62 & 0,68 & 406,19 & 0,74 \\
\hline \multirow{3}{*}{$7-3$} & $A_{105}$ & 158,33 & 0,87 & 165,62 & 0,57 & & & 405,74 & 0,67 \\
\hline & $A_{107}$ & 158,80 & 0,67 & 165,55 & 0,61 & 391,52 & 0,72 & 405,86 & 0,68 \\
\hline & $A_{108}$ & 158,30 & 0,57 & 165,60 & 0,60 & 391,07 & 0,67 & 405,80 & 0,69 \\
\hline \multirow{3}{*}{\multicolumn{2}{|c|}{$\begin{array}{c}\text { Média } \\
\text { Desvio padrão } \\
\text { Coef. Variação }\end{array}$}} & 158,75 & 0,60 & 165,61 & 0,67 & 390,62 & 0,73 & 405,61 & 0,70 \\
\hline & & 0,233 & 0,111 & 0,101 & 0,197 & 0,526 & 0,160 & 0,669 & 0,158 \\
\hline & & $0,1 \%$ & $18,5 \%$ & $0,1 \%$ & $29,2 \%$ & $0,1 \%$ & $21,7 \%$ & $0,2 \%$ & $22,7 \%$ \\
\hline
\end{tabular}


Tabela E.26 - Parâmetros modais da Tora TT-2 para o ensaio com excitação horizontal.

\begin{tabular}{|c|c|c|c|c|c|c|c|c|c|}
\hline \multirow[b]{2}{*}{ Plano } & \multirow[b]{2}{*}{ FRF } & \multicolumn{4}{|c|}{$1^{\circ}$ Modo } & \multicolumn{4}{|c|}{$2^{\circ}$ Modo } \\
\hline & & $\begin{array}{l}\text { Freq. } \\
(\mathrm{Hz})\end{array}$ & $\begin{array}{c}\text { Amort. } \\
(\%)\end{array}$ & $\begin{array}{l}\text { Freq. } \\
(\mathrm{Hz})\end{array}$ & $\begin{array}{c}\text { Amort. } \\
(\%)\end{array}$ & $\begin{array}{l}\text { Freq. } \\
(\mathrm{Hz})\end{array}$ & $\begin{array}{c}\text { Amort. } \\
(\%)\end{array}$ & $\begin{array}{c}\text { Freq. } \\
\text { (Hz) }\end{array}$ & $\begin{array}{c}\text { Amort. } \\
(\%)\end{array}$ \\
\hline \multirow{3}{*}{$0-4$} & $\overline{A_{105}}$ & 149,45 & 0,65 & 156,48 & 0,56 & 367,82 & 0,64 & 378,13 & 0,66 \\
\hline & $A_{107}$ & 149,52 & 0,63 & 156,57 & 0,59 & 367,95 & 0,63 & 378,86 & 0,72 \\
\hline & $\mathrm{A}_{108}$ & 149,53 & 0,64 & 156,57 & 0,59 & 368,22 & 0,60 & 378,61 & 1,07 \\
\hline \multirow{3}{*}{$1-5$} & $A_{105}$ & 149,51 & 0,62 & 156,92 & 0,82 & 367,73 & 0,67 & 378,48 & 0,51 \\
\hline & $A_{107}$ & 149,67 & 0,60 & & & 367,94 & 0,64 & 378,61 & 0,69 \\
\hline & $\mathrm{A}_{108}$ & 149,56 & 0,63 & 156,55 & 0,50 & 367,89 & 0,65 & 378,76 & 0,64 \\
\hline \multirow{3}{*}{$2-6$} & $A_{105}$ & 149,72 & 0,61 & 156,37 & 0,61 & 367,63 & 0,69 & 378,61 & 0,62 \\
\hline & $A_{107}$ & 149,58 & 0,62 & 156,49 & 0,61 & 367,63 & 0,51 & 378,89 & 0,60 \\
\hline & $\mathrm{A}_{108}$ & 149,66 & 0,85 & 156,48 & 0,52 & 368,21 & 0,62 & 378,88 & 0,62 \\
\hline \multirow{3}{*}{$3-7$} & $A_{105}$ & & & 156,28 & 0,62 & & & 378,42 & 0,72 \\
\hline & $A_{107}$ & 150,50 & 0,67 & 156,35 & 0,60 & 367,97 & 0,60 & 378,68 & 0,65 \\
\hline & $A_{108}$ & & & 156,45 & 0,56 & 368,18 & 0,78 & 378,69 & 0,62 \\
\hline \multirow{3}{*}{$4-0$} & $A_{105}$ & 149,58 & 0,58 & 156,23 & 0,68 & 367,91 & 0,67 & 378,29 & 0,61 \\
\hline & $A_{107}$ & 149,52 & 0,60 & 156,53 & 0,65 & 368,26 & 0,63 & 378,46 & 0,68 \\
\hline & $\mathrm{A}_{108}$ & 149,60 & 0,60 & 156,31 & 0,65 & 368,19 & 0,63 & 378,95 & 0,67 \\
\hline \multirow{3}{*}{$5-1$} & $A_{105}$ & 149,24 & 0,66 & & & 368,06 & 0,63 & & \\
\hline & $A_{107}$ & 149,61 & 0,56 & & & 368,13 & 0,66 & & \\
\hline & $A_{108}$ & 149,65 & 0,62 & 156,14 & 0,64 & 368,17 & 0,63 & 378,84 & 0,69 \\
\hline \multirow{3}{*}{$6-2$} & $A_{105}$ & 149,42 & 0,45 & 156,23 & 0,67 & 368,07 & 0,58 & 378,54 & 0,63 \\
\hline & $A_{107}$ & 149,46 & 0,63 & 156,29 & 0,62 & 368,60 & 0,63 & 378,63 & 0,63 \\
\hline & $\mathrm{A}_{108}$ & 149,21 & 0,67 & 156,38 & 0,62 & 368,42 & 0,75 & 378,73 & 0,60 \\
\hline \multirow{3}{*}{$7-3$} & $A_{105}$ & 149,69 & 0,55 & 156,33 & 0,60 & 368,56 & 0,44 & 378,80 & 0,48 \\
\hline & $A_{107}$ & & & 156,29 & 0,73 & 368,45 & 0,40 & 378,88 & 0,45 \\
\hline & $A_{108}$ & 149,33 & 0,82 & 156,42 & 0,59 & 368,30 & 0,30 & 379,35 & 0,45 \\
\hline \multirow{2}{*}{\multicolumn{2}{|c|}{$\begin{array}{c}\text { Média } \\
\text { Desvio padrão } \\
\text { Coef. Variação }\end{array}$}} & 149,57 & 0,63 & 156,41 & 0,62 & 368,10 & 0,61 & 378,69 & 0,64 \\
\hline & & $\begin{array}{r}0,254 \\
0,2 \%\end{array}$ & $\begin{array}{r}0,083 \\
13,1 \%\end{array}$ & $\begin{array}{c}0,168 \\
0,1 \%\end{array}$ & $\begin{array}{c}0,069 \\
11,1 \%\end{array}$ & $\begin{array}{l}0,271 \\
0,1 \%\end{array}$ & $\begin{array}{c}0,107 \\
17,6 \%\end{array}$ & $\begin{array}{l}0,257 \\
0,1 \%\end{array}$ & $\begin{array}{c}0,124 \\
19,5 \%\end{array}$ \\
\hline
\end{tabular}


Tabela E.27 - Parâmetros modais da Tora TT-3 para o ensaio com excitação horizontal.

\begin{tabular}{|c|c|c|c|c|c|c|c|c|c|}
\hline \multirow[b]{2}{*}{ Plano } & \multirow[b]{2}{*}{ FRF } & \multicolumn{4}{|c|}{$1^{\circ}$ Modo } & \multicolumn{4}{|c|}{$2^{\circ}$ Modo } \\
\hline & & $\begin{array}{l}\text { Freq. } \\
(\mathrm{Hz})\end{array}$ & $\begin{array}{c}\text { Amort. } \\
(\%)\end{array}$ & $\begin{array}{l}\text { Freq. } \\
(\mathrm{Hz})\end{array}$ & $\begin{array}{c}\text { Amort. } \\
(\%)\end{array}$ & $\begin{array}{c}\text { Freq. } \\
(\mathrm{Hz})\end{array}$ & $\begin{array}{c}\text { Amort. } \\
(\%)\end{array}$ & $\begin{array}{c}\text { Freq. } \\
(\mathbf{H z})\end{array}$ & $\begin{array}{c}\text { Amort. } \\
(\%)\end{array}$ \\
\hline \multirow{3}{*}{$0-4$} & $A_{105}$ & 140,60 & 0,83 & 146,84 & 0,32 & 349,16 & 0,92 & 358,80 & 0,53 \\
\hline & $A_{107}$ & 140,56 & 0,75 & 147,04 & 0,65 & 349,33 & 0,79 & 359,08 & 0,57 \\
\hline & $A_{108}$ & 140,73 & 0,66 & 146,77 & 0,72 & 349,62 & 0,59 & 359,22 & 0,59 \\
\hline \multirow{3}{*}{$1-5$} & $A_{105}$ & 140,71 & 0,60 & & & 348,09 & 0,58 & & \\
\hline & $A_{107}$ & 140,76 & 0,60 & & & 348,18 & 0,60 & & \\
\hline & $A_{108}$ & 140,75 & 0,60 & & & 348,20 & 0,60 & & \\
\hline \multirow{3}{*}{$2-6$} & $A_{105}$ & 140,36 & 0,76 & 146,73 & 0,60 & 349,52 & 1,01 & 358,58 & 0,62 \\
\hline & $A_{107}$ & 140,53 & 0,83 & 146,73 & 0,54 & 349,75 & 0,80 & 358,99 & 0,61 \\
\hline & $A_{108}$ & 140,73 & 0,76 & 146,57 & 0,55 & 349,83 & 0,87 & 359,03 & 0,69 \\
\hline \multirow{3}{*}{$3-7$} & $A_{105}$ & & & 147,09 & 0,61 & & & 359,65 & 0,63 \\
\hline & $A_{107}$ & & & 147,14 & 0,60 & & & 359,85 & 0,64 \\
\hline & $A_{108}$ & & & 147,13 & 0,60 & & & 359,87 & 0,65 \\
\hline \multirow{3}{*}{$4-0$} & $A_{105}$ & 140,94 & 0,60 & 147,12 & 0,65 & 347,55 & 1,01 & 359,72 & 0,62 \\
\hline & $A_{107}$ & 141,09 & 0,64 & 147,05 & 0,57 & 350,72 & 0,95 & 359,88 & 0,60 \\
\hline & $A_{108}$ & 140,99 & 0,61 & 147,16 & 0,63 & 350,28 & 0,71 & 360,18 & 0,58 \\
\hline \multirow{3}{*}{$5-1$} & $A_{105}$ & 141,06 & 0,60 & & & 349,10 & 0,60 & & \\
\hline & $A_{107}$ & 141,11 & 0,63 & & & 349,21 & 0,60 & & \\
\hline & $A_{108}$ & 141,11 & 0,60 & & & 349,23 & 0,60 & & \\
\hline \multirow{3}{*}{$6-2$} & $A_{105}$ & 141,07 & 0,51 & 146,96 & 0,71 & 348,51 & 0,99 & 360,40 & 0,80 \\
\hline & $A_{107}$ & 141,18 & 0,62 & 146,99 & 0,65 & 347,84 & 0,78 & 360,27 & 0,57 \\
\hline & $A_{108}$ & 141,10 & 0,63 & 147,04 & 0,64 & 348,90 & 0,78 & 360,34 & 0,56 \\
\hline \multirow{3}{*}{$7-3$} & $A_{105}$ & & & 147,00 & 0,61 & & & 360,13 & 0,68 \\
\hline & $A_{107}$ & & & 147,07 & 0,63 & & & 359,77 & 0,59 \\
\hline & $A_{108}$ & & & 147,04 & 0,61 & & & 359,79 & 0,59 \\
\hline \multirow{3}{*}{\multicolumn{2}{|c|}{$\begin{array}{c}\text { Média } \\
\text { Desvio padrão } \\
\text { Coef. Variação }\end{array}$}} & 140,85 & 0,66 & 146,97 & 0,61 & 349,06 & 0,77 & 359,64 & 0,62 \\
\hline & & 0,248 & 0,090 & 0,169 & 0,085 & 0,858 & 0,162 & 0,559 & 0,061 \\
\hline & & $0,2 \%$ & $13,6 \%$ & $0,1 \%$ & $14,0 \%$ & $0,2 \%$ & $21,1 \%$ & $0,2 \%$ & $9,9 \%$ \\
\hline
\end{tabular}


Tabela E.28 - Parâmetros modais da Tora TT-4 para o ensaio com excitação horizontal.

\begin{tabular}{|c|c|c|c|c|c|c|c|c|c|}
\hline \multirow[b]{2}{*}{ Plano } & \multirow[b]{2}{*}{ FRF } & \multicolumn{4}{|c|}{$1^{\circ}$ Modo } & \multicolumn{4}{|c|}{$2^{\circ}$ Modo } \\
\hline & & Freq. (Hz) & $\begin{array}{c}\text { Amort. } \\
(\%)\end{array}$ & Freq. (Hz) & $\begin{array}{c}\text { Amort. } \\
(\%)\end{array}$ & Freq. (Hz) & $\begin{array}{c}\text { Amort. } \\
(\%)\end{array}$ & Freq. (Hz) & $\begin{array}{c}\text { Amort. } \\
(\%)\end{array}$ \\
\hline \multirow{3}{*}{$0-4$} & $A_{105}$ & 136,76 & 0,60 & 139,19 & 0,90 & 337,72 & 0,72 & 350,62 & 0,75 \\
\hline & $A_{107}$ & 136,88 & 0,64 & 139,25 & 0,74 & 338,20 & 0,68 & 350,75 & 0,71 \\
\hline & $A_{108}$ & 136,98 & 0,70 & 139,29 & 0,85 & 338,02 & 0,74 & 350,77 & 0,79 \\
\hline \multirow{3}{*}{$1-5$} & $A_{105}$ & & & 139,21 & 0,68 & & & 350,00 & 0,67 \\
\hline & $A_{107}$ & & & 139,24 & 0,69 & & & 350,15 & 0,69 \\
\hline & $A_{108}$ & & & 139,20 & 0,74 & & & 350,18 & 0,68 \\
\hline \multirow{3}{*}{$2-6$} & $\mathrm{~A}_{105}$ & 136,72 & 0,80 & 139,32 & 0,79 & 338,01 & 0,61 & & \\
\hline & $A_{107}$ & 137,17 & 0,64 & 139,18 & 0,63 & 338,14 & 0,66 & & \\
\hline & $A_{108}$ & 137,30 & 0,79 & 139,34 & 0,49 & 338,12 & 0,62 & & \\
\hline \multirow{3}{*}{$3-7$} & $A_{105}$ & 136,90 & 0,64 & 139,63 & 1,86 & 337,22 & 0,64 & & \\
\hline & $A_{107}$ & 136,98 & 0,69 & & & 337,75 & 0,66 & & \\
\hline & $A_{108}$ & 136,96 & 0,68 & & & 337,68 & 0,90 & & \\
\hline \multirow{3}{*}{$4-0$} & $A_{105}$ & 137,03 & 0,67 & 139,23 & 0,48 & 337,23 & 0,72 & 349,87 & 0,72 \\
\hline & $A_{107}$ & 136,84 & 0,70 & 139,30 & 0,85 & 337,37 & 0,70 & 350,02 & 0,79 \\
\hline & $A_{108}$ & 137,02 & 0,76 & 139,40 & 0,49 & 337,78 & 0,65 & 350,36 & 0,66 \\
\hline \multirow{3}{*}{$5-1$} & $A_{105}$ & & & 139,06 & 0,69 & 337,52 & 0,77 & 349,79 & 0,66 \\
\hline & $A_{107}$ & & & 139,12 & 0,69 & & & 349,63 & 0,75 \\
\hline & $A_{108}$ & & & 139,10 & 0,71 & & & 349,68 & 0,65 \\
\hline \multirow{3}{*}{$6-2$} & $A_{105}$ & 136,63 & 0,47 & 138,95 & 0,74 & 337,48 & 0,70 & & \\
\hline & $A_{107}$ & 136,78 & 1,12 & 139,31 & 0,76 & 337,22 & 0,66 & 350,10 & 0,82 \\
\hline & $A_{108}$ & 136,85 & 0,43 & 139,04 & 0,71 & 337,72 & 0,65 & 350,32 & 0,61 \\
\hline \multirow{3}{*}{$7-3$} & $A_{105}$ & 137,01 & 0,69 & & & 337,72 & 0,65 & & \\
\hline & $A_{107}$ & 136,97 & 0,71 & & & 337,75 & 0,67 & & \\
\hline & $A_{108}$ & 137,00 & 0,71 & & & 337,74 & 0,70 & & \\
\hline \multicolumn{2}{|c|}{ Média } & 136,93 & 0,69 & 139,23 & 0,76 & 337,71 & 0,69 & 350,16 & 0,71 \\
\hline \multirow{2}{*}{\multicolumn{2}{|c|}{$\begin{array}{l}\text { Desvio padrão } \\
\text { Coef. Variação }\end{array}$}} & 0,160 & 0,142 & 0,149 & 0,291 & 0,307 & 0,065 & 0,370 & 0,062 \\
\hline & & $0,1 \%$ & $20,5 \%$ & $0,1 \%$ & $38,1 \%$ & $0,1 \%$ & $9,4 \%$ & $0,1 \%$ & $8,7 \%$ \\
\hline
\end{tabular}


Tabela E.29 - Parâmetros modais da Tora TT-5 para o ensaio com excitação horizontal.

\begin{tabular}{|c|c|c|c|c|c|c|c|c|c|}
\hline \multirow[b]{2}{*}{ Plano } & \multirow[b]{2}{*}{ FRF } & \multicolumn{4}{|c|}{$1^{\circ}$ Modo } & \multicolumn{4}{|c|}{$2^{\circ}$ Modo } \\
\hline & & $\begin{array}{l}\text { Freq. } \\
(\mathrm{Hz})\end{array}$ & $\begin{array}{c}\text { Amort. } \\
(\%)\end{array}$ & $\begin{array}{c}\text { Freq. } \\
(\mathrm{Hz})\end{array}$ & $\begin{array}{c}\text { Amort. } \\
(\%)\end{array}$ & $\begin{array}{c}\text { Freq. } \\
(\mathrm{Hz})\end{array}$ & $\begin{array}{c}\text { Amort. } \\
(\%)\end{array}$ & $\begin{array}{l}\text { Freq. } \\
(\mathrm{Hz})\end{array}$ & $\begin{array}{c}\text { Amort. } \\
(\%)\end{array}$ \\
\hline \multirow{3}{*}{$0-4$} & $A_{105}$ & & & 140,27 & 0,54 & & & 343,69 & 0,92 \\
\hline & $A_{107}$ & & & 139,85 & 0,59 & & & 343,90 & 0,26 \\
\hline & $A_{108}$ & & & 139,90 & 0,67 & & & 344,29 & 0,78 \\
\hline \multirow{3}{*}{$1-5$} & $A_{105}$ & 135,82 & 0,80 & 139,79 & 0,61 & 340,52 & 0,66 & & \\
\hline & $A_{107}$ & 135,76 & 0,64 & 139,78 & 0,78 & 340,80 & 0,67 & & \\
\hline & $A_{108}$ & 135,72 & 0,72 & 140,05 & 0,73 & 340,74 & 0,65 & & \\
\hline \multirow{3}{*}{$2-6$} & $A_{105}$ & 135,54 & 0,73 & & & & & 343,21 & 0,89 \\
\hline & $A_{107}$ & 135,82 & 0,60 & & & 340,12 & 0,56 & & \\
\hline & $A_{108}$ & 135,90 & 0,54 & & & 340,67 & 0,68 & 343,15 & 0,58 \\
\hline \multirow{3}{*}{$3-7$} & $A_{105}$ & 135,58 & 0,67 & 139,88 & 0,70 & & & 343,98 & 0,71 \\
\hline & $A_{107}$ & 135,72 & 0,68 & 139,91 & 0,68 & & & 344,12 & 0,72 \\
\hline & $A_{108}$ & 135,70 & 0,53 & 139,74 & 0,87 & & & 343,84 & 0,68 \\
\hline \multirow{3}{*}{$4-0$} & $A_{105}$ & & & 139,90 & 0,66 & & & 344,06 & 0,73 \\
\hline & $A_{107}$ & & & 139,90 & 0,65 & & & 344,54 & 0,72 \\
\hline & $A_{108}$ & & & 139,91 & 0,66 & & & 344,36 & 0,68 \\
\hline \multirow{3}{*}{ 5-1 } & $\mathrm{A}_{105}$ & 135,56 & 0,61 & 139,94 & 0,81 & 340,54 & 0,53 & 343,27 & 0,76 \\
\hline & $A_{107}$ & 136,00 & 0,77 & 139,74 & 0,55 & 340,25 & 0,64 & 342,90 & 0,80 \\
\hline & $A_{108}$ & 135,86 & 0,89 & 140,06 & 0,50 & 340,41 & 0,68 & & \\
\hline \multirow{3}{*}{$6-2$} & $A_{105}$ & 135,72 & 0,62 & & & 339,67 & 0,53 & & \\
\hline & $A_{107}$ & 135,77 & 0,63 & & & 340,55 & 0,67 & & \\
\hline & $A_{108}$ & 135,73 & 0,68 & & & 340,60 & 0,67 & & \\
\hline \multirow{3}{*}{$7-3$} & $A_{105}$ & & & 140,02 & 0,68 & & & 344,23 & 0,61 \\
\hline & $A_{107}$ & 135,87 & 1,17 & 139,95 & 0,56 & & & 344,65 & 0,66 \\
\hline & $A_{108}$ & 136,25 & 0,71 & 139,90 & 0,60 & & & 344,48 & 0,71 \\
\hline \multirow{3}{*}{\multicolumn{2}{|c|}{$\begin{array}{c}\text { Média } \\
\text { Desvio padrão } \\
\text { Coef. Variação }\end{array}$}} & 135,78 & 0,70 & 139,92 & 0,66 & 340,44 & 0,63 & 343,92 & 0,70 \\
\hline & & 0,172 & 0,151 & 0,129 & 0,098 & 0,326 & 0,059 & 0,537 & 0,147 \\
\hline & & $0,1 \%$ & $21,5 \%$ & $0,1 \%$ & $14,9 \%$ & $0,1 \%$ & $9,3 \%$ & $0,2 \%$ & $21,0 \%$ \\
\hline
\end{tabular}


Tabela E.30 - Parâmetros modais da Tora TT-6 para o ensaio com excitação horizontal.

\begin{tabular}{|c|c|c|c|c|c|c|c|c|c|}
\hline \multirow[b]{2}{*}{ Plano } & \multirow[b]{2}{*}{ FRF } & \multicolumn{4}{|c|}{$1^{\circ}$ Modo } & \multicolumn{4}{|c|}{$2^{\circ}$ Modo } \\
\hline & & $\begin{array}{l}\text { Freq. } \\
(\mathrm{Hz})\end{array}$ & $\begin{array}{c}\text { Amort. } \\
(\%)\end{array}$ & $\begin{array}{l}\text { Freq. } \\
(\mathrm{Hz})\end{array}$ & $\begin{array}{c}\text { Amort. } \\
(\%)\end{array}$ & $\begin{array}{l}\text { Freq. } \\
(\mathrm{Hz})\end{array}$ & $\begin{array}{c}\text { Amort. } \\
(\%)\end{array}$ & $\begin{array}{l}\text { Freq. } \\
(\mathrm{Hz})\end{array}$ & $\begin{array}{c}\text { Amort } \\
(\%)\end{array}$ \\
\hline \multirow{3}{*}{$0-4$} & $A_{105}$ & 137,07 & 0,66 & 142,89 & 0,61 & 337,31 & 0,73 & 347,16 & 0,84 \\
\hline & $A_{107}$ & 137,07 & 0,65 & 142,94 & 0,64 & 337,22 & 0,91 & & \\
\hline & $A_{108}$ & 137,00 & 0,61 & 143,03 & 0,72 & 337,25 & 0,75 & 346,22 & 0,67 \\
\hline \multirow{3}{*}{$1-5$} & $A_{105}$ & 137,10 & 0,74 & & & 337,49 & 0,67 & & \\
\hline & $A_{107}$ & 136,92 & 0,63 & & & 337,57 & 0,71 & & \\
\hline & $\mathrm{A}_{108}$ & 137,19 & 0,65 & & & 337,52 & 0,67 & & \\
\hline \multirow{3}{*}{$2-6$} & $A_{105}$ & 137,11 & 0,60 & 142,81 & 0,67 & 337,50 & 0,64 & 347,41 & 0,64 \\
\hline & $A_{107}$ & 137,13 & 0,65 & 142,83 & 0,64 & 337,56 & 0,67 & 346,59 & 0,62 \\
\hline & $A_{108}$ & 137,02 & 0,65 & 142,92 & 0,65 & 337,57 & 0,64 & 347,64 & 0,81 \\
\hline \multirow{3}{*}{$3-7$} & $A_{105}$ & & & 142,85 & 0,64 & & & 348,47 & 0,67 \\
\hline & $A_{107}$ & & & 142,89 & 0,63 & & & 348,52 & 0,67 \\
\hline & $A_{108}$ & & & 142,86 & 0,62 & & & 348,49 & 0,66 \\
\hline \multirow{3}{*}{$4-0$} & $A_{105}$ & 137,12 & 0,65 & 142,68 & 0,65 & 337,41 & 0,63 & 347,52 & 0,73 \\
\hline & $A_{107}$ & 137,09 & 0,66 & 142,80 & 0,64 & 337,46 & 0,65 & 346,90 & 0,52 \\
\hline & $A_{108}$ & 137,03 & 0,70 & 142,84 & 0,63 & 337,52 & 0,63 & 347,31 & 0,58 \\
\hline \multirow{3}{*}{$5-1$} & $A_{105}$ & 137,12 & 0,63 & & & 337,47 & 0,68 & & \\
\hline & $A_{107}$ & 137,14 & 0,63 & & & 337,50 & 0,67 & & \\
\hline & $A_{108}$ & 137,13 & 0,63 & & & 337,49 & 0,66 & & \\
\hline \multirow{3}{*}{$6-2$} & $A_{105}$ & 137,05 & 0,61 & 142,79 & 0,66 & 337,53 & 0,73 & 347,57 & 0,99 \\
\hline & $A_{107}$ & 137,08 & 0,69 & 142,82 & 0,62 & 337,52 & 0,63 & 348,12 & 1,01 \\
\hline & $\mathrm{A}_{108}$ & 137,04 & 0,74 & 142,85 & 0,59 & 337,66 & 0,79 & 349,25 & 1,11 \\
\hline \multirow{3}{*}{$7-3$} & $A_{105}$ & 142,92 & 0,65 & & & & & 348,46 & 0,70 \\
\hline & $A_{107}$ & 142,82 & 0,68 & & & & & 348,55 & 0,67 \\
\hline & $A_{108}$ & & & 142,85 & 0,63 & & & 348,47 & 0,71 \\
\hline \multirow{3}{*}{\multicolumn{2}{|c|}{$\begin{array}{c}\text { Média } \\
\text { Desvio padrão } \\
\text { Coef. Variação }\end{array}$}} & 137,66 & 0,66 & 142,85 & 0,64 & 337,47 & 0,69 & 347,80 & 0,74 \\
\hline & & 1,783 & 0,037 & 0,074 & 0,028 & 0,113 & 0,071 & 0,823 & 0,162 \\
\hline & & $1,3 \%$ & $5,7 \%$ & $0,1 \%$ & $4,4 \%$ & $0,0 \%$ & $10,3 \%$ & $0,2 \%$ & $21,8 \%$ \\
\hline
\end{tabular}


Tabela E.31 - Parâmetros modais da Tora TT-7 para o ensaio com excitação horizontal.

\begin{tabular}{|c|c|c|c|c|c|c|c|c|c|}
\hline \multirow[b]{2}{*}{ Plano } & \multirow[b]{2}{*}{ FRF } & \multicolumn{4}{|c|}{$1^{\circ}$ Modo } & \multicolumn{4}{|c|}{$2^{\circ}$ Modo } \\
\hline & & $\begin{array}{l}\text { Freq. } \\
(\mathrm{Hz})\end{array}$ & $\begin{array}{c}\text { Amort. } \\
(\%)\end{array}$ & $\begin{array}{l}\text { Freq. } \\
(\mathrm{Hz})\end{array}$ & $\begin{array}{c}\text { Amort. } \\
(\%)\end{array}$ & $\begin{array}{l}\text { Freq. } \\
(\mathrm{Hz})\end{array}$ & $\begin{array}{c}\text { Amort. } \\
(\%)\end{array}$ & $\begin{array}{l}\text { Freq. } \\
(\mathrm{Hz})\end{array}$ & $\begin{array}{c}\text { Amort. } \\
(\%)\end{array}$ \\
\hline \multirow{3}{*}{$0-4$} & $A_{105}$ & 146,81 & 0,65 & & & 362,92 & 0,64 & & \\
\hline & $A_{107}$ & 146,79 & 0,69 & & & 362,99 & 0,66 & & \\
\hline & $A_{108}$ & 146,85 & 0,62 & & & 363,01 & 0,66 & & \\
\hline \multirow{3}{*}{$1-5$} & $A_{105}$ & 146,68 & 0,64 & 154,62 & 0,64 & 363,39 & 0,66 & 375,23 & 0,66 \\
\hline & $A_{107}$ & 146,72 & 0,71 & 154,59 & 0,59 & 363,39 & 0,67 & 375,20 & 0,69 \\
\hline & $A_{108}$ & 146,74 & 0,68 & 154,56 & 0,62 & 363,43 & 0,67 & 375,24 & 0,66 \\
\hline \multirow{3}{*}{$2-6$} & $A_{105}$ & 145,01 & 1,03 & 154,59 & 0,61 & 363,88 & 0,86 & 374,65 & 0,68 \\
\hline & $A_{107}$ & & & 154,63 & 0,61 & & & 374,72 & 0,67 \\
\hline & $\mathrm{A}_{108}$ & & & 154,71 & 0,47 & & & 375,18 & 0,74 \\
\hline \multirow{3}{*}{$3-7$} & $A_{105}$ & 146,66 & 0,67 & 154,48 & 0,62 & 364,23 & 0,64 & 374,86 & 0,70 \\
\hline & $A_{107}$ & 146,63 & 0,64 & 154,64 & 0,62 & 363,67 & 0,64 & 374,89 & 0,66 \\
\hline & $A_{108}$ & 146,67 & 0,64 & 154,56 & 0,63 & 364,10 & 0,63 & 374,88 & 0,29 \\
\hline \multirow{3}{*}{$4-0$} & $A_{105}$ & 146,75 & 0,63 & & & 363,23 & 0,65 & & \\
\hline & $A_{107}$ & 146,79 & 0,63 & & & 363,32 & 0,66 & & \\
\hline & $\mathrm{A}_{108}$ & 146,77 & 0,64 & & & 363,36 & 0,65 & & \\
\hline \multirow{3}{*}{$5-1$} & $A_{105}$ & 146,69 & 0,61 & 154,49 & 0,63 & 363,58 & 0,69 & 375,15 & 0,76 \\
\hline & $A_{107}$ & 146,65 & 0,68 & 154,59 & 0,60 & 363,50 & 0,70 & 375,45 & 0,74 \\
\hline & $A_{108}$ & 146,54 & 0,74 & 154,73 & 0,51 & 363,58 & 0,74 & 375,41 & 0,77 \\
\hline \multirow{3}{*}{$6-2$} & $A_{105}$ & & & 154,61 & 0,63 & & & 374,95 & 0,70 \\
\hline & $A_{107}$ & & & 154,67 & 0,67 & & & 375,10 & 0,18 \\
\hline & $A_{108}$ & & & 154,64 & 0,64 & & & 375,04 & 0,70 \\
\hline \multirow{3}{*}{$7-3$} & $A_{105}$ & 146,72 & 0,68 & 154,54 & 0,53 & 363,63 & 0,69 & 374,84 & 0,68 \\
\hline & $A_{107}$ & 146,81 & 0,63 & 154,53 & 0,65 & 363,73 & 0,68 & 374,96 & 0,65 \\
\hline & $A_{108}$ & 146,74 & 0,62 & 154,73 & 0,65 & 363,74 & 0,66 & 375,03 & 0,68 \\
\hline \multirow{2}{*}{\multicolumn{2}{|c|}{$\begin{array}{c}\text { Média } \\
\text { Desvio padrão } \\
\text { Coef. Variacão }\end{array}$}} & 146,63 & 0,67 & 154,61 & 0,61 & 363,51 & 0,68 & 375,04 & 0,64 \\
\hline & & $\begin{array}{c}0,400 \\
0,3 \%\end{array}$ & $\begin{array}{r}0,093 \\
13.7 \%\end{array}$ & $\begin{array}{c}0,073 \\
0.0 \%\end{array}$ & 0,052 & 0,350 & 0,051 & 0,220 & $\begin{array}{l}0,154 \\
23\end{array}$ \\
\hline
\end{tabular}


Tabela E.32 - Parâmetros modais da Tora TT-8 para o ensaio com excitação horizontal.

\begin{tabular}{|c|c|c|c|c|c|c|c|c|c|}
\hline \multirow[b]{2}{*}{ Plano } & \multirow[b]{2}{*}{ FRF } & \multicolumn{4}{|c|}{$1^{\circ}$ Modo } & \multicolumn{4}{|c|}{$2^{\circ}$ Modo } \\
\hline & & $\begin{array}{l}\text { Freq. } \\
(\mathrm{Hz})\end{array}$ & $\begin{array}{l}\text { Amort. } \\
(\%)\end{array}$ & $\begin{array}{l}\text { Freq. } \\
(\mathrm{Hz})\end{array}$ & $\begin{array}{c}\text { Amort. } \\
(\%)\end{array}$ & $\begin{array}{l}\text { Freq. } \\
(\mathrm{Hz})\end{array}$ & $\begin{array}{l}\text { Amort. } \\
(\%)\end{array}$ & $\begin{array}{l}\text { Freq. } \\
(\mathrm{Hz})\end{array}$ & $\begin{array}{c}\text { Amort } \\
(\%)\end{array}$ \\
\hline \multirow{3}{*}{$0-4$} & $A_{105}$ & & & 149,28 & 0,56 & & & 361,84 & 0,63 \\
\hline & $A_{107}$ & & & 149,23 & 0,59 & & & 361,82 & 0,64 \\
\hline & $A_{108}$ & & & 148,12 & 0,74 & & & 361,30 & 0,55 \\
\hline \multirow{3}{*}{$1-5$} & $A_{105}$ & 144,32 & 0,80 & 149,25 & 0,51 & 355,87 & 0,72 & 361,76 & 0,61 \\
\hline & $A_{107}$ & 144,14 & 0,51 & 149,27 & 0,63 & 355,58 & 0,64 & 361,90 & 0,68 \\
\hline & $\mathrm{A}_{108}$ & 144,10 & 0,55 & 149,31 & 0,62 & 355,52 & 0,71 & 361,98 & 0,67 \\
\hline \multirow{3}{*}{$2-6$} & $A_{105}$ & 143,80 & 0,60 & & & 354,77 & 0,64 & & \\
\hline & $A_{107}$ & 144,12 & 0,62 & & & 354,98 & 0,62 & & \\
\hline & $\mathrm{A}_{108}$ & 144,17 & 0,59 & & & 354,98 & 0,63 & & \\
\hline \multirow{3}{*}{$3-7$} & $A_{105}$ & 144,23 & 0,81 & 149,27 & 0,54 & 355,31 & 0,64 & 362,12 & 0,62 \\
\hline & $A_{107}$ & 144,09 & 0,76 & 149,52 & 0,59 & 355,33 & 0,64 & 362,43 & 0,61 \\
\hline & $\mathrm{A}_{108}$ & 144,00 & 0,79 & 149,75 & 0,82 & 355,36 & 0,63 & 362,38 & 0,61 \\
\hline \multirow{3}{*}{$4-0$} & $A_{105}$ & 144,44 & 1,15 & 149,27 & 0,58 & 356,15 & 0,71 & 361,78 & 0,62 \\
\hline & $A_{107}$ & 144,07 & 0,80 & 149,29 & 0,65 & 356,08 & 0,83 & 361,95 & 0,59 \\
\hline & $A_{108}$ & 144,06 & 1,05 & 149,28 & 0,60 & 356,56 & 0,82 & 361,93 & 0,60 \\
\hline \multirow{3}{*}{$5-1$} & $A_{105}$ & 143,77 & 0,58 & 149,18 & 0,60 & 355,66 & 0,67 & 361,99 & 0,66 \\
\hline & $A_{107}$ & 144,18 & 0,64 & 149,21 & 0,59 & 355,88 & 0,68 & 362,08 & 0,62 \\
\hline & $A_{108}$ & 144,13 & 0,58 & 149,18 & 0,61 & 355,98 & 0,70 & 362,01 & 0,61 \\
\hline \multirow{3}{*}{$6-2$} & $A_{105}$ & 144,28 & 0,63 & 148,06 & 0,54 & 354,91 & 0,62 & 363,80 & 0,41 \\
\hline & $A_{107}$ & 144,22 & 0,58 & 149,36 & 0,64 & 355,02 & 0,62 & 362,19 & 0,66 \\
\hline & $A_{108}$ & 144,19 & 0,60 & 149,42 & 0,65 & 355,04 & 0,63 & 362,59 & 0,24 \\
\hline \multirow{3}{*}{$7-3$} & $A_{105}$ & 144,10 & 0,69 & 148,58 & 0,81 & 355,15 & 0,63 & 362,22 & 0,58 \\
\hline & $A_{107}$ & 144,04 & 0,74 & 149,13 & 0,72 & 355,30 & 0,61 & 362,16 & 0,65 \\
\hline & $A_{108}$ & 144,03 & 0,70 & 148,91 & 0,88 & 355,26 & 0,59 & 362,59 & 0,52 \\
\hline \multirow{3}{*}{\multicolumn{2}{|c|}{$\begin{array}{l}\text { Desvio padrão } \\
\text { Coef. Variação }\end{array}$}} & 144,12 & $\overline{0,70}$ & 149,14 & 0,64 & 355,46 & 0,66 & 362,13 & 0,59 \\
\hline & & 0,153 & 0,162 & 0,412 & 0,098 & 0,477 & 0,065 & 0,484 & 0,101 \\
\hline & & $0,1 \%$ & $22,9 \%$ & $0,3 \%$ & $15,3 \%$ & $0,1 \%$ & $9,8 \%$ & $0,1 \%$ & $17,1 \%$ \\
\hline
\end{tabular}


Tabela E.33 - Parâmetros modais da Tora TT-9 para o ensaio com excitação horizontal.

\begin{tabular}{|c|c|c|c|c|c|c|c|c|c|}
\hline \multirow[b]{2}{*}{ Plano } & \multirow[b]{2}{*}{ FRF } & \multicolumn{4}{|c|}{$1^{\circ}$ Modo } & \multicolumn{4}{|c|}{$2^{\circ}$ Modo } \\
\hline & & $\begin{array}{l}\text { Freq. } \\
(\mathbf{H z})\end{array}$ & $\begin{array}{c}\text { Amort. } \\
(\%)\end{array}$ & $\begin{array}{c}\text { Freq. } \\
(\mathbf{H z})\end{array}$ & $\begin{array}{c}\text { Amort. } \\
(\%)\end{array}$ & $\begin{array}{l}\text { Freq. } \\
(\mathrm{Hz})\end{array}$ & $\begin{array}{c}\text { Amort. } \\
(\%)\end{array}$ & $\begin{array}{l}\text { Freq. } \\
(\mathrm{Hz})\end{array}$ & $\begin{array}{c}\text { Amort. } \\
(\%)\end{array}$ \\
\hline \multirow{3}{*}{$0-4$} & $\overline{A_{105}}$ & 137,17 & 0,55 & 143,51 & 0,83 & 343,06 & $\overline{0,71}$ & 354,15 & 0,22 \\
\hline & $A_{107}$ & 137,43 & 0,50 & 143,42 & 0,83 & 343,27 & 0,52 & 356,27 & 0,71 \\
\hline & $A_{108}$ & 137,24 & 0,54 & 143,48 & 0,80 & 342,92 & 0,74 & 355,84 & 0,77 \\
\hline \multirow{3}{*}{$1-5$} & $A_{105}$ & & & 143,59 & 0,68 & & & 353,94 & 0,68 \\
\hline & $A_{107}$ & & & 143,74 & 0,73 & & & 353,95 & 0,69 \\
\hline & $A_{108}$ & & & 143,61 & 0,69 & & & 353,99 & 0,67 \\
\hline \multirow{3}{*}{$2-6$} & $A_{105}$ & 137,21 & 0,76 & 143,64 & 0,64 & 343,64 & 0,83 & 354,21 & 0,76 \\
\hline & $A_{107}$ & 137,19 & 0,88 & 143,74 & 0,51 & 342,64 & 0,57 & 354,98 & 0,62 \\
\hline & $A_{108}$ & 137,29 & 0,64 & 143,59 & 0,74 & 342,36 & 0,77 & 354,73 & 0,81 \\
\hline \multirow{3}{*}{$3-7$} & $\mathrm{~A}_{105}$ & 137,31 & 0,68 & & & 343,58 & 0,66 & & \\
\hline & $A_{107}$ & 137,34 & 0,67 & & & 343,58 & 0,67 & & \\
\hline & $A_{108}$ & 137,34 & 0,67 & & & 343,76 & 0,61 & & \\
\hline \multirow{3}{*}{ 4-0 } & $\mathrm{A}_{105}$ & 137,33 & 0,63 & 143,56 & 0,77 & 343,14 & 0,65 & 354,60 & 0,66 \\
\hline & $A_{107}$ & 138,38 & 0,59 & 144,51 & 0,54 & 343,16 & 0,56 & 355,08 & 0,68 \\
\hline & $A_{108}$ & 137,14 & 0,56 & 143,81 & 0,84 & 343,82 & 1,35 & 355,54 & 0,67 \\
\hline \multirow{3}{*}{ 5-1 } & $A_{105}$ & & & 143,56 & 0,70 & & & 353,96 & 0,67 \\
\hline & $A_{107}$ & & & 143,59 & 0,68 & & & 354,01 & 0,67 \\
\hline & $A_{108}$ & & & 143,59 & 0,69 & & & 354,02 & 0,66 \\
\hline \multirow{3}{*}{$6-2$} & $A_{105}$ & 137,10 & 0,64 & 143,65 & 0,75 & 342,54 & 0,71 & 354,26 & 0,82 \\
\hline & $A_{107}$ & 137,39 & 0,69 & 143,48 & 0,70 & 342,79 & 1,04 & 354,10 & 0,77 \\
\hline & $A_{108}$ & 137,33 & 0,69 & 143,53 & 0,69 & 342,81 & 0,66 & 354,30 & 0,68 \\
\hline \multirow{3}{*}{$7-3$} & $A_{105}$ & 137,29 & 0,70 & & & 343,62 & 0,64 & & \\
\hline & $A_{107}$ & 137,33 & 0,68 & & & 343,71 & 0,64 & & \\
\hline & $A_{108}$ & 137,32 & 0,68 & & & 343,72 & 0,63 & & \\
\hline \multirow{3}{*}{\multicolumn{2}{|c|}{$\begin{array}{l}\text { Média } \\
\text { svio padrão } \\
\text { ef. Variação }\end{array}$}} & 137,34 & 0,65 & 143,64 & 0,71 & 343,23 & $\overline{0,72}$ & 354,55 & 0,68 \\
\hline & & 0,274 & 0,087 & 0,236 & 0,089 & 0,471 & 0,195 & 0,714 & 0,127 \\
\hline & & $0,2 \%$ & $13,3 \%$ & $0,2 \%$ & $12,6 \%$ & $0,1 \%$ & $27,1 \%$ & $0,2 \%$ & $18,7 \%$ \\
\hline
\end{tabular}


Tabela E.34 - Parâmetros modais da Tora TT-10 para o ensaio com excitação horizontal.

\begin{tabular}{|c|c|c|c|c|c|c|c|c|c|}
\hline \multirow[b]{2}{*}{ Plano } & \multirow[b]{2}{*}{ FRF } & \multicolumn{4}{|c|}{$1^{\circ}$ Modo } & \multicolumn{4}{|c|}{$2^{\circ}$ Modo } \\
\hline & & $\begin{array}{l}\text { Freq. } \\
(\mathrm{Hz})\end{array}$ & $\begin{array}{c}\text { Amort. } \\
(\%)\end{array}$ & $\begin{array}{l}\begin{array}{c}\text { Freq. } \\
(\mathrm{Hz})\end{array} \\
\end{array}$ & $\begin{array}{c}\text { Amort. } \\
(\%)\end{array}$ & $\begin{array}{c}\text { Freq. } \\
(\mathrm{Hz})\end{array}$ & $\begin{array}{c}\text { Amort. } \\
(\%)\end{array}$ & $\begin{array}{r}\text { Freq. } \\
(\mathrm{Hz})\end{array}$ & $\begin{array}{c}\text { Amort. } \\
(\%)\end{array}$ \\
\hline \multirow{3}{*}{$0-4$} & $\mathrm{~A}_{105}$ & 141,47 & 0,59 & 147,19 & 0,65 & 353,24 & 0,78 & 363,16 & 0,73 \\
\hline & $A_{107}$ & 141,51 & 0,61 & 147,23 & 0,63 & 353,11 & 0,73 & 363,45 & 0,40 \\
\hline & $A_{108}$ & 141,43 & 0,61 & 147,31 & 0,63 & 353,24 & 0,71 & 361,88 & 0,61 \\
\hline \multirow{3}{*}{$1-5$} & $A_{105}$ & 141,53 & 0,59 & & & 352,44 & 0,64 & & \\
\hline & $A_{107}$ & 141,48 & 0,61 & & & 352,49 & 0,63 & & \\
\hline & $A_{108}$ & 141,47 & 0,63 & & & 352,52 & 0,64 & & \\
\hline \multirow{3}{*}{$2-6$} & $A_{105}$ & 141,30 & 0,44 & 147,24 & 0,71 & 352,87 & 0,68 & 362,10 & 0,64 \\
\hline & $A_{107}$ & 141,40 & 0,66 & 147,24 & 0,59 & 353,11 & 0,67 & 361,91 & 0,63 \\
\hline & $A_{108}$ & 141,46 & 0,64 & 147,19 & 0,60 & 353,44 & 0,68 & 361,75 & 0,62 \\
\hline \multirow{3}{*}{$3-7$} & $\mathrm{~A}_{105}$ & 141,04 & 1,07 & 147,19 & 0,61 & & & 361,60 & 0,65 \\
\hline & $A_{107}$ & & & 147,01 & 0,76 & & & 361,54 & 0,60 \\
\hline & $A_{108}$ & & & 147,10 & 0,61 & & & 361,61 & 0,65 \\
\hline \multirow{3}{*}{$4-0$} & $\mathrm{~A}_{105}$ & 141,39 & 0,55 & 147,14 & 0,76 & 353,17 & 0,72 & 361,65 & 0,65 \\
\hline & $A_{107}$ & 141,56 & 0,58 & 146,93 & 0,67 & 353,40 & 0,68 & 361,68 & 0,71 \\
\hline & $A_{108}$ & 141,47 & 0,65 & 147,12 & 0,58 & 353,98 & 0,64 & 362,73 & 0,91 \\
\hline \multirow{3}{*}{$5-1$} & $A_{105}$ & 141,49 & 0,61 & & & 352,74 & 0,67 & & \\
\hline & $A_{107}$ & 141,50 & 0,63 & & & 352,81 & 0,66 & & \\
\hline & $A_{108}$ & 141,51 & 0,61 & & & 352,80 & 0,65 & & \\
\hline \multirow{3}{*}{$6-2$} & $\mathrm{~A}_{105}$ & 141,30 & 0,63 & 147,18 & 0,64 & 353,11 & 0,65 & 362,00 & 0,67 \\
\hline & $A_{107}$ & 141,34 & 0,59 & 147,21 & 0,67 & 353,15 & 0,67 & 362,02 & 0,61 \\
\hline & $A_{108}$ & 141,50 & 0,68 & 147,00 & 0,58 & 353,18 & 0,65 & 362,07 & 0,62 \\
\hline \multirow{3}{*}{$7-3$} & $A_{105}$ & & & 147,10 & 0,59 & & & 361,64 & 0,62 \\
\hline & $A_{107}$ & & & 147,08 & 0,64 & & & 361,74 & 0,62 \\
\hline & $A_{108}$ & & & 147,08 & 0,57 & & & 361,66 & 0,63 \\
\hline \multirow{3}{*}{\multicolumn{2}{|c|}{$\begin{array}{l}\text { Média } \\
\text { vio padrão } \\
\text { f. Variação }\end{array}$}} & 141,43 & 0,63 & 147,14 & 0,64 & 353,04 & 0,68 & 362,01 & 0,64 \\
\hline & & 0,119 & 0,117 & 0,097 & 0,058 & 0,381 & 0,038 & 0,550 & 0,093 \\
\hline & & $0,1 \%$ & $18,6 \%$ & $0,1 \%$ & $9,2 \%$ & $0,1 \%$ & $5,6 \%$ & $0,2 \%$ & $14,5 \%$ \\
\hline
\end{tabular}




\section{APÊNDICE F - DADOS DAS TORAS DA AMOSTRA DE VALIDAÇÃO}

Tabela F.1 - Dados da tora 1.

Tora $\mathrm{N}^{\circ} 1$

Data: $08 / 04 / 2010$

Espécie: Eucalyptus citriodora

\begin{tabular}{|c|c|c|c|c|c|c|}
\hline \multicolumn{3}{|c|}{ Características de crescimento } & Medido & \multicolumn{3}{|c|}{ Limite } \\
\hline \multicolumn{3}{|l|}{ Massa (kg) } & 95,8 & \multicolumn{3}{|c|}{-} \\
\hline \multicolumn{3}{|l|}{ Comprimento (cm) } & 409,8 & \multicolumn{3}{|c|}{-} \\
\hline \multicolumn{3}{|l|}{ Linha de terra $(\mathrm{cm})$} & 81,96 & \multicolumn{3}{|c|}{-} \\
\hline \multirow{5}{*}{ Diâmetros (cm) } & Direção & Topo & Base & \multicolumn{3}{|c|}{-} \\
\hline & $0-4$ & 16,9 & 17,5 & \multicolumn{3}{|c|}{-} \\
\hline & $1-5$ & 17,6 & 17,2 & \multicolumn{3}{|c|}{-} \\
\hline & $2-6$ & 17,3 & 18,7 & \multicolumn{3}{|c|}{-} \\
\hline & $3-7$ & 15,9 & $\overline{19,2}$ & \multicolumn{3}{|c|}{-} \\
\hline \multirow{2}{*}{ Teor de umidade (\%) } & Topo & Metade & Base & \multicolumn{3}{|c|}{-} \\
\hline & 20,2 & 24,1 & 22,5 & \multicolumn{3}{|c|}{-} \\
\hline \multirow{2}{*}{\multicolumn{3}{|c|}{$\begin{array}{l}\text { Inclusões contendo casca }(\mathrm{cm}) \\
\text { Madeira comprimida em } 5 \mathrm{~cm}(\mathrm{~S} / \mathrm{N})\end{array}$}} & - & \multicolumn{3}{|c|}{0,5} \\
\hline & & & - & \multicolumn{3}{|c|}{ Não } \\
\hline \multicolumn{3}{|c|}{ Furos de insetos $(\mathrm{mm})$} & 1 & \multicolumn{3}{|c|}{$\leq 2 \mathrm{~mm}$} \\
\hline \multirow{2}{*}{ Fendas (cm) } & \multicolumn{2}{|l|}{ Topo } & 6 & \multicolumn{3}{|c|}{$\leq 30 \mathrm{~cm}$} \\
\hline & \multicolumn{2}{|l|}{ Base } & 26 & \multicolumn{3}{|c|}{$\leq 60 \mathrm{~cm}$} \\
\hline \multirow{2}{*}{ Encurvamento } & \multirow{2}{*}{\multicolumn{2}{|c|}{\begin{tabular}{|l|} 
um plano \\
dois planos $(\mathrm{S} / \mathrm{N})$ \\
\end{tabular}}} & $0,5 \%$ & \multicolumn{3}{|c|}{$\leq 0,8 \%$} \\
\hline & & & - & Nãop & sar pela & rfície \\
\hline \multicolumn{3}{|l|}{ Fibra torcida (m/volta) } & Ver obs. & & $3 \mathrm{~m} / \mathrm{vc}$ & \\
\hline Diâmetro dos nós (cm) & Individual & & - & & $\leq 5 \mathrm{~cm}$ & \\
\hline Diametro dos nos (cm) & Grupo & & - & & seção ol & \\
\hline & & & & & & \\
\hline & 0 & 1 & 2 & 3 & 4 & 5 \\
\hline & $0,00 \mathrm{~L}$ & $0,10 \mathrm{~L}$ & $0,20 \mathrm{~L}$ & $0,30 \mathrm{~L}$ & $0,40 \mathrm{~L}$ & $0,50 \mathrm{~L}$ \\
\hline Circunferência (cm) & 57,9 & 55,7 & 54,9 & 54,9 & 54,5 & 54,1 \\
\hline & & & & & & \\
\hline & 6 & 7 & 8 & 9 & 10 & 11 \\
\hline & $0,60 \mathrm{~L}$ & $\overline{0,70 L}$ & $0,80 \mathrm{~L}$ & $0,90 \mathrm{~L}$ & $0,95 \mathrm{~L}$ & $1,00 \mathrm{~L}$ \\
\hline & 53,6 & 52,8 & 52 & 51,8 & - & 53,9 \\
\hline
\end{tabular}

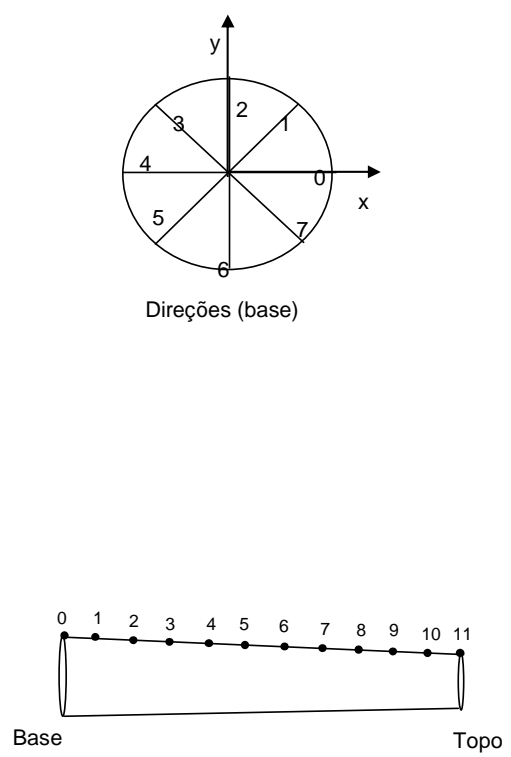

Observações:

Excentricidade da medula: Topo $=2 \mathrm{~cm}$ p/ esquerda $\quad$ Base $=2 \mathrm{~cm} \mathrm{p} /$ cima

Encurvamento curto $=2 \mathrm{~cm}$

Fibras com padrão sinusoidal

\begin{tabular}{|c|c|c|c|c|c|c|c|c|c|c|c|}
\hline \multirow{2}{*}{ Propriedades } & \multicolumn{11}{|c|}{ Seção } \\
\hline & 0 & $0.1 \mathrm{~L}$ & $0.2 \mathrm{~L}$ & $0.3 \mathrm{~L}$ & $0.4 \mathrm{~L}$ & $0.5 \mathrm{~L}$ & $0.6 \mathrm{~L}$ & $0.7 \mathrm{~L}$ & $0.8 \mathrm{~L}$ & $0.9 \mathrm{~L}$ & $1.0 \mathrm{~L}$ \\
\hline $\mathrm{D}(\mathrm{cm})$ & 18,43 & 17,73 & 17,48 & 17,48 & 17,35 & 17,22 & 17,06 & 16,81 & 16,55 & 16,49 & 17,16 \\
\hline $\mathrm{D}_{\text {méd }}(\mathrm{cm})$ & 18,13 & & & & & & & & & & 16,91 \\
\hline$\Delta_{\text {circ }}$ & $1,6 \%$ & & & & & & & & & & $1,4 \%$ \\
\hline$L / D_{\text {meio }}$ & \multicolumn{11}{|c|}{23,80} \\
\hline C & \multicolumn{11}{|c|}{$0,3 \%$} \\
\hline$\Delta \mathrm{D}$ & \multicolumn{11}{|c|}{$3,2 \%$} \\
\hline Densidade $\left(\mathrm{kg} / \mathrm{m}^{3}\right)$ & \multicolumn{11}{|c|}{969,1} \\
\hline
\end{tabular}


Tabela F. 2 - Dados da tora 2.

Tora $\mathrm{N}^{\circ} 2$

Data: $14 / 04 / 2010$

Espécie: Eucalyptus citriodora

\begin{tabular}{|c|c|c|c|c|c|c|}
\hline \multicolumn{3}{|c|}{ Características de crescimento } & Medido & \multicolumn{3}{|c|}{ Limite } \\
\hline \multicolumn{3}{|l|}{ Massa (kg) } & 104,4 & \multicolumn{3}{|c|}{-} \\
\hline \multicolumn{3}{|l|}{ Comprimento (cm) } & 425,5 & \multicolumn{3}{|c|}{-} \\
\hline \multicolumn{3}{|l|}{ Linha de terra $(\mathrm{cm})$} & 85,1 & \multicolumn{3}{|c|}{-} \\
\hline \multirow{5}{*}{ Diâmetros (cm) } & Direção & Topo & Base & \multicolumn{3}{|c|}{-} \\
\hline & $0-4$ & 15,5 & 21 & \multicolumn{3}{|c|}{-} \\
\hline & $1-5$ & 17,2 & 23 & \multicolumn{3}{|c|}{-} \\
\hline & $2-6$ & 17,5 & 23 & \multicolumn{3}{|c|}{-} \\
\hline & $3-7$ & 15,7 & 20,5 & \multicolumn{3}{|c|}{-} \\
\hline \multirow{2}{*}{ Teor de umidade (\%) } & Topo & Metade & Base & \multicolumn{3}{|c|}{-} \\
\hline & 29,5 & 31,5 & 32,4 & \multicolumn{3}{|c|}{-} \\
\hline \multicolumn{3}{|c|}{ Inclusões contendo casca (cm) } & - & \multicolumn{3}{|c|}{0,5} \\
\hline \multicolumn{3}{|c|}{ Madeira comprimida em $5 \mathrm{~cm}(\mathrm{~S} / \mathrm{N})$} & - & \multicolumn{3}{|c|}{ Não } \\
\hline \multicolumn{3}{|l|}{ Furos de insetos (mm) } & 1 & \multicolumn{3}{|c|}{$\leq 2 \mathrm{~mm}$} \\
\hline \multirow{2}{*}{ Fendas $(\mathrm{cm})$} & \multirow{2}{*}{\multicolumn{2}{|c|}{ Topo }} & 25 & \multicolumn{3}{|c|}{$\leq 30 \mathrm{~cm}$} \\
\hline & & & 31 & \multicolumn{3}{|c|}{$\leq 60 \mathrm{~cm}$} \\
\hline \multirow{2}{*}{ Encurvamento } & \multirow{2}{*}{\multicolumn{2}{|c|}{\begin{tabular}{|l|} 
um plano \\
dois planos $(\mathrm{S} / \mathrm{N})$ \\
\end{tabular}}} & $0,4 \%$ & & $\leq 0,8 \%$ & \\
\hline & & & - & Não & sar pela & rfície \\
\hline Fibra torcida (m/volta) & & & - & & $3 \mathrm{~m} / \mathrm{v}$ & \\
\hline Diâmetro dos nós (cm) & Individual & & - & & $\leq 5 \mathrm{~cm}$ & \\
\hline Diametro dos nos (cm) & Grupo & & - & & seção ol & \\
\hline & & & & & & \\
\hline & 0 & 1 & 2 & 3 & 4 & 5 \\
\hline & $0,00 \mathrm{~L}$ & $0,10 \mathrm{~L}$ & $0,20 \mathrm{~L}$ & $0,30 \mathrm{~L}$ & $0,40 \mathrm{~L}$ & $0,50 \mathrm{~L}$ \\
\hline Circunferência $(\mathrm{cm})$ & 69,3 & 62,1 & 58,8 & 56,3 & 55,2 & 54,4 \\
\hline & & & & & & \\
\hline & 6 & 7 & 8 & 9 & 10 & 11 \\
\hline & $0,60 \mathrm{~L}$ & $0,70 \mathrm{~L}$ & $0,80 \mathrm{~L}$ & $0,90 \mathrm{~L}$ & $0,95 \mathrm{~L}$ & $1,00 \mathrm{~L}$ \\
\hline & 53,5 & 52,8 & 52,3 & 51,5 & & 52,2 \\
\hline
\end{tabular}

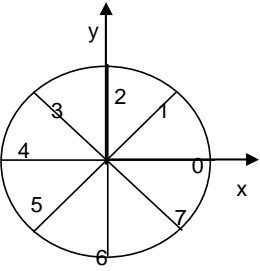

Direções (base)

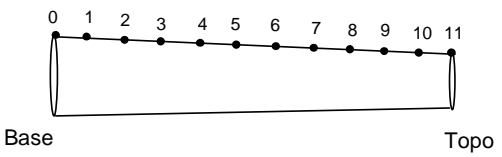

Observações:

\begin{tabular}{|c|c|c|c|c|c|c|c|c|c|c|c|}
\hline \multirow{2}{*}{ Propriedades } & \multicolumn{11}{|c|}{ Seção } \\
\hline & 0 & $0.1 \mathrm{~L}$ & $0.2 \mathrm{~L}$ & $0.3 \mathrm{~L}$ & $0.4 \mathrm{~L}$ & $0.5 \mathrm{~L}$ & $0.6 \mathrm{~L}$ & $\begin{array}{c}0.7 \mathrm{~L} \\
\end{array}$ & $0.8 \mathrm{~L}$ & $0.9 \mathrm{~L}$ & $1.0 \mathrm{~L}$ \\
\hline $\bar{D}(\mathrm{~cm})$ & 22,06 & 19,77 & 18,72 & 17,92 & 17,57 & 17,32 & 17,03 & 16,81 & 16,65 & 16,39 & 16,62 \\
\hline $\mathrm{D}_{\text {méd }}(\mathrm{cm})$ & 21,85 & & & & & & & & & & 16,45 \\
\hline$\Delta_{\text {circ }}$ & $1,0 \%$ & & & & & & & & & & $1,0 \%$ \\
\hline$L / D_{\text {meio }}$ & \multicolumn{11}{|c|}{24,57} \\
\hline C & \multirow{2}{*}{\multicolumn{11}{|c|}{$\frac{1,3 \%}{96 \%}$}} \\
\hline$\Delta \mathrm{D}$ & & & & & & & & & & & \\
\hline
\end{tabular}


Tabela F.3 - Dados da tora 3.

Tora $\mathrm{N}^{\circ} 3$

\begin{tabular}{|c|c|c|c|c|c|c|}
\hline \multicolumn{3}{|c|}{ Características de crescimento } & Medido & \multicolumn{3}{|c|}{ Limite } \\
\hline \multicolumn{3}{|l|}{ Massa (kg) } & 118,45 & \multicolumn{3}{|c|}{-} \\
\hline \multicolumn{3}{|l|}{ Comprimento (cm) } & 417,4 & \multicolumn{3}{|c|}{-} \\
\hline \multicolumn{3}{|l|}{ Linha de terra $(\mathrm{cm})$} & 83,48 & \multicolumn{3}{|c|}{-} \\
\hline \multirow{5}{*}{ Diâmetros (cm) } & Direção & Topo & Base & \multicolumn{3}{|c|}{-} \\
\hline & $0-4$ & 17,7 & 17,2 & \multicolumn{3}{|c|}{-} \\
\hline & $1-5$ & 17,0 & 19,1 & \multicolumn{3}{|c|}{-} \\
\hline & $2-6$ & 17,7 & 20,2 & \multicolumn{3}{|c|}{-} \\
\hline & $3-7$ & 17,2 & 20,5 & \multicolumn{3}{|c|}{-} \\
\hline \multirow{2}{*}{ Teor de umidade (\%) } & Topo & Metade & Base & \multicolumn{3}{|c|}{-} \\
\hline & 18,2 & 14,5 & 16,6 & \multicolumn{3}{|c|}{-} \\
\hline \multicolumn{3}{|c|}{ Inclusões contendo casca (cm) } & - & \multicolumn{3}{|c|}{0,5} \\
\hline \multirow{2}{*}{\multicolumn{3}{|c|}{$\begin{array}{l}\text { Madeira comprimida em } 5 \mathrm{~cm}(\mathrm{~S} / \mathrm{N}) \\
\text { Furos de insetos }(\mathrm{mm})\end{array}$}} & - & \multicolumn{3}{|c|}{ Não } \\
\hline & & & 1 & \multicolumn{3}{|c|}{$\leq 2 \mathrm{~mm}$} \\
\hline \multirow{2}{*}{ Fendas $(\mathrm{cm})$} & \multicolumn{2}{|l|}{ Topo } & - & \multicolumn{3}{|c|}{$\leq 30 \mathrm{~cm}$} \\
\hline & \multicolumn{2}{|l|}{ Base } & - & \multicolumn{3}{|c|}{$\leq 60 \mathrm{~cm}$} \\
\hline \multirow{2}{*}{ Encurvamento } & \multirow{2}{*}{\multicolumn{2}{|c|}{\begin{tabular}{|l|} 
um plano \\
dois planos $(S / N)$ \\
\end{tabular}}} & $0,5 \%$ & \multicolumn{3}{|c|}{$\leq 0,8 \%$} \\
\hline & & & - & Não & sar pela & erfície \\
\hline Fibra torcida (m/volta) & & & - & & $3 \mathrm{~m} / \mathrm{vo}$ & \\
\hline Diâmetro dos nós $(\mathrm{cm})$ & Individual & & ver obs. & & $\leq 5 \mathrm{~cm}$ & \\
\hline Diametro dos nos (cm) & Grupo & & - & & seção ou & \\
\hline & & & & & & \\
\hline & 0 & 1 & 2 & 3 & 4 & 5 \\
\hline & $0,00 \mathrm{~L}$ & $0,10 \mathrm{~L}$ & $0,20 \mathrm{~L}$ & $0,30 \mathrm{~L}$ & $0,40 \mathrm{~L}$ & $0,50 \mathrm{~L}$ \\
\hline Circunferência $(\mathrm{cm})$ & 62,8 & 60,2 & 60 & 59,2 & 58,5 & 58,4 \\
\hline & & & & & & \\
\hline & 6 & 7 & 8 & 9 & 10 & 11 \\
\hline & $0,60 \mathrm{~L}$ & $0,70 \mathrm{~L}$ & $0,80 \mathrm{~L}$ & $0,90 \mathrm{~L}$ & $0,95 \mathrm{~L}$ & $1,00 \mathrm{~L}$ \\
\hline & 58,1 & 57 & 56,8 & 57,8 & - & 55 \\
\hline
\end{tabular}

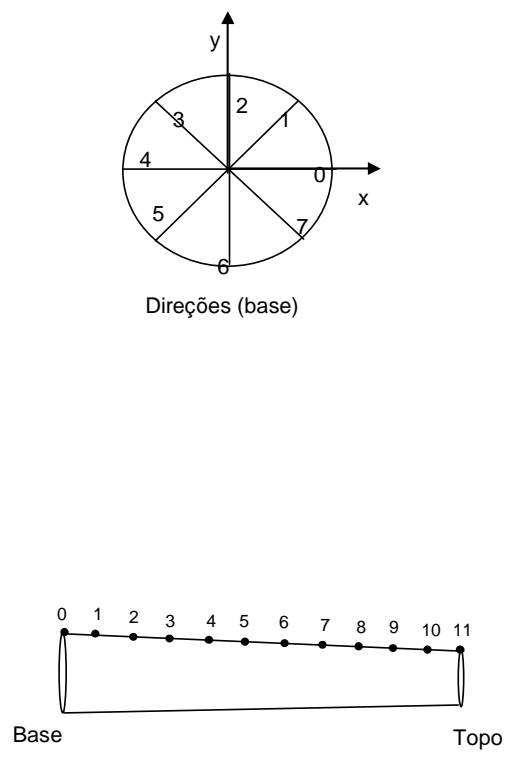

Observações:

Nós: vários nós, porém todos encobertos.

\begin{tabular}{|c|c|c|c|c|c|c|c|c|c|c|c|}
\hline \multirow{2}{*}{ Propriedades } & \multicolumn{11}{|c|}{ Seção } \\
\hline & 0 & $0.1 \mathrm{~L}$ & $0.2 \mathrm{~L}$ & $0.3 \mathrm{~L}$ & $0.4 \mathrm{~L}$ & $0.5 \mathrm{~L}$ & $0.6 \mathrm{~L}$ & $0.7 \mathrm{~L}$ & $0.8 \mathrm{~L}$ & $0.9 \mathrm{~L}$ & $1.0 \mathrm{~L}$ \\
\hline $\mathrm{D}(\mathrm{cm})$ & 19,99 & 19,16 & 19,10 & 18,84 & 18,62 & 18,59 & 18,49 & 18,14 & 18,08 & 18,40 & 17,51 \\
\hline $\mathrm{D}_{\text {méd }}(\mathrm{cm})$ & 19,21 & & & & & & & & & & 17,40 \\
\hline$\Delta_{\text {circ }}$ & $4,1 \%$ & & & & & & & & & & $0,6 \%$ \\
\hline$L / D_{\text {meio }}$ & \multicolumn{11}{|c|}{22,45} \\
\hline $\mathrm{C}$ & \multirow{2}{*}{\multicolumn{11}{|c|}{$\frac{0,4 \%}{3,5 \%}$}} \\
\hline$\Delta \mathrm{D}$ & & & & & & & & & & & \\
\hline Densidade $\left(\mathrm{kg} / \mathrm{m}^{3}\right)$ & \multicolumn{11}{|c|}{1077,9} \\
\hline
\end{tabular}


Tabela F.4 - Dados da tora 4.

Tora $\mathrm{N}^{\circ} 4$

Data: $20 / 04 / 2010$

Espécie: Eucalyptus citriodora

\begin{tabular}{|c|c|c|c|c|c|c|}
\hline \multicolumn{3}{|c|}{ Características de crescimento } & Medido & \multicolumn{3}{|c|}{ Limite } \\
\hline \multicolumn{3}{|l|}{ Massa (kg) } & 122,8 & \multicolumn{3}{|c|}{ - } \\
\hline \multicolumn{3}{|l|}{ Comprimento (cm) } & 429,6 & \multicolumn{3}{|c|}{-} \\
\hline \multicolumn{3}{|l|}{ Linha de terra $(\mathrm{cm})$} & 85,92 & \multicolumn{3}{|c|}{-} \\
\hline \multirow{5}{*}{ Diâmetros (cm) } & Direção & Topo & Base & \multicolumn{3}{|c|}{-} \\
\hline & $0-4$ & 16,9 & 22,6 & \multicolumn{3}{|c|}{-} \\
\hline & $1-5$ & 16,6 & 22,0 & \multicolumn{3}{|c|}{-} \\
\hline & $2-6$ & 15,3 & 23,0 & \multicolumn{3}{|c|}{-} \\
\hline & $3-7$ & 15,9 & 21,0 & \multicolumn{3}{|c|}{-} \\
\hline \multirow{2}{*}{ Teor de umidade (\%) } & Topo & Metade & Base & \multicolumn{3}{|c|}{-} \\
\hline & 22,2 & 20,0 & 25,5 & \multicolumn{3}{|c|}{-} \\
\hline \multicolumn{3}{|c|}{ Inclusões contendo casca $(\mathbf{c m})$} & - & \multicolumn{3}{|c|}{0,5} \\
\hline \multirow{2}{*}{\multicolumn{3}{|c|}{\begin{tabular}{|l} 
Madeira comprimida em $5 \mathrm{~cm}(\mathrm{~S} / \mathrm{N})$ \\
Furos de insetos $(\mathrm{mm})$
\end{tabular}}} & - & \multicolumn{3}{|c|}{ Não } \\
\hline & & & 1 & \multicolumn{3}{|c|}{$\leq 2 \mathrm{~mm}$} \\
\hline \multirow{2}{*}{ Fendas (cm) } & & - & \multicolumn{3}{|c|}{$\leq 30 \mathrm{~cm}$} \\
\hline & & & 10 & \multicolumn{3}{|c|}{$\leq 60 \mathrm{~cm}$} \\
\hline \multirow{2}{*}{ Encurvamento } & Base & & $1,0 \%$ & & $\leq 0,8 \%$ & \\
\hline & \multicolumn{2}{|c|}{ dois planos $(\mathrm{S} / \mathrm{N})$} & - & Não & ssar pela & Iffície \\
\hline Fibra torcida (m/volta) & & & ver obs. & & $\geq 3 \mathrm{~m} / \mathrm{vc}$ & \\
\hline Diâmetro dos nós $(\mathrm{cm})$ & Individual & & 1,5 & & $\leq 5 \mathrm{~cm}$ & \\
\hline Diametro dos nos (cm) & Grupo & & - & & seção ol & \\
\hline & & & & & & \\
\hline & 0 & 1 & 2 & 3 & 4 & 5 \\
\hline & $0,00 \mathrm{~L}$ & $0,10 \mathrm{~L}$ & $0,20 \mathrm{~L}$ & $0,30 \mathrm{~L}$ & $0,40 \mathrm{~L}$ & $0,50 \mathrm{~L}$ \\
\hline Circunferência $(\mathrm{cm})$ & 71,5 & 64,5 & 61 & 59,7 & 58,5 & 56,3 \\
\hline & & & & & & \\
\hline & 6 & 7 & 8 & 9 & 10 & 11 \\
\hline & $0,60 \mathrm{~L}$ & $0,70 \mathrm{~L}$ & $0,80 \mathrm{~L}$ & $0,90 \mathrm{~L}$ & $0,95 \mathrm{~L}$ & $1,00 \mathrm{~L}$ \\
\hline & 54,8 & 55 & 53,7 & 52,3 & - & 52,1 \\
\hline
\end{tabular}

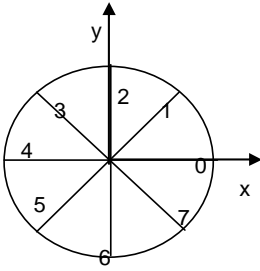

Direções (base)

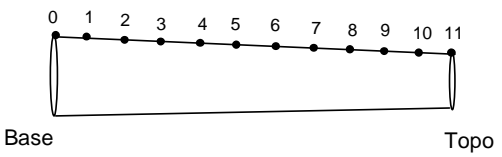

Observações:

Fibras com padrão sinusoidal

\begin{tabular}{|c|c|c|c|c|c|c|c|c|c|c|c|}
\hline \multirow{2}{*}{ Propriedades } & \multicolumn{11}{|c|}{ Seção } \\
\hline & 0 & $0.1 \mathrm{~L}$ & $0.2 \mathrm{~L}$ & $0.3 \mathrm{~L}$ & $0.4 \mathrm{~L}$ & $0.5 \mathrm{~L}$ & $0.6 \mathrm{~L}$ & $\begin{array}{c}0.7 \mathrm{~L} \\
\end{array}$ & $0.8 \mathrm{~L}$ & $0.9 \mathrm{~L}$ & $1.0 \mathrm{~L}$ \\
\hline $\mathrm{D}(\mathrm{cm})$ & 22,76 & 20,53 & 19,42 & 19,00 & 18,62 & 17,92 & 17,44 & 17,51 & 17,09 & 16,65 & 16,58 \\
\hline $\mathrm{D}_{\text {méd }}(\mathrm{cm})$ & 22,14 & & & & & & & & & & 16,16 \\
\hline$\Delta_{\text {circ }}$ & $2,8 \%$ & & & & & & & & & & $2,6 \%$ \\
\hline$L / D_{\text {meio }}$ & \multicolumn{11}{|c|}{23,97} \\
\hline C & \multicolumn{11}{|c|}{$\frac{1,4 \%}{10,1 \%}$} \\
\hline$\Delta \mathrm{D}$ & \multirow{2}{*}{\multicolumn{11}{|c|}{$\frac{10,1 \%}{984,5}$}} \\
\hline Densidade $\left(\mathrm{kg} / \mathrm{m}^{3}\right)$ & & & & & & & & & & & \\
\hline
\end{tabular}


Tabela F.5 - Dados da tora 5.

Tora $\mathrm{N}^{\circ} 5$

\begin{tabular}{|c|c|c|c|c|c|c|}
\hline \multicolumn{3}{|c|}{ Características de crescimento } & Medido & \multicolumn{3}{|c|}{ Limite } \\
\hline \multicolumn{3}{|l|}{ Massa (kg) } & 75,8 & \multicolumn{3}{|c|}{-} \\
\hline \multicolumn{3}{|l|}{ Comprimento $(\mathrm{cm})$} & 412,3 & \multicolumn{3}{|c|}{-} \\
\hline \multicolumn{3}{|l|}{ Linha de terra $(\mathrm{cm})$} & 82,46 & \multicolumn{3}{|c|}{-} \\
\hline \multirow{5}{*}{ Diâmetros (cm) } & Direção & Topo & Base & \multicolumn{3}{|c|}{-} \\
\hline & $0-4$ & 14,7 & 17,9 & \multicolumn{3}{|c|}{-} \\
\hline & $1-5$ & 14,2 & 17,8 & \multicolumn{3}{|c|}{-} \\
\hline & $2-6$ & 14,6 & 18,0 & \multicolumn{3}{|c|}{-} \\
\hline & $3-7$ & 14,8 & 17,6 & \multicolumn{3}{|c|}{-} \\
\hline \multirow{2}{*}{ Teor de umidade (\%) } & Topo & Metade & Base & \multicolumn{3}{|c|}{-} \\
\hline & 26,1 & 28,0 & 26,1 & \multicolumn{3}{|c|}{-} \\
\hline & - & \multicolumn{3}{|c|}{0,5} \\
\hline \multirow{2}{*}{\multicolumn{3}{|c|}{$\begin{array}{l}\text { Madeira comprimida em } 5 \mathrm{~cm}(\mathrm{~S} / \mathrm{N}) \\
\text { Furos de insetos }(\mathrm{mm})\end{array}$}} & - & \multicolumn{3}{|c|}{ Não } \\
\hline & & & 1 & \multicolumn{3}{|c|}{$\leq 2 \mathrm{~mm}$} \\
\hline & 16 & \multicolumn{3}{|c|}{$\leq 30 \mathrm{~cm}$} \\
\hline Fendas (cm) & \multicolumn{2}{|l|}{\begin{tabular}{|l|} 
Topo \\
Base \\
\end{tabular}} & 14 & \multirow{2}{*}{\multicolumn{3}{|c|}{$\begin{array}{l}\leq 60 \mathrm{~cm} \\
\leq 0,8 \%\end{array}$}} \\
\hline \multirow{2}{*}{ Encurvamento } & & - & & & \\
\hline & \multicolumn{2}{|c|}{\begin{tabular}{|l|} 
um plano \\
dois planos $(\mathrm{S} / \mathrm{N})$ \\
\end{tabular}} & - & Não & sar pela & erfície \\
\hline Fibra torcida (m/volta) & & & - & & $3 \mathrm{~m} / \mathrm{vo}$ & \\
\hline Diâmetro dos nós $(\mathrm{cm})$ & Individual & & - & & $\leq 5 \mathrm{~cm}$ & \\
\hline 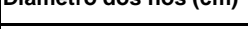 & Grupo & & - & & seção ou & \\
\hline & & & & & & \\
\hline & 0 & 1 & 2 & 3 & 4 & 5 \\
\hline & $0,00 \mathrm{~L}$ & $0,10 \mathrm{~L}$ & $0,20 \mathrm{~L}$ & $0,30 \mathrm{~L}$ & $0,40 \mathrm{~L}$ & $0,50 \mathrm{~L}$ \\
\hline Circunferência $(\mathrm{cm})$ & 56,2 & 53,4 & 52 & 51,2 & 50,5 & 50 \\
\hline & & & & & & \\
\hline & 6 & 7 & 8 & 9 & 10 & 11 \\
\hline & $0,60 \mathrm{~L}$ & $0,70 \mathrm{~L}$ & $0,80 \mathrm{~L}$ & $0,90 \mathrm{~L}$ & $0,95 \mathrm{~L}$ & $1,00 \mathrm{~L}$ \\
\hline & 48,8 & 48,4 & 47,8 & 46,5 & - & 46,2 \\
\hline
\end{tabular}

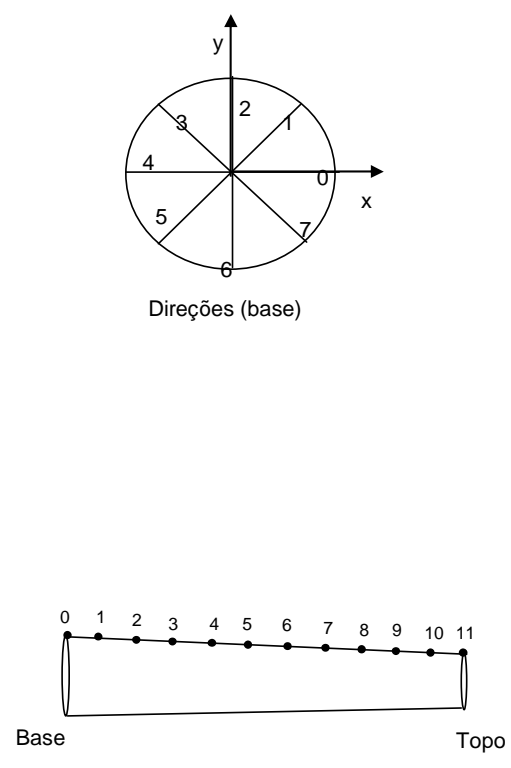

Observações:

\begin{tabular}{|c|c|c|c|c|c|c|c|c|c|c|c|}
\hline \multirow{2}{*}{ Propriedades } & \multicolumn{11}{|c|}{ Seção } \\
\hline & 0 & $0.1 \mathrm{~L}$ & $0.2 \mathrm{~L}$ & $0.3 \mathrm{~L}$ & $0.4 \mathrm{~L}$ & $0.5 \mathrm{~L}$ & $0.6 \mathrm{~L}$ & $0.7 \mathrm{~L}$ & $0.8 \mathrm{~L}$ & $0.9 \mathrm{~L}$ & $1.0 \mathrm{~L}$ \\
\hline $\mathrm{D}(\mathrm{cm})$ & 17,89 & 17,00 & 16,55 & 16,30 & 16,07 & 15,92 & 15,53 & 15,41 & 15,22 & 14,80 & 14,71 \\
\hline $\mathrm{D}_{\text {méd }}(\mathrm{cm})$ & 17,82 & & & & & & & & & & 14,57 \\
\hline$\Delta_{\text {circ }}$ & $0,4 \%$ & & & & & & & & & & $0,9 \%$ \\
\hline$L / D_{\text {meio }}$ & \multicolumn{11}{|c|}{25,91} \\
\hline $\mathrm{C}$ & \multicolumn{11}{|c|}{$0,8 \%$} \\
\hline$\Delta \mathrm{D}$ & \multicolumn{11}{|c|}{$6,0 \%$} \\
\hline Densidade $\left(\mathrm{kg} / \mathrm{m}^{3}\right)$ & \multicolumn{11}{|c|}{889,1} \\
\hline
\end{tabular}


Tabela F.6 - Dados da tora 6.

Tora $\mathrm{N}^{\circ} 6$

Data: 22/04/2010

Espécie: Eucalyptus citriodora

\begin{tabular}{|c|c|c|c|c|c|c|}
\hline \multicolumn{3}{|c|}{ Características de crescimento } & Medido & \multicolumn{3}{|c|}{ Limite } \\
\hline \multicolumn{3}{|l|}{ Massa (kg) } & 108,8 & \multicolumn{3}{|c|}{ - } \\
\hline \multicolumn{3}{|l|}{ Comprimento $(\mathrm{cm})$} & 411,8 & \multicolumn{3}{|c|}{-} \\
\hline \multicolumn{3}{|l|}{ Linha de terra $(\mathrm{cm})$} & 82,36 & \multicolumn{3}{|c|}{-} \\
\hline \multirow{5}{*}{ Diâmetros (cm) } & Direção & Topo & Base & \multicolumn{3}{|c|}{-} \\
\hline & $0-4$ & 16,4 & 20,2 & \multicolumn{3}{|c|}{-} \\
\hline & $1-5$ & 16,7 & 18,5 & \multicolumn{3}{|c|}{-} \\
\hline & $2-6$ & 17,2 & 19,0 & \multicolumn{3}{|c|}{-} \\
\hline & $3-7$ & $\overline{16,5}$ & $\overline{19,1}$ & \multicolumn{3}{|c|}{-} \\
\hline \multirow{2}{*}{ Teor de umidade (\%) } & Topo & Metade & Base & \multicolumn{3}{|c|}{-} \\
\hline & 23,7 & 25,0 & 22,8 & \multicolumn{3}{|c|}{-} \\
\hline \multicolumn{3}{|c|}{ Inclusões contendo casca (cm) } & - & \multicolumn{3}{|c|}{0,5} \\
\hline \multicolumn{3}{|c|}{$\begin{array}{l}\text { Madeira comprimida em } 5 \mathrm{~cm}(\mathrm{~S} / \mathrm{N}) \\
\text { Furos de insetos }(\mathrm{mm})\end{array}$} & - & \multicolumn{3}{|c|}{ Não } \\
\hline \multicolumn{3}{|l|}{ Furos de insetos $(\mathrm{mm})$} & 1 & \multicolumn{3}{|c|}{$\leq 2 \mathrm{~mm}$} \\
\hline \multirow{2}{*}{ Fendas $(\mathrm{cm})$} & & 35 & \multirow{2}{*}{\multicolumn{3}{|c|}{$\frac{\leq 30 \mathrm{~cm}}{\leq 60 \mathrm{~cm}}$}} \\
\hline & & & 25 & & $\leq 60 \mathrm{~cm}$ & \\
\hline \multirow{2}{*}{ Encurvamento } & \multicolumn{2}{|l|}{\begin{tabular}{|l|} 
Base \\
um plano \\
\end{tabular}} & - & \multicolumn{3}{|c|}{$\leq 0,8 \%$} \\
\hline & \multicolumn{2}{|c|}{ dois planos $(\mathrm{S} / \mathrm{N})$} & - & Não & sar pela s & rfície \\
\hline Fibra torcida (m/volta) & & & - & & $3 \mathrm{~m} / \mathrm{vo}$ & \\
\hline Diâmetro dos nós $(\mathrm{cm})$ & Individual & & Ver obs. & & $\leq 5 \mathrm{~cm}$ & \\
\hline 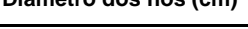 & Grupo & & & & seção ou & \\
\hline & & & & & & \\
\hline & $\mathbf{0}$ & 1 & 2 & 3 & 4 & 5 \\
\hline & $0,00 \mathrm{~L}$ & $0,10 \mathrm{~L}$ & $0,20 \mathrm{~L}$ & $0,30 \mathrm{~L}$ & $0,40 \mathrm{~L}$ & $0,50 \mathrm{~L}$ \\
\hline Circunferência (cm) & 61,0 & 58,9 & 58,8 & 58,6 & 59,5 & 57,0 \\
\hline & & & & & & \\
\hline & 6 & 7 & 8 & 9 & 10 & 11 \\
\hline & $0,60 \mathrm{~L}$ & $0,70 \mathrm{~L}$ & $0,80 \mathrm{~L}$ & $0,90 \mathrm{~L}$ & $0,95 \mathrm{~L}$ & $1,00 \mathrm{~L}$ \\
\hline & 55,6 & 56,0 & 54,0 & 52,9 & - & 52,9 \\
\hline
\end{tabular}

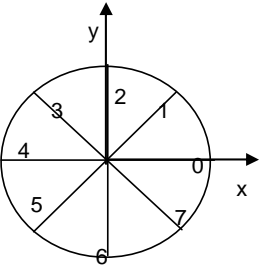

Direções (base)

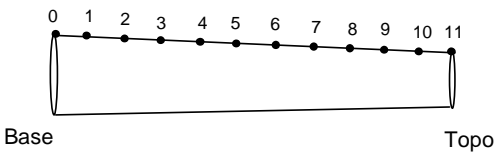

Observações:

Nós encobertos

\begin{tabular}{|c|c|c|c|c|c|c|c|c|c|c|c|}
\hline \multirow{2}{*}{ Propriedades } & \multicolumn{11}{|c|}{ Seção } \\
\hline & 0 & $0.1 \mathrm{~L}$ & $0.2 \mathrm{~L}$ & $0.3 \mathrm{~L}$ & $0.4 \mathrm{~L}$ & $0.5 \mathrm{~L}$ & $0.6 \mathrm{~L}$ & $\begin{array}{l}0.7 \mathrm{~L} \\
\end{array}$ & $0.8 \mathrm{~L}$ & $0.9 \mathrm{~L}$ & $1.0 \mathrm{~L}$ \\
\hline $\mathrm{D}(\mathrm{cm})$ & 19,42 & 18,75 & 18,72 & 18,65 & 18,94 & 18,14 & 17,70 & 17,83 & 17,19 & 16,84 & 16,84 \\
\hline $\mathrm{D}_{\text {méd }}(\mathrm{cm})$ & 19,19 & & & & & & & & & & 16,70 \\
\hline$\Delta_{\text {circ }}$ & $1,2 \%$ & & & & & & & & & & $0,8 \%$ \\
\hline$L / D_{\text {meio }}$ & \multicolumn{11}{|c|}{22,70} \\
\hline C & \multicolumn{11}{|c|}{$0,6 \%$} \\
\hline$\Delta \mathrm{D}$ & \multicolumn{11}{|c|}{$4,9 \%$} \\
\hline Densidade $\left(\mathrm{kg} / \mathrm{m}^{3}\right)$ & \multicolumn{11}{|c|}{1043,1} \\
\hline
\end{tabular}


Tabela F.7 - Dados da tora 7.

Tora $\mathrm{N}^{0} 7$

\begin{tabular}{|c|c|c|c|c|c|c|}
\hline \multicolumn{3}{|c|}{ Características de crescimento } & Medido & \multicolumn{3}{|c|}{ Limite } \\
\hline \multicolumn{3}{|l|}{ Massa (kg) } & 90,6 & \multicolumn{3}{|c|}{-} \\
\hline \multicolumn{3}{|l|}{ Comprimento (cm) } & 427,5 & \multicolumn{3}{|c|}{-} \\
\hline \multicolumn{3}{|l|}{ Linha de terra $(\mathrm{cm})$} & 85,5 & \multicolumn{3}{|c|}{-} \\
\hline \multirow{5}{*}{ Diâmetros (cm) } & Direção & Topo & Base & \multicolumn{3}{|c|}{-} \\
\hline & $0-4$ & 13,7 & 16,0 & \multicolumn{3}{|c|}{-} \\
\hline & $1-5$ & 15,4 & 17,2 & \multicolumn{3}{|c|}{-} \\
\hline & $2-6$ & 15,2 & 17,9 & \multicolumn{3}{|c|}{-} \\
\hline & $3-7$ & 14,5 & 17,6 & \multicolumn{3}{|c|}{-} \\
\hline \multirow{2}{*}{ Teor de umidade (\%) } & Topo & Metade & Base & \multicolumn{3}{|c|}{-} \\
\hline & 20,5 & 24,7 & 21,3 & \multicolumn{3}{|c|}{-} \\
\hline \multicolumn{3}{|c|}{ Inclusões contendo casca $(\mathrm{cm})$} & - & \multicolumn{3}{|c|}{0,5} \\
\hline \multirow{2}{*}{\multicolumn{3}{|c|}{$\begin{array}{l}\text { Madeira comprimida em } 5 \mathrm{~cm}(\mathrm{~S} / \mathrm{N}) \\
\text { Furos de insetos }(\mathrm{mm})\end{array}$}} & - & \multicolumn{3}{|c|}{ Não } \\
\hline & & & 1 & \multicolumn{3}{|c|}{$\leq 2 \mathrm{~mm}$} \\
\hline \multirow{2}{*}{ Fendas (cm) } & \multirow{2}{*}{\multicolumn{2}{|c|}{\begin{tabular}{|l|} 
Topo \\
Base
\end{tabular}}} & - & \multicolumn{3}{|c|}{$\leq 30 \mathrm{~cm}$} \\
\hline & & & - & \multicolumn{3}{|c|}{$\leq 60 \mathrm{~cm}$} \\
\hline \multirow{2}{*}{ Encurvamento } & \multirow{2}{*}{\multicolumn{2}{|c|}{\begin{tabular}{|l|} 
um plano \\
dois planos $(\mathrm{S} / \mathrm{N})$ \\
\end{tabular}}} & $1,3 \%$ & & $\leq 0,8 \%$ & \\
\hline & & & $2 \mathrm{~cm}$ & Não & sar pela & erfície \\
\hline Fibra torcida (m/volta) & & & ver obs. & & $3 \mathrm{~m} / \mathrm{vo}$ & \\
\hline Diâmetro dos nós $(\mathrm{cm})$ & Individual & & - & & $\leq 5 \mathrm{~cm}$ & \\
\hline Diametro dos nos (cm) & Grupo & & - & & seção ou & \\
\hline & & & & & & \\
\hline & 0 & 1 & 2 & 3 & 4 & 5 \\
\hline & $0,00 \mathrm{~L}$ & $0,10 \mathrm{~L}$ & $0,20 \mathrm{~L}$ & $0,30 \mathrm{~L}$ & $0,40 \mathrm{~L}$ & $0,50 \mathrm{~L}$ \\
\hline Circunferência $(\mathrm{cm})$ & 54,5 & 54,7 & 54 & 52,4 & 52,1 & 51,5 \\
\hline & & & & & & \\
\hline & 6 & 7 & 8 & 9 & 10 & 11 \\
\hline & $0,60 \mathrm{~L}$ & $0,70 \mathrm{~L}$ & $0,80 \mathrm{~L}$ & $0,90 \mathrm{~L}$ & $0,95 \mathrm{~L}$ & $1,00 \mathrm{~L}$ \\
\hline & 49,9 & 49,2 & 48,2 & 47,3 & - & 47 \\
\hline
\end{tabular}

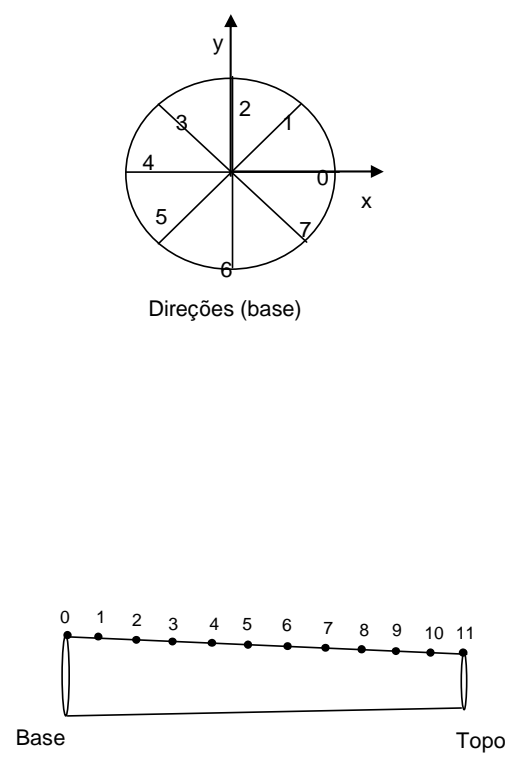

Observações:

Fibras com padrão sinusoidal

\begin{tabular}{|c|c|c|c|c|c|c|c|c|c|c|c|}
\hline \multirow{2}{*}{ Propriedades } & \multicolumn{11}{|c|}{ Seção } \\
\hline & 0 & $0.1 \mathrm{~L}$ & $0.2 \mathrm{~L}$ & $0.3 \mathrm{~L}$ & $0.4 \mathrm{~L}$ & $0.5 \mathrm{~L}$ & $0.6 \mathrm{~L}$ & $\begin{array}{c}0.7 \mathrm{~L} \\
\end{array}$ & $0.8 \mathrm{~L}$ & $0.9 \mathrm{~L}$ & $1.0 \mathrm{~L}$ \\
\hline $\mathrm{D}(\mathrm{cm})$ & 17,35 & 17,41 & 17,19 & 16,68 & 16,58 & 16,39 & 15,88 & 15,66 & 15,34 & 15,06 & 14,96 \\
\hline$D_{\text {méd }}(\mathrm{cm})$ & 17,16 & & & & & & & & & & 14,68 \\
\hline$\Delta_{\text {circ }}$ & $1,1 \%$ & & & & & & & & & & $1,9 \%$ \\
\hline$L / D_{\text {meio }}$ & \multicolumn{11}{|c|}{26,08} \\
\hline C & \multicolumn{11}{|c|}{$0,6 \%$} \\
\hline$\Delta \mathrm{D}$ & \multirow{2}{*}{\multicolumn{11}{|c|}{$5,6 \%$}} \\
\hline Densidade $\left(\mathrm{kg} / \mathrm{m}^{3}\right)$ & & & \multicolumn{7}{|c|}{1062,3} & & \\
\hline
\end{tabular}


Tabela F.8 - Dados da tora 8.

Tora $\mathrm{N}^{\circ} 8$

Data: $23 / 04 / 2010$

Espécie: Eucalyptus citriodora

\begin{tabular}{|c|c|c|c|c|c|c|}
\hline \multicolumn{3}{|c|}{ Características de crescimento } & Medido & \multicolumn{3}{|c|}{ Limite } \\
\hline \multicolumn{3}{|l|}{ Massa (kg) } & 93,6 & \multicolumn{3}{|c|}{-} \\
\hline \multicolumn{3}{|l|}{ Comprimento $(\mathrm{cm})$} & 411,6 & \multicolumn{3}{|c|}{-} \\
\hline \multicolumn{3}{|l|}{ Linha de terra $(\mathrm{cm})$} & 82,32 & \multicolumn{3}{|c|}{-} \\
\hline \multirow{5}{*}{ Diâmetros (cm) } & Direção & Topo & Base & \multicolumn{3}{|c|}{-} \\
\hline & $0-4$ & 15,3 & 17,6 & \multicolumn{3}{|c|}{-} \\
\hline & $1-5$ & 16,1 & 18,0 & \multicolumn{3}{|c|}{-} \\
\hline & $2-6$ & 15,2 & 17,5 & \multicolumn{3}{|c|}{-} \\
\hline & $3-7$ & 14,7 & 17,6 & \multicolumn{3}{|c|}{-} \\
\hline \multirow{2}{*}{ Teor de umidade (\%) } & Topo & Metade & Base & \multicolumn{3}{|c|}{-} \\
\hline & 17,4 & 22,5 & 19,8 & \multicolumn{3}{|c|}{-} \\
\hline \multicolumn{3}{|c|}{ Inclusões contendo casca $(\mathbf{c m})$} & - & \multicolumn{3}{|c|}{0,5} \\
\hline \multirow{2}{*}{\multicolumn{3}{|c|}{\begin{tabular}{|l} 
Madeira comprimida em $5 \mathrm{~cm} \mathrm{(S/N)}$ \\
Furos de insetos $(\mathrm{mm})$
\end{tabular}}} & - & \multicolumn{3}{|c|}{ Não } \\
\hline & & & 1 & \multicolumn{3}{|c|}{$\leq 2 \mathrm{~mm}$} \\
\hline \multirow{2}{*}{ Fendas (cm) } & \multirow{2}{*}{\multicolumn{2}{|c|}{ Topo }} & 22 & \multicolumn{3}{|c|}{$\leq 30 \mathrm{~cm}$} \\
\hline & & & 28 & \multicolumn{3}{|c|}{$\leq 60 \mathrm{~cm}$} \\
\hline Fncurvamento & \multirow{2}{*}{\multicolumn{2}{|c|}{\begin{tabular}{|l|} 
um plano \\
dois planos $(\mathrm{S} / \mathrm{N})$ \\
\end{tabular}}} & $1,0 \%$ & \multicolumn{3}{|c|}{$\leq 0,8 \%$} \\
\hline Encurvamento & & & - & Não & ssar pela & Iffície \\
\hline Fibra torcida (m/volta) & & & - & & $\geq 3 \mathrm{~m} / \mathrm{vc}$ & \\
\hline Diâmetro dos nós $(\mathrm{cm})$ & Individual & & - & & $\leq 5 \mathrm{~cm}$ & \\
\hline Diametro dos nos (cm) & Grupo & & - & & seção ol & \\
\hline & & & & & & \\
\hline & 0 & 1 & 2 & 3 & 4 & 5 \\
\hline & $0,00 \mathrm{~L}$ & $0,10 \mathrm{~L}$ & $0,20 \mathrm{~L}$ & $0,30 \mathrm{~L}$ & $0,40 \mathrm{~L}$ & $0,50 \mathrm{~L}$ \\
\hline Circunferência $(\mathrm{cm})$ & 56,3 & 54,5 & 54,7 & 55 & 53,6 & 53,0 \\
\hline & & & & & & \\
\hline & 6 & 7 & 8 & 9 & 10 & 11 \\
\hline & $0,60 \mathrm{~L}$ & $0,70 \mathrm{~L}$ & $0,80 \mathrm{~L}$ & $0,90 \mathrm{~L}$ & $0,95 \mathrm{~L}$ & $1,00 \mathrm{~L}$ \\
\hline & 51 & 50,3 & 48,5 & 49,1 & - & 48,9 \\
\hline
\end{tabular}

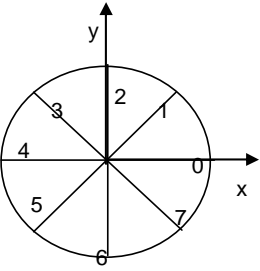

Direções (base)

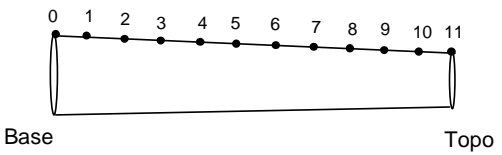

Observações:

Excentricidade da medula na base $=2 \mathrm{~cm}$

\begin{tabular}{|c|c|c|c|c|c|c|c|c|c|c|c|}
\hline \multirow{2}{*}{ Propriedades } & \multicolumn{11}{|c|}{ Seção } \\
\hline & 0 & $0.1 \mathrm{~L}$ & $0.2 \mathrm{~L}$ & $0.3 \mathrm{~L}$ & $0.4 \mathrm{~L}$ & $0.5 \mathrm{~L}$ & $0.6 \mathrm{~L}$ & $0.7 \mathrm{~L}$ & $0.8 \mathrm{~L}$ & $0.9 \mathrm{~L}$ & $1.0 \mathrm{~L}$ \\
\hline $\mathrm{D}(\mathrm{cm})$ & 17,92 & 17,35 & 17,41 & 17,51 & 17,06 & 16,87 & 16,23 & 16,01 & 15,44 & 15,63 & 15,57 \\
\hline $\mathrm{D}_{\text {méd }}(\mathrm{cm})$ & 17,67 & & & & & & & & & & 15,32 \\
\hline$\Delta_{\text {circ }}$ & $1,4 \%$ & & & & & & & & & & $1,6 \%$ \\
\hline$L / D_{\text {meio }}$ & \multicolumn{11}{|c|}{24,40} \\
\hline C & \multirow{2}{*}{\multicolumn{11}{|c|}{$\begin{array}{l}0,6 \% \\
5,3 \% \\
\end{array}$}} \\
\hline$\Delta \mathrm{D}$ & & & & & & & & & & & \\
\hline Densidade $\left(\mathrm{kg} / \mathrm{m}^{3}\right)$ & \multicolumn{11}{|c|}{1062,3} \\
\hline
\end{tabular}


Tabela F.9 - Dados da tora 9.

Tora $\mathrm{N}^{\circ} 9$

\begin{tabular}{|c|c|c|c|c|c|c|}
\hline \multicolumn{3}{|c|}{ Características de crescimento } & Medido & \multicolumn{3}{|c|}{ Limite } \\
\hline \multicolumn{3}{|l|}{ Massa (kg) } & 87,55 & \multicolumn{3}{|c|}{-} \\
\hline \multicolumn{3}{|l|}{ Comprimento (cm) } & 428 & \multicolumn{3}{|c|}{-} \\
\hline \multicolumn{3}{|l|}{ Linha de terra $(\mathrm{cm})$} & 85,6 & \multicolumn{3}{|c|}{-} \\
\hline \multirow{5}{*}{ Diâmetros (cm) } & Direção & Topo & Base & \multicolumn{3}{|c|}{-} \\
\hline & $0-4$ & 14,1 & 17,1 & \multicolumn{3}{|c|}{-} \\
\hline & $1-5$ & 14,0 & 16,7 & \multicolumn{3}{|c|}{-} \\
\hline & $2-6$ & 15,0 & 18,3 & \multicolumn{3}{|c|}{-} \\
\hline & $3-7$ & 14,8 & 18,0 & \multicolumn{3}{|c|}{-} \\
\hline \multirow{2}{*}{ Teor de umidade (\%) } & Topo & Metade & Base & \multicolumn{3}{|c|}{-} \\
\hline & 22,5 & 28,8 & 25,6 & \multicolumn{3}{|c|}{-} \\
\hline \multicolumn{3}{|c|}{ Inclusões contendo casca $(\mathrm{cm})$} & - & \multicolumn{3}{|c|}{0,5} \\
\hline \multirow{2}{*}{\multicolumn{3}{|c|}{$\begin{array}{l}\text { Madeira comprimida em } 5 \mathrm{~cm}(\mathrm{~S} / \mathrm{N}) \\
\text { Furos de insetos }(\mathrm{mm})\end{array}$}} & - & \multicolumn{3}{|c|}{ Não } \\
\hline & & & 1 & \multicolumn{3}{|c|}{$\leq 2 \mathrm{~mm}$} \\
\hline \multirow{2}{*}{ Fendas (cm) } & & 18 & \multicolumn{3}{|c|}{$\leq 30 \mathrm{~cm}$} \\
\hline & & & 9 & \multicolumn{3}{|c|}{$\leq 60 \mathrm{~cm}$} \\
\hline \multirow{2}{*}{ Encurvamento } & \multirow{2}{*}{\multicolumn{2}{|c|}{\begin{tabular}{|l|} 
um plano \\
dois planos $(\mathrm{S} / \mathrm{N})$ \\
\end{tabular}}} & $0,8 \%$ & & $\leq 0,8 \%$ & \\
\hline & & & - & Não & sar pela & erfície \\
\hline Fibra torcida (m/volta) & & & - & & $3 \mathrm{~m} / \mathrm{vo}$ & \\
\hline Diâmetro dos nós $(\mathrm{cm})$ & Individual & & - & & $\leq 5 \mathrm{~cm}$ & \\
\hline Diametro dos nos (cm) & Grupo & & - & & seção ou & \\
\hline & & & & & & \\
\hline & 0 & 1 & 2 & 3 & 4 & 5 \\
\hline & $0,00 \mathrm{~L}$ & $0,10 \mathrm{~L}$ & $\overline{0,20 \mathrm{~L}}$ & $0,30 \mathrm{~L}$ & $0,40 \mathrm{~L}$ & $0,50 \mathrm{~L}$ \\
\hline Circunferência $(\mathrm{cm})$ & 55,3 & 53,1 & 52,7 & 51,2 & 50,5 & 49,7 \\
\hline & & & & & & \\
\hline & 6 & 7 & 8 & 9 & 10 & 11 \\
\hline & $0,60 \mathrm{~L}$ & $0,70 \mathrm{~L}$ & $0,80 \mathrm{~L}$ & $0,90 \mathrm{~L}$ & $0,95 \mathrm{~L}$ & $1,00 \mathrm{~L}$ \\
\hline & 48,6 & 48,2 & 47,4 & 46,4 & - & 45,7 \\
\hline
\end{tabular}

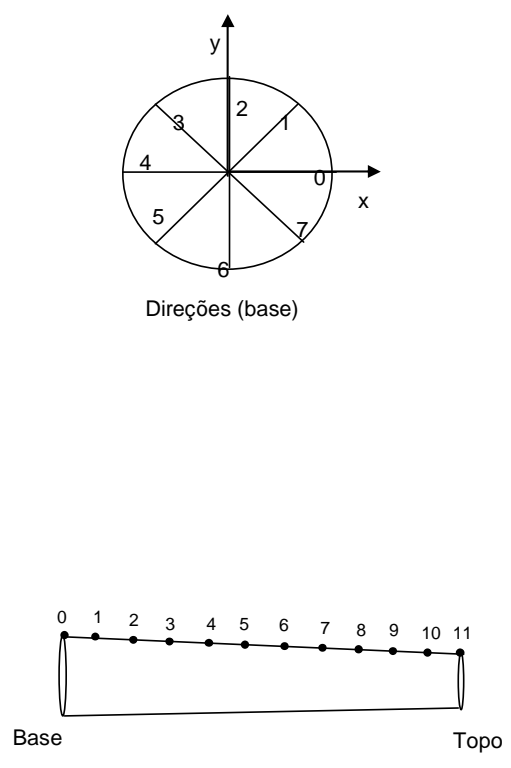

Observações:

\begin{tabular}{|c|c|c|c|c|c|c|c|c|c|c|c|}
\hline \multirow{2}{*}{ Propriedades } & \multicolumn{11}{|c|}{ Seção } \\
\hline & 0 & $0.1 \mathrm{~L}$ & $0.2 \mathrm{~L}$ & $0.3 \mathrm{~L}$ & $0.4 \mathrm{~L}$ & $0.5 \mathrm{~L}$ & $0.6 \mathrm{~L}$ & $0.7 \mathrm{~L}$ & $0.8 \mathrm{~L}$ & $0.9 \mathrm{~L}$ & $1.0 \mathrm{~L}$ \\
\hline $\mathrm{D}(\mathrm{cm})$ & 17,60 & 16,90 & 16,77 & 16,30 & 16,07 & 15,82 & 15,47 & 15,34 & 15,09 & 14,77 & 14,55 \\
\hline $\mathrm{D}_{\text {méd }}(\mathrm{cm})$ & 17,51 & & & & & & & & & & 14,47 \\
\hline$\Delta_{\text {circ }}$ & $0,5 \%$ & & & & & & & & & & $0,5 \%$ \\
\hline$L / D_{\text {meio }}$ & \multicolumn{11}{|c|}{27,05} \\
\hline $\mathrm{C}$ & \multicolumn{11}{|c|}{$0,7 \%$} \\
\hline$\Delta \mathrm{D}$ & \multicolumn{11}{|c|}{$6,0 \%$} \\
\hline Densidade $\left(\mathrm{kg} / \mathrm{m}^{3}\right)$ & \multicolumn{11}{|c|}{1015,5} \\
\hline
\end{tabular}


Tabela F.10 - Dados da tora 10.

Tora $\mathrm{N}^{\circ} 10$

Data: $27 / 04 / 2010$

Espécie: Eucalyptus grandis

\begin{tabular}{|c|c|c|c|c|c|c|}
\hline \multicolumn{3}{|c|}{ Características de crescimento } & Medido & \multicolumn{3}{|c|}{ Limite } \\
\hline \multicolumn{3}{|l|}{ Massa (kg) } & 97,35 & \multicolumn{3}{|c|}{-} \\
\hline \multicolumn{3}{|l|}{ Comprimento (cm) } & 397 & \multicolumn{3}{|c|}{-} \\
\hline \multicolumn{3}{|l|}{ Linha de terra $(\mathrm{cm})$} & 79,4 & \multicolumn{3}{|c|}{-} \\
\hline \multirow{5}{*}{ Diâmetros (cm) } & Direção & Topo & Base & \multicolumn{3}{|c|}{-} \\
\hline & $0-4$ & 16,6 & 19,8 & \multicolumn{3}{|c|}{-} \\
\hline & $1-5$ & 17,1 & 19,5 & \multicolumn{3}{|c|}{-} \\
\hline & $2-6$ & 16,8 & 20,0 & \multicolumn{3}{|c|}{-} \\
\hline & $3-7$ & 16,3 & 19,8 & \multicolumn{3}{|c|}{-} \\
\hline \multirow{2}{*}{ Teor de umidade (\%) } & Topo & Metade & Base & \multicolumn{3}{|c|}{-} \\
\hline & 22,7 & 21,8 & 21,7 & \multicolumn{3}{|c|}{-} \\
\hline \multicolumn{3}{|c|}{ Inclusões contendo casca (cm) } & - & \multicolumn{3}{|c|}{0,5} \\
\hline \multicolumn{3}{|c|}{ Madeira comprimida em $5 \mathrm{~cm}(\mathrm{~S} / \mathrm{N})$} & - & \multicolumn{3}{|c|}{ Não } \\
\hline \multicolumn{3}{|c|}{ Furos de insetos (mm) } & 1 & \multicolumn{3}{|c|}{$\leq 2 \mathrm{~mm}$} \\
\hline \multirow{2}{*}{ Fendas $(\mathrm{cm})$} & \multicolumn{2}{|l|}{ Topo } & 20 & \multicolumn{3}{|c|}{$\leq 30 \mathrm{~cm}$} \\
\hline & \multicolumn{2}{|l|}{ Base } & 15 & \multicolumn{3}{|c|}{$\leq 60 \mathrm{~cm}$} \\
\hline \multirow{2}{*}{ Encurvamento } & \multirow{2}{*}{\multicolumn{2}{|c|}{\begin{tabular}{|l|} 
um plano \\
dois planos $(\mathrm{S} / \mathrm{N})$ \\
\end{tabular}}} & $0,8 \%$ & & $\leq 0,8 \%$ & \\
\hline & & & - & Não & sar pela & effície \\
\hline Fibra torcida (m/volta) & & & - & & $3 \mathrm{~m} / \mathrm{v}$ & \\
\hline Diâmetro dos nós (cm) & Individual & & 3 & & $\leq 5 \mathrm{~cm}$ & \\
\hline Diametro dos nos (cm) & Grupo & & - & & seção ol & \\
\hline & & & & & & \\
\hline & 0 & 1 & 2 & 3 & 4 & 5 \\
\hline & $0,00 \mathrm{~L}$ & $0,10 \mathrm{~L}$ & $0,20 \mathrm{~L}$ & $0,30 \mathrm{~L}$ & $0,40 \mathrm{~L}$ & $0,50 \mathrm{~L}$ \\
\hline Circunferência $(\mathrm{cm})$ & 63,1 & 58,7 & 60,3 & 57,2 & 57,5 & 55,0 \\
\hline & & & & & & \\
\hline & 6 & 7 & 8 & 9 & 10 & 11 \\
\hline & $0,60 \mathrm{~L}$ & $0,70 \mathrm{~L}$ & $0,80 \mathrm{~L}$ & $0,90 \mathrm{~L}$ & $0,95 \mathrm{~L}$ & $1,00 \mathrm{~L}$ \\
\hline & 54 & 54,2 & 52,3 & 52,8 & - & 53,1 \\
\hline
\end{tabular}

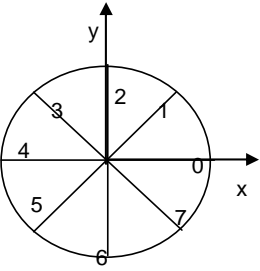

Direções (base)

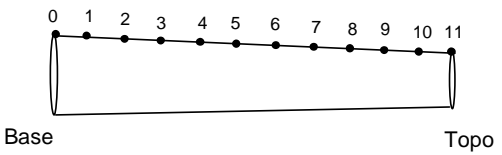

Observações:

\begin{tabular}{|c|c|c|c|c|c|c|c|c|c|c|c|}
\hline \multirow{2}{*}{ Propriedades } & \multicolumn{11}{|c|}{ Seção } \\
\hline & 0 & $0.1 \mathrm{~L}$ & $\begin{array}{c}0.2 \mathrm{~L} \\
\end{array}$ & $0.3 \mathrm{~L}$ & $0.4 \mathrm{~L}$ & $0.5 \mathrm{~L}$ & $0.6 \mathrm{~L}$ & $\begin{array}{c}0.7 \mathrm{~L} \\
\end{array}$ & $0.8 \mathrm{~L}$ & $0.9 \mathrm{~L}$ & $\begin{array}{l}1.0 \mathrm{~L} \\
\end{array}$ \\
\hline $\mathrm{D}(\mathrm{cm})$ & 20,09 & 18,68 & 19,19 & 18,21 & 18,30 & 17,51 & 17,19 & 17,25 & 16,65 & 16,81 & 16,90 \\
\hline$D_{\text {méd }}(\mathrm{cm})$ & 19,77 & & & & & & & & & & 16,70 \\
\hline$\Delta_{\text {circ }}$ & $1,6 \%$ & & & & & & & & & & $1,2 \%$ \\
\hline$L / D_{\text {meio }}$ & \multicolumn{11}{|c|}{22,68} \\
\hline C & \multirow{2}{*}{\multicolumn{11}{|c|}{$0,8 \%$}} \\
\hline$\Delta \mathrm{D}$ & \multirow{2}{*}{\multicolumn{11}{|c|}{$\frac{6,2 \%}{936,6}$}} \\
\hline Densidade $\left(\mathrm{kg} / \mathrm{m}^{3}\right)$ & & & & & & & & & & & \\
\hline
\end{tabular}


Tabela F.11 - Dados da tora 11.

Tora $\mathrm{N}^{0} 11$

Data: $28 / 04 / 2010$

Espécie: Eucalyptus citriodora

\begin{tabular}{|c|c|c|c|c|c|c|}
\hline \multicolumn{3}{|c|}{ Características de crescimento } & Medido & \multicolumn{3}{|c|}{ Limite } \\
\hline \multicolumn{3}{|l|}{ Massa (kg) } & 118,4 & \multicolumn{3}{|c|}{-} \\
\hline \multicolumn{3}{|l|}{ Comprimento (cm) } & 410,4 & \multicolumn{3}{|c|}{-} \\
\hline \multicolumn{3}{|l|}{ Linha de terra $(\mathrm{cm})$} & 82,08 & \multicolumn{3}{|c|}{-} \\
\hline \multirow{5}{*}{ Diâmetros (cm) } & Direção & Topo & Base & \multicolumn{3}{|c|}{-} \\
\hline & $0-4$ & 17,2 & 20,6 & \multicolumn{3}{|c|}{-} \\
\hline & $1-5$ & 18,2 & 19,5 & \multicolumn{3}{|c|}{-} \\
\hline & $2-6$ & 19,5 & 20,2 & \multicolumn{3}{|c|}{-} \\
\hline & $3-7$ & 18,0 & 19,2 & \multicolumn{3}{|c|}{-} \\
\hline \multirow{2}{*}{ Teor de umidade (\%) } & Topo & Metade & Base & \multicolumn{3}{|c|}{ - } \\
\hline & 19,6 & 22,2 & 23 & \multicolumn{3}{|c|}{-} \\
\hline \multicolumn{3}{|c|}{ Inclusões contendo casca $(\mathrm{cm})$} & - & \multicolumn{3}{|c|}{0,5} \\
\hline \multicolumn{3}{|c|}{ Madeira comprimida em $5 \mathrm{~cm}(\mathrm{~S} / \mathrm{N})$} & - & \multicolumn{3}{|c|}{ Não } \\
\hline \multicolumn{3}{|l|}{ Furos de insetos (mm) } & 1 & \multicolumn{3}{|c|}{$\leq 2 \mathrm{~mm}$} \\
\hline \multirow{2}{*}{ Fendas $(\mathrm{cm})$} & \multirow{2}{*}{\multicolumn{2}{|c|}{\begin{tabular}{|l|} 
Topo \\
Base \\
\end{tabular}}} & 25 & \multirow{2}{*}{\multicolumn{3}{|c|}{$\begin{array}{l}\leq 30 \mathrm{~cm} \\
\leq 60 \mathrm{~cm}\end{array}$}} \\
\hline & & & 23 & & & \\
\hline \multirow{2}{*}{ Encurvamento } & \multicolumn{2}{|l|}{\begin{tabular}{|l|} 
um plano \\
\end{tabular}} & - & \multicolumn{3}{|c|}{$\leq 0,8 \%$} \\
\hline & \multicolumn{2}{|c|}{ dois planos (S/N) } & - & Nãop & sar pela & Ifície \\
\hline Fibra torcida (m/volta) & & & & & $3 \mathrm{~m} / \mathrm{vc}$ & \\
\hline Diâmetro dos nós (cm) & Individual & & 14 & & $\leq 5 \mathrm{~cm}$ & \\
\hline 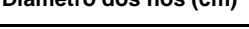 & Grupo & & & & seção ol & \\
\hline & & & & & & \\
\hline & $\begin{array}{l}0 \\
\end{array}$ & 1 & 2 & 3 & 4 & 5 \\
\hline & $0,00 \mathrm{~L}$ & $0,10 \mathrm{~L}$ & $0,20 \mathrm{~L}$ & $0,30 \mathrm{~L}$ & $0,40 \mathrm{~L}$ & $0,50 \mathrm{~L}$ \\
\hline Circunferência $(\mathbf{c m})$ & 64,0 & 68,9 & 61,8 & 61,8 & 63,7 & 62,7 \\
\hline & & & & & & \\
\hline & 6 & 7 & 8 & 9 & 10 & 11 \\
\hline & $0,60 \mathrm{~L}$ & $0,70 \mathrm{~L}$ & $0,80 \mathrm{~L}$ & $0,90 \mathrm{~L}$ & $0,95 \mathrm{~L}$ & $1,00 \mathrm{~L}$ \\
\hline & 60,4 & 59,2 & 58,4 & 57 & - & 58,6 \\
\hline
\end{tabular}

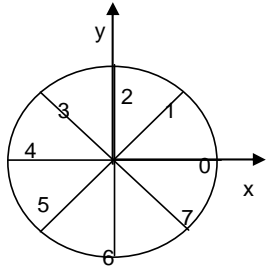

Direções (base)

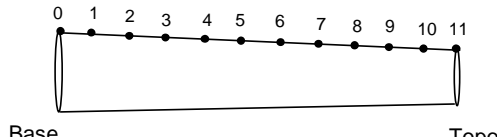

Tora evidenciando desgalho tardio pela presença de muitos nós de grande diâmetro encobertos

\begin{tabular}{|c|c|c|c|c|c|c|c|c|c|c|c|}
\hline \multirow{2}{*}{ Propriedades } & \multicolumn{11}{|c|}{ Seção } \\
\hline & 0 & $0.1 \mathrm{~L}$ & $0.2 \mathrm{~L}$ & $0.3 \mathrm{~L}$ & $0.4 \mathrm{~L}$ & $0.5 \mathrm{~L}$ & $0.6 \mathrm{~L}$ & $0.7 \mathrm{~L}$ & $0.8 \mathrm{~L}$ & $0.9 \mathrm{~L}$ & $1.0 \mathrm{~L}$ \\
\hline $\mathrm{D}(\mathrm{cm})$ & 20,37 & 21,93 & 19,67 & 19,67 & 20,28 & 19,96 & 19,23 & 18,84 & 18,59 & 18,14 & 18,65 \\
\hline $\mathrm{D}_{\text {méd }}(\mathrm{cm})$ & 19,87 & & & & & & & & & & 18,21 \\
\hline$\Delta_{\text {circ }}$ & $2,5 \%$ & & & & & & & & & & $2,5 \%$ \\
\hline$L / D_{\text {meio }}$ & \multicolumn{11}{|c|}{20,56} \\
\hline C & \multirow{2}{*}{\multicolumn{11}{|c|}{$\frac{0,4 \%}{5,4 \%}$}} \\
\hline$\Delta \mathrm{D}$ & & & & & & & & & & & \\
\hline Densidade $\left(\mathrm{kg} / \mathrm{m}^{3}\right)$ & \multicolumn{11}{|c|}{1012,9} \\
\hline
\end{tabular}


Tabela F.12 - Dados da tora 12.

Tora $\mathrm{N}^{\circ} 12$

Data: $28 / 04 / 2010$

Espécie: Eucalyptus citriodora

\begin{tabular}{|c|c|c|c|c|c|c|}
\hline \multicolumn{3}{|c|}{ Características de crescimento } & Medido & \multicolumn{3}{|c|}{ Limite } \\
\hline \multicolumn{3}{|l|}{ Massa (kg) } & 115,6 & \multicolumn{3}{|c|}{-} \\
\hline \multicolumn{3}{|l|}{ Comprimento $(\mathrm{cm})$} & 402,5 & \multicolumn{3}{|c|}{-} \\
\hline \multicolumn{3}{|l|}{ Linha de terra $(\mathrm{cm})$} & 80,5 & \multicolumn{3}{|c|}{-} \\
\hline \multirow{5}{*}{ Diâmetros (cm) } & Direção & Topo & Base & \multicolumn{3}{|c|}{-} \\
\hline & $0-4$ & 17,8 & 20,6 & \multicolumn{3}{|c|}{-} \\
\hline & $1-5$ & 18,2 & 21,0 & \multicolumn{3}{|c|}{-} \\
\hline & $2-6$ & 17,7 & 20,0 & \multicolumn{3}{|c|}{-} \\
\hline & $3-7$ & 17,4 & 19,5 & \multicolumn{3}{|c|}{-} \\
\hline \multirow{2}{*}{ Teor de umidade (\%) } & Topo & Metade & Base & \multicolumn{3}{|c|}{-} \\
\hline & 25,3 & 27,5 & 27 & \multicolumn{3}{|c|}{-} \\
\hline \multicolumn{3}{|c|}{ Inclusões contendo casca $(\mathbf{c m})$} & - & \multicolumn{3}{|c|}{0,5} \\
\hline Madeira comprimida em & $\mathrm{cm}(\mathrm{S} / \mathrm{N})$ & & Sim (base) & \multicolumn{3}{|c|}{ Não } \\
\hline \multicolumn{3}{|l|}{ Furos de insetos (mm) } & 1 & \multicolumn{3}{|c|}{$\leq 2 \mathrm{~mm}$} \\
\hline \multirow{2}{*}{ Fendas (cm) } & \multirow{2}{*}{\multicolumn{2}{|c|}{ Topo }} & 21 & \multicolumn{3}{|c|}{$\leq 30 \mathrm{~cm}$} \\
\hline & & & 41 & \multicolumn{3}{|c|}{$\leq 60 \mathrm{~cm}$} \\
\hline \multirow{2}{*}{ Encurvamento } & \multirow{2}{*}{\multicolumn{2}{|c|}{\begin{tabular}{|l|} 
um plano \\
dois planos $(\mathrm{S} / \mathrm{N})$ \\
\end{tabular}}} & - & & $\leq 0,8 \%$ & \\
\hline & & & - & Não & ssar pela & Iffície \\
\hline Fibra torcida (m/volta) & & & - & & $\geq 3 \mathrm{~m} / \mathrm{vc}$ & \\
\hline Diâmetro dos nós $(\mathrm{cm})$ & Individual & & - & & $\leq 5 \mathrm{~cm}$ & \\
\hline Diametro dos nos (cm) & Grupo & & - & & seção ol & \\
\hline & & & $\mathrm{Se}$ & & & \\
\hline & 0 & 1 & 2 & 3 & 4 & 5 \\
\hline & $0,00 \mathrm{~L}$ & $0,10 \mathrm{~L}$ & $0,20 \mathrm{~L}$ & $0,30 \mathrm{~L}$ & $0,40 \mathrm{~L}$ & $0,50 \mathrm{~L}$ \\
\hline Circunferência $(\mathrm{cm})$ & 64,3 & 63,7 & 62,5 & 59,8 & 59,1 & 58,2 \\
\hline & & & $\mathrm{Se}$ & & & \\
\hline & 6 & 7 & 8 & 9 & 10 & 11 \\
\hline & $0,60 \mathrm{~L}$ & $0,70 \mathrm{~L}$ & $0,80 \mathrm{~L}$ & $0,90 \mathrm{~L}$ & $0,95 \mathrm{~L}$ & $1,00 \mathrm{~L}$ \\
\hline & 58,8 & 56,2 & 57,8 & 54,7 & - & 55,8 \\
\hline
\end{tabular}

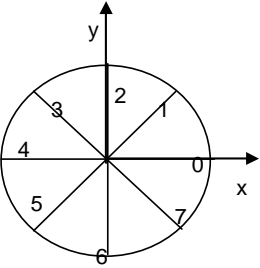

Direções (base)

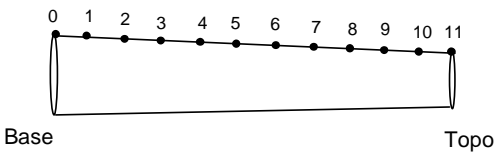

Observações:

Excentricidade da medula na base $=3,5 \mathrm{~cm}$ na direção $2-6$

Excentricidade da medula no topo $=2,0 \mathrm{~cm}$ na direção 2-6

\begin{tabular}{|c|c|c|c|c|c|c|c|c|c|c|c|}
\hline \multirow{2}{*}{ Propriedades } & \multicolumn{11}{|c|}{ Seção } \\
\hline & 0 & $0.1 \mathrm{~L}$ & $0.2 \mathrm{~L}$ & $0.3 \mathrm{~L}$ & $0.4 \mathrm{~L}$ & $0.5 \mathrm{~L}$ & $0.6 \mathrm{~L}$ & $0.7 \mathrm{~L}$ & $0.8 \mathrm{~L}$ & $0.9 \mathrm{~L}$ & $1.0 \mathrm{~L}$ \\
\hline $\mathrm{D}(\mathrm{cm})$ & 20,47 & 20,28 & 19,89 & 19,03 & 18,81 & 18,53 & 18,72 & 17,89 & 18,40 & 17,41 & 17,76 \\
\hline $\mathrm{D}_{\text {méd }}(\mathrm{cm})$ & 20,27 & & & & & & & & & & 17,77 \\
\hline$\Delta_{\text {circ }}$ & $1,0 \%$ & & & & & & & & & & $0,1 \%$ \\
\hline$L / D_{\text {meio }}$ & \multicolumn{11}{|c|}{21,73} \\
\hline $\mathrm{C}$ & \multicolumn{11}{|c|}{$\frac{0,6 \%}{5,4 \%}$} \\
\hline$\Delta \mathrm{D}$ & \multicolumn{11}{|c|}{$5,4 \%$} \\
\hline Densidade $\left(\mathrm{kg} / \mathrm{m}^{3}\right)$ & \multicolumn{11}{|c|}{1009,4} \\
\hline
\end{tabular}


Tabela F.13 - Dados da tora 13.

Tora $\mathrm{N}^{\circ} 13$

\begin{tabular}{|c|c|c|c|c|c|c|}
\hline \multicolumn{3}{|c|}{ Características de crescimento } & Medido & \multicolumn{3}{|c|}{ Limite } \\
\hline \multicolumn{3}{|l|}{ Massa (kg) } & 87,2 & \multicolumn{3}{|c|}{-} \\
\hline \multicolumn{3}{|l|}{ Comprimento $(\mathrm{cm})$} & 409,2 & \multicolumn{3}{|c|}{-} \\
\hline \multicolumn{3}{|l|}{ Linha de terra $(\mathrm{cm})$} & 81,84 & \multicolumn{3}{|c|}{-} \\
\hline \multirow{5}{*}{ Diâmetros (cm) } & Direção & Topo & Base & \multicolumn{3}{|c|}{-} \\
\hline & $0-4$ & 13,5 & 16,8 & \multicolumn{3}{|c|}{-} \\
\hline & $1-5$ & 15,5 & 18,9 & \multicolumn{3}{|c|}{-} \\
\hline & $2-6$ & 15,3 & 18,3 & \multicolumn{3}{|c|}{-} \\
\hline & $3-7$ & 14,5 & 17,2 & \multicolumn{3}{|c|}{-} \\
\hline \multirow{2}{*}{ Teor de umidade (\%) } & Topo & Metade & Base & \multicolumn{3}{|c|}{-} \\
\hline & 18,8 & 18,6 & 16,4 & \multicolumn{3}{|c|}{-} \\
\hline \multirow{2}{*}{\multicolumn{3}{|c|}{\begin{tabular}{|l|} 
Inclusões contendo casca $(\mathrm{cm})$ \\
Madeira comprimida em $5 \mathrm{~cm}(\mathrm{~S} / \mathrm{N})$
\end{tabular}}} & - & \multicolumn{3}{|c|}{0,5} \\
\hline & & & - & \multicolumn{3}{|c|}{ Não } \\
\hline \multicolumn{3}{|c|}{ Furos de insetos (mm) } & 1 & \multicolumn{3}{|c|}{$\leq 2 \mathrm{~mm}$} \\
\hline \multirow{2}{*}{ Fendas $(\mathrm{cm})$} & \multirow{2}{*}{\multicolumn{2}{|c|}{\begin{tabular}{|l|} 
Topo \\
Base \\
\end{tabular}}} & - & \multicolumn{3}{|c|}{$\leq 30 \mathrm{~cm}$} \\
\hline & & & - & \multicolumn{3}{|c|}{$\leq 60 \mathrm{~cm}$} \\
\hline \multirow{2}{*}{ Encurvamento } & \multirow{2}{*}{\multicolumn{2}{|c|}{\begin{tabular}{|l|} 
um plano \\
dois planos $(\mathrm{S} / \mathrm{N})$ \\
\end{tabular}}} & $0,8 \%$ & \multicolumn{3}{|c|}{$\leq 0,8 \%$} \\
\hline & & & - & Não & sar pela & erfície \\
\hline Fibra torcida (m/volta) & & & ver obs. & & $3 \mathrm{~m} / \mathrm{vo}$ & \\
\hline Diâmetro dos nós $(\mathrm{cm})$ & Individual & & - & & $\leq 5 \mathrm{~cm}$ & \\
\hline 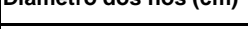 & Grupo & & - & & seção ou & \\
\hline & & & & & & \\
\hline & 0 & 1 & 2 & 3 & 4 & 5 \\
\hline & $0,00 \mathrm{~L}$ & $0,10 \mathrm{~L}$ & $0,20 \mathrm{~L}$ & $0,30 \mathrm{~L}$ & $0,40 \mathrm{~L}$ & $0,50 \mathrm{~L}$ \\
\hline Circunferência $(\mathrm{cm})$ & 56,1 & 55 & 54 & 53,4 & 52,6 & 51,5 \\
\hline & & & & & & \\
\hline & 6 & 7 & 8 & 9 & 10 & 11 \\
\hline & $0,60 \mathrm{~L}$ & $0,70 \mathrm{~L}$ & $0,80 \mathrm{~L}$ & $0,90 \mathrm{~L}$ & $0,95 \mathrm{~L}$ & $1,00 \mathrm{~L}$ \\
\hline & 51,8 & 50,5 & 50,0 & 49,8 & - & 46,8 \\
\hline
\end{tabular}

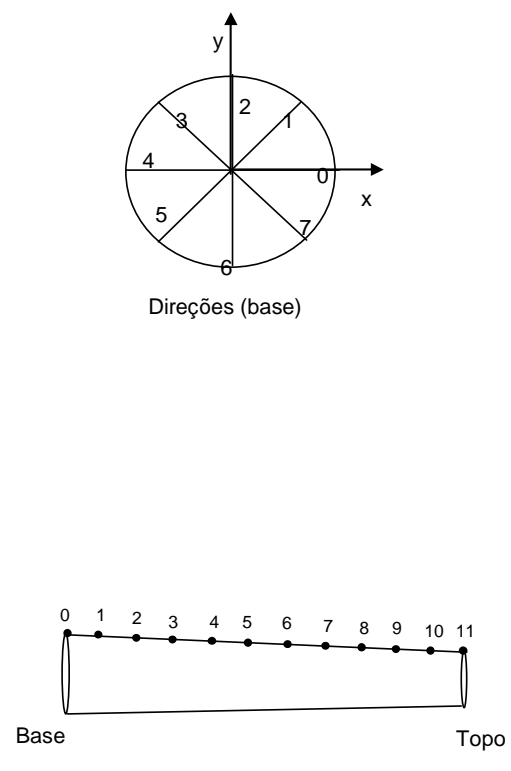

Observações:

Fibras com padrão sinusoidal

\begin{tabular}{|c|c|c|c|c|c|c|c|c|c|c|c|}
\hline \multirow{2}{*}{ Propriedades } & \multicolumn{11}{|c|}{ Seção } \\
\hline & 0 & $0.1 \mathrm{~L}$ & $0.2 \mathrm{~L}$ & $0.3 \mathrm{~L}$ & $0.4 \mathrm{~L}$ & $0.5 \mathrm{~L}$ & $0.6 \mathrm{~L}$ & $\begin{array}{c}0.7 \mathrm{~L} \\
\end{array}$ & $0.8 \mathrm{~L}$ & $0.9 \mathrm{~L}$ & $1.0 \mathrm{~L}$ \\
\hline $\mathrm{D}(\mathrm{cm})$ & 17,86 & 17,51 & 17,19 & 17,00 & 16,74 & 16,39 & 16,49 & 16,07 & 15,92 & 15,85 & 14,90 \\
\hline$D_{\text {méd }}(\mathrm{cm})$ & 17,78 & & & & & & & & & & 14,68 \\
\hline$\Delta_{\text {circ }}$ & $0,4 \%$ & & & & & & & & & & $1,5 \%$ \\
\hline$L / D_{\text {meio }}$ & \multicolumn{11}{|c|}{24,96} \\
\hline C & \multicolumn{11}{|c|}{$0,8 \%$} \\
\hline$\Delta \mathrm{D}$ & \multirow{2}{*}{\multicolumn{11}{|c|}{$5,1 \%$}} \\
\hline Densidade $\left(\mathrm{kg} / \mathrm{m}^{3}\right)$ & & & \multicolumn{9}{|c|}{1027,0} \\
\hline
\end{tabular}


Tabela F.14 - Dados da tora 14.

Tora $\mathrm{N}^{0} 14$

Data: $29 / 04 / 2010$

Espécie: Eucalyptus citriodora

\begin{tabular}{|c|c|c|c|c|c|c|}
\hline \multicolumn{3}{|c|}{ Características de crescimento } & Medido & \multicolumn{3}{|c|}{ Limite } \\
\hline \multicolumn{3}{|l|}{ Massa (kg) } & 96,45 & \multicolumn{3}{|c|}{-} \\
\hline \multicolumn{3}{|l|}{ Comprimento (cm) } & 437,8 & \multicolumn{3}{|c|}{-} \\
\hline \multicolumn{3}{|l|}{ Linha de terra $(\mathrm{cm})$} & 87,56 & \multicolumn{3}{|c|}{-} \\
\hline \multirow{5}{*}{ Diâmetros (cm) } & Direção & Topo & Base & \multicolumn{3}{|c|}{-} \\
\hline & $0-4$ & 14,5 & 18,0 & \multicolumn{3}{|c|}{-} \\
\hline & $1-5$ & 15,0 & 18,4 & \multicolumn{3}{|c|}{-} \\
\hline & $2-6$ & 15,0 & 17,3 & \multicolumn{3}{|c|}{-} \\
\hline & $3-7$ & 15,3 & 18,1 & \multicolumn{3}{|c|}{-} \\
\hline \multirow{2}{*}{ Teor de umidade (\%) } & Topo & Metade & Base & \multicolumn{3}{|c|}{-} \\
\hline & 18,8 & 18,6 & 16,8 & \multicolumn{3}{|c|}{-} \\
\hline \multicolumn{3}{|c|}{\begin{tabular}{|l} 
Inclusões contendo casca $(\mathrm{cm})$ \\
\end{tabular}} & 30 & \multicolumn{3}{|c|}{0,5} \\
\hline \multirow{2}{*}{\multicolumn{3}{|c|}{\begin{tabular}{|l} 
Madeira comprimida em $5 \mathrm{~cm}(\mathrm{~S} / \mathrm{N})$ \\
Furos de insetos $(\mathrm{mm})$
\end{tabular}}} & - & \multicolumn{3}{|c|}{ Não } \\
\hline & & & 1 & \multicolumn{3}{|c|}{$\leq 2 \mathrm{~mm}$} \\
\hline \multirow{2}{*}{ Fendas (cm) } & & 16 & \multicolumn{3}{|c|}{$\leq 30 \mathrm{~cm}$} \\
\hline & & & - & \multicolumn{3}{|c|}{$\leq 60 \mathrm{~cm}$} \\
\hline \multirow{2}{*}{ Encurvamento } & \multirow{2}{*}{\multicolumn{2}{|c|}{\begin{tabular}{|l|} 
um plano \\
dois planos $(\mathrm{S} / \mathrm{N})$ \\
\end{tabular}}} & $0,7 \%$ & & $\leq 0,8 \%$ & \\
\hline & & & - & Não & ssar pela & erfície \\
\hline Fibra torcida (m/volta) & & & - & & $\geq 3 \mathrm{~m} / \mathrm{vc}$ & \\
\hline Diâmetro dos nós $(\mathrm{cm})$ & Individual & & - & & $\leq 5 \mathrm{~cm}$ & \\
\hline Diametro dos nos (cm) & Grupo & & - & & seção ol & \\
\hline & & & & & & \\
\hline & 0 & 1 & 2 & 3 & 4 & 5 \\
\hline & $0,00 \mathrm{~L}$ & $0,10 \mathrm{~L}$ & $0,20 \mathrm{~L}$ & $0,30 \mathrm{~L}$ & $0,40 \mathrm{~L}$ & $0,50 \mathrm{~L}$ \\
\hline Circunferência $(\mathrm{cm})$ & 56,8 & 54,4 & 53,5 & 52,9 & 51,6 & 52,0 \\
\hline & & & & & & \\
\hline & 6 & 7 & 8 & 9 & 10 & 11 \\
\hline & $0,60 \mathrm{~L}$ & $0,70 \mathrm{~L}$ & $0,80 \mathrm{~L}$ & $0,90 \mathrm{~L}$ & $0,95 \mathrm{~L}$ & $1,00 \mathrm{~L}$ \\
\hline & 50,8 & 50,3 & 49,1 & 48,9 & - & 47,7 \\
\hline
\end{tabular}

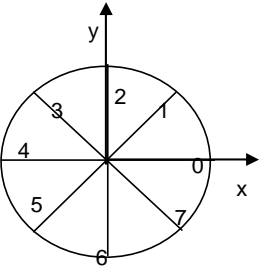

Direções (base)

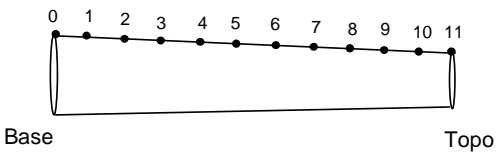

Observações:

opo: excentricidade de $2 \mathrm{~cm}$ no eixo 2-6

Base: excentricidade de $2 \mathrm{~cm}$ no eixo $2-6$

\begin{tabular}{|c|c|c|c|c|c|c|c|c|c|c|c|}
\hline \multirow{2}{*}{ Propriedades } & \multicolumn{11}{|c|}{ Seção } \\
\hline & 0 & $0.1 \mathrm{~L}$ & $\begin{array}{c}0.2 \mathrm{~L} \\
\end{array}$ & $0.3 \mathrm{~L}$ & $0.4 \mathrm{~L}$ & $0.5 \mathrm{~L}$ & $0.6 \mathrm{~L}$ & $\begin{array}{c}0.7 \mathrm{~L} \\
\end{array}$ & $\begin{array}{c}0.8 \mathrm{~L} \\
\end{array}$ & $0.9 \mathrm{~L}$ & $1.0 \mathrm{~L}$ \\
\hline $\mathrm{D}(\mathrm{cm})$ & 18,08 & 17,32 & 17,03 & 16,84 & 16,42 & 16,55 & 16,17 & 16,01 & 15,63 & 15,57 & 15,18 \\
\hline $\mathrm{D}_{\text {méd }}(\mathrm{cm})$ & 17,95 & & & & & & & & & & 14,95 \\
\hline$\Delta_{\text {circ }}$ & $0,7 \%$ & & & & & & & & & & $1,6 \%$ \\
\hline$L / D_{\text {meio }}$ & \multicolumn{11}{|c|}{26,45} \\
\hline C & \multicolumn{11}{|c|}{$0,7 \%$} \\
\hline$\Delta \mathrm{D}$ & \multicolumn{11}{|c|}{$5,2 \%$} \\
\hline Densidade $\left(\mathrm{kg} / \mathrm{m}^{3}\right)$ & \multicolumn{11}{|c|}{1034,2} \\
\hline
\end{tabular}


Tabela F.15 - Dados da tora 15.

Tora $\mathrm{N}^{0} 15$

\begin{tabular}{|c|c|c|c|c|c|c|}
\hline \multicolumn{3}{|c|}{ Características de crescimento } & Medido & \multicolumn{3}{|c|}{ Limite } \\
\hline \multicolumn{3}{|l|}{ Massa $(\mathrm{kg})$} & 81,65 & \multicolumn{3}{|c|}{-} \\
\hline \multicolumn{3}{|l|}{ Comprimento (cm) } & 404,8 & \multicolumn{3}{|c|}{-} \\
\hline \multicolumn{3}{|l|}{ Linha de terra $(\mathrm{cm})$} & 80,96 & \multicolumn{3}{|c|}{-} \\
\hline \multirow{5}{*}{ Diâmetros (cm) } & Direção & Topo & Base & \multicolumn{3}{|c|}{-} \\
\hline & $0-4$ & 14,8 & 16,2 & \multicolumn{3}{|c|}{-} \\
\hline & $1-5$ & 15,0 & 16,3 & \multicolumn{3}{|c|}{-} \\
\hline & $2-6$ & 14,8 & 17,0 & \multicolumn{3}{|c|}{-} \\
\hline & $3-7$ & 14,5 & 16,3 & \multicolumn{3}{|c|}{-} \\
\hline \multirow{2}{*}{ Teor de umidade (\%) } & Topo & Metade & Base & \multicolumn{3}{|c|}{-} \\
\hline & 14,7 & 14,2 & 12,8 & \multicolumn{3}{|c|}{-} \\
\hline \multicolumn{3}{|c|}{ Inclusões contendo casca $(\mathrm{cm})$} & - & \multicolumn{3}{|c|}{0,5} \\
\hline \multirow{2}{*}{\multicolumn{3}{|c|}{$\begin{array}{l}\text { Madeira comprimida em } 5 \mathrm{~cm}(\mathrm{~S} / \mathrm{N}) \\
\text { Furos de insetos }(\mathrm{mm})\end{array}$}} & - & \multicolumn{3}{|c|}{ Não } \\
\hline & & & 1 & \multicolumn{3}{|c|}{$\leq 2 \mathrm{~mm}$} \\
\hline \multirow{2}{*}{ Fendas (cm) } & \multirow{2}{*}{\multicolumn{2}{|c|}{\begin{tabular}{|l|} 
Topo \\
Base \\
\end{tabular}}} & 25 & \multicolumn{3}{|c|}{$\leq 30 \mathrm{~cm}$} \\
\hline & & & 30 & \multicolumn{3}{|c|}{$\leq 60 \mathrm{~cm}$} \\
\hline \multirow{2}{*}{ Encurvamento } & um plano & & $1,4 \%$ & \multicolumn{3}{|c|}{$\leq 0,8 \%$} \\
\hline & dois plano & $(\mathbf{S} / \mathrm{N})$ & - & Não & sar pela & rfície \\
\hline Fibra torcida (m/volta) & & & - & & $3 \mathrm{~m} / \mathrm{vo}$ & \\
\hline Diâmetro dos nós $(\mathrm{cm})$ & Individual & & - & & $\leq 5 \mathrm{~cm}$ & \\
\hline Diametro dos nos (cm) & Grupo & & - & & seção ou & \\
\hline & & & & & & \\
\hline & 0 & 1 & 2 & 3 & 4 & 5 \\
\hline & $0,00 \mathrm{~L}$ & $0,10 \mathrm{~L}$ & $0,20 \mathrm{~L}$ & $0,30 \mathrm{~L}$ & $0,40 \mathrm{~L}$ & $0,50 \mathrm{~L}$ \\
\hline Circunferência $(\mathrm{cm})$ & 52,1 & 51,8 & 50,7 & 49,8 & 49,4 & 48,9 \\
\hline & & & & & & \\
\hline & 6 & 7 & 8 & 9 & 10 & 11 \\
\hline & $0,60 \mathrm{~L}$ & $0,70 \mathrm{~L}$ & $0,80 \mathrm{~L}$ & $0,90 \mathrm{~L}$ & $0,95 \mathrm{~L}$ & $1,00 \mathrm{~L}$ \\
\hline & 48,1 & 47,8 & 47,3 & 46,8 & - & 46,8 \\
\hline
\end{tabular}

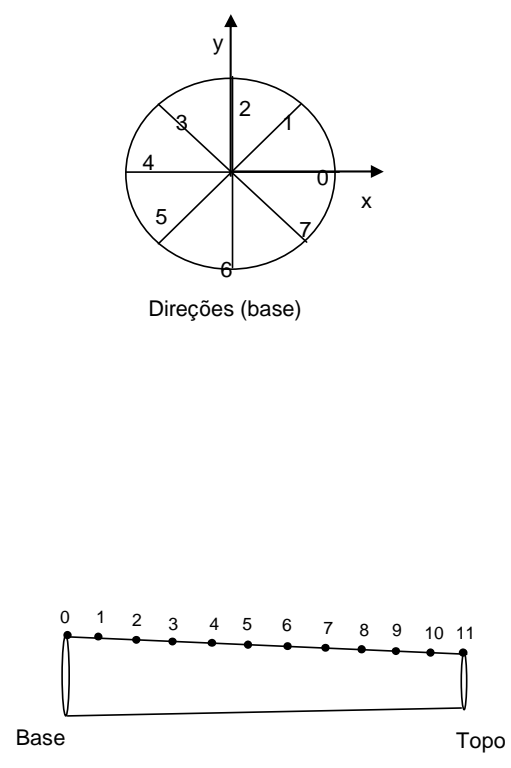

Observações:

Topo: excentricidade de $0,5 \mathrm{~cm}$ no eixo $2-6$ e de $1,2 \mathrm{~cm}$ na direção $0-4$

\begin{tabular}{|c|c|c|c|c|c|c|c|c|c|c|c|}
\hline \multirow{2}{*}{ Propriedades } & \multicolumn{11}{|c|}{ Seção } \\
\hline & 0 & $0.1 \mathrm{~L}$ & $0.2 \mathrm{~L}$ & $0.3 \mathrm{~L}$ & $0.4 \mathrm{~L}$ & $0.5 \mathrm{~L}$ & $0.6 \mathrm{~L}$ & $0.7 \mathrm{~L}$ & $0.8 \mathrm{~L}$ & $0.9 \mathrm{~L}$ & $1.0 \mathrm{~L}$ \\
\hline $\mathrm{D}(\mathrm{cm})$ & 16,58 & 16,49 & 16,14 & 15,85 & 15,72 & 15,57 & 15,31 & 15,22 & 15,06 & 14,90 & 14,90 \\
\hline$D_{\text {méd }}(\mathrm{cm})$ & 16,45 & & & & & & & & & & 14,77 \\
\hline$\Delta_{\text {circ }}$ & $0,8 \%$ & & & & & & & & & & $0,8 \%$ \\
\hline$L / D_{\text {meio }}$ & \multicolumn{11}{|c|}{26,01} \\
\hline C & \multirow{2}{*}{\multicolumn{11}{|c|}{$\begin{array}{l}0,4 \% \\
3,9 \% \\
\end{array}$}} \\
\hline$\Delta \mathrm{D}$ & & & & & & & & & & & \\
\hline Densidade $\left(\mathrm{kg} / \mathrm{m}^{3}\right)$ & \multicolumn{11}{|c|}{1052,9} \\
\hline
\end{tabular}


Tabela F.16 - Dados da tora 16.

Tora $\mathrm{N}^{0} 16$

Data: 30/04/2010

Espécie: Eucalyptus citriodora

\begin{tabular}{|c|c|c|c|c|c|c|}
\hline \multicolumn{3}{|c|}{ Caracteristicas de crescimento } & Medido & \multicolumn{3}{|c|}{ Limite } \\
\hline \multicolumn{3}{|l|}{ Massa (kg) } & 66,85 & \multicolumn{3}{|c|}{-} \\
\hline \multicolumn{3}{|l|}{ Comprimento (cm) } & 401,5 & \multicolumn{3}{|c|}{-} \\
\hline \multicolumn{3}{|l|}{ Linha de terra $(\mathrm{cm})$} & 80,3 & \multicolumn{3}{|c|}{-} \\
\hline \multirow{5}{*}{ Diâmetros (cm) } & Direção & Topo & Base & \multicolumn{3}{|c|}{-} \\
\hline & $0-4$ & 14,7 & 16,5 & \multicolumn{3}{|c|}{-} \\
\hline & $1-5$ & 13,8 & 16,0 & \multicolumn{3}{|c|}{-} \\
\hline & $2-6$ & 13,2 & 15,4 & \multicolumn{3}{|c|}{-} \\
\hline & $3-7$ & 13,5 & 15,2 & \multicolumn{3}{|c|}{-} \\
\hline \multirow{2}{*}{ Teor de umidade (\%) } & Topo & Metade & Base & \multicolumn{3}{|c|}{-} \\
\hline & 16,6 & 18,4 & 15,2 & \multicolumn{3}{|c|}{-} \\
\hline \multicolumn{3}{|c|}{ Inclusões contendo casca $(\mathrm{cm})$} & - & \multicolumn{3}{|c|}{0,5} \\
\hline \multirow{2}{*}{\multicolumn{3}{|c|}{\begin{tabular}{|l} 
Madeira comprimida em $5 \mathrm{~cm}(\mathrm{~S} / \mathrm{N})$ \\
Furos de insetos $(\mathrm{mm})$
\end{tabular}}} & - & \multicolumn{3}{|c|}{ Não } \\
\hline & & & 1 & \multirow{2}{*}{\multicolumn{3}{|c|}{$\begin{array}{l}\leq 2 \mathrm{~mm} \\
\leq 30 \mathrm{~cm}\end{array}$}} \\
\hline \multirow{2}{*}{ Fendas (cm) } & \multicolumn{2}{|c|}{ Furos de insetos (mm) } & 15 & \multirow{2}{*}{\multicolumn{3}{|c|}{$\begin{array}{l}\leq 30 \mathrm{~cm} \\
\leq 60 \mathrm{~cm}\end{array}$}} \\
\hline & \multicolumn{2}{|l|}{\begin{tabular}{|l|} 
Topo \\
Base \\
\end{tabular}} & 20 & & & \\
\hline \multirow{2}{*}{ Encurvamento } & \multicolumn{2}{|l|}{ um plano } & $0,4 \%$ & \multicolumn{3}{|c|}{$\leq 0,8 \%$} \\
\hline & \multicolumn{2}{|c|}{ dois planos $(\mathrm{S} / \mathrm{N})$} & - & Não & ssar pela & fície \\
\hline Fibra torcida (m/volta) & & & $1,46 \mathrm{~m} /$ volta & & $\geq 3 \mathrm{~m} / \mathrm{vo}$ & \\
\hline Diâmetro dos nós $(\mathrm{cm})$ & Individual & & 6 & & $\leq 5 \mathrm{~cm}$ & \\
\hline Diametro dos nos (cm) & Grupo & & 0,11 & & seção ou & \\
\hline & & & Seçã & & & \\
\hline & 0 & 1 & 2 & 3 & 4 & 5 \\
\hline & $0,00 \mathrm{~L}$ & $0,10 \mathrm{~L}$ & $0,20 \mathrm{~L}$ & $0,30 \mathrm{~L}$ & $0,40 \mathrm{~L}$ & $0,50 \mathrm{~L}$ \\
\hline Circunferência $(\mathrm{cm})$ & 50,5 & 49,5 & 50,3 & 49,1 & 51,3 & 49,7 \\
\hline & & & Seçã & & & \\
\hline & 6 & 7 & 8 & 9 & 10 & 11 \\
\hline & $0,60 \mathrm{~L}$ & $0,70 \mathrm{~L}$ & $0,80 \mathrm{~L}$ & $0,90 \mathrm{~L}$ & $0,95 \mathrm{~L}$ & $1,00 \mathrm{~L}$ \\
\hline & 46,3 & 47,6 & 44,0 & 43,8 & - & 44 \\
\hline
\end{tabular}

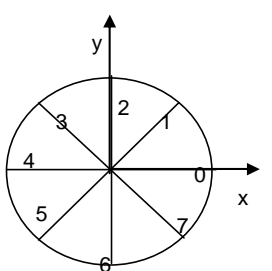

Direções (base)

Observações:

\begin{tabular}{|c|c|c|c|c|c|c|c|c|c|c|c|}
\hline \multirow{2}{*}{ Propriedades } & \multicolumn{11}{|c|}{ Seção } \\
\hline & 0 & $0.1 \mathrm{~L}$ & $0.2 \mathrm{~L}$ & $0.3 \mathrm{~L}$ & $0.4 \mathrm{~L}$ & $0.5 \mathrm{~L}$ & $0.6 \mathrm{~L}$ & $\begin{array}{c}0.7 \mathrm{~L} \\
\end{array}$ & $0.8 \mathrm{~L}$ & $0.9 \mathrm{~L}$ & $1.0 \mathrm{~L}$ \\
\hline $\mathrm{D}(\mathrm{cm})$ & 16,07 & 15,76 & 16,01 & 15,63 & 16,33 & 15,82 & 14,74 & 15,15 & 14,01 & 13,94 & 14,01 \\
\hline $\mathrm{D}_{\text {méd }}(\mathrm{cm})$ & 15,77 & & & & & & & & & & 13,79 \\
\hline$\Delta_{\text {circ }}$ & $2,0 \%$ & & & & & & & & & & $1,6 \%$ \\
\hline$L / D_{\text {meio }}$ & \multicolumn{11}{|c|}{25,38} \\
\hline$C$ & \multirow{2}{*}{\multicolumn{11}{|c|}{$\begin{array}{l}0,5 \% \\
6,0 \%\end{array}$}} \\
\hline$\Delta \mathrm{D}$ & & & & & & & & & & & \\
\hline Densidade $\left(\mathrm{kg} / \mathrm{m}^{3}\right)$ & \multicolumn{11}{|c|}{969,3} \\
\hline
\end{tabular}


Tabela F.17 - Dados da tora 17.

Tora $\mathrm{N}^{\circ} 17$

Data: $03 / 05 / 2010$

Espécie: Eucalyptus citriodora

\begin{tabular}{|c|c|c|c|c|c|c|}
\hline \multicolumn{3}{|c|}{ Características de crescimento } & Medido & \multicolumn{3}{|c|}{ Limite } \\
\hline \multicolumn{3}{|l|}{ Massa (kg) } & 101,65 & \multicolumn{3}{|c|}{-} \\
\hline \multicolumn{3}{|l|}{ Comprimento $(\mathrm{cm})$} & 408,5 & \multicolumn{3}{|c|}{-} \\
\hline \multicolumn{3}{|l|}{ Linha de terra $(\mathrm{cm})$} & 81,7 & \multicolumn{3}{|c|}{-} \\
\hline \multirow{5}{*}{ Diâmetros (cm) } & Direção & Topo & Base & \multicolumn{3}{|c|}{-} \\
\hline & $0-4$ & 17,9 & 19,5 & \multicolumn{3}{|c|}{-} \\
\hline & $1-5$ & 17,5 & 19,6 & \multicolumn{3}{|c|}{-} \\
\hline & $2-6$ & 16,6 & 18,2 & \multicolumn{3}{|c|}{-} \\
\hline & $3-7$ & 16,6 & 18,1 & \multicolumn{3}{|c|}{-} \\
\hline \multirow{2}{*}{ Teor de umidade (\%) } & Topo & Metade & Base & \multicolumn{3}{|c|}{-} \\
\hline & 17,8 & 22,3 & 23,1 & \multicolumn{3}{|c|}{-} \\
\hline & - & \multicolumn{3}{|c|}{0,5} \\
\hline \multirow{2}{*}{\multicolumn{3}{|c|}{$\begin{array}{l}\text { Madeira comprimida em } 5 \mathrm{~cm}(\mathrm{~S} / \mathrm{N}) \\
\text { Furos de insetos }(\mathrm{mm})\end{array}$}} & - & \multicolumn{3}{|c|}{ Não } \\
\hline & & & 1 & \multicolumn{3}{|c|}{$\leq 2 \mathrm{~mm}$} \\
\hline & 30 & \multicolumn{3}{|c|}{$\leq 30 \mathrm{~cm}$} \\
\hline Fendas (cm) & \multicolumn{2}{|l|}{\begin{tabular}{|l|} 
Topo \\
Base \\
\end{tabular}} & 21 & \multirow{2}{*}{\multicolumn{3}{|c|}{$\begin{array}{l}\leq 60 \mathrm{~cm} \\
\leq 0,8 \%\end{array}$}} \\
\hline \multirow{2}{*}{ Encurvamento } & & - & & & \\
\hline & \multicolumn{2}{|c|}{\begin{tabular}{|l|} 
um plano \\
dois planos $(\mathrm{S} / \mathrm{N})$ \\
\end{tabular}} & - & Não & sar pela & erfície \\
\hline Fibra torcida (m/volta) & & & - & & $3 \mathrm{~m} / \mathrm{vo}$ & \\
\hline Diâmetro dos nós $(\mathrm{cm})$ & Individual & & - & & $\leq 5 \mathrm{~cm}$ & \\
\hline 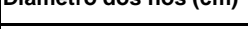 & Grupo & & - & & seção ou & \\
\hline & & & & & & \\
\hline & 0 & 1 & 2 & 3 & 4 & 5 \\
\hline & $0,00 \mathrm{~L}$ & $0,10 \mathrm{~L}$ & $0,20 \mathrm{~L}$ & $0,30 \mathrm{~L}$ & $0,40 \mathrm{~L}$ & $0,50 \mathrm{~L}$ \\
\hline Circunferência $(\mathrm{cm})$ & 60,0 & 58,3 & 57,5 & 56,8 & 56,1 & 55,8 \\
\hline & & & & & & \\
\hline & 6 & 7 & 8 & 9 & 10 & 11 \\
\hline & $0,60 \mathrm{~L}$ & $0,70 \mathrm{~L}$ & $0,80 \mathrm{~L}$ & $0,90 \mathrm{~L}$ & $0,95 \mathrm{~L}$ & $1,00 \mathrm{~L}$ \\
\hline & 55,3 & 54,6 & 54,1 & 54,1 & - & 54 \\
\hline
\end{tabular}

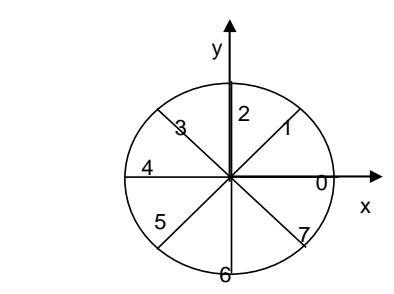

Direções (base)

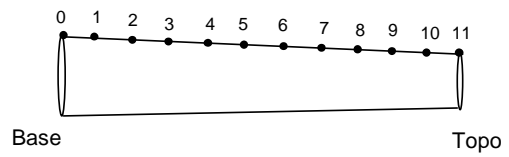

Tora com grandes fendas nas extremidades. Fendas com aberturas superiores a $5 \mathrm{~mm}$.

\begin{tabular}{|c|c|c|c|c|c|c|c|c|c|c|c|}
\hline \multirow{2}{*}{ Propriedades } & \multicolumn{11}{|c|}{ Seção } \\
\hline & 0 & $0.1 \mathrm{~L}$ & $0.2 \mathrm{~L}$ & $0.3 \mathrm{~L}$ & $0.4 \mathrm{~L}$ & $0.5 \mathrm{~L}$ & $0.6 \mathrm{~L}$ & $0.7 \mathrm{~L}$ & $0.8 \mathrm{~L}$ & $0.9 \mathrm{~L}$ & $1.0 \mathrm{~L}$ \\
\hline $\mathrm{D}(\mathrm{cm})$ & 19,10 & 18,56 & 18,30 & 18,08 & 17,86 & 17,76 & 17,60 & 17,38 & 17,22 & 17,22 & 17,19 \\
\hline $\mathrm{D}_{\text {méd }}(\mathrm{cm})$ & 18,84 & & & & & & & & & & 17,14 \\
\hline$\Delta_{\text {circ }}$ & $1,4 \%$ & & & & & & & & & & $0,3 \%$ \\
\hline$L / D_{\text {meio }}$ & \multicolumn{11}{|c|}{23,00} \\
\hline C & \multicolumn{11}{|c|}{$0,4 \%$} \\
\hline$\Delta \mathrm{D}$ & \multicolumn{11}{|c|}{$3,5 \%$} \\
\hline Densidade $\left(\mathrm{kg} / \mathrm{m}^{3}\right)$ & \multicolumn{11}{|c|}{978,4} \\
\hline
\end{tabular}


Tabela F.18 - Dados da tora 18.

Tora $\mathrm{N}^{0} 18$

Data: $03 / 05 / 2010$

Espécie: Eucalyptus citriodora

\begin{tabular}{|c|c|c|c|c|c|c|}
\hline \multicolumn{3}{|c|}{ Características de crescimento } & Medido & \multicolumn{3}{|c|}{ Limite } \\
\hline \multicolumn{3}{|l|}{ Massa (kg) } & 95,5 & \multicolumn{3}{|c|}{ - } \\
\hline \multicolumn{3}{|l|}{ Comprimento (cm) } & 412,7 & \multicolumn{3}{|c|}{-} \\
\hline \multicolumn{3}{|l|}{\begin{tabular}{|l} 
Linha de terra $(\mathrm{cm})$ \\
\end{tabular}} & 82,54 & \multicolumn{3}{|c|}{-} \\
\hline \multirow{5}{*}{ Diâmetros (cm) } & Direção & Topo & Base & \multicolumn{3}{|c|}{-} \\
\hline & $0-4$ & 17,7 & 19,8 & \multicolumn{3}{|c|}{-} \\
\hline & $1-5$ & 16,1 & 18,9 & \multicolumn{3}{|c|}{-} \\
\hline & $2-6$ & 16,7 & 21,0 & \multicolumn{3}{|c|}{-} \\
\hline & $3-7$ & 16,0 & 21,0 & \multicolumn{3}{|c|}{-} \\
\hline \multirow{2}{*}{ Teor de umidade (\%) } & Topo & Metade & Base & \multicolumn{3}{|c|}{-} \\
\hline & 15,9 & 22,4 & 19,6 & \multicolumn{3}{|c|}{-} \\
\hline \multicolumn{3}{|c|}{\begin{tabular}{|l} 
Inclusões contendo casca $(\mathrm{cm})$ \\
\end{tabular}} & - & \multicolumn{3}{|c|}{0,5} \\
\hline \multicolumn{3}{|c|}{$\begin{array}{l}\text { Madeira comprimida em } 5 \mathrm{~cm}(\mathrm{~S} / \mathrm{N}) \\
\text { Furos de insetos }(\mathrm{mm})\end{array}$} & - & \multicolumn{3}{|c|}{ Não } \\
\hline \multicolumn{3}{|l|}{ Furos de insetos (mm) } & 1 & \multicolumn{3}{|c|}{$\leq 2 \mathrm{~mm}$} \\
\hline \multirow{2}{*}{ Fendas (cm) } & \multirow{2}{*}{\multicolumn{2}{|c|}{\begin{tabular}{|l|} 
Topo \\
Base \\
\end{tabular}}} & 30 & \multicolumn{3}{|c|}{$\leq 30 \mathrm{~cm}$} \\
\hline & & & 11 & \\
\hline \multirow{2}{*}{ Encurvamento } & & & $0,9 \%$ & \multicolumn{3}{|c|}{$\leq 0,8 \%$} \\
\hline & dois plano & $(\mathrm{S} / \mathrm{N})$ & - & Não & sar pela & erfície \\
\hline Fibra torcida (m/volta) & & & ver obs. & & $3 \mathrm{~m} / \mathrm{vo}$ & \\
\hline Diâmetro dos nós (cm) & Individual & & - & & $\leq 5 \mathrm{~cm}$ & \\
\hline Diametro dos nos (cm) & Grupo & & - & & seção ou & \\
\hline & & & & & & \\
\hline & 0 & 1 & 2 & 3 & 4 & 5 \\
\hline & $0,00 \mathrm{~L}$ & $\overline{0,10 L}$ & $0,20 \mathrm{~L}$ & $0,30 \mathrm{~L}$ & $0,40 \mathrm{~L}$ & $0,50 \mathrm{~L}$ \\
\hline Circunferência (cm) & 55,7 & 59,3 & 57,0 & 56,6 & 56,3 & 54,3 \\
\hline & & & & & & \\
\hline & 6 & 7 & 8 & 9 & 10 & 11 \\
\hline & $0,60 \mathrm{~L}$ & $0,70 \mathrm{~L}$ & $0,80 \mathrm{~L}$ & $0,90 \mathrm{~L}$ & $0,95 \mathrm{~L}$ & $1,00 \mathrm{~L}$ \\
\hline & 55,9 & 55,7 & 53,2 & 54 & - & 53,7 \\
\hline
\end{tabular}

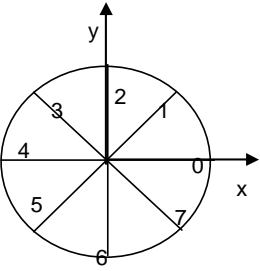

Direções (base)

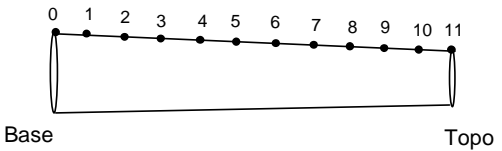

Observações:

Tora com seção transversal irregular e muito diferente da circular.

Fibras com padrão sinusoidal

\begin{tabular}{|c|c|c|c|c|c|c|c|c|c|c|c|}
\hline \multirow{2}{*}{ Propriedades } & \multicolumn{11}{|c|}{ Seção } \\
\hline & 0 & $0.1 \mathrm{~L}$ & $0.2 \mathrm{~L}$ & $0.3 \mathrm{~L}$ & $0.4 \mathrm{~L}$ & $0.5 \mathrm{~L}$ & $0.6 \mathrm{~L}$ & $0.7 \mathrm{~L}$ & $0.8 \mathrm{~L}$ & $0.9 \mathrm{~L}$ & $1.0 \mathrm{~L}$ \\
\hline $\mathrm{D}(\mathrm{cm})$ & 17,73 & 18,88 & 18,14 & 18,02 & 17,92 & 17,28 & 17,79 & 17,73 & 16,93 & 17,19 & 17,09 \\
\hline $\mathrm{D}_{\text {méd }}(\mathrm{cm})$ & 20,16 & & & & & & & & & & 16,61 \\
\hline$\Delta_{\text {circ }}$ & $12,0 \%$ & & & & & & & & & & $2,9 \%$ \\
\hline$L / D_{\text {meio }}$ & \multicolumn{11}{|c|}{23,88} \\
\hline$C$ & \multirow{2}{*}{\multicolumn{11}{|c|}{$\begin{array}{l}0,9 \% \\
3,2 \%\end{array}$}} \\
\hline$\Delta \mathrm{D}$ & & & & & & & & & & & \\
\hline Densidade $\left(\mathrm{kg} / \mathrm{m}^{3}\right)$ & \multicolumn{11}{|c|}{869,1} \\
\hline
\end{tabular}


Tabela F.19 - Dados da tora 19.

Tora $\mathrm{N}^{\circ} 19$

\begin{tabular}{|c|c|c|c|c|c|c|}
\hline \multicolumn{3}{|c|}{ Características de crescimento } & Medido & \multicolumn{3}{|c|}{ Limite } \\
\hline \multicolumn{3}{|l|}{ Massa (kg) } & 78,3 & \multicolumn{3}{|c|}{-} \\
\hline \multicolumn{3}{|l|}{ Comprimento (cm) } & 426 & \multicolumn{3}{|c|}{-} \\
\hline & 85,2 & \multicolumn{3}{|c|}{-} \\
\hline \multicolumn{3}{|l|}{ Linha de terra $(\mathrm{cm})$} & Base & \multicolumn{3}{|c|}{-} \\
\hline \multirow{4}{*}{ Diâmetros (cm) } & $0-4$ & 14,9 & 16,0 & \multicolumn{3}{|c|}{-} \\
\hline & $1-5$ & 15,2 & 15,8 & \multicolumn{3}{|c|}{-} \\
\hline & $2-6$ & 14,0 & 16,0 & \multicolumn{3}{|c|}{-} \\
\hline & $3-7$ & 14,6 & 16,3 & \multicolumn{3}{|c|}{-} \\
\hline \multirow{2}{*}{ Teor de umidade (\%) } & Topo & Metade & Base & \multicolumn{3}{|c|}{-} \\
\hline & 20,7 & 19,3 & 17,1 & \multicolumn{3}{|c|}{-} \\
\hline \multirow{2}{*}{\multicolumn{3}{|c|}{\begin{tabular}{|l} 
Inclusões contendo casca $(\mathrm{cm})$ \\
Madeira comprimida em $5 \mathrm{~cm}(\mathrm{~S} / \mathrm{N})$
\end{tabular}}} & - & \multicolumn{3}{|c|}{0,5} \\
\hline & & & - & \multicolumn{3}{|c|}{ Não } \\
\hline \multicolumn{3}{|l|}{ Furos de insetos (mm) } & 1 & \multicolumn{3}{|c|}{$\leq 2 \mathrm{~mm}$} \\
\hline \multirow{2}{*}{ Fendas $(\mathrm{cm})$} & \multicolumn{2}{|l|}{ Topo } & 7 & \multicolumn{3}{|c|}{$\leq 30 \mathrm{~cm}$} \\
\hline & \multicolumn{2}{|l|}{\begin{tabular}{|l} 
Base \\
\end{tabular}} & 10 & \multicolumn{3}{|c|}{$\leq 60 \mathrm{~cm}$} \\
\hline \multirow{2}{*}{ Encurvamento } & \multirow{2}{*}{\multicolumn{2}{|c|}{\begin{tabular}{|l|} 
um plano \\
dois planos $(\mathrm{S} / \mathrm{N})$ \\
\end{tabular}}} & $0,8 \%$ & \multicolumn{3}{|c|}{$\leq 0,8 \%$} \\
\hline & & & - & Não & sar pela & rfície \\
\hline Fibra torcida (m/volta) & & & $3,1 \mathrm{~m} / \mathrm{volta}$ & & $3 \mathrm{~m} / \mathrm{vo}$ & \\
\hline Dî̂matro dos nós (am) & Individual & & - & & $\leq 5 \mathrm{~cm}$ & \\
\hline Diametro dos nos (cm) & Grupo & & - & & seção ou & \\
\hline & & & Sec & & & \\
\hline & $\mathbf{0}$ & 1 & 2 & 3 & 4 & 5 \\
\hline & $0,00 \mathrm{~L}$ & $0,10 \mathrm{~L}$ & $0,20 \mathrm{~L}$ & $0,30 \mathrm{~L}$ & $0,40 \mathrm{~L}$ & $0,50 \mathrm{~L}$ \\
\hline Circunferência $(\mathrm{cm})$ & 51,2 & 50,0 & 49,4 & 49,4 & 47,4 & 47,4 \\
\hline & & & $\mathrm{Sec}$ & & & \\
\hline & 6 & 7 & 8 & 9 & 10 & 11 \\
\hline & $0,60 \mathrm{~L}$ & $\overline{0,70 L}$ & $0,80 \mathrm{~L}$ & $0,90 \mathrm{~L}$ & $0,95 \mathrm{~L}$ & $1,00 \mathrm{~L}$ \\
\hline & 47,8 & 46,2 & 45,8 & 44,5 & - & 46,5 \\
\hline
\end{tabular}

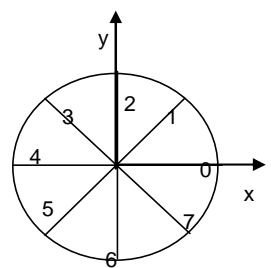

Direções (base)

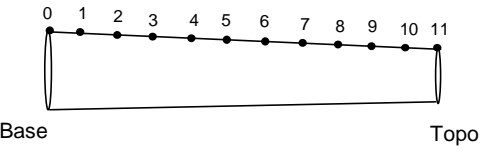

oservações:

Base: Excentricidade de $1 \mathrm{~cm}$ na direção 2-6

Bolsões de resina e fibra torcida na região central da tora

\begin{tabular}{|c|c|c|c|c|c|c|c|c|c|c|c|}
\hline \multirow{2}{*}{ Propriedades } & \multicolumn{11}{|c|}{ Seção } \\
\hline & 0 & $0.1 \mathrm{~L}$ & $0.2 \mathrm{~L}$ & $0.3 \mathrm{~L}$ & $0.4 \mathrm{~L}$ & $0.5 \mathrm{~L}$ & $0.6 \mathrm{~L}$ & $0.7 \mathrm{~L}$ & $0.8 \mathrm{~L}$ & $0.9 \mathrm{~L}$ & $1.0 \mathrm{~L}$ \\
\hline $\mathrm{D}(\mathrm{cm})$ & 16,30 & 15,92 & 15,72 & 15,72 & 15,09 & 15,09 & 15,22 & 14,71 & 14,58 & 14,16 & 14,80 \\
\hline$D_{\text {méd }}(\mathrm{cm})$ & 16,02 & & & & & & & & & & 14,67 \\
\hline$\Delta_{\text {circ }}$ & $1,7 \%$ & & & & & & & & & & $0,9 \%$ \\
\hline$L / D_{\text {meio }}$ & \multicolumn{11}{|c|}{28,23} \\
\hline C & \multirow{2}{*}{\multicolumn{11}{|c|}{$\begin{array}{l}0,3 \% \\
4,2 \% \\
\end{array}$}} \\
\hline$\Delta \mathrm{D}$ & & & & & & & & & & & \\
\hline Densidade $\left(\mathrm{kg} / \mathrm{m}^{3}\right)$ & \multicolumn{11}{|c|}{993,1} \\
\hline
\end{tabular}


Tabela F.20 - Dados da tora 20.

Tora $\mathrm{N}^{\circ} 20$

Data: 04/05/2010

Espécie: Eucalyptus citriodora

\begin{tabular}{|c|c|c|c|c|c|c|}
\hline \multicolumn{3}{|c|}{ Características de crescimento } & Medido & \multicolumn{3}{|c|}{ Limite } \\
\hline \multicolumn{3}{|l|}{ Massa $(\mathrm{kg})$} & 80,55 & \multicolumn{3}{|c|}{-} \\
\hline \multicolumn{3}{|l|}{ Comprimento $(\mathrm{cm})$} & 412 & \multicolumn{3}{|c|}{-} \\
\hline \multicolumn{3}{|l|}{ Linha de terra $(\mathrm{cm})$} & 82,4 & \multicolumn{3}{|c|}{-} \\
\hline \multirow{5}{*}{ Diâmetros (cm) } & Direção & Topo & Base & \multicolumn{3}{|c|}{-} \\
\hline & $0-4$ & 14,6 & 17,2 & \multicolumn{3}{|c|}{-} \\
\hline & $1-5$ & 14,5 & 16,7 & \multicolumn{3}{|c|}{-} \\
\hline & $2-6$ & 14,6 & 16,6 & \multicolumn{3}{|c|}{-} \\
\hline & $3-7$ & 14,0 & 16,2 & \multicolumn{3}{|c|}{-} \\
\hline \multirow{2}{*}{ Teor de umidade (\%) } & Topo & Metade & Base & \multicolumn{3}{|c|}{-} \\
\hline & 18,1 & 17,5 & 20,8 & \multicolumn{3}{|c|}{-} \\
\hline \multirow{2}{*}{\multicolumn{3}{|c|}{\begin{tabular}{|l|} 
Inclusões contendo casca $(\mathrm{cm})$ \\
Madeira comprimida em $5 \mathrm{~cm}(\mathrm{~S} / \mathrm{N})$
\end{tabular}}} & - & \multicolumn{3}{|c|}{0,5} \\
\hline & & & - & \multicolumn{3}{|c|}{ Não } \\
\hline \multicolumn{3}{|c|}{ Furos de insetos $(\mathrm{mm})$} & 1 & \multicolumn{3}{|c|}{$\leq 2 \mathrm{~mm}$} \\
\hline \multirow{2}{*}{ Fendas $(\mathrm{cm})$} & \multicolumn{2}{|l|}{ Topo } & 17 & \multicolumn{3}{|c|}{$\leq 30 \mathrm{~cm}$} \\
\hline & \multicolumn{2}{|c|}{ Base } & 20 & \multicolumn{3}{|c|}{$\leq 60 \mathrm{~cm}$} \\
\hline \multirow{2}{*}{ Encurvamento } & \multirow{2}{*}{\multicolumn{2}{|c|}{\begin{tabular}{|l|} 
um plano \\
dois planos $(\mathrm{S} / \mathrm{N})$ \\
\end{tabular}}} & $0,6 \%$ & \multicolumn{3}{|c|}{$\leq 0,8 \%$} \\
\hline & & & - & Não & ssar pela & erfície \\
\hline Fibra torcida (m/volta) & & & - & & $\geq 3 \mathrm{~m} / \mathrm{vc}$ & \\
\hline Diâmetro dos nós $(\mathrm{cm})$ & Individual & & 11 & & $\leq 5 \mathrm{~cm}$ & \\
\hline Diantion & Grupo & & $1 / 3$ seção & & seção ol & \\
\hline & & & & & & \\
\hline & 0 & 1 & 2 & 3 & 4 & 5 \\
\hline & $0,00 \mathrm{~L}$ & $0,10 \mathrm{~L}$ & $0,20 \mathrm{~L}$ & $0,30 \mathrm{~L}$ & $0,40 \mathrm{~L}$ & $0,50 \mathrm{~L}$ \\
\hline Circunferência $(\mathrm{cm})$ & 53,1 & 51,4 & 51,5 & 50,3 & 49,2 & 48,5 \\
\hline & & & & & & \\
\hline & 6 & 7 & 8 & 9 & 10 & 11 \\
\hline & $0,60 \mathrm{~L}$ & $0,70 \mathrm{~L}$ & $0,80 \mathrm{~L}$ & $0,90 \mathrm{~L}$ & $0,95 \mathrm{~L}$ & $1,00 \mathrm{~L}$ \\
\hline & 50,8 & 54,0 & 47,7 & 46,5 & - & 45,8 \\
\hline
\end{tabular}

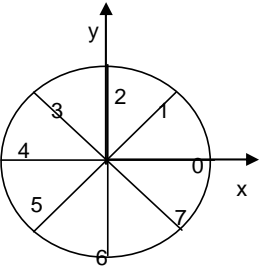

Direções (base)

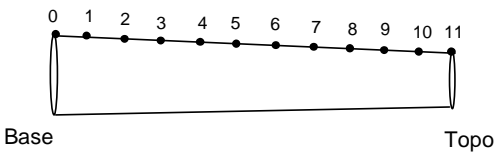

Observações:

\begin{tabular}{|c|c|c|c|c|c|c|c|c|c|c|c|}
\hline \multirow{2}{*}{ Propriedades } & \multicolumn{11}{|c|}{ Seção } \\
\hline & 0 & $0.1 \mathrm{~L}$ & $\begin{array}{c}0.2 \mathrm{~L} \\
\end{array}$ & $0.3 \mathrm{~L}$ & $0.4 \mathrm{~L}$ & $0.5 \mathrm{~L}$ & $0.6 \mathrm{~L}$ & $\begin{array}{c}0.7 \mathrm{~L} \\
\end{array}$ & $0.8 \mathrm{~L}$ & $0.9 \mathrm{~L}$ & $\begin{array}{l}1.0 \mathrm{~L} \\
\end{array}$ \\
\hline $\mathrm{D}(\mathrm{cm})$ & 16,90 & 16,36 & 16,39 & 16,01 & 15,66 & 15,44 & 16,17 & 17,19 & 15,18 & 14,80 & 14,58 \\
\hline$D_{\text {méd }}(\mathrm{cm})$ & 16,67 & & & & & & & & & & 14,42 \\
\hline$\Delta_{\text {circ }}$ & $1,4 \%$ & & & & & & & & & & $1,1 \%$ \\
\hline$L / D_{\text {meio }}$ & \multicolumn{11}{|c|}{26,69} \\
\hline C & \multirow{2}{*}{\multicolumn{11}{|c|}{$0,5 \%$}} \\
\hline$\Delta \mathrm{D}$ & \multirow{2}{*}{\multicolumn{11}{|c|}{$\begin{array}{c}\frac{5,2 \%}{1028,1} \\
\end{array}$}} \\
\hline Densidade $\left(\mathrm{kg} / \mathrm{m}^{3}\right)$ & & & & & & & & & & & \\
\hline
\end{tabular}


Tabela F.21 - Dados da tora 21.

Tora $\mathrm{N}^{0} 21$

Data: $06 / 05 / 2010$

Espécie: Eucalyptus citriodora

\begin{tabular}{|c|c|c|c|c|c|c|}
\hline \multicolumn{3}{|c|}{ Caracteristicas de crescimento } & Medido & \multicolumn{3}{|c|}{ Limite } \\
\hline \multicolumn{3}{|l|}{ Massa (kg) } & 75,4 & \multicolumn{3}{|c|}{-} \\
\hline \multicolumn{3}{|l|}{ Comprimento $(\mathrm{cm})$} & 408,6 & \multicolumn{3}{|c|}{-} \\
\hline \multicolumn{3}{|l|}{ Linha de terra $(\mathrm{cm})$} & 81,72 & \multicolumn{3}{|c|}{-} \\
\hline \multirow{5}{*}{ Diâmetros (cm) } & Direção & Topo & Base & \multicolumn{3}{|c|}{-} \\
\hline & $0-4$ & 13,7 & 17,3 & \multicolumn{3}{|c|}{-} \\
\hline & $1-5$ & 14,0 & 17,0 & \multicolumn{3}{|c|}{-} \\
\hline & $2-6$ & 14,4 & 19,0 & \multicolumn{3}{|c|}{-} \\
\hline & $3-7$ & 14,5 & 19,0 & \multicolumn{3}{|c|}{-} \\
\hline \multirow{2}{*}{ Teor de umidade (\%) } & Topo & Metade & Base & \multicolumn{3}{|c|}{-} \\
\hline & 17,8 & 17,4 & 17,3 & \multicolumn{3}{|c|}{-} \\
\hline \multicolumn{3}{|c|}{ Inclusões contendo casca (cm) } & - & \multicolumn{3}{|c|}{0,5} \\
\hline \multicolumn{3}{|c|}{ Madeira comprimida em $5 \mathrm{~cm}(\mathrm{~S} / \mathrm{N})$} & - & \multicolumn{3}{|c|}{ Não } \\
\hline \multicolumn{3}{|l|}{ Furos de insetos (mm) } & 1 & \multicolumn{3}{|c|}{$\leq 2 \mathrm{~mm}$} \\
\hline \multirow{2}{*}{ Fendas (cm) } & \multicolumn{2}{|l|}{ Topo } & 30 & \multicolumn{3}{|c|}{$\leq 30 \mathrm{~cm}$} \\
\hline & \multicolumn{2}{|l|}{ Base } & 16 & \multicolumn{3}{|c|}{$\leq 60 \mathrm{~cm}$} \\
\hline \multirow{2}{*}{ Encurvamento } & \multirow{2}{*}{\multicolumn{2}{|c|}{\begin{tabular}{|l|} 
um plano \\
dois planos $(\mathrm{S} / \mathrm{N})$ \\
\end{tabular}}} & - & & $\leq 0,8 \%$ & \\
\hline & & & - & Não & sar pela & rfície \\
\hline Fibra torcida (m/volta) & & & $1,86 \mathrm{~m} / 90^{\circ}$ & & $3 \mathrm{~m} / \mathrm{vc}$ & \\
\hline & Individual & & & & $\leq 5 \mathrm{~cm}$ & \\
\hline Diämetro dos nos (cm) & Grupo & & & & seção ol & \\
\hline & & & & & & \\
\hline & 0 & 1 & 2 & 3 & 4 & 5 \\
\hline & $0,00 \mathrm{~L}$ & $0,10 \mathrm{~L}$ & $0,20 \mathrm{~L}$ & $0,30 \mathrm{~L}$ & $0,40 \mathrm{~L}$ & $0,50 \mathrm{~L}$ \\
\hline Circunferência (cm) & 56,3 & 51,5 & 50,5 & 49,7 & 49 & 48,5 \\
\hline & & & Se & & & \\
\hline & 6 & 7 & 8 & 9 & 10 & 11 \\
\hline & $0,60 \mathrm{~L}$ & $0,70 \mathrm{~L}$ & $0,80 \mathrm{~L}$ & $0,90 \mathrm{~L}$ & $0,95 \mathrm{~L}$ & $1,00 \mathrm{~L}$ \\
\hline & 47,7 & 46,7 & 46,2 & 45,3 & - & 45,1 \\
\hline
\end{tabular}

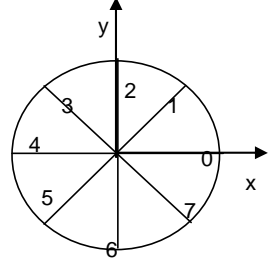

Direções (base)

Observações:

Ruptura por compressão no ensaio estático

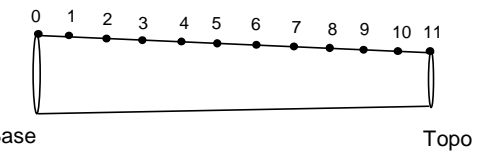

\begin{tabular}{|c|c|c|c|c|c|c|c|c|c|c|c|}
\hline \multirow{2}{*}{ Propriedades } & \multicolumn{11}{|c|}{ Seção } \\
\hline & 0 & $0.1 \mathrm{~L}$ & $0.2 \mathrm{~L}$ & $0.3 \mathrm{~L}$ & $0.4 \mathrm{~L}$ & $0.5 \mathrm{~L}$ & $0.6 \mathrm{~L}$ & $0.7 \mathrm{~L}$ & $0.8 \mathrm{~L}$ & $0.9 \mathrm{~L}$ & $1.0 \mathrm{~L}$ \\
\hline $\mathrm{D}(\mathrm{cm})$ & 17,92 & 16,39 & 16,07 & 15,82 & 15,60 & 15,44 & 15,18 & 14,87 & 14,71 & 14,42 & 14,36 \\
\hline $\mathrm{D}_{\text {méd }}(\mathrm{cm})$ & 18,05 & & & & & & & & & & 14,15 \\
\hline$\Delta_{\text {circ }}$ & $0,7 \%$ & & & & & & & & & & $1,5 \%$ \\
\hline$L / D_{\text {meio }}$ & \multicolumn{11}{|c|}{26,47} \\
\hline C & \multicolumn{11}{|c|}{$1,0 \%$} \\
\hline$\Delta \mathrm{D}$ & \multicolumn{11}{|c|}{$6,7 \%$} \\
\hline Densidade $\left(\mathrm{kg} / \mathrm{m}^{3}\right)$ & \multicolumn{11}{|c|}{902,2} \\
\hline
\end{tabular}


Tabela F. 22 - Dados da tora 22.

Tora $\mathrm{N}^{0} 22$

Data: 06/05/2010

Espécie: Eucalyptus citriodora

\begin{tabular}{|c|c|c|c|c|c|c|}
\hline \multicolumn{3}{|c|}{ Características de crescimento } & Medido & \multicolumn{3}{|c|}{ Limite } \\
\hline \multicolumn{3}{|l|}{ Massa (kg) } & 60,35 & \multicolumn{3}{|c|}{-} \\
\hline \multicolumn{3}{|l|}{ Comprimento $(\mathrm{cm})$} & 415,5 & \multicolumn{3}{|c|}{-} \\
\hline \multicolumn{3}{|l|}{ Linha de terra $(\mathrm{cm})$} & 83,1 & \multicolumn{3}{|c|}{-} \\
\hline \multirow{5}{*}{ Diâmetros (cm) } & Direção & Topo & Base & \multicolumn{3}{|c|}{-} \\
\hline & $0-4$ & 13,3 & 18,3 & \multicolumn{3}{|c|}{-} \\
\hline & $1-5$ & 12,3 & 17,0 & \multicolumn{3}{|c|}{-} \\
\hline & $2-6$ & 11,7 & 15,0 & \multicolumn{3}{|c|}{-} \\
\hline & $3-7$ & 12,4 & 16,7 & \multicolumn{3}{|c|}{-} \\
\hline \multirow{2}{*}{ Teor de umidade (\%) } & Topo & Metade & Base & \multicolumn{3}{|c|}{-} \\
\hline & 17,0 & 15,5 & 18 & \multicolumn{3}{|c|}{-} \\
\hline \multicolumn{3}{|c|}{\begin{tabular}{|l|} 
Inclusões contendo casca $(\mathrm{cm})$ \\
\end{tabular}} & - & \multicolumn{3}{|c|}{0,5} \\
\hline \multicolumn{3}{|c|}{ Madeira comprimida em $5 \mathrm{~cm}(\mathrm{~S} / \mathrm{N})$} & - & \multicolumn{3}{|c|}{ Não } \\
\hline \multicolumn{3}{|c|}{ Furos de insetos $(\mathrm{mm})$} & 1 & \multicolumn{3}{|c|}{$\leq 2 \mathrm{~mm}$} \\
\hline \multirow{2}{*}{ Fendas $(\mathrm{cm})$} & \multicolumn{2}{|l|}{ Topo } & - & \multicolumn{3}{|c|}{$\leq 30 \mathrm{~cm}$} \\
\hline & \multicolumn{2}{|l|}{ Base } & 39 & \multicolumn{3}{|c|}{$\leq 60 \mathrm{~cm}$} \\
\hline \multirow{2}{*}{ Encurvamento } & \multirow{2}{*}{\multicolumn{2}{|c|}{\begin{tabular}{|l|} 
um plano \\
dois planos $(\mathrm{S} / \mathrm{N})$ \\
\end{tabular}}} & $0,4 \%$ & & $\leq 0,8 \%$ & \\
\hline & & & - & $\overline{N a ̃ o p}$ & sar pela & erfície \\
\hline Fibra torcida (m/volta) & & & - & & $23 \mathrm{~m} / \mathrm{vo}$ & \\
\hline Diâmetro dos nós $(\mathrm{cm})$ & Individual & & - & & $\leq 5 \mathrm{~cm}$ & \\
\hline Diametro dos nos (cm) & Grupo & & - & & seção ou & \\
\hline & & & & & & \\
\hline & 0 & 1 & 2 & 3 & 4 & 5 \\
\hline & $0,00 \mathrm{~L}$ & $0,10 \mathrm{~L}$ & $0,20 \mathrm{~L}$ & $0,30 \mathrm{~L}$ & $0,40 \mathrm{~L}$ & $0,50 \mathrm{~L}$ \\
\hline Circunferência (cm) & 42,7 & 47,7 & 45,7 & 44,2 & 43,5 & 43,0 \\
\hline 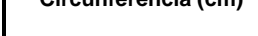 & & & & & & \\
\hline & 6 & 7 & 8 & 9 & 10 & 11 \\
\hline & $0,60 \mathrm{~L}$ & $0,70 \mathrm{~L}$ & $0,80 \mathrm{~L}$ & $0,90 \mathrm{~L}$ & $0,95 \mathrm{~L}$ & $1,00 \mathrm{~L}$ \\
\hline & 42,3 & 41,7 & 40,9 & 40,3 & - & 39,6 \\
\hline
\end{tabular}

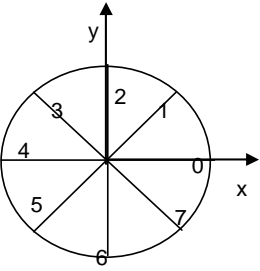

Direções (base)

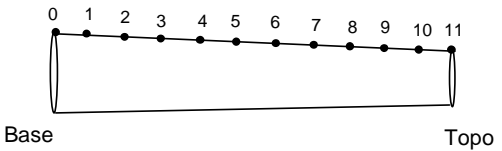

Observações:

\begin{tabular}{|c|c|c|c|c|c|c|c|c|c|c|c|}
\hline \multirow{2}{*}{ Propriedades } & \multicolumn{11}{|c|}{ Seção } \\
\hline & 0 & $0.1 \mathrm{~L}$ & $\begin{array}{c}0.2 \mathrm{~L} \\
\end{array}$ & $0.3 \mathrm{~L}$ & $0.4 \mathrm{~L}$ & $0.5 \mathrm{~L}$ & $0.6 \mathrm{~L}$ & $\begin{array}{c}0.7 \mathrm{~L} \\
\end{array}$ & $0.8 \mathrm{~L}$ & $0.9 \mathrm{~L}$ & $\begin{array}{l}1.0 \mathrm{~L} \\
\end{array}$ \\
\hline $\mathrm{D}(\mathrm{cm})$ & 13,59 & 15,18 & 14,55 & 14,07 & 13,85 & 13,69 & 13,46 & 13,27 & 13,02 & 12,83 & 12,61 \\
\hline$D_{\text {méd }}(\mathrm{cm})$ & 16,71 & & & & & & & & & & 12,41 \\
\hline$\Delta_{\text {circ }}$ & $18,7 \%$ & & & & & & & & & & $1,6 \%$ \\
\hline$L / D_{\text {meio }}$ & \multicolumn{11}{|c|}{30,36} \\
\hline C & \multicolumn{11}{|c|}{$1,0 \%$} \\
\hline$\Delta \mathrm{D}$ & \multirow{2}{*}{\multicolumn{11}{|c|}{$\begin{array}{l}5,5 \% \\
866,1\end{array}$}} \\
\hline Densidade $\left(\mathrm{kg} / \mathrm{m}^{3}\right)$ & & & & & & & & & & & \\
\hline
\end{tabular}


Tabela F.23 - Dados da tora 23.

Tora $\mathrm{N}^{0} 23$

\begin{tabular}{|c|c|c|c|c|c|c|}
\hline \multicolumn{3}{|c|}{ Características de crescimento } & Medido & \multicolumn{3}{|c|}{ Limite } \\
\hline \multicolumn{3}{|l|}{ Massa (kg) } & 63,6 & \multicolumn{3}{|c|}{-} \\
\hline \multicolumn{3}{|l|}{ Comprimento (cm) } & 397,2 & \multicolumn{3}{|c|}{-} \\
\hline & 79,44 & \multicolumn{3}{|c|}{-} \\
\hline \multirow{5}{*}{ Diâmetros $(\mathrm{cm})$} & Linha de terra $(\mathrm{cm})$ & Topo & Base & \multicolumn{3}{|c|}{-} \\
\hline & $0-4$ & 13,1 & 13,5 & \multicolumn{3}{|c|}{-} \\
\hline & $1-5$ & 13,2 & 17,0 & \multicolumn{3}{|c|}{-} \\
\hline & $2-6$ & 14,7 & 16,5 & \multicolumn{3}{|c|}{-} \\
\hline & $3-7$ & 14,9 & 15,2 & \multicolumn{3}{|c|}{-} \\
\hline \multirow{2}{*}{ Teor de umidade (\%) } & Topo & Metade & Base & \multicolumn{3}{|c|}{-} \\
\hline & 14,3 & 14,7 & 13,0 & \multicolumn{3}{|c|}{-} \\
\hline \multirow{2}{*}{\multicolumn{3}{|c|}{$\begin{array}{l}\text { Inclusões contendo casca }(\mathrm{cm}) \\
\text { Madeira comprimida em } 5 \mathrm{~cm}(\mathrm{~S} / \mathrm{N})\end{array}$}} & - & \multicolumn{3}{|c|}{0,5} \\
\hline & & & - & \multicolumn{3}{|c|}{ Não } \\
\hline \multicolumn{3}{|c|}{ Furos de insetos $(\mathrm{mm})$} & 1 & \multicolumn{3}{|c|}{$\leq 2 \mathrm{~mm}$} \\
\hline \multirow{2}{*}{ Fendas $(\mathrm{cm})$} & \multicolumn{2}{|l|}{ Topo } & 11 & \multicolumn{3}{|c|}{$\leq 30 \mathrm{~cm}$} \\
\hline & \multicolumn{2}{|l|}{ Base } & 20 & \multicolumn{3}{|c|}{$\leq 60 \mathrm{~cm}$} \\
\hline \multirow{2}{*}{ Encurvamento } & \multirow{2}{*}{\multicolumn{2}{|c|}{\begin{tabular}{|l|} 
um plano \\
dois planos $(\mathrm{S} / \mathrm{N})$ \\
\end{tabular}}} & $0,5 \%$ & \multicolumn{3}{|c|}{$\leq 0,8 \%$} \\
\hline & & & - & Nãop & sar pela & Ifície \\
\hline Fibra torcida (m/volta) & & & - & & $3 \mathrm{~m} / \mathrm{vc}$ & \\
\hline & Individual & & - & & $\leq 5 \mathrm{~cm}$ & \\
\hline Diametro dos nos (cm) & Grupo & & - & & seção ol & \\
\hline & & & & & & \\
\hline & 0 & 1 & 2 & 3 & 4 & 5 \\
\hline & $0,00 \mathrm{~L}$ & $0,10 \mathrm{~L}$ & $0,20 \mathrm{~L}$ & $0,30 \mathrm{~L}$ & $0,40 \mathrm{~L}$ & $0,50 \mathrm{~L}$ \\
\hline Circunferência (cm) & 51,5 & 47,3 & 45,7 & 44,9 & 44,2 & 43,9 \\
\hline & & & & & & \\
\hline & 6 & 7 & 8 & 9 & 10 & 11 \\
\hline & $0,60 \mathrm{~L}$ & $0,70 \mathrm{~L}$ & $0,80 \mathrm{~L}$ & $0,90 \mathrm{~L}$ & $0,95 \mathrm{~L}$ & $1,00 \mathrm{~L}$ \\
\hline & 43,3 & 42,6 & 42,6 & 42,3 & - & 44,6 \\
\hline
\end{tabular}

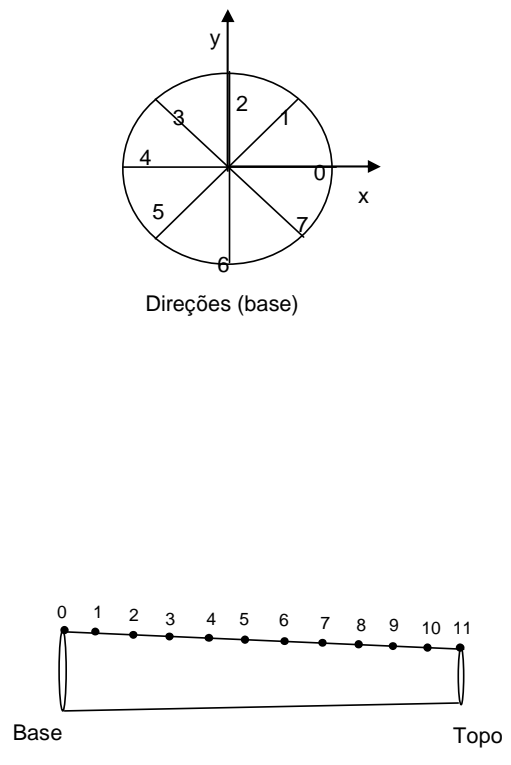

Observações:

Excentricidade Topo: $2 \mathrm{~cm}$ na direção 0-4 e 1,2cm na direção 2-6

\begin{tabular}{|c|c|c|c|c|c|c|c|c|c|c|c|}
\hline \multirow{2}{*}{ Propriedades } & \multicolumn{11}{|c|}{ Seção } \\
\hline & 0 & $0.1 \mathrm{~L}$ & $0.2 \mathrm{~L}$ & $0.3 \mathrm{~L}$ & $0.4 \mathrm{~L}$ & $0.5 \mathrm{~L}$ & $0.6 \mathrm{~L}$ & $0.7 \mathrm{~L}$ & $0.8 \mathrm{~L}$ & $0.9 \mathrm{~L}$ & $1.0 \mathrm{~L}$ \\
\hline $\mathrm{D}(\mathrm{cm})$ & 16,39 & 15,06 & 14,55 & 14,29 & 14,07 & 13,97 & 13,78 & 13,56 & 13,56 & 13,46 & 14,20 \\
\hline $\mathrm{D}_{\text {méd }}(\mathrm{cm})$ & 15,49 & & & & & & & & & & 13,95 \\
\hline$\Delta_{\text {circ }}$ & $5,8 \%$ & & & & & & & & & & $1,8 \%$ \\
\hline$L / D_{\text {meio }}$ & \multicolumn{11}{|c|}{28,42} \\
\hline $\mathrm{C}$ & \multirow{2}{*}{\multicolumn{11}{|c|}{$\frac{0,4 \%}{6,0 \%}$}} \\
\hline$\Delta \mathrm{D}$ & & & & & & & & & & & \\
\hline Densidade $\left(\mathrm{kg} / \mathrm{m}^{3}\right)$ & \multicolumn{11}{|c|}{940,1} \\
\hline
\end{tabular}


Tabela F.24 - Dados da tora 24.

Tora $\mathrm{N}^{0} 24$

Data: $10 / 05 / 2010$

Espécie: Eucalyptus citriodora

\begin{tabular}{|c|c|c|c|c|c|c|}
\hline \multicolumn{3}{|c|}{ Características de crescimento } & Medido & \multicolumn{3}{|c|}{ Limite } \\
\hline \multicolumn{3}{|l|}{ Massa (kg) } & 85,7 & \multicolumn{3}{|c|}{ - } \\
\hline \multicolumn{3}{|l|}{ Comprimento $(\mathrm{cm})$} & 405,3 & \multicolumn{3}{|c|}{-} \\
\hline \multicolumn{3}{|l|}{ Linha de terra $(\mathrm{cm})$} & 81,06 & \multicolumn{3}{|c|}{-} \\
\hline \multirow{5}{*}{ Diâmetros (cm) } & Direção & Topo & Base & \multicolumn{3}{|c|}{-} \\
\hline & $0-4$ & 14,2 & 18,7 & \multicolumn{3}{|c|}{-} \\
\hline & $1-5$ & 14,5 & 18,2 & \multicolumn{3}{|c|}{-} \\
\hline & $2-6$ & 15,5 & 20,3 & \multicolumn{3}{|c|}{-} \\
\hline & $3-7$ & 14,6 & 20,4 & \multicolumn{3}{|c|}{-} \\
\hline \multirow{2}{*}{ Teor de umidade (\%) } & Topo & Metade & Base & \multicolumn{3}{|c|}{-} \\
\hline & 15,4 & 17,0 & 18,1 & \multicolumn{3}{|c|}{-} \\
\hline \multicolumn{3}{|c|}{ Inclusões contendo casca $(\mathbf{c m})$} & - & \multicolumn{3}{|c|}{0,5} \\
\hline Madeira comprimida em & $\mathrm{cm} \mathrm{(S/N)}$ & & - & \multicolumn{3}{|c|}{ Não } \\
\hline \multicolumn{3}{|l|}{ Furos de insetos (mm) } & 1 & \multicolumn{3}{|c|}{$\leq 2 \mathrm{~mm}$} \\
\hline \multirow{2}{*}{ Fendas $(\mathrm{cm})$} & \multirow{2}{*}{\multicolumn{2}{|c|}{ Topo }} & 1 & \multicolumn{3}{|c|}{$\leq 30 \mathrm{~cm}$} \\
\hline & & & 9 & \multicolumn{3}{|c|}{$\leq 60 \mathrm{~cm}$} \\
\hline Fncurvamento & \multirow{2}{*}{\multicolumn{2}{|c|}{\begin{tabular}{|l|} 
um plano \\
dois planos $(\mathrm{S} / \mathrm{N})$ \\
\end{tabular}}} & $0,6 \%$ & \multicolumn{3}{|c|}{$\leq 0,8 \%$} \\
\hline Encurvamento & & & - & Não & ssar pela & Iffície \\
\hline Fibra torcida (m/volta) & & & ver obs. & & $\geq 3 \mathrm{~m} / \mathrm{vc}$ & \\
\hline Diâmetro dos nós $(\mathrm{cm})$ & Individual & & 5 & & $\leq 5 \mathrm{~cm}$ & \\
\hline Diametro dos nos (cm) & Grupo & & - & & seção ol & \\
\hline & & & & & & \\
\hline & 0 & 1 & 2 & 3 & 4 & 5 \\
\hline & $0,00 \mathrm{~L}$ & $0,10 \mathrm{~L}$ & $0,20 \mathrm{~L}$ & $0,30 \mathrm{~L}$ & $0,40 \mathrm{~L}$ & $0,50 \mathrm{~L}$ \\
\hline Circunferência $(\mathrm{cm})$ & 62,0 & 58,1 & 55,8 & 53,8 & 54 & 51,8 \\
\hline & & & & & & \\
\hline & 6 & 7 & 8 & 9 & 10 & 11 \\
\hline & $0,60 \mathrm{~L}$ & $0,70 \mathrm{~L}$ & $0,80 \mathrm{~L}$ & $0,90 \mathrm{~L}$ & $0,95 \mathrm{~L}$ & $1,00 \mathrm{~L}$ \\
\hline & 51,1 & 49,6 & 48,4 & 47,2 & - & 49,5 \\
\hline
\end{tabular}

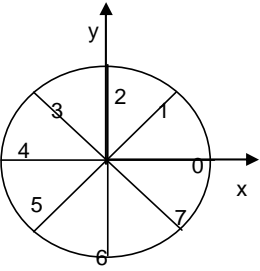

Direções (base)

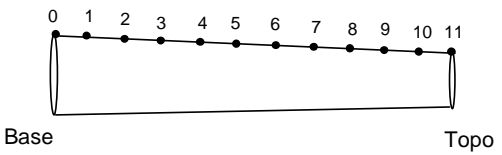

Observações:

Excentricidade Topo: $2 \mathrm{~cm}$ na direção 0-4 e 1,2 cm na direção 2-6

Fibras com padrão sinusoidal

\begin{tabular}{|c|c|c|c|c|c|c|c|c|c|c|c|}
\hline \multirow{2}{*}{ Propriedades } & \multicolumn{11}{|c|}{ Seção } \\
\hline & 0 & $0.1 \mathrm{~L}$ & $0.2 \mathrm{~L}$ & $0.3 \mathrm{~L}$ & $0.4 \mathrm{~L}$ & $0.5 \mathrm{~L}$ & $0.6 \mathrm{~L}$ & $0.7 \mathrm{~L}$ & $0.8 \mathrm{~L}$ & $0.9 \mathrm{~L}$ & $1.0 \mathrm{~L}$ \\
\hline $\mathrm{D}(\mathrm{cm})$ & 19,74 & 18,49 & 17,76 & 17,13 & 17,19 & 16,49 & 16,27 & 15,79 & 15,41 & 15,02 & 15,76 \\
\hline$D_{\text {méd }}(\mathrm{cm})$ & 19,38 & & & & & & & & & & 14,69 \\
\hline$\Delta_{\text {circ }}$ & $1,9 \%$ & & & & & & & & & & $7,2 \%$ \\
\hline$L / D_{\text {meio }}$ & \multicolumn{11}{|c|}{24,58} \\
\hline $\mathrm{C}$ & \multicolumn{11}{|c|}{$1,2 \%$} \\
\hline$\Delta \mathrm{D}$ & \multicolumn{11}{|c|}{$8,5 \%$} \\
\hline Densidade $\left(\mathrm{kg} / \mathrm{m}^{3}\right)$ & \multicolumn{11}{|c|}{922,1} \\
\hline
\end{tabular}


Tabela F.25 - Dados da tora 25.

Tora $\mathrm{N}^{0} 25$

Data: $11 / 05 / 2010$

Espécie: Eucalyptus citriodora

\begin{tabular}{|c|c|c|c|c|c|c|}
\hline \multicolumn{3}{|c|}{ Caracteristicas de crescimento } & Medido & \multicolumn{3}{|c|}{ Limite } \\
\hline \multicolumn{3}{|l|}{ Massa (kg) } & 64 & \multicolumn{3}{|c|}{ - } \\
\hline \multicolumn{3}{|l|}{ Comprimento (cm) } & 399,5 & \multicolumn{3}{|c|}{-} \\
\hline \multicolumn{3}{|l|}{ Linha de terra $(\mathrm{cm})$} & 79,9 & \multicolumn{3}{|c|}{-} \\
\hline \multirow{5}{*}{ Diâmetros (cm) } & Direção & Topo & Base & \multicolumn{3}{|c|}{-} \\
\hline & $0-4$ & 17,6 & 14,6 & \multicolumn{3}{|c|}{-} \\
\hline & $1-5$ & 13,1 & 14,8 & \multicolumn{3}{|c|}{-} \\
\hline & $2-6$ & 13,1 & 14,7 & \multicolumn{3}{|c|}{-} \\
\hline & $3-7$ & 12,7 & 14,8 & \multicolumn{3}{|c|}{-} \\
\hline \multirow{2}{*}{ Teor de umidade (\%) } & Topo & Metade & Base & \multicolumn{3}{|c|}{-} \\
\hline & 12,1 & 12,8 & 12,5 & \multicolumn{3}{|c|}{-} \\
\hline \multicolumn{3}{|c|}{ Inclusões contendo casca $(\mathrm{cm})$} & - & \multicolumn{3}{|c|}{0,5} \\
\hline \multirow{2}{*}{\multicolumn{3}{|c|}{$\begin{array}{l}\text { Madeira comprimida em } 5 \mathrm{~cm}(\mathrm{~S} / \mathrm{N}) \\
\text { Furos de insetos }(\mathrm{mm})\end{array}$}} & - & \multicolumn{3}{|c|}{ Não } \\
\hline & & & 1 & \multicolumn{3}{|c|}{$\leq 2 \mathrm{~mm}$} \\
\hline \multirow{2}{*}{ Fendas (cm) } & \multirow{2}{*}{\multicolumn{2}{|c|}{\begin{tabular}{|l|} 
Topo \\
Base
\end{tabular}}} & 20 & \multicolumn{3}{|c|}{$\leq 30 \mathrm{~cm}$} \\
\hline & & & 9 & \multicolumn{3}{|c|}{$\leq 60 \mathrm{~cm}$} \\
\hline \multirow{2}{*}{ Encurvamento } & \multirow{2}{*}{\multicolumn{2}{|c|}{\begin{tabular}{|l|} 
um plano \\
dois planos $(\mathrm{S} / \mathrm{N})$ \\
\end{tabular}}} & $0,5 \%$ & \multicolumn{3}{|c|}{$\leq 0,8 \%$} \\
\hline & & & - & $\overline{\text { Nãop }}$ & sar pela & rfície \\
\hline Fibra torcida (m/volta) & & & - & & $3 \mathrm{~m} / \mathrm{vc}$ & \\
\hline & Individual & & - & & $\leq 5 \mathrm{~cm}$ & \\
\hline Diâmetro dos nós $(\mathrm{cm})$ & Grupo & & - & & seção ol & \\
\hline & & & & & & \\
\hline & $\mathbf{0}$ & 1 & 2 & 3 & 4 & 5 \\
\hline & $0,00 \mathrm{~L}$ & $0,10 \mathrm{~L}$ & $0,20 \mathrm{~L}$ & $0,30 \mathrm{~L}$ & $0,40 \mathrm{~L}$ & $0,50 \mathrm{~L}$ \\
\hline Circunferência (cm) & 47,4 & 47,5 & 46,5 & 46,1 & 45,5 & 44,6 \\
\hline & & & & & & \\
\hline & 6 & 7 & 8 & 9 & 10 & 11 \\
\hline & $0,60 \mathrm{~L}$ & $0,70 \mathrm{~L}$ & $0,80 \mathrm{~L}$ & $0,90 \mathrm{~L}$ & $0,95 \mathrm{~L}$ & $1,00 \mathrm{~L}$ \\
\hline & 43,9 & 43,2 & 43,1 & 41,8 & - & 40,9 \\
\hline
\end{tabular}

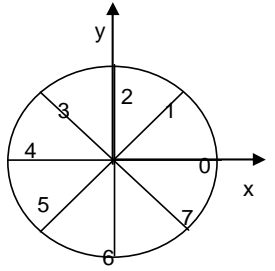

Direções (base)
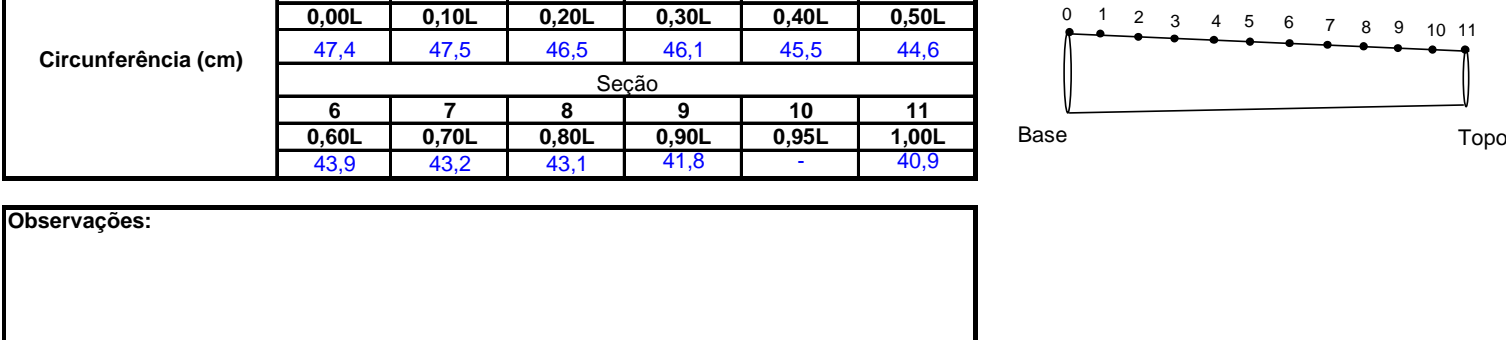

\begin{tabular}{|c|c|c|c|c|c|c|c|c|c|c|c|}
\hline \multirow{2}{*}{ Propriedades } & \multicolumn{11}{|c|}{ Seção } \\
\hline & 0 & $0.1 \mathrm{~L}$ & $0.2 \mathrm{~L}$ & $0.3 \mathrm{~L}$ & $0.4 \mathrm{~L}$ & $0.5 \mathrm{~L}$ & $0.6 \mathrm{~L}$ & $0.7 \mathrm{~L}$ & $0.8 \mathrm{~L}$ & $0.9 \mathrm{~L}$ & $1.0 \mathrm{~L}$ \\
\hline $\mathrm{D}(\mathrm{cm})$ & 15,09 & 15,12 & 14,80 & 14,67 & 14,48 & 14,20 & 13,97 & 13,75 & 13,72 & 13,31 & 13,02 \\
\hline$D_{\text {méd }}(\mathrm{cm})$ & 14,72 & & & & & & & & & & 13,99 \\
\hline$\Delta_{\text {circ }}$ & $2,5 \%$ & & & & & & & & & & $7,0 \%$ \\
\hline$L / D_{\text {meio }}$ & \multicolumn{11}{|c|}{28,14} \\
\hline C & \multirow{2}{*}{\multicolumn{11}{|c|}{$\begin{array}{l}0,2 \% \\
5,0 \%\end{array}$}} \\
\hline$\Delta \mathrm{D}$ & & & & & & & & & & & \\
\hline Densidade $\left(\mathrm{kg} / \mathrm{m}^{3}\right)$ & \multicolumn{11}{|c|}{989,0} \\
\hline
\end{tabular}


Tabela F.26 - Dados da tora 26.

Tora $\mathrm{N}^{0} 26$

Data: $11 / 05 / 2010$

Espécie: Eucalyptus citriodora

\begin{tabular}{|c|c|c|c|c|c|c|}
\hline \multicolumn{3}{|c|}{ Características de crescimento } & Medido & \multicolumn{3}{|c|}{ Limite } \\
\hline \multicolumn{3}{|l|}{ Massa (kg) } & 110,3 & \multicolumn{3}{|c|}{-} \\
\hline \multicolumn{3}{|l|}{ Comprimento $(\mathrm{cm})$} & 425,6 & \multicolumn{3}{|c|}{-} \\
\hline \multicolumn{3}{|l|}{ Linha de terra $(\mathrm{cm})$} & 85,12 & \multicolumn{3}{|c|}{-} \\
\hline \multirow{5}{*}{ Diâmetros (cm) } & Direção & Topo & Base & \multicolumn{3}{|c|}{-} \\
\hline & $0-4$ & 17,6 & 23,0 & \multicolumn{3}{|c|}{-} \\
\hline & $1-5$ & 16,8 & 22,0 & \multicolumn{3}{|c|}{-} \\
\hline & $2-6$ & 16,2 & 20,0 & \multicolumn{3}{|c|}{-} \\
\hline & $3-7$ & 16,8 & 21,0 & \multicolumn{3}{|c|}{-} \\
\hline \multirow{2}{*}{ Teor de umidade (\%) } & Topo & Metade & Base & \multicolumn{3}{|c|}{-} \\
\hline & 11,5 & 14,5 & 16,3 & \multicolumn{3}{|c|}{-} \\
\hline \multicolumn{3}{|c|}{ Inclusões contendo casca (cm) } & - & \multicolumn{3}{|c|}{0,5} \\
\hline \multicolumn{3}{|c|}{ Madeira comprimida em $5 \mathrm{~cm}(\mathrm{~S} / \mathrm{N})$} & - & \multicolumn{3}{|c|}{ Não } \\
\hline \multicolumn{3}{|c|}{ Furos de insetos $(\mathrm{mm})$} & 2 & \multicolumn{3}{|c|}{$\leq 2 \mathrm{~mm}$} \\
\hline \multirow{2}{*}{ Fendas $(\mathrm{cm})$} & \multicolumn{2}{|l|}{ Topo } & - & \multicolumn{3}{|c|}{$\leq 30 \mathrm{~cm}$} \\
\hline & \multicolumn{2}{|l|}{ Base } & 23 & \multicolumn{3}{|c|}{$\leq 60 \mathrm{~cm}$} \\
\hline \multirow{2}{*}{ Encurvamento } & \multirow{2}{*}{\multicolumn{2}{|c|}{\begin{tabular}{|l|} 
um plano \\
dois planos $(\mathrm{S} / \mathrm{N})$ \\
\end{tabular}}} & $0,5 \%$ & & $\leq 0,8 \%$ & \\
\hline & & & - & $\overline{N a ̃ o p}$ & sar pela & erfície \\
\hline Fibra torcida (m/volta) & & & - & & $23 \mathrm{~m} / \mathrm{vo}$ & \\
\hline Diâmetro dos nós $(\mathrm{cm})$ & Individual & & - & & $\leq 5 \mathrm{~cm}$ & \\
\hline Diametro dos nos (cm) & Grupo & & - & & seção ou & \\
\hline & & & & & & \\
\hline & 0 & 1 & 2 & 3 & 4 & 5 \\
\hline & $0,00 \mathrm{~L}$ & $0,10 \mathrm{~L}$ & $0,20 \mathrm{~L}$ & $0,30 \mathrm{~L}$ & $0,40 \mathrm{~L}$ & $0,50 \mathrm{~L}$ \\
\hline Circunferência (cm) & 67,7 & 62,3 & 59,0 & 58,3 & 57,2 & 56,7 \\
\hline 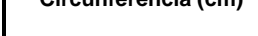 & & & & & & \\
\hline & 6 & 7 & 8 & 9 & 10 & 11 \\
\hline & $0,60 \mathrm{~L}$ & $0,70 \mathrm{~L}$ & $0,80 \mathrm{~L}$ & $0,90 \mathrm{~L}$ & $0,95 \mathrm{~L}$ & $1,00 \mathrm{~L}$ \\
\hline & 55,5 & 55,3 & 54,8 & 54,3 & - & 53,5 \\
\hline
\end{tabular}

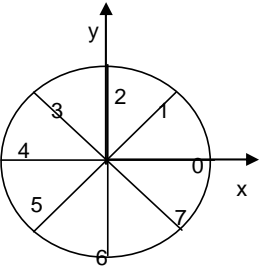

Direções (base)

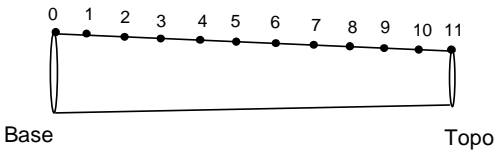

Observações:

\begin{tabular}{|c|c|c|c|c|c|c|c|c|c|c|c|}
\hline \multirow{2}{*}{ Propriedades } & \multicolumn{11}{|c|}{ Seção } \\
\hline & 0 & $0.1 \mathrm{~L}$ & $0.2 \mathrm{~L}$ & $0.3 \mathrm{~L}$ & $0.4 \mathrm{~L}$ & $0.5 \mathrm{~L}$ & $0.6 \mathrm{~L}$ & $\begin{array}{c}0.7 \mathrm{~L} \\
\end{array}$ & $0.8 \mathrm{~L}$ & $0.9 \mathrm{~L}$ & $1.0 \mathrm{~L}$ \\
\hline $\mathrm{D}(\mathrm{cm})$ & 21,55 & 19,83 & 18,78 & 18,56 & 18,21 & 18,05 & 17,67 & 17,60 & 17,44 & 17,28 & 17,03 \\
\hline$D_{\text {méd }}(\mathrm{cm})$ & 21,47 & & & & & & & & & & 16,84 \\
\hline$\Delta_{\text {circ }}$ & $0,4 \%$ & & & & & & & & & & $1,1 \%$ \\
\hline$L / D_{\text {meio }}$ & \multicolumn{11}{|c|}{23,58} \\
\hline C & \multirow{2}{*}{\multicolumn{11}{|c|}{$1,1 \%$}} \\
\hline$\Delta \mathrm{D}$ & \multirow{2}{*}{\multicolumn{11}{|c|}{$\begin{array}{l}7,2 \% \\
894,8 \\
\end{array}$}} \\
\hline Densidade $\left(\mathrm{kg} / \mathrm{m}^{3}\right)$ & & & & & & & & & & & \\
\hline
\end{tabular}


Tabela F.27 - Dados da tora 27.

Tora $\mathrm{N}^{\circ} 27$

Data: 12/05/2010

Espécie: Eucalyptus citriodora

\begin{tabular}{|c|c|c|c|c|c|c|}
\hline \multicolumn{3}{|c|}{ Caracteristicas de crescimento } & Medido & \multicolumn{3}{|c|}{ Limite } \\
\hline \multicolumn{3}{|l|}{ Massa (kg) } & 92,25 & \multicolumn{3}{|c|}{-} \\
\hline \multicolumn{3}{|l|}{ Comprimento (cm) } & 424,3 & \multicolumn{3}{|c|}{-} \\
\hline \multicolumn{3}{|l|}{ Linha de terra $(\mathrm{cm})$} & 84,86 & \multicolumn{3}{|c|}{-} \\
\hline \multirow{5}{*}{ Diâmetros (cm) } & Direção & Topo & Base & \multicolumn{3}{|c|}{-} \\
\hline & $0-4$ & 15,5 & 18,2 & \multicolumn{3}{|c|}{-} \\
\hline & $1-5$ & 15,1 & 18,2 & \multicolumn{3}{|c|}{-} \\
\hline & $2-6$ & 14,6 & 17,9 & \multicolumn{3}{|c|}{ - } \\
\hline & $3-7$ & 14,9 & 17,6 & \multicolumn{3}{|c|}{-} \\
\hline \multirow{2}{*}{ Teor de umidade (\%) } & Topo & Metade & Base & \multicolumn{3}{|c|}{-} \\
\hline & 15,8 & 11,4 & 15,1 & \multicolumn{3}{|c|}{-} \\
\hline \multicolumn{3}{|c|}{ Inclusões contendo casca (cm) } & - & \multicolumn{3}{|c|}{0,5} \\
\hline \multirow{2}{*}{\multicolumn{3}{|c|}{\begin{tabular}{|l} 
Madeira comprimida em $5 \mathrm{~cm}(\mathrm{~S} / \mathrm{N})$ \\
Furos de insetos $(\mathrm{mm})$
\end{tabular}}} & - & \multicolumn{3}{|c|}{ Não } \\
\hline & & & 1 & \multicolumn{3}{|c|}{$\leq 2 \mathrm{~mm}$} \\
\hline \multicolumn{3}{|l|}{ Furos de insetos (mm) } & 33 & \multicolumn{3}{|c|}{$\leq 30 \mathrm{~cm}$} \\
\hline Fendas (cm) & \multicolumn{2}{|l|}{\begin{tabular}{|l|} 
Topo \\
Base \\
\end{tabular}} & - & \multicolumn{3}{|c|}{$\leq 60 \mathrm{~cm}$} \\
\hline \multirow{2}{*}{ Encurvamento } & \multirow{2}{*}{\multicolumn{2}{|c|}{\begin{tabular}{|l|} 
um plano \\
dois planos $(\mathrm{S} / \mathrm{N})$ \\
\end{tabular}}} & $0,5 \%$ & \multicolumn{3}{|c|}{$\leq 0,8 \%$} \\
\hline & & & - & Não & sar pela & erfície \\
\hline \multicolumn{3}{|l|}{ Fibra torcida (m/volta) } & $3,2 \mathrm{~m} /$ volta & & $3 \mathrm{~m} / \mathrm{vc}$ & \\
\hline Diâmetro dos nós $(\mathrm{cm})$ & Individual & & - & & $\leq 5 \mathrm{~cm}$ & \\
\hline J Diametro dos nos (cmi) & Grupo & & - & & seção ol & \\
\hline & & & & & & \\
\hline & $\mathbf{0}$ & 1 & 2 & 3 & 4 & 5 \\
\hline & $0,00 \mathrm{~L}$ & $0,10 \mathrm{~L}$ & $0,20 \mathrm{~L}$ & $0,30 \mathrm{~L}$ & $0,40 \mathrm{~L}$ & $0,50 \mathrm{~L}$ \\
\hline Circunferência (cm) & 56,5 & 55,1 & 54,8 & 53,3 & 52,2 & 51,9 \\
\hline & & & Se & & & \\
\hline & 6 & 7 & 8 & 9 & 10 & 11 \\
\hline & $0,60 \mathrm{~L}$ & $0,70 \mathrm{~L}$ & $0,80 \mathrm{~L}$ & $0,90 \mathrm{~L}$ & $0,95 \mathrm{~L}$ & $1,00 \mathrm{~L}$ \\
\hline & 51,5 & 50,5 & 49,4 & 48,3 & - & 47,5 \\
\hline
\end{tabular}

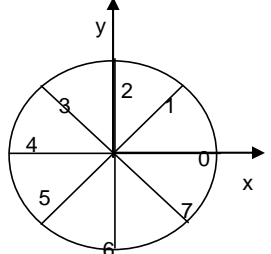

Direções (base)

Observações:

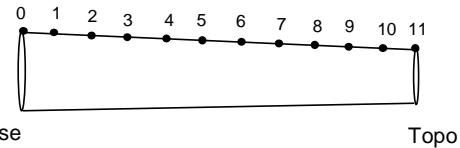

\begin{tabular}{|c|c|c|c|c|c|c|c|c|c|c|c|}
\hline \multirow{2}{*}{ Propriedades } & \multicolumn{11}{|c|}{ Seção } \\
\hline & 0 & $0.1 \mathrm{~L}$ & $0.2 \mathrm{~L}$ & $0.3 \mathrm{~L}$ & $0.4 \mathrm{~L}$ & $0.5 \mathrm{~L}$ & $0.6 \mathrm{~L}$ & $0.7 \mathrm{~L}$ & $0.8 \mathrm{~L}$ & $0.9 \mathrm{~L}$ & $1.0 \mathrm{~L}$ \\
\hline $\mathrm{D}(\mathrm{cm})$ & 17,98 & 17,54 & 17,44 & 16,97 & 16,62 & 16,52 & 16,39 & 16,07 & 15,72 & 15,37 & 15,12 \\
\hline $\mathrm{D}_{\text {méd }}(\mathrm{cm})$ & 17,97 & & & & & & & & & & 15,02 \\
\hline$\Delta_{\text {circ }}$ & $0,1 \%$ & & & & & & & & & & $0,7 \%$ \\
\hline$L / D_{\text {meio }}$ & \multicolumn{11}{|c|}{25,68} \\
\hline $\mathrm{C}$ & \multicolumn{11}{|c|}{$0,7 \%$} \\
\hline$\Delta \mathrm{D}$ & \multicolumn{11}{|c|}{$5,5 \%$} \\
\hline Densidade $\left(\mathrm{kg} / \mathrm{m}^{3}\right)$ & \multicolumn{11}{|c|}{1014,4} \\
\hline
\end{tabular}


Tabela F.28 - Dados da tora 28.

Tora $\mathrm{N}^{0} 28$

Data: $12 / 05 / 2010$

Espécie: Eucalyptus citriodora

\begin{tabular}{|c|c|c|c|c|c|c|}
\hline \multicolumn{3}{|c|}{ Características de crescimento } & Medido & \multicolumn{3}{|c|}{ Limite } \\
\hline \multicolumn{3}{|l|}{ Massa $(\mathrm{kg})$} & 64,35 & \multicolumn{3}{|c|}{-} \\
\hline \multicolumn{3}{|l|}{ Comprimento (cm) } & 417,8 & \multicolumn{3}{|c|}{-} \\
\hline & 83,56 & \multicolumn{3}{|c|}{-} \\
\hline \multirow{5}{*}{ Diâmetros $(\mathrm{cm})$} & Linha de terra $(\mathrm{cm})$ & Topo & Base & \multicolumn{3}{|c|}{-} \\
\hline & $0-4$ & 13,6 & 14,9 & \multicolumn{3}{|c|}{ - } \\
\hline & $1-5$ & 12,5 & 15,6 & \multicolumn{3}{|c|}{-} \\
\hline & $2-6$ & 12,6 & 14,0 & \multicolumn{3}{|c|}{-} \\
\hline & $3-7$ & 12,5 & 14,3 & \multicolumn{3}{|c|}{-} \\
\hline \multirow{2}{*}{ Teor de umidade (\%) } & Topo & Metade & Base & \multicolumn{3}{|c|}{-} \\
\hline & 16,4 & 17,8 & 14,9 & \multicolumn{3}{|c|}{-} \\
\hline \multicolumn{3}{|c|}{ Inclusões contendo casca $(\mathrm{cm})$} & - & \multicolumn{3}{|c|}{0,5} \\
\hline \multicolumn{3}{|c|}{ Madeira comprimida em $5 \mathrm{~cm}(\mathrm{~S} / \mathrm{N})$} & - & \multicolumn{3}{|c|}{ Não } \\
\hline \multirow{2}{*}{\multicolumn{3}{|c|}{ Furos de insetos (mm) }} & 1 & \multicolumn{3}{|c|}{$\leq 2 \mathrm{~mm}$} \\
\hline & & & 20 & \multicolumn{3}{|c|}{$\leq 30 \mathrm{~cm}$} \\
\hline Fendas $(\mathrm{cm})$ & \multicolumn{2}{|l|}{\begin{tabular}{|l|} 
Topo \\
Base
\end{tabular}} & - & \multicolumn{3}{|c|}{$\leq 60 \mathrm{~cm}$} \\
\hline \multirow{2}{*}{ Encurvamento } & \multicolumn{2}{|l|}{\begin{tabular}{|l|} 
Base \\
um plano \\
\end{tabular}} & - & & $\leq 0,8 \%$ & \\
\hline & \multicolumn{2}{|c|}{ dois planos $(\mathrm{S} / \mathrm{N})$} & - & Não & ssar pela & rfície \\
\hline Fibra torcida (m/volta) & & & $2,2 \mathrm{~m} /$ volta & & $23 \mathrm{~m} / \mathrm{vo}$ & \\
\hline Diâmetro desnéc $(\mathrm{cm})$ & Individual & & 4 & & $\leq 5 \mathrm{~cm}$ & \\
\hline Diametro dos nos $(\mathrm{cm})$ & Grupo & & - & & seção ou & \\
\hline & & & Sec & & & \\
\hline & $\mathbf{0}$ & 1 & 2 & 3 & 4 & 5 \\
\hline & $0,00 \mathrm{~L}$ & $0,10 \mathrm{~L}$ & $0,20 \mathrm{~L}$ & $0,30 \mathrm{~L}$ & $0,40 \mathrm{~L}$ & $0,50 \mathrm{~L}$ \\
\hline Circunferência $(\mathrm{cm})$ & 46,2 & 45,1 & 44,5 & 44,5 & 43,5 & 42,7 \\
\hline & & & $\mathrm{Sec}$ & & & \\
\hline & 6 & 7 & 8 & 9 & 10 & 11 \\
\hline & $0,60 \mathrm{~L}$ & $\overline{0,70 L}$ & $0,80 \mathrm{~L}$ & $0,90 \mathrm{~L}$ & $0,95 \mathrm{~L}$ & $1,00 \mathrm{~L}$ \\
\hline & 41,8 & 42,5 & 41,1 & 41,2 & 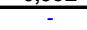 & 39,9 \\
\hline
\end{tabular}

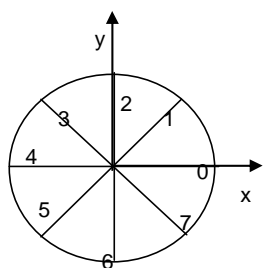

Direções (base)

Observações:

\begin{tabular}{|c|c|c|c|c|c|c|c|c|c|c|c|}
\hline \multirow{2}{*}{ Propriedades } & \multicolumn{11}{|c|}{ Seção } \\
\hline & 0 & $0.1 \mathrm{~L}$ & $0.2 \mathrm{~L}$ & $0.3 \mathrm{~L}$ & $0.4 \mathrm{~L}$ & $0.5 \mathrm{~L}$ & $0.6 \mathrm{~L}$ & $0.7 \mathrm{~L}$ & $0.8 \mathrm{~L}$ & $0.9 \mathrm{~L}$ & $1.0 \mathrm{~L}$ \\
\hline $\mathrm{D}(\mathrm{cm})$ & 14,71 & 14,36 & 14,16 & 14,16 & 13,85 & 13,59 & 13,31 & 13,53 & 13,08 & 13,11 & 12,70 \\
\hline $\mathrm{D}_{\text {méd }}(\mathrm{cm})$ & 14,69 & & & & & & & & & & 12,79 \\
\hline$\Delta_{\text {circ }}$ & $0,1 \%$ & & & & & & & & & & $0,7 \%$ \\
\hline$L / D_{\text {meio }}$ & \multicolumn{11}{|c|}{30,74} \\
\hline C & \multirow{2}{*}{\multicolumn{11}{|c|}{$0,5 \%$}} \\
\hline$\Delta \mathrm{D}$ & \multirow{2}{*}{\multicolumn{11}{|c|}{$\frac{4,5 \%}{1037 ?}$}} \\
\hline Densidade $\left(\mathrm{kg} / \mathrm{m}^{3}\right)$ & & & & & & & & & & & \\
\hline
\end{tabular}


Tabela F.29 - Dados da tora 29.

Tora $\mathrm{N}^{\circ} 29$

\begin{tabular}{|c|c|c|c|c|c|c|}
\hline \multicolumn{3}{|c|}{ Características de crescimento } & Medido & \multicolumn{3}{|c|}{ Limite } \\
\hline \multicolumn{3}{|l|}{ Massa $(\mathrm{kg})$} & 101,4 & \multicolumn{3}{|c|}{-} \\
\hline \multicolumn{3}{|l|}{ Comprimento $(\mathrm{cm})$} & 400,5 & \multicolumn{3}{|c|}{-} \\
\hline \multicolumn{3}{|l|}{ Linha de terra $(\mathrm{cm})$} & 80,1 & \multicolumn{3}{|c|}{-} \\
\hline \multirow{5}{*}{ Diâmetros (cm) } & Direção & Topo & Base & \multicolumn{3}{|c|}{-} \\
\hline & $0-4$ & 15,7 & 19,3 & \multicolumn{3}{|c|}{-} \\
\hline & $1-5$ & 16,1 & 20,2 & \multicolumn{3}{|c|}{-} \\
\hline & $2-6$ & 16,8 & 20,7 & \multicolumn{3}{|c|}{-} \\
\hline & $3-7$ & 16,6 & 19,8 & \multicolumn{3}{|c|}{-} \\
\hline \multirow{2}{*}{ Teor de umidade (\%) } & Topo & Metade & Base & \multicolumn{3}{|c|}{-} \\
\hline & 21,7 & 16,3 & 18,6 & \multicolumn{3}{|c|}{-} \\
\hline & - & \multicolumn{3}{|c|}{0,5} \\
\hline \multirow{2}{*}{\multicolumn{3}{|c|}{$\begin{array}{l}\text { Madeira comprimida em } 5 \mathrm{~cm}(\mathrm{~S} / \mathrm{N}) \\
\text { Furos de insetos }(\mathrm{mm})\end{array}$}} & - & \multicolumn{3}{|c|}{ Não } \\
\hline & & & 1 & \multicolumn{3}{|c|}{$\leq 2 \mathrm{~mm}$} \\
\hline & 5 & \multicolumn{3}{|c|}{$\leq 30 \mathrm{~cm}$} \\
\hline Fendas (cm) & \multicolumn{2}{|l|}{\begin{tabular}{|l|} 
Topo \\
Base \\
\end{tabular}} & 14 & \multirow{2}{*}{\multicolumn{3}{|c|}{$\begin{array}{l}\leq 60 \mathrm{~cm} \\
\leq 0,8 \%\end{array}$}} \\
\hline \multirow{2}{*}{ Encurvamento } & & - & & & \\
\hline & \multicolumn{2}{|c|}{\begin{tabular}{|l|} 
um plano \\
dois planos $(\mathrm{S} / \mathrm{N})$ \\
\end{tabular}} & - & Não & sar pela & erfície \\
\hline Fibra torcida (m/volta) & & & ver obs. & & $3 \mathrm{~m} / \mathrm{vc}$ & \\
\hline Diâmetro dos nós $(\mathrm{cm})$ & Individual & & - & & $\leq 5 \mathrm{~cm}$ & \\
\hline 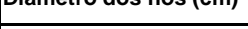 & Grupo & & - & & seção ol & \\
\hline & & & & & & \\
\hline & 0 & 1 & 2 & 3 & 4 & 5 \\
\hline & $0,00 \mathrm{~L}$ & $0,10 \mathrm{~L}$ & $0,20 \mathrm{~L}$ & $0,30 \mathrm{~L}$ & $0,40 \mathrm{~L}$ & $0,50 \mathrm{~L}$ \\
\hline Circunferência $(\mathrm{cm})$ & 63,3 & 62,3 & 60,2 & 51,4 & 58,5 & 57,5 \\
\hline & & & & & & \\
\hline & 6 & 7 & 8 & 9 & 10 & 11 \\
\hline & $0,60 \mathrm{~L}$ & $0,70 \mathrm{~L}$ & $0,80 \mathrm{~L}$ & $0,90 \mathrm{~L}$ & $0,95 \mathrm{~L}$ & $1,00 \mathrm{~L}$ \\
\hline & 56 & 54,6 & 54,3 & 53,4 & - & 52 \\
\hline
\end{tabular}

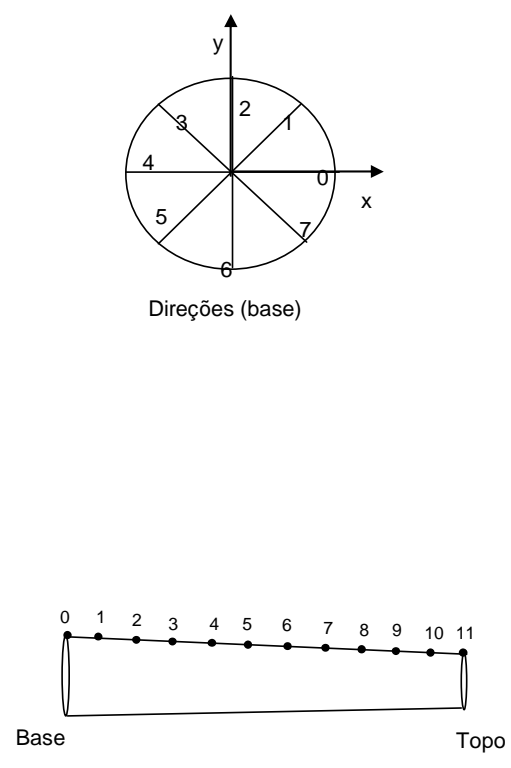

Observações:

Fibras com padrão sinusoidal

\begin{tabular}{|c|c|c|c|c|c|c|c|c|c|c|c|}
\hline \multirow{2}{*}{ Propriedades } & \multicolumn{11}{|c|}{ Seção } \\
\hline & 0 & $0.1 \mathrm{~L}$ & $0.2 \mathrm{~L}$ & $0.3 \mathrm{~L}$ & $0.4 \mathrm{~L}$ & $0.5 \mathrm{~L}$ & $0.6 \mathrm{~L}$ & $\begin{array}{c}0.7 \mathrm{~L} \\
\end{array}$ & $0.8 \mathrm{~L}$ & $0.9 \mathrm{~L}$ & $1.0 \mathrm{~L}$ \\
\hline $\mathrm{D}(\mathrm{cm})$ & 20,15 & 19,83 & 19,16 & 16,36 & 18,62 & 18,30 & 17,83 & 17,38 & 17,28 & 17,00 & 16,55 \\
\hline$D_{\text {méd }}(\mathrm{cm})$ & 19,99 & & & & & & & & & & 16,29 \\
\hline$\Delta_{\text {circ }}$ & $0,8 \%$ & & & & & & & & & & $1,6 \%$ \\
\hline$L / D_{\text {meio }}$ & \multicolumn{11}{|c|}{21,88} \\
\hline C & \multicolumn{11}{|c|}{$0,9 \%$} \\
\hline$\Delta \mathrm{D}$ & \multirow{2}{*}{\multicolumn{11}{|c|}{$7,1 \%$}} \\
\hline Densidade $\left(\mathrm{kg} / \mathrm{m}^{3}\right)$ & & \multicolumn{10}{|c|}{975,9} \\
\hline
\end{tabular}


Tabela F.30 - Dados da tora 30.

Tora $\mathrm{N}^{\circ} 30$

Data: $19 / 05 / 2010$

Espécie: Eucalyptus citriodora

\begin{tabular}{|c|c|c|c|c|c|c|}
\hline \multicolumn{3}{|c|}{ Características de crescimento } & Medido & \multicolumn{3}{|c|}{ Limite } \\
\hline \multicolumn{3}{|l|}{ Massa (kg) } & 76,35 & \multicolumn{3}{|c|}{-} \\
\hline \multicolumn{3}{|l|}{ Comprimento (cm) } & 424,5 & \multicolumn{3}{|c|}{-} \\
\hline & 84,9 & \multicolumn{3}{|c|}{-} \\
\hline \multirow{5}{*}{ Diâmetros (cm) } & Linha de terra $(\mathrm{cm})$ & Topo & Base & \multicolumn{3}{|c|}{-} \\
\hline & $0-4$ & 14,7 & 16,5 & \multicolumn{3}{|c|}{-} \\
\hline & $1-5$ & 15,7 & 16,2 & \multicolumn{3}{|c|}{-} \\
\hline & $2-6$ & 14,3 & 16,1 & \multicolumn{3}{|c|}{-} \\
\hline & $3-7$ & 15,2 & 16,0 & \multicolumn{3}{|c|}{-} \\
\hline \multirow{2}{*}{ Teor de umidade (\%) } & Topo & Metade & Base & \multicolumn{3}{|c|}{-} \\
\hline & 13,4 & 12,0 & 12,6 & \multicolumn{3}{|c|}{-} \\
\hline & - & \multicolumn{3}{|c|}{0,5} \\
\hline \multicolumn{3}{|c|}{ Madeira comprimida em $5 \mathrm{~cm}(\mathrm{~S} / \mathrm{N})$} & - & \multicolumn{3}{|c|}{ Não } \\
\hline \multicolumn{3}{|c|}{ Furos de insetos (mm) } & 1 & \multicolumn{3}{|c|}{$\leq 2 \mathrm{~mm}$} \\
\hline \multirow{2}{*}{ Fendas $(\mathrm{cm})$} & \multirow{2}{*}{\multicolumn{2}{|c|}{\begin{tabular}{|l|} 
Topo \\
Base \\
\end{tabular}}} & 12 & \multicolumn{3}{|c|}{$\leq 30 \mathrm{~cm}$} \\
\hline & & & 15 & \multicolumn{3}{|c|}{$\leq 60 \mathrm{~cm}$} \\
\hline \multirow{2}{*}{ Encurvamento } & & $1,1 \%$ & \multicolumn{3}{|c|}{$\leq 0,8 \%$} \\
\hline & dois plano & $(\mathrm{S} / \mathrm{N})$ & - & Não & sar pela & rfície \\
\hline Fibra torcida (m/volta) & & & - & & $3 \mathrm{~m} / \mathrm{v}$ & \\
\hline Diâmetro dos nós $(\mathrm{cm})$ & Individual & & 9 & & $\leq 5 \mathrm{~cm}$ & \\
\hline 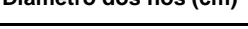 & Grupo & & - & & seção ol & \\
\hline & & & & & & \\
\hline & 0 & 1 & 2 & 3 & 4 & 5 \\
\hline & $0,00 \mathrm{~L}$ & $0,10 \mathrm{~L}$ & $0,20 \mathrm{~L}$ & $0,30 \mathrm{~L}$ & $0,40 \mathrm{~L}$ & $0,50 \mathrm{~L}$ \\
\hline Circunferência $(\mathrm{cm})$ & 51,7 & 52,2 & 52,0 & 53,8 & 49,5 & 52,6 \\
\hline & & & & & & \\
\hline & 6 & 7 & 8 & 9 & 10 & 11 \\
\hline & $0,60 \mathrm{~L}$ & $0,70 \mathrm{~L}$ & $0,80 \mathrm{~L}$ & $0,90 \mathrm{~L}$ & $0,95 \mathrm{~L}$ & $1,00 \mathrm{~L}$ \\
\hline & 47,8 & 46,3 & 49,3 & 45,4 & - & 46,5 \\
\hline
\end{tabular}

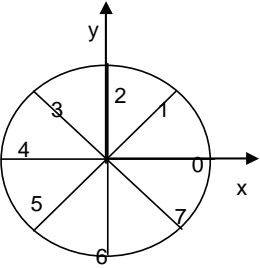

Direções (base)

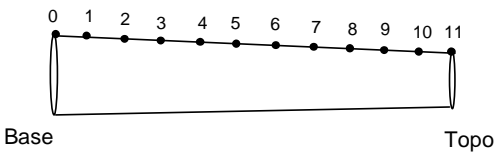

Observações:

Topo: excentricidade de $1.3 \mathrm{~cm}$ na direção $2-6$

\begin{tabular}{|c|c|c|c|c|c|c|c|c|c|c|c|}
\hline \multirow{2}{*}{ Propriedades } & \multicolumn{11}{|c|}{ Secão } \\
\hline & 0 & $0.1 \mathrm{~L}$ & $0.2 \mathrm{~L}$ & $0.3 \mathrm{~L}$ & $0.4 \mathrm{~L}$ & $0.5 \mathrm{~L}$ & $0.6 \mathrm{~L}$ & $0.7 \mathrm{~L}$ & $0.8 \mathrm{~L}$ & $0.9 \mathrm{~L}$ & $1.0 \mathrm{~L}$ \\
\hline $\mathrm{D}(\mathrm{cm})$ & 16,46 & 16,62 & 16,55 & 17,13 & 15,76 & 16,74 & 15,22 & 14,74 & 15,69 & 14,45 & 14,80 \\
\hline $\mathrm{D}_{\text {méd }}(\mathrm{cm})$ & 16,20 & & & & & & & & & & 14,97 \\
\hline$\Delta_{\text {circ }}$ & $1,6 \%$ & & & & & & & & & & $1,1 \%$ \\
\hline$L / D_{\text {meio }}$ & \multicolumn{11}{|c|}{25,35} \\
\hline $\mathrm{C}$ & \multirow{2}{*}{\multicolumn{11}{|c|}{$\frac{0,3 \%}{5.9 \%}$}} \\
\hline$\Delta \mathrm{D}$ & & & & & & & & & & & \\
\hline Densidade $\left(\mathrm{kg} / \mathrm{m}^{3}\right)$ & \multicolumn{11}{|c|}{942,6} \\
\hline
\end{tabular}


Tabela F.31 - Dados da tora 31.

Tora $\mathrm{N}^{0} 31$

Data: $20 / 05 / 2010$

Espécie: Eucalyptus citriodora

\begin{tabular}{|c|c|c|c|c|c|c|}
\hline \multicolumn{3}{|c|}{ Características de crescimento } & Medido & \multicolumn{3}{|c|}{ Limite } \\
\hline \multicolumn{3}{|l|}{ Massa $(\mathrm{kg})$} & 82,9 & \multicolumn{3}{|c|}{ - } \\
\hline \multicolumn{3}{|l|}{ Comprimento $(\mathrm{cm})$} & 431 & \multicolumn{3}{|c|}{-} \\
\hline \multicolumn{3}{|l|}{ Linha de terra $(\mathrm{cm})$} & 86,2 & \multicolumn{3}{|c|}{-} \\
\hline \multirow{5}{*}{ Diâmetros (cm) } & Direção & Topo & Base & \multicolumn{3}{|c|}{-} \\
\hline & $0-4$ & 14,7 & 17,5 & \multicolumn{3}{|c|}{-} \\
\hline & $1-5$ & 14,2 & 17,4 & \multicolumn{3}{|c|}{-} \\
\hline & $2-6$ & 14,2 & 18,0 & \multicolumn{3}{|c|}{-} \\
\hline & $3-7$ & 14,7 & 18,0 & \multicolumn{3}{|c|}{-} \\
\hline \multirow{2}{*}{ Teor de umidade (\%) } & Topo & Metade & Base & \multicolumn{3}{|c|}{-} \\
\hline & 17,4 & 17,5 & 15,4 & \multicolumn{3}{|c|}{ - } \\
\hline & - & \multicolumn{3}{|c|}{0,5} \\
\hline \multicolumn{3}{|c|}{ Madeira comprimida em $5 \mathrm{~cm}(\mathrm{~S} / \mathrm{N})$} & - & \multicolumn{3}{|c|}{ Não } \\
\hline \multicolumn{3}{|c|}{ Furos de insetos $(\mathrm{mm})$} & 1 & \multicolumn{3}{|c|}{$\leq 2 \mathrm{~mm}$} \\
\hline \multirow{2}{*}{ Fendas $(\mathrm{cm})$} & \multirow{2}{*}{\multicolumn{2}{|c|}{\begin{tabular}{|l|} 
Topo \\
Base \\
\end{tabular}}} & - & \multicolumn{3}{|c|}{$\leq 30 \mathrm{~cm}$} \\
\hline & & & 15 & \multicolumn{3}{|c|}{$\leq 60 \mathrm{~cm}$} \\
\hline \multirow{2}{*}{ Encurvamento } & & $0,7 \%$ & \multicolumn{3}{|c|}{$\leq 0,8 \%$} \\
\hline & dois plano & $(\mathrm{S} / \mathrm{N})$ & - & Não & sar pela & Ifície \\
\hline Fibra torcida (m/volta) & & & - & & $3 \mathrm{~m} / \mathrm{vc}$ & \\
\hline & Individual & & - & & $\leq 5 \mathrm{~cm}$ & \\
\hline Dlametro dos nos (cm) & Grupo & & - & & seção ol & \\
\hline & & & & & & \\
\hline & 0 & 1 & 2 & 3 & 4 & 5 \\
\hline & $0,00 \mathrm{~L}$ & $0,10 \mathrm{~L}$ & $0,20 \mathrm{~L}$ & $0,30 \mathrm{~L}$ & $0,40 \mathrm{~L}$ & $0,50 \mathrm{~L}$ \\
\hline Circunferência (cm) & 56,1 & 56,3 & 51,0 & 50 & 49,6 & 49,3 \\
\hline & & & & & & \\
\hline & 6 & 7 & 8 & 9 & 10 & 11 \\
\hline & $0,60 \mathrm{~L}$ & $0,70 \mathrm{~L}$ & $0,80 \mathrm{~L}$ & $0,90 \mathrm{~L}$ & $0,95 \mathrm{~L}$ & $1,00 \mathrm{~L}$ \\
\hline & 47,5 & 47,0 & 46,5 & 45,8 & - & 46 \\
\hline
\end{tabular}

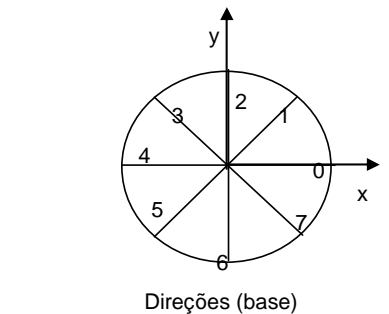

Observações:
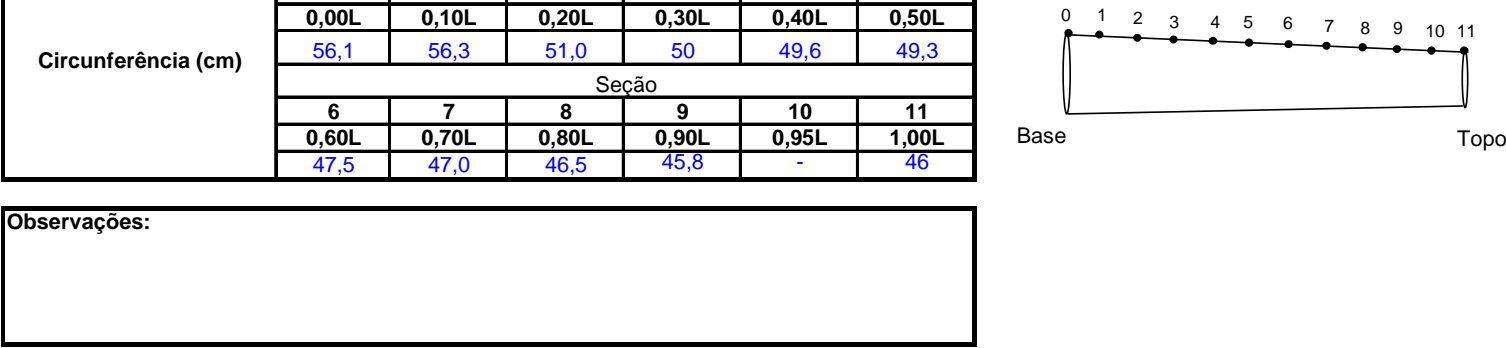

\begin{tabular}{|c|c|c|c|c|c|c|c|c|c|c|c|}
\hline \multirow{2}{*}{ Propriedades } & \multicolumn{11}{|c|}{ Secão } \\
\hline & 0 & $0.1 \mathrm{~L}$ & $0.2 \mathrm{~L}$ & $0.3 \mathrm{~L}$ & $0.4 \mathrm{~L}$ & $0.5 \mathrm{~L}$ & $0.6 \mathrm{~L}$ & $0.7 \mathrm{~L}$ & $0.8 \mathrm{~L}$ & $0.9 \mathrm{~L}$ & $1.0 \mathrm{~L}$ \\
\hline $\mathrm{D}(\mathrm{cm})$ & 17,86 & 17,92 & 16,23 & 15,92 & 15,79 & 15,69 & 15,12 & 14,96 & 14,80 & 14,58 & 14,64 \\
\hline$D_{\text {méd }}(\mathrm{cm})$ & 17,72 & & & & & & & & & & 14,45 \\
\hline$\Delta_{\text {circ }}$ & $0,8 \%$ & & & & & & & & & & $1,3 \%$ \\
\hline$L / D_{\text {meio }}$ & \multicolumn{11}{|c|}{27,47} \\
\hline C & \multirow{2}{*}{\multicolumn{11}{|c|}{$\begin{array}{l}0,8 \% \\
7,5 \% \\
\end{array}$}} \\
\hline$\Delta \mathrm{D}$ & & & & & & & & & & & \\
\hline Densidade $\left(\mathrm{kg} / \mathrm{m}^{3}\right)$ & \multicolumn{11}{|c|}{943,3} \\
\hline
\end{tabular}


Tabela F. 32 - Dados da tora 32.

Tora $\mathrm{N}^{0} 32$

Data: 20/05/2010

Espécie: Eucalyptus citriodora

\begin{tabular}{|c|c|c|c|c|c|c|}
\hline \multicolumn{3}{|c|}{ Características de crescimento } & Medido & \multicolumn{3}{|c|}{ Limite } \\
\hline \multicolumn{3}{|l|}{ Massa (kg) } & 118,85 & \multicolumn{3}{|c|}{-} \\
\hline \multicolumn{3}{|l|}{ Comprimento (cm) } & 440,8 & \multicolumn{3}{|c|}{-} \\
\hline \multicolumn{3}{|l|}{ Linha de terra $(\mathrm{cm})$} & 88,16 & \multicolumn{3}{|c|}{-} \\
\hline \multirow{5}{*}{ Diâmetros (cm) } & Direção & Topo & Base & \multicolumn{3}{|c|}{-} \\
\hline & $0-4$ & 17,2 & 19,2 & \multicolumn{3}{|c|}{-} \\
\hline & $1-5$ & 17,1 & 19,4 & \multicolumn{3}{|c|}{-} \\
\hline & $2-6$ & 16,7 & 18,3 & \multicolumn{3}{|c|}{-} \\
\hline & $3-7$ & 17,0 & 19,2 & \multicolumn{3}{|c|}{-} \\
\hline \multirow{2}{*}{ Teor de umidade (\%) } & Topo & Metade & Base & \multicolumn{3}{|c|}{-} \\
\hline & 15,1 & 16,2 & 14,3 & \multicolumn{3}{|c|}{-} \\
\hline \multicolumn{3}{|c|}{ Inclusões contendo casca $(\mathbf{c m})$} & - & \multicolumn{3}{|c|}{0,5} \\
\hline \multirow{2}{*}{\multicolumn{3}{|c|}{\begin{tabular}{|l} 
Madeira comprimida em $5 \mathrm{~cm}(\mathrm{~S} / \mathrm{N})$ \\
Furos de insetos $(\mathrm{mm})$
\end{tabular}}} & - & \multicolumn{3}{|c|}{ Não } \\
\hline & & & 1 & \multicolumn{3}{|c|}{$\leq 2 \mathrm{~mm}$} \\
\hline \multirow{2}{*}{ Fendas (cm) } & \multirow{2}{*}{\multicolumn{2}{|c|}{ Topo }} & 23 & \multicolumn{3}{|c|}{$\leq 30 \mathrm{~cm}$} \\
\hline & Base & & 11 & \multicolumn{3}{|c|}{$\leq 60 \mathrm{~cm}$} \\
\hline Fncurvamento & \multirow{2}{*}{\multicolumn{2}{|c|}{\begin{tabular}{|l|} 
um plano \\
dois planos $(\mathrm{S} / \mathrm{N})$ \\
\end{tabular}}} & $0,7 \%$ & \multicolumn{3}{|c|}{$\leq 0,8 \%$} \\
\hline Encurvamento & & & - & Não & ssar pela & Iffície \\
\hline Fibra torcida (m/volta) & & & - & & $\geq 3 \mathrm{~m} / \mathrm{vc}$ & \\
\hline Diâmetro dos nós $(\mathrm{cm})$ & Individual & & 5 & & $\leq 5 \mathrm{~cm}$ & \\
\hline Diametro dos nos (cm) & Grupo & & - & & seção ol & \\
\hline & & & & & & \\
\hline & 0 & 1 & 2 & 3 & 4 & 5 \\
\hline & $0,00 \mathrm{~L}$ & $0,10 \mathrm{~L}$ & $0,20 \mathrm{~L}$ & $0,30 \mathrm{~L}$ & $0,40 \mathrm{~L}$ & $0,50 \mathrm{~L}$ \\
\hline Circunferência $(\mathrm{cm})$ & 60,2 & 58,8 & 57,6 & 56,9 & 56,5 & 55,7 \\
\hline & & & & & & \\
\hline & 6 & 7 & 8 & 9 & 10 & 11 \\
\hline & $0,60 \mathrm{~L}$ & $0,70 \mathrm{~L}$ & $0,80 \mathrm{~L}$ & $0,90 \mathrm{~L}$ & $0,95 \mathrm{~L}$ & $1,00 \mathrm{~L}$ \\
\hline & 55,1 & 55,3 & 53,8 & 53,3 & - & 53,7 \\
\hline
\end{tabular}

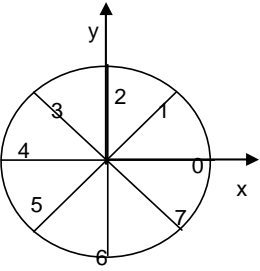

Direções (base)

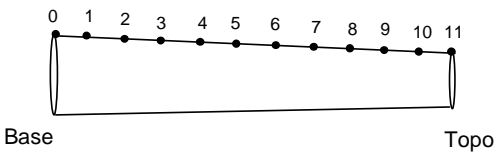

Observações:

\begin{tabular}{|c|c|c|c|c|c|c|c|c|c|c|c|}
\hline \multirow{2}{*}{ Propriedades } & \multicolumn{11}{|c|}{ Seção } \\
\hline & 0 & $0.1 \mathrm{~L}$ & $\begin{array}{c}0.2 \mathrm{~L} \\
\end{array}$ & $0.3 \mathrm{~L}$ & $0.4 \mathrm{~L}$ & $0.5 \mathrm{~L}$ & $0.6 \mathrm{~L}$ & $\begin{array}{c}0.7 \mathrm{~L} \\
\end{array}$ & $\begin{array}{c}0.8 \mathrm{~L} \\
\end{array}$ & $0.9 \mathrm{~L}$ & $\begin{array}{l}1.0 \mathrm{~L} \\
\end{array}$ \\
\hline $\mathrm{D}(\mathrm{cm})$ & 19,16 & 18,72 & 18,33 & 18,11 & 17,98 & 17,73 & 17,54 & 17,60 & 17,13 & 16,97 & 17,09 \\
\hline $\mathrm{D}_{\text {méd }}(\mathrm{cm})$ & 19,02 & & & & & & & & & & 17,00 \\
\hline$\Delta_{\text {circ }}$ & $0,7 \%$ & & & & & & & & & & $0,6 \%$ \\
\hline$L / D_{\text {meio }}$ & \multicolumn{11}{|c|}{24,86} \\
\hline $\mathrm{C}$ & \multicolumn{11}{|c|}{$0,5 \%$} \\
\hline$\Delta \mathrm{D}$ & \multirow{2}{*}{\multicolumn{11}{|c|}{$3,9 \%$}} \\
\hline Densidade $\left(\mathrm{kg} / \mathrm{m}^{3}\right)$ & & \multicolumn{10}{|c|}{1057,3} \\
\hline
\end{tabular}


Tabela F.33 - Dados da tora 33.

Tora $\mathrm{N}^{\circ} 33$

\begin{tabular}{|c|c|c|c|c|c|c|}
\hline \multicolumn{3}{|c|}{ Características de crescimento } & Medido & \multicolumn{3}{|c|}{ Limite } \\
\hline \multicolumn{3}{|l|}{ Massa (kg) } & 85,4 & \multicolumn{3}{|c|}{-} \\
\hline \multicolumn{3}{|l|}{ Comprimento (cm) } & 412,5 & \multicolumn{3}{|c|}{-} \\
\hline \multicolumn{3}{|l|}{ Linha de terra $(\mathrm{cm})$} & 82,5 & \multicolumn{3}{|c|}{-} \\
\hline \multirow{5}{*}{ Diâmetros (cm) } & Direção & Topo & Base & \multicolumn{3}{|c|}{-} \\
\hline & $0-4$ & 14,4 & 19,9 & \multicolumn{3}{|c|}{-} \\
\hline & $1-5$ & 14,5 & 17,4 & \multicolumn{3}{|c|}{-} \\
\hline & $2-6$ & 14,1 & 15,3 & \multicolumn{3}{|c|}{-} \\
\hline & $3-7$ & 13,9 & 16,5 & \multicolumn{3}{|c|}{-} \\
\hline \multirow{2}{*}{ Teor de umidade (\%) } & Topo & Metade & Base & \multicolumn{3}{|c|}{-} \\
\hline & 14,5 & 15,5 & 15,5 & \multicolumn{3}{|c|}{-} \\
\hline \multicolumn{3}{|c|}{ Inclusões contendo casca $(\mathrm{cm})$} & - & \multicolumn{3}{|c|}{0,5} \\
\hline \multirow{2}{*}{\multicolumn{3}{|c|}{$\begin{array}{l}\text { Madeira comprimida em } 5 \mathrm{~cm}(\mathrm{~S} / \mathrm{N}) \\
\text { Furos de insetos }(\mathrm{mm})\end{array}$}} & - & \multicolumn{3}{|c|}{ Não } \\
\hline & & & 1 & \multicolumn{3}{|c|}{$\leq 2 \mathrm{~mm}$} \\
\hline \multirow{2}{*}{ Fendas (cm) } & \multirow{2}{*}{\multicolumn{2}{|c|}{\begin{tabular}{|l|} 
Topo \\
Base \\
\end{tabular}}} & 24 & \multicolumn{3}{|c|}{$\leq 30 \mathrm{~cm}$} \\
\hline & & & - & \multicolumn{3}{|c|}{$\leq 60 \mathrm{~cm}$} \\
\hline \multirow{2}{*}{ Encurvamento } & \multirow{2}{*}{\multicolumn{2}{|c|}{\begin{tabular}{|l|} 
um plano \\
dois planos $(\mathrm{S} / \mathrm{N})$ \\
\end{tabular}}} & $0,8 \%$ & & $\leq 0,8 \%$ & \\
\hline & & & - & Não & sar pela & erfície \\
\hline Fibra torcida (m/volta) & & & ver obs. & & $3 \mathrm{~m} / \mathrm{vo}$ & \\
\hline Diâmetro dos nós $(\mathrm{cm})$ & Individual & & 15 & & $\leq 5 \mathrm{~cm}$ & \\
\hline Diametro dos nos (cm) & Grupo & & - & & seção ou & \\
\hline & & & & & & \\
\hline & 0 & 1 & 2 & 3 & 4 & 5 \\
\hline & $0,00 \mathrm{~L}$ & $0,10 \mathrm{~L}$ & $0,20 \mathrm{~L}$ & $0,30 \mathrm{~L}$ & $0,40 \mathrm{~L}$ & $0,50 \mathrm{~L}$ \\
\hline Circunferência $(\mathrm{cm})$ & 55,7 & 54,3 & 52,7 & 52,1 & 52,8 & 51,8 \\
\hline & & & & & & \\
\hline & 6 & 7 & 8 & 9 & 10 & 11 \\
\hline & $0,60 \mathrm{~L}$ & $0,70 \mathrm{~L}$ & $0,80 \mathrm{~L}$ & $0,90 \mathrm{~L}$ & $0,95 \mathrm{~L}$ & $1,00 \mathrm{~L}$ \\
\hline & 49,9 & 48,4 & 47,4 & 46,2 & - & 45,3 \\
\hline
\end{tabular}

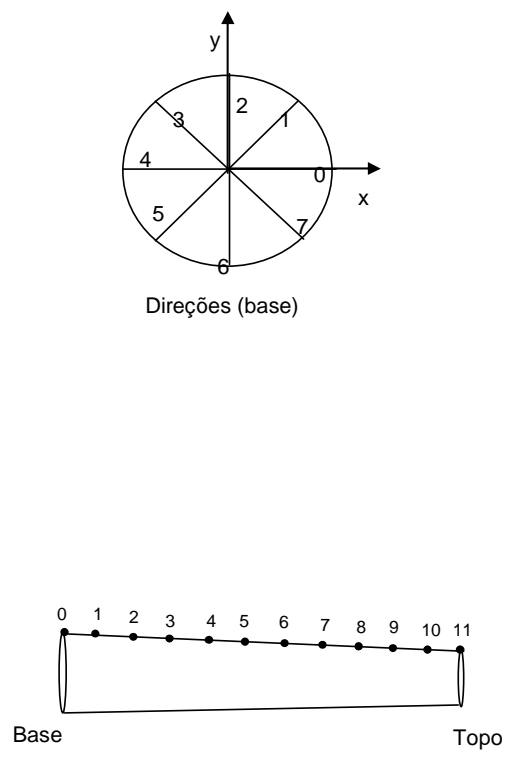

Observações:

Excentricidade na base: 3,5 cm na direção 0-4 e 1,8 cm na direção 2-6

Fibras com padrão sinusoidal

\begin{tabular}{|c|c|c|c|c|c|c|c|c|c|c|c|}
\hline \multirow{2}{*}{ Propriedades } & \multicolumn{11}{|c|}{ Seção } \\
\hline & 0 & $0.1 \mathrm{~L}$ & $0.2 \mathrm{~L}$ & $0.3 \mathrm{~L}$ & $0.4 \mathrm{~L}$ & $0.5 \mathrm{~L}$ & $0.6 \mathrm{~L}$ & $0.7 \mathrm{~L}$ & $0.8 \mathrm{~L}$ & $0.9 \mathrm{~L}$ & $1.0 \mathrm{~L}$ \\
\hline $\mathrm{D}(\mathrm{cm})$ & 17,73 & 17,28 & 16,77 & 16,58 & 16,81 & 16,49 & 15,88 & 15,41 & 15,09 & 14,71 & 14,42 \\
\hline$D_{\text {méd }}(\mathrm{cm})$ & 17,19 & & & & & & & & & & 14,22 \\
\hline$\Delta_{\text {circ }}$ & $3,1 \%$ & & & & & & & & & & $1,4 \%$ \\
\hline$L / D_{\text {meio }}$ & \multicolumn{11}{|c|}{25,02} \\
\hline C & \multicolumn{11}{|c|}{$0,7 \%$} \\
\hline$\Delta \mathrm{D}$ & \multicolumn{11}{|c|}{$6,7 \%$} \\
\hline Densidade $\left(\mathrm{kg} / \mathrm{m}^{3}\right)$ & \multicolumn{11}{|c|}{1065,0} \\
\hline
\end{tabular}


Tabela F.34 - Dados da tora 34.

Tora $\mathrm{N}^{0} 34$

Data: 25/05/2010

Espécie: Eucalyptus citriodora

\begin{tabular}{|c|c|c|c|c|c|c|}
\hline \multicolumn{3}{|c|}{ Características de crescimento } & Medido & \multicolumn{3}{|c|}{ Limite } \\
\hline \multicolumn{3}{|l|}{ Massa (kg) } & 84,95 & \multicolumn{3}{|c|}{ - } \\
\hline \multicolumn{3}{|l|}{ Comprimento (cm) } & 409 & \multicolumn{3}{|c|}{-} \\
\hline \multicolumn{3}{|l|}{ Linha de terra $(\mathrm{cm})$} & 81,8 & \multicolumn{3}{|c|}{-} \\
\hline \multirow{5}{*}{ Diâmetros (cm) } & Direção & Topo & Base & \multicolumn{3}{|c|}{-} \\
\hline & $0-4$ & 15,0 & 19,5 & \multicolumn{3}{|c|}{-} \\
\hline & $1-5$ & 14,6 & 18,5 & \multicolumn{3}{|c|}{-} \\
\hline & $2-6$ & 14,5 & 18,5 & \multicolumn{3}{|c|}{-} \\
\hline & $3-7$ & 14,9 & 18,1 & \multicolumn{3}{|c|}{-} \\
\hline \multirow{2}{*}{ Teor de umidade (\%) } & Topo & Metade & Base & \multicolumn{3}{|c|}{-} \\
\hline & 14,3 & 16,5 & 15,7 & \multicolumn{3}{|c|}{-} \\
\hline \multicolumn{3}{|c|}{ Inclusões contendo casca $(\mathbf{c m})$} & - & \multicolumn{3}{|c|}{0,5} \\
\hline Madeira comprimida em & $\mathrm{cm} \mathrm{(S/N)}$ & & - & \multicolumn{3}{|c|}{ Não } \\
\hline \multicolumn{3}{|l|}{ Furos de insetos (mm) } & 1 & \multicolumn{3}{|c|}{$\leq 2 \mathrm{~mm}$} \\
\hline \multirow{2}{*}{ Fendas (cm) } & \multirow{2}{*}{\multicolumn{2}{|c|}{ Topo }} & 23 & \multicolumn{3}{|c|}{$\leq 30 \mathrm{~cm}$} \\
\hline & & & - & \multicolumn{3}{|c|}{$\leq 60 \mathrm{~cm}$} \\
\hline Fncurvamento & \multirow{2}{*}{\multicolumn{2}{|c|}{\begin{tabular}{|l|} 
um plano \\
dois planos $(\mathrm{S} / \mathrm{N})$ \\
\end{tabular}}} & $0,2 \%$ & \multicolumn{3}{|c|}{$\leq 0,8 \%$} \\
\hline Encurvamento & & & - & Não & ssar pela & Iffície \\
\hline Fibra torcida (m/volta) & & & - & & $\geq 3 \mathrm{~m} / \mathrm{vc}$ & \\
\hline Diâmetro dos nós $(\mathrm{cm})$ & Individual & & - & & $\leq 5 \mathrm{~cm}$ & \\
\hline Diametro dos nos (cm) & Grupo & & - & & seção ol & \\
\hline & & & & & & \\
\hline & 0 & 1 & 2 & 3 & 4 & 5 \\
\hline & $0,00 \mathrm{~L}$ & $0,10 \mathrm{~L}$ & $0,20 \mathrm{~L}$ & $0,30 \mathrm{~L}$ & $0,40 \mathrm{~L}$ & $0,50 \mathrm{~L}$ \\
\hline Circunferência $(\mathrm{cm})$ & 58,7 & 53,6 & 51,4 & 50,5 & 49,7 & 49,0 \\
\hline & & & & & & \\
\hline & 6 & 7 & 8 & 9 & 10 & 11 \\
\hline & $0,60 \mathrm{~L}$ & $0,70 \mathrm{~L}$ & $0,80 \mathrm{~L}$ & $0,90 \mathrm{~L}$ & $0,95 \mathrm{~L}$ & $1,00 \mathrm{~L}$ \\
\hline & 48,4 & 48,1 & 47,0 & 46,7 & - & 47,1 \\
\hline
\end{tabular}

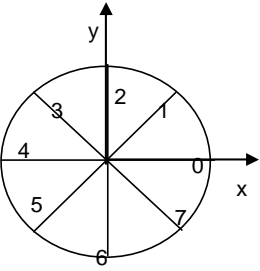

Direções (base)

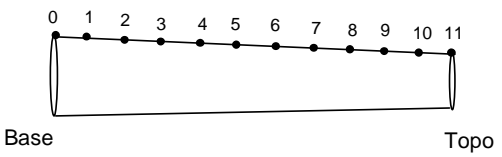

Observações:

\begin{tabular}{|c|c|c|c|c|c|c|c|c|c|c|c|}
\hline \multirow{2}{*}{ Propriedades } & \multicolumn{11}{|c|}{ Seção } \\
\hline & 0 & $0.1 \mathrm{~L}$ & $\begin{array}{c}0.2 \mathrm{~L} \\
\end{array}$ & $0.3 \mathrm{~L}$ & $0.4 \mathrm{~L}$ & $0.5 \mathrm{~L}$ & $0.6 \mathrm{~L}$ & $\begin{array}{c}0.7 \mathrm{~L} \\
\end{array}$ & $\begin{array}{c}0.8 \mathrm{~L} \\
\end{array}$ & $\begin{array}{c}0.9 \mathrm{~L} \\
\end{array}$ & $\begin{array}{l}1.0 \mathrm{~L} \\
\end{array}$ \\
\hline $\mathrm{D}(\mathrm{cm})$ & 18,68 & 17,06 & 16,36 & 16,07 & 15,82 & 15,60 & 15,41 & 15,31 & 14,96 & 14,87 & 14,99 \\
\hline$D_{\text {méd }}(\mathrm{cm})$ & 18,64 & & & & & & & & & & 14,75 \\
\hline$\Delta_{\text {circ }}$ & $0,2 \%$ & & & & & & & & & & $1,7 \%$ \\
\hline$L / D_{\text {meio }}$ & \multicolumn{11}{|c|}{26,22} \\
\hline C & \multicolumn{11}{|c|}{$\frac{1,0 \%}{7,1 \%}$} \\
\hline$\Delta \mathrm{D}$ & \multirow{2}{*}{\multicolumn{11}{|c|}{$\frac{7,1 \%}{944,4}$}} \\
\hline Densidade $\left(\mathrm{kg} / \mathrm{m}^{3}\right)$ & & & & & & & & & & & \\
\hline
\end{tabular}


Tabela F.35 - Dados da tora 35.

Tora $\mathrm{N}^{\circ} 35$

Data: $25 / 05 / 2010$

Espécie: Eucalyptus citriodora

\begin{tabular}{|c|c|c|c|c|c|c|}
\hline \multicolumn{3}{|c|}{ Características de crescimento } & Medido & \multicolumn{3}{|c|}{ Limite } \\
\hline \multicolumn{3}{|l|}{ Massa (kg) } & 109,95 & \multicolumn{3}{|c|}{-} \\
\hline \multicolumn{3}{|l|}{ Comprimento (cm) } & 404,9 & \multicolumn{3}{|c|}{-} \\
\hline \multicolumn{3}{|l|}{ Linha de terra $(\mathrm{cm})$} & 80,98 & \multicolumn{3}{|c|}{-} \\
\hline \multirow{5}{*}{ Diâmetros $(\mathrm{cm})$} & Direção & Topo & Base & \multicolumn{3}{|c|}{-} \\
\hline & $0-4$ & 17,6 & 19,8 & \multicolumn{3}{|c|}{-} \\
\hline & $1-5$ & 18,4 & 19,4 & \multicolumn{3}{|c|}{-} \\
\hline & $2-6$ & 18,0 & 22,0 & \multicolumn{3}{|c|}{-} \\
\hline & $3-7$ & 17,2 & 21,6 & \multicolumn{3}{|c|}{-} \\
\hline \multirow{2}{*}{ Teor de umidade (\%) } & Topo & Metade & Base & \multicolumn{3}{|c|}{-} \\
\hline & 14,7 & 13,8 & 15,2 & \multicolumn{3}{|c|}{-} \\
\hline \multicolumn{3}{|c|}{ Inclusões contendo casca $(\mathrm{cm})$} & - & \multicolumn{3}{|c|}{0,5} \\
\hline \multirow{2}{*}{\multicolumn{3}{|c|}{ Madeira comprimida em $5 \mathrm{~cm}(\mathrm{~S} / \mathrm{N})$}} & - & \multicolumn{3}{|c|}{ Não } \\
\hline & \multicolumn{2}{|c|}{ Furos de insetos (mm) } & 1 & \multicolumn{3}{|c|}{$\leq 2 \mathrm{~mm}$} \\
\hline \multirow{2}{*}{ Fendas $(\mathrm{cm})$} & \multirow{2}{*}{\multicolumn{2}{|c|}{\begin{tabular}{|l|} 
Topo \\
Base \\
\end{tabular}}} & - & \multicolumn{3}{|c|}{$\leq 30 \mathrm{~cm}$} \\
\hline & & & 18 & \multicolumn{3}{|c|}{$\leq 60 \mathrm{~cm}$} \\
\hline \multirow{2}{*}{ Encurvamento } & \multirow{2}{*}{\multicolumn{2}{|c|}{\begin{tabular}{|l|} 
um plano \\
dois planos $(\mathrm{S} / \mathrm{N})$ \\
\end{tabular}}} & $1,1 \%$ & & $\leq 0,8 \%$ & \\
\hline & & & - & Não & sar pela & Ifície \\
\hline Fibra torcida (m/volta) & & & - & & $3 \mathrm{~m} / \mathrm{vc}$ & \\
\hline Diâmetro dos nós $(\mathrm{cm})$ & Individual & & - & & $\leq 5 \mathrm{~cm}$ & \\
\hline 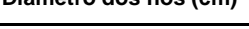 & Grupo & & - & & seção ol & \\
\hline & & & & & & \\
\hline & 0 & 1 & 2 & 3 & 4 & 5 \\
\hline & $0,00 \mathrm{~L}$ & $0,10 \mathrm{~L}$ & $0,20 \mathrm{~L}$ & $0,30 \mathrm{~L}$ & $0,40 \mathrm{~L}$ & $0,50 \mathrm{~L}$ \\
\hline Circunferência (cm) & 65,5 & 63,0 & 60,7 & 60,9 & 59,7 & 57,8 \\
\hline & & & & & & \\
\hline & 6 & 7 & 8 & 9 & 10 & 11 \\
\hline & $0,60 \mathrm{~L}$ & $0,70 \mathrm{~L}$ & $0,80 \mathrm{~L}$ & $0,90 \mathrm{~L}$ & $0,95 \mathrm{~L}$ & $1,00 \mathrm{~L}$ \\
\hline & 56,5 & 56,3 & 55,3 & 56,1 & - & 59,4 \\
\hline
\end{tabular}

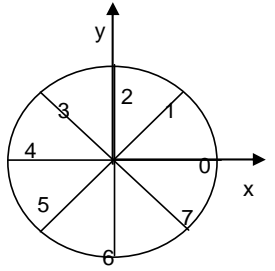

Direções (base)

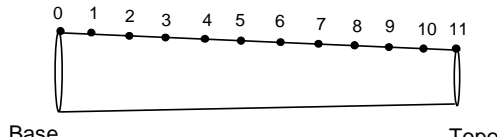

Observações:

Excentricidade: $0,5 \mathrm{~cm}$ na base na direção 2-6

\begin{tabular}{|c|c|c|c|c|c|c|c|c|c|c|c|}
\hline \multirow{2}{*}{ Propriedades } & \multicolumn{11}{|c|}{ Seção } \\
\hline & 0 & $0.1 \mathrm{~L}$ & $0.2 \mathrm{~L}$ & $0.3 \mathrm{~L}$ & $0.4 \mathrm{~L}$ & $0.5 \mathrm{~L}$ & $0.6 \mathrm{~L}$ & $\overline{0.7 \mathrm{~L}}$ & $0.8 \mathrm{~L}$ & $0.9 \mathrm{~L}$ & $\overline{1.0 \mathrm{~L}}$ \\
\hline $\mathrm{D}(\mathrm{cm})$ & 20,85 & 20,05 & 19,32 & 19,39 & 19,00 & 18,40 & 17,98 & 17,92 & 17,60 & 17,86 & 18,91 \\
\hline$D_{\text {méd }}(\mathrm{cm})$ & 20,67 & & & & & & & & & & 17,79 \\
\hline$\Delta_{\text {circ }}$ & $0,9 \%$ & & & & & & & & & & $6,3 \%$ \\
\hline$L / D_{\text {meio }}$ & \multicolumn{11}{|c|}{22,01} \\
\hline C & \multicolumn{11}{|c|}{$0,7 \%$} \\
\hline$\Delta \mathrm{D}$ & \multicolumn{11}{|c|}{$5,4 \%$} \\
\hline Densidade $\left(\mathrm{kg} / \mathrm{m}^{3}\right)$ & \multicolumn{11}{|c|}{933,0} \\
\hline
\end{tabular}


Tabela F.36 - Dados da tora 36.

Tora $\mathrm{N}^{\circ} 36$

Data: $26 / 05 / 2010$

Espécie: Eucalyptus citriodora

\begin{tabular}{|c|c|c|c|c|c|c|}
\hline \multicolumn{3}{|c|}{ Características de crescimento } & Medido & \multicolumn{3}{|c|}{ Limite } \\
\hline \multicolumn{3}{|l|}{ Massa (kg) } & 61,7 & \multicolumn{3}{|c|}{-} \\
\hline \multicolumn{3}{|l|}{ Comprimento (cm) } & 399,8 & \multicolumn{3}{|c|}{-} \\
\hline & 79,96 & \multicolumn{3}{|c|}{-} \\
\hline \multicolumn{3}{|l|}{ Linha de terra $(\mathrm{cm})$} & Base & \multicolumn{3}{|c|}{-} \\
\hline \multirow{4}{*}{ Diâmetros $(\mathrm{cm})$} & $0-4$ & 12,9 & 17,3 & \multicolumn{3}{|c|}{ - } \\
\hline & $1-5$ & 12,8 & 16,2 & \multicolumn{3}{|c|}{-} \\
\hline & $2-6$ & 13,5 & 17,6 & \multicolumn{3}{|c|}{-} \\
\hline & $3-7$ & 12,9 & 18,1 & \multicolumn{3}{|c|}{-} \\
\hline \multirow{2}{*}{ Teor de umidade (\%) } & Topo & Metade & Base & \multicolumn{3}{|c|}{-} \\
\hline & 16,0 & 15,0 & 15,5 & \multicolumn{3}{|c|}{-} \\
\hline \multicolumn{3}{|c|}{ Inclusões contendo casca (cm) } & - & \multicolumn{3}{|c|}{0,5} \\
\hline \multirow{2}{*}{\multicolumn{3}{|c|}{\begin{tabular}{|l} 
Madeira comprimida em $5 \mathrm{~cm}(\mathrm{~S} / \mathrm{N})$ \\
Furos de insetos $(\mathrm{mm})$
\end{tabular}}} & - & \multicolumn{3}{|c|}{ Não } \\
\hline & & & 1 & \multicolumn{3}{|c|}{$\leq 2 \mathrm{~mm}$} \\
\hline \multicolumn{3}{|l|}{ Furos de insetos (mm) } & 123 & \multicolumn{3}{|c|}{$\leq 30 \mathrm{~cm}$} \\
\hline Fendas $(\mathrm{cm})$ & \multicolumn{2}{|l|}{\begin{tabular}{|l|} 
Topo \\
Base \\
\end{tabular}} & 50 & \multicolumn{3}{|c|}{$\leq 60 \mathrm{~cm}$} \\
\hline \multirow{2}{*}{ Encurvamento } & \multirow{2}{*}{\multicolumn{2}{|c|}{\begin{tabular}{|l|} 
um plano \\
dois planos $(\mathrm{S} / \mathrm{N})$ \\
\end{tabular}}} & $0,5 \%$ & & $\leq 0,8 \%$ & \\
\hline & & & - & Não & ssar pela & rfície \\
\hline Fibra torcida (m/volta) & & & $9,1 \mathrm{~m} /$ volta & & $23 \mathrm{~m} / \mathrm{vo}$ & \\
\hline Diâmetro desnéc $(\mathrm{cm})$ & Individual & & 3 & & $\leq 5 \mathrm{~cm}$ & \\
\hline Diametro dos nos $(\mathrm{cm})$ & Grupo & & - & & seção ou & \\
\hline & & & Sec & & & \\
\hline & $\mathbf{0}$ & 1 & 2 & 3 & 4 & 5 \\
\hline & $0,00 \mathrm{~L}$ & $0,10 \mathrm{~L}$ & $0,20 \mathrm{~L}$ & $0,30 \mathrm{~L}$ & $0,40 \mathrm{~L}$ & $0,50 \mathrm{~L}$ \\
\hline Circunferência $(\mathrm{cm})$ & 58,8 & 48,7 & 47,4 & 45,8 & 45,4 & 43,9 \\
\hline & & & $\overline{\mathrm{Sec}}$ & & & \\
\hline & 6 & 7 & 8 & 9 & 10 & 11 \\
\hline & $0,60 \mathrm{~L}$ & $\overline{0,70 L}$ & $0,80 \mathrm{~L}$ & $0,90 \mathrm{~L}$ & $0,95 \mathrm{~L}$ & $1,00 \mathrm{~L}$ \\
\hline & 44,5 & 42,9 & 42,4 & 42,0 & 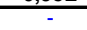 & 41,8 \\
\hline
\end{tabular}

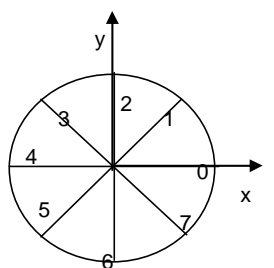

Direções (base)

Observações:

\begin{tabular}{|c|c|c|c|c|c|c|c|c|c|c|c|}
\hline \multirow{2}{*}{ Propriedades } & \multicolumn{11}{|c|}{ Seção } \\
\hline & 0 & $0.1 \mathrm{~L}$ & $0.2 \mathrm{~L}$ & $0.3 \mathrm{~L}$ & $0.4 \mathrm{~L}$ & $0.5 \mathrm{~L}$ & $0.6 \mathrm{~L}$ & $0.7 \mathrm{~L}$ & $0.8 \mathrm{~L}$ & $0.9 \mathrm{~L}$ & $1.0 \mathrm{~L}$ \\
\hline $\mathrm{D}(\mathrm{cm})$ & 18,72 & 15,50 & 15,09 & 14,58 & 14,45 & 13,97 & 14,16 & 13,66 & 13,50 & 13,37 & 13,31 \\
\hline $\mathrm{D}_{\text {méd }}(\mathrm{cm})$ & 17,29 & & & & & & & & & & 13,02 \\
\hline$\Delta_{\text {circ }}$ & $8,3 \%$ & & & & & & & & & & $2,2 \%$ \\
\hline$L / D_{\text {meio }}$ & \multicolumn{11}{|c|}{28,61} \\
\hline $\mathrm{C}$ & \multirow{2}{*}{\multicolumn{11}{|c|}{$\begin{array}{l}1,1 \% \\
10,6 \%\end{array}$}} \\
\hline$\Delta \mathrm{D}$ & & & & & & & & & & & \\
\hline Densidade $\left(\mathrm{kg} / \mathrm{m}^{3}\right)$ & \multicolumn{11}{|c|}{$\frac{10,6 \%}{850,1}$} \\
\hline
\end{tabular}


Tabela F.37 - Dados da tora 37.

Tora $\mathrm{N}^{\circ} 37$

Data: 26/05/2010

Espécie: Eucalyptus citriodora

\begin{tabular}{|c|c|c|c|c|c|c|}
\hline \multicolumn{3}{|c|}{ Caracteristicas de crescimento } & Medido & \multicolumn{3}{|c|}{ Limite } \\
\hline \multicolumn{3}{|l|}{ Massa (kg) } & 112,15 & \multicolumn{3}{|c|}{-} \\
\hline \multicolumn{3}{|l|}{ Comprimento (cm) } & 424,3 & \multicolumn{3}{|c|}{-} \\
\hline \multicolumn{3}{|l|}{ Linha de terra $(\mathbf{c m})$} & 84,86 & \multicolumn{3}{|c|}{-} \\
\hline \multirow{5}{*}{ Diâmetros (cm) } & Direção & Topo & Base & \multicolumn{3}{|c|}{-} \\
\hline & $0-4$ & 17,1 & 19,0 & \multicolumn{3}{|c|}{-} \\
\hline & $1-5$ & 16,0 & 19,2 & \multicolumn{3}{|c|}{-} \\
\hline & $2-6$ & 16,0 & 18,3 & \multicolumn{3}{|c|}{-} \\
\hline & $3-7$ & 17,3 & 18,2 & \multicolumn{3}{|c|}{-} \\
\hline \multirow{2}{*}{ Teor de umidade (\%) } & Topo & Metade & Base & \multicolumn{3}{|c|}{-} \\
\hline & 15,0 & 13,5 & 15,6 & \multicolumn{3}{|c|}{-} \\
\hline \multicolumn{3}{|c|}{ Inclusões contendo casca $(\mathrm{cm})$} & - & \multicolumn{3}{|c|}{0,5} \\
\hline \multirow{2}{*}{\multicolumn{3}{|c|}{\begin{tabular}{|l} 
Madeira comprimida em $5 \mathrm{~cm}(\mathrm{~S} / \mathrm{N})$ \\
Furos de insetos $(\mathrm{mm})$
\end{tabular}}} & - & \multicolumn{3}{|c|}{ Não } \\
\hline Furos de insetos (mm) & & & 1 & \multicolumn{3}{|c|}{$\leq 2 \mathrm{~mm}$} \\
\hline \multirow{2}{*}{ Fendas (cm) } & & - & \multicolumn{3}{|c|}{$\leq 30 \mathrm{~cm}$} \\
\hline & & & - & \multicolumn{3}{|c|}{$\leq 60 \mathrm{~cm}$} \\
\hline \multirow{2}{*}{ Encurvamento } & \multicolumn{2}{|l|}{\begin{tabular}{|l|} 
Base \\
um plano
\end{tabular}} & $0,8 \%$ & & $\leq 0,8 \%$ & \\
\hline & \multicolumn{2}{|c|}{ dois planos $(\mathrm{S} / \mathrm{N})$} & - & Não & sar pela & Ifície \\
\hline Fibra torcida (m/volta) & & & ver obs. & & $3 \mathrm{~m} / \mathrm{vo}$ & \\
\hline Diâmetro dos nós $(\mathrm{cm})$ & Individual & & 5 & & $\leq 5 \mathrm{~cm}$ & \\
\hline Diametro dos nos (cm) & Grupo & & - & & seção ou & \\
\hline & & & & & & \\
\hline & $\mathbf{0}$ & 1 & 2 & 3 & 4 & 5 \\
\hline & $0,00 \mathrm{~L}$ & $0,10 \mathrm{~L}$ & $0,20 \mathrm{~L}$ & $0,30 \mathrm{~L}$ & $0,40 \mathrm{~L}$ & $\overline{0,50 \mathrm{~L}}$ \\
\hline Circunferência (cm) & 59,2 & 61,3 & 57,6 & 56,9 & 55,3 & 55,5 \\
\hline & & & & & & \\
\hline & 6 & 7 & 8 & 9 & 10 & 11 \\
\hline & $0,60 \mathrm{~L}$ & $0,70 \mathrm{~L}$ & $0,80 \mathrm{~L}$ & $0,90 \mathrm{~L}$ & $0,95 \mathrm{~L}$ & $1,00 \mathrm{~L}$ \\
\hline & 54,2 & 53,4 & 53,5 & 53,5 & - & 52,9 \\
\hline
\end{tabular}

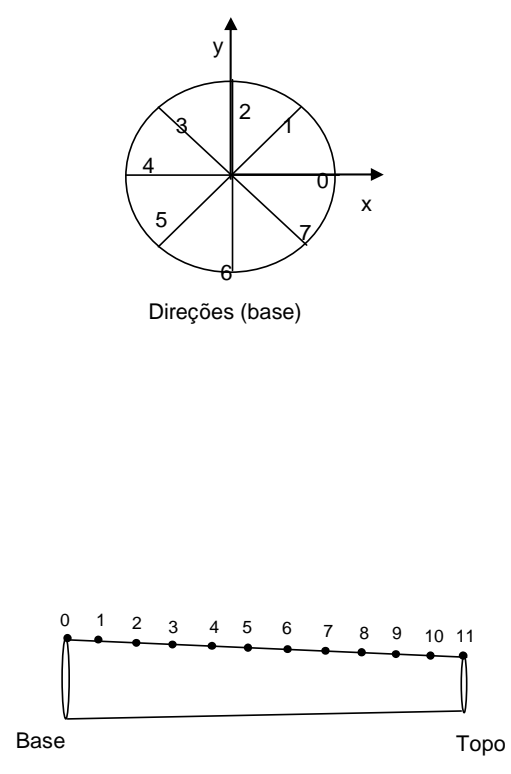

Observações:

Fibras com padrão sinusoidal

\begin{tabular}{|c|c|c|c|c|c|c|c|c|c|c|c|}
\hline \multirow{2}{*}{ Propriedades } & \multicolumn{11}{|c|}{ Seção } \\
\hline & 0 & $0.1 \mathrm{~L}$ & $0.2 \mathrm{~L}$ & $0.3 \mathrm{~L}$ & $0.4 \mathrm{~L}$ & $0.5 \mathrm{~L}$ & $0.6 \mathrm{~L}$ & $\begin{array}{c}0.7 \mathrm{~L} \\
\end{array}$ & $0.8 \mathrm{~L}$ & $0.9 \mathrm{~L}$ & $1.0 \mathrm{~L}$ \\
\hline $\mathrm{D}(\mathrm{cm})$ & 18,84 & 19,51 & 18,33 & 18,11 & 17,60 & 17,67 & 17,25 & 17,00 & 17,03 & 17,03 & 16,84 \\
\hline$D_{\text {méd }}(\mathrm{cm})$ & 18,67 & & & & & & & & & & 16,59 \\
\hline$\Delta_{\text {circ }}$ & $0,9 \%$ & & & & & & & & & & $1,5 \%$ \\
\hline$L / D_{\text {meio }}$ & \multicolumn{11}{|c|}{24,02} \\
\hline C & \multicolumn{11}{|c|}{$0,5 \%$} \\
\hline$\Delta \mathrm{D}$ & \multicolumn{11}{|c|}{$4,9 \%$} \\
\hline Densidade $\left(\mathrm{kg} / \mathrm{m}^{3}\right)$ & \multicolumn{11}{|c|}{1081,6} \\
\hline
\end{tabular}


Tabela F.38 - Dados da tora 38.

Tora $\mathrm{N}^{\circ} 38$

Data: $27 / 05 / 2010$

Espécie: Eucalyptus citriodora

\begin{tabular}{|c|c|c|c|c|c|c|}
\hline \multicolumn{3}{|c|}{ Características de crescimento } & Medido & \multicolumn{3}{|c|}{ Limite } \\
\hline \multicolumn{3}{|l|}{ Massa (kg) } & 94,9 & \multicolumn{3}{|c|}{ - } \\
\hline \multicolumn{3}{|l|}{ Comprimento (cm) } & 406,2 & \multicolumn{3}{|c|}{-} \\
\hline \multicolumn{3}{|l|}{\begin{tabular}{|l} 
Linha de terra $(\mathrm{cm})$ \\
\end{tabular}} & & \multicolumn{3}{|c|}{-} \\
\hline \multirow{5}{*}{ Diâmetros (cm) } & Direção & Topo & Base & \multicolumn{3}{|c|}{-} \\
\hline & $0-4$ & 16,1 & 18,1 & \multicolumn{3}{|c|}{-} \\
\hline & $1-5$ & 15,1 & 17,9 & \multicolumn{3}{|c|}{-} \\
\hline & $2-6$ & 15,8 & 17,2 & \multicolumn{3}{|c|}{-} \\
\hline & $3-7$ & 16,3 & 17,1 & \multicolumn{3}{|c|}{-} \\
\hline \multirow{2}{*}{ Teor de umidade (\%) } & Topo & Metade & Base & \multicolumn{3}{|c|}{-} \\
\hline & 10,9 & 11,3 & 11,2 & \multicolumn{3}{|c|}{-} \\
\hline \multicolumn{3}{|c|}{\begin{tabular}{|l} 
Inclusões contendo casca (cm) \\
\end{tabular}} & - & \multicolumn{3}{|c|}{0,5} \\
\hline \multicolumn{3}{|c|}{ Madeira comprimida em $5 \mathrm{~cm}(\mathrm{~S} / \mathrm{N})$} & - & \multicolumn{3}{|c|}{ Não } \\
\hline \multicolumn{3}{|l|}{ Furos de insetos (mm) } & 1 & \multicolumn{3}{|c|}{$\leq 2 \mathrm{~mm}$} \\
\hline \multirow{2}{*}{ Fendas $(\mathrm{cm})$} & \multirow{2}{*}{\multicolumn{2}{|c|}{ Topo }} & - & \multicolumn{3}{|c|}{$\leq 30 \mathrm{~cm}$} \\
\hline & & & 20 & \multicolumn{3}{|c|}{$\leq 60 \mathrm{~cm}$} \\
\hline \multirow{2}{*}{ Encurvamento } & \multirow{2}{*}{\multicolumn{2}{|c|}{\begin{tabular}{|l|} 
um plano \\
dois planos $(\mathrm{S} / \mathrm{N})$ \\
\end{tabular}}} & $0,7 \%$ & & $\leq 0,8 \%$ & \\
\hline & & & - & $\overline{\text { Não }}$ & sar pela & rfície \\
\hline Fibra torcida (m/volta) & & & $4 \mathrm{~m} /$ volta & & $3 \mathrm{~m} / \mathrm{v}$ & \\
\hline Diâmetro dos nós (cm) & Individual & & - & & $\leq 5 \mathrm{~cm}$ & \\
\hline Diametro dos nos (cm) & Grupo & & - & & seção ol & \\
\hline & & & $\mathrm{Se}$ & & & \\
\hline & 0 & 1 & 2 & 3 & 4 & 5 \\
\hline & $0,00 \mathrm{~L}$ & $0,10 \mathrm{~L}$ & $0,20 \mathrm{~L}$ & $0,30 \mathrm{~L}$ & $0,40 \mathrm{~L}$ & $0,50 \mathrm{~L}$ \\
\hline Circunferência $(\mathrm{cm})$ & 55,8 & 55,8 & 54,8 & 53,8 & 52,6 & 52,1 \\
\hline 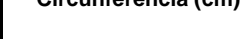 & & & $\mathrm{Se}$ & & & \\
\hline & 6 & 7 & 8 & 9 & 10 & 11 \\
\hline & $0,60 \mathrm{~L}$ & $0,70 \mathrm{~L}$ & $0,80 \mathrm{~L}$ & $0,90 \mathrm{~L}$ & $0,95 \mathrm{~L}$ & $1,00 \mathrm{~L}$ \\
\hline & 51,4 & 50,8 & 50,3 & 50,1 & - & 50,2 \\
\hline
\end{tabular}

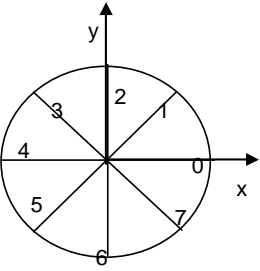

Direções (base)

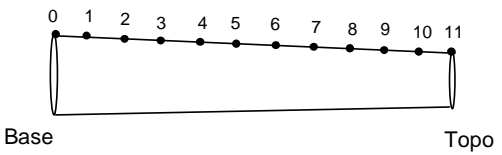

Observações:

\begin{tabular}{|c|c|c|c|c|c|c|c|c|c|c|c|}
\hline \multirow{2}{*}{ Propriedades } & \multicolumn{11}{|c|}{ Seção } \\
\hline & 0 & $0.1 \mathrm{~L}$ & $\begin{array}{c}0.2 \mathrm{~L} \\
\end{array}$ & $0.3 \mathrm{~L}$ & $0.4 \mathrm{~L}$ & $0.5 \mathrm{~L}$ & $0.6 \mathrm{~L}$ & $\begin{array}{c}0.7 \mathrm{~L} \\
\end{array}$ & $\begin{array}{c}0.8 \mathrm{~L} \\
\end{array}$ & $0.9 \mathrm{~L}$ & $\begin{array}{l}1.0 \mathrm{~L} \\
\end{array}$ \\
\hline $\mathrm{D}(\mathrm{cm})$ & 17,76 & 17,76 & 17,44 & 17,13 & 16,74 & 16,58 & 16,36 & 16,17 & 16,01 & 15,95 & 15,98 \\
\hline $\mathrm{D}_{\text {méd }}(\mathrm{cm})$ & 17,57 & & & & & & & & & & 15,82 \\
\hline$\Delta_{\text {circ }}$ & $1,1 \%$ & & & & & & & & & & $1,0 \%$ \\
\hline$L / D_{\text {meio }}$ & \multicolumn{11}{|c|}{24,49} \\
\hline C & \multicolumn{11}{|c|}{$\frac{0,4 \%}{4,2 \%}$} \\
\hline$\Delta \mathrm{D}$ & \multirow{2}{*}{\multicolumn{11}{|c|}{$\begin{array}{c}4,2 \% \\
1066,4\end{array}$}} \\
\hline Densidade $\left(\mathrm{kg} / \mathrm{m}^{3}\right)$ & & & & & & & & & & & \\
\hline
\end{tabular}


Tabela F.39 - Dados da tora 39.

Tora $\mathrm{N}^{\circ} 39$

\begin{tabular}{|c|c|c|c|c|c|c|}
\hline \multicolumn{3}{|c|}{ Características de crescimento } & Medido & \multicolumn{3}{|c|}{ Limite } \\
\hline \multicolumn{3}{|l|}{ Massa (kg) } & 64,2 & \multicolumn{3}{|c|}{-} \\
\hline \multicolumn{3}{|l|}{ Comprimento (cm) } & 400,2 & \multicolumn{3}{|c|}{-} \\
\hline \multicolumn{3}{|l|}{ Linha de terra $(\mathrm{cm})$} & & \multicolumn{3}{|c|}{-} \\
\hline \multirow{5}{*}{ Diâmetros (cm) } & Direção & Topo & Base & \multicolumn{3}{|c|}{-} \\
\hline & $0-4$ & 13,2 & 16,5 & \multicolumn{3}{|c|}{-} \\
\hline & $1-5$ & 13,2 & 16,8 & \multicolumn{3}{|c|}{-} \\
\hline & $2-6$ & 12,5 & 15,3 & \multicolumn{3}{|c|}{-} \\
\hline & $3-7$ & 12,8 & 16,0 & \multicolumn{3}{|c|}{-} \\
\hline \multirow{2}{*}{ Teor de umidade (\%) } & Topo & Metade & Base & \multicolumn{3}{|c|}{-} \\
\hline & 10,8 & 11,3 & 11,5 & \multicolumn{3}{|c|}{-} \\
\hline \multicolumn{3}{|c|}{ Inclusões contendo casca $(\mathrm{cm})$} & - & \multicolumn{3}{|c|}{0,5} \\
\hline \multirow{2}{*}{\multicolumn{3}{|c|}{$\begin{array}{l}\text { Madeira comprimida em } 5 \mathrm{~cm}(\mathrm{~S} / \mathrm{N}) \\
\text { Furos de insetos }(\mathrm{mm})\end{array}$}} & - & \multicolumn{3}{|c|}{ Não } \\
\hline & & & 1 & \multicolumn{3}{|c|}{$\leq 2 \mathrm{~mm}$} \\
\hline \multirow{2}{*}{ Fendas $(\mathrm{cm})$} & \multicolumn{2}{|l|}{ Topo } & 30 & \multicolumn{3}{|c|}{$\leq 30 \mathrm{~cm}$} \\
\hline & \multicolumn{2}{|l|}{ Base } & 17 & \multicolumn{3}{|c|}{$\leq 60 \mathrm{~cm}$} \\
\hline \multirow{2}{*}{ Encurvamento } & \multirow{2}{*}{\multicolumn{2}{|c|}{\begin{tabular}{|l|} 
um plano \\
dois planos $(\mathrm{S} / \mathrm{N})$
\end{tabular}}} & $0,6 \%$ & \multicolumn{3}{|c|}{$\leq 0,8 \%$} \\
\hline & & & - & Não & sar pela & erfície \\
\hline Fibra torcida (m/volta) & & & - & & $3 \mathrm{~m} / \mathrm{vo}$ & \\
\hline Diâmetro dos nós $(\mathrm{cm})$ & Individual & & - & & $\leq 5 \mathrm{~cm}$ & \\
\hline Diametro dos nos (cm) & Grupo & & - & & seção ou & \\
\hline & & & & & & \\
\hline & 0 & 1 & 2 & 3 & 4 & 5 \\
\hline & $0,00 \mathrm{~L}$ & $0,10 \mathrm{~L}$ & $0,20 \mathrm{~L}$ & $0,30 \mathrm{~L}$ & $0,40 \mathrm{~L}$ & $0,50 \mathrm{~L}$ \\
\hline Circunferência $(\mathrm{cm})$ & 51,0 & 49,0 & 47,5 & 46,6 & 45,5 & 44,9 \\
\hline & & & & & & \\
\hline & 6 & 7 & 8 & 9 & 10 & 11 \\
\hline & $0,60 \mathrm{~L}$ & $0,70 \mathrm{~L}$ & $0,80 \mathrm{~L}$ & $0,90 \mathrm{~L}$ & $0,95 \mathrm{~L}$ & $1,00 \mathrm{~L}$ \\
\hline & 43,6 & 43,0 & 42,5 & 41,5 & - & 40,8 \\
\hline
\end{tabular}

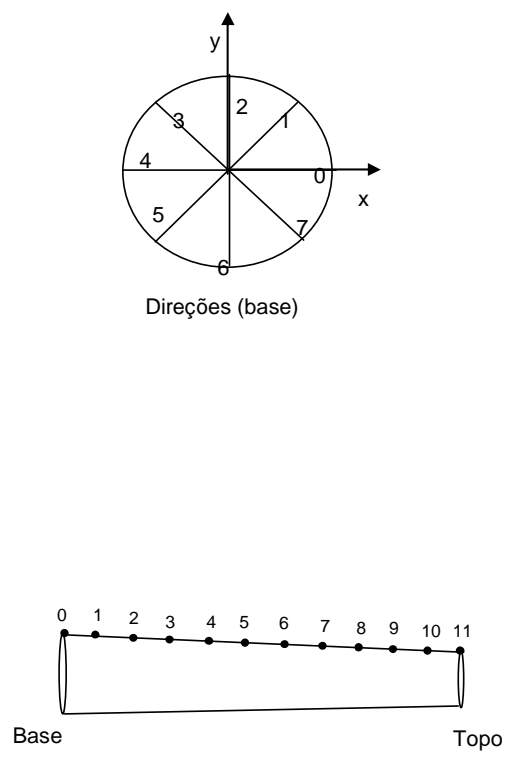

Observações:

Excentricidade na base 1,3cm na direção $0-4,1,0 \mathrm{~cm}$ na direção 2-6

\begin{tabular}{|c|c|c|c|c|c|c|c|c|c|c|c|}
\hline \multirow{2}{*}{ Propriedades } & \multicolumn{11}{|c|}{ Seção } \\
\hline & 0 & $0.1 \mathrm{~L}$ & $0.2 \mathrm{~L}$ & $0.3 \mathrm{~L}$ & $0.4 \mathrm{~L}$ & $0.5 \mathrm{~L}$ & $0.6 \mathrm{~L}$ & $0.7 \mathrm{~L}$ & $0.8 \mathrm{~L}$ & $0.9 \mathrm{~L}$ & $1.0 \mathrm{~L}$ \\
\hline$\overline{D(c m)}$ & 16,23 & 15,60 & 15,12 & 14,83 & 14,48 & 14,29 & 13,88 & 13,69 & 13,53 & 13,21 & 12,99 \\
\hline$D_{\text {méd }}(\mathrm{cm})$ & 16,14 & & & & & & & & & & 12,92 \\
\hline$\Delta_{\text {circ }}$ & $0,6 \%$ & & & & & & & & & & $0,5 \%$ \\
\hline $\mathrm{L} / \mathrm{D}_{\text {meio }}$ & \multicolumn{11}{|c|}{28,00} \\
\hline C & \multicolumn{11}{|c|}{$0,8 \%$} \\
\hline$\Delta \mathrm{D}$ & \multicolumn{11}{|c|}{$7,1 \%$} \\
\hline Densidade $\left(\mathrm{kg} / \mathrm{m}^{3}\right)$ & \multicolumn{11}{|c|}{963,4} \\
\hline
\end{tabular}


Tabela F.40 - Dados da tora 40.

Tora $\mathrm{N}^{\circ} 40$

Data: $28 / 05 / 2010$

Espécie: Eucalyptus citriodora

\begin{tabular}{|c|c|c|c|c|c|c|}
\hline \multicolumn{3}{|c|}{ Características de crescimento } & Medido & \multicolumn{3}{|c|}{ Limite } \\
\hline \multicolumn{3}{|l|}{ Massa (kg) } & 82,9 & \multicolumn{3}{|c|}{-} \\
\hline \multicolumn{3}{|l|}{ Comprimento $(\mathrm{cm})$} & 431 & \multicolumn{3}{|c|}{-} \\
\hline \multicolumn{3}{|l|}{ Linha de terra $(\mathrm{cm})$} & & \multicolumn{3}{|c|}{-} \\
\hline \multirow{5}{*}{ Diâmetros (cm) } & Direção & Topo & Base & \multicolumn{3}{|c|}{-} \\
\hline & $0-4$ & 14,7 & 17,5 & \multicolumn{3}{|c|}{-} \\
\hline & $1-5$ & 14,2 & 17,4 & \multicolumn{3}{|c|}{-} \\
\hline & $2-6$ & 14,2 & 18,0 & \multicolumn{3}{|c|}{-} \\
\hline & $3-7$ & 14,7 & 18,0 & \multicolumn{3}{|c|}{-} \\
\hline \multirow{2}{*}{ Teor de umidade (\%) } & Topo & Metade & Base & \multicolumn{3}{|c|}{-} \\
\hline & 10,9 & 11,1 & 10,8 & \multicolumn{3}{|c|}{-} \\
\hline \multicolumn{3}{|c|}{ Inclusões contendo casca $(\mathrm{cm})$} & - & \multicolumn{3}{|c|}{0,5} \\
\hline \multirow{2}{*}{\multicolumn{3}{|c|}{\begin{tabular}{|l} 
Madeira comprimida em $5 \mathrm{~cm}(\mathrm{~S} / \mathrm{N})$ \\
Furos de insetos $(\mathrm{mm})$
\end{tabular}}} & - & \multicolumn{3}{|c|}{ Não } \\
\hline & & & 1 & \multicolumn{3}{|c|}{$\leq 2 \mathrm{~mm}$} \\
\hline \multirow{2}{*}{ Fendas (cm) } & \multirow{2}{*}{\multicolumn{2}{|c|}{\begin{tabular}{|l|} 
Topo \\
Base \\
\end{tabular}}} & - & \multicolumn{3}{|c|}{$\leq 30 \mathrm{~cm}$} \\
\hline & & & 15 & \multicolumn{3}{|c|}{$\leq 60 \mathrm{~cm}$} \\
\hline \multirow{2}{*}{ Encurvamento } & \multirow{2}{*}{\multicolumn{2}{|c|}{\begin{tabular}{|l|} 
um plano \\
dois planos $(S / N)$
\end{tabular}}} & $0,7 \%$ & \multicolumn{3}{|c|}{$\leq 0,8 \%$} \\
\hline & & & - & Não & ssar pela & Iffície \\
\hline Fibra torcida (m/volta) & & & - & & $\geq 3 \mathrm{~m} / \mathrm{vc}$ & \\
\hline Diâmetro dos nós $(\mathrm{cm})$ & Individual & & - & & $\leq 5 \mathrm{~cm}$ & \\
\hline Diametro dos nos (cm) & Grupo & & - & & seção ol & \\
\hline & & & & & & \\
\hline & 0 & 1 & 2 & 3 & 4 & 5 \\
\hline & $0,00 \mathrm{~L}$ & $0,10 \mathrm{~L}$ & $0,20 \mathrm{~L}$ & $0,30 \mathrm{~L}$ & $0,40 \mathrm{~L}$ & $0,50 \mathrm{~L}$ \\
\hline Circunferência $(\mathrm{cm})$ & 56,1 & 56,3 & 51,0 & 50 & 49,6 & 49,3 \\
\hline & & & & & & \\
\hline & 6 & 7 & 8 & 9 & 10 & 11 \\
\hline & $0,60 \mathrm{~L}$ & $0,70 \mathrm{~L}$ & $0,80 \mathrm{~L}$ & $0,90 \mathrm{~L}$ & $0,95 \mathrm{~L}$ & $1,00 \mathrm{~L}$ \\
\hline & 47,5 & 47,0 & 46,5 & 45,8 & - & 46 \\
\hline
\end{tabular}

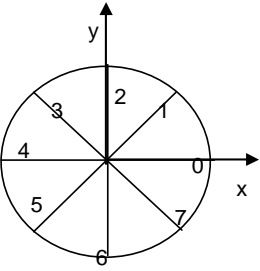

Direções (base)

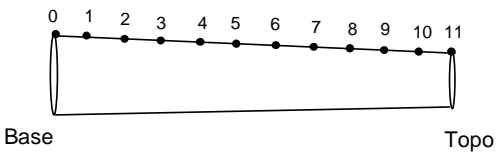

Observações:

\begin{tabular}{|c|c|c|c|c|c|c|c|c|c|c|c|}
\hline \multirow{2}{*}{ Propriedades } & \multicolumn{11}{|c|}{ Seção } \\
\hline & 0 & $0.1 \mathrm{~L}$ & $\begin{array}{c}0.2 \mathrm{~L} \\
\end{array}$ & $0.3 \mathrm{~L}$ & $0.4 \mathrm{~L}$ & $0.5 \mathrm{~L}$ & $0.6 \mathrm{~L}$ & $\begin{array}{c}0.7 \mathrm{~L} \\
\end{array}$ & $0.8 \mathrm{~L}$ & $0.9 \mathrm{~L}$ & $\begin{array}{l}1.0 \mathrm{~L} \\
\end{array}$ \\
\hline $\mathrm{D}(\mathrm{cm})$ & 17,86 & 17,92 & 16,23 & 15,92 & 15,79 & 15,69 & 15,12 & 14,96 & 14,80 & 14,58 & 14,64 \\
\hline$D_{\text {méd }}(\mathrm{cm})$ & 17,72 & & & & & & & & & & 14,45 \\
\hline$\Delta_{\text {circ }}$ & $0,8 \%$ & & & & & & & & & & $1,3 \%$ \\
\hline$L / D_{\text {meio }}$ & \multicolumn{11}{|c|}{27,47} \\
\hline C & \multicolumn{11}{|c|}{$0,8 \%$} \\
\hline$\Delta \mathrm{D}$ & \multirow{2}{*}{\multicolumn{11}{|c|}{$\begin{array}{l}7,5 \% \\
943,3 \\
\end{array}$}} \\
\hline Densidade $\left(\mathrm{kg} / \mathrm{m}^{3}\right)$ & & & & & & & & & & & \\
\hline
\end{tabular}




\section{ANEXO A - CRITÉRIOS DA NORMA ANSI O5.1 (2002) PARA INSPEÇÃO VISUAL DE TORAS DE MADEIRA}

Este anexo mostra os critérios definidos na norma ANSI O5.1 (2002) para inspeção visual de toras de madeira destinadas à utilização como postes.

\section{A.1. DEFINIÇÕES}

Linha de terra: porção medida a partir da base do poste a qual ficará aterrada. O comprimento de linha de terra depende do diâmetro do poste como mostra a Tabela A.1.

Tabela A.1 - Linha de terra dos postes.

\begin{tabular}{cc}
\hline $\begin{array}{c}\text { Comprimento } \\
\text { do poste (m) }\end{array}$ & $\begin{array}{c}\text { Linha de terra } \\
(\mathbf{m})\end{array}$ \\
\hline 6,1 & 1,20 \\
7,6 & 1,50 \\
9,1 & 1,70 \\
10,7 & 1,70 \\
12,2 & 1,80 \\
\hline
\end{tabular}

Face do poste: lado côncavo de maior curvatura em postes com encurvamento em um plano e uma direção, ou o lado de maior curvatura entre a linha de terra e o topo de postes tendo encurvamento duplo ou reverso.

Conjunto de nós: dois ou mais nós agrupados como uma unidade, com as fibras contornando os nós diferenciando-se de um grupo de nós únicos no qual as fibras circundam cada nó individualmente.

Diâmetro do nó: diâmetro de um nós na superfície do poste medido em direção perpendicular com a linha do eixo do poste. Tanto o cerne quanto o alburno devem ser medidos. 
Racha: separação entre as fibras que ocorre entre os anéis de crescimento.

Curvatura: desvio do eixo do poste em relação a uma linha reta (Figuras A.1 e A.2).

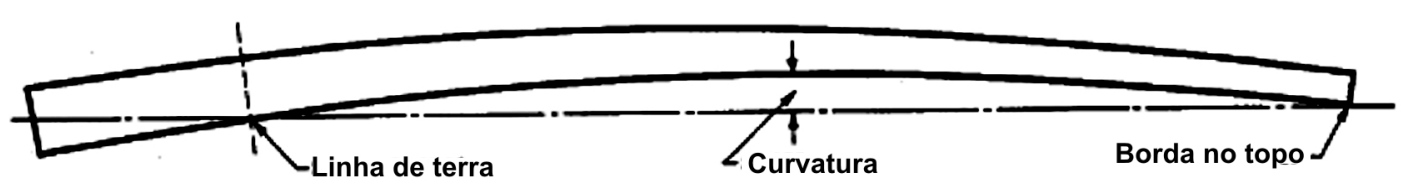

Figura A.1 - Medição da curvatura em um plano ou uma direção.

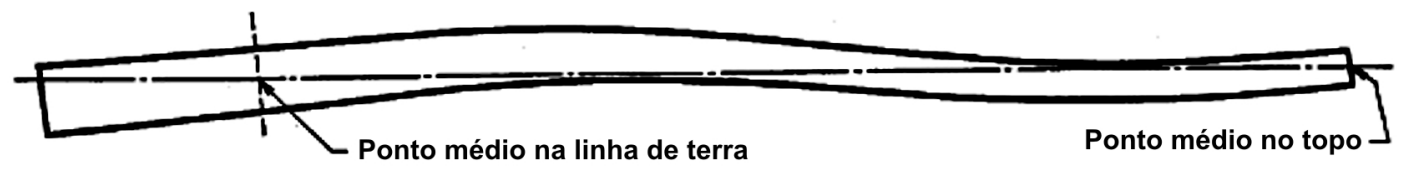

Figura A. 2 - Medição da curvatura em dois planos ou em duas direções.

Curvatura curta: é um desvio localizado do eixo longitudinal da tora com comprimento de $1,5 \mathrm{~m}$ ou menos em qualquer posição ao longo do comprimento da tora e cujo desvio é maior do que metade do diâmetro da seção curvada.

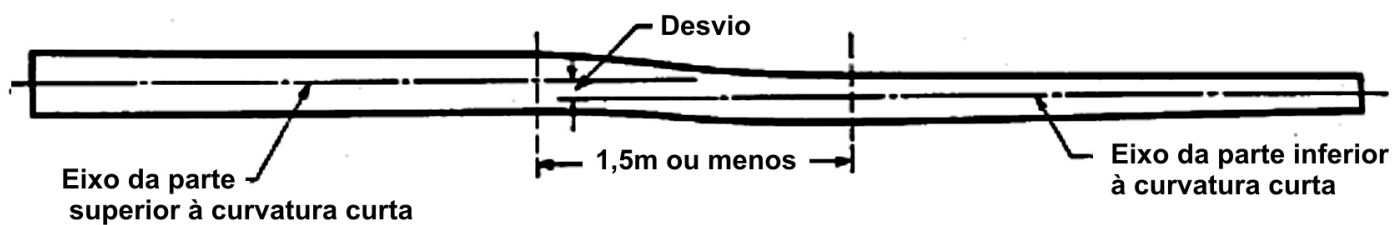

Caso 1: quando os eixos de referência são aproximadamente paralelos.

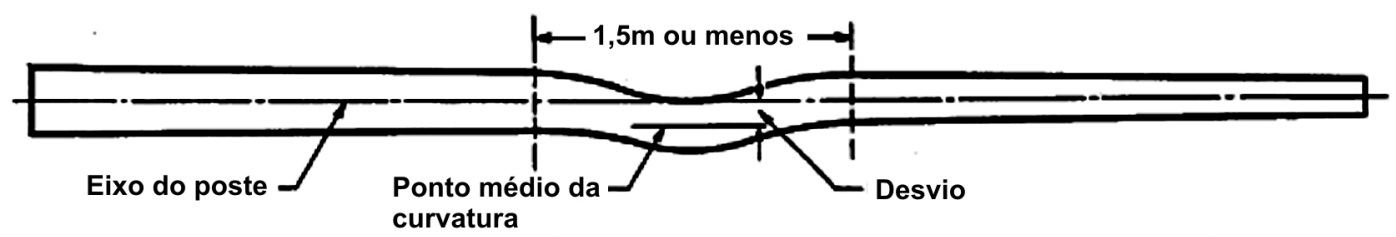

Caso 2: quando os eixos das seções acima e abaixo do encurvamento são praticamente conicidentes

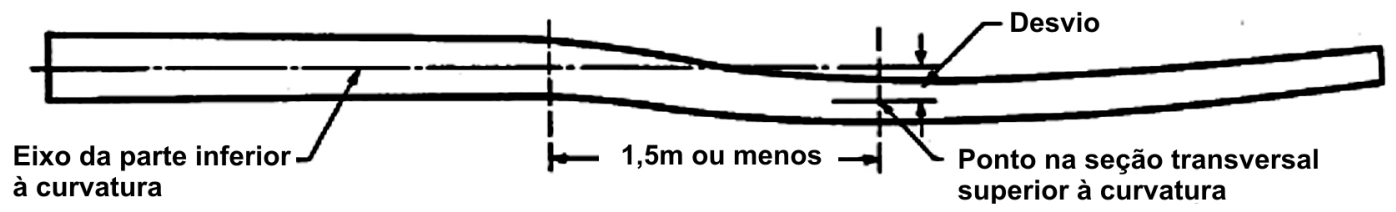

Caso 3: quando os eixos das seções superior e inferior ao encurvamento curto não são paralelos e nem coincidentes

Figura A.3 - Medição da curvatura curta. 
Fenda: separação da madeira na direção do comprimento que se estende completamente através do diâmetro da peça de uma superfície à outra.

Fibras espiraladas/torcidas: fibras que assumem uma geometria espiral ao longo do comprimento do poste.

\section{A. 2. DEFEITOS}

\section{A.2.1. Defeitos proibidos}

1) Rachaduras ao longo de todo o comprimento

2) Podridão;

3) Furos, abertos ou tampados;

5) Presença de buracos ou vazios nas extremidades;

6) Broca marinha;

7) Pregos, parafusos e outros metais não especificamente autorizados pelo comprador.

\section{A.2.2. Defeitos limitados}

Inclusões contendo casca: depressões contendo casca devem ter profundidade inferior a $5 \mathrm{~mm}$.

Madeira comprimida: a costaneira de todas as toras deve ser livre de madeira comprimida em $2,5 \mathrm{~cm}$ de espessura;

Furos de insetos: são permitidos desde que o diâmetro não seja maior do que $2 \mathrm{~mm}$. Qualquer outra forma de dano causado por insetos é proibida;

Rachas: rachas na base do poste cuja largura deixa uma folga igual ou maior do que 5 cm da superfície da tora são permitidas desde que seu comprimento não atinja a linha de terra. Rachas ou combinações de rachas cuja largura fique próxima de a $5 \mathrm{~cm}$ da superfície oposta são permitidas desde que o comprimento seja inferior a $60 \mathrm{~cm}$ e não tenha largura superior a 3 $\mathrm{mm}$; rachas no topo dos postes são permitidas em postes tratados desde que a racha esteja mais próxima da medula do que a superfície da tora.

Forma: os postes devem ser isentos de curvaturas curtas. Um poste pode ter uma curvatura sujeita às seguintes limitações:

Quando a curvatura é em um plano e apenas uma direção: Para toras as espécies, com exceção para o Northern White Cedar (Thuja occidentalis L.) uma linha ligando a linha de 
terra do poste até a aresta do topo do poste não deve ter desvio maior do que $2,5 \mathrm{~cm}$ para cada $3 \mathrm{~m}$ de comprimento. Para a espécie Northern White Cedar o limite de encurvamento é 2,5 cm para $1,5 \mathrm{~m}$ de comprimento.

Quando o encurvamento ocorre em dois planos ou em duas direções em um mesmo plano, uma linha passando entre o ponto médio de linha de terra e o ponto médio no topo da tora não deve em nenhum ponto intermediário passar através da superfície do poste (Figura A.2).

Fibras torcidas: A limitação nessa característica é mostrada na Tabela A.2.

Tabela A.2 - Limitações no torcimento das fibras.

\begin{tabular}{cc}
\hline Comprimento do poste & Torcimento máximo permitido \\
\hline 9 metros ou inferior & 1 volta completa em $3 \mathrm{~m}$ \\
de $10,7 \mathrm{~m}$ a $13,7 \mathrm{~m}$ & 1 volta completa em $5 \mathrm{~m}$ \\
$15,2 \mathrm{~m}$ ou superior & 1 volta completa em $20 \mathrm{~m}$ \\
\hline
\end{tabular}

\section{Fendas:}

No topo: uma fenda ou uma combinação de duas fendas simples (cada fenda terminando no centro da medula e separadas por não menos que 1/6 da circunferência) e com ângulos de até $30^{\circ}$ em relação ao furo do parafuso da cruzeta não devem se estender mais do que $15 \mathrm{~cm}$. Todas as demais combinações de fendas não devem se estender por mais de $30 \mathrm{~cm}$.

Na base: uma fenda ou uma combinação de duas fendas simples não devem ter comprimento maior do que $61 \mathrm{~cm}$.

Nós: o diâmetro de um único nó ou de um conjunto de nós em um comprimento de 30 cm não deve exceder os limites mostrados na Tabela A.3. 
Tabela A.3 - Limite nas dimensões dos nós em postes.

\begin{tabular}{|c|c|c|c|}
\hline \multirow{3}{*}{ Comprimento do poste } & \multicolumn{3}{|c|}{ Dimensões máximas permitidas } \\
\hline & \multicolumn{2}{|c|}{$\begin{array}{l}\text { Diâmetro de nós } \\
\text { individuais }\end{array}$} & \multirow{2}{*}{$\begin{array}{c}\begin{array}{c}\text { Soma dos diâmetros de } \\
\text { todos os nós em } 30 \mathrm{~cm} \text { de } \\
\text { comprimento. }\end{array} \\
\text { Todas as classes }\end{array}$} \\
\hline & $\begin{array}{l}\text { Grupos } \\
\text { H6 a H3 }\end{array}$ & $\begin{array}{c}\text { Grupos } \\
4 \text { a } 10\end{array}$ & \\
\hline $13,7 \mathrm{~m}$ ou inferior & & & \multirow{3}{*}{$\begin{array}{l}\text { 1/3 da circunferência média na } \\
\text { seção transversal ou } 20 \mathrm{~cm} ; 0 \\
\text { que for maior, mas não } \\
\text { excedendo } 30 \mathrm{~cm}\end{array}$} \\
\hline Metade inferior & $8 \mathrm{~cm}$ & $5 \mathrm{~cm}$ & \\
\hline Metade superior & $13 \mathrm{~cm}$ & $10 \mathrm{~cm}$ & \\
\hline $15,2 \mathrm{~m}$ ou superior & & & \multirow{3}{*}{$\begin{array}{l}\text { 1/3 da circunferência média na } \\
\text { seção transversal ou } 25 \mathrm{~cm} ; \text { o } \\
\text { que for maior, mas não } \\
\text { excedendo } 36 \mathrm{~cm}\end{array}$} \\
\hline Metade inferior & $10 \mathrm{~cm}$ & $10 \mathrm{~cm}$ & \\
\hline Metade superior & $15 \mathrm{~cm}$ & $15 \mathrm{~cm}$ & \\
\hline
\end{tabular}

